\title{
Results of Archeological Significance Testing at 41TV410 and 41TV540 and Associated Geomorphological Investigations on a Segment of Onion Creek in Travis County, Texas
}

Antonia Figueroa

Center for Archeological Research, University of Texas at San Antonio

Raymond Mauldin

Center for Archeological Research, University of Texas at San Antonio

Charles D. Frederick

Steve A. Tomka

Raba Kistner

Jennifer L. Thompson

Follow this and additional works at: https://scholarworks.sfasu.edu/ita

Part of the American Material Culture Commons, Archaeological Anthropology Commons, Environmental Studies Commons, Other American Studies Commons, Other Arts and Humanities Commons, Other History of Art, Architecture, and Archaeology Commons, and the United States History Commons

Tell us how this article helped you.

This Article is brought to you for free and open access by the Center for Regional Heritage Research at SFA ScholarWorks. It has been accepted for inclusion in Index of Texas Archaeology: Open Access Gray Literature from the Lone Star State by an authorized editor of SFA ScholarWorks. For more information, please contact cdsscholarworks@sfasu.edu. 


\section{Results of Archeological Significance Testing at 41TV410 and 41TV540 and Associated Geomorphological Investigations on a Segment of Onion Creek in Travis County, Texas}

\section{Licensing Statement}

This is a work for hire produced for the Texas Department of Transportation (TxDOT), which owns all rights, title, and interest in and to all data and other information developed for this project under its contract with the report producer. The report may be cited and brief passages from this publication may be reproduced without permission provided that credit is given to TxDOT and the firm that produced it. Permission to reprint an entire chapter, section, figures or tables must be obtained in advance from the Supervisor of the Archeological Studies Branch, Environmental Affairs Division, Texas Department of Transportation, 125 East 11th Street, Austin, Texas, 78701 


\section{Results of Archeological Significance Testing at 41TV410 and 41TV540 and Associated Geomorphological Investigations on a Segment of Onion Creek in Travis County, Texas}
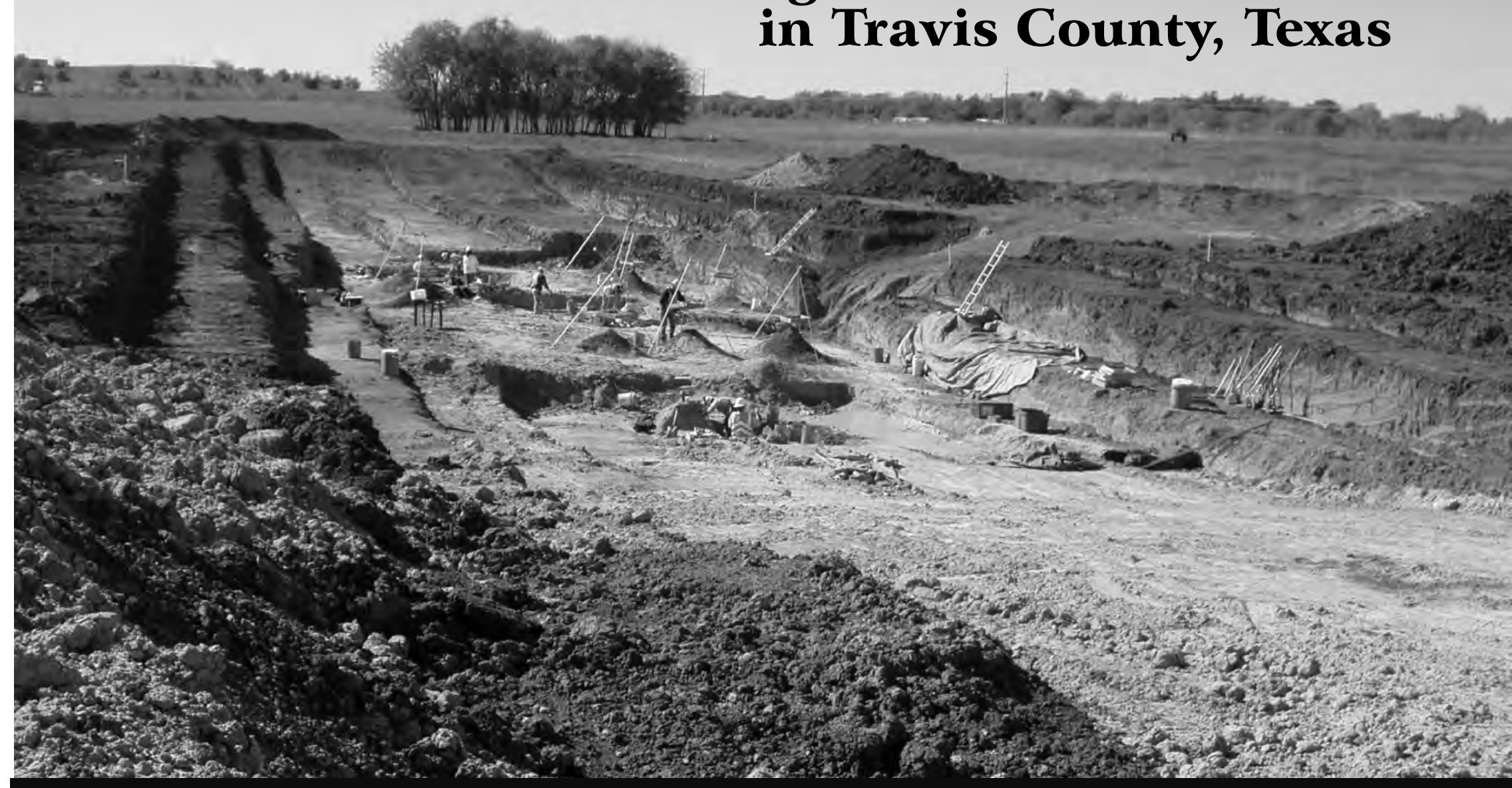

by

Antonia Figueroa, Raymond Mauldin, Charles Frederick, Steve A. Tomka, and Jennifer L. Thompson

\section{with contributions by}

Richard Anderson, Steven Bozarth, Jon Budd, J. Phil Dering, Darrell Kaufman, Barbara Meissner, Manuel Palacios-Fest, Jason Perez, and Terri Woodburn

Work Authorization \#57-901SAoo1

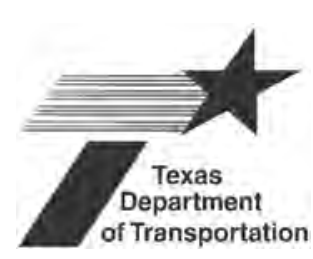

Texas Department of Transportation

Environmental Affairs Division Archeological Studies Program, Report No. 134 Austin

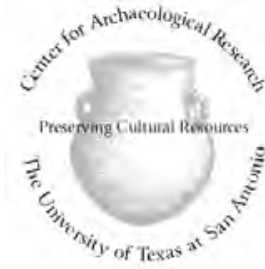

Center for Archaeological Research University of Texas at San Antonio Archaeological Report No. 420 


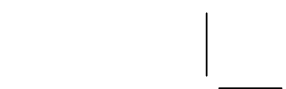

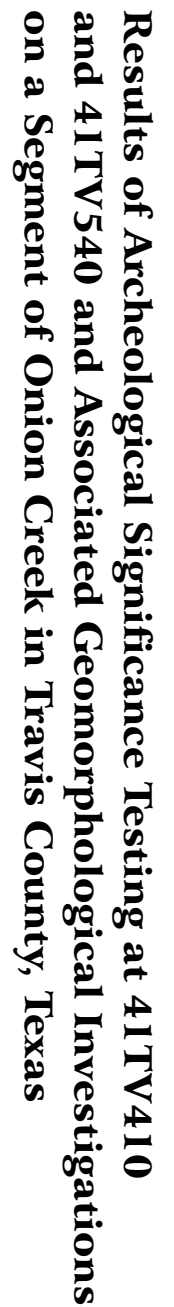

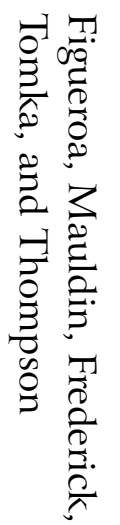

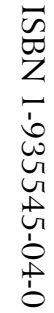

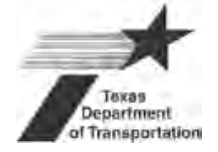

AR \#420

ASPR \# 134

2011 


\title{
Results of Archeological Significance Testing at 41 TV410 and 41 TV540 and Associated Geomorphological Investigations on a Segment of Onion Creek in Travis County, Texas
}

\author{
by \\ Antonia Figueroa, Raymond Mauldin, Charles Frederick, Steve A. Tomka, \\ and Jennifer L. Thompson \\ with contributions by \\ Richard Anderson, Steven Bozarth, Jon Budd, J. Phil Dering, \\ Darrell Kaufman, Barbara Meissner, Manuel Palacios-Fest, \\ Jason Perez, and Terri Woodburn \\ Center for Archaeological Research \\ University of Texas at San Antonio \\ Archaeological Report No. 420
}

ISBN 1-935545-04-0

TxDOT-ENV Archeological Studies Program, Report No. 134

Work Authorization \#57-901SA001

TxDOT Statewide Contract \#57-9XXSA001

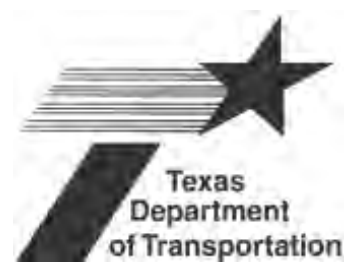

Texas Department of Transportation

Environmental Affairs Division

Archeological Studies Program, Report No. 134

Austin

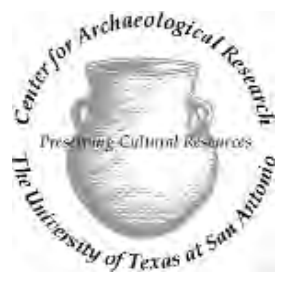

Center for Archaeological Research University of Texas at San Antonio Archaeological Report No. 420 
Copyright $@ 2011$

by the Texas Department of Transportation

This is a work for hire produced for the Texas Department of Transportation (TxDOT), which owns all rights, title, and interest in and to all data and other information developed for this project under contract [\#57-9XXSA001]. brief passages of this publication may be reproduced without permission provided that credit is given to TxDOT. Permission to reprint an entire chapter or section must be obtained in advance from the Supervisor of the Archeological Studies Program, Environmental Affairs Division, Texas Department of Transportation, 125 East $11^{\text {th }}$ Street, Austin, Texas, 78701. Copies of this publication have been deposited with the Texas State Library in compliance with the State Depository Compliance.

\author{
printed by: \\ Blue Tape \\ San Antonio, Texas
}

published by:

Texas Department of Transportation

Environmental Affairs Division

Archeological Studies Program

Scott Pletka, Ph.D., Supervisor

Archeological Studies Program Report No.134

A. McGraw, Series Editor

ISBN 1-935545-04-0 


\begin{abstract}
In late 2005, the Texas Department of Transportation (TxDOT) contracted the Center for Archaeological Research at the University of Texas at San Antonio (CAR-UTSA) to conduct significance testing at 41TV410 and 41TV540, two prehistoric archeological sites located in the floodplain of Onion Creek in southeast Austin in Travis County. The work was conducted in advance of a borrow pit excavation related to the construction on State Highway (SH) 130. The borrow pit represented a project specific location (PSL). PSLs are normally not part of the project per Federal Highway Administration policy. PSLs are the responsibility of the contractor in most cases. However, the testing reported here was mandated by language of the SH 130 comprehensive development agreement. Significance testing was performed late in 2005 and early in 2006. For 41TV540, Dr. Raymond Mauldin served as Principal Investigator and Jennifer Thompson served as the Project Archeologist. At 41TV410, Dr. Mauldin served as Project Archeologist and Dr. Steve Tomka served as Principal Investigator. The archeological work at these sites was not under the purview of either Section 106 or the Antiquities Code of Texas. The work was not conducted under a Texas Antiquities Permit. However, testing at both sites was conducted in accordance with the Secretary of the Interior's Standards and Guidelines for Archeology and Historic Preservation and guidelines provided by the Texas Historical Commission (THC).
\end{abstract}

CAR completed fieldwork in early January of 2006. At 41TV410, 11 features were uncovered with radiocarbon dates that fell in the Early/Middle Archaic and in the Late Archaic. Recovery of artifacts and ecofacts was extremely low. The 41TV540 work also produced a low density of chipped stone artifacts and tools, and exposed 17 features, many of which dated to the close of the Early Archaic. Preliminary observations on flotation returns suggested good quantities of burned material and faunal remains were present at 41TV540. CAR prepared post-field reports summarizing the work and provided recommendations for both sites. Because both locations appeared to contain intact deposits that could, in our view, contribute to an understanding of the prehistoric cultural development of the region, CAR recommended that the sites were eligible to the NRHP under criterion d. TxDOT agreed with CAR recommendations that 41TV540 was eligible for listing in the NRHP, though they did not request any additional work at the site. TxDOT concluded that site 41TV410 was not eligible for listing on the NRHP. At TxDOT's instruction, CAR prepared a research design for the analysis of the testing data from 41TV540, as well as a summary of the 41TV410 work. That document (Tomka et al. 2007), which outlined a series of analyses including several new geomorphic studies and a project area geomorphic synthesis, served as a guideline for the present document.

Since the archeological and geomorphological investigations reported here, the construction of SH 130 has been completed and deposits containing the sites discussed have been removed. All artifacts, notes, photos, and other material associated with the project are stored at CAR. At this time, decisions regarding the disposal of selected artifact classes, as well as the location for permanent curation of the remaining artifacts and associated records, have not been made. However, it is expected that all project related records and artifacts retained will be permanently curated at CAR. 



\section{Table of Contents:}

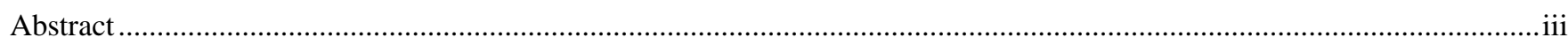

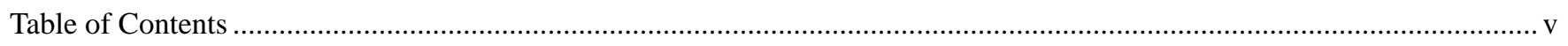

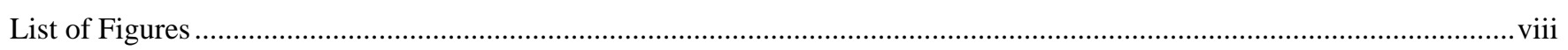

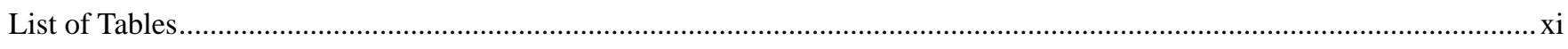

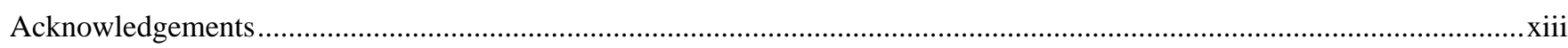

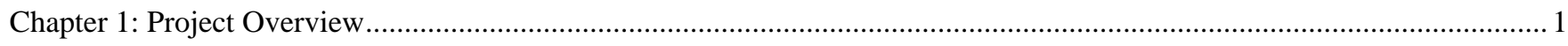

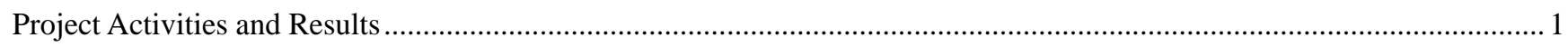

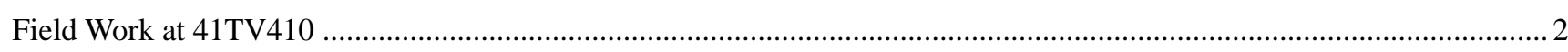

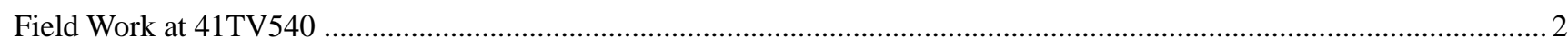

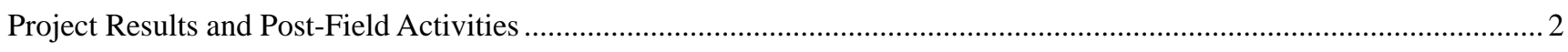

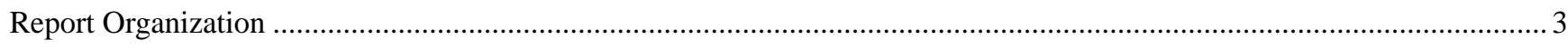

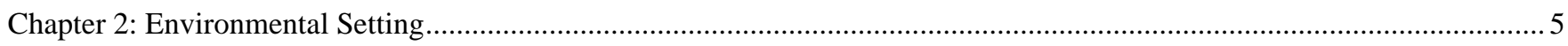

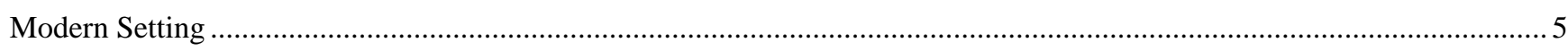

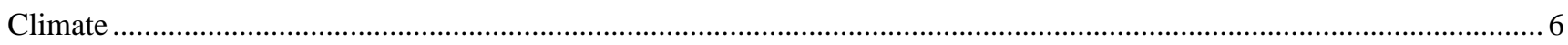

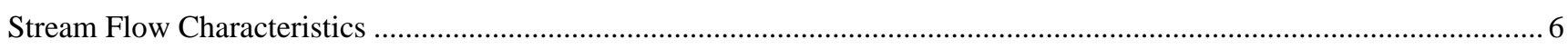

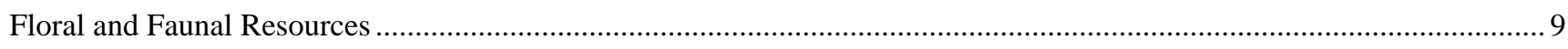

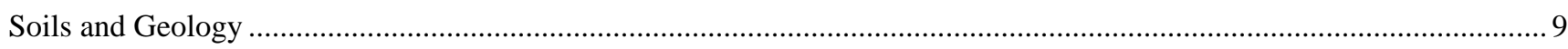

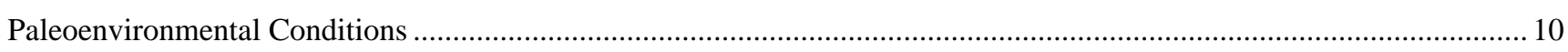

Chapter 3: Archeological Background and Previous Investigations................................................................................. 13

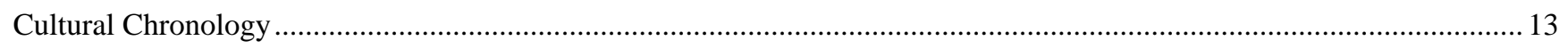

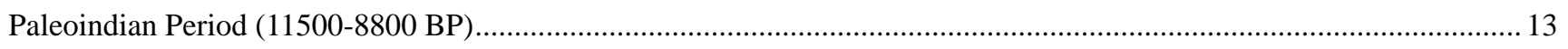

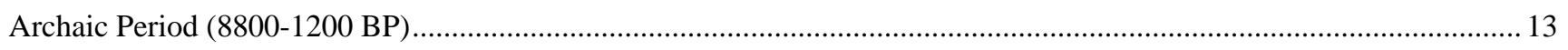

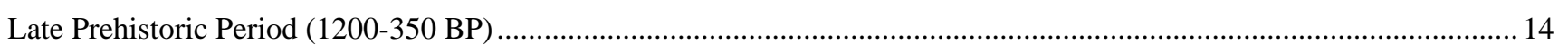

Previous Archeological Research in Travis County and the Onion Creek Area ................................................................... 15

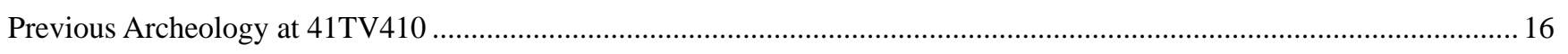

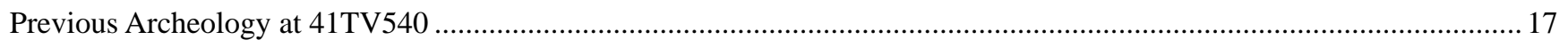

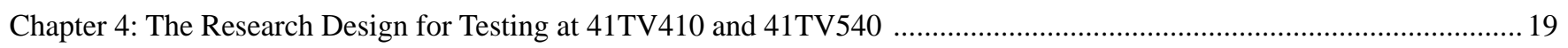

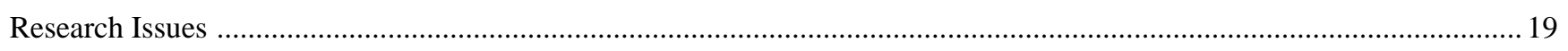

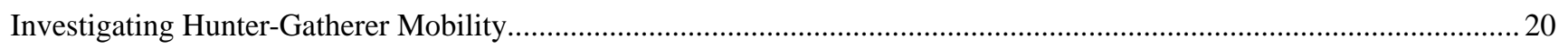

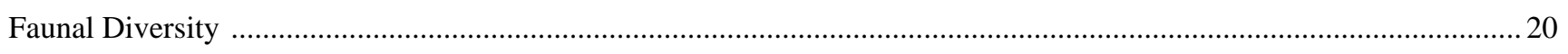

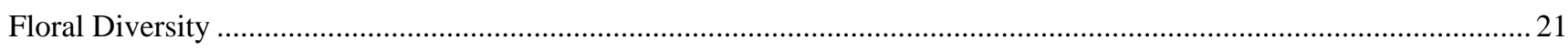



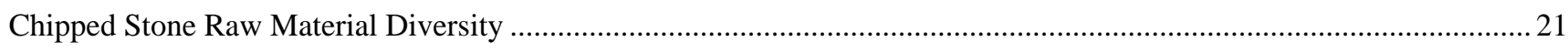

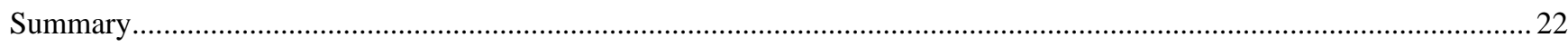

Chapter 5: Archeological Investigations at 41TV410- Field and Laboratory Methods and

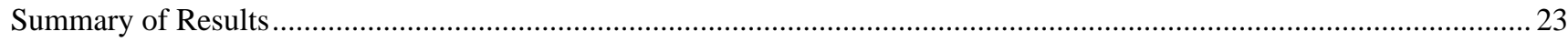

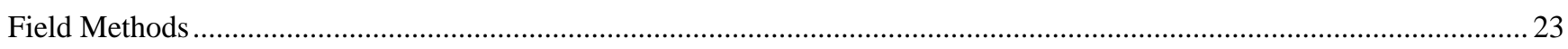

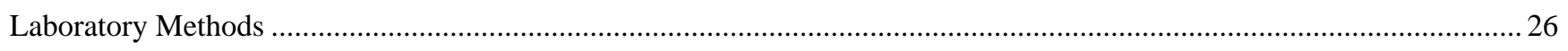

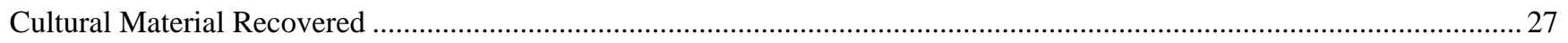

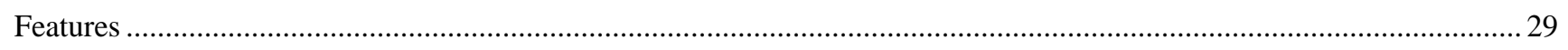








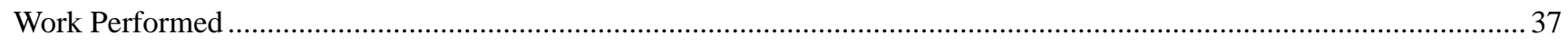

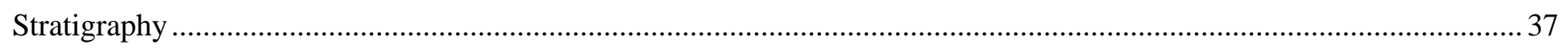

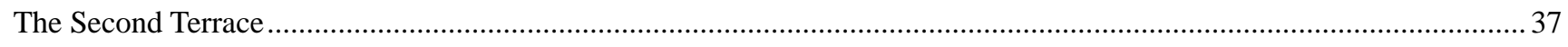

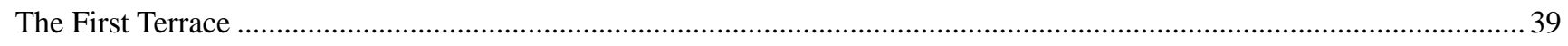

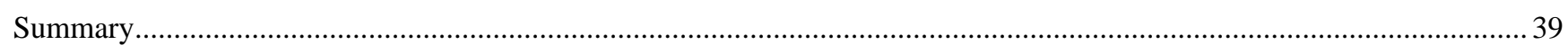

Chapter 6: Archeological Investigations at 41TV540-Field and Laboratory Methods and

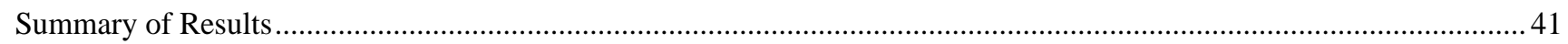

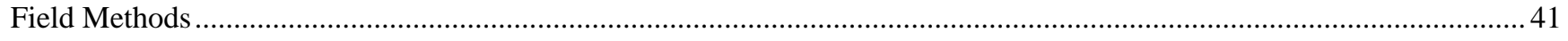

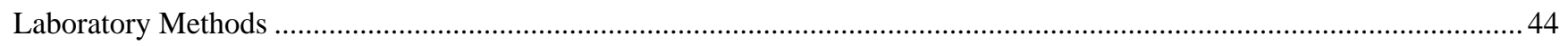

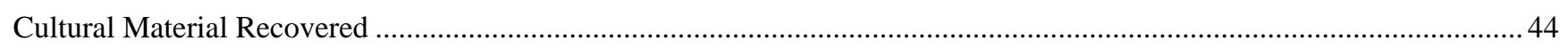

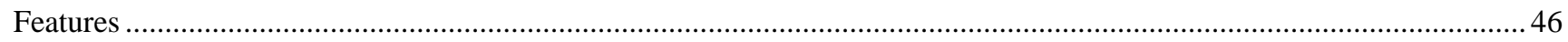

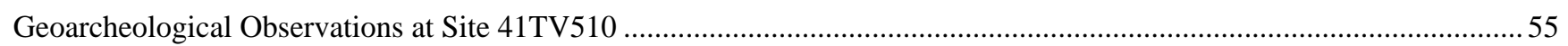

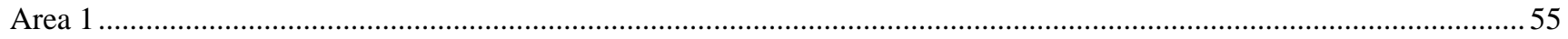

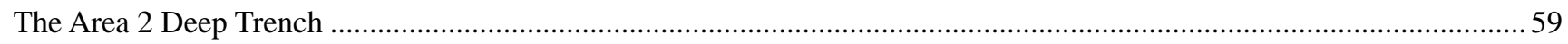

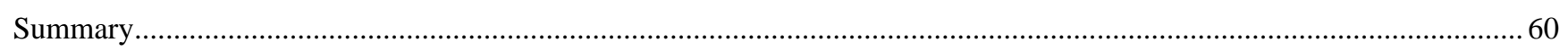

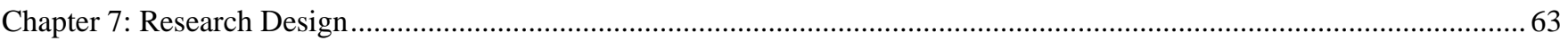

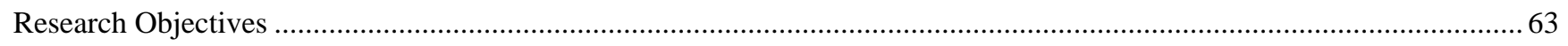

Geomorphic Reconstruction of Holocene Sequences in the Lower Onion Creek Valley ..................................................63

Documenting Trends in Paleoenvironmental Conditions and Resource Structure ..............................................................63

Determining Site use and Function within the Overall Hunter-Gatherer Land Use System ...............................................6 65

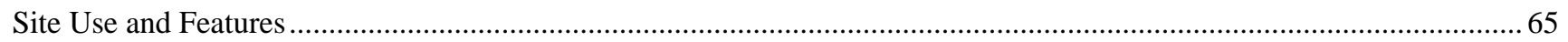

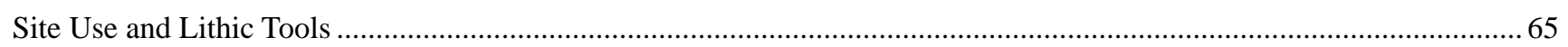

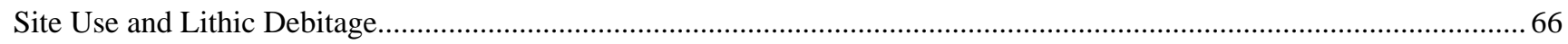



Site Function, Occupation Length, Lithic Technology and Measures of Diversity ........................................................... 67

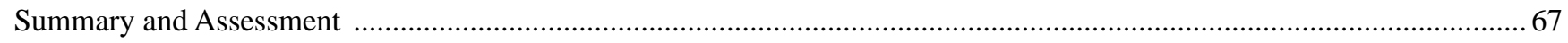

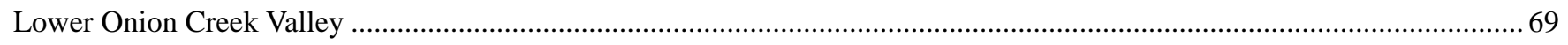

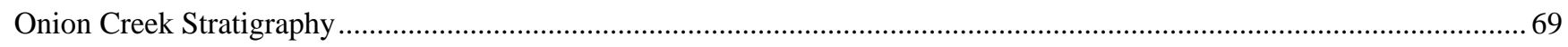

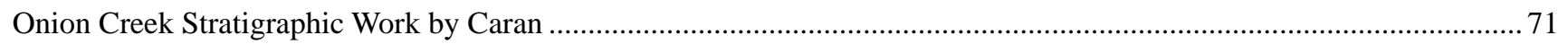

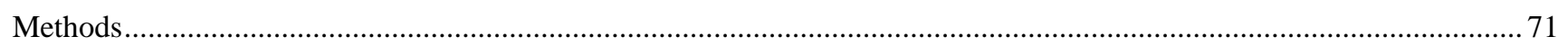

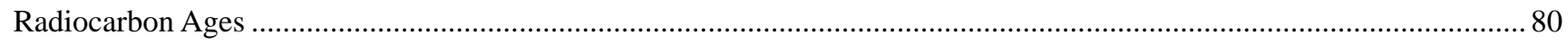

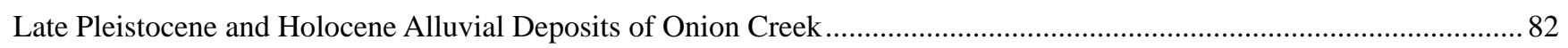

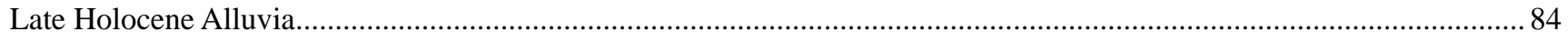

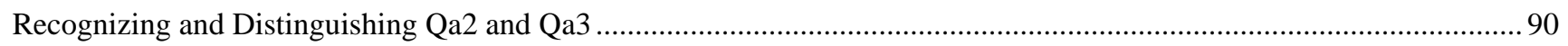

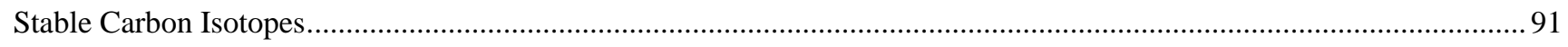

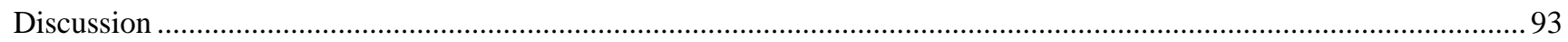

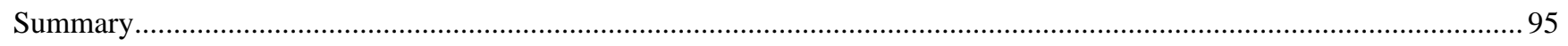

and Resource Structure on the Onion Creek Floodplain .............................................................................................. 97

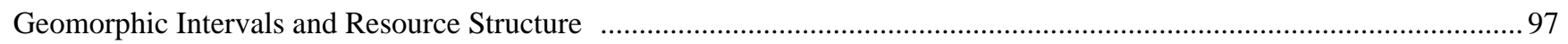

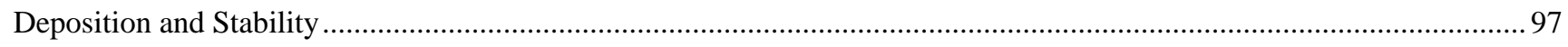

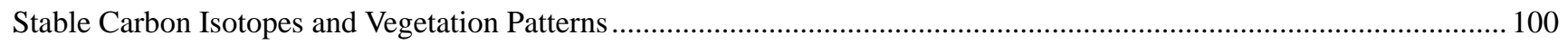




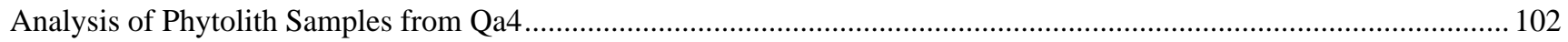

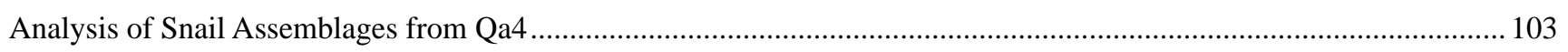

Analysis of Macrobotanical Samples Obtained from Deposits at 41TV540 and 41TV410 ............................................. 107

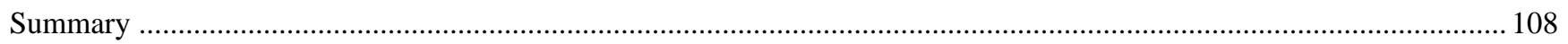

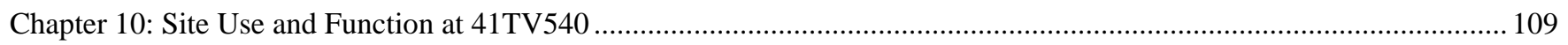

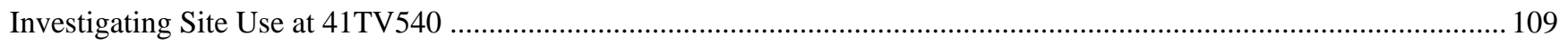



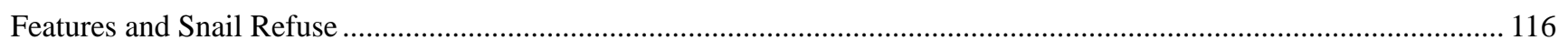

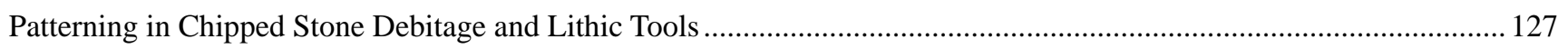

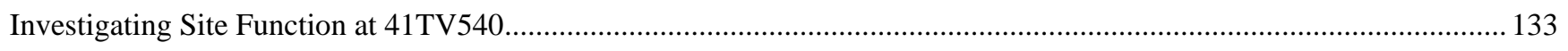

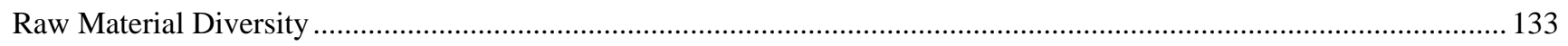

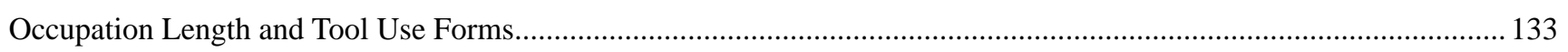

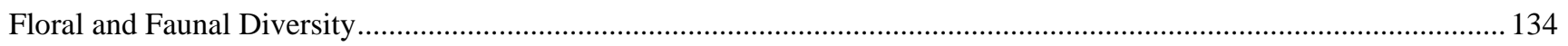

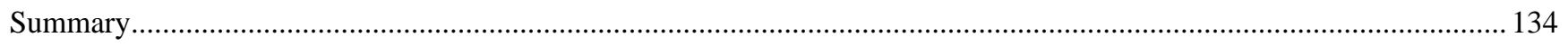

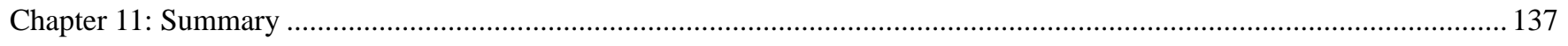

Notes to Text:

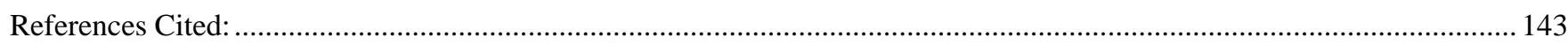

APPENDIX A: Plant Remains from 41TV410 and 41TV540

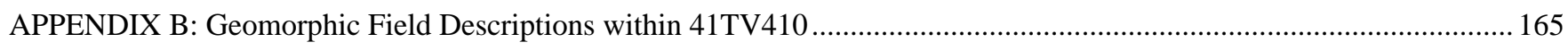

APPENDIX C: Geomorphic Field Descriptions within 41TV540 ............................................................................. 171

APPENDIX D: Geomorphic Field Descriptions and Data Table for Selected Profiles in the

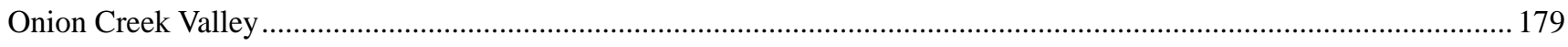

APPENDIX E: Stable Carbon Analysis, 41TV410 and 41TV540, Travis County, Texas .................................................... 205

APPENDIX F: Paleoenvironmental Reconstruction at 41TV410 (Area-3) based on Biosilicate,

Charred Phytolith, and Particulate Charcoal Analysis .................................................................................................... 209

APPENDIX G: The Paleoenvironmental History of the Onion Creek Site (41TV410, Area-3),

Travis County, Texas, based on Land Snails.............................................................................................................. 227

APPENDIX H: Modern Land Snails at McKinney Roughs Nature Park, Bastrop County, Texas........................................2237

APPENDIX I: Micro-snails from McKinney Roughs Nature Park, Bastrop County, Texas.................................................. 281

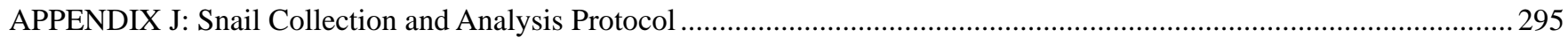

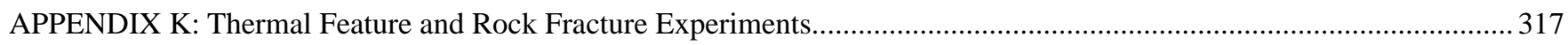

APPENDIX L: Amino Acid Racemization Results for Modern and Archeological Snails Associated

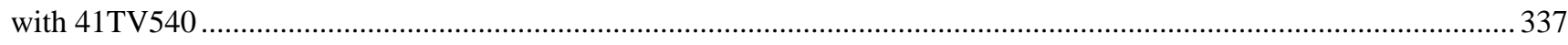

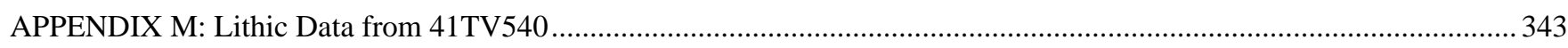

APPENDIX N: Faunal Material from 41TV540 ……............................................................................................... 357

APPENDIX O: TxDOT Comments on the UTSA Conclusions Regarding Dense Concentrations

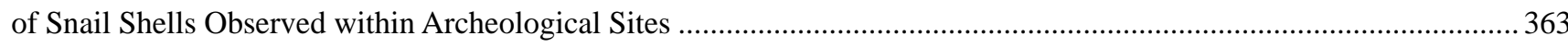




\section{List of Figures:}

Figure 2-1. Morphology of the landforms and relationship between the Colorado River and the

Lower Onion Creek.

Figure 2-2. Average maximum and minimum temperatures for Austin, Texas (1971-2000). ............................................ 6

Figure 2-3. Average monthly rainfall for Austin, Texas (1971-2000)........................................................................... 7

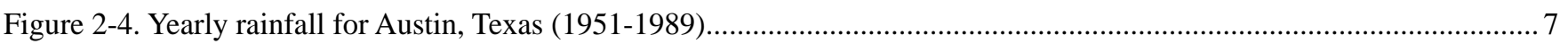

Figure 2-5. Yearly rainfall and discharge at Onion Creek (1925-1929; 1977-2003)...................................................... 8

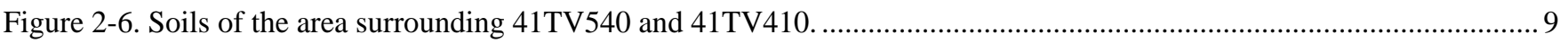

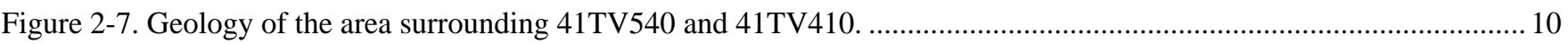

Figure 2-8. Stable carbon isotope variation in soils from Medina River and Hall's Cave. ................................................. 12

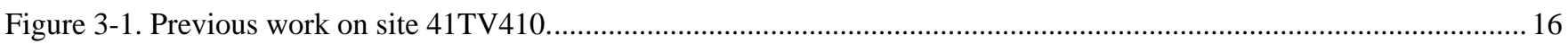

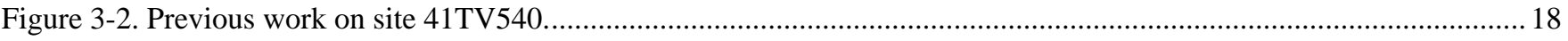

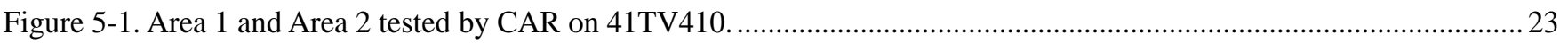

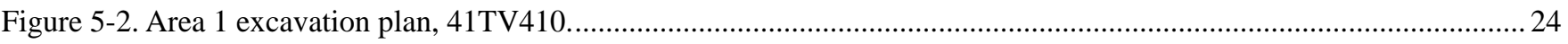

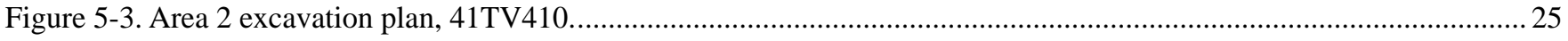

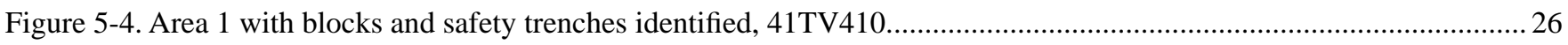

Figure 5-5. Area 2, Block 4 excavations with benches and safety trenches identified, 41TV410 .......................................27

Figure 5-6. Vertical distribution of debitage and burned rock in Block 3, Area 2......................................................... 28

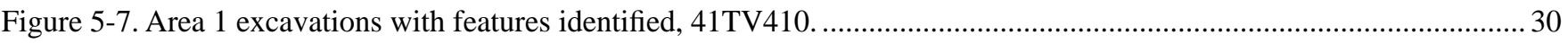

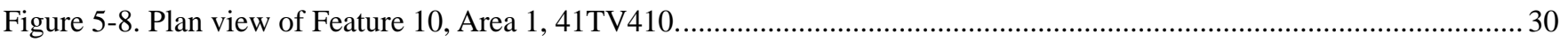

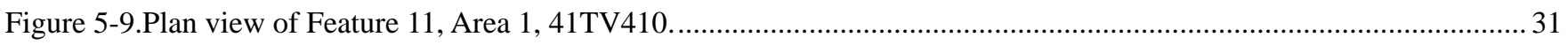

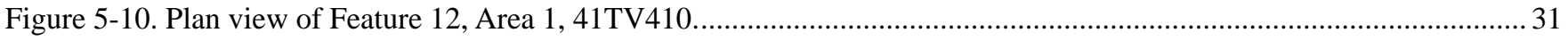

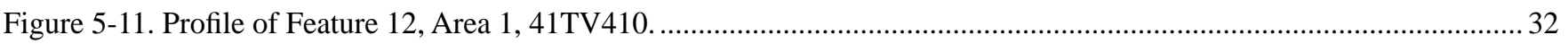

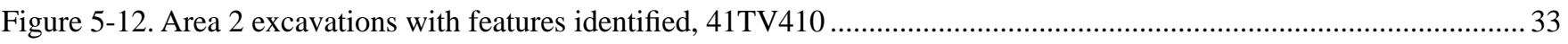

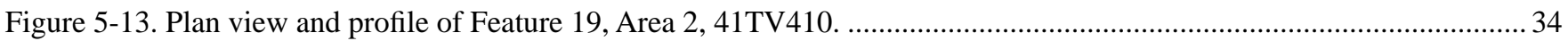

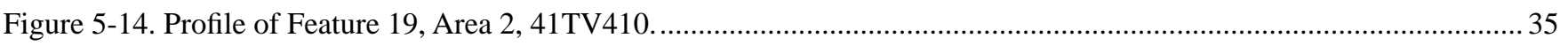

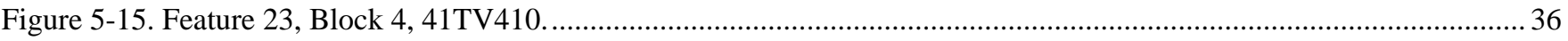

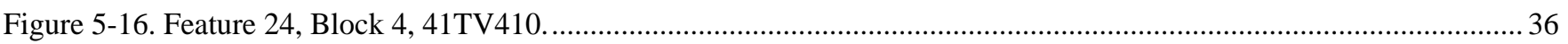

Figure 5-17. Drawing of the stratigraphy exposed within the deep trench on the first terrace and the deep trench on the second terrace (located in Area 2, immediately adjacent to Hicks \& Company

Trench 6, and in between Blocks 3 and 4) at 41TV410.

Figure 6-1. Schematic illustration of the deposits near 41TV540. The eastern valley slope is underlain by prominent shrink-swell clays of the Sprinkle Formation, and the adjacent hill is capped by an ancient Colorado River Terrace gravel Campbell et al. (2005:12) indentified as the Capital Terrace

Figure 6-2. Plan view of Phase II excavations showing the area of mechanical stripping, the location of hand excavations and the distribution of features.

Figure 6-3. Metate excavated with the trackhoe and refit at the CAR laboratory, 41TV540...........................................46

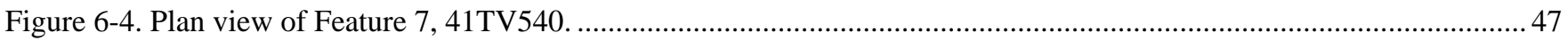

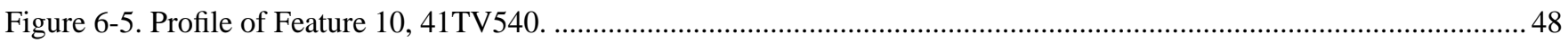

Figure 6-6. Feature 11 exposed in the west wall profile of southern safety bench, 41 TV540.............................................49 


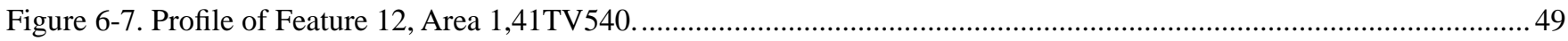

Figure 6-8. Feature 13, Block 3, 41TV540. Insert shows the estimated extent of the feature. ..............................................50

Figure 6-9. Feature 13, Block 3. Top: Photograph of 2-x-2 m unit at $15 \mathrm{cmdb}$. Note dominance of snail shell in eastern portion of block. Bottom: Plan view showing decreasing eastern margin with increasing depth. 51



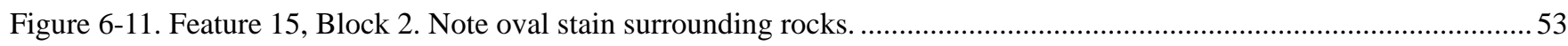

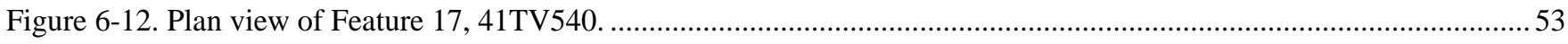

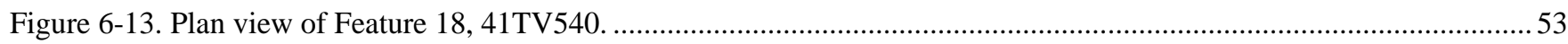

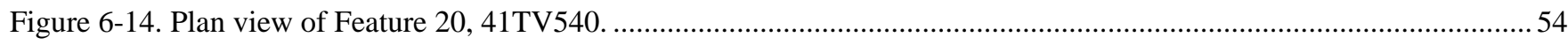

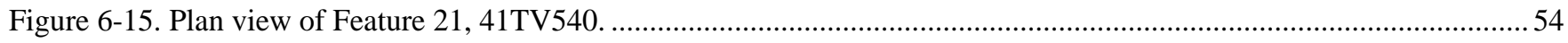

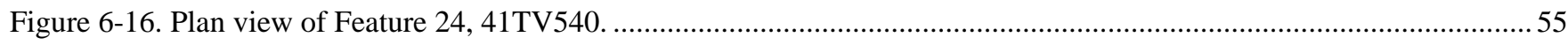

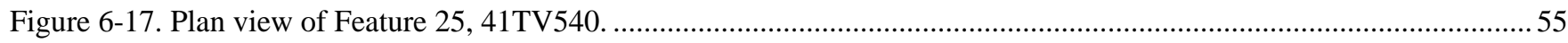

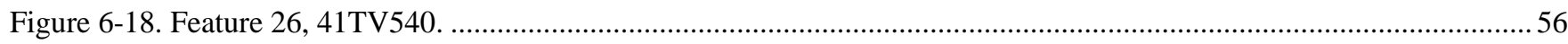

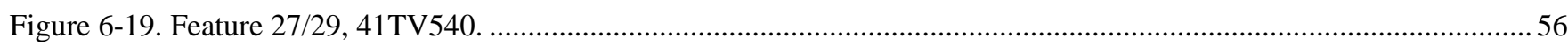

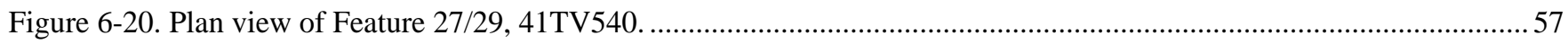

Figure 6-21. Drawing of the south wall of the deep trench in Area 2 excavated immediately north

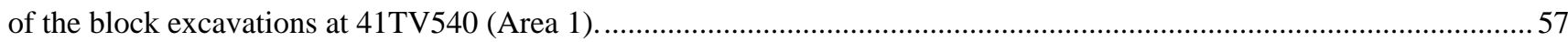

Figure 6-22. Drawing of the strata exposed on the eastern wall of Test Unit 1 at 41TV540.............................................58

Figure 6-23. Drawing of the strata exposed on the eastern wall of Test Unit 2 at 41 TV540. ..............................................59

Figure 6-24. Drawing of the strata exposed on the east wall of Test Unit 3, 41TV540......................................................... 60

Figure 6-25. Photo of the deep trench in Area 2 as it appeared during profile drawing in

December 2005.

Figure 6-26. Photo of one of the burn zones exposed in the south wall of Trench 2, 41TV540 ........................................... 61

Figure 8-1. Geology of the area examined in the Onion Creek Valley (Barnes 1981)............................................................ 70

Figure 8-2. Photomosiac and line drawing made from same of the eastern borrow pit wall near

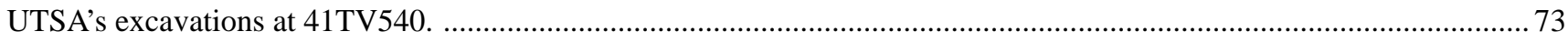

Figure 8-3. Plot of selected physical properties from Field Profile LH1, Depositional Unit Qa5b......................................... 74

Figure 8-4. Plot of selected physical properties from Field Profile LH2, Depositional Unit Qa5a........................................... 75

Figure 8-5. Plot of selected physical properties from Field Profile P1, Depositional Unit Qa3.............................................. 76

Figure 8-6. Plot of selected physical properties from Field Profile P5, Depositional Unit Qa3.............................................. 77

Figure 8-7. Plot of selected physical properties from Field Profile L1 (41TV2125), Depositional

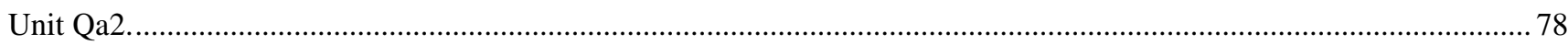

Figure 8-8. Plot of selected physical properties from Field Profile LP1, Depositional Unit Qa1.......................................... 79

Figure 8-9. Geomorphological map of the Lower Onion Creek valley depicting the approximate

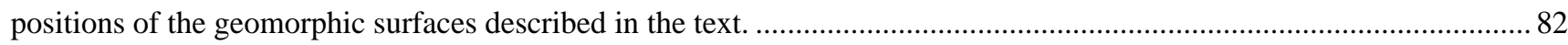

Figure 8-10. Schematic illustration showing the stratigraphic relationships observed in the lower

Onion Creek valley and selected radiocarbon ages.

Figure 8-11. Photo micrographs of selected calcium carbonate features from depositional Unit Qa1,

Qa2 and Qa3.

Figure 8-12. Top panel: Plot of the column average citrate-bicarbonate-dithionite extractable iron

obtained from each profile analyzed in this study. Middle panel: Plot of the column average

oxalate extractable iron obtained from each profile analyzed in this study. Bottom panel: Plot of

the ratio of $\mathrm{Fe}_{\mathrm{ox}} / \mathrm{Fe}_{\mathrm{d}}$ for each alluvial fill. 
Figure 8-13. Plot of the maximum and average topsoil magnetic susceptibility for each depositional unit except Qa1, for which a topsoil was not available.

Figure 8-14. Plot of the results of stable carbon isotopic variation obtained from the bulk sediment/soil samples collected from the alluvial fills within the Lower Onion Creek Valley.

Figure 9-1. Schematic drawing of Area 3 trench near 41TV410. Depositional Unit Qa4 shown in light brown.

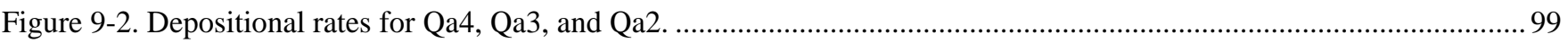

Figure 9-3. Stable carbon isotope results for dated sections of Qa2 through Qa4....................................................... 101

Figure 9-4. Changes in the percentage of $\mathrm{C}_{4}$ phytoliths within the Qa4 profile.

Figure 9-5. Scatter plot of the percentage of $\mathrm{C}_{4}$ phytoliths and stable carbon isotope values within the Qa4 deposit.

Figure 9-6. Shifts in the density of xeric and mesic snail groups in the Qa4 deposit. Levels with buried soils identified by blue lines.

Figure 9-7. Scatter plot of the density of grassland favoring snails against those favoring forest and riparian settings within the Qa4 deposit

Figure 10-1. Mean rock size and hearth temperature for repeated burning events (1-6) of the same weight of Onion Creek Limestone.

Figure 10-2. Changes in Onion Creek Limestone and Quartzite size with repeated feature use

(see Appendix K).

Figure 10-3. Size distribution of burned and fractured rock recovered from Feature 11 at 41TV410 (top). Unburned Onion Creek Limestone and Quartzite (bottom) shown for contrast

Figure 10-4. Size distribution of burned and fractured rock recovered from Feature 19 at 41TV410 (top). Unburned Onion Creek Limestone and Quartzite (bottom) shown for contrast....

Figure 10-5. Burned rock raw material size by raw material type for probable Early Archaic features at 41 TV5 50.

Figure 10-6. Size distribution of burned and fractured rock recovered from all Limestone and

Quartzite Feature Rock at 41TV540 (top). Unburned Onion Creek Limestone and Quartzite (bottom) shown for contrast.

Figure 10-7. The remains of two small Onion Creek chert cobbles following a single heating event in an open fire.

Figure 10-8. The percentage of Rabdotus shells recovered in the $1 / 2$ inch screen size by context. 122

Figure 10-9. D/L ratios of aspartic and glutamic acids in modern snail (Rabdotus) heated at $125^{\circ} \mathrm{C}$ for 0 to 240 hours.

Figure 10-10. D/L ratios of glutamic and aspartic acid in Rabdotus snail boiled for 10 to 30 minutes................................125

Figure 10-11. D/L ratios for archeological and modern samples by selected features at 41TV540..................................126

Figure 10-12. Examples of raw material color groups defined at 41 TV540. ................................................................. 128

Figure 10-13. Maximum 41TV540 debitage size for flakes classified as reflecting bifacial and core reduction. 130

Figure 10-14. Size attributes by color group (CG). Data are in Table 10-4. 


\section{List of Tables:}

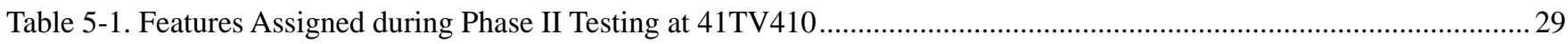

Table 6-1. Distribution of Artifacts and Organic Material by Depth and Block................................................................... 45

Table 6-2. Feature Location, Depth, and Probable Temporal Assignment ...................................................................47

Table 8-1. Comparison of Matched Pairs of Radiocarbon Ages from Hearth Charcoal and Bulk Sediment . .80

Table 8-2. Comparison of Matched Pairs of Radiocarbon Ages from Hearth Charcoal and Rabdotus Shells 81

Table 8-3. Comparison of Matched Pairs of Radiocarbon Ages from Bulk Sediment and

Rabdotus Shells . .81

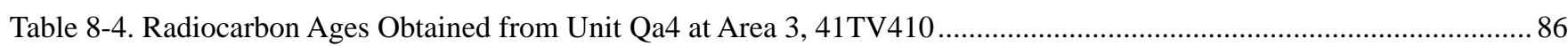

Table 8-5. Variation in Iron and Topsoil Magnetic Susceptibility by Alluvial Fill.................................................................. 91

Table 9-1. Surface Expected and Actual Distributions of Macro-snails at McKinney Roughs.............................................. 107

Table 9-2. Comparison of Expected and Actual Distributions of Micro-snails at McKinney Roughs.................................... 107

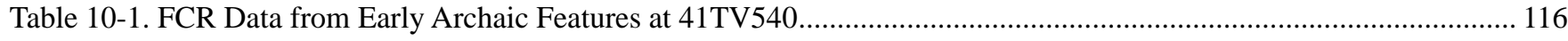

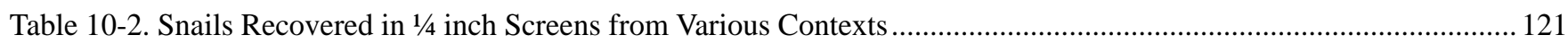

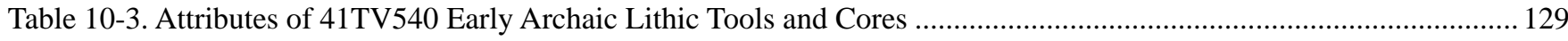

Table 10-4. Debitage Attributes by Revised (new) Color Groupings .......................................................................... 131 



\section{Acknowledgements:}

Constructing acknowledgements for projects that were in the field over five years ago is problematic. I am sure to forget folks. So, I will apologize in advance. First off, I need to acknowledge the Center for Archaeological Research (CAR) field and lab crews who worked on this project over the years in various capacities. This group includes Eric Ball, Wilbur Barrick, William Battles, Christopher Crozier, Cyndi Dickey, Nathaniel DiVito, Jon Dowling, Larissa Galenes, Karl Huebchen, Leonard Kemp, Michael Kirby, Lindy Martinez, Bruce Moses, Jason Perez, Bryant Saner, Shirley Shirley, Charles Smith, Charles Speer, Cathy Stacy, Gregory Staples, Penan Stewart, Daniel Teague, Joey Thompson, Jeffery Williams, and Richard Young. Antonia Figueroa and Cynthia Munoz served as crew chiefs on the field work at 41TV540 and 41TV410, and Jennifer Thompson was the project archeologist on 41TV540. Thanks for all your efforts.

Antonia Figueroa served as project archeologist for much of the analysis and write-up stages of this project. When other duties pulled her away, I was directed to take over and complete the write-up. Marybeth Tomka oversaw the laboratory work throughout the project, with the help of Cyndi Dickey. Dr. Charles Frederick served as project geoarcheologist and, along with CAR director Dr. Steve Tomka, wrote much of the research design that guided the analysis. Charles provided geomorphic descriptions of both sites, and his synthesis of the geomorphology of Onion Creek in Chapter 8 is a significant contribution to both archeological and geological investigations in that region of Texas. It is fun to work with Charles, and I always seem to learn something from our encounters. Thanks for your help.

Bruce Moses and Rick Young of CAR helped with graphics, and Dr. Steve Tomka provided helpful comments on an initial draft. Steve also was the driving force behind the research directions on the project. He, along with Jason Perez and Antonia Figueroa, conducted the chipped stone analysis, and he was instrumental in designing much of the snail research as well as the experiential work on burned rock features. Barbara Meissner of CAR, assisted by Antonia Figueroa, undertook much of the macro-snail identification. Barbara also conducted all of the vertebrate faunal analysis of the 41TV540 material. Cynthia Munoz, Bruce Moses, and Rick Young helped with final editing and report production.

A number of current and former TxDOT folks facilitated the work. Thanks initially to Dr. G. Lain Ellis who helped design much of the fieldwork and facilitated all aspects of the field and initial lab work. Jon Budd has skillfully managed the project, and has helped both with comments on specific tasks, as well as with administrative issues. He provided comments on the first draft of this document, and authored Appendix O, which encapsulates TxDOT's position regarding snail accumulations at 41TV540. Dr. James Abbott has, as always, provided insightful comments on various tasks and the draft report. Much like working with Dr. Frederick, whenever I get a chance to work with Jim I seem to be just a little bit smarter by the end of the project than I was at the beginning.

Several other organizations and individuals have provided assistance. Lone Star Infrastructure provided extensive help in the field, both with equipment and personnel, as well as safety training. John Campbell and other folks at Hick and Company helped in multiple ways, providing draft reports, samples, and advice. It was a pleasure to work with them, and I hope that they find something of use here. The folks at McKinney Roughs Nature Park, especially Beth W. Banks, Supervisor, Natural Science Programs, and Nicholas Cowey, Natural Science Education Specialist, along with Andy Malof, helped facilitate access to the Nature Park. In addition, Dr. Ken Brown and Andy Malof provided detailed comments on the snail protocol in Appendix J. Ken, along with Jon Budd, came down to CAR to discuss TxDOT's concerns that my interpretation of snail deposits in Feature 13 at 41TV540 was both not adequate and misguided. I think that we continue to disagree on these points, but I do appreciate Ken's insights. Thanks also to John DeLaHunt of the Environmental Health, Safety \& Risk Management office at UTSA, as well as the UTSA Safety Office Fire Team, for facilitating the burned rock experiments.

Finally, thanks to all of the outside consultants and contributors who participated on the project. These include Richard Anderson, Steven Bozarth, J. Phil Dering, Darrell Kaufman, Manuel Palacios-Fest, Terri Woodburn, and Jon Budd.

\section{Dr. Raymond Mauldin}

Center for Archaeological Research, UTSA

June, 2011 



\title{
Chapter 1: Project Overview
}

\author{
Antonia Figueroa and Raymond Mauldin
}

In 2005, Hicks and Company conducted a pedestrian survey of a portion of the Onion Creek floodplain that was to be impacted by the construction of State Highway (SH) 130 in southeast Austin. The survey revealed three archeological sites 41TV410, 41TV540, and 41TV2125. The three sites were located within a proposed borrow pit area of approximately 151 acres (Campbell et al. 2005). Their survey efforts recovered artifacts and thermal feature data from 20 to $540 \mathrm{~cm}$ below surface (cmbs). Radiocarbon dates from a deep feature in the northern portion of 41TV2125 produced dates that fell into the late Paleoindian period. No dates were returned from the other two sites at the time of their reporting, but subsequent to the survey report, radiocarbon dates were returned from both 41TV540 and 41TV410. Four samples from 41TV540 returned calibrated, corrected dates that ranged from BP 6290 to 5950 for depths of between 381 and $479 \mathrm{~cm}$ below datum (cmbd). The radiocarbon dating confirmed an Early Archaic deposit at the site. A single sample from Feature 9, excavated by Hicks and Company at 41TV410, produced a calibrated date of BP 5570 to 5540 . Given the age of the deposits, their apparent intact nature, and the potential contribution of the archeological components to regional research, TxDOT-ENV sought to discover more about the sites. It was hoped that the three sites could provide a record of adaptation that reflects much of the Archaic and late Paleoindian periods, time frames that are poorly understood in Central Texas.

Subsequently, the Center for Archaeological Research (CAR) at The University of Texas at San Antonio was contracted by the Texas Department of Transportation (TxDOT) to conduct significance testing of sites 41TV540 and 41TV410 (WA \#575 07 SA005). CAR's testing of 41TV540 began November 14, 2005 and concluded December 15, 2005 under the direction of Dr. Raymond Mauldin who served as the Principal Investigator and Jennifer Thompson who served as the Project Archeologist. Testing of 41TV410 began in the field on December 1, 2005 and concluded January 12, 2006. Dr. Mauldin served as Project Archeologist on 41TV410 and Dr. Steve Tomka served as the Principal Investigator. The work was conducted in advance of a borrow pit excavation related to the SH 130 construction. The borrow pit represented a project specific location (PSL). PSLs are normally not part of the project per Federal Highway Administration policy. PSLs are the responsibility of the contractor in most cases. However, the testing reported here was mandated by language of the $\mathrm{SH}$ 130 comprehensive development agreement associated with the SH 130 construction. The archeological work at these two sites was not under the purview of either Section 106 or the Antiquities Code of Texas. The work was not associated with an Antiquities Permit. However, testing at both sites was conducted in accordance with the Secretary of the Interior's Standards and Guidelines for Archeology and Historic Preservation and guidelines provided by the Texas Historical Commission (THC). In addition, TxDOT coordinated with the THC regarding most aspects of the project.

\section{Project Activities and Results}

Construction priorities associated with the building of $\mathrm{SH}$ 130 dictated an extremely short period during which field investigations had to be completed. The testing on 41TV540 and 41 TV410 conducted by CAR sought to 1 ) determine the integrity of the two sites, 2) collect data that would allow for an assessment of their significance, 3) provide TxDOT with recommendations for further data recovery excavations, if warranted, and 4) design the investigation such that additional excavations could begin immediately following completion of testing field work. Given the short time frame, the plan developed for the excavations by CAR relied heavily on the preliminary results, including backhoe trench data, that Hicks and Company had gathered from their survey work at 41TV410 and 41TV540 (Campbell et al. 2005).

Results from the Hicks and Company trenching suggested that at least four concentrations of material were present at various locations within 41TV410. A low-density upper deposit, between roughly 40 to 120/140 cmbs, was underlain by a second deposit consisting of slightly higher densities of materials between 120/140 and 240/260 cmbs. The third and fourth concentrations of materials were present between 260-340 and 340-420 cmbs. It appeared that the lower two concentrations were Early or Middle Archaic in age, while the upper deposit was suggested to date to the Late Archaic. The Middle Archaic radiocarbon dates from Feature 9 (5570 to $5540 \mathrm{BP}$ ), associated with the third concentration of material at 41TV410, supported that temporal assignment. At 41TV540, results from the backhoe trenching conducted by Hicks and Company suggested that three zones of artifacts were present. They consisted of an upper deposit between 20 and $80 \mathrm{cmbs}$, a deposit between 380 and $420 \mathrm{cmbs}$, and a lower deposit between 460 and $540 \mathrm{cmbs}$. The deepest deposits at 41TV540 were thought to date to the late Paleoindian/Early Archaic boundary. Subsequent radiocarbon dates from 381 and 479 cmbd confirmed a terminal Early Archaic or early Middle Archaic (6290 to 5950 BP) temporal placement for some of this material. 
Given the anticipated ages of the deposits at the two sites, and in consultation with archeologists from the Environmental Affairs Division at TxDOT, CAR's testing strategy targeted the uppermost and the deepest deposits at 41TV410, and the deeper deposits at 41TV540. The strategy was designed to sample material from the late Paleoindian and Early Archaic through the Late Archaic. The strategy at 41TV540 was, in consultation with TxDOT archeologists, altered in the field to focus primarily on the Early Archaic. The work at 41TV540 and 41TV410, in conjunction with other work conducted by Hicks and Company on what was thought to be a late Paleoindian occupation at 41TV2125 (see Campbell et al. 2009), was designed to provide a diachronic perspective on the use of this section of Onion Creek.

\section{Field Work at 41TV410}

CAR's archeological work focused on two locations at 41TV410, designated Areas 1 and 2. Hicks and Company previously excavated backhoe trenches in both locations (Campbell et al. 2005). A third area (Area 3), located just to the southeast of 41TV410, was sampled for geomorphic and paleoenvironmental information using a trackhoe to expose a $7 \mathrm{~m}$ vertical face.

The archeological deposits targeted for investigation were covered by a thick layer of overburden. Given time constraints, and the extreme depth of the deposits, portions of both Areas 1 and 2 were stripped using heavy machinery before the start of hand excavations. CAR staff monitored this stripping. We hand-excavated two 2-x-2 m blocks starting at roughly $50 \mathrm{cmbs}$ down to depths of about 190 cmbs in Area 1. Area 2 was also sampled by the excavation of two 2-x-2 m blocks. In Block 1 of Area 1, roughly 49m² was stripped before the start of hand excavation. About $70 \mathrm{~m}^{2}$ was stripped around Block 2 in Area 1. Both for ease of excavation, as well as safety considerations, two trenches, each roughly $120 \mathrm{~cm}$ in width and five meters in length, were cut adjacent to the blocks. These trenches were machine excavated to roughly $130 \mathrm{~cm}$ below the surface. For the much deeper excavations in Area 2, it was necessary to mechanically strip a large area centered on a previously excavated Hicks and Company trench. About $560 \mathrm{~m}^{2}$ were removed with a trackhoe to various depths below surface in Area 2 prior to the start of hand excavation. Benches and ramps were placed for both ease of access and to accommodate safety concerns. Hand excavation in Block 3 of Area 2 began at about $180 \mathrm{cmbs}$ and terminated at 430 cmbs. In Block 4 of Area 2 hand excavation began at about $200 \mathrm{cmbs}$ and terminated at $450 \mathrm{cmbs}$. Overall, CAR hand excavated $33.02 \mathrm{~m}^{3}$ of sediment at $41 \mathrm{TV} 410$, with $1.31 \mathrm{~m}^{3}$ removed to explore features discovered during mechanical stripping of the two excavation areas.

\section{Field Work at 41 TV540}

To sample the deeply buried deposit at 41TV540, CAR initially proposed to mechanically strip an area spanning $25-\mathrm{x}-75 \mathrm{~m}$ to a depth of 3.0 to $3.5 \mathrm{mbs}$, and place three $2-x-2 m$ hand excavated blocks evenly across the bottom of the trench. The massive trench was placed in the northern portion of the site to entirely encompass BHT 10 excavated by Hicks and Company (see Campbell et al. 2005). CAR staff monitored the trackhoe-stripping of the upper sediments for features. In the northern half of the graded trench, an area measuring approximately $15-\mathrm{x}-40 \mathrm{~m}$ was stripped down to between 3.0 and 3.5 mbs. Because several features were uncovered above the $3.5 \mathrm{~m}$ target depth in the southern portion of the trench, the mechanical stripping ceased about $1.3 \mathrm{~m}$ higher than proposed to preserve these deposits for examination. This altered placement of the blocks, which were initially designed to target the older deposits. Block 1 was located on the northern edge of the trench. Block 2 was placed near the old Hicks and Company trench (BHT 10, see Campbell et al. 2005). Block 3 was moved north from its original planned location and placed over a large shell and burned rock feature (Feature 13), $5.0 \mathrm{~m}$ southeast of Block 2. Opening elevations in Block 3 began $20 \mathrm{~cm}$ higher than the proposed beginning depth to capture snail shell and burned rock deposits designated Feature 13. In addition, with TxDOT concurrence, a single 1-x-1 m unit was dug to provide context for the features within the same elevation range, and to overlap the deposit that was sampled in the first level of Block 3.

In all, CAR staff hand-excavated three 2-x-2 $\mathrm{m}$ units from 350 to $550 \mathrm{cmbs}$, a volume of $24.0 \mathrm{~m}^{3}$. An additional $2.35 \mathrm{~m}^{3}$ were removed for feature exploration and characterization including the $1-\mathrm{x}-1 \mathrm{~m}$ unit mentioned above. All excavations were done in $10 \mathrm{~cm}$ levels. In addition to the archeological excavations associated with the blocks, a large trackhoe trench was cut just off the northeastern boundary of the site to provide geomorphological data. This trench terminated at between 6 and $7 \mathrm{~m}$ below the surface.

\section{Project Results and Post-Field Activities}

Because of the construction schedule, laboratory cleaning, organization, and preliminary description of material recovered from both 41TV540 and 41TV410 was conducted concurrently with the fieldwork. Artifacts and sediment samples were transported from Travis County to the UTSACAR laboratory in San Antonio on a weekly basis for processing. Preliminary counts of materials, including initial scans of flotation samples from features, were supplied to the Project Archeologist weekly. 
CAR completed the archeological field work at 41TV410 in January of 2006. Eleven features were encountered during testing at this site, along with a single temporally diagnostic projectile point (Andice stem) found in Area 2. Radiocarbon assays obtained on features dated between Cal. BP 5990 and 2060, effectively documenting use in both the Early/Middle Archaic and the Late Archaic. Artifact recovery at the site was extremely low, especially in light of the feature count, but we did recover debitage, burned rock, vertebrate fauna, scattered charcoal, and a moderate quantity of snail shell.

Testing at 41TV540 was completed in December of 2005. Like 41TV410, the 41TV540 work uncovered few artifacts, but excavation did expose 17 features. Radiocarbon assays from several burned rock features returned dates between Cal. BP 6200 and 5940, confirming a terminal Early Archaic or initial Middle Archaic occupation of the site. Testing produced artifacts, including debitage, burned rock, and ground stone in low quantities, along with vertebrate faunal material, some mussel shell, scattered charcoal, and preliminary observations on flotation returns suggested good quantities of burned material.

Following the completion of the field work, CAR prepared post-field reports summarizing the work conducted at 41TV540 (Thompson 2006) and 41TV410 (Mauldin 2006). CAR argued that both sites contained intact deposits that could contribute to an understanding of the prehistoric cultural development of the Central Texas Region. As such, CAR recommended that both sites were eligible to the NRHP under criterion $d$. Given construction schedules, we recommended monitoring at both sites during the removal of sediments in order to document additional features. TxDOT agreed with CAR recommendations that 41TV540 was eligible for listing on the NRHP, though they did not concur with recommendations for further monitoring of the site. TxDOT concluded that site 41TV410 was not eligible for listing in the NRHP and that monitoring was not warranted. TxDOT did agree that results of the testing of $41 \mathrm{TV} 410$ be included in the research design addressing the analysis and reporting of the investigations.

While we provide a description of the work conducted at site 41TV410, most data types recovered from the site were not analyzed beyond the preliminary descriptions derived from the laboratory efforts conducted during the field work. This was in conformance with TxDOT's determination that 41TV410 was not eligible. The archeological focus of this report, then, is primarily centered on the Middle/ Early Archaic occupations documented at 41TV540, along with observations on larger scales concerns related to the geomorphology of the Lower Onion Creek Valley and reconstruction of the resource structure available to past hunters and gatherers.

\section{Material Disposal and Curation Activities}

Since the archeological and geomorphological investigations reported here, the construction of SH 130 has been completed and deposits containing the sites discussed have been removed. A draft of the report was completed in June of 2010. All artifacts, notes, photos, and other material associated with the project are currently stored at CAR. At this time, no decisions regarding curation location, curation preparation, or artifact disposal have been made. However, we anticipate that the material will be permanently housed at CAR.

\section{Report Organization}

This report consists of 11 chapters and 15 appendices. Following this project overview, Chapter 2 provides a summary of the environmental setting. The third chapter summaries the cultural history, including a review of previous work in the general area and on sites 41TV410 and 41TV540. Chapter 4 provides a short summary of the research directions that guided the initial testing. The fifth and sixth chapters summarize CAR's field work at 41TV410 and 41TV540, respectively. Chapter 7 summarizes the research design that governed the analysis of the archeological material, primarily gathered from 41TV540, and geomorphological work conducted by Dr. Charles Frederick in the broader project setting. Chapter 8 presents the geomorphic results. The ninth chapter uses a variety of different data sets to try to reconstruct aspects of the resource structure on Onion Creek as conditioned by geomorphic processes. Chapter 10 focuses on research related exclusively to 41TV540, and the final chapter provides an overall summary of the project and report.

Fifteen appendices (A through O) support this report. These include general summaries of ethnobotanical results from both sites by Dering (Appendix A). Frederick provides geomorphic descriptions, analysis, and data from 41TV410 (Appendix B), 41TV540 (Appendix C), and the Lower Onion Creek Valley (Appendix D). There are a series of analytical summaries associated with various data sets that focus on a deep trench adjacent to 41TV410 that are related to environmental reconstruction. These include results from the analyses of stable carbon isotope (Appendix E), phytoliths $(F)$, and snails $(G)$. Modern snails collected from various locations at McKinney Roughs State Park are discussed in Appendix $\mathrm{H}$, while additional information on micro snails from those collections are presented by Palacios-Fest in Appendix I. Appendix J presents a general protocol for snail collection procedures and analysis in archeological contexts. A series of appendices ( $\mathrm{K}$ through $\mathrm{N}$ ) focuses on 41TV540 data. These include experimental data on rock features using Onion Creek materials (Appendix K), amino 
acid racemization results from modern boiling experiments and archeological samples (Appendix L), lithic tool and debitage data (Appendix M), and 41TV540 faunal data (Appendix N). Finally, Appendix O, authored by Jon Budd of
TxDOT, outlines TxDOT's position regarding land snail shell accumulations in light of the conclusions reached by CARUTSA that accumulations were likely to be natural rather than cultural, at least in most features at 41TV540. 


\section{Chapter 2: Environmental Setting}

\section{Raymond Mauldin, Charles Frederick, Antonia Figueroa, and Steve Tomka}

This chapter introduces the environment of the project area. Included are discussions of the setting, climate, hydrology, vegetation, faunal resources, geology, and soils present in the project area. Additional information, especially on the geomorphology of the area, is presented in Chapter 8. The second section of this chapter provides a short summary of aspects of the paleoenvironmental conditions during the period of occupation reflected at 41TV410 and 41TV540. Again, additional information on this topic can also be found in Chapters 8 and 9 of this report.

\section{Modern Setting}

The project area is located in what is now south Austin in Travis County on the Montopolis, Texas 7.5' topographic quadrangle map. Sites 41 TV410 and 41TV540 are on the right descending bank and floodplain of Onion Creek (Figure 2-1). The confluence of Onion Creek and the Colorado River is a flat expansive plain at an elevation of roughly $410 \mathrm{ft}$ amsl. 41TV410 is 4,334 $\mathrm{m}$ and 41TV540 is 5,045 m west of the confluence. Both sites are at an elevation of about 440

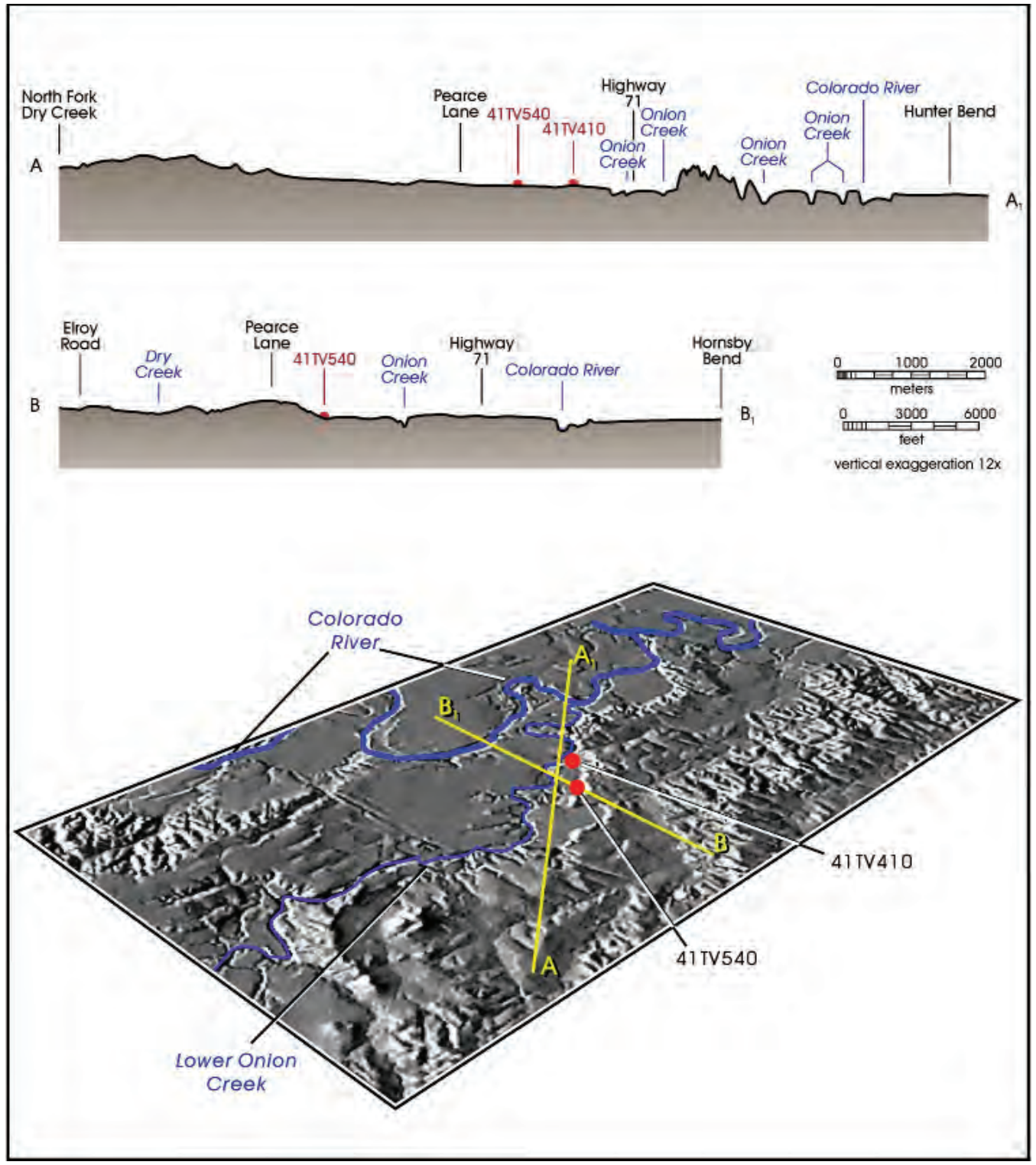

Figure 2-1. Morphology of the landforms and relationship between the Colorado River and the Lower Onion Creek. 
feet amsl. Site 41TV410 is roughly $120 \mathrm{~m}$ east of the modern Onion Creek channel while 41 TV540 is $695 \mathrm{~m}$ east of the modern channel at the toe slope of the uplands that bound the Onion Creek floodplain along its eastern margin. The channel of Onion Creek was closer to the two sites at the time of their occupation (see Chapter 9). Prior to the work described here, the area was used as pasture for cattle. In the early 1900s the area was forested (see Anderson 1904 cited in Campbell et al. 2009).

West of the confluence of the Colorado River and Onion Creek, the landform between the two streams consists of a broad and flat floodplain as shown in the Digital Elevation Model presented in Figure 2-1. The floodplain along the right descending bank of Onion Creek is also flat near the two sites and southwest of 41TV540. However, this lowlying area is bounded by a rapidly rising upland immediately east of 41TV540. The upland margin continues west of the confluence of the two streams and turns northeastward toward the Colorado River meeting it at Hornsby Bend. While the topography rises gradually from the confluence to the two sites along Onion Creek (see cross-section A-A' in Figure 2-1), the floodplain between Onion Creek and the Colorado River is relatively flat (see cross-section B-B' in Figure 2-1). Overall, the hook-shaped upland margin running from the confluence of the Colorado River and Onion Creek west-southwest along Onion Creek and then north-northeast back to Hornsby Bend of the Colorado River bounds a flat floodplain.

\section{Climate}

The climate in the area is classified as humid subtropical with hot summers and mild winters (Werchan et al. 1974:117). Figure 2-2 presents the average minimum and maximum temperatures for Austin between 1971 and 2000 (Southern Regional Climate Center [SRCC] 2003a, 2003b). During this period, July and August were the warmest months, with December and January being the coolest. The growing season at Austin averages around 274 days per year. An average of 21 days a year are at or below freezing, with 10 days at or above $100^{\circ} \mathrm{F}$. Using pre-1995 records, the coldest temperature ever recorded was a $-2^{\circ} \mathrm{F}$ in late January in 1949 , with the hottest being $109^{\circ} \mathrm{F}$ in July of 1994 (Bomar 1995:214-225).

Figure 2-3 shows that rainfall tends to be bimodal during a year, with peaks in May and October and minimums in January, February, and July (SRCC 2003c). Figure 2-4 presents the yearly rainfall totals for Austin between 1951 and 1989 (National Climate Data Center [NCDC] 2001). While the average annual precipitation over this period was 31.3 inches, the data are highly variable with an annual high of 51.3 inches recorded in 1957 and a low of about 10 inches three years earlier in 1954. Using pre-1995 records, the wettest day was on June $11^{\text {th }}$ of 1981 when 5.66 inches of rain fell on the city (Bomar 1995:227).

\section{Stream Flow Characteristics}

In order to characterize the frequency, seasonality, and severity of modern flooding in the project area, we used two different USGS gauging stations (see inset in Figure 2-5). The first is along the Colorado River, and is located roughly 9 $\mathrm{km}$ northwest of the project area (USGS 2007a). The second station is along Onion Creek, and is approximately $5.5 \mathrm{~km}$ west of the project area (USGS 2007b). Data sets used in this discussion include flow rates, expressed as cubic feet per second, water height, expressed in feet, and the timing of various events.

Note that both the Onion Creek and Colorado data sets have limitations with regard to providing information on past flood events. For the Colorado station, dam construction and other water control efforts began early in the last century (NOAA 2007; USGS 2007a). However, examination of peak yearly flow rates (USGS 2007a) suggests that prior to 1938, these efforts were not effective at controlling the rate of flow as evidenced by several devastating Austin floods in the early 1900s (Flood Safety Education Project 2007). The Colorado

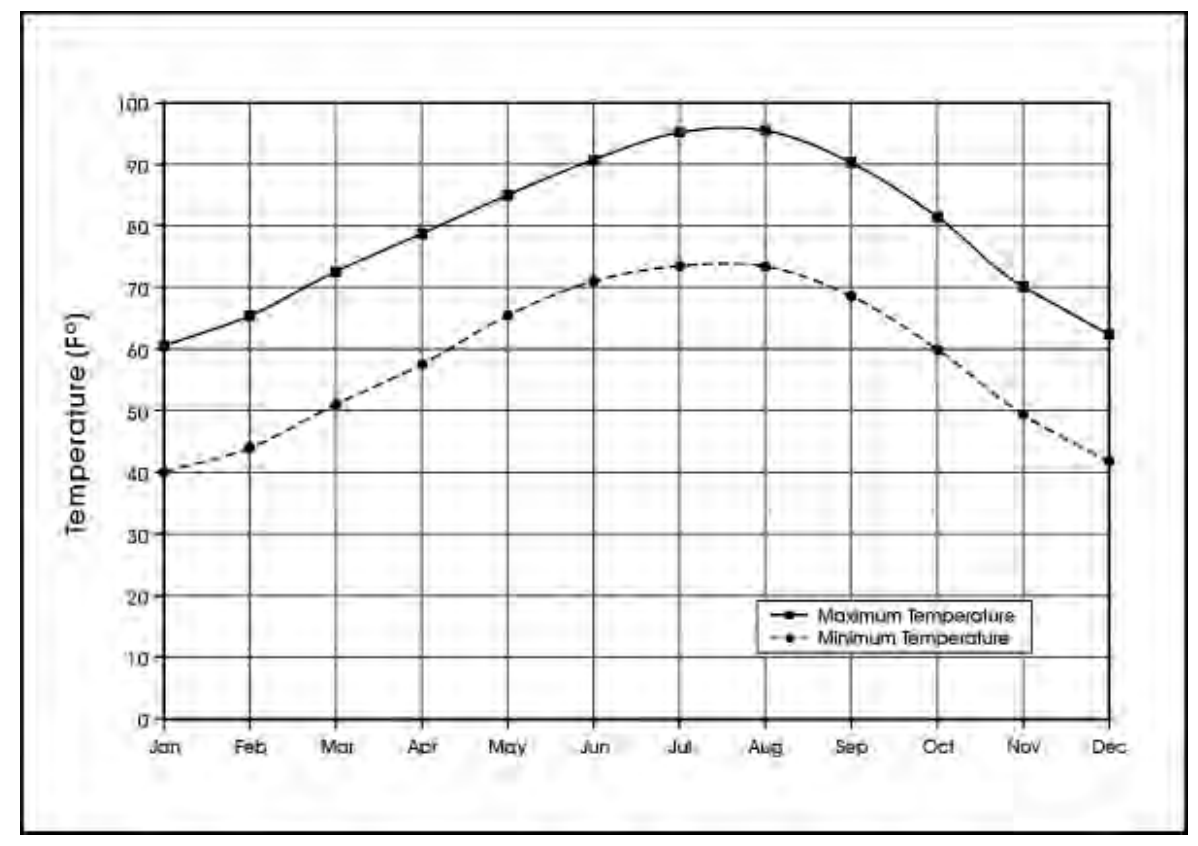

Figure 2-2. Average maximum and minimum temperatures for Austin, Texas (1971-2000). 


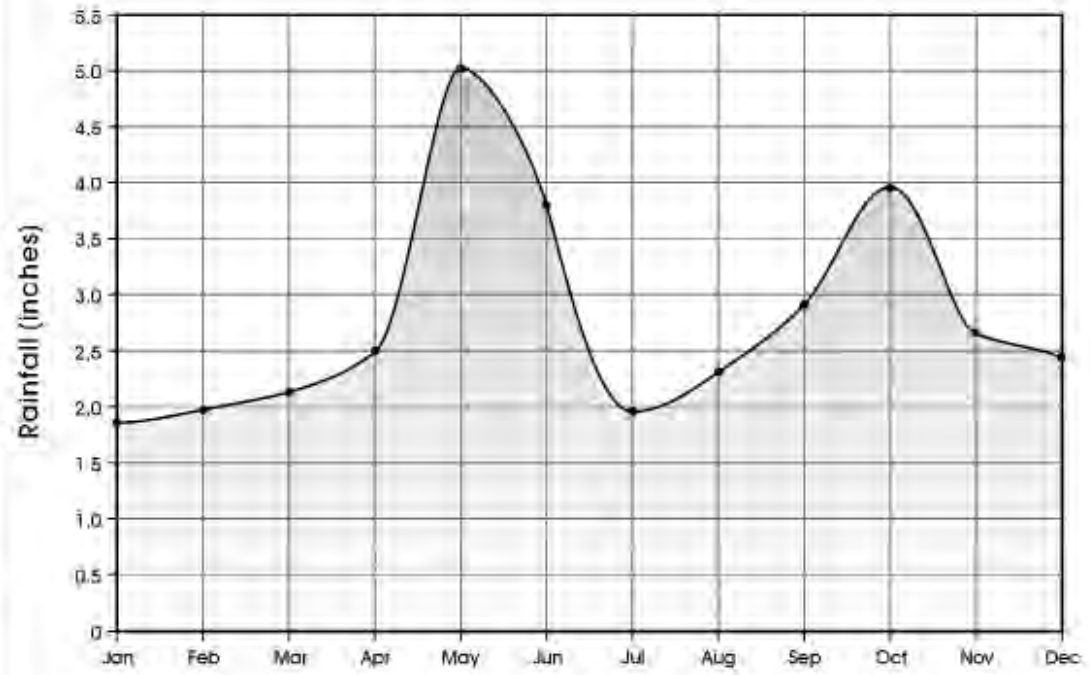

Figure 2-3. Average monthly rainfall for Austin, Texas (1971-2000).

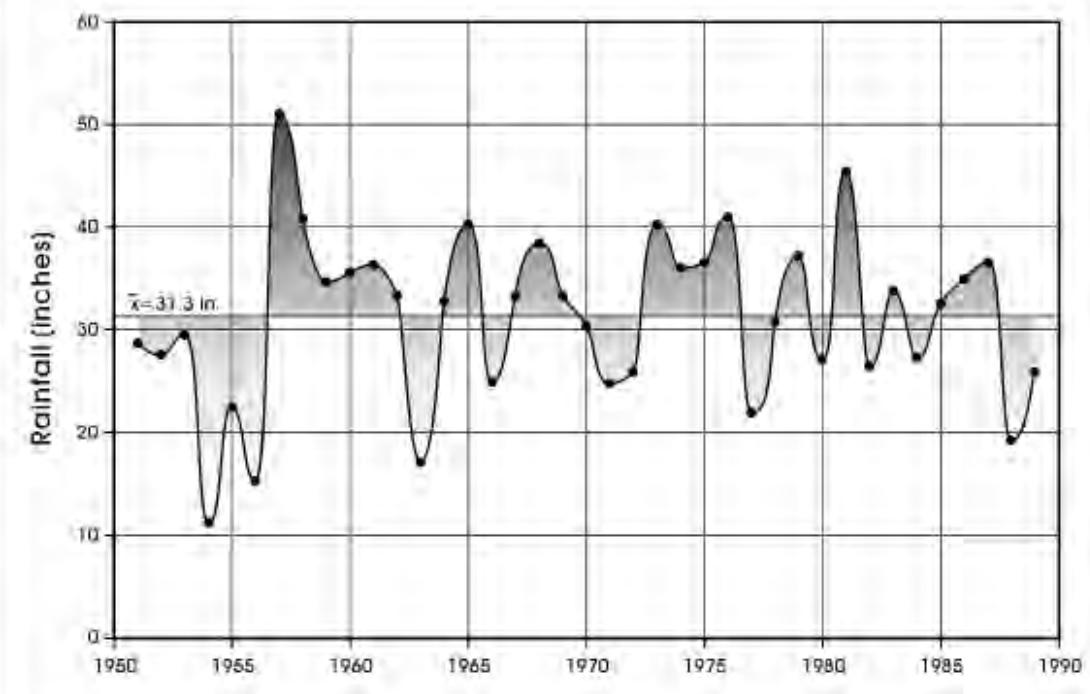

Figure 2-4. Yearly rainfall for Austin, Texas (1951-1989).

River Station, then, provides 40 years of data between 1898 and 1937 that minimizes both the impacts of flood control, as well as potential problems with increased runoff as a function of urbanization. In addition, the Colorado River has a large contributing water shed, estimated at roughly 27,606 square miles above the current gauge station (USGS 2007a). Local rainfall and associated runoff is only one component of water flow for the Colorado. Finally, note that only the timing of peak flow events is available for these initial 40 years. Unlike the Colorado River, patterns of water flow at Onion Creek are unlikely to have been significantly influenced by dam construction, though indirect efforts such as runoff control would certainly have reduced flow rates and water height. In addition, much of the Onion Creek data used here are recent, including water height data from 1998 through 2007 (USGS 2007b). Increased urbanization should have produced increased rates of runoff and associated water levels in this data set. The impacts of both flood control efforts and urbanization are not quantifiable and render any past reconstructions extrapolated from these two data sets tenuous. Nevertheless, the data sets do provide a general understanding of the timing, frequency, and magnitude of flooding in the project area.

Prior to 1938, the pattern of peak flow events for the Colorado suggests that flooding is likely to be bimodal at this location. While peak flows, the day with the highest flow rate during a year, do not necessarily correlate with flood events, if floods occurred during a year, then peak flow periods would represent floods. About $48 \%$ of all yearly peak flow events between 1898 and 1937 occurred during the months of April, May, and June, with no events recorded for March, $5 \%$ in July, and only 2.5\% occurring in August. A second mode is represented by the months of September $(15 \%)$ and October (12.5\%). No other month had peak flow frequencies exceeding $5 \%$ during this 40-year period (USGS 2007a).

The bimodal pattern of peak flow is consistent with that of rainfall in the region (see Figure 2-3). Figure 2-5 uses 32 years of average flow data from Onion Creek (USGS 2007b) and corresponding yearly rainfall totals at Austin (National Weather Service 2007) to further document the relationship between rainfall and water flow. Unlike the Colorado, the contributing watershed at Onion Creek is relatively small, consisting of 321 square miles above this gauge station (USGS 2007b). Figure 2-5 clearly shows that water flow and Austin rainfall are correlated in Onion Creek $(r=0.762)$. The Onion Creek data, in combination with the 


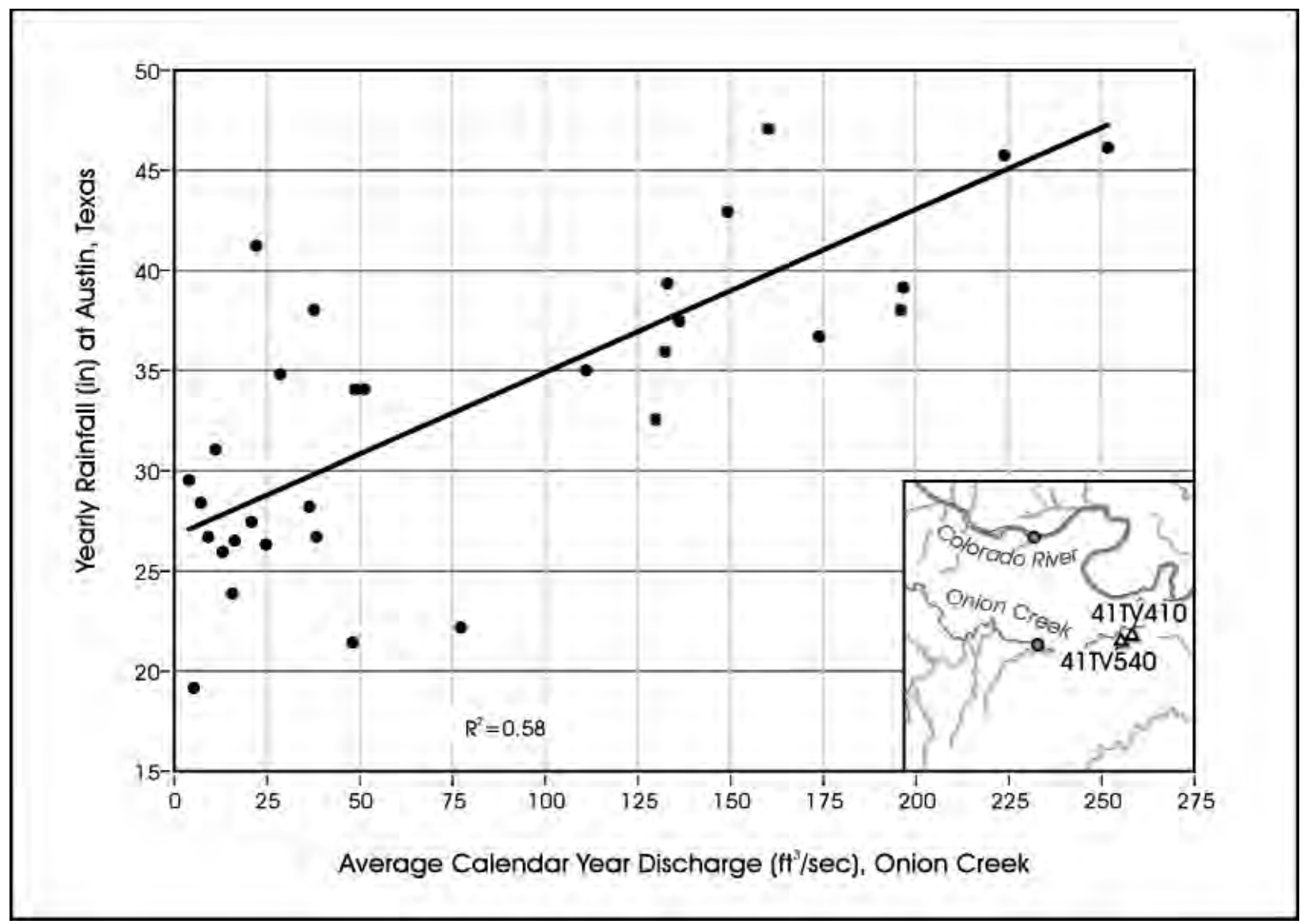

Figure 2-5. Yearly rainfall and discharge at Onion Creek (1925-1929; 1977-2003). Inset shows location of stations and project area.

Colorado peak flow data discussed previously, suggest that to the degree that the patterns of modern rainfall are applicable to the past, a similar bimodal peak flow can be anticipated for area rivers.

As noted above, annual peak-flow events do not necessarily reflect flood events. For the Colorado gauge station, we lack water height data on actual flood events prior to the late 1930s when more effective flood control measures were implemented. However, there are water gauge height data for Onion Creek that can be used to monitor the timing, frequency, and severity of recent flood events at this station. Flood stage at the Onion Creek station is at 17 feet (USGS 2007b). Water heights at or above 17 feet, then, will result in a flood event at this location. From February of 1998 to February of 2007, only on 20 of 3,507 days with data $(0.6 \%)$ was water height at or above 17 feet. Not surprisingly, these 20 days often clustered, with several consecutive days of high water recorded and representing a single flood event. During the 10 years represented by the Onion Creek data, there were 9 flood events. As with the data presented earlier, the pattern is bimodal. The pattern, however, does not match precisely that defined by peak flow data from the Colorado River. Three of the nine Onion Creek floods occurred in June and July, with four floods happening in October and November, periods slightly later than the Colorado pattern. June and July floods exceeded the banks at the Onion Creek station by an average of 4 feet, with October and November floods averaging 10.3 feet above flood stage (USGS 2007b). Though data on Colorado flood events is not available for the pre 1939 period, water levels in excess of 17 feet at the station location would result in flooding. Interestingly, water levels above 27 feet would result in the Colorado River backing up into Onion Creek, causing significant flooding throughout the low areas (NOAA 2007).

In summary, floods in the project area are probably bimodal, with a higher frequency in both the spring and fall. Generally, it appears that fall floods are more severe than those in the spring. A frequency of roughly 0.9 floods per year is present in the Onion Creek data. These patterns are primarily a function of the timing of rainfall as well as rainfall intensity. Under modern conditions, flooding of the Colorado River would inundate portions of the Lower Onion Creek valley immediately adjacent to the 
confluence. However, note that the severity of flooding may have been dramatically increased by hydraulic damming if both streams are flooded at the same time. We do not known how far up the Onion Creek channel such floodwaters would move, although reddish lenses of Colorado River-derived alluvial deposits found at a depth of approximately 3.5 meters below surface at $41 \mathrm{TV} 410$ suggest that at some point in time they probably backed up at least to this site.

\section{Floral and Faunal Resources}

Riskind and Diamond (1988) provide an overview of the current vegetation of the Edwards Plateau, including the Balcones Escarpment. Much of the area can be described as brush land. Dominant trees and shrubs found in the area include juniper (Juniperus ashei) and several species of oak (Quercus sp.), with cedar elm (Ulmus crassifolia), hackberry (Celtis sp.), and Arizona walnut (Juglans major) also present in many areas. The understory layer commonly includes yaupon (Ilex vomitoria), hoptree (Ptelea trifoliata), Mexican buckeye (Ungnadia sceciosa), and deciduous holly (Ilex deciduas). A variety of grasses are also present. A species list from the Balcones Canyonlands National Wildlife Refuge, an 80,000-acre refuge managed by the U.S. Fish and Wildlife Service (USFWS) and located about 40 miles to the northwest of the current project area, lists over 690 species and varieties of plants observed on the refuge (USFWS 2003).

Currently, the project area is in an urban setting. However, before development, it is likely that large numbers of white-tailed deer (Odocoileus virginianus) were present in the region. Historically and prehistorically, significant numbers of grazers such as bison and antelope were also present (see Davis and Schmidly 1994). The current vegetation communities support a variety of mammals, and Davis and Schmidly (1994) note that the Plateau has one of the highest mammalian diversities within the state. The species lists from the Balcones Canyonlands National Wildlife Refuge note 35 mammalian species in the confines of the preserve. Some of the more common species listed include black-tailed jackrabbit (Lepus californicus), raccoon (Procyon lotor), eastern cottontail (Sylvilagus floridanus), and a variety of carnivores (USFWS 2003).

\section{Soils and Geology}

Figure 2-6 shows the soils within the immediate area surrounding sites 41TV410 and 41TV540 (Werchan et al. 1974). Clays and silty clays dominate. Lewisville silty clays (LcA, LcB), Altoga silty clays (AgB), Trinity clay (Tv), Helden Clay (HeB), and Houston Black clay (HnB, HnC2) are all present in the floodplain setting. With the exception of the Helden and Houston Black soils, these are alluvial transported sediments associated with both Onion Creek and the Colorado River. The Ferris-Helden complex (FhF3) and Houston Black clay dominate the elevated landform to the south (Figure 2-6; see Werchan et al. 1974).

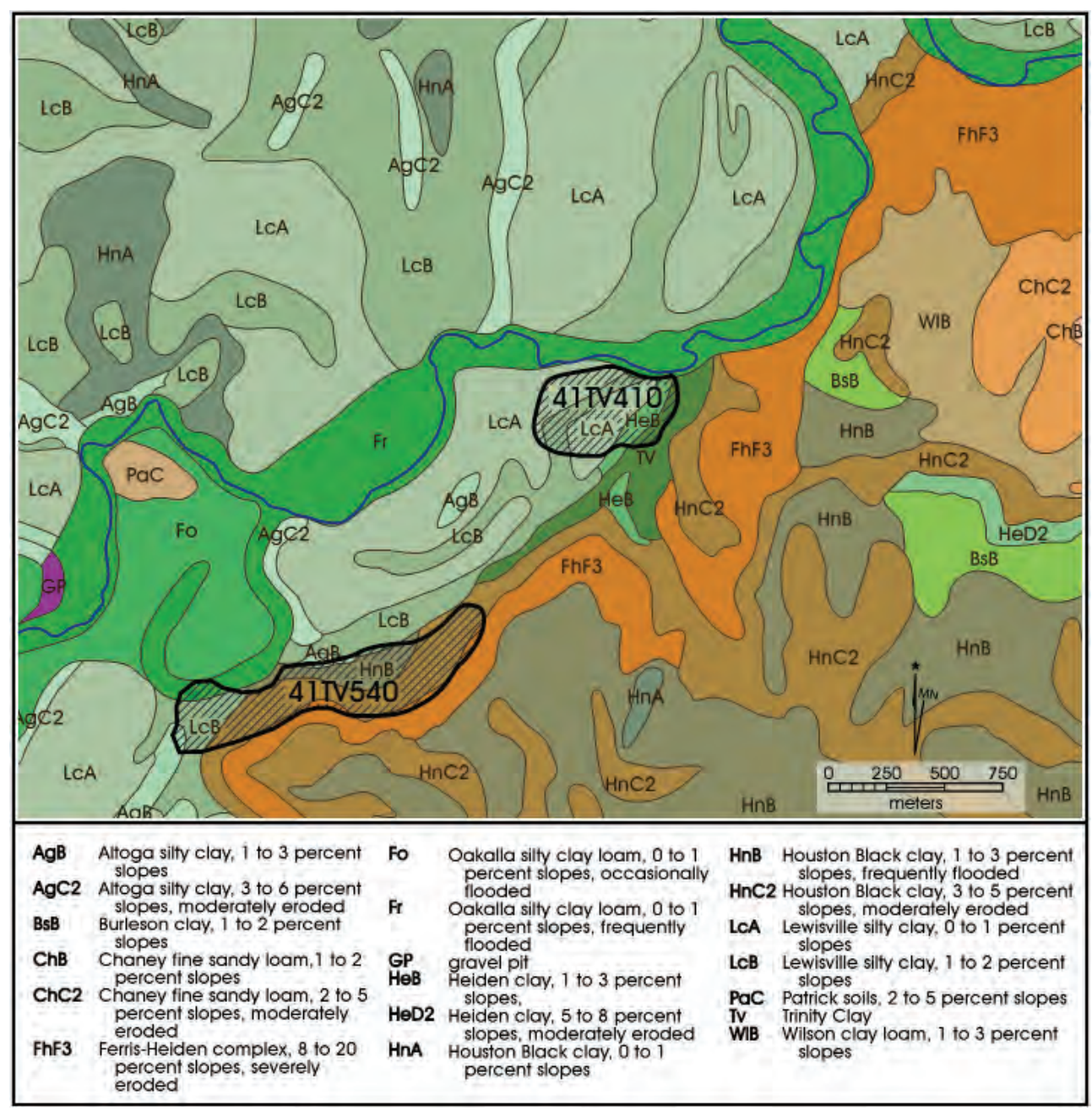

Figure 2-6. Soils of the area surrounding $41 T V 540$ and $41 T V 410$ (adapted from Werchan et al. 1974). 
Figure 2-7 shows the geological deposits in the general area as mapped by the Bureau of Economic Geology (Barnes 1981). The sites are located on Quaternary terrace (Qt) and alluvium (Qal) deposits, with Cretaceous age Navarro Group and Marlbrook Marl (Kknm) located to the south. In the immediate area are a number of other Quaternary and Cretaceous age deposits, including Pecan Gap Chalk (Kpg), Austin chalk (Kau), and deposits assigned to the Ozan Formation (Ko). Chert deposits are not common in any of these formations, though chert resources are available in the broader region.

\section{Paleoenvironmental Conditions}

Several researchers have, using different proxy measures of temperature and precipitation, concluded that major changes have occurred in temperature and precipitation during the last 12,000 years that directly impacted floral and faunal resources (see Bousman 1998; Camper 1991; Collins 2004; Cooke 2005; Johnson and Goode 1994; Toomey 1993; Toomey et al. 1993). What is not clear, however, is the exact nature of these temperature and precipitation changes. There is little consensus on when these changes began, their magnitude, or even the direction of change in some cases (see Ellis et al. 1995). In part, this lack of consensus is related to the use of a wide variety of proxy data types that are responding to different temporal and spatial scales. That is, shifts in rainfall and temperature that impact the frequency of occurrence of different shrew species (e.g., Toomey 1993) operate at radically different scales than climate shifts that change the relative frequencies of arboreal and grass pollen (e.g., Bousman 1998). In addition to these problems of scale, many of the commonly used data sets are plagued by temporal uncertainty regarding the placement of samples (e.g., +/- 250 years), a small number of data points in the sequence, and sequences that have significant gaps at critical periods.

Here we will rely on a single data type, variation in stable carbon isotopes in organic matter in soils, to provide some sense of vegetation and climate reconstruction. This is the same data type that we use to explore shifts in vegetation within the current project area in Chapters 8 and 9. The technique measures shifts in vegetation types associated with a given soil. Briefly, terrestrial plants rely on one of three photosynthetic pathways, termed $\mathrm{C}_{3}, \mathrm{C}_{4}$, and CAM, to fix carbon from atmospheric $\mathrm{CO}_{2}$. These different pathways produce distinct stable carbon isotopic signatures, in part as a function of different environmental conditions. The $\mathrm{C}_{3}$ pathway is the most common. Plants that thrive in cool, moist settings use this pathway. All trees, most shrubs, and all cool season grasses use $C_{3}$ (O’Leary 1988; Sharp 2007). The stable carbon isotope signatures of $\mathrm{C}_{3}$ plants range from around $-32 \%$ to $-22 \%$, with an average of around

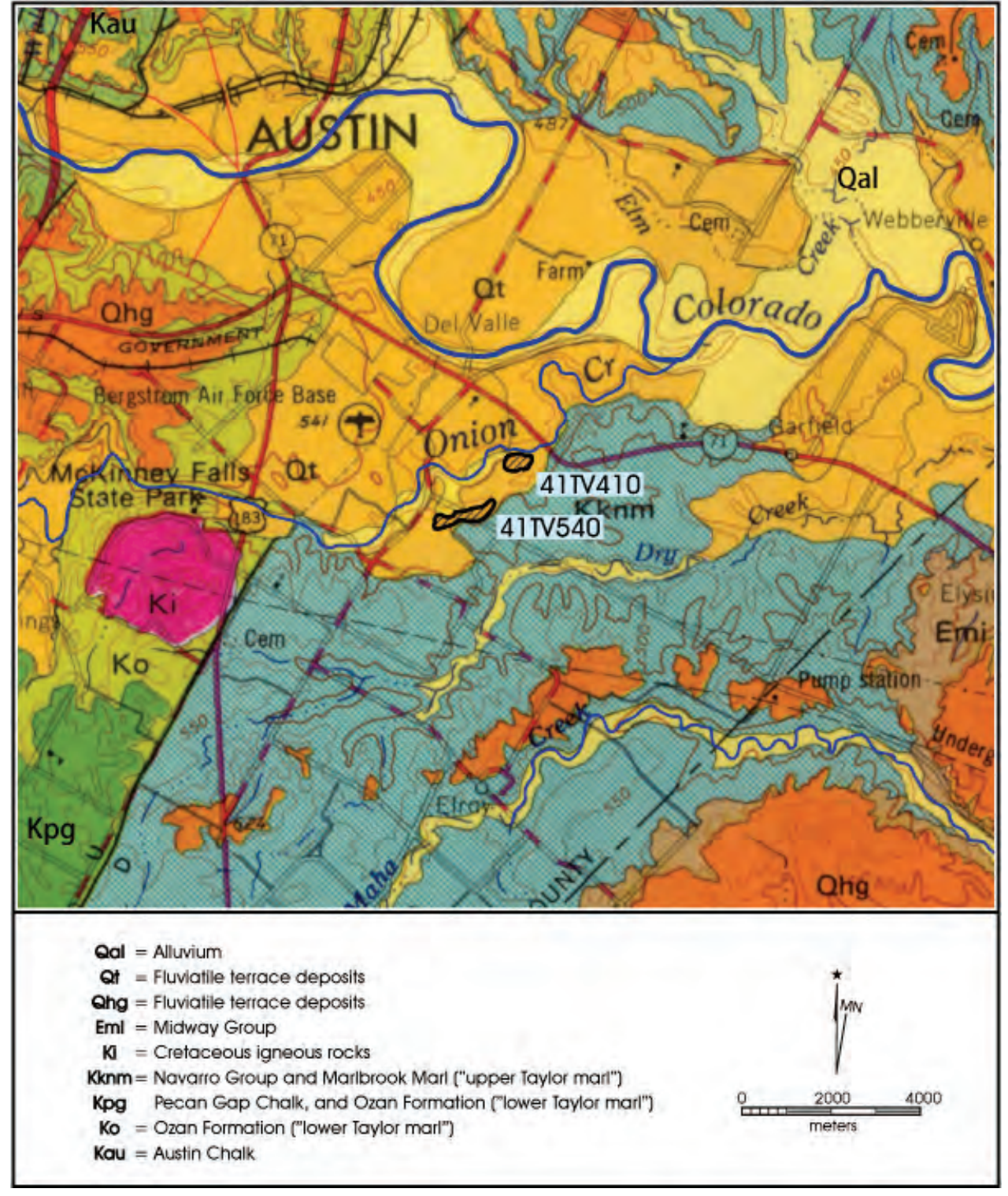

Figure 2-7. Geology of the area surrounding 41 TV540 and 41TV410 (adapted from Barnes 1981). 
-27\% (Deines 1980; O’Leary 1988). In contrast, warm season grasses, as well as a few dicotyledonous taxa (e.g., Amaranthus, Euporbia, Portulaca), use the $\mathrm{C}_{4}$ pathway (Ehleringer et al. 1997). The stable carbon isotopic values of $\mathrm{C}_{4}$ plants do not overlap with the $\mathrm{C}_{3}$ values. $\mathrm{C}_{4}$ plants have stable carbon isotopic signatures that range from -17 to $-9 \%$, with an average of around -13\% (Deines 1980; O'Leary 1988). The $\mathrm{C}_{4}$ pathway in grasses is favored by warmer temperatures (Ehleringer et al. 1997; Long 1999; Teeri and Stowe 1976), while $\mathrm{C}_{4}$ dicotyledonous taxa are associated with increased aridity (Ehleringer et al. 1997; Long 1999). The final pathway, termed CAM (crassulacean acid metabolism), is used by most succulents (Bender et al. 1973; Ranson and Thomas 1960). CAM plants can mimic either $\mathrm{C}_{3}$ or $\mathrm{C}_{4}$ stable carbon isotopic signatures and have ranges from around -33 to $-14 \%$ o (Bender et al. 1973; Griffiths 1992). In Central Texas, CAM plants seem to produce isotopic signatures that are comparable to the lower range of $\mathrm{C}_{4}$ plants (see Boutton et al. 1998: 18).

The isotopic values produced by these three different vegetation pathways are not significantly altered by decomposition, though ${ }^{13} \mathrm{C}$ values appear to be 1 to $3 \%$ greater at depths below surface in many cases (see Boutton et al. 1998). Consequently, measurements of stable carbon isotope ratios in organic mater in soil from Central and South Texas can provide an estimate of the relative contribution of $\mathrm{C}_{4} / \mathrm{CAM}$ and $\mathrm{C}_{3}$ plants at a location. By measuring the stable carbon isotopic signatures from several dated, buried soils within a profile, or from multiple dated locations from the same general area, researchers can monitor shifts in vegetation and, by extension, shifts in temperature and moisture.

Soils are commonly dated by radiocarbon dates, with an associated error range, as well as stratigraphic position within a profile. In addition, note that the stable carbon isotopic value for a given data point represents a pooled value of vegetation that existed on that surface. The value is a function of the turnover rate in soil organic matter, soil formation, and patterns of deposition and erosion (Boutton et al. 1998). Given these consideration, any shifts in carbon isotopic values observed will probably reflect long temporal periods, approximating several centuries under most depositional conditions. Spatial scales appear to be local though erosion and redeposition of deposits can, especially in stream settings, complicate interpretations of the spatial as well as the temporal scale.

Figure 2-8 compares two stable carbon isotopic sequences derived from organic matter in soils. The first sequence, Medina River, described by Nordt et al. (2002), is located about $135 \mathrm{~km}$ to the southwest in southern Bexar County. Hall's Cave, located in Kerr County, is about $165 \mathrm{~km}$ to the west of the current project area and provides the second sequence (see Cooke 2005). Both sequences span over 10,000 years. The Hall's Cave carbon isotope data, shown as a solid line in the figure, are derived from buried sediments from an extremely well-dated sinkhole deposit in Kerr County (see Cooke 2005; Toomey 1993). Unfortunately, there are only 16 sample points over the 10,000 year sequence shown in Figure 2-8 or one data point for every 625 calendar years. Examination of the Figure 2-8 Hall's Cave sequence shows a gradual, though variable increase in $\mathrm{C}_{4}$ vegetation from just before $7000 \mathrm{BP}$ to around $1800 \mathrm{BP}$. This suggests warming temperatures and possibly increasing summer rainfall over this period. A rapid decline is then initiated, suggesting a return to cooler temperatures over the last 1,800 years. The Medina River sequence is shown as a dashed line in Figure 2-8 (see Nordt et al. 2002). These stable carbon isotope data come from a series of stream terrace deposits. For the 10,000 years shown in the figure, seven radiocarbon dates are present, and there are 32 data points. Examination of the Medina sequence suggests a gradual, though variable increase in $\mathrm{C}_{4}$ plants, and by extension an increase in temperatures, from the beginning of the sequence until just before $3000 \mathrm{BP}$. The contribution of $\mathrm{C}_{4}$ plants appears to remain constant for the next 1,700 years, though this period lacks data points. Over the last 1,400 years, decreased $C_{4}$ production occurs with a sharp decline occurring late in the sequence suggesting a return to cooler temperatures.

The stable carbon isotope sequences discussed in this section vary in specifics. For example, the overall position of the Hall's Cave stable carbon isotope sequence in Figure 2-8 is consistently more negative, suggesting a more $C_{3}$ dominated setting, than the Medina River sequence. Medina River reflects more $\mathrm{C}_{4}$ production during all periods shown. This is not surprising given that the sequences are primarily reflecting local conditions. The sequences do, however, seem to reflect roughly similar overall temporal trends. Both show a variable but consistent increase in $C_{4}$ production probably reflecting an increase in temperature and/or aridity from early in time through around 2000 to 3000 BP. Stable or declining $C_{4}$ contributions are present for the remainder of the sequences. This decline appears to be rapid, at least in the case of Hall's Cave. This post-3000 BP pattern is consistent with decreasing temperatures, especially near the end of the sequences. Note also that the general timeframes represented by radiocarbon dates from 41 TV410 and 41 TV540 are also highlighted on Figure 2-8. At around $6000 \mathrm{BP}$, when the major dated occupation at 41 TV540 and some of the occupation at 41TV410 is present, both of the Figure 2-8 sequences show an increase in $\mathrm{C}_{3}$ plants, thought neither pattern is particularly strong. 


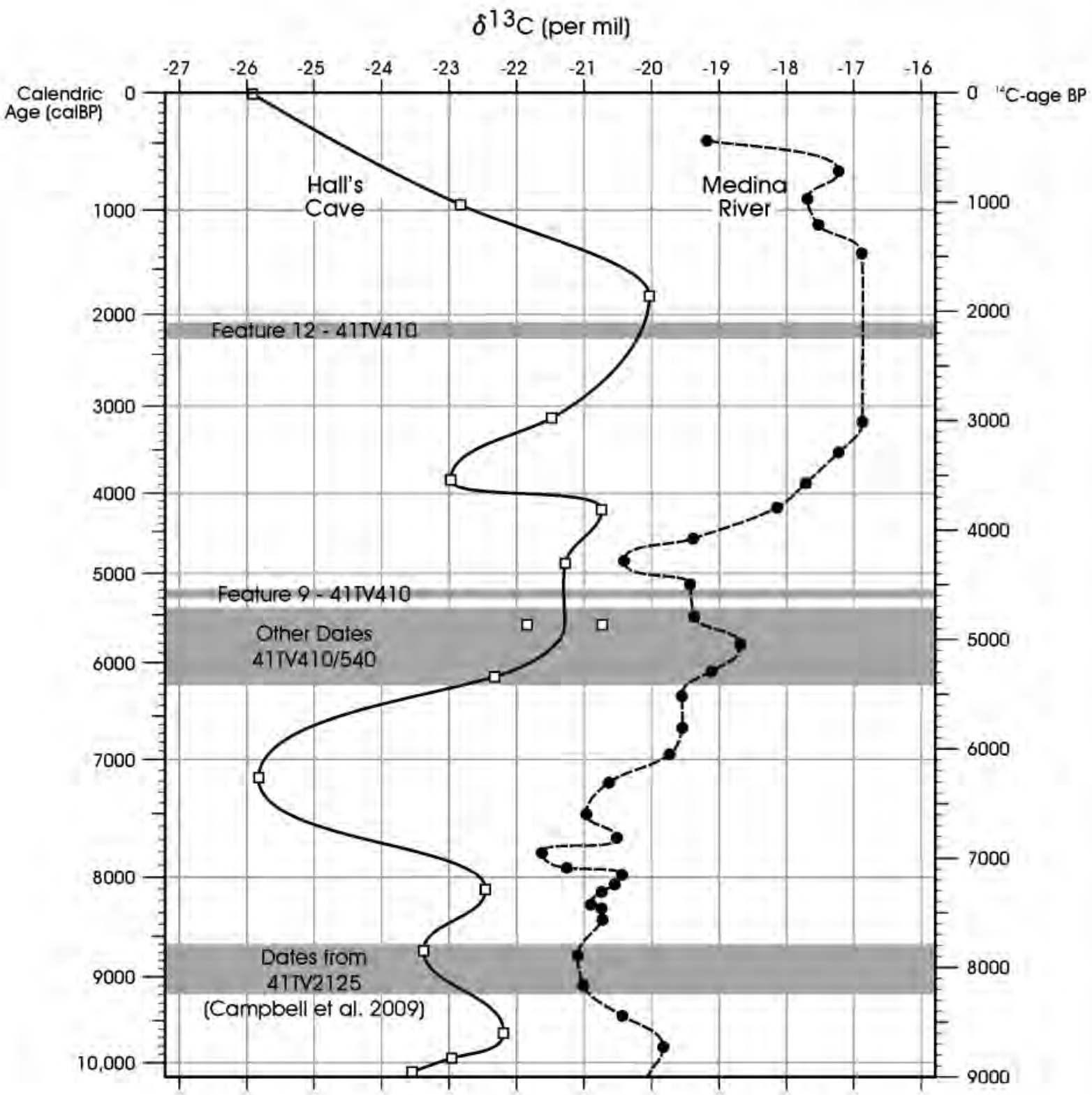

Figure 2-8. Stable carbon isotope variation in soils from Medina River (dashed line) and Hall's Cave (solid line). 


\section{Chapter 3: Archeological Background and Previous Investigations}

\section{Antonia Figueroa}

The first section of this chapter discusses the cultural chronology of Central Texas by combining information developed by classic chronologies (Collins 2004, Johnson and Goode 1994) and from data obtained from various cultural resource management reports. In the second section of the chapter, we review the previous archeological investigations that have been conducted in Travis County, with a focus on Onion Creek and the immediate project area. The previous archeology discussion concentrates on sites with known Archaic components and focuses on land use and subsistence patterns.

\section{Cultural Chronology}

Human occupation in Central Texas spans nearly 11,500 years. The cultural chronology developed by Collins (2004) for Central Texas is a commonly used reference as are others developed by Prewitt (1983) and Johnson and Goode (1994). Recently, Houk et al. (2009) discussed the use of relative rather than absolute dates in establishing the culture chronology for Central Texas. In the Archaic period section below, we attempt to incorporate data from Archaic components that have been identified by both relative and absolute dating methods.

\section{Paleoindian Period (11500-8800 BP)}

This period, associated with the earliest documented presence of humans in Texas, is typically divided into early and late segments, with the early segments associated with Clovis and Folsom artifact traditions. Populations at this time were traditionally argued to consist of small groups of mobile hunters, pursuing primarily mega fauna or bison. However, recent data suggests that these populations exploited a broad range of plants and animals and that mobility may have been lower than previously thought (Bousman 2004; Collins 2002, 2004).

For the Clovis period, Meltzer and Bever (1995) documented over 400 points in Texas. Clovis age sites usually consist of kill localities, quarry/workshops, residential camps and burial caches that are indicative of repeated return to the same locations (Collins 2004). The earliest documented Paleoindian site in Texas may be the Aubrey site in Denton County with radiocarbon dates of $11542 \pm 111 \mathrm{BP}$ and 11590 \pm 93 BP (Bousman et al. 2004:48). Paleoindian sites have been documented in Central and South-Central Texas. These include excavated sites such as 41BX52 (Collins and Hudler
2003) and St. Mary's Hall (Hester 1990). In the latter portion of the period, there were stylistic changes in projectile point technology seen in Dalton, Scottsbluff, and Golondrina traditions. While widespread in geographic range, these types occurred in high densities in the High Plains and Central Texas (Meltzer and Bever 1995). As the climate warmed, mega fauna gradually died off, and subsistence patterns shifted to increased use of medium and smaller game and plant resources.

\section{Archaic Period (8800-1200 BP)}

This period is subdivided into the Early, Middle and Late subperiods. The subperiods are distinguished by differences in climate conditions, resource availability, subsistence practices and diagnostic projectile points (Collins 2004). Plant gathering appears to have become an important part of subsistence strategies during this time and was probably even more important during xeric periods. This may explain the appearance of burned rock earth ovens. They were used to cook a variety of plant foods that were otherwise, inedible or difficult to digest, such as sotol (Johnson and Goode 1994).

In the Early Archaic (8800-6000 BP), there was a shift in subsistence, with an increased emphasis on plant foods and the acquisition of medium and small animals (Collins 2004). Projectile point styles present during this period included Angostura and Early Split Stemmed forms. Task-specific tools include Clear Fork gouges and Guadalupe and Nueces bifaces (Turner and Hester 1993:246-256). Early Archaic sites were differentially located along the eastern and southern portions of the Edwards Plateau in areas with reliable water sources (McKinney 1981). Population densities are thought to have been relatively low during this subperiod and consisted of small highly mobile bands (Story 1985). Both radiocarbon dates and barbed dart points were used to date burials to the Early Archaic at the Bering Sinkhole site (Bement 1991; Johnson and Goode 1994).

Prewitt (1983) has proposed several phases for the Early Archaic period based primarily on relative dating and point types. Early Archaic phases include Circleville, San Geronimo, Jarrell, and Oakalla (Prewitt 1983). The Circleville Phase is characterized by Angostura, Golondrina, Meserve and Scottsbulf projectile points (Prewitt 1983). San Geronimo projectile points include Gower, Howie, and Wells types. The Jarrell Phase is indentified by the presence 
of Bell, Andice, Martindale and Uvalde points (see Ricklis and Collins 1994:93). Clear Fork Gouges, along with Baird and Taylor projectile points are part of the Oakalla Phase. However, only a few absolute dates have been produced to support these intervals of the Early Archaic (Prewitt 1983).

Evidence from the Wilson-Leonard site (41WM235) indicates that a majority of features from the Early Archaic were in the form of small to medium burned rock clusters. Dating of these components included relative and absolute dating techniques. Cultural material from the site suggests a continued use of Lanceolate projectile points and subsistence patterns evident in the Paleoindian Period at the site (Collins 1998). Newer manifestations that began in the Early Archaic Period, seen at the Wilson Leonard site, consist of use of earth ovens to cook geophytes (Collins 1998:239).

41TV285, along the lower Onion Creek drainage, contained scant evidence of Early Archaic occupation (Lohse and Ireguas 1998). Temporal components were inferred by the presence of diagnostic materials (Split Stem preforms and a triangular biface). Investigations at the site indicate a shortterm occupation and lithic reduction activities, evident from a single hearth and scattered chipped stone debitage.

Excavations from the Gatlin site (Houk et al. 2009) have yielded radiocarbon assays and relative dates (based on projectile point typology) from the Early Archaic Period. Houk et al. (2009) inferred from the data extrapolated from the Early Archaic component that the site was sparsely populated and may have functioned as a hunting camp or hunting/ butchering locality rather than a residential camp (Houk et al. 2009:13-17). Moreover, feature data indicates that, “... social organization includes small groups, moving regularly through the landscape to exploit various resources with a heavy emphasis on large game..." (Houk et al. 2009:1317). Houk and others suggest that the lack of ground stone at the Gatlin site indicates seasonal (winter through spring) use. Moreover, the lack of ground stone could mean that the processing of plant foods did not require the intensification of labor, or processing was achieved through the use of wood or bone tools (Houk et al. 2009:13-18).

The Middle Archaic spans from 6000 to 4000 BP (Collins 2004) and has been described as a transition into "advanced plant collecting and hunting” (Johnson and Goode 1994:26). Diagnostic projectile points from this period include Bell, Andice, Taylor, Nolan, and Travis. Radiometric dates for this period have been secured at sites in Central Texas. According to Collins (2004), during the Middle Archaic there was a focus on bison hunting in Central Texas. Johnson and Goode (1994) note that the Middle Archaic was comprised of mixed subsistence economies but there was an emphasis on plant collecting and processing in pit ovens toward the end of the period. Climate was gradually drying as the onset of the Altithermal drought began. Researchers report an abandonment and sparse settlement of the Middle Onion Creek Valley (Ricklis and Collins 1994:318). Similar patterns are seen at the Wilson-Leonard site, where cultural material and features are less frequent than in the Early Archaic components (Collins 1998).

Investigations by Loshe and Ireguas (1998) also encountered a Middle Archaic component along Onion Creek (41TV412). The component was identified by a Pedernales point fragment, a type that Collins (2004) places early in the Late Archaic but that has been assigned to the Middle Archaic in some chronologies (see Turner and Hester 1993). Loshe and Ireguas (1998) suggested that site 41TV412 was a lithic procurement locale, indicated by the chipped stone material recovered from the site.

The last subperiod of the Archaic is the Late Archaic that spans 4000 to 1200 B.P. (Collins 2004). Dart point diagnostics of the Late Archaic are triangular points with corner notches that include Ensor and Ellis forms, among others (see Turner and Hester 1993). Other Late Archaic projectile points are Pedernales, Marshall, and Marcos types (Collins 2004). Research indicates that the accumulation of burned rock middens (Prewitt 1981) ceased at this time though this notion has been challenged (Black et al. 1997; Johnson and Goode 1994).

Site 41HY209 (Mustang Branch site) and 41HY202 (Barton site) along Onion Creek contain evidence of a Late Archaic occupation. Several hearth features at the Barton site and a large burned rock midden at the Mustang Branch site imply that burned rock middens represented dumping episodes associated with hunting, carcass processing, stone boiling associated with bone grease processing and plant collecting and processing (Ricklis and Collins 1994).

\section{Late Prehistoric Period (1200-350 BP)}

The Late Prehistoric is divided into the Austin and Toyah phases. During the Austin Phase, the bow and arrow was introduced. Nickels and Mauldin (2001) suggested that at the beginning of this period environmental conditions were warm and dry. More mesic conditions appear to occur sometime after 1000 BP. The Austin Phase may represent the most intensive use of burned rock middens (Black et al. 1997; Mauldin et al. 2003) and includes diagnostic point types Scallorn and Edwards (Collins 2004; Turner and Hester 1993). 
The presence of bone tempered ceramics (Leon Plain) during the Toyah Phase suggests interaction between Central Texas and ceramic producing traditions in East and North Texas (Perttula et al. 1995). According to Pertulla and others (1995), ceramics were in common use in East Texas by 2000 BP, but the first Central Texas wares did not appear until ca. 700 BP. Other technological traits of this Phase include Perdiz points and beveled bifaces. During the Toyah Phase subsistence behaviors may be an adaptation to flourishing bison populations (e.g., Ricklis 1992) or reflect intensification as a result of declining bison populations (see Mauldin et al. 2010; Mauldin and Kemp 2005).

\section{Previous Archeological Research in Travis County and the Onion Creek Area}

According to the Texas Archeological Sites Atlas, over 2,000 sites are recorded in Travis County. Some of the earliest professional work in the county was conducted in 1919 by J.E. Pearce. Jackson was involved in archeological work in the 1930s, some of which was associated with the Works Progress Administration Program (Shafer and Tomka 2004). During the 1970s, Millican Bench was one of the first sites to be mitigated by the Texas Department of Transportation (TxDOT) in compliance with the National Historic Preservation Act of 1966 (see Mauldin et al. 2004). The occupation of the site began during the Early Archaic Period and continued through the Late Prehistoric Period. Chipped stone analysis from the site indicates that during the Early and Middle Archaic non-local sources of raw lithic material were used. Data from the site suggest changes in mobility strategies and subsistence patterns particularly between the Late Archaic and Late Prehistoric Periods (Mauldin et al. 2004).

Archeological investigations by Ricklis and Collins (1994) on the south side of the Onion Creek valley, in association with the construction of FM 1626, revealed Archaic and Late Prehistoric components at the Barton (41HY202) and Mustang Branch sites (41HY209). An Early Archaic component was identified on the Barton site by the presence of several diagnostic projectile point fragments. Researchers noted the material represented the Jarrell Phase of the Early Archaic Period (Ricklis and Collins 1994). A Late Archaic component was identified at the Mustang Branch site. Dates obtained from a burned rock midden suggest that there could be some overlap between Late Archaic and Late Prehistoric diagnostic artifacts (Ricklis and Collins 1994:166).

Lohse and Iregueas (1998) investigated several sites with archaic components along the lower Onion Creek drainage. Site 41TV285 contained Early Archaic materials, while
41TV412 dated to the Middle Archaic. An additional site, 41TV1372, was not assigned to any time period. However, a Marshall point, associated with the Middle Archaic, was found in backhoe trench deposits. Archeological investigations at site 41TV1631 revealed a multi-component site with historic and prehistoric material present. Excavations of the prehistoric component uncovered several buried features. Radiometric dating of two of the features indicated that they were Late Archaic in age. Work on 41TV1635 revealed a historic and prehistoric component of unknown age. None of the prehistoric sites investigated during the project were eligible for NHRP listing (Lohse and Irgueas 1998).

In 2006, Hicks and Company conducted testing on site 41TV2125 (Campbell et al. 2009), located 645 meters northeast of 41TV540. The site is situated at the base of an upland ridge on the edge of the Onion Creek floodplain. The investigations revealed late Paleoindian/Early Archaic components. Seven excavation blocks were opened during investigations. Ten features were identified including an earth oven, burned rock hearths, burned rock concentrations, and concentrations of charcoal and snail shell (Campbell et al. 2009: 41). High variability in features, subsistence remains, and other culture material, suggests that 41TV2125 was "a temporary occupied campsite for broad spectrum resource exploitation” (Campbell et al. 2009:129).

Three features (7, 8, and 9) were encountered in Block A at 41TV2125. Feature 7 was a circular concentration of snail shells, charcoal and burned rock and was interpreted as a possible hearth feature. Feature 8 consisted of charcoal and snails shells. The size of the feature was not determined. It was suggested that the feature could be the result of flooding episodes or a refuse scatter from a nearby living surface. Feature 9 consisted of a charcoal stain and scatter of snail shells. Portions of this feature may have been removed by borrow pit excavations (Campbell et al. 2009).

Feature 6, located in Block B, contained a small amount of burned rock $(n=2)$, charcoal, burned earth, ash, debitage and faunal material. It was concluded that the feature, with a conventional radiocarbon age of $8291 \pm 66$ B.P., was used to cook animals. Feature 12, in Block G, was a basinshaped hearth. Feature 14, encountered in Block H, was a concentration of burned rock. This feature may have been used to process plants and animals (Campbell et al. 2009).

Four features $(4,10,11$, and 13$)$ were discovered by Trench 12. The trench was originally opened to explore Feature 4 (Test Unit 10) but due to the high density of artifacts, subsequent test units were opened. These additional units uncovered Features 10, 11 and 13. Feature 4 was at $4.71 \mathrm{mbs}$ 
and was identified as a hearth. Both Feature 4 and Feature 11 are associated with the same occupational horizon. Feature 11 consisted of a large burned rock lined earth oven (200-x-130 $\mathrm{cm}$ ) used for cooking plant material. Conventional radiocarbon dates ranged from $8103 \pm 66$ to $7854 \pm 56$ BP. Feature 10 was thought to be discard piles associated with Feature 11 . Feature 13 was a 93-x-83 cm concentration of burned rock and is associated temporally with Features 4, 10, and 11 (Campbell et al. 2009).

\section{Previous Archeology at 41TV410}

Site 41TV410 was originally recorded in 1979 by Whitsett and Fox (THC 2010) as a prehistoric site that covered approximately nine acres. The site is located 1,024 meters northeast of the boundaries of $41 T V 540$. At the time of its original recording the site consisted of dense chipped stone debitage and burned rock. Moreover, four features were noted between 60-150 cmbs in a cut bank of Onion Creek near the site. A thick occupation layer (20-40 cm thick), composed of mussel shell, rock-lined hearths, and large quantities of lithic debitage, bone and heavy charcoal staining, was present at $150 \mathrm{cmbs}$.
In 2005, Hicks and Company (Campbell et al. 2005) excavated seven backhoe trenches (BHT's 1, 2, 2E, 2Ea, 2N, 2S and 6 ) and 53 shovel tests within the boundary of 41TV410 (see Figure 3-1). Four of the shovel tests (7.5\%) were positive for cultural material (Campbell et al. 2005: Plate 1). During backhoe excavations, nine features were recorded. BHT 1 was located adjacent to the northern property fence line and excavated to a terminal depth of $761 \mathrm{cmbs}$. Cultural material was observed at varying densities from roughly $80 \mathrm{cmbs}$ down to 200 cmbs (Campbell et al. 2005:19). BHT 2 was located at the southwestern edge of the site. The backhoe trench reached a depth of 704 cmbs with cultural materials occurring to a depth of 240 cmbs. The majority of the materials were distributed between $60-140 \mathrm{cmbs}$ with only a single flake occurring below this depth (220-240 cmbs). A 6-X-8 m block, near Feature 1, revealed a small concentration of burned rock found at 45-55 cmbs.

Backhoe Trench 2N was to the north of BHT 2. Excavations reached a depth of 152 cmbs. Debitage and burned rock was noted between 120-140 cmbs. A small cluster of burned rock was identified as Feature 2 at 137 cmbs. BHT 2E was

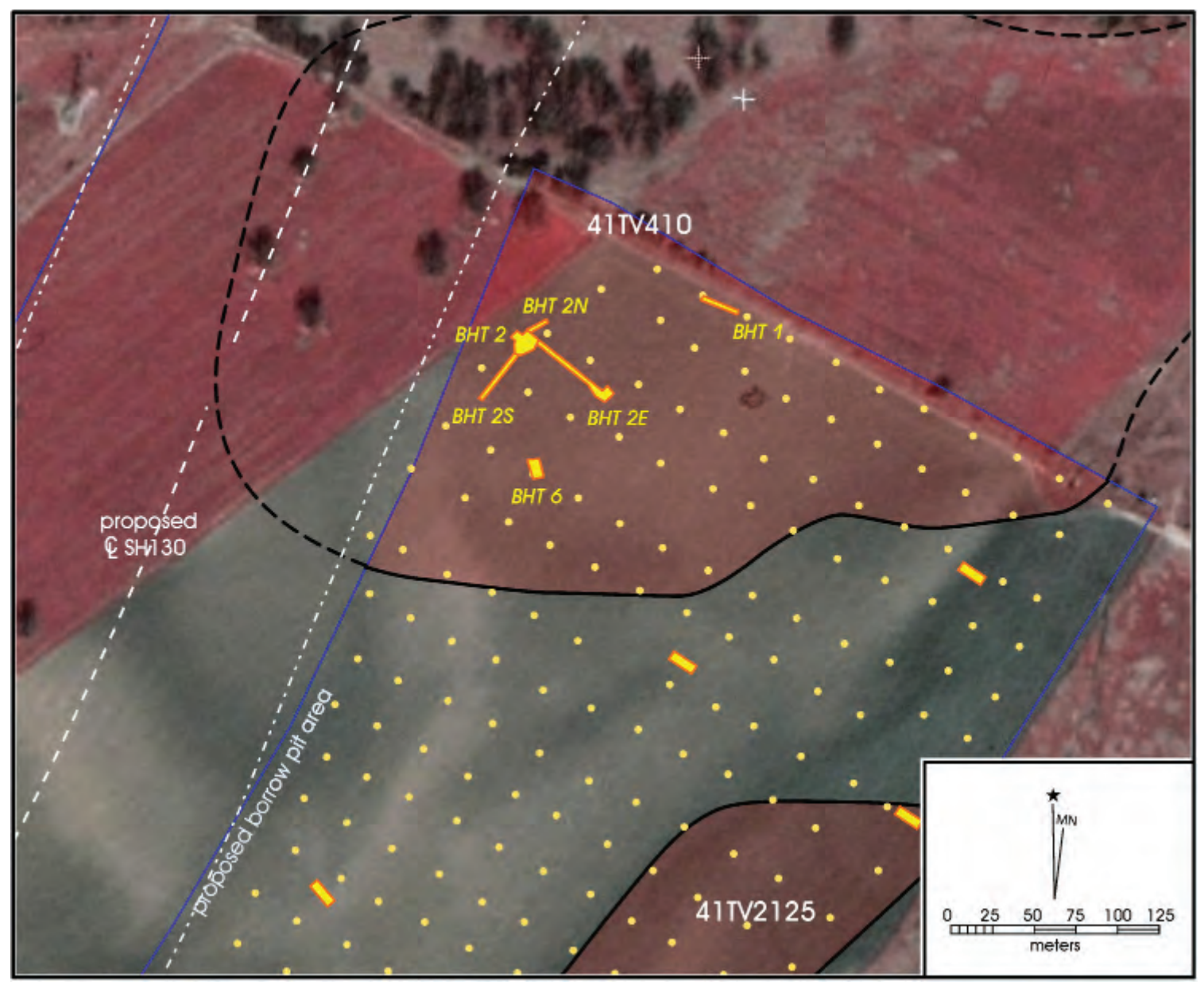

Figure 3-1. Previous work on site 41TV410. 
excavated to the northwest of BHT 2 and at a depth of 190 cmbs two clusters of materials were identified. The first cluster extended from $60-100$ cmbs and the second from 120$190 \mathrm{cmbs}$. Two features were identified. Feature 3 consisted of a broad scatter of artifacts at about 90 cmbs. Feature 4 was a small cluster of burned rock between 156-160 cmbs. BHT 2Ea was located at the extreme eastern end of BHT 2 and extended to a depth of $365 \mathrm{cmbs}$. BHT 2Ea was located at the extreme eastern end of BHT 2E, extending to a depth of 365 cmbs. The cultural material derived from the trench consisted of only two pieces of burned rock ( $178 \mathrm{cmbs}$ and $190 \mathrm{cmbs}$ ) and two flakes (215 cmbs and $220 \mathrm{cmbs})$. BHT 2S was on the southwestern edge of site 41TV410 on a high alluvial terrace of Onion Creek. No features were identified in this trench but cultural materials were present from a depth of 40 to $165 \mathrm{cmbs}$. The artifacts consisted of burned rock, lithics, and charcoal and mussel shell (see Campbell et al. 2005).

BHT 6 was located approximately 65 meters east-south east of the southern end of BHT 2S. Cultural material was present 40-420 cmbs with low densities from 40 to 200 cmbs. Three zones associated with small peaks in material distribution were apparent below $200 \mathrm{cmbs}$. The first zone extended to $340 \mathrm{cmbs}$ with a peak in materials occurring between 260$300 \mathrm{cmbs}$. The third zone may encompass materials between 340-420 cmbs (Campbell et al. 2005).

Four features (6, 7, 8 and 9) were documented and consisted of stains of burned earth, burned rock fragments and charcoal. Feature 6 was found at $225 \mathrm{cmbs}$, associated with the uppermost zone and peak in cultural materials. The feature consisted of an elongated area of burned soil along with flakes and bone fragments. Feature 9 consisted of a scatter of burned rock, debitage, a core, mussel shell and charcoal at 260-280 cmbs. Radiocarbon assays from a depth of $254 \mathrm{cmbs}$ near Feature 9 returned a date in the early Middle Archaic (3620-3360 BC, two sigma range). Feature 7 was associated with the second concentration and peak in cultural materials. Feature 8 (identified at $372 \mathrm{cmbs}$ ) was a patch of burned earth associated with charcoal, ash, burned soil and snail shells (Campbell et al. 2005).

Previous work at $41 \mathrm{TV} 410$ produced a low density of artifacts and a variety of burned rock features. Organic materials, such as bone, mussel shell and charcoal were sparse at the site. Though not firmly established, occupation of the site seemed to have components representing the Early, Middle, and Late Archaic periods.

\section{Previous Archeology at 41TV540}

The site was first documented in 1981 by Brown (Campbell et al. 2005). 41TV540 was recorded as a dense surface scatter of chipped stone. In 2005, Hicks and Company excavated shovel tests and backhoe trenches across areas within the proposed borrow pit (Figure 3-2). Two of the excavated trenches (BHT 10 and BHT 13) and 20 shovel tests were placed within the boundary of 41TV540. The two trenches contained cultural material.

BHT 10, on the northeastern edge of the site, terminated at 5.40 mbs. Within this trench cultural material was observed from 0.80 to 5.40 mbs with the highest artifact concentration occurring between 3.60 and $5.40 \mathrm{mbs}$. The lower $1.8 \mathrm{~m}$ of BHT 10 was identified as containing two zones of cultural deposits (Campbell et al. 2005: Table 21). The upper zone (3.80 and $4.20 \mathrm{mbs)}$ ) contained debitage, fire-cracked rock (FCR), charcoal, bone, shell, burned earth, and a sandstone metate fragment. This assemblage of artifacts was designated Feature 5. A lower cultural zone, between 4.60 and $5.40 \mathrm{mbs}$, contained artifacts including debitage, burned rock, a core and animal bone.

Feature1, a collection of burned rock and four pieces of debitage, was recorded just below the plow zone ( 0.20 to 0.40 mbs) in BHT 13 (Campbell et al. 2005:48). No other material was observed in this BHT.

The results of the Phase I survey at 41TV540 suggested that the site contained three low-density zones of cultural material: an upper deposit between 0.20 and $0.80 \mathrm{mbs}$ seen in both trenches, a deposit between 3.80 and 4.20 mbs seen in BHT 10, and a lower deposit between 4.60 and $5.40 \mathrm{mbs}$, also seen in BHT 10. Due to the position of BHT 10 in close proximity to 41TV2125 (dating to the Paleoindian Period), intensive testing was recommended at the site (Campbell et al. 2005). 


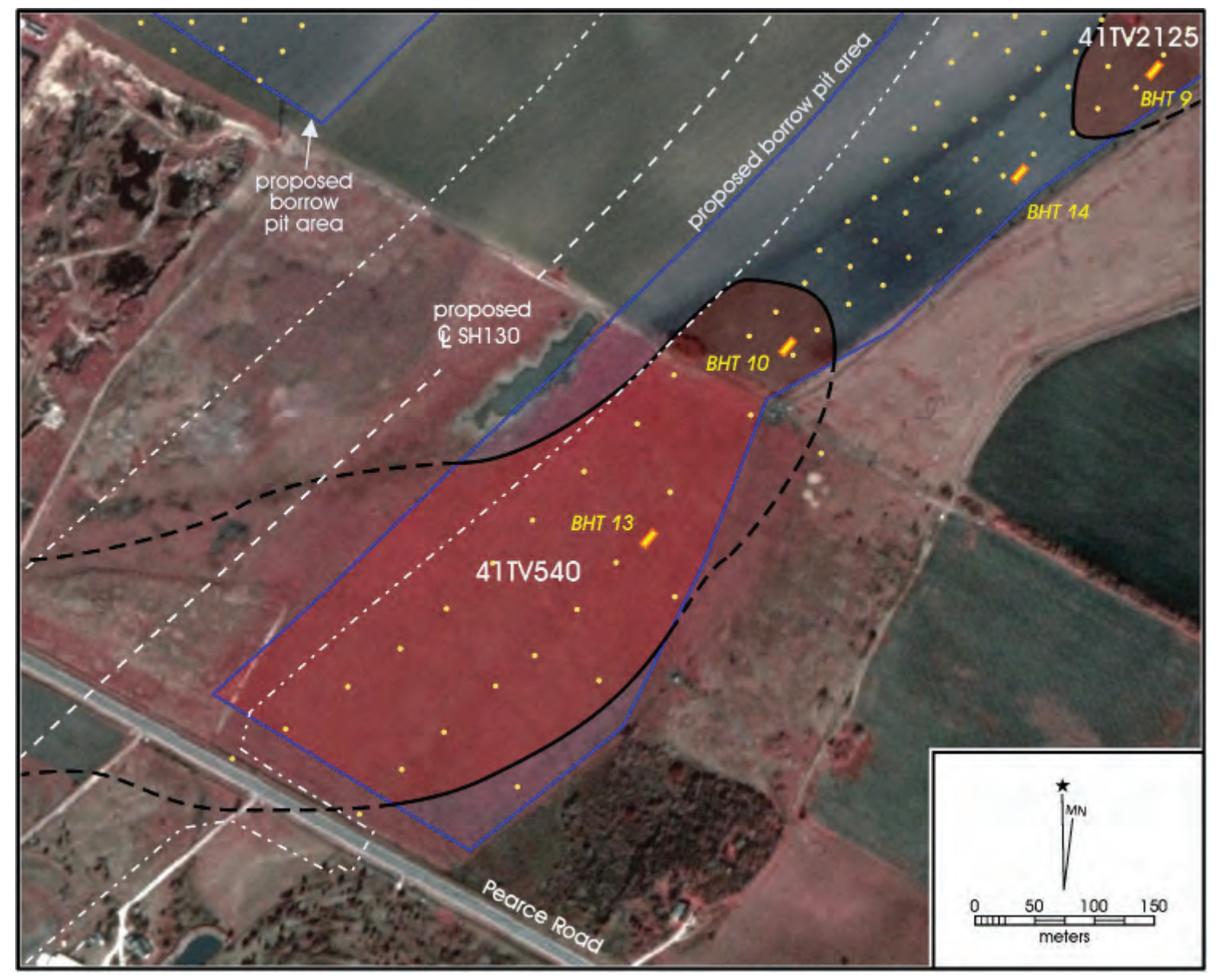

Figure 3-2. Previous work on site 41TV540. 


\title{
Chapter 4: The Research Design for Testing at 41TV410 and 41TV540
}

\author{
Steve Tomka, Raymond Mauldin and Antonia Figueroa
}

As summarized in the previous chapter, the initial survey, backhoe trenching, and small scale excavations at 41TV410 and 41TV540 suggested that both sites contained multiple peaks of cultural material. In several cases, these peaks were associated with features, faunal material, and charcoal. While 41TV410 contained a low density of material, Phase I results showed that one of these peaks dated early in the Middle Archaic (ca. 3490 BC). Material was present both above and below that dated peak, suggesting the possibility that Late Archaic and Early Archaic/late Paleoindian remains were present at this location. Phase I results from 41 TV540 suggested that the site contained three low-density zones of artifacts and features. Of primary concern were deposits observed in BHT 10 (Campbell et al. 2005). The first zone was between 380 and 420 cmbs, and this was underlain by deposits between 460 and 540 cmbs. BHT 10 was located on the northern edge of the site, near 41TV2125. Late Paleoindian materials had been recovered from 41TV2125 at depths comparable to the lower deposit at 41TV540, suggesting that Early Archaic and possibly late Paleoindian material was present at 41TV540. Both 41TV410 and 41TV540, then, had the potential to provide information on Early Archaic, and possibly late Paleoindian occupations. In addition, 41TV410 had the potential to provide data on the Middle and Late Archaic Periods.

Given the paucity of information on the Early Archaic and Late Paleoindian periods, as well as the possibility that when considered together sites 41TV410 and 41TV540 could provide a diachronic perspective that minimally sampled much of the Archaic, TxDOT requested that CAR conduct significance testing at both 41TV410 and 41TV540. The purpose of the testing was 1) to conduct investigations and analyses to determine the integrity and significance of deposits at both sites, and 2) to recommend further data recovery efforts at these sites, if warranted. The work was conducted in advance of a borrow pit excavation related to the construction of SH 130 and was mandated by language of the SH 130 comprehensive development agreement. The testing and subsequent analysis was not governed by State or Federal regulations and was not conducted under a Texas Antiquities Permit. However, the work was conducted in accordance with guidelines provided by the Texas Historical Commission and with the Secretary of the Interior's Standards and Guidelines for Archeology and Historic Preservation.

Testing both sites presented significant logistical and design challenges. When CAR began designing the fieldwork, final reports on the results of Phase 1 work at the two sites were not available, although TxDOT provided available information to CAR. Conversations with Hicks and Company representatives, who conducted the initial work at the sites, were also extremely helpful. Many of the deposits of interest were at depths in excess of 4 meters below the surface. This required the extensive use of heavy machinery for the removal of overburden, much of which contained low density cultural deposits, and the establishment of large surfaces from which we could initiate hand excavations while conforming with OSHA regulations regarding trench safety.

The SH 130 Project was a “design-build" with short construction schedules. While site specific information on field and laboratory procedures are provided in Chapters 5 (41TV410) and 6 (41TV540), note that we designed the fieldwork and preliminary laboratory processing to run concurrently, with rapid feedback to the field from the lab. Construction schedules were short and windows to conduct the archeological testing were limited. If CAR, in consultation with TxDOT, determined additional work was needed on these sites, the project was required to be ready to rapidly transition from testing into data recovery once TxDOT made that decision. In anticipation of such a transition, the testing was designed, to the degree possible, to address general research issues focused primarily on the Archaic and late Paleoindian time periods. Of course, it was impossible to know in detail what data sets would be available from 41 TV540 and 41TV410 before we conducted the work. We realized that data types needed to address some research questions may not be available or may be of low quality. In addition, new data types, not anticipated prior to their recovery, could provide unique learning opportunities. Nevertheless, these initial research issues outlined below provided guidelines for the field and laboratory efforts, as well as criteria relevant for assessment of the significance of the deposits at the two sites.

\section{Research Issues}

Our initial research concerns focused on documenting aspects of hunter-gatherer mobility and, indirectly, changes in subsistence. As outlined in Chapter 7, these initial concerns were altered somewhat, and additional issues were suggested following the completion of testing. These new research issues, discussed in Chapter 7, centered on shifts in geomorphology, vegetation, and climate. They focused on how these shifts implicated patterns of human occupation and reoccupation on sites along Onion Creek. Nevertheless, the primary focus of our initial research efforts, the focus that 
guided the testing fieldwork and initial analysis of 41TV410 and 41TV540, was on mobility. Note that the research directions summarized below were developed in consultation with TxDOT Environmental Affairs Archeologists in November of 2005 and were in place prior to the initiation of testing at 41TV410 and 41TV540.

\section{Investigating Hunter-Gatherer Mobility}

The concept of hunter-gatherer mobility includes several elements (see Binford 1980, 2001: 269-276, 311-313; Kelly 1995:111-152). Discussions of mobility, especially from ethnographic accounts of hunter-gatherers, can focus on 1) the overall scale used by a given system during some period of time, 2) the annual frequency of residential camp moves, 3) the average and total distance that residential camps move over a year, 4) the average length of occupation and frequency of reoccupation, and 5) the way that mobility is organized. Archeological investigations of mobility are more limited in some respects in that we lack fine-grained temporal control. In addition, we lack well developed methodological links that would tie together specific occupations. However, in other respects, archeological studies have a substantial advantage over ethnographic descriptions. Specifically, archeological studies of mobility can look at long-term diachronic patterns that are simply unavailable in ethnographic studies.

The time frame potentially represented by the $41 \mathrm{TV} 410$ and41TV540 occupations, which appeared to encompass the late Paleoindian and Archaic Periods, provides one such example of the potential for long-term diachronic investigations of mobility. As is evidenced in our review of cultural chronology presented in Chapter 3 , at a general level Paleoindian subsistence is often depicted as primarily dependent on large game (but see Collins 2004). Because of that perceived focus, these early hunter-gatherers are seen as highly mobile. In contrast, Archaic occupations are characterized as having a diverse, broad-spectrum subsistence base, with a greater dependence on plants and smaller game, and with a concomitant reduction in mobility levels. Regardless of the validity of these characterizations of Paleoindian and Archaic subsistence and associated mobility levels in Central Texas, a reduction in mobility probably is present between the Paleoindian and the Early Archaic periods. However, the pattern of mobility during the long Archaic period is unclear. We anticipate an overall decline in mobility from the Early to the Late Archaic, but levels associated with the Middle Archaic are not clear and likely will be more variable (see Collins 2004; Johnson and Goode 1994; Ricklis 1995:277-278).

While there is general agreement on this broad scale pattern of reduced mobility from the late Paleoindian through the
Late Archaic, few studies attempt to document the suggested pattern of declining mobility in the archeological record. We suggest that such documentation may be possible, at least for some aspects of mobility. Specifically, we are concerned with assessing the relative length of occupation, and levels of reoccupation for a location over time. This is only one aspect of mobility. This particular aspect is not necessarily correlated with others such as total distance moved or changes in the scale of the overall system. However, documenting long-term changes in this initial element would be a useful step in building a methodology capable of documenting and assessing changes in mobility systems. We suggest that there should be an inverse relationship between mobility levels and several aspects of assemblage diversity, including the diversity of subsistence items, aspects of raw material use, and diversity of processing facilities. Components of low mobility systems, those adaptations that have longer occupations of a given location and/or more frequent reoccupation, are more likely to contain a wide variety of subsistence items, a wide variety of processing facilities, and a wide variety of lithic raw materials. Conversely, adaptations that have shorter occupations and lower frequencies of reoccupation should produce a low diversity of these same items. While several complications exist with this proposition, including potential shifts in the way that mobility was organized (Binford 1980) and problems with differential preservation for some sets of items (e.g., faunal and floral remains), these suggestions were used to structure the testing at 41TV410 and TV540. If during earlier periods at 41TV540 occupation was short and reoccupation was minimal, possibly as a function of a general dependence on large, more mobile game, then a low diversity should be present within the monitored data types. That diversity should increase later in time, as subsistence becomes more varied. For assemblages and occupations considered here, diversity should peak in the late occupations at 41TV410.

\section{Faunal Diversity}

In order to assess these potential shifts, we proposed to initially gather data on the number of animal taxa reflected in faunal remains from the various components at these two sites. Higher numbers of taxa should occur on components with longer occupation, and lower numbers on components with shorter occupations. However, we anticipated that lower number of taxa may also be associated with degradation of the assemblages. That is, earlier occupations would have fewer taxa represented simply as a function of taphonomic processes affecting the faunal assemblage (see Lyman 2001). In order to consider this possibility, we proposed to monitor the percentage of unidentified fragments within assemblages at a phase level to look for directional change through time. While the percentage of unidentified fragments can also be impacted by processing decisions, if there is no directional 
change in this percentage with earlier assemblages consistently having an increasing percentage of unidentified fragments, then any directional patterning in the number of identified taxa is unlikely to be accounted for solely in terms of differential preservation.

\section{Floral Diversity}

Plant remains can be treated in a similar manner to faunal remains. All else being equal, we anticipate that higher numbers of taxa will occur on components that were occupied longer, and fewer taxa will be present on short occupations. With plant remains, however, the potential impact of preservation is likely to be significant, especially given the time frames considered here. In addition, plant recovery is likely to primarily be from flotation samples, so decisions on sampling rates and sediment volume processed can dramatically influence recovery (see Hastorf and Popper 1988). In order to initially assess the potential impact of preservation, we proposed to consider the percentage of flotation samples with any recovery by temporal period. As with the faunal measures discussed above, if there is no directional change in the rate of recovery, then preservation as such is unlikely to account for any directional changes in the number of plant taxa.

\section{Feature Diversity}

The third element considered here involves the types of features present. We suggest that components that are occupied for longer periods should have a greater variety of feature types present, primarily as a function of the increasing range of processing requirements related to subsistence. As discussed by Wandsnider (1997; see also Black 2003; Ellis 1997; Thoms 2009), many plant resources, including roots, bulbs, and several varieties of nuts (e.g., acorns) contain compounds that are not readily digestible by humans. Some of these plant classes require extended cooking time, often in excess of 10 hours, with some high inulin plants (e.g., camus bulbs, sotol hearts) requiring several days of cooking to convert complex carbohydrates into easily digestible sugars. In contrast, cooking times for meats are often below 5 hours, with package size being the primary determinant of cooking length (see Wandsnider 1997). Cooking facilities such as unlined hearths appear to be adequate for preparing foods that require short cooking times. When longer cooking times are necessary, rock is often used to increase heat storage and lengthen the period of heat dissipation. Wandsnider's (1997) review of ethnographic sources revealed a series of case studies that support these suggested relationships. Seventy six percent (55 of 72) of hearth facilities used to cook plants contained rock. In contrast, the majority of cases documenting facilities used to process animal tissue lacked stone (Wandsnider 1997). We further anticipate that different quantities of rock might be used to generate different thermal profiles in order to process different types of plants as well as different quantities of plants (see Black 2003; Ellis 1997).

In order to assess these proposed relationships, we initially need to develop a typology of thermal feature types. We proposed that different quantities of rock, as measured by total rock weight at a feature level, might be one way to begin to empirically partition those features with rock into smaller groups. A second variable suggested was feature volume. While this is unlikely to be commonly reported in the literature, and while difficult to measure in many cases given a lack of feature depth, it may be the case that features with radically different volumes were used to process different types of plants, as well as different amounts of plants. Feature area, as defined by length and width for a given plan view shape, can be used as a proxy for feature volume. We proposed, then, to consider both area and total rock weight independently, as well as in bivariate plots, in an effort to empirically define feature types. Flotation data and lipid residue analysis of rocks and soil (see Malainey 2000; Quigg et al. 2002) were suggested as independent indicators of any developed typology.

\section{Chipped Stone Raw Material Diversity}

Chipped stone raw material diversity is the final data type considered. Several researchers have suggested that aspects of lithic raw material can be used to track mobility (e.g., Amick 1995). We suggested that the longer a component is occupied, the more likely it is that locally available raw materials will dominate the debitage and tool assemblages present. This suggestion is related to the need to replace exhausted or failed tools, a need that will increase over time. Conversely, under high mobility levels and short term use of a given location, materials brought to that location from non-local sources should be relatively more common. Furthermore, we suggested that on longer occupied sites, non-local raw materials would be differentially represented in exhausted tools. Unfortunately, we have no independent way to identify local and non-local resources in most settings. Consequently, in order to investigate these suggested relationships, we outlined three attributes that could be monitored to identify local and non-local sources. First, we proposed to divide raw materials into general classes based on geological types (e.g., chert, quartzite, etc.), color, and inclusions. This initial sort will attempt to identify the minimum number of nodules present in an assemblage (see Larson and Kornfeld 1997). For each group, we then proposed to look at cortex percentages and attributes of size. Local materials should have higher percentages of cortical flakes, especially those with more than $50 \%$ cortex cover, and be characterized by a wide range 
in flake sizes. Non-local materials should be dominated by flakes with little or no cortex and have a more restricted size range. While we lack an independent measure of this local and non-local identification, these broad distinctions should allow us to provisionally identify two broad groups that have a high probability of reflecting local and non-local materials. Once established, we proposed to then consider the relative contribution of these two groups, and suggested relationships with exhausted tools, in assemblages.

\section{Summary}

We have discussed possible links between levels of occupation and reoccupation and diversity in four data types (faunal, floral, feature types, and chipped stone raw materials) that provided direction for designing testing efforts at 41TV410 and 41TV540. The use of each of these data sets for documenting change in mobility levels has a series of potential problems, including differential preservation in the case of plant and animal taxa diversity, and potential problems with independently defining feature types and local/ non-local raw material groups. While we have suggested ways to address these problems, it is still the case that for a given data set the relationship with mobility is not clear cut. Nevertheless, the use of all four data sets will provide some general guidelines for field collections and laboratory analysis efforts at 41TV410 and 41TV540. In order to consider the research issues outlined here, a variety of different data sets were required. The focus on the acquisition of these data sets provided direction for preliminary laboratory analyses of materials while fieldwork was ongoing. As noted in the introduction to this chapter, the short construction schedule required that decisions regarding additional work at the site be made as soon as possible. If data recovery level work, or additional testing, was required at either site, ideally that work would be initiated at the close of testing. Ongoing laboratory analysis was, therefore, a critical element in making those field decisions, and the research issues outlined in this chapter essentially governed both the overall testing strategy as well as the preliminary laboratory analysis at 41TV410 and 41TV540. 


\title{
Chapter 5: Archeological Investigations at 41TV410- Field and Laboratory Methods and Summary of Results
}

\author{
Raymond P. Mauldin, Antonia L. Figueroa, and Charles Frederick
}

In order to consider the research issues outlined in the previous chapter, and given logistical considerations of limited field time, deep deposits, and the possible need to rapidly transition into data recovery work, CAR began testing of 41TV410 on December 1, 2005, with preliminary laboratory processing and analysis conducted simultaneously. While a variety of features were recovered at 41TV410, charcoal and bone were limited. Artifact recovery was minimal. Following a series of on-site field meetings in December involving TxDOT archeologists and CAR personnel, and given the low recovery for many of the artifact classes, TxDOT determined that no additional controlled excavation on the site was warranted following the completion of testing. Fieldwork at 41TV410 was completed on January 12, 2006, and CAR completed and submitted a postfieldwork report summarizing the testing activities and preliminary results in early February of 2006 (Mauldin 2006). In the post-field report, CAR suggested that given the relatively high frequency of features, monitoring and controlled stripping of areas associated with the site would provide data on features with minimal disruption of construction schedules. TxDOT archeologists did not agree with these suggestions. They determined that site 41TV410 was not eligible for listing on the NRHP, and that no analysis beyond that conducted at the time of fieldwork was required. The initial sections of this chapter, then, provide a summary of the field and laboratory methods used at 41TV410. These sections are followed by a descriptive summary of the archeological material recovered. Finally, the chapter concludes with a short summary of geomorphic investigations carried out in conjunction with the site excavation.

\section{Field Methods}

Testing at 41TV410 focused on two areas of the site. Area 1, located off BHT 2E and Area
2, located off BHT 6 excavated by Hicks and Company (Figure 5-1). The hand excavation of two 2-x-2 m blocks from roughly $50 \mathrm{cmbs}$ to depths of about $190 \mathrm{cmbs}$ (Figure 5-2) sampled Area 1. These excavations were designed to sample a low-density upper archeological deposit identified during Hicks and Company's excavations. This deposit appeared to be distributed between 40 and 120/140 cmbs in BHTs 1, 2, 2E, and 2S (Campbell et al. 2005). No age estimate was available for this deposit. Area 2, centered on BHT 6, was also sampled by the excavation of two 2-x$2 \mathrm{~m}$ units designated Blocks 3 and 4 (Figure 5-3). These excavations were designed to sample the lower deposits at 41TV410 identified between 260-420 cmbs (Campbell et al. 2005). A charcoal date from Feature 9 from a depth of



Figure 5-1. Area 1 and Area 2 tested by CAR on 41TV410. Insert shows location of areas within site. 


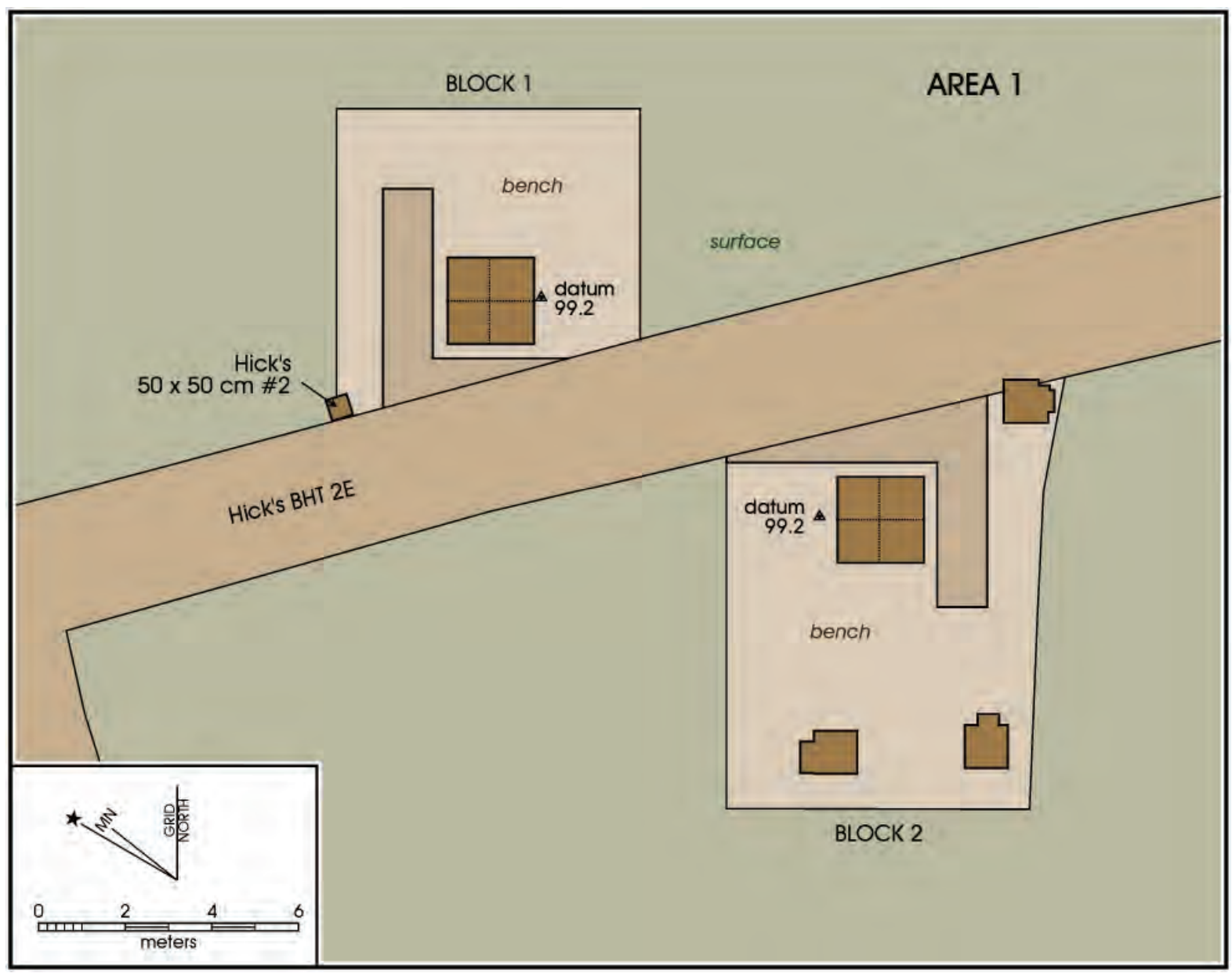

Figure 5-2. Area 1 excavation plan, 41TV410.

288 cmbs places these deposits early in the Middle Archaic Period (ca. 3620-3360 BC). Finally, an area just south of Area 2, designated Area 3, was cut to a depth of about 7 mbs with a trackhoe in order to evaluate the age and stratigraphic affiliation of the alluvial deposits in this portion of Onion Creek. This trench is described at the end of this chapter and is also used in the geomorphic descriptions presented in Chapter 8. The trench was also sampled for paleoenvironmental data, which are discussed in Chapter 9.

A thick layer of overburden covered the archeological deposits targeted for investigation in both Areas 1 and 2. Prior to the start of hand-excavations, portions of both areas were stripped using heavy machinery. CAR staff monitored this stripping. In Block 1, Area 1, located to the north of BHT 2E, an area of roughly $49 \mathrm{~m}^{2}$ was stripped (Figures 5-2, 5-4). About $70 \mathrm{~m}^{2}$ was stripped around Block 2 located to the south of BHT 2E. Both for ease of excavation, as well as safety considerations, two trenches, each roughly $1.2 \mathrm{~m}$ in width and five meters in length, also were cut adjacent to the blocks. These trenches were excavated to roughly $1.0 \mathrm{~m}$ below the surface.

For the much deeper excavations in Area 2, it was necessary to mechanically strip a large area around BHT 6 (see Figures 5-3, 5-5). Roughly $560 \mathrm{~m}^{2}$ (ca. 40-x-14 m) were removed with a trackhoe to various depths below surface. Benches and ramps were placed for both ease of access and to accommodate safety considerations. Within Area 2, Block 3 (north of BHT 6) and Block 4 (south) were pre-benched by excavating trenches on all four sides (see Figure 5-3). These pre-bench safety trenches were roughly $1 \mathrm{~m}$ in depth, and $1.5 \mathrm{~m}$ in width. These trenches were excavated with a backhoe. Hand excavation in the northern block (Block 3) of units in Area 2 began at about 1.8 mbs and terminated at 4.3 mbs. In the southern block (Block 4) of units in Area 2, hand excavation began at about $2.0 \mathrm{mbs}$ and terminated at $4.5 \mathrm{mbs}$.

With the exception of some initial levels that were slightly thicker than $10 \mathrm{~cm}$ in some units, excavation levels were 


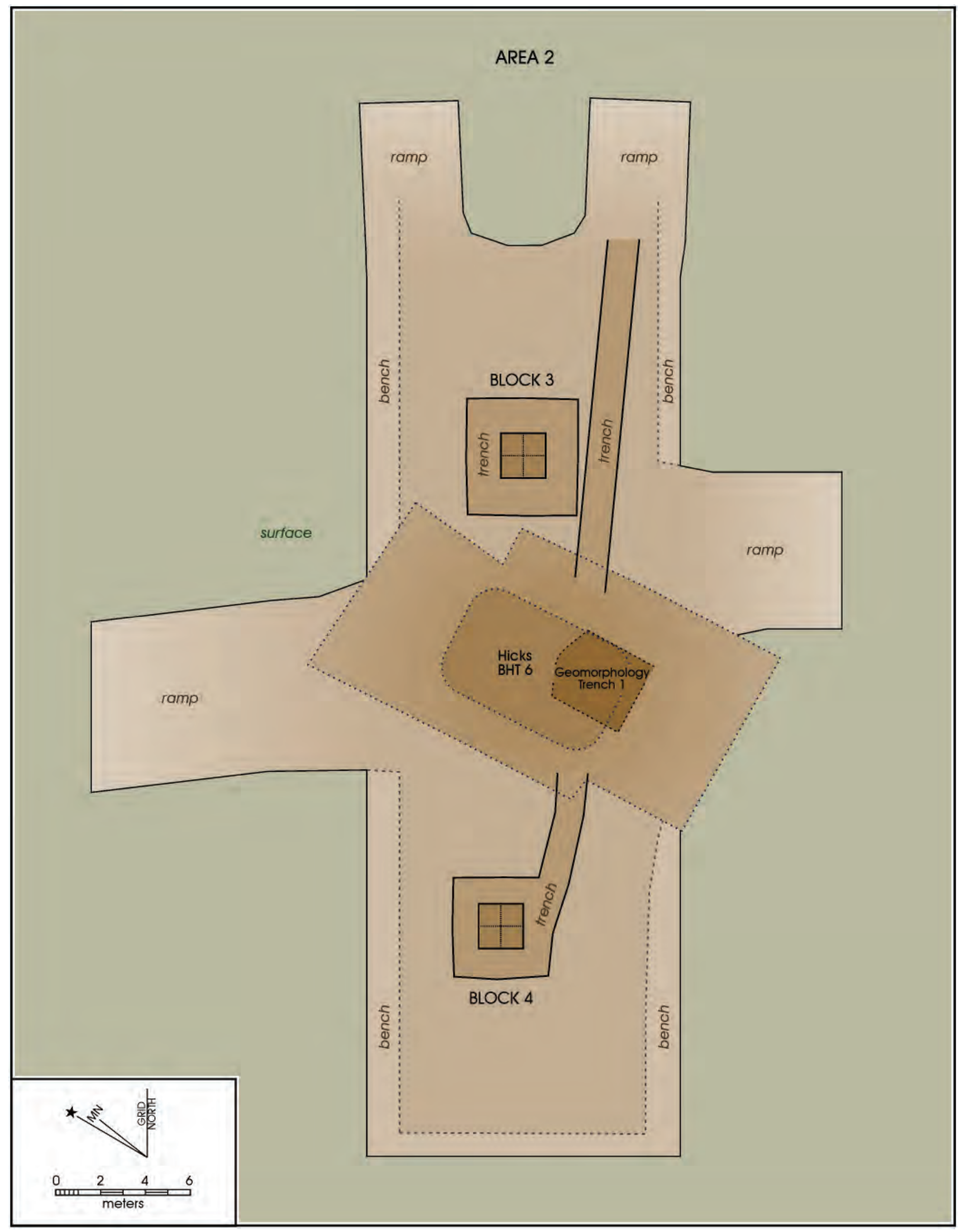

Figure 5-3. Area 2 excavation plan, 41TV410. 


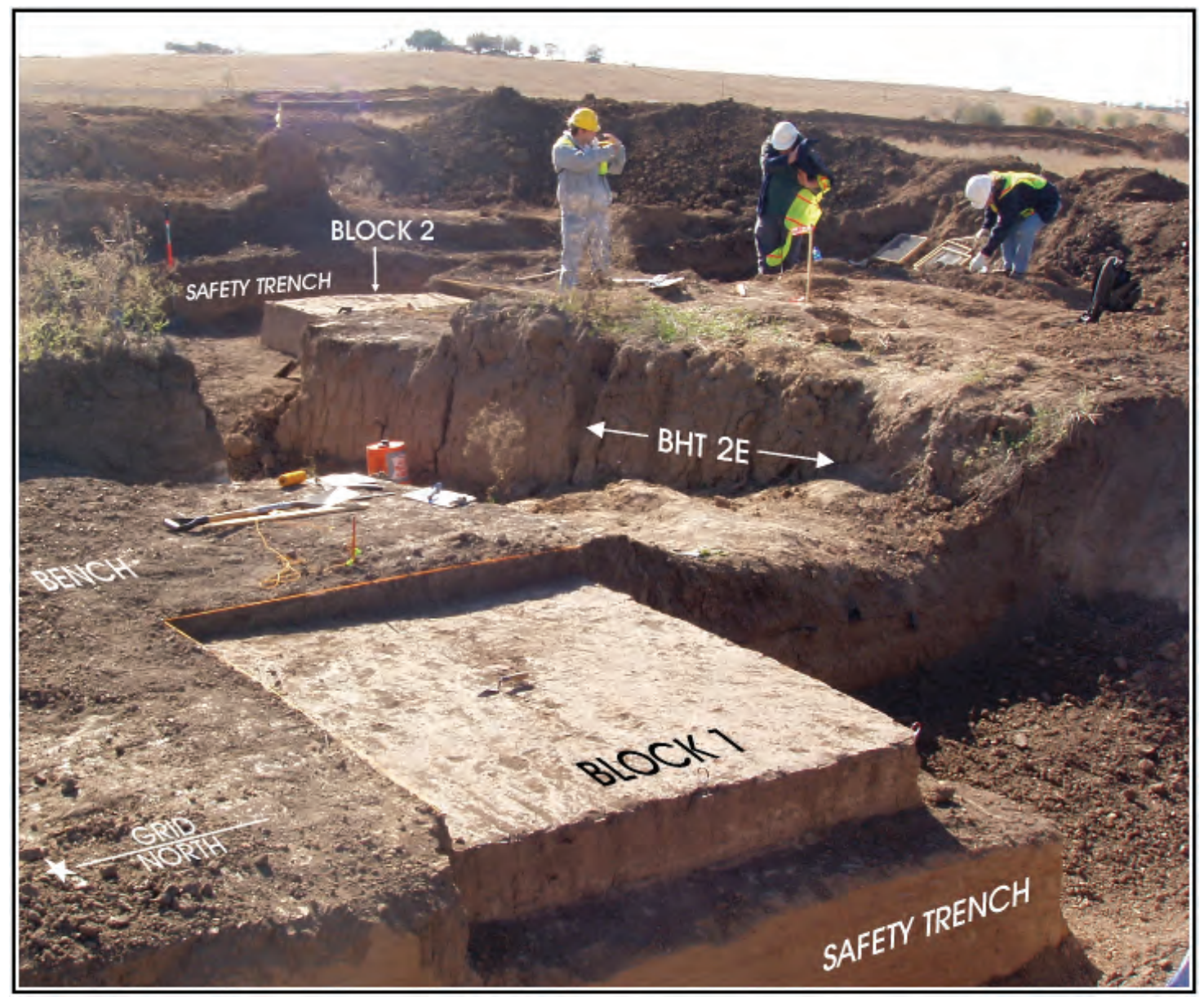

Figure 5-4. Area 1 with blocks and safety trenches identified, 41TV410.

$10 \mathrm{~cm}$ thick. To ensure that artifact recovery was not biased against the recovery of small specimens (e.g., late reduction debitage), a two-liter sample of sediment was collected from each level of a selected $1 \times 1 \mathrm{~m}$ unit in each block. These were transported to the CAR laboratory and water-screened through $1 / 8$ inch mesh. All other sediment was screened through $1 / 4$ inch mesh, with all artifacts as well as snail shell, mussel shell, and bone collected and bagged by level. Charcoal was collected when observed in context. In order to expedite results from the significance testing at 41TV410, material collected in the field was transported to the CAR lab facility on a weekly basis for initial processing.

CAR excavated several features at the site. Unfortunately, many of these features were uncovered by the stripping operation, and therefore were partially damaged prior to any hand-excavation. Where possible, features were drawn in plan view, bisected, and profiled. When seen in primary context, charcoal was collected from features. All feature fill not associated with special samples was screened through $1 / 4$ inch mesh, with artifacts and ecofacts collected. Matrix samples were collected from within features for flotation analysis, and a matrix sample from outside of the feature was obtained in each instance. In those cases where the feature represented a hearth, several pieces of burned rock were collected for lipid residue analysis and all other burned rock within the thermal features was collected in a separate bag.

Overall, CAR hand excavated $33.02 \mathrm{~m}^{3}$ at $41 \mathrm{TV} 410$. This total included $1.31 \mathrm{~m}^{3}$ that was used to explore features discovered during the course of mechanical stripping of the two excavation areas.

\section{Laboratory Methods}

Because of time constraints associated with the project, the laboratory portion of the project was conducted concurrently with the field work summarized above. Material was transported from the site to the CAR laboratory on a weekly basis. A variety of tasks were undertaken once the material was at CAR. These included the processing of flotation samples gathered from features, including preliminary screening of samples for organics, cleaning and preliminary review of 


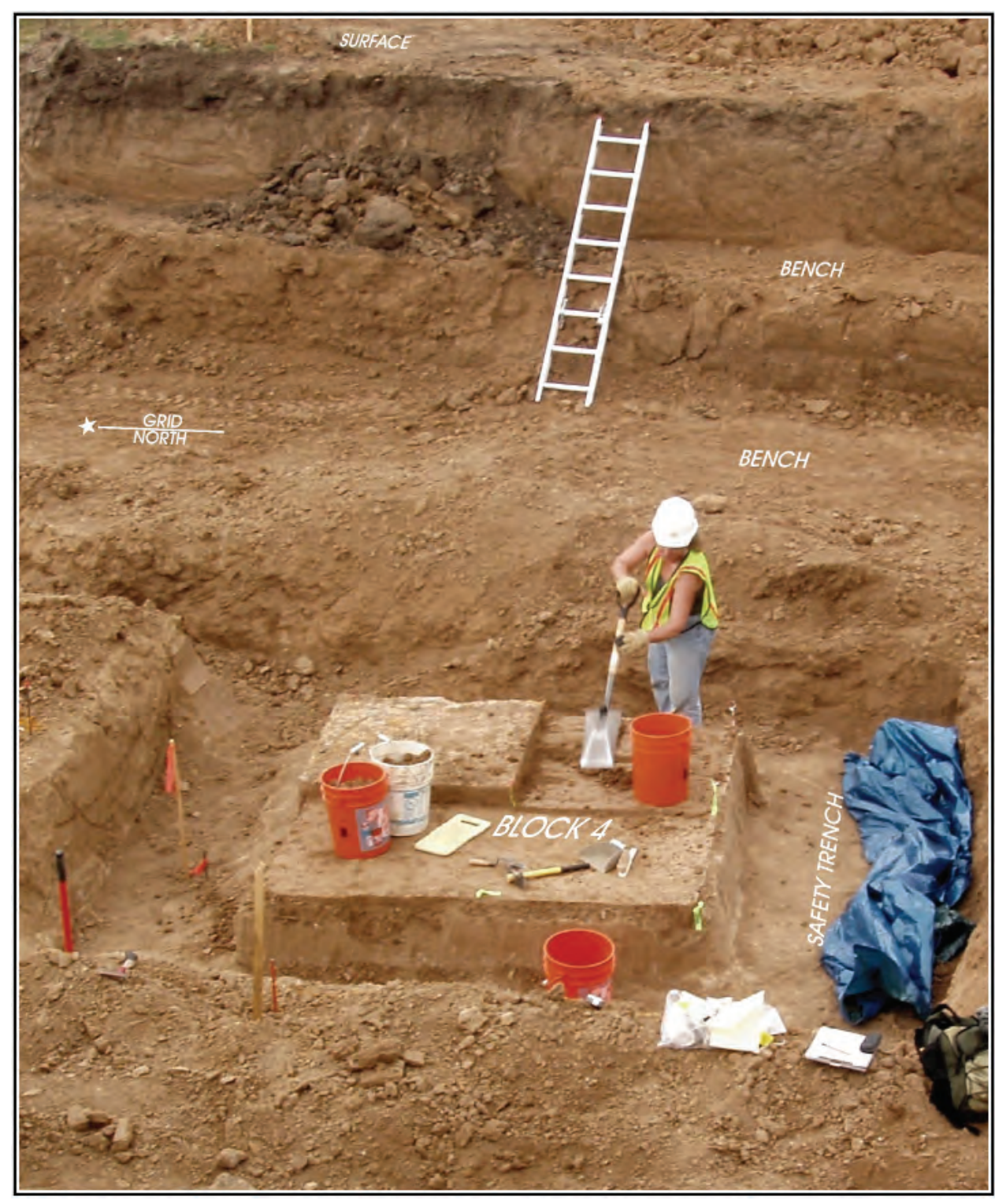

Figure 5-5. Area 2, Block 4 excavations with benches and safety trenches identified, 41TV410. regarding where permanent curation will occur, remain to be made. However, we assume that all material not discarded will be curated at CAR.

\section{Cultural Material Recovered}

While a variety of artifacts, including debitage, burned rock, ground stone, and chipped stone tools were recovered from the 2-x-2 m block excavations, the quantities were extremely low. The Block 1 excavations in Area 1 , in which we screened $6.15 \mathrm{~m}^{3}$ of sediment, produced roughly 53 pieces of small burned rock, and nine pieces of debitage. The vast majority of the burned rock (ca. 94\%) and all of the debitage came from the upper six levels of the excavation. These materials are consistent with the upper peak revealed in the previous testing in this area (see Campbell et al. 2005). However, the bottom peak, present in the results from the previous work, was not evident. Below Level 10, only a single piece of burned rock was recovered. Snails were frequent, with over $6.6 \mathrm{~kg}$ being collected in the four 1-x-1 m units. No features were identified and no charcoal collected. Bone and mussel shell were also absent. Water screening all bone recovered, cleaning and description of chipped stone tools, the acquisition of data on burned rock weight and feature size, and the water-screening of matrix samples.

Theresults of these preliminary summaries were used to generate the post-field report (Mauldin 2006) noted above. Following the generation of that document, and the determination by TxDOT that no additional work was necessary on the materials, CAR ceased work on the collections. Currently, all notes, photographs, artifacts, burned rock, bone, and other associated materials and other documents are temporarily stored at the CAR in accordance with federal regulations 36 CFR part 79, THC requirements, and in accordance with current guidelines of the Texas Archeological Laboratory. At the present time, decisions regarding discard of material, along with decisions of sediment samples collected from each level of a single 1-x-1 $\mathrm{m}$ unit produced snails, along with a single piece of debitage in the $1 / 8^{\text {th }}$ inch screen.

In Block 2 of Area 1, the screening of $6.06 \mathrm{~m}^{3}$ of sediment produced roughly similar debitage recovery (ca. 12 pieces), but did have higher recovery of burned rock. Approximately 340 pieces of burned rock, most representing heat spalls and all small in size, were recovered from this excavation. As with the Block 1 work, this material was confined to the upper levels, with all material coming from the upper eight levels. Much of the burned rock was concentrated in Level 5 of the excavation (ca. 159 pieces), a level roughly equivalent to the depths where previous research defined Feature 3, a burned rock feature (see Campbell et al. 2005). Several pieces 
of burned clay were noted, but no charcoal, bone, or mussel shell was recovered in the $1 / 4$ inch screen, and no features were defined within the 2-x-2 m block. Snails were frequent, with roughly $6.7 \mathrm{~kg}$ collected. The water screening of control samples from each level produced snail, and a single piece of charcoal was also noted in the control samples.

In Block 3 in Area 2, recovery of artifacts was higher than in the Area 1 blocks. While we excavated a larger volume of sediment $\left(9.70 \mathrm{~m}^{3}\right)$, over 60 pieces of debitage were recovered, along with roughly 60 pieces of burned rock, some pieces of burned clay, about 20 grams of bone, several lithic tools and cores, and mussel shell. Charcoal was collected from 11 of the 97 levels excavated in Block 3. A plot of the distribution of the debitage (blue) and burned rock (red) is presented in Figure 5-6. A number of peaks can be identified in the debitage and burned rock, as well as in the overlaps of debitage and rock (purple). Note that several levels also had no recovery. Peaks in debitage numbers are in Levels 14 through 17 and in Levels 21 through 23. Burned rock is highest near the bottom of the excavation, with 17 pieces in Levels 22 and 23. Radiocarbon assays on non-feature-associated charcoal from these peaks yielded calibrated, corrected dates of between Cal. BP 5590-5330 (4760+/- 40, Beta \#216434) for the higher peak at $3.5 \mathrm{mbs}$ and Cal. BP 5620-5480 (4830 +/- 40, Beta \#216435) for the lower peak in lithics and burned rock at 4.25 mbs. Low recovery rates of either artifact class are apparent in Levels 1 and 2, Levels 10 and 11, and Level 18. While based on small samples, these peaks may reflect different intensities of use in the block through time. As with other excavations at 41TV410, snails were common in Block 3 with about $6.4 \mathrm{~kg}$ recovered. No features were identified in the excavation. Water screening of sediment samples collected from a selected 1-x-1 m unit produced a variety of snails. No artifacts or charcoal was noted in the fine screen matrix.

The excavation of $9.80 \mathrm{~m}^{3}$ of sediment in Block 4 within Area 2 produced roughly 95 pieces of burned rock, but only 32 pieces of debitage. Also recovered were a stem of an Early Archaic Andice projectile point (Level 1), a

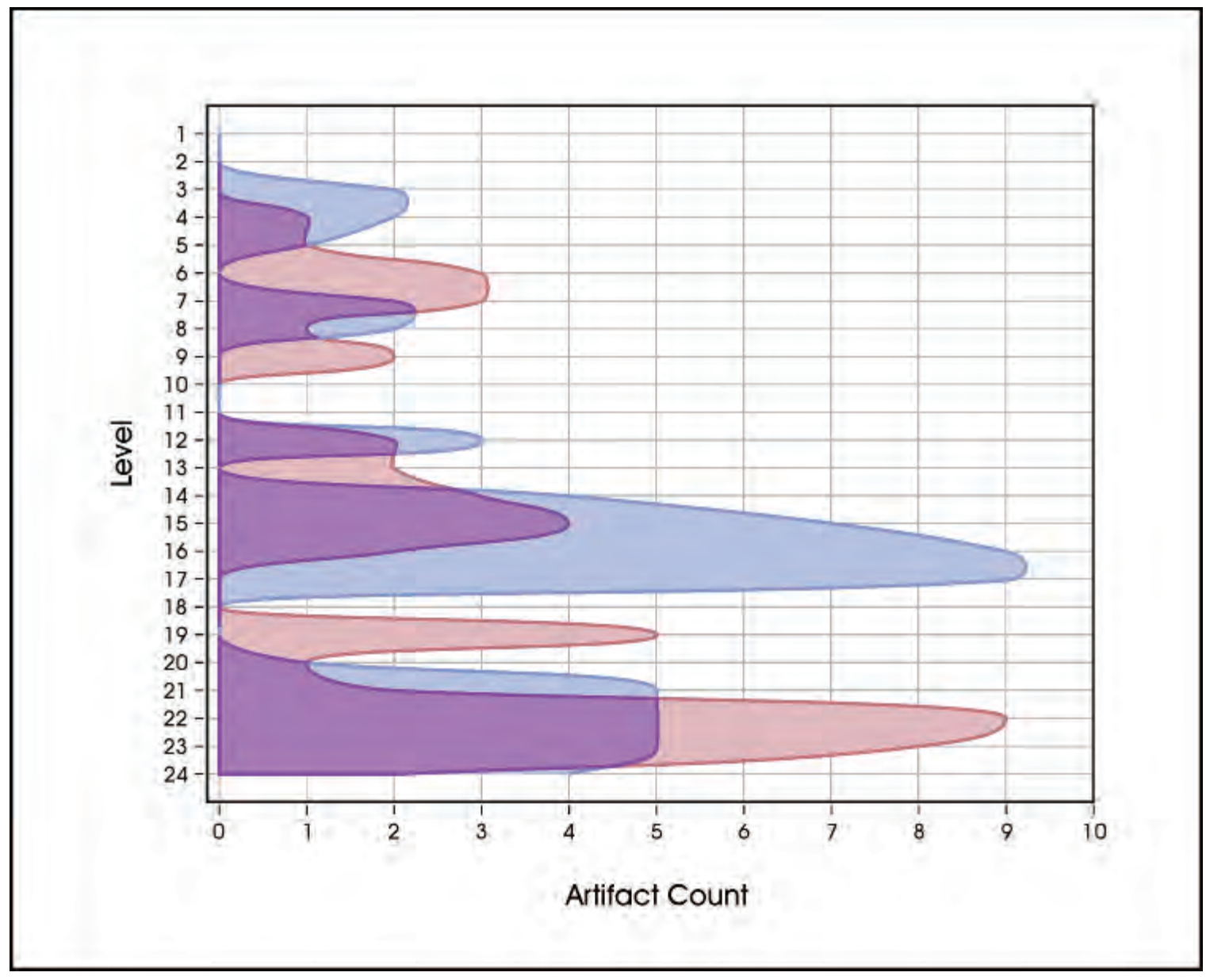

Figure 5-6. Vertical distribution of debitage (light blue) and burned rock (red) in Block 3, Area 2, Purple indicates areas of overlap 
mano fragment, about $60 \mathrm{~g}$ of burned clay, $2 \mathrm{~g}$ of bone, roughly $20 \mathrm{~g}$ of mussel shell, and over $5.1 \mathrm{~kg}$ of snail shell. Charcoal was more common in this excavation area, with 37 different samples collected. The vertical distribution of the artifacts suggests two concentrations, with most of the debitage (ca. 93\%) being recovered within the upper 7 levels of the excavation. No debitage was recovered from Levels 8 through 12, from levels 14, 15, or 16, and no debitage was recovered from Levels 19 through 23. Level 24 produced 2 pieces of chipped stone debitage. Burned rock had a roughly similar distribution, with the upper 8 levels containing the vast majority of the burned rock. However, unlike previous excavations, two features were identified in the Block 4 excavations. Feature 23 was identified in Level 21, while Feature 24 was defined in Level 22 of an adjacent 1-x-1 m unit. As discussed below, both features were small, circular stains with charcoal flecks and small quantities of burned rock. Finally, note that other than snails, only five pieces of debitage were recovered from the water screening of the control samples from this excavation area.

\section{Features}

CAR archeologists identified eleven features during our testing at the site. All were excavated by hand (Table 5-1). Two of the eleven features (Features 23 and 24) were defined within 2-x-2 m blocks. The other nine features were identified outside of the block excavations. These features were primarily uncovered during backhoe and trackhoe excavation. Previous excavations at the site had identified 9 features. We assigned 15 additional feature numbers (10 through 24), though subsequent exploration of the locations suggested that four of the 15 were not features, being represented only by two or three rocks with no associated staining. Table 5-1 lists the features, and each is briefly discussed below.

Three features were defined in Area 1 (Figure 5-7). All were in proximity to Block 2. All three were at a similar elevation. Feature 10 (Figures 5-7, 5-8) was a circular cluster of limestone cobbles roughly $55 \mathrm{~cm}$ by $60 \mathrm{~cm}$ in size. The southern portion of the feature was damaged by the backhoe though the northern portion seemed to be intact. Only some of the rocks appeared to have been fire-cracked. No charcoal was observed, but a small amount of bone was present. Over $12.2 \mathrm{~kg}$ of rock was in this feature. A small number of snails were noted both inside and outside of the feature.

Feature 11 (Figure 5-7, 5-9) was a roughly circular scatter of limestone rock, associated with a slight discoloration in the soil. The eastern portion of the feature was damaged by backhoe excavation. Over $25 \mathrm{~kg}$ of rock was associated with this feature. Charcoal was collected, along with several pieces of debitage. No snails were present in the feature matrix.

Feature 12 was similar to the previous two features (see Figure 5-7), though significantly larger in size. The western portion of the feature was badly damaged during trackhoe excavation, but the eastern portion, as well as the bottom of the feature, was intact (Figure 5-10 and 5-11). Composed of over $40.8 \mathrm{~kg}$ of limestone rock, some of which was clearly fire-cracked, the feature had charcoal and staining present, and several samples were collected for radiocarbon dating. Radiocarbon assays taken from this feature ranged from Cal. BP 2320-2060 (2180 +/- 40, Beta \# 216439) and Cal. BP 2340-2130 (2220 +/- 40, Beta \# 216436). A small number of snail shells were present in the feature matrix.

Table 5-1. Features Assigned during Phase II Testing at 41TV410

\begin{tabular}{|c|c|c|c|l|l|l|}
\hline $\begin{array}{c}\text { Feature } \\
\text { No. }\end{array}$ & Area & $\begin{array}{c}\text { Center } \\
\text { Northing }\end{array}$ & $\begin{array}{c}\text { Center } \\
\text { Easting }\end{array}$ & \multicolumn{1}{|c|}{ Type } & $\begin{array}{l}\text { Conventional } \\
\text { Radiocarbon } \\
\text { Age }\end{array}$ & \multicolumn{1}{|c|}{ Comments } \\
\hline 10 & 1 & 96.9 & 82.5 & Burned rock & NA & $\begin{array}{l}\text { Exposed by backhoe- southern } \\
\text { portion of feature. }\end{array}$ \\
\hline 11 & 1 & 96.3 & 78.5 & $\begin{array}{l}\text { Burned rock w/ } \\
\text { charcoal }\end{array}$ & NA & $\begin{array}{l}\text { Exposed by backhoe- eastern } \\
\text { 2/3rds of feature is badly scattered. }\end{array}$ \\
\hline 12 & 1 & 4.6 & 83.5 & $\begin{array}{l}\text { Burned rock with } \\
\text { charcoal staining }\end{array}$ & $\begin{array}{l}2180 \pm 40 \text { BP } \\
2220 \pm 40 \text { BP }\end{array}$ & $\begin{array}{l}\text { Exposed by trackhoe-western } \\
\text { portion of featura is badly scattered. } \\
\text { Lots of staining. }\end{array}$ \\
\hline 13 & 2 & 24.5 & 58 & Burned rock & $4820 \pm 40$ BP & $\begin{array}{l}\text { Exposed by trackhoe- may have } \\
\text { been several features in this area, } \\
\text { but only one could be defined- } \\
\text { charcoal present. }\end{array}$ \\
\hline 16 & 2 & 9 & 45 & metate and rock & NA & $\begin{array}{l}\text { Probably single metate- shattered } \\
\text { by trackhoe. Rock appears burned, } \\
\text { but no staining. }\end{array}$ \\
\hline 18 & 2 & 13 & 56 & $\begin{array}{l}\text { scattered burned } \\
\text { rock }\end{array}$ & NA & $\begin{array}{l}\text { No definite shape. Charcoal present } \\
\text { in low density. }\end{array}$ \\
\hline 19 & 2 & 10 & 55.2 & $\begin{array}{l}\text { Burned rock w/ } \\
\text { charcoal staining }\end{array}$ & $4700 \pm 40$ BP & $\begin{array}{l}\text { Well defined cluster of rock with lots } \\
\text { of charcoal present. Basin shaped. }\end{array}$ \\
\hline 21 & 2 & 10 & 49 & scattered rock & NA & $\begin{array}{l}\text { Low density scatter- no real pattern } \\
\text { evident. }\end{array}$ \\
\hline 22 & 2 & 7.9 & 48.5 & scattered rock & NA & $\begin{array}{l}\text { Much like Feature 21, but with little } \\
\text { better resolution. Ground stone } \\
\text { fragments. }\end{array}$ \\
\hline 23 & 2 & 16.3 & 50.2 & Charcoal stain & $5170 \pm 40$ BP & $\begin{array}{l}\text { Small-rock and burned clay also } \\
\text { present in discoloration. }\end{array}$ \\
\hline 24 & 2 & 16.45 & 49.5 & Charcoal stain & NA & $\begin{array}{l}\text { Small- fcr present, burned clay, and } \\
\text { charcoal- similar to Feature 23. }\end{array}$ \\
\hline
\end{tabular}




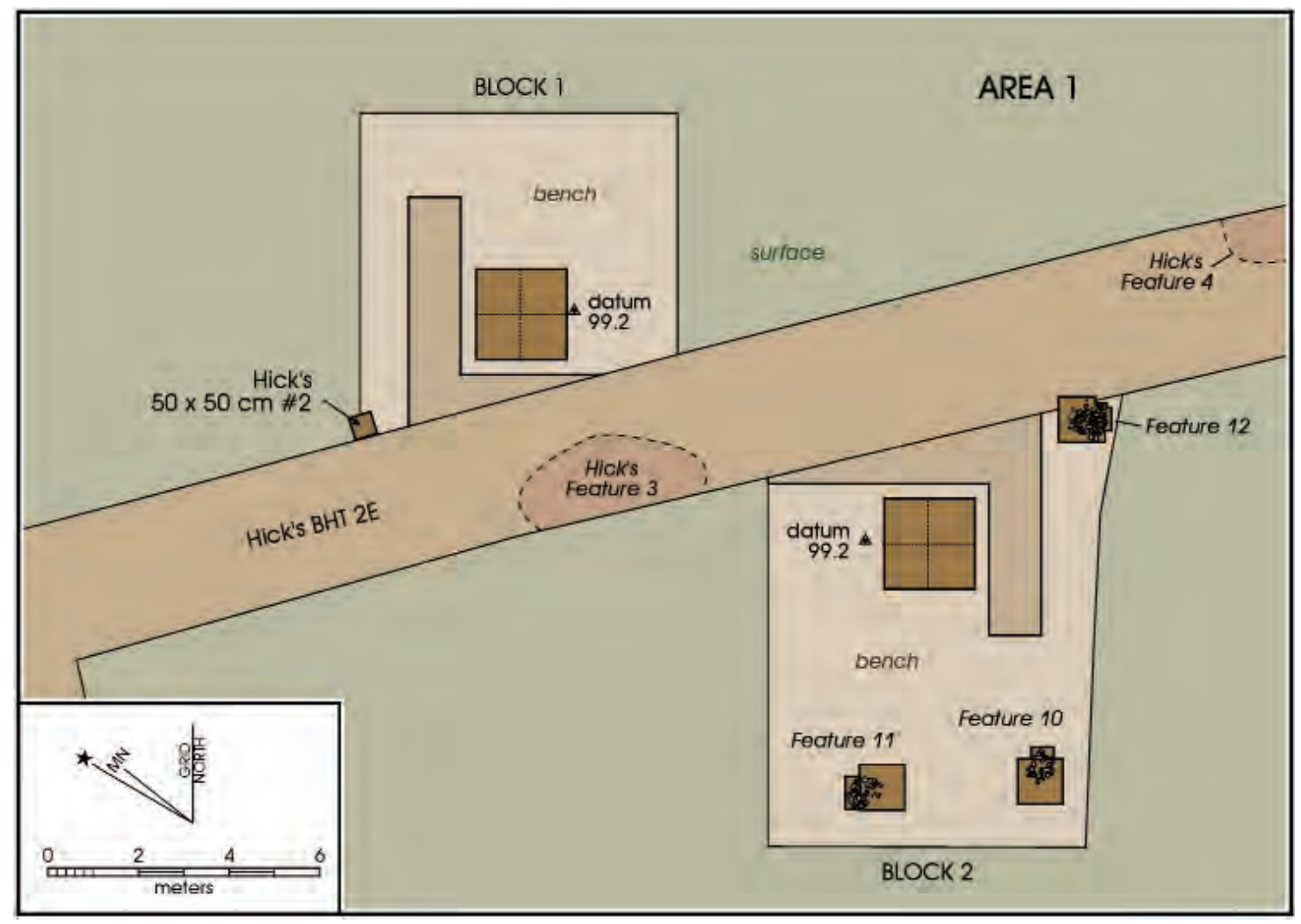

Figure 5-7. Area 1 excavations with features identified, 41TV410.

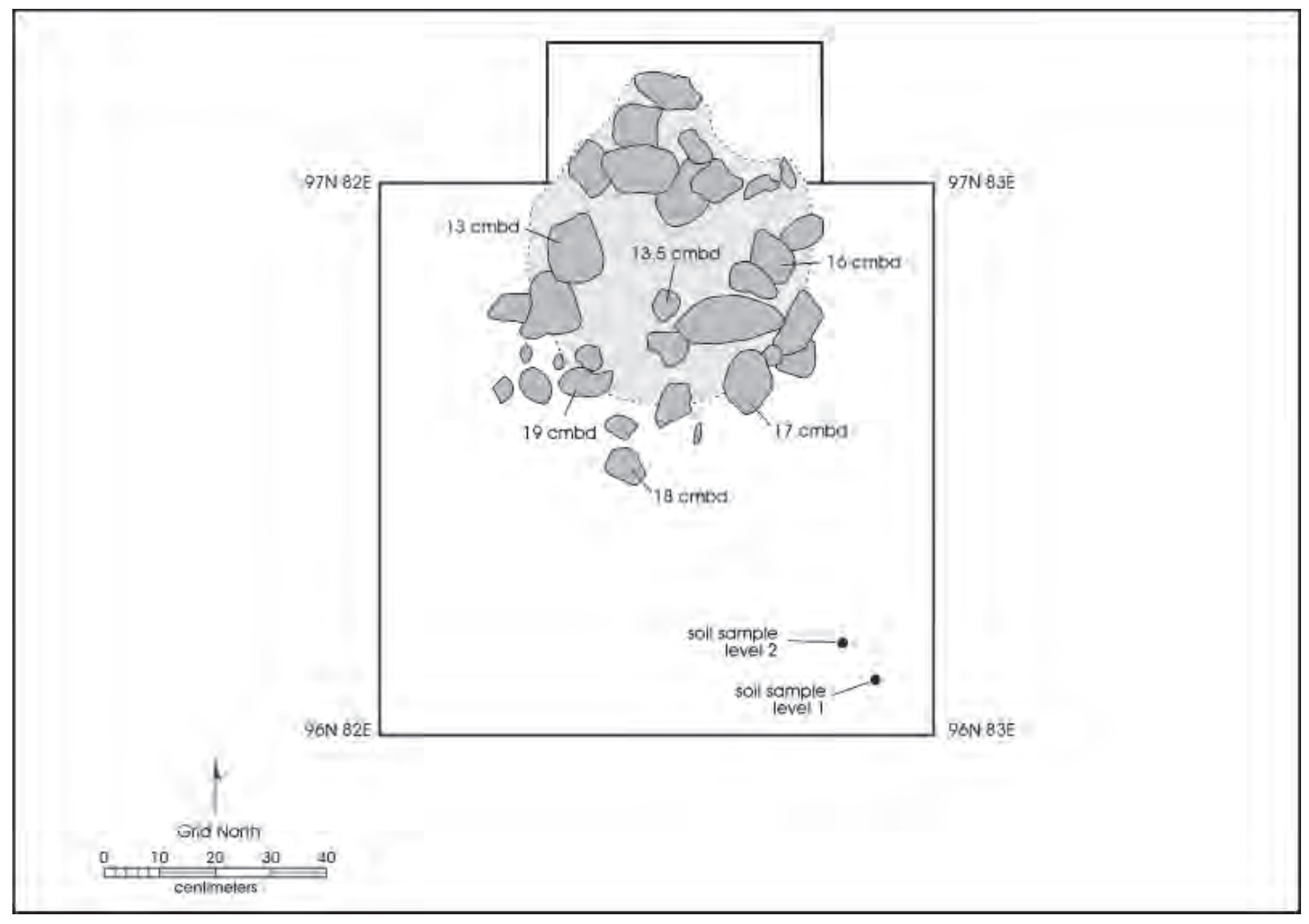

Figure 5-8. Plan view of Feature 10, Area 1, 41TV410. 


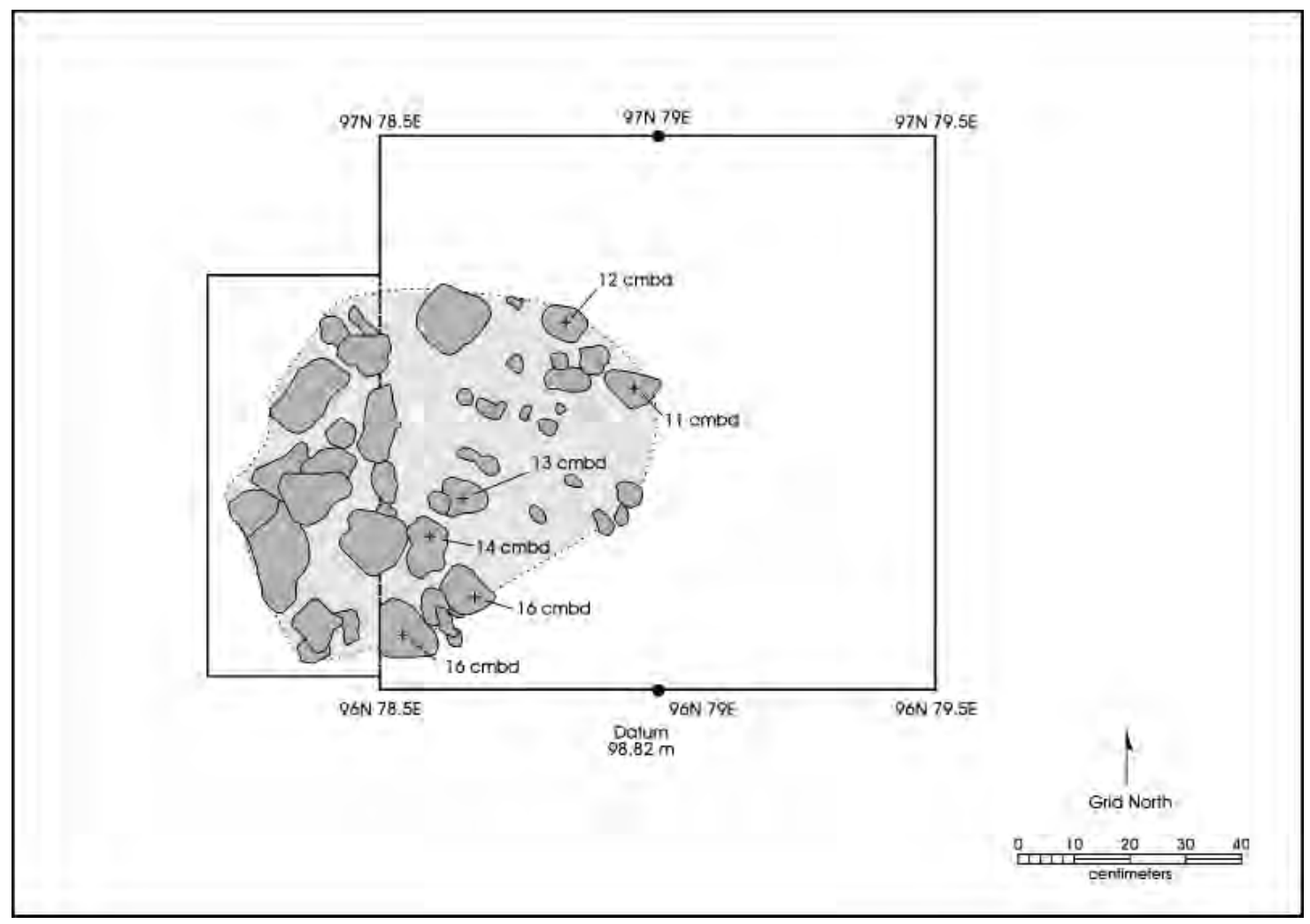

Figure 5-9.Plan view of Feature 11, Area 1, 41TV410.


Figure 5-10. Plan view of Feature 12, Area 1, 41TV410. 


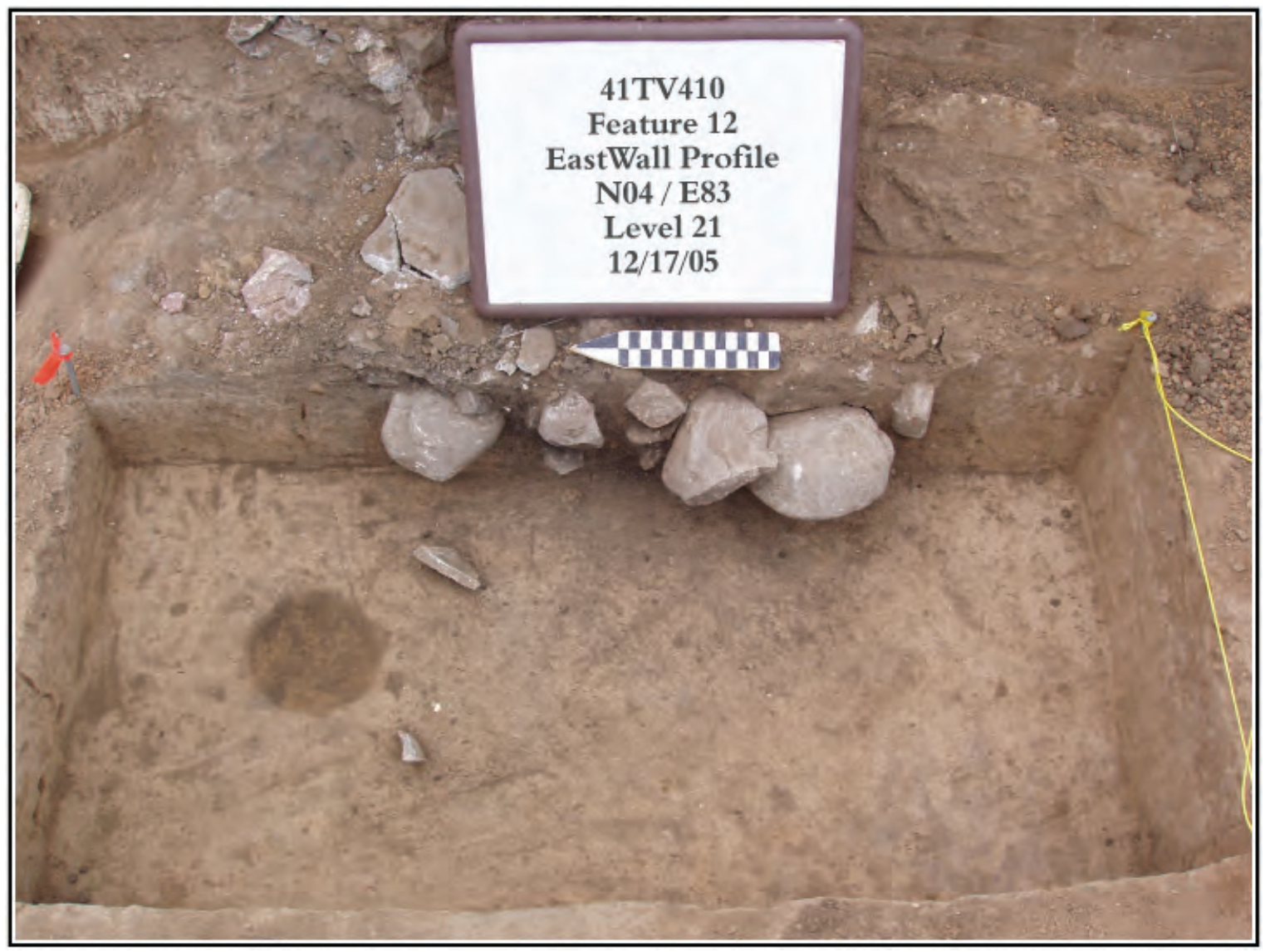

Figure 5-11. Profile of Feature 12, Area 1, 41 TV410.

In Area 2, most of the features were clustered near Block 4 in the southern portion of the larger area (Figure 5-12). Feature 13 was badly damaged by the trackhoe, and the subsequent scatter was originally thought to represent three different features. Ultimately, a small portion of the scatter, representing the bottom of what was once a larger feature, was identified and excavated as Feature 13. Debitage and mussel shell and scattered charcoal were present in the general area of the feature, but the feature itself was basin shaped in crosssection, roughly circular in plan, and defined by rock and soil discoloration. The feature was roughly $70-\mathrm{x}-70 \mathrm{~cm}$. Several large limestone rocks were present in the portion of the feature excavated. A radiocarbon assays from this feature clustered at Cal. BP 5610-5570 and Cal. BP 5540-5470 BP (4820 +/40, Beta \# 216440). Snails were recovered from the matrix above the feature but appear not to have been present within the feature fill itself.

Feature 16 was thought to be a burned rock feature in the southwestern wall of one of the safety benches in Area 2. Upon excavation, the feature was determined to represent at least one metate that had been shattered by the trackhoe bucket. Also present were several limestone rocks that appeared to have been burned, though no charcoal or staining was present.
Feature 18 was present in the southeastern wall of the Area 2 excavation. The feature consisted of scattered burned and fire-cracked limestone, several pieces of debitage, scattered charcoal, and small amounts of mussel shell and bone. No pattern could be discerned from the rock and scattered artifacts. Large quantities of snail shells were present in the feature fill.

Feature 19 was substantial, and largely undamaged by the trackhoe. Only a small portion of the feature was exposed in the southwestern wall of the Area 2 excavation (see Figure $5-12)$. The feature consisted of a tight, circular, $85-x-65 \mathrm{~cm}$ cluster of burned limestone and discolored soil (Figure 5-13). To the southwest of this concentration was an additional, smaller cluster of burned rock that appeared to be associated with the larger cluster. The larger cluster was basin-shaped in profile (Figure 5-13 and 5-14). Moderate quantities of snails were present in the feature fill. A radiocarbon date on this feature produced a CAL. BP range of 5580 to 5520 and 5490 to $5320(4700+/-40$, Beta \# 216438).

Feature 21, located in the south-central portion of Area 2 (Figure 5-12) consisted of a low density scatter of 


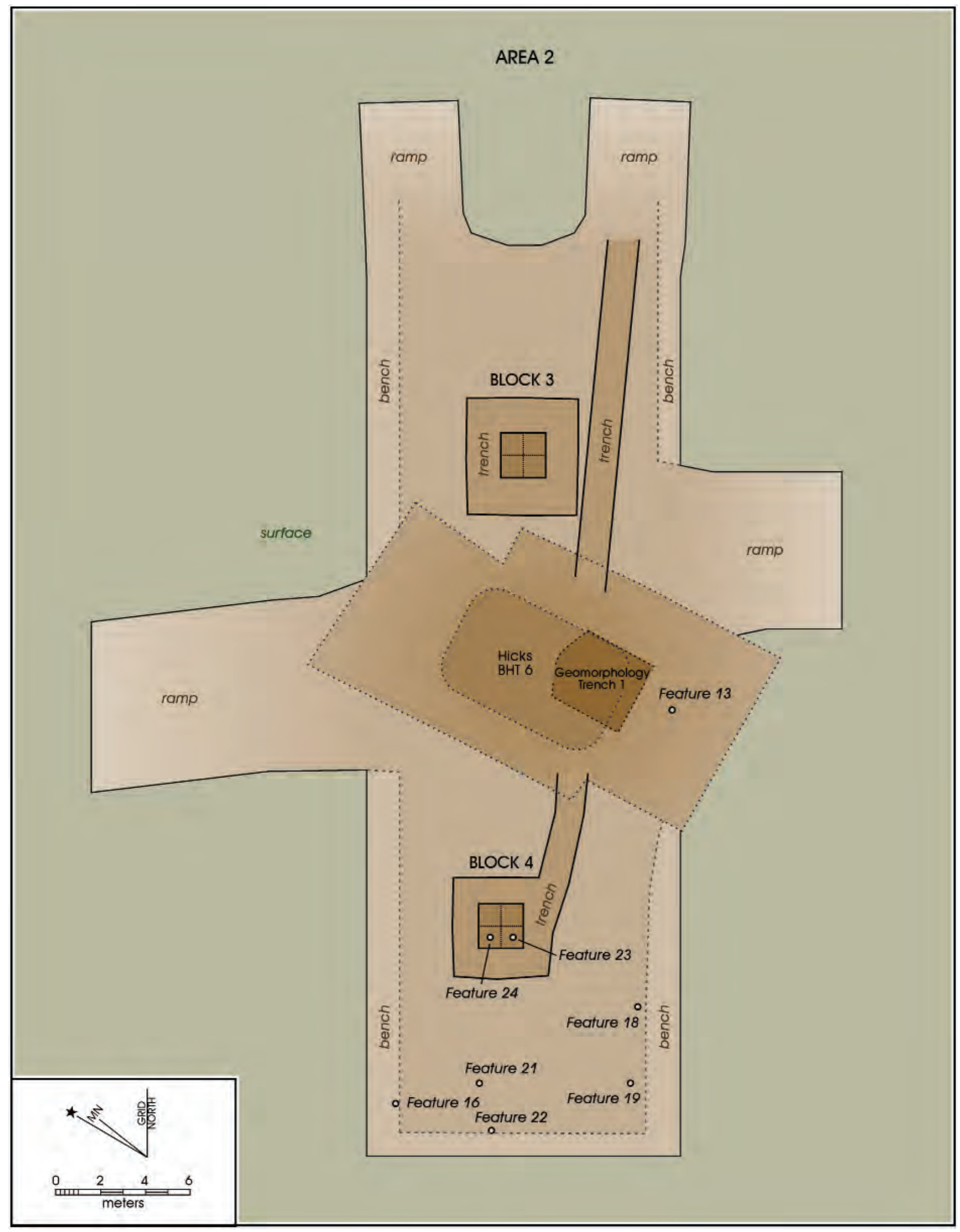

Figure 5-12. Area 2 excavations with features identified, $41 T V 410$ 

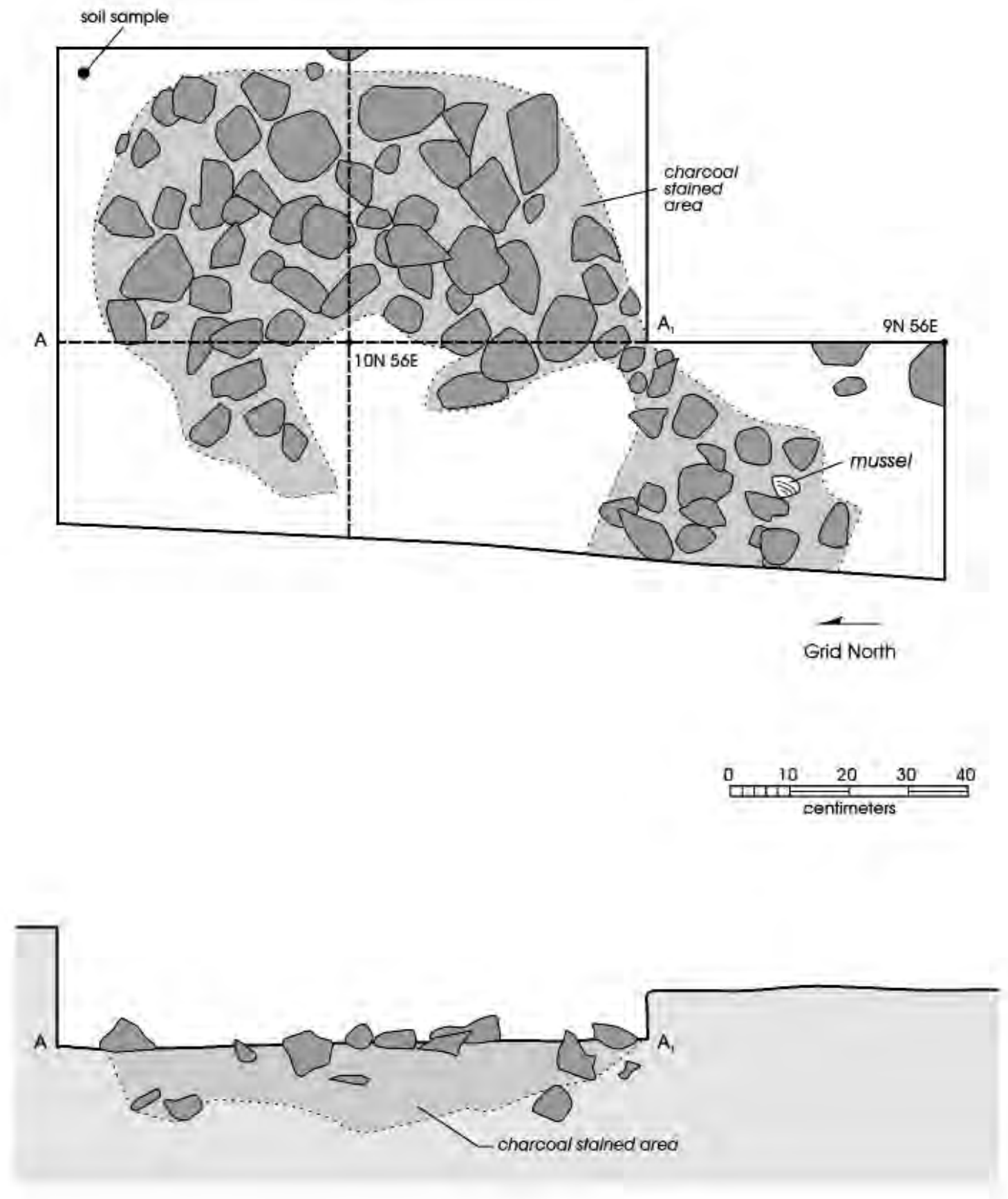

Figure 5-13. Plan view (top) and profile (bottom) of Feature 19, Area 2, 41 TV410. 


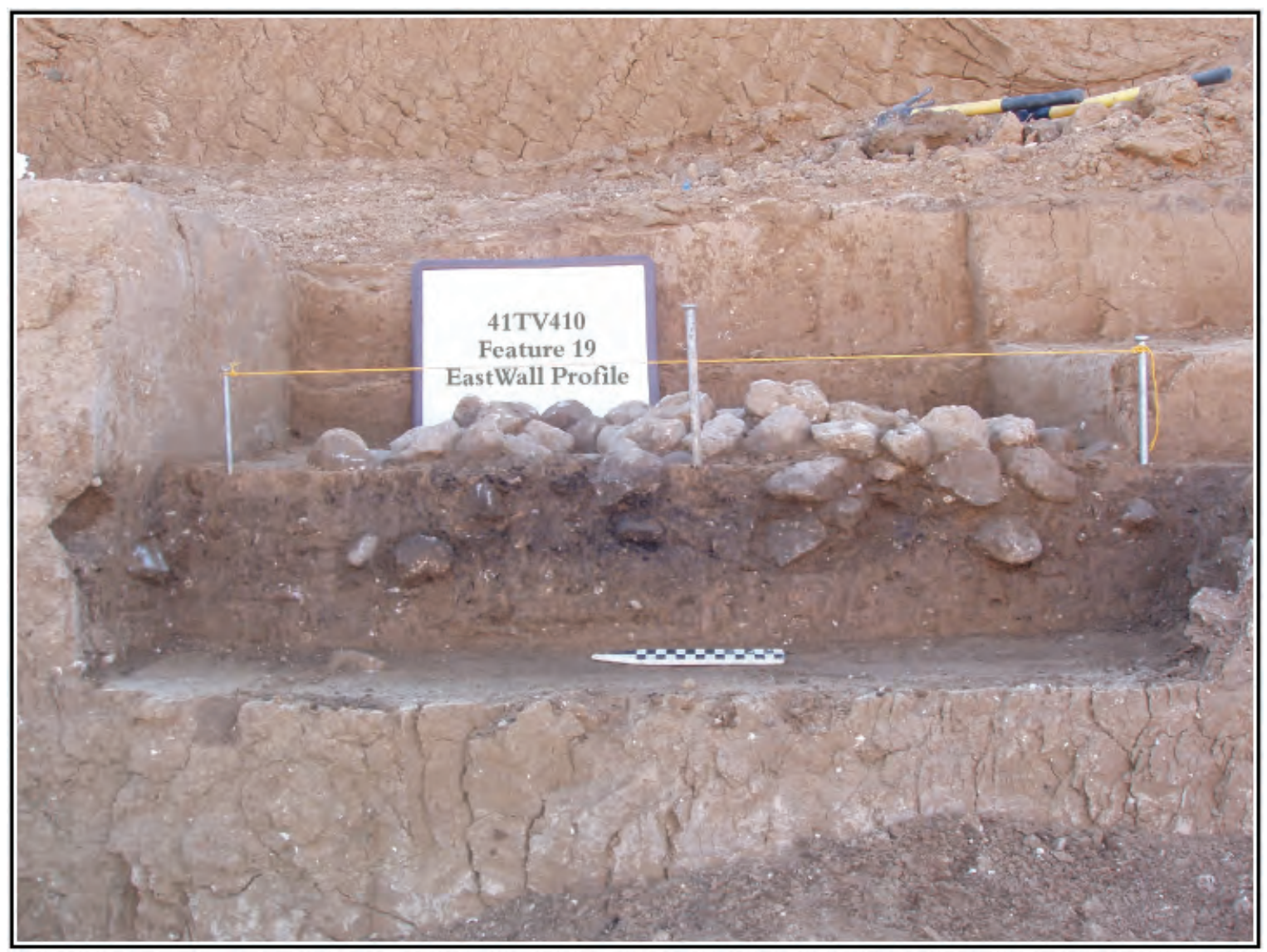

Figure 5-14. Profile of Feature 19, Area 2, 41 TV410.

burned rock and a broken biface. No charcoal or soil discoloration was present. No shape could be discerned for the rock distribution. As the area had been excavated with a trackhoe, it is probable that a significant portion of the feature was destroyed.

Feature 22 was located in the south-central portion of Area 2, on the same surface as Feature 21 described above. Feature 22 was slightly better defined than Feature 21, however. Feature 22 consisted of a tight cluster (ca. $35-x-30 \mathrm{~cm}$ ) of several burned rocks, a single metate fragment, small quantities of mussel shell, and two pieces of debitage. No soil discoloration was noted and charcoal was not observed. Small pockets of snails were present within the feature fill.

Features 23 and 24 were defined near the bottom of the Block 3 excavation in Area 2 (see Figure 5-12). Feature 23 consisted of a small (ca. 20-x-22 cm), circular soil discoloration identified in Level 21 of Unit 16N/50E (Figure 5-15). There was no depth to the discoloration, though two pieces of fire cracked rock, along with charcoal, were present in the feature. Radiocarbon assays from this feature ranged from Cal. BP 5990-5890 (5170
+/- 40, Beta \#216441). Snails were present within the general excavation level but not in the feature fill.

Feature 24 (Figure 5-16) was similar to Feature 23, though located in Unit 16N/49E. The soil discoloration was small (ca. 22-x-30 cm), circular, and had no depth. Feature 24 did contain several pieces of burned rock, a small amount of burned clay, and charcoal. Snails were observed in the fill.

\section{Summary}

The CAR testing at 41TV410 produced a low density of artifacts. Though bone preservation seemed to be good, little bone was recovered (ca. $33.75 \mathrm{~g}$ ) and the specimens found were fragmented. Snails were common in the excavation, though mussel shell was rarely encountered. A variety of burned rock features was present. These features all seemed to be intact prior to exposure. However, macrobotanical recovery from flotation of feature matrix samples is minimal in most cases (see Appendix A), and charcoal was not common in any context. While the stem of an Early Archaic Andice point was recovered along with several pieces of ground stone, lithic material was not common. Chipped stone 


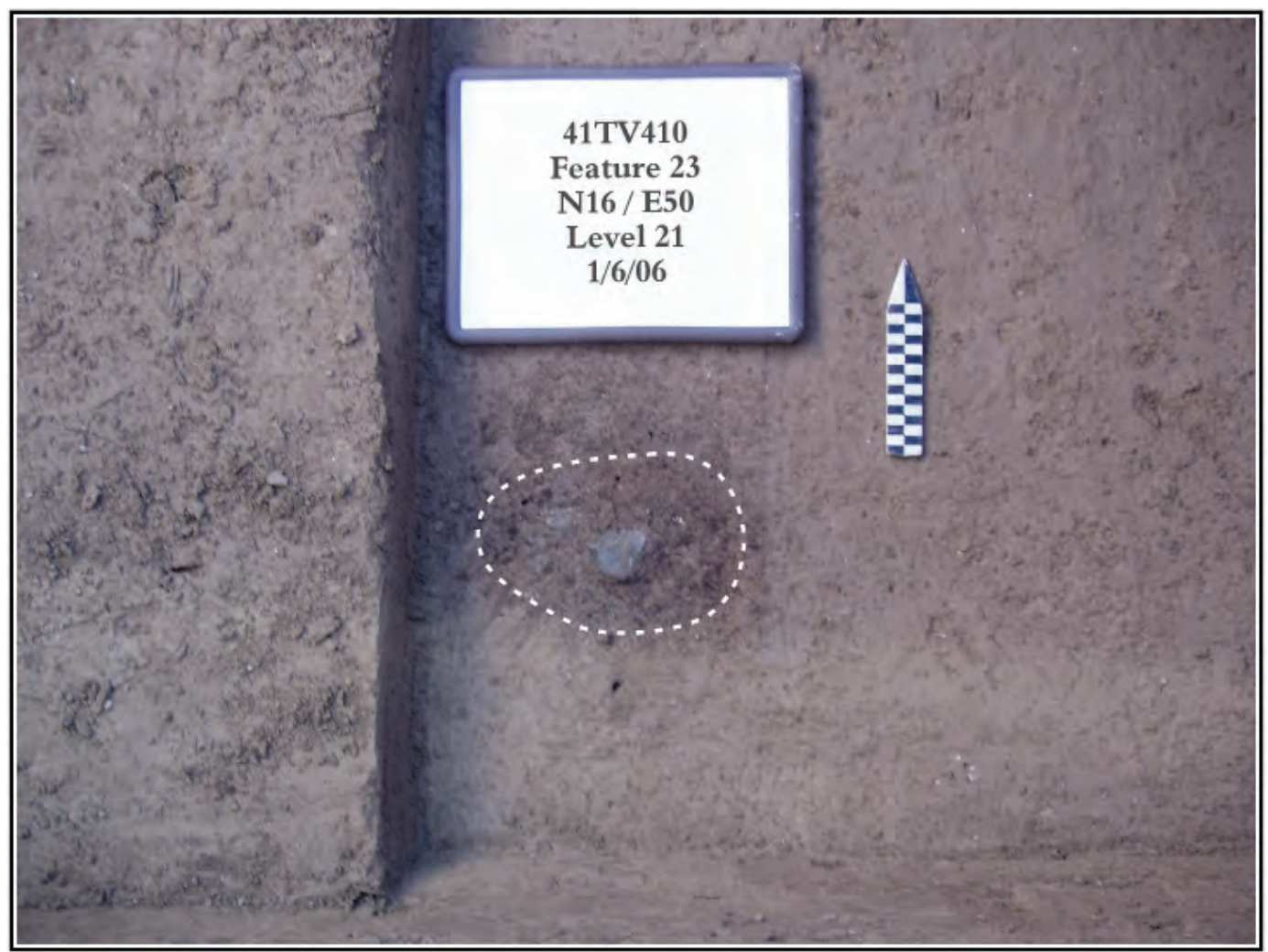

Figure 5-15. Feature 23, Block 4, 41TV410.

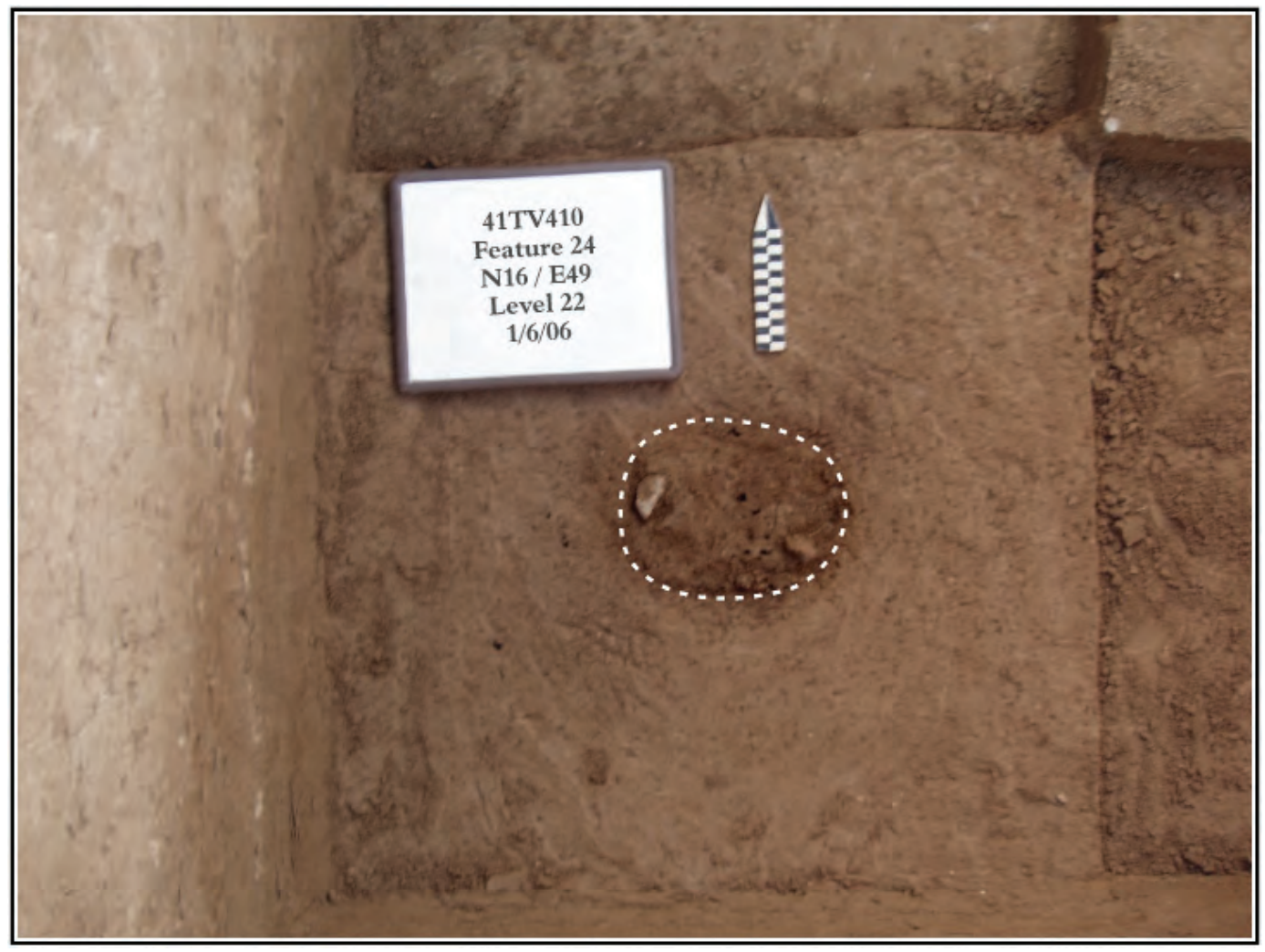

Figure 5-16. Feature 24, Block 4, 41TV410. 
items number less than 225 for the entire CAR testing effort. Finally, it appears the site area tested produced evidence of occupation, of low levels of intensity, dating to the Early Archaic, Middle Archaic, and the Late Archaic periods.

\section{Geoarcheological Observations at Site 41TV410}

Three constructional geomorphic surfaces are present within the boundaries of this site: T0, T1 and T2. The floodplain (T0) lies immediately adjacent to the Onion Creek channel and rises between 5-7 $\mathrm{m}$ above the channel. The surface of the floodplain is flat to slightly undulatory, and in places two subtle but different surfaces can be distinguished (TOa and TOb), separated by a gentle meter-tall scarp. The floodplain, within this site, is inset into the First Terrace (T1), which rises about $8 \mathrm{~m}$ above the channel and has a relatively flat tread. A prominent arcuate swale was noted in the middle of the site adjacent to the second terrace (T2) which rises about 1 to $2 \mathrm{~m}$ above the first terrace. This swale was considered by Campbell et al. (2005) to be a paleochannel of Onion Creek. The second terrace has a flat to gently convex tread and is a relatively featureless surface, except for a long, northeasttrending linear depression that lies roughly parallel to the eastern Onion Creek Valley wall.

\section{Work Performed}

During testing profiles of the alluvial deposits exposed by the Area 1 and 2 excavations were examined and described. Two profiles were drawn in Area 1, one adjacent to each block excavation. In Area 2 attention focused on the deep trench that was opened immediately adjacent to Hicks \& Company BHT 6, which exposed approximately $5 \mathrm{~m}$ of alluvial sediments (Figure 5-17). A third excavation was made in order to evaluate the age and stratigraphic affiliation of the alluvial deposits beneath the first terrace. This trench (Area 3 Deep Trench) was described in detail (Figure 5-17) and sampled twice for dating and paleoenvironmental analysis. Descriptions of the strata observed at the site are provided in Appendix B.

\section{Stratigraphy}

At least three different age alluvial deposits appear to be present within the boundaries of the site, judging by the geomorphology and radiocarbon dating performed in conjunction with the excavations (see Figure 5-17 schematic stratigraphic illustration inset into lower right part of figure). The eastern and southern portions of the site are underlain by Depositional Unit Qa3, which dates to the Middle Holocene between approximately 5400 and 4000 radiocarbon years
BP. The arcuate scarp that separates the T1 and T2 surface within this site denotes the boundary between Depositional Units Qa3 and Qa4. The latter (Qa4) appears to have been deposited sometime between 3800 and 2000 radiocarbon years BP, although the geochronology obtained from these deposits is less than clear. The floodplain surface is underlain by depositional Unit Qa5, which appears to represent Onion Creek sedimentation during the last 1500 years. All of the UTSA excavations targeted prehistoric occupations upon the second terrace, and the shallow excavations of Area 1 uncovered occupations within a thin drape of Depositional Unit Qa4 that mantles the leading edge of the second terrace surface at this site. The deeper excavations in Area 2 uncovered prehistoric occupations within depositional Unit Qa3. These deposits are discussed in more detail, below.

\section{The Second Terrace}

The second terrace at 41TV410 exhibited a thin (approximately 1.3 m thick) drape of depositional Unit Qa4 on top of a slightly older alluvial fill, depositional Unit Qa3. The deposits of Qa4 in this veneer exhibit 10YR hues and the soil formed in the drape exhibited an $\mathrm{A}-\mathrm{AB}-\mathrm{Bw}$ or Bk profile, where the B horizon had some structural development and variable degrees of secondary calcium carbonate. The textural trends within this veneer were nearly identical in the two profiles examined in Area 1 and in Area 2. Charcoal collected from Feature 12 in Area 1, near Block 2 provides an age for the deposition of sediment in the upper meter of the profile on the second terrace. Two samples were dated from this feature and one of these yielded an age of $2180 \pm 40$ years BP (106 $\mathrm{cm}$ below surface; Beta-216439) and the other returned a date of $2220 \pm 40$ years BP (117 cm below surface; Beta-216436). The Area 1 excavations exposed a small amount of the older depositional unit (Qa3) but not enough to clearly recognize the deposit. The deep trench in Area 2 revealed the older deposits in great detail.

The top of Unit Qa3 appears to have been truncated by erosion, with the uppermost deposits clearly associated with this unit being the Stage II calcic horizon, which, unlike the overlying veneer of Qa4 has prominent 7.5YR hues above $2.5 \mathrm{~m}$. This calcic horizon, like at 41TV540, ranged in expression from a Stage I (filamentous) to a Stage II (nodular) morphology, and in Area 2 it contained a small number (1-3\%) of small (1-5 mm) calcium carbonate nodules. The deposits below the calcic horizon consisted of many thin beds of vertically accreted overbank sediment that are primarily attributable to Onion Creek given their yellowish brown (10YR 5/4) color. A few thin mud drapes with a more red hue (usually a brown 7.5YR 5/4) are thought to be associated with Colorado River floodwaters backing up into the Onion Creek valley (e.g., Zones 23, 27, 30 and 34). The thin bedded nature of these 


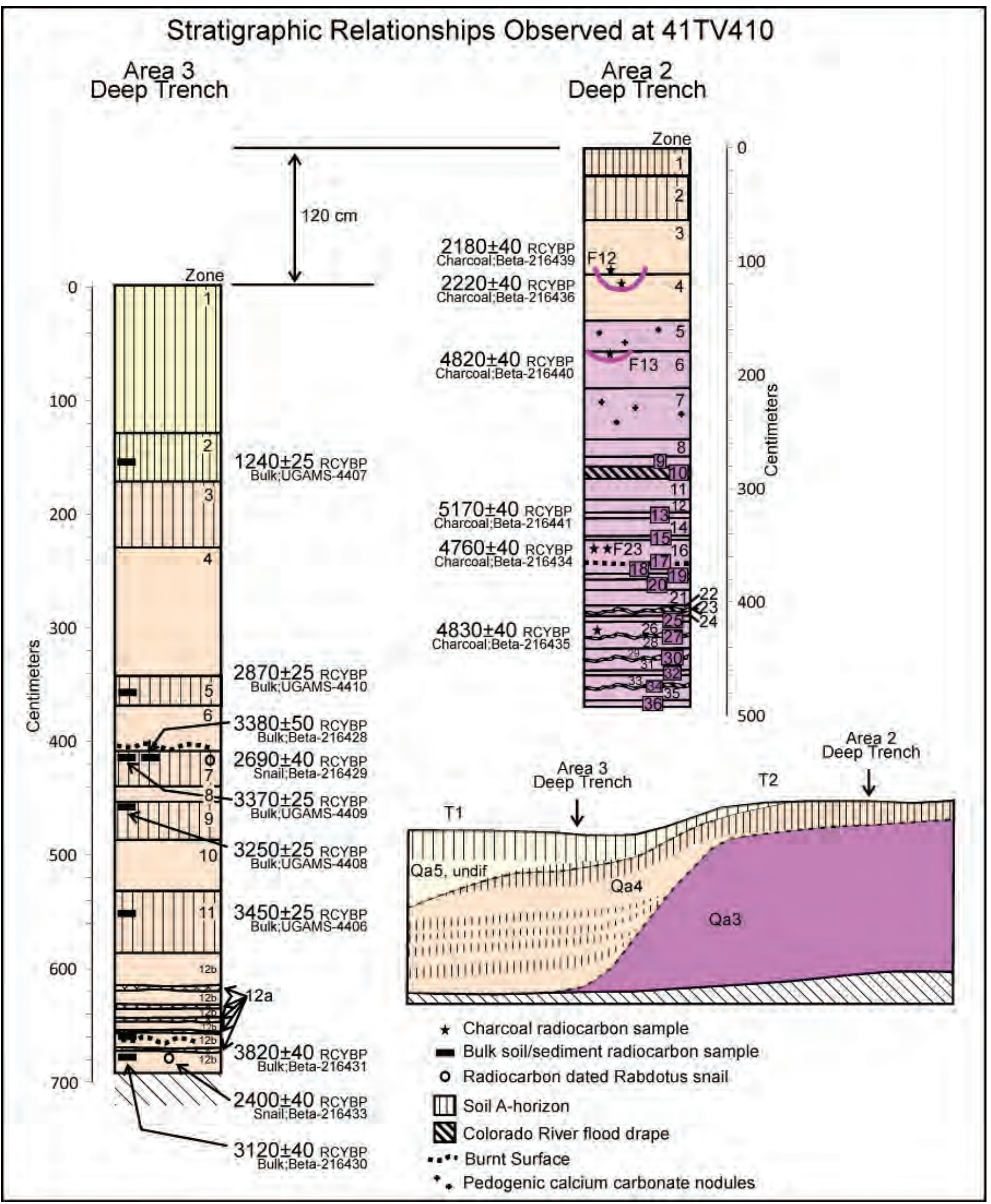

Figure 5-17. Drawing of the stratigraphy exposed within the deep trench on the first terrace and the deep trench on the second terrace (located in Area 2, immediately adjacent to Hicks \& Company Trench 6, and in between Blocks 3 and 4 ) at 41 TV410. 
deposits is clearly different from the more massive floodplain facies observed within this deposit elsewhere, and imply that this location was relatively near the channel during Qa3 deposition in this location.

Four radiocarbon ages were obtained from these deposits during testing and there is no clear pattern revealed by the ages other than to suggest that approximately $3 \mathrm{~m}$ of sediment was deposited in this locality around 4800 years ago. The lowest sample dated was collected from $4.25 \mathrm{~m}$ below the surface and yielded an age of $4830 \pm 40$ years BP (Beta-216435) whereas the highest sample within Qa3 was collected from Feature 13 at a depth of approximately $1.8 \mathrm{~m}$ below surface and yielded an age of $4820 \pm 40$ years BP (Beta216440). Two other ages were obtained from Feature 23 and the surface around it (around $3.5 \mathrm{~m}$ below surface) and these samples yielded ages older and younger than 4820/4830, specifically 5170 \pm 40 years BP (Beta-216441) and $4760 \pm 40$ years BP (Beta-216434).

\section{The First Terrace}

A single trench (Area 3) was excavated on the first terrace surface across the center of the depression Campbell et al. (2005) interpreted as a former channel of Onion Creek. The trench exposed $6.9 \mathrm{~m}$ of Late Holocene floodplain alluvium that was resting unconformably on the Cretaceous Sprinkle Formation, but no channel deposits were observed within the trench. The deposits of the bottom meter consisted of multiple thin bedded, often fining upward flood deposits that represent sedimentation in a near channel floodplain setting, whereas all of the sediments above this were relatively massive floodplain sediments within which several weakly developed soils had formed.

Ten radiocarbon ages are available from this trench, in part owing to the fact that it was sampled on two separate occasions by different individuals. Despite having numerous radiocarbon dates, the age of the alluvial sediments is less than clear. Three dates were obtained from near the base of the deposit between 6.6 and $6.9 \mathrm{~m}$, and these samples yielded ages ranging from 3800 to 2400 years BP. The oldest sample was charred sediment collected from a burnt zone at a depth of $6.6 \mathrm{~m}$ and this sample yielded an age of $3820 \pm 40$ years BP (Beta-216431) and the youngest age was obtained from a Rabdotus snail collected at $6.85 \mathrm{~m}$ that yielded an age of $2400 \pm 40$ years BP (Beta-216433) that, after correction for the age error, yields an age of approximately 1950 years BP. A bulk sediment sample collected from the same depth as the snail yielded an age $3120 \pm 40$ years BP (Beta-216430). A suite of bulk soil samples were collected from weakly developed paleosols within this exposure that seem to yield ages that are more or less in order and repeatable and suggest that this deposit formed in a punctuated fashion between 3800 and approximately 1000 years ago. One particular soil (Zone 7) was independently dated twice (once by Beta and a second time by University of Georgia) and the bulk soil samples yielded ages within 10 years of each other (3380 \pm 50 years BP, Beta-216428; 3370 \pm 25 , UGAMS-4409) which would inspire confidence were it not for a radiocarbon date on a Rabdotus snail shell from this soil that yielded an age of $2690 \pm 40$ years BP (Beta-216429) which after correction of age error yields an age of 2240 years BP. These dates indicate that the radiocarbon age of the carbon within the bulk sediment deposit is consistent, but whether this carbon accurately dates the time of sedimentation remains in doubt given that the snail shell appears to be about 1140 years younger in Zone 7, and 1170 years different in Zone 12. The relatively consistent age error between snail shell carbonate and bulk sediment/soil may indicate a consistent age error in the bulk sediment/soil samples, but the age reversal between the two snail shells (the shell in Zone 7 at $4.1 \mathrm{~m}$ yielded an age 290 years older than the snail in Zone 12 at the base of the profile around $6.85 \mathrm{~m}$ ) suggests that even the snails are not without problems.

The uppermost paleosol yielded an age of $1240 \pm 25$ years BP (UGAMS-4407) which overlaps with the period of deposition of Unit Qa5, the deposition of which appears to have started around 1500 years BP. Hence, the upper $1.6 \mathrm{~m}$ of this trench is interpreted as a veneer of Unit Qa5.

In general terms, the degree of soil development exhibited by the deposits exposed by this trench is consistent with a Late Holocene age, as all of the soils exhibited A-C profiles and no significant secondary calcium carbonate was observed within these deposits. Additional information on the dating of these deposits is provided in Chapter 8.

\section{Summary}

The deposits exposed by the UTSA excavations at 41TV410 indicate that occupation of the site in the middle Holocene occurred in a near channel setting around 4800 years ago. This floodplain was abandoned by Onion Creek around 4000 years BP, at which time the upper part of these terrace deposits appear to have experienced some erosion. A new floodplain was established around 3800 years ago, immediately west of the site, and the occupations exposed in Area 1 that date to about 2200 years BP were situated on a terrace surface overlooking a floodplain that was about 3-4 m lower in elevation. The deep trench in Area 3 exposed no evidence of occupation of this surface, but this floodplain wrapped around the present day second terrace surface and this interface was not comprehensively examined. 
Site 41TV410 contained a variety of features, several of which were substantial, and a dearth of artifacts. The scarcity of artifacts relative to the number of features makes the site of some interest, however, because it may represent a common occurrence: a repeatedly revisited site, used on a short-term basis, on a rapidly aggrading landform. These ephemeral occupations likely exist across the entire landform, but are not likely to have created dense artifact concentrations from which to excavate a significant sample of cultural material. Instead, the terrace seems to represent low-density areas of artifacts and features. With few exceptions, ephemeral sites with low densities of artifacts are usually not subjected to intensive archeological investigations. 


\title{
Chapter 6: Archeological Investigations at 41TV540-Field and Laboratory Methods and Summary of Results
}

\author{
Raymond Mauldin, Steve Tomka, Charles Frederick, Jennifer Thompson, and Antonia Figueroa
}

In order to consider the research issues outlined in Chapter 4, and given logistical considerations of limited field time, deep deposits, and the possible need to rapidly transition into data recovery work, CAR began testing of 41 TV540 on November 14, 2005. As with 41TV410, preliminary laboratory processing and analysis was conducted simultaneously. Site 41TV540 was situated on the eastern margin of the Onion Creek Holocene valley floor. The site is adjacent to a moderately steep slope that is underlain by Cretaceous age marls of the Navarro Group (Barnes 1981) that Campbell et al. (2005:10) identify as the Sprinkle Formation of the Upper Cretaceous Taylor Group. A prominent linear depression lies along the western margin of the site and slopes gently to the northeast about $50 \mathrm{~m}$ west of the valley wall. Campbell et al. (2005) considered this depression an abandoned channel of Onion Creek. The entire valley floor near the site has been mapped by the Bureau of Economic Geology (Barnes 1981) as Pleistocene age fluviatile terrace deposits (map unit $\mathrm{Qt}$ ). Campbell et al. (2005:12) identified a Colorado River lag gravel on the hill top immediately east of the site, not mapped by the Bureau of Economic Geology (Barnes 1981), as the Capitol Terrace. The soils in the immediate vicinity of the site mapped by Werchan et al. (1974) include the Lewisville Silty clay (1-2 percent slopes) on the swale and the Houston Black Clay (3-5 percent slopes) on the valley floor at the foot of the upland. The sloping valley wall underlain by the Navarro Group marls is mapped as the Ferris-Heiden complex (8-20 percent slopes, severely eroded).

Like 41TV410, the archeological material recovered from 41TV540 was dominated by features. Few artifacts were recovered. However, macrobotanical and charcoal recovery was more common at this site than at 41TV410. Bone recovery was low, though bone preservation was good, and snails were common, especially in the matrix of several large features. Following a series of on-site field meetings in early December involving TxDOT archeologists and CAR personnel, and given the low recovery for many of the artifact classes, TxDOT determined that no additional controlled excavation on the site was warranted following the completion of testing. Fieldwork at 41TV540 was completed on December 15, 2005, and CAR completed and submitted a post-fieldwork report summarizing the testing activities and preliminary results in early January of 2006 (Thompson 2006). In the post-field report, CAR suggested that given the high frequency of features, many of which contained charcoal and other macrobotanical material, monitoring and controlled stripping of areas associated with the site would provide data on features with minimal disruption of construction schedules. TxDOT archeologists did not agree with these suggestions. They determined that that while the site was eligible for listing on the NRHP under criterion d, the testing activities conducted by CAR had effectively recovered significant data. TxDOT argued that any additional work was likely to result in redundant data ${ }^{\text {(note } 1)}$. As such, TxDOT directed CAR to review the recovered data and to develop a research design for the analysis of that data. The initial sections of this chapter, then, provide a summary of the field and laboratory methods used at 41TV540. These sections are followed by a descriptive summary of the archeological material recovered. Finally, the chapter concludes with a short summary of geomorphic investigations carried out in conjunction with the site excavation. We present the research design governing the analysis of that data in the following chapter. That research design is a revised and expanded version of the one that governed the initial testing, summarized in Chapter 4.

\section{Field Methods}

Based on observations of trenches excavated within 41TV540, Campbell et al. (2005) suggested that the top 0.5 to $2 \mathrm{~m}$ of this site was covered with colluvium shed from the adjacent Taylor Clay hill slope, and the core of the site was Onion Creek alluvium. However, only basic descriptions of these deposits were made and no estimate of the age of the deposits was advanced. At the time of the CAR fieldwork, the alluvial stratigraphy of Onion Creek was poorly understood. The deposits at 41TV540 were thought to be of EarlyMiddle Holocene age on the basis of soil development and appearance of the alluvial deposit.

CAR testing of 41 TV540 was designed, then, to sample the deeper deposits, thought to date to the Early Archaic or late Paleoindian time frame, associated with Hicks \& Company Trench 361-BHT-10 excavated by Campbell et al. (2005:4447). To sample these lower deposits, CAR relied on heavy machinery to strip a roughly $25-\mathrm{X}-75 \mathrm{~m}$, northeast-southwest oriented trench (Area 1) around BHT 10. Subsequently, CAR was to hand-excavate $24.0 \mathrm{~m}^{3}$ in three $2-\mathrm{x}-2 \mathrm{~m}$ units. An additional $2.35 \mathrm{~m}^{3}$ was used to explore features and sample upper-level deposits that were impacted in the course of mechanical stripping. A second long trench (Area 2) was excavated extending from the toe slope out towards the center of the depression that bordered the western side of the site. 
This deep trench was excavated to a depth of about $7 \mathrm{~m}$. This trench failed to reach the base of the alluvial fill but did expose the channel gravels. Subsequent stratigraphic work (Chapter 8) suggests that this site is situated within a single alluvial stratigraphic unit, informally identified as depositional Unit Qa3, which dates from about 5400 to 4000 radiocarbon years BP. Figure 6-1 provides a schematic illustration of the deposits observed in our excavations at 41TV540. Given the size of the site and the complexity of the Onion Creek alluvial deposits, it is unlikely that this stratigraphic situation applies to all parts of 41TV540, especially deposits to the south, where older alluvial units may be inset against the valley wall.

The original excavation plan, developed by CAR in conjunction with TxDOT archeologists, called for the mechanical stripping in Area 1 to terminate at about 3.0 to $3.5 \mathrm{~m}$ below the original ground surface. Three 2-x-2 m hand-excavated blocks were then to be evenly spaced across the bottom of the trench. However, during the mechanical stripping, monitored by CAR staff, a series of features began to appear in the southern end of the trench. In consultation with TxDOT archeologists, the terminal depth of the mechanical stripping was changed. As shown in Figure 6-2, in the northern half of the trench, an area measuring approximately $15-\mathrm{x}-40$ $\mathrm{m}$ was stripped down to roughly $3.5 \mathrm{mbs}$. In the southern portion of the trench, the stripping operation was terminated about $1.3 \mathrm{~m}$ higher than originally proposed because of the number of feature encountered (Figure 6-2). This altered the original placement of the blocks. Block 1 remained located on the northern end of the trench as originally proposed (Figure 6-2). Block 2 was moved slightly north, though it was still within the original area sampled by BHT 10. Finally, Block 3 was moved north of the originally planned location and was centered on a large snail shell and burned rock lens (Figure 6-2) that was subsequently identified as Feature 13.

Before stripping, CAR established a point with an assigned elevation of $100 \mathrm{~m}$. We recorded all excavations relative to that point. The original ground surface of the trench area sloped about 1.2 meters, from a high of $100.61 \mathrm{~m}$ above datum (mad) in the southeast corner down to 99.41 in the northwest corner of the proposed block. The opening elevations within Block 3 began roughly $20 \mathrm{~cm}$ higher than originally proposed, at $96.85 \mathrm{mad}$, in order to capture portions of Feature 13. Also shown on Figure 6-2 is the location of a single $1 \times 1 \mathrm{~m}$ unit excavated on an upper bench. The opening elevation of this excavation, located about $10 \mathrm{~m}$ to the southwest of Block

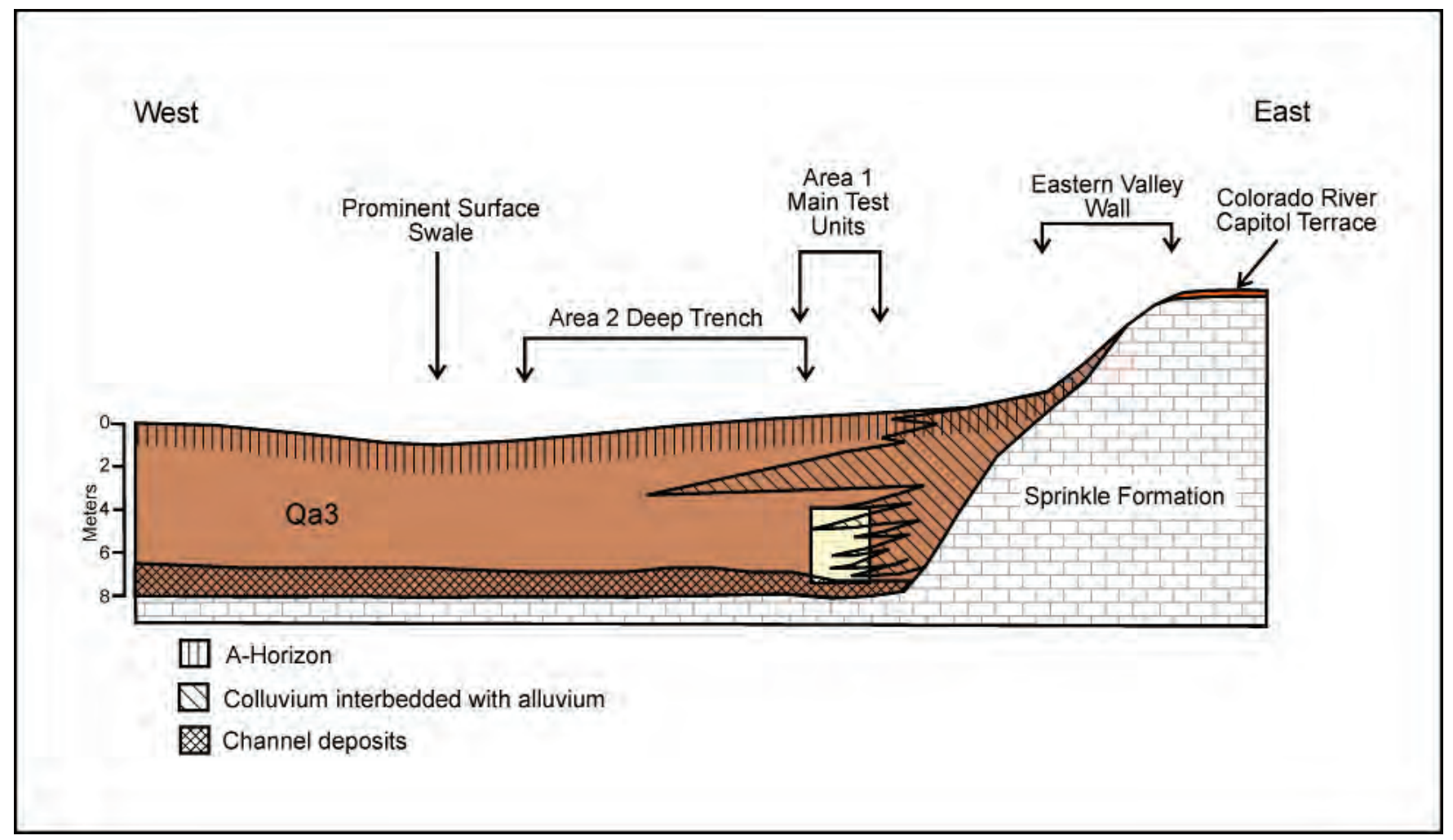

Figure 6-1. Schematic illustration of the deposits near 41TV540. The eastern valley slope is underlain by prominent shrink-swell clays of the Sprinkle Formation, and the adjacent hill is capped by an ancient Colorado River Terrace gravel Campbell et al. (2005:12) indentified as the Capital Terrace. The yellow box highlights the approximate stratigraphic position of the $2 \times 2$ block excavations within Area 1 and the arrows above show the approximate location of the large trench in Area 2. 


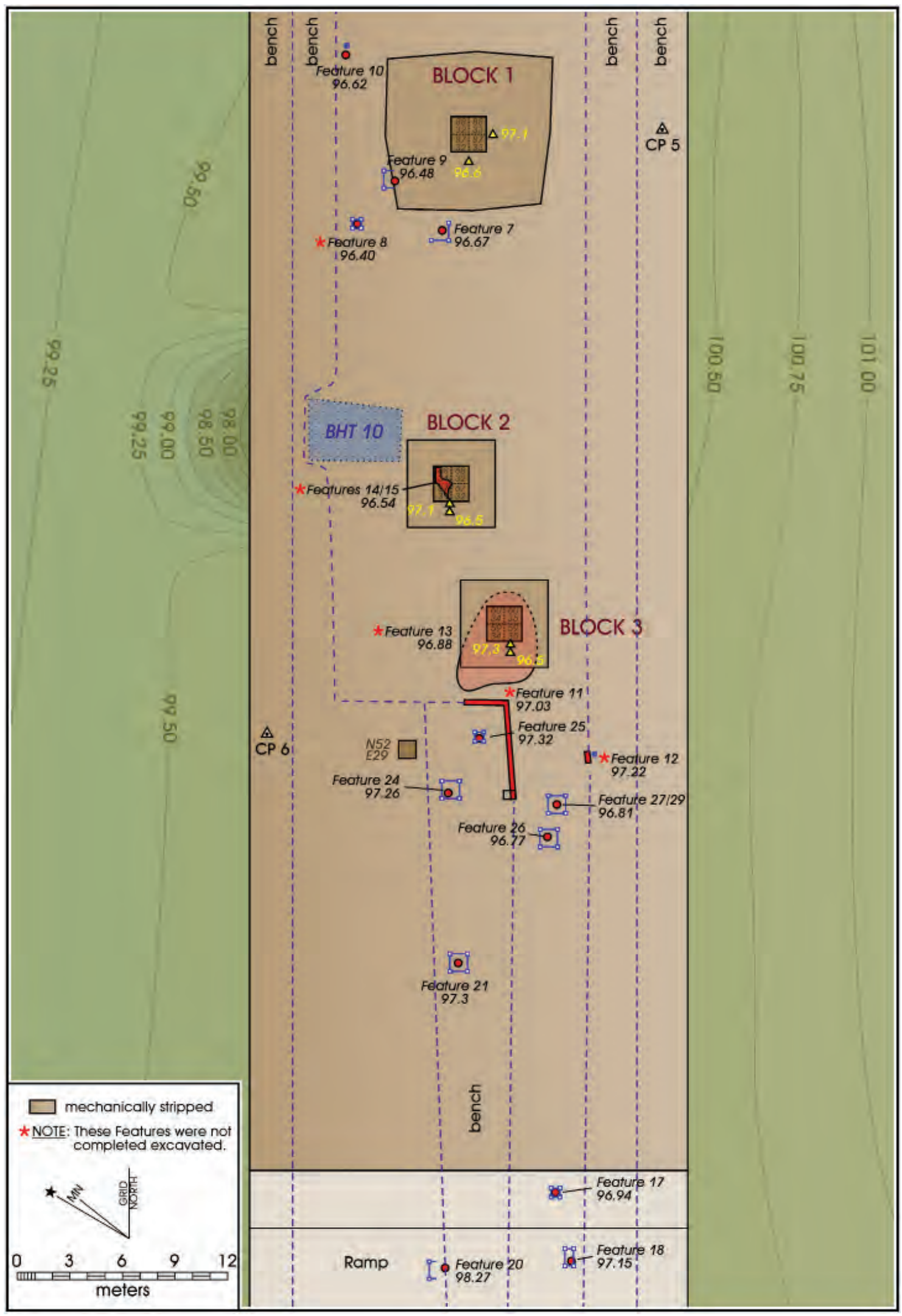

Figure 6-2. Plan view of Phase II excavations showing the area of mechanical stripping, the location of hand excavations and the distribution of features. 
3, was $98.01 \mathrm{mad}$, about $1.2 \mathrm{~m}$ above the opening Block 3 elevation. This single unit was excavated to a depth of 96.60 mad (ca. $1.4 \mathrm{~m}$ ) in an attempt to better understand the context of Feature 13, sampled extensively in Block 3, as well as features found on this upper bench surface.

All hand-excavated units were dug in $10 \mathrm{~cm}$ levels. With the exception of a 2.0 liter sample of sediment collected from most levels of each block excavated, all material was screened through $1 / 4$ inch mesh. All cultural and organic material, including snail and mussel shell, bone, and burned material was collected and bagged by unit and level. The 2.0 liter sediment samples were transported to the CAR laboratory where they were water-screened through $1 / 8^{\text {th }}$ inch mesh.

With the exception of two large snail shell and burned rock lens, designated Feature 13 in Block 3 and Feature 14 in Block 2, CAR staff excavated all features encountered during hand excavation within the blocks. Feature 13 extended beyond the $2 \times 2$ block, and beyond the safety trench to the south and west (Figure 6-2). The feature was only sampled within the block. Similarly, a small portion of Feature 14 extended beyond Block 2 and was removed by the safety bench construction (Figure 6-2). Photographs, and plan and profile drawings were made where appropriate, and matrix samples were collected from within and outside the feature boundaries. When features containing burned rock were encountered, we collected up to four rock samples for lipid residue analysis. All other burned rock were collected at a feature level. Some features at 41TV540 were seen in the profiles of the large trench. These were frequently too deep to efficiently excavate from an upper surface. They were, however, generally drawn, photographed and sampled. In addition, several features were seen in the floors of benches or in the trench floor. These were documented through photographs and drawings. Excavation and sampling followed the procedures outlined for block features.

\section{Laboratory Methods}

Laboratory procedures were similar to those described previously for 41TV410. The initial sorting, cleaning, and preliminary analysis were conducted concurrently with the field work. Material was transported from the site to the CAR laboratory on a weekly basis. A variety of tasks were undertaken once the material was at CAR. These included the processing of flotation samples gathered from features, including preliminary screening of samples for organics, cleaning and preliminary review of all bone recovered, cleaning and description of chipped stone tools, the acquisition of data on burned rock weight and feature size, selection of radiocarbon samples, and the water-screening of matrix samples.
The results of these preliminary summaries were used to generate the post-field report (Thompson 2006). Following the generation of that document, and the determination by TxDOT that no additional work was necessary at the site, CAR developed a research design for completion of the analysis of the 41TV540 material. Following the acceptance of that research design, CAR processed selected data types for more detailed analysis by specialists. Following completion of those analyses, all notes, photographs, artifacts, burned rock, bone, and other associated materials and related documents were assembled in anticipation of curation preparation. Currently, this material is temporarily stored at the CAR in accordance with federal regulations 36 CFR part 79, THC requirements, and in accordance with current guidelines of the Texas Archeological Laboratory. At present, decisions regarding discard of material, along with decisions regarding where permanent curation will occur, remain to be made. We assume, however, that all material and associated records retained from our work at 41TV540 will be permanently housed at CAR.

\section{Cultural Material Recovered}

CAR removed $26.35 \mathrm{~m}^{3}$ of sediment through hand-excavations at the site. The terminal maximum depth of 94.5 mad was achieved in Block 1. This was roughly $5.42 \mathrm{~m}$ below the original ground surface in this area. We documented 17 features, and recovered a variety of chipped stone and ground stone artifacts, and organic material. Radiocarbon dates suggest that most of the features and associated material that are between 97.22 and 96.37 mad date to the close of the Early Archaic, with a probable range of between about 6200 and 5950 BP. In addition, a series of features and artifacts were located at higher elevations. These probably reflect Middle and Late Archaic occupations, although we lack any firm dates. Finally, there are a small number of items, including burned rock, chipped stone, and charcoal at depths below $95.90 \mathrm{mad}$, including material down to the terminal maximum depth of 94.50. Radiocarbon dates on this material were not acquired, but given the rapid sediment deposition, these items probably fall primarily in the Early Archaic.

As noted previously, most of the hand-excavation was associated with the three 2-x-2 m blocks and the excavation of features identified outside of those blocks. The only other controlled excavation was associated with the isolated $1-x-1 \mathrm{~m}$ unit adjacent to Block 3, located at N52/E29 (see Figure 6-2). We began this unit at an elevation of $98.01 \mathrm{mad}$ and terminated the excavation following the removal of 14 levels at a depth of $96.60 \mathrm{mad}$ to overlap vertically with the Block 3 work. A variety of different materials were recovered from this 1-x-1 m unit, including small quantities of charcoal, bone, mussel shell, and burned clay. In addition, 211 pieces of burned rock, 6 pieces of chipped stone, and just over 146 grams of snail shell were 
recovered from this unit. Two peaks are suggested by shifts in the numbers of burned rock. Burned rock increased from Level 2, which started at $97.90 \mathrm{mad}$, through Level 5 (97.60-97.50 mad), which contained a high of 78 pieces of FCR. Burned rock then began to decline, with only 3 pieces of FCR in Level 9 (97.20-97.10 mad). A second smaller peak is present in the bottom levels, with 9 FCR present in Level 11, 8 FCR recovered from Level 12, 6 FCR collected from Level 13, and a single burned rock present in the final level, Level 14. Levels 9 though 13 also contained all chipped stone $(n=6)$ recovered from this Unit. Note that the increased frequency of items at the bottom of this excavation, in Levels 10 (97.10-97.00 mad) through 14 (96.70-96.60 mad), may be related to a surface or activities associated with Feature 13. Levels 12 though 14 in N52/E29 overlap in elevation with the top of Block 3/Feature 13, located roughly 10 meters away.

Table 6-1 provides a summary of recovery by depth for the major artifact categories and organic materials in the $2-x-2$ m units designated Blocks 3, 2 and 1 (see Figure 6-2). The starting and terminal elevations for each block are tied to mad listed in the last column. Levels are assigned starting with the highest level in Block 3 (Level 1) and terminating with Level 24 in Block 1. All weights listed are in grams, and while the recovery of charcoal was not quantified, if charcoal was collected, a designation of " 1 " is provided in the appropriate level. In addition to the artifact and organic categories listed in Table 6-1, small quantities of burned clay were recovered from Block 1 and Block 3. Examination of Table 6-1 will show that Block 3 had the highest overall return in all quantified categories among the three blocks while Block 1 had the lowest return for each category. The low Block 1 recovery may be related to the fact that deposits comparable to Levels 1 through 4 in Block 3, and Levels 3 and 4 in Block 2 were removed by heavy equipment prior to starting the Block 1 work at 96.5 mad. These upper levels, which were associated with Feature 13 in Block 3, and Feature 14 in Block 2, contained the majority of chipped stone and burned rock recovered from those blocks, along with significant quantities of snail shell,

Table 6-1. Distribution of Artifacts and Organic Material by Depth and Block

\begin{tabular}{|c|c|c|c|c|c|c|c|c|c|c|c|c|c|c|c|c|c|c|c|}
\hline \multirow[b]{2}{*}{$\begin{array}{l}\text { Assigned } \\
\text { Level }\end{array}$} & \multicolumn{6}{|c|}{ Block 3} & \multicolumn{6}{|c|}{ Block 2} & \multicolumn{6}{|c|}{ Block 1} & \multirow[b]{2}{*}{$\begin{array}{l}\text { Terminal } \\
\text { Level } \\
\text { Depth } \\
\text { (mad) }\end{array}$} \\
\hline & $\begin{array}{c}\text { Bone } \\
\text { wt. }\end{array}$ & $\begin{array}{l}\text { FCR } \\
\text { Cnt. }\end{array}$ & $\begin{array}{c}\text { Chipped } \\
\text { Stone } \\
\text { Cnt. }\end{array}$ & \begin{tabular}{|c} 
Mussel \\
Shell \\
Wt.
\end{tabular} & \begin{tabular}{|c|} 
Snail \\
Shell \\
Wt. \\
\end{tabular} & $\left|\begin{array}{c}\text { Charcoal } \\
+I-\end{array}\right|$ & $\begin{array}{c}\text { Bone } \\
\text { wt. }\end{array}$ & \begin{tabular}{|l|} 
FCR \\
Cnt.
\end{tabular} & \begin{tabular}{|c|} 
Chipped \\
Stone \\
Cnt.
\end{tabular} & \begin{tabular}{|c} 
Mussel \\
Shell \\
Wt.
\end{tabular} & \begin{tabular}{|c|} 
Snail \\
Shell \\
Wt. \\
\end{tabular} & $\begin{array}{c}\text { Charcoal } \\
+l-\end{array}$ & $\begin{array}{c}\text { Bone } \\
\text { wt. }\end{array}$ & $\begin{array}{l}\text { FCR } \\
\text { Cnt. }\end{array}$ & \begin{tabular}{|c} 
Chipped \\
Stone \\
Cnt.
\end{tabular} & \begin{tabular}{|c|}
$\begin{array}{c}\text { Mussel } \\
\text { Shell } \\
\text { Wt. }\end{array}$ \\
\end{tabular} & \begin{tabular}{|c|} 
Snail \\
Shell \\
Wt. \\
\end{tabular} & $\begin{array}{c}\text { Charcoal } \\
+I-\end{array} \mid$ & \\
\hline 1 & 0.01 & 7 & 3 & & 56.5 & 1 & & & & & & & & & & & & & 96.8 \\
\hline 2 & 6.9 & 24 & 116 & 89.6 & \begin{tabular}{|l}
7782.3 \\
\end{tabular} & 1 & & & & & & & & & & & & & 96.7 \\
\hline 3 & 8.3 & 16 & 36 & 73.9 & 1639.9 & 1 & 0 & 8 & 5 & & 38.9 & 1 & & & & & & & 96.6 \\
\hline 4 & 1.2 & 27 & 8 & 20.5 & 218.5 & 1 & 1.3 & 33 & 68 & & 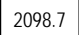 & 1 & & & & & & & 96.5 \\
\hline 5 & \begin{tabular}{|l|l|} 
& 11.38
\end{tabular} & 42 & 19 & 30.1 & 59.4 & 1 & 0.7 & 7 & 8 & & \begin{tabular}{|l|}
102.5 \\
\end{tabular} & 1 & & & & 5 & 17.5 & 1 & 96.4 \\
\hline 6 & 2.77 & 26 & 12 & 7.1 & 36 & 1 & & 35 & 4 & 1.8 & 159.8 & 1 & 0.9 & & & & 23.5 & 1 & 96.3 \\
\hline 7 & & 1 & 3 & 4.5 & 13.89 & & & 9 & 6 & 12.5 & 62.4 & 1 & & & 1 & & 4.3 & & 96.2 \\
\hline 8 & & & & & 3.1 & & 4.15 & 2 & 2 & & 34.46 & 1 & & & & & 12.6 & & 96.1 \\
\hline 9 & & & 1 & & 2.41 & & 0.2 & 4 & 2 & 40.1 & 53.1 & 1 & & & & & 3.9 & 1 & 96.0 \\
\hline 10 & & & & & 4.13 & & 0.3 & 1 & & 66.08 & 55.64 & 1 & & & & & 6.9 & & 95.9 \\
\hline 11 & & & & & & & 0 & 2 & & & 73.6 & 1 & & & 1 & & 18.9 & & 95.8 \\
\hline 12 & & & & & 1.7 & 1 & 0.51 & 1 & 2 & & \begin{tabular}{|l|}
73.87 \\
\end{tabular} & 1 & & 1 & 1 & & 5.9 & & 95.7 \\
\hline 13 & & & & & 1.93 & & & & & & 46.2 & 1 & & & & & 3.09 & & 95.6 \\
\hline 14 & & & & & 0.43 & & & & 1 & & \begin{tabular}{|l|}
56.35 \\
\end{tabular} & & & & & & & & 95.5 \\
\hline 15 & & & & & 0.99 & & & & & & 41.5 & 1 & & & & 0.62 & 0.38 & 1 & 95.4 \\
\hline 16 & & & & & & & & & & & \begin{tabular}{|l}
132.28 \\
\end{tabular} & 1 & & & & & 2.1 & & 95.3 \\
\hline 17 & & & & & & & & 10 & 1 & & \begin{tabular}{|l}
75.63 \\
\end{tabular} & 1 & & 1 & 1 & 0.08 & 0.31 & 1 & 95.2 \\
\hline 18 & & 1 & 1 & & 4.97 & 1 & & & & & 5.52 & 1 & & & & 0.03 & 3.53 & 1 & 95.1 \\
\hline 19 & & & & & 1.2 & & & & & & 7.26 & & & 2 & & & 0.05 & & 95.0 \\
\hline 20 & & & & & & & & & & & 3.43 & 1 & & 1 & & & 0.06 & & 94.9 \\
\hline 21 & & & & & & & & & & & 6.04 & & 0.39 & 14 & 2 & 0.3 & 0.01 & & 94.8 \\
\hline 22 & & 1 & & & & & & & & & 9.46 & 1 & & 10 & & & 0.11 & & 94.7 \\
\hline 23 & & & 3 & & & & & & & & & & 1.11 & 3 & 1 & & & & 94.6 \\
\hline 24 & & & & & & & & & & & & & 0.2 & 8 & 3 & & & & 94.5 \\
\hline totals & 30.56 & 145 & 202 & 225.7 & 5827.35 & & 7.16 & 112 & 99 & 120.48 & 3136.64 & & 2.6 & 40 & 10 & 6.03 & 103.14 & & \\
\hline
\end{tabular}


mussel shell, and bone. The overall recovery rate in these block excavations, even in the densest area (Block 3), is low relative to most occupations. For example, while 116 chipped stone items were recovered from Level 2 in Block 3, recall that this represents a 2-x-2-x-.1 m excavation. Similarly, the high count of 42 pieces of FCR from Level 5 in Block 3 averages 10.5 FCR per 1-x-1 m excavation level, well below the maximum density of 78 FCR present in a single level of Unit N52/E29 discussed above.

Note that the mechanical removal of these upper levels from Block 1 provided a lower starting elevation (ca. $96.5 \mathrm{mad}$ ), allowing us to sample slightly deeper deposits. The increased FCR counts, bone weight, and chipped stone counts shown for the lower levels in Block 1 provide evidence for at least one (Levels 21-24) and possibly two (Levels 17,18, and 19) earlier accumulations of material. These lower Block 1 accumulations may also be present in Block 3 (Levels 18 and 19; Levels 22 and 23) and in Block 2 (Level 17). Unfortunately, we lack any chronometric information on these lower deposits.

Finally, we recovered one metate during the scraping of the southern portion of the trench (Figure 6-3). The item was broken by the trackhoe bucket, but pieced together at the CAR laboratory. We recovered the item at $97.89 \mathrm{mad}$, roughly $2.0 \mathrm{~m}$ below the surface in this section of the trench, and well above the elevations selected for controlled handexcavations. It is likely, given the elevation, that this ground stone dates in the Middle or Late Archaic Period.

\section{Features}

While the amount of artifacts and ecofacts recovered from the excavations at $41 T V 540$ was minimal, a surprisingly high number of features were present. CAR recorded 17 features during investigations at 41TV540 (Figure 6-2). Features were assigned numbers 7 though 29 . Feature numbers 16, 19, 22, 23 and 28 were assigned in the field but subsequently they were determined not to be features. In addition, Features 27 and 29 were originally defined as separate features, but were combined in the lab and referenced as Feature 27/29. Three of the 17 features (Features 13, 14 and 15) were sampled during block excavations. The remaining 14 features were encountered during trackhoe excavations.

Table 6-2 provides summary information on these features, including data on location, depths for the tops and bottoms of the feature, feature size, a summary of content, and information on temporal assignment. The temporal placement is based initially on radiocarbon dates for Features 12, 13, and 27/29.

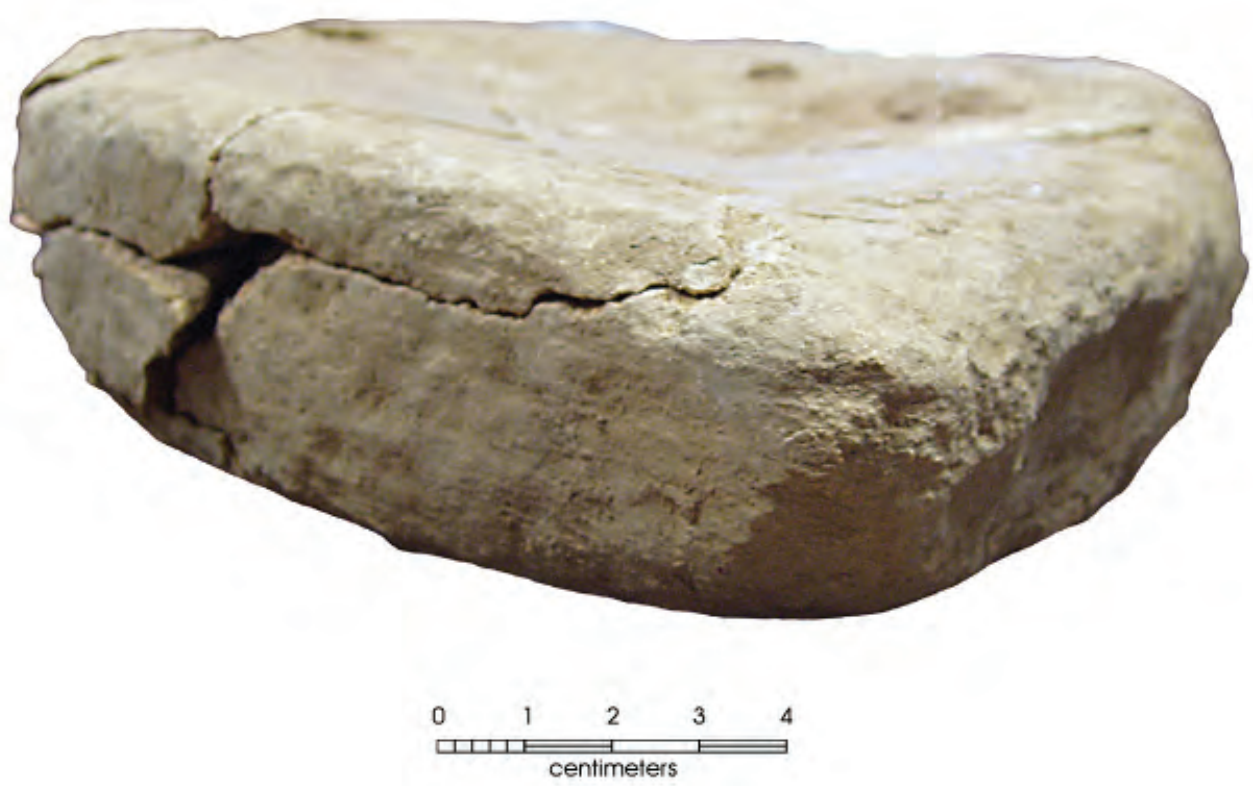

Figure 6-3. Metate excavated with the trackhoe and refit at the CAR laboratory, 41TV540. 
Table 6-2. Feature Location, Depth, and Probable Temporal Assignment

\begin{tabular}{|c|c|c|c|c|c|c|c|}
\hline $\begin{array}{c}\text { Feature } \\
\#\end{array}$ & North & East & $\begin{array}{c}\text { Top of } \\
\text { Feature } \\
\text { (mad) }\end{array}$ & $\begin{array}{c}\text { Bottom of } \\
\text { Feature } \\
\text { (mad) }\end{array}$ & Size $(\mathbf{c m})$ & Description & Temporal Assignment \\
\hline 7 & 81.95 & 31.93 & 96.67 & 96.63 & $50 \times 60$ & FCR, mussel, charcoal scatter. & Ealy Archaic based on depth. \\
\hline 8 & 83.12 & 26.56 & 96.4 & - & $40 \times 40$ & $\begin{array}{l}\text { Oxidized soil, bisected by machinery, not } \\
\text { excavated. }\end{array}$ & Ealy Archaic based on depth. \\
\hline 9 & 84.95 & 28.14 & 96.48 & 96.43 & $40 \times 20$ & Bone concentration, poor condition. & Ealy Archaic based on depth. \\
\hline 10 & 92.43 & 26.84 & 96.62 & 96.53 & $80 \times ?$ & $\begin{array}{l}\text { Amorphous lens of FCR, shell, charcoal, } \\
\text { bisected by machinery. }\end{array}$ & Ealy Archaic based on depth. \\
\hline 11 & 52.49 & 40.15 & 97.24 & - & ? & $\begin{array}{l}\text { Amorphous lens of FCR, shell, charcoal } \\
\text { impacted by machinery. }\end{array}$ & Early or Middle Archaic based on depth. \\
\hline 12 & 52.48 & 40.14 & 97.22 & 97.17 & $50 \times ?$ & Hearth, bisected by machinery. & Early Archaic based on radiocarbon dates. \\
\hline 13 & 60 & 35 & 96.88 & 96.5 & $>200 x>200$ & $\begin{array}{l}\text { Amorphous lens of FCR/shell/charcoal. Bone } \\
\text { present. }\end{array}$ & Early Archaic based on radiocarbon dates. \\
\hline 14 & 67.4 & 31.4 & 96.54 & 96.4 & $>230 x>120$ & Amorphous lens of FCR/shell/charcoal. & Early Archaic based on depth. \\
\hline 15 & 68.5 & 31.6 & 96.37 & 96.28 & $30 \times 32$ & Partial Hearth. & Early Archaic based on depth. \\
\hline 17 & 27.31 & 37.76 & 96.94 & 96.89 & $40 \times 25$ & FCR scatter. & Early Archaic based on depth. \\
\hline 18 & 23.35 & 38.53 & 97.15 & 97.1 & $59 \times 15$ & FCR scatter. & Early Archaic based on depth. \\
\hline 20 & 22.62 & 30.8 & 98.27 & - & $40 \times 30$ & FCR scatter. & Middle or Late Archaic based on depth. \\
\hline 21 & 40.15 & 32.01 & 97.3 & 97.22 & $67 \times 47$ & Partial Hearth. & Early or Middle Archaic based on depth. \\
\hline 24 & 50.04 & 31.57 & 97.26 & 97.2 & $95 \times 90$ & FCR scatter. & Early or Middle Archaic based on depth. \\
\hline 25 & 53.33 & 31.5 & 97.32 & 97.26 & $33 \times 25$ & Circular Hearth. & Early or Middle Archaic based on depth. \\
\hline 26 & 47.3 & 37.13 & 96.77 & 96.71 & $30 \times 34$ & Circular stain of charcoal, bone, and snail shell. & Early Archaic based on depth. \\
\hline $27 / 29$ & 49.79 & 37.43 & 96.81 & 96.67 & $50 \times 65$ & $\begin{array}{l}\text { Amorphous lens of FCR/shell/charcoal over } \\
\text { small complete hearth. }\end{array}$ & Early Archaic based on radiocarbon dates. \\
\hline
\end{tabular}

As is discussed below, radiocarbon dates from these features cluster between about 5950 and $6200 \mathrm{BP}$, placing them the close of the Early Archaic or at the start of the Middle Archaic. As these dated features were found between elevations of 97.22 and $96.81 \mathrm{mad}$, we also assigned two feature (17 and 18) in that elevation range to the Early Archaic Period, though note that the date ranges overlap into the Middle Archaic. Five features are above the top elevation of the dated features (97.22), and seven are below the bottom depth (96.81). Given that the dated features fall at the close of the Early Archaic, and given that the lowest feature is at $96.37 \mathrm{mad}$, we feel confident in assigning these lower features (7, 8, 9, 10, 14, 15 and 26) to the Early Archaic. Four of the five higher features cluster between 97.24 and $97.32 \mathrm{mad}$, an $8 \mathrm{~cm}$ elevation range that begins $2 \mathrm{~cm}$ above the dated Early Archaic elevation range. These features (11, 21, 24, and 25) probably date to the close of the Early Archaic or early in the Middle Archaic. Finally, Feature 20 is significantly higher than the other features recorded. It probably reflects a Middle or Late Archaic use of the area. Below we provide a brief description of each of the 17 features.

Feature 7 was located about 5 meters south of Block 1 just outside of the benched area (Figure 6-2). It consisted of a 50-x-60 cm semi-circular arrangement of burned rock surrounding a slightly darker matrix that contained several pockets of charcoal-rich sediment (Figure 6-4; Table 6-2). A

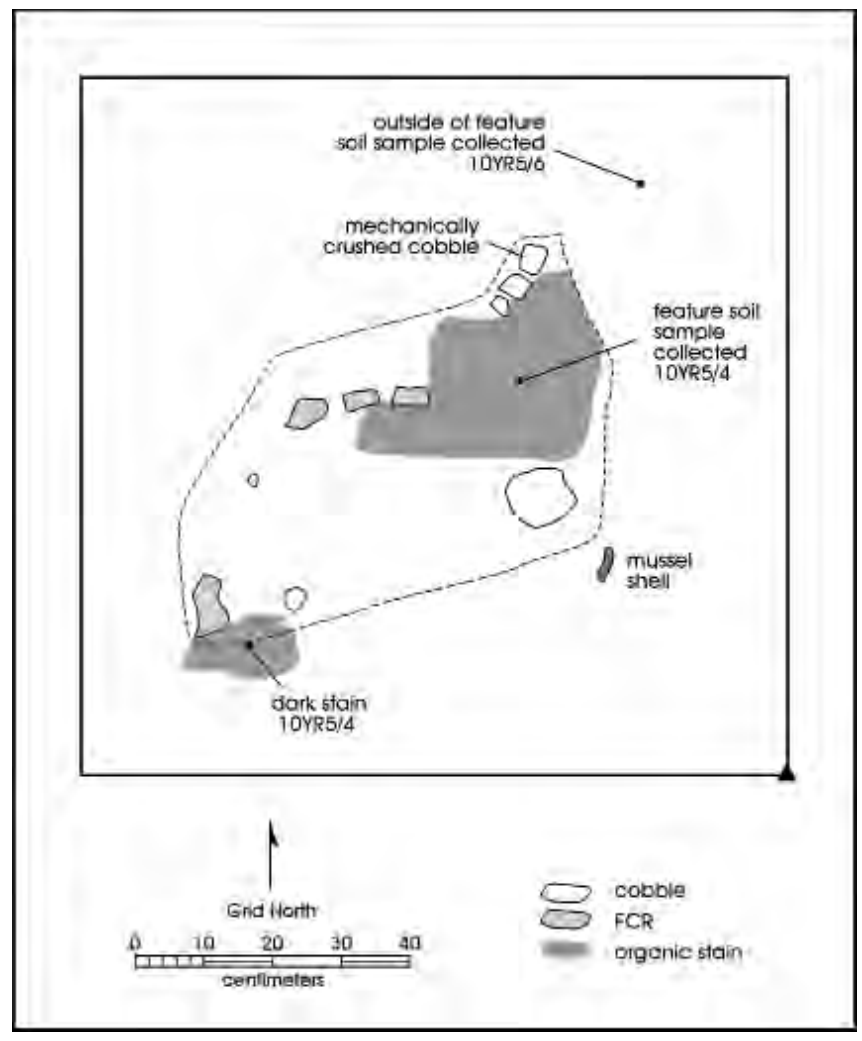

Figure 6-4. Plan view of Feature 7, 41TV540. 
single mussel shell valve was present near the southeastern edge of the feature. Mechanical stripping may have affected the eastern and southern portions of the feature. We exposed the feature at $96.67 \mathrm{mad}$, roughly $3.28 \mathrm{~m}$ below the original ground surface in this area. Based on depth, this feature dates to the Early Archaic. No vertebrate faunal material was recovered from the matrix.

Feature 8 (not shown) consisted of an oxidized patch of soil bisected during scraping. The feature was about 7 meters southwest of Block 1 (Figure 6-2). The reddish stain was circular in plan, measuring at least $40-\mathrm{x}-40 \mathrm{~cm}$ although it was never fully exposed. Snail shells and charred materials were noted within the oxidized matrix. Following a weekend of rains and after the additional volume of matrix excavation was approved by TxDOTENV, crews returned to the site but could not relocate the stain. The feature may have been either covered by silt or eroded by sheet wash. Therefore, the feature was neither excavated nor sampled. Feature 8 was one of the deeper features, being exposed at $96.4 \mathrm{mad}$, or roughly $3.36 \mathrm{~m}$ below surface in this area. The feature probably dated to the Early Archaic (see Table 6-2).

Feature 9 (not shown) was identified as a $20-\mathrm{x}-40 \mathrm{~cm}$ concentration of mammal bone approximately 4 meters east-southeast of Block 1 (Figure 6-2). The bone was in poor condition and snail shells were also present in the surrounding matrix. No soil discoloration, charcoal, or burned rock was noted. We identified this feature at $96.48 \mathrm{mad}$, roughly $3.38 \mathrm{mbs}$ in this area. Based on the depth, this feature probably dates to the Early Archaic (see Table 6-2).

Feature 10 was identified as an $80 \mathrm{~cm}$ long amorphous lens of oxidized soil containing charcoal, burned rock, and some snail (Figure 6-5). The feature was about 7 meters northeast of Block 1 (Figure 6-2). The oxidized lens varied from 10-12 $\mathrm{cm}$ in thickness. It was bisected during mechanical stripping. Identified at 96.62 mad, (ca. 3.06 mbs), Feature 10 probably dates to the Early Archaic (see Table 6-2). A matrix sample was collected, and the feature profiled.

Feature 11 appeared as an amorphous lens of snail, small quantities of burned rock, and scattered charcoal within a slightly oxidized deposit in the western and northern wall of the safety bench at the southern end of the stripped basin immediately south of Block 3 (Figure 6-2; Figure 6-6). The lens appeared to continue to the west within the bench and emerged on the surface of the bench about 5 meters from its edge at an elevation of $97.24 \mathrm{mbs}$. The contents of the feature appeared to be the same as Feature 13, identified in Block 3 (see Table 6-2), though no excavation was conducted in Feature 11. At the time of the excavation of Feature 13, excavators thought that the lens of deposit seen in the nearby profile may have been a continuation of the same feature. However, we retained the separate feature number because the deposits in the bench were not dated and the continuity between the deposits in Block 3 and the bench was not documented at the time the smaller safety bench around Block 3 was being excavated. Given the depth, the feature is assumed to date to the Early Archaic.

Feature 12 is an approximately $45 \mathrm{~cm}$ long charcoal and firecracked rock lens (Figure 6-7) exposed in profile in a safety bench located about seven meters to the southeast of Block 3 (Figure 6-2). The feature was encountered at a depth of $97.22 \mathrm{mad}$, about $3.17 \mathrm{~m}$ below the original ground surface in this area. Snail shells were also present in the feature fill, which was collected in its entirety. The feature penetrated into the profile and was about $5 \mathrm{~cm}$ thick (Table 6-2). Heavy equipment removed much of the feature. A radiocarbon assay on a charcoal fragment from the feature returned a data of $5320+/-40 \mathrm{BP}$ (Beta \# 212808). When corrected and calibrated, the radiocarbon date suggests that the feature dates to the close of the Early Archaic or the beginning of the Middle Archaic, sometime between CAL. BP 6200 and 5990.

Feature 13 is an amorphous lens of snail shell, with scattered FCR, small quantities of charcoal, mussel shell, and faunal material, exposed throughout Block 3 (see Figure 6-2). Feature 13 was found at a depth of $96.88 \mathrm{mad}$, or roughly $3.32 \mathrm{~m}$ below the original ground surface (Table 6-2). At that depth, Feature 13 covered the entire $2 \times 2 \mathrm{~m}$ block. Some of the feature

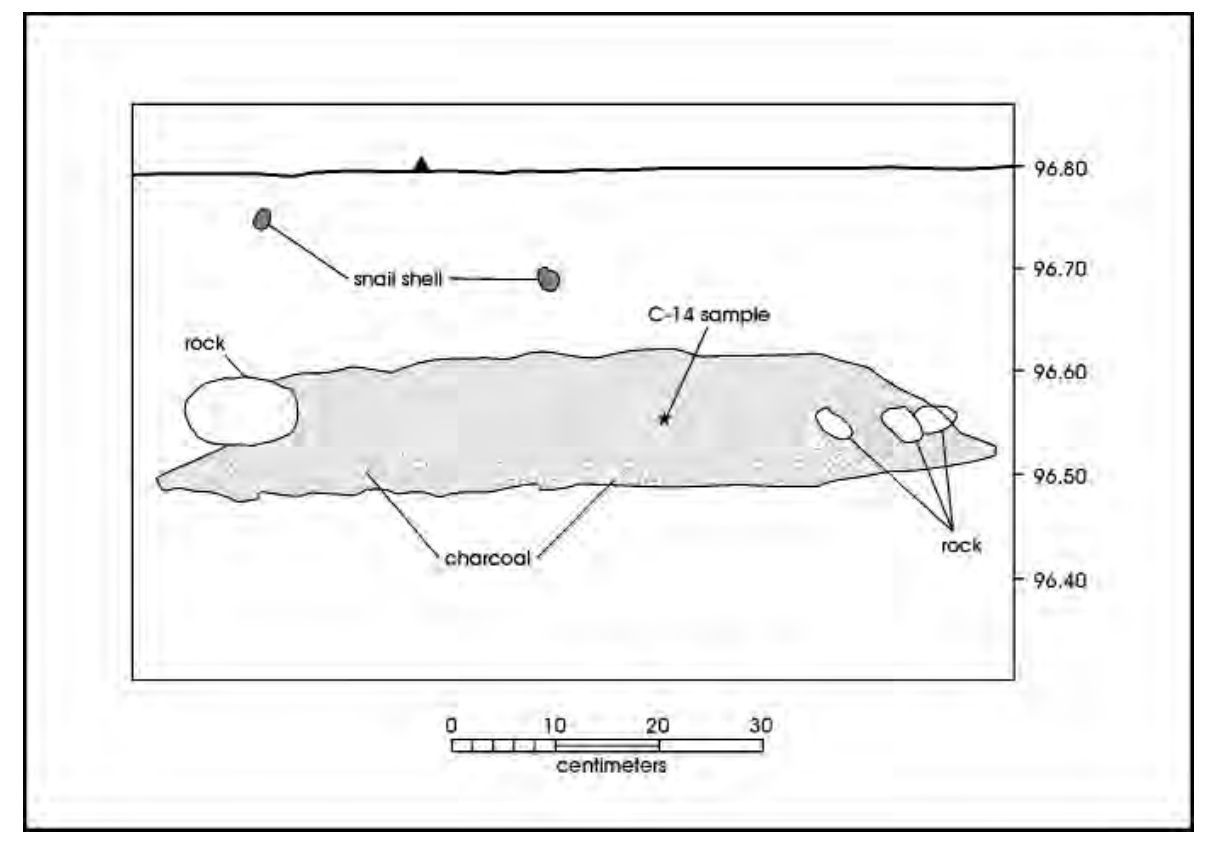

Figure 6-5. Profile of Feature 10, 41TV540. 


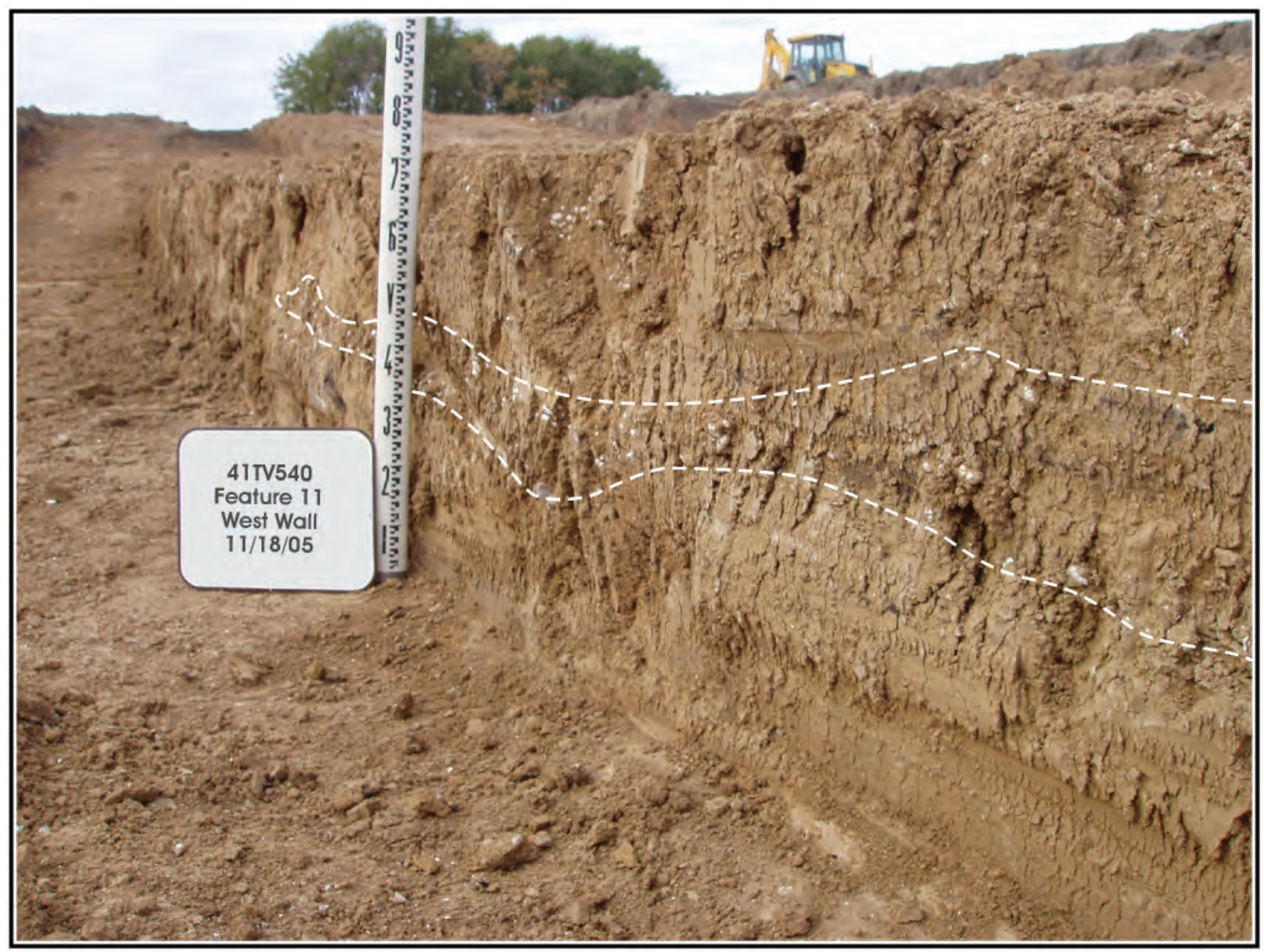

Figure 6-6. Feature 11 exposed in the west wall profile of southern safety bench, 41TV540.

was removed by the excavations of the safety benches (Figure 6-8, and 6-8 insert). The feature continued south and west, with portions visible in the walls of the safety bench and on the elevated surface. The feature is oblong and is roughly $4.1 \mathrm{~m}$ by $5.5 \mathrm{~m}$ (ca. 19.6 $\mathrm{m}^{3}$ ) in size (Figure 6-8). The portion within the block seems to be roughly basin shaped, with the maximum thickness $(35 \mathrm{~cm})$ present at 59N/ 34E (Figure 6-8, 6-9). Only the portion of the feature within the $2 \times 2 \mathrm{~m}$ block was excavated. In addition to snail, burned rock, debitage, and small quantities of charcoal in pockets of oxidized soil, the feature contained a variety of faunal material, most of which in avian in character (Appendix N). Radiocarbon assays on charcoal from two locations within Feature $13(5240+/-40$, Beta \# 212809; $5300+/-40$, Beta \# 212810) returned calibrated, corrected dates that

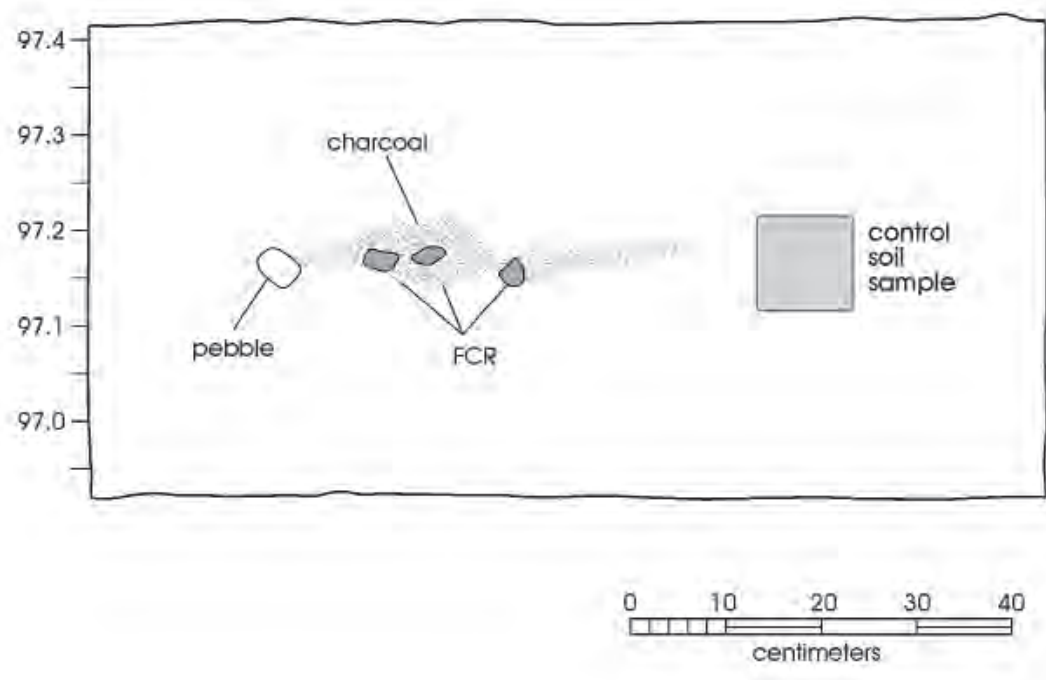

Figure 6-7. Profile of Feature 12, Area 1,41TV540. 


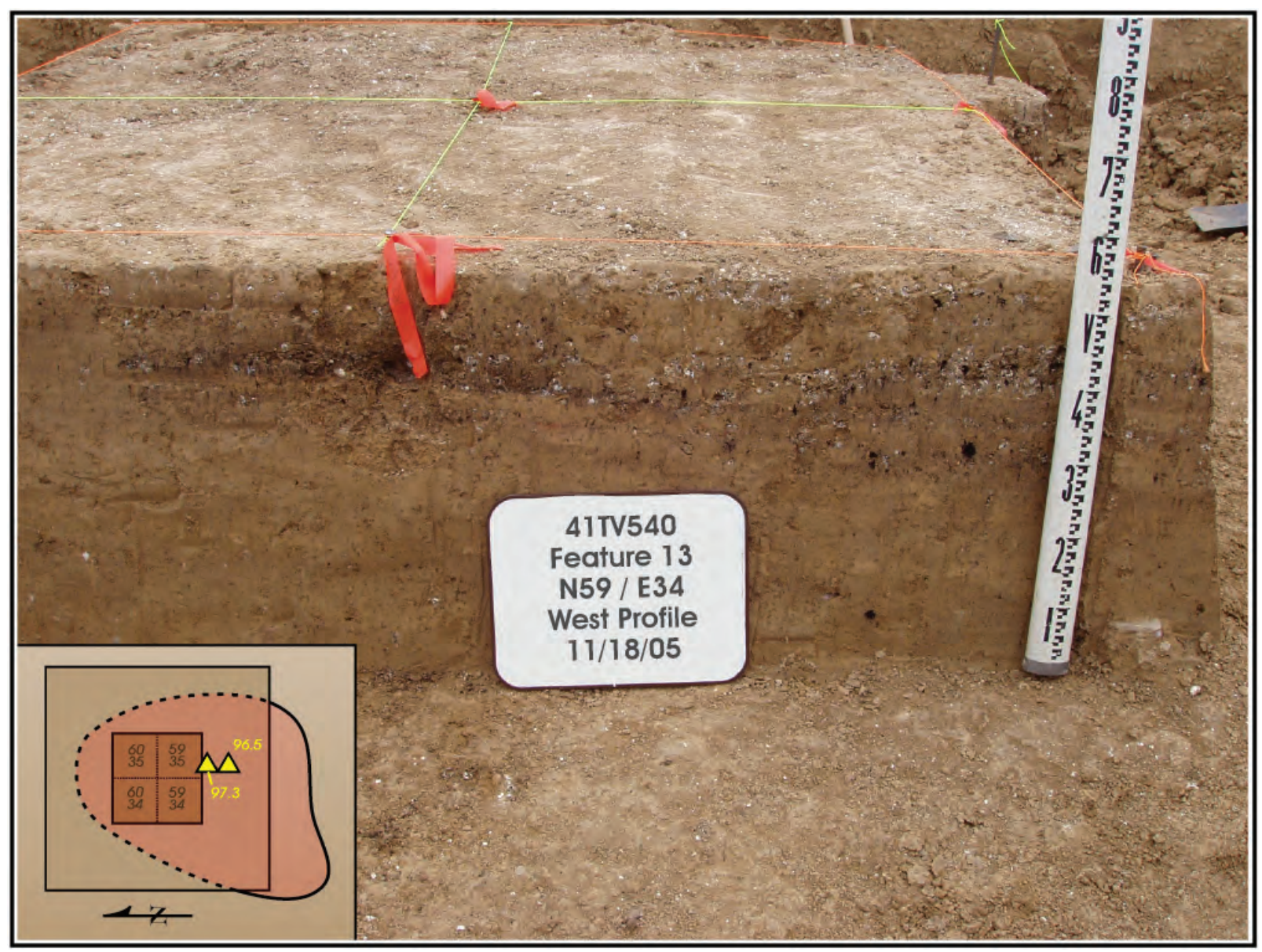

Figure 6-8. Feature 13, Block 3, 41TV540. Insert shows the estimated extent of the feature.

range between 6190 and $5920 \mathrm{BP}$, placing the feature at the close of the Early Archaic or the beginning of the Middle Archaic.

Feature 14 is an elongated lens of refuse, including moderate quantities of snail shell, scattered, small clusters of fire-cracked rock, sparse lithic debitage, tools, and specks of charcoal. The feature was encountered in Block 2 (Figure 6-2) at a depth of $96.54 \mathrm{mad}$, or about $3.46 \mathrm{~m}$ below the original ground surface. The feature is similar in content to Feature 13 and Feature 11. Feature 14 minimally measures $230-x-120 \mathrm{~cm}$. Patches of oxidized soil can be seen across the feature and three relatively well defined concentrations of snail shell are present in the eastern two units of the block (Figure 6-10; Table 6-2). Portions of the feature were removed by the excavations of the safety bench. The depth of Feature 14 suggests that the deposit dates to the Early Archaic.

Feature 15 was found in unit N68/E31 of Block 2 (Figure 6-2). Several pieces of rock form a semi-circle adjacent to patches of charcoal-rich matrix. The rocks and charcoal cover an area about $30-x-32 \mathrm{~cm}$. Based on the oxidized soil discoloration that surrounds the rocks (Figure 6-11), the feature may be the remnants of a slightly larger oval hearth. The top of the feature was identified at $96.37 \mathrm{mad}$, about 3.63 mbs. This is the lowest feature uncovered during CAR's work at the site. Given that depth, the feature is assumed to date to the Early Archaic (Table 6-2).

Feature 17 is a fire-cracked rock scatter (Figure 6-12) associated with oxidized soil located at the southern end of the excavation trench (Figure 6-2). The scatter measures 40-x-25 cm and was exposed by heavy machinery during stripping at an elevation of $96.94 \mathrm{mad}$, roughly $3.44 \mathrm{~m}$ below surface (Table 6-2). No charcoal staining was evident around the rocks and a single piece of debitage was noted in their vicinity during excavation. Based on the feature depth, Feature 17 dates to the Early Archaic.

Feature 18 is a linear scatter of fire-cracked rock (Figure 6-13; Table 6-2) that represents the disturbed remnants of a hearth. The scatter measures about $59-x-15 \mathrm{~cm}$, but clearly has been disturbed by machinery. Identified during stripping, the feature is about 5 meters south of Feature 17 (Figure 6-2) at an elevation of 97.15 mad (3.24 mbs). No oxidized soil 


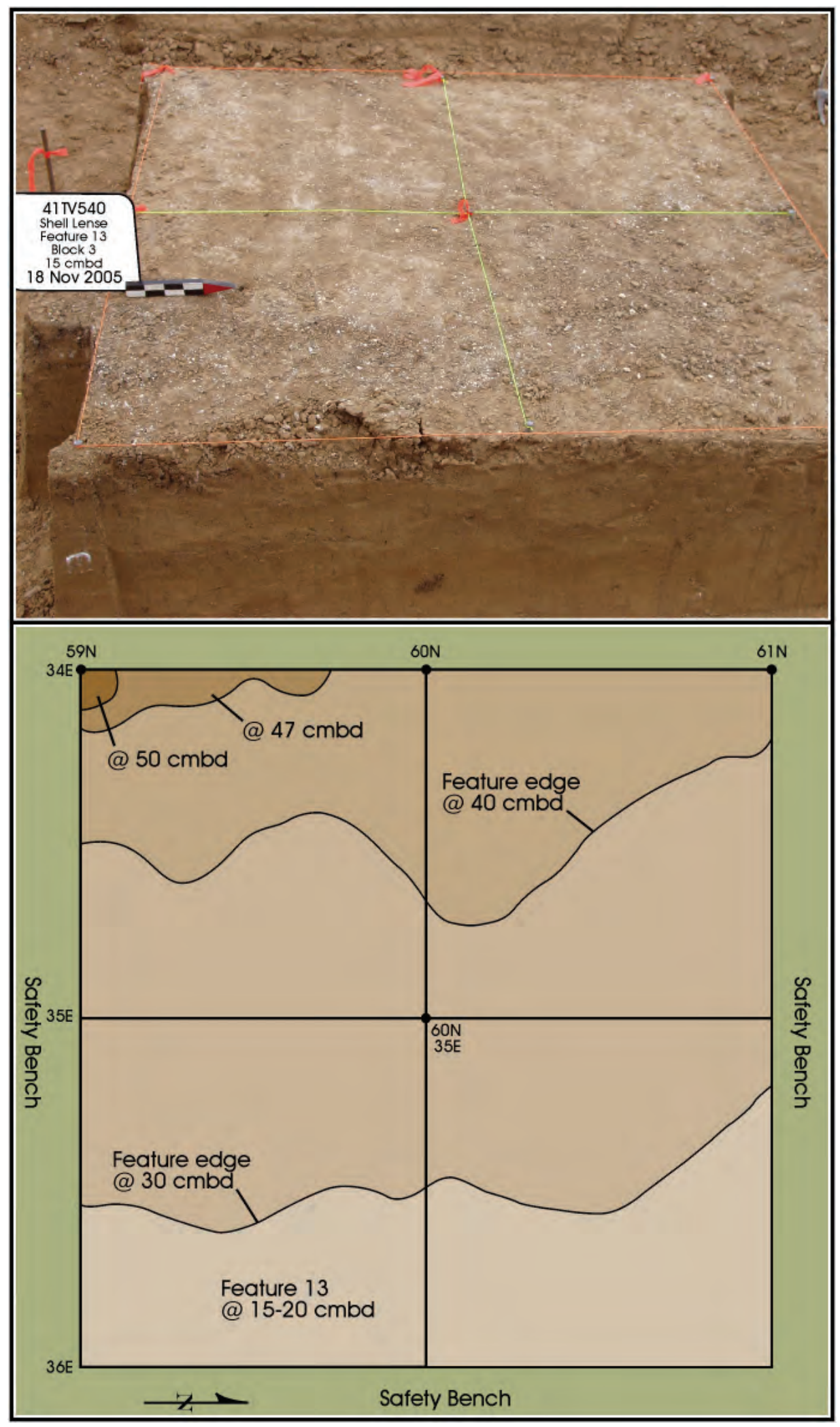

Figure 6-9. Feature 13, Block 3. Top: Photograph of 2-x-2 m unit at $15 \mathrm{cmdb}$. Note dominance of snail shell in eastern portion of block. Bottom: Plan view showing decreasing eastern margin with increasing depth. At $50 \mathrm{cmbd}$ (ca. $96.50 \mathrm{mad}$ ) feature is present only in extreme southwestern corner of block. was noted and charcoal staining was also absent in the vicinity of the rocks. Based on depth, the feature dates to the Early Archaic.

Feature 20, located on the southern ramp of the stripped area (see Figure 6-2), appears to represent the remnants of a hearth. FCR, some oxidation of the surrounding soil and charcoal flecks were noted during excavation, along with snail shells. The hearth, which measures about 40-x-30 cm (Figure 6-14; Table 6-2), was exposed during mechanical stripping and some of the burned rock have been crushed. At an elevation of $98.27 \mathrm{mad}$, or about $1.76 \mathrm{~m}$ below the original ground surface, Feature 20 is the highest feature recorded during CAR's work at 41TV540. Given the relatively shallow location of Feature 20, it is likely that the feature dates to the Middle or Late Archaic.

Feature 21 was identified some 20 meters south of Block 3 (Figure 6-2) at an elevation of $97.3 \mathrm{mad}$, or about 2.75 mbs. The feature consists of two clusters of firecracked rock (Figure 6-15). Oxidized soil is present in the vicinity of the clusters and pockets of charcoal were noted immediately under several of the rocks. Snails were present in small numbers in the feature matrix. Debitage and bone fragments were present in the matrix outside of the feature and some heavily weathered bone also was found in the feature fill. The feature measures $67-\mathrm{x}-47 \mathrm{~cm}$ and appears to represent the remains of a hearth. Given that Feature 21 is located slightly above the highest Early Archaic radiocarbon date, this feature dates to the Early or Middle Archaic (Table 6-2).

Feature 24 consisted of an amorphous scatter of fire-cracked rock identified on a bench 15 meters 


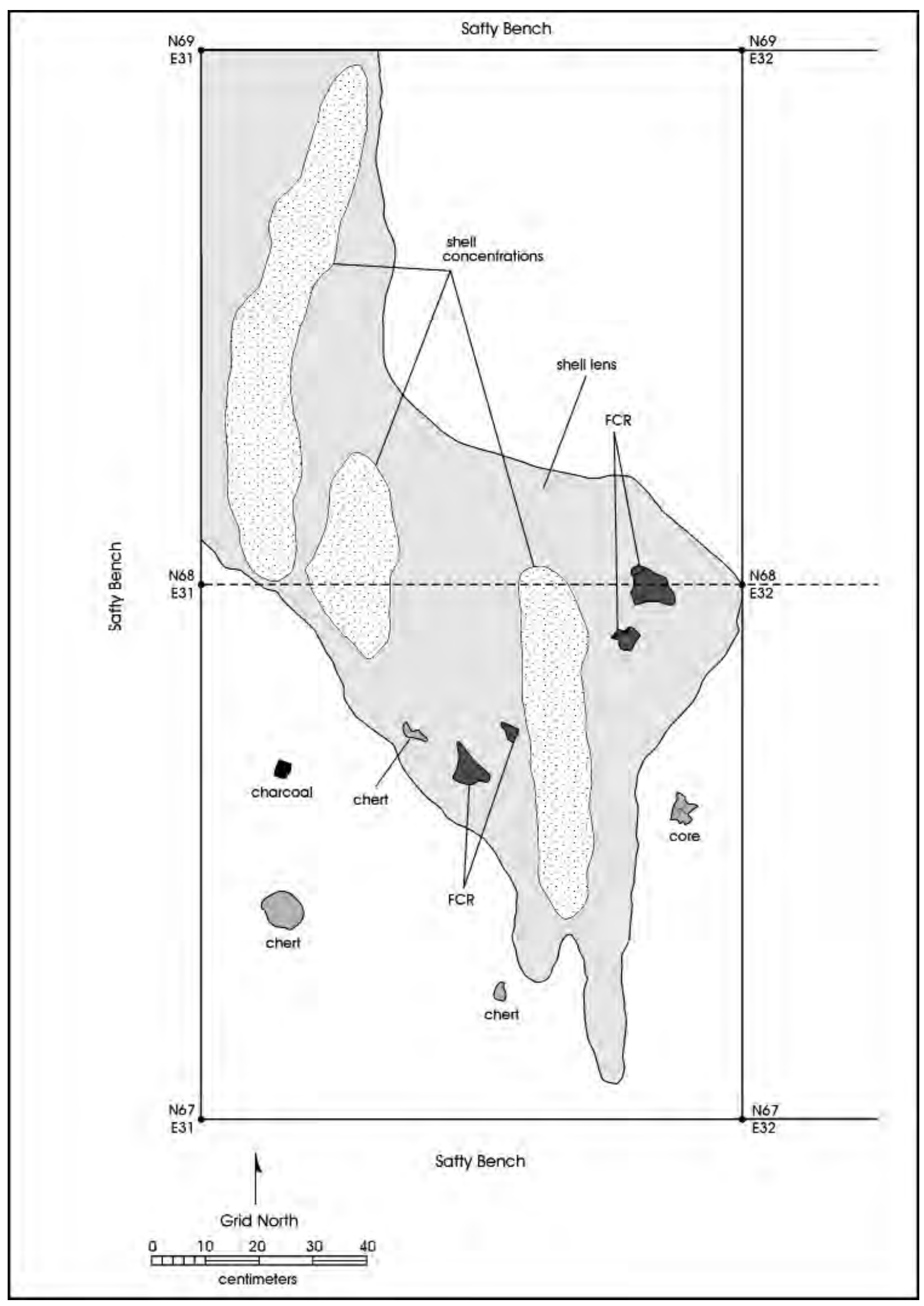

Figure 6-10. Plan view of Feature 14, Level 3, Block 2, 41 TV540. 


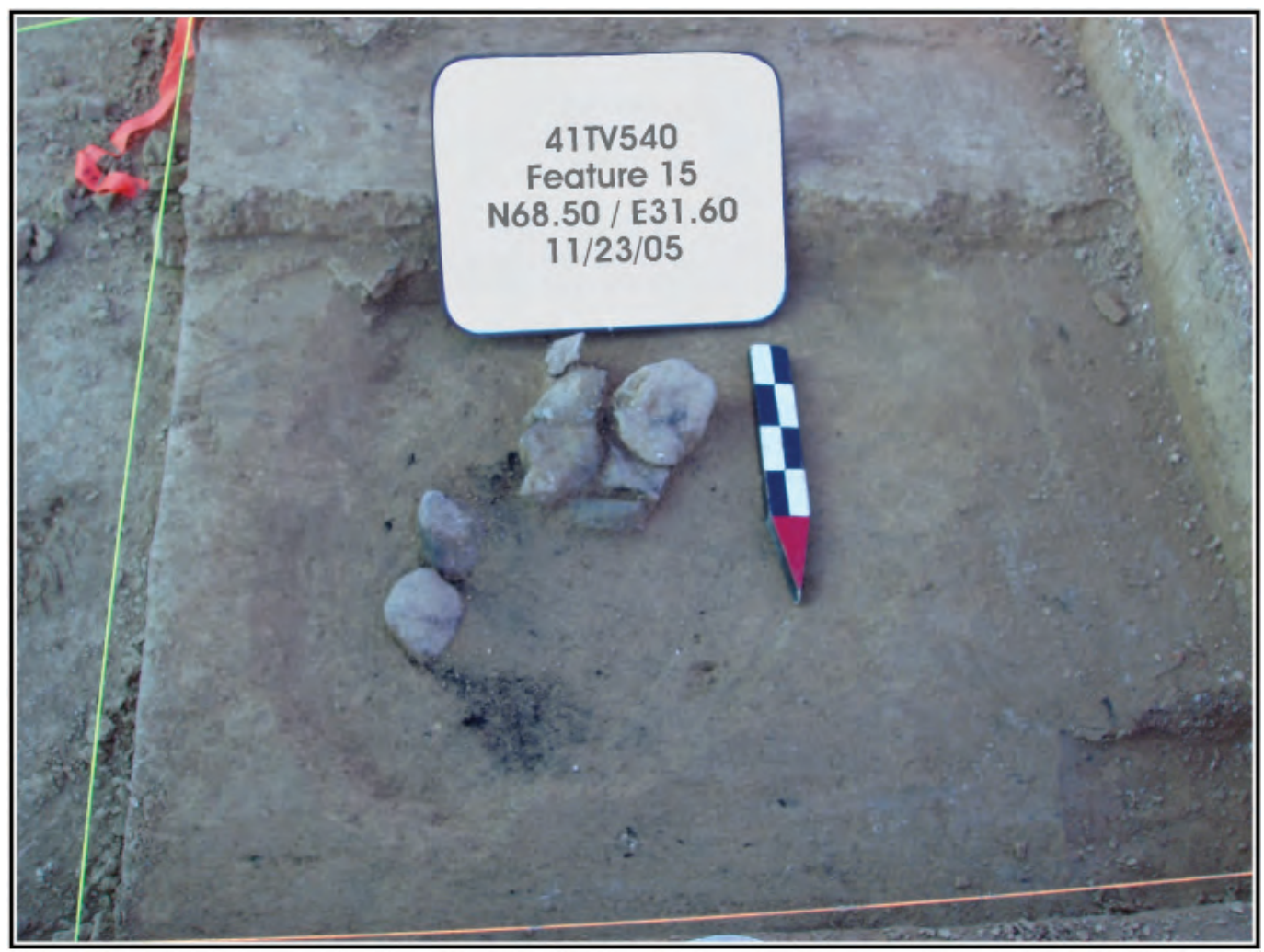

Figure 6-11. Feature 15, Block 2. Note oval stain surrounding rocks.

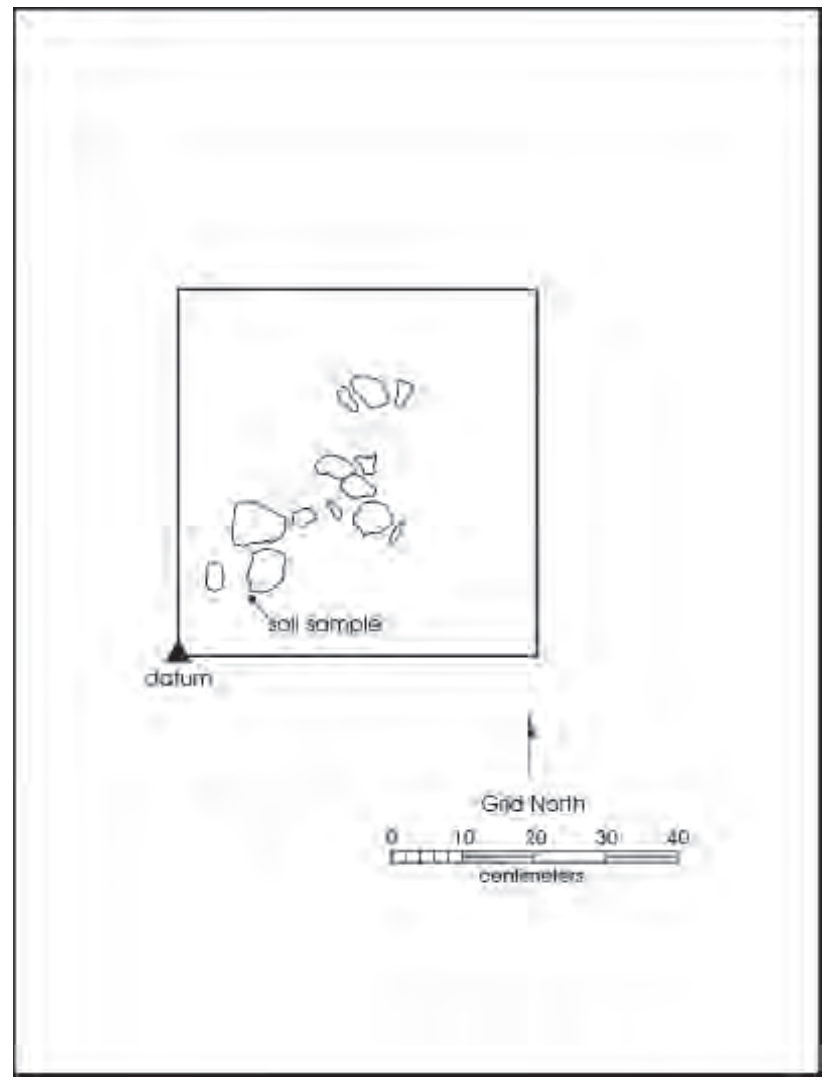

Figure 6-12. Plan view of Feature 17, 41TV540.

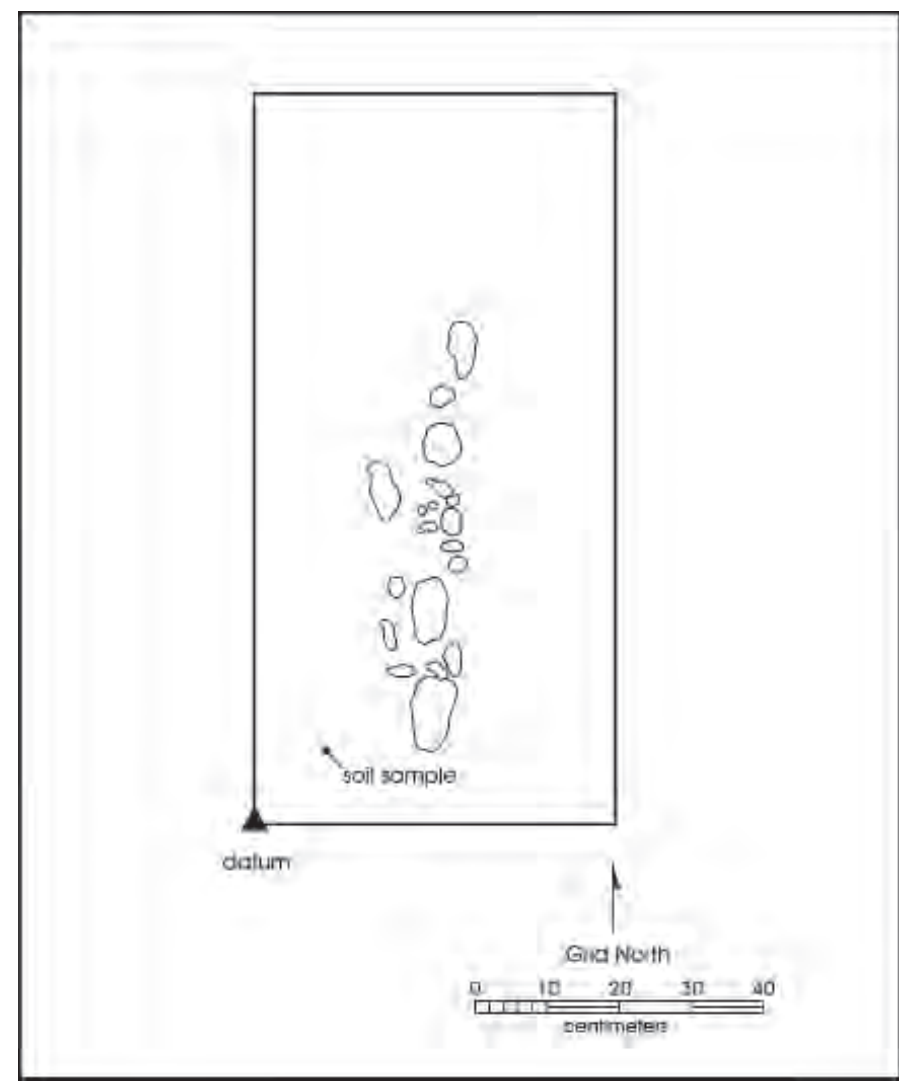

Figure 6-13. Plan view of Feature 18, 41 TV540. 


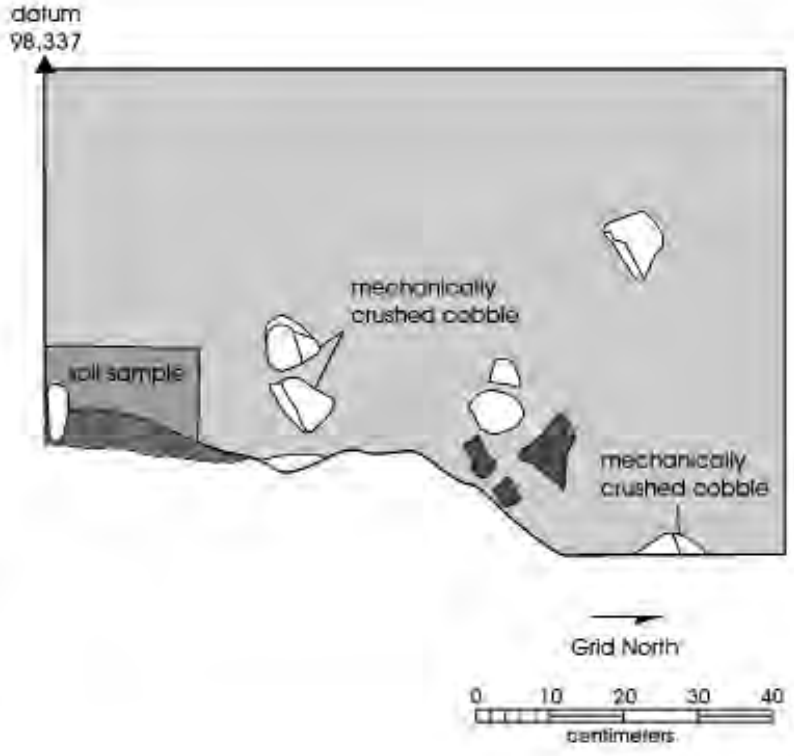

Figure 6-14. Plan view of Feature 20, 41 TV540.

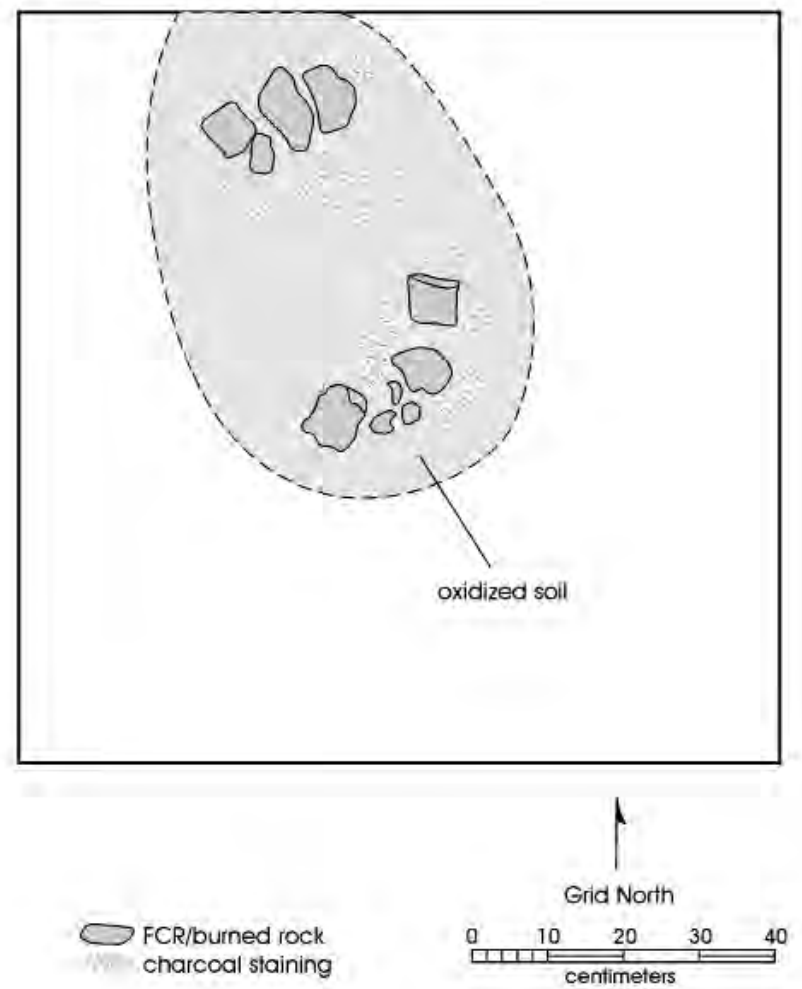

Figure 6-15. Plan view of Feature 21, 41TV540. south of Block 3 (Figure 6-2; Figure 6-16). Oxidized soils are present in the vicinity of the rocks but no cohesive morphology could be identified. Snail shells, a mussel valve, and chert flakes were present among the rock scatter. The scatter extended across much of the surface of the 1-x-1 m unit and was identified at an elevation of 97.26 mad (2.79 mbs). Minimally, the scatter is $95-\mathrm{x}-90 \mathrm{~cm}$. Given the depth, it is likely that the feature dates to the Early or Middle Archaic (Table 6-2).

Feature 25 was a well-defined, small circular cluster of fire-cracked rock located about $6 \mathrm{~m}$ south of Block 3 (Figure 6-2). The feature was a hearth in a shallow basin and measured 33-x-25 cm (Figure 6-17). Snails and lithic debitage were noted in the charcoal-rich fill. It was identified at a depth of $97.32 \mathrm{mad}$ (2.80 mbs). The feature probably dates to the Middle or Early Archaic Periods (Table 6-2).

Feature 26 consists of a 34-x-30 cm roughly circular cluster of charcoal (Figure 6-18) found some 18 meters southeast of Block 3 (Figure 6-2). A single piece of fire-cracked rock was noted in the fill, along with bone fragments and snail shells. The feature was identified at 96.77 mad (3.51 mbs) during mechanical stripping. The depth of the feature is consistent with an Early Archaic date (Table 6-2).

Feature 27 was found approximately 10 meters south of Block 3 (Figure 6-2). The amorphous lens measured approximately 45-x-65 cm and contains burned bone fragments, abundant snail shells, small fragments of fire-cracked rock, and charcoal in an oxidized reddish matrix (Figure 6-19). This feature was defined at an elevation of $96.81 \mathrm{mad}$, or about $3.51 \mathrm{mbs}$. A radiocarbon assay on a charcoal sample from the feature yielded a date of 5320 +/- 40 (Beta \# 212815), which when corrected and calibrated provides a date range of 6200 to $5990 \mathrm{BP}$, placing the feature at the end of the Early Archaic. Like Feature 13, faunal material was common in this feature (Appendix N). Feature 29 is a circular cluster of fire-cracked rock (Figures 6-20) measuring $50 \mathrm{~cm}$ in diameter. The feature was initially recorded as being in the same location as Feature 27 (Figure 6-2). The top of Feature 29 is recorded as $96.74 \mathrm{mad}$ (3.58 mbs), just below Feature 27 (96.81 mad; $3.51 \mathrm{mbs}$ ), but 
Feature 29 is described as intruding into Feature 27. However, there is no evidence of this intrusion in the drawings or photo (Figure 6-19) of Feature 27. The Feature 29 fill contained abundant quantities of charcoal, snail shells, heavily weathered bone, and mussel shell. A radiocarbon assay on charcoal samples from Feature 29 produced a date of 5310 +/- 40, (Beta \#212816) that yielded corrected, calibrated dates ranging from 6190 to $5950 \mathrm{BP}$, virtually identical to the date of Feature 27. It is probable that Feature 27 and 29 represent the same feature, referred to here as Feature 27/29.

\section{Geoarcheological Observations at Site 41TV510}

Following the feature and block excavations, the project geoarcheologist (Frederick) described the lower 1.5 to $1.8 \mathrm{~m}$ of deposits in Blocks 1, 2, and 3 in the bottom of Area 1 as well as the deposits in the deep Area 2 trench (see Appendix $\mathrm{C}$ for field descriptions). The deep trench excavations (Area 2) and the Area 1 block excavations revealed different aspects of the Holocene depositional history of the site. The block excavations provide a close view of the basal deposits of depositional Unit Qa3 immediately adjacent to the valley wall, whereas the deep trench in Area 2 provides a slightly larger scale frame for the site deposits that, while close to the valley wall, extends out onto the former Onion Creek floodplain. As Campbell et al. (2005) suggested, the deposits at the site contained a considerable quantity of colluviums. In the lower part of the excavations, these colluvial deposits were recognizable as small alluvial fan and landslide deposits. Higher in the excavations, they were not recognizable as distinct depositional events, but rather as a large (upwards of $3 \mathrm{~m}$ thick) wedge of clayey sediment that exhibited prominent vertic (shrink-swell) tendencies expressed in the field as slickensides. This colluvial wedge pinched and thinned to the west away from the Taylor Clay that crops out on the eastern valley wall, as the section became dominated by alluvium of Onion Creek (Figure 6-21).

\section{Area 1}

The 2-x-2 m block excavations at 41TV540 examined the lower parts of stratigraphic unit Qa3. The three test units excavated at the site were situated at the very margin of the Onion Creek valley, where Qa3 is inset into the Cretaceous

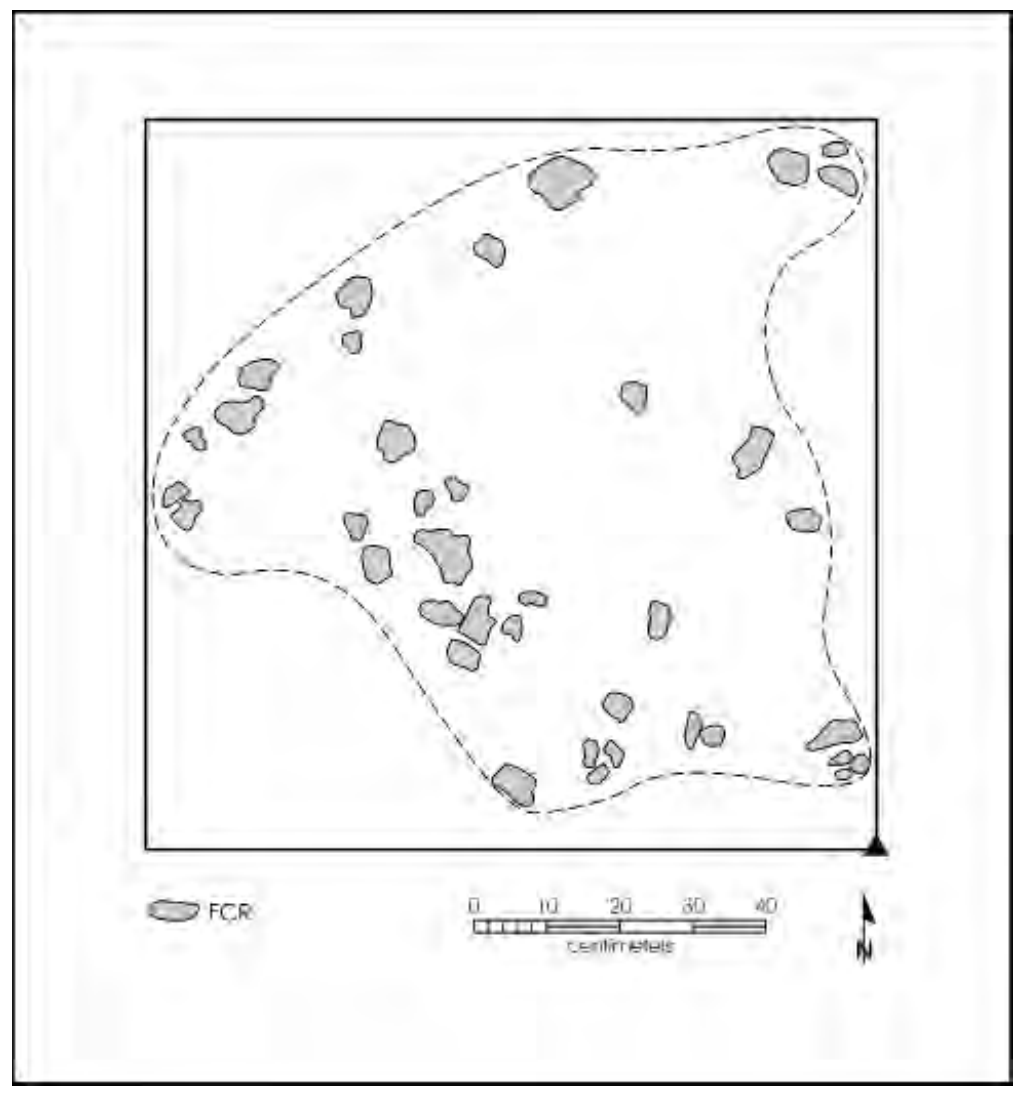

Figure 6-16. Plan view of Feature 24, 41TV540.

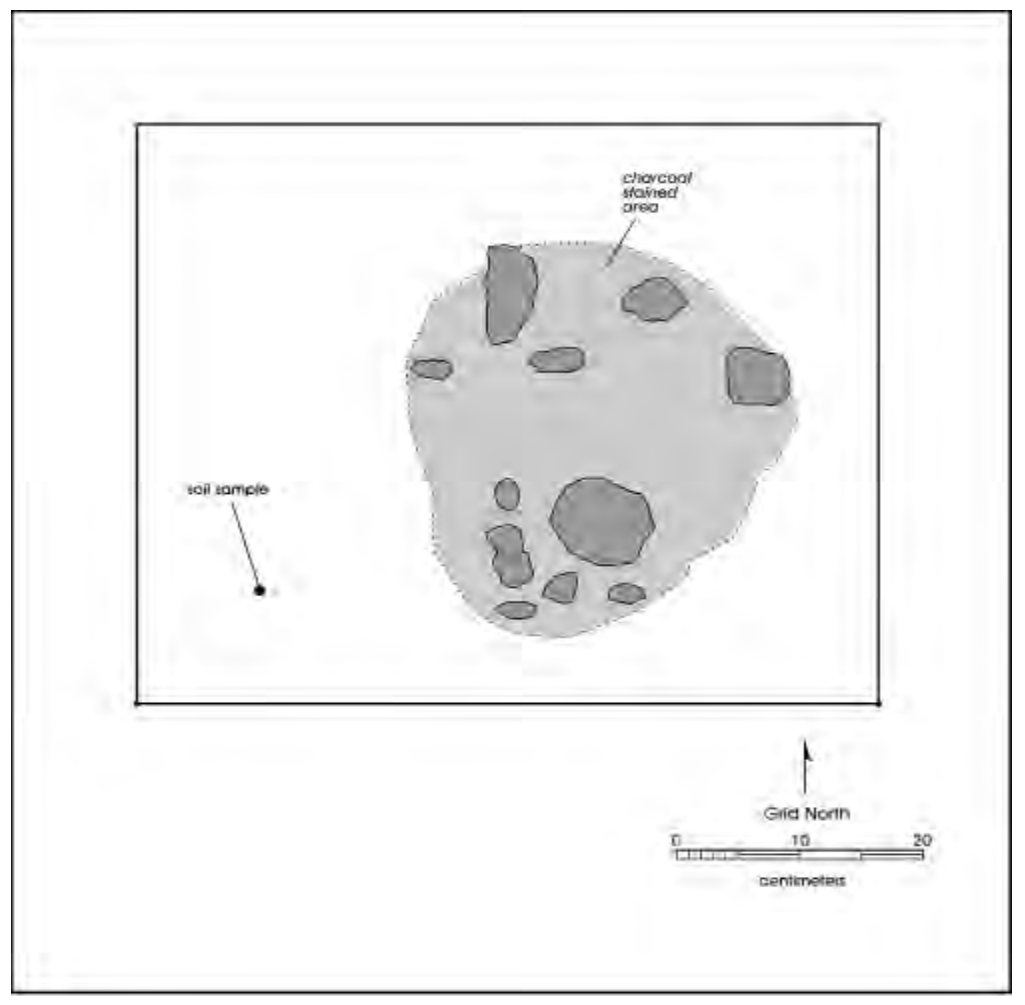

Figure 6-17. Plan view of Feature 25, 41TV540. 


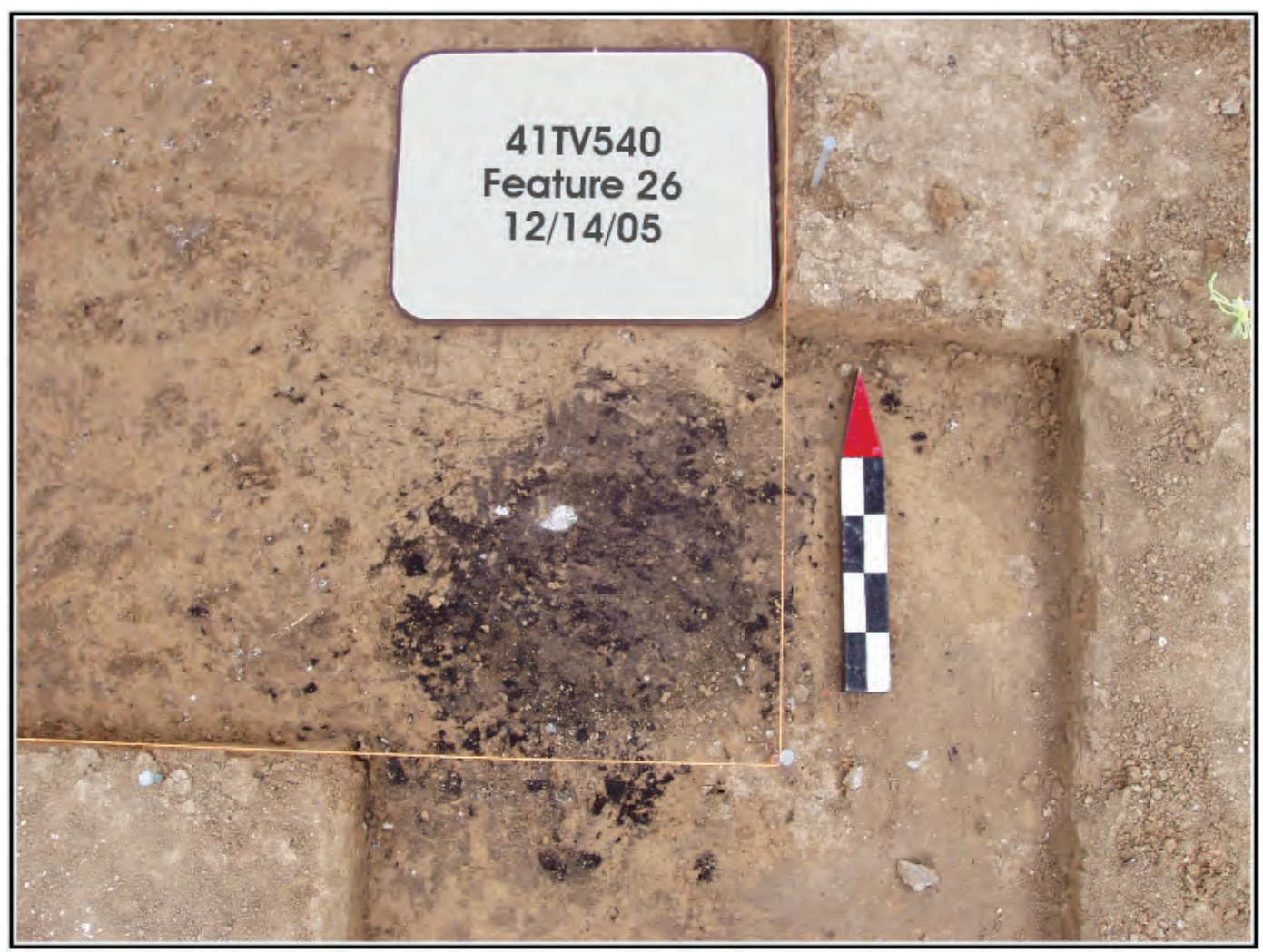

Figure 6-18. Feature 26, 41TV540.

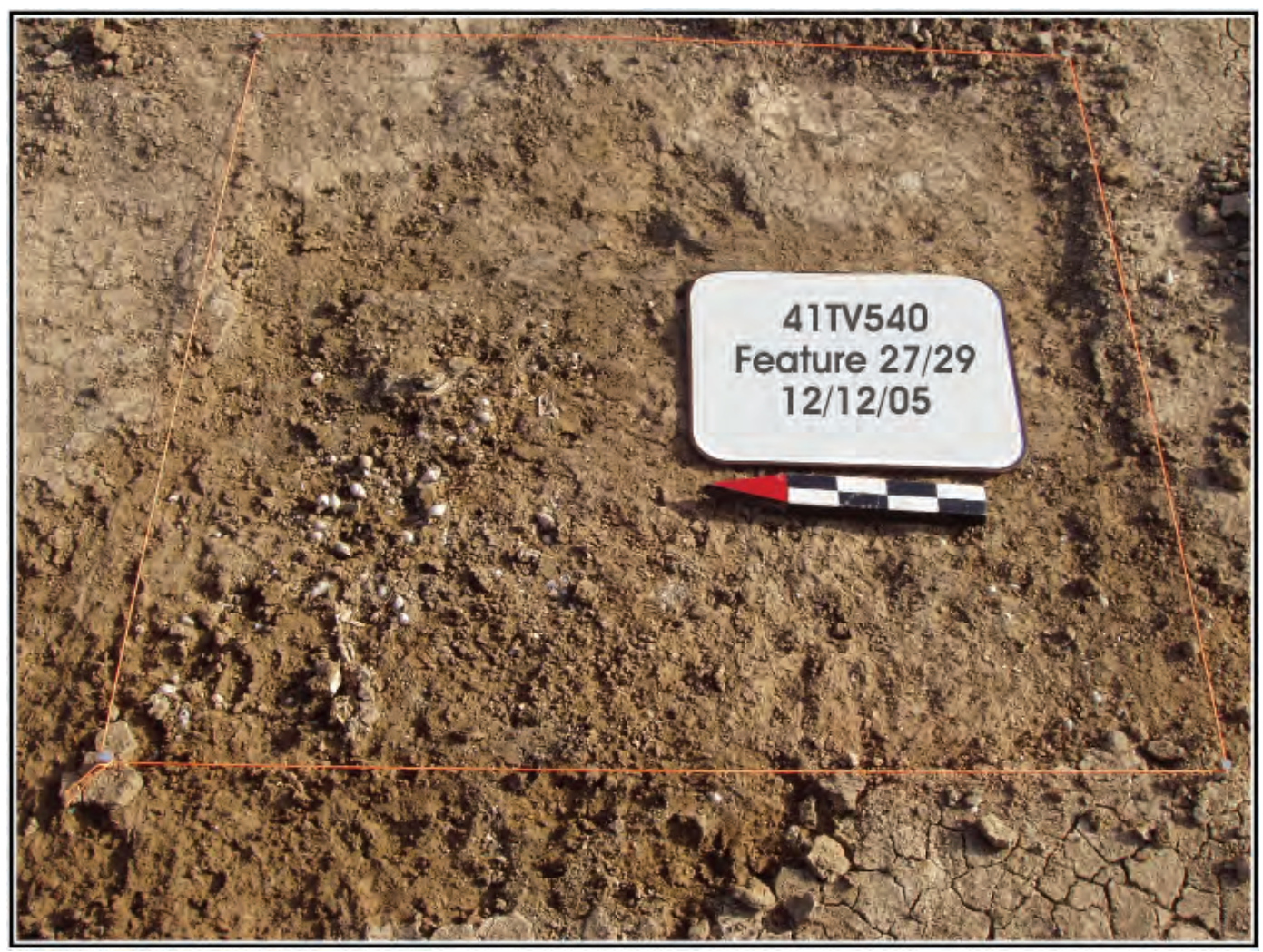

Figure 6-19. Feature 27/29, 41TV540. 


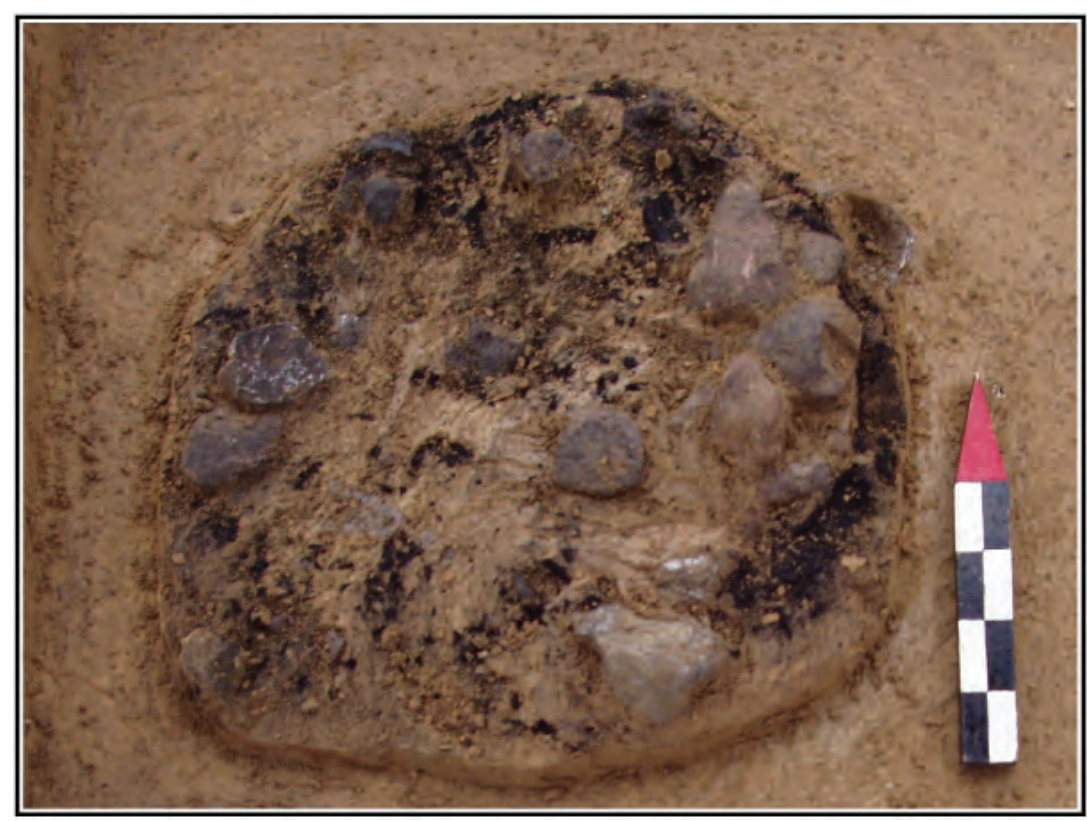

Figure 6-20. Plan view of Feature 27/29, 41 TV540.

age Sprinkle Formation (see Figure 6-1). These three test units were also situated toward the base of the alluvial fill and encountered a suite of highly stratified deposits that include the margin of the Onion Creek channel, colluvial fans forming at the foot of the bedrock slope, and massive floodplain alluvium. Of these three units, Block 1 was dominantly Onion Creek alluvium, whereas Block 3 was dominantly colluvial fan deposits, and Block 2 was a mixture of the two. In general terms, all three test units exposed two components: 1 ) a highly stratified basal section which comprised slightly different depositional settings or facies in each unit, and 2) a significantly less stratified floodplain facies in the upper half of the units. The majority of the cultural materials were situated in the floodplain facies in the upper parts of the block excavations (see Table 6-1). This stratigraphic position is likely to represent occupation of the floodplain close to the active channel of Onion Creek at that time, but the precise distance to the channel is difficult to determine. The paleotopography implied by the deposits exposed by the three test units suggests that the valley wall exhibited a crenulated (rilled or gullied) appearance during the early phases of Qa3 deposition, and that the alluvial deposits draped this undulating topography and gradually leveled the floodplain surface with time and incremental sedimentation.

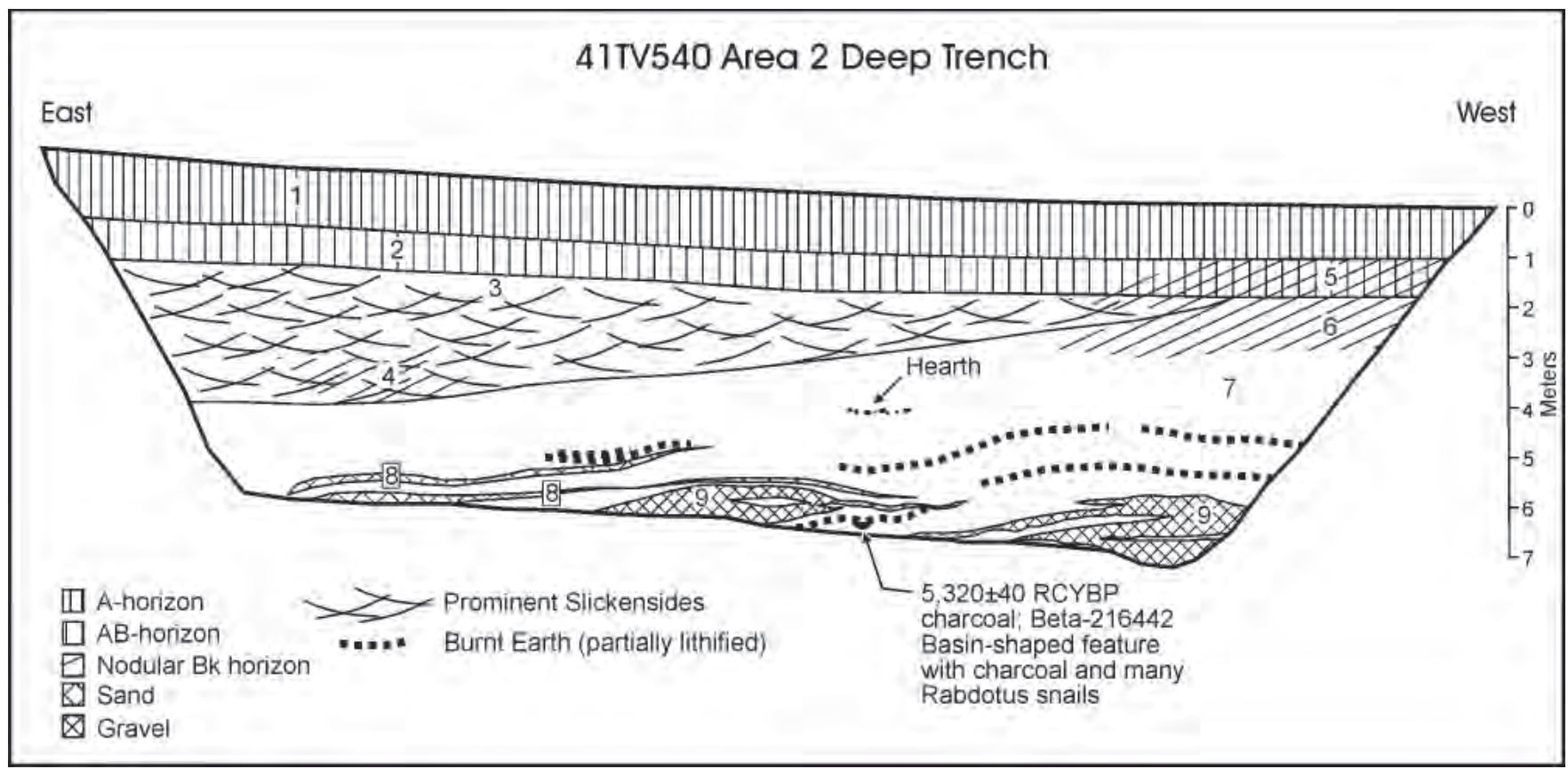

Figure 6-21. Drawing of the south wall of the deep trench in Area 2 excavated immediately north of the block excavations at $41 T V 540$ (Area 1). This trench was oriented normal to the axis of a prominent linear depression that paralleled the bedrock upland immediately west of the block excavations. Note the extent and stratigraphic position of the burnt zones near the base of the alluvial deposits. The lateral accretion deposits of the channel near the base of this fill suggest that the channel was migrating from west to east during the period of occupations targeted by the block excavations. The prominent triangular wedge of sediment with slicken side is interpreted as a wedge of unstratified colluvium derived from the Sprinkle Formation deposits exposed along the eastern Onion Creek valley wall adjacent to the site. See Appendix C for detailed soil descriptions. 


\section{Block 1}

Figure 6-22 provides a profile of the lower $180 \mathrm{~cm}$ of deposit (96.3 to $94.5 \mathrm{mad}$ ) in the eastern wall of this block. Note that the upper $20 \mathrm{~cm}$ were removed prior to this description. The lowest $50 \mathrm{~cm}$ of Block 1 exposed a suite of channel and near channel deposits of Onion Creek that were dipping steeply $\left(15^{\circ}-20^{\circ}\right)$ away from the valley/floodplain margin. The deposits clearly indicated that the SE corner of the block was a high spot and the alluvial deposits dipped both west and north away from this point as if this were the margin of a rill or on a small alluvial fan.

The upper half of the block (ca. upper 1.2-1.3 m of the unit)
The lower set of deposits were dominantly derived from Onion Creek and consisted of mostly thin bedded near-channel overbank deposits. A single thin Colorado River mud drape (Zone 13) was observed in this suite of sediments, as was a single colluvial fan deposit that consisted of re-deposited fragments of Sprinkle Formation clays (clay fragment breccia; Zone 12). A prominent concave erosional unconformity crosscut zones 7 to 12, and on this erosional surface another set of sediments were deposited. One of these was distinctly more red and may be a Colorado River flood drape (Zone 5). A deposit that was probably sediment transported down the rill from the adjacent valley wall (Zones $4 a \mathrm{a} 4 \mathrm{~b}$ ) overlay this zone. The upper $50-70 \mathrm{~cm}$ of this profile appeared to be massive Onion Creek overbank deposits (Figure 6-23). consisted of vertically accreted overbank muds that also dipped to the west and north but the dip gradually leveled out up-section as incremental sedimentation by standing floodwaters preferentially deposited thicker sediments in the low spots. Although most of the deposit in the upper part of the test unit were Onion Creek deposits, two (zones 5 and 7) were notably redder in the field and appeared to have had a greater contribution of sediment from the Colorado River. These muds were likely deposited when the Colorado River was in flood and backed water up the Onion Creek valley resulting in a drape of slackwater sediment across a wide area of the lower Onion Creek valley floor. Both of these mud drapes were located close to the channel/floodplain facies interface.

\section{Block 2}

Figure 6-23 shows the bottom $1.5 \mathrm{~m}$ of deposits $(96.20-94.7 \mathrm{mad})$ in the east wall of Block 2. The upper $50 \mathrm{~cm}$ of this block were removed prior to the profiling. The deposits in this block excavation shared attributes with Blocks 1 and 3, and appears to have exposed alluvial sediments that drape and/or fill a small rill that originated on the colluvial slope to the east. Two sets of vertically aggraded sediment were present in the block, separated by an erosional unconformity. Both sets draped a prominent concave surface that appeared to be oriented roughly east-west (parallel to the valley wall slope).

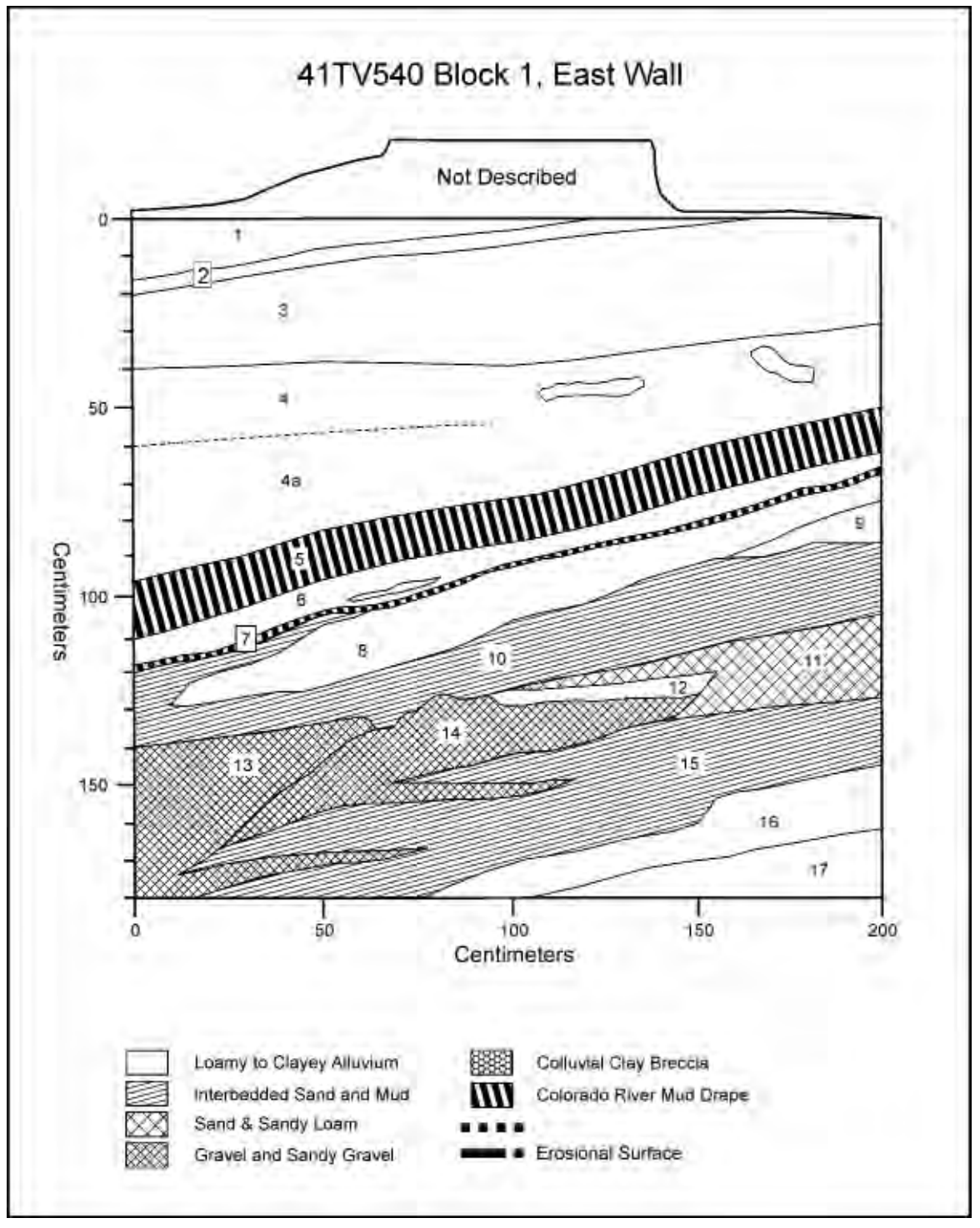

Figure 6-22. Drawing of the strata exposed on the eastern wall of Test Unit 1 at 41TV540. Note the greater degree of stratification in the lower half of the unit, and the more homogeneous floodplain sediments in the upper half of the test unit. See Appendix $C$ for detailed soil descriptions. 


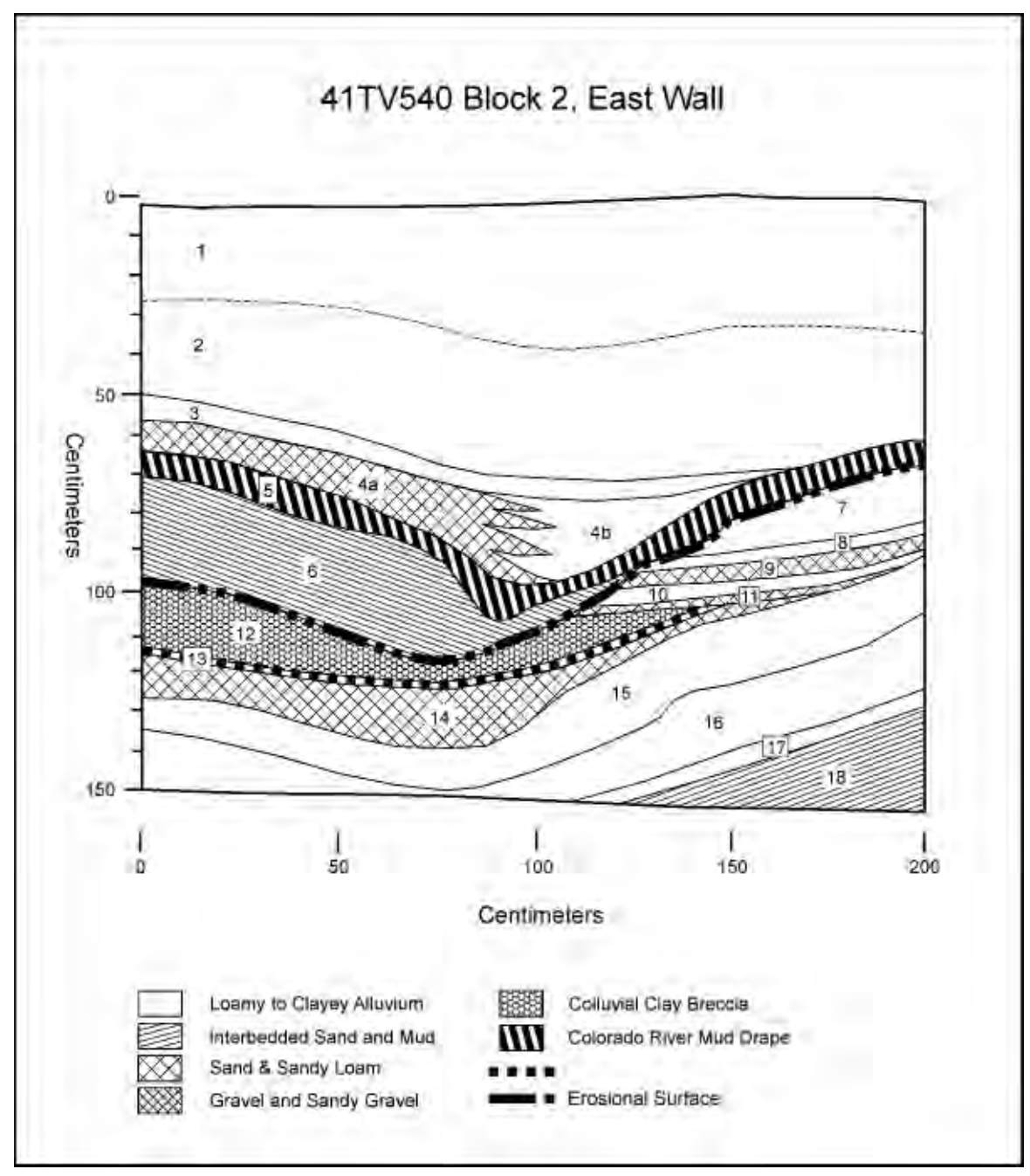

Figure 6-23. Drawing of the strata exposed on the eastern wall of Test Unit 2 at 41TV540. Note the greater degree of stratification in the lower half of the unit, and the more homogeneous floodplain sediments in the upper half of the test unit. See Appendix $C$ for detailed soil descriptions

\section{Block 3}

Figure 6-24 shows the bottom $1.8 \mathrm{~m}$ of deposits (96.40 $94.6 \mathrm{mad}$ ) in the east wall of Block 3 . The upper $50 \mathrm{~cm}$ of this block were removed prior to the profiling. By far the most complex stratigraphy observed among the excavated blocks was found in Block 3, which cut through a series of colluvial fans that were being deposited at the foot of the valley wall slope. Based on the deposits exposed here, these small fans appear to have been between 1 and $4 \mathrm{~m}$ wide, with primarily flat basal surfaces and convex upper surfaces. Multiple fan deposits were interleaved in the lower $80 \mathrm{~cm}$ of this unit, and these deposits ranged from very striking breccias of angular reworked mud clays from the Sprinkle Formation, to more conglomeratic deposits where the clay fragments were more rounded and possibly somewhat decomposed in situ.
As with the other two blocks, the upper meter of the profile was dominated by deposits that were slack water overbank sediments or near channel overbank sediments. A few discrete colluvial fan deposits were present in the upper meter but they were discrete and entirely encapsulated within Onion Creek alluvium. As with the other two blocks, several thin Colorado River overbank mud drapes were also present in the top meter (Zones 8, 13 and 15).

\section{The Area 2 Deep Trench}

The deep trench in Area 2 revealed the larger structure of the alluvial deposits near the block excavations. The east end of the trench was placed on the valley floor at the toe of the colluvial slope, more or less in line with the test units in Area 1, whereas the west end terminated slightly east of the center of the gentle depression (the unnamed tributary of Campbell et al. 2005) that parallels the upland margin and that lies just outside the site boundary (see Figure 6-21; Figure 6-25). At the base of the profile were several channel gravels and interbedded sands that represent lateral accretion channel deposits of Onion Creek. The physical orientation of these deposits suggest that around the time the site was occupied Onion Creek had been laterally migrating from west to east, eventually running up against the valley wall. A piece of charcoal collected from a basin-shaped feature that contained charcoal and numerous Rabdotus shells that was located between two of the gravel lenses yielded a radiocarbon age of $5320 \pm 40$ years BP (Beta216442) which indicates the period of activity of this channel (see Figure 6-21). This hearth is situated at the rear of an Onion Creek point bar and indicates habitation almost all the way down to the channel during this period. A second hearth comprising several fist sized burned rocks was also observed in this trench around $4.2 \mathrm{~m}$ below surface, in a stratigraphic position indicative of occupation of the near channel floodplain but this feature was not dated.

Also apparent in this site and several others in the lower reaches of Onion Creek were extensive burnt surfaces that were often thought by different excavation teams to be culturally derived (see Figure 6-26). These surfaces were prominently reddened, often partially lithified, and 
accompanied by dark layers that were thought to be charcoal but were often found to contain no charcoal when processed for radiocarbon dating. The Trench 2 profile (Figure 6-21) shows the stratigraphic position of several distinct but discontinuous burnt zones, and all of these were situated in proximity to the channel deposits of Onion Creek. The close relationship with the near channel deposits, the extensive areas covered by these burns, the lack of a good correlation with cultural material, and the high temperature nature of the heating in places suggests that these were probably fires of flotsam that had accumulated on the Onion Creek floodplain.

The upper $5 \mathrm{~m}$ of the deposit exposed by this trench ranged from mostly Onion Creek alluvium at the west end to a large but poorly defined mass of colluvial debris shed from the valley wall at the east end. The colluvial wedge stood out in the field on the basis of its vertic (shrink-swell) properties and these deposits formed a triangular wedge that was thickest on the east and pinched and thinned to the west. In one place near the eastern end, the deposits near the base of this colluvial wedge exhibited a Stage II (nodular) calcic horizon, and at the east end of the trench, the alluvial sediments in approximately the same stratigraphic position also exhibited a stage II calcic horizon. But a significant proportion of the sediments in between exhibited no calcium carbonate nodules. The top of the profile across the trench exhibited an $\mathrm{A}-\mathrm{AB}$ soil profile where the A-horizon was clearly cumulic and was about $1 \mathrm{~m}$ thick. A plow zone was recognized as well but it is not shown on the drawing.

\section{Summary}

The cultural deposits documented at 41TV540, which primarily date to the close of the Early Archaic, appear to represent occupations of the floodplain of Onion Creek. These occupations appear to have been situated near the Onion Creek channel, and as the trench in Area 2 demonstrated, some occupations extended down onto the point bar surface immediately adjacent to the channel. The local sedimentation rate within the alluvial fill (Unit Qa3) during these occupations was rapid and repeated inundation of the

\section{TV540 Block 3, East Wall}
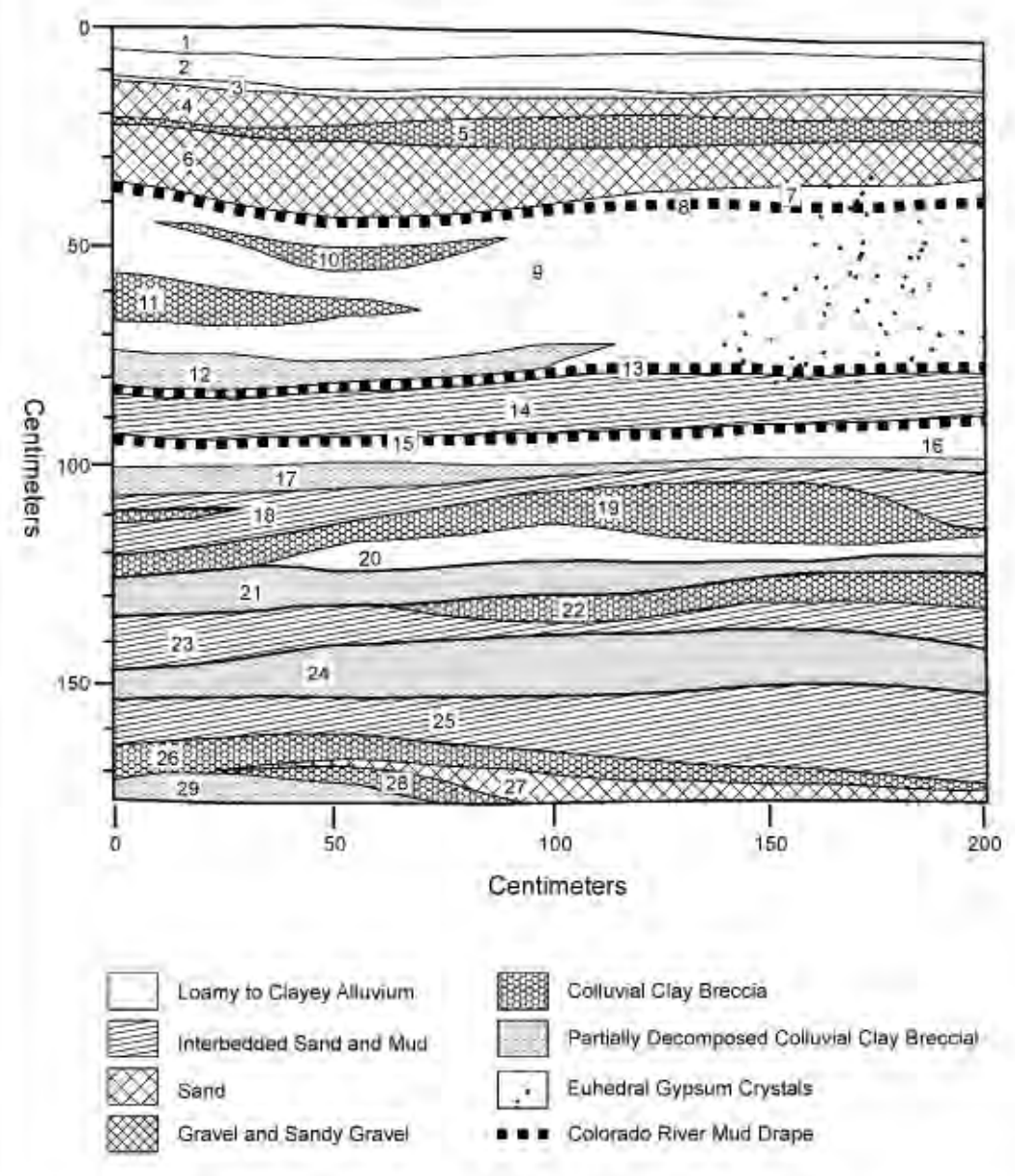

Figure 6-24. Drawing of the strata exposed on the east wall of Test Unit 3, 41TV540. See Appendix C for detailed soil descriptions.

floodplain sealed multiple short term occupation surfaces that contained features and a low density of expedient tools and debitage.

Given this pattern of recovery and the rapid sedimentation rates, we focus our analyses efforts on the Early Archaic features (see Table 6-2) and associated cultural material recovered primarily from block excavations (Table 6-1) at 41TV540. Multiple radiocarbon dates are available from Features 12, 13, and 27/29. These features are spread over a $41 \mathrm{~cm}$ elevation range ( 97.22 to $96.81 \mathrm{mad}$ ) and they all date to a relatively short period (6200 to $5950 \mathrm{BP}$ ) at the close of the Early Archaic. Other features within this elevation range, as well as features and artifacts below the 96.81 elevation, are assumed to also reflect Early Archaic (6000 - 8000 BP) material given the rapid sedimentation rates. If these 


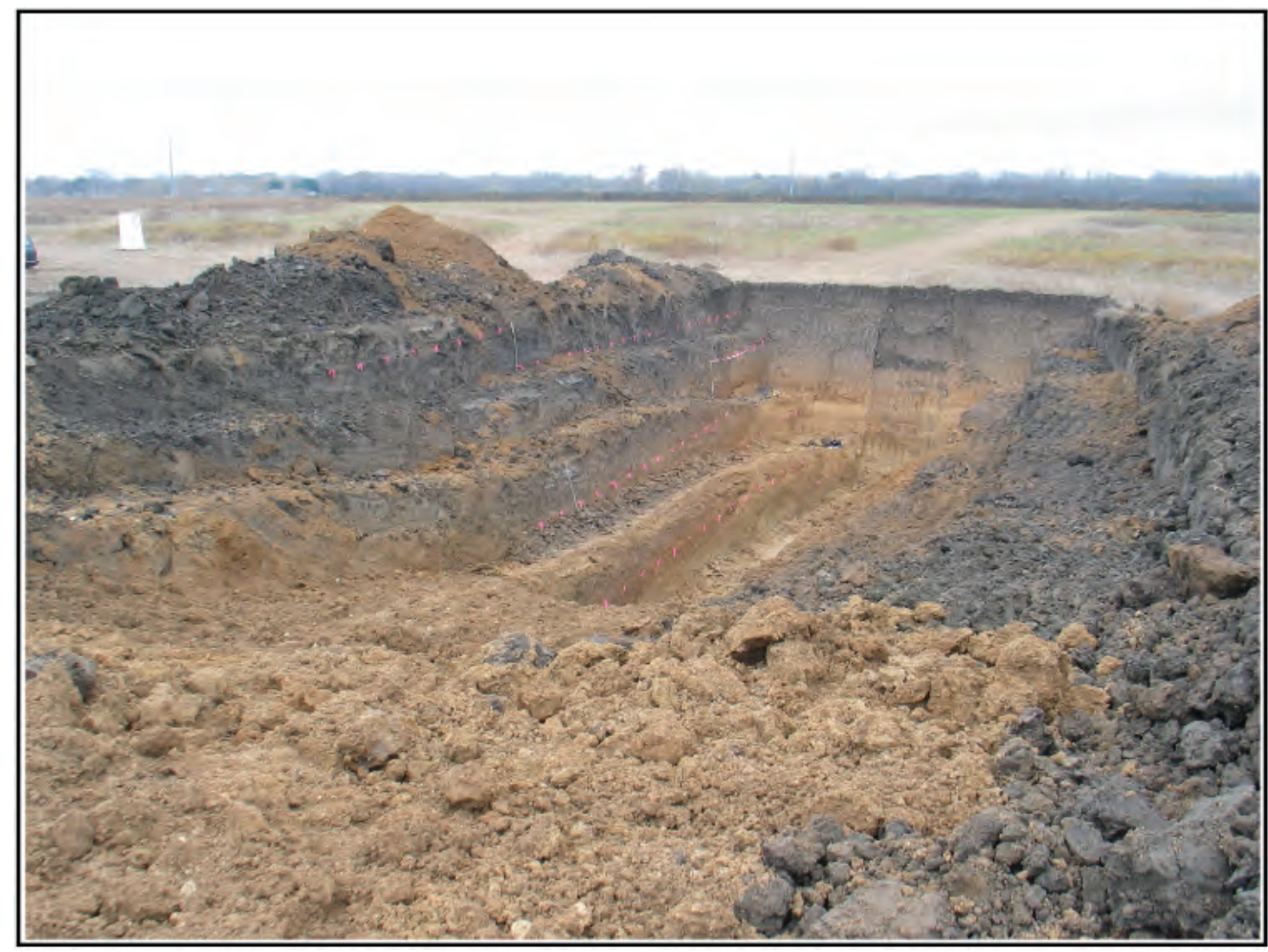

Figure 6-25. Photo of the deep trench in Area 2 as it appeared during profile drawing in December 2005.

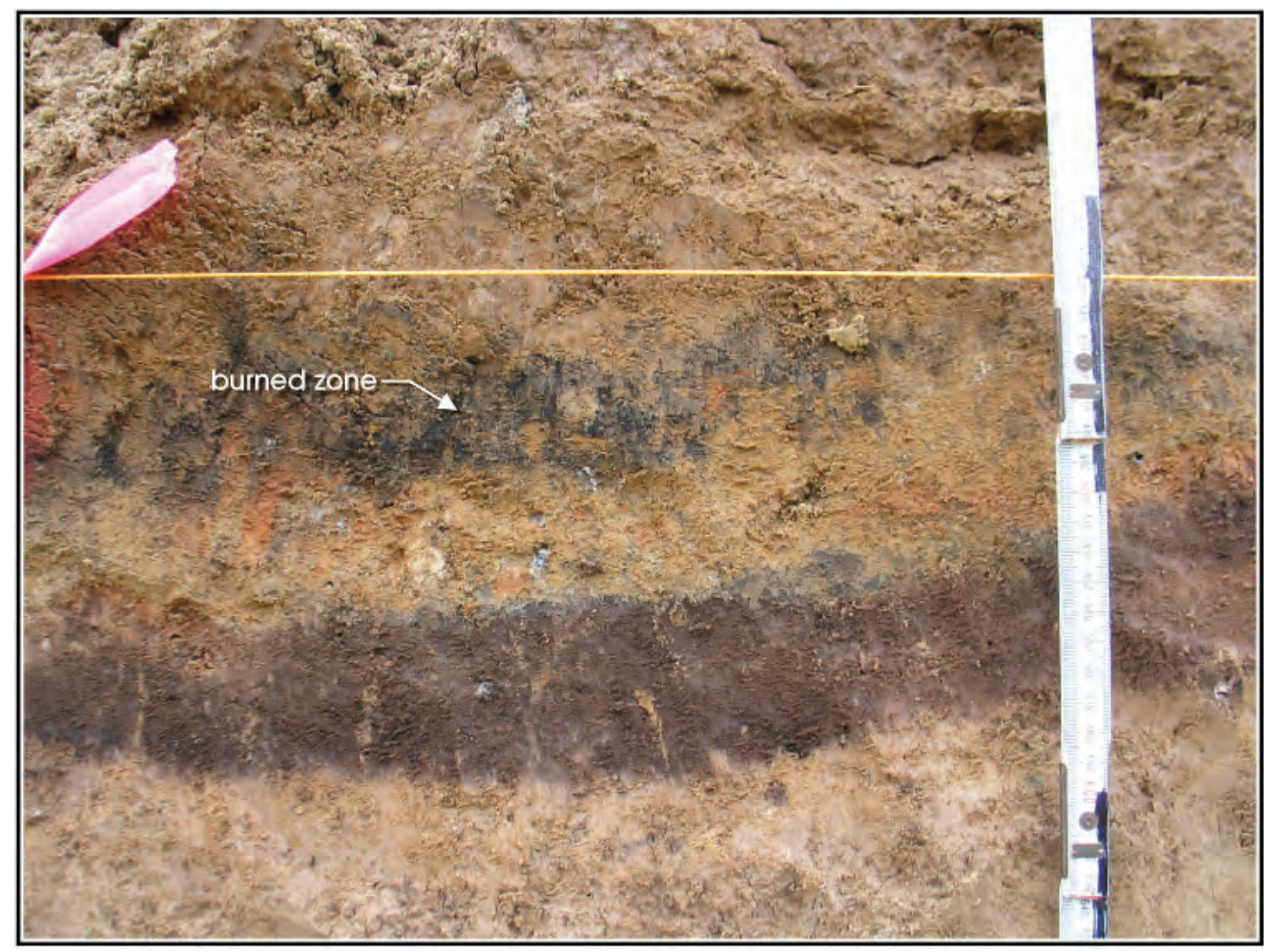

Figure 6-26. Photo of one of the burn zones exposed in the south wall of Trench 2, 41TV540. Note the thick pervasively reddened basal surface, and the overlaying sediment with material that looks like charcoal and bright orange areas which are partially lithified burnt earth. 
assumptions are accurate, we then have 12 features from 41 TV540 that are in the Early Archaic, and an additional four features that probably fall either at the end of the Early Archaic, or the beginning of the Middle Archaic (see Table 6-2). This relatively high count of 16 features contrasts with the low recovery of other cultural material. The block excavations summarized in Table 6-1, all of which probably reflect Early Archaic occupations, produced only 311 pieces of chipped stone, about 40 grams of bone, and about 350 grams of mussel shell. The dominant material recovered was snail shell (ca. $9 \mathrm{~kg}$ ) which may not reflect cultural activity. In addition, note that most of the cultural material in Table 6-1 comes from feature context, with Features 13, 14, and
15 dominating the upper levels of Blocks 2 and 3. This pattern of low density artifact recovery relative to features is consistent with higher mobility and short-term occupations.

While the Early and Late Archaic deposits documented at 41TV410 are not the focus of our analysis, this is essentially the same pattern seen at that site. A similar pattern has been has been documented in the late Paleoindian/ Early Archaic occupations at 41TV2125 (Campbell et al. 2009). The fact that these occupations are all characterized by a high frequency of features associated with low numbers of artifacts reveals an apparent continuity in hunter-gatherer land use strategies in the lower Onion Creek valley. 


\title{
Chapter 7: Research Design
}

\author{
Steve Tomka, Raymond Mauldin, Charles Frederick, and Antonia Figueroa
}

Following the determination by TxDOT and THC regarding the eligibility status of $41 \mathrm{TV} 410$ and $41 \mathrm{TV} 540$, TxDOT tasked CAR with development of a research design for the analysis of materials collected from 41TV540. This chapter summarizes that effort. Expanding on the original testing research design presented in Chapter 4, the research design focused on three broad objectives (Tomka et al. 2007). These were (1) reconstruction of the geomorphic history of the confluence of the Colorado River and Onion Creek and of the processes that influenced site formation, (2) reconstruction of the paleoenvironmental conditions and resource structure on the Onion Creek floodplain, and (3) the determination of site use and site function at 41TV540 within the overall huntergatherer land use strategy. Both the geomorphic reconstruction and the documentation of variations in resource structure on the floodplain required the acquisition of data at scales well beyond the CAR testing boundaries of 41TV540. In this chapter, we provide a short summary of these major research objectives. Chapters 8, 9, and 10 present the results of these research efforts.

\section{Research Objectives}

We suggest that a critical element in the analyses of the data types recovered from 41TV540, as well as developing an understanding of hunter-gatherer behavior in the Lower Onion Creek valley, is related to the reconstructions of past climate and geomorphic conditions. In this particular setting, the reconstruction of paleoclimate can help explain floodplain resource structure, as well as some of the geomorphic conditions that account for the burial of the material record, and paleoclimate also impacts aspects of the organization of the hunter-gatherer activities through conditioning resource structure. That is, the organization of hunter-gatherer behavior is conditioned, to a significant extent, by the distribution of different types of floral and faunal resources. The structure of these resources on floodplains is itself conditioned by the impact of flood periodicity and intensity. Flood periodicity and intensity is affected by proximate factors such as floodplain morphology, substrate characteristics, and broader paleoclimate conditions. Many of these proximate factors are related to, or can be estimated from, focused geomorphological investigations.

\section{Geomorphic Reconstruction of Holocene Sequences in the Lower Onion Creek Valley}

Working from this perspective, the first research objective focuses on the geomorphic reconstruction of major aspects of the Lower Onion Creek Valley. The geomorphic work was designed to provide a stratigraphic context for all of the archeological fieldwork done by multiple CRM firms associated with the SH 130 project in the Lower Onion Creek valley. The work outlined in the research design under this component involved sampling, characterization, and dating of soil profiles from a variety of locations within the borrow pit and from natural cutbank exposures. These exposures sampled a series of alluvial sequences proposed for the region that, based on available dates, represented at least four different active periods. Major depositional events were suggested from 10000-8000 years BP, 6000-4500 years BP, 3800-2300 BP, and post 1300 BP. A variety of detailed analyses, including granulometry, organic carbon, calcium carbonate equivalent, free iron $\left(\mathrm{Fe}_{\mathrm{d}}\right)$, magnetic susceptibility, and micromorphology were suggested to characterize sediment samples from Onion Creek alluvial sequences. We also suggested that additional radiocarbon ages from different parts within each alluvial fill would be necessary to examine the depositional chronology in more detail. Samples collected for radiocarbon dating included charcoal, Rabdotus sp. snails, and bulk sediment. In addition to these assays, we suggested dating of selected samples of charcoal collected by Hicks \& Company during several testing excavations in the Onion Creek valley.

\section{Documenting Trends in Paleoenvironmental Conditions and Resource Structure}

The second research objective, which also hinged on geomorphology to a significant extent, was focused on investigating trends in paleoenvironmental conditions within the Onion Creek valley and on documenting the manner in which those trends influenced plant and animal communities. The reconstruction of resource structure was to be built, in part, on information supplied by the completion of the first objective, which would identify intervals of sediment deposition and stability. We argued that deposition intervals would have been dynamic, characterized by frequent flooding, variable rates of floodplain aggradation, and stream migration. Under these conditions, habitats for vegetation would have been frequently disturbed and somewhat unpredictable. Plant communities should be dominated by weedy plants and mammalian assemblages rich in small (e.g., lagomorphs) to medium-bodied (e.g., ungulates) animals. Many weedy plant species will be economically significant (e.g., quinopodium and amaranth) and will occur in dense patches amenable to efficient exploitation. Animal population densities will be highest at the margins of open and wooded settings near the edges of the active floodplain. In contrast, as the landscape 
matures and the stream begins to down cut, the vegetation communities present on the floodplain will begin to shift to woodland dominated species and animal assemblages will consist of a mix of small-body woodland species (e.g., squirrels) and medium ungulates such as deer. Weedy species, well adapted to disturbed settings will be replaced by slower-growing tree species as the plant community moves towards a climax vegetation pattern. Some tree species will produce significant cyclical mast yields that will encourage high deer population densities, as well as the presence of human consumers.

The geomorphological investigations in the first research objective will help document periods of aggradation and stability across the Lower Onion Creek floodplain. Given the possible impacts of intervals of aggradation and stability on the plant and animal communities and potentially huntergatherer land use, our objective was to investigate what effect these intervals actually did have on the composition and structure of the resources present on the floodplain. We suggested that an analysis of several different data sets extracted primarily from geomorphic samples would provide information on resource structure during periods of floodplain aggradation and periods of stability. These included the analysis of stable carbon isotopes from dated soil profiles to document changes in proportions of $\mathrm{C}_{3}$ and $\mathrm{C}_{4}$ vegetation (see Boutton et al. 1998; Jessup et al. 2003; Tieszen et al. 1979) in geomorphic profiles from throughout the Onion Creek Valley.

In addition to the analysis of soil carbon from sediment samples, a series of additional analyses were proposed for sediments extracted from the $7 \mathrm{~m}$ profile exposed next to 41TV410 (see Chapter 5). From samples extracted from this particular profile, we proposed an analysis of plant phytolith to provide a more precise, species-specific, indicator of the composition of the vegetation communities (see Fredlund et al. 1998). We anticipated that phytolith assemblages from the paleosols, the existence of which imply some relative stability, would reflect a vegetation community dominated by woody species while grass and weedy species would be most common in more active intermediary sediment zones.

We also suggested a number of studies of snails that would be extracted from the $7 \mathrm{~m}$ profile. These included an analysis of snail populations, particularly those species in the smaller size ranges, as they tend to have relatively narrow habitat tolerances (Clark 1969) and small home-ranges (Cook 2001; Lokke 1963), both of which are advantageous for reconstructing paleoenvironmental conditions (Brown 1999, 2006; Clark 1969, 1973; Malof 2001). We anticipated that snail assemblages from the paleosols would consist of a mix of species tolerant of partial-shade and open-settings, while assemblages from the intervening zones would be dominated by species that prefer or at least tolerate open-settings characterized by grassland cover (Tomka et al. 2007).

In addition to characterizing these assemblages, we further proposed to conduct research designed to elucidate the habitat conditions preferred by species of snails commonly found in archeological sites (e.g., Polygyra texasiana; Helicina orbiculata; and Rabdotus dealbatus). To begin to construct a baseline of snail species habitat preference, the research design (Tomka et al. 2007) proposed to collect snail population samples from three different vegetation settings that may be characteristic of the evolution of habitat conditions across a floodplain. Specifically, we suggested collection and assessment of samples from open grasslands, brushy woodland, and near climax forest settings. The proposed collection procedure involved the recovery of sub-fossil and estivating populations found on surface as well as a sample of snails buried in the upper $5 \mathrm{~cm}$ of soil. Surface samples would be collected from roughly 30-x-30 $\mathrm{m}$ areas within each habitat type and subsurface samples would be assessed through the excavation of a $1-x-1 \mathrm{~m}$ unit to $5 \mathrm{cmbs}$. The 500 cubic centimeter of soil would be collected and water screened at the CAR laboratory through window mesh to extract all micro-snails. Up to three 1-x-1 $\mathrm{m}$ excavation units were proposed per sampling locality to obtain a representative sample of shallowly buried snails. We proposed to submit the micro-snail assemblages for gastropod analysis to identify the species and quantify gastropod frequency. A series of observations designed to recover size information on these natural populations, providing comparative data for archeological assemblages, was also proposed (Tomka et al. 2007).

As a final method of monitoring available vegetation, and changes in that vegetation, we proposed the analysis of macrobotanical samples derived from the flotation of feature fill and macrobotanical samples. Unprocessed flotation and analysis of macrobotanical samples from features documented on 41TV540, as well as non-feature associated charred plant samples collected from levels assigned to the Early Archaic at 41TV540, should proved a sample of material available, as least for fuel. In addition, to provide a contrast with Middle and Late Archaic paleoenvironmental conditions, we propose to submit selected samples from dated features at 41TV410. These would provide some diachronic indicator of changes in vegetation communities across the landform. The inventory of species would, at a minimum, provide information as to whether the plants are representative of a brushy or woodland vegetation community and may even provide rare glimpses into foodstuffs consumed. 


\section{Determining Site use and Function within the Overall Hunter-Gatherer Land Use System}

The third and final research objective outlined in the research design focused on determining site use and function within the overall hunter-gatherer land use system. Specifically, we proposed to investigate a series of research areas, some of which were originally outlined in Chapter 4 , that we argued would help define the organizational components of huntergatherer behavior that were responsible for aspects of the material record recovered at 41TV540 (Tomka et al. 2007). We argued that the range of activities carried out at a site is related to the role of the site within the overall land use system (i.e., site function) and the length of site occupation (Shott 1989; Smith and McNess 1999). In defining site use, our goal is to determine the range of activities carried out at 41TV540 during the Early Archaic. Site function, or the role of the site within the regional land use system, focuses more on where and when different activities are carried out across the landscape, involving questions of mobility and the length of site occupation. Site use will be manifested in various aspects of data types including elements of features, lithic tools and chipped stone debitage. Variations in site function, conversely, will be seen in differences in mobility and occupation length, and will be manifested in aspects of raw material diversity, the presence of different tool types, and diversity in the floral and faunal remains recovered (see Tomka et al. 2007). The proposed analysis of each of these data types is briefly reviewed below.

\section{Site Use and Features}

As was outlined in the previous chapter (see Table 6-2), the principal features found at 41TV540 dating to the Early Archaic were thermal features, probably used for cooking of various food stuffs, and three larger features (11, 13, 14) that contained concentrations of snail shell (primarily Rabdotus sp), burned rock, and charcoal within an oxidized matrix. After reviewing the feature data, the research design (Tomka et al. 2007) proposed to focus on two aspects of these feature data. These are 1) an evaluation of the relationship between feature reuse and rock size and 2) the development of a protocol focused on the collection and analysis of archeological snails and the establishment, through amino acid racemization, of whether boiling of snails produces identifiable signatures.

To evaluate the relationships between frequency of reuse and rock size at 41TV540, Tomka et al. (2007) proposed to conduct a series of experimental burns following several earlier researchers (see Johnson 2000; Mauldin et al. 1998; Mauldin et al. 2009; Quigg and Peck 1995). These earlier studies suggested that when thermal features used rock, increasing frequencies of feature reuse would result in increasing fragmentation with a higher percentage of rocks falling in the smaller size ranges. While scavenging of rock, hearth maintenance and clean-out, and the addition of new rock complicate interpretations of feature rock size distributions, the experimentally gathered size data have the potential to provide information on feature use frequency.

Features 13 and 14, and possibly Feature 11 on 41TV540, appear to represent a different type of feature relative to the rock hearths that were the proposed focus of the thermal feature experimental work. While some burned rock, charcoal, and dark sediments were present in these features, and while none were completely excavated, the nature of these features, which are dominated by large quantities of snail shell, remains unclear. Do the snail concentrations represent the residues of food consumption or massive dieoffs of natural populations attracted to organic rich sediments found on anthropogenically enriched surfaces (e.g., hearths or trash middens)? Tomka et al. (2007), building on the results of earlier researchers (see Brown 1999, 2006; Lubell 2004a, 2004b; Mallof 2001), proposed to construct an analysis protocol for use during future projects to help answer these questions. The protocol was to focus on archeological sample collection procedures, suggestions for off-site sample collections and a consideration of gastropod analysis procedures to help determine age structure and modifications due to food processing and consumption. In addition, they proposed to expand early work done on amino acid racemization (see Abbott et al. 1996:619; Ellis et al. 1996; Goodfriend et al. 1996) by using reverse phase liquid chromatography (RP-LC) to look for exposure of shell to high temperatures (note 2). It appears that some degree of heating was probably necessary if snails were a component of hunter-gather diet at 41TV540.

\section{Site Use and Lithic Tools}

The identification of the classes of functional tools present at a site can provide relatively direct evidence of the subset of activities that require the use of chipped or ground stone tools carried out there. Therefore, we proposed to classify each of the small number of informal and formal tools from the Early Archaic material at 41TV540 into functional tool categories (i.e., scraper, knife, etc). The classification relied on a combination of macroscopic (i.e., morphology, hafting features; breakage cause) and microscopic use wear traits (i.e., polish, striations, micro-flaking), noted under low magnification (30X-120X). Although the number of lithic tools is small, the richness of the sample (i.e., number of functional tool classes) and the specialized (i.e., limited function) versus generalized (i.e., used for performance of a number of distinct tasks) nature of the tools can be related 
to a number of broad hunter-gatherer organizational aspects. We suggested that activities at special-purpose locations would require the use of fewer tools and some of the tools used would have been specialized rather than generalized instruments. Reoccupations of special purpose locations for the same set of activities will differentially increase the number of artifacts relative to the number of artifact types. At longer occupied residential locations, the number of different artifact types would increase at a faster rate because a wider variety of activities were conducted.

With these parameters in mind, and based on the earlier suggested shifts in resource base between geomorphologically active and stable periods, Tomka et al. (2007) proposed that during dynamic periods hunter-gatherers would visit a locality for short periods in possession of generalized tools. Some tool manufacture and repair debris may be generated during such site visits but the majority of the lithic tools will be expedient specimens discarded immediately following use. During stable periods as the floodplain forests mature and mast production increases, hunter-gatherers will increase residence time along the steam. The increase in occupation length will lead to the discard of a wider range of tools involved in a broader range of activities. We suggested that the analysis of the small tool assemblage will serve as independent test of the hypothesis that the use of the site changed over time as the conditions on the Onion Creek floodplain oscillated between dynamic and stable conditions.

\section{Site Use and Lithic Debitage}

Just as the overall range of activities carried out at a location varies among other things with the length of stay, so to will the range of lithic reduction activities. Assuming a similar organizational component, as the length of occupation increases the likelihood that worn tools will be resharpened and failed tools will be rejuvenated or replaced will increase. Short occupations, either within the context of a special purpose site or a forager residential camp, will yield a limited range of lithic debitage correlated with a narrow range of reduction activities. As occupation length increases, the need to carry out tool maintenance (i.e., resharpening and rejuvenation) and the manufacture of new and/or replacement specimens will result in the performance of a wider range of lithic reduction activities. This will, in turn, correlate with a wider range of lithic debitage.

We therefore expect that the composition of the lithic debitage will vary between our two idealized geomorphic conditions. A greater range of tool manufacture and reduction activities should characterize lithic debris recovered from stable surfaces. Collections from rapidly aggrading surfaces should exemplify a limited range of reduction activities. We further proposed that during short occupation periods, the bulk of the lithic debris deposited on site will derive from core reduction while in the process of producing debitage for use as expedient tools. In contrast, during stable periods, we suggested that the refurbishing and replacement of failed or exhausted formal tools will produce debris from tool rejuvenation and manufacture and much of this debris should be representative of bifacial reduction. Therefore, we propose that the identification of the lithic raw material reduction strategies (i.e., core vs. bifacial reduction) represented at the site will aid in defining and serving as independent measures of site use. To document this relationship, we proposed to perform the following analyses on each piece of lithic debitage from the Early Archaic at 41TV540: (1) classify all unmodified debitage into categories using maximum dimension (i.e., 1-10 mm; 11-20 mm; etc); (2) record cortex (i.e., primary, secondary, tertiary); and (3) classify flakes into one of several reduction categories (e.g., biface thinning flakes, early reduction, resharpening debitage). Once the debitage analysis was done, Tomka et al. (2007) proposed to sort all Early Archaic debitage from the site based on color and inclusions to arrive at Minimum Analytical Nodule (MAN) analytical groups (Hall 2004; Larson and Kornfeld 1997).

\section{Site Function, Mobility and Raw Material Variety}

Approaches seeking to define site function, or the role of the site within the regional and annual hunter-gatherer land use system, focus on where and when populations carry out different activities on the landscape. These approaches combine information on aspects of site use (e.g., length and season of occupation) with regional-scale aspects of mobility (e.g., distances moved, number of residential moves), and the differential organization of activities (e.g., specialized resource procurement) across the landscape. We proposed to investigate the archeological record of 41TV540 to address two related aspects of site function, mobility and the length of site occupation.

Studies (e.g., Amick 1995) have shown that debitage and tools can be used to track mobility. While these studies are often conducted by tracing specific raw materials with known source locations, the relationship demonstrated by these earlier studies is applicable even if the specific tool stone sources are not known. We proposed a general relationship between the number of raw material types present and mobility. Whether the acquisition of tool stone is embedded in other activities, or is a task-specific activity, logistical residential sites should exhibit the greatest range in raw material types due to the greater distances covered during camp relocations. Taskspecific locations should have a smaller range of raw material types present assuming that they are always occupied for the same purpose. Similarly, foraging components should 
also encounter a smaller range of raw materials simply as a function of the more limited scale of mobility.

To investigate the relationships between raw material variety and different mobility strategies, we proposed to use the data obtained from the MAN analysis outlined above as an indicator of the number of raw material types present within the debitage sample. In addition, we proposed a similar MAN analysis for the lithic tools and cores. Once completed, we suggested a comparison of the MANs defined in the tools and cores with those defined in the unmodified debitage to determine whether debitage and/or tool color subgroups are present that have no equivalents among the cores and/or early and middle reduction stage manufacture failed bifaces. Those functional artifacts and subgroups of debitage that are not represented by a complete reduction sequence may have been brought into the site as either stage manufactured items and or finished items.

\section{Site Function, Occupation Length, Lithic Technology and Measures of Diversity}

As several mobility models (Binford 1980; Cannon et al. 2004; Lieberman 1993) have suggested, the length of occupation is contingent on the organizational aspects of mobility. When considering sites established by huntergatherers within the context of collector/forager strategies, highly mobile residential sites (forager) will be occupied for short durations, as will logistical resource extraction or other limited activity sites (collector). Collector residential sites will be occupied for long periods of time.

As discussed in Chapter 4, the diversity of raw material present at a site should reflect not only mobility patterns but also occupation length. Travis County is an area of high chert availability and prehistoric hunter gatherers would have always been within a reasonable distance of good quality material. Keeping in mind that longer occupation spans of residential camps will result in a higher diversity of material, the longer a residential site is occupied the more likely it is that both local and non-local material will be introduced. In part, this expectation is based on the relationship between occupation length and tool use life. Schiffer (1975) and Shott (1989) argue that one aspect of technology that affects the types and number of artifacts encountered in the archeological record is the use-life of tools versus the length of site occupation. Simply, if the length of site occupation exceeds the use life of a tool, it is expected that the tool will be discarded on site. If the use life of the tool is greater than the occupation length of the site, it will likely be curated and removed to the next occupied site.
To address occupation length as reflected by the lithic technology, we proposed to document the functional types of tools used on site and group them into use-life categories. Specifically, we proposed to scan each tool under up to 80X magnification to determine whether it was used in any task and what that task may have been. Two use life categories, (1) short and (2) other, would then be created based on an assumed relationship between manufacture costs and anticipated tool use-life. While tool failure is, to some degree, a stochastic phenomenon, tool failure probabilities are conditioned by the physical demands of the tasks being performed. However, we also expect that, other things being equal, the more effort that has gone into the manufacture of a tool the more likely it is that it will be systematically curated and used over a long time. Therefore, we expected that expedient tools, such as use-modified flakes, have shorter anticipated use-lives than, for example, hafted hide-scrapers. Using this conceptual approach, we proposed to approximate occupation length by determining the ratio of expedient usemodified tools to other finished functional tool forms. We suggested that a short occupation will be manifested through the presence of predominantly expedient tools while a long occupation will have a mix of both expedient and curated long-use-life specimens.

In addition to the diversity in lithic raw materials noted above, length of occupation also tends to co-vary with the diversity of faunal and floral remains exploited by hunter-gatherers and showing up in archeological deposits (Cannon et al. 2004; Shoocongdej 2000). In highly mobile adaptations where there is a low occurrence of reoccupation, there should be shorter occupations possessing a lower diversity of subsistence resources. As the length of occupation increases and/or the frequency of reoccupation under different organizational stances increases, the number of diverse activities at residential sites should be reflected by a wider variety of subsistence resources brought to, processed and consumed at the site. Based on these generalizations, we hypothesized that there would be an inverse relationship between the level of mobility and the resulting diversity of plant and animal taxa present. That is, as mobility increased the diversity of faunal and floral taxa should decrease and as mobility decreases, especially in aspects that increase occupation length, there should be an increase in taxa represented.

\section{Summary and Assessment}

Following the determination by TxDOT, with THC concurrence, that archeological remains from 41TV410 were not significant and that while no additional work was necessary, Early Archaic remains from 41TV540 were significant, TxDOT instructed CAR to develop a research design for the analysis of the 41TV540 material. We argued 
that to understand the behavior of the Early Archaic huntergatherers that created the 41TV540 record, we need to develop an understanding of three aspects. Consequently, the research design focused on (1) reconstruction of the geomorphic history of the confluence of the Colorado River and Onion Creek and of the general processes that influenced site formation, (2) reconstruction of the paleoenvironmental conditions and resource structure on the Onion Creek floodplain, and (3) the determination of site use and site function at 41TV540 within the overall hunter-gatherer land use strategy (Tomka et al. 2007).

The successful completion of the first objective, which was primarily geomorphological in nature, and the second objective, which relied on the completion of the first as well as the acquisition and analysis of several paleoenvironmental measures (e.g., stable carbon isotopes, phytoliths, snail reconstructions), hinged, to a substantial degree, on establishing an accurate, precise, and fairly detailed radiocarbon chronology. This is especially the case for the second objective, where we were attempting to identify periods of time that were active from those that were stable, develop an understanding of the resource structure of each, and then match those periods with archeological material, the chronology of which was, itself, based on radiocarbon dates with their associated standard errors. As Frederick discusses in the subsequent chapter, there are substantial problems with the radiocarbon chronology in the geomorphic sequences, especially those dates that rely on bulk sediments. Comparisons to charcoal and snail dates suggest that bulk sediment dates in this particular area are approximately 900 to 1500 years too old. While by making a number of assumptions, and discounting some clearly problematic dates, Frederick is able to overcome many of these chronological problems for the geomorphic work, the implications of these problems for the completion of the second research objective, which are discussed in Chapter 9, are more damaging.

In addition to the specific chronological problems associated with the bulk sediment dates, successful completion of the second research objective was further hindered by a lack of relevant paleoenvironmental data. Detailed paleoenvironmental data, consisting primarily of snail and phytolith information, were obtained from a single profile adjacent to 41TV410. Along with the stable isotopes on soil carbon and macrobotanical information on wood use from features, these 41TV410 data formed the core of the paleoenvironmental measures. The time frame reflected by the deposits in that profile, using corrections suggested by Frederick in the subsequent Chapter, covers the last 3,000 years. This is roughly 3,000 years later than the archeological deposits at 41TV540. While there is a single feature date (ca. $2200 \mathrm{BP}$ ) that falls within this time frame, that date is from the site of 41TV410. As this site was not analyzed in any detail given the non-significant determination by TxDOT, comparative information is limited. We will report and discuss the results of the analysis of phytolithis, snails, and soil stable carbon isotopes in Chapter 9. However, any detailed comparisons with the archeological material are not possible as the 41TV540 material is separated in time from the paleoclimate data by several thousand years (note 3). Note that while we can outline broad periods of stability and instability using Frederick's work in Chapter 8, comparative archeological material is limited to those sites with radiocarbon dates.

The final research objective is primarily concerned with 41TV540. Many of the issues discussed under this third research objective were phrased as contrasting expectations under conditions of stability relative to conditions that were more dynamic. For example, we suggested that a greater range of tool manufacture and reduction activities should characterize lithic debris recovered from stable surfaces, while collections from rapidly aggrading surfaces should exemplify a limited range of reduction activities. We further proposed that during short occupation periods, characteristic of aggrading surfaces, that the bulk of the lithic debris deposited on site would derive from core reduction while in the process of producing debitage for use as expedient tools. In contrast, during stable periods, we suggested that the refurbishing and replacement of failed or exhausted formal tools will produce debris from tool rejuvenation and manufacture and much of this debris should be representative of bifacial reduction. We propose that the identification of the lithic raw material reduction strategies (i.e., core vs. bifacial reduction) represented at 41 TV540 will aid in defining and serving as independent measures of site use. At first glance, then, the limited success of the second research objective would seem to undermine aspects of the third objective. However, in Chapter 10 we did conduct the more detailed analysis outlined in most cases, but any use of the results as an "independent measure" will be limited. 


\title{
Chapter 8: Late Quaternary Alluvial Stratigraphy of the Lower Onion Creek Valley
}

\author{
Charles Frederick
}

The geomorphic work reported here evolved in a rather unusual manner, starting with CAR's site specific testing excavations at two sites, 41TV540 and 41TV410, in December of 2005. At that time, multiple archeological teams were in the field at the same time testing sites situated within the alluvial deposits of the lower Onion Creek valley. In addition to CAR's testing, teams from TRC investigated site 41TV2165, PBS \& J conducted work at 41TV410, and Hicks \& Company worked at 41TV2125. Subsequent discussions with teams from PBS\&J, Hicks \& Company, TRC and UTSA-CAR revealed that no systematic work on the deposits of Onion Creek was being performed in association with any single excavation. Upon request, each group shared the results of their radiocarbon ages, and this revealed that several discrete age alluvial deposits appeared to be present in the area being examined in association with the construction of State Highway (SH) 130.

Nothing more was done until 2007, when most of the highway construction was completed. At that time, discussions with TxDOT personnel indicated that borrow pit exposures might be useful in obtaining samples of the alluvial deposits in proximity to tested archeological sites. Field examination of the borrow pits, following consultation with Lone Star Infrastructure (LSI), revealed that these exposures, although sloped, were sufficient to document the age of what were, at that time interpreted as discrete alluvial deposits, and in some cases, the borrow pits clearly revealed the bounding unconformities between different age deposits.

Following up on these discussions, between 2007 and 2008, several profiles were collected from the two borrow pits that border SH 130 immediately south of the bridge over Onion Creek, taking advantage of TxDOT access to the land. This was done independent of any contract in order to guarantee access to the borrow pit exposures, but the sampling was ended when financial conditions at TxDOT appeared to have terminated any further work on the Onion Creek sites. However, in 2009, TxDOT once again moved forward on completing this work and at this time we proposed to radiocarbon date and analyze columns from several borrow pit exposures situated in proximity to some of the tested sites, and then supplement these sample columns with a suite of additional columns collected from cut bank exposures of Onion Creek.
Upon acceptance of the research design (Tomka et al. 2007), the channel of Onion Creek from just north of Pierce Lane to Highway 71 was walked to examine cutbank exposures that would be useful in completing the sampling of the alluvial deposits of different age. The portion of the Onion Creek valley examined is situated in the lower reach of the stream, a short distance from its confluence with the Colorado River. In this area Onion Creek flows across in a large arcuate paleomeander scar that is bounded on the west by US Highway 71, on the south by FM 812 and the Cretaceous volcanic neck known locally as Pilot Knob (Unit Ki on the Bureau of Economic Geology 1974), and on the east by an outcrop of the Cretaceous age Navarro Group and Marlbrook Marl. The size and orientation of this paleomeander suggests that it was initially cut by the Colorado River, and in the period since then Onion Creek has flowed across the southern and eastern portion of this meander adjacent to the valley wall as it makes its way towards its confluence with the modern Colorado River, which today lies about halfway between Webberville and Del Valle. Today, the Austin Bergstrom Airport lies near the center of this ancient meander of the Colorado River, and much of this area appears to be underlain by deposits of the Colorado River. The section of the Onion Creek valley examined here is shown on Figure 8-1. Ultimately, three additional exposures were described and sampled, most of which were quite close the original borrow pits. The section that follows reports the results of the analysis of these sampled sections and presents a new stratigraphic framework for Onion Creek that applies to several of the sites tested during the SH130 fieldwork.

\section{Onion Creek Stratigraphy}

The late Quaternary deposits of Onion Creek have been examined previously by contract archeological projects, most notably near Buda (Ricklis and Collins 1994), at the site of Austin Bergstrom Airport (Lohse and Iruegas 1998), and in association with proposed State Highway 130 (Campbell et al. 2005).

The latest Pleistocene and Holocene alluvial deposits of Onion Creek have been examined in detail by three studies: Abbott (1994) near Buda, Caran (1998) at Austin-Bergstrom International Airport, and most recently at the Berdoll Tract of State Highway 130 (Campbell et al. 2005). Of these, only the first two have detailed discussions of the stratigraphy. 


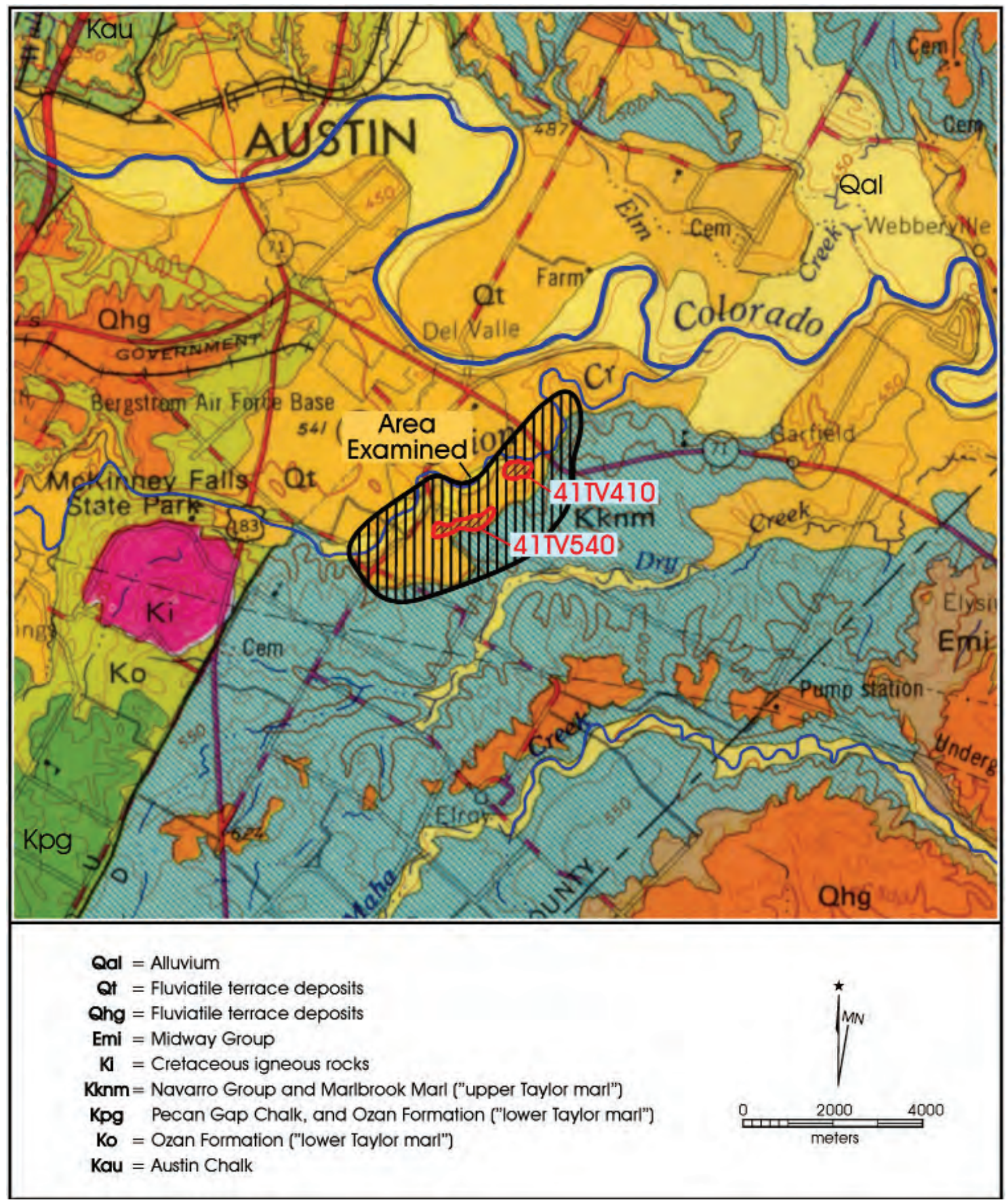

Figure 8-1. Geology of the area examined in the Onion Creek Valley (Barnes 1981).

Abbott (1994) examined the deposits of Onion Creek and a tributary (Mustang Branch) at the Barton and Mustang Branch Sites in Hays County, Texas, approximately $30 \mathrm{~km}$ (linear) upstream from the confluence of Onion Creek and the Colorado River. Although the majority of the alluvial deposits examined by Abbott were Pleistocene-age Onion Creek deposits, both streams experienced deposition in the Holocene, albeit in a locally asynchronous manner. Five distinct geomorphic surfaces were present in the area Abbott examined, but only the lowest two terraces were of Holocene age. The second terrace of Onion Creek lies 9-10 m above the stream channel and the deposits beneath this surface were first deposited in the Late Pleistocene and continued into the Early Holocene. Abbott obtained a radiocarbon date of $5310 \pm 90$ years BP (Tx-7170) from a buried soil B horizon at the top of the point bar deposits from $1.7 \mathrm{~m}$ below surface. 
He also noted that a Bell point was recovered from the same gravelly deposits elsewhere on the site. Abbott correlated this phase of deposition with Unit E on the Pedernales River (Blum 1987) and the Columbus Bend Alloformation Member 1 (early-middle Holocene fill; Blum 1992).

During the Middle to Late Holocene, Onion Creek was locally incising and the only significant deposits associated with this period were found in the lower parts of the abandoned channel associated with the second terrace. Bulk sediment samples derived from these deposits yielded radiocarbon dates of $3220 \pm 100$ years BP (Tx-6650) and $2780 \pm 60$ years BP (Tx-6649). After 2700 years BP deposition within this slough shifted from overbank flooding by Onion Creek to local slope sources, and Abbott inferred this to mean that channel incision by the trunk channel of Onion Creek had proceeded to a point where flooding of this surface was no longer possible.

Although the main channel of Onion Creek was not depositing sediment in the this area in the Late Holocene, the modern floodplain of Mustang Branch did form in this period. Radiocarbon dates on charcoal collected from this deposit indicate that this deposit began forming around 2,000 years ago and continued through at least 600 years ago. Abbott (1994) demonstrated a significant difference in radiocarbon age between bulk sediment and charcoal ages within this alluvial fill.

\section{Onion Creek Stratigraphic Work by Caran}

Some of the most recent work on the alluvial stratigraphy of Onion Creek has been performed by Chris Caran (1998; Campbell et al. 2005). Caran (1998) recognized four geomorphic terrains in the vicinity of Austin-Bergstrom International Airport:

1. the stream banks and channel floor,

2. the active floodplain (T1; 4-5 $\mathrm{m}$ above the channel floor)

3. the Onion Creek Terrace (T2; 6-11 m above the channel floor)

4. a Late Holocene flood terrace developed on Late Pleistocene to Middle(?) Holocene channel deposits.

Caran describes the majority of the Holocene deposits in the Onion Creek valley as part of the Onion Creek Terrace (his T2 surface) which he views as correlative with the First Street Terrace in downtown Austin because the Onion Creek terrace and the First Street Terrace merge near the mouth of
Onion Creek. Caran specifically describes all of the deposits beneath the Onion Creek Terrace as part of a flood terrace that is a surface that has been abandoned by the stream channel but continues to be inundated by floods. Such surfaces are separated from the floodplain by a steep bank, but continue to vertically aggrade through inundation by overbank flooding. Unfortunately, Caran makes no attempts to subdivide the deposits of the Onion Creek Terrace, and few of the deposits examined in this volume were radiocarbon dated.

Caran suggests that the Onion Creek Terrace is a single flood terrace that is time transgressive from the late Pleistocene through to today. However, it seems more likely that the core of this terrace deposit was formed episodically at different times in different places, whereas the upper portions of the terrace is comprised of vertically accreted sediment that is time transgressive with the length of cumulic deposition being dependent on the time the core at depth was abandoned and the elevation of the surface. In other words, the deposits of the Onion Creek Terrace at any single location are bipartite. Radiocarbon dating done at specific archeological sites in association with the construction of SH 130 by various CRM contractors, specifically CAR-UTSA at $41 \mathrm{TV} 410$ and 41TV540, TRC at 41TV2165, PBS\&J at 41TV410, and Hicks \& Company at 41TV2125 appear to support this interpretation. The goal of the work reported here is to test this impression by detailed description and radiocarbon dating of exposures in the lower reaches of Onion Creek examined by the SH 130 excavations.

\section{Methods}

During archeological testing, trenches were excavated with a trackhoe. Where significant lateral stratigraphic variability was present, one wall of the trench was drawn with the aid of a string line and tape. If no significant horizontal variability was noted, then the stratigraphy of a single column was described. To describe and sample borrow pit exposures, stair-step benches $50 \mathrm{~cm}$ tall were generally excavated from the ground surface to the borrow pit floor and a single $8 \mathrm{~cm}$ wide monolith was collected from each standing vertical face. Some of these exposures were described in the field whereas others were described in the lab. Where significant longitudinal variability was observed, this was recorded by means of photomosaics (see Figure 8-2). Cutbank exposures were cleaned with a pick and knife and accessed by means of a ladder. Field descriptions of the profiles examined are presented in Appendix D.

A single column of bulk soil samples was collected from each profile and used to characterize the physical properties of the sedimentary matrix. Two hundred seventy eight samples were collected from six profiles. For each sample the texture 
(or particle size distribution), calcium carbonate content, magnetic susceptibility, citrate-bicarbonate-dithionite extractable iron, organic carbon, total carbon and stable carbon isotopic composition were determined. A select suite of samples was also analyzed for bulk density and oxalate extractable iron and micromorphlogic examination. The details of the analytical methods employed are described below, and the results of the lab work are presented in the data table in Appendix D, and in graphic form on Figures 8-3 through 8-8.

\section{Particle Size Analysis (texture)}

Texture analysis was performed using the hydrometersieve method (cf. ASTM 1985; Gee and Bauder 1986; Bouyoucos 1962). Samples were first weighed moist and then gently passed through a $2 \mathrm{~mm}$ sieve taking care not to crush fragile bits of burnt earth that might be present. When more than $200 \mathrm{~g}$ of $<2 \mathrm{~mm}$ sediment was obtained, the remainder of the sample was transferred to a $100 \mathrm{ml}$ beaker and a $5 \%$ sodium hexameta phosphate solution was added to break down the clays and to permit separation of the $>2 \mathrm{~mm}$ artifacts and gravels. After soaking for two days during which time the samples were repeatedly stirred, the samples were wet sieved through a $2 \mathrm{~mm}$ sieve and the coarse fraction separated and dried. Coarse material caught on the $2 \mathrm{~mm}$ sieve, if detrital sediment (and not artifactual), was then sieved at a 1 phi interval and the mass on each sieve recorded. In this particular case, cultural material (see micro-artifacts, below) were counted and weighed separately for each size class, so their vertical depth distribution could be examined, as well as to exclude them from the detrital totals used to determine the properties of the alluvial sediments. A split of the $<2 \mathrm{~mm}$ size material (roughly 40 grams) was then soaked in $50 \mathrm{ml}$ of a $5 \%$ sodium hexametaphosphate solution overnight, and then mixed in a mechanical mixer for 5 minutes before being diluted to 1 liter with distilled water. This mixture was placed in a 1 liter settling jar, mechanically agitated for 1 minute, and then set on a table, after which point hydrometer readings were made at different time intervals (specifically 1, 3.5, 15, 45, 300, and 1440 minutes). A control hydrometer and temperature reading on an empty jar with nothing but distilled water and the sodium hexametaphosphate solution was made at intervals throughout the analysis to permit calibration of the hydrometer. A small split of the $<2 \mathrm{~mm}$ soil was also oven dried to determine the moisture content and correct the sample mass used in the hydrometer analysis (hygroscopic moisture correction). After 24 hours, the contents of the hydrometer jar were wet sieved through 37 micron sieve, and the sand retained on the sieve was transferred to a beaker and oven dried at $105^{\circ} \mathrm{C}$. This sand was subsequently sieved at 0.5 phi intervals once dry and the mass retained on each sieve recorded. From these data, the percentage of gravel, sand, silt and clay, as well as various descriptive statistics were calculated for the grain size distribution using a spreadsheet written by Paul Lehman.

\section{Calcium Carbonate Content (C.C.E)}

A small split (either $1.7 \mathrm{~g}$ or $0.85 \mathrm{~g}$ ) of the ground $<2$ $\mathrm{mm}$ fraction of each soil sample was used to determine the calcium carbonate equivalent (C.C.E.) by means of a Chittick apparatus (Dreimanis 1962; Machette 1986). This sample was finely ground (to pass a $0.075 \mathrm{~mm}$ sieve), and then weighed, and placed into a small $(250 \mathrm{ml})$ Erlenmeyer flask. Once attached to the Chittick apparatus, the liquid level in the measuring burette was set to $-10 \mathrm{ml}$, then the stopcock was closed so no gas could leave the system, and the leveling bulb was dropped in order to establish a vacuum inside the sample chamber. At this point, the barometric pressure and temperature in the room were recorded. Then $10 \mathrm{ml}$ of $50 \%$ hydrochloric acid (ca. $6 \mathrm{~N} \mathrm{HCl}$ ) was delivered to the sample flask, which was agitated intermittently until the reaction had ceased (usually 1-2 minutes). At this point, the leveling bulb was raised to the point that the liquid level inside of it was equal in elevation to the liquid in the burette, and the volume of gas evolved was then measured and the calcium carbonate equivalent calculated.

\section{Magnetic Susceptibility}

Samples for magnetic susceptibility analysis were first air dried, then crushed in a ceramic mortar and pestle, and subsequently passed through a $1 \mathrm{~mm}$ sieve. Material passing the sieve was then packed into plastic pots, and the mass of the sample determined by subtracting the weight of the pot prior to introducing the sample. The volume susceptibility (kappa) was measured in SI units on a Bartington MS2 meter and an MS2b sensor, and the mass corrected magnetic susceptibility (chi, X) values were calculated using the dry sample mass. The values obtained are presented in the data table in Appendix D and are reported in SI units $\left(10^{-8} \mathrm{~m}^{3} \mathrm{~kg}^{-1}\right)$.

\section{Organic Carbon and Total Carbon}

In order to determine the carbon content of each sample, splits of the $<2 \mathrm{~mm}$ size fraction were submitted to the Analytical Chemistry Lab at Institute of Ecology, University of Georgia. The carbon content was determined on a Micro-Dumas NA1500 Combustion Elemental (C/H/N) Analyzer (Carlo Erba Strumentazione, Milan). Details of the procedures used may be found on the institute's web page (http://www.uga.edu/ sisbl/soilerb.html) and general aspects of the method are discussed by Schulte and Hopkins (1996). Organic carbon content was determined from a $2 \mathrm{gm}$ split of the $<2 \mathrm{~mm}$ size soil was treated with $6 \mathrm{~N} \mathrm{HCl}$ to remove 


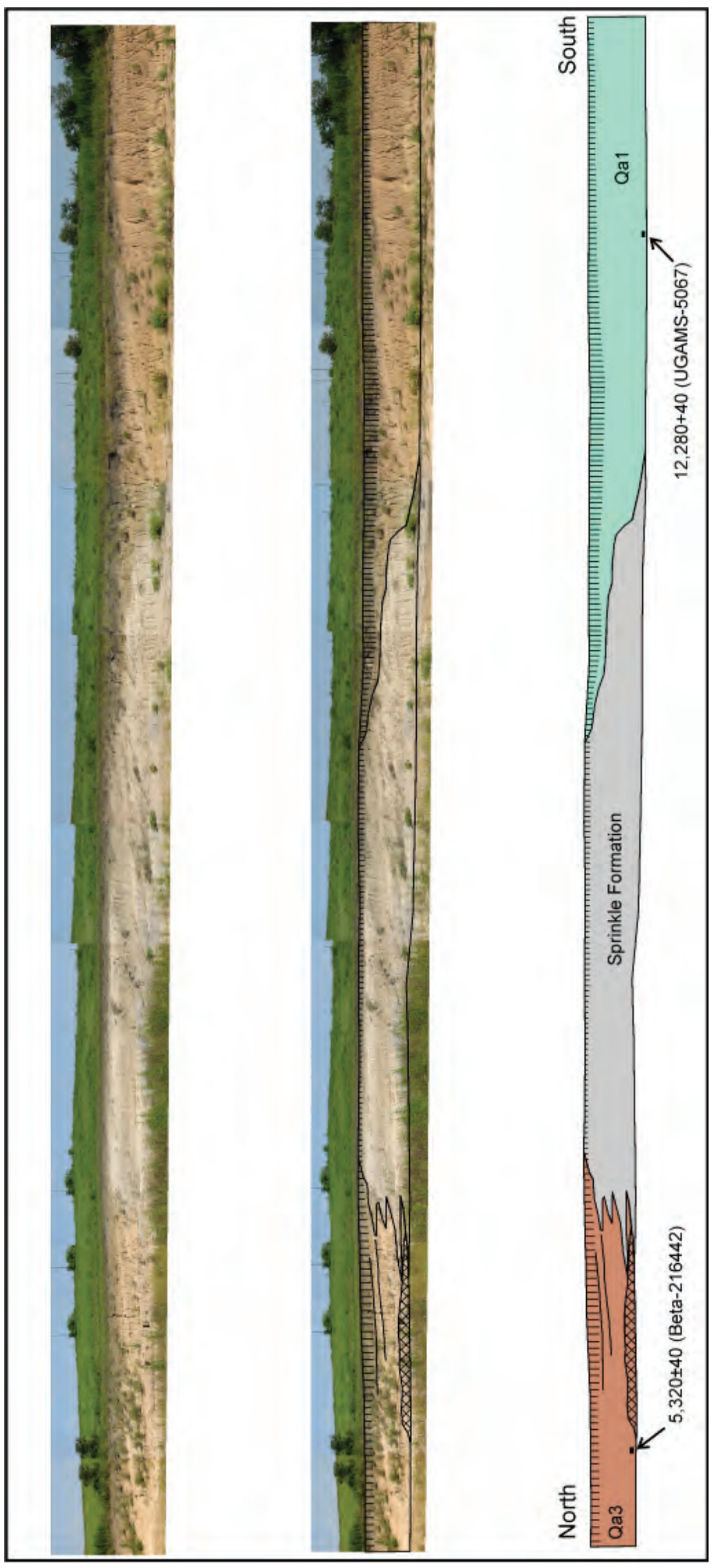

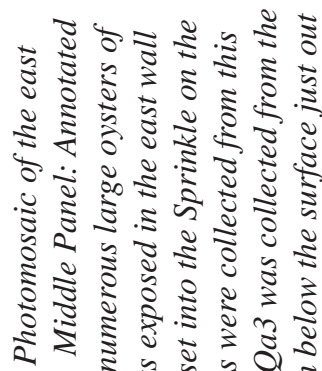

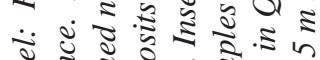

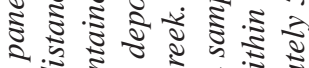

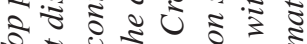

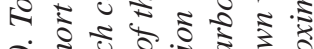

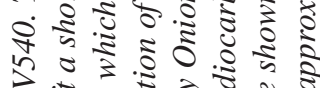

स⿺辶⿻

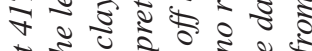

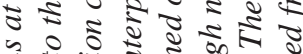

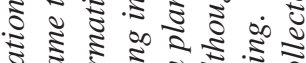


ปै



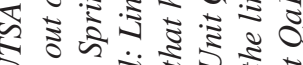



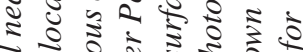

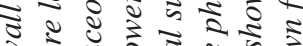

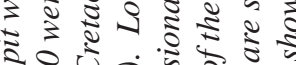
年

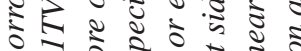
878 की


ปิ

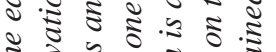
పे

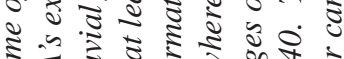
हิ है โ5 ะ

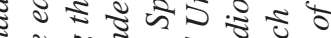

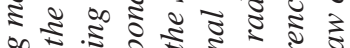

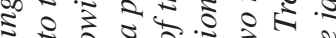

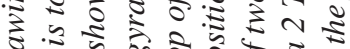



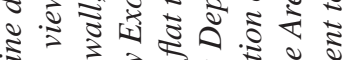

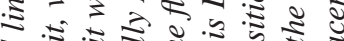
ปี

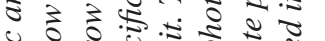

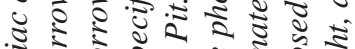


हิ ฐ

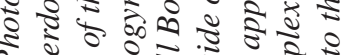
ฉ ชิ

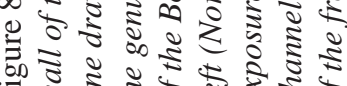

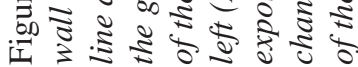




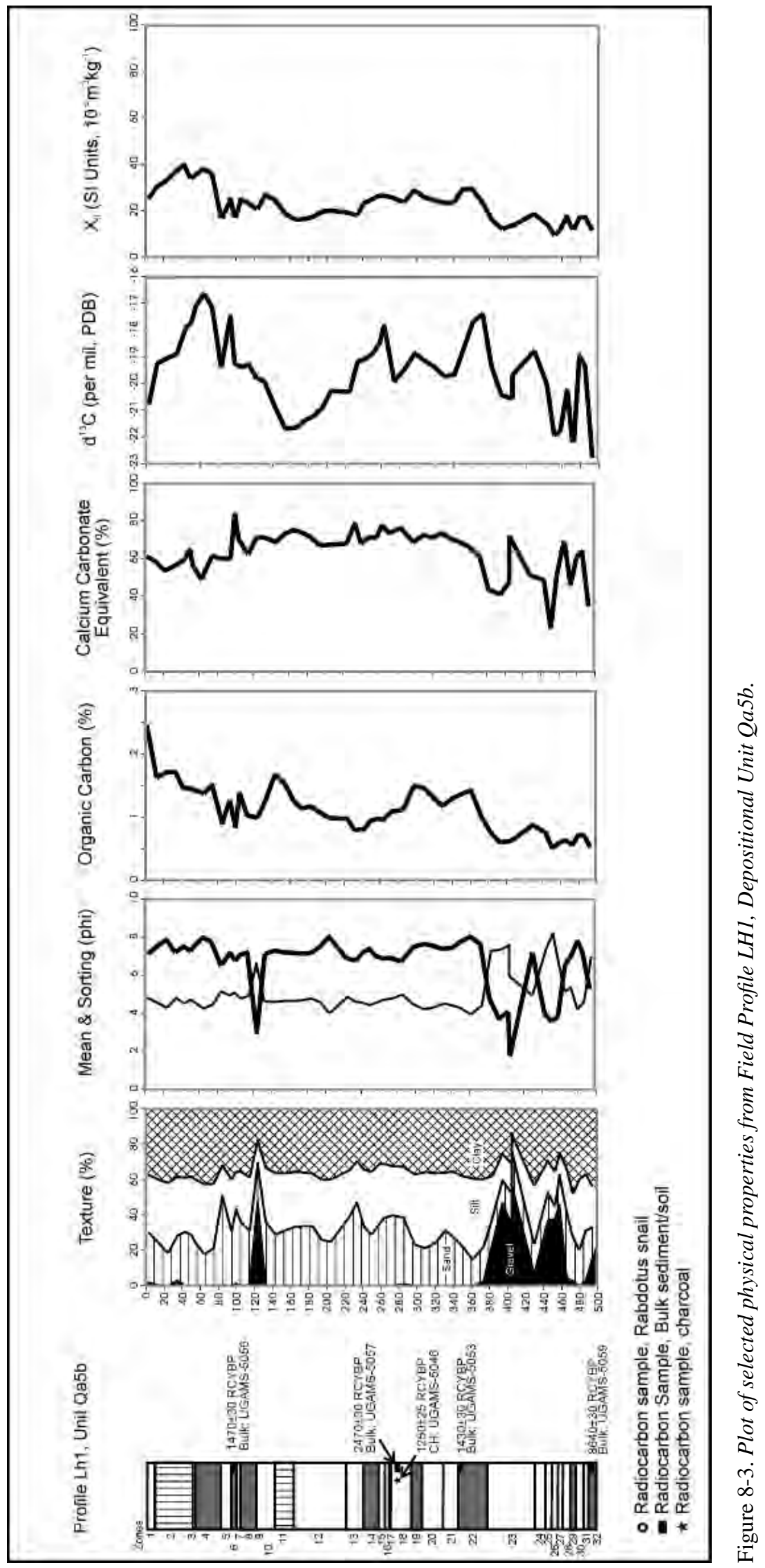




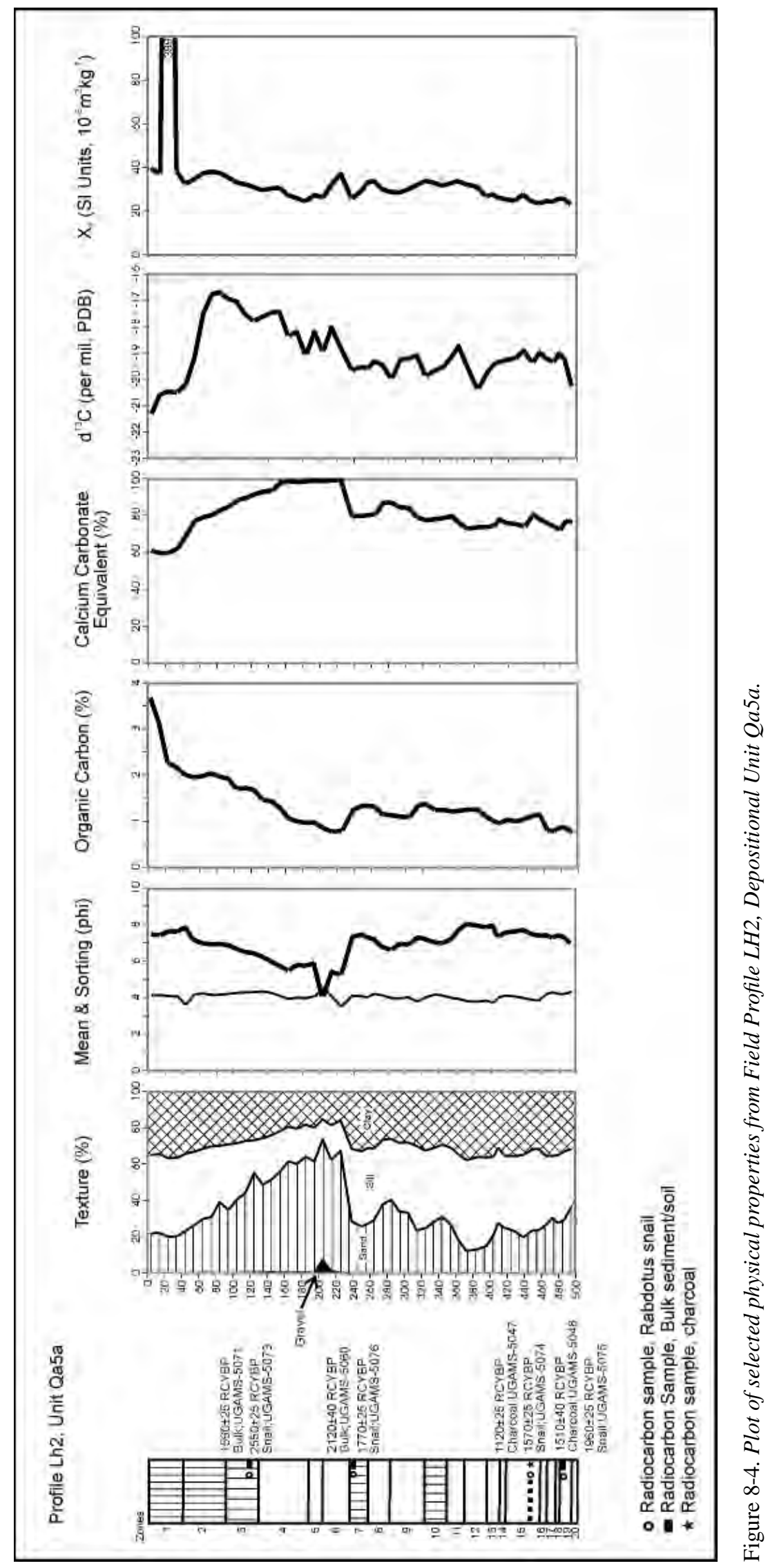




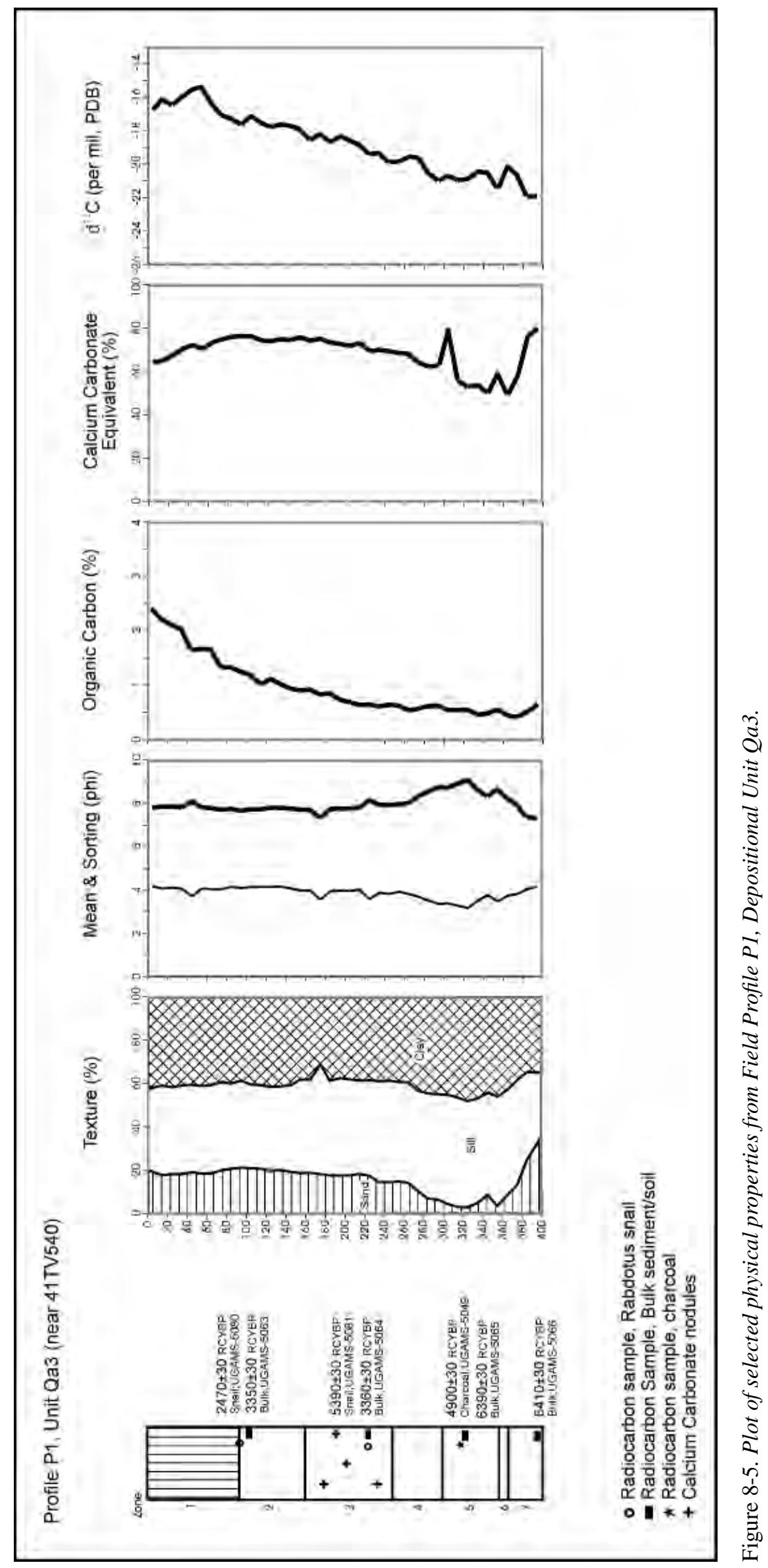




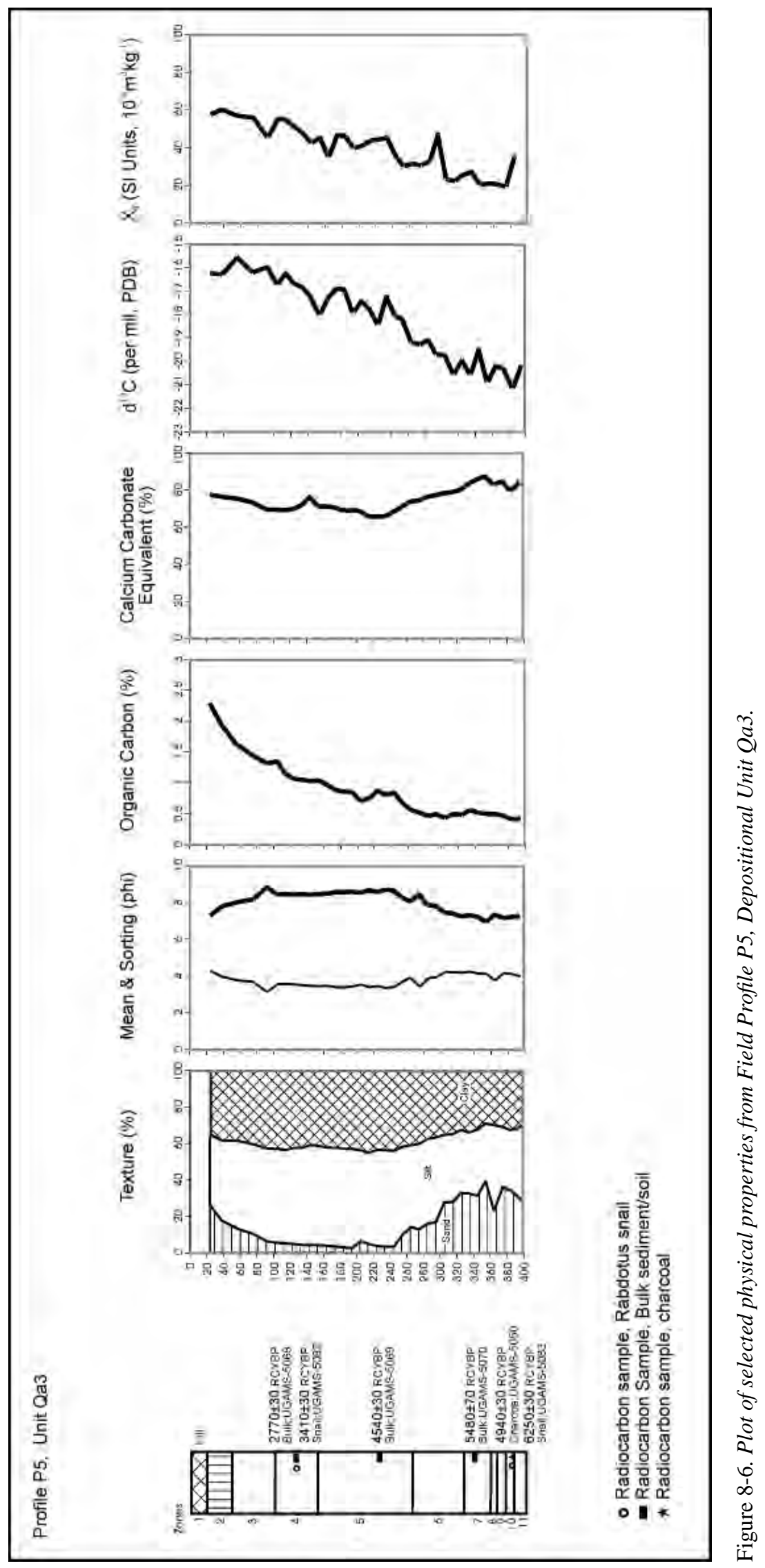











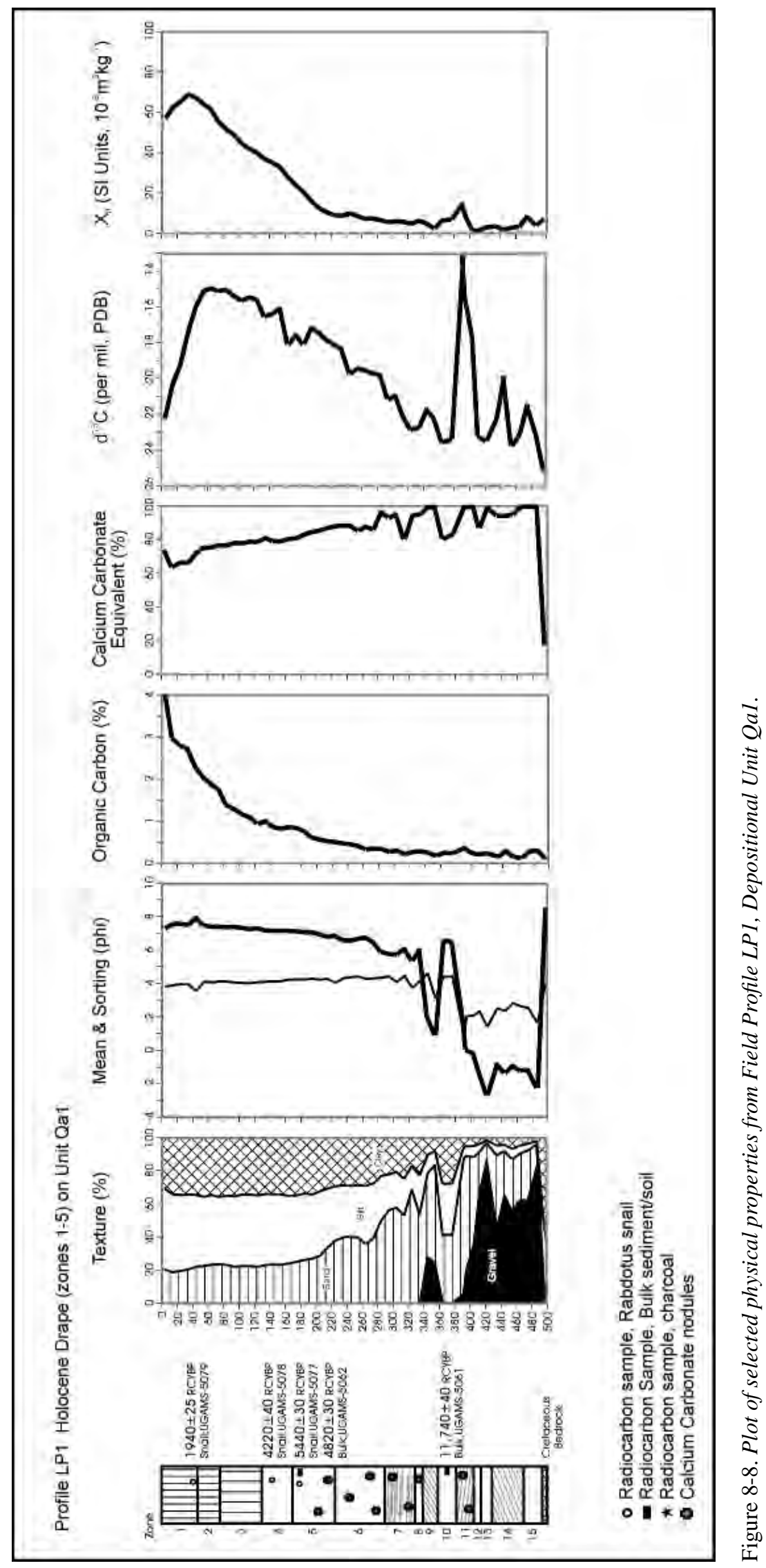


calcium carbonate, then rinsed repeatedly, subsequently dried at $105^{\circ} \mathrm{C}$, and then finely ground once dry. Total carbon was obtained from a $2 \mathrm{gm}$ split of the $<2 \mathrm{~mm}$ size soil that had been dried and ground.

\section{Stable Carbon Isotopic Composition}

The majority of the stable carbon isotopic value of the organic carbon for each sample was determined at the Stable Isotope/ Soil Biology Laboratory at Institute of Ecology, University of Georgia. These values were determined from the carbonate free $<2 \mathrm{~mm}$ soil used to determine the organic carbon content and were determined on an element ratio mass spectrometer by converting the organic carbon to a gas phase by extremely rapid and complete flash combustion of the sample material. Coastal Science Labs (Austin, Texas) also analyzed a suite of 15 samples, and these results are presented in Appendix E.

\section{Iron}

Central Analytical Lab, Oregon State University, determined the citrate-bicarbonate-dithionite extractable iron and oxalate extractable iron.

\section{Micromorphology}

A select suite of samples taken at irregular intervals from the sampled columns were embedded in polyester resin under a vacuum and once set, were trimmed on a rock saw and submitted to National Petrographic for thin section preparation. Slides were scanned on a flat bed scanner, subsequently examined at low magnification with a Leica S8 APO stero microscope equipped with transmitted polarized light base, and at higher magnification with a Leica DMEP compound polarizing light microscope.

\section{Radiocarbon Ages}

In order to evaluate the age of the different alluvial deposits in the lower Onion Creek valley, radiocarbon ages were obtained on a number of different materials from the described sections and investigated archeological sites. Where charcoal from a cultural context (either scattered upon an occupation surface, or from a feature such as a hearth) was observed, this material was preferentially dated. If charcoal was absent, then either Rabdotus snail shells or bulk sediment/soil was radiocarbon dated, and in some cases both. The selection of Rabdotus shells is supported by the work by Ellis et al., (1996), which demonstrated that the carbon error associated with the ingestion of old (radiocarbon dead) carbon by living Rabdotus snails was relatively consistent and of known magnitude (445 years). Radiocarbon dating snail shells in certain specific geomorphic and stratigraphic contexts is preferable to bulk soil radiocarbon ages where the latter are expected to yield radiocarbon ages that do not reflect the time of deposition (as may be the case in cumulic soils). But both snails and bulk sediment hold inherent potentials for erroneous radiocarbon ages, and for this reason, a number of pairs of different materials were made in order to assess the reliability of the radiocarbon ages on different materials. The following discusses some of these comparisons and their implications for understanding the age of the Onion Creek alluvial deposits.

\section{Bulk sediment/soil radiocarbon ages}

Many of the radiocarbon ages obtained from this project were obtained from bulk sediment when charcoal or Rabdotus snails were not available for sampling. Previous work on Onion Creek alluvium by Abbott (1994) suggests that such samples may yield anomalously old radiocarbon ages, and at the Mustang Branch Site Abbott found that late Holocene alluvial deposits yielded bulk sediment/soil radiocarbon ages that were as much as 1,000 years too old as compared to charcoal collected from hearths. To be specific, the range of difference exhibited between the two materials depicted on Abbott (1994: Figure 168) ranges from 180 to 1,200 years older than the time of deposition.

In order to investigate this issue, we obtained pairs of radiocarbon ages from charcoal collected from occupation surfaces and bulk sediment from the same approximate depth in three different places (see Table 8-1 for details). In each case, the bulk sediment radiocarbon ages were older than the charcoal, with the magnitude of the age error ranging from 940 to 1,490 years, which is consistent with Abbott's observations. More recently Campbell et al. (2009:60-63) discuss the age discrepancies obtained from a suite of radiocarbon samples that were run as bulk sediment (albeit soot-like in appearance) collected during the survey phase work at 41TV2125 and good quality charcoal collected from the same provenience during testing. The bulk sediment samples yielded ages of 9420 and 9190 RCYBP whereas the charcoal from the same context yielded ages of 7878, 7736, 7606 and 7920 RCYBP

Table 8-1. Comparison of Matched Pairs of Radiocarbon Ages from Hearth Charcoal and Bulk Sediment

\begin{tabular}{|c|c|c|c|}
\hline Profile/depth & Charcoal Age & Bulk Sediment Age & $\begin{array}{c}\text { Age Erro } \\
\text { (years) }\end{array}$ \\
\hline $\mathrm{P} 1,320 \mathrm{~cm}$ & $\begin{array}{l}4900 \pm 30 \\
\text { (UGAMS-5049) }\end{array}$ & $\begin{array}{l}6390 \pm 30 \\
\text { (UGAMS-5065) }\end{array}$ & 1490 \\
\hline $\mathrm{L} 1,380 \mathrm{~cm}$ & $\begin{array}{l}9420 \pm 30 \\
\text { (UGAMS-5055) }\end{array}$ & $\begin{array}{l}8290 \pm 30 \\
\text { (UGAMS-5045) }\end{array}$ & 1130 \\
\hline $\mathrm{L} 1,465 \mathrm{~cm}$ & $\begin{array}{l}9190 \pm 30 \\
\text { (UGAMS-5051) }\end{array}$ & $\begin{array}{l}8250 \pm 30 \\
\text { (UGAMS-5054) }\end{array}$ & 940 \\
\hline LH1, $280 \mathrm{~cm}$ & $\begin{array}{l}1250 \pm 25 \\
\text { (UGAMS-5046) }\end{array}$ & $\begin{array}{l}2470 \pm 30 \\
\text { (UGAMS-5057 }\end{array}$ & 1220 \\
\hline
\end{tabular}

Note: The charcoal collected in the LH1 profile was scattered charcoal, and no demonstrable occupation was observed. 
indicating a maximum age error of 1814 RCYBP and a minimum age error of 1270 RCYBP. Given the origin of errors in bulk sediment dates, it is likely that any correction or adjustment to a given age will vary throughout the Holocene. In the remaining text, bulk sediment radiocarbon ages will be presented at face value, but pragmatically assessed as if they are 900 to 1,500 years too old.

\section{Snail shell}

In the absence of charcoal, radiocarbon dating the alluvial deposits presented a dilemma. Bulk sediment/soil samples can be obtained everywhere, but as demonstrated above, often yield inaccurate radiocarbon ages. Sub-fossil snails shells of the genus Rabdotus are widespread in Central Texas alluvial deposits and the age error associated with the ingestion of old carbon by these snails when alive can be used to correct radiocarbon ages obtained from snail shell so that they accurately reflect the age of the snail at the time of its death. Rabdotus shell can be used as an alternative to charcoal for radiocarbon dating. But, dating shell is not without problems, most notably the erosion and subsequent re-deposition of snails from older alluvial deposits. Unlike charcoal, which is a rather fragile, Rabdotus shell are often quite durable and may easily survive stream transportation, and many, if not filled with sediment, float and can be easily transported into floodplain settings by floodwater. To assess the utility of radiocarbon dating Rabdotus, we dated three pairs of Rabdotus and charcoal collected from prehistoric occupation surfaces, as well as several pairs of Rabdotus and bulk sediment.

\section{Pairs of snails with charcoal}

Paired radiocarbon ages of Rabdotus and charcoal collected from prehistoric occupation surfaces were obtained in profiles LH2 and P5 (Table 8-2). The samples collected from Depositional Unit Qa5 in profile LH2 both yielded Rabdotus radiocarbon ages only 5 years older than the associated charcoal after correction for age error by subtracting 445 years from the conventional radiocarbon. These data appear to solidly support the age error established by Ellis et al. (1996). The third pair was collected from depositional Unit

Table 8-2. Comparison of Matched Pairs of Radiocarbon Ages from Hearth Charcoal and Rabdotus Shells

\begin{tabular}{|c|l|l|c|c|}
\hline $\begin{array}{c}\text { Profilel } \\
\text { depth }\end{array}$ & \multicolumn{1}{|c|}{ Charcoal Age } & $\begin{array}{c}\text { Rabdotus } \\
\text { Radiocarbon } \\
\text { Age }\end{array}$ & $\begin{array}{c}\text { Corrected- } \\
\text { Adjusted } \\
\text { Age }\end{array}$ & $\begin{array}{c}\text { Difference } \\
\text { (years) }\end{array}$ \\
\hline LH2, $440 \mathrm{~cm}$ & $\begin{array}{l}1120 \pm 25 \\
\text { (UGAMS-5047) }\end{array}$ & $\begin{array}{l}1570 \pm 25 \\
\text { (UGAMS-5076) }\end{array}$ & 1125 & 5 \\
\hline LH2, $475 \mathrm{~cm}$ & $\begin{array}{l}1510 \pm 40 \\
\text { (UGAMS-5048) }\end{array}$ & $\begin{array}{l}1960 \pm 25 \\
\text { (UGAMS-5075) }\end{array}$ & 1515 & 5 \\
\hline P5, $380 \mathrm{~cm}$ & $\begin{array}{l}4930 \pm 30 \\
\text { (UGAMS-5050) }\end{array}$ & $\begin{array}{l}\text { 6250 } \pm 30 \\
\text { (UGAMS-5083) }\end{array}$ & 5805 & 875 \\
\hline
\end{tabular}

Qa3 in profile P5, and here the age error corrected radiocarbon age from the Rabdotus shell was 875 years older than the charcoal, suggesting that either the snail was re-deposited from an older context or that this particular snail ingested more old carbon than the average snail.

\section{Pairs of snails with bulk sediment}

Seven pairs of radiocarbon dated Rabdotus shells and bulk sediment were obtained during this work (see Table 8-3). In the best of all possible worlds, where the bulk sediment ages accurately reflect the time of deposition, radiocarbon ages on Rabdotus, once corrected for age error, should agree. In the Onion Creek valley, where radiocarbon ages obtained from bulk sediment appear to overestimate the time of deposition from 940 to 1,490 years, ages obtained from Rabdotus snails (corrected for age error) should date younger than bulk sediment by approximately the same margin. Of the seven sets of matched bulk sediment and Rabdotus radiocarbon ages, two appear to fit this scenario: LH2/235 cm and P1/100-105 cm. The LH2 snail dates 795 years younger than the sediment after age correction, which is slightly younger than the age error observed in this study between bulk sediment and charcoal, but it is within the range of error observed previously (see Abbott 1994). The sample from $P 1$ dated 1,325 years younger than the sediment, which is consistent with the observed age error of bulk sediment radiocarbon ages.

However, the majority of the Rabdotus snail shells dated here yielded radiocarbon ages an average of 809 years older than the bulk sediment age, with the difference ranging from 195 to 1,590 years. These shells, like the shell from profile P5 that dated 875 years older than the charcoal deposited with it, appear to be either older shells that have been redeposited or shells of snails that ingested more carbon than average while living. The fact that only $28 \%$ of the snails

Table 8-3. Comparison of Matched Pairs of Radiocarbon Ages from Bulk Sediment and Rabdotus Shells

\begin{tabular}{|c|c|c|c|c|}
\hline Profile/depth & $\begin{array}{c}\text { Bulk Sediment } \\
\text { Age }\end{array}$ & $\begin{array}{c}\text { Rabdotus } \\
\text { Radiocarbon } \\
\text { Age }\end{array}$ & $\begin{array}{c}\text { Corrected } \\
\text { Age }\end{array}$ & $\begin{array}{c}\text { Difference } \\
\text { (years) }\end{array}$ \\
\hline $\mathrm{LH} 2,120 \mathrm{~cm}$ & $\begin{array}{l}1560 \pm 25 \\
\text { (UGAMS-5071) }\end{array}$ & $\begin{array}{l}2550 \pm 25 \\
\text { (UGAMS-5073) }\end{array}$ & 2100 & 540 \\
\hline $\mathrm{LH} 2,235 \mathrm{~cm}$ & $\begin{array}{l}2120 \pm 40 \\
\text { (UGAMS-5060) }\end{array}$ & $\begin{array}{l}1770 \pm 25 \\
\text { (UGAMS-5076) }\end{array}$ & 1325 & -795 \\
\hline $\begin{array}{l}\mathrm{P} 5,120-130 \\
\mathrm{~cm}\end{array}$ & $\begin{array}{l}2770 \pm 30 \\
\text { (UGAMS-5068) }\end{array}$ & $\begin{array}{l}3410 \pm 30 \\
\text { (UGAMS-5082) }\end{array}$ & 2965 & 195 \\
\hline $\begin{array}{l}\mathrm{P} 1,100-105 \\
\mathrm{~cm}\end{array}$ & $\begin{array}{l}3350 \pm 30 \\
\text { (UGAMS-5063) }\end{array}$ & $\begin{array}{l}2470 \pm 30 \\
\text { (UGAMS-5080) }\end{array}$ & 2025 & -1325 \\
\hline $\begin{array}{l}\mathrm{P} 1,215-220 \\
\mathrm{~cm}\end{array}$ & $\begin{array}{l}3360 \pm 30 \\
\text { (UGAMS-5064) }\end{array}$ & $\begin{array}{l}5390+30 \\
\text { (UGAMS-5081) }\end{array}$ & 4950 & 1590 \\
\hline $\mathrm{L} 1,120 \mathrm{~cm}$ & $\begin{array}{l}5140 \pm 30 \\
\text { (UGAMS-5052) }\end{array}$ & $\begin{array}{l}7130 \pm 30 \\
\text { (UGAMS-5072) }\end{array}$ & 6685 & 1545 \\
\hline LP1, $180 \mathrm{~cm}$ & $\begin{array}{l}4820 \pm 30 \\
\text { (UGAMS-5062) }\end{array}$ & $\begin{array}{l}5440 \pm 30 \\
\text { (UGAMS-5077) }\end{array}$ & 4995 & 175 \\
\hline
\end{tabular}


paired with sediments are within expectations, and only $40 \%$ overall (if the charcoal-snail date pairs are included) suggests that radiocarbon dating Rabdotus shells may be just as problematic as bulk sediment radiocarbon ages.

\section{Late Pleistocene and Holocene Alluvial Deposits of Onion Creek}

Although Caran identified only two geomorphic surfaces in previous studies, the work performed here identified three distinct surfaces: the floodplain (T0), the first terrace (T1) and the second terrace (T2). The floodplain surface is a compound one, with two recognizable parts. These are an active floodplain (T0b) which lies about $5 \mathrm{~m}$ above the channel, and a slightly higher surface (T0a) which lies at the rear of the T0b surface. The floodplain is inset into the first terrace, which lies about 7-8 m above the Onion Creek channel. A subtle 1-2 m scarp separates the first and second terraces in most places, with the second terrace being situated toward the valley margin. Figure 8-9 shows the location of these surfaces in the areas examined by this project. It should be noted that this map used existing topographic maps to project these surfaces from areas where they were known into adjoining lands, but most of the area on the west side of the map was not field checked as it was on private land.

Work in the Lower Onion Creek valley for this project identified five alluvial deposits based on observations of the lithology, degree of soil development, radiocarbon age and relative stratigraphic position of the different exposures examined. The exposures examined as part of this work are shown on Figure 8-9.

The five depositional units are essentially informal allostratigraphic units and are numbered Qa1 through Qa5, from oldest to youngest, respectively. The relative stratigraphic relationships between the different units and the ages of select radiocarbon dates obtained from each deposit are shown on Figure 8-10.

The intention at the start of the fieldwork was for a single column profile to be obtained for each depositional unit, for which detailed field descriptions and subsequent physical characterization would be performed. But given that these

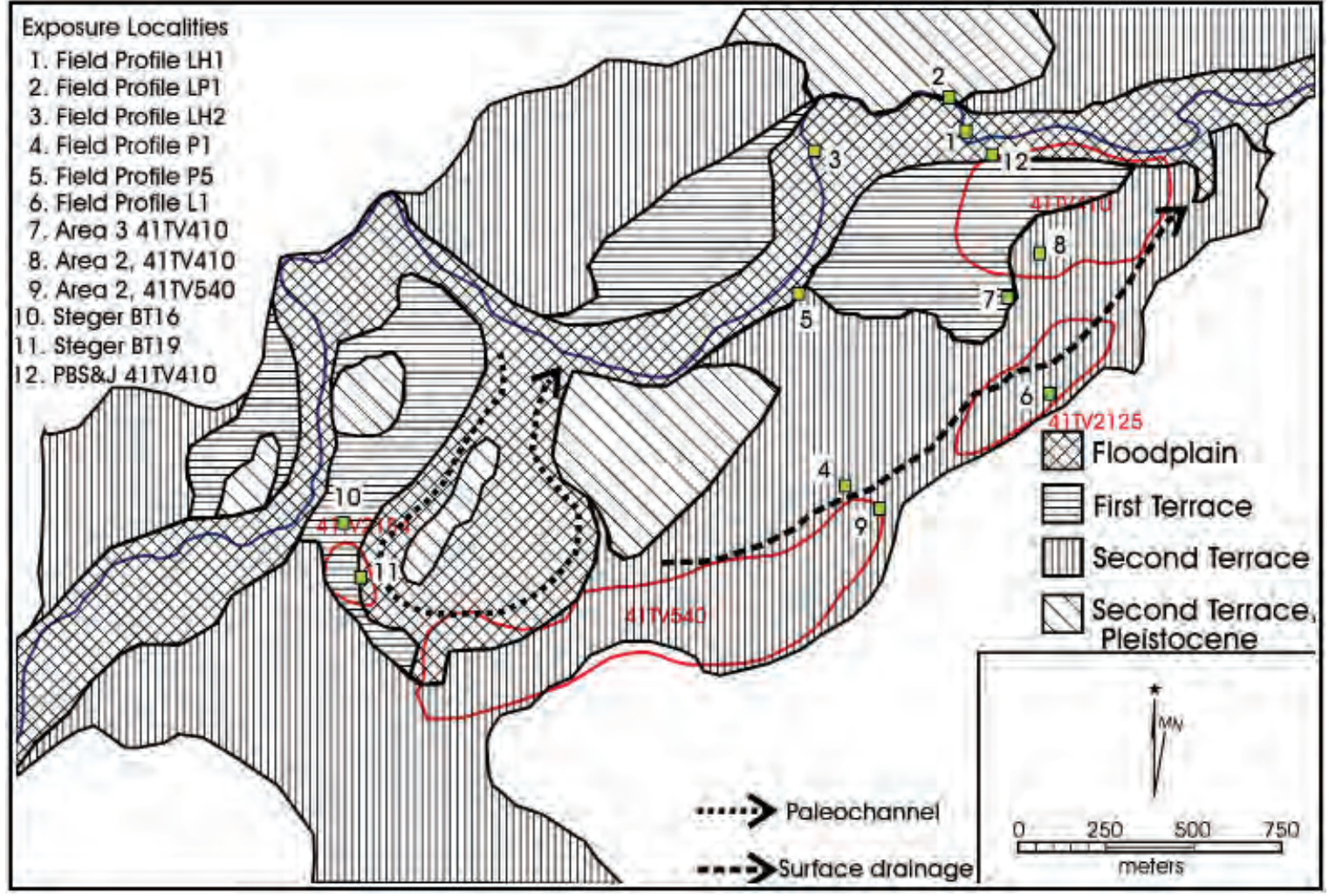

Figure 8-9. Geomorphological map of the Lower Onion Creek valley depicting the approximate positions of the geomorphic surfaces described in the text. Based on fieldwork done for this project the floodplain is underlain by Unit Qa5, the First Terrace is cored by Unit Qa4 and draped by Unit Qa5, and the second terrace is underlain by Qa1, Qa2, and Qa3. The map unit described as "Second Terrace, Pleistocene" are places where the second terrace is known or suspected to be underlain by Qa1 or older alluvium at a shallow depth. 


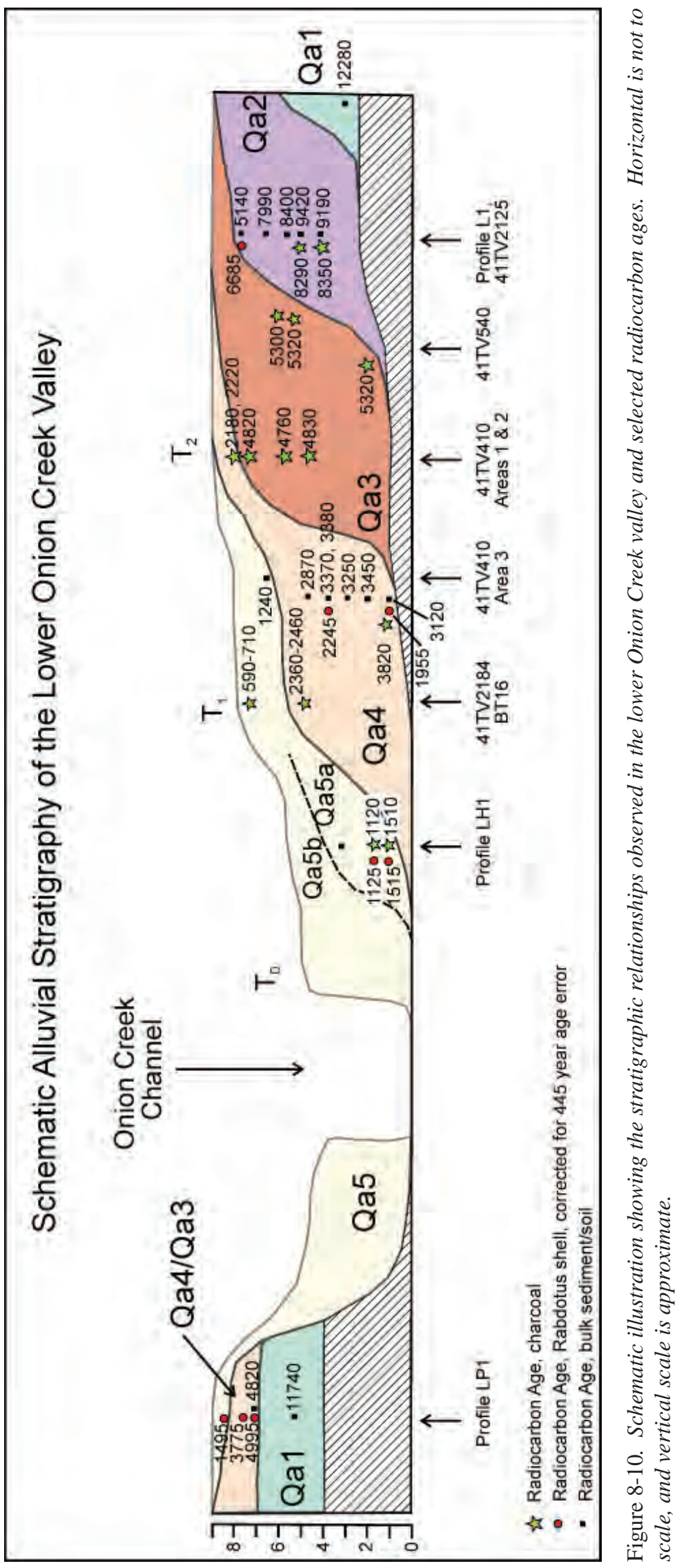


decisions had to be made in the absence of radiocarbon dating, and in some cases estimated from borrow pit walls that were subsequently found to be covered with reworked sediment, in the final analysis, two depositional units were sampled twice (Qa3 and Qa5) and one was described in the field and sampled for dating but a continuous column for full characterization was not obtained (Qa4). For each sampled alluvial fill, the deposits were described in the field and the physical properties of the deposits characterized in the lab (descriptions and results presented in Appendix D).

\section{Late Holocene Alluvia}

The floodplain of Onion Creek today comprises two distinct constructional surfaces that are immediately adjacent to the present channel and expose deposits that are significantly different in appearance. These two surfaces are at subtly different elevations in places, with the presumably active floodplain surface (T0b) being about $5 \mathrm{~m}$ above the channel floor and inset into a slightly older surface (T0a) that lies about $6 \mathrm{~m}$ above the channel. Two profiles were described and sampled to represent these deposits.

Prior to detailed field investigation of these deposits, the older of the two floodplain deposits was thought to be of Late Prehistoric age given the similarity of this setting to the portion of site 41TV410 excavated by Rogers and Dixon (2008). The portion of 41TV410 they investigated was in the highway right-of-way immediately adjacent to the modern channel of Onion Creek and backhoe trenching in this area revealed several sparse Late Prehistoric age occupations buried within the upper $3 \mathrm{~m}$ of the higher of the two floodplain surfaces. Detailed field investigations of a small portion of one occupation surface uncovered a stone lined hearth at $3 \mathrm{~m}$ below the surface from which a radiocarbon age of $1290 \pm 40$ RCYBP (Beta-213174; ${ }^{13} \mathrm{C} /{ }^{12} \mathrm{C}$ $=-25.8 \%$ PDB) was obtained. Identification of charcoal floated from the feature fill suggested that sycamore and oak wood were used for fuel. When construction of the highway was nearly complete, a deeply buried occupation, presumably of similar age was observed cropping out of the northwest end of the borrow pit that lies immediately southwest of the point where SH 130 crosses Onion Creek. Plans were made to collect a column in this location but the borrow pit margin was graded and sculpted before this could be accomplished.

Eventually, two profiles were described and sampled from cutbank exposures of the youngest floodplain deposits of Onion Creek. Profile LH1 represents the deposits beneath the present floodplain (TOb) surface and the section was sampled from a cutbank that lies immediately west of the SH
130 Bridge over Onion Creek. Profile LH2 was also sampled from a cutbank adjacent to the Onion Creek channel that is located immediately west of the borrow pit (see Figure 8-8). The field relationships suggested that these two exposures were of different age but radiocarbon assays do not support this interpretation.

\section{Unit Q5b: Modern Alluvium Beneath the T0b Surface: Profile: LH1}

In the field, this deposit was thought to be the active floodplain of Onion Creek. On relative stratigraphic grounds, this deposit is the younger of two recent age alluvial fills, and the sediments beneath this surface exhibit prominent event specific bedding, minimal soil development, a wide range of textural variation and dark colored detrital clays. Several exposures revealing similar attributes were observed during pedestrian reconnaissance of the lower Onion Creek valley and the sampled cutbank exposure presents the entire deposit in cross-section, where Q5b is inset against the Cretaceous age Sprinkle Formation/ Late Pleistocene Depositional Unit Qa1. Little pedogenic alteration of the deposit was apparent (see the field description in Appendix D and Figure 8-3) and the granulometric data clearly show highly variable textures, which would fit the near channel overbank setting of this cutbank. There is subtle evidence of leaching of calcium carbonate from the upper part of the profile, and the organic carbon is also quite variable and tracks well with deposit texture, specifically fine grained sediments that suggests that much of this is detrital and not pedogenic.

Five radiocarbon ages (4 bulk sediment, one charcoal) were obtained from this profile and provide little agreement on the age of the deposit (see Figure 8-3 for an illustration showing radiocarbon ages, stratigraphy and bulk sediment properties). A piece of scattered charcoal collected at a depth of $2.8 \mathrm{~m}$ in the middle of the exposure yielded an age of $1250 \pm 25$ RCYBP (UGAMS-5046) whereas the bulk sediment ages from this deposit are widely scattered and not in stratigraphic order. An age of $8640 \pm 30$ RCYBP (UGAMS-5059) was obtained from bulk sediment at the base of the cutbank, and the old age may be attributable to a mixture of different age carbon sources in this sediment, specifically old carbon contributed from rip-up clasts of the Sprinkle Formation clays. No prehistoric occupations were observed within the cutbank from which LH1 was described and sampled.

A couple of dark colored deposits appeared as if they could be soil A-horizons, but most of these deposits retained clear evidence of sedimentary bedding suggesting that their dark color is detrital organic matter rather than post-depositional. Regardless, even if these deposits are considered A-horizons, the soils exhibit little development and A-C profiles. 


\section{Unit Q5a: Latest Holocene Alluvium Beneath the T0a Surface: Profile LH2}

The landscape position of this deposit is slightly higher and further away from the channel of Onion Creek, and in the field a clear but low ( $<1 \mathrm{~m})$ scarp separated the two surfaces. Although the deposit is still very stratified, the magnitude of the granulometric variation is significantly less than the LH1 profile and all of the other physical attributes are less variable as well. The lack of variation here may be a reflection of age of the deposit (that is presumed to be slightly older than LH1) or alternatively, that this deposit represents more of a distal floodplain environment and was prone to less variation in discharge and therefore exhibits less textural variation. In general, the appearance of this deposit was more consistent with the deposit exposed by Rogers and Dixon (2008) at their excavation of part of 41TV410 in the right-of-way of $\mathrm{SH}$ 130 than the LH1 exposure. Furthermore, two prehistoric occupation surfaces were observed in this profile, one at 441 $\mathrm{cm}$ and a second at $475 \mathrm{~cm}$. Both surfaces exhibited scattered charcoal, and Rabdotus shells, as well as a few burned rocks and pieces of debitage. The stratigraphic position of these occupations is similar to the occupation observed in the borrow pit that is situated about $100 \mathrm{~m}$ east of this profile.

Unlike the LH1 profile and Depositional Unit Q5b, the deposits of Unit Q5a observed in Profile LH2 exhibited two (and arguably three) clearly defined soils (near the modern surface and a buried soil at $2.4 \mathrm{~m}$, and a third possible buried soil around $3.2 \mathrm{~m}$ (see Figure 8-4 and the field description in Appendix D). The dominant attribute of the profile is a prominent fining upward package of floodplain sediment in the upper $2.3 \mathrm{~m}$ of the profile. Below this, the deposits are thinner bedded and more event specific, and the pedogenic alteration less significant as well.

The base of unit Qa5 appears to be solidly dated by charcoal collected from two prehistoric occupation surfaces near the base of the profile, but the upper $2 \mathrm{~m}$ is more problematic. A piece of scattered charcoal was collected from the lower occupation surface at $475 \mathrm{~cm}$ and it yielded an radiocarbon age of 1510 \pm 40 RCYBP (UGAMS-5048) and a Rabdotus snail from the same depth yielded a radiocarbon age of 1960+25 RCYBP (UGAMS-5075). A piece of scattered charcoal was collected from the upper occupation surface at $440 \mathrm{~cm}$ yielded a radiocarbon age of $1125 \pm 25$ RCYBP (UGAMS-5047) whereas a Rabdotus snail collected from the same position in the profile yielded an age of $1570 \pm 25$ RCYBP (UGAMS-5074). In both instances, the snail shells yielded radiocarbon ages 450 years older than the charcoal and this, interestingly enough, is only 5 years older than the best estimate Ellis et al. (1996) obtained for the radiocarbon error associated with a suite of two modern and eight fossil
Rabdotus shells at Fort Hood, Texas (their estimate was 445 years). The concordance of the charcoal and age error corrected Rabdotus shell dates suggest that these radiocarbon ages are solid evidence that the lower half meter of this alluvial fill was deposited between 1500 and 1100 years ago.

Two additional pairs of bulk sediment and Rabdotus snail radiocarbon ages were obtained from this profile, one from the paleosol at approximately $235 \mathrm{~cm}$, and a second from the base of the modern soil at $115-120 \mathrm{~cm}$, and both sets were older than the lowest radiocarbon ages. The bulk soil sample collected from the paleosol at 233-240 cm yielded an age of $2120 \pm 40$ RCYBP (UGAMS-5060), which using a ballpark age error range of 800 to 1500 years, suggests that the true age of this deposit lies between 720 and 1320 RCYBP. A Rabdotus snail collected from the same depth $(235 \mathrm{~cm})$ yielded an age of 1770+25 RCYBP (UGAMS-5076) which when corrected for age error yields an age of 1325 RCYBP, which is older than the radiocarbon age of the upper prehistoric occupation at a depth of $440 \mathrm{~cm}$. This suggests that this snail does not accurately date the sedimentation of this deposit.

The bulk sediment sample from near the base of the modern

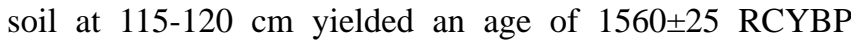
(UGAMS-5071) that, in light of the known age error of bulk sediment samples, suggests that the true age of the deposit may be essentially modern (50 RCYBP) or as old as 760 RCYBP. The Rabdotus snail collected from $118 \mathrm{~cm}$ yielded an age of 2550 25 RCYBP (UGAMS-5073) which when corrected for age error of 445 years suggests the snail died around 2105 years ago, which is clearly too old, indicating that this snail was re-deposited from an older sediment.

Regardless of the age discrepancies in the upper half of this deposit, the concordance between the charcoal and snail ages in the lower part of this profile suggests that deposition of Unit Q5 (undifferentiated) began slightly before 1500 years $\mathrm{BP}$, and continued through at least 720 years BP.

The soil formed in the upper part of the profile exhibits an A-Bk-C profile where the Bk horizon is a Stage I calcic horizon. The A-horizon has clearly been leached of some ( $15-20 \%$ ) calcium carbonate but the bulge in calcium carbonate content between 1.4 and $2.2 \mathrm{~m}$ is associated with the coarser textured (sand dominated) sediments which are more carbonate rich than the silt and clay fractions. In addition to the modern soil, two incipient buried soils were present in the profile and both exhibit subtle elevations in organic carbon. The buried soil at 233-257 cm (Zone 7) exhibits considerably less organic carbon than the modern soil, but only a slight depletion of calcium carbonate ( 7\%). The second buried soil (zone 10) exhibits a very slight 
increase in organic carbon over the bounding deposits, and no significant leaching, suggesting that it was the product of a very limited period of surface exposure.

\section{Unit Qa4: Late Holocene Alluvium}

Of the five depositional units identified during the fieldwork, Unit Qa4 was not sampled for characterization but was sampled for paleoenvironmental analysis. This deposit was exposed by a $7 \mathrm{~m}$ deep mechanically excavated trench in Area 3 near 41TV410. The deposits were independently sampled for dating by two different people unbeknownst to each other, and this is one of the most dated sedimentary profiles in this study. But just because there are many radiocarbon ages does not mean that the age of the deposit is well established owing to the fact that all of the dated materials (Rabdotus snails and bulk sediment) carry an age error.

Three radiocarbon ages are available from near the base of the exposure, and two of these roughly agree after age errors are considered. A bulk sediment sample collected from 680-685 $\mathrm{cm}$ yielded an age of $3120 \pm 40$ RCYBP (Beta-216430) and a Rabdotus snail shell collected from the same depth $(685 \mathrm{~cm})$ yielded an age of $2400 \pm 40$ RCYBP (685 cm; Beta-216433). When the age errors are considered, they suggest that the snail died around 1995 RCYBP and the sediment was deposited sometime between 2220 and 1620 RCYBP. A bulk sample from a charred surface at a depth of $660 \mathrm{~cm}$ yielded an age of $3820 \pm 40$ RCYBP (Beta-216431) and if corrected for carbon error, suggests deposition between 2320 and 2920 RCYBP, but the fact that this is out of sequence (it is older than both of the samples from $685 \mathrm{~cm}$ ) suggests that this may not be an accurate depositional age. Support for the depositional age implied by the corrected bulk sediment and snail radiocarbon ages may be found in the radiocarbon age of a hearth buried near the base of Unit Qa4 on the adjacent second terrace, which yielded charcoal ages of $2180 \pm 40$ RCYBP (Beta216439) and 2220 \pm 40 RCYBP (Beta-216436).

Ascertaining the depositional age of this unit given the material dated is difficult but is summarized on Table 8-4. Overall, it seems that this deposit began to aggrade slightly before 2200 RCYBP and continued until around 1500 years BP, which is the oldest age for Qa5. It is also considered possible that this deposit is the same as Qa5a, and dates slightly older here. The two deposits bear a striking resemblance in that both exhibit weakly developed buried soils with A-C profiles. And if this was the case, it would be consistent with observations made by Abbott (1994) for the Late Holocene deposits of Mustang Branch, a tributary of Onion Creek near Buda that formed a floodplain within the last 2,000 years. The chronological ambiguity associated with the dating of this deposit is impossible to resolve and will await additional work which will, hopefully obtain radiocarbon ages on charcoal derived from cultural features in firm stratigraphic contexts.

Unit Qa3: Middle Holocene Alluvium (ca. 5.4 ka-4 ka)

Depositional Unit Qa3, which appears to have been deposited by Onion Creek between approximately 5400 and 4000 RCYBP, was the most extensively documented deposit in this study with formal descriptions and radiocarbon dates obtained from four different localities (site excavations at 41TV540, 41TV410, and field profiles P1 and P5). Descriptions of these deposits are presented in Appendix D. The sediments of this deposit examined in the field ranged from deeply buried channel sands and gravels, to thin bedded near channel overbank deposits and massive floodbasin muds. Where the thin bedded sediments occurred in the upper part of the profile, the bedding was difficult to distinguish owing to pedogenic alteration. This deposit generally exhibited minor rubification (typically the B horizon has 7.5YR hues) and occasionally exhibited a Stage I to incipient Stage II calcic horizon.

Both of the archeological sites excavated by UTSA in association with Berdoll Borrow Pits (41TV540 and 41TV410) exposed and radiocarbon dated this unit. At 41TV540, excavations revealed the basal unconformity of this deposit and channel facies deposits overlain by massive floodplain muds and a significant wedge of colluvium derived from the Cretaceous age Sprinkle Formation that crops out along the eastern valley wall above the site. A radiocarbon sample collected from a burnt surface between two lateral accretion channel deposits about $7 \mathrm{~m}$ below surface yielded an age of $5320 \pm 40$ RCYBP (Beta-216422) and provides a solid age for the early phase of Qa3 deposition. Site test excavations by UTSA, which were closer to the valley wall, yielded a suite
Table 8-4. Radiocarbon Ages Obtained from Unit Qa4 at Area 3, 41TV410

\begin{tabular}{|c|c|c|c|c|l|}
\hline $\begin{array}{c}\text { Depth } \\
(\mathbf{c m})\end{array}$ & Zone & $\begin{array}{c}\text { Material } \\
\text { Dated }\end{array}$ & $\begin{array}{c}\text { Conventional } \\
\text { Age (RCYBP) }\end{array}$ & $\begin{array}{c}\text { Corrected Age } \\
\text { (RCYBP) }\end{array}$ & Lab Number \\
\hline $150-160$ & 2 & Soil & $1240 \pm 25$ & Modern to 350 & UGAMS-4407 \\
\hline $350-360$ & 5 & Soil & $2870 \pm 25$ & $1370-1970$ & UGAMS-4410 \\
\hline \multirow{2}{*}{$400-410$} & \multirow{2}{*}{7} & Soil & $3380 \pm 25$ & $1880-2480$ & Beta-216428 \\
\cline { 3 - 6 } & & Soil & $3370 \pm 50$ & $1870-2470$ & UGAMS-4409 \\
\cline { 3 - 6 } & Rabdotus & $2690 \pm 40$ & 2240 & Beta-216429 \\
\hline 460 & 9 & Soil & $3250 \pm 25$ & $1750-2350$ & UGAMS-4408 \\
\hline $550-560$ & 11 & Soil & $3450 \pm 25$ & $1950-2550$ & UGAMS-4406 \\
\hline \multirow{2}{*}{660} & 12 & $\begin{array}{c}\text { Charred } \\
\text { Sediment }\end{array}$ & $3820 \pm 40$ & $2320-2920$ & Beta-216431 \\
\hline \multirow{2}{*}{685} & \multirow{2}{*}{12} & Sediment & $3120 \pm 40$ & $1620-2220$ & Beta-216430 \\
\cline { 3 - 6 } & & Rabdotus & $2400 \pm 40$ & 1995 & Beta-216433 \\
\hline
\end{tabular}


of radiocarbon ages derived from charcoal collected from cultural features that were situated about $1.5 \mathrm{~m}$ above the base of the fill (and about 3.2-3.5 m below the surface) and these ages ranged from 5320 to 5300 RCYBP, corroborating the age of the channel complex. The top of the profile was not dated at this site. The soil formed in unit Qa3 at 41TV540 exhibited an A-ABk-Bk-Bw-C profile where the calcic horizon in some places exhibited a Stage I (filamentous) morphology and elsewhere exhibited a Stage II (nodular) morphology with 2-7\% irregular shaped calcium carbonate nodules that ranged in size from 2 to $15 \mathrm{~mm}$, with most in the 3-5 $\mathrm{mm}$ range.

At 41TV410, a deep mechanically excavated trench within Area 2 exposed a truncated profile of Unit Qa3 and this 5 $\mathrm{m}$ deep excavation failed to expose the base of the alluvial deposit. Radiocarbon dated charcoal collected from a prehistoric occupation surfaces within the top 3 meters of this alluvial fill suggest that these sediments aggraded rapidly in a near channel overbank setting around 4820 RCYBP. Radiocarbon dates obtained from hearth charcoal collected from 106 to $117 \mathrm{~cm}$ below the surface yielded ages of 21802220 RCYBP and indicate that the top of this profile is draped by a veneer of the next younger alluvial deposit, Qa4. The soil formed in Unit Qa3 at 41TV410 exhibited a Bk-C profile where the calcic horizon had a Stage II morphology consisting of about $1 \%$ calcium carbonate nodules that ranged in size from 1-5 mm.

Two other profiles were examined from this deposit. One from the borrow pit wall west of the UTSA excavations at 41TV540 (Field Profile P1), and a second from a borrow pit west of SH 130, and south of the Onion Creek bridge (Field Profile P5). Both of these profiles were sampled for laboratory characterization and radiocarbon dated.

\section{Profile P1: (near 41TV540)}

The P1 profile was situated close to 41TV540 but outside the site boundaries to the west, and exposed deposits similar to those observed in the upper half of the profile observed at the west end of the Area 2 Trench at that site. The P1 profile was logged to $4 \mathrm{~m}$ below surface and exposed massive sediments that had been deposited in a distal floodplain setting. A total of seven radiocarbon ages on bulk sediment, Rabdotus snail shells and charcoal were obtained from profile P1 but the results are somewhat difficult to interpret (see Figure 8-5). A radiocarbon age of $6410 \pm 30$ RCYBP (UGAMS-066) was obtained from massive floodplain sediment at $4 \mathrm{~m}$ depth. Considered in light of bulk sediment potential age error, the date suggests that deposition at this point occurred between approximately 4910-5510 RCYBP, which is relatively consistent with dates obtained from 41TV540. A charcoal-bulk sediment pair was dated from $315 \mathrm{~cm}$ depth in this profile and the dates indicate that this sediment was deposited around 4900 years BP, and that the sediment here dates about 1490 years too old. A pair of radiocarbon dates, obtained from bulk sediment and a Rabdotus snail, collected from approximately $220 \mathrm{~cm}$ within a Stage II nodular calcic horizon, when corrected for age error, yielded a date of 4945 RCYBP (or slightly older than the charcoal a meter lower in the profile). The bulk sediment sample here yielded an age of 3360 RCYBP which, in light of the age error, suggests deposition between 1860 and 2460 RCYBP. This date range seems too young given the degree of soil development exhibited at this point in the profile (discussed in detail subsequently). The last two ages were obtained from the cambic B horizon at a depth of approximately $100 \mathrm{~cm}$. Here a Rabdotus snail yielded a radiocarbon age of approximately 2025 RCYBP after correction, whereas the bulk sediment sample yielded an age nearly identical to the sample from 220 $\mathrm{cm}$, which implies deposition of the sediment between 1850 and 2450 RCYBP. Unfortunately, these radiocarbon ages do little to clarify the depositional age of Qa3, other than to say sedimentation was underway around $4900 \mathrm{BP}$.

The soil formed in this deposit was consistent with that observed away from the colluvial wedge at 41TV540, namely an A-Bw-Bk-C profile formed within slightly rubified sediment. At $90 \mathrm{~cm}$ thick, the A horizon appears to have been cumulic and probably represents imcremental sedimentation in the period following abandonment of the Qa3 floodplain, probably in the last two millennia. Only a small amount of leaching of calcium carbonate from this deposit is apparent. The cambic B horizon exhibited clear structure and minor calcium carbonate deposition (only filaments) whereas the calcic (Bk) horizon exhibited an incipient stage II morphology with a few (1\%) small (2-3 mm) calcium carbonate nodules (Figure 8-11a and 8-11b). The C horizon comprised massive silty clay to silty clay loam.

\section{Profile P5}

This section was also sampled from a borrow pit wall, very close to the active channel southwest of the SH 130 bridge over Onion Creek. Initially this exposure was thought to be Unit Qa4, but upon sampling it was discovered that the borrow pit wall was covered with a veneer of sediment and that the underlying deposits were considerably different. Subsequent radiocarbon dating confirmed that this deposit was indeed Unit Qa3. A deeper profile could have been sampled but the profile was terminated when the veneer of cover sediments became more than $1 \mathrm{~m}$ thick.

The deposits sampled consisted of a near channel overbank setting between 3 and $4 \mathrm{~m}$ below surface to a massive floodplain facies until around $1.2 \mathrm{~m}$ depth, above which the profile becomes cumulic and based on radiocarbon ages, 


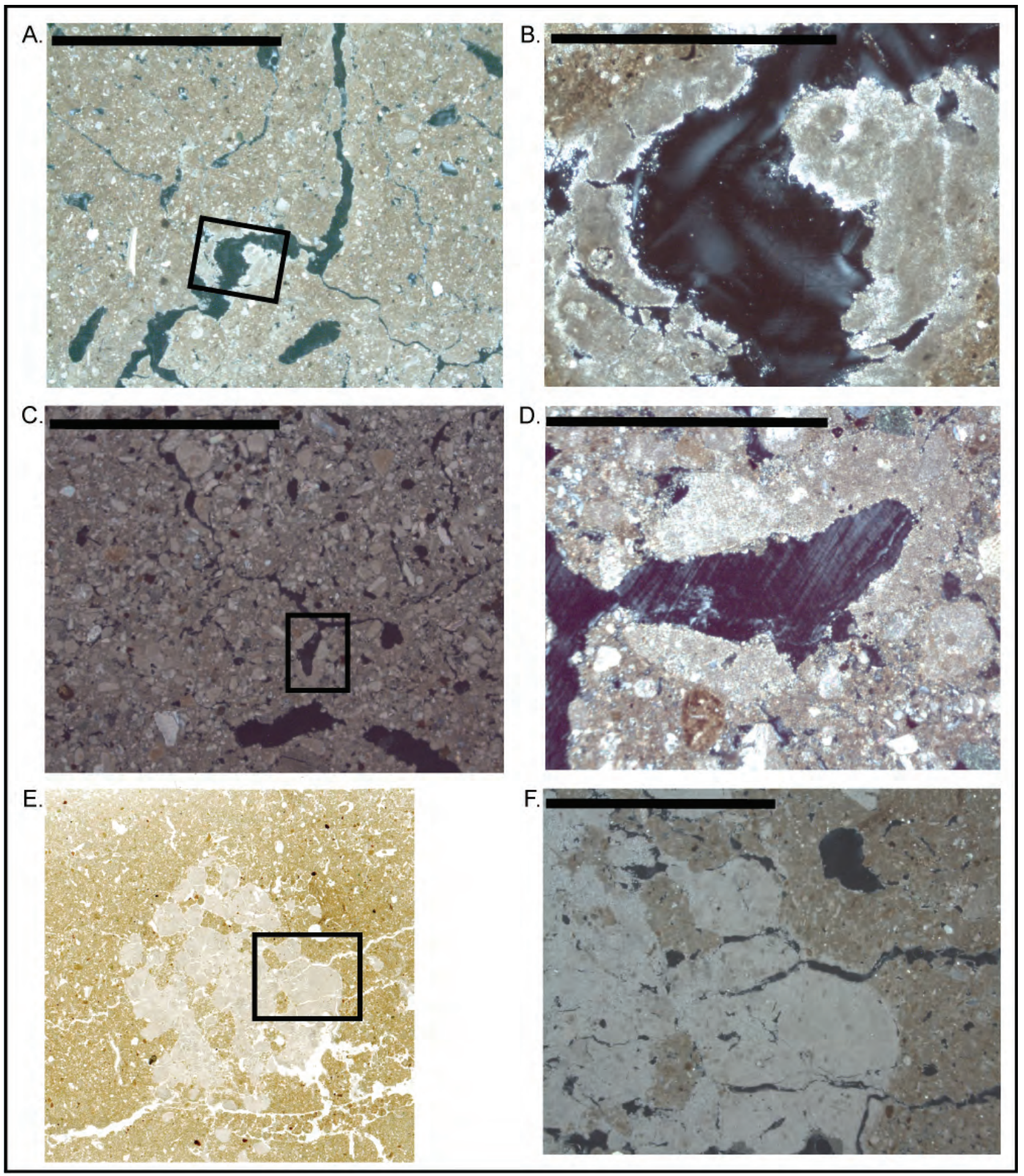

Figure 8-11. Photo micrographs of selected calcium carbonate features from depositional Unit Qa1, Qa2 and Qa3. A. Small calcium carbonate nodule formed on a ped face in Unit Qa3 (Field Profile P1, Zone 3, Bk1 horizon, 180-190 cm depth). View is in cross-polarized light, scale bar is $5 \mathrm{~mm}$. Box shows area amplified in B. Same view as A, but higher magnification. Scale bar is $1 \mathrm{~mm}$. C. Example of a small calcium carbonate nodule/ thick pore coat formed in Unit Qa2 (Field Profile L1; Zone 6, Bk3 horizon). D. Same view as C, but higher magnification. Scale bar is $1 \mathrm{~mm}$. E. Transmitted light scan of a thin section from Unit Qa1, field profile LP1, zone 6 (2Bk2 horizon, 258-270 cm) showing a large calcium carbonate nodule and weakly defined prismatic structure. Box shows the area shown at higher magnification in F. Nodule is approximately $1.8 \mathrm{~cm}$ in diameter. F. Same sample as shown in E, but magnified and in cross-polarized light. Scale bar is $5 \mathrm{~mm}$. 
this upper deposit dated to the last 2,000 to 3,000 years (see Figure 8-6). The base of this exposure appears to have been deposited around 4940 RCYBP based on a radiocarbon age obtained from a piece of charcoal at a depth of $377 \mathrm{~cm}$. A Rabdotus snail collected from the same depth yielded an age after correction of 5805 RCYBP and the age difference suggests that this snail was re-deposited from older sediment or ingested more old carbon than average during its lifetime. A bulk sediment sample collected $340 \mathrm{~cm}$ yielded an age of 5480 RCYBP which given the age error on bulk sediment suggests actual sedimentation occurred between approximately 4580 and 3980 RCYBP. Another bulk sediment sample collected from $220 \mathrm{~cm}$ yielded an age of 4520 RCYBP and implies actual deposition may have occurred between 3640 and 3040 RCYBP. A pair of radiocarbon samples was collected from the top of the calcic horizon around $120 \mathrm{~cm}$ depth, where a bulk sample yielded an age of 2770 RCYBP (UGAMS-5068) and a Rabdotus shell yielded an age of $3410 \pm 30$ RCYBP (UGAMS-5082). When corrected for their associated age errors, these dates suggest that the top meter of this profile aggraded in the period since 1870-1270 RCYBP (the bulk sample) or since 2965 RCYBP (snail).

The soil formed in this profile exhibited an A-AB-Bk-C profile where the $A$ and $A B$ horizons are a drape of post-Qa3 sediment. Clear evidence for changing conditions in this locality in the last 3 millennia is visible in the granulometric data from the profile which shows a prominent coarsening of the deposit in the upper meter, most like in association with the channel of Onion Creek moving to its present position during deposition of Units Qa4/Qa5.

Considered together, the multiple exposures of Unit Qa3 suggest deposition began around 5400 RCYBP, and the top of the exposure continued to aggrade from overbank flooding throughout the late Holocene. The majority of Qa3 deposition occurred in most exposures before about 4,000 RCYBP.

\section{Unit Qa2: Early Holocene Alluvium (ca. $>9$ ka to 7 ka; Field Profile L1)}

This profile was collected from the eastern side of the borrow pit adjacent to site 41TV2125 (The Berdoll Site), that was the subject of Data Recovery excavations by Hicks and Company (Campbell et al. 2005, 2009). This is the only known exposure of sediment of this age in the lower reaches of Onion Creek, and it was intensively sampled and radiocarbon dated to determine if this deposit was a discrete alluvial fill or a time transgressive alluvial deposit.

The sediments exposed in this $5 \mathrm{~m}$ long section range from channel deposits below $490 \mathrm{~cm}$, which were exposed in the borrow pit but not sampled, to near channel overbank sediments to a depth of approximately $200 \mathrm{~cm}$ (see field description in Appendix D; and Figure 8-7). The upper $2 \mathrm{~m}$ are clearly fine-grained sediment which may be flood basin muds, slope colluvium derived from the Sprinkle Formation (as Campbell et al. 2009 suggest) or a combination of the two. These deposits, although clayey, did not exhibit the exquisite wedge structure that dominated the Sprinkle Formation colluvium at $41 \mathrm{TV} 540$.

The profile logged from the borrow pit wall encountered two prehistoric occupations, one at $470 \mathrm{~cm}$ and a second around $380 \mathrm{~cm}$. These correspond well with the two components described from this locality by Campbell et al. (2009). The lowest occupation was the subject of data recovery excavations by Hicks \& Company, and Campbell et al. (2009: Table 7.23) report six radiocarbon ages from Feature 11 within this component that range in age from 7854 \pm 56 RCYBP to $8103 \pm 66$ RCYBP. A piece of charcoal collected from a hearth exposed in the borrow pit wall at a depth of $470 \mathrm{~cm}$ yielded an age of $8250 \pm 30$ RCYBP (UGAMS-5044) which is consistent with, if not slightly older than the component documented by Campbell et al. (2009). A bulk sediment sample collected from the same depth yielded an age 940 years older than the charcoal (9190 \pm 40 RCYBP (UGAMS-5051). A piece of charcoal was also collected from the upper occupation surface at a depth of $380 \mathrm{~cm}$ and this returned an age of 8290+30 RCYBP (UGAMS-5045), and a paired bulk sediment sample dated 9420+30 RCYBP (UGAMS-5055) indicates a 1,130 year age error for the bulk sediment.

Three more bulk sediment radiocarbon samples were dated from this profile:

1. 320 cm, 8400 \pm 30 (UGAMS-5054; са. 6900-7500 RCYBP),

2. $220 \mathrm{~cm}, 7990 \pm 30$ RCYBP (UGAMS-5053; са. 64907090 RCYBP), and

3. $120 \mathrm{~cm}, 5140 \pm 30$ RCYBP (UGAMS-5052; ca. 36404240 RCYBP).

In addition, a Rabdotus snail was dated from $118 \mathrm{~cm}$. It yielded an age of $7130 \pm 30$ RCYBP (UGAMS-5072) which after correction yields an age of 6685 RCYBP. This is about 1,500 years older than the conventional bulk sediment age and may be as much as 3,000 years older than the minimum age error adjusted bulk sediment age. Either the bulk sediment age is too young, owing to organic carbon filtering down from the soil, or the snail was re-deposited from older sediment. While we cannot be certain which is more likely, it is clear from the analytical data that the point in the profile 
where this bulk sample was collected is within the lower zone of organic enrichment of the A horizon. Organic carbon values in this profile stabilize around $0.6 \%$ at a depth of 140 $\mathrm{cm}$, so the bulk sediment age appears anomalously young.

The soil formed in this deposit exhibited an A-AB-Bk-C-Bk'-C profile where the upper $\mathrm{Bk}$ horizon contained a Stage II calcic horizon with $3 \%$ pinkish gray calcium carbonate nodules that were between 3 and $7 \mathrm{~mm}$ long (Figure 8-11c and 8-11d). The Bk' horizon exhibited a few (3\%) calcium carbonate nodules that were often cylindrical in shape and around $5 \mathrm{~mm}$ wide and $20 \mathrm{~mm}$ long. The A-horizon appears to have been leached of approximately $20-30 \%$ calcium carbonate.

Considered together, Unit Qa2 appears to have started to aggrade sometime before 8300 RCYBP and been abandoned sometime around 7,000 RCYBP, after which the surface was incrementally inundated throughout the rest of the Holocene.

\section{Unit Qa1: Late Pleistocene Alluvium beneath the T2 surface (Field Profile LP1)}

The oldest deposit examined in this study was observed in two localities: 1) within the borrow pit immediately south of the UTSA excavations at 41TV540 where it was observed to be inset into the Cretaceous Sprinkle Formation, and 2) in a cutbank exposure immediately west of the State Highway 130 bridge over Onion Creek (Field Profile LP1). The borrow pit exposure near 41TV540 revealed two different alluvial deposits inset into an exposure of the Cretaceous Sprinkle Formation (see Figure 8-2). The deposit of Qa1 in this section was a floodplain facies that would have been directly comparable to most of the other sampled sections, but it was not possible to sample this section.

In the cutbank exposure (Field Profile LP1), the base of the alluvium was about $5 \mathrm{~m}$ above the channel floor of Onion Creek and at 41TV540 the base was more than $5 \mathrm{~m}$ below surface of the second terrace suggesting that this fill approaches $9 \mathrm{~m}$ thick in places. In the sampled exposure (field locality LP1), the upper $2 \mathrm{~m}$ appears to be a drape of middle-late Holocene overbank alluvium that rests upon a truncated core of Pleistocene alluvium. The core of the Pleistocene deposit is comprised of channel sands and gravels which grade from very gravelly loamy sand at the base of the exposure, and fine upwards into gravelly and slightly gravelly loamy sand, and eventually into an overbank facies that is comprised of sandy loam, sandy clay loam and clay loam. A single bulk sediment age was obtained from this deposit in zone $10(370-375 \mathrm{~cm})$ which yielded an age of $11,740 \pm 40$ years BP. This is remarkably close to the radiocarbon age obtained on bulk sediment from the exposure of this unit in the east wall of the Berdoll borrow pit south of 41 TV540 (see Figure 8-2). In this location, a bulk sample about $5 \mathrm{~m}$ below surface collected adjacent to the fragmented mandible of a horse or camel, dated to $12,280 \pm 40$ RCYBP (UGAMS-5067). A mandible fragment returned an apatite age of 8,630 \pm 30 RCYBP (UGAMS-5084) which is clearly too young. When the age error associated with bulk sediment ages is considered, the two bulk sediment radiocarbon ages indicate that deposition of Qa1 was occurring between 10,240 and 11,380 RCYBP.

As noted previously, the top $2 \mathrm{~m}$ of Profile LP1 consisted of a drape of middle to late Holocene floodplain alluvium that unconformably drapes a truncated fragment of Unit Qa1. The top of Qa1 was most likely eroded sometime between the late Pleistocene and Middle Holocene, but the precise timing of this erosional event is unknown. The soil formed in Qa1 here consists of a truncated Bk-BC-Bk'-Bt-C profile where the Bk horizon is a prominent Stage II to incipient Stage III calcic horizon. Nodules within the calcic horizon were upwards of 20 $\mathrm{mm}$ in diameter in places (see Figure 8-2 and 8-11a and 8-11f).

The drape of flood basin muds that buried Qa1 in profile LP1 is comprised of massive clay loam. Four radiocarbon ages were obtained from the drape. A pair of samples were collected around $175-180 \mathrm{~cm}$, where a bulk sediment sample yielded an age of 4820 \pm 30 RCYBP (UGAMS-5062), which when considered in light of the inherent carbon error for bulk sediment radiocarbon ages suggest deposition of this sediment occurred between approximately 3000 to 4000 RCYBP. A Rabdotus snail shell from the same depth yielded an age of $5440 \pm 30$ years RCYBP (UGAMS-5077), which when corrected for carbon error suggest this snail died around 4995 RCYBP. Which, if either of these samples is a more accurate reflection of the age of sediment deposition is unclear. Two more snails were dated from the upper $1.5 \mathrm{~m}$ of this exposure. A snail from $145 \mathrm{~cm}$ depth returned an age of $4220 \pm 40$ years BP (UGAMS-5078), which after correction for age error is 3775 RCYBP. A Rabdotus snail collected from $45 \mathrm{~cm}$ depth yielded an age of 1940 25 (UGAMS-5079) which when corrected for age error suggests that the top half meter of this profile accumulated during the during the last 1,500 years, and is attributable to depositional unit Qa5.

The soil formed within the Late Holocene drape over Qa1 exhibts an A-AB-Bk profile. It appears that a small amount (20-30\%) of calcium carbonate has been leached from the A-horizon, and organic carbon declines gradually through this drape.

\section{Recognizing and Distinguishing Qa2 and Qa3}

One of the points noted in the field was the difficulty in distinguishing depositional Units Qa2 and Qa3, and given the rubified nature of these deposits it was thought that 
examining some measure of pedogenic iron accumulation may provide evidence useful in distinguishing the deposits. To evaluate this, two different iron extractions were obtained for each field profile that was characterized in the lab: 1) the citrate-bicarbonate-dithionite extractable iron $\left(\mathrm{Fe}_{\mathrm{d}}\right)$ and 2) the oxalate extractable iron $\left(\mathrm{Fe}_{\mathrm{ox}}\right)$. The citrate-bicarbonatedithionite extractable iron removes iron from most pedogenic iron minerals (Birkeland 1999:91) whereas the oxalate extractable iron mainly extracts more chemically active forms of iron such as ferrihydrite (Birkeland 1999; Walker 1986). The oxalate-dithionite ratio is an indicator of iron oxide crystallinity and the ratio decreases as amorphous iron oxides are depleted relative to crystalline iron oxide (Jackson et al. 1986). This ratio has been shown to decrease systematically as a function of increasing soil age in soil chronosequence studies (McFadden and Hendricks 1985).

The whole profile average values for $\mathrm{Fe}_{\mathrm{d}}$ and $\mathrm{Fe}_{\mathrm{ox}}$ are listed on Table 8-5 and plotted on Figure 8-12. Two of the alluvial fills were sampled twice (Qa5 and Qa3) whereas Units Qa1 and Qa2 are represented by single profiles. The results show that dithionite extractable iron generally increases with unit age, although Qa1 exhibits lower values than expected, and this may be in part due to the fact that this unit is the only one in the sample represented as a channel component rather than a floodplain facies. Interestingly Qa2 and Qa3 exhibit clearly different values of $\mathrm{Fe}_{\mathrm{d}}$. The oxalate extractable iron decreases fairly consistently with increasing unit age, and as is to be expected, the ratio of $\mathrm{Fe}_{\mathrm{ox}} / \mathrm{Fe}_{\mathrm{d}}$ decreases with increasing unit age, but it is interesting to note that the values obtained for Qa2 and Qa3 overlap, with the P1 (Unit Qa3) profile having an almost identical value to the L1 profile (Unit Qa2).

Conceptually, the A horizon magnetic susceptibility may be useful in distinguishing deposits of different age, as A horizons are widely considered to developed enhanced magnetic susceptibility with increasing age (cf. Gale and Hoare 1991). In this particular case, the low frequency mass corrected magnetic susceptibility $\left(\mathrm{X}_{\mathrm{lf}}\right)$ does clearly distinguish the modern Qa5 deposits from older units, but it does not discriminate the topsoils of Qa2 and Qa3 from each other (see Table 8-5). Figure 8-13 plots the maximum value as well as the A-horizon average for each alluvial fill and as is clear that for both measures Qa2 and Qa3 exhibit overlapping values, with the greatest magnetic susceptibility value obtained from profile P1 (Unit Qa3). It should be noted that a single anomalous observation was excluded from profile LH2 (Unit Qa5) as it was ten times the value of all other observations from that unit and thought not to be representative.

\section{Stable Carbon Isotopes}

Stable carbon isotopic values were obtained for the bulk organic carbon for each bulk sediment sample analyzed, and the results of these analyses are shown on the lab data plots for each profile and summarized on Figure 8-14 where they are compared to the record obtained by Nordt et al. (2002) from the Medina River south of San Antonio. Given the general problems with the geochronology from these profiles, it is difficult to assign ages to individual samples with any degree of certainty. Hence, the results of the stable carbon isotopic work will be summarized in a general fashion and the chronology shown on Figure 8-14 should be considered very approximate. Furthermore, the top meter or so of several of the examined profiles (e.g. Qa2, Qa3, Qa4) may actually be cumulic and younger than the core of the alluvial fill. All of the samples discussed below were processed at the Analytical Chemistry Lab at Institute of Ecology, University of Georgia, with the exception of the profile from Unit Qa4. A suite of 15 bulk sediment/soil samples were collected at $50 \mathrm{~cm}$ intervals from this $7 \mathrm{~m}$ Qa4 exposure and submitted for stable carbon isotopic analysis to the Coastal Science Lab (Austin, Texas).

\section{Late Pleistocene (Unit Qa1, ca. 11,740 RCYBP)}

The basal portion of Unit Qa1 exhibits wide swings in $\delta^{13} \mathrm{C}$, with values starting around $-25 \%$, and shifting by as much as 4 to $8 \%$ in short stratigraphic distances, reaching a maximum value of $-13 \%$ (equating to $100 \% \mathrm{C}_{4}$ plants) at $385 \mathrm{~cm}$. At $370 \mathrm{~cm}$ with values around $-23 \%$, the record starts a gradual

Table 8-5. Variation in Iron and Topsoil Magnetic Susceptibility by Alluvial Fill

\begin{tabular}{|c|c|c|c|c|c|c|c|}
\hline $\begin{array}{c}\text { Depositional } \\
\text { Unit }\end{array}$ & $\begin{array}{l}\text { Sampled } \\
\text { Column } \\
\end{array}$ & $\begin{array}{l}\text { Average } \\
\text { Age (ka) } \\
\end{array}$ & $\begin{array}{c}\mathrm{Fe}_{\mathrm{d}} \\
\mathrm{g} / 100 \mathrm{~g}\end{array}$ & $\begin{array}{c}\mathrm{Fe}_{\mathrm{ox}} \\
\mathrm{g} / 100 \mathrm{~g}\end{array}$ & $\mathrm{Fe}_{o x} / \mathrm{Fe}_{\mathrm{d}}$ & $\begin{array}{l}\text { Topsoil } \\
\mathrm{X}_{\mathrm{lf}} \operatorname{Max} \\
\end{array}$ & 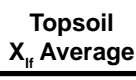 \\
\hline \multirow{2}{*}{ Qa5 } & LH1 & 1 & 0.915 & 0.121 & 0.1322 & 40.6 & 34.9 \\
\hline & LH2 & 1 & 0.912 & 0.108 & 0.1184 & 40.1 & 37.5 \\
\hline Qa4 & na & 2 & -- & -- & -- & -- & -- \\
\hline \multirow{2}{*}{ Qa3 } & $\mathrm{P} 1$ & \multirow[t]{2}{*}{4.8} & 1.021 & 0.083 & 0.0812 & 86.2 & 73.7 \\
\hline & P5 & & 0.852 & 0.103 & 0.1208 & 60.9 & 58.3 \\
\hline Qa2 & L1 & 8 & 1.153 & 0.093 & 0.0806 & 60.1 & 57.8 \\
\hline Qa1 & LP1 & 12 & 0.948 & 0.057 & 0.0601 & -- & -- \\
\hline
\end{tabular}

$\mathrm{Fe}_{\mathrm{d}}=$ citrate-bicarbonate-dithionite extractable iron

$\mathrm{Fe}_{\mathrm{ox}}=$ oxalate extractable iron 


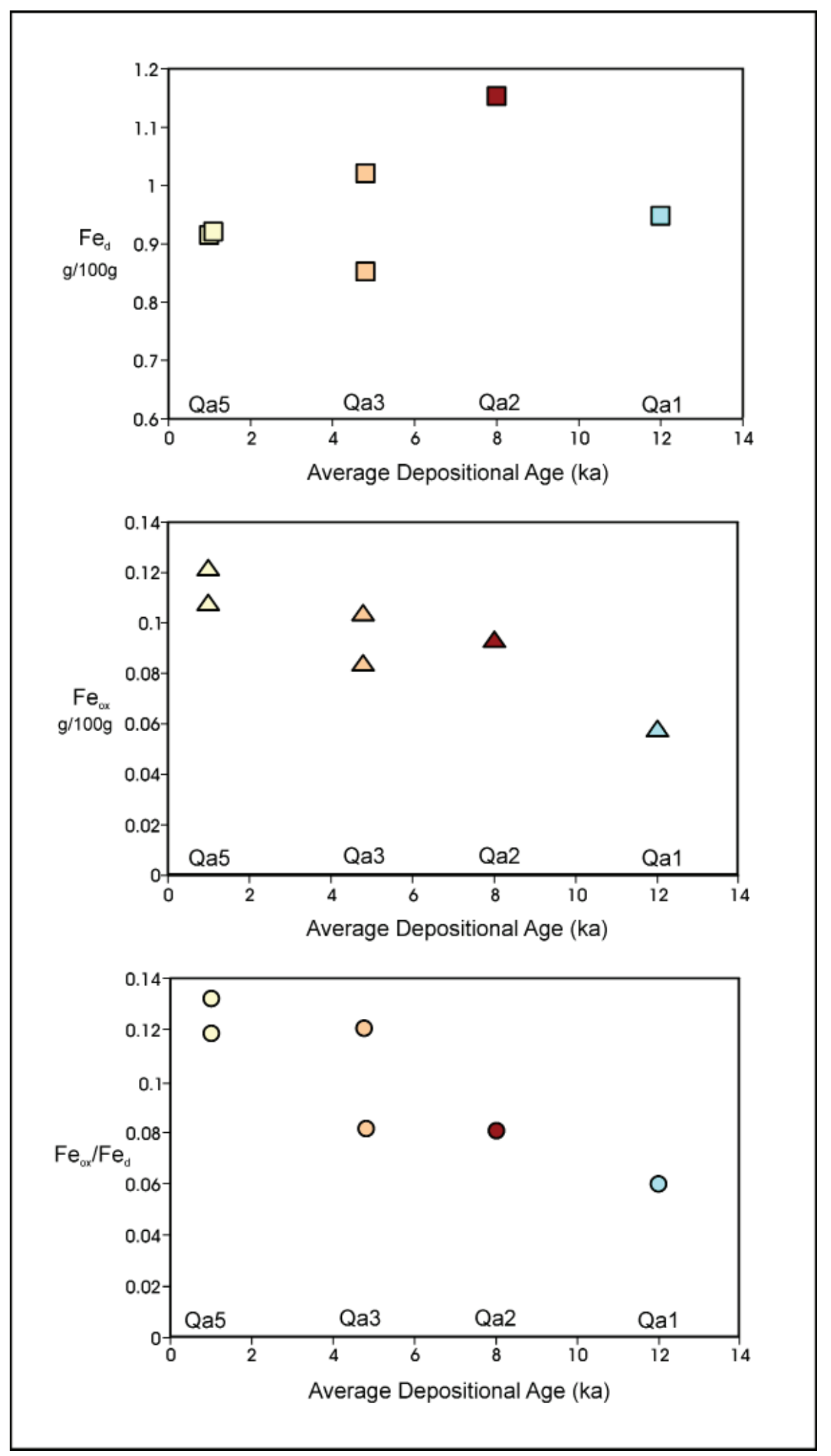

Figure 8-12. Top panel: Plot of the column average citrate-bicarbonate-dithionite extractable iron obtained from each profile analyzed in this study. Middle panel: Plot of the column average oxalate extractable iron obtained from each profile analyzed in this study. Bottom panel: Plot of the ratio of $\mathrm{Fe}_{o x} / \mathrm{Fe}_{d}$ for each alluvial fill. 


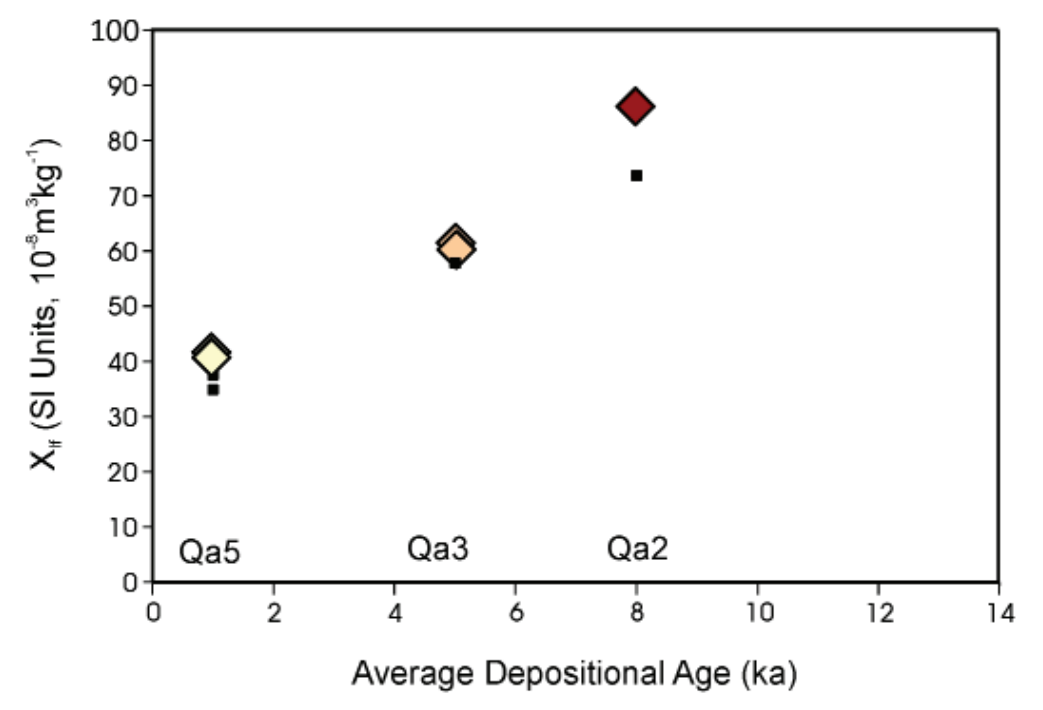

Maximum Topsoil Value

- Average Topsoil Value to the soil/sediment organic carbon of approximately $30 \%$. The record from Field Profile P1 is slightly less variable and appears to be about 1 per mil lighter than the record obtained from profile P5 for similar depths below surface.

Late Holocene (Unit Qa4, ca. 3,800-1,500 RCYBP)

Although a complete lithological column was not collected from the exposure of this unit in Area 3 at 41TV410, samples of 15 bulk sediment/ soil samples were submitted for stable carbon isotopic analysis. These samples start off with values around $-16.2 \%$ at the base of the section and then proceed to lighten somewhat and vary around $-18 \%$ o $( \pm 0.6)$ until a depth of about $3 \mathrm{~m}$, when the values increase to a maximum of $-15.1 \%$ at $205 \mathrm{~cm}$. From this point the values decline to $-17.6 \%$ at $105 \mathrm{~cm}$, after which they became slightly heavier once again and ending at $-16.3 \%$ at the modern surface. The range of variation expressed within these samples equates to about a $15 \%$ variation in contribution of $\mathrm{C}_{4}$ plants.

and progressive trend towards steadily heavier values indicative of an increasingly significant $\mathrm{C}_{4}$ plant contribution to the sediment/ soil organic carbon from around $30 \% \mathrm{C}_{4}$ at $370 \mathrm{~cm}$ to around $65 \%$ (ca. -18 per mil) at the top of the unit around $220 \mathrm{~m}$.

\section{Early Holocene (Unit Qa2, ca. 9,000-7,000 RCYBP)}

The lowest portions of Unit Qa2 (Field Profile L1) start off varying around $-23 \%$ for the basal $1.3 \mathrm{~m}$ of the sampled section, and then begins a steady increase in values to the ground surface eventually ending around $-16.2 \%$. This represents an almost $50 \%$ increase in $\mathrm{C}_{4}$ biomass through this period.

Middle Holocene (Unit Qa3, ca. 5,400-ca. 4,000 $R C Y B P$ )

The two columns examined from Unit Qa3 exhibit nearly identical trends in stable carbon isotopes, although there are a couple of differences between the two records. In general terms, both sections start out around $4 \mathrm{~m}$ below the surface with values of around $-20 \%$, and steadily increase towards the top of the section, peaking around $50 \mathrm{~cm}$ depth with values of $-15.9 \%$, which represents an approximate increase in $\mathrm{C}_{4}$ contribution

\section{Latest Holocene (Unit Qa5, <1,500 RCYBP)}

Given the questions about the validity of the geochronology from profile LH1, this discussion will only consider the carbon isotopic results from field profile LH2. The lower $2.8 \mathrm{~m}$ of this section oscillates around values of $-19 \%$, but begin to get heavier around $2.3 \mathrm{~m}$ and eventually peak at $-16.6 \%$ at $85 \mathrm{~cm}$, after which the values increase almost $5 \%$ to the modern ground surface. The dramatic increase in $\mathrm{C}_{4}$ organic matter in the upper $85 \mathrm{~cm}$ may reflect establishment of the galleria forest on this site, or it may reflect a true increase in regional $\mathrm{C}_{4}$ biomass. The only other section to show a similar trend near the surface is profile LP1, where the stable carbon isotopic values for the veneer of late Holocene sediment draping Unit Qa1, exhibits a dramatic shift of 7\%o in the top $50 \mathrm{~cm}$, and this section, like LH2, is immediately adjacent to the modern stream channel.

\section{Discussion}

The summary of the stable carbon isotopic results illustrated on Figure 8-14 shows how the results from Lower Onion Creek compare to the stable carbon isotopic record obtained 


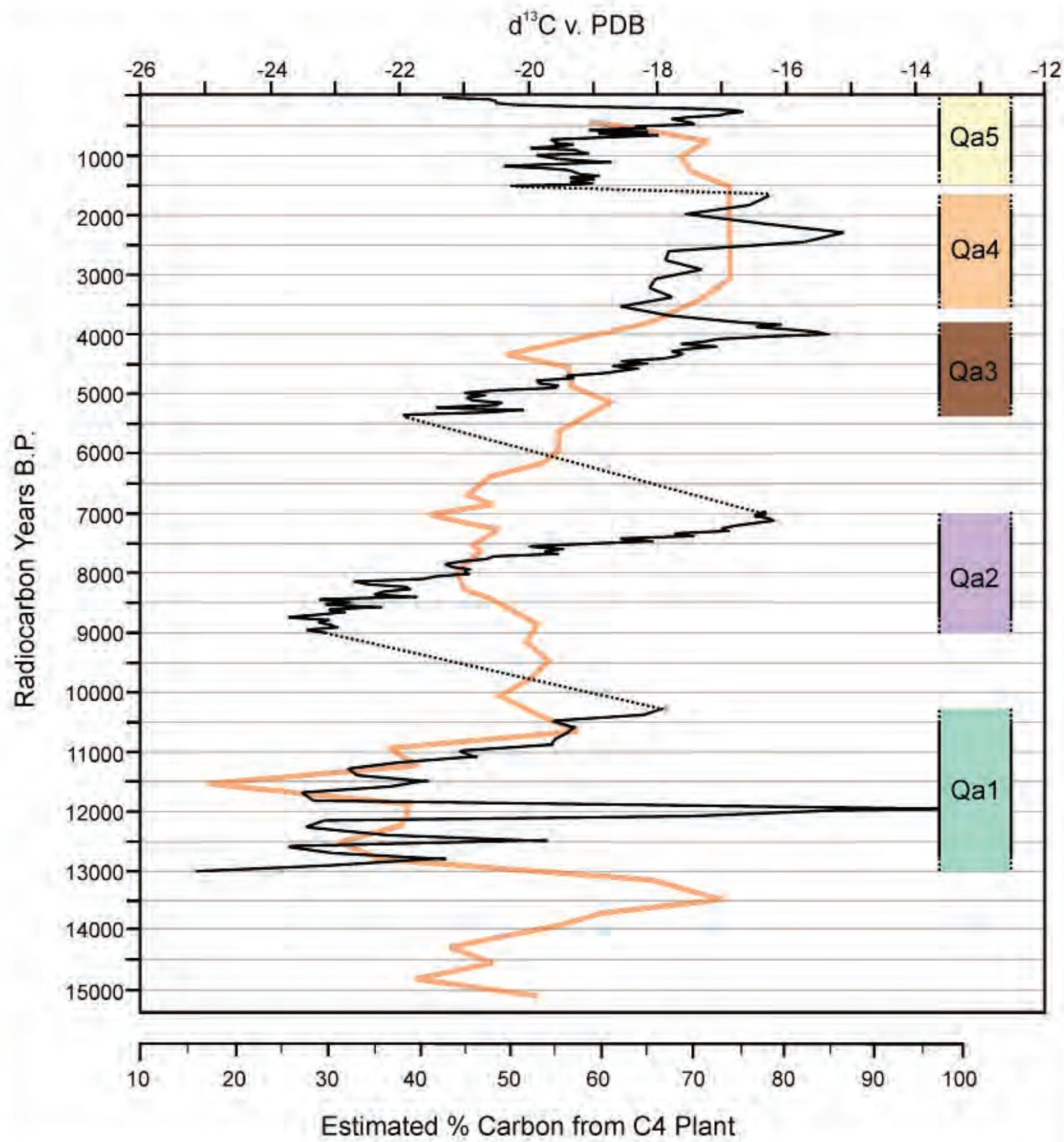

Figure 8-14. Plot of the results of stable carbon isotopic variation obtained from the bulk sediment/soil samples collected from the alluvial fills within the Lower Onion Creek Valley. The colored bars on the right hand side represent the approximate time periods of the different alluvial fills, and the black lines are the stable carbon isotopic results obtained during this work. The dotted lines are presumed connections between the different age sections. The pale orange line is the results of stable carbon isotopic work at the Richard Beene Site, near San Antonio (Nordt et al. 2002). 
from the deposits of the Medina River at the Richard Beene Site (Nordt et al. 2002). Although there are some similarities, many of the Onion Creek profiles show a prominent trend with depth below surface, whereby the sediments become increasingly enriched with ${ }^{13} \mathrm{C}$ towards the top of the profile. Although there are several prominent slopes such as this in the Applewhite record, the repetitive nature of this trend in the Onion Creek samples begs the question if this is related to changes in plant community composition with respect to facies variation within the alluvial fills.

\section{Summary}

Geoarcheological work performed in the lower Onion Creek valley in conjunction with archeological investigations has led to the development of a new stratigraphic sequence for the late Quaternary deposits of Onion Creek. At the outset of this work it was anticipated that the alluvial chronology for Onion Creek would be very close to or even identical to that of the Colorado River (cf. Blum 1992) but the results of extensive radiocarbon dating and very deep trenches has demonstrated that the Onion Creek deposits differ in age from those of the Colorado River. Five informal alluvial depositional units (Qa1 to Qa5) were recognized, but radiocarbon dating problems with the youngest deposits (Qa4 and Qa5) may require revision when more accurate radiocarbon ages from good contexts are available in the future. Although many of the depositional units are readily distinguished on the basis of relative stratigraphic position and degree of soil development, Units Qa3 and Qa2 are of very similar appearance, a point confirmed by field observation and chemical analysis of the deposits. Both of these deposits may exhibit Stage II calcic horizons, but the nodules in Unit Qa2 are larger and more common than those in Qa3.

The extensive radiocarbon dating done as part of this work supports previous observations that the bulk sediment/ soil radiocarbon ages in this catchment overestimate the age of sedimentation by 900 to 1500 years. Furthermore, radiocarbon dating of Rabdotus snail shells in conjunction with other materials (hearth/occupation surface charcoal and bulk sediment) support previous work by Ellis et al. (1996) that established the approximate age error associated with the ingestion of old carbon by living snails, and demonstrates that such dates may be a good alternative for charcoal when it is not readily present. However, the majority of the pairs of snail and sediment ages obtained here suggest that old snails are commonly redeposited and that this process may result in erroneously old radiocarbon ages, even after the ages have been corrected for the ingestion of old, dead carbon during the life of the snail.

The alluvial chronology established here differs from that of the Colorado River, of which Onion Creek is a tributary. The three-dimensional arrangement of the deposits is similar to the Colorado River, but the chronology of the different deposits appears to be significantly different. The source of these age differences are not known at this time but may be due to the reliance of the Colorado River chronology on bulk sediment/humate radiocarbon ages, the age error of which are relatively poorly understood in the Colorado catchment. Furthermore, the similarity of the soils formed in Units Qa2 and Qa3 is such that these could easily be mistaken for a single allostratigraphic unit when sampled at widely separated localities. The deep, relatively close trenches employed here and detailed dating highlighted the distinction between the deposits in the lower Onion Creek valley.

Ultimately, the work done here draws into sharp focus the manner in which the chronology and three-dimensional arrangement of the late Pleistocene and Holocene alluvial deposits conditions the presentation and visibility of archeological sites in such dynamic settings. Both of the sites described here were situated in relatively rapidly aggrading floodplain depositional settings, but the deposits at 41TV540 in particular exemplify the ephemeral nature of some hunter-gatherer occupations which can be preserved by frequent inundation and burial. The extremely rapid sedimentation rate at this site preserves occupation surfaces with little time averaging and which contain minimal artifact assemblages with well-preserved spatial patterning. The scarcity of artifacts challenges behavioral interpretation in such depositional settings, while simultaneously raising the question of the degree of time averaging associated with archeological sites with more substantial artifact assemblages. Is this difference one of the intensity of single event occupations, or is it really a reflection that the results of a single occupation during a seasonal round may be very ephemeral and it is only in depositional settings with slow sedimentation rates that multiple generations of repeated visits to the same spot result in occupation surfaces with significant artifact densities. This cannot, of course, be answered here, but rather draws attention to the fact that the age structure of the alluvial deposits may strongly influence the appearance of prehistoric sites in such dynamic settings and that finding sites of a specific age clearly rely upon a clear threedimensional understanding of the alluvial stratigraphy. 



\title{
Chapter 9: Attempts at Reconstruction of Paleoenvironmental Conditions and Resource Structure on the Onion Creek Floodplain
}

\author{
Raymond Mauldin, Steve Tomka, and Antonia Figueroa
}

As outlined in Chapter 7 (see also Tomka et al. 2007), the second general research objective presented in the research design focused on documenting trends in the plant and animal communities available to hunter-gatherers exploiting the Lower Onion Creek valley. We suggested that periods of aggradation would produce a highly variable environment that maintained plant and associated animal communities in constant flux. In contrast, periods of stability would have resulted in more mature plant and animal communities present on the floodplain. Weedy species, well adapted to disturbed settings, would have been replaced by slower-growing tree species. Those tree species would include those that might produce significant cyclical mast yields, encouraging high deer population densities and human consumers (Tomka et al. 2007). While hampered by stratigraphic problems, the geomorphological investigation presented in the previous chapter documented several major intervals of aggradation, separated by short intervals of what we suggest are periods of relative stability. We proposed to use those intervals to frame our investigation of shifting resource structures, and supplement that work by an analysis of four data sets. These data sets included stable carbon isotopes from sediments, phytoliths, snail populations, and macrobotanical results from features at 41TV540 and 41TV410. We hoped that these data would flesh out the paleoenvironmental details by identifying the types of plants and animals available to hunter-gatherers. This chapter presents the results of those investigations.

\section{Geomorphic Intervals and Resource Structure}

The geomorphic results, summarized in the previous chapter, suggest that there were probably five periods of major deposition, designated Qa1 through Qa5 by Frederick (Chapter 8), represented in the Lower Onion Creek valley. The principal interest here is in the periods defined by Qa2, 3, and 4 , and the intervening periods, as these encompass much of the prehistoric archeological record in the valley. These periods of deposition should be characterized by a highly variable resource structure, possibly resulting in short-term or specialized use. Conversely, we suggested that intervening periods should produce a more mature, stable resource structure, possibly resulting in longer-term occupations. Given the possible impacts of intervals of aggradation and stability on the plant and animal communities and potentially hunter-gatherer land use, our objectives were to define these periods, and then investigate what effect these intervals did have on the composition and structure of the resources present. To define the intervals in time, we rely heavily on Frederick's geomorphic descriptions presented in the previous chapter. To investigate the impact that these periods of deposition and stability have on the resource structure, we have a variety of different data sets. These include stable carbon isotope data, presented in the previous chapter, which should track shifts in $\mathrm{C}_{3}$ and $\mathrm{C}_{4}$ plants. They also include data on phytoliths that should provide finer details on the types of plants present, and data on the composition of land snails present which should track fine-grained vegetation shifts. We also have macrobotanical results from features at 41TV410 and 41TV540 that provide additional information on the types of plants potentially available for food and fuel.

Unfortunately, statements that can be made about the actual impacts of periods of stability and aggradation on resources are limited, as are connections with the archeological record at 41TV540. In part, this is because not all data sets are available for all settings, there are significant gaps in the temporal coverage of the data types and in some cases, data are of questionable quality. For example, the phytolith and snail data are only available from the Qa4 interval, which dates within the last 3,000 years. The best available data on resource structure, then, starts about 3,000 years after the Early Archaic occupation at 41TV540 ends. There was minimal recovery of macrobotanical material from features at 41TV410, and the macrobotanical material from 41TV540 features reflects only a single period around $6000 \mathrm{BP}$. The Qa4 paleoclimate data overlap with some of the material from 41TV410, though we did not analyze any of this archeological material in detail given the non-significant determination of this site. While the utility of any paleoclimate and resource reconstruction is limited, at least for understanding the record at 41TV540, patterns may be applicable to other occupations in the Lower Onion Creek Valley.

\section{Deposition and Stability}

We begin by reviewing the radiocarbon dates from these three intervals (Qa2, 3, and 4) in an attempt to more clearly define the periods of deposition, and intervening periods of stability. Throughout this discussion we use estimates based on corrected, calibrated age ranges and report dates as calendar age (BP). We assume, following the discussion by Frederick in the previous chapter, that radiocarbon dates on Rabdotus average about 445 years too old (see Ellis et al. 1996). We also assume that bulk sediment dates are 
consistently about 1,000 years too old. We ignore dates that are clearly out of stratigraphic sequence. We assume that the available dates at the bottom and top of a profile identify the onset and termination of a given sequence, and that intervals between these sequences are stable. We further assume that the sequences described are characteristic of the Lower Onion Creek Valley as a whole.

With these assumptions, and using dates presented by Frederick in the previous chapter, it appears that sediment identified as Qa2 began deposition sometime around $9300 \mathrm{BP}$ as indicated by a series of charcoal and sediment dates near the base of Profile L1 at $470 \mathrm{cmbs}$. The sequence terminates at $7900 \mathrm{BP}$ at $220 \mathrm{cmbs}$ with a bulk sediment date of 7990 +/- 30 RCYBP (see Figure 8-7; Appendix D). Frederick’s describes Qa3, the next sequence, in several places, including deposits associated with $41 T V 540$ and 41TV410. The longest sequence with the most consistent dates appears to be associated with profile P5 (see Figure 8-6; Appendix D). The onset of the Qa3 deposits in that profile dates to about $6600 \mathrm{BP}$ based on snail and charcoal dates at about 380 cmbs. The upper date for the sequence is a bulk sediment date that, when corrected and adjusted yields a date of around $4000 \mathrm{BP}$ at $220 \mathrm{cmbs}$. The final sequence of concern here is Qa4. This is described in the deep trench adjacent to 41TV410, and is the best dated of the three alluvial sequences considered here with 10 different radiocarbon dates. Figure 9-1 shows the profile and associated dates. Given the overall stratigraphic pattern, we discount two of the three radiocarbon dates near the base of this profile (snail at $2400+/-$ 40 RCYBP and bulk sediment at $3120+/-40$ RCYBP) and accept the bulk sediment date of $3820+/-40$ RCYBP. In our opinion, this older initial date makes more internal sense given the stratigraphy in the upper portion of the profile. This decision is different from that of Frederick who accepts the two overlapping dates and discounts the oldest bulk sediment date. The practical difference between the two decisions is to shift the onset of the Qa4 by about 800 years. We suggest that the deposition began at about $3000 \mathrm{BP}(660 \mathrm{cmbs})$ and terminated just before $230 \mathrm{BP}$ at roughly 150 cmbs (see Figure 9-1).

Using this slightly revised chronology, periods of deposition were present between 9300 and $7900 \mathrm{BP}$, between 6600 and 4000BP, and between 3000 and $230 \mathrm{BP}$. We assume that these dates do, in fact, represent the onset and termination of each period, and that no other depositional periods are present during the Qa2 through Qa4 periods. Gaps in the record, such as those between 7900 and $6000 \mathrm{BP}$, may result from several processes. They may reflect periods of erosion. They may reflect inadequate sampling. They may reflect periods of stability, though long-term stability would produce recognizable soils. Here, we will assume that gaps in the record are increasingly likely to reflect periods of stability, and contrast these periods with those reflected by deposition. However, consideration of Figure 9-1 suggests that not all periods of instability are equivalent, as at least five buried soils are present within the Qa4 profile suggesting some periods of stability within the depositional sequence. This issue is further complicated by patterns shown in Figure 9-2. Here,



Figure 9-1. Schematic drawing of Area 3 trench near 41TV410. Depositional Unit Qa4 shown in light brown. 




Figure 9-2. Depositional rates for Qa4, Qa3, and Qa2. 
we have calculated deposition rates for the Qa2 (bottom), Qa3 (middle), and Qa4 (top) sequences for the three profiles discussed in the previous paragraphs (L1, P5, and Figure 9-1). All three are presented at the same relative scale. The fastest depositional rate of $.166 \mathrm{~cm}$ per year is associated with the most recent period (Qa4), the same depositional sequence that has evidence for repeated periods of stability, conditions where we would expect low depositional rates. Conversely, the slowest rate $(.063 \mathrm{~cm}$ per year) is present in the Qa3 deposition, the onset of which is associated not with slow deposition, but with what appears to be extremely rapid deposition in the Early Archaic deposits, at least at 41TV540. During the onset of the Qa3 period, Frederick notes that 41TV540 was located on a point bar in close proximity to the active Onion Creek channel. This may explain in part the high rate of aggradation at this location. Clearly, however, the Figure 9-1 and 9-2 data and the rapid onset of deposition at 41TV540 show that aggregation and stability are more complicated than the simple dichotomy outlined previously. Radically different rates are present at different locations on the landscape, and rates are highly variable with periods of stability interspersed with periods of rapid deposition at the same location. The notion that these periods or aggradation would produce a highly variable environment and that periods of relative stability would produce a more mature resource structure may be true, but unambiguously defining these periods in sufficient detail through time and across the Onion Creek landscape given the current data sets will prove difficult.

An example of this potential difficulty is provided by Munson's (1984; see also Anderson 1952) study of a variety of flood disturbed areas along the central Illinois River, in Fulton County, Illinois. Munson (1984:379-380) identified four plant community zones associated with the river. The first zone, immediately adjacent to the water's edge, had sparse vegetation present because the surface was recently exposed by retreating flood waters. The second zone had a concentration of short, young plants since this zone had been exposed slightly longer. The third zone, at a slightly higher elevation, had taller and more mature plants and greater plant densities. Only the fourth zone, the highest and longest exposed, had permanent woody vegetation. If a similar spatial zonation was associated with Onion Creek, then where a given profile is located relative to the shifting location of the Creek is equally as important as when a given portion of that profile dates. A location that was adjacent to Onion Creek at $6000 \mathrm{BP}$, such as the Early Archaic occupation at 41TV540, will have a different pattern of inundation than a higher elevation location dating to the same time. Given the patterns in 9-1 and 9-2, any designation regarding periods of deposition and stability and associated resource structures in the Onion Creek data should be used with caution.

\section{Stable Carbon Isotopes and Vegetation Patterns}

The use of stable carbon isotope analyses for documenting changes in vegetation communities in response to climatic changes is well established (Nordt et al. 1994; Tieszen et al. 1979). Stable carbon isotope ratios from soil organic carbon can be used to infer vegetation changes in ecosystems over long periods of time (Jessup et al. 2003; Nordt et al. 2002). As noted previously, plants use one of three types of photosynthesis pathways. The majority of plant species use the $\mathrm{C}_{3}$ pathway. $\mathrm{C}_{3}$ plants are frequent in temperate zones and forest communities, with all trees, and many bushes and shrubs using this pathway. $\mathrm{C}_{4}$ and CAM species tend to occupy warm, arid or semi-arid environments (Long 1999). In Texas, $C_{4}$ plants are going to be primarily warm season grasses. CAM plants are primarily succulents (e.g., cactus). The $\delta^{13} \mathrm{C}$ isotopic signatures on organic matter produced by the decay of $\mathrm{C}_{3}, \mathrm{C}_{4}$, and CAM plants differ. While isotopic signatures for each pathway vary, the values produced by $\mathrm{C}_{4}$ plants center around $-12 \%$ with a range of -16 to $-9 \%$. Plants that use the $\mathrm{C}_{3}$ pathway average around $-26 \%$ and vary between -33 and -23\%o (Sharp 2007). In Central Texas, most CAM plants tend to mimic $\mathrm{C}_{4}$ value. Given these ranges, shifts in the carbon isotopic values of sediment in a profile can track changes in the vegetation that was present on a surface. We expect, then, that the stable carbon isotope signatures of samples derived from the stable surfaces, including the buried paleosols shown in Figure 9-1 for the Qa4 deposits, will reflect a vegetation community dominated by woody species that use a $\mathrm{C}_{3}$ pathway. Conversely, the stable carbon isotope signatures of the samples from aggrading zones will reflect more of a grassland community and have a more $\mathrm{C}_{4}$ signature.

As discussed in Chapter 8, sediment samples for stable carbon isotope analysis were collected from profiles associated with the three sequences (Qa2, Qa3, and Qa4) and specific profiles (L1, P5, and Area 3 at 41TV410) used here. The Qa2 and Qa3 depositional sequences were generally sampled in $10 \mathrm{~cm}$ increments. The Stable Isotope/Soil Biology Laboratory at the University of Georgia determined stable carbon isotopic values of the organic carbon for these samples. These values are reported in Appendix D. For the Qa4 profile, samples were collected in $50 \mathrm{~cm}$ increments. Coastal Science Labs in Austin analyzed the stable carbon isotopic values for these samples (see Appendix C).

Figure 9-3 presents isotopic results for Qa2 (bottom), Qa3 (middle), and Qa4 (top). The profile sections and temporal assignments are the same ones used in Figure 9-2. They do not represent complete profiles as in most cases some portion of the upper deposits have been ignored. For example, the upper $1.45 \mathrm{~m}$ of the Qa4 profile (see Figure 9-1) appears to 


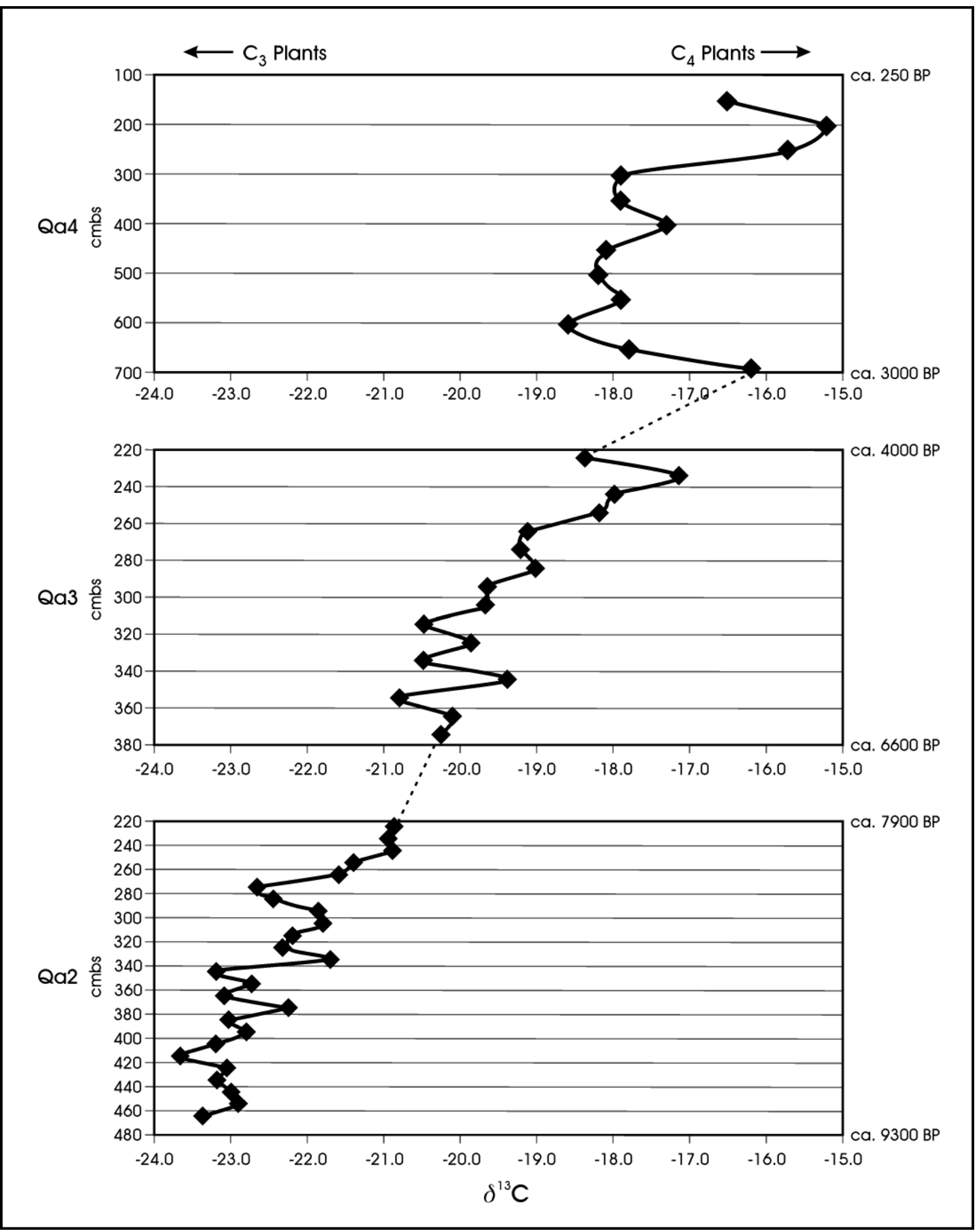

Figure 9-3. Stable carbon isotope results for dated sections of Qa2 through Qa4. 
represent later depositional events. In the previous chapter, Frederick plotted the carbon isotopic signatures derived from samples representing Qa1 through Qa5 in order to look at shifting contributions of $\mathrm{C}_{4}$ plants (see Figure 8-14). His plot included the Qa4 and Qa2 data used here, though he uses isotope data from profile P1 for the Qa3 rather than P5. Given that isotopic results from the lower three meters of P1 and P5 are significantly correlated $\left(\mathrm{R}^{2}=.847\right)$, this substitution should not significantly affect the interpretation. The primary difference between the two figures is in the decision we made regarding the elimination of the upper sections of specific profiles.

The overall pattern shown in Figure 9-3 is one in which an increasing component of the vegetation is $\mathrm{C}_{4}$ or CAM. There is, in fact, a roughly 7\%o shift from 9300 to 250 BP. While there are some short term fluctuations, overall the pattern shows a consistent decrease in the contribution of $\mathrm{C}_{3}$ plants that is independent of the specific depositional sequences. This is not the pattern anticipated, where $\mathrm{C}_{4}$ and CAM plants would dominate depositional sequences. Qa2 is strongly $\mathrm{C}_{3}$ in composition, as is the lower section of Qa3. The figure reveals a gradual shift to $\mathrm{C}_{4}$, which dominates the most recent period.

The Figure 9-3 data focuses only on periods that have been characterized as depositional. We lack data on stable periods following Qa2 and Qa3 for comparison with these depositional patterns. However, we do have samples from the Qa4 buried soils that can be contrasted with the depositional sequences at this same time (see Figure 9-1). Carbon isotopic values from six samples extracted from relatively more stable buried soils at approximate depths of 150, 200, 350, 400, 450, and 550 cmbs have a slightly stronger $\mathrm{C}_{4}$ signature when contrasted with six samples from more active periods. The carbon signatures associated with the stable soils average $-17.15 \%$ (range -15.2 to -18.1) while more active sediment zones have a slightly stronger $C_{3}$ signature with an average of $-17.4 \%$ (range -15.7 to -18.6). The stable carbon isotope values, then, do not pattern as anticipated. There is no obvious difference between the two groups. This could reflect problems with the identifications of the depositional and stable periods, problems with the stable isotope samples, problems with original assumptions, or some combination of all three.

\section{Analysis of Phytolith Samples from Qa4}

While we lack phytolith samples from other locations, the analysis of phytoliths extracted from sediments in the Qa4 depositional unit was designed to complement the relatively coarse-grained stable isotope data. As noted in Chapter 7 (see also Tomka et al. 2007), we anticipated that phytolith analysis could provide a more precise, species-specific, indicator of the composition of the vegetation communities (see Fredlund et al. 1998). We anticipated that phytolith assemblages from the paleosols would reflect a vegetation community dominated by woody species while grassland species would be most common in intermediary zones. In order to explore the potential of phytoliths, CAR submitted 15 samples, extracted at $50 \mathrm{~cm}$ intervals from the Qa4 profile near 41TV410 (Area 3, Figure 9-1) to Dr. Steve Bozarth, Department of Geography, at the University of Kansas for analysis. These were essentially subsamples of the carbon isotope samples discussed previously.

Bozarth and Woodburn present background, methods, and results of the analysis in Appendix F. They note that 15 different types of phytoliths were present in the samples, with good preservation in both biosilicates and particulate charcoal. A variety of grass phytoliths dominate the assemblages in all periods, with Chloridoids (short warm season grasses) generally dominating through out the seven meter section. There is little evidence of trees and shrubs (see Figure 2, Appendix F). Bozarth and Woodburn suggest that 10 different paleoenvironmental zones are present in the $7 \mathrm{~m}$ profile (see Appendix F). In general, it seems that phytolith assemblages that prefer relatively warm and dry conditions dominated the bottom 4 meters of deposits that are designated climate Zones A through E. Indices of temperature and aridity constructed by Bozarth and Woodburn (see Figure 3, Appendix F) show little change between 3.0 and 7.0 meters. Phytolith assemblages from the upper 3.0 meters are more variable, and, at least in some samples, suggest a cooler, moister regime. The major change, a dramatic cool, moist episode, is indicated by the phytolith data at $2.5 \mathrm{mbs}$ (climate Zone F). There is a dramatic increase in cool season grass phytoliths (Pooids), a decrease in charred phytoliths, and an absence of large particulate charcoal, which suggest that fires were less frequent as well. Subsequent periods seem to show a variable, gradual shift back to warm and dry conditions (see Figure 2 and Figure 3 in Appendix F).

In order to specifically consider vegetation shifts relative to geomorphic contexts as outlined in the research design, we used the data presented by Bozarth and Woodburn (see Figure 2, Appendix F) and focused on the 12 lower phytolith samples (150 to 700 cmbs; Figure 9-1). These 12 samples all fall within the Qa4 depositional sequence. Six of the 12 are from stable surface where we anticipated phytolith assemblages dominated by woody species. The remaining six samples are from depositional zones. We suggested that grassland species should be more common in these active settings. However, as there is little evidence for trees and shrubs at any point and as grass phytoliths dominate all of the depositional units, we can suggest that the proposed relationship is not supported. 
While the relationship between stability, aggradation, and shifts in frequencies of woody vegetation types is not supported by the phytolith data, we can use the percentages to further track shifts in $\mathrm{C}_{3}$ and $\mathrm{C}_{4}$ vegetation. Using the Figure 2 data in Appendix F, we combined warm season grass phytolith percentages (e.g., chloridoids, panicoids) to identify relative $\mathrm{C}_{4}$ grass contributions. Figure 9-4 shows the percentages of grass phytoliths that are potentially associated with the $\mathrm{C}_{4}$ pathway within the Qa4 deposits. Overall, $\mathrm{C}_{4}$ grass phytolith production is higher near the bottom of the profile, with a variable though gradual decrease from $700 \mathrm{cmbs}$ up through 300 cmbs. At $250 \mathrm{cmbs}$, there is a dramatic shift with $\mathrm{C}_{4}$ phytoliths dropping significantly. This is essentially the same shift identified as climate Zone F by Bozarth and Woodburn (see Figure 3, Appendix F) and reflects a relative increase in cool season grass phytoliths. Increased $\mathrm{C}_{4}$ is clearly present at the top of the Qa4 deposit.

Surprisingly, the overall trend shown in Figure 9-4 contrasts with the stable isotope values for this same profile (see Figure 9-3-Top). Carbon isotope values show an increase in $\mathrm{C}_{4}$ production through time, while the relative contribution of $\mathrm{C}_{4}$ grass phytolith data are decreasing. Figure 9-5 plots the two data sets. The two highest $\delta^{13} \mathrm{C}$ values, suggestive of higher $\mathrm{C}_{4}$ contributions, are both associated with low percentages of $\mathrm{C}_{4}$ phytolith production. The overall relationship is actually negative. If we remove these two highest $\delta^{13} \mathrm{C}$ cases, there is no relationship between $\mathrm{C}_{4}$ production and $\mathrm{C}_{4}$ phytoliths in the remaining 10 cases. Increased $\delta^{13} \mathrm{C}$ values should be associated with high $\mathrm{C}_{4}$ phytolith production. This is not the pattern shown in Figure 9-5. While CAM production might account for some of these differences, increasing the stable carbon isotope value without contributing to an increase in $\mathrm{C}_{4}$ grass phytoliths, the lack of patterning further calls into question the vegetation reconstructions.

\section{Analysis of Snail Assemblages from Qa4}

The final data set considered for this particular Qa4 deposit focuses on shifts in snail assemblages. Terrestrial snail populations, especially those in the smaller size ranges, are commonly thought to have narrow environmental tolerances (Clark 1969) and small home-ranges (Cook 2001; Lokke 1963). If accurate, these characteristics suggest that shifts in snail populations could be used to reconstruct paleoenvironmental conditions at small scales (Brown 1999, 2002, 2006). Following the extraction of phytolith and stable carbon isotope samples, we fine-screened all remaining sediment to recover all snails in a given matrix sample from the Qa4 profile (see Figure 9-1). The extracted snails were then submitted for gastropod analysis to Dr. Manuel Palacios-Fest of Terra Nostra Earth Science Research in Tucson, Arizona. As discussed in Chapter 7 (see also Tomka et al. 2007), we anticipated that snail assemblages from the paleosols within the Qa4 would consist of a mix of species tolerant of partial-shade and open-settings. We suggested that snail assemblages from the intervening zones would be dominated by species that prefer, or at least tolerate, opensettings characterized by grassland cover.

Palacios-Fest's analysis is presented in Appendix G. Unfortunately, the quantity of sediment that remained following the stable isotope and phytolith analysis was often

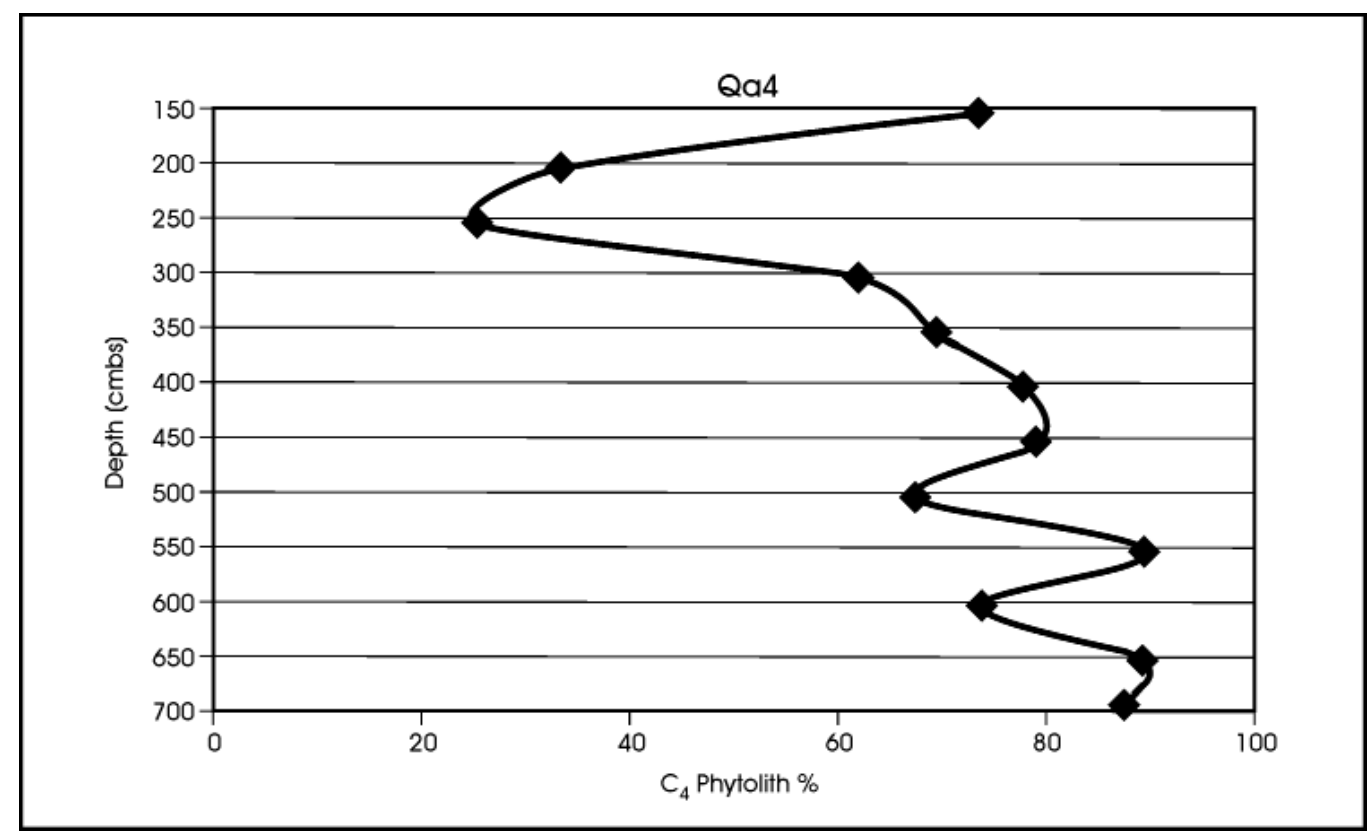

Figure 9-4. Changes in the percentage of $C_{4}$ phytoliths within the Qa4 profile. 


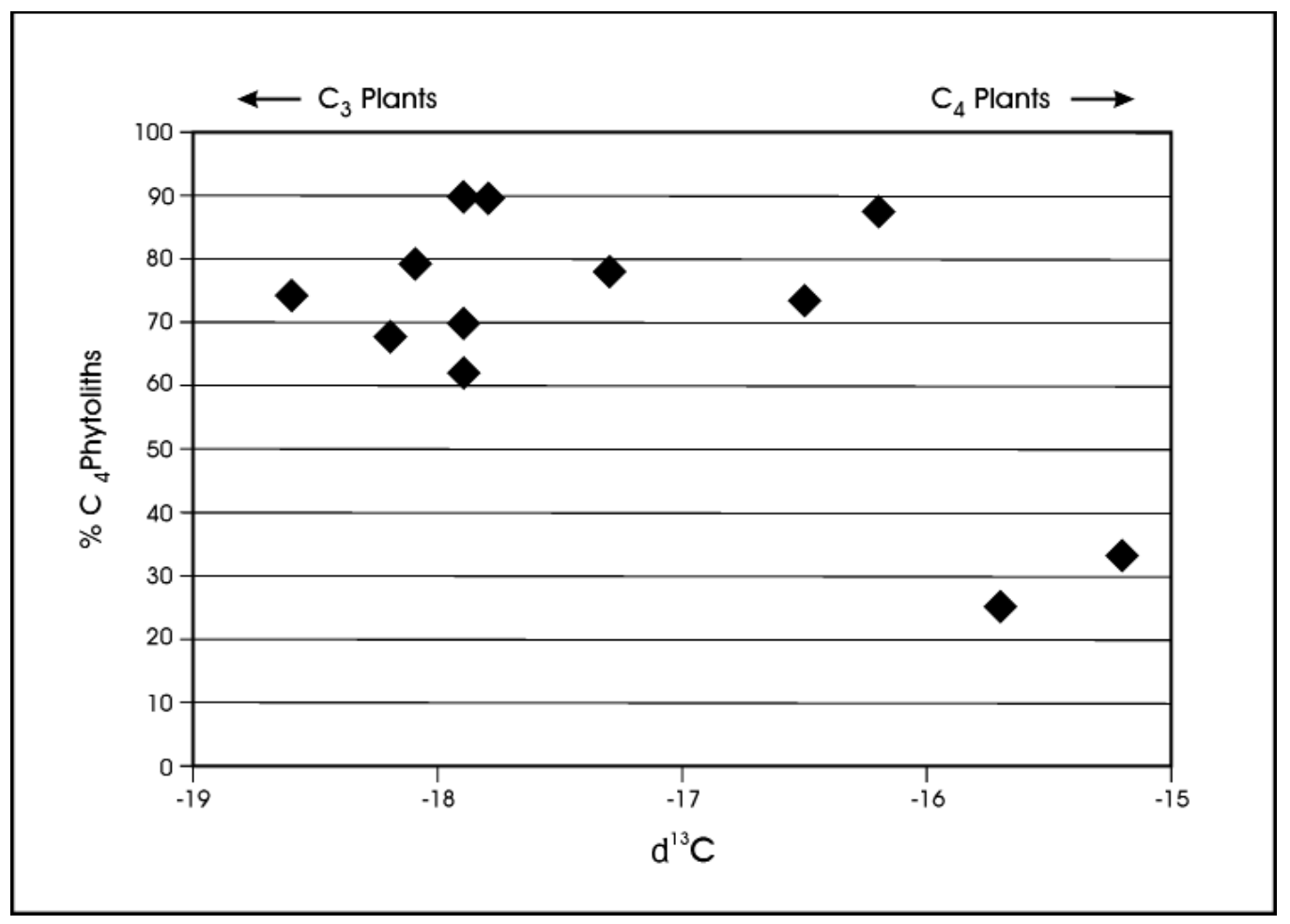

Figure 9-5. Scatter plot of the percentage of $C_{4}$ phytoliths and stable carbon isotope values within the Qa4 deposit.

quite small, as was the resulting samples of snail. For the 15 sediment samples extracted at $50 \mathrm{~cm}$ intervals between 0 and 700 cmbs (see Figure 9-1), we recovered only 148 snails, or an average sample of less than 10 individuals per location. It appears that no snails were recovered from samples processed at 700,550 , and $500 \mathrm{cmbs}$ and sample sizes of 10 or fewer snails were recovered from five other levels. The largest sample from any single provenience was only 31 snails. Note that these totals include 33 snails that were collected between 0 and $100 \mathrm{cmbs}$ that are above the Qa4 deposits. In addition, while Palacios-Fest recorded 10 different species in the 148 individuals from the entire profile, 100 specimens reflect only two species within the genus Rabdotus (Appendix G, Table 2 and Figure 1). Conclusions regarding habitat shifts in the snail assemblages in the Qa4 sequence are limited, then, in part by small sample sizes and limited snail diversity.

Palacios-Fest list the general environment and habitat preference for each of the 10 snail species recovered from the deposits (Table 1, Appendix G). Semi-arid, open settings referred to as "grassland environments" are preferred by two species representing 100 individuals. Twelve snails representing three species are listed as preferring moist, wet settings referred to as either a "riparian" or a "wetland" environment. Moist, "forest" settings are preferred by three species. Eight individual snails fall in this third group. Finally, two species represented by 28 individual snails, appear to have a wide range of habitat tolerances, or their preferences are not clear. These are irrelevant with regard to ecological reconstruction. The effective sample size for discussions of environmental conditions within the Qa4 portion of the profile, then, is 98 snails. We used the environmental preferences listed by Palacios-Fest for snail species (Table 1, Appendix G) and the individual species counts and amount of soil processed (Table 2, Appendix G) to constructed Figure 9-6. The figure shows the snails per liter of soil that prefer open, xeric conditions and those that prefer closed, mesic settings along the Qa4 deposits. Because of small sample size, the mesic group is a combination of the riparian/wetland species and the forest species, though the overall sample size before converting the counts to density per liter for this group was 19 snails. Also highlighted in the figure are those sample depths that were associated with buried soils.

Reference to Figure 9-6 show that the density of xeric snails is relatively low in the bottom 2 meters, with snails from this group only present in one of the five levels, at $600 \mathrm{cmbs}$, and at a relatively low density (ca. 7.8 per liter). However, the same pattern is also present for the mesic curve. Only a single level, again as $600 \mathrm{cmbs}$, has snails present and the density is slightly lower than that of the xeric curve. Rather than reflecting environmental preference for mesic or xeric conditions, these lower five levels, including the sample from the buried soil at $550 \mathrm{cmbs}$, simple do not have any snails. 


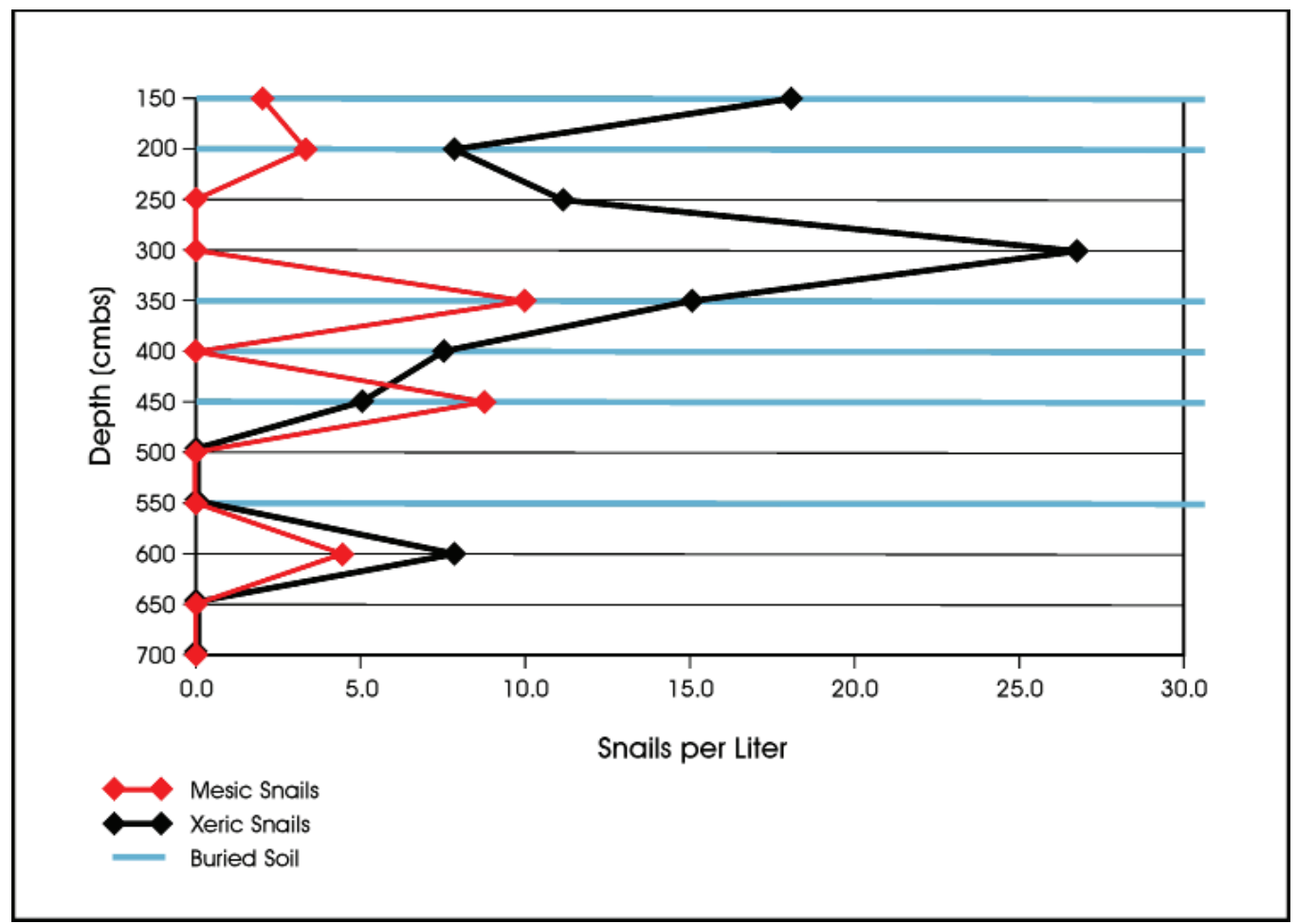

Figure 9-6. Shifts in the density of xeric and mesic snail groups in the Qa4 deposit. Levels with buried soils identified by blue lines.

Above 500 cmbs the xeric group density begins to steadily increase. Xeric density peaks at $300 \mathrm{cmbs}$ at 26.7 snails per liter of soil. This trend and peak suggests increasingly dry conditions. Interestingly, at this peak density there are no mesic snails present, though mesic species are absent from over half of the 12 levels considered. Xeric species then decline through $200 \mathrm{cmbs}$, but increase at the top of the Qa4 deposit. The pattern of increasing xeric snail density from 500 through $300 \mathrm{cmbs}$ includes three samples representing buried soils, settings that we expected to be dominated by snails that prefer mesic conditions. Contrary to expectations, the density of xeric snails is slightly higher under stable conditions (mean $=8.9$ snails per liter) than under aggradation conditions (mean $=7.6$ snails per liter). The mesic curve is difficult to interpret given the low numbers, but there does seem to be some correspondence in Figure 9-6 between buried soils and higher mesic snail density. In the six samples that come from buried soils, five have mesic snails present and the overall average is 4.02 mesic snails per liter. Mesic snails are present in only one of the six samples from depositional context, and the overall average is 0.73 snails per liter.

\section{Exploring Snail Habitat Preference}

There seems to be some interpretable patterning, then, in density shifts in mesic snails, though the sample sizes are alarmingly low. The xeric snail group, however, shows no such patterning. Figure 9-7 plots xeric and mesic snail densities for those Qa4 settings that have snails present. We would expect there to be a strong, negative relationship such that increased density in one group should correlate with decreased density in the other group. While there is a slight negative relationship, the coefficient of variation is only 0.096 and not significant. Figure 9-7 suggests that our understanding of the habitat conditions preferred by species of snails may be far from complete. This lack of understanding extends to species commonly found on archeological sites (e.g., Polygyra texasiana, Helicina orbiculata, various species of Rabdotus). A review of the literature suggests that there may, in fact, be significant overlap in the habitat conditions preferred by the these relatively common species (Cheatum and Fullington 1971a, 1971b; 1973; Fullington and Pratt 1974; Malof 2001:26-27; Randolph 1973).

As outlined in Chapter 7, to begin to construct a baseline of snail species habitat preference, and quantify the degree of habitat overlap between species, we proposed to collect snail population samples from three different vegetation settings that may be characteristic of the evolution of habitat conditions across a floodplain (see Tomka et al. 2007). Specifically, we suggested collection and assessment of snail samples from open grasslands, brushy woodland, and near climax forest settings. With the cooperation of the Lower Colorado River Authority (LCRA), personnel from CAR undertook that work 


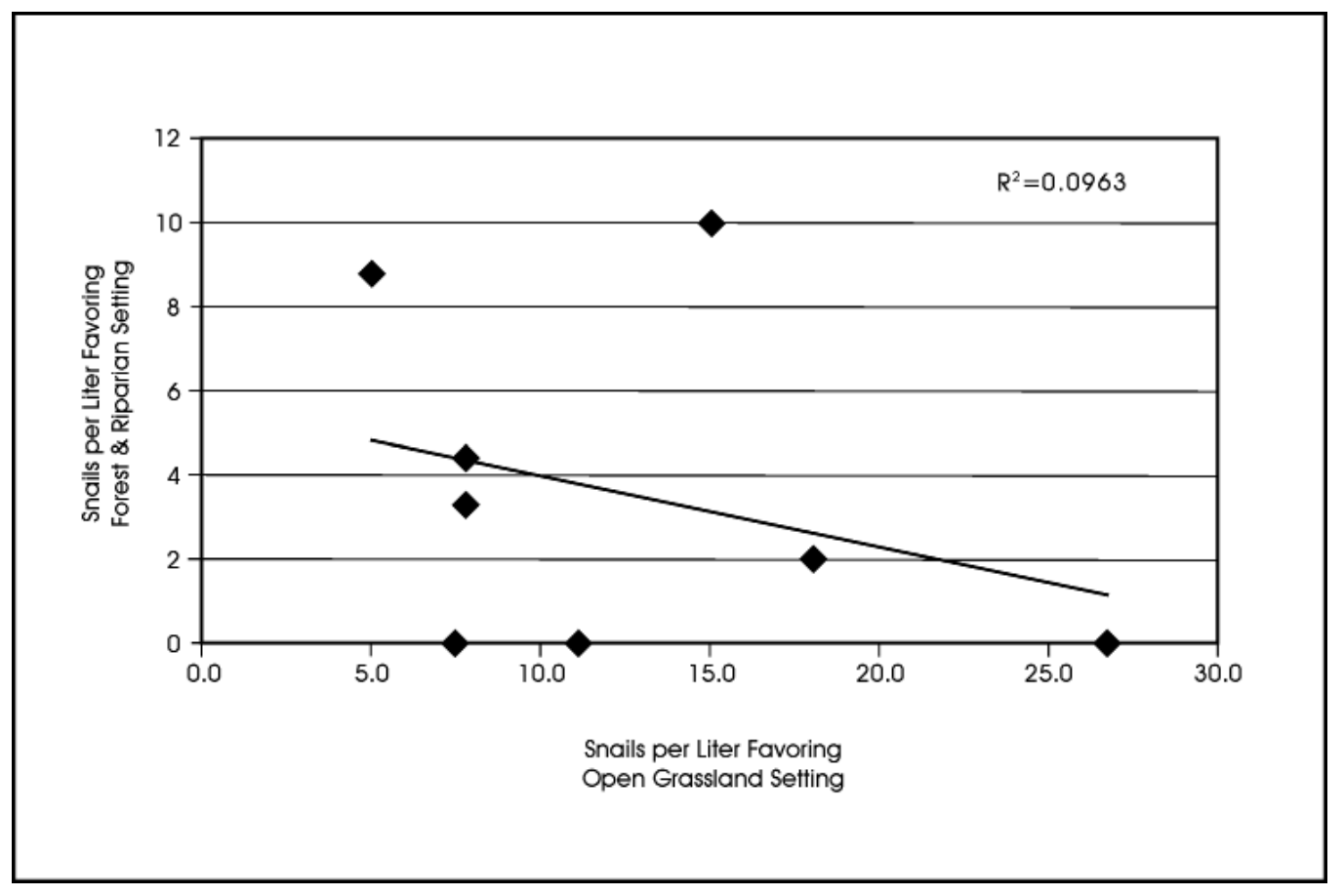

Figure 9-7. Scatter plot of the density of grassland favoring snails against those favoring forest and riparian settings within the Qa4 deposit.

in the spring of 2009 in McKinney Roughs Nature Park located in Bastrop County, Texas. The park consists of 1,110 acres along the Colorado River. CAR personnel sampled five different areas representing environments classified as brushy woodlands (mixed brush/midgrass vegetation), climax forest (dense woodland vegetation), and grassland (tallgrass-cottonwood savannah vegetation) communities. Surface collections of all observed snails were made by three individuals walking closely spaced transects in areas measuring roughly $30-x-30$ meters. In addition, we excavated a 1-x-1 meter unit to 5 cmbs in each locality and water-screened the recovered soil in order to sample micro-snails. Figueroa, Meissner, and Tomka present the methodology in Appendix H. The macro-snail assemblages (> $1 / 4$ inch) were analyzed for species composition, and characteristics of size and age were obtained for Rabdotus species to provide a natural baseline against which archeological material could be compared in the hope of identifying signatures of human predation. This work was done at CAR. The micro-snail portions of the collection were submitted for gastropod analysis to Manuel PalaciosFest of Earth Sciences Research in Tucson, Arizona (see Appendix I). While details on the methods and results for the macro and micro snails are presented in Appendices $\mathrm{H}$ and $\mathrm{I}$, we provide a short summary here focused on species distribution relative to habitat preference. The size and age distribution for Rabdotus, species diversity, and comparisons to the 41TV540, are discussed in Chapter 10 (see also Appendices J).
Overall, the brushy woodlands setting had the lowest snail density. In fact, three different areas were collected, as the number of snails for any given surface collection was so low. Similarly, the three 1-x-1 m test units excavated in the brushy woodlands (Areas 1, 2 and 3) failed to produce snail specimens in the macro-range. Overall, 393 snails were collected from the 2,700 square meters walked, a density of only 0.146 snails per square meter. Surface densities were highest in the climax forest (Area 4) setting with 1,271 snails, a density of 1.412 snails per meter. Densities within the grassland/ floodplain setting (Area 5) were roughly equivalent to that of the forest, with 1,255 snails in 900 square meters (1.39 snails per meter). Excavation in Area 4 produced 40 macro-snails, and Area 5 produced the highest excavation density with 374 snails recovered.

Table 9-1 presents the macro-snail surface density (snails per square meter) for four species by vegetation community using data in Appendices G, H, and I. Expected locations, derived from lists researched by Palacios-Fest (Appendix G, I) and based on habitat preference, are highlighted in blue. The actual highest densities are identified in red. Actual density follows expectations in only one of the four cases (Polygyra texasiana in the Brushy Woodlands). Even in that single case, the density figure of 0.012 in the brushy woodlands (31 snails in 2,700 meters) is virtually identical to the 0.011 density for Polygyra within the forest (10 snails in 900 meters). Table 9-2 list the micro-snail species identified in each of the three ecological settings by excavation at 
Table 9-1. Surface Expected and Actual Distributions of Macro-snails at McKinney Roughs

\begin{tabular}{|l|c|c|c|}
\hline \multicolumn{1}{|c|}{ Species } & $\begin{array}{c}\text { Area 3: Brushy } \\
\text { Woodland Density }\end{array}$ & $\begin{array}{c}\text { Area 4: Climax } \\
\text { Forest Density }\end{array}$ & $\begin{array}{c}\text { Area 5: Grassland- } \\
\text { Floodplain Density }\end{array}$ \\
\hline Rabdotus Sp. & 0.112 & 0.431 & 0.357 \\
\hline Mesodon thyroidus & 0.000 & 0.173 & 0.207 \\
\hline Mesodon zaletus & 0.008 & 0.049 & 0.101 \\
\hline Polygyra texasiana & 0.012 & 0.011 & 0.000 \\
\hline
\end{tabular}

* The expected habitat cell is shaded in blue. Highest densities are identified in red.

Table 9-2. Comparison of Expected and Actual Distributions of Micro-snails at McKinney Roughs

\begin{tabular}{|l|c|c|c|}
\hline \multicolumn{1}{|c|}{ Species } & $\begin{array}{c}\text { Area 3: Brushy } \\
\text { Woodland \# }\end{array}$ & $\begin{array}{c}\text { Area 4: Climax } \\
\text { Forest \# }\end{array}$ & $\begin{array}{c}\text { Area 5: Open } \\
\text { Grassland- } \\
\text { Floodplain \# }\end{array}$ \\
\hline Gastrocopta cristata & 3 & 4 & 14 \\
\hline Rabdotus mooreanus & 9 & 26 & 120 \\
\hline Euconulus chersinus & 0 & 3 & 0 \\
\hline Hawaiia minuscula & 8 & 7 & 13 \\
\hline Mesomphix inornatus & 33 & 77 & 244 \\
\hline Mesodon thyroidus & 2 & 0 & 32 \\
\hline Polygyra texasiana & 1 & 28 & 14 \\
\hline
\end{tabular}

* Expected habitat cell is shaded in blue. Highest counts are identified in red.

McKinney Roughs. All three areas represent a single 1-x-1 $\mathrm{m}$ excavation down to $5 \mathrm{cmbs}$. As with the previous table, when a habitat preference was identified by PalaciosFest, we highlighted that cell in blue and the highest snail density represented by a given species is listed in red. In only 2 of the 7 cases is the actual distribution consistent with the expected ecological setting (see Table 9-2). The first of these is Rabdotus mooreanus, which has its highest density within the expected open grassland habitat. Note, however, that the species also occurs in the climax forest and brushy woodland settings. The second species with a correspondence between expected and actual distribution is Euconulus chersinus. All three mico-snails were recovered from the expected forest setting.

Given these results, we clearly do not understand snail habitat tolerances, or the tolerances are at such a scale that they are irrelevant for the scale of environmental reconstruction commonly undertaken using snail populations in Texas archeology. Using parameters suggested in the literature, in only three out of 11 cases (27.3\%) were the highest densities for a given species associated with their "preferred" habitat. One of those correct assignments, the association of Rabdotus with open, grassland settings, works at the macro-level but not at the micro-level. The movement of two Polygyra snails from their preferred location in the brushy woodlands (Area 3) to the forest (Area 4) would eliminate one of the remaining correct assignments, and the final case is based on a total sample of three micro-snails. The lack of patterning is such that it calls into question the interpretations made previously based on "mesic" and "xeric" snails in Figure 9-7, especially given the small sample sizes. Aspects of these issue are subsequently addressed in Appendix $\mathrm{J}$, which presents a protocol related to snail analysis in archeology, and in discussions on features at 41 TV540 (Chapter 10).

\section{Analysis of Macrobotanical Samples Obtained from Deposits at 41 TV540 and 41TV410.}

The final environmental indicator involves the identification of charcoal from dated deposits at 41TV540 and 41TV410. As discussed in Chapter 7 (see also Tomka et al.2007), the analysis of macrobotanical samples derived from the flotation of feature fill, as well as samples collected from dated contexts outside of features, may provide direct information on vegetation species that were available and used as fuel in thermal features. In order to investigate this possibility, CAR submitted 76 macrobotanical samples for botanical analysis from selected, dated features and other dated contexts from 41TV410 and 41TV540 to Dr. Phil Dering. Our primary interest, at least in the present context, was to document the types of wood used, and look for changes in the wood types through time.

The results of his analysis are presented in Appendix A. At 41TV540, recovery from flotation was good, and 37 samples were identified to some taxonomic level. Dering documented a variety of wood types and several bulbs (cf. onion) that were present between about 6200 and about 5950 BP. Wood types included black walnut, elm, oak, cherry/plum-type, and willow/cottonwoodtype. Oak was the most widespread of the wood types, occurring in $24.6 \%$ of the samples and the most abundant, totaling 1.7 grams. Unfortunately, recovery from 41 TV410 was minimal. Only a single sample recovered from Feature 19 was identified. This feature, which dates to between 5580 and 5320 BP or roughly 500 years later than the 41TV540 deposits, had oak recovered.

Frederick observed that during the terminal Early Archaic occupation of 41TV540, the site may have been located adjacent to a past location of Onion Creek. Consistent with these observations, the wood taxa recovered from the terminal Early Archaic deposits at 41TV540 are typical of a riparian vegetation regime. The application of these 41TV540 data, 
then, beyond the immediate site area, is unclear. However, note that comparative ethnobotanical data are available from site 41TV2125. Campbell et al. (2009:112-114) provide a summary of recovery associated with features dating to around $9100 \mathrm{BP}$, roughly 3,000 years earlier than the 41TV540 deposits. Interestingly, the list of fuel woods from 41TV2125 is almost identical to that for 41TV540. Charred wood includes black walnut, elm, oak, and willow/cottonwood, with oak being the most common type. Only cherry/plum-type wood is missing from the list. Like 41TV540, site 41TV2125 also had bulbs recovered. If wood carbonized and recovered from features reflects the general vegetation community, then both 41TV2125 and 41TV540 exploited similar vegetation settings.

\section{Summary}

The reconstruction of resource structure was to be built, in part, on information supplied by the completion of the geomorphological descriptions by Frederick. Based on that work, presented in the previous chapter, we identified periods of aggradation and stability in the Onion Creek area. We argued that aggradation intervals would have been dynamic, characterized by frequent flooding, variable rates of floodplain aggradation, and stream migration. Under these conditions, habitats for vegetation would have been frequently disturbed and somewhat unpredictable. In contrast, as the landscape matured and the stream begins to down cut, the vegetation communities present on the floodplain will begin to shift to woodland dominated species. This may culminate in the establishment of climax-like plant and associated animal communities that would encourage longer term human occupation.

We investigated a variety of different data sets in order to reconstruct the paleoenvironmental conditions, including the use of stable isotopes, phytoliths, shifts in snail populations, and macrobotanical analysis of charcoal from dated archeological deposits. While stable carbon isotope data were available for the period of interest, the pattern suggested by this material was of a long term change from a $\mathrm{C}_{3}$ dominated setting to a $\mathrm{C}_{4}$ dominated setting. The expected pattern of oscillations in vegetation related to depositional conditions was not supported. In addition, the detailed snail and phytolith data were only obtained from a single profile adjacent to 41TV410. Using corrections suggested by Frederick in the previous chapter, those deposits date within the last 3,000 years, roughly 3,000 years later than the archeological deposits at 41TV540. Nevertheless, focusing on the last 3,000 year, the patterns suggested by the phytolith data contradict those suggested by the stable carbon isotopes in the same profile. Interpretations of the snail population data was hampered by both small sample sizes and minimal understanding of snail habitat preferences. Only the macrobotanical data from 41TV540 provided any solid information on the environment.
The utility of these data, however, was limited by a lack of comparative information at 41TV410. Ethnobotanical data from features at 41TV2125 (Campbell et al. 2009) show virtually the same range of wood types even though the site dates roughly 3,000 years earlier than most of $41 \mathrm{TV} 540$. The variety of taxa at both 41TV540 and 41TV2125 seems to reflect a riparian setting. For 41TV540, this is consistent with observations by Frederick regarding proximity of the site to Onion Creek. The site level data in this case may simply reflect location relative to Onion Creek rather than the more general vegetation conditions within the entire Lower Onion Creek Valley.

Clearly, the results of the paleoenvironmental analysis are disappointing. As demonstrated by Frederick in the previous chapter, the bulk sediment samples that were used to date much of the material discussed in this chapters are consistently 900 to 1,500 years older than dates on charcoal from comparable locations. This suggests that the dated sediment samples were mixed, with varying quantities of older ${ }^{14} \mathrm{C}$ being incorporated into the deposit. This observation is consistent with several snail shell dates that are too old and out of stratigraphic sequence even after correcting for possible carbonate absorption. In fact, as Frederick notes in the previous chapter, when paired adjusted snail shell dates are compared to adjusted sediment dates and charcoal dates, only $40 \%$ of the shell dates are within expectations. The stable carbon isotope values, snail populations, and phytolith samples are all derived from the same sediment packages as the old ${ }^{14} \mathrm{C}$ dates. This observation alone should be sufficient to call into question the validity of any interpretations based on these data sets. As sediment associated with overbank flooding appear to be the primary source for deposition, it is reasonable to assume that the deposits of sediment brought in by flooding would also have contained, to varying degrees, phytoliths, snails, and carbon that were eroded, suspended, and eventually re-deposited, producing a mixed deposit.

Finally, note that many of the research issues discussed under the third research objective, which centered on the terminal Early Archaic deposits at 41TV540, were phrased as contrasting expectations under conditions of geomorphic stability and a mature plant and animal community relative to conditions that were more dynamic in both deposition and resources. At first glance, the failure of the second research objective would seem to undermine aspects of the third objective. However, we were able to conduct most of the detailed analysis outlined under this third objective in the following chapter, though we obviously have no contrasts between periods that were dynamic relative to those that were stable. In addition, note that many of the contrasts phrased in the research design also relied on comparisons of the 41TV540 pattern with other Onion Creek assemblages. As we have minimal comparative material from other archeological assemblages in the area, these comparisons were, in general, not conducted. 


\title{
Chapter 10: Site Use and Function at 41TV540
}

\author{
Raymond Mauldin, Antonia Figueroa, and Steven Tomka
}

This chapter considers the final research objective discussed in Chapter 7 which focused on determining aspects of site use and function at 41TV540 (see also Tomka et al. 2007). We argued previously that the range of activities carried out at a site is related, in part, to the site's role within the overall land use system, the length of occupation, and the level and nature of reoccupation (see Shott 1989; Smith and McNess 1999). In defining site use, our goal was to determine the range of activities carried out at 41TV540 during the end of the Early Archaic. Site function, or the role that $41 T V 540$ played within the regional land use system, is concerned more with questions of mobility and occupation length. The analysis suggested for these issues centered more on diversity measures, including diversity in floral and faunal remains. These studies primarily relied on placing 41TV540 into a broader, comparative framework. However, given the minimal comparative data available, these studies were curtailed.

\section{Investigating Site Use at 41TV540}

Aspects of site use are potentially manifested in a variety of data types. For the terminal Early Archaic deposits at 41TV540, these data types include elements of features, lithic tools, and chipped stone debitage. This section discusses aspects of each of these data types in an attempt to identify some of the activities carried out at 41TV540 between 6200 and $5900 \mathrm{BP}$.

\section{Features}

As reviewed in Chapter 6, there may be two different types of features present in the terminal Early Archaic deposits at 41TV540 (see Table 6-2). Some features (e.g., Feature 27/29) appear to be the remains of hearths probably used for cooking various foods. A second group, represented by Features 13, 14, and possibly Feature 11, are large, amorphous scatters defined by concentrations of primarily unbroken snail shell, dominated by Rabdotus, and variable frequencies of burned rock and charcoal within an oxidized matrix. In this section, we consider two aspects of the 41TV540 features.

The first aspect involves an evaluation of the relationship between feature reuse and rock size. We designed and carried out a series of heating experiments that, among other things, monitored changes in temperature parameters as rock size changed with feature reuse (see Appendix K).
We then used these parameters to consider changes in rock size at the feature level on 41TV540. Surprisingly, rocks in feature contexts at 41TV540 are small and highly fractured. While this pattern is consistent with extensive feature reuse, and is very different from that shown for selected features reviewed at $41 \mathrm{TV} 410$ where minimal use is suggested, chert and quartzite make up about $50 \%$ of all feature rock at 41TV540. Chert, and to a lesser degree, quartzite, tend to explode when rapidly heated, resulting in extensive shatter and small overall rock size. As discussed subsequently, the pattern of small rock size at 41TV540 may be due, in part, to raw material access differences rather than feature reuse.

The second aspect of features investigated here involves the recovery of large quantities of Rabdotus snails in Features 13 and 14. Similar snail concentrations may have been present in Feature 11, but this feature was not sampled by the CAR excavation. Our primary concern in this second aspect is determining if these snail concentrations reflect the use of Rabdotus for food, or if they are secondary accumulations reflecting natural populations. Methods for investigating this question are limited, in part, by our primary dependence on $1 / 4$ inch screens in the field for most contexts and the resulting lack of snails below that size range. We also lacked off-site comparative material. These, along with several other concerns, resulted in the production of a protocol (Appendix $\mathrm{J}$ ) that outlines recommendations for collection and analysis of snail remains in future archeological investigations. However, in spite of the lack of consistently acquired smaller size fraction in our archeological snail samples, we were able to look at several elements to investigate the snail deposits at the site. Most of these involved comparisons between Features 13 and 14, and collections from other features as well as comparisons with snails collected from non-feature deposits at 41TV540. These included consideration of the percentage of Rabdotus snail size fractions, comparisons of species diversity, and limited investigations of amino acid racemization rates as a possible indicator of snail processing. We are not able to conclude that snails in Features 13 and 14 are related to human consumption. The overall weight of the evidence suggests that the accumulations are probably natural rather than cultural in origin, though several interpretations are possible. Note that TxDOT archeologists disagree with this conclusion (see Appendix O). They suggest that there is not sufficient information to make a determination regarding these features. 


\section{Feature Reuse and Rock Size}

Several researchers have suggested a relationship between patterns in rock size and the frequency with which features are reused (see Black et al. 1997; Johnson 2000; Mauldin et al. 1998; Mauldin et al. 2009; Pagoulatos 2005). There are several primary assumptions underlining this proposed relationship (see discussions in Black 2003; Black and Creel 1997; Ellis 1997; Leach et al. 2001; Thoms 2009). One of the key assumptions is that people primarily add rock to hearths in order to control temperature and patterns of heat dissipation. We also assume that as rocks are repeatedly heated and cooled through feature reuse, some proportion of those rocks will fracture, increasing the surface area exposed and reducing the capacity of individual rocks, and by extension the feature, to hold heat. Scavenging of rock, hearth maintenance and clean-out, different rock type characteristics, and the possible addition of new rock as feature efficiency declines complicate interpretations of feature rock size distributions. However, increasing frequency of rock feature reuse should, if these assumptions are correct, result in increasing fragmentation with a higher percentage of rocks falling in the smaller size ranges.

In order to investigate these proposed relationships, CAR undertook a series of experiments using limestone and quartzite cobbles collected primarily from Onion Creek. Our goals were to document and quantify trends in rock fracturing with repeated cycles of heating and cooling, and to investigate the impact of rock type, surface area, and size and density on patterns of heating and heat dissipation. These included both the construction, firing, and monitoring of experimental hearth features as well as controlled heating of rock in the CAR laboratory. While we summarize critical elements of the experiments here, and while aspects of the data are used in comparisons below, details of the experiments, as well as the raw data and more detailed discussions of the results, are presented in Appendix K.

Under laboratory conditions, we initially measured the surface area of a single cobble of Onion Creek limestone. We then heated that cobble to $200^{\circ} \mathrm{C}$ for 1 hour. We removed the cobble, and placed it into a controlled setting where we monitored changes in air temperature at 1 minute intervals. The cobble was then broken, the surface area recalculated, and the process repeated. The weight of the sample, then, was constant but the surface area increased with breakage. We conducted similar runs on an Onion Creek quartzite cobble. For both the Onion Creek limestone and quartzite cobbles, with weight held constant, smaller surface areas dissipate heat more slowly and maintain heat for a longer period of time. Conversely, when surface area increases, as rocks fracture, heat dissipates more quickly (see Appendix
$\mathrm{K}$ ). Without replacement, then, repeated burnings of the same rock-laden feature under the same conditions (i.e., ambient temperature, wood quantity and type) should produce hotter effective cooking temperatures early on, as heat is more quickly dissipated by larger surface areas as rocks fracture. In addition, as the heat stored in rocks is dissipated early, this should result in a more rapid temperature fall-off.

These suggested impacts of changing surface area, breakage, and temperature changes are derived from controlled experiments on individual rocks. We began to investigate these patterns at the feature level by focusing on five limestone cobbles collected from Onion Creek near site 41TV410. We recorded the maximum size of each rock, and then placed all five in a feature with 20 wooden survey stakes of a standard size. These were ignited and allowed to burn down. After cooling for 24 hours, we removed and again measured the maximum size of the rock. This process was repeated seven times. We attempted to measure temperature changes by suspending a thermocouple over the hearth once the fire had subsided. While this produced variable temperature measurements, and ultimately resulted in the destruction of the thermocouple during event seven, we do have consistent temperature measurements from the period between 1 and 3 hours following the initiation of the first six events (see Appendix K).

Figure 10-1 contrasts mean feature rock size by average temperature for these six events (see Appendix $\mathrm{K}$ for data and details). Focusing first on the rock size, note that overall, the mean limestone rock size declines with increasing use. No breakage occurred between event 1 and 2, but following event 2 there is a steady decrease in average size. At the feature level, the weight of the rock, however, remained the same, but as breakage occurred, the overall surface area increased. As can be seen along the $\mathrm{X}$-axis, this increase in surface area had an impact on heat dissipation, with a drop of just over $9^{\circ} \mathrm{C}$ between event 1 and event 6 . Breakage increased through time, resulting in increased surface area and decreased average temperatures, at least over the period between 1 and 3 hours following the initial firing.

The experiments above demonstrate that with increased use, increased rock breakage occurs and that breakage appears to result in a reduction of the thermal efficiency of features. The final set of experiments focused on repeated feature burnings using quantities of Onion Creek limestone and quartzite that were analogous to those observed in the archeological record. While temperature data was monitored (see Appendix K), our concern here is with patterns in rock breakage. Prior to the initial burn, the maximum size of 23 cobbles of Onion Creek limestone and quartzite was recorded. We then subjected these cobbles to seven burns, with the rocks removed and measured following burns three, five, and seven. Note that 


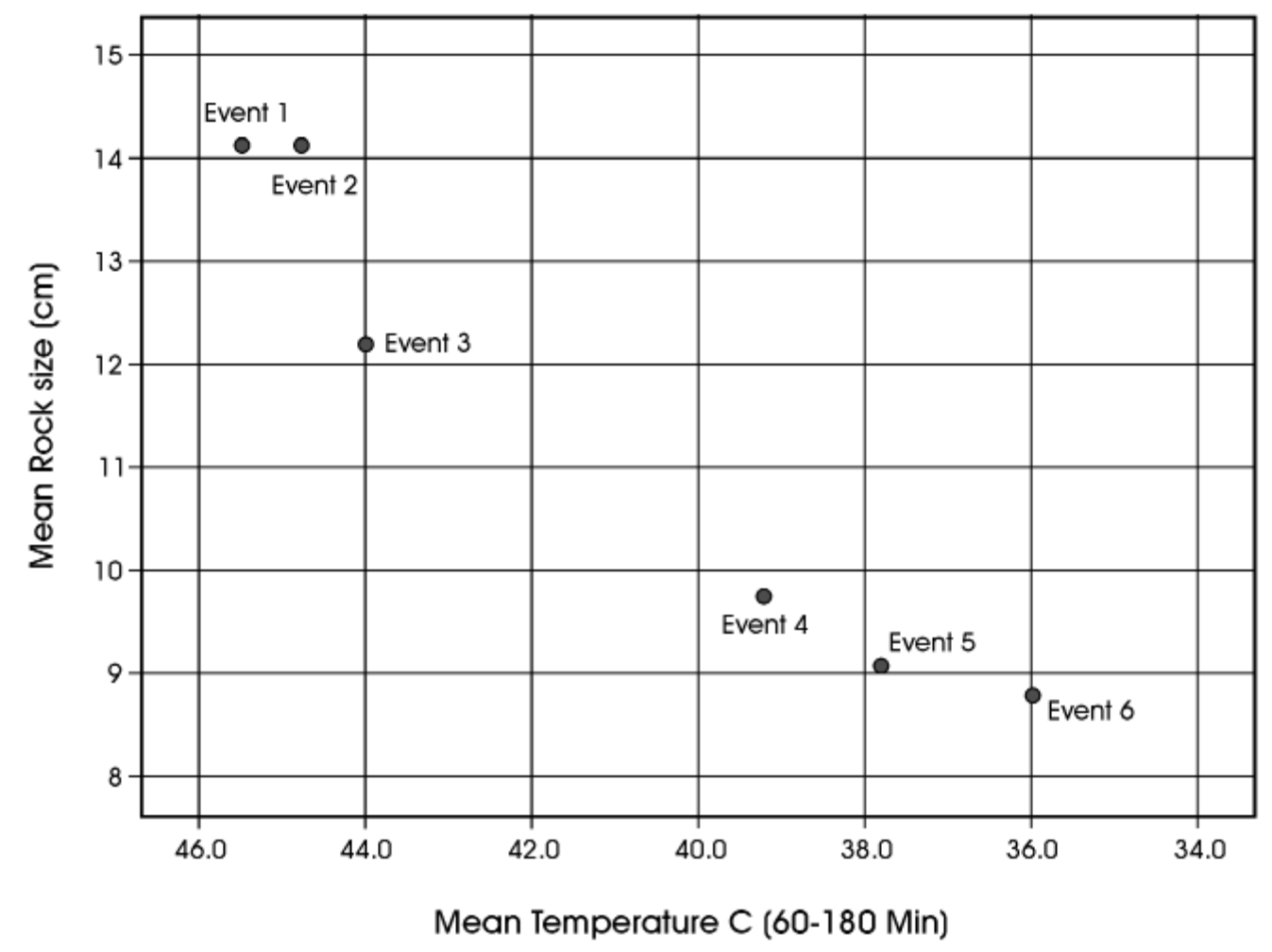

Figure 10-1. Mean rock size and hearth temperature for repeated burning events (1-6) of the same weight of Onion Creek Limestone.

only those fragments greater than 1 inch $(2.54 \mathrm{~cm})$ were recorded. Figure 10-2 presents the initial size distribution in 1 $\mathrm{cm}$ intervals, along with the patterns after burn three, five, and seven. Prior to any burning, the 23 items averaged $14.83 \mathrm{~cm}$ in maximum size, with a mode of $14 \mathrm{~cm}$. There were no items less than $10 \mathrm{~cm}$ in maximum size (Figure 10-2, Unburned). With each successive firing some rocks fracture, resulting in a decline in the average rock length, (terminating at 7.88 $\mathrm{cm}$ ), and increase in the number of rocks present (from 23 to 77), and shifts in their overall size distribution (see Figure 10-2). Following the third burn, for examples, there are 50 rocks, with $32 \%$ being less than $5 \mathrm{~cm}$ in maximum size, and $18 \%$ greater than $15 \mathrm{~cm}$ in maximum size. By the seventh burn, 30 of the 77 items (39\%) are below $5 \mathrm{~cm}$, and items greater than $15 \mathrm{~cm}$ accounts for $9 \%(n=7)$ of the feature (see also Appendix K). Increasing use does result in increasing fragmentation in this experimental case.

However, in an archeological case, several elements will complicate any direct use of the Figure 10-2 patterns for interpretation. Even if we assume that the initial firing of a prehistoric feature used a similar mix and size range of limestone and quartzite, and that feature clean-out is minimal, it is likely, given thermal shifts with increasing breakage, that prehistoric hunter-gatherers would add larger rock to the feature following the initial few burns to maintain thermal characteristic. This would change, somewhat, the patterns seen in Figure 10-2. The percentage of items in the larger size range would increase with this addition, and we might expect multiple modes as lager rocks are incorporated at various points in time. However, the rate of breakage shown in Figure 10-2 is likely to be such that the smaller size fraction will still increase faster than the addition of new rock. It is also the case that any interpretation of breakage patterns will be complicated by time and exposure patterns. That is, over several thousand years of exposure to temperature variations, rainfall, and wind, it is likely that small fractures, present in many of the rocks following burn seven, would break, again resulting in a different pattern then the one seen here. Furthermore, it is likely that these postabandonment breakage patterns would be higher in features that are exposed relative to those that are quickly buried. 


\section{Onion Creek Limestone and Quartzite}

Unburned

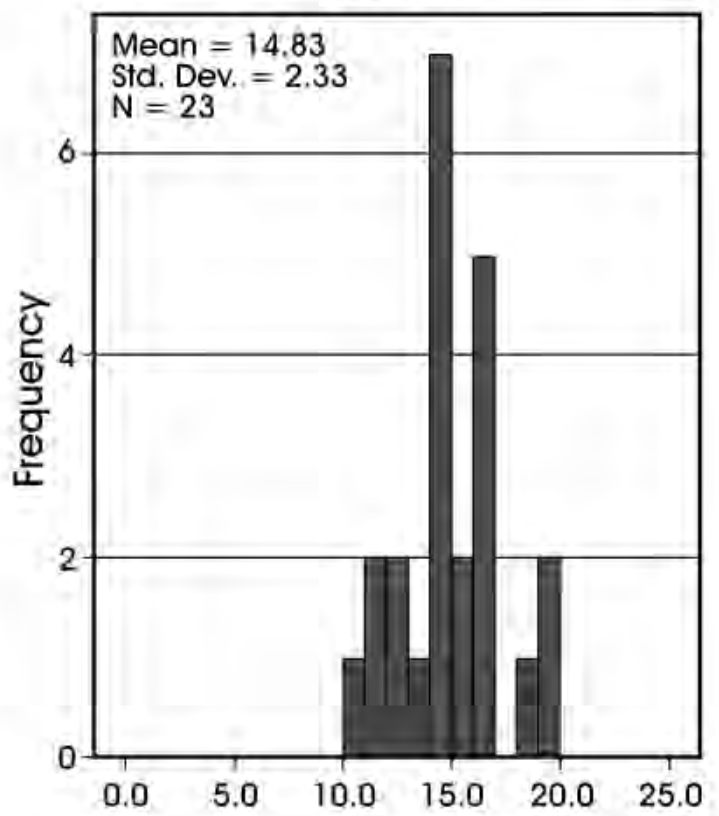

After 3 Burns

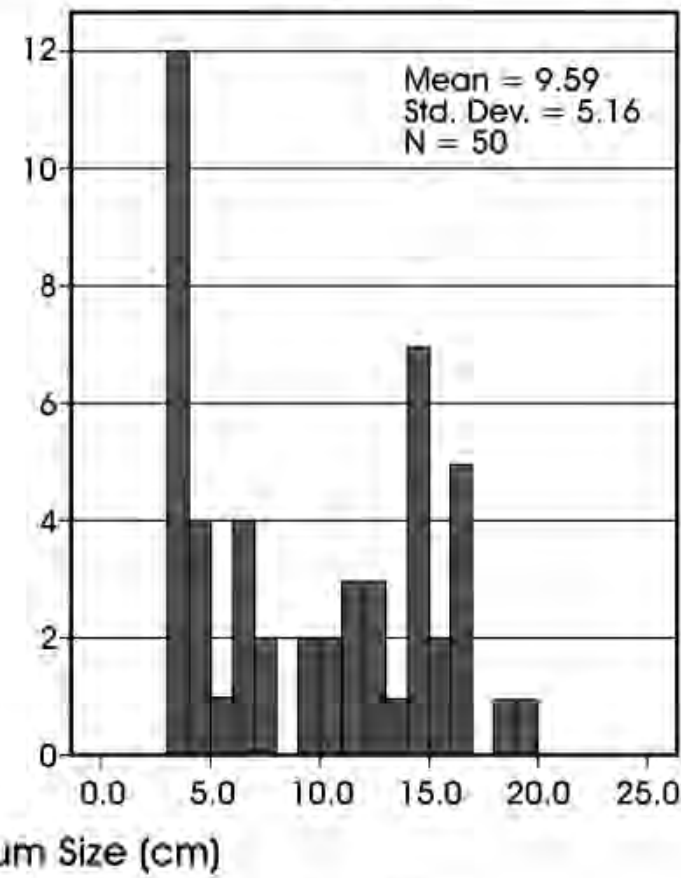

After 7 Burns

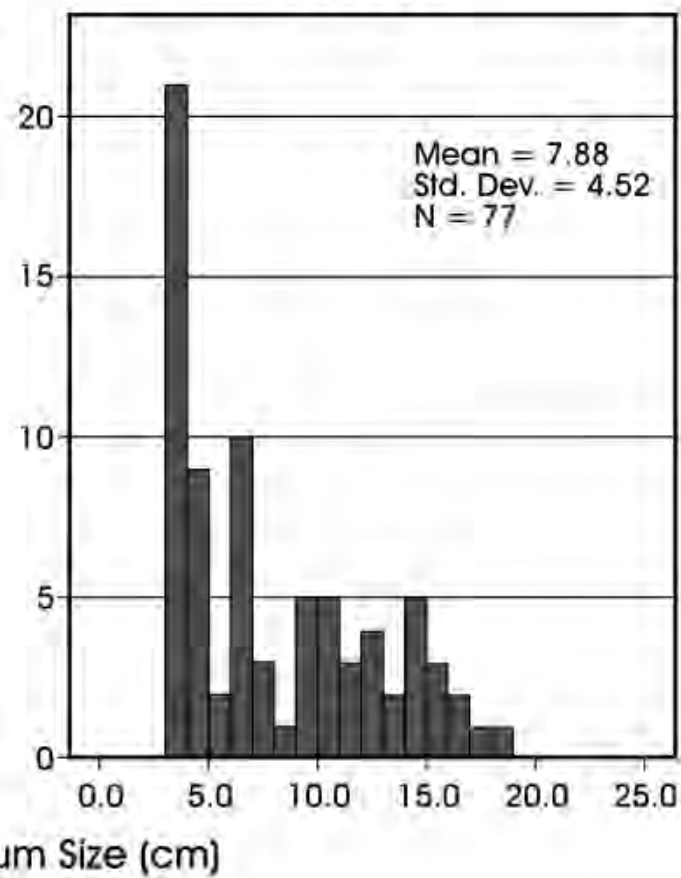

Figure 10-2. Changes in Onion Creek Limestone and Quartzite size with repeated feature use (see Appendix K). 
While we cannot use the Figure 10-2 patterns, then, to quantitatively determine the number of events represented by an archeological feature, they do provide a general, more qualitative measure of reuse patterns. For example, Figure 10-3 contrasts the maximum rock size distribution patterns for Feature 11, a probable Late Archaic limestone and quartzite dominated feature at 41TV410 (Figure 10-3, top), with the pattern for the unburned Onion Creek limestone and quartzite (Figure 10-3, bottom) shown previously in Figure 10-2. While the 47 rocks from Feature 11 are certainly smaller than the unburned distribution, rocks greater than 10 $\mathrm{cm}$ in maximum size dominate the Feature 11 distribution and the contribution of items less than $5 \mathrm{~cm}$ is minimal. These characteristics suggest a low frequency of reuse for Feature 11. In contrast, Figure 10-4 presents a similar comparison for limestone and quartzite dominated Middle Archaic Feature 19 (top) from 41TV410. The unburned limestone and quartzite distribution pattern is included (10-4, bottom) for reference. The Feature 19 data has 431 pieces of rock, with only about $15 \%$ larger than $10 \mathrm{~cm}$, and less than $1 \%$ larger than $15 \mathrm{~cm}$. Thirty-four percent of the rocks are below $5 \mathrm{~cm}$ in length, and multiple, well defined modes are present. The 41TV410 Feature 19 data, then, clearly has a substantially higher frequency of reuse than shown by the Feature 11 data from the same site.

\section{Patterning in Feature Rock Use at 41 TV540}

In order to investigate patterns of feature reuse at the probable terminal Early Archaic occupation of 41TV540, we gathered data from each of the temporally assigned excavated features at the site. We recorded raw material type, weight, and maximum size for 292 items from 11 different features. Only those items that would not pass through a 1-inch mesh screen were included in the analysis. Table 10-1 presents the features, total number of items present, total weight of rock, and breakdown of number of rock by type for limestone, quartzite, chert, and conglomerate. In addition to the raw material types listed in the table, a single piece of basalt was recorded.

As shown in Table 10-1, several of the features have both low rock counts and low rock weight that may indicate that rock was not a major component of the features, or was incorporated in the feature as a secondary deposit. These low count and low weight features include Features 7, 17, 18 and 26 , with an average of only 6.5 rocks that weigh 416 grams. In contrast, two features, Feature 13 and Feature 27/29, contain $61 \%$ of all rock and $52.5 \%$ of all rock weight. These features average 89.5 pieces of burned rock with an average feature weight of $5.853 \mathrm{~kg}$. This is surprising as Feature 13 probably does not represent a hearth or oven, being an amorphous stain spread over several meters. While the feature did have small amounts of charcoal present and pockets of oxidized soil, the dominant characteristic was the concentration of Rabdotus shell. Yet, this feature contained 38\% of all burned rock recorded in the terminal Early Archaic occupation at the site. In part, this dominance of burned rock may be related to the feature size, as Feature 13 material was collected from several levels of four 1-x-1 m units within Block 3. But, the relative dominance is also related to the surprisingly small quantities of burned rock present in other features at the site. For example, Feature 19 at 41TV410 (Figure 10-4, top) had 431 pieces of burned rock, about 1.5 times as much as all 11 features shown in Table 10-1 at 41TV540.

An additional consideration is that several other features listed in Table 10-1 have high concentrations of chert (e.g., Feature 18, 27/29). In fact, chert makes up $24.4 \%$ of all feature rock associated with the Table 10-1 features. Figure 10-5 presents the burned rock size distribution for the four major raw material types represented in the Table 10-1 features. Note that we recorded size data at $1 \mathrm{~cm}$ intervals, a recording pattern clearly reflected in the plot by a lack of data points falling between integers. Nevertheless, the presentation does show that limestone burned rock is, overall, larger than the other burned rock material types. Quartzite and conglomerate burned rock have roughly the same size distribution, and as a group, these materials are much smaller than the limestone group. Finally, chert has the smallest overall size distribution. This is not surprising given the tendency of chert cobbles to explode with rapid heating, a factor that would serve to inflate the burned rock counts.

The high frequency of chert, the low counts of burned rock in several of the features, and the concentrations of most material in essentially two feature, complicates interpretations based on the experimental patterns outlined above (see also Appendix K). The reuse patterns were developed primarily for limestone and quartzite at a feature level. If we eliminate conglomerate and chert burned and broken rock, only three features have more than 15 items. Plotting distributions in features with an average of seven rocks is unlikely to reveal any meaningful patterns. We can, however, consider all limestone and quartzite at an analytical unit level. Figure 10-6 (top) does this by showing the overall distribution of limestone and quartzite burned rock associated with the features listed in Table 10-1. Surprisingly, the pattern is one clearly consistent with extensive reuse, even when we remove chert and conglomerate rock. There are no items greater than $13 \mathrm{~cm}$ in maximum size in any of the features, and a high percentage of rock is less than $5 \mathrm{~cm}$ in maximum size. The overall mean maximum size of the burned limestone and quartzite is $6.05 \mathrm{~cm}$. The unburned sample of limestone and quartzite collected from Onion Creek and used in the feature experiments is reproduced for comparison (Figure 10-6, bottom). 


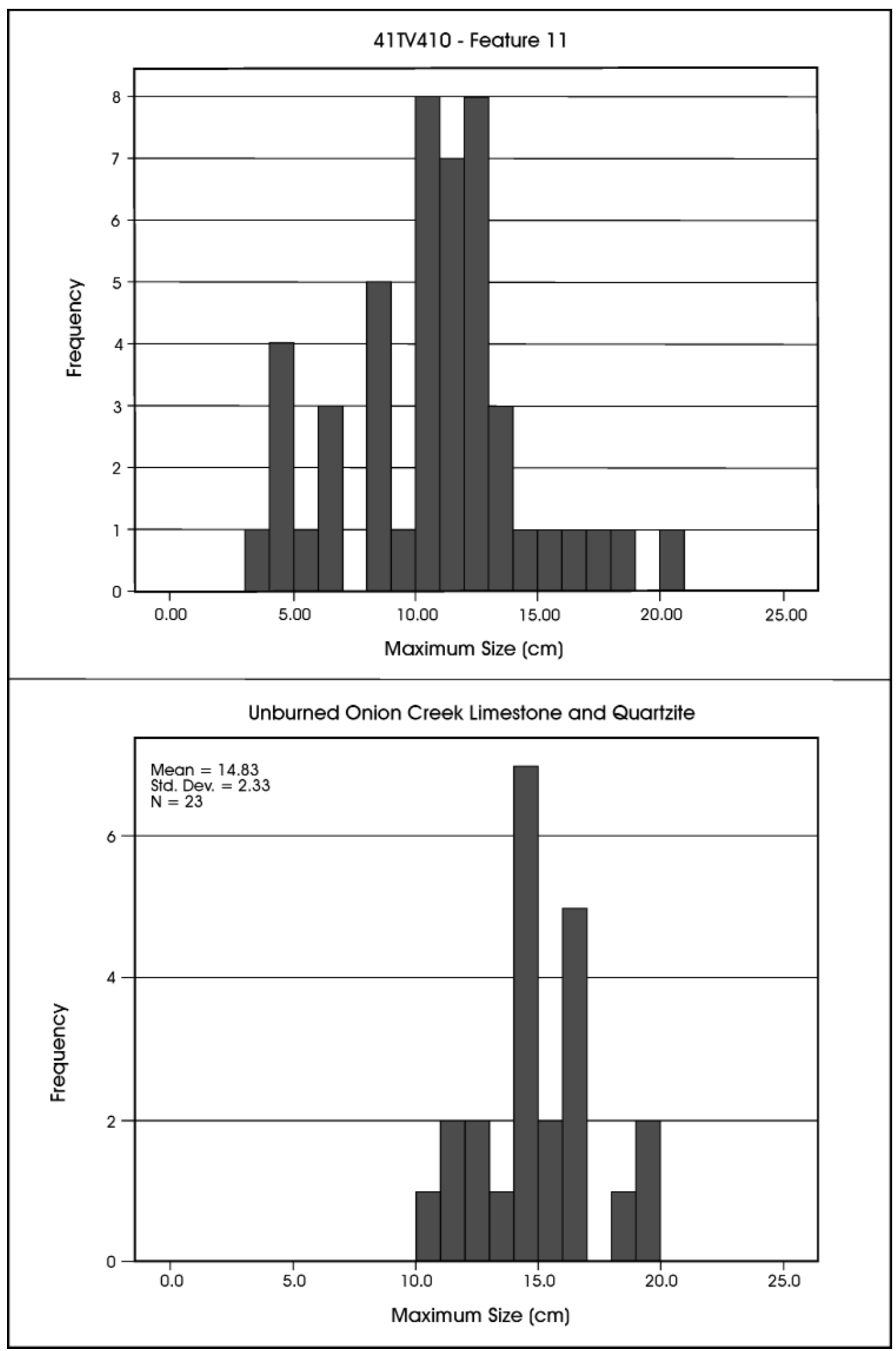

Figure 10-3. Size distribution of burned and fractured rock recovered from Feature 11 at 41 TV410 (top). Unburned Onion Creek Limestone and Quartzite (bottom) shown for contrast. 


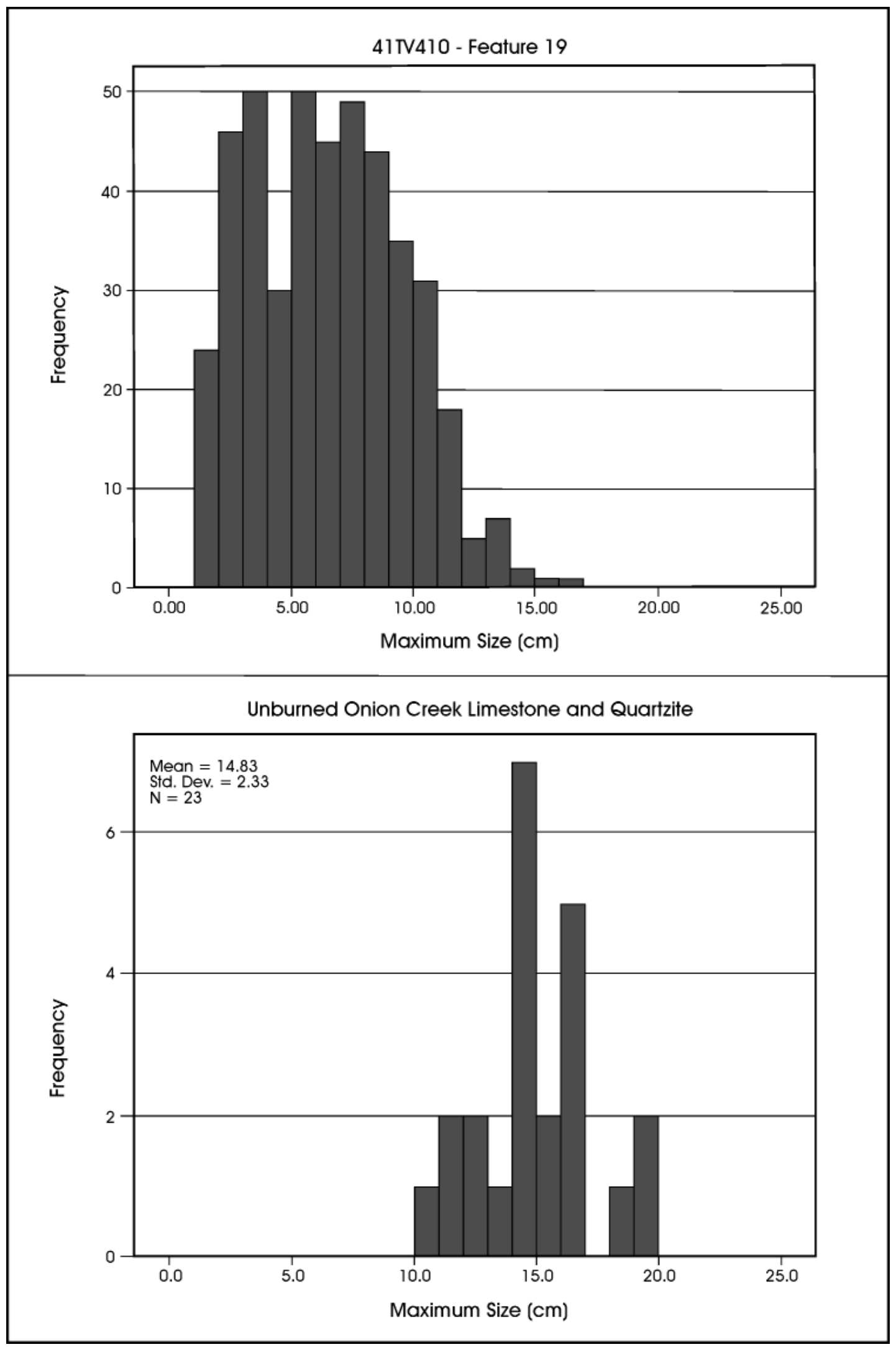

Figure 10-4. Size distribution of burned and fractured rock recovered from Feature 19 at 41 TV410 (top). Unburned Onion Creek Limestone and Quartzite (bottom) shown for contrast. 
Table 10-1. FCR Data from Early Archaic Features at 41TV540

\begin{tabular}{|c|c|c|c|c|c|c|c|c|c|c|}
\hline Feature & Total N & Limestone & $\%$ & Quartzite & $\%$ & Chert & $\%$ & Conglomerate & \% & Total Wt. (g) \\
\hline 7 & 5 & 3 & 60.0 & 2 & 40.0 & 0 & 0.0 & 0 & 0.0 & 605 \\
\hline 13 & 110 & 52 & 47.3 & 26 & 23.6 & 19 & 17.3 & 13 & 11.8 & 6341 \\
\hline 14 & 19 & 10 & 52.6 & 4 & 21.1 & 5 & 26.3 & 0 & 0.0 & 1452 \\
\hline 15 & 7 & 7 & 100.0 & 0 & 0.0 & 0 & 0.0 & 0 & 0.0 & 1519 \\
\hline 17 & 7 & 0 & 0.0 & 5 & 71.4 & 2 & 28.6 & 0 & 0.0 & 296 \\
\hline 18 & 8 & 0 & 0.0 & 3 & 37.5 & 5 & 62.5 & 0 & 0.0 & 645 \\
\hline 21 & 13 & 8 & 61.5 & 1 & 7.7 & 1 & 7.7 & 3 & 23.1 & 1918 \\
\hline 24 & 39 & 19 & 48.7 & 5 & 12.8 & 9 & 23.1 & 6 & 15.4 & 2790 \\
\hline 25 & 8 & 8 & 100.0 & 0 & 0.0 & 0 & 0.0 & 0 & 0.0 & 1241 \\
\hline 26 & 6 & 5 & 83.3 & 0 & 0.0 & 0 & 0.0 & 1 & 16.7 & 118 \\
\hline $27 / 29$ & 69 & 9 & 13.0 & 27 & 39.1 & 30 & 43.5 & 3 & 4.3 & 5366 \\
\hline Totals & 291 & 121 & 41.6 & 73 & 25.1 & 71 & 24.4 & 26 & 8.9 & 22291 \\
\hline
\end{tabular}

\section{Summary}

The burned rock features at 41TV540, then, have low frequencies of rock, high overall frequencies of chert, and a limestone and quartzite distribution pattern that suggests extensive reuse. Yet, extensive reuse should result in higher numbers of burned rock, not the low number seen here. In addition, the use of chert, at least in some contexts at Onion Creek, appears to be common. While not used extensively at 41TV410, Campbell et al. (2009) report that several Late Paleoindian/Early Archaic features at 41TV2125 are dominated by chert cobbles, including Features 4 and Feature 11. Feature 11, which appears to be an early burned rock oven, contains about 650 chert cobbles with chert comprising over $94 \%$ of the feature rock (see Campbell et al. 2009: 74). The use of chert, especially in high quantity, is curious. Chert cobbles are present in Onion Creek. In fact, we mistakenly collected several such cobbles during activities associated with Appendix K. When rapidly heated, however, chert has a tendency to explode, producing a high frequency of small, sharp items that we would guess are difficult to digest. As an example of this, Figure 10-7 shows the results of rapidly heating two Onion Creek Chert cobbles from our raw material collection in an open fire. After a single heating, the cobbles essentially shattered into small, sharp blades. Given this, we think that chert is unlikely to be a first choice for rocks if the goal is to control heating, especially if food preparation is involved. If we assume that prehistoric hunter-gatherers could recognize chert cobbles and knew of their propensity to shatter when rapidly heated, then the incorporation of chert into features suggests alternative stone in suitable size ranges was not readily available. In the case of features at 41TV540, this reduced availability of alternatives is consistent with the smaller size ranges of limestone and quartzite cobbles, as well as the low overall frequency of rock in features. Rather than reflect patterns of reuse as we had hoped, the patterns in feature rock size at 41TV540 may be determined, to a substantial degree, by the differential rock availability. If the primary source for rock was Onion Creek, then during the time when 41TV540 was occupied, and perhaps 41TV2125 as well, bed loads and exposures were substantially different then those currently available. Deposits within the Lower Onion Creek bed are currently dominated by limestone and quartzite cobbles, many of which are in the 15 to $20 \mathrm{~cm}$ size range.

\section{Features and Snail Refuse}

As we noted above, as well as in Chapter 6, several features recorded at 41TV540 do not appear to represent the remains of hearths or ovens. In spite of the relatively high numbers of burned rock in Features 13 and 14 (see Table 10-1), these two features, and possibly Feature 11, fall into this group. While none of these features were excavated completely, and while Feature 11 was not excavated at all, all these features contained some charcoal and organic sediments, in addition to burned rock. The primary defining characteristics of these amorphous features, however, is the presence of large quantities of primarily unbroken snail shell derived from the genus Rabdotus. Such dense shell concentrations are often observed on archeological sites in Central and South Texas (e.g., 41TV2121, Campbell et al. 2009). Many researchers (e.g., Allen and Cheatum 1960; Hester and Hill 1975; Jelks 1962; Johnson 1964) have assumed that these concentrations are the result of human consumption, but clear empirical evidence of snail consumption has been difficult to obtain (see discussion is Brown 2002; Clark 1973, 1976; Malof 2001). Do the snail shell concentrations, such as those in Features 13 and 14 at 41TV540 represent the remains of 


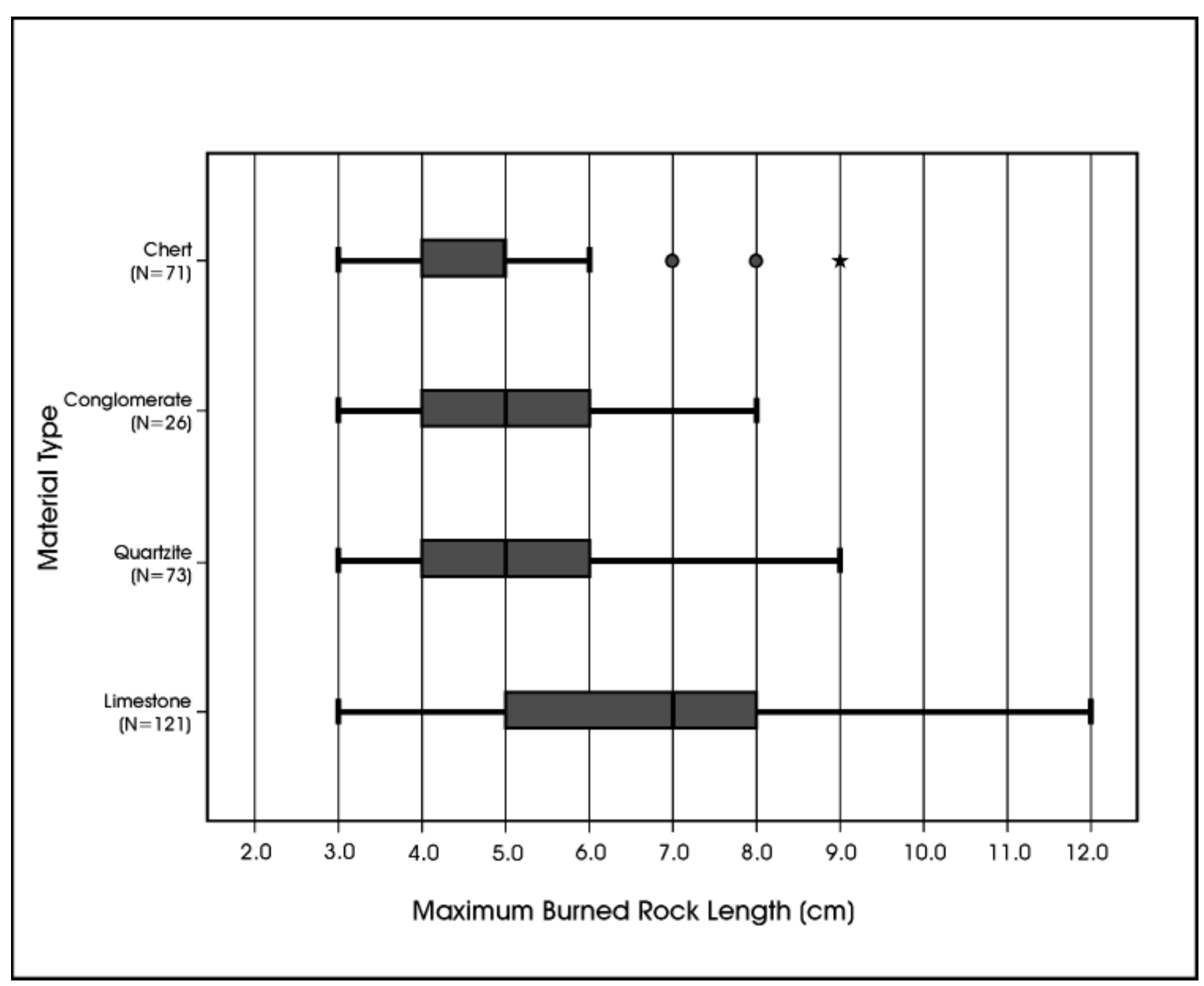

Figure 10-5. Burned rock raw material size by raw material type for probable Early Archaic features at 41 TV540.

human consumption of snails or do they reflect natural snail populations, perhaps attracted to anthropogenically enriched organic deposits or other characteristics of feature sediment? Could they reflect secondary accumulations, perhaps redeposited and mixed by geomorphic processes? As noted in Chapter 7 (see also Tomka et al. 2007), part of the research effort associated with the analysis of the 41TV540 deposits was devoted to investigating the question of snail use at the site, as well as the development of a protocol for the collection and analysis of snails in future archeological investigations. That protocol is presented as Appendix J.

As outlined in Appendix J, past efforts to investigate this question have primarily taken two different approaches, though both of these involve comparisons between parameters of snail populations recovered from archeological contexts with those collected from the natural environment. The first focuses on attributes of snail size, often as manifested in ratios of adults to sub-adult individuals collected from archeological sites relative to those ratios found in natural Rabdotus populations. When the ratios from archeological deposits differentially reflect more adult Rabdotus than are present in a natural population, researchers have argued that the archeological deposits reflect subsistence remains (see Brown 2002, 2006; Malof 2001). Questions of establishing age criteria for Rabdotus (see Malof 2001), concerns with different mixes of Rabdotus species that tend to have different size ranges, the effects of varying environmental conditions on snail sizes used for the development of natural baselines, and archeological screen size issues, complicate this line of inquiry (see discussion in Appendix J).

The second line of inquiry frequently used to investigate possible snail consumption involves consideration of differences in the frequency and variety of snail species recovered in archeological and non-archeological contexts (see Appendix J; Brown 2002, 2006). If a single Rabdotus species dominates a given snail assemblage on an archeological site, this is often used as evidence that the species was targeted by human collectors (e.g., Neck 1994). However, while natural baselines of snail diversity have not been well developed, Fullington and Pratt (1974) note that several species, including species of Rabdotus, can occur in large, dense colonies of varying sizes. Collections by CAR at 


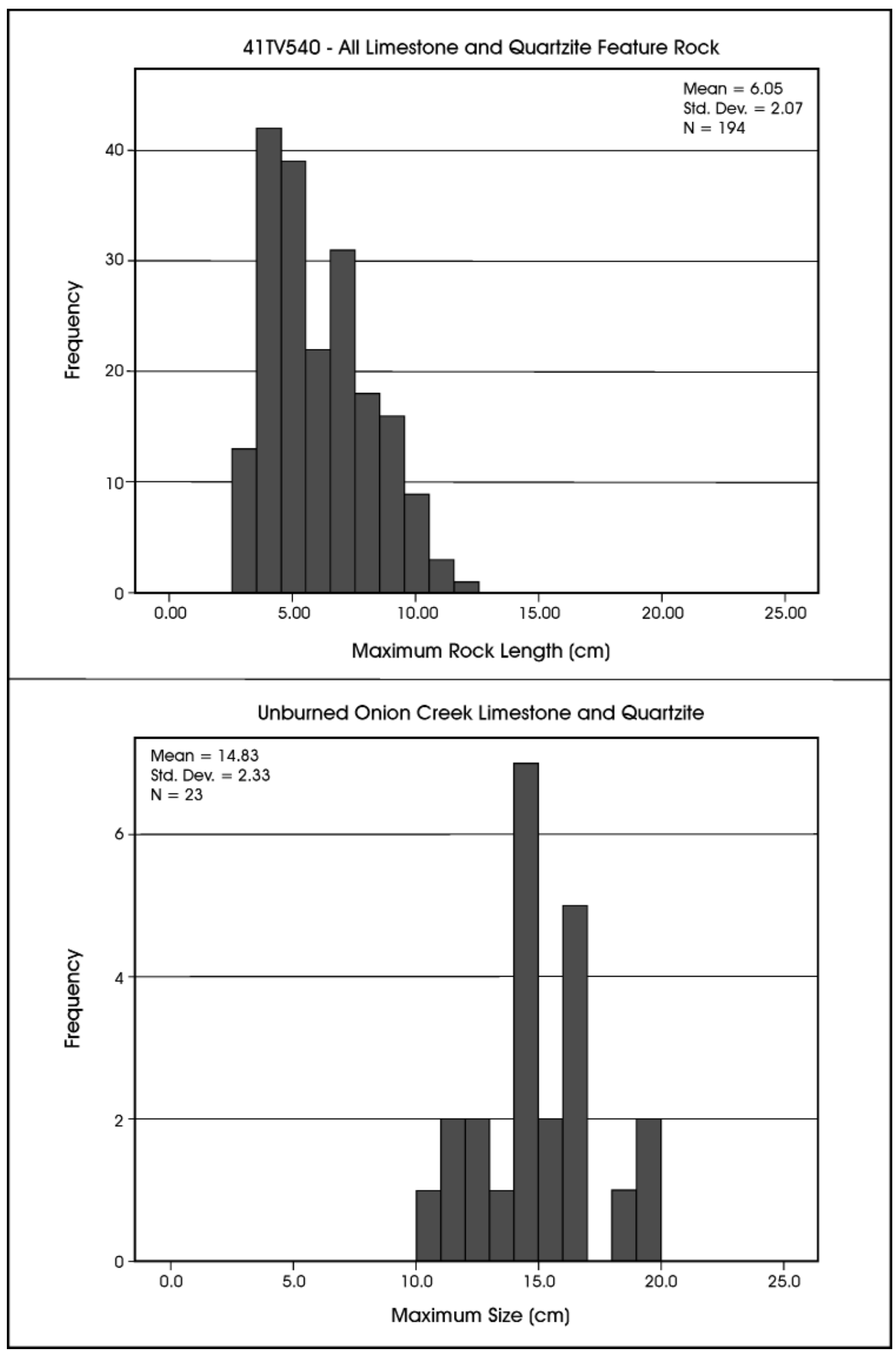

Figure 10-6. Size distribution of burned and fractured rock recovered from all Limestone and Quartzite Feature Rock at 41 TV540 (top). Unburned Onion Creek Limestone and Quartzite (bottom) shown for contrast. 


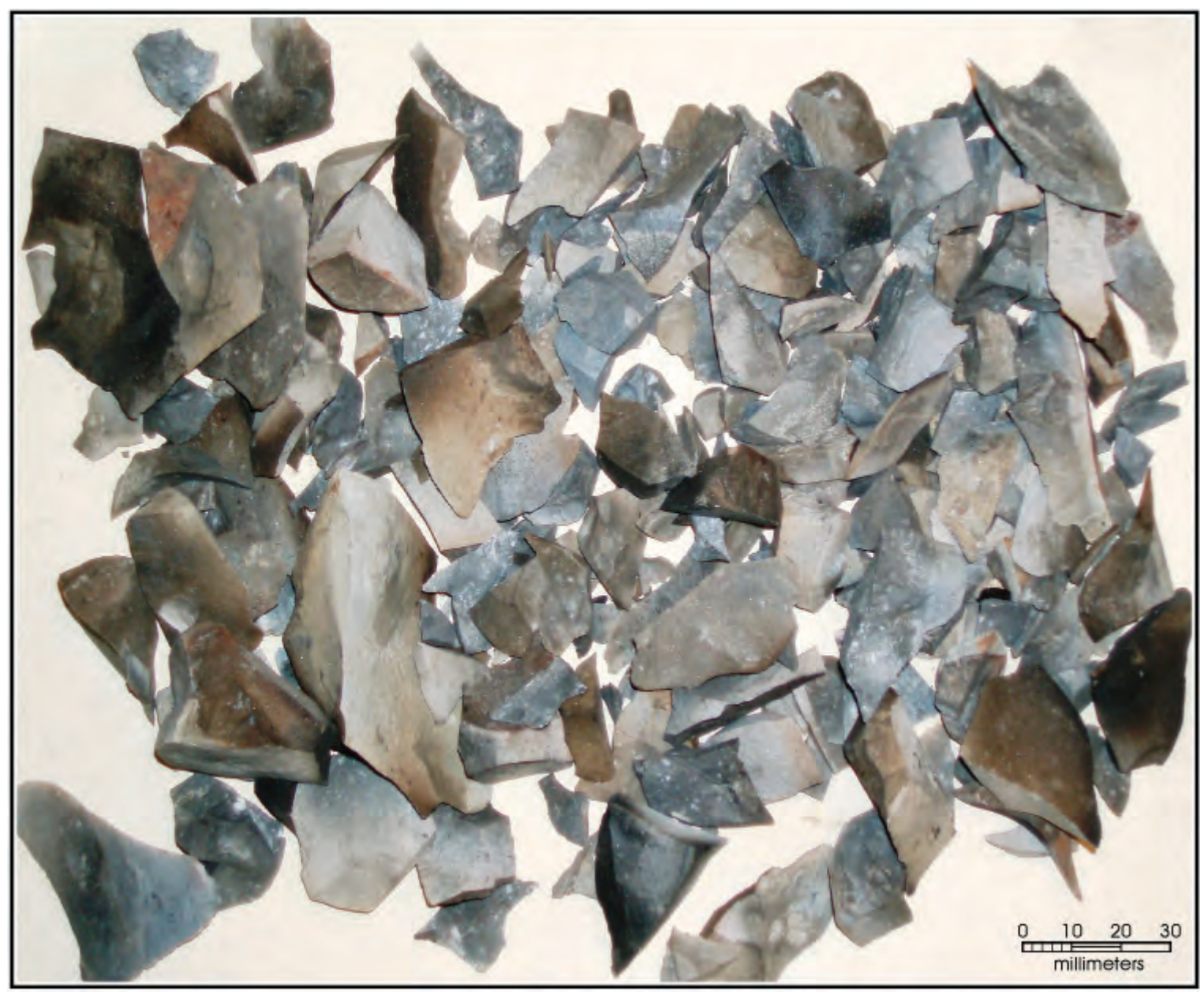

Figure 10-7. The remains of two small Onion Creek chert cobbles following a single heating event in an open fire.

different locations within McKinney Roughs (see Appendices H, I, J) show, not surprisingly, that variation in snail species composition is influenced by vegetation regimes, though as demonstrated in the previous chapter (see Table 9-1, 9-2) we do not have a good understanding of that influence. Finally, as snail species tend to vary significantly in size, selection of screen size can drastically influence sample size and species richness (Appendix J).

A final line of inquiry, though not commonly used, focuses on possible processing requirements related to snail consumption. Given the large quantities of unburned, unbroken shell, snails are assumed to have been processed by boiling, steaming, or indirect heating under beds of coals or near fires (e.g., Bonizzoni et al. 2009:167; Miracle 2002). In the case of Rabdotus, Hester and Hill (1975) conducted experiments that indicate that boiling made the extraction of meat from the shell relatively easy, and that this often occurred with no damage to the shell. CAR archeologists have conducted similar experiments, which are in agreement with Hester and Hill's (1975) conclusions. Deisler
(1986:17), working at the Tucker site (41NU46), uncovered a clay pit that he assumed represented a processing facility where Rabdotus snails were steamed between layers of damp vegetation. These suggested processing methods (i.e., steaming, boiling, or indirect heating in coals) all involve the application of heat, usually in situations with high moisture, and this opens up the possibility that geochemical methods, such as amino acid racemization (AAR), may help clarify aspects of snail processing.

In brief, AAR measures the extent to which certain amino acids, present in living animals only in structural forms referred to as levogyrous, or L forms, convert to dextrogyrous, or D structural forms following the death of an organism. The conversion, or racemization, of $\mathrm{L}$ to $\mathrm{D}$ forms is measured by the $\mathrm{D} / \mathrm{L}$ ratio. $\mathrm{D}$ to $\mathrm{L}$ ratios within a given species are related to time and temperature exposure (see Goodfriend 1991; Johnson and Miller 1997). Several researchers have used changes in $\mathrm{L}$ to $\mathrm{D}$ forms in the amino acid isoleucine (L-isoleucine to D-alloisoleucine, referred to as the A/I ratio) in Rabdotus shell to establish chronology 
and assess depositional integrity in archeological deposits (see Abbott et al. 1995; Ellis and Goodfriend 1994; Ellis et al. 1996; Goodfriend 1991; Goodfriend and Ellis 2000; Goodfriend et al. 1996). While AAR also has potential for identifying snails that were processed with heat and moisture, there are a variety of processes that can result in shifts in racemization rates in archeological shell, primarily by impacting temperature at various scales. Abbott et al. (1995) suggest that differential burial, exposure to fire, slope-aspect of exposure, and exposure to groundwater will all impact $\mathrm{A} / \mathrm{I}$ rates to varying degrees by altering heating histories. At present, separating the impacts of these various conditions on snails, let alone identifying those that were related to human processing in any particular case, is daunting. Furthermore, experiments conducted by Goodfriend suggested that boiling snails at $100^{\circ} \mathrm{C}$ for several hours has no effect on the $\mathrm{A} / \mathrm{I}$ ratios (Abbott et al. 1995:801). The application of AAR for measuring aspects of snail heating, especially if boiling or some other form of indirect heating is involved (e.g., steaming), will prove difficult.

\section{Land Snails from $41 T V 540$}

The analysis of land snails from 41TV540 focused on exploring the question of predation of snails by humans. We focus initially on species variety and on snail size. We ultimately conclude that at least for Features 13 and probably Feature 14 at $41 \mathrm{TV} 540$, which are the two most likely cases, evidence suggests that these features do not represent human predation. Note, however, that TxDOT disagrees with our conclusion. They outline their position in Appendix $\mathrm{O}$, suggesting that the interpretations we suggest are based on insufficient evidence and are, in all likelihood, incorrect (see Appendix O). Obviously, we do not agree. While there certainly may be features and sites in Texas that show human predation on snails, and while we would encourage researchers to continue to look for such features (see Appendix J), we do not think that Feature 13 at 41 TV540 is the result of human predation on snails.

We base our conclusion, in part, on patterning in the size of snails recovered during excavation at 41TV540. Snail samples were collected from both feature and non-feature contexts primarily in $1 / 4$ inch screens, though specimens were also recovered from some 2.0 liter sediment samples water screened through smaller mesh, as well as from both heavy and light fractions in flotation samples associated with some features. Unfortunately, screen size varied with context, and not all locations had similar sampling procedures with regard to the use of screen sizes smaller than $1 / 4$ inch. As snail size is closely related to assessment of human predation, and as size will dramatically impact species composition, establishing a consistent screen size for comparison is critical. For analytical purposes, then, we will focus primarily on snails recovered in the $1 / 4$ inch mesh. While the use of $1 / 4$ inch screens resulted in the loss of snails in the smaller size ranges, this screen size was consistently used across all proveniences. The exception to this $1 / 4$ inch focus is a brief consideration of all snails recovered from roughly eight liters of sediment collected from four different proveniences in Feature 13. That sediment was water screened through $1 / 16^{\text {th }}$ inch mesh ${ }^{\text {(note } 4)}$.

Barbara Meissner of CAR looked at all snails recovered, and species identifications were made through comparison with in-house samples as well as literature searches. Including all screen mesh sizes and contexts, 16,274 snails representing 39 different species were identified. Several snails could not be assigned to a species, and these were classified as unidentified. The $1 / 4$ inch mesh sample used in this analysis numbered 15,336 snails, with 19 different samples represented, including three different species of Rabdotus. Specimens from that genus (i.e., Rabdotus) dominated the $1 / 4$ inch counts, numbering 15,182 items. For specimens that were identified as Rabdotus, samples were passed through nested screens with $1 / 2$ and $1 / 4$ inch mesh, and the number of specimens in each screen size counted. Note that some material passed through the $1 / 4$ inch mesh, but this was primarily shell that were broken post-excavation. At the time of field collection, these were caught in the $1 / 4$ inch mesh. As noted above, we also considered the size distribution of 71 snails captured in eight liters of sediment in Feature 13 and screened through window screen.

In addition to concerns with screen size, methods for investigating the question of human predation of snails at the site were further limited by a lack of off-site comparative material. However, in spite of these limitations, we were able to use aspects of each of the three methods outlined above (i.e., species variety, comparisons of Rabdotus size, and amino acid racemization in shell) to begin to assess the origin of snail deposits at 41TV540.

\section{Snail Distribution and Species Variety at 41TV540}

Table 10 -2 presents the number of snails recovered in $1 / 4$ inch mesh, the percentage of that total accounted for by Rabdotus, and the total number of species present for a number of different contexts at the site. These contexts include snails from all non-feature locations, as well as Features 13 and 14. Portions of these two features (13 and 14) were removed prior to the initiation of hand excavation in conjunction with the safety bench construction (see Chapter 6). Consequently, CAR only excavated the portions of those features that were within the $2 \times 2$ meter blocks. Estimating the number of snails contained in the features, especially in the case of Feature 13, 
Table 10-2. Snails Recovered in 1/4 inch Screens from Various Contexts

\begin{tabular}{|l|c|c|c|}
\hline \multicolumn{1}{|c|}{ Context } & $\begin{array}{c}\text { Number of Snails } \\
\text { Present }\end{array}$ & $\begin{array}{c}\text { Rabdotus as } \\
\text { Percent of Total }\end{array}$ & $\begin{array}{c}\text { Species } \\
\text { Present }\end{array}$ \\
\hline Feature 13 & 9318 & 99.9 & 6 \\
\hline Feature 14 & 2605 & 99.9 & 5 \\
\hline Feaure 29 & 183 & 96.4 & 4 \\
\hline Other Features & 58 & 100 & 2 \\
\hline Non-Features & 3172 & 95.6 & 18 \\
\hline All 1/4inch & 15336 & 99.0 & 19 \\
\hline
\end{tabular}

is problematic given the lack of complete excavation. Several different estimates can be made, however, which suggest that there are roughly 55,000 Rabdotus larger than $1 / 4$ inch in size present within Feature 13. For Feature 14, we estimate that about 4,850 snails larger than $1 / 4$ inch in size were present at the feature level (note 5). The Table 10-2 counts, then, under represent the actual number of snails present, especially in the case of Feature 13. A separate row is also presented for Feature 27/29 in Table 10-2. This feature had a moderate number of snails, and was completely excavated. Finally, a row for all other Early Archaic features that had snails present but had low individual counts is provided. This other feature group is composed of all snails recovered in $1 / 4$ inch mesh from Features 9, 12, 21, 25, and 26. Reference to Table 10-2 will show that the two features of primary interest (Features 13 and 14) dominate most contexts, with Feature 13 excavations accounting for $60.8 \%$ of all $1 / 4$ inch snail recovery and Feature 14 snails comprising an additional $17 \%$. Rabdotus species clearly dominate all locations, making up between 95.6 and $100 \%$ of the snails recovered in the $1 / 4$ inch screen in each of the five contexts shown in the table.

Interestingly, the principal contrast shown in Table 10-2 is not between snails in Features 13 and 14 and the remaining locations, but between all feature proveniences, and the non-feature provenience row. The number of species represented primarily defines that contrast. Feature settings average 4.25 different species while the non-feature context has 18 different species present. While we should expect a relationship between the number of snails recovered and the number of species represented, reference to Table 10-2 demonstrates that these diversity differences are not simply a function of sample size. The sample size for the non-feature row $(n=3,172)$ falls well below the Feature 13 total and is roughly comparable to the Feature 14 total $(n=2,605)$. There are, however, about three times more species represented in the non-feature setting $(\mathrm{n}=18)$ than in either Feature $13(\mathrm{n}=6)$ or $14(\mathrm{n}=5)$.

The species variety shown in Table 10-2 could be interpreted as evidence for the selective collection, consumption, and discard of Rabdotus in all feature contexts by Early
Archaic hunter-gathers (see Neck 1994). That is, species variety appears to be underrepresented in all features, not just Features 13 and 14, when feature variety is compared to non-feature contexts. The validity of that interpretation hinges on documenting what factors are conditioning the distribution of snail species. Is human predation conditioning snail populations in these features? Did hunter-gatherers selectively focus on Rabdotus with the number of snails and feature size depending on other elements (e.g., number of consumers, frequency of discard)? We have suggested (see Appendix J) that small scale, micro-environmental conditions (e.g., surface relative humidity, temperature, sun light, soil moisture content, food availability) are likely to control the distribution of snail species in the natural environment. Features, even large features such as Feature 13, have a limited spatial distribution. In this particular case, the sample reviewed in Table 10-2 comes from 11 different $1 \mathrm{~m} \mathrm{x} 1 \mathrm{~m} \mathrm{x}$ $10 \mathrm{~cm}$ adjacent proveniences all at the top of the Block 3 excavation (see Figure 6-2; 6-8). Similarly, the Feature 14 samples primarily come from three adjacent proveniences all near the top of Block 1 (Figure 6-2; 6-9), and other features tend to be represented by a few, spatially discrete locations. By definition, these locations have micro-environmental characteristics (e.g., high organic content, differences in soil moisture, etc.) that are similar to one another and different from the surround matrix. These may well reflect environmental settings that are preferred by Rabdotus. In contrast, the non-feature snails in Table 10-2 come from 167 proveniences representing a variety of depths, both above and within the excavation blocks, as well as a variety of locations outside of the blocks. The acquisition of snails from what are, in effect, a wide variety of micro-environments reflected by the 167 non-feature settings is consistent with the increase in snail species variety for those contexts. The snail species variety data at the site is, at best, ambiguous with regard to the question of human predation on snails. Clearly, this line of inquiry should be pursued if we are able to develop a better understanding of particular micro-environmental preferences in snails.

\section{Rabdotus Size at 41TV540}

The second element considered here involves Rabdotus size by context. If, in fact, hunter-gatherers were collecting, processing, and consuming Rabdotus, we anticipate that there will be differences in the size distributions when compared to that in a natural population. This anticipated size bias assumes that human collectors would differentially select bigger specimens because larger snails are more likely to be seen, they are easier to handle, and larger snails should produce higher returns (see Appendix J). While we can envision collection methods that would exacerbate these anticipated differences (e.g., individual snail collections), and others that would reduce those biases (e.g., beating snails from plants 
into baskets), several researchers have investigated, both directly and through age profiles, the notion that humanprocured snails would produce size differences different from those in nature. Unfortunately, our review of several types of data (e.g., widthllength ratios; population age structures) in the protocol (Appendix J) suggests that there still exists considerable variability in these measures. Environmental factors, for example, may have an impact on Rabdotus size, and there are size differences between different species within the genus (see Appendix J).

In the case of 41TV540, consideration of differences in snail sizes is limited as we lack off-site collections, and we only have consistent data for snails caught in the $1 / 4$ inch screen. However, while we lack data in the smaller size ranges for most contexts, we can consider size differences in the frequency of snails in the larger size ranges and contrast non-feature and several different feature contexts. If human predation of Rabdotus resulted in the selection of larger snails, and if Features 13 and 14 shell are the result of human predation, then these features should have a higher percentage of larger snails present when compared to other $41 \mathrm{TV} 540$ features, as well as to the size patterns in Rabdotus from non-feature settings. In fact, size distributions in non-feature settings can serve as a baseline against which to measure feature percentage. Figure 10-8 presents data relevant to these suggestions by showing the percentages of Rabdotus recovered in the $1 / 2$ inch mesh for several different contexts. Feature 13 has by far the lowest percentage of large snails, followed by Feature 14. Both are below the non-feature percentages, though the difference between those non-feature patterns and Feature 14 is minimal. The Figure 10-8 pattern is exactly opposite of what we would expect if snails collected by hunter-gatherers were the principal source of Feature 13 Rabdotus. Interestingly, the highest percentages of large snails occur in the "other features" group. While this pattern is consistent with our expectations concerning human predation, this group is represented by a relatively small sample size ( $\mathrm{n}=235$ snails), most of which comes from Feature $27 / 29$, and the $1 / 2$ inch percentages exceed expectations only by about $1.7 \%$. Given the large sample sizes in the case of Feature 13, we suggest that any human predation that would result in a bias in favor of larger snails is unlikely to account for differences between Feature 13 and the off-feature size data shown in Figure 10-8. Size patterns in Feature 13 do not exceed the non-feature

\section{Rabdotus at $41 \mathrm{TV} 540$}

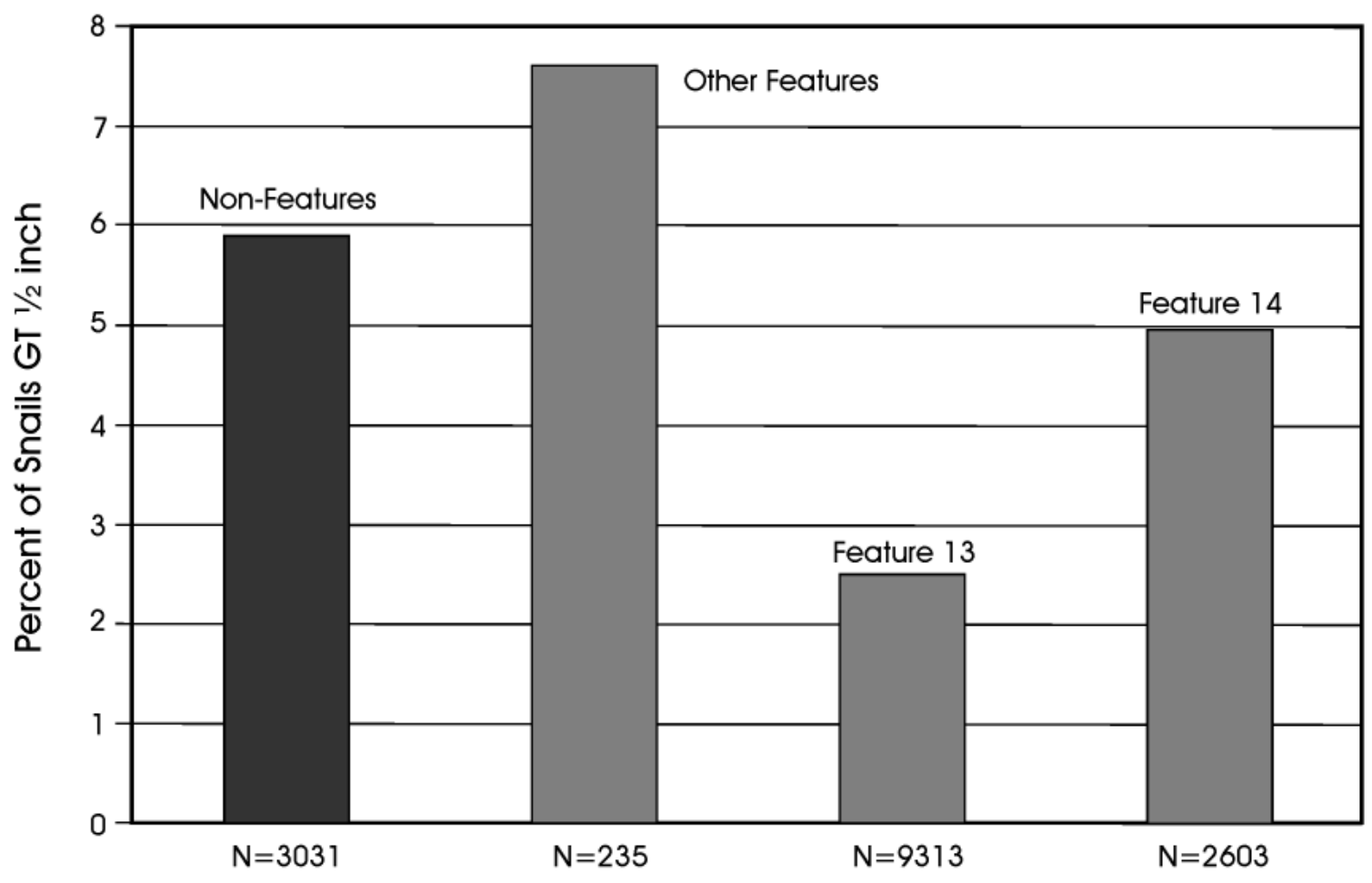

Figure 10-8. The percentage of Rabdotus shells recovered in the $1 / 2$ inch screen size by context. Sample sizes are listed below the bar. 
expectation, but in fact fall well below those expectations. Based on these size data, it appears that the Feature 13 snails do not result from human predation.

As noted above, for Feature 13 we also have limited snail data in the smaller $(<1 / 4$ inch) size range. These are based on four samples, all two liters in size, which were collected during the $2 \mathrm{x}$ 2 meter excavation in this feature. These eight liters, representing only $0.16 \%$ (ca. $0.008 \mathrm{~m}^{3}$ ) of the estimated $5 \mathrm{~m}^{3}$ within the feature, recovered 71 Rabdotus. Sixteen of these (22.5\%) appear to be juveniles as they are less than $1 / 4$ inch in size. If this sample is representative of the entire feature, then there would have been roughly 10,000 juvenile snails present in Feature $13^{\text {(note 6). As }}$ TxDOT notes in Appendix O, the small sediment sample may not, however, be representative of the entire feature. The sample may also contain some level of background noise. In addition, the smaller size fraction within the sample may be underrepresented as a function of differential preservation. Nevertheless, small Rabdotus are present in this feature, and they may be present in substantial numbers. When coupled with the earlier observation that there are relatively fewer larger Rabdotus ( $1 \frac{1}{2}$ inch mesh) when compared to non-feature Rabdotus snail sizes, the Feature 13 size data are not consistent with human predation ${ }^{(\text {note } 7)}$.

Finally, note that the snail size pattern in both the other feature group, as well as the Feature 14 assemblage, is less clear cut than in Feature 13. While it seems unlikely given the small number of snails present in other features, and the hearthlike appearance of some, that all snails found in features in this group reflect human predation, the snails in at least some of these features could represent single dumping events. Feature 14, conversely, has large number of snails, though snail size distributions do not reflect the pattern anticipated for human consumption of snails.

Given the size patterns, we suggest that Features 13 and 14 do not reflect human predation. As summarized in Appendix $\mathrm{O}$, TxDOT does not share this view, especially with regard to Feature 13 at 41 TV540 (note 8).

\section{Amino Acid Racemization in 41 TV540 Rabdotus}

The final set of investigations undertaken in this section involves possible geochemical shifts associated with snail processing. As noted previously, while the heating of a shell does not necessarily mean that the associated snail was intentionally collected, processed, or eaten, some degree of heating (e.g., boiling, steaming in coals) was probably necessary if snails were, in fact, a component of huntergather diets. Amino acid racemization (AAR) of snail shell has the potential to identify heating, but as we discussed previously, shifts in $\mathrm{D} / \mathrm{L}$ ratios of various amino acids may be the result of a variety of processes (see also Appendix J). Here we focus on D/L ratios in two amino acids, glutamic acid and aspartic acid. Both of these have shown potential for monitoring aspects of heating (see Goodfriend 2003; Kaufman 2006).

Previously we had conducted several controlled heating experiments with Rabdotus collected from the San Antonio area (Mauldin2007). Theseexperimentsinvolvedtwomoderncollected shells. One shell was sampled prior to heating, and then both shells were placed in an Ecotherm oven heated to $125^{\circ} \mathrm{C}$. Two samples were removed from the shell at 36 hours, two at 180 hours, and two at 228 hours. These seven samples were then submitted to Dr. Darrell Kaufman of the Amino Acid Geochronology Laboratory (AAGL) at Northern Arizona University for analysis. The AAGL analyses used reverse phase liquid chromatography (RP-LC). Unlike conventional ion-exchange liquid chromatography, which is primarily used to separate isoleucine and alloisoleucine , RPLC separate the $\mathrm{D}$ and $\mathrm{L}$ forms of several amino acids, including $\mathrm{D}$ and $\mathrm{L}$ forms of aspritic and glutamic acid. Results are highly reproducible, especially for aspartic and glutamic acid (see Kaufman and Manley 1998), and the extremely small sample sizes required allow for multiple analysis.

Figure 10-9 plots the $\mathrm{D} / \mathrm{L}$ ratios of aspritic acid (10-9a) and glutamic acid (10-9b) against heating times for these data. Both plots are non-linear, with an initially rapid increase in the $\mathrm{D}$ to $\mathrm{L}$ ratios, and then a declining rate with increased heating time. Aspritic acid seems to increase at a faster rate relative to glutamic acid. Figure $10-9 \mathrm{c}$ plots D/L ratios of both amino acids with heating times for individual points identified. Figure 10-9d applies a transformation to the X-axis allowing for a linear description of the data. These plots show that heating at high temperatures over several days clearly results in dramatic and rapid increases in the $\mathrm{D} / \mathrm{L}$ ratios of these amino acids.

In order to explore the potential of these particular amino acids in the context of identifying heating in snail shell from 41TV540, and as we had previously conducted limited direct heating experiments that are summarized in Figure $10-9$, we initially consider impacts of boiling snails on $\mathrm{D} / \mathrm{L}$ ratios. Previous research on boiling Rabdotus focused on the conversion of L-isoleucine to D-alloisoleucine (A/I ratio) and showed that boiling had no effect on the ratio even after several hours (see Abbott et al. 1995). We boiled three live snails from McKinney Roughs, removing animals at 10, 20, and 30 minutes. We extracted the snail, cleaned the shells, and sent these to the AAGL at Northern Arizona University for analysis. Three samples were processed for each shell. The raw data and discussion of aspects of the results can be found in Appendix L. Figure 10-10 plots D/L ratios for aspartic and glutamic acid with each of the three boiled shells identified. While there is good clustering of the results 


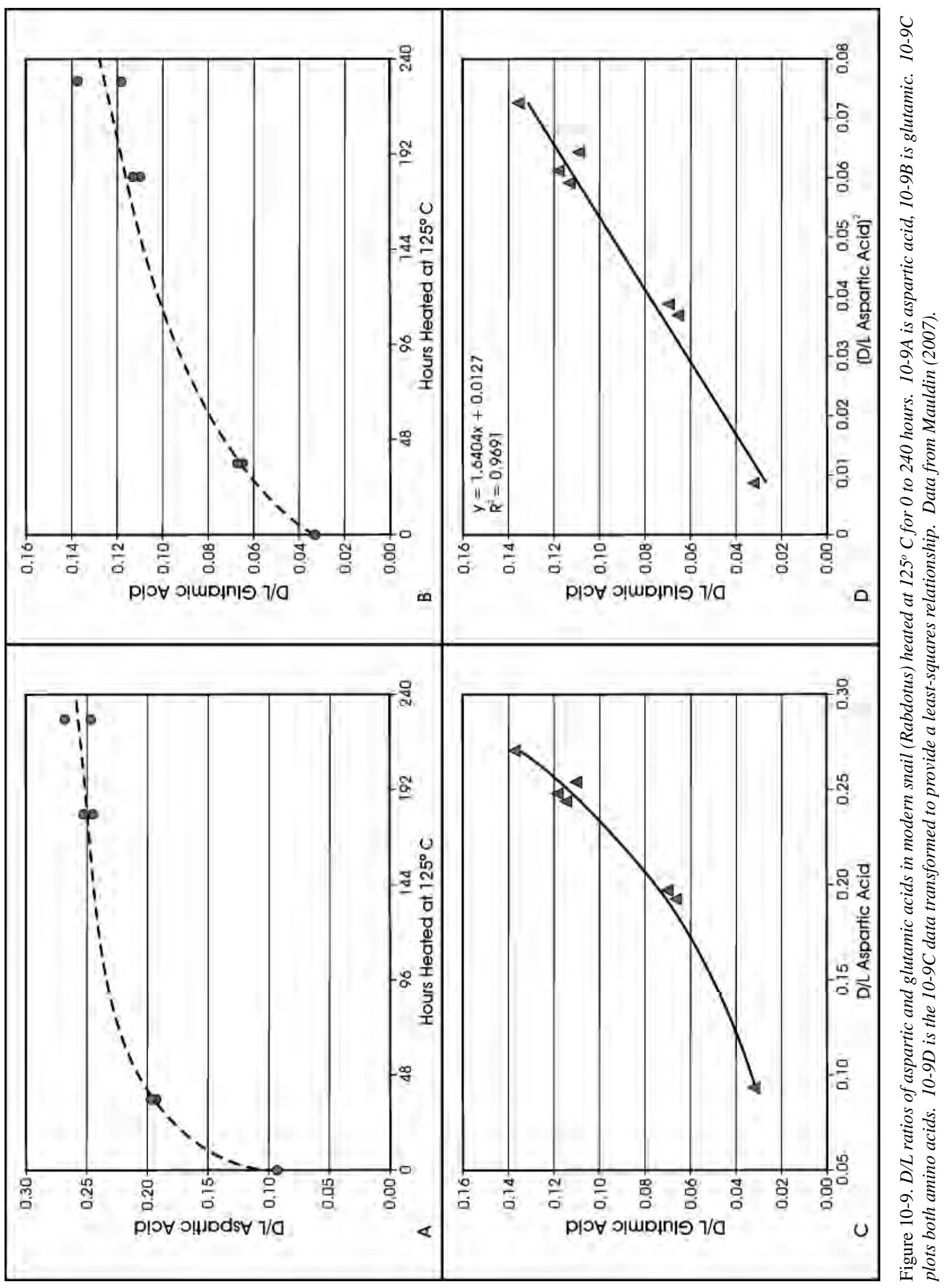




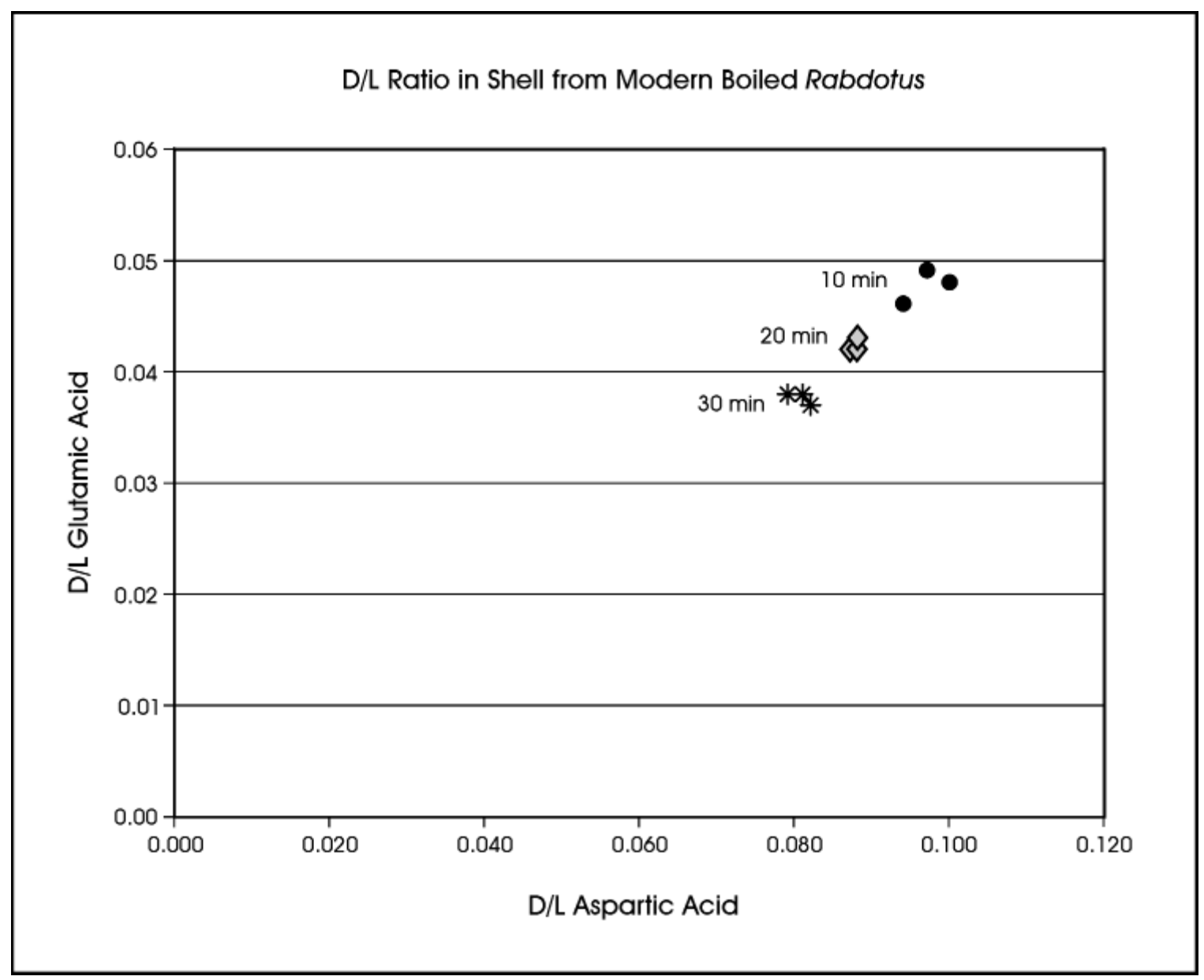

Figure 10-10. D/L ratios of glutamic and aspartic acid in Rabdotus snail boiled for 10 to 30 minutes.

from multiple analyses on each shell, and while there is some small separation between each shell, the results appear to be opposite of what we expected. Increased boiling time should result in an increase in the $\mathrm{D} / \mathrm{L}$ ratios, not the small decrease seen in the figure. The counter-intuitive pattern is present across other amino acids (e.g., serine). We are undertaking additional research with variable boiling times to further define the impacts

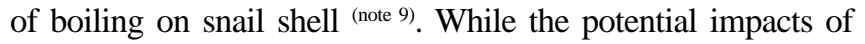
boiling remain unclear, the patterns in Figure 10-9 suggest that heating will have a dramatic impact on overall $\mathrm{D} / \mathrm{L}$ ratios.

In order to consider archeological patterns, three samples of Rabdotus shell were extracted from each of three features (Features 13, 14, and 27/29) at 41TV540. We again submitted these nine samples to Dr. Kauffman of the AAGL for analysis. All three features have radiocarbon dates that fall between 6200 and 5900 BP. While additional information can be found in Appendix L, Figure 10-11 (top) plots the D/L ratios for glutamic and aspartic acid for the archeological samples. The $\mathrm{D} / \mathrm{L}$ values for glutamic and aspartic acid from the single, unheated sample used in Figure 10-9 are included as a reference.
Five of the nine prehistoric samples, including all three samples from Feature 13 and one sample each from Feature 14 and Feature 27/29, cluster around the .128 glutamic and .419 aspartic point (Figure 10-11). While several different interpretations are possible, it seems likely that this clustering reflects racemization over the last 6,000 years, especially in light of the "natural" population pattern shown previously for Feature 13 snails (see Figure 10-8). Regardless, however, of the validity of this interpretation, the significant spreads in values from both Features 27/29 and 14 minimally suggest that snails within these features have variable temporal and/ or heating histories. This spread could simply mean that older snails were incorporated within these two features, but given the magnitude of the differences shown, they would have to be considerably older, especially if the 6,000 year estimate above for the Feature 13 pattern is accurate. A more likely explanation given the magnitude of these differences is that some snails within these two features have been heated, while others have not. As we have seen above (Figure 10-9), heating would result in an accelerated rate of racemization, and might account for the overall spread of $\mathrm{D} / \mathrm{L}$ values shown in these two features. 


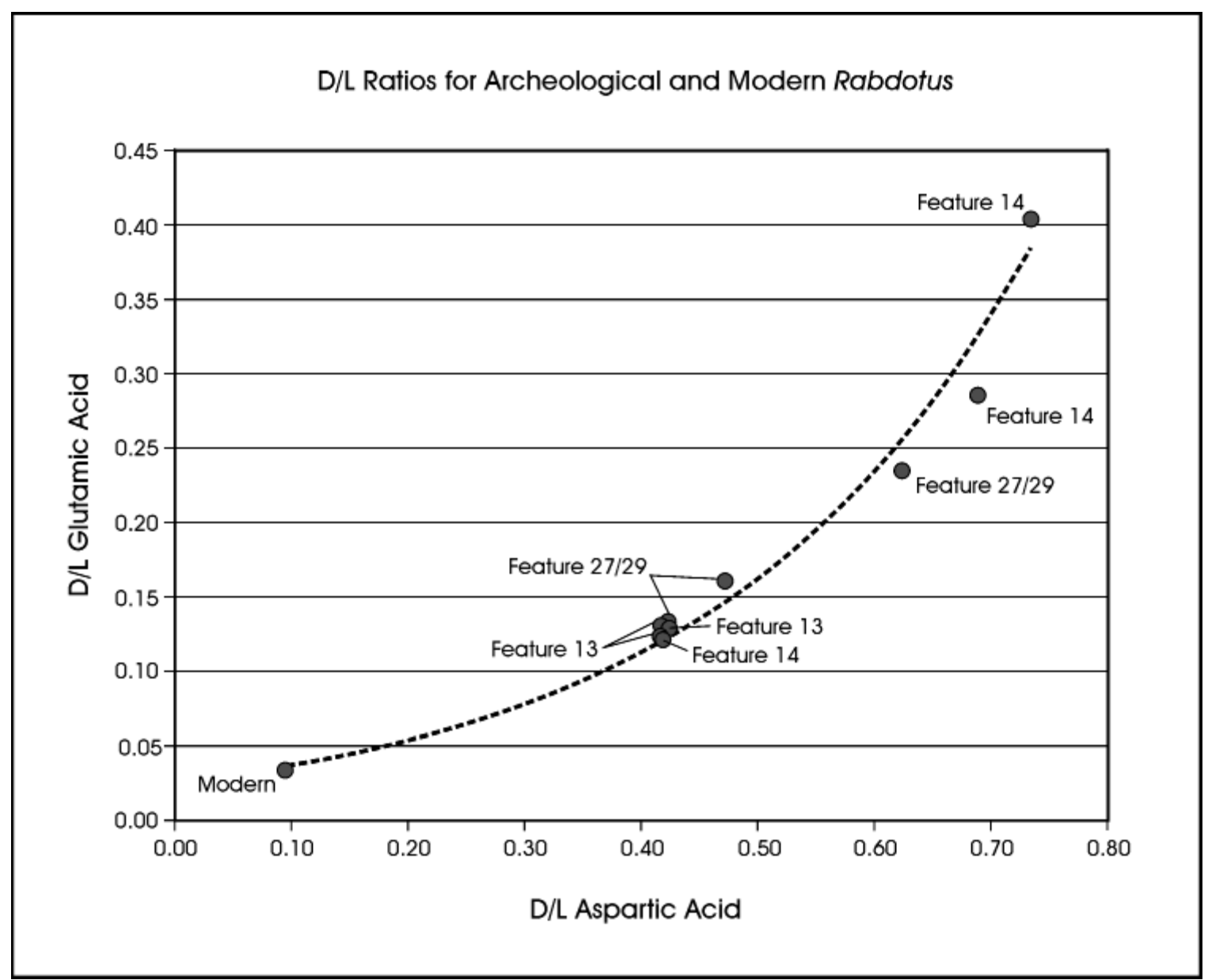

Figure 10-11. D/L ratios for archeological and modern samples by selected features at 41TV540. Modern value is from Figure 10-9A, $B$.

Of course, we can envision a number of different scenarios that would produce heating, and many of these do not necessarily involve snail predation by hunter-gatherers. Feature 27/29, for example, clearly was used as a hearth. Some snails, present in the soil at the time of use, could have been exposed to higher temperatures, while others could have inhabited the feature following abandonment. Given the small number of snails recovered in this feature, it seems likely that heating was incidental rather than intentional. Nevertheless, the pattern of heating in this feature is consistent with our expectations for human predation.

Explanations for Feature 14 are more complicated. This feature has large numbers of snail, and given the features relatively large size and amorphous shape, it is unlikely to have functioned primarily as a hearth even though some charcoal, rock, and darker sediment were present. The feature probably represents some form of secondary deposit. While the snails associated with this feature are smaller than expected (see Figure 10-8), and while some snails probably represent occupation of the feature following abandonment, if the $\mathrm{D} / \mathrm{L}$ ratios of two of the three snails submitted are any indication, a significant proportion of Feature 14 snails were heated. The simplest explanation for the Feature 14 pattern is that some component of this snail assemblage is the result of human predation. However, note that heating can occur under a variety of situations that do not necessarily involve human predation.

\section{Summary}

A number of suggestions regarding future investigations of the role of snails in hunter-gatherer diets in Central and South Texas are presented in Appendix J. Here, we focus primarily on the $41 T V 540$ features. In that regard, we conclude that there is little evidence that Feature 13 represents a cultural accumulation. While the feature is dominated by Rabdotus, all $1 / 4$-inch collections are dominated by Rabdotus at the site. The size distribution of the population recovered is much smaller than those observed in other features or in off-feature contexts, and sub-adult Rabdotus, those smaller than $1 / 4$ inch, are present, perhaps in substantial numbers. 
Finally, while only three snails were considered, plots of the $\mathrm{D} / \mathrm{L}$ ratios of aspartic and glutamic acids do not differ significantly from one another suggesting that the time and temperature exposure histories of these snails were similar. Given the Feature 13 clustering, and the co-clustering of similarly dated samples from Features 14 and 27/29, it seems unlikely that the $\mathrm{D} / \mathrm{L}$ ratios from Feature 13 reflect exposure to extensive heating.

For Feature 14, and possibly Feature 27/29, the story is more complicated. We started out this investigation of snails considering two different scenarios. One where snails in features represented a natural accumulation and one in which they were the remains of human consumption. Certainly, the results from Feature 14, and possibly Feature 27/29, introduce the possibility of a middle ground. That is, several processes can potentially contribute to the characteristics of the snail population in a feature. This observation also complicates recognition criteria based on snail size distributions, or size proxies such as age. A distinctive "cultural" pattern in a feature could easily be diluted by the addition of a natural population following abandonment, especially if younger, smaller snails, like those in Feature 13, dominated the occupying population. This scenario, in fact, fits well with Feature 14. In addition, we had assumed that snails would be attracted to cultural features because the higher organic content in those features would provide a food source for snails. Certainly, this may be the case. However, it is possible that features create a micro-environment that snails may find attractive for reasons other than food (e.g., sediment, moisture, and/or temperature characteristics). As implied in the discussion in Appendix J, we need to develop a better understanding of the factors that condition snail habitat preference, and consider if cultural features possess any of those characteristics. Finally, we need to continue to explore the use of amino acid racemization for distinguishing snails with different temporal and heating histories, especially when we have independent temporal control. Additional D/L samples of snails from data contexts at 41TV410 and 41TV2125 would help to define racemization patterns for aspartic and glutamic acids in Rabdotus, allowing the clear recognition of samples that do not fit, and therefore have a high probability of having been heated. While heating of snails can occur under a variety of scenarios, it does appear that some heating is a necessary step if, in fact, snails were a dietary item.

\section{Patterning in Chipped Stone Debitage and Lithic Tools}

A second broad data set that can provide evidence of activities conducted at 41TV540 is the recovered Early Archaic chipped stone debitage and lithic tools. In Chapter 7 (see also Tomka et al. 2007), we suggested that during geomorphically active periods, hunter-gatherers would occupy a location for short periods and would tend to do so with generalized tool kits. Some tool manufacture and repair may occur during those periods, generating distinctive chipped stone debris, but we suggested that the majority of the lithic tools would have been expedient specimens, generally discarded following use. Conversely, during stable periods characterized by a more mature resource structure, length of occupation would increase. This, in turn, would lead to the discard of a wider range of tools reflecting a broader range of activities, including more formal tools. With increasing occupation length, chipped stone debitage would also increasingly reflect a broader range of reduction activities, including tool production and repair. We also proposed that during short occupations, lithic debitage would be dominated by core reduction associated with the production of expedient tools. In contrast, during stable periods, an increasing component of reduction would be focused on refurbishing formal tools, or producing replacement tools as formal tools are exhausted. An increasing component of this debitage, then, would reflect bifacial reduction strategies (Tomak et al. 2007; but see Perry and Kelly 1987).

Unfortunately, the previous two chapters failed to document either the anticipated geomorphic relationships, or the associated resource structures, and so any specific consideration of the above suggestions in the context of 41TV540 was not undertaken. However, we do summarize the analysis of both the debitage and tools associated with the Early Archaic at the site. Details of that analysis, as well as the raw data, are presented in Appendix M. The analysis included the classification of tools into functional (e.g., scraper, knife) groups, including an examination of specimens under low power magnification (30X), and classifications into manufacturing (i.e., formal, expedient) groups. On each piece of debitage, we recorded the maximum dimension, the percentage of the dorsal surface covered with cortex, flake type (e.g., early reduction, bifacial), and platform type. Aspects of these data, especially those related to platform attributes, were used to assess debitage reduction. Where platforms existed, flakes were assigned to either bifacial or core reduction groups. When platforms were absent, the item was not classified.

The analysis of the tools and debitage also examined raw material color by reference to a standardized rock color chart to create broad groups. These groups were further divided based on inclusions and raw material grain (fine, medium, coarse) to arrive at an approximation of a Minimum Analytical Nodule (see Larson and Kornfeld 1997). Figure 10-12 presents two examples of these color groups. The top panel shows all eight pieces of color group 2, while the bottom panel presents examples of color category 15, which 


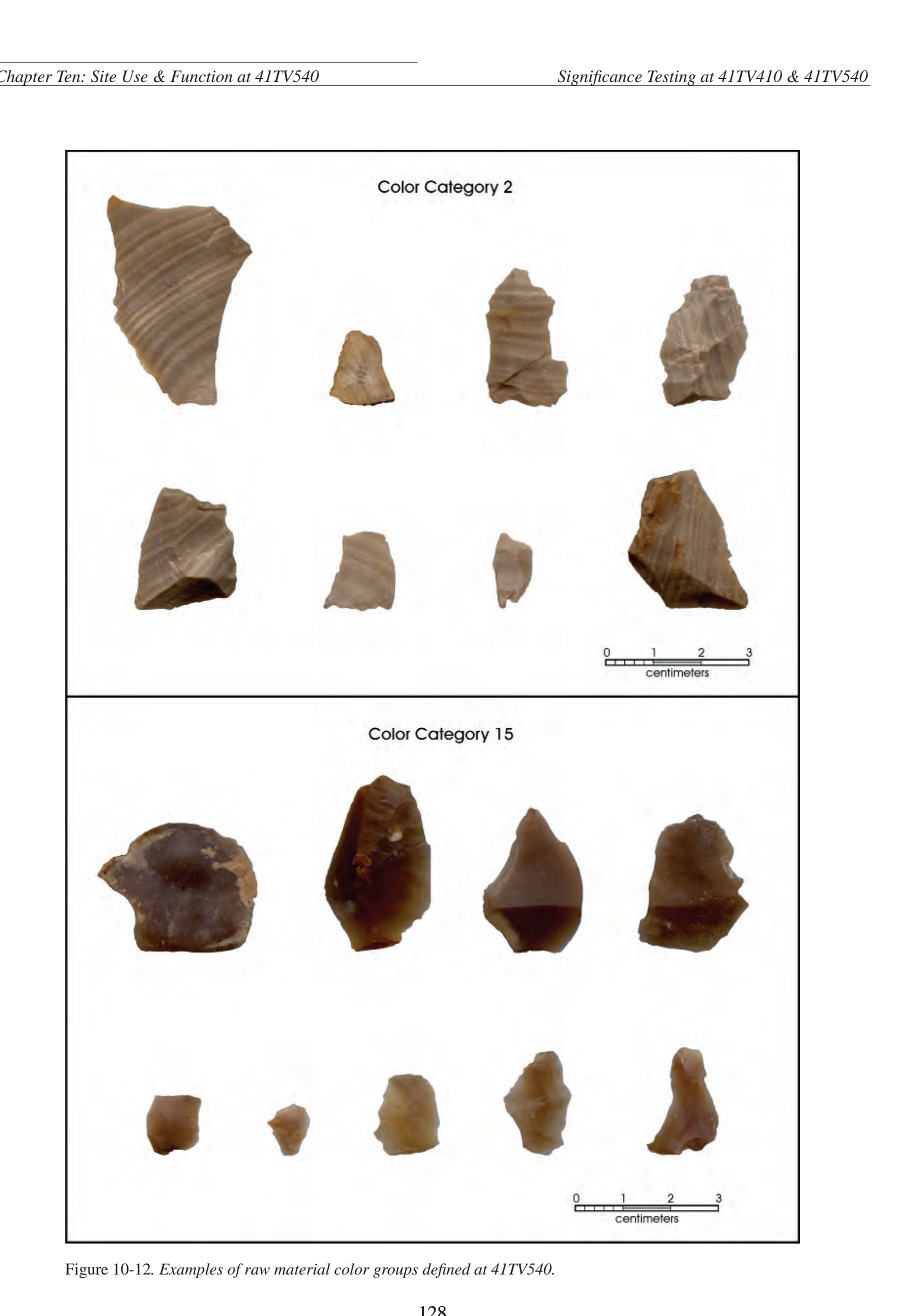


had a total sample size of 26 items. We initially defined 36 different groups within the 15 chipped stone tools, 4 cores, and 309 pieces of debitage recovered (Appendix M), including a category of burned items. We subsequently eliminated this burned category, which contained 22 items. Eighteen of the remaining 35 color groups had five or fewer items, and these were combined into a single miscellaneous group. Color groups combined, and here after referenced as Group 1, included former members of Groups 1, 4, 5, 6, 7, 8, $11,17,24,26,27,28,29,31,32,33,34$, and 35.

Table 10-3 presents information, including color group assignment, for the lithic tools and cores recovered from 41TV540. Focusing on the tools in Table 10-3, six different functional groups are present, including expedient scrapes $(n=4)$, a chopper with crushed portions of the working edge, a bifacially retouched cortex-backed cobble tool that appears to be a wedge based on use wear, a mano, a miscellaneous biface group ( $n=7)$, and a miscellaneous uniface group $(n=2)$. Reference to the comments in Table 10-3 will suggest that most items in both the miscellaneous biface and uniface groups lacked any evidence of use. Items classified as formal tools outnumber expedient items (see also Appendix M). Recalling that the Group 1 designation is a miscellaneous group, Groups 9, 13, and 18, each with two occurrences, dominate raw materials within the tools.

Based on platform attributes, debitage was assigned to broad reduction groups (core, bifacial) that should reflect these tool distinctions. Those flakes with single faceted or cortex platforms were assigned to a core reduction group $(n=153)$ while those with multiple facets were placed in the bifacial reduction group $(n=51)$. If platforms were absent, or specific faceting characteristics could not be determined, the flake was not assigned to a reduction mode $(n=83)$. In addition, flakes were assigned to one of five categories that reflect aspects of reduction. Early/middle reduction stage flakes $(n=254)$ are characterized by striking platforms with cortical, single, or two facets, larger bulbs of percussion and partially corticate dorsal faces. Flake scars on the dorsal faces of these flakes tend to be deeply concave indicative of hard hammer precursor removals. Early/middle reduction stage flakes are thought to be the result of hard hammer removals and tend to be relatively thick and short. Late reduction stage flakes $(n=12)$ tend to have three or more facets on their platform surfaces, ground platform edges, diffuse bulbs of percussion and tend to have decorticate dorsal faces. Flake scars on the dorsal faces of late reduction flakes tend to be

Table 10-3. Attributes of 41TV540 Early Archaic Lithic Tools and Cores

\begin{tabular}{|c|c|c|c|}
\hline Functional Category & Manufacture & $\begin{array}{c}\text { New Color } \\
\text { Group* }\end{array}$ & Comments \\
\hline mano & formal & $\mathrm{n} / \mathrm{a}$ & bifacially used mano; quartzite. \\
\hline bifacial cobble tool (wedge?) & formal & 1 & possible wedge; shows battering on corticate backing. \\
\hline chopper & formal & 13 & cortex-backed with partially refurbished working edge. \\
\hline miscellaneous biface & formal & 1 & found in backdirt; lanceolate biface proximal fragment; manufacture break. \\
\hline miscellaneous biface & formal & 1 & medial fragment of thin biface. \\
\hline miscellaneous biface & formal & 9 & retouched flake; no use wear. \\
\hline miscellaneous biface & formal & 9 & marginally retouched: discarded due to poor raw material quality. \\
\hline miscellaneous biface & formal & 14 & large flake frag with bifacial retouch along one edge; medial flake fragment. \\
\hline miscellaneous biface & formal & 18 & marginally retouched flake; no use wear. \\
\hline miscellaneous biface & formal & 21 & nodule fragment with cortex on proximal end. \\
\hline miscellaneous uniface & formal & 18 & retouched flake; no use wear. \\
\hline miscellaneous uniface & formal & 20 & retouched flake; no use wear. \\
\hline scraper & expedient & 1 & on complete tertiary flake. \\
\hline scraper & expedient & 1 & on large longitudinally split secondary flake. \\
\hline scraper & expedient & 13 & on incomplete tertiary flake. \\
\hline scraper & expedient & 15 & Incomplete tool; on distal flake fragment. \\
\hline bifacial core & $\mathrm{n} / \mathrm{a}$ & 16 & small bifacial core; could also be considered multi-directional core. \\
\hline multi-directional core & $\mathrm{n} / \mathrm{a}$ & 1 & small multi-directional core. \\
\hline multi-directional core & $\mathrm{n} / \mathrm{a}$ & 18 & may be end fragment of biface. \\
\hline multi-directional core & $\mathrm{n} / \mathrm{a}$ & 22 & with cortex; may be very small biface fragment. \\
\hline
\end{tabular}

* see Appendix M. 
shallow and indicative of a variety of flake removal angles. Late reduction stage flakes are thought to be the result of soft hammer removals and are relatively thin, long and longitudinally curved. Uniface reduction flakes $(n=13)$ tend to have a trapezoidal shape, single faceted striking platforms, longitudinal curvature near their distal ends and a distinctive flake scar at the distal end of the dorsal face that is the remnant of the parent flake's dorsal face. In some instances, the dorsal flake scar remnant is replaced with cortex that is derived from the dorsal face of the parent flake. Biface thinning flakes $(n=3)$ are a unique variety of late reduction stage flakes. They exhibit ground striking platform edges, and because they are removed near the very end of the manufacture process, they are smaller than the typical late reduction stage flake. Finally, if the flake could not be assigned to a group, it was called indeterminate $(\mathrm{n}=5)$.

As our primary interest is in documenting the degree to which the assemblage is dominated by core reduction relative to biface reduction, and as this distinction was defined by a single variable (platform attributes), we briefly consider how other reduction parameters pattern with that distinction. Core debitage is, on average, about $3 \mathrm{~mm}$ larger than bifacial debitage (means $=31.47 \mathrm{~mm}$ and $28.52 \mathrm{~mm}$ ), but there is no significant difference in the overall size distributions. This can be seen in Figure 10-13, a box plot of flake size by the two groups. While a number of factors (e.g. core size, reduction goal) condition flake size, it should be the case that debitage associated with core reduction is larger than bifacial debitage, primarily because flakes produced during bifacial reduction are thinner, and therefore have a higher breakage rate. However, the minimal difference shown in Figure 10-3 may also be related to the way that we defined these two groups. By definition, all flakes assigned had platforms. If bifacial flakes are differentially broken, then we eliminated the broken, non-platform component of those flakes from consideration. While not all flakes that lack platforms are necessarily biface related, it is the case that as a group, flakes that lack platforms in this assemblage are significantly smaller than other groups with an average size of $25.9 \mathrm{~mm}$.

We also considered cortex coverage within these two broad reduction groups. Non-cortical flakes dominate the overall,

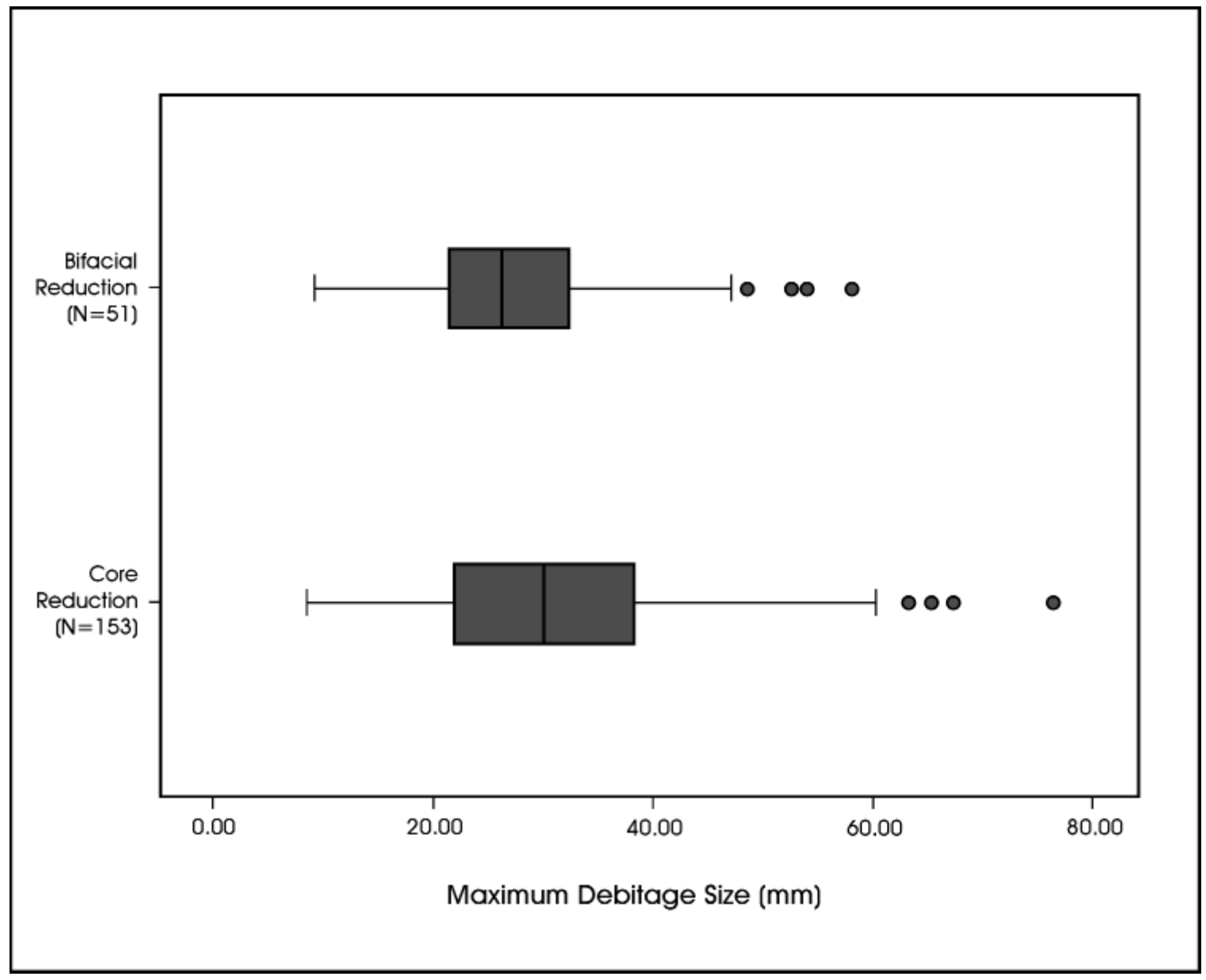

Figure 10-13. Maximum 41TV540 debitage size for flakes classified as reflecting bifacial and core reduction. 
site level patterns. We recovered 14 primary flakes, those with $100 \%$ dorsal cortex coverage, 105 secondary (1 to $99 \%$ cortex) flakes, and 168 tertiary flakes. When we consider only those flakes that could be assigned to either the core or bifacial group $(n=204)$, there are major differences between the two groups. Approximately $84 \%$ (43 of 51) of the flakes in the bifacial group lacked cortex, a significantly higher percentage than is present in the core reduction group (43.8\%). While, once again, some of this difference may be related to the way the groups were defined, with cortexed platforms being assigned to core reduction, only 24 of these platforms were noted among the 153 core reduction flakes. Removing these, tertiary flakes still only account for $52 \%$ of the core reduction assemblage.

The debitage in the assemblage, then, seems to be dominated by core reduction, an observation consistent with the flake type assignment where over $88 \%$ of all flakes were classified as reflecting early or middle reduction, and only three (1\%) biface thinning flakes were observed. These patterns, however, contrast with the tools, where the miscellaneous biface group, many of which appear to be abandoned during manufacture at 41TV540, accounts for $47 \%$ of the 15 chipped stone tools. The pattern is curious, especially given the observation that formal tools, including finished bifaces, are likely to be removed from the site, whereas more expedient tools produced through core reduction are increasingly likely to be deposited at the location of use.

Table 10-4 summarizes attributes of debitage by color group. For each group, the number of items, along with attributes of size, cortex cover, and the breakdown of the different reduction groups (core, bifacial, and unassigned), are presented. Size attributes are summarized by the minimum, mean, and maximum size of debitage recorded in $\mathrm{mm}$. Within the debitage, five raw material groups $(15,16,18,19$, and 23) dominate, accounting for 132 items (45.7\%) though no single group has more than 29 items (10\%).

Figure 10-14 (top) plots the maximum and minimum size of flakes for color groups with group 1 eliminated. The bottom plot in Figure 10-14 presents the same color groups, but here we show the size range (max-min size) and the average size of debitage for each group. While several elements interact to produce these size data sets, color groups located in the upper right potions of both graphs are generally associated with larger parent raw materials, larger core sizes, or larger blanks/ performs brought to the site. Group 9, and to a lesser extent 18 and 16, seem to fall in this portion of the graph. Reference to Table 10-4 will show that Group 9 also has a low tertiary cortex percentage (36.4\%) and high frequencies of core reduction ( $72.73 \%)$. This appears to be consistent with a focus on early reduction, and larger materials. Group 16 and 18, however, do not follow this pattern, having higher tertiary flake percentages $(65.5,70.4)$ and moderate frequencies of core reduction debitage $(48.28,6.67)$.

The bottom left sections of the Figure 10-14 plots should contain debitage from smaller cores or blanks, as well as debitage color groups that were primarily associated with tool rejuvenation. Several color groups fall in this area, with groups 13, 15, and 19 being present in both plots. Color

Table 10-4. Debitage Attributes by Revised (new) Color Groupings

\begin{tabular}{|c|c|c|c|c|c|c|c|c|c|c|}
\hline $\begin{array}{c}\text { New } \\
\text { Color } \\
\text { Group* }\end{array}$ & $\mathbf{N}$ & $\begin{array}{c}\text { Minimum } \\
\text { Size (mm) }\end{array}$ & $\begin{array}{c}\text { Mean size } \\
(\mathbf{m m})\end{array}$ & $\begin{array}{c}\text { Maximum } \\
\text { Size (mm) }\end{array}$ & \% Primary & \% Secondary & \% Tertiary & $\begin{array}{c}\text { \% Bifacial } \\
\text { Reduction }\end{array}$ & $\begin{array}{c}\text { \% Core } \\
\text { Reduction }\end{array}$ & \begin{tabular}{c} 
\% Unassigned \\
\hline 1
\end{tabular} \\
\hline 47 & 9.26 & 32.96 & 76.40 & 4.3 & 48.9 & 46.8 & 14.9 & 59.6 & 25.5 \\
\hline 2 & 8 & 15.53 & 25.83 & 48.59 & 12.5 & 12.5 & 75.0 & 50.0 & 25.0 & 25.0 \\
\hline 3 & 6 & 16.34 & 32.11 & 56.13 & 0.0 & 33.3 & 66.7 & 33.3 & 50.0 & 16.7 \\
\hline 9 & 11 & 20.10 & 33.57 & 67.09 & 9.1 & 54.5 & 36.4 & 18.2 & 72.7 & 9.1 \\
\hline 10 & 11 & 14.67 & 23.43 & 42.23 & 0.0 & 45.5 & 54.5 & .0 & 54.6 & 45.5 \\
\hline 12 & 9 & 14.42 & 28.30 & 58.08 & 0.0 & 22.2 & 77.8 & 77.8 & 11.1 & 11.1 \\
\hline 13 & 7 & 10.29 & 24.19 & 29.03 & 14.3 & 57.1 & 28.6 & 14.3 & 28.6 & 57.1 \\
\hline 14 & 15 & 15.66 & 30.81 & 50.24 & 0.0 & 46.7 & 53.3 & 26.7 & 53.3 & 20.0 \\
\hline 15 & 26 & 8.51 & 22.71 & 39.41 & 0.0 & 7.7 & 92.3 & 53.9 & 34.6 & 11.5 \\
\hline 16 & 29 & 13.40 & 33.11 & 65.33 & 0.1 & 34.4 & 65.5 & 13.8 & 48.3 & 37.9 \\
\hline 18 & 27 & 13.47 & 33.81 & 67.32 & 3.7 & 25.9 & 70.4 & 3.7 & 66.7 & 29.6 \\
\hline 19 & 21 & 10.42 & 24.49 & 38.33 & 0.0 & 19.0 & 81.0 & 4.8 & 42.9 & 52.4 \\
\hline 20 & 17 & 11.05 & 22.05 & 60.32 & 0.0 & 23.5 & 76.5 & 17.7 & 41.2 & 41.2 \\
\hline 21 & 8 & 16.87 & 25.39 & 39.06 & 0.0 & 37.5 & 62.5 & 12.5 & 75.0 & 12.5 \\
\hline 22 & 6 & 18.71 & 32.25 & 42.83 & 0.0 & 66.7 & 33.3 & .0 & 83.3 & 16.7 \\
\hline 23 & 29 & 14.87 & 30.79 & 55.98 & 10.3 & 62.1 & 27.6 & .0 & 69.0 & 31.0 \\
\hline 25 & 10 & 15.91 & 31.55 & 59.61 & 50.0 & 30.0 & 20.0 & .0 & 70.0 & 30.0 \\
\hline
\end{tabular}

* See Appendix M. 


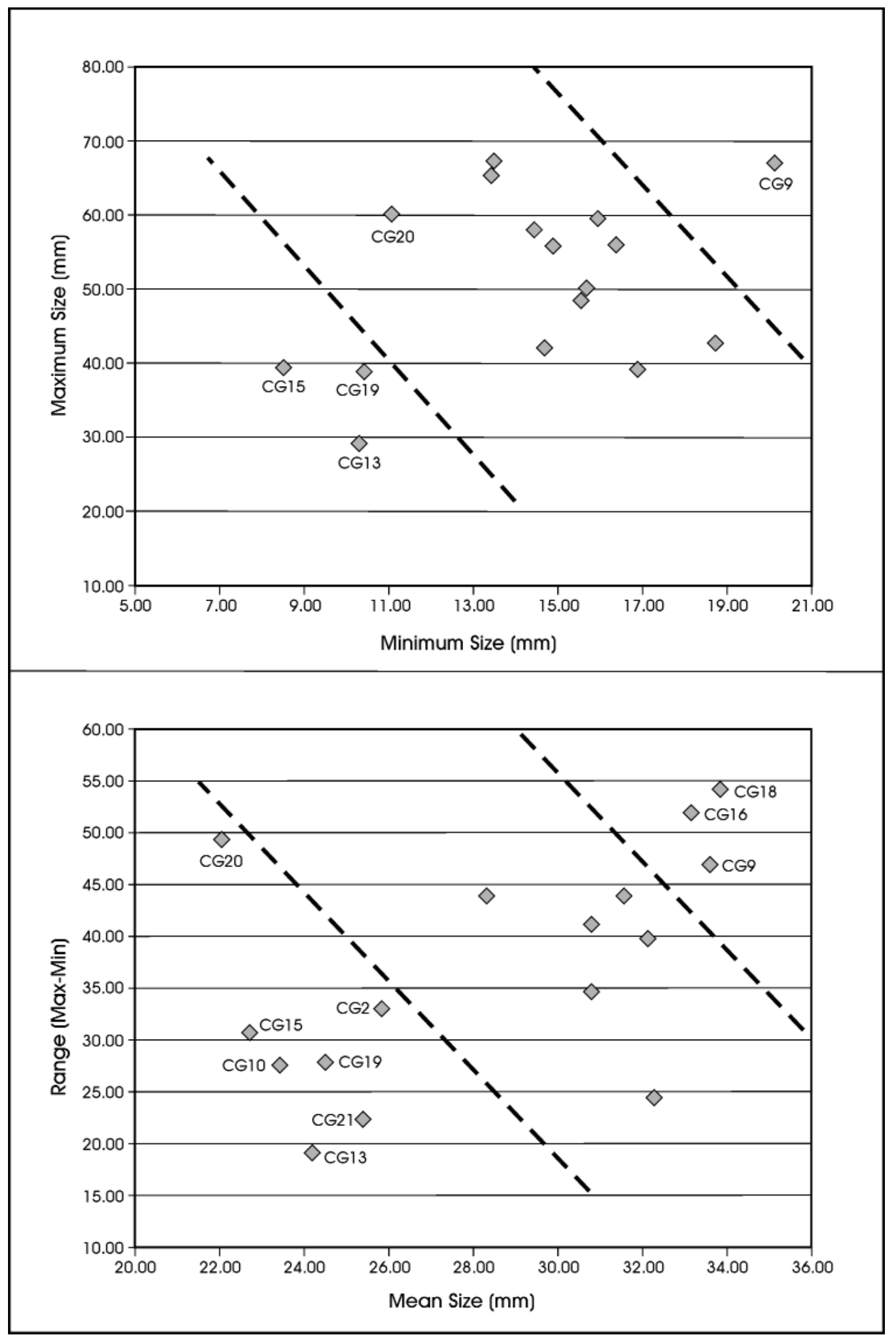

Figure 10-14. Size attributes by color group (CG). Data are in Table 10-4. Top plots maximum and minimum size. Bottom plots size range by mean size. 
groups 15 and 19 both have high tertiary percentages (92.4\% and $81.0 \%$ ), suggesting later reduction, and over half of the flakes with platforms in Group 15 had multifaceted platforms consistent with biface reduction. While most of the flakes in Group 19 lacked platforms, and thus could not be classified, the items with platforms tended to reflect core rather than bifacial reduction (Table 10-4). Finally, in spite of the smaller size of debitage in Group $13(n=7)$, this color group had among the lowest percentages of tertiary flakes (28.6\%). In addition, 4 of the 7 flakes lacked platforms, and 2 of the 3 flakes with platforms had cortexed or single facet platforms suggesting core reduction (see Table 10-4). Interestingly, reference to Table 10-3 shows that one of the two tools made of this material is a "cortexed-back" chopper with a "refurbished working edge" while the other is an expedient flake.

Finally, materials involved in the entire range of reduction should be characterized by a large range of flake sizes, as both small and larger flakes would be produced, and a small mean size, as small flakes should dominate the reduction sequence. These cases should fall in the upper-left portion of the bottom plot in Figure 10-14. Color group 20 may be one such case, but as only 17 items of this material were uncovered, it seems unlikely that this reflects extensive reduction.

\section{Summary}

The chipped stone tool assemblage recovered from the Early Archaic deposits at 41TV540 consists of 15 tools, most of which $(73 \%)$ are formal. Tool seem to reflect a narrow range of activities, with no drills, perforators, or other highly specialized tools present in the assemblage, but with a sample size of 15 , this conclusion is tenuous. The debitage consists of 287 flakes, dominated by what appears to be early and middle stage core reduction, a reduction sequence differentially associated with expedient rather than formal tool production. The same range of color groups seems to be present in both the tools and the debitage, but given the small overall sample sizes, and the large number of color categories, we did not undertake any formal consideration of the color group relationships. Only three biface thinning flakes were recovered in the debitage, yet miscellaneous bifaces are the most commonly recovered functional category in the tools. Many of the bifaces have no indication of use wear, suggesting that they may have been abandoned during the manufacturing process. Interpretations of the pattern are further compounded by the observation that expedient tools are likely to be abandoned at the location of use, while more formal tools, including finished bifaces, are likely to be curated. Finally, some of the raw material groups (e.g., color group 15) in the debitage have consistent indicators of later reduction with small flake sizes and high tertiary flake percentages, while others are consistent with early reduction of larger cores (e.g., color group 9). Clearly, none of the materials seem to represent the full range of reduction. To the degree that there is a relationship between occupation length and the range of reduction activities, we can conclude that occupation at 41TV540 was relatively short term. This is also consistent with the narrow range of tools.

\section{Investigating Site Function at 41TV540}

As outlined in Chapter 7 (see also Tomka et al. 2007), we suggested that variation in what we have termed site function might be seen in differences in mobility and site occupation length. We suggested that focusing on three different areas (i.e., raw material diversity, tool types as related to use-life, and diversity in floral and faunal recovery) would provide insights into aspects of site function (see also Chapter 4). Each of these is briefly discussed below.

\section{Raw Material Diversity}

The diversity of raw material present at a site should reflect both mobility patterns as well as occupation length. Travis County is an area of high chert availability and prehistoric hunter gatherers would have always been within a reasonable distance of good quality material (see Chapter 2, Figure 2-7). Logistical residential sites should exhibit the greatest range in raw material types due to the greater distances covered during camp relocations and to inputs from task-specific locations that extend the areal coverage of the system. Taskspecific locations should have a smaller range of raw material types present assuming that they are always occupied for the same purpose. Similarly, foraging components should also encounter a smaller range of raw materials simply as a function of the more limited scale of mobility. In addition, the longer a residential site is occupied the more likely it is that both local and non-local material will be introduced. Unfortunately, while we do have the analysis of tool stone from 41TV540, no other components were investigated with this same method. The small tool and debitage samples from this site further limit any meaningful contrast between these two data sets. We have, in Appendix M, as well as in Table 10-3 and Table 10-4 above, listed the number of distinct raw material colors present, and descriptions of the groups are presented in that Appendix. However, given that no comparable color group analysis data exists for other sites in the region, no additional analysis was preformed.

\section{Occupation Length and Tool Use Forms}

The second element suggested as a monitor of occupation length was based on expectations between occupation length and tool use life. If the length of site occupation exceeds the 
use life of a tool, it is expected that the tool will be discarded on site. If the use life of the tool is greater than the occupation length of the site, it will likely be curated and removed to the next occupied site (see Schiffer 1975; Shott 1989). We also assume a positive relationship between manufacture costs and anticipated tool use-life. Other things being equal, the more effort that has gone into the manufacture of a tool the more likely it is that it will be systematically curated and used over a long time. Therefore, we expected that expedient tools, such as use-modified flakes, would have shorter anticipated use-lives than, for example, hafted hide-scrapers or finished dart points. Using this conceptual approach, we proposed to approximate occupation length by determining the ratio of expedient use-modified tools to other finished functional tool forms. We suggested that a short occupation will be manifested through the presence of predominantly expedient tools while a long occupation will have a mix of both expedient and curated long-use-life specimens. However, we have shown previously (see Table 10-3) that formal tools dominate the Early Archaic tool assemblage at 41TV540. While the overall number of tools is only 16, 12 of these are classified as formal tools. Formal tools are three times more common than expedient tools, suggesting that the occupation was "long." This seems unlikely given other data sets.

\section{Floral and Faunal Diversity}

For subsistence remains, we suggested that in highly mobile adaptations where there is a low occurrence of reoccupation, there should be shorter occupations possessing a lower diversity of subsistence resources. As the length of occupation increases and/or the frequency of reoccupation under different organizational stances increases, the number of diverse activities at residential sites should be reflected by a wider variety of subsistence resources brought to, processed and consumed at the site. Based on these generalizations, we hypothesized that there would be an inverse relationship between the level of mobility and the resulting diversity of plant and animal taxa present. As mobility increased the diversity of faunal and floral taxa should decrease and as mobility decreases, especially in aspects that increase occupation length, there should be an increase in taxa represented.

Not surprisingly in an open site that dates to the Early Archaic, the diversity in floral resources is minimal. Dering (Appendix A) recorded a single possible economically important plant type (bulb fragments) from the flotation at 41TV540 and there was no recovery from the limited flotation at either the Middle Archaic or Late Archaic features at 41TV410. Campbell et al. (2009) identified two possible food plant types (acorns and bulb fragments) in the Late Paleoindian/ Early Archaic occupations at 41TV2125. All of these three assemblages have low diversity, but given flotation recovery levels in general on open sites, and the age ranges involved with most of this material, any conclusions regarding occupation levels and diversity in plants are unlikely to be meaningful.

For faunal material, the situation is somewhat improved, though the same problems with preservation are present in collections that are over 6,000 years old. As summarized by Meissner (Appendix N), we recovered 260 vertebrate bones as well as a variety of mussels associated with the Early Archaic deposits at 41TV540. Here, we assume that with one exception, these remains reflect animals consumed at the site. Bone preservation at 41TV540 was poor, and the recovered material was highly fragmentary and small. The average bone weighed less than .4 grams. In addition, most bones showed severe chemical weathering. Eliminating a single shark tooth, only nine of the 259 remaining specimens could be identified to the genus taxonomic level. The identified bone included specimens from Whitetailed Deer (Odocoileus virginianus), Cottontail Rabbit (Sylvilagus sp.), Blacktailed Jackrabbit (Lepus californicus), and duck (Anas sp.). Also present in the collection were turtle, snake, rodent, and bird bones from several size categories. The most interesting aspect of the collection is the large proportion of bird bones. Most of these were not identifiable, but the 157 bird bones comprise $60.4 \%$ of all bones recovered. Interestingly, 57 of the 157 were found in a single provenience in Feature 27/29, and 56 of the 57 are consistent with a duck or duck-sized bird. Feature 13 also contains 55 bird bones, though the size ranges are more variable than was present in Feature 27/29. With the four genus level identifications and the presence of at least one species of turtle, one species of snake, one of rodent, and two different sizes of birds, a minimum of nine different species are represented at the site

While no comparative data is available from 41TV410, Campbell et al. (2009) reported significantly higher recovery of vertebrate fauna from 41TV2125. It appears that roughly $27 \%$ more excavation was conducted at this site relative to 41TV540, a fact that should produce more faunal recovery. However, Campbell et al. (2009) recovered 1,763 pieces of vertebrate fauna, significantly more than would be expected by volume differences alone. In spite of the larger recovery, 41TV2125 had a similar number of species present as we recovered from 41TV540. The 41TV2125 data included at least two types of fish, one species of frog or toad, one species of turtle, deer, snake, cottontail rabbit, jackrabbit, and rodent.

\section{Summary}

Focusing on 41TV540, this chapter has explored various aspects of feature, snail, lithic, and subsistence data. Relying 
on experimental data developed for Onion Creek limestone and quartzite, we investigated variations in rock size within burned rock features as possible indicators of site reuse. The burned rock features at 41TV540 had high frequencies of chert and patterns in limestone and quartzite sizes that are consistent with extensive reuse. However, extensive rock reuse should produce high numbers of burned rock as rock breaks. The features at 41TV540 had low numbers of rock, even with the use of chert that tends to shatter with heating. Chert is unlikely to be a first choice for rocks if the goal is to control temperature. Assuming that prehistoric huntergatherers could recognize chert cobbles and knew of their propensity to shatter when rapidly heated, the incorporation of chert into features suggest that alternative stone in suitable size ranges was not readily available. In the case of features at $41 \mathrm{TV} 540$, this reduced availability of alternatives is consistent with the smaller size ranges of limestone and quartzite cobbles, as well as the low overall frequency of rock in features. Rather than reflect patterns of reuse, rock availability seems to determine feature rock size at 41TV540.

A second component of feature use investigated at 41TV540 involved the possible use of snails as a food source. Two of the features investigated at the site, Features 13 and 14, had dense concentrations of Rabdotus shell. The large size and amorphous shape of both features was not consistent with their use as hearths, and the accumulation of unburned and primarily unbroken shell was the defining characteristic of both features. While we lacked consistent data from below 1/4-inch mesh, as well as any off-site data, we were able to consider both species variety and some size data from these two features, other features, and non-feature contexts. These data suggested that the largest feature, Feature 13, probably represented a natural rather than a cultural accumulation (see notes 4, 5, 6, 7, and Appendix O). Shifts in $\mathrm{D} / \mathrm{L}$ ratios within selected amino acids from snails collected from this feature were consistent with that assessment. The patterning in the species composition and site data from Feature 14 were less clear, and amino acid $\mathrm{D} / \mathrm{L}$ ratios suggested that snails within this feature, as well as several within the much smaller and hearth-like Feature 27/29, were exposed to variable temperatures. While heating of snails does not necessarily indicate their use as a food resource, it is unlikely that prehistoric hunter-gatherers ate snails without some form of heating. While it is possible, then, that some snail shell within Feature 14 represent discard associated with human consumption, the same variable $\mathrm{D} / \mathrm{L}$ ratios indicative of heating is present on snails from Feature 27/29. Developing unambiguous signatures of snail consumption in archeological features, then, remains problematic, but a combination of comparisons of feature and off-site snail size distributions and further development of the impacts associated with heating in selected amino acids, along with a better understanding of snail habitats, appear to be promising avenues for research.

We investigated several different aspects of the small assemblage of lithic tools and chipped stone debitage recovered from the Early Archaic deposits at 41TV540. The few tools recovered seem to reflect a narrow range of activities and the majority of tools are formal rather than expedient. The 287 pieces of debitage are dominated by what appears to be early and middle stage core reduction rather than bifacial work. The same range of color groups seems to be present in both the tools and the debitage, but sample sizes in both cases are small. While there is some patterning in the use of specific color groups, none of the materials seem to represent the full range of reduction. To the degree that there is a relationship between occupation length and the range of reduction activities, we can conclude that occupation at $41 \mathrm{TV} 540$ was relatively short term.

Finally, we reviewed suggestions designed to monitor aspects of mobility and occupation length in the Early Archaic materials from $41 T V 540$ (see Tomka et al. 2007; Chapters 4 and 7 of this document). These included an investigation of chipped stone material diversity as indicated by differences in chert colors, a focus on tool types and aspects of tool use life, and measures of diversity. Any conclusions regarding these aspects, however, were limited by a lack of comparative data and by preservation and recovery issues. 



\section{Chapter 11: Summary}

\section{Raymond Mauldin}

In late 2005, the Texas Department of Transportation (TxDOT) contracted the Center for Archaeological Research (CAR-UTSA) to conduct significance testing at 41TV410 and 41TV540, two prehistoric archeological sites located in the floodplain of Onion Creek in southeast Austin in Travis County. As summarized in Chapter 3, preliminary work on both sites had been completed by Hicks and Company in association with a survey of a borrow pit related to the construction of State Highway 130 (see Campbell 2005). Radiocarbon dates from the Hicks and Company work produced four dates from 41TV540 that, when calibrated and corrected, returned ages from 6290 to 5950 BP for depths of between 381 and $479 \mathrm{cmbd}$. A single sample from Feature 9, excavated by Hicks and Company at 41TV410, produced a calibrated, corrected date of 5570 to $5540 \mathrm{BP}$. The low density deposits were apparently intact, and could potential contribution to an increased understanding of these understudied periods. TxDOT-ENV sought to discover more about both sites, and contracted with CAR to conduct additional research.

CAR's work was conducted in advance of a borrow pit excavations. The borrow pit represented a project specific location (PSL). PSLs are normally not part of the project per Federal Highway Administration policy. PSLs are the responsibility of the contractor in most cases. However, the testing reported here was mandated by language of the $\mathrm{SH}$ 130 comprehensive development agreement. Testing was performed on both sites starting late in 2005. For site 41TV540, Dr. Raymond Mauldin served as Principal Investigator and Jennifer Thompson served as the Project Archeologist. At 41TV410, Mauldin served as Project Archeologist and Dr. Steve Tomka served as Principal Investigator. The archeological work at these two sites was not governed by Federal or State regulations, and the work was not conducted under a Texas Antiquities Permit. However, testing at both sites was conducted in accordance with the Secretary of the Interior's Standards and Guidelines for Archeology and Historic Preservation and guidelines provided by the Texas Historical Commission. Testing priorities were dictated by a preliminary research design, summarized in Chapter 4 of the current document.

As outlined in Chapters 5 and 6 of this report, given time constraints and the extreme depth of the deposits, portions of both sites were stripped using heavy machinery prior to the start of hand excavations. CAR staff monitored this stripping. CAR hand-excavated $33.02 \mathrm{~m}^{3}$ at $41 \mathrm{TV} 410$, with $1.31 \mathrm{~m}^{3}$ of this total being used to explore features discovered during the course of mechanical stripping of the two excavation areas. At 41TV540, CAR staff hand-excavated a volume of $24.0 \mathrm{~m}^{3}$ with an additional $2.35 \mathrm{~m}^{3}$ used to explore features and characterize deposits. All excavations were done in 10 $\mathrm{cm}$ levels. In addition to the archeological excavations, deep trenches were cut adjacent to both sites to provide geomorphological data. CAR completed fieldwork on both site by early January of 2006. At 41TV410, 11 features were uncovered with radiocarbon dates that fell in the Early/ Middle Archaic and in the Late Archaic. Recovery of artifacts and ecofacts were extremely low. The 41TV540 work also produced a low density of chipped stone artifacts and tools, and exposed 17 features, many of which dated to a small window at the close of the Early Archaic. Preliminary observations on flotation returns suggested that good quantities of burned material and faunal remains were present at $41 \mathrm{TV} 540$.

CAR prepared post-field reports summarizing the work at both sites (see Mauldin 2006; Thompson 2006). We recommended that as both locations contained intact deposits that could contribute to an understanding of the prehistoric cultural development of the region, the sites were eligible to the NRHP under criterion d. TxDOT agreed with CAR recommendations that 41TV540 was eligible for listing in the NRHP, though they did not request any additional work at the site. TxDOT concluded that site 41TV410 was not eligible for listing on the NRHP. While we provide a description of what was done at site 41TV410 in Chapter 5 of this document, most data types recovered from the site were not analyzed beyond that preliminary descriptions derived from the laboratory efforts conducted during the field work. This was in conformance with TxDOT's determination that 41TV410 was not eligible.

At TxDOT's instruction, CAR prepared a research design for the analysis of the testing data from 41TV540. That research design, summarized in Chapter 7 of the current report (see Tomka et al. 2007), outlined a series of investigations focused on the Early Archaic occupations at 41TV540, along with observations on larger scales concerns related to the geomorphology and resource structure of the Lower Onion Creek Valley. The geoarcheological work performed by Frederick (Chapter 8) within the lower Onion Creek valley has produced a new stratigraphic sequence for the late Quaternary deposits in the area. Five alluvial depositional units (Qa1 to Qa5) were recognized, but radiocarbon dating 
problems with the youngest deposits (Qa4 and Qa5) may require revision should additional dates from good contexts become available. Extensive radiocarbon dating done as part of this work supports previous observations that the bulk sediment/soil radiocarbon ages in this catchment overestimate the age of sedimentation by 900 to 1,500 years. The alluvial chronology established here appears to be significantly different from that of the Colorado River.

As discussed in Chapter 9, the reconstruction of resource structure along Onion Creek was to be built, to a substantial degree, on information supplied in Chapter 8 and hinged on the identification of periods of aggradation and periods of relative stability in the Lower Onion Creek area. Aggradation intervals, characterized by frequent flooding, variable rates of floodplain aggradation, and stream migration, were argued to be associated with frequently disturbed habitats and somewhat unpredictable plant resources. In contrast, as the landscape matured and stability was increasingly present, we suggested that the vegetation communities would shift to woodland dominated species, perhaps culminating in the establishment of climax-like plant and associated animal communities that would encourage longer term human occupation. This particular characterization, however, especially with regards to periods of stability, was misguided. A handful of buried soils were present, especially in Unit Qa4, that did represent brief periods of stability, but these were present during a broader aggradation sequence. The depositional sequences were not separated by any dated stable surfaces reflected by buried soils, but rather by gaps in the sequence. For analytical purposes, we assumed that these gaps reflected relatively more stable periods, but we have no independent evidence to support that assumption.

Using this dichotomy of aggradation and stability, we subsequently investigated a variety of different data sets in order to reconstruct the paleoenvironmental conditions, including the use of stable isotopes, phytoliths, shifts in snail populations, and macrobotanical analysis of charcoal from dated archeological deposits. The results of those investigations were disappointing. While stable carbon isotope date were available for the period of interest, the pattern suggested by this material was a long term change from a $\mathrm{C}_{3}$ dominated setting to a $\mathrm{C}_{4}$ dominated setting rather than the expected pattern of oscillations in vegetation related to depositional conditions. In addition, the detailed snail and phytolith data were only obtained from a single profile adjacent to 41TV410 that dated within the last 3,000 years. Within that profile, the patterns suggested by the phytolith data contradict those suggested by the stable carbon isotopes. Interpretations of the snail population data was hampered by both small sample sizes and minimal understanding of snail habitat preferences. Only the macrobotanical data from 41TV540 provided any solid information on the environment. A lack of comparative information, and the fact that the site level ethnobotanical data seemed to reflect the site location relative to Onion Creek rather than the more general vegetation conditions within the entire Lower Onion Creek Valley, limited the utility of these data. The high sedimentation rates and frequent flooding, which in many ways contributed to the integrity of the archeological deposits in the area, also may have transported significant amounts of snails, phytolithis, and organic material including carbon. In retrospect, a high-energy floodplain was not the best place to conduct this type of paleoenvironmental research.

Chapter 10 focused on various aspects of feature, snail, lithic, and subsistence data from the Early Archaic material at 41TV540. Appendices extensively supported this work. Relying on experimental data developed for Onion Creek limestone and quartzite, we investigated variations in rock size within burned rock features as possible indicators of site reuse. However, rather than reflect patterns of reuse, rock availability seems to determine feature rock size at 41TV540. The experimental work, however, summarized in Appendix $\mathrm{K}$, should be of general utility.

An extensive investigation of snails focused on Features 13 and 14 at 41TV540. Using several different lines of evidence, we concluded that Feature 13 probably represented a natural rather than a cultural accumulation. TxDOT did not agree with that characterization (see Appendix O). Conclusions regarding Feature 14 were more ambiguous, as amino acid $\mathrm{D} / \mathrm{L}$ ratios suggested that snails within this feature, as well as several within the much smaller and hearth-like Feature $27 / 29$, were exposed to variable temperatures. It is possible, then, that some snail shell within Feature 14 represent discard associated with human consumption, though developing unambiguous signatures of snail consumption in archeological features remain problematic. We hope that the snail protocol, developed here and presented in Appendix J, will allow for improved collection and comparison methods in the future.

Finally, we investigated several different aspects of the small assemblage of lithic tools and chipped stone debitage. The small tool assemblage seems to reflect a narrow range of activities, and most tools are formal rather than expedient. The 287 pieces of debitage are dominated by what appears to be early and middle stage core reduction rather than bifacial work. The same range of color groups seems to be present in both the tools and the debitage, but sample sizes in both cases are small. While there is some patterning in the use of specific color groups, none of the materials seem to represent the full range of reduction. To the degree that there is a relationship between occupation length and the 
range of reduction activities, we concluded that occupation at 41TV540 was relatively short. We summarized aspects of chipped stone material diversity as indicated by differences in chert colors, tool types and tool use life, and measures of diversity for $41 \mathrm{TV} 540$.

The deposits at 41TV540, as well as those at 41TV410, seem to reflect short term occupations, similar in many respects to those summarized by Campbell et al. (2009) at 41TV2125. Taken together, the three sites reflect ephemeral occupation, perhaps lasting no more than a few days or weeks, by small groups of hunter-gatherers. These occupations occurred at various points in time, with documented use present as early as $9000 \mathrm{BP}$ and as late as 2200BP. The sites are dominated by burned rock features, have few artifacts, low recovery of organics, and small quantities of fauna. As Frederick noted in Chapter 8, to a substantial degree the rapid sedimentation characteristic of the Onion Creek floodplain at various points in the past limited any significant overprinting of these deposits by subsequent occupations. Because of their low visibility, we suspect that these types of occupations are often overlooked. When they are recorded, they usually are not the focus of investigations. We tend to focus on larger sites, those with denser, more substantial assemblages. We are fortunate to have had the opportunity to investigate these ephemeral sites. These types of occupations present unique challenges. In hind sight, we probably should have done a better job in meeting those challenges in some phases of the project. 



\section{Notes to Text:}

Note 1. In Appendix $\mathrm{O}$ of this document, as well as in their comments on the initial draft of this report, TxDOT archeologists suggest that the primary reason that 41TV540 was determined to be significant was the presence of a large concentration of unbroken, unburned Rabdotus shell that was subsequently identified as Feature 13. In our post-field report (Thompson 2006), CAR argued for NRHP eligibility based on the presents of features that clustered in the Early Archaic, macrobotanical recovery, and the apparently high integrity of the deposits. In their letter to the THC, summarizing their position regarding eligibility (Budd 2006), TxDOT concurs with the CAR position regarding why the site is eligible. TxDOT states that "based upon the clustering of the radiocarbon assays and the presence of at least a minimal amount of macrobotanical remains documented during the UTSA investigation, it is TxDOT's opinion that the portion of 41TV540 located within the Berdoll PSL is eligible for listing in the NRHP in that is meets criterion d....”. Feature 13, or the presence of dense Rabdotus concentrations, were not mentioned as contributing to the site's eligibility by either CAR (Thompson 2006) or TxDOT (Budd 2006). The focus on snail shell concentrations at 41TV540 was developed in the initial research design by Tomka et al. (2007).

Note 2. In their review of the initial draft of this report, TxDOT (2010:4) states that as boiling of snails was the probable method of cooking, and as "the temperature required for boiling has been previously proven not to be intense enough or long enough to chemically alter the snail shell to the degree that it could be recognizable" that this part of the study should not have been undertaken. The proof they reference appears to be a comment by Abbott et al. (1995) that references a single experiments conducted by Goodfriend that considers the impact of boiling on shell A/I ratios. Abbott et al. (1995:801) note that

“ Goodfriend (unpublished data) has conducted an experiment where boiling of shells over a several hour period had no noticeable effect on the ratio. Thus, moderately high heat $\left(100^{\circ} \mathrm{C}\right)$ over relatively short spans of time (hours) appears to have little effect.”

The results of the Goodfriend study have, to our knowledge, never been published. The above reference is all that is available. The study appeared to have focused only on a single amino acid and most likely used a less sensitive (Ion Exchange Chromatography) method than the method we proposed.

Note 3. At least some of the radiocarbon dates associated with the deep (Area 3) trench adjacent to 41TV410 and the much earlier dates from 41TV540 features were known to CAR at the time when the research design outlining this work (Tomka et al. 2007) was being produced. It appears that the hope was that the analysis of this Area 3 column would support, and would be supported by, the geomophological work conducted by Frederick. There are overlapping dates with the trench material and features at 41TV410, but there was no significant recovery of ethobotanical material from the 41TV410 features and the 41TV410 material was not analyzed in any detail. Yet, the detailed phytolith, stable carbon isotope, and snail analysis was explicitly proposed in the context of reconstructing Holocene paleoenvironmental conditions associated with the Early Archaic material at 41TV540. Why this particular strategy was proposed by CAR in that specific context, or why it was approved by TxDOT, remains unclear.

Note 4. We excluded all snail samples from these eight liters in Feature 13 from the initial draft of this report as we lacked consistent comparative data from other contexts and were unsure of the representativeness of the samples. These samples and associated snail data are included in this final report at the specific request of TxDOT. They suggested in their review of the initial draft that the $1 / 4$ inch screen size used in Feature 13 was "much too large to catch sub-adult snails whose presence indicates natural populations and whose absence indicates human predation" (TxDOT 2010: 6). As summarized in Appendix O of this report, TxDOT now suggests that 1 ) these $1 / 16^{\text {th }}$ inch samples encompass too small a volume to be representative of Feature 13 and 2) the recovered snails, which included 16 sub-adult ( $<1 / 4$ inch) and 55 adult ( $>1 / 4$ inch) Rabdotus, probably represents some level of background snail populations not associated with the feature. They also suggest (Appendix O) that even if these samples are assumed to be associated with Feature 13, the mere "presence" of sub-adult snails does not indicate a natural population. Rather, they now state that as "82\%" of the recovered material is adult (actually, 77.5\%, 55 out of 71), this high percentage "would seem to reinforce the notion that the assemblage is the result of human predation." See Appendix $\mathrm{O}$ for additional comments on this issue.

Note 5. Three different estimates are used to arrive at this range for Feature 13. The feature covered slightly less than 20 square meters based on Figures 6-8 and 6-9. We estimate that the volume of the feature was roughly $5 \mathrm{~m}^{3}$ based on the estimated area and the depth of the feature within the 2 x 2 m block. We recovered 9,313 Rabdotus from this feature in $1 / 4$ inch mesh in our $2 \times$ 
2 block excavation, which removed about $1.2 \mathrm{~m}^{3}$. The average number of snails per $10 \mathrm{~cm}$ level within a $1 \mathrm{x} 1 \mathrm{~m}$ unit within the feature was 776, with the maximum number of snails recorded for a given level in our excavation within the feature being 1,583. The first estimate relies only on feature area. We excavated four 1 x $1 \mathrm{~m}$ units, recovering 9,313 Rabdotus. Given the feature area of about 20 square meters, the recovery rate of 2,328 snails per 1 x $1 \mathrm{~m}$ would produce roughly 46,565 snails larger than 1/4 inch at the feature level. If we rely on volume estimates, then the recovery of 7,761 snails per cubic meter (9,313 snails / 1.2 cubic meters) would produce an estimate of 38,805 snails given the estimated feature volume of $5 \mathrm{~m}^{3}$. If we use the maximum recovery for a level (1,583 snails), and assume that this is characteristic of the entire feature, we arrive at an upper end estimate of 79,150 snails. At the level of Feature 13, the number of Rabdotus larger than $1 / 4$ inch is likely to be substantially less than 79,150, and probably somewhat more than 38,805. For discussion purposes, we will take the average of these three estimates, and assume that there were roughly 54,850 Rabdotus larger than $1 / 4$ inch in the feature. Feature 14 was much smaller (Figure 6-10), with fewer numbers of snails. We recovered 2,603 Rabdotus in roughly $0.87 \mathrm{~m}^{3}$ of excavation. Feature 14 is estimated to have been about $1.62 \mathrm{~m}^{3}$ in area, providing an estimate of 4,850 Rabdotus larger than $1 / 4$ inch in size.

Note 6. Contrary to TxDOT's statements in Appendix O, the eight liters discussed here (see also Notes 4 and 5 , above) were not used to estimate the numbers of Rabdotus in the $>1 / 4$ inch range. If, however, we had used these totals, that estimate would yield roughly 34,375 snails larger than $1 / 4$ inch (8 liters $=0.008 \mathrm{~m}^{3}$, 55 adults), an estimate fairly close to our lower end estimate of 38,895 Rabdotus derived from different data sets as discussed above (see Note 5). The close correspondence between our earlier estimates and the 34,375 total derived from the eight liter sample estimates suggests that the eight liter sample may, in fact, be representative of the larger feature total. If, on the other hand, they represent background noise, then the number of snails in Feature 13 is greatly reduced.

Note 7. Could roughly 55,000 to 65,000 snails accumulate in $5 \mathrm{~m}^{3}$ area under natural conditions? Is a population structure consisting of $22.5 \%$ sub-adult and $77.5 \%$ adult Rabdotus observed in nature? We do not know. Our modern excavation data from McKinney Roughs certainly does not approach the density of 13,000 Rabdotus per cubic meter seen in Feature 13 data. Our maximum density was only 1,540 per cubic meter. Recent work by Tomka and Meissner (2011) on natural accumulations of Rabdotus in southern Bexar County that are within the compounds of several abandoned household structures, however, reports considerably higher densities. Tomka and Meissner report a maximum density of roughly 11,820 Rabdotus per cubic meter in that study, a density in the same range as Feature 13. The Tomka and Meissner (2011) study, however, was dominated by smaller Rabdotus, with from 58 to $65 \%$ being under $1 / 4$ inch in size. Only $22.5 \%$ of the Feature 13 data are in this size range, assuming that the eight liters are representative (see also Malof 2001). Additional work on documenting variability in natural snail populations is clearly needed to further define these issues and ultimately develop a resolution. See Appendix J for additional information on this topic.

Note 8. Several researchers have suggested that snails are attracted to micro-environment, possibly by the accumulation of organic material as a food source. This is consistent with the observations of Tomka and Meissner (2011) noted above, where there is significant organic refuse associated with recently abandon modern and historic structures. Snails may also be attracted to features for a variety of other reasons, including potentially higher soil moisture or higher relative humidity, and in some cases, secondary runoff can result in dense concentrations of snails that are dominated by larger Rabdotus. TxDOT (Appendix O) dismisses many of these possibilities, as least for Feature 13. They suggest that as 41 TV540 appears to have been occupied only for a brief time, that there was not sufficient opportunity to generate enough organic refuse to attract tens of thousands of snails. We could, of course, argue that if the snail concentration was, as TxDOT seems to suggest, the result of human predation, then given the short occupation span of the site, there was not sufficient time to collect tens of thousands of snails. In reality, neither TxDOT nor CAR have any concrete idea regarding the necessary time frames for refuse generation sufficient to attract snails (assuming they are attracted) or for time frames required to collect thousands of snails (assuming they were collected) under conditions similar to those that existed several thousand years ago at 41TV540.

Note 9. Those additional boiling studies (Mauldin et al. 2011) involved three modern snails. All three shells were sampled initially (no boiling), and then sampled after 30, 60, 90, and 120 minutes of boiling. Four different amino acids were tracked using Reverse Phase Liquid Chromatography by Kaufman at Northern Arizona University. These data conclusively show that there is no change immediately following boiling. There remains the possibility, however, that boiling changes the rate of shifts in amino acids relative to specimens that were not boiled. 


\section{References Cited:}

Abbott, J.T.

1994 Geomorphic Context of the Barton Site (41HY202) and the Mustang Branch Site (41HY209). In Archaic and Late Prehistoric Human Ecology in the Middle Onion Creek Valley, Hays County, Texas, edited by R.A. Ricklis and M.B. Collins, pp. 353-380. Studies in Archeology 19, Texas Archeological Research Laboratory, the University of Texas at Austin.

Abbott, J.T., G.L. Ellis, and G.A. Goodfriend

1995 Chronometric and Integrity Analyses Using Land Snails. In NRHP Significance Testing of 57 Prehistoric Archeological Sites on Fort Hood, Texas, Volume II, edited by J.T. Abbott and W.N. Trierweiler, pp. 801-814. Archeological Resource Management Series, Research Report no. 34, U.S. Army, Fort Hood.

Abbott, J.T., G.A. Goodfriend and G.L. Ellis

1996 Landsnail investigations. In Archeological Testing at Fort Hood: 1994-1995 Vol. II, edited by W.N. Trierweiler, pp. 619-636. Archeological Resource Management Series, Research Report no. 35, U.S. Army, Fort Hood.

Allen, D.C. and E.P. Cheatum

1960 Ecological Implications of Fresh-Water and Land Gastropods in Texas Archeological Studies. Bulletin of the Texas Archeological Society 31:291-316.

American Society for Testing Materials (ASTM)

1985 Standard test method for particle size analysis of soils. D-422-63 (1972). 1985 Annual Book of ASTM Standards 04.08:117-127. American Society for Testing Materials, Philadelphia.

Amick, D.S.

1995 Regional Patterns of Folsom Mobility and Land Use in the American Southwest. World Archaeology 27:411-426.

Anderson, E., 1952 Plants, Man and Life. Little Brown and Co., Boston.

Barnes, V.E. 1981 Geologic Atlas of Texas: Austin Sheet. Bureau of Economic Geology, the University of Texas at Austin.

Bement, L.C.

1991 Hunter-Gatherer Mortuary Practices during the Archaic in Central Texas. Unpublished Ph.D. dissertation, Department of Anthropology, the University of Texas at Austin.

Bender, M.M., I. Rouhanib, H.M. Vinesb, and C.C. Black, Jr.

1973 13C/12C Ratio Changes in Crassulacean Acid Metabolism Plants. Plant Physiology 52:427-430.

Binford, L.

1980 Willow Smoke and Dog's Tails: Hunter-Gatherer Settlement Systems and Archaeological Site Formation. American Antiquity 43:255-273.

2001 Constructing Frames of Reference: An Analytical Method for Archaeological Theory Building Using Hunter-Gatherer and Environmental Data Sets. University of California Press, Berkeley. 
Birkeland, P.W.

1999 Soils and Geomorphology. Third Edition. Oxford University Press, New York.

Black, S.L.

2003 Research Module 2: Studying the Hearths of the Greater Edwards Plateau. In Pavo Real (41BX52): A Paleoindian and Archaic Camp and Workshop on the Balcones Escarpment, South-Central Texas, edited by M.B. Collins, D.B. Hudler and S.L. Black, pp. 375-405. Studies in Archeology, No. 41, Texas Archeological Research Laboratory, the University of Texas at Austin. And Archeological Studies Program, Report No. 50, Environmental Affairs Division, Texas Department of Transportation, Austin.

Black, S.L., and D.G. Creel

1997 The Central Texas Burned Rock Midden Reconsidered. In Hot Rock Cooking on the Greater Edwards Plateau: Four Burned Rock Midden Sites in West Central Texas, edited by Black, S.L., L.W. Ellis, D.G. Creel and G.T. Goode, pp.446515. Studies in Archaeology, No. 22. Texas Archeological Research Laboratory, the University of Texas at Austin.

Black, S.L., L.W. Ellis, D.G. Creel and G.T. Goode

1997 Hot Rock Cooking on the Greater Edwards Plateau: Four Burned Rock Midden Sites in West Central Texas. Studies in Archaeology, No. 22. Texas Archeological Research Laboratory, the University of Texas at Austin.

Blum, M.D.

1987 Late Quaternary Sedimentation by the Upper Pedernales River, Texas. Unpublished Master's Thesis, Department of Geography, the University of Texas at Austin.

1992 Modern Depositional Environments and Recent Alluvial History of the Colorado River, Gulf Coastal Plain of Texas. Unpublished PhD Dissertation, Department of Geography. The University of Texas at Austin.

Bomar, G. W.

1995 Texas Weather. Second edition, revised. University of Texas Press, Austin.

Bonizzoni, S., A. Bruni, A. Girod and V. Guglielmi

2009 Archaeometric Study of Shells of Helicidae from the Edera Cave (Northeastern Italy). Archaeometry 51(1): 151-173.

Bousman, C.B.

1998 Paleoenvironmental Change in Central Texas: The Palynological Evidence. Plains Anthropologist 43(1):201-219.

Bousman, C.B., B.W. Baker and A.C. Kerr 2004 Paleoindian Archeology Change in Central Texas: The Palynological Evidence. Plains Anthropologist 23(164):201-219.

Boutton, T.W., S.A. Archer, A.J. Midwood, S.F. Zitzer, and R. Bol.

$1998 \delta^{13} \mathrm{C}$ Values of Soil Organic Carbon and their Use in Documenting Vegetation Changes in a Subtropical Savanna Ecosystem. Geoderma 82:5-41.

Bouyoucos, G.J.

1962 Hydrometer method improved for making particle size analyses of soils. Agronomy Journal 54:464-465.

\section{Brown, K.M.}

1999 Snails from the Quarter-inch and Eight-inch Screens. Appendix F. In The Smith Creek Bridge Site (41DW270) A Terrace Site in DeWitt County, Texas. D. Hudler, K. Prilliman, and T. Gustavson authors, Pp. 213-275. Texas Archeological Research Laboratory, Studies in Archeology No. 35 and Archeology Studies Program, Report Number 17, Environmental Affairs Division, Texas Department of Transportation, Austin. 
2002 Appendix F: Snails from the Quarter-Inch and Eighteen-Inch Screens. In The Smith Creek Bridge Site (41DW70): A Terrace Site in DeWitt County, Texas., edited by D. Hudler, K. Prilliman, and T. Gustavson, pp. 213-275. Studies in Archeology 35, Texas Archeological Research Laboratory, the University of Texas at Austin.

2006 The Bench Deposits at Berger Bluff: Early Holocene-Late Pleistocene Depositional and Climatic History. Unpublished $\mathrm{PhD}$ dissertation, Department of Anthropology, the University of Texas at Austin.

Budd, J.

2006 Courtesy Review, NRHP Eligibility Testing of 41TV540: SH 130 Segment B4: Berdoll PSL in Travis County, Austin District: CSJ: 0440-06-006. Letter to J. Bruseth at the THC. Copy on file at Center for Archaeological Research, University of Texas at San Antonio.

Bureau of Economic Geology

1974 Geologic Atlas of Texas, Austin Sheet. The Bureau of Economic Geology, the University of Texas at Austin.

Campbell, J.A., S.C. Caran, J.W. Karbula, and B. King

2005 Results of Archeological Field Investigations at the Berdoll SH 130 Project Specific Location along Onion Creek, Austin, Travis County, Texas (Draft). Hicks and Company, Austin.

Campbell, J.A., J.W. Karbula, B.M. Jones, M.C. Shotts

2009 The Berdoll Site: A Transitional Late Paleoindian-Early Archaic Camp in the Lower Onion Creek Basin, Travis County, Texas (Draft). Hicks and Company, Austin.

Camper, H.A.

1991 Pollen Analysis of Patschke Bog. Unpublished M.S. thesis, Department of Botany, Texas A\&M University, Bryant. Data archived at the World Data Center for paleoclimatology data. NOAA/NGDC Paleoclimatology Program, Boulder.

Cannon, K.P., D.R. Bringelson and M.B. Cannon

2004 Hunter-Gatherer in Jackson Hole, Wyoming: Testing Assumptions about Site Function. In Hunter and Gatherers in Theory and Archeology, Edited by G.M Crothers, Pp. 103-124. Center for Archeological Investigations, Occasional Paper No. 31. Southern Illinois University, Carbondale.

Caran, S.C.

1998 Quaternary stratigraphy and geomorphology of the property acquisition area. In Archeological Testing for the New Austin-Bergstrom International Airport in the Lower Onion Creek Drainage of Travis County, edited by J.C. Lohse and S. Iruegas, pp.7-32. Hicks \& Company Archeology Series 50, Hicks \& Company, Austin.

Cheatum, E.P., and R.W. Fullington

1971a The Aquatic and Land Mollusca of Texas. Part One: The Recent and Pleistocene Members of the Gastropod Family Polygyridae in Texas. Bulletin 1. Dallas Museum of Natural History, Dallas.

1971b The Aquatic and Land Mollusca of Texas. Supplement: Keys to the Families of the Recent Land and Fresh-water Snails of Texas. Bulletin 1. Dallas Museum of Natural History, Dallas.

1973 The Aquatic and Land Mollusca of Texas. Part Two: The Recent and Pleistocene Members of the Puplidae and Urocoptidae (Gastropoda) in Texas. Bulletin 1. Dallas Museum of Natural History, Dallas.

Clark, J.W.

1969 Implications of Land and Fresh-Water Gastropods in Archeological Sites. Arkansas Academy of Science Proceedings 23:38-53. 
1973 The Problem of the Land Snail Genus Rabdotus in Texas Archeological Sites. The Nautilus 87:24.

1976 Alvar Nuñez and the Snail Rabdotus in Texas. The Nautilus 90: 13-14.

Collins, M.B.

1998 Wilson-Leonard: An 11,000-year Archeological Record of Hunter-Gatherers in Central Texas. Volume I. Archeological Studies Program, Report 10. Texas Archeological Research Laboratory, the University of Texas at Austin.

2002 The Gault Site, Texas, And Clovis Research. Athena Review 3(2): 31-41, 100-101.

2004 Archeology in Central Texas. In The Prehistory of Texas, edited by T.K. Pertulla, Pp. 101-126. Texas A\&M University Press. College Station.

Collins, M.B. and D.B. Hudler

2003 Pavo Reale (41BX52): A Paleoindian and Archaic Camp and Workshop on the Balcones Escarpment, South-Central, Texas. Archeological Studies Program, Report 41. Texas Archeological Research Laboratory, the University of Texas at Austin.

Cook, A.

2001 Behavioral Ecology: On Doing the Right Thing, in the Right Place at the Right Time. In The Biology of Terrestrial Molluscs, edited by G.M. Barker., pp. 447-487. CABI Publishing. Sterling.

Cooke, M.J.

2005 Soil Formation and Erosion in Central Texas: Insights from Relict Soil and Cave Deposits. Unpublished Doctoral Dissertation, Department of Geology, the University of Texas at Austin.

Davis, W.B., and D.J. Schmidly

1994 The Mammals of Texas. Texas Parks and Wildlife, Austin.

Deines, $\mathrm{P}$.

1980 The Isotopic Composition of Reduced Organic Carbon. In Handbook of Environmental Isotope Geochemistry, edited by P. Fritz and J. C. Fontes. Elsevier, Amsterdam.

Deisler, J.E.

1986 Consumption of Rabdotus Alternatus Alternatus by the Aboriginal Inhabitants of the Tucker Archeological Site, 41NU46, in South Texas. Malacology Data Net. 1:13-20

Dreimani, A.

1962 Quantitative gasometric determination of calcite and dolomite by using a Chittick apparatus. Journal of Sedimentary Petrography 32(3):520-529.

Ehleringer, J.R., T.E. Cerling, and B.R. Helliker.

$1997 \mathrm{C}_{4}$ photosynthesis, atmospheric CO2, and climate. Oecologia 112:285-299.

Ellis, G.L. and G.A. Goodfriend

1994 Chronometric and Site-Formation Studies Using Land Snail Shells: Preliminary Results. In W. N. Trierweiler, Ed., Archeological Investigations on 571 Prehistoric Sites at Fort Hood, Bell and Coryell Counties, Texas, pp. $183-201$. Archeological Resource Management Series, Research Report no. 31. U.S. Army, Fort Hood. 
Ellis, G.L., G.A. Goodfriend, J.T. Abbott, P.E. Hare, and D.W. Von Endt 1996 Assessment of Integrity and Geochronology of Archaeological Sites Using Amino Acid Racemization in Land Snail Shells: Examples from Central Texas. Geoarchaeology 11(3): 189-213.

Ellis, L.W.

1997 Hot Rock Technology. In Hot Rock Cooking on the Greater Edwards Plateau: Four Burned Rock Midden Sites in West Central Texas, Volume 1. by S.L. Black, L.W. Ellis, D.G. Creel, and G.T. Goode, pp. 43-81. Studies in Archeology Number 22. Texas Archeological Research Laboratory, the University of Texas at Austin, and Report 2, Environmental Affairs Division, Archeology Studies Program, Texas Department of Transportation, Austin.

Ellis, L.W., G.L. Ellis, and C.D. Frederick

1995 Implications of Environmental Diversity in the Central Texas Archeological Region. Bulletin of the Texas Archeological Society 66:401-426.

Flood Safety Education Project

2007 Flood Safety, Austin Zone http://www.floodsafety.com/texas/regionalinfo/regionalinfo/austin_zone.htm. Accessed July, 2007.

Fredlund, G.G., C.B. Bousman, and D.K. Boyd

1998 The Holocene Phytolith Record from Morgan Playa in the Rolling Plains of Texas. Plains Anthropologist 43(164):187-200.

Fullington, R.W., and W.L. Pratt

1974 The Aquatic and Land Mollusca of Texas. Part Three: The Helicinidae, Carychiidae, Achatinidae, Bradybaenidae, Bulimidae, Cionellidae, Hapalotremaidae, Helicinae, Oreohelicidae, Spiraxidae, Streptaxidae; Strobilopsidae, Thysanophoridae, Valloniidae, Valloniidae (Gastropods) in Texas. Bulletin 1. Dallas Museum of Natural History, Dallas.

Gale, S.J., and P.G. Hoare 1991 Quaternary Sediments: Petrographic Methods for the Study of Unlithified Rocks. Belhaven Press, London.

Gee, G.W., and J.W. Bauder

1986 Particle Size Analysis. In Methods of Soil Analysis, Part 1. Physical and Mineralogical Methods. Agronomy Monograph No. 9 ( $2^{\text {nd }}$ Edition), edited by Arnold Klute, pp. 383-412. American Society of Agronomy - Soil Science Society of America, Madison.

Goodfriend, G.A.

1991 Holocene Trends in 18 O in Land Snail Shells from the Negev Desert and their Implications for Changes in Rainfall Source Areas. Quaternary Research 35:417-426.

2003 Appendix D: Mussel Shell Analysis. In Archaeological Testing to Determine the National Register Eligibility Status of 18 Prehistoric Sites on Camp Bowie, Brown County, Texas, Volume 2. eds. R.P. Mauldin, D.L. Nickels, and C.J. Broehm. Archaeological Survey Report, No. 334. Center for Archaeological Research, the University of Texas at San Antonio.

Goodfriend, G.A. and G.L. Ellis

2000 Stable Carbon Isotope Record of Middle to Late Holocene Climate Changes from Land Snail Shells at Hinds Cave, Texas. Quaternary International 67: 47-60.

Goodfriend, G.A., J. Brigham-Grette, and G.H. Miller

1996 Enhanced Age Resolution of the Marine Quaternary Record in Artic Using Aspartic Acid Racemization Dating of Bivalve Shells. Quaternary Research 45:176-187. 
Griffiths, H.

1992 Carbon Isotope Discrimination and the Integration of Carbon Assimilation Pathways in Terrestrial CAM Plants. Plant Cell Environment 15:1051-1062.

Hall, C.T.

2004 Evaluating Prehistoric Hunter-Gatherer Mobility, Land Use, and Technological Organization Strategies Using Minimum Analytical Nodule Analysis. In Aggregate Analysis in Chipped Stone, edited by C.T. Hall and M.L. Larson. Pp. 139-155. The University of Utah Press, Salt Lake City.

Hastorf, C.A., and V.S. Popper (editors)

1988 Paleoethnobotany: Analytic Methods and Cultural Interpretations of Archaeological Plant Remains. University of Chicago Press, Chicago.

Hester, T.R.

1990 Plainview Artifacts at the St. Mary’s Hall Site, South Central Texas. Current Research in the Pleistocene 8:26-28.

Hester, T.R. and T.C. Hill, Jr.

1975 Eating Land Snails in Prehistoric Southern Texas: Ethnohistoric and Experimental Data. The Nautilus 89(2): 37-38.

Houk, B.A., K.A. Miller and E.R. Oksanen

2009 The Gatlin Site and the Early to Middle Archaic Chronology of the Southern Edwards Plateau, Texas. Bulletin of the Texas Archeological Society 80:51-75.

Jackson, M.L., C.H. Lim, and L.W. Zelazny

1986 Oxides, Hydroxides, and Aluminosilicates. In Methods of Soil Analysis, Part 1. Physical and Mineralogical Methods, edited by Arnold Klute, pp.101-150. Agronomy Monograph No. 9, American Society of Agronomy-Soil Science Society of America, Madison.

Jelks, E.B.

1962 The Kyle Site: A Stratified Central Texas Aspect Site in Hill County, Texas. Anthropology Series, No. 5. Department of Anthropology, the University of Texas at Austin.

Jessup, K.E., P.W. Barnes and T.W. Boutton

2003 Vegetation Dynamics in a Quercus-Juniperus Savanna: An Isotopic Assessment. Journal of Vegetation Science, Vol. 14 (6): 841-852.

Johnson, B.J. and Miller, G.H.

1997 Archaeological applications of amino acid racemization. Archaeometry 39: 265-287.

Johnson, L.

1964 The Devil's Mouth Site: A Stratified Campsite at Amistad Reservoir, Val Verde County, Texas. Archeology Series, No.

6. Department of Anthropology, the University of Texas at Austin.

2000 Life and Death as Seen at the Bessie Kruze Site (41WM13) on the Blackland Prairie of Williamson County, Texas. Report 22, Texas Department of Transportation, Austin.

Johnson, L. and G.T. Goode

1994 A New Try at Dating and Characterizing Holocene Climates, as well as Archeological Periods, on the Eastern Edwards Plateau. Bulletin of the Texas Archeological Society 65:1-51. 
Kaufman, D.S.

2006 Temperature sensitivity of aspartic and glutamic acid racemization in the foraminifera Pulleniatina. Quaternary GeoChronology 1(3):188-207.

Kaufman, D.S., and W.F. Manley

1998 A new procedure for determining enantiomeric (D/L) amino acid ratios in fossils using reverse phase liquid chromatography. Quaternary Science Reviews 17, 987-1000.

Kelly, R.L.

1995 The Foraging Spectrum: Diversity in Hunter-Gatherer Lifeways. Smithsonian Institution Press, Washington.

Larson, M.L., and M. Kornfeld

1997 Chipped Stone Nodules: Theory, Method, and Examples. Lithic Technology 22(1):4-18.

Leach, J.D., D.L. Nickels, B.K. Moses, and R. Jones

2001 Appendix D: Estimating Rates of Burned Rock Discard: Results from an Experimental Earth Oven, In Test Excavations at the Culebra Creek Site, 41BX126, Bexar County, Texas, by D.L. Nickels, C.B. Bousman, J.D. Leach, and D.A. Cargill, pp. 275283. Archaeological Survey Report, no. 265, Center for Archaeological Research, The University of Texas at San Antonio and Archeology Studies Program, Report 3, Environmental Affairs Division, Texas Department of Transportation, Austin.

Lieberman, D.E.

1993 The Rise and Fall of Seasonal Mobility among Hunter-Gatherers. Current Anthropology 34:599-631.

Lohse, J.C., and S.A. Iruegas (eds.)

1998 Archeological Testing for the New Austin-Bergstrom International Airport in the Lower Onion Creek Drainage of Travis County, Texas. Archeology Series 50, Hicks \& Company, Austin.

Lokke, D.H.

1963 Homing and Home Range for the Terrestrial Gastropod Rumina decollate Linne. Texas Journal of Science 15(2):14-21.

Long, S.P.

1999 Environmental Responses. In C4 Plant Biology, edited by R.F. Sage and R.K. Monson, pp. 215-249. Academic Press, New York.

Lubell, D.

2004a Prehistoric Edible Land Snails in the Circum-Mediterranean: The Archaeological Evidence. In Petits Animaux et Societes Humaines. Du Complement Alimentaire Aux Ressources Utilitaire, edited by J.J. Brugal and J. Desse, pp. 4162. XXIVe Rencontres Internationales d'archeologie et d'histoire d'Antibes. Antibes.

2004b Are Land Snails a Signature for the Mesolithic-Neolithic Transition in the Circum-Mediterranean? In The Neolithization of Eurasia - paradigms, Models, and Concepts Involved. Documenta Praehistorica XXXI:1-24.

Lyman, R.L.

2001 Vertebrate Taphonomy. Cambridge University Press, Cambridge.

Machette, M.

1986 Calcium and Magnesium Carbonates. In Field and Laboratory Procedures Used in Soil Chronosequence Studies, edited by M.J. Singer and P. Janitzky, pp. 30-33. U.S. Geological Survey Bulletin 1648, United States Government Printing Office, Washington. 
Malainey, M.E.

2000 Analysis of Fatty Acid Compositions of Burned Rock Residues from site 41ZP364, Zapata County, Texas. Appendix K in Data Recovery at 41ZP364: An Upland Campsite at Falcon Reservoir, Zapata County, Texas, by J.M. Quigg and C. Cordova, pp. 331-345. Technical Report, No. 22317. TRC Mariah Associates Inc., Austin.

Malof, A.F.

2001 Feast of Famine: The Dietary Role of Rabdotus Species Snails in Prehistoric Central Texas. Unpublished Master's Thesis, Department of Anthropology, the University of Texas at San Antonio.

Mauldin, R.

2006 Post-Fieldwork Report for Phase II Significance Testing of 41TV410, Travis County, Texas. Manuscript on File, Center for Archaeological Research, the University of Texas at San Antonio.

2007 Amino Acid Racemization in Rabdotus exposed to high temperatures. Manuscript on File, Center for Archaeological Research, the University of Texas at San Antonio.

Mauldin, R.P., A. Figueroa, and C. Munoz

2011 Exploring chemical indicators of the use of the land snail Rabdotus as a food resource in prehistoric Texas. Paper presented at the $114^{\text {th }}$ annual meeting of the Texas Academy of Science, Austin.

Mauldin, R.P., D.L. Nickels, and C.J. Broehm

2003 Archaeological Testing to Determine the National Register Eligibility Status of 18 Prehistoric Sites on Camp Bowie, Brown County, Texas. Archaeological Survey Report no. 334 1. Center for Archaeological Research, The University of Texas at San Antonio.

Mauldin, R.P., J. Thompson, C.M. Munoz, and L. Kemp

2009 Hunter-Gatherer Research Intensification and Changing Patterns of Fire-Cracked Rock Features in Central and South Texas. Poster Presented at the $74^{\text {th }}$ Annual Meeting of the Society for American Archaeology, Atlanta.

Mauldin, R.P. and L. Kemp

2005 An Initial Summary of Bison Presence/Absence Associated with Data Recovery at 41ZV202. Report on File at the Center for Archaeological Research, the University of Texas at San Antonio.

Mauldin, R.P., R.D. Greaves, J.L. Thompson, C.M. Munoz, L. Kemp, B.A. Meissner, B.K. Moses, and S.A. Tomka.

2010 Archeological Testing and Data Recovery at 41ZV202, Zavala County, Texas. Archaeological Report, No. 409. Center for Archaeological Research, the University of Texas at San Antonio and Archeological Studies Program, Report No. 121, Environmental Affairs Division, Texas Department of Transportation, Austin.

Mauldin, R.P., S.A. Tomka and H.J. Shafer

2004 Millican Bench (41TV163): a Multicomponent Site in Travis County, Texas. Archaeological Survey Report No. 351. Center for Archaeological Research, The University of Texas at San Antonio and Archeological Studies Program, Report No. 66, Environmental Affairs Division, Texas Department of Transportation, Austin.

Mauldin, R.P., T. Graves, and M. Bentley

1998 Small Sites in the Central Hueco Bolson: A Final Report on Project 90-11. Published by Lopez and Associates, Dallas, Texas for Ft. Bliss Environmental Office, Ft. Bliss.

McFadden, L.D., and D.M. Hendricks.

1985 Changes in the content and composition of pedogenic iron oxyhydroxides in a chronosequence of soils in southern California. Quaternary Research 23:189-204. 
McKinney, W.W.

1981 Early Holocene Adaptations in Central and Southern Texas: The Problem of the Paleo-Indian-Archaic Transition. Bulletin of the Texas Archeological Society 52:92-120.

Meltzer, D.J. and M.R. Bever

1995 Paleoindians of Texas: An Update on the Texas Clovis Fluted Point Survey. Bulletin of the Texas Archeological Society 66:47-81.

Miracle, $\mathrm{P}$.

2002 Mesolithic Meals from Mesolithic Middens. In Consuming Passions and Patterns of Consumption, edited by N. Milner and P. Miracle, pp. 65-88. McDonald Institute for Archaeological Research, Cambridge.

Munson, P.J.

1984 Weedy Plant Communities on Mud-Flats and Other Disturbed Habitats in the Central Illinois River Valley. In Experiments and Observations on Aboriginal Wild Plant Food Utilization in Eastern North America, edited by P.J. Munson, pp. 379-385. Prehistoric Research Series Volume VI, Number 2. Indiana Historical Society, Indianapolis.

National Climate Data Center (NCDC)

2001 Online Climate Data for Austin, Texas. Available at http://wf.ncdc.noaa.gov/oa/climate/ climatedata.html. Accessed July, 2007.

National Oceanic and Atmospheric Administration (NOAA)

2007 Advanced hydrological prediction service, Colorado River at Austin, Tx. http://ahps.srh.noaa.gov /ahps2/hydrograph. php?wfo=ewx\&gage=acrt2. Accessed July, 2007.

National Weather Service

2007 Forecast Office, Austin/San Antonio. http://www.weather.gov/climate/index.php?wfo =ewx. Accessed July, 2007.

Neck, R.W.

1994 Interpretations of Molluscan Remains from the Mustang Branch Site (41HY209). In Human Ecology in the Middle Onion Creek Valley, Hays County, Texas, edited by R.A. Ricklis and M.B. Collins, pp. 491-497. Studies in Archeology 10. Texas Archeological Research Laboratory, the University of Texas at Austin.

Nickels, D.L., and R.P. Mauldin

2001 Chapter 3: The Project Environment. In An Archaeological Survey of Twin Buttes Reservoir, Tom Green County, Texas. Volume I. By R.P. Mauldin and D.L. Nickels, pp 25-38. Archaeological Survey Report No. 300. Center for Archaeological Research, the University of Texas at San Antonio.

Nordt, L.C., T.W. Boutton, and M.R. Waters

1994 Late Quaternary Vegetation and Climate Changes in Central Texas Based on the Isotopic Composition of Organic Carbon. Quaternary Research 41:109-120.

Nordt, L.C., T.W. Boutton, J.S. Jacob, and R.D. Mandel

2002 C4 Plant Productivity and Climate-CO2 Variations in South Central Texas during the Late Quaternary. Quaternary Research 58: 182-188.

O’Leary, M.H.

1988 Carbon Isotopes in Photosynthesis. BioScience 38 (5):328-336.

Pagoulotus, P.

2005 Experimental Burned Rock Studies on the Edwards Plateau: A view from Camp Bullis, Texas. North American Archaeologist 23: 289-329. 
Parry, W.J. and R.L. Kelly

1987 Expedient Core Technology and Sedentism. In The Organization of Core Technology, edited by J. Johnson and C. Morrow, pp. 285-304. Westview Press, Boulder.

Perttula, T.K., G.H. Miller, R.A. Ricklis, D.J. Prikryl and C. Lintz

1995 Prehistoric and Historic Aboriginal Ceramics in Texas. Bulletin of the Texas Archeological Society 66:175-235.

Prewitt, E.R.

1981 Cultural Chronology in Central Texas. Bulletin of the Texas Archeological Society. 52:65-89.

1983 From Circleville to Toyah: Comments on Central Texas Chronology. Bulletin of the Texas Archeological Society. 54:201-238

Quigg, J.M., and J. Peck

1995 The Rush Site (41TG346), A Stratified Late Prehistoric Locale in Tom Green County, Texas. Mariah Associates, Inc., Technical Report No. 816c, Austin.

Quigg, J.M., S. Pritchard, and G. Smith

2002 The Boiler Site (41WB557): Utilization of an Upland Setting Over the Last 4200 Years, Webb County, Texas. Technical Report No. 27277, TRC Mariah Associates. Archeological Studies Program, Report No. 45, Environmental Affairs Division, Texas Department of Transportation, Austin.

Randolph, P.A.

1973 Influence of Environmental Variability on Land Snail Population Properties. Ecology 54(4):933-955.

Ranson S.L. and M. Thomas

1960 Crassulacean acid metabolism. Annual Rev Plant Physiology 11: 81-110.

Ricklis, R.A.

1992 Aboriginal Karankawan Adaptation and Colonial Period Acculturation: Archeological and Ethnohistorical Evidence. Bulletin of the Texas Archeological Society 63:211-243.

1995 Prehistoric Occupation of the Central and Lower Texas Coast: A Regional Overview. Bulletin of the Texas Archeological Society 66: 265-300.

Ricklis, R.A., and M.B. Collins (eds.)

1994 Archaic and late Prehistoric Human Ecology in the Middle Onion Creek Valley, Hays County, Texas. Studies in Archeology 19, Texas Archeological Research Lab, the University of Texas at Austin.

Riskind, D.H., and D.D. Diamond

1988 An Introduction to Environments and Vegetation. In Edwards Plateau Vegetation: Plant Ecological Studies in Central Texas, edited by B. B. Amos and F. R. Gehlbach, pp. 1-15. Baylor University Press, Waco.

Rogers, R. and B. Dixon

2008 Appendix C: Archaeological Investigation of Site 41TV410 State Highway 130, Segment B, Travis County, Texas in An Intensive Archaeological Survey of State Highway 130: Segments A, B, and C Caldwell, Guadalupe, Travis, and Williamson Counties, Texas. Compiled by R. Rogers and M.K. Russell, with contributions by R. Rogers, B. Dixon, J. Hales, M.K. Russell, S. Victor, L. West, L. Acuna, C. McMurtrie, R. Marie, and C. Caren. PBS\&J Document 060270, PBS\&J Inc., Austin. 


\section{Schiffer, M.B.}

1975 The Effects of Occupation Span on Site Content. In The Cache River Project, edited by M.B. Schiffer and J. House. Pp. 265-269. Arkansas Archaeological Survey, Fayetteville.

Schulte, E.E. and B.G. Hopkins.

1996 Estimation of soil organic matter by weight by weight Loss-On-Ignition. In Soil Organic matter: Analysis and Interpretation, edited by F.R. Magdoff, M.A. Tabatabai and E.A.Hanlon, Jr. pp. 21-32. Special publication No. 46. Soil Sci. Soc. Amer. Madison.

Shafer, H.J and S.A. Tomka

2004 Previous Research and Archeological Background. In Millican Bench (41TV163): a Multicomponent Site in Travis County, Texas. Archaeological Survey Report No. 351. Center for Archaeological Research, the University of Texas at San Antonio and Archeological Studies Program, Report No. 66, Environmental Affairs Division, Texas Department of Transportation, Austin.

Sharp, Z. 2007 Principles of Stable Isotope Geochemistry. Prentiss Hall, Upper Saddle River.

Shoocongdej, R.

2000 Forager Mobility Organization in Seasonal Tropical Environments of Western Thailand. World Archeology. 32(1):14-40.

Shott, M.J.

1989 Diversity, Organization, and Behavior in the Material Record: Ethnographic and Archaeological Examples. Current Anthropology 30:283-315.

Smith, C.S., and L.M. McNees

1999 Facilities and Hunter-Gatherer Long-Term Land Use Patterns: An Example from Southwest Wyoming. American Antiquity 64:117-136.

Southern Regional Climate Center (SRCC)

2003a Normal Daily Minimum Temperature. http://www.srcc.lsu.edu/7100/tmin/USMap.html. Accessed February 2003.

2003b Normal Daily Maximum Temperature. http://www.srcc.lsu.edu/7100/tmax/TX.html. Accessed February 2003.

2003c Normal Monthly Precipitation. http://www.srcc.lsu.edu/7100/prcp/TX.html. Accessed February 2003.

Story, D.A.

1985 Adaptive Strategies of Archaic Cultures of the West Gulf Coastal Plain. In Prehistoric Food Production in North America, edited by R. I. Ford, pp. 19-56. Anthropological Papers No. 75. Museum of Anthropology, University of Michigan, Ann Arbor.

Terri, J.A., and L.G. Stowe 1976 Climatic Patterns and the Distribution of $C_{4}$ Grasses in North American. Oecologia 23:1-12.

Texas Historical Commission 2010 Texas Archaeological Sites Atlas. http://nueces.thc.state.tx.us. Accessed January 15, 2010. 
Texas Department of Transportation

2010 Review of Results of Significance Testing at 41 TV410 and 41 TV540 and Associated Geomorphological Investigations on a Segment of Onion Creek in Travis County, Texas by A. Figueroa, R. Mauldin, C. Frederick, S.A. Tomka and J.L. Thompson. Manuscript on File, Center for Archaeological Research, the University of Texas at San Antonio.

Thompson, J.L.

2006 Post-Fieldwork Report for Phase II Significance Testing of 41TV540, Travis County, Texas. Manuscript on File, Center for Archaeological Research, the University of Texas at San Antonio.

Thoms, A.

2009 Rocks of Ages: Propagation of Hot-Rock Cookery in Western North America. Journal of Archaeological Science 36(3):573-591.

Tieszen, L.L., M. Senyimba, S. Imbamba, and J. Troughton

1979 The distribution of $C_{3}$ and $C_{4}$ grasses and carbon isotope discrimination along an altitudinal and moisture gradient in Kenya. Oecologia 37:337-350.

Tomka, S.A. and B. Meissner

2011 The implications of a modern snail assemblage for archaeological research. Paper presented at the $114^{\text {th }}$ annual meeting of the Texas Academy of Science, Austin.

Tomka, S.A., C. Frederick, A.L. Figueroa, J.L. Thompson, and R.P. Mauldin

2007 Research Design for the Analysis of Archeological Materials Recovered from Phase II Significance Testing of $41 T V 540$ and 41TV410, Travis County, Texas. Manuscript on File, Center for Archaeological Research, University of Texas at San Antonio and Texas Department of Transportation, Environmental Affairs Division, Austin.

Toomey, R.S.

1993 Late Pleistocene and Holocene Faunal Environmental Changes at Hall's Cave, Kerr County, Texas. Ph.D. dissertation, The University of Texas at Austin. University Microfilms, Ann Arbor.

Toomey, R.S., M.D. Blum, and S. Valastro, Jr.

1993 Late Quaternary Climates and Environments of the Edwards Plateau, Texas. Global and Planetary Change 7:299-320.

Turner, E.S. and T.R. Hester

1993 A Field Guide to Stone Artifacts of Texas Indians. 2nd ed. Gulf Publishing, Houston.

United States Fish and Wildlife Service (USFWS)

2003 Balcones Canyonlands National Wildlife Refuge. United States Fish and Wildlife Service. http://southwest.fws.gov/ refuges/texas/balcones/index.htm. Accessed August 23, 2003.

USGS

2007a USGS08158000 Colorado Rv at Austin, TX. no=08158000\&agency cd=USGS. Accessed July, 2007.

2007b USGS 08159000 Onion Ck at US Hwy 183, Austin, TX. http://nwis.waterdata.usgs.gov/tx/nwis/ nwisman/?site_

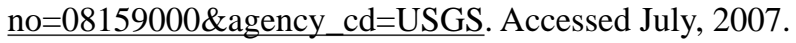

Walker, A.

1986 Oxalate-Extractable Iron and Aluminum. In Field and Laboratory Procedures Used in a Soil Chronosequence Study, edited by M.J. Singer and P. Janitzky, pp. 41-42. U.S. Geological Survey Bulletin 1648, U. S. Geological Survey, Denver. 
Wandsnider, L.

1997 The Roasted and the Boiled: Food Composition and Heat Treatment with Special Emphasis on Pit-Hearth Cooking. Journal of Anthropological Archaeology 16(1):1-48.

Werchan, L.E., A.C. Lowther, and R.N. Ramsey

1974 Soil Survey of Travis County, Texas. United States Department of Agriculture, Soil Conservation Service, in cooperation with the Texas Agricultural Experiment Station. U.S. Government Printing Office, Washington. 



\section{APPENDIX A:}

Plant Remains from 41TV410 and 41TV540

J. Phil Dering 



\section{APPENDIX A \\ Plant Remains from 41TV410 and $41 T V 540$}

\section{Dr. J. Phil Dering}

The purpose of this analysis of 76 macrobotanical samples is to provide an assessment of the botanical assemblages from two sites, 41TV410 and 41TV540. Both of these sites contain Early Archaic features. The data will be utilized to assess the nature and condition of the plant remains from these sites and provide some evidence for plant utilization and local environmental conditions during the Early Archaic along the southeastern periphery of the Edwards Plateau.

\section{Methods}

The analysis followed standard archeobotanical laboratory procedures. Plant material is sorted into two categories -woody fragments, and seed/fruit/bulb fragments. Identification of carbonized wood is accomplished by using the snap technique, examining the fragments at 8 to 45 magnifications with a hand lens or a binocular dissecting microscope, and comparing the material to samples in the archeobotanical herbarium. All seed identifications are made using seed manuals and reference collections at Shumla Archeobotanical Services. Only charred plant material is included in the analysis, because uncarbonized material is consumed by insects, fungi and bacteria and does not survive more than a few years in the deposits of open sites.

Up to 25 wood charcoal fragments large enough to be manipulated are examined and identified from each flotation sample. Fragments smaller than 2- or 3- mm cannot be manipulated and are usually placed in the indeterminate category.

Many of the macrobotanical samples submitted by UTSA-CAR were actually fragments of hardened silty clay with imbedded charred plant material. The plant material was removed by either chipping the clay from the charcoal using a sharp probe or by carefully dropping distilled water on the hard clay to dissolve the material from the charred plant fragments. Many of the black fragments had no remaining internal structure and some of the samples simply dissolved into black flecks. These samples were not identifiable. However, the process worked to free much of the material from the clay and provided fragments large enough to identify.

\section{Results: 41TV540}

Table A-1 presents the identifications, counts, and weights of plant material in the macrobotanical samples arranged by feature and/or field sample (FS) number. Most of the weight in the submitted samples was contributed by the clay in which the charcoal was imbedded. Once the clay was removed, charcoal weight in the 69 samples totaled about 3 grams.

Eight taxa or wood types were identified in the samples (Table A-1,A-2). These include hackberry, persimmon, black walnut, oak, cherry/plum-type, cottonwood/willow-type, and elm wood. The only edible plant material identified in the samples was the lily family bulb-type.

Table A-1. Plant remains from 41TV540

\begin{tabular}{|c|c|c|c|c|c|c|c|}
\hline F.S & Ext. & Feature & Taxon & Common & Part & Count & Wt (g) \\
\hline \multicolumn{8}{|c|}{ Samples from Features } \\
\hline 17 & 1 & 13 & Quercus sp. & Oak & Wood & 13 & 0.2 \\
\hline 18 & 0 & 13 & Liliaceae & cf onion & Bulb fragment & 3 & $<.1$ \\
\hline 18 & 0 & 13 & Quercus sp. & Oak & Wood & 10 & 0.4 \\
\hline 18 & 1 & 13 & Indeterminate & N.A. & Wood & 3 & $<.1$ \\
\hline 22 & 0 & 13 & Indeterminate & N.A. & Wood & 6 & $<.1$ \\
\hline 22 & 3 & 13 & Indeterminate & N.A. & Wood & 3 & $<.1$ \\
\hline 29 & 0 & 13 & Liliaceae & cf onion & Bulb fragment & 2 & $<.1$ \\
\hline 29 & 0 & 13 & Ulmus sp. & Elm & Wood & 9 & 0.3 \\
\hline 29 & 2 & 13 & Rosaceae & Cherry/chokecherry/plum - type & Wood & 6 & 0.2 \\
\hline 56 & 0 & 13 & Indeterminate & N.A. & Wood & 5 & $<.1$ \\
\hline
\end{tabular}


Table A-1. Continued...

\begin{tabular}{|c|c|c|c|c|c|c|c|}
\hline F.S & Ext. & Feature & Taxon & Common & Part & Count & Wt (g) \\
\hline \multicolumn{8}{|c|}{ Samples from Features } \\
\hline 56 & 3 & 13 & Indeterminate & N.A. & Wood & 3 & $<.1$ \\
\hline 56 & 4 & 13 & Quercus sp. & Oak & Wood & 3 & $<.1$ \\
\hline 56 & 6 & 13 & Ulmus sp. & Elm & Wood & 7 & 0.1 \\
\hline 56 & 6 & 13 & Indeterminate & N.A. & Wood & 2 & $<.1$ \\
\hline 59 & 1 & 13 & Indeterminate & N.A. & Wood & 1 & $<.1$ \\
\hline 63 & 0 & 13 & Indeterminate & N.A. & Wood & 2 & $<.1$ \\
\hline 63 & 3 & 13 & Indeterminate & N.A. & Wood & 1 & $<.1$ \\
\hline 25 & 0 & 14 & Indeterminate & N.A. & Wood & 2 & $<.1$ \\
\hline 31 & 0 & 14 & Quercus sp. & Oak & Wood & 2 & $<.1$ \\
\hline 39 & 0 & 14 & Indeterminate & N.A. & Flecks & -- & -- \\
\hline 48 & 1 & 15 & Quercus sp. & Oak & Wood & 6 & 0.1 \\
\hline 227 & 5 & 21 & Indeterminate & N.A. & Wood & 7 & $<.1$ \\
\hline 232 & 3 & $27 / 29$ & Quercus sp. & Oak & Wood & 2 & 0.1 \\
\hline 232 & 5 & $27 / 29$ & Liliaceae & cf onion & Bulb fragment & 2 & 0.1 \\
\hline 243 & 0 & 26 & Disopyros sp. & Persimmon & Wood & 7 & 0.1 \\
\hline 249 & 0 & $27 / 29$ & Quercus sp. & Oak & Wood & 4 & 0.1 \\
\hline 249 & 4 & $27 / 29$ & Liliaceae & cf onion & Bulb fragment & 2 & $<.1$ \\
\hline 249 & 4 & $27 / 29$ & Ulmus sp. & Elm & Wood & 4 & $<.1$ \\
\hline 249 & 4 & $27 / 29$ & Quercus sp. & Oak & Wood & 21 & \\
\hline \multicolumn{8}{|c|}{ Samples from Non-feature Contexts } \\
\hline F.S & Ext. & Feature & Taxon & Common & Part & Count & Wt (g) \\
\hline 6 & 0 & -- & Quercus sp. & Oak & Wood & 4 & $<.1$ \\
\hline 9 & 0 & -- & Salicaceae & Cottonwood/ willow & Wood & 2 & $<.1$ \\
\hline 12 & 0 & -- & Indeterminate & N.A. & Wood & 2 & $<.1$ \\
\hline 14 & 0 & -- & Juglans nigra & Black walnut & Wood & 4 & $<.1$ \\
\hline 15 & 0 & -- & Indeterminate & N.A. & Wood & 2 & $<.1$ \\
\hline 47 & 0 & -- & Indeterminate & N.A. & Wood & 7 & $<.1$ \\
\hline 51 & 1 & -- & Rosaceae & Cherry/chokecherry/plum - type & Wood & 4 & $<.1$ \\
\hline 55 & 0 & $\overline{--}$ & Ulmus sp. & Elm & Wood & 4 & $<.1$ \\
\hline 55 & 5 & -- & Indeterminate & N.A. & Wood & 1 & $<.1$ \\
\hline 74 & 1 & -- & Indeterminate & N.A. & Wood & 3 & $<.1$ \\
\hline 74 & 2 & -- & Indeterminate & N.A. & Wood & 3 & $<.1$ \\
\hline 75 & 0 & -- & Quercus sp. & Oak & Wood & 5 & $<.1$ \\
\hline 75 & 1 & -- & Indeterminate & N.A. & Flecks & -- & -- \\
\hline 83 & 0 & -- & Indeterminate & N.A. & Wood & 2 & $<.1$ \\
\hline 83 & 2 & -- & Quercus sp. & Oak & Wood & 7 & 0.1 \\
\hline 91 & 0 & $\overline{--}$ & Salicaceae & Cottonwood/ willow & Wood & 5 & $<.1$ \\
\hline 92 & 0 & -- & Rosaceae & Cherry/chokecherry/plum - type & Wood & 2 & $<.1$ \\
\hline 92 & 1 & -- & Indeterminate & N.A. & Wood & 2 & $<.1$ \\
\hline 93 & 2 & -- & Ulmus sp. & Elm & Wood & 6 & $<.1$ \\
\hline 99 & 1 & -- & Salicaceae & Cottonwood/ willow & Wood & 5 & $<.1$ \\
\hline 99 & 2 & -- & Quercus sp. & Oak & Wood & 11 & 0.1 \\
\hline 101 & 2 & -- & Rosaceae & Cherry/chokecherry/plum - type & Wood & 2 & $<.1$ \\
\hline 105 & 4 & -- & Ulmus sp. & Elm & Wood & 4 & 0.1 \\
\hline 108 & 0 & -- & Indeterminate & N.A. & Flecks & -- & -- \\
\hline 111 & 1 & -- & Indeterminate & N.A. & Wood & 8 & $<.1$ \\
\hline 119 & 2 & -- & Indeterminate & N.A. & Wood & 2 & $<.1$ \\
\hline 124 & 0 & -- & Quercus sp. & Oak & Wood & 7 & 0.1 \\
\hline 126 & 1 & -- & Celtis sp. & Hackberry & Wood & 9 & 0.1 \\
\hline 129 & 2 & -- & Quercus sp. & Oak & Wood & 6 & 0.1 \\
\hline 132 & 0 & -- & Indeterminate & N.A. & Wood & 1 & $<.1$ \\
\hline 133 & 0 & -- & Indeterminate & N.A. & Wood & 1 & $<.1$ \\
\hline 140 & 0 & -- & Quercus sp. & Oak & Wood & 5 & 0.1 \\
\hline 152 & 1 & -- & Indeterminate & N.A. & Wood & 8 & $<.1$ \\
\hline 156 & 3 & -- & Indeterminate & N.A. & Wood & 1 & $<.1$ \\
\hline 160 & 1 & -- & Diospyros sp. & Persimmon & Wood & 9 & $<.1$ \\
\hline 161 & 1 & -- & Indeterminate & N.A. & Wood & 1 & $<.1$ \\
\hline 190 & 0 & -- & Indeterminate & N.A. & Wood & 6 & $<.1$ \\
\hline 210 & 1 & -- & Quercus sp. & Oak & Wood & 28 & 0.1 \\
\hline 211 & 1 & -- & Quercus sp. & Oak & Wood & 8 & 0.2 \\
\hline 226 & 1 & -- & Indeterminate & N.A. & Wood & 1 & $<.1$ \\
\hline
\end{tabular}


Wood. Carbonized wood was the most common material in the macrobotanical samples. Wood charcoal fragments total approximately 2.8-g. Wood types include taxa typical of riparian vegetation in the region, including black walnut, elm, oak, cherry/plum-type, and willow/cottonwood-type. Oak was the most widespread of the wood types, occurring in $24.6 \%$ of the samples. Elm was noted in $8.7 \%$, cherry/plum-type in 5.8\%, cottonwood/willow type $4.3 \%$, , persimmon in $2.9 \%$, and black walnut and hackberry in $1.4 \%$ of the samples. Oak wood was most abundant, weighing $1.7-\mathrm{g}$, followed by elm at $0.4-\mathrm{g}$ and chokecherry/plum-type weighing about 0.2-g.

Table A-2. Presence value of taxa identified from 41TV540 samples

\begin{tabular}{|l|l|c|c|c|}
\hline \multicolumn{1}{|c|}{ Taxon } & \multicolumn{1}{c|}{ Common } & Part & Samples Present & Percent Present \\
\hline Liliaceae & cf onion & Bulb fragment & 4 & $5.80 \%$ \\
\hline Celtis sp. & Hackberry & Wood & 1 & $1.40 \%$ \\
\hline Juglans nigra & Black walnut & Wood & 1 & $1.40 \%$ \\
\hline Diospyros sp. & Persimmon & Wood & 2 & $2.90 \%$ \\
\hline Salicaceae & Cottonwood/ willow & Wood & 3 & $4.30 \%$ \\
\hline Rosaceae & Cherry/chokecherry/plum - type & Wood & 4 & $5.80 \%$ \\
\hline Ulmus sp. & Elm & Wood & 6 & $8.70 \%$ \\
\hline Quercus sp. & Oak & Wood & 17 & $24.60 \%$ \\
\hline Indeterminate & N.A. & Wood & 28 & $40.60 \%$ \\
\hline
\end{tabular}

Food Resources. Bulb fragments, most likely from plants in the lily family (eg. onion), were identified in 5.8\% of the samples. The fragments were small and the total weight was less than 0.1 -g. Still it is significant that 3 of the features contained evidence for processing bulbs.

Bulbs fragments were present in Features 13 and 27/29. Feature 13 is an amorphous lens of fire cracked rock (FCR), shell, and charcoal. The portion of the feature excavated was $2 \times 2 \mathrm{~m}$, with the estimated size being roughly $5 \mathrm{~m}^{3}$. It is dated to $6160-6140$ and 6190-5940 cal. BP. Feature 27/29 is a much smaller lens of FCR, shell, and charcoal measuring about $50 \mathrm{x} 55 \mathrm{~cm}$ in plan view with multiple dates placing the feature between 6200 and 5900 cal. BP.

\section{Results: 41TV410}

Table A-3 presents the identifications, count, and weight of plant material in the macrobotanical samples arranged by feature and/or field sample (FS) number. Charcoal weight in the seven samples totaled a little over 0.2-grams. Most of the weight in the submitted samples was contributed by the clay in which the charcoal was imbedded.

No edible plant parts were noted and only one wood type, oak, was identified in the samples from 41TV410. Wood charcoal weighed a little over 0.2 -g, and preservation in all of the samples was poor compared to the material from 41TV540. The site probably does not hold much promise for future botanical analysis.

Table A-3. Plant remains from 41TV410

\begin{tabular}{|c|c|c|l|c|c|c|c|}
\hline F.S & Ext. & Feature & Taxon & Common & Part & Count & Wt (g) \\
\hline 346 & 1 & 13 & Indeterminate & N.A. & Wood & 2 & $<.1$ \\
\hline 346 & 2 & 13 & Indeterminate & N.A. & Wood & 7 & $<.1$ \\
\hline 331 & 6 & 19 & Quercus sp. & Oak & Wood & 11 & 0.2 \\
\hline 331 & 13 & 19 & Indeterminate & N.A. & Wood & 1 & $<.1$ \\
\hline 332 & 2 & 19 & Indeterminate & N.A. & Flecks & -- & -- \\
\hline 335 & 3 & 19 & Indeterminate & N.A. & Flecks & -- & -- \\
\hline
\end{tabular}

\section{Discussion}

The recovery of charred bulbs from fire-cracked rock feature contexts at 41V540 is very characteristic of the earth oven cooking process. However, these features do not appear to match the description of earth ovens because they do not contain enough 
rock to comprise a large enough heating element. There are a few explanations for this inconsistency, but first I would like to review some details concerning the earth oven cooking process and its relationship to plant bulbs.

Bulb-producing plants are a type of geophyte, a plant that stores food in below-ground anatomical structures such as a stem or a root. A bulb is composed of modified, thickened leaves arranged around a central compressed stem, such as an onion. The most common plants that produce an edible bulb in Texas belong to the Lily family, including Allium (onion), Nothoscordum (false garlic), Erythronium (dogtooth violet), and Camassia (eastern camas).

At archeological sites, the association of the carbonized remains of these bulbs with fire-cracked rock usually suggests that they were cooked in an earth oven. Earth ovens are utilized for cooking a variety of foods derived from both plants and animals. Although smaller ovens may be used to cook meat for short time periods, the largest and hottest ovens with the longest duration are utilized to cook fatty meats or plant foods (Wandsnider 1997). The use of earth oven cooking would be necessary for individuals to eat large quantities of most bulbs in the Lily family, including onion (Allium sp.), because of the allelopathic or secondary metabolites such as sulfites that are present in most underground storage organs.

In addition, a significant (but variable) percentage of the carbohydrates in most bulbs consist of very large and complex molecules that cannot be digested by humans. They must be broken down by hydrolysis into simpler, smaller compounds before digestion. Hydrolysis, the splitting of chemical bonds by the addition of water, usually at relatively high temperatures, breaks down long chain carbohydrates into digestible short chain sugars (Thoms 1989:157). Wild onions may contain up to 18.1\% non-reducing sugars that need to be broken down before humans can digest them (Yanovsky and Kingsbury 1938).

Hydrolysis of the chemicals in most plants is accomplished by baking them for extended time periods in an earth oven. Using a pit filled with hot rocks that serve as the heating element, the bulbs are wrapped in moist vegetal packing material and buried for at least 24 hours. The resulting steam and heat provide the environment necessary to break down inulin and other indigestible chemicals within the plant. The large chain carbohydrates are reduced in a low oxygen, high temperature environment in the presence of steam, for an extended time in an earth oven, a process that may take from a few hours to over 24 hours.

The archeological signature of large earth ovens is usually characterized by the fire-cracked rock remains of the heating element arranged in a roughly circular fashion in plan-view (Black 1997; Thoms 1989). The features with bulb remains in the current study, notably Features 13 and 27/29, do not fit this description neatly. However, these may be disarticulated features or clean-out areas of other features. Black (1997:262-265) described archeological evidence for oven clean-out events at the Honey Creek site (41MS32). He identified an area of scattered rock, charcoal, and other organic matter associated with an oven that extended $1 \mathrm{~m}$ beyond the perimeter of Feature 7 and Feature 8 at 41MS32 (Black 1997:263). Feature 8 was argued to be the clean-out debris from Feature 7. Carbonized plant remains, which included charred fuel wood and food, were associated with both the oven (Feature 7) and debris located beyond the oven (Feature 8) (Dering 1997:590). The charred plant debris recovered from the clean-out area, which was adjacent to the inferred earth oven, included fragments of yucca/sotol leaf. The plant debris was argued to be a part of the food load that had been accidentally carbonized during the baking process in the oven. Although the surviving fire-cracked rock concentration identified as a clean-out area was given boundaries and designated Feature 8, it consisted of trash, especially charcoal, scattered across the living surface of the site by human activities and other forces such as wind and rain. Therefore, it is probably not unusual to have evidence of bulb remains from features that do not fit the description of a typical oven, as is the case with 41TV540.

Another consideration is that onions do not necessarily have to be cooked as long as other bulbs, such as camas or crow-poison, and the size of the rock heating element could be smaller. Following this argument, Feature 27/29 may have been used to cook onions, even though it is about $50 \mathrm{~cm}$ in width, about half the size of an earth oven (Dering 1999). It is possible that the charred bulb fragments recovered from this smaller feature may have been the by-product of a cooking episode inside that feature.

\section{Early Records of Bulb Cooking along the Eastern Edge of the Edwards Plateau}

The earliest clear record of bulb-baking in an earth oven comes from Wilson-Leonard (41WM235), located on the Edwards Plateau near its eastern edge. Nine AMS assays from Feature 181 were obtained on these bulbs, ranging from $7890+70$ BP to $8130+70$ BP. (Stafford 1998:1054). The heating element of Feature 181 underlies a large concentration of discarded, fire- 
cracked rock that accumulated from the use of numerous earth ovens over the next several centuries. Feature 8, described as a large burned rock accumulation, also yielded a camas bulb with a direct date of $8250+80$ BP.

However, bulbs have been recovered from a growing number of components in the Blackland Prairie just east of the plateau, and two of these are now dated to the late Paleoindian or Early Archaic, (Dering 2007). The Armstrong Site (41CW54) is located east of the Edwards Plateau escarpment on the Blackland Prairie (Schroeder and Oksanen 2002). Two lily family bulb fragments, possibly eastern camas, were recovered from Feature 2, an area covering approximately 1-m diameter and which was composed of three burned rock concentrations and burned caliche in Occupation Zone 3 dated to 6780 BP (Schroeder 2002:23).

Bulb fragments have also been reported from nearby 41TV2125. Feature 11 at 41 TV2125 has been dated to approximately 8000 BP (Dering 2006). This may be roughly contemporaneous with Feature 181 at the Wilson-Leonard site (Bousman et al. 2002). Therefore, the plant assemblage from 41 TV540 is a significant addition to a short list of early components from which bulb remains have been recovered (Dering 2007).

\section{Summary and Conclusion}

The analysis of plant remains from 41TV410 and 41TV540 has noted seven wood types and the presence of bulb fragments, possibly from edible plant bulbs. The yield of charcoal was low, and only about 3-g was identified from 41 TV540 and about 0.2-g from 41TV410. However, low yields are common from sites of this age.

The woody taxa, most of which were identified only from 41TV540, typify vegetation found in the riparian corridor of the Blackland Prairie. The bulb fragments add one more to a growing list of early components from which they have been recovered.

The southern edge of the Blackland Prairie probably was an excellent region for collecting bulb plants, because fire in such ecosystems encourages the growth of plants that keep food in underground storage organs. The use of geophytes likely increased rapidly during the late Paleoindian and Early Archaic periods as reliance on carbohydrates increased (Dering 2007). Streams that cross the Blackland Prairie would have been ideal areas for the exploitation and preparation of bulb-bearing plants because the stream-prairie interface provides the wood necessary to fuel the ovens, and the stream beds the rocks needed for heating elements. The edge effect along the stream would also attract a diversity of wildlife that would complement carbohydrates provided by the bulb foods.

Although the area just beyond the southeastern edge of the escarpment might not ultimately provide the earliest dates for earth oven use, it might show the best evidence for the speed of transition to intensified earth oven use, simply because there may be so many sites with deeply buried contexts in the region. A combination of formation processes and intensive prehistoric use might make the Onion Creek terraces a place which would be expected to produce a larger archeological signature and many more examples of charred bulbs. When considered along with the material from 41TV2125, the record of bulb fragments from three features at 41TV540 suggests that Onion Creek is appropriately named. 


\section{References}

Black, S.L., L.W. Ellis, D.G. Creel and G.T. Goode 1997 Hot Rock Cooking on the Greater Edwards Plateau: Four Burned Rock Midden Sites in West Central Texas. Studies in Archaeology, No. 22. Texas Archeological Research Laboratory, the University of Texas at Austin, Austin.

Bousman, C.B., M. Collins, P. Goldberg, T. Stafford, J. Guy, B. Baker, D.G. Steele, M. Kay, A. Kerr, G. Fredlund, P. Dering, V. Holliday, D. Wilson, W. Gose, S. Dial, Pl Takac, R. Balinsky, M. Masson, and J. Powell 2002 The Palaeoindian-Archaic Transition in North America: New Evidence from Texas. Antiquity 76:980-990.

Dering, J. Phil 1999 Earth-oven Plant Processing in Archaic Period Economies: An Example from a Semi- arid Savannah in Southcentral North America. American Antiquity 64:659-674.

2006 Plant Remains From 41TV2125, Travis County, Texas. Report submitted to Hicks \& Associates, Inc. Austin, Texas. 2007 Assessment of Botanical and Faunal Assemblages from Paleoindian and Early Archaic Components on the Periphery of the Southern Plains. Bulletin of the Texas Archeological Society 78.

Schroeder, E.A

2002 Data Recovery at the Armstrong Site (41CW54) Caldwell County, Texas. Volume II: Cultural Interpretations. Cultural Resources Report No. 0284. Paul Price Associates, Inc., Austin.

Schroeder, E.A, and E.R. Oksanen

2002 Data Recovery at the Armstrong Site (41CW54) Caldwell County, Texas. Volume I: Background, Methods, and Site Contexts. Cultural Resources Report No. 0284. Paul Price Associates, Inc., Austin.

Thoms, Alston V.

1989 The Northern Roots of Hunter-Gatherer Intensification: Camas and the Pacific Northwest. Unpublished Ph.D. dissertation, Department of Anthropology, Washington State University, Pullman.

Wandsnider, LuAnn

1997 The Roasted and the Boiled: Food Composition and Heat Treatment with Special Emphasis on Pit-Hearth Cooking. Journal of Anthropological Archaeology 16:14:8.

Yanovsky, E. \& R.M. Kingsbury 1938. Analyses of some Indian food plants. Association of Official Agricultural Chemists 21(4): 648-655. 


\section{APPENDIX B: \\ Geomorphic Field Descriptions within 41TV410 Charles Frederick}





\section{APPENDIX B \\ Geomorphic Field Descriptions within 41TV410 \\ Dr. Charles Frederick}

Table B-1. 41TV10 Field Descriptions (see Figure 5-17).

Area 1, Block 1.

Geologic Units: A thin drape of Depositional Unit Qa4 rests upon Depositional Unit Qa3.

Comment: The deposits exposed by both Block 1 and Block 2 in Area 1 exhibited similar lithological trends and pedogenic alteration and for this reason, only a column was described.

\begin{tabular}{|c|c|c|c|}
\hline Zone & Depth & Horizon & Description \\
\hline 1 & $0-21$ & $A$ & $\begin{array}{l}\text { Very dark grayish brown (10YR 3/2, m) loam to silty loam, friable, moderate coarse subangular blocky } \\
\text { structure, clear smooth boundary, violently effervescent; Depositional Unit Qa4. }\end{array}$ \\
\hline 2 & $21-61$ & $\mathrm{ABk}$ & $\begin{array}{l}\text { Brown }(10 \text { YR } 4 / 3, \mathrm{~m}) \text { silt loam, friable, weak to moderate coarse subangular blocky structure, gradual smooth } \\
\text { boundary, violently effervescent, many }(\sim 7 \%) \text { calcium carbonate filaments, few patchy coats of calcium } \\
\text { carbonate on ped faces; Depositional Unit Qa4. }\end{array}$ \\
\hline 3 & 61-110 & Bk1 & $\begin{array}{l}\text { Yellowish brown (10YR 5/4, m) loam, friable, weak medium subangular blocky structure, gradual smooth boundary, } \\
\text { violently effervescent, many (10\%) calcium carbonate filaments; charcoal derived from Feature } 12 \text { (in Area 1, in } \\
\text { this approximate stratigraphic position) yielded a radiocarbon ages of } 2180 \pm 40 \text { RCYBP (106 cm below surface; } \\
\text { Beta-216439) and } 2220 \pm 40 \text { RCYBP (117 cm below surface; Beta-216436); Depositional Unit Qa4. }\end{array}$ \\
\hline 4 & $110-130$ & Bk2 & $\begin{array}{l}\text { Brown-strong brown }(7.5 Y R 5 / 5, \mathrm{~m}) \text { silty clay loam to loam, friable, moderate medium subangular blocky } \\
\text { structure, clear smooth boundary, common (7\%) calcium carbonate filaments; Depositional Unit Qa4. }\end{array}$ \\
\hline 5 & $130-170$ & Bk3 & $\begin{array}{l}\text { Brown (7.5YR 5/4 to 7.5YR 4/4, m) silty clay loam, firm, strong medium subangular blocky structure, gradual } \\
\text { smooth boundary, violently effervescent, few }(1 \%) \text { fine }(1-5 \mathrm{~mm}) \text { irregular shaped calcium carbonate nodules; } \\
\text { Depositional Unit Qa3 }\end{array}$ \\
\hline
\end{tabular}

Area 1, Block 2.

Geologic Units: A thin drape of Depositional Unit Qa4 rests upon Depositional Unit Qa3.

Comment: See above.

\begin{tabular}{|c|c|c|c|}
\hline Zone & Depth & Horizon & Description \\
\hline 1 & $0-23$ & A & $\begin{array}{l}\text { Very dark grayish brown (10YR } 3 / 2, \mathrm{~m}) \text { silty clay loam, hard, strong medium to coarse prismatic structure, } \\
\text { clear smooth boundary, violently effervescent, few (1-3\%) calcium carbonate filaments; Depositional Unit Qa4. }\end{array}$ \\
\hline 2 & $23-50$ & $A B$ & $\begin{array}{l}\text { Brown }(10 Y R \text { R/3, m) silt loam to silty clay loam, friable, moderate fine subangular blocky structure parting } \\
\text { to strong medium granular structure, gradual smooth boundary, violently effervescent, few (3\%) calcium } \\
\text { carbonate filaments; Depositional Unit Qa4. }\end{array}$ \\
\hline 3 & $50-76$ & Bw1 & $\begin{array}{l}\text { Dark yellowish brown (10YR 4/4, m) loam, hard, moderate medium to coarse subangular blocky structure, } \\
\text { gradual smooth boundary, violently effervescent, common (5\%) calcium carbonate filaments; Depositional } \\
\text { Unit Qa4. }\end{array}$ \\
\hline 4 & $76-100$ & Bw2 & $\begin{array}{l}\text { Brown-strong brown }(7.5 Y R 5 / 5, \mathrm{~m}) \text { silt loam to loam, friable, moderate to strong medium angular blocky } \\
\text { structure, gradual smooth boundary, common }(7 \%) \text { calcium carbonate filaments; Depositional Unit Qa4. }\end{array}$ \\
\hline 5 & $100-134$ & Bw3 & $\begin{array}{l}\text { Brown ( } 7.5 \text { YR } 5 / 4 \text { to } 7.5 Y R 4 / 4, \mathrm{~m} \text { ) silty clay, firm, strong fine prismatic structure parting to strong fine } \\
\text { subangular blocky structure, , gradual smooth boundary, violently effervescent, charcoal derived from Feature } \\
12 \text { (in Area } 1 \text {, in this approximate stratigraphic position about } 4 \text { northwest of this profile) yielded a radiocarbon } \\
\text { ages of } 2180 \pm 40 \text { RCYBP }(106 \mathrm{~cm} \text { below surface; Beta-216439) and } 2220 \pm 40 \text { RCYBP (117 cm below surface; } \\
\text { Beta-216436); Depositional Unit Qa4. }\end{array}$ \\
\hline 6 & $134-160$ & Bw4 & $\begin{array}{l}\text { Brown }(7.5 Y R \text { 5/4, } m) \text { silty clay, friable, strong medium subangular blocky structure, violently effervescent, few } \\
(3 \%) \text { calcium carbonate filaments; Depositional Unit Qa3. }\end{array}$ \\
\hline
\end{tabular}


Deep Trench, Area 2, Second Terrace.

Geologic Units: A thin drape of Depositional Unit Qa4 rests upon Depositional Unit Qa3.

Comment: Below $2.6 \mathrm{~m}$ the deposits of Depositional Unit Qa3 are a near channel overbank facies comprised of thin bedded occasionally laminated vertically accreted sediment. The stratigraphy of the near surface sediments at 41TV410 was all similar and easily correlated, and in the description below radiocarbon ages from the Area 1 and Area 2 excavations have been projected onto this deep section to provide an image of the chronological structure of the deposits at 41TV410.

\begin{tabular}{|c|c|c|c|}
\hline Zone & Depth & Horizon & Description \\
\hline 1 & $0-21$ & A & $\begin{array}{l}\text { Very dark grayish brown }(10 Y R 3 / 2, \mathrm{~m}) \text { loam to silty loam, friable, moderate coarse subangular blocky } \\
\text { structure, clear smooth boundary, violently effervescent; Depositional Unit Qa4. }\end{array}$ \\
\hline 2 & $21-61$ & ABk & $\begin{array}{l}\text { Brown }(10 Y R \quad 4 / 3, m) \text { silt loam, friable, weak to moderate coarse subangular blocky structure, gradual smooth } \\
\text { boundary, violently effervescent, many }(\sim 10 \%) \text { calcium carbonate filaments, few patchy coats of calcium } \\
\text { carbonate on ped faces; Depositional Unit Qa4. }\end{array}$ \\
\hline 3 & $61-110$ & Bw1 & $\begin{array}{l}\text { Yellowish brown (10YR 5/4, m) loam, friable, weak medium subangular blocky structure, gradual smooth boundary, } \\
\text { violently effervescent, many (10\%) calcium carbonate filaments; charcoal derived from Feature } 12 \text { (in Area 1, in } \\
\text { this approximate stratigraphic position) yielded a radiocarbon ages of } 2180 \pm 40 \text { RCYBP ( } 106 \mathrm{~cm} \text { below surface; } \\
\text { Beta-216439) and } 2220 \pm 40 \text { RCYBP ( } 117 \mathrm{~cm} \text { below surface; Beta-216436); Depositional Unit Qa4. }\end{array}$ \\
\hline 4 & $110-130$ & Bw2 & $\begin{array}{l}\text { Brown-strong brown }(7.5 \text { YR } 5 / 5, \mathrm{~m}) \text { silty clay loam to loam, friable, moderate medium subangular blocky } \\
\text { structure, clear smooth boundary, common (7\%) calcium carbonate filaments; Depositional Unit Qa4. }\end{array}$ \\
\hline 5 & $130-180$ & Bk1 & $\begin{array}{l}\text { Brown }(7.5 \text { YR } 5 / 4 \text { to } 7.5 \text { YR } 4 / 4, \mathrm{~m}) \text { silty clay to silty clay loam, firm, strong medium subangular blocky } \\
\text { structure, gradual smooth boundary, violently effervescent, few }(1 \%) \text { fine }(1-5 \mathrm{~mm}) \text { irregular shaped calcium } \\
\text { carbonate nodules; Depositional Unit Qa3 }\end{array}$ \\
\hline 6 & $180-210$ & Bk2 & $\begin{array}{l}\text { Brown }(7.5 Y R \text { R } 4 / 3, \mathrm{~m}) \text { silty clay, friable, strong fine to medium prismatic structure, gradual smooth boundary, } \\
\text { violently effervescent, few }(1 \%) \text { calcium carbonate filaments, a piece of charcoal collected from Feature } 13 \\
\text { (Area 1, in this approximate stratigraphic position) yielded an age of } 4820 \pm 40 \text { RCYBP (181 cm below surface; } \\
\text { Beta-216440); Depositional Unit Qa3. }\end{array}$ \\
\hline 7 & $210-255$ & Bk3 & $\begin{array}{l}\text { Brown }(7.5 Y R \text { R/3, m) clay, friable, strong medium to coarse subangular blocky structure, clear smooth } \\
\text { boundary, violently effervescent, few }(3 \%) \text { calcium carbonate filaments, few }(1-2 \%) \text { fine to medium (3-5 mm) } \\
\text { irregular shaped calcium carbonate nodules; Depositional Unit Qa3. }\end{array}$ \\
\hline 8 & $255-268$ & C & $\begin{array}{l}\text { Pale brown (10YR 6/3, M) loamy sand to sandy loam, very friable, weak fine subangular blocky structure, } \\
\text { abrupt smooth boundary, violently effervescent, boundary somewhat blurred by worm passage features; } \\
\text { Depositional Unit Qa3. }\end{array}$ \\
\hline 9 & $268-280$ & C & $\begin{array}{l}\text { Yellowish brown (10YR 5/4, m) loam to silt loam, very friable, weak coarse subangular blocky structure, clear } \\
\text { smooth boundary, violently effervescent; Depositional Unit Qa3. }\end{array}$ \\
\hline 10 & $280-290$ & C & $\begin{array}{l}\text { Yellowish brown (10YR 5/4, m) silty clay loam, very friable, moderate medium subangular blocky structure, } \\
\text { abrupt smooth boundary, violently effervescent; Depositional Unit Qa3. }\end{array}$ \\
\hline 11 & $290-307$ & C & $\begin{array}{l}\text { Yellowish brown }(10 \mathrm{YR} 5 / 4, \mathrm{~m}) \text { loam, very friable, weak medium to fine prismatic structure, clear smooth } \\
\text { boundary, violently effervescent, contains small flecks of charcoal throughout, and subtle hints of lamination; } \\
\text { Depositional Unit Qa3. }\end{array}$ \\
\hline 12 & $307-312$ & C & $\begin{array}{l}\text { Yellowish brown (10YR 5/4, m) clay, friable, moderate medium subangular blocky structure, abrupt smooth } \\
\text { boundary, violently effervescent; Depositional Unit Qa3. }\end{array}$ \\
\hline 13 & $312-316$ & C & $\begin{array}{l}\text { Light yellowish brown (10YR 6/4, m) loam, very friable, massive, abrupt smooth boundary, violently } \\
\text { effervescent, laminated; Depositional Unit Qa3. }\end{array}$ \\
\hline 14 & 316-339 & C & $\begin{array}{l}\text { Yellowish brown (10YR 5/4, m) clay, friable, weak medium subangular blocky structure, clear smooth } \\
\text { boundary, violently effervescent; Depositional Unit Qa3. }\end{array}$ \\
\hline 15 & $339-341$ & C & $\begin{array}{l}\text { Pale brown }(10 Y R \text { 6/3, m) silty clay to clay, very friable, weak fine subangular blocky structure, abrupt wavy } \\
\text { boundary, violently effervescent; Depositional Unit Qa3. }\end{array}$ \\
\hline 16 & $341-363$ & C & $\begin{array}{l}\text { Yellowish brown (10YR } 5 / 4, \mathrm{~m} \text { ) silty clay to clay; very friable, weak to moderate medium to fine subangular } \\
\text { blocky structure, diffuse smooth boundary, strongly effervescent, two pieces of charcoal from this zone } \\
\text { were radiocarbon dated, one from Feature } 23 \text { yielded an age of } 5170 \pm 40 \text { RCYBP ( } 352 \mathrm{~cm} \text { below surface; } \\
\text { Beta-216441) and a second not associated with a feature yielded an age } 4760 \pm 40 \text { years BP (Beta-216434); } \\
\text { Depositional Unit Qa3. }\end{array}$ \\
\hline
\end{tabular}


Deep Trench, Area 2, Second Terrace, Continued.

\begin{tabular}{|c|c|c|c|}
\hline Zone & Depth & Horizon & Description \\
\hline 17 & 363-368 & $\mathrm{C}$ & $\begin{array}{l}\text { Burnt zone comprised of yellowish red (5YR 4/6, m, at top) to dark reddish brown ( } 5 \text { YR } 2.5 / 2, \mathrm{~m} \text {, at base) silt } \\
\text { loam, friable to extremely hard, massive to strong angular blocky structure, abrupt smooth boundary, top of } \\
\text { the burnt zone is lithified in places; Burn Zone, Depositional Unit Qa3. }\end{array}$ \\
\hline 18 & 368-374 & $\mathrm{C}$ & $\begin{array}{l}\text { Light yellowish brown (10YR 6/4, m) silt loam, very friable, weak fine subangular blocky structure, abrupt } \\
\text { smooth boundary, violently effervescent; Depositional Unit Qa3 }\end{array}$ \\
\hline 19 & 374-378 & C & $\begin{array}{l}\text { Yellowish brown (10YR 5/4, m) sand and clay, interbedded, firm, weak fine angular blocky structure, abrupt } \\
\text { smooth boundary, violently effervescent; Depositional Unit Qa3. }\end{array}$ \\
\hline 20 & $378-387$ & C & $\begin{array}{l}\text { Yellowish brown (10YR 5/4, m) clay, friable, moderate medium subangular blocky structure, clear smooth } \\
\text { boundary, violently effervescent; Depositional Unit Qa3. }\end{array}$ \\
\hline 21 & $387-404$ & C & $\begin{array}{l}\text { Yellowish brown (10YR 5/4, m) silty clay loam, weak medium to fine subangular blocky structure, abrupt } \\
\text { smooth boundary, violently effervescent,; Depositional Unit Qa3. }\end{array}$ \\
\hline 22 & 404-406 & C & $\begin{array}{l}\text { Yellowish brown (10YR 5/4, m) clay, friable, strong very fine prismatic structure parting to strong fine granular } \\
\text { structure, abrupt smooth boundary, violently effervescent; Depositional Unit Qa3. }\end{array}$ \\
\hline 23 & $406-408$ & C & $\begin{array}{l}\text { Brown }(7.5 Y R 5 / 4, \mathrm{~m}) \text { clay, friable, strong medium granular structure parting to strong fine angular blocky } \\
\text { structure, abrupt smooth boundary, violently effervescent, Colorado River Mud drape; Depositional Unit Qa3. }\end{array}$ \\
\hline 24 & $408-410$ & C & $\begin{array}{l}\text { Yellowish brown (10YR 5/4, m) clay, friable, strong fine angular blocky structure, abrupt smooth boundary, } \\
\text { violently effervescent; Depositional Unit Qa3. }\end{array}$ \\
\hline 25 & $410-415$ & C & $\begin{array}{l}\text { Yellowish brown (10YR 5/4, m) clay, very friable, moderate medium, angular blocky structure, abrupt smooth } \\
\text { boundary, violently effervescent; Depositional Unit Qa3. }\end{array}$ \\
\hline 26 & $415-428$ & C & $\begin{array}{l}\text { Yellowish brown (10YR 5/4, m) loam to silt loam, very friable, weak to moderate medium subangular blocky } \\
\text { structure, abrupt smooth to wavy boundary, violently effervescent; Depositional Unit Qa3. }\end{array}$ \\
\hline 27 & $428-430$ & C & $\begin{array}{l}\text { Yellowish brown (10YR } 5 / 4, \mathrm{~m}) \text { clay, friable, moderate fine angular blocky structure, abrupt smooth boundary, } \\
\text { strongly effervescent, numerous charcoal flecks and Rabdotus snails throughout, a piece of charcoal from this } \\
\text { zone yielded a radiocarbon age of } 4830 \pm 40 \text { RCYBP }(428 \mathrm{~cm} \text { below surface; Beta-216435); Depositional Unit } \\
\text { Qa3. }\end{array}$ \\
\hline 28 & $430-439$ & C & $\begin{array}{l}\text { Yellowish brown (10YR 5/4, m) silty clay to clay, very friable, weak to moderate medium subangular blocky } \\
\text { structure, clear smooth boundary, violently effervescent; Depositional Unit Qa3. }\end{array}$ \\
\hline 29 & $439-448$ & C & $\begin{array}{l}\text { Yellowish brown (10YR 5/4, m) sandy loam to loam, very friable, massive, abrupt wavy boundary, violently } \\
\text { effervescent; Depositional Unit Qa3. }\end{array}$ \\
\hline 30 & $448-450$ & C & $\begin{array}{l}\text { Brown }(7.5 Y R 5 / 4, m) \text { silty clay, very friable, massive to weak medium subangular blocky structure, abrupt } \\
\text { wavy boundary, violently effervescent, Colorado River flood drape; Depositional Unit Qa3. }\end{array}$ \\
\hline 31 & $450-460$ & C & $\begin{array}{l}\text { Light brown (10YR 6/4, m) loam, very friable, massive, abrupt wavy boundary, violently effervescent; } \\
\text { Depositional Unit Qa3. }\end{array}$ \\
\hline 32 & $460-462$ & C & $\begin{array}{l}\text { Yellowish brown to light yellowish brown (10YR 5.5/4, m) slightly gravelly loamy sand, loose to very friable, } \\
\text { single grain, abrupt smooth boundary, violently effervescent, few fine }(1-2 \mathrm{~cm}) \text { matrix supported gravels } \\
\text { scattered across this surface; Depositional Unit Qa3. }\end{array}$ \\
\hline 33 & $462-474$ & C & $\begin{array}{l}\text { Light brown (10YR 6/4, m) loam to sandy loam, very friable, massive to weak medium platy structure, abrupt } \\
\text { wavy boundary, violently effervescent, traces of laminations; Depositional Unit Qa3. }\end{array}$ \\
\hline 34 & $474-475$ & C & $\begin{array}{l}\text { Brown (7.5YR 5/4, m) clay, very friable, massive, abrupt wavy boundary, strongly effervescent, Colorado River } \\
\text { flood drape; Depositional Unit Qa3. }\end{array}$ \\
\hline 35 & $475-488$ & C & $\begin{array}{l}\text { Yellowish brown (10YR 5/4, m) silt loam, very friable, massive, abrupt smooth boundary, violently } \\
\text { effervescent,few fine distinct to prominent strong brown (7.5YR 4/6) cylindrical mottles around pores; } \\
\text { Depositional Unit Qa3 }\end{array}$ \\
\hline 36 & $488-490$ & C & $\begin{array}{l}\text { Pale brown (10YR 6/3, m) silty clay, very friable, weak fine subangular blocky structure, violently effervescent, } \\
\text { common fine to very fine prominent yellowish red }(5 \mathrm{YR} 4 / 6, \mathrm{~m}) \text { cylindrical mottles; Depositional Unit Qa3 }\end{array}$ \\
\hline
\end{tabular}




\section{Deep Trench, Area 3, First Terrace \\ Geologic Units: Depositional Unit Qa4}

Comment: Trench was excavated in the center of a swale at the foot of the T2 scarp anticipating that this arcuate depression was a paleo-channel of Onion Creek. The trench extended to a depth of $7.2 \mathrm{~m}$ and the base of the alluvium was exposed at 6.9 $\mathrm{m}$. No channel deposits were exposed, but a punctuated set of floodplain sediments was recorded in this exposure. Trench was described and sampled for radiocarbon dating by C. Frederick and independently sampled by S. Tomka for radiocarbon and paleoenvironmental analysis. Ground surface elevation at this trench was $98.08 \mathrm{~m}$ using the arbitrary site datum.

\begin{tabular}{|c|c|c|c|}
\hline Zone & Depth & Horizon & Description \\
\hline 1 & $0-110$ & A & $\begin{array}{l}\text { Very dark grayish brown (10YR 3/2, m) clay, friable to firm, strong medium to coarse subangular blocky } \\
\text { structure, gradual smooth boundary, strongly effervescent, this deposit is a clearly cumulic soil with very } \\
\text { subtle hints of bedding; Depositional Unit Qa5. }\end{array}$ \\
\hline 2 & $110-170$ & $2 \mathrm{Ab}$ & $\begin{array}{l}\text { Black to very dark brown (10YR } 2 / 1 \text { to } 10 Y R \text { R } 2 / 2, \mathrm{~m} \text { ) clay, friable, strong medium to coarse angular blocky } \\
\text { structure, diffuse smooth boundary, strongly effervescent, a bulk soil sample collected from a depth of } \\
150-160 \mathrm{~cm} \text { within this zone yielded an age of } 1240 \pm 25 \text { RCYBP (UGSAMS-4407); cumulic soil formed in } \\
\text { Depositional Unit Qa5. }\end{array}$ \\
\hline 3 & $170-230$ & $2 \mathrm{ABb}$ & $\begin{array}{l}\text { Very dark grayish brown (10YR } 3 / 2, \mathrm{~m}) \text { silty clay, friable, strong coarse prismatic structure parting to strong } \\
\text { fine subangular blocky structure, diffuse smooth boundary, violently effervescent, few (3\%) calcium carbonate } \\
\text { filaments; Depositional Unit Qa4. }\end{array}$ \\
\hline 4 & $230-340$ & 2Bwb & $\begin{array}{l}\text { Brown (10YR 4/3, m) silty clay, friable, strong coarse prismatic structure parting to strong fine angular blocky } \\
\text { structure, abrupt smooth boundary, violently effervescent, common (5\%) calcium carbonate filaments; } \\
\text { Depositional Unit Qa4. }\end{array}$ \\
\hline 5 & $340-368$ & $3 A b$ & $\begin{array}{l}\text { Dark brown }(10 Y R 3 / 3, \mathrm{~m}) \text { silty clay, friable, moderate medium subangular blocky structure, clear smooth } \\
\text { boundary, violently effervescent, common ( } 5 \% \text { ) calcium carbonate filaments; a bulk soil sample collected } \\
\text { from } 350-360 \mathrm{~cm} \text { yielded a radiocarbon age of } 2870 \pm 25 \text { RCYBP (UGSAMS-4410); Depositional Unit Qa4. }\end{array}$ \\
\hline 6 & $368-400$ & $3 C$ & $\begin{array}{l}\text { Brown (10YR 4/3, m) silt loam, friable, weak coarse subangular blocky to massive structure, abrupt } \\
\text { smooth boundary, violently effervescent, a prominent burnt zone at } 400 \mathrm{~cm} \text { separated zone } 6 \text { from zone } 7 \text {; } \\
\text { Depositional Unit Qa4. }\end{array}$ \\
\hline 7 & $400-440$ & $4 \mathrm{Ab}$ & $\begin{array}{l}\text { Dark brown }(10 Y R 3 / 3, \mathrm{~m}) \text { silty clay to clay, friable, massive structure, gradual smooth boundary, violently } \\
\text { effervescent, Two bulk soil samples were radiocarbon dated from this zone, one from the top } 5 \mathrm{~cm} \text { of the } \\
\text { deposit }(400-405 \mathrm{~cm}) \text { yielded an age of } 3380 \pm 50 \text { RCYBP (Beta-216428), and a second encompassing the top } \\
10 \mathrm{~cm}(400-410 \mathrm{~cm}) \text { yielded an age of } 3370 \pm 25 \text { RCYBP (UGSAMS-4409); a Rabdotus snail shell collected } \\
\text { from } 410 \mathrm{~cm} \text { was also radiocarbon dated and yielded an age of } 2690 \pm 40 \text { RCYBP (Beta-216429) which when } \\
\text { adjusted for carbon error of } 450 \text { years yields a corrected age of } 2240 \text { RCYBP; Depositional Unit Qa4. }\end{array}$ \\
\hline 8 & $440-450$ & $4 C$ & $\begin{array}{l}\text { Yellowish brown (10YR 5/4, m) silt loam to loam, very friable, massive, abrupt smooth boundary, violently } \\
\text { effervescent; Depositional Unit Qa4. }\end{array}$ \\
\hline 9 & $450-485$ & $5 A b$ & $\begin{array}{l}\text { Dark brown (10YR } 3 / 3, \mathrm{~m}) \text { silty clay, friable, massive, gradual smooth boundary, violently effervescent, } \\
\text { a bulk soil sample collected from a depth of } 460 \mathrm{~cm} \text { yielded a radiocarbon age of } 3250 \pm 25 \text { RCYBP } \\
\text { (UGSAMS-4408). }\end{array}$ \\
\hline 10 & $485-532$ & $5 C$ & $\begin{array}{l}\text { Brown (10YR 4/3, m) silty clay, friable, weak medium subangular blocky structure, gradual smooth boundary, } \\
\text { violently effervescent; Depositional Unit Qa4. }\end{array}$ \\
\hline 11 & $532-585$ & $6 b$ & $\begin{array}{l}\text { Brown (10YR 5/3, m) silty clay, friable, weak medium subangular blocky structure, gradual smooth boundary, } \\
\text { numerous worm casts at base of zone; a bulk soil sample collected from a depth of } 550-560 \mathrm{~cm} \text { within this } \\
\text { zone yielded an radiocarbon age of } 3450 \pm 25 \text { (UGSAMS-4406); Depositional Unit Qa4. }\end{array}$ \\
\hline \multirow[b]{2}{*}{$12 \mathrm{a}$} & \multirow[b]{2}{*}{$585-690$} & \multirow[b]{2}{*}{$6 \mathrm{C}$} & $\begin{array}{l}\text { Zone } 12 \text { was comprised of alternating thin bedded fining upward couplets of sand-loamy sand (zone 12a) and } \\
\text { silt to silty clay/clay (zone 12b) that appear to represent a near channel floodplain depositional environment. }\end{array}$ \\
\hline & & & $\begin{array}{l}\text { Yellowish brown }(10 Y R \text { 5/6, m) sand to loamy sand, loose, single grain to massive, abrupt smooth boundary, } \\
\text { violently effervescent, sandy beds were present at } 613-618 \mathrm{~cm}, 632-636 \mathrm{~cm}, 648-651 \mathrm{~cm}, 659-660 \mathrm{~cm} \text {, and } \\
672-674 \mathrm{~cm} \text {; Depositional Unit Qa4. }\end{array}$ \\
\hline $12 b$ & $585-690$ & $6 C$ & $\begin{array}{l}\text { Pale brown (10YR } 6 / 3, \mathrm{~m}) \text { silt, silty clay and clay, friable, weak medium subangular blocky structure to } \\
\text { massive, abrupt smooth boundary, violently effervescent, most of these deposits fine upward, few fine } \\
\text { prominent reddish brown (5YR 4/6, m) mottles around pores and lining ped faces; a burnt surface was } \\
\text { observed at } 660 \mathrm{~cm} \text { and a sample of this charred sediment yielded a radiocarbon age of } 3820 \pm 40 \text { (Beta- } \\
216431) \text { whereas a sample of bulk sediment from } 680-685 \mathrm{~cm} \text { yielded a radiocarbon age of } 3120 \pm 40 \mathrm{RCYBP} \\
\text { (Beta-216430) and a Rabdotus snail shell collected from the same depth }(685 \mathrm{~cm} \text { ) yielded an age of } 2400 \pm 40 \\
\text { RCYBP (685 cm; Beta-216433) which after correction for carbon error of } 450 \text { years BP yields an age of } 1950 \\
\text { RCYBP; Depositional Unit Qa4. }\end{array}$ \\
\hline
\end{tabular}




\section{APPENDIX C: \\ Geomorphic Field Descriptions within 41TV540 \\ Charles Frederick}





\section{APPENDIX C \\ Geomorphic Field Descriptions within 41TV540 \\ Dr. Charles Frederick}

Table C-1. 41TV540 Test Unit and Trench Descriptions (see Figures 6-22, 6-23, and Figure 6-24 for the thickness and stratigraphic position of each zone in the test units, and Figure 6-21 for the position of the different zones in Trench 2).

Area 1, Test Unit 1.

Geologic Units: Basal beds of Qa3.

Comment: This test unit exposed channel deposits of Onion Creek in the bottom half-meter of the excavation. Overlying these sands and gravels were a series of more massive overbank muds and a single Colorado River mud Drape (Zone 7). Depth s for each zone are not listed below, but the relative position of each can be observed on Figure 6-22). When left to dry the walls of this unit developed a gypsum efflorescence, and although no gypsum was observed when describing the deposits it is likely present and inherited from the Cretaceous bedrock.

\begin{tabular}{|c|c|c|}
\hline Zone & Horizon & Description \\
\hline 1 & C & $\begin{array}{l}\text { Light yellowish brown (10YR 6/4, M) silt loam, friable to firm, moderate medium subangular blocky structure, abrupt } \\
\text { smooth boundary, violently effervescent, faint traces of laminations in places. }\end{array}$ \\
\hline 2 & C & $\begin{array}{l}\text { Strong brown }(7.5 Y R 5 / 6, m) \text { loam, very friable, weak fine subangular blocky structure, abrupt smooth boundary, } \\
\text { violently effervescent. }\end{array}$ \\
\hline 3 & C & $\begin{array}{l}\text { Brown }(7.5 Y R 5 / 4, m) \text { loam to silt loam, friable, weak medium subangular blocky structure, abrupt smooth boundary, } \\
\text { violently effervescent. }\end{array}$ \\
\hline 4 & $\mathrm{C}$ & $\begin{array}{l}\text { Brown }(7.5 Y R 5 / 4, m) \text { loam (zone } 4 a) \text { to silty clay loam (zone } 4) \text {, friable, weak medium to coarse subangular blocky } \\
\text { structure, abrupt smooth boundary, strongly effervescent, together the two zones form a singe gradually fining upward } \\
\text { thick bed. }\end{array}$ \\
\hline 5 & $\mathrm{C}$ & $\begin{array}{l}\text { Brown (7.5YR 5/4, m) loam to clay loam friable, moderate medium prismatic structure parting to moderate medium } \\
\text { angular blocky structure, abrupt smooth boundary, strongly effervescent, this zone looked redder in the field than } \\
\text { bounding deposits but Munsell color failed to show this, but the deposit is thought to be slightly rubified from either: a) } \\
\text { subtle pedogenesis (a less likely interpretation), b) heating associated with one of the ephemeral burn zones (more } \\
\text { likely), or a greater contribution of Colorado River sediment (equally likely as b). }\end{array}$ \\
\hline 6 & C & Pale brown (10YR 6/3, m) loam to silt loam, very friable, massive, abrupt smooth boundary, violently effervescent. \\
\hline 7 & $\mathrm{C}$ & $\begin{array}{l}\text { Brown }(7.5 \mathrm{YR} 5 / 4, \mathrm{~m}) \text { silty clay, friable, weak to moderate fine subangular blocky structure, abrupt smooth boundary, } \\
\text { strongly effervescent, uniform thickness, redder color and clayier texture suggest that this is a Colorado River flood } \\
\text { drape. }\end{array}$ \\
\hline 8 & C & Yellowish brown (10YR 5/4, m) loam, very friable, massive, abrupt smooth boundary, strongly effervescent. \\
\hline 9 & $\mathrm{C}$ & $\begin{array}{l}\text { Yellowish brown-light yellowish brown (10YR 5.5/4) loam, friable, moderate medium to fine subangular blocky structure, } \\
\text { abrupt smooth boundary, violently effervescent. }\end{array}$ \\
\hline 10 & $\mathrm{C}$ & $\begin{array}{l}\text { Light yellowish brown (10YR } 6 / 4, \mathrm{~m}) \text { sandy loam, very friable, weak coarse platy structure to massive, abrupt smooth } \\
\text { boundary, strongly effervescent, faintly laminated, with alternating subtly lighter color sand and slightly darker clay; top } \\
\text { of this bed dips } 15^{\circ}-20^{\circ} \text { to the west. }\end{array}$ \\
\hline 11 & $\mathrm{C}$ & $\begin{array}{l}\text { Pale brown }(10 Y R 6 / 3, m) \text { slightly gravelly sandy loam, very friable to loose, weak coarse platy structure parting to } \\
\text { single grain, abrupt smooth boundary, strongly effervescent, clearly laminated slightly gravelly loamy sand and thin } \\
1-2 \text { mm clay laminae, } \sim 5 \% \text { coarse fragments (matrix supported, subrounded to rounded, } 2-5 \mathrm{~mm} \text { average diameter } \\
\text { limestone and chert). }\end{array}$ \\
\hline 12 & C & $\begin{array}{l}\text { Light olive brown }(2.5 \mathrm{Y} 5 / 3, \mathrm{~m}) \text { slightly gravelly sandy clay, firm, massive, abrupt smooth boundary, strongly } \\
\text { effervescent, } \sim 10 \% \text { coarse fragments (matrix supported, subrounded to rounded, } 2-5 \mathrm{~mm} \text { average diameter limestone } \\
\text { and chert). }\end{array}$ \\
\hline 13 & C & $\begin{array}{l}\text { Light brown very gravelly coarse sand, loose, single grain, abrupt smooth boundary, violently effervescent, } 40-70 \% \\
\text { coarse fragments (clast supported, moderately sorted (better sorted than zone } 14 \text { ), subrounded to rounded limestone } \\
\text { and chert, } 2-5 \mathrm{~mm} \text { average diameter, locally imbricated). }\end{array}$ \\
\hline
\end{tabular}


Area 1, Test Unit 1, Continued.

\begin{tabular}{|c|c|l|}
\hline Zone & Horizon & \multicolumn{1}{|c|}{ Description } \\
\hline 14 & $\mathrm{C}$ & $\begin{array}{l}\text { Dark grayish brown }(2.5 \mathrm{Y} \text { 4/2, m) extremely gravelly clay loam, friable, single grain, abrupt smooth boundary, violently } \\
\text { effervescent, }>90 \% \text { coarse fragments (clast supported, very poorly sorted rounded to subrounded limestone and chert, } \\
\text { average size of which was 5-20 mm in diameter, and imbricated; dark color appears to be inherited from Cretaceous } \\
\text { marl. }\end{array}$ \\
\hline 15 & $\mathrm{C}$ & $\begin{array}{l}\text { Interbedded light olive brown (2.5Y 5/3, m) clay and light yellowish brown (10YR 6/4, m) sand, firm, strong medium } \\
\text { angular blocky structure parting to stromg medium platy structure, abrupt smooth boundary, slightly effervescent, the } \\
\text { clays look like redeposited Cretaceous marl, and contains numerous small snail shell fragments. }\end{array}$ \\
\hline 16 & $\mathrm{C}$ & $\begin{array}{l}\text { Pale brown (10YR 6/3, m) clay loam to sandy clay loam, friable, moderate medium angular blocky structure, abrupt } \\
\text { smooth boundary, violently effervescent, common fine prominent yellowish red (5YR 4/6) mottles along bedding planes } \\
\text { and pores. }\end{array}$ \\
\hline 17 & $\mathrm{C}$ & $\begin{array}{l}\text { Light brownish gray (2.5Y 6/2, m) sandy clay, firm, strong medium angular blocky structure, violently effervescent, } \\
\text { common fine prominent yellowish red (5YR 4/6) mottles along bedding planes and pores. }\end{array}$ \\
\hline
\end{tabular}

\section{Area 1, Test Unit 2.}

Geologic Units: Basal beds of Qa3.

Comment: The central part of the East wall exhibited a concave erosional cut made by a gully that originated on the Cretaceous marl slope immediately to the east. This gully exhibits two cycles of filling in this unit, separated by an erosional surface. The majority of the alluvium filling this gully is Onion Creek overbank or near-channel deposits, but there was one prominent slope deposit (Zone 12) which is a striking clay fragment breccia. A Colorado River mud drape was also present in the first gully fill phase (Zone 13). The relative position of each can be observed on Figure 6-23.

\begin{tabular}{|c|c|c|}
\hline Zone & Horizon & Description \\
\hline 1 & $\mathrm{C}$ & $\begin{array}{l}\text { Yellowish brown (10YR 5/4, m) clay, firm, strong medium prismatic structure parting to strong medium to fine angular } \\
\text { blocky structure, gradual smooth boundary, slightly effervescent, few brown }(10 \mathrm{YR} 5 / 3, \mathrm{~m}) \text { coats on ped faces and lining } \\
\text { pores. }\end{array}$ \\
\hline 2 & $\mathrm{C}$ & $\begin{array}{l}\text { Yellowish brown (10YR 5/4, m) silty clay loam, friable, weak to moderate medium subangular blocky structure, clear } \\
\text { smooth boundary, strongly effervescent. }\end{array}$ \\
\hline 3 & C & $\begin{array}{l}\text { Yellowish brown-light yellowish brown (10YR 5.5/4, m) clay, friable, weak to moderate fine angular blocky structure, } \\
\text { abrupt smooth boundary, violently effervescent. }\end{array}$ \\
\hline 4 & C & $\begin{array}{l}\text { Light olive brown }(2.5 Y 5 / 3, \mathrm{~m}) \text { clay (zone } 4 \mathrm{~b}) \text { and yellowish brown }(10 \mathrm{YR} 5 / 4, \mathrm{~m}) \text { sandy loam (zone } 4 \mathrm{a}) \text {, friable to firm, } \\
\text { massive to moderate medium subangular blocky structure, abrupt smooth boundary, violently effervescent. }\end{array}$ \\
\hline 5 & C & $\begin{array}{l}\text { Brown (7.5YR 5/4, m) clay to silty clay, friable, weak medium subangular blocky structure, abrupt wavy boundary, } \\
\text { strongly effervescent, prominent reddish-hued Colorado River flood drape. }\end{array}$ \\
\hline 6 & C & $\begin{array}{l}\text { Light yellowish brown -very pale brown (10YR } 6.5 / 5, \mathrm{~m}) \text { sandy loam, very friable, weak coarse platy structure, abrupt } \\
\text { smooth boundary, violently effervescent, prominently laminated parallel to lower bounding surface. }\end{array}$ \\
\hline 7 & C & $\begin{array}{l}\text { Yellowish brown-light yellowish brown (10YR 5.5/4, m) sandy loam to sandy clay loam, very friable, weak medium } \\
\text { subangular blocky structure, abrupt smooth boundary, violently effervescent, traces of bedding in places. }\end{array}$ \\
\hline 8 & $\mathrm{C}$ & Yellowish brown (10YR 5/4, m) silty clay, friable, massive, abrupt smooth boundary, violently effervescent. \\
\hline 9 & C & $\begin{array}{l}\text { Yellowish brown (10YR 5/4, m) sandy clay, very friable, weak medium subangular blocky structure top massive, abrupt } \\
\text { discontinuous, slightly effervescent, horizontally laminated. }\end{array}$ \\
\hline 10 & C & $\begin{array}{l}\text { Yellowish brown (10YR 5/4, m) silty clay, friable, massive, abrupt smooth boundary, violently effervescent, horizontally } \\
\text { laminated. }\end{array}$ \\
\hline 11 & C & $\begin{array}{l}\text { Yellowish brown-light yellowish brown (10YR 5.5/4, m) loamy sand, very friable, single grain to massive, abrupt smooth } \\
\text { boundary, violently effervescent, horizontally laminated. }\end{array}$ \\
\hline 12 & C & $\begin{array}{l}\text { Light yellowish brown }(10 Y R 6 / 4, \mathrm{~m}) \text { sandy loam and light olive brown }(2.5 \mathrm{Y} 5 / 3, \mathrm{~m}) \text { clay, very friable, weak medium } \\
\text { platy structure, abrupt smooth boundary, violently effervescent, prominent cross-laminations with silty clay drapes } \\
\text { highlighting bedding, few to common }(10-15 \%) \text { rounded to subangular reworked Cretaceous marl clay balls derived } \\
\text { from upslope. }\end{array}$ \\
\hline
\end{tabular}


Area 1, Test Unit 2, Continued.

\begin{tabular}{|c|c|l|}
\hline Zone & Horizon & \multicolumn{1}{|c|}{ Description } \\
\hline 13 & C & $\begin{array}{l}\text { Yellowish brown (10YR 5/4, m) silty clay, friable, massive, abrupt smooth boundary, strongly effervescent, probably } \\
\text { Colorado River flood drape. }\end{array}$ \\
\hline 14 & C & $\begin{array}{l}\text { Light yellowish brown }(10 Y R \text { 6/4, m) sandy loam, very friable, weak coarse subangular blocky structure, abrupt smooth } \\
\text { boundary, violently effervescent, numerous charcoal flecks throughout, traces of lamination. }\end{array}$ \\
\hline 15 & C & $\begin{array}{l}\text { light olive brown (2.5Y 5/4, m) silty clay, friable, weak coarse platy structure, abrupt smooth boundary, violently } \\
\text { effervescent, numerous charcoal flecks throughout, subtle traces of lamination. }\end{array}$ \\
\hline 16 & $\mathrm{C}$ & $\begin{array}{l}\text { Yellowish brown-light yellowish brown (10YR 5.5/4, m) loam to sandy loam, very friable, weak very coarse platy } \\
\text { structure, abrupt smooth boundary, violently effervescent, multiple thin beds comprise this zone, most appear to be of } \\
\text { similar texture and visual differences are faint. }\end{array}$ \\
\hline 17 & $\mathrm{C}$ & $\begin{array}{l}\text { Light yellowish brown (10YR 6/4, m) silt loam to silty clay loam, very friable, weak medium platy structure, abrupt } \\
\text { smooth boundary, violently effervescent, laminated in places. }\end{array}$ \\
\hline $\mathrm{C}$ & $\begin{array}{l}\text { Yellowish brown-light yellowish brown (10YR 5.5/4, m) sandy loam, very friable, weak coarse platy structure, violently } \\
\text { effervescent, laminated parallel to bounding surface, platy structure is an artifact of the lamination. }\end{array}$ \\
\hline
\end{tabular}

\section{Area 1, Test Unit 3}

Geologic Units: Basal beds of Qa3

Comment: The lower half of this test unit penetrated a complex suite of colluvial-fan deposits which are comprised of strikingly well preserved and partially decomposed clay breccias. These deposits gradually gave way to Onion Creek floodplain sediments in the upper half of the test unit. Three Colorado River mud drapes were observed within the upper half of this test unit. Depths are not listed but the relative position of each can be observed on Figure 6-24.

\begin{tabular}{|c|c|c|}
\hline Zone & Horizon & Description \\
\hline 1 & C & $\begin{array}{l}\text { Very pale brown (10YR } 7 / 3, \mathrm{~d}) \text { silt loam to silty clay loam, firm, strong coarse subangular blockly structure, abrupt } \\
\text { smooth boundary, violently effervescent, few fine }(1 \mathrm{~mm}) \text { distinct brownish yellow (10YR 6/8) mottles. }\end{array}$ \\
\hline 2 & C & $\begin{array}{l}\text { Brown }(10 Y R 5 / 3, m) \text { clay, firm, strong fine angular blocky structure, abrupt smooth boundary, strongly effervescent, few } \\
(1-3 \%) \text { calcium carbonate filaments. }\end{array}$ \\
\hline 3 & C & $\begin{array}{l}\text { Light yellowish brown (10YR 6/4, m) loam, friable, weak medium to coarse subangular blocky structure, abrupt smooth } \\
\text { boundary, strongly effervescent. }\end{array}$ \\
\hline 4 & C & Light yellowish brown (10YR 6/4, m) sand, loose, single grain, abrupt smooth boundary, violently effervescent. \\
\hline 5 & $\mathrm{C}$ & $\begin{array}{l}\text { Grayish brown }(2.5 \mathrm{Y} 5 / 2, \mathrm{~m}) \text { clay and light yellowish brown }(10 \mathrm{YR} 6 / 4, \mathrm{~m}) \text { sand to sandy clay (clay fragment breccia; } \\
\text { angular to subrounded fragments of Taylor Marl embedded within a sand matrix), firm, moderate medium to coarse platy } \\
\text { structure, abrupt smooth boundary, violently effervescent, colluvial fan deposit. }\end{array}$ \\
\hline 6 & C & $\begin{array}{l}\text { Light yellowish brown (10YR 6/4, m) loamy sand, very friable to loose, weak fine platy structure, abrupt smooth to wavy } \\
\text { boundary, strongly effervescent, prominently laminated. }\end{array}$ \\
\hline 7 & Cy & $\begin{array}{l}\text { Pale brown }(10 Y R \text { 6/3, m) sandy loam, very friable, massive, abrupt smooth boundary, strongly effervescent, few }(<1 \%) \\
\text { euhedral 3-5 mm gypsum crystals. }\end{array}$ \\
\hline 8 & C-Cy & $\begin{array}{l}\text { Yellowish brown (10YR 5/4) silt loam, very friable, we medium angular blocky structure, abrupt smooth boundary, } \\
\text { violently effervescent, Colorado River flood drape; few }(<1 \%) \text { euhedral 3-5 mm gypsum crystals. }\end{array}$ \\
\hline 9 & Cy & $\begin{array}{l}\text { Light yellowish brown (10YR 6/4, } \mathrm{m} \text { ) loam to sandy loam, very friable, massive, abrupt smooth boundary, violently } \\
\text { effervescent, few (<1\%) euhedral 3-5 mm gypsum crystals, clearly laminated but appears massive in places. }\end{array}$ \\
\hline 10 & C & $\begin{array}{l}\text { Grayish brown }(2.5 \mathrm{Y} 5 / 2, \mathrm{~m}) \text { clay and light yellowish brown }(10 \mathrm{YR} 6 / 4, \mathrm{~m}) \text { sand to sandy clay (clay fragment breccia; } \\
\text { angular to subrounded fragments of Taylor Marl embedded within a sand matrix), firm, moderate medium to coarse platy } \\
\text { structure, abrupt smooth boundary, violently effervescent, colluvial fan deposit. }\end{array}$ \\
\hline 11 & C & $\begin{array}{l}\text { Grayish brown }(2.5 \mathrm{Y} 5 / 2, \mathrm{~m}) \text { clay and light yellowish brown (10YR } 6 / 4, \mathrm{~m}) \text { sand to sandy clay (clay fragment breccia; } \\
\text { angular to subrounded fragments of Taylor Marl embedded within a sand matrix), firm, moderate medium to coarse platy } \\
\text { structure, abrupt smooth boundary, violently effervescent, colluvial fan deposit. }\end{array}$ \\
\hline
\end{tabular}


Area 1, Test Unit 3, Continued.

\begin{tabular}{|c|c|c|}
\hline Zone & Horizon & Description \\
\hline 12 & $\mathrm{C}$ & $\begin{array}{l}\text { Light olive brown }(2.5 Y 5 / 3, \mathrm{~m}) \text { clay, firm, weak medium to coarse subangular blocky structure, abrupt smooth boundary, } \\
\text { strongly effervescent, few to common 1-5mm rounded fragments of reworked Taylor Marl, traces of lamination, colluvial } \\
\text { fan deposit, partially degraded. }\end{array}$ \\
\hline 13 & $\mathrm{C}$ & $\begin{array}{l}\text { Brown ( } 7.5 Y R 5 / 3, m) \text { silty clay, very friable, weak medium subangular blocky structure, abrupt smooth boundary, } \\
\text { slightly effervescent, Colorado River flood drape. }\end{array}$ \\
\hline 14 & C & $\begin{array}{l}\text { Light yellowish brown (10YR 6/4, m) loam, very friable, single grain to massive, abrupt wavy boundary, violently } \\
\text { effervescent, prominent horizontal laminations composed of alternating sandy and slightly loamier thin beds. }\end{array}$ \\
\hline 15 & C & $\begin{array}{l}\text { Brown ( } 7.5 Y R 5 / 3, m) \text { silty clay, very friable, weak medium subangular blocky structure, abrupt smooth boundary, } \\
\text { slightly effervescent, Colorado River flood drape. }\end{array}$ \\
\hline 16 & $\mathrm{C}$ & $\begin{array}{l}\text { Light yellowish brown (10YR 6/4, m) loam to clay loam, very friable, massive, abrupt smooth boundary, violently } \\
\text { effervescent. }\end{array}$ \\
\hline 17 & C & $\begin{array}{l}\text { Light olive brown }(2.5 Y 5 / 3, \mathrm{~m}) \text { clay, firm, moderate medium to fine angular blocky structure, abrupt smooth boundary, } \\
\text { slightly effervescent, few }(3-5 \%) \text { rounded gray clay clasts derived from the Taylor Marl upslope, few very fine faint } \\
\text { reddish brown (5YR 4/4, m) mottles; colluvial fan deposit, partially degraded. }\end{array}$ \\
\hline 18 & C & $\begin{array}{l}\text { Pale brown }(10 Y R 6 / 3, m) \text { sandy loam, very friable, massive, abrupt smooth boundary, few }(<3 \%) \text { calcium carbonate } \\
\text { filaments, prominently laminated, few fine faint yellowish brown }(10 Y R 5 / 4, m) \text { mottles. }\end{array}$ \\
\hline 19 & $\mathrm{C}$ & $\begin{array}{l}\text { Grayish brown }(2.5 \mathrm{Y} 5 / 2, \mathrm{~m}) \text { clay and light yellowish brown (10YR } 6 / 4, \mathrm{~m}) \text { sand to sandy clay (clay fragment breccia; } \\
\text { angular to subrounded fragments of Taylor Marl embedded within a sand matrix), firm, moderate medium to coarse platy } \\
\text { structure, abrupt smooth boundary, violently effervescent, colluvial fan deposit. }\end{array}$ \\
\hline 20 & C & Yellowish brown (10YR 5/4) loam to sandy clay loam, friable, massive, abrupt smooth boundary, very effervescent. \\
\hline 21 & C & $\begin{array}{l}\text { Grayish brown }(2.5 \mathrm{Y} 5 / 2, \mathrm{~m}) \text { clay loam to clay, friable, weak coarse platy structure, abrupt smooth boundary, violently } \\
\text { effervescent, clearly thin bedded to laminated, few to common } 1-3 \mathrm{~mm} \text { platy light gray }(2.5 \mathrm{Y} 7 / 2) \text { clay fragments; } \\
\text { colluvial fan deposit, partially degraded. }\end{array}$ \\
\hline 22 & C & $\begin{array}{l}\text { Light gray }(2.5 \mathrm{Y} 7 / 1, \mathrm{~m}) \text { to light yellowish brown }(2.5 \mathrm{Y} 6 / 3, \mathrm{~m}) \text { sandy clay (clay fragment breccia), firm, single grain, } \\
\text { abrupt smooth boundary, moderately effervescent, }>90 \% \text { coarse fragments where the coarse fragments are gray } \\
\text { angular clay fragments of Taylor marl; colluvial fan deposit. }\end{array}$ \\
\hline 23 & C & $\begin{array}{l}\text { Light yellowish brown-brownish yellow }(10 \mathrm{YR} 6 / 5, \mathrm{~m}) \text { sand to loamy sand, loose, single grain, abrupt smooth boundary, } \\
\text { violently effervescent, few discontinuous }<1 \mathrm{~mm} \text { clay laminae. }\end{array}$ \\
\hline 24 & C & $\begin{array}{l}\text { Light brownish yellow }(2.5 \mathrm{Y} 6 / 3, \mathrm{~m}) \text { clay to sandy clay, friable to firm, strong medium angular blocky structure parting } \\
\text { to strong fine granular structure, abrupt smooth boundary, slightly effervescent, few (3-5\%) rounded gray clay clasts } \\
\text { derived from the Taylor Marl upslope, colluvial fan deposit, partially degraded. }\end{array}$ \\
\hline 25 & C & $\begin{array}{l}\text { Light yellowish brown (10YR 6/4, m) loam to sandy loam, very friable, massive to single grain, abrupt smooth boundary, } \\
\text { violently effervescent, clearly laminated, minor textural variation within this zone. }\end{array}$ \\
\hline 26 & C & $\begin{array}{l}\text { Light gray }(2.5 \mathrm{Y} 7 / 1, \mathrm{~m}) \text { to light yellowish brown }(2.5 \mathrm{Y} 6 / 3, \mathrm{~m}) \text { sandy clay (clay fragment breccia), firm, single grain, } \\
\text { abrupt smooth boundary, moderately effervescent, }>90 \% \text { coarse fragments where the coarse fragments are gray } \\
\text { angular clay fragments of Taylor marl; colluvial fan deposit. }\end{array}$ \\
\hline 27 & $\mathrm{C}$ & Light yellowish brown (10YR 6/4, m) loamy sand, loose, single grain, abrupt wavy boundary, violently effervescent. \\
\hline 28 & $\mathrm{C}$ & $\begin{array}{l}\text { Light gray }(2.5 \mathrm{Y} 7 / 1, \mathrm{~m}) \text { to light yellowish brown }(2.5 \mathrm{Y} 6 / 3, \mathrm{~m}) \text { sandy clay (clay fragment breccia), firm, single grain, } \\
\text { abrupt smooth boundary, moderately effervescent, }>90 \% \text { coarse fragments where the coarse fragments are gray } \\
\text { angular clay fragments of Taylor marl; colluvial fan deposit. }\end{array}$ \\
\hline 29 & C & $\begin{array}{l}\text { Grayish brown }(2.5 Y 5 / 2, \mathrm{~m}) \text { clay, firm, strong fine granular structure, slightly effervescent, few }(3-5 \%) \text { rounded gray clay } \\
\text { clasts derived from the Taylor Marl upslope, colluvial fan deposit, partially degraded. }\end{array}$ \\
\hline
\end{tabular}


Area 2 Deep Trench

Geologic Units: Depositional Unit Qa3

Comment: Generalized description of the deposits exposed in deep trench excavated in Area 2 at 41TV540. See the long wall drawing (Figure 6-21) for stratigraphic position of each zone.

\begin{tabular}{|c|c|c|}
\hline Zone & Horizon & Description \\
\hline 1 & A & $\begin{array}{l}\text { Very dark gray }(10 \mathrm{YR} 3 / 1, \mathrm{~d}) \text { to black }(10 \mathrm{YR} 2 / 1, \mathrm{~m}) \text { clay, extremely hard, stong extremely coarse prismatic structure } \\
\text { parting to strong coarse subangular blocky structure, clear smooth boundary, violently effervescent, contains numerous } \\
\text { widely dispersed small }(1-3 \mathrm{~mm}) \text { snail shell fragments. }\end{array}$ \\
\hline 2 & $A B$ & $\begin{array}{l}\text { Black (10YR } 2 / 1, m) \text { to very dark gray }(10 Y R 3 / 1, d) \text { clay, extremely hard, strong extremely coarse wedge structure, } \\
\text { gradual smooth boundary, strongly effervescent, common slickensides on ped faces. }\end{array}$ \\
\hline 3 & Bss & $\begin{array}{l}\text { Dark grayish brown (10YR 4/2, d) clay, extremely hard, strong coarse wedge structure, diffuse smooth boundary, } \\
\text { violently effervescent, many slickensides on ped faces. }\end{array}$ \\
\hline 4 & Bssk & $\begin{array}{l}\text { Grayish brown (10YR } 5 / 2, \text { d) clay, extremely hard, strong coarse wedge structure, diffuse smooth boundary, violently } \\
\text { effervescent, few }(2-5 \%) \text { medium to medium }(3 \mathrm{~mm} \text { to } 5 \mathrm{~mm}) \text { faint gray }(10 \mathrm{Y} \text { R } 6 / 1) \text { irregular shaped calcium carbonate } \\
\text { nodules formed between ped faces, few }(3-5 \%) \text { calcium carbonate filaments, many slickensides on ped faces. }\end{array}$ \\
\hline 5 & $\mathrm{ABk}$ & $\begin{array}{l}\text { Dark grayish brown (10YR 4/2, d) clay, extremely hard, strong extremely coarse prismatic structure parting to strong } \\
\text { coarse to fine angular blocky structure, trending towards wedge in a few places diffuse smooth boundary, violently } \\
\text { effervescent, common } 1-3 \mathrm{~mm} \text { wide tongues of very dark gray }(10 \mathrm{YR} 3 / 1, \mathrm{~d}) \text { zone } 1 \text { material (crack fills), common } \\
(5-25 \%) \text { faint pressure faces on ped faces, few }(2-3 \%) \text { fine }(2-5 \mathrm{~mm}) \text { faint gray (10YR } 6 / 1) \text { irregular shaped calcium } \\
\text { carbonate nodules. }\end{array}$ \\
\hline 6 & $\mathrm{Bk}$ & $\begin{array}{l}\text { Grayish brown (10YR } 5 / 2, d) \text { to yellowish brown }(10 Y R 5 / 4, d) \text { clay, extremely hard, strong coarse angular blocky to } \\
\text { strong coarse wedge structure, diffuse smooth boundary, violently effervescent, few to common }(2-7 \%) \text { medium to large } \\
(2 \mathrm{~mm} \text { to } 15 \mathrm{~mm}) \text { faint gray }(10 \mathrm{Y} \mathrm{R} 6 / 1) \text { irregular shaped calcium carbonate nodules, few }(3-5 \%) \text { calcium carbonate } \\
\text { filaments, common to many faint pressure faces on ped surfaces. }\end{array}$ \\
\hline 7 & Bw & $\begin{array}{l}\text { Brown }(7.5 Y R 5 / 4, d) \text { clay, extremely hard, strong medium to fine angular blocky structure, gradual smooth boundary, } \\
\text { violently effervescent, common 5-7\% calcium carbonate filaments, }\end{array}$ \\
\hline 8 & $\mathrm{C} 2$ & $\begin{array}{l}\text { Yellowish brown (10YR 5/4, m) to brownish yellow }(10 \text { YR } 6 / 6, d) \text { loam to sandy loam, friable, weak coarse subangular } \\
\text { blocky structure to massive, abrupt smooth boundary, violently effervescent, few to common }(1-5 \%) \text { calcium carbonate } \\
\text { filaments. }\end{array}$ \\
\hline 9 & C3 & $\begin{array}{l}\text { Yellowish brown (10YR 5/6, m) extremely gravelly loam, loose, single grain, abrupt wavy boundary, } 70-90 \% \text { coarse } \\
\text { fragments which consist of subrounded to rounded limestone ranging from } 2 \text { to } 10 \mathrm{~cm} \text { in diameter, with average clast } \\
\text { size of about } 3 \mathrm{~cm} \text {, some clasts imbricated, most covered entirely with thin calcium carbonate coats. }\end{array}$ \\
\hline
\end{tabular}





\section{APPENDIX D: \\ Geomorphic Field Descriptions and Data Table for Selected Profiles in the Onion Creek Valley Charles Frederick}





\section{APPENDIX D \\ Geomorphic Field Descriptions and Data Table for Selected Profiles within the Onion Creek Valley Dr. Charles Frederick}

Field Descriptions: See Chapter 8 for discussion and selected profiles (Figures 8-3 through 8-8).

Geologic Units: Qa5b (Field Profile LH1).

Comments: Cut bank exposure of Onion Creek. UTM 14R 632078E 3340493N NAD 83.

\begin{tabular}{|c|c|c|c|}
\hline Zone & Depth & Horizon & Description \\
\hline 1 & $0-7$ & $A C$ & $\begin{array}{l}\text { Very dark grayish brown (10YR } 3 / 2, \mathrm{~m}) \text { clay loam, friable, weak fine subangular blocky structure, abrupt } \\
\text { smooth boundary, strongly effervescent, } 1-2 \% \text { coarse fragments. }\end{array}$ \\
\hline 2 & $7-49$ & $A C$ & $\begin{array}{l}\text { Very dark brown }(10 \mathrm{YR} 2 / 2, \mathrm{~m}) \text { clay to clay loam, hard, weak coarse prismatic structure parting to strong } \\
\text { medium subangular blocky structure, clear smooth boundary, strongly effervescent, } 0-3 \% \text { coarse fragments, } \\
\text { contains clear traces of bedding in the form of two intermittent slightly coarser stringers of sand and gravel } \\
\text { around } 17 \text { and } 38 \mathrm{~cm} \text {. }\end{array}$ \\
\hline 3 & $49-52$ & $A C$ & $\begin{array}{l}\text { Grayish brown }(10 \mathrm{YR} 5 / 2, \mathrm{~m}) \text { clay loam, slightly hard to hard, weak medium to fine subangular blocky } \\
\text { structure, clear smooth boundary, strongly effervescent, looks to have been sandier when originally deposited } \\
\text { but finer material has been dispersed into the zone by worm passages. }\end{array}$ \\
\hline 4 & $52-80$ & $A C$ & $\begin{array}{l}\text { Very dark grayish brown }(10 \mathrm{YR} 3 / 2, \mathrm{~m}) \text { clay to clay loam, slightly hard to hard, weak to moderate fine to } \\
\text { medium prismatic structure parting to strong fine subangular blocky structure, abrupt smooth boundary, } \\
\text { strongly effervescent, zone has clear evidence of bedding in the form of thin sand stringers and very faint } \\
\text { traces of lamination. }\end{array}$ \\
\hline 5 & $80-92$ & C & $\begin{array}{l}\text { Brown (10YR } 5 / 3, \mathrm{~m}) \text { sandy clay loam, slightly hard, weak to moderate medium subangular blocky structure, } \\
\text { abrupt smooth boundary, strongly effervescent, many worm casts, } 0-2 \% \text { coarse fragments. }\end{array}$ \\
\hline 6 & $92-98$ & C & $\begin{array}{l}\text { Very dark grayish brown }(10 Y R 3 / 2, \mathrm{~m}) \text { clay loam, hard, moderate medium to fine subangular blocky } \\
\text { structure, abrupt smooth boundary, strongly effervescent, a bulk sediment radiocarbon sample from this zone } \\
\text { yielded an age of } 1470 \pm 30 \text { years BP (UGAMS-5056). }\end{array}$ \\
\hline 7 & $98-102$ & C & $\begin{array}{l}\text { Brown (10YR } 5 / 3, \mathrm{~m} \text { ) clay loam, slightly hard, weak medium subangular blocky structure, abrupt smooth } \\
\text { boundary, violently effervescent, many worm casts. }\end{array}$ \\
\hline 8 & $102-120$ & $A C$ & $\begin{array}{l}\text { Dark grayish brown }(10 Y R 3 / 2, \mathrm{~m}) \text { clay loam, hard to slightly hard, moderate fine prismatic structure parting to } \\
\text { strong fine subangular blocky structure, abrupt smooth to wavy boundary, violently effervescent. }\end{array}$ \\
\hline 9 & $120-127$ & C & $\begin{array}{l}\text { Grayish brown (10YR } 5 / 2, \mathrm{~m}) \text { gravelly clay loam, loose to slightly hard, single grain, abrupt smooth boundary, } \\
50 \% \text { coarse fragments, violently effervescent. }\end{array}$ \\
\hline 10 & $127-139$ & C & $\begin{array}{l}\text { Dark grayish brown (10YR } 4 / 2, \mathrm{~m} \text { ) clay loam, slightly hard, weak to moderate medium subangular blocky } \\
\text { structure, clear smooth boundary, violently effervescent, many worm passages, clear traces of bedding. }\end{array}$ \\
\hline 11 & $139-162$ & $2 \mathrm{Ab}$ & $\begin{array}{l}\text { Very dark grayish brown (10YR } 3 / 2, \mathrm{~m} \text { ) clay loam, slightly hard to hard, moderate medium subangular blocky } \\
\text { structure, clear smooth boundary, strongly effervescent, } 1-2 \% \text { coarse fragments. }\end{array}$ \\
\hline 12 & $162-220$ & C & $\begin{array}{l}\text { Brown (10YR } 5 / 3, \mathrm{~m} \text { ) clay loam to clay, slightly hard to hard, weak to moderate medium to coarse subangular } \\
\text { blocky structure, abrupt smooth boundary, violently effervescent, }<1 \% \text { coarse fragments. }\end{array}$ \\
\hline 13 & $220-240$ & C & $\begin{array}{l}\text { Brown (10YR } 4 / 3, m) \text { sandy clay loam to clay loam, slightly hard, weak coarse subangular blocky structure, } \\
\text { abrupt smooth to wavy boundary, violently effervescent. }\end{array}$ \\
\hline 14 & $238-255$ & C & $\begin{array}{l}\text { Brown (10YR } 4 / 3, \mathrm{~m}) \text { clay loam, slightly hard to hard, weak medium prismatic structure parting to moderate } \\
\text { medium subangular blocky structure, abrupt wavy boundary, violently effervescent. }\end{array}$ \\
\hline 15 & $255-263$ & C & $\begin{array}{l}\text { Brown (10YR } 5 / 3, \mathrm{~m} \text { ) clay loam, slightly hard, weak medium to coarse prismatic structure parting to moderate } \\
\text { medium subangular blocky structure, clear smooth boundary, violently effervescent, }<1 \% \text { coarse fragments. }\end{array}$ \\
\hline 16 & $263-268$ & C & $\begin{array}{l}\text { Brown (10YR } 4 / 3, m) \text { clay loam, slightly hard, massive, abrupt smooth boundary, violently effervescent, }<2 \% \\
\text { coarse fragments, laminated. }\end{array}$ \\
\hline 17 & 268-269 & C & $\begin{array}{l}\text { Black (10YR 2/1, m) clay loam, slightly hard to hard, weak fine angular blocky structure, abrupt discontinuous } \\
\text { boundary, violently effervescent, discontinuous mud drape. }\end{array}$ \\
\hline
\end{tabular}


Geologic Units: Qa5b (Field Profile LH1), Continued.

\begin{tabular}{|c|c|c|c|}
\hline Zone & Depth & Horizon & Description \\
\hline 18 & 269-292 & C & $\begin{array}{l}\text { Brown (10YR 4/3, m) clay loam, friable, weak coarse to medium subangular blocky structure, abrupt smooth } \\
\text { boundary, strongly effervescent, a piece of charcoal collected from this zone at a depth of } 280 \mathrm{~cm} \text { yielded an age of } \\
1250 \pm 25 \text { (UGAMS-5046) and a bulk sediment sample collected from about the same depth }(275-280 \mathrm{~cm}) \text { yielded } \\
\text { an age of } 2470 \pm 30 \text { years BP (UGAMS-5057) which when corrected for age error gives an age of } 2020 \text { years BP. }\end{array}$ \\
\hline 19 & 292-304 & $\mathrm{C}$ & $\begin{array}{l}\text { Dark grayish brown (10YR 4/2, m) clay loam, hard, moderate medium subangular blocky structure, abrupt } \\
\text { smooth boundary, strongly effervescent. }\end{array}$ \\
\hline 20 & 304-328 & $\mathrm{C}$ & $\begin{array}{l}\text { Dark grayish brown (10YR } 4 / 2, \mathrm{~m}) \text { clay loam, slightly hard to hard, weak coarse subangular blocky structure, } \\
\text { clear smooth boundary, strongly effervescent, }<1 \% \text { coarse fragments. }\end{array}$ \\
\hline 21 & $328-345$ & $\mathrm{C}$ & Brown (10YR 4/3, m) clay loam, slightly hard, massive, abrupt smooth boundary, strongly effervescent. \\
\hline 22 & $345-378$ & $\mathrm{C}$ & $\begin{array}{l}\text { Very dark grayish brown to dark grayish brown (10YR } 3.5 / 2, \mathrm{~m} \text { ) clay loam to silty clay loam, friable, weak coarse } \\
\text { subangular blocky structure, abrupt wavy boundary, strongly effervescent, }<3 \% \text { coarse fragments, a bulk sediment } \\
\text { sample collected from } 345-350 \mathrm{~cm} \text { at the top of this zone yielded a radiocarbon age of } 1430+25 \text { (UGAMS-5053). }\end{array}$ \\
\hline 23 & $378-430$ & C & $\begin{array}{l}\text { Very dark grayish brown (10YR } 3 / 2, \mathrm{~m}) \text { slightly gravelly clay loam to very gravelly clay, friable, strong fine } \\
\text { granular structure, abrupt smooth boundary, strongly to violently effervescent, } 20-60 \% \text { coarse fragments. }\end{array}$ \\
\hline 24 & $430-441$ & C & $\begin{array}{l}\text { Very dark grayish brown (10YR } 3 / 2, \mathrm{~m}) \text { clay, friable, weak medium subangular blocky structure, abrupt } \\
\text { smooth boundary, strongly effervescent, } 5-7 \% \text { coarse fragments. }\end{array}$ \\
\hline 25 & 441-449 & C & $\begin{array}{l}\text { Grayish brown (10YR } 5 / 2, \mathrm{~m}) \text { clay, friable, strong fine granular structure, abrupt wavy boundary, strongly } \\
\text { effervescent, } 7 \% \text { coarse fragments. }\end{array}$ \\
\hline 26 & $449-457$ & C & $\begin{array}{l}\text { Dark grayish brown (10YR } 4 / 2, \mathrm{~m}) \text { slightly gravelly clay, friable, strong fine angular blocky structure, clear } \\
\text { wavy boundary, strongly effervescent, } 10-40 \% \text { coarse fragments. }\end{array}$ \\
\hline 27 & $457-462$ & C & $\begin{array}{l}\text { Brown (10YR } 4 / 3, \mathrm{~m}) \text { slightly gravelly clay, very friable, strong fine angular blocky structure, abrupt wavy } \\
\text { boundary, strongly effervescent, } 30-40 \% \text { coarse fragments. }\end{array}$ \\
\hline 28 & $462-470$ & C & $\begin{array}{l}\text { Dark yellowish brown (10YR } 4 / 4, \mathrm{~m}) \text { clay loam, friable, massive, abrupt smooth boundary, strongly } \\
\text { effervescent, } 5 \% \text { coarse fragments. }\end{array}$ \\
\hline 29 & $470-476$ & C & $\begin{array}{l}\text { Brown }(10 Y R 4 / 3, m) \text { clay, friable to very friable, moderate to strong fine to medium granular structure, abrupt } \\
\text { smooth boundary, } 3 \% \text { coarse fragments. }\end{array}$ \\
\hline 30 & $476-484$ & C & $\begin{array}{l}\text { Yellowish brown (10YR 5/4, m) clay loam, very friable, weak medium subangular blocky structure, abrupt } \\
\text { wavy boundary, strongly effervescent. }\end{array}$ \\
\hline 31 & $484-490$ & C & $\begin{array}{l}\text { Brown ( } 7.5 \text { YR } 4 / 3, \mathrm{~m} \text { ) clay loam, very friable, weak medium subangular blocky structure, abrupt smooth to } \\
\text { wavy boundary, strongly effervescent, } 3 \% \text { coarse fragments. }\end{array}$ \\
\hline 32 & $490-500$ & C & $\begin{array}{l}\text { Dark grayish brown (10YR } 4 / 2, \mathrm{~m} \text { ) clay, very friable, strong fine angular blocky structure, many pressure } \\
\text { faces, numerous redeposited Cretaceous Sprinkle Formation clay clasts, a bulk sediment sample collected } \\
\text { from } 490-500 \mathrm{~cm} \text { depth within this zone yielded an age of } 8640 \pm 30 \text { years BP (UGAMS-5059). }\end{array}$ \\
\hline
\end{tabular}

\section{Depositional Units Qa5a (Field Profile LH2)}

Comment: Cut bank exposure of Onion Creek. UTM 14R 631669E 3340322N NAD 83. The radiocarbon ages obtained from near the base of this exposure were both from prehistoric occupation surfaces that contained sparse burned rock and debitage in addition to charcoal and Rabdotus shells.

\begin{tabular}{|c|c|c|l|}
\hline Zone & Depth & Horizon & \multicolumn{1}{|c|}{ Description } \\
\hline 1 & $0-40$ & A & $\begin{array}{l}\text { Very dark grayish brown (10YR 3/2, m) clay loam, firm, strong medium to fine subangular blocky structure, } \\
\text { clear wavy boundary, strongly effervescent. }\end{array}$ \\
\hline 2 & $40-90$ & A to Bk & $\begin{array}{l}\text { Dark brown (10YR 3/3, m) clay loam, firm, strong medium to fine subangular blocky structure, gradual smooth } \\
\text { boundary, strongly effervescent, few to common (3-5\%) calcium carbonate filaments. }\end{array}$ \\
\hline 3 & $90-128$ & A to Bk & $\begin{array}{l}\text { Brown (10YR 4/3, m) clay loam to sandy clay loam, hard, weak very coarse prismatic structure parting } \\
\text { to weak to moderate coarse subangular blocky structure, gradual smooth boundary, strongly to violently } \\
\text { effervescent, few to common (3-5\%) calcium carbonate filaments, a bulk soil sample collected from 115-120 } \\
\text { cm depth in this zone yielded an age of 1560 } 25 \text { RCYBP (UGAMS-5071) and a Rabdotus snail collected } \\
\text { from a depth of 118 cm was also radiocarbon dated and yielded an age of 2550 } 25 \text { RCYBP (UGAMS-5073) } \\
\text { which when corrected for age error yields an age of 2100 RCYBP. }\end{array}$ \\
\hline
\end{tabular}


Geologic Units: Qa5b (Field Profile LH2), Continued.

\begin{tabular}{|c|c|c|c|}
\hline Zone & Depth & Horizon & Description \\
\hline 4 & 128-185 & $\mathrm{Bk}$ & $\begin{array}{l}\text { Dark yellowish brown }(10 \mathrm{YR} 4 / 4, \mathrm{~m}) \text { sandy clay loam to sandy loam, hard, weak very coarse prismatic } \\
\text { structure, clear smooth boundary, violently effervescent, few (3\%) calcium carbonate filaments, }<1 \% \text { coarse } \\
\text { fragments. }\end{array}$ \\
\hline 5 & $185-200$ & $\mathrm{C}$ & $\begin{array}{l}\text { Brown }(7.5 Y R \quad 4 / 4, m) \text { sandy loam, slightly hard, massive, clear smooth boundary, violently effervescent, }<1 \% \\
\text { coarse fragments. }\end{array}$ \\
\hline 6 & $200-233$ & C & $\begin{array}{l}\text { Dark yellowish brown (10YR 4/4, m) sandy loam, slightly hard, single grain, abrupt smooth boundary, violently } \\
\text { effervescent, } 2-7 \% \text { coarse fragments. }\end{array}$ \\
\hline 7 & 233-257 & $2 A b$ & $\begin{array}{l}\text { Dark brown (10YR } 3 / 3, \mathrm{~m}) \text { clay loam, friable, weak medium to coarse subangular blocky structure, clear } \\
\text { smooth boundary, strongly effervescent, few to common (3-5\%) calcium carbonate filaments, a bulk soil } \\
\text { sample from the top of this zone yielded an age of } 2120 \pm 40 \text { RCYBP }(233-240 \mathrm{~cm} \text {; UGAMS-5060) and } \\
\text { a Rabdotus snail collected from } 235 \mathrm{~cm} \text { yielded an age of } 1770 \pm 25 \text { RCYBP (UGAMS-5076) which after } \\
\text { correction for carbon error yields an age of } 1325 \text { RCYBP. }\end{array}$ \\
\hline 8 & $257-280$ & $2 B w$ & $\begin{array}{l}\text { Brown }(7.5 \text { YR } 4 / 3, \mathrm{~m}) \text { clay loam to loam, friable, weak medium subangular blocky structure, diffuse smooth } \\
\text { boundary, strongly to violently effervescent, few to common }(3-5 \%) \text { calcium carbonate filaments. }\end{array}$ \\
\hline 9 & $280-320$ & $2 \mathrm{C}$ & $\begin{array}{l}\text { Brown }(7.5 Y R \quad 4 / 3, m) \text { clay loam to loam, very friable, massive to weak medium subangular blocky structure, } \\
\text { abrupt smooth boundary, strongly effervescent. }\end{array}$ \\
\hline 10 & $320-345$ & $3 A b$ & $\begin{array}{l}\text { Dark brown }(10 Y R 3 / 3, \mathrm{~m}) \text { clay loam, friable, weak to moderate medium to fine subangular blocky structure, } \\
\text { clear smooth boundary, strongly effervescent, few }(3 \%) \text { calcium carbonate filaments. }\end{array}$ \\
\hline 11 & $345-366$ & $3 C$ & $\begin{array}{l}\text { Brown }(7.5 Y R 4 / 3, m) \text { clay loam, friable, weak coarse subangular blocky structure, clear smooth boundary, } \\
\text { strongly effervescent. }\end{array}$ \\
\hline 12 & 366-392 & $3 A C$ & $\begin{array}{l}\text { Brown }(7.5 Y R \quad 4 / 3, m) \text { silty clay loam, friable, weak medium subangular blocky structure, clear smooth } \\
\text { boundary, strongly effervescent. }\end{array}$ \\
\hline 13 & $392-407$ & $3 C$ & $\begin{array}{l}\text { Brown }(7.5 Y R \quad 4 / 3, m) \text { silty clay loam, very friable, weak medium subangular blocky structure, clear smooth } \\
\text { boundary, strongly effervescent. }\end{array}$ \\
\hline 14 & $407-413$ & $3 C$ & Brown $(7.5 Y R$ 4/3, m) clay loam, very friable, massive, clear smooth boundary, strongly effervescent. \\
\hline 15 & $413-453$ & $3 C$ & $\begin{array}{l}\text { Brown }(7.5 Y R 4 / 3, \mathrm{~m}) \text { clay loam, very friable, weak moderate subangular blocky structure, clear smooth } \\
\text { boundary, strongly effervescent, a prehistoric occupation surface was noted in the exposure at ca. } 440 \mathrm{~cm} \\
\text { depth within this zone, which contained a few burnt rock, debitage and a scatter of charcoal. A piece of this } \\
\text { charcoal was radiocarbon dated and yielded an age of } 1120 \pm 25 \text { RCYBP (UGAMS-5047) and a Rabdotus } \\
\text { snail collected from the occupation surface was also radiocarbon dated and yielded an age of } 1570 \pm 25 \\
\text { RCYBP (UGAMS-5074) which when corrected for age error of } 445 \text { years yields an age of } 1125 \text { RCYBP (very } \\
\text { close to the age of the charcoal). }\end{array}$ \\
\hline 16 & $453-461$ & $3 C$ & $\begin{array}{l}\text { Brown }(7.5 Y R 5 / 3, m) \text { clay loam, very friable, weak fine subangular blocky structure to massive, abrupt } \\
\text { smooth boundary, strongly effervescent, few fine faint reddish yellow }(7.5 Y R \text { 6/8) mottles. }\end{array}$ \\
\hline 17 & $461-471$ & $3 C$ & $\begin{array}{l}\text { Brown (10YR 4/3, m) clay loam, very friable, massive, abrupt smooth boundary, strongly effervescent, few } \\
\text { fine faint reddish yellow (7.5YR 6/8) mottles. }\end{array}$ \\
\hline 18 & $471-475$ & $3 \mathrm{C}$ & Brown (10YR 4/3, m) clay loam, very friable, massive, abrupt smooth boundary, strongly effervescent. \\
\hline 19 & $475-490$ & $3 \mathrm{C}$ & $\begin{array}{l}\text { Brown }(7.5 Y R 4 / 3, \mathrm{~m}) \text { clay loam, very friable, massive, abrupt smooth boundary, strongly effervescent, a } \\
\text { prehistoric occupation surface was observed within this zone at a depth of } 475 \mathrm{~cm} \text { and a piece of charcoal } \\
\text { collected from this surface yielded a radiocarbon age of } 1510 \pm 40 \text { RCYBP (UGAMS-5048) and a Rabdotus } \\
\text { snail collected from the same surface yielded a radiocarbon age of } 1960 \pm 25 \text { RCYBP (UGAMS-5075), } \\
\text { which when corrected for age error of } 445 \text { years yields an age of } 1515 \text { RCYBP, very close to the age of the } \\
\text { charcoal. }\end{array}$ \\
\hline 20 & $490-500$ & $3 C$ & rk yellowish brown (10YR 4/4, m) clay loam, very friable, massive, strongly effervescent. \\
\hline
\end{tabular}


Depositional Unit Qa3 (Profile P5).

Comment: This profile was described and collected from the west wall of a borrow pit located west of SH130, south of the Onion Creek Bridge at UTM Zone 14, 631576E 3339764N NAD27.

\begin{tabular}{|c|c|c|c|}
\hline Zone & Depth & Horizon & Description \\
\hline 1 & $0-18$ & Fill & Not described in detail. \\
\hline 2 & $18-46$ & A & $\begin{array}{l}\text { Very dark grayish brown (10YR } 3 / 2, \mathrm{~m} ; 10 \mathrm{YR} 4 / 2, \mathrm{~m}) \text { silty clay loam, friable, moderate to strong coarse } \\
\text { subangular blocky structure, clear smooth boundary, strongly effervescent. }\end{array}$ \\
\hline 3 & $46-100$ & $A B$ & $\begin{array}{l}\text { Very dark grayish brown-dark grayish brown (10YR 3.5/2, m; } 10 \mathrm{YR} 5 / 2 \text {, d) silty clay loam to silty clay, friable, } \\
\text { moderate medium subangular blocky structure, gradual smooth boundary, strongly effervescent. }\end{array}$ \\
\hline 4 & $100-150$ & Bk1 & $\begin{array}{l}\text { Brown }(7.5 Y R \text { 5/2, m; 7.5YR 6/3, d) silty clay, firm, moderate fine subangular blocky structure, gradual smooth } \\
\text { boundary, strongly effervescent, common (3-5\%) calcium carbonate filaments, a bulk sediment sample } \\
\text { collected from } 120-125 \mathrm{~cm} \text { within this zone yielded a radiocarbon age of } 2770 \pm 30 \text { RCYBP (UGAMS-5068) } \\
\text { and a Rabdotus shell collected from slightly deeper }(130-140 \mathrm{~cm} \text { ) yielded a radiocarbon age of } 3410 \pm 30 \\
\text { RCYBP (UGAMS-5082) which after correction for age error yields an adjusted age of } 2965 \text { RCYBP. }\end{array}$ \\
\hline 5 & $150-260$ & Bk2 & $\begin{array}{l}\text { Brown }(7.5 Y R 5 / 3, \mathrm{~m} ; 7.5 Y R 6 / 3, \mathrm{~d}) \text { silty clay, friable, moderate fine to very fine subangular blocky structure, } \\
\text { gradual smooth boundary, strongly effervescent, common } 5-7 \% \text { calcium carbonate filaments, a bulk } \\
\text { sediment sample collected from } 220-225 \mathrm{~cm} \text { within this zone yielded a radiocarbon age of } 4540 \pm 30 \mathrm{RCYBP} \\
\text { (UGAMS-5069). }\end{array}$ \\
\hline 6 & $260-320$ & $\mathrm{C}$ & $\begin{array}{l}\text { Yellowish brown (10YR 5/4, m; 10YR 6/4, d) silty clay loam to silty clay, very friable, weak coarse subangular } \\
\text { blocky structure, clear smooth boundary, strongly effervescent. }\end{array}$ \\
\hline 7 & $320-355$ & $\mathrm{C}$ & $\begin{array}{l}\text { Yellowish brown (10YR 5/4, m; 10YR } 7 / 4 \text {, d) clay loam, friable, moderate medium subangular blocky } \\
\text { structure, abrupt smooth boundary, strongly effervescent, a bulk sediment sample collected from } 340-345 \mathrm{~cm} \\
\text { within this zone yielded a radiocarbon age of } 5480 \pm 70 \text { RCYBP (UGAMS-5070). }\end{array}$ \\
\hline 8 & $355-363$ & $\mathrm{C}$ & $\begin{array}{l}\text { Pale brown }(10 Y R 6 / 3, m ; 10 Y R 7 / 3, d) \text { clay loam, very friable, weak fine subangular blocky structure, abrupt } \\
\text { wavy boundary, violently effervescent. }\end{array}$ \\
\hline 9 & $363-376$ & $\mathrm{C}$ & $\begin{array}{l}\text { Pale brown (10YR 6/3, m; 10YR 7/3, d) clay loam, friable, strong fine angular blocky structure, abrupt smooth } \\
\text { boundary, violently effervescent. }\end{array}$ \\
\hline 10 & $376-384$ & C & $\begin{array}{l}\text { Pale brown (10YR 6/3, m; 10YR 7/3, d) clay loam, very friable, massive, abrupt smooth boundary, violently } \\
\text { effervescent, a piece of charcoal collected from a depth of } 377 \mathrm{~cm} \text { within this zone yielded a radiocarbon age } \\
\text { of } 4940 \pm 30 \text { RCYBP (UGAMS-5050) and a Rabdotus snail shell collected from } 6 \mathrm{~cm} \text { lower }(383 \mathrm{~cm}) \text { yielded a } \\
\text { radiocarbon age of } 6250 \pm 30 \text { RCYBP (UGAMS-5083) which after correction for age error yields an adjusted } \\
\text { age of } 5805 \text { RCYBP. }\end{array}$ \\
\hline 11 & $384-400$ & C & $\begin{array}{l}\text { Pale brown (10YR } 6 / 3, \mathrm{~m} ; 10 \mathrm{YR} 7 / 3, \mathrm{~d}) \text { clay loam, friable, weak fine angular blocky structure, abrupt smooth } \\
\text { boundary, strongly effervescent. }\end{array}$ \\
\hline
\end{tabular}

Depositional Unit Qa3 (Profile P1, near 41TV540).

Comment: This profile was described and collected from the west wall of a borrow pit located east of SH130, south of the Onion Creek Bridge at UTM Zone 14, 631883E 3339307N NAD27.

\begin{tabular}{|c|c|c|c|}
\hline Zone & Depth & Horizon & Description \\
\hline 1 & $0-90$ & $A$ & $\begin{array}{l}\text { Dark brown }(7.5 Y R 3 / 2 \text { to } 4 / 2, \mathrm{~m} ; 7.5 \mathrm{YR} 5 / 3, \mathrm{~d}) \text { clay to silty clay loam, firm, moderate coarse subangular } \\
\text { blocky structure, strongly effervescent, few }(1 \%) \text { calcium carbonate filaments. }\end{array}$ \\
\hline 2 & $90-160$ & Bw & $\begin{array}{l}\text { Brown }(7.5 \text { YR } 5 / 3, \mathrm{~m} ; 7.5 \text { YR } 6 / 3, \mathrm{~m} \text { ) clay to silty clay loam, friable, moderate medium subangular blocky } \\
\text { structure parting to strong fine subangular blocky structure, gradual smooth boundary, violently effervescent, } \\
\text { few to common ( } 3-5 \% \text { ) calcium carbonate filaments, a sample of bulk sediment collected from } 105-110 \mathrm{~cm} \\
\text { within this zone yielded a radiocarbon age of } 3350 \pm 30 \text { RCYBP (UGAMS-5063) and a Rabdotus snail shell } \\
\text { collected from } 90-100 \mathrm{~cm} \text { yielded a age of } 2470 \pm 30 \text { RCYBP (UGAMS-5080) which after correction for age } \\
\text { error yields an age of } 2025 \text { RCYBP. }\end{array}$ \\
\hline
\end{tabular}


Depositional Unit Qa3 (Profile P1, near 41TV540), Continued.

\begin{tabular}{|c|c|c|c|}
\hline Zone & Depth & Horizon & Description \\
\hline 3 & $160-250$ & Bk1 & $\begin{array}{l}\text { Brown }(7.5 Y R 5 / 3, \mathrm{~m} ; 7.5 Y R \text { R } 6 / 4, \mathrm{~m}) \text { silty clay loam, firm, strong medium subangular blocky structure, gradual } \\
\text { smooth boundary, violently effervescent, few }(1 \%) \text { fine }(2-3 \mathrm{~mm}) \text { irregular shaped calcium carbonate nodules, } \\
\text { few }(1 \%) \text { calcium carbonate filaments, a sample of bulk sediment collected from } 220-225 \mathrm{~cm} \text { within this zone } \\
\text { yielded a radiocarbon age of } 3360 \pm 30 \text { RCYBP (UGAMS-5064) and a Rabdotus snail shell collected from } 219 \text { - } \\
226 \mathrm{~cm} \text { yielded a age of } 5390+30 \text { RCYBP (UGAMS-5081) which after correction for age error yields an age of } \\
4950 \text { RCYBP. }\end{array}$ \\
\hline 4 & $250-300$ & Bk2 & $\begin{array}{l}\text { Brown }(7.5 \text { YR } 5 / 3, \mathrm{~m} ; 7.5 \mathrm{YR} 7 / 3, \mathrm{~m}) \text { silty clay loam to silty clay, friable, strong fine to medium prismatic } \\
\text { structure, gradual smooth boundary, violently effervescent, common }(5 \%) \text { calcium carbonate filaments. }\end{array}$ \\
\hline 5 & $300-358$ & C & $\begin{array}{l}\text { Brown }(7.5 Y R 5 / 3, \mathrm{~m} ; 7.5 Y R 7 / 3, \mathrm{~m}) \text { silty clay, friable, moderate medium subangular blocky structure, abrupt } \\
\text { smooth boundary, violently effervescent, a prehistoric occupation surface was noted at } 315 \mathrm{~cm} \text { depth and } \\
\text { a piece of charcoal from this surface yielded a radiocarbon age of } 4900 \pm 30 \mathrm{RCYBP}(\text { UGAMS-5049) and a } \\
\text { sample of bulk sediment collected from } 321-325 \mathrm{~cm} \text { within this zone yielded a radiocarbon age of } 6390 \pm 30 \\
\text { RCYBP (UGAMS-5065). }\end{array}$ \\
\hline 6 & 358-368 & C & $\begin{array}{l}\text { Brown }(7.5 Y R \text { R } 5 / 4, \mathrm{~m} ; 7.5 \mathrm{YR} 6 / 4, \mathrm{~m}) \text { silty clay, very friable, weak to moderate medium to fine subangular } \\
\text { blocky structure, diffuse smooth boundary, strongly effervescent, a prominent burnt zone was noted within } \\
\text { this zone. }\end{array}$ \\
\hline 7 & $368-400$ & C & $\begin{array}{l}\text { Brown }(7.5 \text { YR } 5 / 3, \mathrm{~m} ; 7.5 \mathrm{YR} 6 / 4, \mathrm{~m}) \text { silty clay loam to clay loam, friable, weak to moderate coarse prismatic } \\
\text { structure, abrupt wavy boundary, violently effervescent, few (1\%) calcium carbonate filaments, a sample of } \\
\text { bulk sediment collected from } 395-400 \mathrm{~cm} \text { within this zone yielded a radiocarbon age of } 6410 \pm 30 \mathrm{RCYBP} \\
\text { (UGAMS-5066). }\end{array}$ \\
\hline
\end{tabular}

\section{Depositional Unit Qa2 (Profile L1; 41TV2125).}

Comment: This profile was described and collected from the east wall of a borrow pit located east of SH130, south of the Onion Creek Bridge at UTM Zone 14, 632231E 3339461N NAD83.

\begin{tabular}{|c|c|c|c|}
\hline Zone & Depth & Horizon & Description \\
\hline 1 & $0-25$ & $A$ & $\begin{array}{l}\text { Very dark grayish brown (10YR } 3.5 / 2, \mathrm{~m} ; 10 \mathrm{YR} 5 / 2 \text {, d) clay, very hard, moderate coarse subangular blocky } \\
\text { structure, clear smooth boundary, strongly effervescent. }\end{array}$ \\
\hline 2 & $25-65$ & $A B$ & $\begin{array}{l}\text { Dark grayish brown (10YR 4/2, m; 10YR } 5 / 2.5 \text {, d) clay, hard, strong to moderate coarse subangular blocky } \\
\text { structure, gradual smooth boundary, strongly effervescent. }\end{array}$ \\
\hline 3 & $65-90$ & Bw & $\begin{array}{l}\text { Brown (10YR 5/3, m; 10YR 4/3, d) clay, hard, moderate medium to coarse subangular blocky structure, } \\
\text { strongly effervescent, few (1\%) calcium carbonate filaments. }\end{array}$ \\
\hline 4 & $90-110$ & Bk1 & $\begin{array}{l}\text { Brown }(7.5 Y R 5 / 3, \mathrm{~m} ; 7.5 \mathrm{YR} 7 / 4, \mathrm{~d}) \text { clay, hard, moderate coarse to medium subangular blocky structure, } \\
\text { gradual smooth boundary, strongly effervescent, common (5-7\%) calcium carbonate filaments, common (3- } \\
5 \% \text { ) medium ( } 3-7 \mathrm{~mm}) \text { pinkish gray }(7.5 \mathrm{YR} 7 / 2) \text { irregular shaped calcium carbonate nodules. }\end{array}$ \\
\hline 5 & $110-150$ & Bk2 & $\begin{array}{l}\text { Brown }(7.5 Y R 5 / 3, \mathrm{~m} ; 7.5 Y R \text { R } 6 / 4, \mathrm{~d}) \text { clay loam, hard, moderate medium prismatic structure parting to } \\
\text { moderate medium tom fine subangular blocky structure, gradual wavy boundary, strongly effervescent, few } \\
(3 \%) \text { medium }(3-7 \mathrm{~mm}) \text { pinkish gray }(7.5 \mathrm{YR} 7 / 2) \text { irregular shaped calcium carbonate nodules, a bulk sediment } \\
\text { sample collected from a depth of } 120-125 \mathrm{~cm} \text { yielded a radiocarbon age of } 5140 \pm 30 \text { RCYBP (UGAMS-5052) } \\
\text { and a Rabdotus snail shell collected from } 118 \mathrm{~cm} \text { depth yielded an age of } 7130 \pm 30 \text { RCYBP (UGAMS-5072) } \\
\text { which when corrected for age error yields an age of } 6685 \text { RCYBP. }\end{array}$ \\
\hline 6 & $150-200$ & Bk3 & $\begin{array}{l}\text { Brown }(7.5 Y R 5 / 4, \mathrm{~m} ; 7.5 \text { YR } 6 / 4, \mathrm{~d}) \text { clay loam, hard, moderate medium to coarse subangular blocky structure, } \\
\text { clear smooth boundary, strongly effervescent, common (3-5\%) calcium carbonate filaments. }\end{array}$ \\
\hline 7 & $200-240$ & C & $\begin{array}{l}\text { Brown }(7.5 Y R \text { 5/4, m; } 7.5 Y R \text { R/4, d) clay loam, hard to slightly hard, weak coarse subangular blocky structure, } \\
\text { clear smooth boundary, strongly effervescent, few }(1 \%) \text { calcium carbonate filaments, a bulk sediment } \\
\text { sample collected from a depth of } 220-225 \mathrm{~cm} \text { within this zone yielded a radiocarbon age of } 7990 \pm 30 \mathrm{RCYBP} \\
\text { (UGAMS-5053). }\end{array}$ \\
\hline 8 & $240-270$ & C & $\begin{array}{l}\text { Yellowish brown (10YR 5/4, m; 10YR 6/4, d) clay loam, hard, moderate fine to medium subangular blocky } \\
\text { structure, gradual smooth boundary, strongly effervescent, few (1-3\%) calcium carbonate filaments. }\end{array}$ \\
\hline
\end{tabular}


Depositional Unit Qa2 (Profile L1; 41TV2125), Continued.

\begin{tabular}{|c|c|c|c|}
\hline Zone & Depth & Horizon & Description \\
\hline 9 & $270-328$ & Bk' & $\begin{array}{l}\text { Yellowish brown (10YR } 5 / 4, \mathrm{~m} \text {; 10YR } 6 / 4, \mathrm{~d}) \text { clay loam to clay, hard to slightly hard, strong medium to } \\
\text { fine subangular blocky structure, clear smooth boundary, strongly effervescent, common }(3-5 \%) \text { calcium } \\
\text { carbonate filaments, few }(3 \%) \text { very coarse }(5-20 \mathrm{~mm} \text { ) cylindrical white calcium carbonate nodules, a bulk } \\
\text { sediment sample collected from a depth of } 320-325 \mathrm{~cm} \text { within this zone yielded a radiocarbon age of } 8400 \pm 30 \\
\text { RCYBP (UGAMS-5054). }\end{array}$ \\
\hline 10 & $328-360$ & C & $\begin{array}{l}\text { Brown-yellowish brown (10YR 5.5/3, m; 10YR 6.5/3, d) clay loam, hard, massive, clear smooth boundary, } \\
\text { strongly effervescent. }\end{array}$ \\
\hline 11 & $360-365$ & C & $\begin{array}{l}\text { Brown (10YR } 5 / 3, \mathrm{~m} \text {; } 10 \mathrm{YR} 7 / 3 \text {, d) clay loam, slightly hard, massive, clear smooth boundary, strongly } \\
\text { effervescent } 5-7 \% \text { coarse fragments. }\end{array}$ \\
\hline 12 & $365-405$ & C & $\begin{array}{l}\text { Brown-yellowish brown (10YR } 5.5 / 3, \mathrm{~m} ; 10 \mathrm{YR} 7 / 3, \mathrm{~d}) \text { clay loam to clay, hard, moderate coarse to medium } \\
\text { subangular blocky structure, clear smooth boundary, strongly effervescent, few (1\%) calcium carbonate } \\
\text { filaments, a bulk sediment sample collected from a depth of } 381-386 \mathrm{~cm} \text { within this zone yielded a } \\
\text { radiocarbon age of } 9420 \pm 30 \text { RCYBP (UGAMS- } 5055) \text { whereas a piece of charcoal collected from a prehistoric } \\
\text { occupation surface at the same depth yielded an age of } 8290 \pm 30 \text { years BP (UGAMS-5045). }\end{array}$ \\
\hline 13 & $405-425$ & C & $\begin{array}{l}\text { Light yellowish brown (10YR 6/4, m; 10YR 7/3, d) clay, hard, weak coarse subangular blocky structure, clear } \\
\text { smooth boundary, strongly effervescent. }\end{array}$ \\
\hline 14 & $425-480$ & $\mathrm{C}$ & $\begin{array}{l}\text { Brown (7.5YR 5/4, m; } 7.5 Y R \text { R/4, d) clay loam to sandy clay loam, hard, weak medium prismatic structure } \\
\text { parting to weak coarse subangular blocky structure, abrupt smooth boundary, strongly effervescent, a bulk } \\
\text { sediment sample collected from a depth of } 460-465 \mathrm{~cm} \text { within this zone yielded an age of } 9190 \pm 30 \text { RCYBP } \\
\text { (UGAMS-5051) and charcoal collected from a prehistoric occupation surface at } 470 \mathrm{~cm} \text { yielded an age of } \\
8250 \pm 30 \text { RCYBP (UGAMS-5054). }\end{array}$ \\
\hline 15 & $480-500$ & C & Brown (7.5YR 5/4, m; 7.5YR 6/4, d) sandy clay loam, slightly hard, massive, strongly effervescent. \\
\hline
\end{tabular}

\section{Depositional Unit Qa1 (Profile LP-1).}

Geologic Units: Depositional Unit Qa1 draped by a time transgressive veneer of Holocene alluvium.

Comment: Cutbank exposure of Onion Creek, UTM: Zone 14R, 632011E, 3340595N NAD83.

\begin{tabular}{|c|c|c|c|}
\hline Zone & Depth & Horizon & Description \\
\hline 1 & $0-45$ & A & $\begin{array}{l}\text { Very dark gray (10YR 3/1, m; 10YR3/1.5, d) clay loam to silty clay loam, hard, strong medium to fine } \\
\text { subangular blocky structure, gradual smooth boundary, strongly effervescent, Depositional Unit Qa5. }\end{array}$ \\
\hline 2 & $45-77$ & $A B$ & $\begin{array}{l}\text { Very dark grayish brown (10YR } 3 / 2, \mathrm{~m} ; 10 \mathrm{YR} 4 / 2 \text {, d) clay loam, hard, weak medium prismatic structure } \\
\text { parting to strong medium to fine subangular blocky structure, clear smooth boundary, strongly effervescent, } \\
\text { common ( } 7 \% \text { ) calcium carbonate filaments, common worm casts, a Rabdotus snail collected from } 45 \mathrm{~cm} \\
\text { depth yielded an age of } 1940 \pm 25 \text { (UGAMS-5079; } 1495 \text { RCYBP after correction for age error), Depositional } \\
\text { Unit Qa4. }\end{array}$ \\
\hline 3 & $77-130$ & $\begin{array}{l}\text { AB to } \\
\text { Bk }\end{array}$ & $\begin{array}{l}\text { Brown }(7.5 \mathrm{YR} 4 / 3, \mathrm{~m} ; 10 \mathrm{YR} 6 / 3, \mathrm{~d}) \text { clay loam, hard, weak to moderate medium to fine prismatic structure } \\
\text { parting to moderate fine subangular blocky structure, diffuse smooth boundary, strongly effervescent, } \\
\text { common (5-7\%) calcium carbonate filaments, Depositional Unit Qa3/Qa4. }\end{array}$ \\
\hline 4 & $130-170$ & Bk1 & $\begin{array}{l}\text { Brown (10YR } 4 / 3, \mathrm{~m} ; 7.5 \mathrm{YR} 5 / 3, \mathrm{~d}) \text { clay loam, slightly hard to hard, strong medium subangular blocky } \\
\text { structure, gradual wavy boundary, strongly effervescent, few to common }(2-5 \%) \text { calcium carbonate filaments, } \\
\text { common } 1-1.5 \mathrm{~cm} \text { wide black line wasp burrows, a Rabdotus snail collected from } 145 \mathrm{~cm} \text { depth yielded a } \\
\text { radiocarbon age of } 4220 \pm 40 \text { RCYBP (UGAMS-5078), which after correction for age error is } 3775 \mathrm{RCYBP} \text {, } \\
\text { Depositional Unit Qa3. }\end{array}$ \\
\hline 5 & $170-225$ & 2Bk1 & $\begin{array}{l}\text { Light yellowish brown (10YR 6/4, m; 10YR 6/4, d) clay loam, hard, weak to moderate medium subangular } \\
\text { blocky structure, diffuse smooth boundary, strongly effervescent, few to common (2-3\%) } 5-8 \mathrm{~mm} \text { prominent } \\
\text { white irregular shaped calcium carbonate nodules, common } 1-1.5 \mathrm{~cm} \text { wide black line wasp burrows, a } \\
\text { bulk sediment sample collected from } 175-180 \mathrm{~cm} \text { within this zone yielded an age of } 4820 \pm 30 \text { RCYBP } \\
\text { (UGAMS-5062) and a Rabdotus snail shell from } 180 \mathrm{~cm} \text { yielded an age of } 5440 \pm 30 \text { RCYBP (UGAMS-5077), } \\
\text { which when corrected for carbon error of } 445 \text { years yields an age of } 4995 \text { RCYBP which is only slightly (175 } \\
\text { years) older than the bulk sample, Depositional Unit Qa1/Qa3. }\end{array}$ \\
\hline
\end{tabular}


Depositional Unit Qa1 (Profile LP-1), Continued.

\begin{tabular}{|c|c|c|c|}
\hline Zone & Depth & Horizon & Description \\
\hline 6 & $225-290$ & 2Bk2 & $\begin{array}{l}\text { Brownish yellow (10YR 6/6, m; 10YR 7/5, d) clay loam, hard, weak fine prismatic structure parting to weak } \\
\text { fine to medium subangular blocky structure, abrupt smooth boundary, violently effervescent, common (7- } \\
15 \% \text { ) coarse }(3-15 \mathrm{~mm} \text { ) prominent white pisolitic/irregular calcium carbonate nodules, matrix appears to have } \\
\text { abundant finely disseminated secondary calcium carbonate, Depositional Unit Qa1. }\end{array}$ \\
\hline 7 & $290-330$ & 2Bk3 & $\begin{array}{l}\text { Yellowish brown (10YR 5/6, m; 10YR 6/6, d) sandy clay loam to sandy clay, slightly hard, massive, abrupt } \\
\text { smooth boundary, violently effervescent, few coarse distinct reddish yellow ( } 7.5 \mathrm{YR} 6 / 8) \text { mottles, common } \\
\text { to many ( } 5-15 \%) \text { medium to coarse }(2-7 \mathrm{~mm}) \text { prominent white calcium carbonate nodules occurring in } \\
\text { sub-horizontal bands about } 5 \mathrm{~cm} \text { wide and containing about } 7-15 \% \text { nodules, sediment has prominent sub- } \\
\text { horizontal lamination, Depositional Unit Qa1. }\end{array}$ \\
\hline 8 & $330-340$ & 2Bk4 & $\begin{array}{l}\text { Light yellowish brown-brownish yellow (10YR 6/5, m; 10YR 6/4, d) sandy loam, hard, massive, abrupt wavy } \\
\text { boundary, violently effervescent, common }(5 \%) \text { fine to medium }(2-7 \mathrm{~mm}) \text { prominent white irregular shaped } \\
\text { calcium carbonate nodules, Depositional Unit Qa1. }\end{array}$ \\
\hline 9 & $340-360$ & $2 B C$ & $\begin{array}{l}\text { Yellowish brown (10YR 5/6, m; 10YR 6/6, d) slightly gravelly sandy loam, loose, single grain, abrupt wavy } \\
\text { boundary, strongly effervescent, prominent cross-laminations, } 20-30 \% \text { coarse fragments, Depositional } \\
\text { Unit Qa1. }\end{array}$ \\
\hline 10 & $360-385$ & 2Bk1' & $\begin{array}{l}\text { Pale yellow }(2.5 Y 7 / 3, \mathrm{~m} \text {; 10YR } 6 / 4, \mathrm{~d}) \text { clay loam, friable, strong medium to coarse angular blocky structure, } \\
\text { abrupt smooth boundary, violently effervescent, many coarse prominent reddish yellow }(7.5 \mathrm{YR} 6 / 8) \text { thread } \\
\text { like mottles on ped faces and lining pores, many coarse prominent white irregular shaped calcium carbonate } \\
\text { nodules, a bulk sediment sample collected from } 370-375 \mathrm{~cm} \text { within this zone yielded an age of } 11740 \pm 40 \\
\text { RCYBP (UGAMS-5061), Depositional Unit Qa1. }\end{array}$ \\
\hline 11 & $385-408$ & 2Bk2' & $\begin{array}{l}\text { Yellowish brown (10YR 5/6, m; 10YR 6/6, d) slightly gravelly to gravelly loamy sand, loose to soft, single } \\
\text { grain, abrupt smooth boundary, violently effervescent, common medium distinct white irregular shaped } \\
\text { calcium carbonate nodules, few coarse distinct strong brown (7.5YR 5/6) mottles, 20-40\% coarse fragments, } \\
\text { Depositional Unit Qa1. }\end{array}$ \\
\hline 12 & $408-415$ & $2 \mathrm{C}$ & $\begin{array}{l}\text { Yellowish brown (10YR 5/6, m; 10YR 6/6, d) very gravelly sandy loam, loose to soft, single grain, abrupt } \\
\text { smooth boundary, } 70 \% \text { coarse fragments, Depositional Unit Qa1 }\end{array}$ \\
\hline 13 & $415-430$ & $2 \mathrm{Bt}$ & $\begin{array}{l}\text { Yellowish red }(5 Y R 5 / 6, \mathrm{~m} ; 5 \mathrm{YR} 6 / 6, \mathrm{~d}) \text { extremely gravelly sandy loam, loose, single grain, abrupt smooth } \\
\text { boundary, violently effervescent, many clasts }(5-0-90 \%) \text { have black }(\mathrm{N} 2 / 0) \text { manganese coats, many }(50-90 \%) \\
\text { have thick prominent yellowish red clay coats around clasts and bridging grains, Depositional Unit Qa1. }\end{array}$ \\
\hline 14 & $430-470$ & $2 \mathrm{Bt}$ & $\begin{array}{l}\text { Yellowish red ( } 5 \text { YR } 5 / 6, \mathrm{~m} \text {; } 5 \text { YR } 6 / 6, d \text { ) very gravelly sandy loam, loose, single grain, abrupt smooth boundary, } \\
\text { violently effervescent, prominently fining upward cross-beds, top half of zone has clay coats and manganese } \\
\text { coats like zone } 13 \text {, lower half does not, 50-60\% coarse fragments, Depositional Unit Qa1. }\end{array}$ \\
\hline 15 & $470-495$ & $2 \mathrm{C}$ & $\begin{array}{l}\text { Yellowish brown (10YR 5/6, m; 10YR 6/6, d) very gravelly loamy sand and extremely gravelly sandy loam, } \\
\text { loose, single grain, abrupt wavy boundary, >60\% coarse fragments, Depositional Unit Qa1. }\end{array}$ \\
\hline
\end{tabular}




\section{Characterization Data for Sediments from Profiles Used in Chapter 8}

P5 Profile with Gravel

\begin{tabular}{|c|c|c|c|c|c|c|c|c|c|c|c|c|}
\hline \multicolumn{3}{|l|}{ P5 Profile } & \multicolumn{10}{|c|}{ With Gravel } \\
\hline $\begin{array}{l}\text { Interval } \\
\text { Depth }\end{array}$ & \# & depth & $\begin{array}{c}\% \\
\geq 63 \mu\end{array}$ & $\% \geq 2 \mu$ & $\begin{array}{c}\% \\
\text { gravel }\end{array}$ & $\begin{array}{c}\% \\
\text { sand }\end{array}$ & $\%$ silt & $\begin{array}{c}\% \\
\text { clay }\end{array}$ & mean & $\mathrm{sd}$ & skew & kurt \\
\hline $18-32$ & 1 & 25 & 26.2 & 65.1 & 0.0 & 26.2 & 38.9 & 34.9 & 7.35 & 4.32 & 0.04 & 0.31 \\
\hline $32-46$ & 2 & 39 & 17.9 & 61.9 & 0.0 & 17.9 & 44.0 & 38.1 & 7.86 & 4.00 & 0.03 & 0.35 \\
\hline $46-66$ & 3 & 57 & 13.6 & 61.7 & 0.0 & 13.6 & 48.1 & 38.3 & 8.08 & 3.79 & 0.09 & 0.33 \\
\hline $66-86$ & 4 & 76 & 10.6 & 59.7 & 0.0 & 10.6 & 49.1 & 40.3 & 8.23 & 3.72 & 0.06 & 0.33 \\
\hline $86-100$ & 5 & 93 & 6.6 & 57.4 & 0.0 & 6.6 & 50.8 & 42.6 & 8.92 & 3.16 & 0.22 & 0.07 \\
\hline $100-110$ & 6 & 105 & 5.8 & 57.2 & 0.0 & 5.8 & 51.4 & 42.8 & 8.50 & 3.60 & 0.07 & 0.32 \\
\hline $110-120$ & 7 & 115 & 5.3 & 56.6 & 0.0 & 5.3 & 51.3 & 43.4 & 8.52 & 3.60 & 0.07 & 0.31 \\
\hline $120-130$ & 8 & 125 & 5.1 & 57.7 & 0.0 & 5.1 & 52.6 & 42.3 & 8.49 & 3.57 & 0.09 & 0.32 \\
\hline $130-140$ & 9 & 135 & 4.5 & 57.9 & 0.0 & 4.5 & 53.4 & 42.1 & 8.52 & 3.54 & 0.10 & 0.32 \\
\hline $140-150$ & 10 & 145 & 4.7 & 59.4 & 0.0 & 4.7 & 54.7 & 40.6 & 8.48 & 3.49 & 0.11 & 0.33 \\
\hline $150-160$ & 11 & 155 & 4.4 & 58.8 & 0.0 & 4.4 & 54.4 & 41.2 & 8.53 & 3.47 & 0.11 & 0.34 \\
\hline $160-170$ & 12 & 165 & 4.2 & 58.0 & 0.0 & 4.2 & 53.8 & 42.0 & 8.55 & 3.51 & 0.09 & 0.32 \\
\hline $170-180$ & 13 & 175 & 3.8 & 57.9 & 0.0 & 3.8 & 54.2 & 42.1 & 8.63 & 3.42 & 0.12 & 0.34 \\
\hline $180-190$ & 14 & 185 & 3.4 & 57.4 & 0.0 & 3.4 & 54.0 & 42.6 & 8.63 & 3.42 & 0.10 & 0.34 \\
\hline $190-200$ & 15 & 195 & 3.3 & 57.1 & 0.0 & 3.3 & 53.9 & 42.9 & 8.64 & 3.46 & 0.11 & 0.11 \\
\hline $200-210$ & 16 & 205 & 6.9 & 56.4 & 0.0 & 6.9 & 49.6 & 43.6 & 8.60 & 3.56 & 0.09 & 0.36 \\
\hline $210-220$ & 17 & 215 & 5.1 & 55.0 & 0.0 & 5.1 & 49.9 & 45.0 & 8.74 & 3.43 & 0.07 & 0.38 \\
\hline $220-230$ & 18 & 225 & 4.0 & 56.7 & 0.0 & 4.0 & 52.7 & 43.3 & 8.63 & 3.49 & 0.09 & 0.33 \\
\hline $230-240$ & 19 & 235 & 3.8 & 56.5 & 0.0 & 3.8 & 52.7 & 43.5 & 8.78 & 3.38 & 0.14 & 0.37 \\
\hline $240-250$ & 20 & 245 & 3.8 & 56.2 & 0.0 & 3.8 & 52.4 & 43.8 & 8.70 & 3.43 & 0.10 & 0.35 \\
\hline $250-260$ & 21 & 255 & 10.2 & 58.4 & 0.0 & 10.2 & 48.2 & 41.6 & 8.32 & 3.74 & 0.06 & 0.34 \\
\hline $260-270$ & 22 & 265 & 14.5 & 59.1 & 0.0 & 14.5 & 44.6 & 40.9 & 8.11 & 3.94 & 0.05 & 0.31 \\
\hline $270-280$ & 23 & 275 & 13.2 & 60.0 & 0.0 & 13.2 & 46.8 & 40.0 & 8.53 & 3.44 & 0.20 & 0.08 \\
\hline $280-290$ & 24 & 285 & 16.2 & 62.6 & 0.0 & 16.2 & 46.5 & 37.4 & 7.92 & 3.93 & 0.10 & 0.29 \\
\hline $290-300$ & 25 & 295 & 17.2 & 63.4 & 0.0 & 17.2 & 46.1 & 36.6 & 7.88 & 3.96 & 0.13 & 0.29 \\
\hline $300-310$ & 26 & 305 & 28.0 & 65.0 & 0.0 & 28.0 & 37.1 & 35.0 & 7.51 & 4.25 & 0.09 & 0.27 \\
\hline $310-320$ & 27 & 315 & 28.4 & 65.2 & 0.0 & 28.4 & 36.8 & 34.8 & 7.47 & 4.24 & 0.12 & 0.27 \\
\hline $320-330$ & 28 & 325 & 33.2 & 67.5 & 0.0 & 33.2 & 34.3 & 32.5 & 7.30 & 4.22 & 0.16 & 0.26 \\
\hline $330-340$ & 29 & 335 & 32.8 & 66.2 & 0.0 & 32.8 & 33.3 & 33.8 & 7.37 & 4.27 & 0.13 & 0.25 \\
\hline $340-350$ & 30 & 345 & 31.6 & 67.8 & 0.0 & 31.6 & 36.2 & 32.2 & 7.28 & 4.16 & 0.16 & 0.28 \\
\hline $350-360$ & 31 & 355 & 39.7 & 71.2 & 0.0 & 39.7 & 31.5 & 28.8 & 7.02 & 4.15 & 0.43 & 0.29 \\
\hline $360-370$ & 32 & 365 & 23.4 & 70.3 & 0.0 & 23.4 & 46.9 & 29.7 & 7.41 & 3.78 & 0.22 & 0.36 \\
\hline $370-380$ & 33 & 375 & 36.4 & 69.4 & 0.0 & 36.4 & 33.0 & 30.6 & 7.23 & 4.18 & 0.30 & 0.21 \\
\hline $380-390$ & 34 & 385 & 34.6 & 67.5 & 0.0 & 34.6 & 32.9 & 32.5 & 7.27 & 4.15 & 0.11 & 0.28 \\
\hline $390-400$ & 35 & 395 & 30.5 & 68.9 & 0.0 & 30.5 & 38.4 & 31.1 & 7.33 & 4.01 & 0.23 & 0.31 \\
\hline
\end{tabular}

P5 Profile without Gravel

\begin{tabular}{|c|c|c|c|c|c|c|c|c|c|c|c|c|}
\hline \multicolumn{1}{|c|}{ P5 Profile Continued } & \multicolumn{1}{l|}{ Without Gravel } \\
\hline $\begin{array}{c}\text { Interval } \\
\text { Depth }\end{array}$ & $\#$ & depth & $\begin{array}{c}\% \\
\geq 63 \mu\end{array}$ & $\% \geq 2 \mu$ & $\begin{array}{c}\% \\
\text { gravel }\end{array}$ & $\begin{array}{c}\% \\
\text { sand }\end{array}$ & $\%$ silt & $\begin{array}{c}\% \\
\text { clay }\end{array}$ & mean & sd & skew & kurt \\
\hline $18-32$ & 1 & 25 & 26.2 & 65.1 & 0.0 & 26.2 & 38.9 & 34.9 & 7.35 & 4.32 & 0.04 & 0.31 \\
\hline $32-46$ & 2 & 39 & 17.9 & 61.9 & 0.0 & 17.9 & 44.0 & 38.1 & 7.86 & 4.00 & 0.03 & 0.35 \\
\hline $46-66$ & 3 & 57 & 13.6 & 61.7 & 0.0 & 13.6 & 48.1 & 38.3 & 8.04 & 3.83 & 0.08 & 0.32 \\
\hline $66-86$ & 4 & 76 & 10.6 & 59.7 & 0.0 & 10.6 & 49.1 & 40.3 & 8.22 & 3.73 & 0.06 & 0.33 \\
\hline $86-100$ & 5 & 93 & 6.6 & 57.4 & 0.0 & 6.6 & 50.8 & 42.6 & 8.49 & 3.59 & 0.07 & 0.34 \\
\hline $100-110$ & 6 & 105 & 5.8 & 57.2 & 0.0 & 5.8 & 51.4 & 42.8 & 8.50 & 3.60 & 0.07 & 0.32 \\
\hline $110-120$ & 7 & 115 & 5.3 & 56.6 & 0.0 & 5.3 & 51.3 & 43.4 & 8.52 & 3.60 & 0.07 & 0.31 \\
\hline
\end{tabular}


P5 Profile without Gravel, Continued...

\begin{tabular}{|c|c|c|c|c|c|c|c|c|c|c|c|c|}
\hline \multicolumn{3}{|l|}{ P5 Profile } & \multicolumn{10}{|c|}{ Without Gravel } \\
\hline $\begin{array}{c}\text { Interval } \\
\text { Depth }\end{array}$ & $\#$ & depth & $\begin{array}{c}\% \\
\geq 63 \mu \\
\end{array}$ & $\% \geq 2 \mu$ & \begin{tabular}{|c|}
$\%$ \\
gravel \\
\end{tabular} & $\begin{array}{c}\% \\
\text { sand }\end{array}$ & $\%$ silt & $\begin{array}{c}\% \\
\text { clay }\end{array}$ & mean & sd & skew & kurt \\
\hline $120-130$ & 8 & 125 & 5.1 & 57.7 & 0.0 & 5.1 & 52.6 & 42.3 & 8.49 & 3.57 & 0.09 & 0.32 \\
\hline $130-140$ & 9 & 135 & 4.5 & 57.9 & 0.0 & 4.5 & 53.4 & 42.1 & 8.52 & 3.54 & 0.10 & 0.32 \\
\hline $140-150$ & 10 & 145 & 4.7 & 59.4 & 0.0 & 4.7 & 54.7 & 40.6 & 8.48 & 3.49 & 0.11 & 0.34 \\
\hline $150-160$ & 11 & 155 & 4.4 & 58.8 & 0.0 & 4.4 & 54.4 & 41.2 & 8.53 & 3.47 & 0.11 & 0.34 \\
\hline $160-170$ & 12 & 165 & 4.2 & 58.0 & 0.0 & 4.2 & 53.8 & 42.0 & 8.55 & 3.51 & 0.09 & 0.33 \\
\hline $170-180$ & 13 & 175 & 3.8 & 57.9 & 0.0 & 3.8 & 54.2 & 42.1 & 8.63 & 3.42 & 0.12 & 0.35 \\
\hline $180-190$ & 14 & 185 & 3.4 & 57.4 & 0.0 & 3.4 & 54.0 & 42.6 & 8.63 & 3.42 & 0.10 & 0.35 \\
\hline $190-200$ & 15 & 195 & 3.3 & 57.1 & 0.0 & 3.3 & 53.9 & 42.9 & 8.64 & 3.46 & 0.11 & 0.34 \\
\hline $200-210$ & 16 & 205 & 6.9 & 56.4 & 0.0 & 6.9 & 49.6 & 43.6 & 8.60 & 3.56 & 0.09 & 0.36 \\
\hline $210-220$ & 17 & 215 & 5.1 & 55.0 & 0.0 & 5.1 & 49.9 & 45.0 & 8.74 & 3.43 & 0.07 & 0.38 \\
\hline $220-230$ & 18 & 225 & 4.0 & 56.7 & 0.0 & 4.0 & 52.7 & 43.3 & 8.63 & 3.49 & 0.09 & 0.34 \\
\hline $230-240$ & 19 & 235 & 3.8 & 56.5 & 0.0 & 3.8 & 52.7 & 43.5 & 8.78 & 3.38 & 0.14 & 0.37 \\
\hline $240-250$ & 20 & 245 & 3.8 & 56.2 & 0.0 & 3.8 & 52.4 & 43.8 & 8.70 & 3.43 & 0.10 & 0.35 \\
\hline $250-260$ & 21 & 255 & 10.2 & 58.4 & 0.0 & 10.2 & 48.2 & 41.6 & 8.32 & 3.74 & 0.06 & 0.34 \\
\hline $260-270$ & 22 & 265 & 14.5 & 59.1 & 0.0 & 14.5 & 44.6 & 40.9 & 8.10 & 3.95 & 0.05 & 0.30 \\
\hline $270-280$ & 23 & 275 & 13.2 & 60.0 & 0.0 & 13.2 & 46.8 & 40.0 & 8.11 & 3.87 & 0.07 & 0.31 \\
\hline $280-290$ & 24 & 285 & 16.2 & 62.6 & 0.0 & 16.2 & 46.5 & 37.4 & 7.92 & 3.93 & 0.10 & 0.29 \\
\hline $290-300$ & 25 & 295 & 17.2 & 63.4 & 0.0 & 17.2 & 46.1 & 36.6 & 7.88 & 3.96 & 0.13 & 0.29 \\
\hline $300-310$ & 26 & 305 & 28.0 & 65.0 & 0.0 & 28.0 & 37.1 & 35.0 & 7.51 & 4.25 & 0.09 & 0.27 \\
\hline $310-320$ & 27 & 315 & 28.4 & 65.2 & 0.0 & 28.4 & 36.8 & 34.8 & 7.47 & 4.24 & 0.12 & 0.27 \\
\hline $320-330$ & 28 & 325 & 33.2 & 67.5 & 0.0 & 33.2 & 34.3 & 32.5 & 7.30 & 4.22 & 0.16 & 0.26 \\
\hline $330-340$ & 29 & 335 & 32.8 & 66.2 & 0.0 & 32.8 & 33.3 & 33.8 & 7.37 & 4.27 & 0.13 & 0.25 \\
\hline $340-350$ & 30 & 345 & 31.6 & 67.8 & 0.0 & 31.6 & 36.2 & 32.2 & 7.28 & 4.16 & 0.16 & 0.28 \\
\hline $350-360$ & 31 & 355 & 39.7 & 71.2 & 0.0 & 39.7 & 31.5 & 28.8 & 7.02 & 4.15 & 0.43 & 0.29 \\
\hline $360-370$ & 32 & 365 & 23.4 & 70.3 & 0.0 & 23.4 & 46.9 & 29.7 & 7.41 & 3.78 & 0.22 & 0.36 \\
\hline $370-380$ & 33 & 375 & 36.4 & 69.4 & 0.0 & 36.4 & 33.0 & 30.6 & 7.23 & 4.18 & 0.30 & 0.27 \\
\hline $380-390$ & 34 & 385 & 34.6 & 67.5 & 0.0 & 34.6 & 32.9 & 32.5 & 7.27 & 4.15 & 0.11 & 0.28 \\
\hline $390-400$ & 35 & 395 & 30.5 & 68.9 & 0.0 & 30.5 & 38.4 & 31.1 & 7.33 & 4.01 & 0.23 & 0.31 \\
\hline
\end{tabular}

P5 Profile

\begin{tabular}{|c|c|c|c|c|c|c|c|c|c|c|}
\hline \multicolumn{11}{|l|}{ P5 Profile } \\
\hline $\begin{array}{l}\text { Interval } \\
\text { Depth }\end{array}$ & $\#$ & depth & $X$ & $\begin{array}{c}\text { Total } \\
\text { C }\end{array}$ & $\begin{array}{c}\text { Organic } \\
\mathrm{C}\end{array}$ & $\begin{array}{c}\% \\
\text { CCE }\end{array}$ & $\mathrm{d}^{13} \mathrm{C}$ & Fed & $\mathrm{Fe} \mathrm{ox}$ & $\begin{array}{c}\text { Bulk } \\
\text { Density }\end{array}$ \\
\hline $18-32$ & 1 & 25 & 58.24 & 7.82 & 2.30 & 78.1 & -16.21 & 4707 & 459 & 1.82 \\
\hline $32-46$ & 2 & 39 & 60.85 & 7.60 & 1.96 & 76.9 & -16.26 & 4750 & & \\
\hline $46-66$ & 3 & 57 & 57.38 & 7.21 & 1.64 & 76.0 & -15.53 & 4275 & & \\
\hline $66-86$ & 4 & 76 & 56.59 & 7.11 & 1.46 & 73.9 & -16.17 & 4612 & & \\
\hline $86-100$ & 5 & 93 & 45.96 & 6.65 & 1.33 & 70.0 & -15.94 & 4946 & 447 & \\
\hline $100-110$ & 6 & 105 & 56.09 & 6.87 & 1.36 & 70.0 & -16.69 & 4810 & & \\
\hline $110-120$ & 7 & 115 & 55.37 & 6.66 & 1.16 & 69.7 & -16.19 & 5195 & & \\
\hline $120-130$ & 8 & 125 & 51.56 & 6.69 & 1.08 & 70.3 & -16.65 & 4774 & & 1.70 \\
\hline $130-140$ & 9 & 135 & 48.09 & 6.82 & 1.06 & 72.7 & -16.81 & 5531 & & \\
\hline $140-150$ & 10 & 145 & 43.10 & 6.86 & 1.04 & 77.1 & -17.21 & 4916 & & \\
\hline $150-160$ & 11 & 155 & 46.27 & 6.52 & 1.05 & 71.7 & -17.98 & 5459 & & \\
\hline $160-170$ & 12 & 165 & 35.86 & 6.81 & 0.99 & 71.7 & -17.25 & 4813 & & \\
\hline $170-180$ & 13 & 175 & 47.38 & 6.65 & 0.90 & 71.1 & -16.86 & 5183 & 517 & \\
\hline $180-190$ & 14 & 185 & 46.69 & 6.41 & 0.87 & 69.3 & -16.91 & 4642 & & \\
\hline $190-200$ & 15 & 195 & 40.32 & 6.53 & 0.87 & 69.6 & -17.90 & 4734 & & \\
\hline $200-210$ & 16 & 205 & 41.62 & 6.40 & 0.72 & 69.3 & -17.37 & 6374 & & \\
\hline
\end{tabular}


P5 Profile, Continued...

\begin{tabular}{|c|c|c|c|c|c|c|c|c|c|c|}
\hline \multicolumn{1}{|l|}{ P5 Profile } \\
$\begin{array}{c}\text { Interval } \\
\text { Depth }\end{array}$ & $\#$ & depth & $\mathrm{X}$ & $\begin{array}{c}\text { Total } \\
\text { C }\end{array}$ & $\begin{array}{c}\text { Organic } \\
\text { C }\end{array}$ & $\begin{array}{c}\% \\
\text { CCE }\end{array}$ & $\mathrm{d}^{13}$ C & Fed & Fe ox & $\begin{array}{c}\text { Bulk } \\
\text { Density }\end{array}$ \\
\hline $210-220$ & 17 & 215 & 44.44 & 6.17 & 0.78 & 66.4 & -17.71 & 5117 & 497 & \\
\hline $220-230$ & 18 & 225 & 44.75 & 6.18 & 0.89 & 66.4 & -18.39 & 5037 & & 1.78 \\
\hline $230-240$ & 19 & 235 & 45.97 & 6.23 & 0.82 & 66.3 & -17.16 & 5154 & & \\
\hline $240-250$ & 20 & 245 & 36.53 & 6.37 & 0.87 & 69.0 & -18.00 & 5626 & & \\
\hline $250-260$ & 21 & 255 & 30.84 & 6.56 & 0.69 & 71.6 & -18.20 & 4941 & & \\
\hline $260-270$ & 22 & 265 & 32.15 & 6.63 & 0.58 & 74.5 & -19.15 & 6300 & & \\
\hline $270-280$ & 23 & 275 & 31.15 & 6.88 & 0.54 & 74.8 & -19.24 & 4960 & 583 & \\
\hline $280-290$ & 24 & 285 & 33.59 & 6.95 & 0.48 & 76.9 & -19.05 & 4854 & & 1.59 \\
\hline $290-300$ & 25 & 295 & 48.06 & 6.99 & 0.51 & 77.7 & -19.68 & 5528 & & \\
\hline $300-310$ & 26 & 305 & 23.92 & 7.55 & 0.45 & 78.9 & -19.71 & 5794 & 798 & \\
\hline $310-320$ & 27 & 315 & 22.87 & 7.46 & 0.52 & 79.5 & -20.51 & 6155 & & \\
\hline $320-330$ & 28 & 325 & 26.30 & 7.61 & 0.50 & 80.6 & -19.90 & 4714 & & 1.54 \\
\hline $330-340$ & 29 & 335 & 27.84 & 7.14 & 0.58 & 84.1 & -20.52 & 4553 & 614 & \\
\hline $340-350$ & 30 & 345 & 21.03 & 7.03 & 0.53 & 86.5 & -19.42 & 4550 & & \\
\hline $350-360$ & 31 & 355 & 21.57 & 8.09 & 0.52 & 87.9 & -20.84 & 4832 & & \\
\hline $360-370$ & 32 & 365 & 21.29 & 7.72 & 0.51 & 83.5 & -20.14 & 4997 & & 1.43 \\
\hline $370-380$ & 33 & 375 & 19.92 & 7.51 & 0.49 & 85.5 & -20.30 & 4897 & 1097 & \\
\hline $380-390$ & 34 & 385 & 36.02 & 7.97 & 0.43 & 80.2 & -21.10 & 4889 & & \\
\hline $390-400$ & 35 & 395 & & 7.69 & 0.44 & 84.6 & -20.15 & 5437 & & \\
\hline
\end{tabular}

LH1 Profile with Gravel

\begin{tabular}{|c|c|c|c|c|c|c|c|c|c|c|c|c|}
\hline \multicolumn{3}{|c|}{ LH1 Profile } & \multicolumn{10}{|c|}{ With Gravel } \\
\hline $\begin{array}{l}\text { Interval } \\
\text { Depth }\end{array}$ & \# & depth & $\begin{array}{c}\% \\
\geq 63 \mu\end{array}$ & $\% \geq 2 \mu$ & $\begin{array}{c}\% \\
\text { gravel }\end{array}$ & $\begin{array}{c}\% \\
\text { sand }\end{array}$ & $\%$ silt & $\begin{array}{c}\% \\
\text { clay }\end{array}$ & mean & $\mathrm{sd}$ & skew & kurt \\
\hline $0-7$ & 52 & 3.5 & 30.3 & 62.8 & 1.8 & 28.5 & 32.5 & 37.2 & 7.12 & 4.82 & 0.01 & 0.28 \\
\hline $7-20$ & 51 & 13 & 25.2 & 60.4 & 0.6 & 24.6 & 35.1 & 39.6 & 7.51 & 4.60 & 0.01 & 0.26 \\
\hline $20-30$ & 50 & 25 & 18.7 & 58.2 & 0.0 & 18.7 & 39.5 & 41.8 & 7.91 & 4.30 & 0.03 & 0.32 \\
\hline $30-40$ & 49 & 35 & 28.5 & 61.7 & 3.3 & 25.2 & 33.2 & 38.3 & 7.22 & 4.83 & 0.00 & 0.30 \\
\hline $40-49$ & 48 & 44 & 30.7 & 61.0 & 0.0 & 30.7 & 30.4 & 39.0 & 7.55 & 4.53 & 0.11 & 0.15 \\
\hline $49-52$ & 47 & 51 & 28.8 & 61.8 & 0.0 & 28.8 & 33.0 & 38.2 & 7.31 & 4.73 & 0.02 & 0.24 \\
\hline $52-59$ & 46 & 55 & 24.8 & 60.3 & 0.0 & 24.8 & 35.5 & 39.7 & 7.57 & 4.61 & 0.05 & 0.24 \\
\hline $60-70$ & 45 & 65 & 18.1 & 57.4 & 0.0 & 18.1 & 39.3 & 42.6 & 8.02 & 4.26 & 0.08 & 0.31 \\
\hline $70-80$ & 44 & 75 & 21.3 & 57.7 & 0.1 & 21.2 & 36.4 & 42.3 & 7.78 & 4.46 & 0.01 & 0.31 \\
\hline $80-90$ & 43 & 85 & 51.3 & 68.2 & 0.5 & 50.9 & 16.8 & 31.8 & 6.54 & 5.16 & 0.54 & 0.23 \\
\hline $92-98$ & 42 & 95 & 31.1 & 60.2 & 0.0 & 31.1 & 29.1 & 39.8 & 7.24 & 4.95 & -0.02 & 0.22 \\
\hline $98-102$ & 41 & 100 & 43.5 & 64.6 & 1.4 & 42.1 & 21.1 & 35.4 & 6.76 & 5.11 & 0.03 & 0.22 \\
\hline $102-110$ & 40 & 106 & 36.1 & 64.6 & 0.2 & 35.9 & 28.5 & 35.4 & 7.09 & 4.79 & 0.08 & 0.23 \\
\hline $110-120$ & 39 & 115 & 31.1 & 61.3 & 0.6 & 30.5 & 30.2 & 38.7 & 7.23 & 4.92 & 0.01 & 0.21 \\
\hline $120-127$ & 38 & 124 & 69.7 & 82.6 & 47.9 & 21.8 & 12.9 & 17.4 & 2.93 & 6.67 & 0.33 & 0.22 \\
\hline $127-139$ & 37 & 133 & 36.2 & 66.7 & 0.1 & 36.1 & 30.5 & 33.3 & 7.12 & 4.63 & 0.17 & 0.25 \\
\hline $139-150$ & 36 & 144 & 29.1 & 63.7 & 0.1 & 29.1 & 34.5 & 36.3 & 7.32 & 4.61 & 0.04 & 0.25 \\
\hline $150-162$ & 35 & 156 & 31.8 & 63.6 & 0.0 & 31.8 & 31.8 & 36.4 & 7.23 & 4.66 & 0.01 & 0.24 \\
\hline $162-170$ & 34 & 166 & 33.5 & 64.5 & 0.0 & 33.5 & 31.0 & 35.5 & 7.19 & 4.66 & 0.03 & 0.24 \\
\hline $170-180$ & 33 & 175 & 33.9 & 64.0 & 0.0 & 33.9 & 30.1 & 36.0 & 7.16 & 4.70 & 0.00 & 0.23 \\
\hline $180-190$ & 32 & 185 & 33.9 & 63.5 & 0.3 & 33.6 & 29.6 & 36.5 & 7.19 & 4.79 & -0.02 & 0.22 \\
\hline $190-200$ & 31 & 195 & 26.0 & 60.0 & 0.0 & 26.0 & 34.0 & 40.0 & 7.55 & 4.59 & -0.04 & 0.24 \\
\hline $200-210$ & 30 & 205 & 25.0 & 60.2 & 0.0 & 25.0 & 35.2 & 39.8 & 8.08 & 4.02 & 0.23 & 0.05 \\
\hline $220-230$ & 29 & 225 & 38.9 & 65.2 & 0.0 & 38.9 & 26.3 & 34.8 & 6.92 & 4.88 & 0.06 & 0.22 \\
\hline $230-238$ & 28 & 234 & 47.3 & 70.4 & 0.1 & 47.2 & 23.1 & 29.6 & 6.78 & 4.62 & 0.44 & 0.25 \\
\hline
\end{tabular}


LH1 Profile with Gravel, Continued...

\begin{tabular}{|c|c|c|c|c|c|c|c|c|c|c|c|c|}
\hline \multicolumn{3}{|c|}{ LH1 Profile } & \multicolumn{10}{|c|}{ With Gravel } \\
\hline $\begin{array}{l}\text { Interval } \\
\text { Depth }\end{array}$ & \# & depth & $\begin{array}{c}\% \\
\geq 63 \mu\end{array}$ & $\% \geq 2 \mu$ & $\begin{array}{c}\% \\
\text { gravel }\end{array}$ & $\begin{array}{c}\% \\
\text { sand }\end{array}$ & $\%$ silt & $\begin{array}{c}\% \\
\text { clay }\end{array}$ & mean & sd & skew & kurt \\
\hline $238-246$ & 27 & 242 & 33.7 & 65.8 & 0.0 & 33.7 & 32.2 & 34.2 & 7.22 & 4.57 & 0.14 & 0.24 \\
\hline $246-255$ & 26 & 250 & 28.9 & 64.5 & 0.0 & 28.9 & 35.5 & 35.5 & 7.43 & 4.44 & 0.16 & 0.26 \\
\hline $255-263$ & 25 & 259 & 35.3 & 69.0 & 0.3 & 35.0 & 33.7 & 31.0 & 6.98 & 4.61 & 0.14 & 0.26 \\
\hline 263-268 & 24 & 265 & 38.6 & 68.7 & 0.1 & 38.5 & 30.1 & 31.3 & 6.90 & 4.73 & 0.22 & 0.24 \\
\hline $269-280$ & 23 & 274 & 39.9 & 67.7 & 0.3 & 39.6 & 27.8 & 32.3 & 6.94 & 4.77 & 0.19 & 0.23 \\
\hline 280-292 & 22 & 286 & 38.5 & 67.3 & 1.1 & 37.5 & 28.8 & 32.7 & 6.74 & 5.00 & 0.10 & 0.26 \\
\hline 292-304 & 21 & 298 & 23.4 & 63.0 & 0.1 & 23.3 & 39.6 & 37.0 & 7.49 & 4.50 & 0.05 & 0.28 \\
\hline $304-315$ & 20 & 310 & 21.4 & 64.3 & 0.0 & 21.4 & 42.8 & 35.7 & 7.66 & 4.23 & 0.12 & 0.17 \\
\hline $315-328$ & 19 & 321 & 24.6 & 63.7 & 0.0 & 24.5 & 39.2 & 36.3 & 7.57 & 4.31 & 0.09 & 0.29 \\
\hline $328-337$ & 18 & 332 & 31.4 & 63.9 & 0.0 & 31.4 & 32.5 & 36.1 & 7.40 & 4.53 & 0.11 & 0.24 \\
\hline $337-345$ & 17 & 341 & 27.6 & 64.7 & 0.0 & 27.6 & 37.0 & 35.3 & 7.45 & 4.42 & 0.07 & 0.27 \\
\hline $345-355$ & 16 & 350 & 23.0 & 62.1 & 0.0 & 22.9 & 39.2 & 37.9 & 7.77 & 4.31 & 0.14 & 0.29 \\
\hline $355-370$ & 15 & 362 & 15.1 & 60.6 & 0.1 & 15.0 & 45.5 & 39.4 & 8.07 & 3.95 & 0.18 & 0.35 \\
\hline $370-378$ & 14 & 374 & 22.2 & 60.3 & 2.6 & 19.6 & 38.0 & 39.7 & 7.65 & 4.41 & 0.02 & 0.34 \\
\hline $378-390$ & 13 & 384 & 38.8 & 62.2 & 23.8 & 15.0 & 23.4 & 37.8 & 4.79 & 7.28 & -0.22 & 0.19 \\
\hline $390-400$ & 12 & 395 & 59.9 & 74.8 & 47.0 & 12.9 & 14.9 & 25.2 & 3.69 & 7.34 & 0.47 & \\
\hline $400-410$ & 11 & 405 & 52.5 & 69.2 & 35.2 & 17.2 & 16.7 & 30.8 & 4.08 & 7.60 & 0.11 & 0.17 \\
\hline $410-420$ & 10 & 405 & 77.8 & 86.5 & 57.9 & 19.9 & 8.7 & 13.5 & 1.77 & 5.95 & 0.57 & 0.43 \\
\hline $421-440$ & 9 & 430 & 23.7 & 56.7 & 6.8 & 17.0 & 32.9 & 43.3 & 7.23 & 4.96 & -0.16 & 0.53 \\
\hline 441-449 & 8 & 445 & 52.9 & 70.8 & 36.9 & 16.0 & 17.9 & 29.2 & 4.01 & 7.37 & 0.19 & 0.20 \\
\hline $449-457$ & 7 & 453 & 45.1 & 64.5 & 37.7 & 7.4 & 19.4 & 35.5 & 3.59 & 8.23 & -0.29 & \\
\hline $457-462$ & 6 & 458 & 63.1 & 75.4 & 46.1 & 17.0 & 12.3 & 24.6 & 3.78 & 7.03 & 0.53 & 0.23 \\
\hline $462-470$ & 5 & 466 & 42.1 & 66.5 & 4.7 & 37.4 & 24.5 & 33.5 & 6.56 & 5.15 & 0.19 & 0.34 \\
\hline $470-476$ & 4 & 473 & 27.4 & 52.2 & 2.7 & 24.7 & 24.8 & 47.8 & 7.03 & 5.37 & -0.30 & 0.21 \\
\hline $476-484$ & 3 & 480 & 20.5 & 60.1 & 0.0 & 20.4 & 39.7 & 39.9 & 7.85 & 4.24 & 0.16 & 0.31 \\
\hline $484-490$ & 2 & 487 & 31.2 & 63.3 & 2.6 & 28.6 & 32.2 & 36.7 & 7.23 & 4.60 & 0.24 & 0.10 \\
\hline $490-500$ & 1 & 495 & 33.4 & 56.1 & 16.6 & 16.8 & 22.7 & 43.9 & 5.30 & 6.99 & -0.35 & 0.29 \\
\hline
\end{tabular}

LH1 Profile without Gravel

\begin{tabular}{|c|c|c|c|c|c|c|c|c|c|c|c|c|}
\hline \multicolumn{2}{|l|}{ LH1 Profile } & \multicolumn{1}{l|}{ Without Gravel } \\
\hline $\begin{array}{c}\text { Interval } \\
\text { Depth }\end{array}$ & $\#$ & depth & $\begin{array}{c}\% \\
\geq 63 \mu\end{array}$ & $\% \geq 2 \mu$ & $\begin{array}{c}\% \\
\text { gravel }\end{array}$ & $\begin{array}{c}\% \\
\text { sand }\end{array}$ & $\%$ silt & $\begin{array}{c}\% \\
\text { clay }\end{array}$ & mean & sd & skew & kurt \\
\hline $0-7$ & 52 & 3.5 & 29.1 & 62.1 & 1.8 & 29.1 & 33.0 & 37.9 & 7.20 & 4.78 & 0.01 & 0.25 \\
\hline $7-20$ & 51 & 13 & 24.7 & 60.1 & 0.6 & 24.7 & 35.4 & 39.9 & 7.54 & 4.58 & 0.01 & 0.25 \\
\hline $20-30$ & 50 & 25 & 18.7 & 58.2 & 0.0 & 18.7 & 39.5 & 41.8 & 7.91 & 4.30 & 0.03 & 0.32 \\
\hline $30-40$ & 49 & 35 & 26.1 & 60.4 & 3.3 & 26.1 & 34.3 & 39.6 & 7.40 & 4.72 & 0.00 & 0.25 \\
\hline $40-49$ & 48 & 44 & 30.7 & 61.0 & 0.0 & 30.7 & 30.4 & 39.0 & 7.21 & 4.87 & 0.03 & 0.22 \\
\hline $49-52$ & 47 & 51 & 28.8 & 61.8 & 0.0 & 28.8 & 33.1 & 38.2 & 7.31 & 4.73 & 0.02 & 0.24 \\
\hline $52-59$ & 46 & 55 & 24.8 & 60.3 & 0.0 & 24.8 & 35.5 & 39.7 & 7.57 & 4.61 & 0.05 & 0.24 \\
\hline $60-70$ & 45 & 65 & 18.1 & 57.4 & 0.0 & 18.1 & 39.3 & 42.6 & 8.02 & 4.26 & 0.08 & 0.31 \\
\hline $70-80$ & 44 & 75 & 21.2 & 57.6 & 0.1 & 21.2 & 36.4 & 42.4 & 7.79 & 4.46 & 0.01 & 0.31 \\
\hline $80-90$ & 43 & 85 & 51.1 & 68.1 & 0.5 & 51.1 & 16.9 & 31.9 & 6.55 & 5.16 & 0.54 & 0.22 \\
\hline $92-98$ & 42 & 95 & 31.1 & 60.2 & 0.0 & 31.1 & 29.1 & 39.8 & 7.24 & 4.95 & -0.02 & 0.22 \\
\hline $98-102$ & 41 & 100 & 42.7 & 64.1 & 1.4 & 42.7 & 21.4 & 35.9 & 6.81 & 5.10 & 0.01 & 0.21 \\
\hline $102-110$ & 40 & 106 & 36.0 & 64.5 & 0.2 & 36.0 & 28.6 & 35.5 & 7.09 & 4.78 & 0.08 & 0.23 \\
\hline $110-120$ & 39 & 115 & 30.6 & 61.0 & 0.6 & 30.6 & 30.4 & 39.0 & 7.25 & 4.91 & 0.01 & 0.21 \\
\hline $120-127$ & 38 & 124 & 41.9 & 66.6 & 47.9 & 41.9 & 24.7 & 33.4 & 6.75 & 4.98 & 0.12 & 0.24 \\
\hline $127-139$ & 37 & 133 & 36.1 & 66.6 & 0.1 & 36.1 & 30.5 & 33.4 & 7.13 & 4.63 & 0.17 & 0.24 \\
\hline $139-150$ & 36 & 144 & 29.1 & 63.7 & 0.1 & 29.1 & 34.6 & 36.3 & 7.32 & 4.61 & 0.04 & 0.25 \\
\hline $150-162$ & 35 & 156 & 31.8 & 63.6 & 0.0 & 31.8 & 31.8 & 36.4 & 7.23 & 4.66 & 0.01 & 0.24 \\
\hline
\end{tabular}


LH1 Profile without Gravel, Continued...

\begin{tabular}{|c|c|c|c|c|c|c|c|c|c|c|c|c|}
\hline \multicolumn{3}{|c|}{ LH1 Profile } & \multicolumn{10}{|c|}{ Without Gravel } \\
\hline $\begin{array}{c}\text { Interval } \\
\text { Depth }\end{array}$ & \# & depth & $\begin{array}{c}\% \\
\geq 63 \mu\end{array}$ & $\% \geq 2 \mu$ & $\begin{array}{c}\% \\
\text { gravel }\end{array}$ & $\begin{array}{c}\% \\
\text { sand }\end{array}$ & $\%$ silt & $\begin{array}{c}\% \\
\text { clay }\end{array}$ & mean & sd & skew & kurt \\
\hline $162-170$ & 34 & 166 & 33.5 & 64.5 & 0.0 & 33.5 & 31.0 & 35.5 & 7.19 & 4.66 & 0.03 & 0.24 \\
\hline $170-180$ & 33 & 175 & 33.9 & 64.0 & 0.0 & 33.9 & 30.1 & 36.0 & 7.16 & 4.70 & 0.00 & 0.23 \\
\hline $180-190$ & 32 & 185 & 33.7 & 63.4 & 0.3 & 33.7 & 29.7 & 36.6 & 7.19 & 4.78 & -0.02 & 0.22 \\
\hline $190-200$ & 31 & 195 & 26.0 & 60.0 & 0.0 & 26.0 & 34.0 & 40.0 & 7.55 & 4.59 & -0.04 & 0.24 \\
\hline $200-210$ & 30 & 205 & 25.0 & 60.2 & 0.0 & 25.0 & 35.2 & 39.8 & 7.55 & 4.54 & 0.09 & 0.26 \\
\hline $220-230$ & 29 & 225 & 38.9 & 65.2 & 0.0 & 38.9 & 26.3 & 34.8 & 6.92 & 4.88 & 0.06 & 0.22 \\
\hline $230-238$ & 28 & 234 & 47.2 & 70.4 & 0.1 & 47.2 & 23.2 & 29.6 & 6.78 & 4.62 & 0.43 & 0.25 \\
\hline $238-246$ & 27 & 242 & 33.7 & 65.8 & 0.0 & 33.7 & 32.2 & 34.2 & 7.22 & 4.57 & 0.14 & 0.24 \\
\hline $246-255$ & 26 & 250 & 28.9 & 64.4 & 0.0 & 28.9 & 35.5 & 35.6 & 7.43 & 4.44 & 0.16 & 0.26 \\
\hline $255-263$ & 25 & 259 & 35.1 & 68.9 & 0.3 & 35.1 & 33.8 & 31.1 & 6.99 & 4.61 & 0.13 & 0.25 \\
\hline 263-268 & 24 & 265 & 38.6 & 68.7 & 0.1 & 38.6 & 30.1 & 31.3 & 6.90 & 4.73 & 0.22 & 0.24 \\
\hline $269-280$ & 23 & 274 & 39.7 & 67.6 & 0.3 & 39.7 & 27.9 & 32.4 & 6.95 & 4.77 & 0.19 & 0.23 \\
\hline $280-292$ & 22 & 286 & 37.8 & 66.9 & 1.1 & 37.8 & 29.1 & 33.1 & 6.78 & 4.98 & 0.08 & 0.25 \\
\hline 292-304 & 21 & 298 & 23.3 & 63.0 & 0.1 & 23.3 & 39.7 & 37.0 & 7.50 & 4.50 & 0.06 & 0.28 \\
\hline $304-315$ & 20 & 310 & 21.4 & 64.3 & 0.0 & 21.4 & 42.8 & 35.7 & 7.66 & 4.23 & 0.12 & 0.31 \\
\hline $315-328$ & 19 & 321 & 24.5 & 63.7 & 0.0 & 24.5 & 39.2 & 36.3 & 7.58 & 4.31 & 0.09 & 0.29 \\
\hline 328-337 & 18 & 332 & 31.4 & 63.9 & 0.0 & 31.4 & 32.5 & 36.1 & 7.40 & 4.53 & 0.11 & 0.24 \\
\hline $337-345$ & 17 & 341 & 27.6 & 64.6 & 0.0 & 27.6 & 37.0 & 35.4 & 7.45 & 4.42 & 0.07 & 0.27 \\
\hline $345-355$ & 16 & 350 & 23.0 & 62.1 & 0.0 & 23.0 & 39.2 & 37.9 & 7.77 & 4.31 & 0.14 & 0.29 \\
\hline $355-370$ & 15 & 362 & 15.0 & 60.6 & 0.1 & 15.0 & 45.6 & 39.4 & 8.06 & 3.96 & 0.18 & 0.34 \\
\hline $370-378$ & 14 & 374 & 20.2 & 59.2 & 2.6 & 20.2 & 39.1 & 40.8 & 7.83 & 4.29 & 0.03 & 0.32 \\
\hline $378-390$ & 13 & 384 & 19.7 & 50.4 & 23.8 & 19.7 & 30.7 & 49.6 & 7.84 & 4.69 & -0.22 & 0.37 \\
\hline $390-400$ & 12 & 395 & 24.4 & 52.5 & 47.0 & 24.4 & 28.0 & 47.5 & 7.31 & 5.11 & -0.24 & 0.32 \\
\hline $400-410$ & 11 & 405 & 26.6 & 52.4 & 35.2 & 26.6 & 25.8 & 47.6 & 7.42 & 5.08 & -0.19 & 0.31 \\
\hline $410-420$ & 10 & 405 & 47.3 & 68.1 & 57.9 & 47.3 & 20.7 & 31.9 & 5.82 & 5.81 & 0.13 & 0.20 \\
\hline 421-440 & 9 & 430 & 18.2 & 53.5 & 6.8 & 18.2 & 35.3 & 46.5 & 7.93 & 4.38 & -0.13 & 0.40 \\
\hline 441-449 & 8 & 445 & 25.4 & 53.7 & 36.9 & 25.4 & 28.3 & 46.3 & 7.02 & 5.33 & -0.25 & 0.26 \\
\hline $449-457$ & 7 & 453 & 11.8 & 42.9 & 37.7 & 11.8 & 31.1 & 57.1 & 8.90 & 3.74 & -0.23 & 0.71 \\
\hline $457-462$ & 6 & 458 & 31.5 & 54.4 & 46.1 & 31.5 & 22.9 & 45.6 & 6.75 & 5.54 & -0.29 & 0.24 \\
\hline $462-470$ & 5 & 466 & 39.2 & 64.9 & 4.7 & 39.2 & 25.7 & 35.1 & 6.72 & 5.10 & 0.12 & 0.21 \\
\hline $470-476$ & 4 & 473 & 25.4 & 50.9 & 2.7 & 25.4 & 25.5 & 49.1 & 7.15 & 5.29 & -0.32 & 0.19 \\
\hline $476-484$ & 3 & 480 & 20.4 & 60.1 & 0.0 & 20.4 & 39.7 & 39.9 & 7.85 & 4.23 & 0.16 & 0.31 \\
\hline $484-490$ & 2 & 487 & 29.3 & 62.3 & 2.6 & 29.3 & 33.0 & 37.7 & 7.38 & 4.51 & 0.24 & 0.30 \\
\hline $490-500$ & 1 & 495 & 20.1 & 47.4 & 16.6 & 20.1 & 27.3 & 52.6 & 7.61 & 4.96 & -0.36 & 0.26 \\
\hline
\end{tabular}

LH1 Profile

\begin{tabular}{|c|c|c|c|c|c|c|c|c|c|c|}
\hline \multicolumn{3}{|c|}{ LH1 Profile } & \multirow[b]{2}{*}{$x$} & \multirow[b]{2}{*}{$\begin{array}{c}\text { Total } \\
\text { C }\end{array}$} & \multirow[b]{2}{*}{$\begin{array}{c}\text { Organic } \\
\text { C }\end{array}$} & \multirow[b]{2}{*}{ \%CCE } & \multirow[b]{2}{*}{$\mathrm{d}^{13} \mathrm{C}$} & \multirow[b]{2}{*}{ Fed } & \multirow[b]{2}{*}{ Feox } & \multirow[b]{2}{*}{$\begin{array}{c}\text { Bulk } \\
\text { Density }\end{array}$} \\
\hline $\begin{array}{l}\text { Interval } \\
\text { Depth }\end{array}$ & \# & depth & & & & & & & & \\
\hline $0-7$ & 52 & 3.5 & 25.64 & 7.17 & 2.47 & 61.5 & -20.77 & 4686 & & \\
\hline $7-20$ & 51 & 13 & 30.82 & 6.51 & 1.64 & 59.0 & -19.23 & 4898 & & \\
\hline $20-30$ & 50 & 25 & 33.93 & 6.09 & 1.73 & 53.5 & -19.01 & 4884 & 696 & 1.73 \\
\hline $30-40$ & 49 & 35 & 37.80 & 6.39 & 1.72 & 57.0 & -18.86 & 5150 & & \\
\hline $40-49$ & 48 & 44 & 40.58 & 6.46 & 1.47 & 59.8 & -17.92 & 5132 & & \\
\hline $49-52$ & 47 & 51 & 34.46 & 6.54 & 1.47 & 65.7 & -17.66 & 5329 & & \\
\hline $52-59$ & 46 & 55 & 35.54 & 5.98 & 1.45 & 56.6 & -17.11 & 5023 & & \\
\hline $60-70$ & 45 & 65 & 38.78 & 5.28 & 1.39 & 49.0 & -16.59 & 4283 & 766 & \\
\hline $70-80$ & 44 & 75 & 36.39 & 5.83 & 1.53 & 61.9 & -17.14 & 4935 & & \\
\hline $80-90$ & 43 & 85 & 17.18 & 7.00 & 0.90 & 60.6 & -19.39 & 5799 & & 1.77 \\
\hline
\end{tabular}


LH1 Profile, Continued...

\begin{tabular}{|c|c|c|c|c|c|c|c|c|c|c|}
\hline \multicolumn{3}{|c|}{ LH1 Profile } & \multirow[b]{2}{*}{$x$} & \multirow[b]{2}{*}{$\begin{array}{c}\text { Total } \\
\text { C }\end{array}$} & \multirow[b]{2}{*}{$\begin{array}{c}\text { Organic } \\
\text { C }\end{array}$} & \multirow[b]{2}{*}{$\%$ CCE } & \multirow[b]{2}{*}{$\mathrm{d}^{13} \mathrm{C}$} & \multirow[b]{2}{*}{ Fed } & \multirow[b]{2}{*}{ Feox } & \multirow[b]{2}{*}{$\begin{array}{c}\text { Bulk } \\
\text { Density }\end{array}$} \\
\hline $\begin{array}{l}\text { Interval } \\
\text { Depth }\end{array}$ & \# & depth & & & & & & & & \\
\hline $92-98$ & 42 & 95 & 25.97 & 6.25 & 1.29 & 59.7 & -17.41 & 5238 & 1045 & \\
\hline $98-102$ & 41 & 100 & 17.39 & 7.51 & 0.84 & 84.3 & -19.28 & 5723 & & \\
\hline $102-110$ & 40 & 106 & 25.74 & 7.18 & 1.41 & 70.5 & -19.37 & 5912 & 590 & \\
\hline $110-120$ & 39 & 115 & 23.76 & 6.30 & 1.03 & 62.5 & -19.23 & 5552 & & \\
\hline $120-127$ & 38 & 124 & 21.29 & 7.19 & 1.00 & 71.4 & -19.77 & 5248 & & \\
\hline $127-139$ & 37 & 133 & 27.60 & 7.29 & 1.27 & 71.8 & -19.92 & 5058 & 708 & \\
\hline $139-150$ & 36 & 144 & 25.31 & 7.19 & 1.69 & 68.7 & -20.83 & 5718 & & 1.59 \\
\hline $150-162$ & 35 & 156 & 19.26 & 7.41 & 1.55 & 73.6 & -21.67 & 5176 & 457 & \\
\hline $162-170$ & 34 & 166 & 16.77 & 7.35 & 1.28 & 75.7 & -21.64 & 6166 & & \\
\hline $170-180$ & 33 & 175 & 16.91 & 7.19 & 1.15 & 74.5 & -21.37 & 5238 & & \\
\hline $180-190$ & 32 & 185 & 17.80 & 7.19 & 1.19 & 72.0 & -21.20 & 5270 & 539 & 1.70 \\
\hline $190-200$ & 31 & 195 & 20.16 & 6.83 & 1.09 & 67.4 & -20.88 & 5974 & & \\
\hline $200-210$ & 30 & 205 & 20.62 & 6.71 & 1.00 & 67.7 & -20.25 & 5659 & & \\
\hline $220-230$ & 29 & 225 & 19.69 & 7.56 & 0.99 & 68.4 & -20.31 & 5730 & & \\
\hline $230-238$ & 28 & 234 & 18.52 & 7.82 & 0.80 & 79.3 & -19.15 & 5884 & 674 & \\
\hline $238-246$ & 27 & 242 & 23.85 & 6.90 & 0.82 & 68.0 & -19.07 & 5755 & & \\
\hline 246-255 & 26 & 250 & 25.26 & 6.96 & 0.96 & 71.9 & -18.89 & 5937 & & 1.65 \\
\hline $255-263$ & 25 & 259 & 27.14 & 7.15 & 0.99 & 71.5 & -18.46 & 6191 & & \\
\hline $263-268$ & 24 & 265 & 26.90 & 7.18 & 0.97 & 78.1 & -17.77 & 6001 & & \\
\hline $269-280$ & 23 & 274 & 26.31 & 7.42 & 1.11 & 73.5 & -19.92 & 5937 & & \\
\hline 280-292 & 22 & 286 & 24.21 & 7.21 & 1.13 & 76.8 & -19.46 & 5824 & & 1.53 \\
\hline 292-304 & 21 & 298 & 29.56 & 7.20 & 1.51 & 69.0 & -18.82 & 5098 & 680 & \\
\hline $304-315$ & 20 & 310 & 26.34 & 7.41 & 1.48 & 72.8 & -19.11 & 4601 & & \\
\hline $315-328$ & 19 & 321 & 24.96 & 7.38 & 1.32 & 71.6 & -19.36 & 4740 & 765 & \\
\hline 328-337 & 18 & 332 & 23.92 & 7.41 & 1.18 & 74.1 & -19.71 & 4948 & & 1.53 \\
\hline $337-345$ & 17 & 341 & 24.05 & 7.39 & 1.32 & 71.1 & -19.68 & 5457 & & \\
\hline $345-355$ & 16 & 350 & 29.66 & 7.10 & 1.38 & 69.5 & -18.79 & 6459 & & \\
\hline $355-370$ & 15 & 362 & 30.18 & 7.05 & 1.45 & 66.7 & -17.66 & 5315 & 650 & 1.57 \\
\hline $370-378$ & 14 & 374 & 23.81 & 6.13 & 1.03 & 61.5 & -17.34 & 6124 & & \\
\hline $378-390$ & 13 & 384 & 16.45 & 4.70 & 0.78 & 43.3 & -19.37 & 6736 & & \\
\hline $390-400$ & 12 & 395 & 12.61 & 3.96 & 0.60 & 41.1 & -20.45 & 7104 & 817 & \\
\hline $400-410$ & 11 & 405 & 14.31 & 4.66 & 0.63 & 47.5 & -20.57 & 6055 & & 1.59 \\
\hline $410-420$ & 10 & 405 & 13.78 & 5.92 & 0.63 & 72.3 & -19.68 & 5391 & & \\
\hline $421-440$ & 9 & 430 & 19.38 & 5.32 & 0.90 & 51.5 & -18.74 & 5304 & & \\
\hline $441-449$ & 8 & 445 & 14.61 & 5.23 & 0.77 & 49.1 & -20.02 & 5513 & & \\
\hline $449-457$ & 7 & 453 & 10.23 & 2.38 & 0.51 & 23.2 & -21.95 & 6091 & 1152 & 1.65 \\
\hline $457-462$ & 6 & 458 & 12.28 & 5.16 & 0.61 & 52.1 & -21.77 & 5219 & & \\
\hline $462-470$ & 5 & 466 & 18.43 & 6.53 & 0.65 & 69.5 & -20.18 & 6325 & 634 & \\
\hline $470-476$ & 4 & 473 & 12.30 & 4.28 & 0.57 & 46.0 & -22.19 & 5937 & & \\
\hline $476-484$ & 3 & 480 & 17.89 & 6.04 & 0.73 & 60.9 & -18.89 & 5215 & & \\
\hline $484-490$ & 2 & 487 & 17.64 & 6.69 & 0.74 & 64.8 & -19.33 & 5648 & & \\
\hline $490-500$ & 1 & 495 & 11.96 & 3.38 & 0.54 & 35.0 & -22.76 & 5451 & & \\
\hline
\end{tabular}


LH2 Profile with Gravel

\begin{tabular}{|c|c|c|c|c|c|c|c|c|c|c|c|c|}
\hline \multicolumn{3}{|c|}{ LH2 Profile } & \multicolumn{10}{|c|}{ With Gravel } \\
\hline $\begin{array}{c}\text { Interval } \\
\text { Depth }\end{array}$ & \# & depth & $\begin{array}{c}\% \\
\geq 63 \mu\end{array}$ & $\% \geq 2 \mu$ & $\begin{array}{c}\% \\
\text { gravel }\end{array}$ & $\begin{array}{c}\% \\
\text { sand }\end{array}$ & $\%$ silt & $\begin{array}{c}\% \\
\text { clay }\end{array}$ & mean & $\mathrm{sd}$ & skew & kurt \\
\hline $0-10$ & 1 & 5 & 22.0 & 65.1 & 0.2 & 21.8 & 43.1 & 34.9 & 7.52 & 4.16 & 0.09 & 0.35 \\
\hline $10-20$ & 2 & 15 & 22.4 & 65.7 & 0.1 & 22.4 & 43.3 & 34.3 & 7.48 & 4.15 & 0.08 & 0.35 \\
\hline $20-30$ & 3 & 25 & 20.2 & 63.4 & 0.1 & 20.1 & 43.2 & 36.6 & 7.69 & 4.12 & 0.06 & 0.36 \\
\hline $30-40$ & 4 & 35 & 20.5 & 63.7 & 0.0 & 20.5 & 43.3 & 36.3 & 7.67 & 4.11 & 0.07 & 0.35 \\
\hline $40-50$ & 5 & 45 & 23.5 & 65.8 & 0.1 & 23.4 & 42.3 & 34.2 & 7.92 & 3.62 & 0.23 & 0.21 \\
\hline $50-60$ & 6 & 55 & 26.6 & 67.0 & 0.0 & 26.6 & 40.4 & 33.0 & 7.22 & 4.21 & 0.09 & 0.35 \\
\hline $60-70$ & 7 & 65 & 30.1 & 68.7 & 0.5 & 29.6 & 38.6 & 31.3 & 7.03 & 4.25 & 0.14 & 0.35 \\
\hline $70-80$ & 8 & 75 & 31.0 & 69.9 & 0.1 & 30.9 & 38.9 & 30.1 & 6.97 & 4.18 & 0.19 & 0.36 \\
\hline $80-90$ & 9 & 85 & 39.4 & 70.2 & 0.1 & 39.3 & 30.8 & 29.8 & 6.99 & 4.18 & 0.22 & 0.35 \\
\hline $90-100$ & 10 & 95 & 35.1 & 71.0 & 0.2 & 34.9 & 35.9 & 29.0 & 6.93 & 4.23 & 0.19 & 0.34 \\
\hline $100-110$ & 11 & 105 & 40.6 & 71.7 & 0.3 & 40.3 & 31.1 & 28.3 & 6.73 & 4.28 & 0.39 & 0.35 \\
\hline $110-120$ & 12 & 115 & 44.7 & 72.9 & 0.3 & 44.4 & 28.2 & 27.1 & 6.54 & 4.31 & 0.43 & 0.36 \\
\hline $120-130$ & 13 & 125 & 55.5 & 73.2 & 0.5 & 55.0 & 17.7 & 26.8 & 6.49 & 4.33 & 0.67 & 0.36 \\
\hline $130-140$ & 14 & 135 & 48.9 & 74.3 & 0.5 & 48.4 & 25.4 & 25.7 & 6.30 & 4.36 & 0.48 & 0.38 \\
\hline $140-150$ & 15 & 145 & 51.6 & 76.1 & 0.7 & 50.9 & 24.4 & 23.9 & 6.04 & 4.28 & 0.51 & 0.18 \\
\hline $150-160$ & 16 & 155 & 56.0 & 78.2 & 0.5 & 55.4 & 22.2 & 21.8 & 5.79 & 4.13 & 0.57 & 0.46 \\
\hline $160-170$ & 17 & 165 & 61.6 & 80.7 & 0.6 & 61.0 & 19.1 & 19.3 & 5.56 & 3.95 & 0.66 & 0.52 \\
\hline $170-180$ & 18 & 175 & 60.3 & 79.6 & 0.4 & 59.9 & 19.3 & 20.4 & 5.85 & 4.03 & 0.68 & 0.45 \\
\hline $180-190$ & 19 & 185 & 64.3 & 81.9 & 0.6 & 63.8 & 17.6 & 18.1 & 5.80 & 3.98 & 0.72 & 0.46 \\
\hline $190-200$ & 20 & 195 & 61.8 & 80.0 & 0.3 & 61.5 & 18.3 & 20.0 & 5.95 & 4.10 & 0.70 & 0.45 \\
\hline $200-210$ & 21 & 205 & 73.9 & 84.9 & 7.7 & 66.2 & 11.0 & 15.1 & 4.11 & 4.56 & 0.46 & 0.51 \\
\hline $210-220$ & 22 & 215 & 62.7 & 81.6 & 1.2 & 61.4 & 19.0 & 18.4 & 5.51 & 4.10 & 0.66 & 0.53 \\
\hline $220-233$ & 23 & 226 & 67.8 & 84.4 & 0.5 & 67.3 & 16.6 & 15.6 & 5.31 & 3.54 & 0.80 & 0.16 \\
\hline $233-245$ & 24 & 239 & 28.7 & 68.6 & 0.0 & 28.7 & 39.9 & 31.4 & 7.37 & 4.13 & 0.19 & 0.32 \\
\hline $245-255$ & 25 & 250 & 25.9 & 67.2 & 0.0 & 25.9 & 41.2 & 32.8 & 7.53 & 4.09 & 0.16 & 0.30 \\
\hline $255-260$ & 26 & 257 & 27.1 & 69.0 & 0.0 & 27.1 & 41.9 & 31.0 & 7.36 & 4.05 & 0.26 & 0.32 \\
\hline $260-270$ & 27 & 265 & 29.4 & 68.7 & 0.0 & 29.4 & 39.3 & 31.3 & 7.27 & 4.23 & 0.24 & 0.30 \\
\hline $270-280$ & 28 & 275 & 37.8 & 73.6 & 0.0 & 37.8 & 35.7 & 26.4 & 6.84 & 4.14 & 0.23 & 0.32 \\
\hline $280-290$ & 29 & 285 & 40.7 & 74.0 & 0.0 & 40.7 & 33.4 & 26.0 & 6.68 & 3.99 & 0.36 & 0.36 \\
\hline $290-300$ & 30 & 295 & 34.0 & 71.7 & 0.0 & 34.0 & 37.7 & 28.3 & 7.01 & 3.98 & 0.31 & 0.35 \\
\hline $300-310$ & 31 & 305 & 33.5 & 72.2 & 0.0 & 33.5 & 38.7 & 27.8 & 6.95 & 4.05 & 0.28 & 0.34 \\
\hline $310-320$ & 32 & 315 & 23.6 & 70.1 & 0.0 & 23.6 & 46.5 & 29.9 & 7.36 & 3.81 & 0.24 & 0.38 \\
\hline $320-330$ & 33 & 325 & 24.9 & 67.5 & 0.0 & 24.9 & 42.7 & 32.5 & 7.27 & 4.04 & 0.13 & 0.21 \\
\hline $330-340$ & 34 & 335 & 28.6 & 69.0 & 0.0 & 28.6 & 40.4 & 31.0 & 7.09 & 4.19 & 0.12 & 0.34 \\
\hline $340-350$ & 35 & 345 & 31.2 & 70.9 & 0.0 & 31.2 & 39.7 & 29.1 & 7.03 & 4.13 & 0.24 & 0.34 \\
\hline $350-360$ & 36 & 355 & 27.0 & 69.1 & 0.0 & 27.0 & 42.1 & 30.9 & 7.27 & 4.00 & 0.22 & 0.35 \\
\hline $360-366$ & 37 & 363 & 19.0 & 65.9 & 0.0 & 19.0 & 46.9 & 34.1 & 7.76 & 3.96 & 0.19 & 0.33 \\
\hline $366-380$ & 38 & 373 & 12.5 & 62.3 & 0.0 & 12.5 & 49.9 & 37.7 & 8.09 & 3.82 & 0.21 & 0.31 \\
\hline $380-390$ & 39 & 385 & 13.2 & 63.9 & 0.0 & 13.2 & 50.7 & 36.1 & 8.01 & 3.80 & 0.16 & 0.32 \\
\hline $392-400$ & 40 & 396 & 15.2 & 63.9 & 0.0 & 15.2 & 48.7 & 36.1 & 7.92 & 3.85 & 0.17 & 0.33 \\
\hline $400-407$ & 41 & 404 & 20.9 & 64.1 & 0.0 & 20.9 & 43.2 & 35.9 & 8.01 & 3.74 & 0.28 & 0.13 \\
\hline $407-413$ & 42 & 410 & 27.9 & 69.2 & 0.0 & 27.9 & 41.3 & 30.8 & 7.39 & 4.05 & 0.25 & 0.30 \\
\hline $413-424$ & 43 & 418 & 25.0 & 64.8 & 0.0 & 25.0 & 39.8 & 35.2 & 7.62 & 4.13 & 0.21 & 0.29 \\
\hline 424-434 & 44 & 429 & 23.4 & 64.6 & 0.0 & 23.4 & 41.2 & 35.4 & 7.68 & 4.09 & 0.19 & 0.29 \\
\hline $434-444$ & 45 & 439 & 20.0 & 65.2 & 0.0 & 20.0 & 45.2 & 34.8 & 7.77 & 3.99 & 0.26 & 0.29 \\
\hline $444-453$ & 46 & 449 & 23.5 & 68.1 & 0.0 & 23.5 & 44.6 & 31.9 & 7.53 & 3.91 & 0.26 & 0.32 \\
\hline $453-461$ & 47 & 457 & 23.8 & 68.6 & 0.0 & 23.8 & 44.8 & 31.4 & 7.46 & 3.87 & 0.22 & 0.34 \\
\hline $461-471$ & 48 & 466 & 27.0 & 64.6 & 0.0 & 27.0 & 37.6 & 35.4 & 7.48 & 4.24 & 0.08 & 0.28 \\
\hline $471-475$ & 49 & 473 & 30.6 & 64.7 & 0.0 & 30.6 & 34.1 & 35.3 & 7.35 & 4.31 & 0.08 & 0.27 \\
\hline $475-485$ & 50 & 480 & 27.8 & 65.1 & 0.0 & 27.8 & 37.3 & 34.9 & 7.47 & 4.21 & 0.09 & 0.28 \\
\hline $485-490$ & 51 & 487 & 29.6 & 67.1 & 0.0 & 29.6 & 37.5 & 32.9 & 7.36 & 4.23 & 0.31 & 0.14 \\
\hline $490-500$ & 52 & 495 & 36.6 & 68.4 & 0.0 & 36.6 & 31.8 & 31.6 & 7.02 & 4.34 & 0.28 & 0.28 \\
\hline
\end{tabular}


LH2 Profile without Gravel

\begin{tabular}{|c|c|c|c|c|c|c|c|c|c|c|c|c|}
\hline \multicolumn{3}{|c|}{ LH2 Profile } & \multicolumn{10}{|c|}{ Without Gravel } \\
\hline $\begin{array}{l}\text { Interval } \\
\text { Depth }\end{array}$ & \# & depth & $\begin{array}{c}\% \\
\geq 63 \mu\end{array}$ & $\% \geq 2 \mu$ & $\begin{array}{c}\% \\
\text { gravel }\end{array}$ & $\begin{array}{c}\% \\
\text { sand }\end{array}$ & $\%$ silt & $\begin{array}{l}\% \\
\text { clay }\end{array}$ & mean & $\mathrm{sd}$ & skew & kurt \\
\hline $0-10$ & 1 & 5 & 21.8 & 65.1 & 0.2 & 21.8 & 43.2 & 34.9 & 7.53 & 4.15 & 0.09 & 0.35 \\
\hline $10-20$ & 2 & 15 & 22.4 & 65.7 & 0.1 & 22.4 & 43.3 & 34.3 & 7.48 & 4.15 & 0.08 & 0.35 \\
\hline $20-30$ & 3 & 25 & 20.1 & 63.4 & 0.1 & 20.1 & 43.2 & 36.6 & 7.69 & 4.11 & 0.06 & 0.36 \\
\hline $30-40$ & 4 & 35 & 20.5 & 63.7 & 0.0 & 20.5 & 43.3 & 36.3 & 7.67 & 4.11 & 0.07 & 0.35 \\
\hline $40-50$ & 5 & 45 & 23.4 & 65.7 & 0.1 & 23.4 & 42.3 & 34.3 & 7.42 & 4.13 & 0.08 & 0.35 \\
\hline $50-60$ & 6 & 55 & 26.6 & 67.0 & 0.0 & 26.6 & 40.5 & 33.0 & 7.23 & 4.21 & 0.09 & 0.35 \\
\hline $60-70$ & 7 & 65 & 29.7 & 68.5 & 0.5 & 29.7 & 38.8 & 31.5 & 7.06 & 4.24 & 0.14 & 0.35 \\
\hline $70-80$ & 8 & 75 & 31.0 & 69.9 & 0.1 & 31.0 & 38.9 & 30.1 & 6.98 & 4.17 & 0.19 & 0.36 \\
\hline $80-90$ & 9 & 85 & 39.3 & 70.2 & 0.1 & 39.3 & 30.9 & 29.8 & 7.00 & 4.18 & 0.22 & 0.35 \\
\hline $90-100$ & 10 & 95 & 35.0 & 71.0 & 0.2 & 35.0 & 36.0 & 29.0 & 6.94 & 4.22 & 0.19 & 0.34 \\
\hline $100-110$ & 11 & 105 & 40.4 & 71.6 & 0.3 & 40.4 & 31.2 & 28.4 & 6.74 & 4.28 & 0.39 & 0.34 \\
\hline $110-120$ & 12 & 115 & 44.5 & 72.8 & 0.3 & 44.5 & 28.3 & 27.2 & 6.56 & 4.31 & 0.42 & 0.36 \\
\hline $120-130$ & 13 & 125 & 55.3 & 73.1 & 0.5 & 55.3 & 17.8 & 26.9 & 6.51 & 4.33 & 0.67 & 0.36 \\
\hline $130-140$ & 14 & 135 & 48.6 & 74.2 & 0.5 & 48.6 & 25.6 & 25.8 & 6.32 & 4.35 & 0.48 & 0.37 \\
\hline $140-150$ & 15 & 145 & 51.3 & 75.9 & 0.7 & 51.3 & 24.6 & 24.1 & 6.07 & 4.27 & 0.51 & 0.41 \\
\hline $150-160$ & 16 & 155 & 55.7 & 78.1 & 0.5 & 55.7 & 22.3 & 21.9 & 5.81 & 4.13 & 0.57 & 0.45 \\
\hline $160-170$ & 17 & 165 & 61.4 & 80.6 & 0.6 & 61.4 & 19.2 & 19.4 & 5.58 & 3.94 & 0.66 & 0.51 \\
\hline $170-180$ & 18 & 175 & 60.1 & 79.5 & 0.4 & 60.1 & 19.4 & 20.5 & 5.87 & 4.03 & 0.68 & 0.45 \\
\hline $180-190$ & 19 & 185 & 64.1 & 81.8 & 0.6 & 64.1 & 17.7 & 18.2 & 5.82 & 3.98 & 0.72 & 0.45 \\
\hline $190-200$ & 20 & 195 & 61.6 & 80.0 & 0.3 & 61.6 & 18.4 & 20.0 & 5.96 & 4.10 & 0.70 & 0.44 \\
\hline $200-210$ & 21 & 205 & 71.7 & 83.7 & 7.7 & 71.7 & 11.9 & 16.3 & 4.60 & 4.47 & 0.53 & 0.47 \\
\hline $210-220$ & 22 & 215 & 62.2 & 81.4 & 1.2 & 62.2 & 19.2 & 18.6 & 5.57 & 4.09 & 0.67 & 0.51 \\
\hline $220-233$ & 23 & 226 & 67.6 & 84.3 & 0.5 & 67.6 & 16.7 & 15.7 & 5.21 & 3.66 & 0.74 & 0.57 \\
\hline 233-245 & 24 & 239 & 28.7 & 68.6 & 0.0 & 28.7 & 39.9 & 31.4 & 7.37 & 4.13 & 0.19 & 0.32 \\
\hline $245-255$ & 25 & 250 & 25.9 & 67.2 & 0.0 & 25.9 & 41.2 & 32.8 & 7.53 & 4.09 & 0.16 & 0.30 \\
\hline $255-260$ & 26 & 257 & 27.1 & 69.0 & 0.0 & 27.1 & 41.9 & 31.0 & 7.36 & 4.05 & 0.26 & 0.32 \\
\hline $260-270$ & 27 & 265 & 29.4 & 68.7 & 0.0 & 29.4 & 39.3 & 31.3 & 7.27 & 4.23 & 0.24 & 0.30 \\
\hline $270-280$ & 28 & 275 & 37.8 & 73.6 & 0.0 & 37.8 & 35.7 & 26.4 & 6.84 & 4.14 & 0.23 & 0.32 \\
\hline $280-290$ & 29 & 285 & 40.7 & 74.0 & 0.0 & 40.7 & 33.4 & 26.0 & 6.68 & 3.99 & 0.36 & 0.36 \\
\hline $290-300$ & 30 & 295 & 34.0 & 71.7 & 0.0 & 34.0 & 37.7 & 28.3 & 7.01 & 3.98 & 0.31 & 0.35 \\
\hline $300-310$ & 31 & 305 & 33.5 & 72.2 & 0.0 & 33.5 & 38.7 & 27.8 & 6.95 & 4.05 & 0.28 & 0.34 \\
\hline $310-320$ & 32 & 315 & 23.6 & 70.1 & 0.0 & 23.6 & 46.5 & 29.9 & 7.36 & 3.81 & 0.24 & 0.38 \\
\hline $320-330$ & 33 & 325 & 24.9 & 67.5 & 0.0 & 24.9 & 42.7 & 32.5 & 7.27 & 4.04 & 0.13 & 0.37 \\
\hline $330-340$ & 34 & 335 & 28.6 & 69.0 & 0.0 & 28.6 & 40.4 & 31.0 & 7.09 & 4.19 & 0.12 & 0.34 \\
\hline $340-350$ & 35 & 345 & 31.2 & 70.9 & 0.0 & 31.2 & 39.7 & 29.1 & 7.03 & 4.13 & 0.24 & 0.34 \\
\hline $350-360$ & 36 & 355 & 27.0 & 69.1 & 0.0 & 27.0 & 42.1 & 30.9 & 7.27 & 4.00 & 0.22 & 0.35 \\
\hline $360-366$ & 37 & 363 & 19.0 & 65.9 & 0.0 & 19.0 & 46.9 & 34.1 & 7.76 & 3.96 & 0.19 & 0.33 \\
\hline $366-380$ & 38 & 373 & 12.5 & 62.3 & 0.0 & 12.5 & 49.9 & 37.7 & 8.10 & 3.81 & 0.22 & 0.31 \\
\hline $380-390$ & 39 & 385 & 13.2 & 63.9 & 0.0 & 13.2 & 50.7 & 36.1 & 8.01 & 3.80 & 0.16 & 0.32 \\
\hline $392-400$ & 40 & 396 & 15.2 & 63.9 & 0.0 & 15.2 & 48.7 & 36.1 & 7.91 & 3.85 & 0.17 & 0.33 \\
\hline $400-407$ & 41 & 404 & 20.9 & 64.1 & 0.0 & 20.9 & 43.2 & 35.9 & 7.72 & 4.04 & 0.18 & 0.30 \\
\hline $407-413$ & 42 & 410 & 27.9 & 69.2 & 0.0 & 27.9 & 41.3 & 30.8 & 7.39 & 4.05 & 0.25 & 0.30 \\
\hline $413-424$ & 43 & 418 & 25.0 & 64.8 & 0.0 & 25.0 & 39.8 & 35.2 & 7.62 & 4.13 & 0.21 & 0.29 \\
\hline $424-434$ & 44 & 429 & 23.4 & 64.6 & 0.0 & 23.4 & 41.2 & 35.4 & 7.68 & 4.09 & 0.19 & 0.29 \\
\hline $434-444$ & 45 & 439 & 20.0 & 65.2 & 0.0 & 20.0 & 45.2 & 34.8 & 7.77 & 3.99 & 0.26 & 0.29 \\
\hline $444-453$ & 46 & 449 & 23.5 & 68.1 & 0.0 & 23.5 & 44.6 & 31.9 & 7.53 & 3.91 & 0.26 & 0.32 \\
\hline $453-461$ & 47 & 457 & 23.8 & 68.6 & 0.0 & 23.8 & 44.8 & 31.4 & 7.46 & 3.87 & 0.22 & 0.34 \\
\hline $461-471$ & 48 & 466 & 27.0 & 64.6 & 0.0 & 27.0 & 37.6 & 35.4 & 7.48 & 4.24 & 0.08 & 0.28 \\
\hline $471-475$ & 49 & 473 & 30.6 & 64.7 & 0.0 & 30.6 & 34.1 & 35.3 & 7.35 & 4.31 & 0.08 & 0.27 \\
\hline $475-485$ & 50 & 480 & 27.8 & 65.1 & 0.0 & 27.8 & 37.3 & 34.9 & 7.47 & 4.21 & 0.09 & 0.28 \\
\hline $485-490$ & 51 & 487 & 29.6 & 67.1 & 0.0 & 29.6 & 37.5 & 32.9 & 7.36 & 4.23 & 0.31 & 0.28 \\
\hline $490-500$ & 52 & 495 & 36.6 & 68.4 & 0.0 & 36.6 & 31.8 & 31.6 & 7.02 & 4.34 & 0.28 & 0.28 \\
\hline
\end{tabular}


LH2 Profile

\begin{tabular}{|c|c|c|c|c|c|c|c|c|c|c|}
\hline \multicolumn{3}{|l|}{ LH2 Profile } & \multirow[b]{2}{*}{$x$} & \multirow[b]{2}{*}{ Total C } & \multirow[b]{2}{*}{ Organic C } & \multirow[b]{2}{*}{$\%$ CCE } & \multirow[b]{2}{*}{$\mathrm{d}^{13} \mathrm{C}$} & \multirow[b]{2}{*}{ Fed } & \multirow[b]{2}{*}{ Feox } & \multirow[b]{2}{*}{ Bulk Density } \\
\hline Interval Depth & $\#$ & depth & & & & & & & & \\
\hline $0-10$ & 1 & 5 & 40.08 & 7.91 & 3.68 & 61.4 & -21.30 & 7199 & & \\
\hline $10-20$ & 2 & 15 & 37.86 & 7.58 & 3.13 & 60.2 & -20.56 & 6296 & & \\
\hline $20-30$ & 3 & 25 & 399.61 & 7.28 & 2.28 & 60.2 & -20.44 & 5854 & & 1.59 \\
\hline $30-40$ & 4 & 35 & 38.90 & 7.35 & 2.19 & 62.6 & -20.47 & 8415 & & \\
\hline $40-50$ & 5 & 45 & 33.17 & 7.62 & 2.02 & 69.8 & -20.16 & 6298 & 634 & \\
\hline $50-60$ & 6 & 55 & 35.30 & 7.70 & 1.97 & 77.6 & $\mid-19.14$ & 8309 & & \\
\hline $60-70$ & 7 & 65 & 37.95 & 8.37 & 2.00 & 79.7 & -17.50 & 9573 & 1152 & \\
\hline $70-80$ & 8 & 75 & 38.62 & 8.49 & 2.06 & 80.5 & -16.76 & 7498 & & 1.52 \\
\hline $80-90$ & 9 & 85 & 38.17 & 8.78 & 1.98 & 83.5 & -16.65 & 6752 & & \\
\hline $90-100$ & 10 & 95 & 36.06 & 8.38 & 1.94 & 85.3 & -16.92 & 7150 & & 1.53 \\
\hline $100-110$ & 11 & 105 & 33.68 & 8.73 & 1.73 & 88.9 & -17.01 & 6524 & & \\
\hline $110-120$ & 12 & 115 & 32.96 & 8.79 & 1.75 & 90.1 & -17.50 & 7494 & 817 & \\
\hline $120-130$ & 13 & 125 & 31.56 & 8.86 & 1.71 & 92.1 & -17.75 & 6833 & & \\
\hline $130-140$ & 14 & 135 & 30.16 & 9.18 & 1.49 & 93.3 & -17.58 & 5620 & & \\
\hline $140-150$ & 15 & 145 & 31.03 & 9.45 & 1.46 & 93.9 & -17.44 & 5084 & 650 & \\
\hline $150-160$ & 16 & 155 & 31.29 & 8.85 & 1.32 & 98.4 & -17.41 & 5091 & & \\
\hline $160-170$ & 17 & 165 & 27.83 & 9.13 & 1.09 & 99.0 & -18.31 & 5553 & & 1.44 \\
\hline $170-180$ & 18 & 175 & 26.59 & 9.18 & 1.02 & 98.7 & -18.15 & 4883 & & \\
\hline $180-190$ & 19 & 185 & 25.12 & 9.18 & 0.99 & 98.9 & -19.04 & 5215 & 765 & \\
\hline $190-200$ & 20 & 195 & 28.02 & 9.52 & 1.00 & 99.5 & $\mid-18.12$ & 5432 & & \\
\hline $200-210$ & 21 & 205 & 26.91 & 9.41 & 0.88 & 99.2 & $\mid-18.89$ & 4920 & 680 & 1.48 \\
\hline $210-220$ & 22 & 215 & 32.80 & 9.20 & 0.80 & 99.5 & -17.97 & 6033 & & \\
\hline $220-233$ & 23 & 226 & 38.03 & 9.57 & 0.82 & 99.8 & -18.75 & 6616 & & \\
\hline $233-245$ & 24 & 239 & 26.46 & 8.01 & 1.28 & 80.1 & $\mid-19.61$ & 5146 & & \\
\hline $245-255$ & 25 & 250 & 30.00 & 7.97 & 1.36 & 80.3 & $\mid-19.50$ & 6056 & & \\
\hline $255-260$ & 26 & 257 & 33.83 & 8.19 & 1.36 & 80.6 & -19.56 & 4957 & & \\
\hline $260-270$ & 27 & 265 & 34.39 & 8.04 & 1.35 & 81.2 & $\mid-19.26$ & 5019 & & 1.53 \\
\hline $270-280$ & 28 & 275 & 30.58 & 8.31 & 1.17 & 87.5 & -19.43 & 6444 & 674 & \\
\hline $280-290$ & 29 & 285 & 29.24 & 8.49 & 1.16 & 87.5 & -19.94 & 5374 & & 1.39 \\
\hline $290-300$ & 30 & 295 & 29.22 & 8.25 & 1.12 & 84.8 & $\mid-19.21$ & 5294 & & \\
\hline $300-310$ & 31 & 305 & 30.60 & 8.47 & 1.12 & 84.8 & -19.18 & 5472 & & \\
\hline $310-320$ & 32 & 315 & 32.54 & 8.04 & 1.37 & 79.4 & $\mid-19.04$ & 5349 & 539 & \\
\hline $320-330$ & 33 & 325 & 34.43 & 7.69 & 1.40 & 77.9 & $\mid-19.83$ & 5481 & & \\
\hline $330-340$ & 34 & 335 & 33.70 & 7.90 & 1.28 & 78.5 & -19.65 & 5767 & & 1.47 \\
\hline $340-350$ & 35 & 345 & 32.20 & 7.89 & 1.28 & 79.1 & $\mid-19.49$ & 5601 & 457 & \\
\hline $350-360$ & 36 & 355 & 33.53 & 7.89 & 1.23 & 80.3 & $\mid-19.09$ & 4968 & & \\
\hline $360-366$ & 37 & 363 & 34.38 & 7.78 & 1.25 & 77.0 & -18.68 & 5386 & 708 & \\
\hline $366-380$ & 38 & 373 & 32.88 & 7.25 & 1.28 & 73.4 & -19.44 & 7056 & & 1.52 \\
\hline $380-390$ & 39 & 385 & 31.78 & 7.32 & 1.28 & 74.1 & -20.34 & 5773 & & \\
\hline $392-400$ & 40 & 396 & 27.50 & 7.41 & 1.11 & 74.3 & -19.70 & 5446 & 590 & 1.50 \\
\hline $400-407$ & 41 & 404 & 28.36 & 7.54 & 1.02 & 75.2 & -19.40 & 5016 & & \\
\hline $407-413$ & 42 & 410 & 26.78 & 7.81 & 0.98 & 78.7 & $\mid-19.30$ & 5689 & 1045 & \\
\hline $413-424$ & 43 & 418 & 26.12 & 7.60 & 1.06 & 76.3 & $\mid-19.24$ & 5707 & & \\
\hline
\end{tabular}


LH2 Profile, Continued...

\begin{tabular}{|c|c|c|c|c|c|c|c|c|c|c|}
\hline \multicolumn{1}{|l|}{ LH2 Profile } & \multicolumn{10}{|c|}{} \\
\hline Interval Depth & $\#$ & depth & $\mathrm{X}$ & Total C & Organic C & $\%$ CCE & $\mathrm{d}^{13} \mathrm{C}$ & Fed & Feox & Bulk Density \\
\hline $424-434$ & 44 & 429 & 25.38 & 7.75 & 1.02 & 76.0 & -19.17 & 6778 & & 1.39 \\
\hline $434-444$ & 45 & 439 & 28.27 & 7.55 & 1.07 & 74.5 & -18.86 & 6315 & 766 & \\
\hline $444-453$ & 46 & 449 & 25.20 & 8.45 & 1.15 & 81.1 & -19.33 & 6556 & & \\
\hline $453-461$ & 47 & 457 & 24.19 & 8.35 & 1.16 & 78.7 & -18.94 & 6370 & & 1.47 \\
\hline $461-471$ & 48 & 466 & 25.23 & 7.82 & 0.83 & 76.3 & -19.19 & 6865 & & \\
\hline $471-475$ & 49 & 473 & 25.00 & 7.61 & 0.82 & 74.8 & -19.31 & 6941 & & \\
\hline $475-485$ & 50 & 480 & 26.28 & 7.57 & 0.90 & 72.7 & -18.96 & 5850 & 696 & \\
\hline $485-490$ & 51 & 487 & 26.33 & 7.81 & 0.89 & 77.4 & -19.21 & 5803 & & \\
\hline $490-500$ & 52 & 495 & 23.69 & 8.07 & 0.78 & 77.1 & -20.25 & 6271 & & \\
\hline
\end{tabular}

P1 Profile with Gravel

\begin{tabular}{|c|c|c|c|c|c|c|c|c|c|c|c|c|}
\hline \multicolumn{3}{|l|}{ P1 Profile } & \multicolumn{10}{|c|}{ With Gravel } \\
\hline $\begin{array}{l}\text { Interval } \\
\text { Depth }\end{array}$ & \# & depth & $\begin{array}{c}\% \\
\geq 63 \mu\end{array}$ & $\% \geq 2 \mu$ & $\begin{array}{c}\% \\
\text { gravel }\end{array}$ & $\begin{array}{c}\% \\
\text { sand }\end{array}$ & $\%$ silt & $\%$ clay & mean & sd & skew & kurt \\
\hline $0-10$ & 1 & 5 & 19.4 & 58.3 & 0.1 & 19.4 & 38.9 & 41.7 & 7.86 & 4.20 & -0.03 & 0.32 \\
\hline $10-20$ & 2 & 15 & 18.0 & 59.3 & 0.0 & 18.0 & 41.2 & 40.7 & 7.92 & 4.09 & 0.01 & 0.32 \\
\hline $20-30$ & 3 & 25 & 18.3 & 58.6 & 0.0 & 18.3 & 40.3 & 41.4 & 7.92 & 4.13 & 0.02 & 0.31 \\
\hline $30-40$ & 4 & 35 & 18.4 & 59.4 & 0.0 & 18.4 & 40.9 & 40.6 & 7.88 & 4.09 & 0.01 & 0.31 \\
\hline $40-50$ & 5 & 45 & 19.3 & 59.6 & 0.0 & 19.3 & 40.3 & 40.4 & 8.18 & 3.74 & 0.10 & 0.11 \\
\hline $50-60$ & 6 & 55 & 18.7 & 59.2 & 0.0 & 18.7 & 40.5 & 40.8 & 7.88 & 4.10 & 0.00 & 0.31 \\
\hline $60-70$ & 7 & 65 & 18.8 & 59.4 & 0.0 & 18.8 & 40.6 & 40.6 & 7.85 & 4.08 & 0.00 & 0.31 \\
\hline $70-80$ & 8 & 75 & 20.1 & 60.8 & 0.0 & 20.0 & 40.8 & 39.2 & 7.77 & 4.08 & 0.01 & 0.31 \\
\hline $80-90$ & 9 & 85 & 20.9 & 60.2 & 0.0 & 20.9 & 39.3 & 39.8 & 7.82 & 4.18 & 0.04 & 0.29 \\
\hline $90-100$ & 10 & 95 & 21.5 & 61.6 & 0.0 & 21.5 & 40.1 & 38.4 & 7.72 & 4.12 & 0.07 & 0.31 \\
\hline $100-110$ & 11 & 105 & 21.1 & 59.7 & 0.0 & 21.1 & 38.5 & 40.3 & 7.79 & 4.16 & 0.02 & 0.29 \\
\hline $110-120$ & 12 & 115 & 20.9 & 59.4 & 0.0 & 20.9 & 38.5 & 40.6 & 7.79 & 4.18 & -0.01 & 0.30 \\
\hline $120-130$ & 13 & 125 & 20.0 & 58.7 & 0.0 & 20.0 & 38.7 & 41.3 & 7.87 & 4.17 & 0.00 & 0.29 \\
\hline $130-140$ & 14 & 135 & 20.2 & 58.9 & 0.0 & 20.2 & 38.7 & 41.1 & 7.86 & 4.18 & 0.00 & 0.29 \\
\hline $140-150$ & 15 & 145 & 19.5 & 59.5 & 0.0 & 19.5 & 40.0 & 40.5 & 7.82 & 4.10 & -0.02 & 0.16 \\
\hline $150-160$ & 16 & 155 & 18.9 & 62.1 & 0.0 & 18.9 & 43.3 & 37.9 & 7.78 & 4.00 & 0.02 & 0.33 \\
\hline $160-170$ & 17 & 165 & 19.1 & 62.1 & 0.0 & 19.1 & 43.0 & 37.9 & 7.77 & 4.01 & 0.00 & 0.33 \\
\hline $170-180$ & 18 & 175 & 18.5 & 69.1 & 0.0 & 18.5 & 50.7 & 30.9 & 7.39 & 3.59 & 0.10 & 0.44 \\
\hline $180-190$ & 19 & 185 & 17.9 & 61.7 & 0.0 & 17.9 & 43.8 & 38.3 & 7.80 & 3.97 & 0.02 & 0.34 \\
\hline $190-200$ & 20 & 195 & 17.9 & 62.7 & 0.0 & 17.9 & 44.8 & 37.3 & 7.83 & 3.99 & 0.04 & 0.33 \\
\hline $200-210$ & 21 & 205 & 17.9 & 62.2 & 0.0 & 17.9 & 44.3 & 37.8 & 7.83 & 3.99 & 0.03 & 0.32 \\
\hline $210-220$ & 22 & 215 & 18.5 & 61.7 & 0.0 & 18.5 & 43.3 & 38.3 & 7.85 & 4.04 & 0.03 & 0.31 \\
\hline $220-230$ & 23 & 225 & 17.7 & 61.7 & 0.0 & 17.7 & 44.0 & 38.3 & 8.24 & 3.61 & 0.17 & 0.14 \\
\hline $230-240$ & 24 & 235 & 15.1 & 61.4 & 0.0 & 15.1 & 46.4 & 38.6 & 8.01 & 3.89 & 0.05 & 0.35 \\
\hline $240-250$ & 25 & 245 & 14.7 & 61.5 & 0.0 & 14.7 & 46.8 & 38.5 & 7.98 & 3.85 & 0.04 & 0.36 \\
\hline $250-260$ & 26 & 255 & 15.1 & 60.9 & 0.0 & 15.1 & 45.9 & 39.1 & 8.03 & 3.95 & 0.06 & 0.33 \\
\hline $260-270$ & 27 & 265 & 14.3 & 60.7 & 0.0 & 14.3 & 46.4 & 39.3 & 8.07 & 3.84 & 0.03 & 0.36 \\
\hline $270-280$ & 28 & 275 & 10.5 & 56.8 & 0.0 & 10.5 & 46.4 & 43.2 & 8.41 & 3.72 & 0.03 & 0.37 \\
\hline $280-290$ & 29 & 285 & 7.2 & 55.6 & 0.0 & 7.2 & 48.4 & 44.4 & 8.61 & 3.53 & 0.05 & 0.39 \\
\hline $290-300$ & 30 & 295 & 6.7 & 55.3 & 0.0 & 6.7 & 48.6 & 44.7 & 8.82 & 3.38 & 0.12 & 0.44 \\
\hline $300-310$ & 31 & 305 & 4.7 & 55.1 & 0.0 & 4.7 & 50.4 & 44.9 & 8.79 & 3.41 & 0.10 & 0.37 \\
\hline $310-320$ & 32 & 315 & 3.3 & 53.8 & 0.0 & 3.3 & 50.4 & 46.2 & 8.97 & 3.29 & 0.12 & 0.35 \\
\hline $320-330$ & 33 & 325 & 3.1 & 52.1 & 0.0 & 3.1 & 49.0 & 47.9 & 9.14 & 3.19 & 0.13 & 0.11 \\
\hline $330-340$ & 34 & 335 & 5.3 & 53.4 & 0.0 & 5.3 & 48.1 & 46.6 & 8.70 & 3.55 & 0.02 & 0.34 \\
\hline $340-350$ & 35 & 345 & 9.2 & 56.0 & 0.0 & 9.2 & 46.9 & 44.0 & 8.39 & 3.80 & 0.04 & 0.30 \\
\hline $350-360$ & 36 & 355 & 3.9 & 54.1 & 0.0 & 3.9 & 50.2 & 45.9 & 8.72 & 3.50 & 0.05 & 0.33 \\
\hline $360-370$ & 37 & 365 & 8.8 & 57.6 & 0.0 & 8.8 & 48.7 & 42.4 & 8.32 & 3.77 & 0.07 & 0.31 \\
\hline $370-380$ & 38 & 375 & 13.6 & 61.8 & 0.0 & 13.6 & 48.2 & 38.2 & 8.01 & 3.84 & 0.13 & 0.33 \\
\hline $380-390$ & 39 & 385 & 25.4 & 65.5 & 0.0 & 25.4 & 40.1 & 34.5 & 7.44 & 4.08 & 0.09 & 0.30 \\
\hline $390-400$ & 40 & 395 & 32.2 & 65.3 & 0.0 & 32.2 & 33.1 & 34.7 & 7.36 & 4.18 & 0.06 & 0.27 \\
\hline
\end{tabular}


P1 Profile without Gravel

\begin{tabular}{|c|c|c|c|c|c|c|c|c|c|c|c|c|}
\hline \multicolumn{3}{|c|}{ P1 Profile } & \multicolumn{10}{|c|}{ Without Gravel } \\
\hline $\begin{array}{l}\text { Interval } \\
\text { Depth }\end{array}$ & \# & depth & $\begin{array}{c}\% \\
\geq 63 \mu\end{array}$ & $\% \geq 2 \mu$ & $\begin{array}{c}\% \\
\text { gravel }\end{array}$ & $\begin{array}{c}\% \\
\text { sand }\end{array}$ & $\%$ silt & $\begin{array}{l}\% \\
\text { clay }\end{array}$ & mean & sd & skew & kurt \\
\hline $0-10$ & 1 & 5 & 19.4 & 58.3 & 0.1 & 19.4 & 38.9 & 41.7 & 7.87 & 4.20 & -0.03 & 0.32 \\
\hline $10-20$ & 2 & 15 & 18.0 & 59.3 & 0.0 & 18.0 & 41.2 & 40.7 & 7.92 & 4.09 & 0.01 & 0.32 \\
\hline $20-30$ & 3 & 25 & 18.3 & 58.6 & 0.0 & 18.3 & 40.3 & 41.4 & 7.92 & 4.13 & 0.02 & 0.31 \\
\hline $30-40$ & 4 & 35 & 18.4 & 59.4 & 0.0 & 18.4 & 40.9 & 40.6 & 7.88 & 4.09 & 0.01 & 0.31 \\
\hline $40-50$ & 5 & 45 & 19.3 & 59.6 & 0.0 & 19.3 & 40.3 & 40.4 & 7.83 & 4.09 & 0.01 & 0.31 \\
\hline $50-60$ & 6 & 55 & 18.7 & 59.2 & 0.0 & 18.7 & 40.5 & 40.8 & 7.89 & 4.10 & 0.00 & 0.31 \\
\hline $60-70$ & 7 & 65 & 18.8 & 59.4 & 0.0 & 18.8 & 40.6 & 40.6 & 7.85 & 4.08 & 0.00 & 0.31 \\
\hline $70-80$ & 8 & 75 & 20.0 & 60.8 & 0.0 & 20.0 & 40.8 & 39.2 & 7.77 & 4.08 & 0.01 & 0.31 \\
\hline $80-90$ & 9 & 85 & 20.9 & 60.2 & 0.0 & 20.9 & 39.3 & 39.8 & 7.82 & 4.18 & 0.04 & 0.29 \\
\hline $90-100$ & 10 & 95 & 21.5 & 61.6 & 0.0 & 21.5 & 40.1 & 38.4 & 7.72 & 4.12 & 0.07 & 0.31 \\
\hline $100-110$ & 11 & 105 & 21.1 & 59.7 & 0.0 & 21.1 & 38.5 & 40.3 & 7.79 & 4.16 & 0.02 & 0.29 \\
\hline $110-120$ & 12 & 115 & 20.9 & 59.4 & 0.0 & 20.9 & 38.5 & 40.6 & 7.79 & 4.18 & -0.01 & 0.30 \\
\hline $120-130$ & 13 & 125 & 20.0 & 58.7 & 0.0 & 20.0 & 38.7 & 41.3 & 7.87 & 4.17 & 0.00 & 0.29 \\
\hline $130-140$ & 14 & 135 & 20.2 & 58.9 & 0.0 & 20.2 & 38.7 & 41.1 & 7.86 & 4.18 & 0.00 & 0.29 \\
\hline $140-150$ & 15 & 145 & 19.5 & 59.5 & 0.0 & 19.5 & 40.0 & 40.5 & 7.82 & 4.10 & -0.02 & 0.31 \\
\hline $150-160$ & 16 & 155 & 18.9 & 62.1 & 0.0 & 18.9 & 43.3 & 37.9 & 7.78 & 4.00 & 0.02 & 0.33 \\
\hline $160-170$ & 17 & 165 & 19.1 & 62.1 & 0.0 & 19.1 & 43.0 & 37.9 & 7.77 & 4.01 & 0.00 & 0.33 \\
\hline $170-180$ & 18 & 175 & 18.5 & 69.1 & 0.0 & 18.5 & 50.7 & 30.9 & 7.39 & 3.59 & 0.10 & 0.44 \\
\hline $180-190$ & 19 & 185 & 17.9 & 61.7 & 0.0 & 17.9 & 43.8 & 38.3 & 7.80 & 3.97 & 0.02 & 0.34 \\
\hline $190-200$ & 20 & 195 & 17.9 & 62.7 & 0.0 & 17.9 & 44.8 & 37.3 & 7.83 & 3.99 & 0.04 & 0.33 \\
\hline $200-210$ & 21 & 205 & 17.9 & 62.2 & 0.0 & 17.9 & 44.3 & 37.8 & 7.83 & 3.99 & 0.03 & 0.32 \\
\hline $210-220$ & 22 & 215 & 18.5 & 61.7 & 0.0 & 18.5 & 43.3 & 38.3 & 7.85 & 4.04 & 0.03 & 0.31 \\
\hline $220-230$ & 23 & 225 & 17.7 & 61.7 & 0.0 & 17.7 & 44.0 & 38.3 & 7.85 & 4.00 & 0.06 & 0.33 \\
\hline $230-240$ & 24 & 235 & 15.1 & 61.4 & 0.0 & 15.1 & 46.4 & 38.6 & 8.00 & 3.91 & 0.05 & 0.34 \\
\hline $240-250$ & 25 & 245 & 14.7 & 61.5 & 0.0 & 14.7 & 46.8 & 38.5 & 7.98 & 3.84 & 0.04 & 0.36 \\
\hline $250-260$ & 26 & 255 & 15.1 & 60.9 & 0.0 & 15.1 & 45.9 & 39.1 & 8.03 & 3.94 & 0.06 & 0.33 \\
\hline $260-270$ & 27 & 265 & 14.3 & 60.7 & 0.0 & 14.3 & 46.4 & 39.3 & 8.04 & 3.87 & 0.02 & 0.35 \\
\hline $270-280$ & 28 & 275 & 10.5 & 56.8 & 0.0 & 10.5 & 46.4 & 43.2 & 8.41 & 3.72 & 0.03 & 0.37 \\
\hline $280-290$ & 29 & 285 & 7.2 & 55.6 & 0.0 & 7.2 & 48.4 & 44.4 & 8.61 & 3.53 & 0.05 & 0.39 \\
\hline $290-300$ & 30 & 295 & 6.7 & 55.3 & 0.0 & 6.7 & 48.6 & 44.7 & 8.82 & 3.38 & 0.12 & 0.44 \\
\hline $300-310$ & 31 & 305 & 4.7 & 55.1 & 0.0 & 4.7 & 50.4 & 44.9 & 8.79 & 3.41 & 0.10 & 0.38 \\
\hline $310-320$ & 32 & 315 & 3.3 & 53.8 & 0.0 & 3.3 & 50.4 & 46.2 & 8.97 & 3.29 & 0.12 & 0.40 \\
\hline $320-330$ & 33 & 325 & 3.1 & 52.1 & 0.0 & 3.1 & 49.0 & 47.9 & 9.14 & 3.19 & 0.13 & 0.43 \\
\hline $330-340$ & 34 & 335 & 5.3 & 53.4 & 0.0 & 5.3 & 48.1 & 46.6 & 8.70 & 3.55 & 0.02 & 0.34 \\
\hline $340-350$ & 35 & 345 & 9.2 & 56.0 & 0.0 & 9.2 & 46.9 & 44.0 & 8.39 & 3.80 & 0.04 & 0.30 \\
\hline $350-360$ & 36 & 355 & 3.9 & 54.1 & 0.0 & 3.9 & 50.2 & 45.9 & 8.72 & 3.50 & 0.05 & 0.33 \\
\hline $360-370$ & 37 & 365 & 8.8 & 57.6 & 0.0 & 8.8 & 48.7 & 42.4 & 8.33 & 3.76 & 0.08 & 0.32 \\
\hline $370-380$ & 38 & 375 & 13.6 & 61.8 & 0.0 & 13.6 & 48.2 & 38.2 & 8.02 & 3.83 & 0.13 & 0.33 \\
\hline $380-390$ & 39 & 385 & 25.4 & 65.5 & 0.0 & 25.4 & 40.1 & 34.5 & 7.44 & 4.08 & 0.09 & 0.30 \\
\hline $390-400$ & 40 & 395 & 32.2 & 65.3 & 0.0 & 32.2 & 33.1 & 34.7 & 7.36 & 4.18 & 0.06 & 0.27 \\
\hline
\end{tabular}


P1 Profile

\begin{tabular}{|c|c|c|c|c|c|c|c|c|c|c|}
\hline \multicolumn{3}{|c|}{ P1 Profile } & \multirow[b]{2}{*}{$x$} & \multirow[b]{2}{*}{$\begin{array}{c}\text { Total } \\
\text { C }\end{array}$} & \multirow[b]{2}{*}{$\begin{array}{c}\text { Organic } \\
\text { C }\end{array}$} & \multirow[b]{2}{*}{ \%CCE } & \multirow[b]{2}{*}{$\mathrm{d}^{13} \mathrm{C}$} & \multirow[b]{2}{*}{ Fed } & \multirow[b]{2}{*}{ Feox } & \multirow[b]{2}{*}{$\begin{array}{c}\text { Bulk } \\
\text { Density }\end{array}$} \\
\hline $\begin{array}{l}\text { Interval } \\
\text { Depth }\end{array}$ & \# & depth & & & & & & & & \\
\hline $0-10$ & 1 & 5 & 76.09 & 6.83 & 2.43 & 64.9 & -16.68 & 5649 & & \\
\hline $10-20$ & 2 & 15 & 86.21 & 6.73 & 2.23 & 65.5 & -16.04 & 5722 & & \\
\hline $20-30$ & 3 & 25 & 79.37 & 7.00 & 2.14 & 68.1 & -16.40 & 5432 & & \\
\hline $30-40$ & 4 & 35 & 76.36 & 6.98 & 2.05 & 71.1 & -15.90 & 5435 & & \\
\hline $40-50$ & 5 & 45 & 66.06 & 7.17 & 1.67 & 72.8 & -15.46 & 5249 & & \\
\hline $50-60$ & 6 & 55 & 64.50 & 7.06 & 1.69 & 71.0 & -15.31 & 6583 & & \\
\hline $60-70$ & 7 & 65 & 67.44 & 7.15 & 1.68 & 74.0 & -16.26 & 5285 & & \\
\hline $70-80$ & 8 & 75 & 58.88 & 7.24 & 1.35 & 75.4 & -16.99 & 5342 & & 1.80 \\
\hline $80-90$ & 9 & 85 & 57.56 & 7.18 & 1.35 & 76.6 & -17.21 & 5294 & & \\
\hline $90-100$ & 10 & 95 & 53.52 & 7.23 & 1.27 & 76.9 & -17.55 & 6194 & & \\
\hline $100-110$ & 11 & 105 & 52.97 & 7.25 & 1.21 & 76.9 & -17.04 & 5180 & & \\
\hline $110-120$ & 12 & 115 & 51.21 & 7.16 & 1.04 & 74.9 & -17.45 & 7052 & & \\
\hline $120-130$ & 13 & 125 & 50.31 & 7.10 & 1.15 & 74.6 & -17.70 & 6729 & 375 & 1.80 \\
\hline $130-140$ & 14 & 135 & 47.13 & 7.00 & 1.05 & 75.5 & -17.55 & 5754 & & \\
\hline $140-150$ & 15 & 145 & 48.06 & 7.05 & 0.96 & 75.1 & -17.64 & 5827 & & \\
\hline $150-160$ & 16 & 155 & 46.07 & 6.98 & 0.93 & 76.3 & -17.85 & 6645 & & \\
\hline $160-170$ & 17 & 165 & 45.28 & 6.78 & 0.95 & 74.8 & -18.48 & 5419 & 385 & 1.83 \\
\hline $170-180$ & 18 & 175 & 44.34 & 4.26 & 0.85 & 75.7 & -18.10 & - & & \\
\hline $180-190$ & 19 & 185 & 43.59 & 7.00 & 0.88 & 73.9 & -18.62 & 5462 & & \\
\hline $190-200$ & 20 & 195 & 44.34 & 6.87 & 0.76 & 73.3 & -18.25 & 5425 & & \\
\hline $200-210$ & 21 & 205 & 43.15 & 6.79 & 0.71 & 72.4 & -18.51 & 5763 & 472 & \\
\hline $210-220$ & 22 & 215 & 43.73 & 6.74 & 0.66 & 73.8 & $\mid-18.78$ & 5769 & & \\
\hline $220-230$ & 23 & 225 & 42.62 & 6.31 & 0.67 & 70.0 & -19.34 & 5667 & & \\
\hline $230-240$ & 24 & 235 & 42.36 & 6.42 & 0.63 & 70.5 & -19.26 & 5889 & & \\
\hline $240-250$ & 25 & 245 & 41.27 & 6.39 & 0.66 & 69.9 & -19.80 & 5776 & & \\
\hline $250-260$ & 26 & 255 & 38.50 & 6.50 & 0.65 & 69.0 & $\mid-19.76$ & 5465 & & \\
\hline $260-270$ & 27 & 265 & 38.83 & 6.25 & 0.56 & 68.7 & \begin{tabular}{|l|}
-19.48 \\
\end{tabular} & 4986 & 513 & 1.82 \\
\hline $270-280$ & 28 & 275 & 41.02 & 5.99 & 0.59 & 64.5 & $\mid-19.53$ & 5495 & & \\
\hline $280-290$ & 29 & 285 & 37.58 & 5.94 & 0.65 & 62.7 & -20.44 & 5630 & & \\
\hline $290-300$ & 30 & 295 & 40.56 & 5.52 & 0.65 & 63.3 & -20.92 & 5261 & & \\
\hline $300-310$ & 31 & 305 & 39.29 & 5.50 & 0.56 & 80.2 & -20.61 & 5147 & 530 & \\
\hline $310-320$ & 32 & 315 & 45.66 & 4.11 & 0.57 & 56.4 & -20.89 & 5426 & & \\
\hline $320-330$ & 33 & 325 & 43.89 & 4.57 & 0.57 & 53.4 & -20.81 & 5696 & & \\
\hline $330-340$ & 34 & 335 & 53.13 & 4.62 & 0.48 & 54.3 & -20.37 & 5340 & 396 & \\
\hline $340-350$ & 35 & 345 & 54.11 & 4.40 & 0.50 & 50.5 & -20.44 & 6243 & & \\
\hline $350-360$ & 36 & 355 & 52.81 & 4.61 & 0.58 & 59.9 & -21.37 & 5923 & & \\
\hline $360-370$ & 37 & 365 & 54.34 & 4.32 & 0.46 & 49.8 & \begin{tabular}{|l|}
-20.04 \\
\end{tabular} & 6004 & 431 & 1.77 \\
\hline $370-380$ & 38 & 375 & 44.72 & 5.20 & 0.44 & 58.7 & -20.58 & 5194 & & \\
\hline $380-390$ & 39 & 385 & 35.89 & 6.51 & 0.54 & 76.5 & -21.87 & 4992 & & \\
\hline $390-400$ & 40 & 395 & 32.90 & 7.23 & 0.67 & 80.3 & $\mid-21.82$ & 4948 & 557 & \\
\hline
\end{tabular}


LP1 Profile with Gravel

\begin{tabular}{|c|c|c|c|c|c|c|c|c|c|c|c|c|}
\hline \multicolumn{3}{|c|}{ LP1 Profile } & \multicolumn{10}{|c|}{ With Gravel } \\
\hline $\begin{array}{l}\text { Interval } \\
\text { Depth }\end{array}$ & \# & depth & $\begin{array}{c}\% \\
\geq 63 \mu\end{array}$ & $\% \geq 2 \mu$ & $\begin{array}{c}\% \\
\text { gravel }\end{array}$ & $\begin{array}{c}\% \\
\text { sand }\end{array}$ & $\%$ silt & $\begin{array}{c}\% \\
\text { clay }\end{array}$ & mean & $\mathrm{sd}$ & skew & kurt \\
\hline $0-10$ & 1 & 5 & 20.6 & 69.1 & 0.0 & 20.6 & 48.5 & 30.9 & 7.36 & 3.83 & 0.16 & 0.43 \\
\hline $10-20$ & 2 & 15 & 19.0 & 65.9 & 0.3 & 18.7 & 46.9 & 34.1 & 7.64 & 3.91 & 0.16 & 0.40 \\
\hline $20-30$ & 3 & 25 & 19.8 & 65.5 & 0.1 & 19.7 & 45.7 & 34.5 & 7.64 & 3.99 & 0.12 & 0.38 \\
\hline $30-40$ & 4 & 35 & 20.7 & 65.8 & 0.0 & 20.7 & 45.1 & 34.2 & 7.56 & 3.99 & 0.13 & 0.38 \\
\hline $40-50$ & 5 & 45 & 22.3 & 65.6 & 0.0 & 22.3 & 43.3 & 34.4 & 8.02 & 3.58 & 0.26 & 0.14 \\
\hline $50-60$ & 6 & 55 & 22.7 & 64.4 & 0.0 & 22.7 & 41.7 & 35.6 & 7.53 & 4.13 & 0.07 & 0.35 \\
\hline $60-70$ & 7 & 65 & 23.6 & 65.3 & 0.0 & 23.6 & 41.8 & 34.7 & 7.46 & 4.09 & 0.08 & 0.36 \\
\hline $70-80$ & 8 & 75 & 23.9 & 64.3 & 0.0 & 23.9 & 40.4 & 35.7 & 7.47 & 4.15 & 0.08 & 0.35 \\
\hline $80-90$ & 9 & 85 & 23.5 & 65.1 & 0.0 & 23.4 & 41.7 & 34.9 & 7.42 & 4.14 & 0.12 & 0.36 \\
\hline $90-100$ & 10 & 95 & 22.3 & 64.8 & 0.0 & 22.3 & 42.5 & 35.2 & 7.46 & 4.08 & 0.02 & 0.37 \\
\hline $100-110$ & 11 & 105 & 22.8 & 65.8 & 0.0 & 22.7 & 43.0 & 34.2 & 7.40 & 4.06 & 0.00 & 0.39 \\
\hline $110-120$ & 12 & 115 & 22.7 & 65.7 & 0.0 & 22.7 & 43.0 & 34.3 & 7.31 & 4.04 & -0.02 & 0.39 \\
\hline $120-130$ & 13 & 125 & 22.3 & 65.3 & 0.0 & 22.3 & 43.0 & 34.7 & 7.35 & 4.09 & -0.01 & 0.38 \\
\hline $130-140$ & 14 & 135 & 23.3 & 66.1 & 0.1 & 23.2 & 42.8 & 33.9 & 7.24 & 4.13 & -0.02 & 0.38 \\
\hline $140-150$ & 15 & 145 & 23.7 & 66.0 & 0.0 & 23.7 & 42.3 & 34.0 & 7.22 & 4.16 & -0.03 & 0.20 \\
\hline $150-160$ & 16 & 155 & 23.4 & 65.8 & 0.0 & 23.4 & 42.4 & 34.2 & 7.22 & 4.16 & -0.03 & 0.37 \\
\hline $160-170$ & 17 & 165 & 24.4 & 65.0 & 0.0 & 24.3 & 40.7 & 35.0 & 7.22 & 4.25 & -0.05 & 0.34 \\
\hline $170-180$ & 18 & 175 & 25.2 & 65.2 & 0.2 & 25.0 & 40.0 & 34.8 & 7.18 & 4.27 & -0.05 & 0.34 \\
\hline $180-190$ & 19 & 185 & 26.4 & 66.5 & 0.1 & 26.3 & 40.1 & 33.5 & 7.13 & 4.25 & -0.02 & 0.34 \\
\hline $190-200$ & 20 & 195 & 27.1 & 65.8 & 0.1 & 27.0 & 38.6 & 34.2 & 7.14 & 4.31 & -0.03 & 0.32 \\
\hline $200-210$ & 21 & 205 & 28.9 & 67.7 & 0.0 & 28.9 & 38.8 & 32.3 & 7.01 & 4.25 & -0.09 & 0.33 \\
\hline $210-220$ & 22 & 215 & 33.8 & 69.4 & 0.0 & 33.8 & 35.6 & 30.6 & 6.84 & 4.30 & 0.05 & 0.32 \\
\hline $220-230$ & 23 & 225 & 38.0 & 70.8 & 0.0 & 38.0 & 32.7 & 29.2 & 6.92 & 4.06 & 0.16 & 0.21 \\
\hline $230-240$ & 24 & 235 & 39.9 & 71.3 & 0.0 & 39.9 & 31.4 & 28.7 & 6.65 & 4.34 & 0.25 & 0.32 \\
\hline $240-250$ & 25 & 245 & 40.6 & 71.1 & 0.0 & 40.6 & 30.4 & 28.9 & 6.62 & 4.39 & 0.21 & 0.31 \\
\hline $250-260$ & 26 & 255 & 39.9 & 71.4 & 0.0 & 39.9 & 31.5 & 28.6 & 6.74 & 4.43 & 0.21 & 0.30 \\
\hline $260-270$ & 27 & 265 & 36.0 & 71.0 & 0.0 & 36.0 & 34.9 & 29.0 & 6.82 & 4.29 & 0.20 & 0.32 \\
\hline $270-280$ & 28 & 275 & 39.5 & 72.5 & 0.0 & 39.5 & 33.1 & 27.5 & 6.54 & 4.32 & 0.24 & 0.33 \\
\hline $280-290$ & 29 & 285 & 49.9 & 77.0 & 0.0 & 49.8 & 27.2 & 23.0 & 5.96 & 4.37 & 0.45 & 0.35 \\
\hline $290-300$ & 30 & 295 & 56.4 & 77.8 & 0.1 & 56.3 & 21.5 & 22.2 & 5.84 & 4.45 & 0.68 & 0.33 \\
\hline $300-310$ & 31 & 305 & 58.0 & 79.5 & 0.1 & 57.9 & 21.5 & 20.5 & 5.79 & 4.11 & 0.71 & 0.40 \\
\hline $310-320$ & 32 & 315 & 53.4 & 75.5 & 0.1 & 53.4 & 22.0 & 24.5 & 6.14 & 4.50 & 0.63 & 0.31 \\
\hline $320-330$ & 33 & 325 & 69.0 & 83.0 & 0.1 & 69.0 & 14.0 & 17.0 & 5.40 & 3.77 & 0.79 & 0.40 \\
\hline $330-340$ & 34 & 335 & 54.0 & 77.4 & 0.0 & 54.0 & 23.4 & 22.6 & 6.11 & 4.18 & 0.61 & 0.37 \\
\hline $340-350$ & 35 & 345 & 78.3 & 89.6 & 28.2 & 50.2 & 11.2 & 10.4 & 2.06 & 4.66 & 0.20 & 0.68 \\
\hline $350-360$ & 36 & 355 & 83.7 & 92.3 & 24.6 & 59.1 & 8.6 & 7.7 & 0.96 & 3.14 & -0.06 & 1.27 \\
\hline $360-370$ & 37 & 365 & 41.4 & 72.2 & 0.8 & 40.6 & 30.8 & 27.8 & 6.61 & 4.43 & 0.34 & 0.31 \\
\hline $370-385$ & 38 & 377 & 41.3 & 72.4 & 0.3 & 41.1 & 31.1 & 27.6 & 6.56 & 4.43 & 0.33 & 0.32 \\
\hline $385-390$ & 39 & 392 & 87.5 & 94.1 & 6.1 & 81.3 & 6.6 & 5.9 & 1.63 & 0.96 & 0.16 & 4.91 \\
\hline $390-400$ & 40 & 395 & 89.1 & 94.8 & 20.0 & 69.1 & 5.8 & 5.2 & 0.09 & 2.06 & -0.52 & 2.15 \\
\hline $400-410$ & 41 & 405 & 88.3 & 95.0 & 35.5 & 52.7 & 6.7 & 5.0 & -0.14 & 2.12 & -0.28 & 1.32 \\
\hline 410-415 & 42 & 412 & 91.4 & 96.1 & 65.9 & 25.5 & 4.7 & 3.9 & -1.22 & 2.37 & 0.33 & 1.60 \\
\hline $415-430$ & 43 & 422 & 96.7 & 98.4 & 86.6 & 10.2 & 1.7 & 1.6 & -2.63 & 1.45 & 0.06 & 1.10 \\
\hline $430-440$ & 44 & 435 & 89.4 & 95.4 & 45.4 & 44.0 & 6.0 & 4.6 & -0.72 & 2.54 & -0.13 & 1.50 \\
\hline $440-450$ & 45 & 445 & 92.0 & 95.7 & 65.1 & 26.9 & 3.7 & 4.3 & -1.29 & 2.38 & 0.30 & 1.71 \\
\hline $450-460$ & 46 & 455 & 87.1 & 93.3 & 55.9 & 31.2 & 6.2 & 6.7 & -0.82 & 2.86 & 0.22 & 1.55 \\
\hline $460-470$ & 47 & 465 & 90.5 & 95.3 & 62.5 & 28.0 & 4.8 & 4.7 & -1.14 & 2.66 & 0.37 & 1.54 \\
\hline $470-480$ & 48 & 475 & 92.4 & 96.3 & 62.4 & 30.1 & 3.8 & 3.7 & -1.08 & 2.56 & 0.28 & 1.42 \\
\hline 480-495 & 49 & 487 & 96.1 & 98.1 & 82.7 & 13.5 & 2.0 & 1.9 & -2.19 & 1.67 & 0.49 & 1.12 \\
\hline $495-500$ & 50 & 497 & 4.9 & 44.0 & 0.0 & 4.9 & 39.1 & 56.0 & 8.54 & 4.02 & -0.24 & 0.12 \\
\hline
\end{tabular}


LP1 Profile without Gravel

\begin{tabular}{|c|c|c|c|c|c|c|c|c|c|c|c|c|}
\hline \multicolumn{3}{|c|}{ LP1 Profile } & \multicolumn{10}{|c|}{ Without Gravel } \\
\hline $\begin{array}{c}\text { Interval } \\
\text { Depth }\end{array}$ & \# & depth & $\begin{array}{c}\% \\
\geq 63 \mu\end{array}$ & $\% \geq 2 \mu$ & $\begin{array}{c}\% \\
\text { gravel }\end{array}$ & $\begin{array}{c}\% \\
\text { sand }\end{array}$ & $\%$ silt & $\begin{array}{l}\% \\
\text { clay }\end{array}$ & mean & sd & skew & kurt \\
\hline $0-10$ & 1 & 5 & 20.6 & 69.1 & 0.0 & 20.6 & 48.5 & 30.9 & 7.36 & 3.83 & 0.16 & 0.43 \\
\hline $10-20$ & 2 & 15 & 18.8 & 65.8 & 0.3 & 18.8 & 47.0 & 34.2 & 7.65 & 3.91 & 0.16 & 0.40 \\
\hline $20-30$ & 3 & 25 & 19.7 & 65.5 & 0.1 & 19.7 & 45.8 & 34.5 & 7.64 & 3.99 & 0.12 & 0.38 \\
\hline $30-40$ & 4 & 35 & 20.7 & 65.8 & 0.0 & 20.7 & 45.1 & 34.2 & 7.56 & 3.99 & 0.13 & 0.38 \\
\hline $40-50$ & 5 & 45 & 22.3 & 65.6 & 0.0 & 22.3 & 43.3 & 34.4 & 7.52 & 4.07 & 0.11 & 0.36 \\
\hline $50-60$ & 6 & 55 & 22.7 & 64.4 & 0.0 & 22.7 & 41.7 & 35.6 & 7.53 & 4.13 & 0.07 & 0.35 \\
\hline $60-70$ & 7 & 65 & 23.6 & 65.3 & 0.0 & 23.6 & 41.8 & 34.7 & 7.46 & 4.09 & 0.08 & 0.36 \\
\hline $70-80$ & 8 & 75 & 23.9 & 64.3 & 0.0 & 23.9 & 40.4 & 35.7 & 7.47 & 4.15 & 0.08 & 0.35 \\
\hline $80-90$ & 9 & 85 & 23.5 & 65.1 & 0.0 & 23.5 & 41.7 & 34.9 & 7.42 & 4.14 & 0.12 & 0.36 \\
\hline $90-100$ & 10 & 95 & 22.3 & 64.8 & 0.0 & 22.3 & 42.5 & 35.2 & 7.46 & 4.08 & 0.02 & 0.37 \\
\hline $100-110$ & 11 & 105 & 22.7 & 65.8 & 0.0 & 22.7 & 43.1 & 34.2 & 7.40 & 4.06 & 0.00 & 0.39 \\
\hline $110-120$ & 12 & 115 & 22.7 & 65.7 & 0.0 & 22.7 & 43.0 & 34.3 & 7.31 & 4.04 & -0.02 & 0.39 \\
\hline $120-130$ & 13 & 125 & 22.3 & 65.3 & 0.0 & 22.3 & 43.0 & 34.7 & 7.35 & 4.09 & -0.01 & 0.38 \\
\hline $130-140$ & 14 & 135 & 23.3 & 66.1 & 0.1 & 23.3 & 42.8 & 33.9 & 7.24 & 4.13 & -0.02 & 0.38 \\
\hline $140-150$ & 15 & 145 & 23.7 & 66.0 & 0.0 & 23.7 & 42.3 & 34.0 & 7.22 & 4.16 & -0.03 & 0.37 \\
\hline $150-160$ & 16 & 155 & 23.4 & 65.8 & 0.0 & 23.4 & 42.4 & 34.2 & 7.23 & 4.16 & -0.03 & 0.37 \\
\hline $160-170$ & 17 & 165 & 24.4 & 65.0 & 0.0 & 24.4 & 40.7 & 35.0 & 7.22 & 4.25 & -0.05 & 0.34 \\
\hline $170-180$ & 18 & 175 & 25.0 & 65.1 & 0.2 & 25.0 & 40.1 & 34.9 & 7.20 & 4.26 & -0.05 & 0.34 \\
\hline $180-190$ & 19 & 185 & 26.3 & 66.4 & 0.1 & 26.3 & 40.2 & 33.6 & 7.13 & 4.25 & -0.02 & 0.34 \\
\hline $190-200$ & 20 & 195 & 27.0 & 65.7 & 0.1 & 27.0 & 38.7 & 34.3 & 7.14 & 4.31 & -0.03 & 0.32 \\
\hline $200-210$ & 21 & 205 & 28.9 & 67.7 & 0.0 & 28.9 & 38.8 & 32.3 & 7.01 & 4.25 & -0.09 & 0.33 \\
\hline $210-220$ & 22 & 215 & 33.8 & 69.4 & 0.0 & 33.8 & 35.6 & 30.6 & 6.84 & 4.30 & 0.05 & 0.32 \\
\hline $220-230$ & 23 & 225 & 38.0 & 70.8 & 0.0 & 38.0 & 32.7 & 29.2 & 6.67 & 4.31 & 0.09 & 0.32 \\
\hline $230-240$ & 24 & 235 & 39.9 & 71.3 & 0.0 & 39.9 & 31.4 & 28.7 & 6.65 & 4.34 & 0.25 & 0.32 \\
\hline $240-250$ & 25 & 245 & 40.6 & 71.1 & 0.0 & 40.6 & 30.4 & 28.9 & 6.63 & 4.39 & 0.21 & 0.31 \\
\hline $250-260$ & 26 & 255 & 39.9 & 71.4 & 0.0 & 39.9 & 31.5 & 28.6 & 6.74 & 4.43 & 0.21 & 0.30 \\
\hline $260-270$ & 27 & 265 & 36.0 & 71.0 & 0.0 & 36.0 & 34.9 & 29.0 & 6.82 & 4.29 & 0.20 & 0.32 \\
\hline $270-280$ & 28 & 275 & 39.5 & 72.5 & 0.0 & 39.5 & 33.1 & 27.5 & 6.54 & 4.33 & 0.24 & 0.33 \\
\hline $280-290$ & 29 & 285 & 49.8 & 77.0 & 0.0 & 49.8 & 27.2 & 23.0 & 5.97 & 4.37 & 0.44 & 0.34 \\
\hline $290-300$ & 30 & 295 & 56.3 & 77.8 & 0.1 & 56.3 & 21.5 & 22.2 & 5.84 & 4.45 & 0.68 & 0.33 \\
\hline $300-310$ & 31 & 305 & 57.9 & 79.5 & 0.1 & 57.9 & 21.5 & 20.5 & 5.79 & 4.11 & 0.71 & 0.40 \\
\hline $310-320$ & 32 & 315 & 53.4 & 75.4 & 0.1 & 53.4 & 22.0 & 24.6 & 6.15 & 4.50 & 0.63 & 0.31 \\
\hline $320-330$ & 33 & 325 & 69.0 & 83.0 & 0.1 & 69.0 & 14.0 & 17.0 & 5.41 & 3.77 & 0.79 & 0.49 \\
\hline $330-340$ & 34 & 335 & 54.0 & 77.4 & 0.0 & 54.0 & 23.4 & 22.6 & 6.11 & 4.18 & 0.61 & 0.37 \\
\hline $340-350$ & 35 & 345 & 69.8 & 85.5 & 28.2 & 69.8 & 15.6 & 14.5 & 4.53 & 3.94 & 0.71 & 0.57 \\
\hline $350-360$ & 36 & 355 & 78.4 & 89.7 & 24.6 & 78.4 & 11.4 & 10.3 & 3.70 & 3.08 & 0.71 & 0.89 \\
\hline $360-370$ & 37 & 365 & 41.0 & 72.0 & 0.8 & 41.0 & 31.1 & 28.0 & 6.64 & 4.42 & 0.34 & 0.31 \\
\hline $370-385$ & 38 & 377 & 41.2 & 72.4 & 0.3 & 41.2 & 31.2 & 27.6 & 6.57 & 4.43 & 0.33 & 0.32 \\
\hline $385-390$ & 39 & 392 & 86.7 & 93.7 & 6.1 & 86.7 & 7.1 & 6.3 & 1.86 & 0.95 & 0.35 & 4.12 \\
\hline $390-400$ & 40 & 395 & 86.3 & 93.5 & 20.0 & 86.3 & 7.2 & 6.5 & 1.71 & 1.06 & 0.33 & 3.74 \\
\hline $400-410$ & 41 & 405 & 81.8 & 92.2 & 35.5 & 81.8 & 10.4 & 7.8 & 2.56 & 2.35 & 0.61 & 1.34 \\
\hline $410-415$ & 42 & 412 & 74.8 & 88.6 & 65.9 & 74.8 & 13.8 & 11.4 & 3.64 & 3.91 & 0.67 & 0.59 \\
\hline $415-430$ & 43 & 422 & 75.8 & 88.5 & 86.6 & 75.8 & 12.7 & 11.5 & 3.46 & 3.94 & 0.72 & 0.61 \\
\hline $430-440$ & 44 & 435 & 80.6 & 91.5 & 45.4 & 80.6 & 10.9 & 8.5 & 2.94 & 2.97 & 0.63 & 0.93 \\
\hline $440-450$ & 45 & 445 & 77.0 & 87.7 & 65.1 & 77.0 & 10.7 & 12.3 & 3.83 & 4.04 & 0.71 & 0.55 \\
\hline $450-460$ & 46 & 455 & 70.7 & 84.7 & 55.9 & 70.7 & 14.0 & 15.3 & 4.39 & 4.39 & 0.71 & 0.47 \\
\hline $460-470$ & 47 & 465 & 74.6 & 87.4 & 62.5 & 74.6 & 12.7 & 12.6 & 4.13 & 3.92 & 0.72 & 0.58 \\
\hline $470-480$ & 48 & 475 & 79.9 & 90.1 & 62.4 & 79.9 & 10.2 & 9.9 & 3.33 & 3.53 & 0.59 & 0.67 \\
\hline 480-495 & 49 & 487 & 77.5 & 88.9 & 82.7 & 77.5 & 11.4 & 11.1 & 3.73 & 3.54 & 0.61 & 0.73 \\
\hline $495-500$ & 50 & 497 & 4.9 & 44.0 & 0.0 & 4.9 & 39.1 & 56.0 & 8.74 & 3.83 & -0.20 & 0.25 \\
\hline
\end{tabular}


LP1 Profile

\begin{tabular}{|c|c|c|c|c|c|c|c|c|c|c|}
\hline \multicolumn{3}{|c|}{ LP1 Profile } & \multirow[b]{2}{*}{$x$} & \multirow[b]{2}{*}{$\begin{array}{c}\text { Total } \\
\text { C }\end{array}$} & \multirow[b]{2}{*}{$\begin{array}{c}\text { Organic } \\
\text { C }\end{array}$} & \multirow[b]{2}{*}{$\%$ CCE } & \multirow[b]{2}{*}{$\mathrm{d}^{13} \mathrm{C}$} & \multirow[b]{2}{*}{ Fed } & \multirow[b]{2}{*}{ Feox } & \multirow[b]{2}{*}{$\begin{array}{c}\text { Bulk } \\
\text { Density }\end{array}$} \\
\hline $\begin{array}{l}\text { Interval } \\
\text { Depth }\end{array}$ & \# & depth & & & & & & & & \\
\hline $0-10$ & 1 & 5 & 57.48 & 8.16 & 4.17 & 74.3 & -22.19 & 5215 & & \\
\hline $10-20$ & 2 & 15 & 62.96 & 7.50 & 2.99 & 63.9 & -20.28 & 4593 & & \\
\hline $20-30$ & 3 & 25 & 65.79 & 7.54 & 2.82 & 66.9 & -19.19 & 4371 & 388 & 1.62 \\
\hline $30-40$ & 4 & 35 & 69.46 & 7.32 & 2.73 & 66.4 & -17.38 & 5723 & & \\
\hline $40-50$ & 5 & 45 & 67.91 & 7.69 & 2.30 & 72.2 & -15.96 & 4036 & & \\
\hline $50-60$ & 6 & 55 & 64.89 & 7.65 & 2.06 & 75.7 & -15.05 & 4644 & 309 & \\
\hline $60-70$ & 7 & 65 & 62.05 & 7.64 & 1.90 & 75.7 & -14.89 & 4125 & & \\
\hline $70-80$ & 8 & 75 & 55.71 & 7.35 & 1.77 & 77.1 & -15.03 & 4446 & & \\
\hline $80-90$ & 9 & 85 & 52.00 & 7.45 & 1.41 & 76.8 & -14.98 & 4463 & 255 & \\
\hline $90-100$ & 10 & 95 & 49.33 & 7.55 & 1.30 & 78.6 & -15.30 & 4300 & & \\
\hline $100-110$ & 11 & 105 & 44.89 & 7.42 & 1.19 & 78.3 & -15.58 & 4223 & & 1.70 \\
\hline $110-120$ & 12 & 115 & 42.54 & 7.41 & 1.11 & 79.2 & -15.39 & 4290 & 237 & \\
\hline $120-130$ & 13 & 125 & 40.38 & 7.40 & 0.96 & 79.2 & -15.52 & 4038 & & \\
\hline $130-140$ & 14 & 135 & 37.27 & 7.42 & 1.03 & 81.5 & -16.47 & 4109 & & 1.75 \\
\hline $140-150$ & 15 & 145 & 35.62 & 7.49 & 0.88 & 79.7 & -16.31 & 5510 & 226 & \\
\hline $150-160$ & 16 & 155 & 33.31 & 7.51 & 0.84 & 79.4 & -15.99 & 4355 & & \\
\hline $160-170$ & 17 & 165 & 28.47 & 7.51 & 0.89 & 80.9 & -18.05 & 4261 & & \\
\hline $170-180$ & 18 & 175 & 24.63 & 7.76 & 0.85 & 81.2 & -17.46 & 4249 & 160 & \\
\hline $180-190$ & 19 & 185 & 20.87 & 7.65 & 0.79 & 83.5 & -18.04 & 3970 & & 1.66 \\
\hline $190-200$ & 20 & 195 & 16.77 & 7.71 & 0.63 & 85.0 & -17.07 & 4994 & & \\
\hline $200-210$ & 21 & 205 & 13.14 & 7.60 & 0.58 & 85.8 & -17.36 & 4509 & 157 & \\
\hline $210-220$ & 22 & 215 & 10.97 & 7.90 & 0.54 & 87.3 & -17.77 & 5787 & & \\
\hline $220-230$ & 23 & 225 & 9.47 & 7.96 & 0.52 & 88.5 & -18.02 & 4671 & & \\
\hline $230-240$ & 24 & 235 & 9.26 & 8.03 & 0.49 & 88.7 & -18.30 & 4316 & 166 & \\
\hline $240-250$ & 25 & 245 & 10.62 & 8.07 & 0.47 & 88.7 & -19.66 & 4355 & & \\
\hline $250-260$ & 26 & 255 & 9.19 & 8.12 & 0.43 & 85.6 & -19.35 & 4457 & & 1.68 \\
\hline $260-270$ & 27 & 265 & 7.79 & 8.06 & 0.35 & 88.3 & -19.47 & 4155 & 181 & \\
\hline $270-280$ & 28 & 275 & 7.94 & 6.63 & 0.37 & 86.5 & -19.65 & 4322 & & \\
\hline $280-290$ & 29 & 285 & 7.04 & 8.53 & 0.36 & 97.1 & -19.72 & 4697 & & \\
\hline $290-300$ & 30 & 295 & 6.14 & 8.57 & 0.30 & 93.4 & -21.09 & 6243 & 322 & \\
\hline $300-310$ & 31 & 305 & 6.45 & 8.73 & 0.32 & 95.5 & -20.87 & 4904 & & \\
\hline $310-320$ & 32 & 315 & 6.33 & 7.80 & 0.24 & 80.4 & -22.04 & 5777 & & 1.56 \\
\hline $320-330$ & 33 & 325 & 5.21 & 8.95 & 0.29 & 94.6 & -22.80 & 4151 & & \\
\hline $330-340$ & 34 & 335 & 6.77 & 8.39 & 0.30 & 95.3 & -22.67 & 4641 & & 1.59 \\
\hline $340-350$ & 35 & 345 & 5.50 & 9.32 & 0.28 & 99.8 & -21.62 & 6242 & 419 & 1.65 \\
\hline $350-360$ & 36 & 355 & 2.91 & 8.74 & 0.20 & 99.8 & -22.16 & 6162 & & \\
\hline $360-370$ & 37 & 365 & 6.95 & 7.05 & 0.27 & 80.7 & -23.50 & 5432 & & 1.64 \\
\hline $370-385$ & 38 & 377 & 7.40 & 7.39 & 0.26 & 83.5 & -23.34 & 4556 & & \\
\hline $385-390$ & 39 & 392 & 15.34 & 10.71 & 0.39 & 99.9 & -13.10 & 5483 & 243 & \\
\hline $390-400$ & 40 & 395 & 9.63 & 10.75 & 0.33 & 99.9 & -15.40 & 5044 & & \\
\hline $400-410$ & 41 & 405 & 2.05 & 10.10 & 0.24 & 99.9 & -17.61 & 6227 & & \\
\hline
\end{tabular}


LP1 Profile, Continued...

\begin{tabular}{|c|c|c|c|c|c|c|c|c|c|c|}
\hline \multicolumn{11}{|c|}{ LP1 Profile } \\
\hline $\begin{array}{l}\text { Interval } \\
\text { Depth }\end{array}$ & $\#$ & depth & $x$ & $\begin{array}{c}\text { Total } \\
\text { C }\end{array}$ & $\begin{array}{c}\text { Organic } \\
\text { C }\end{array}$ & $\%$ CCE & $\mathrm{d}^{13} \mathrm{C}$ & Fed & Feox & $\begin{array}{c}\text { Bulk } \\
\text { Density }\end{array}$ \\
\hline $410-415$ & 42 & 412 & 1.76 & 9.28 & 0.23 & 87.2 & -23.18 & 8952 & & \\
\hline $415-430$ & 43 & 422 & 3.48 & 8.85 & 0.26 & 99.8 & -23.43 & 21334 & 1236 & \\
\hline $430-440$ & 44 & 435 & 4.09 & 10.25 & 0.17 & 94.6 & -22.22 & 9243 & & \\
\hline $440-450$ & 45 & 445 & 2.32 & 9.43 & 0.32 & 94.5 & -19.83 & 10395 & & \\
\hline $450-460$ & 46 & 455 & 3.38 & 8.43 & 0.18 & 95.2 & -23.72 & 9154 & & \\
\hline $460-470$ & 47 & 465 & 3.75 & 9.04 & 0.14 & 100.0 & -23.06 & 9444 & 573 & \\
\hline $470-480$ & 48 & 475 & 9.01 & 10.01 & 0.30 & 100.1 & -21.36 & 5878 & & \\
\hline $480-495$ & 49 & 487 & 4.46 & 9.99 & 0.31 & 100.0 & -23.05 & 4638 & & \\
\hline $495-500$ & 50 & 497 & 7.71 & 1.65 & 0.12 & 17.9 & -25.14 & 11997 & & \\
\hline
\end{tabular}





\section{APPENDIX E: \\ Stable Carbon Analysis, 41TV410 and 41TV540, Travis County, Texas Richard Anderson}





\section{APPENDIX E \\ Stable Carbon Analysis \\ 41TV410 and 41TV540, Travis County, Texas \\ Dr. Richard Anderson \\ Costal Science Laboratories, Inc., Austin, Texas}

Fifteen soil samples from Area 3 adjacent to 41TV410 were submitted to Costal Scientific for stable carbon isotope analysis. Subsamples of the soils (ca. $3 \mathrm{~g}$ ) were ground and covered with $2 \mathrm{~N} \mathrm{HCl}$, freshened over several days to eliminate carbonates. Many of the samples continued to show activity (bubbling) after more than two weeks of acidification. An initial aliquot of each sample was filtered and washed after three weeks. Samples were dried, pulverized and analyzed. Those early results showed that several samples had surprisingly heavy isotope values, so I continued the acidification process for three more weeks. Finally, samples were filtered, washed and dried and re-analyzed, obtaining the same values as before. These are presented below in Table E-1.

Table E-1

\begin{tabular}{|c|c|c|c|}
\hline Sample Depth & Sample Type & $\begin{array}{c}\text { Initial Reading } \\
\text { (delta }{ }^{13} \mathbf{C} \text { pdb) }\end{array}$ & $\begin{array}{c}\text { Final Reading } \\
\text { (delta }{ }^{13} \mathbf{C} \text { pdb) }\end{array}$ \\
\hline $0-10$ & Sediment & -16.3 & -16.3 \\
\hline $50-60$ & Sediment & -16.6 & -16.6 \\
\hline $100-110$ & Sediment & -17.6 & -17.6 \\
\hline $150-160$ & Sediment & -16.4 & -16.5 \\
\hline $200-210$ & Sediment & -15.1 & -15.2 \\
\hline $250-260$ & Sediment & -15.8 & -15.7 \\
\hline $300-310$ & Sediment & -17.8 & -17.9 \\
\hline $350-360$ & Sediment & -17.9 & -17.9 \\
\hline $400-410$ & Sediment & -17.4 & -17.3 \\
\hline $450-460$ & Sediment & -18.0 & -18.1 \\
\hline $500-510$ & Sediment & -18.1 & -18.2 \\
\hline $550-560$ & Sediment & -17.8 & -17.9 \\
\hline $600-610$ & Sediment & -18.6 & -18.6 \\
\hline $650-660$ & Sediment & -17.9 & -17.8 \\
\hline $690-700$ & Sediment & -16.2 & -16.2 \\
\hline
\end{tabular}





\section{APPENDIX F:}

\section{Paleoenvironmental}

Reconstruction at 41TV410 (Area-3)

based on Biosilicate, Charred Phytolith, and Particulate Charcoal Analysis

Steven Bozarth and Terri Woodburn 



\section{APPENDIX F \\ Paleoenvironmental Reconstruction at 41TV410 (Area-3) based on Biosilicate, Charred Phytolity, and Particulate Charcoal Analysis Steven Bozarth and Terri Woodburn \\ University of Kansas Palynology Laboratory \\ Department of Geography}

INTRODUCTION

\section{Project Goal}

The goal of this study was to reconstruct vegetative histories near site 41TV410 based on phytolith analysis. Differences in vegetation were then used to reconstruct paleoenvironments. Other biosilicates (diatoms, algal statospores, and sponge spicules) were also analyzed to glean as much paleoenvironmental information as possible. Concentrations of charred phytoliths and particulate charcoal were studied to understand fire-history in the study area.

\section{Phytolith Formation}

Growing plants typically absorb water containing dissolved silica through their roots. Microscopic silica bodies are subsequently produced by the precipitation of hydrated silicon dioxide $\left(\mathrm{SiO}_{2} \cdot \mathrm{nH}_{2} \mathrm{O}\right)$ within the plant's cells, cell walls, and intercellular spaces. Silica bodies which have characteristic shapes and sizes are called opal phytoliths (Wilding and Drees 1971). The term phytolith is derived from the Greek words phyton, meaning plant, and lithos, meaning stone. Opal is the common name for amorphous, hydrated silica dioxide. Opaline bodies formed in plants without specific shapes are simply plant opal.

Phytoliths form in most plants and are produced in a multitude of shapes and sizes. Many phytolith types are specific to particular groups of plants. A phytolith type is considered "characteristic" if it is common in one specific taxon but also produced in very limited amounts in one or more other taxa. A phytolith type is "diagnostic" if its shape and/or size are specific to a particular taxon. Fortunately, many phytoliths are resistant to weathering and are preserved in most soils for long periods of time. Because phytoliths are formed primarily in the vegetative parts of plants and are released on soil surfaces when the plant decays, a large proportion of the phytolith record represents localized deposition (Piperno 1988).

\section{Phytolith Stability}

The dissolution and stability of phytoliths in soils and sediments is not fully understood. Laboratory experiments demonstrate, however, that the solubility of silica is a function of temperature, particle size, $\mathrm{pH}$, and the presence of a disrupted surface layer. Studies show that the solubility of amorphous silica increases linearly with temperature from $0^{\circ} \mathrm{C}$. Particle size is another factor affecting stability as opal dissolution is greater with a decrease in size (Wilding et al. 1977, 1979). Pease (1967) experimentally determined that there appears to be a slight increase in phytolith solubility in the range of 5.0 to 8.5, an added increase between $\mathrm{pH} 8.5$ and $\mathrm{pH}$ 9.0, and a large increase beginning at $\mathrm{pH}$ 9.0. Opal stability is also a function of the presence of certain metallic ions and sesquioxides. The adsorption of $\mathrm{Al}$ and $\mathrm{Fe}$ ions onto the surface of opal will decrease silica dissolution due to the formation of relatively insoluble silicate coatings. The presence of sesquioxides may increase dissolution of phytoliths due to the adsorption of monosilicic acid (Wilding et al. 1977).

\section{Morphology and Taxonomy}

Monocotyledons, particularly the Poaceae, produce a wide variety of morphologically distinctive phytolith forms. The most taxonomically useful types of grass phytoliths are silicified short cells that range in size from 10 to $35 \mu \mathrm{m}$ long. Several types of trapezoidal circular, rectangular, and elliptical short cells are diagnostic of the Pooideae (Brown 1984; Twiss 1987; Bozarth 1992b), a grass subfamily adapted to cool temperatures and high available soil moisture (Twiss 1987). 
Saddle-shaped bodies occur most commonly in the Chloridoideae (Brown 1984; Twiss 1987; Mulholland and Rapp 1992), a grass subfamily that flourishes in areas with warm temperatures and low available soil moisture. Saddle-shaped phytoliths are similar in appearance to double-edged battle axes formed by two opposite convex edges and two opposite concave edges. However, a few saddle-shaped phytoliths have only one concave side. There appears to be a direct relationship between soil moisture and size of saddle-shaped phytoliths (Brown 1984).

Bilobate and cross-shaped phytoliths are formed in the Panicoideae (Brown 1984; Twiss 1987; Mulholland and Rapp 1992), a grass subfamily that thrives in warm temperatures and high available soil moisture (Twiss 1987). Bilobates with indented, concave, or pointed lobes are formed only in the Panicoid subfamily. Bilobates with raised lobes edges and round or flat ends which are symmetrical in side view are also formed only in the Panicoids (Bozarth 1992b). Little bluestem (Schizachyrium scoparium) produces characteristic bilobates with round/flat ends (Brown 1984). Maize (Zea mays) cobs produce another type of phytolith that is diagnostic of the species (1993b).

Bilobate phytoliths with raised lobe edges and round ends are also formed in three-awn grasses (Aristida species), a genus in the Chloridoid subfamily (Gould and Shaw 1968). However, bilobates formed in Aristida differ from Panicoid bilobates in that the raised edges on the top (the longer part) slope down at the ends. In addition, they are asymmetrical in side view as the top is more concave than the bottom (Bozarth 1992b). Needlegrass, a genus (Stipa) in the Pooid subfamily (Gould and Shaw 1968), also produces bilobates (Bozarth 1992b). These bilobates differ from those produced in Panicoids and Aristida by not having raised lobe edges. Many have a small lobe on one side in the middle. Unlike most Pooids, Stipa species grow in dry areas (Pohl 1968).

There are several other types of phytoliths in addition to short cells produced in grass. Long cells are relatively large (30 to $150 \mu \mathrm{m}$ long) elongate bodies with smooth or wavy edges (Twiss 1987). Bulliform cells are large keystone shaped-cells. Trichomes are silicified prickly-hairs composed of two parts, an outer sheath and an inner core. The outer sheath dissolves soon after being deposited on the soil, while the inner core remains well preserved. Silicified tracheids are also formed in grasses, albeit rarely. Silicified stomata are taxonomically useful at various levels, but are typically not well preserved.

Grass floral bracts produce at least three distinctive types of phytoliths not formed in other parts of the plant. Dendriforms are cylindrical rods of varying length with protrusions or spines radiating from a central core. Asteriforms consist of platy bodies with peg like protrusions. Scutiform phytoliths are saucer-shaped bodies that have a unique, slanted apex (Piperno 1988). Scutiforms appear to be diagnostic of Pooideae, whereas dendriforms are formed in most, if not all, native grasses. These three types of phytoliths can be used to identify areas/artifacts used to process native grass seeds as they occur only rarely in natural environments (Bozarth 1998a).

Non-grass monocots also produce numerous taxonomically valuable phytoliths. Sedge (Cyperus) produces distinctive phytoliths in the form of cone shaped-bodies with round wavy margins. These phytoliths occur both singly and in multiples. Truncated cones with multiple peaks and round wavy bases are formed in bulrush (Scripus pallidus). Both of these phytolith types appear to be diagnostic of the genera that produce them (Bozarth 1995). Sedge phytoliths with angular and verrucate bases and knobby apices may be restricted to inflorescences (Ollendorf 1992).

Several types of phytoliths are formed in woody dicotyledons (deciduous shrubs and trees) and herbaceous dicotyledons (forbs and weeds). The two most common types of diagnostic dicot phytoliths are flat or cupped polyhedrons with 5-8 sides and anticlinal cells (Rovner 1971; Wilding and Drees 1971; Geis 1973; Wilding et al. 1977; Bozarth 1992a). Anticlinal cells have wavy, undulating walls with the appearance of jigsaw-puzzle pieces. Most of these polyhedral and anticlinal phytoliths consist only of silicified cell walls and are not well preserved in sediment (Wilding and Drees 1974; Bozarth 1992a). Other phytolith types formed only in dicots include branched elements with spiral thickened rings and honeycomb-shaped assemblages (Geis 1973; Wilding and Drees 1973, 1974; Bozarth 1992a).

Several species of arboreal dicots produce opal spheres that range in size from 1 to $50 \mu \mathrm{m}$ (Wilding and Drees 1973, 1974). Opal spheres are also produced in conifers (Klein and Geis 1978), but are much smaller (3 to $8 \mu \mathrm{m}$ ). Opaque 
opal spheres have been extracted from the A horizon of several forested soils in Ohio demonstrating that they are well preserved (Wilding and Drees 1973, 1974). Wilding and Drees (1973) also reported opaque bladed forms (which appear to be opaque platelets), in white oak (Quercus alba). Similar particles were observed in isolates from a soil formed under deciduous forest.

Distinctive spinulose spheres are produced, although only rarely, in the leaves of chinkapin oak (Q. muehlenbergii), red oak (Q. rubra) and red oak (Q. rubra), as well as the endocarp of black walnut (Juglans nigra). Spinulose spheres have been identified with other deciduous tree phytoliths in late-Pleistocene and Holocene loessal sites in Nebraska (Bozarth 1998a, 1998b, 1998c, 2000, 2008.

Phytolith analysis of 14 dicots and one cactus native to the Central Great Plains shows that diagnostic phytoliths are only rarely formed in edible fruits and nuts. Most of the fruits and nuts studied were from trees and shrubs, including shagbark hickory (Carya ovata), hackberry (Celtis occidentalis), persimmon (Diospyros virginiana), black walnut (Juglans nigra), sandhill plum (Prunus angustifolia), wild plum (P. americana), choke cherry (P. virginiana), currants (Ribes odoratum), elderberry (Sambucus canadensis), white oak (Quercus alba), and burr oak (Q. macrocarpus). Other reference species include two forbs, devil's claw (Proboscidea louisianica) and groundcherry (Physalis virginiana), a wild grape (Vitis riparia), and a cactus prickly pear (Opuntia macrorhiza). Of these 15 species, diagnostic phytoliths were formed only in hackberry fruits. These phytoliths, produced in the fruit stone, are in the form of platelets with irregular edges and short echinate (spiny) sculpturing on one side (Bozarth 1987b).

Subsequent to this study, four additional samples from economic species were analyzed: nuts and bracts from hazelnut (Corylus americana), achenes from marsh elder (Iva annua), and achenes with bracts from Pennsylvania smartweed (Polygonum pensylvanicum). No taxonomically useful phytoliths were found. Furthermore, previous unpublished studies indicate that Palmer's pigweed (Amaranthus palmeri), rough pigweed (A. retroflexus), and lamb’s quarters (Chenopodium album) do not produce diagnostic phytoliths.

Other dicots produce phytoliths diagnostic at various taxonomic levels. Opaque platelets with systematic perforations and certain types of segmented hairs are diagnostic of Asteraceae (the Sunflower family). Flat polyhedrons with 5-8 sides that are filled with coarse verrucae (bumps) appear to be unique to Ulmaceae (the Elm family) (Bozarth 1985a, 1992a). Silicified, multi-celled hair bases are formed in the disks of common sunflower (Helianthus annuus) and domesticated sunflowers (H. annuus var. macrocarpa) (Bozarth 1986b). Certain types of stalked verrucate phytoliths are specific to hackberry, mulberry (Morus), false nettle (Boehmeria), or nettle (Urtica). Elongate verrucate phytoliths with one or both ends tapering to a point are unique to clearweed (Pilea) (Bozarth 1992a). Phytoliths with deeply scalloped surfaces of contiguous concavities are diagnostic of squash and wild buffalo gourd (Cucurbita species) (Bozarth 1987a). Common beans (Phaseolus vulgaris) also produce diagnostic phytoliths (Bozarth 1990b).

Several types of phytoliths are produced in the pine family (Pinaceae). Silicified, irregularly-shaped, polyhedral cells are the most common taxonomically useful Pinaceae phytolith. This type of phytolith is produced in red spruce (Picea rubens), black spruce (P. mariana), white spruce (P. glauca), Engelmann spruce (P. engelmannii), and jack pine (Pinus banksiana) (Norgren 1973; Klein and Geis 1978; Bozarth 1988, 1993a). Blocky polyhedra with smooth surfaces and at least eight non-parallel sides are characteristic but not diagnostic of Pinaceae, because they are also produced, although relatively infrequently, in grasses (Bozarth 1993a).

In contrast to smooth polyhedrons, polyhedrons with bordered pit impressions on the surface are unique to the Pinaceae. This type of phytolith is abundant in pine (Pinus), spruce (Picea), Douglas-fir (Pseudotsuga menziesii), and less commonly in larch (Larix), hemlock (Tsuga), and fir (Abies) (Klein and Geis 1978). Douglas-fir needles produce distinctive, branched, silicified particles (Brydon et al. 1963). This same type of phytolith was also reported in Douglasfir by Garber (1966) as irregular shapes with spiny processes and by Norgren (1973) as amoeboid bodies with tapering, conical protrusions. Thin plates with wavy margins on all four sides are formed in needles of white spruce and appear to be unique to that species. Phytoliths with spiny irregular bodies are commonly formed in needles of jack pine and appear to be diagnostic of that species (Bozarth 1993a). 


\section{Other Biosilicates}

There are two groups of algae that produce siliceous bodies, both of which are quite distinct from phytoliths. The Chrysophyceae (golden algae) produce spherical cysts with siliceous walls. These statospores are smooth, spiny, or bumpy and have a distinctive bottle-shaped opening through which motile spores are released. Fresh water forms of Chrysophyceae are more common than marine forms, and many prefer relative cool to cold temperatures (Bold and Wynne 1978). Jones and others (1964) demonstrated that statospores can be useful in interpreting changes in ecology.

Diatoms are another type of algae (division Chrysophycophyta, class Bacillariophyceae) that produce siliceous cell walls (Bold 1967) which are well preserved in sediment. Diatoms occur in both marine and freshwater habitats and in some moist and dry habitats where light, temperature, and chemical conditions are suitable for their growth (Patrick and Reimer 1966). Diatoms may comprise from $1 / 3$ to $1 / 2$ of the opal isolate of soils developed under ponded or poorly drained conditions (Wilding and Drees 1971).

Freshwater sponges are plant-like animals that produce distinctive silicified spicules. Sponges spicules are identified microscopically based on the presence of an axial canal (Baker 1959; Jones and Beavers 1963). Complete spicules have tapering cylindrical forms which terminate in a pointed end (Jones and Beavers 1963). Abundant sponge spicules in soils are indicative of an aquatic habitat favorable for sponge growth (Jones et al. 1964). An abundance of undamaged sponge spicules suggests formation on or near the site (Smithson 1959). For example, the presence of freshwater sponge spicules in loess is evidence that the eolian sediment was derived from river flood plains (Jones and Beavers 1963).

\section{Particulate charcoal}

Analysis of microscopic particles of charcoal is the most direct measure of fire history. Charcoal is formed when organic material is incompletely combusted at temperatures between 280 and 500 degrees Centigrade. Particulate charcoal is angular, black and completely opaque. It is inert and thus a stable component of sediment. Charcoal particles larger than $80 \mu \mathrm{m}$ in length are probably of local origin, usually within 100 meters of the site (Clark 1988).

\section{Charred phytoliths}

Charred phytoliths with a black coating are produced when plant materials burn. The melting point of phytoliths is about 1,000 degrees Centigrade but most fires are not nearly that hot. Therefore, phytolith shapes remain unchanged and can still be taxonomically classified. The best way to understand fire history is analyze both charred phytoliths and particulate charcoal (Piperno 2006).

\section{Applied Phytolith Research in the Great Plains}

Phytoliths are largely a "decay in place” fossil (Rovner 1975) and represent the vegetation of a site at the time of deposition (Piperno 1988). Opal phytoliths can be isolated from buried sediment samples and analyzed to reconstruct the paleoenvironment for a particular area. This has been successful on a number of sediment types, including loessal sites in Nebraska (Fredlund et al. 1985; Bozarth 1992b, 2008; Johnson 1993), Kansas (Bozarth 1984a; Johnson and Bozarth 1996), and Texas (Bozarth 1995), as well as alluvium in Kansas (Bozarth 1986a, 1990a) and Texas (Bozarth 1995; Bozarth and Woodburn 2009). Modern phytolith assemblages from the Great Plains were reported by Fredlund and Tieszen (1994). Regional fossil phytoliths were first recognized by Twiss et al. (1969) in buried soils in north-central Kansas but the paleoenvironments were not reconstructed.

Phytolith analysis has also been used to identify cultigens and other economic species in prehistoric archeological sites. Phytolith analysis was first applied to Great Plains paleoethnobotanical studies by Bozarth (1984b) who identified sunflowerlike phytoliths in sediment samples collected in features at Site 23DX3, a Central Plains Tradition village in northeast Nebraska. These silicified, multi-celled hair bases are commonly formed in the disks of common sunflower (Helianthus annuus) and domesticated sunflower (Helianthus annuus var. macrocarpa (Bozarth 1986b). 
Additional taxonomic classification demonstrated that diagnostic phytoliths are formed in the rinds of selected varieties of squash (Cucurbita species) (Bozarth 1985b, 1986b, 1987a) and in the pods of common beans (Phaseolus vulgaris) (Bozarth 1986b, 1990b). Squash phytoliths (scalloped spheroids) were recovered at Site 23DX3 (described above)(Bozarth 1986b) and Site 3CT50, a Late Woodland site in northeast Arkansas (Bozarth 1985b, 1987a). Bean phytoliths (silicified hooked hairs) were identified in an isolate from Site 14MN328, a Great Bend Aspect village located in central Kansas (Bozarth 1989a, 1990b).

Mulholland $(1986,1987)$ reported two types of phytoliths characteristic of maize, one in chaff and the other in leaves and husks, which could be used as indicators of maize in archeological sites in North Dakota. Extensive taxonomic research by Bozarth (1989a, 1989b, 1993b) demonstrated that maize cobs produce diagnostic phytoliths. Based on these studies, maize was identified in two features at Site 14MN328 (described above).

As previously reported, most archeological phytolith analyses reconstruct paleoenvironments or plant subsistence strategies. However, other types of studies can be done with phytoliths. For example, at the Hatcher Site (14DO19), a Plains Village period habitation structure located in northeastern Kansas, a study of phytoliths from a daub concentration demonstrates that Panicoids (tall-grasses) and Pooids (cool-moist season grasses) were the most common grasses used in construction at the site (Bozarth 1987c). A phytolith analysis of prehistoric bison tooth calculus and impacta from sites in Kansas and Oklahoma demonstrates that this type of study can be used to reconstruct the diet of prehistoric bison in the central Great Plains (Bozarth 1993c, 1998d). Phytolith analysis has also been used to study mammoth and mastodon diets (Gobetz and Bozarth 2000, 2001).

\section{METHODOLOGY}

Ten $\mathrm{cm}$ thick sediment samples were collected at $50 \mathrm{~cm}$ intervals from a seven meter deep section for a total of 15 samples from Area 3 in the deep trench adjacent to 41TV410.

Biosilicates were isolated from 5 gram sediment samples using a procedure based on heavy-liquid (zinc bromide) flotation and centrifugation. This procedure consists of five basic steps: 1) removal of carbonates with dilute hydrochloric acid; 2) removal of colloidal organics, clays, and very fine silts by deflocculation with sodium pyrophosphate, centrifugation, and decantation through a 7- $\mu \mathrm{m}$ filter; 3) oxidation of sample to remove organics; 4) heavy-liquid flotation of phytoliths from the heavier clastic mineral fraction using zinc bromide concentrated to a specific gravity of 2.3 ; 5) washing and dehydration of phytoliths with butanol; and 6) dry storage in 1-dram glass vials.

Representative portions of the isolates were mounted on microscope slides in immersion oil under 22x40 mm cover glasses and sealed with clear nail lacquer. A minimum of 200 phytoliths were taxonomically classified in each slide. Phytoliths were analyzed at a magnification of $625 \mathrm{X}$ with a petrographic Zeiss microscope. Biosilicate data were reported with TG View. Phytolith concentrations were calculated using an indirect method reported by Piperno (1988). A known number of exotic spores (in this case Lycopodium) were added to each sample after the oxidation stage. The concentration of phytoliths (per gram) was computed as follows:

Phytolith conc. $=$ no. of phytoliths counted $x$ (total no. exotics added / no. exotics counted) / sample wt.

Concentration permits an evaluation of the phytolith production, preservation, and sedimentation rate for a given sample interval.

Phytoliths were classified according to a convention that has been developed and used in other reports and publications. An extensive reference collection of plants native to the Great Plains has been developed in the palynology laboratory through field collection, research plots, solicited samples, and specimens supplied by the University of Kansas Herbarium. The phytolith reference collection consists of phytoliths extracted from complete or representative aerial portions of the following: 1) 25 species of 20 genera of 11 tribes of 6 subfamilies of the Poaceae (grass); 2) 11 species of 4 genera of 4 non-grass monocot families; 3) 65 species of 62 genera of 11 families of herbaceous dicots; 4) 20 species of 18 genera of 13 families of woody (mostly arboreal) dicots; 5) 14 species of 7 genera of 5 families of gymnosperms; and 6) 2 species of Equisetum. 
Biosilicate frequencies and concentrations are shown in Figure F-1. The more environmentally useful phytoliths (grass short cell and tree and shrub phytolith frequencies) are presented in Figure F-2. A temperature index (Pooids/ Pooids + Chloridoids + Panicoids) and an aridity index (Chloridoids/ Chloridoids + Panicoids + Pooids) reported by Twiss (1987) and are shown in Figure F-3.

\section{RESULTS AND DISCUSSION}

Biosilicates and particulate charcoal were well-preserved in all 15 samples. Fifteen types of phytoliths were identified, in addition to rare occurrences of diatoms, algal statospores and sponge spicules. Interpretation of biosilicate assemblages, charred phytoliths and particulate charcoal revealed 10 paleoenvironmental zones.

Zone A (700-600 cmbs): The lower part of Zone A was the warmest and driest of the entire section based the temperature and aridity indexes (Figure F-3). Vegetation in the study area was dominated by Chloridoids (short grasses) with a limited number of trees and shrubs. Fire was clearly an important part of the area ecology based on frequency of charred phytoliths. Conditions cooled and became moister throughout this zone. There was a slight increase in sedimentation rate at $650 \mathrm{cmbs}$ based on a decrease in phytolith concentration.

Zone B (600-550 cmbs): The study area became warmer and drier in this zone based on an increase in Chloridoids as shown in the climate indexes. Lack of evidence of woody plants at $600 \mathrm{cmbs}$ may relate to increased burning as there was an increase in charred phytoliths and an even larger increase in particulate charcoal larger than $80 \mu \mathrm{m}$ at this level.

Zone C (550-500 cmbs): Conditions were cooler and moister based on the climate indexes. There were a limited number of woody plants at $500 \mathrm{cmbs}$ even though there was a slight increase in charred phytoliths and concentration of charcoal larger than $80 \mu \mathrm{m}$ at this level. Evidently, an increase in moisture was more important than the increase in burning with regards to the presence of trees.

Zone D (500-400 cmbs): The study area was significantly warmer and drier up to $450 \mathrm{cmbs}$ and then became slightly cooler and moister (Figure F-3). There was no evidence of trees or shrubs. Fire was still an important part of the ecosystem based on an increase in frequency of charred phytoliths.

Zone E (400-300 cmbs): Conditions were slightly warmer and significantly drier. More trees and shrubs are present at 300 cmbs than any other level. An increase in frequency of charred phytoliths and particulate charcoal larger than $80 \mu \mathrm{m}$ indicate that there was more localized burning at $300 \mathrm{cmbs}$ than any previous time.

Zone F (300-250 cmbs): There was a major change in climate to much cooler and moister conditions. This may explain a decrease in charred phytoliths and absence of large particulate charcoal.

Zone G (250-150 cmbs): Another major change in climate was found in this zone but one that was much warmer and drier in contrast to the previous zone. No evidence of trees or shrubs was found. There was less local burning based on a lower frequency of charred phytoliths. However, regional burning increased based on an increase in concentration of particulate charcoal $20-80 \mu \mathrm{m}$ at $150 \mathrm{cmbs}$. This level was also the most stable given the phytolith concentration of 1,124,891, several times higher than any other sample.

Zone H (150-100 cmbs): Conditions were cooler and moister based on an increase in Pooids and Stipa (a genus in the Pooid subfamily) and a decrease in Chloridoids (Figure F-3). No evidence of woody plants was found. Local burning increased based on a slight increase in charred phytolith and an even larger increase in concentration of particulate charcoal larger than $80 \mu \mathrm{m}$.

Zone I (100-50 cmbs): The site was warmer and drier during the time in which this sediment was deposited based on an increase in Chloridoids. Trees/shrubs were present but in low numbers. More local burning occurred at $50 \mathrm{cmbs}$ than any other level 
as the highest frequency (57 percent) of charred phytoliths was found at this level. There was also a high concentration of particulate charcoal larger than $80 \mu \mathrm{m}$. Moreover, the presence of an opaque sphere, which appears to be a carbon spherule, may indicate the occurrence of a high-stand fire in the study area (Firestone et al. 2007). The sudden increase in burning was most likely from cultural activities and may reflect the intentional burning of grassland to attract game.

Zone J (0-100 cmbs): The climate shifted to one that was cooler and moister in the uppermost zone. Trees/shrubs were present in low numbers as in the previous zone. The degree of localized burning was second highest of any of the zones based on charred phytolith frequencies and concentrations of particulate charcoal larger than $80 \mu \mathrm{m}$. Evidence of regional burning remained high as well, including the identification of another opaque sphere.

In summary, analysis of phytoliths and particulate charcoal show a dynamic vegetational history and paleoenvironment for the study area. Ten paleoenvironmental zones were delineated. Vegetation was dominated by Chloridoids (short grasses adapted to arid environments) throughout the seven meter section in Area 3. Analysis of charred phytoliths and particulate charcoal provided abundant evidence of the importance of burning to the local ecology. The most dramatic climate changes occurred in the upper three meters. 


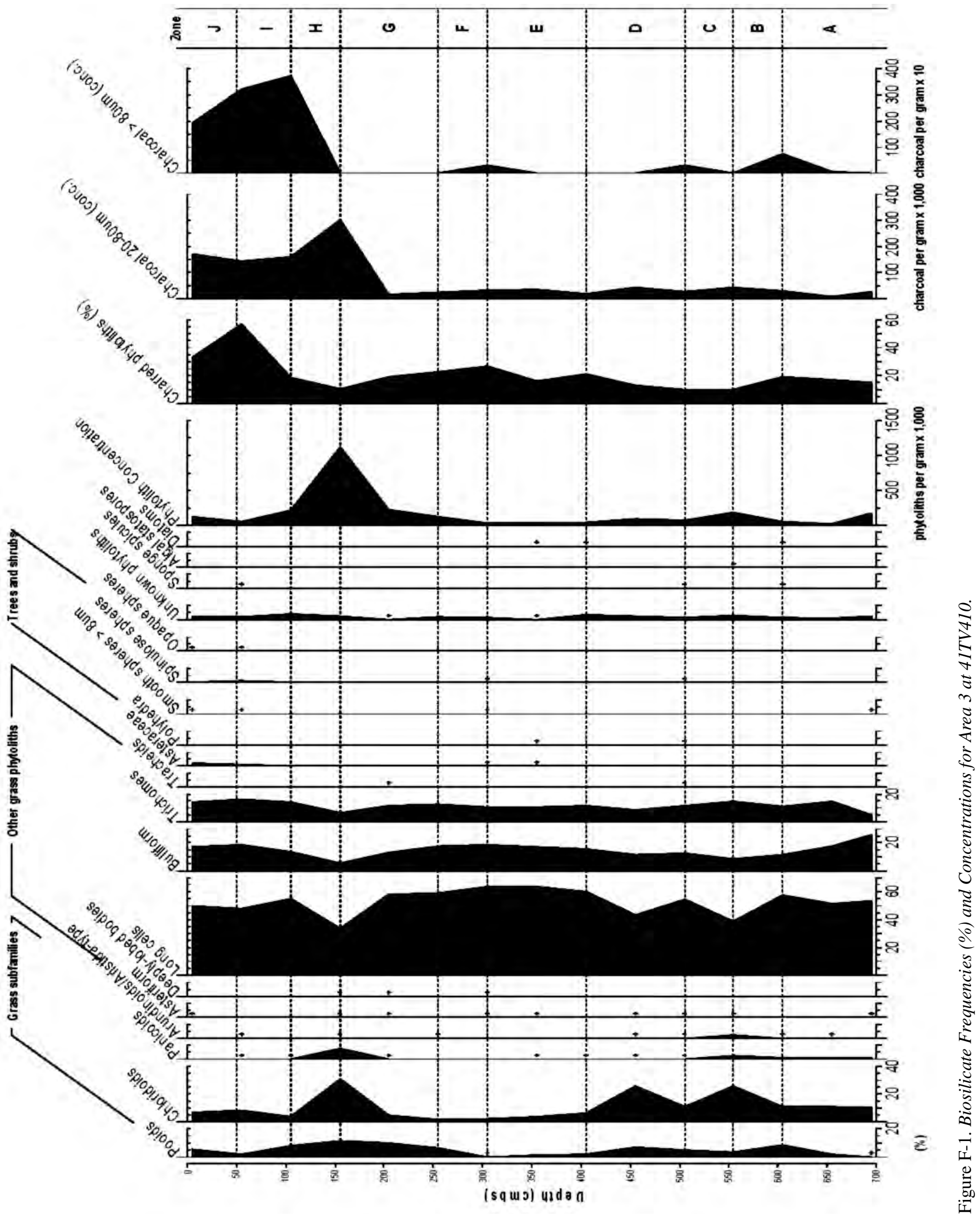




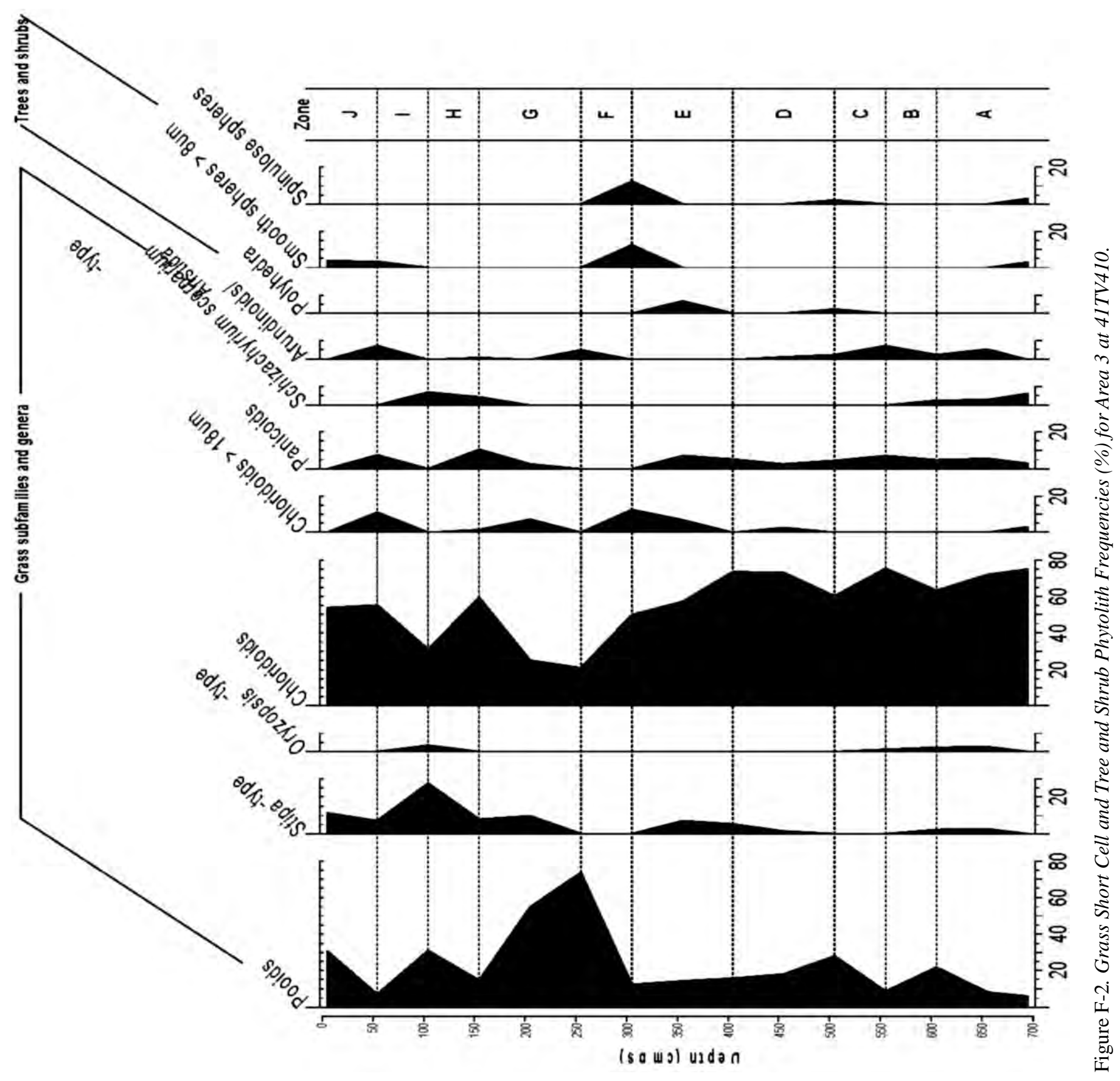




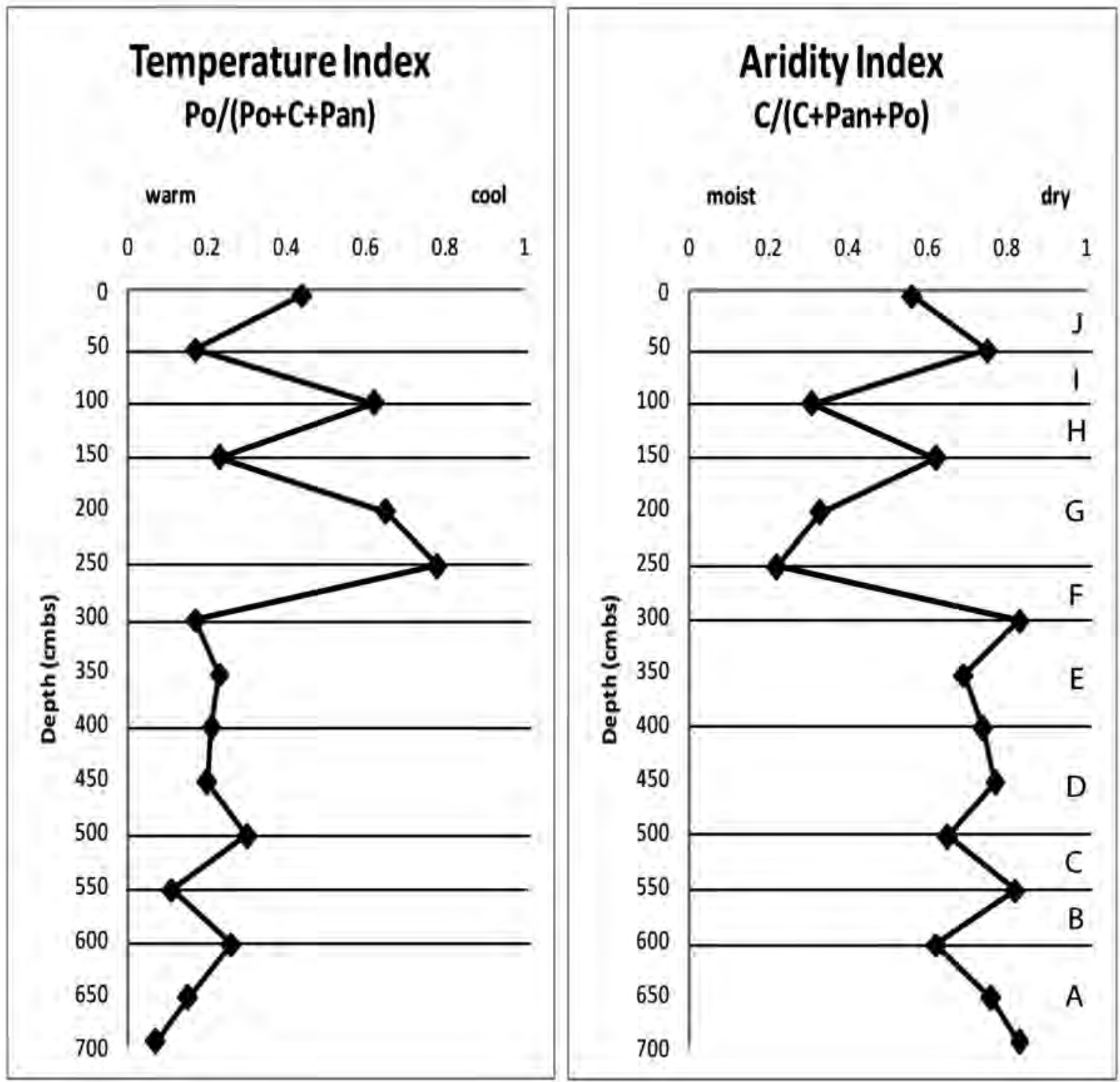

Figure F-3. Climate indices calculated from phytolith frequencies of Pooids (Po), Chloridoids (C), and Panicoids (Pan), indicating relative temperature and moisture changes through time. Letters A-J denote climate zones depicted on phytolith frequency figures. 


\section{REFERENCES CITED}

Baker, G.

1959 Opal Phytoliths in Some Victorian Soils and “Red Rain” Residues. Australian Journal of Botany 1:64-87.

Bold, H.C.

1967 Morphology of Plants, 2nd edition. Harper and Roe, New York.

Bold, H.C., and M.J. Wynne

1978 Introduction to the Algae. Prentice-Hall, Englewood Cliffs, New Jersey.

Bozarth, Steven R.

1984a Pollen and Opal Phytolith Analysis, the Jetmore Mammoth Site, 14HO1. In Kansas Preservation Plan for the Conservation of Archaeological Resources, edited by K.L. Brown and A.H. Simmons, pp. 4-56 to 4-67. Ms. on file, Office of Archaeological Research, Museum of Anthropology, University of Kansas, Lawrence.

1984b Cultigen Phytolith Analysis at 23DX3. Ms. on file, Department of Anthropology, Wichita State University, Kansas, and the Nebraska State Historical Society.

1985a Distinctive Phytoliths from Various Dicot Species: Paper presented at the 2nd Phytolith Conference, University of Minnesota, Duluth.

1985b An Analysis of Opal Phytoliths from Rinds of Selected Cucurbitaceae Species. M.A. thesis, Department of Anthropology, University of Kansas, Lawrence, Kansas.

1986a Phytoliths. In Along the Pawnee Trail, Cultural Resources at Wilson Lake, by D. Blakeslee, R. Blasing, and H. Garcia, pp. 86-101. U.S. Army Corps of Engineers (Kansas City District), Contract DACW41-85-C-0135.

1986b Morphological Distinctive Phaseolus, Cucurbita, and Helianthus annuus Phytoliths. In Plant Opal Phytolith Analysis in Archeology and Paleoecology; Proceedings of the 1984 Phytolith Research Workshop, edited by I. Rovner, pp. 5666. Occasional Papers No. 1 THE PHYTOLITHARIEN, North Carolina State University, Raleigh.

1987a Diagnostic Opal Phytoliths from Rinds of Selected Cucurbita Species. American Antiquity 52: 607-615.

1987b Opal Phytolith Analysis of Edible Fruits and Nuts Native to the Central Plains. Phytolitharien Newsletter 4(3): 9-10.

1987c Opal Phytolith Analysis of Daub Samples from the Hatcher Site. In Archaeological Investigations of the Clinton Reservoir Area in Northeastern Kansas - National Register Evaluation of 27 Prehistoric Sites, edited by B. Logan, pp. 237-244. Kaw Valley Engineering and Development, Inc., Junction City, Kansas. Submitted to the U.S. Army Corps of Engineers, Kansas City District, Contract DACW41-86-C-0072.

1988 Preliminary Opal Phytolith Analysis of Modern Analogs from Parklands, Mixed Forest, and Selected Conifer Stands in Prince Albert National Park, Saskatchewan. Current Research in the Pleistocene 5: 45-46.

1989a Opal Phytoliths. In Final Summary Report, 1986 Archaeological Investigations at 14MN328, a Great Bend Aspect Site Along U. S. Highway 56, Marion, Kansas, by W.B. Lees, J.D. Reynolds, T.J. Martin, M. Adair, and S. Bozarth, pp. 8590. Archaeology Department, Kansas State Historical Society. Submitted to the Kansas Department of Transportation. 
1989b Evidence for Zea Mays at 14MN328 Based on Opal Phytolith Analysis. Paper presented at the 11th Annual Flint Hills Archaeological Conference.

1990a Results of Preliminary Biosilicate Analysis of 14LT351. In The Archaeology of the Stigenwalt Site, 14LT351, by Randall Thies, pp. 149-156. Contract Archaeological Series, Publication Number 7, Kansas State Historical Society.

1990b Diagnostic Opal Phytoliths from Pods of Selected Varieties of Common Beans (Phaseolus vulgaris). American Antiquity 55:98-104.

1991 Paleoenvironmental Reconstruction of the La Sena Site Based on Opal Phytolith Analysis. In The La Sena Mammoth Site, 25FT177 - Medicine Creek Reservoir, Frontier County, edited by S. Holen, pp. 129-142. Technical Report 200809, Denver Museum of Nature and Science.

1992a Classification of Opal Phytoliths Formed in Selected Dicotyledons Native to the Great Plains. In Phytolith SystematicsEmerging Issues, edited by G. Rapp, Jr. and S. Mulholland, pp. 193-214. Plenum Press, New York.

1992b Paleoenvironmental Reconstruction of the Sargent Site, a Fossil Biosilicate Analysis. Ms. on file, Department of Geology, University of Kansas, Lawrence, Kansas, 22 p.

1993a Biosilicate Assemblages of Boreal Forests and Aspen Parklands. In Current Research in Phytolith Analysis: Applications in Archaeology and Paleoecology, edited by D. Pearsall and D. Piperno, pp. 95-105. MASCA (Museum Applied Science Center for Archaeology) Series, University off Pennsylvania, Vol. 10.

1993b Maize (Zea mays) Cob Phytoliths from a Central Kansas Great Bend Aspect Archaeological Site. Plains Anthropologist 38(146):279-286.

1993c Phytolith Analysis of Bison Teeth Calculus and Impacta from Sites in Kansas and Oklahoma. In Investigations of Seasonality, Herd Structure, Taphonomy, and Paleoecology at Folsom Bison Kill Sites on the Great Plains: 10,500 B.P., edited by Jack Hoffman, Department of Anthropology, University of Kansas, Lawrence.

1995 Analysis of Fossil Biosilicates from the Valley Fill. In Stratigraphy and Paleoenvironments of Late Quaternary Valley Fills on the Southern High Plains, edited by Vance Holliday, pp. 161-171. Geological Society of America Memoir 186.

1998a Opal Phytolith Analysis at 14LV1071. In Prehistoric Settlement of the Lower Missouri Uplands, the View form DB Ridge, Fort Leavenworth, Kansas, edited by Brad Logan, pp. 74-85. Museum of Anthropology, University of Kansas, Project Report Series 98.

1998b Paleoenvironmental Reconstruction of the Great Plains Based on Biosilicate Analysis. Abstracts - Annual Meetings of the Great Plains/Rocky Mountain Division of the Association of the American Geographers.

1998cPaleoenvironmental Reconstruction of the Sargent Site, Southwestern Nebraska - a Fossil Biosilicate Analysis. Abstracts - Institute for Tertiary-Quaternary Studies.

1998d Phytolith Analysis of Bison Teeth Calculus and Impacta from Sites in Kansas and Oklahoma, by S.R. Bozarth and J. Hofman. Current Research in the Pleistocene 15:95-96.

2000 Reconstruction of Vegetative Histories and Paleoenvironments in Northeastern Kansas Based on Opal Phytolith Analysis. Current Research in the Pleistocene 15:95-96. 
2008 Paleoenvironmental Reconstruction of the La Sena Site Based on Biosilicate Analysis. In The La Sena Mammoth Site, 25FT177 - Medicine Creek Reservoir, Frontier County, Nebraska - Volume 1: History of Investigations, Paleoecology and Stratigraphy, edited by S. Holen, pp. 129-142. Technical Report 2008-09, Denver Museum of Nature and Science.

Bozarth, Steven R., and Terri Woodburn

2009 Paleoenvironmental Reconstruction at West Amarillo Creek, Potter County, Texas, Based on Biosilicate Analysis and Palynology. In Landis Property: Data Recovery at Three Prehistoric Sites (41PT185, 41PT186, and 41PT245) in Potter County, Texas, edited by J.M. Quigg, C.D. Frederick, P.M. Matchen, and K.G. DuBois. Bureau of Land Management, Rio Puerco Field Office, Albuquerque, New Mexico. TRC Environmental Corporation, Austin, Texas. TRC Project No. 150832., in press.

Brown, Dwight A.

1984 Prospects and Limits of a Phytolith Key for Grasses in the Central United States. Journal of Archaeological Science 11:345-368.

Bryant, Vaughn M. Jr., and Stephen A. Hall

1993 Archaeological Palynology in the United States: a Critique. American Antiquity 58:277-286.

Brydon, James E., William G. Dore, and John S. Clark

1963 Silicified Plant Asterosclereids Preserved in Soil. Proceedings of the Soil Science Society of America 27:476-477.

Clark, J.S.

1988 Particle Motion and the Theory of Charcoal Analysis: Source Area, Transport Deposition, and Sampling. Quaternary Research 30:81-91.

Firestone, R.B., A. West, J.P. Kennett, L. Becker, T.E. Bunch, Z.S. Revay, P.H. Schultz, T. Belgya, D.J. Kennett, J.M. Erlandson, O.J. Dickenson, A.C. Goodyear, R.S. Harris, G.A. Howard, J.B. Kloosterman, P. Lechler, P.A. Mayewski. J. Montgomery, R. Poreda, T. Darrah, S.S. Que Hee, A.R. Smith, A. Stich, W. Topping, J.H. Wittke, and W.S. Wolbach 2007 Evidence for an Extraterrestrial Impact 12,900 Years Ago that Contributed to the Megafaunal Extinctions and the Younger Dryas Cooling. Proceedings of the National Academy of Sciences, Vol. 104, No. 41.

Fredlund, Glen, W.C. Johnson, and W. Dort, Jr.

1985 A preliminary analysis of opal phytoliths from the Eustis ash pit, Frontier County, Nebraska: Nebraska Academy of Sciences, Institute for Tertiary-Quaternary Studies, TER-QUA Symposium Series 1:147-162.

Fredlund, Glen and Larry Tieszen 1994 Modern phytolith assemblages from the North American Great Plains. Journal of Biogeography 21:321-335.

Geis, James W. 1973 Biogenic Silica in Selected Species of Deciduous Angiosperms. Soil Science 116:113-130.

Gobetz, Katrina, and Steven R. Bozarth

2000 Diet and Paleoecology of Columbian Mammoth (Mammuthus columbi) Determined from Phytoliths and Diatoms in Teeth. Current Research in the Pleistocene 17:120-122.

Gobetz, Katrina, and Steven R. Bozarth 2001 Implications for Late Pleistocene Mastodon Diet from Opal Phytoliths in Tooth Calculus. Quaternary Research 55:115-122.

Gould, F.W., and R.B Shaw

1968 Grass Systematics, 2nd edition. Texas A \& M University Press, College Station. 
Johnson, William C. (editor)

1993 Second International Paleopedology Symposium Field Excursion: Kansas Geological Survey Open-File Report No. 93-30.

Johnson, William C., and Steven R. Bozarth

1996 Variation in Opal Phytolith Assemblages as an Indicator of Late Quaternary Environmental Change on Fort Riley, Kansas, review draft. Prepared under contract No. DACA88-95-M-0422, for the U.S. Army Construction Engineering Research Laboratory (USACERL).

Jones, R.L., and A.H. Beavers 1963 Sponge Spicules in Illinois Soils. Proceedings of the Soil Science Society of America 27 (4):438-440.

Jones, R.L., L.J. McKenzie, and A.H. Beavers 1964 Opaline Microfossils in Some Michigan Soils. The Ohio Journal of Science 64(6):417-423.

Kapp, Ronald O.

1969 Pollen and Spores. Wm. C. Brown Company, Dubuque, Iowa.

Klein, Robert L., and James W. Geis

1978 Biogenic Silica in the Pinaceae. Soil Science 126:145-155.

Lewis, Walter H., Prathibha Vinay, and Vincent E. Zenger 1983 Airborne and Allergenic Pollen of North America. The John Hopkins University Press, Baltimore.

McAndrews, John H., Albert A. Berti, and Geoffrey Norris 1973 Key to the Quaternary Pollen and Spores of the Great Lakes Region. Life Sciences Miscellaneous Publication, Royal Ontario Museum, Canada.

Moore, P. D., and J. A. Webb 1978 An Illustrated Guide to Pollen Analysis. Halstead Press, John Wiley and Sons, New York.

Mulholland, Susan C.

1986 Phytolith Studies at Big Hidatsa, North Dakota: Preliminary Results. In The Prairie: Past, Present and Future. Proceedings of the Ninth North American Prairie Conference, July 29 to August 1, 1984, Moorhead, Minnesota, edited by G.K. Clambey and R.H. Pemble, pp. 21-24. Tri-College University Center for Environmental Studies.

1987 Phytolith Studies at Big Hidatsa. Ph. D. dissertation, University of Minnesota.

Mulholland, Susan C., and George Rapp, Jr.

1992 A Morphological Classification of Grass Silica-Bodies. In Phytolith Systematics, edited by G. Rapp, Jr. and S.C. Mulholland, pp. 65-89. Plenum Press, New York.

Norgren, J.

1973 Distribution, Form and Significance of Plant Opal in Oregon Soils: Ph.D. Thesis, Department of Soil Science, Oregon State University, Corvallis, 176 p.

Ollendorf, Amy L.

1992 A Morphological Classification of Grass Silica-Bodies. In Phytolith Systematics, edited by G. Rapp, Jr. and S.C. Mulholland, pp. 65-89. Plenum Press, New York. 
Patrick, R., and C. Reimer

1966 The Diatoms of the United States, Vol. 1. Monographs of the Academy of Natural Sciences of Philadelphia, Number 13.

Pease, D.S.

1967 Opal Phytoliths as Indicators of Paleosols. Master’s thesis, New Mexico State University, University Park.

Piperno, Dolores R.

1988 Phytolith Analysis - An Archaeological and Geological Perspective. Academic Press, Inc. New York.

2006 Phytoliths - a Comprehensive Guide for Archaeologists and Paleoecologists. Altamira Press, Lanham, Maryland.

Pohl, R. W.

1968 How to Know the Grasses, 3rd edition. The Pictured Key Nature Series, Wm. C. Brown Company Publishers, Dubuque, Iowa.

Rovner, Irwin

1971 Potential of Opal Phytoliths for Use in Paleoecological Reconstruction. Quaternary Research 1:343-359.

1975 Plant Opal Phytolith Analysis in Midwestern Archaeology. Michigan Academician 8:591.

Smithson, F.

1959 Opal Sponge Spicules in Soils. Journal of Soil Science 10(1):105-109.

Twiss, P.C.

1987 Grass Opal Phytoliths as Climatic Indicators of the Great Plains Pleistocene. In Quaternary Environments of Kansas, edited by W.C. Johnson, pp. 179-188. Kansas Geological Guide Book, Series 5, Lawrence, Kansas.

Twiss, P.C., E. Suess, and R.M. Smith

1969 Morphological Classification of Grass Phytoliths. Soil Science Society of America, Proceedings, Vol. 33, p. 109-115

Wilding, L.P., and L.R. Drees

1971 Biogenic Opal in Ohio Soils. Proceedings of the Soil Science Society of America 35:1004-1010.

1973 Scanning Electron Microscopy of Opaque Opaline Forms Isolated from Forest Soils in Ohio. Proceedings of the Soil Science Society of America 37:647-650.

1974 Contributions of Forest Opal and Associated Crystalline Phases of Fine Clay Fractions of Soils. Clays and Clay Minerals 22:295-306.

Wilding, L.P., C.T. Hallmark, and N.E. Smeck

1979 Dissolution and Stability of Biogenic Opal. Journal of Soil Science Society of America 43:800-802.

Wilding, L.P., N.E. Smeck, and L.R. Drees

1977 Silica in Soils: Quartz, Cristobalite, Tridymite, and Opal. In Minerals in Soils Environment, edited by J.B. Dixon and S.B. Weed, pp. 471-552. Soil Science Society of America, Madison, Wisconsin. 



\section{APPENDIX G: \\ The Paleoenvironmental History of the Onion Creek Site (41TV410, Area-3) Travis County, Texas, based on Land Snails Manuel R. Palacios-Fest}





\author{
APPENDIX G \\ The Paleoenvironmental History of the Onion Creek Site (41TV410 Area-3), \\ Travis County, Texas, based on Land Snails \\ Manuel R. Palacios-Fest \\ Terra Nostra Earth Sciences Research, \\ P.O. 37195 Tucson, AZ 85740-7195 \\ TNESR Report No. 0910
}

\begin{abstract}
Land snails are an important tool for reconstructing environmental change as a result climatic variations. In archeological sites these organisms, however, may be artificially accumulated in shell middens biasing and masking the natural signal offered by land snails. This study deals with the significance of a limited gastropod fauna recovered from Area 3 excavations in association with site 41TV410 near Onion Creek in Travis County in an attempt to distinguish anthropogenic use from climate change.
\end{abstract}

\title{
INTRODUCTION
}

The use of land snails as indicators of the environmental conditions that prevailed in a region occupied by humans is a common feature of archeological sites where shell mounds not only attest for the occurrence of the species but the use people made of them. Recognizing the natural from the anthropogenic signatures is of paramount relevance for identifying the effects of human adaptation on native species or otherwise the magnitude of change imposed by the environment. Malof (September 2007, http://www.dirtbrothers. org/editorial/malof.htm) indicates that faunal density and diversity are two of the most important parameters in recognizing the human from the natural signatures. He summarizes the current literature on snails in archeological sites in Texas. Two of the most prominent studies cited by Malof (2007) because of their particular relevance to paleoenvironmental reconstructions in archeological contexts are the papers of Allen and Cheatum (1960) and Goodfriend (1992). By no means does this selection represents all the points of view on the issue, but they are appropriate for the purpose of this study described later in this section.

The work of Allen and Cheatum (1960) and Goodfriend (1992) are some of the most relevant research studies on the implications of the ecological characteristics of fresh-water and land snails for reconstructing past environments related to human activity. For example, Allen and Cheatum (1960) highlighted the value of ethnoconchology focusing on the identification of mollusk remains from the natural environment or shell artifacts as aids in interpreting the environment in which they existed. These authors concentrate on the ecological implications of mollusks as indicators of climate change, as there is difference in the ecological requirements of each individual species. They propose that natural associations, consisting of an array of adult and juvenile forms, are distinguished from the selectively humanly gathered populations of mostly adults. This provides a starting point for the paleoenvironmental reconstruction of the Area 3 deposits associated with 41TV410 in Travis County, Texas.

Goodfriend (1992) used land snails for reconstructing Quaternary paleoenvironments by means of several methods including radiocarbon dating, amino-acid racemization and epimerization, and suggested the use of the $\mathrm{Th} / \mathrm{U}$ series. Once the age of the stratigraphic units have been established, he proposed to examine the faunal composition of the assemblages for identifying paleoenvironmental characteristics such as biome, temperature, and moisture conditions. Stable isotope analysis and aminoacid epimerization are two powerful tools for reconstructing paleotemperatures.

Using land snails to reconstructing climate change often requires the extrapolation of the patterns of occurrence or abundance of certain species. These organisms are sensitive to and selective of the environment where they settle and grow. Therefore, gastropods may indicate the particular characteristics of the habitat. For example, some species prefer more mesic, deeply wooded forests (e.g., Mesomphix inornatus, Columella simplex, and Gastrocopta cristata); other species favor open grassy areas to sparsely wooded areas (e.g., Rabdotus dealbatus dealbatus, Rabdotus mooreanus). Some other prefer moss-rich to moist forest soils to shallow riffle streams (e.g., Helicodiscus parallelus, Polygyra cereolus and Succinea luteola). Other species are eurytopic able to live in a wide range of environmental settings (e.g., Pupoides albilabris and Helicina (Olygyra) orbiculata). Sometimes, however, the paleoenvironmental signature may be biased by human selection. Species like Rabdotus dealbatus dealbatus or Helicina (Olygyra) orbiculata may have been consumed by indigenous people. Recognition of natural from anthropogenic assemblages is crucial for an accurate paleoenvironmental reconstruction. 
Site 41TV410 offers the unique opportunity to identify the natural from the anthropogenic signature during its occupation between the Late Archaic (4000-1250 B.P.) to Late Prehistoric Period (1250-300 B.P.). Through a semi-quantitative analysis, the purpose of this study is to identify the land snail species present at Onion Creek and to infer its environmental history. Relative abundance per species and their known ecological requirements are used to establish the patterns of environmental change.

\section{AREA OF STUDY}

Site 41TV410 is located in the northern portion of the borrow pit in the floodplain of Onion Creek. State Highway 130 borders the site immediately to the west. Figures 5-1 and 5-17 (see also Figure 1 of Tomka et al. 2007) shows the location of the site on the right bank and floodplain of Onion Creek about $4 \mathrm{~km}$ west of the confluence with the Colorado River. At an elevation of $133 \mathrm{~m}$ above mean sea level (amsl), the site is about $119 \mathrm{~m}$ east of the creek's modern channel but based on geomorphological features, Frederick (in Tomka et al. 2007) proposes that the old Onion Creek channel was closer to the site.

Chapter 2 presents a stream flow analysis in order to establish the flooding patterns in the area. That analysis suggests that floods were probably bimodal, with higher frequency in spring and fall. Intensity and timing of rainfall were the main factors controlling stream flow in the Onion Creek drainage. It is important to this study to consider the rainfall and flooding patterns affecting the project area, as these factors impact the faunal occurrence and diversity discussed later in this paper. Further details on the geomorphological and environmental settings are available in Tomka et al. (2007) and in Chapters 2 and 8 of the current report.

\section{MATERIALS AND METHODS}

Twelve bags containing mollusk shells from flotation samples collected from Trench A (Area 3) near site 41TV410 were sent to Terra Nostra Earth Sciences Research in Tucson, Arizona for identification, quantification, and paleoecological analysis. The Area 3 profile (see Figure 5-17 and 9-1) was also sampled for a variety of other paleoclimate data, including phytoliths and stable carbon isotopic patterns (see Appendices E and F). In general, two sets of bags per sample were shipped for analysis, large and small screen fractions. The large screen fraction represented snails above $1 / 4$ inch size generally collected in the heavy fraction of the flotation samples. The small size fraction represented those recovered from the light fraction of the flotation samples. Each size fraction frequently contained different snail species. The specimens were, when possible, identified to the species level. Diversity, total and relative abundance, and population maturity (a ratio of adult/juvenile shells) were recorded to reconstruct the paleoenvironmental history of the site. However, because at least two species (Rabdotus mooreanus [Pfeiffer, 1868]; and Helicina (Olygyra) orbiculata [Say, 1818]) were probably used as a food source, an effort for identifying natural from anthropogenic conditions will be assessed in the Interpretation section of this report. The snail population per sample was calculated by dividing the number of specimens by the sample volume (in liters, L). This number produced an estimate of the number of organisms per liter of soil that will be used in the Interpretation section for the paleoenvironmental reconstruction of the site.

Taphonomic parameters, like fragmentation, abrasion, and encrustation, as well as the maturity ratios per species, were recorded to infer the living and burial conditions of the shells. For example, high degree of fragmentation and/or abrasion is interpreted as an indicator of transport (Adams et al. 2002), whereas increasing mineral overgrowth on the shells indicates excess salt concentration in the soils favoring the adherence of "exotic" minerals to the shells after burial (Adams et al. 2002). The maturity ratio was used to identify a biocenosis (life assemblage) from a tanathocenosis (dead assemblage). That is, faunal assemblages consisting of a suite of adults and juvenile shells more frequently represent a local, living population (Whatley 1983). By contrast, a tanathocenosis is generally skewed by one of the size groups, either heavily or exclusively dominated by adults or juveniles. This type of assemblages usually suggests that the population was not local but either transported (if naturally) or selectively gathered (if by human activity).

\section{RESULTS}

\section{Species Identification}

In all, 147 snail were assigned to ten land species from Onion Creek Site 41TV410 including Rabdotus dealbatus dealbatus (Say 1821), Rabdotus mooreanus (Pfeiffer 1868), Helicina (Olygyra) orbiculata (Say 1818), Polygyra cereolus (Mühlfeld 1818), Helicodiscus parallelus, Pupoides albilabris (Adams 1841), Gastrocopta cristata (Pilsbry and Vanatta 1900), Mesomphix 
Table G-2. Total and relative abundance, and adulthood (A/J) ratios of gastropods identified from the Onion Creek Site

\begin{tabular}{|c|c|c|c|c|c|c|c|c|c|c|c|c|}
\hline \multirow[b]{2}{*}{ Sample \# } & \multirow[b]{2}{*}{ Years B.P.* } & \multirow[b]{2}{*}{ elevation (cmbs) } & \multirow[b]{2}{*}{ Liters } & \multirow[b]{2}{*}{ Fraction $(\mathrm{g})$} & \multirow{2}{*}{$\begin{array}{l}\text { Shell } \\
\text { Wt. }\end{array}$} & \multirow{2}{*}{$\begin{array}{c}\text { Shells/ } \\
\text { Liter }\end{array}$} & \multicolumn{3}{|c|}{ Rabdotus dealbatus } & \multirow{2}{*}{$\begin{array}{c}\begin{array}{c}\text { Columella } \\
\text { simplex }\end{array} \\
\# \\
\#\end{array}$} & \multirow[b]{2}{*}{$\%$} & \multirow[b]{2}{*}{$A / J$} \\
\hline & & & & & & & \# & $\%$ & $\mathrm{~A} / \mathrm{J}$ & & & \\
\hline 2 & & $650-660$ & 1 & 10.0 & 1 & 1.0 & & & & & & \\
\hline 3 & & $600-610$ & 0.9 & 11.3 & 11 & 12.2 & & & & 1 & 9.1 & 0 \\
\hline 6 & $3250 \pm 25$ & $450-460$ & 0.8 & 22.6 & 11 & 13.8 & & & & & & \\
\hline 7 & $3370 \pm 25$ & $400-410$ & 0.4 & 0.2 & 3 & 7.5 & & & & & & \\
\hline 8 & $2870 \pm 25$ & $350-360$ & 0.4 & 2.4 & 10 & 25.0 & 4 & 40 & 0.25 & & & \\
\hline 9 & & $300-310$ & 0.9 & 33.0 & 25 & 27.8 & 3 & 12 & 1 & & & \\
\hline 10 & & $250-260$ & 0.9 & 23.0 & 31 & 34.4 & & & & & & \\
\hline 11 & & $200-210$ & 0.9 & 31.5 & 12 & 13.3 & 3 & 25 & 0.67 & & & \\
\hline 12 & $1240 \pm 25$ & $150-160$ & 0.5 & 20.0 & 10 & 20.0 & 4 & 40 & 1 & & & \\
\hline 13 & & $100-110$ & 0.9 & 9.5 & 7 & 7.8 & & & & & & \\
\hline 14 & & $50-60$ & 1 & 12.2 & 3 & 3.0 & & & & & & \\
\hline \multirow[t]{2}{*}{15} & & $0-10$ & 1 & 4.3 & 23 & 23.0 & 23 & 100 & 1 & & & \\
\hline & \multicolumn{3}{|c|}{ Rabdotus mooreanus } & \multicolumn{3}{|c|}{ Helicodiscus parallelus } & \multicolumn{3}{|c|}{ Gastrocopta cristata } & $\begin{array}{l}\text { Helicina } \\
\text { orbiculata }\end{array}$ & & \\
\hline Sample \# & \# & $\%$ & $\mathrm{~A} / \mathrm{J}$ & $\#$ & $\%$ & A/J & \# & $\%$ & $\mathrm{~A} / \mathrm{J}$ & $\#$ & $\%$ & $A / J$ \\
\hline 2 & & & & & & & & & & 1 & 100 & 1 \\
\hline 3 & 7 & 63.6 & 0.29 & & & & 2 & 18.2 & 0 & 1 & 9.1 & 1 \\
\hline 6 & 4 & 36.4 & 0.25 & 1 & 9.1 & 0 & & & & & & \\
\hline 7 & 3 & 100 & 1 & & & & & & & & & \\
\hline 8 & 2 & 20 & 0 & 2 & 20 & 0.5 & & & & & & \\
\hline 9 & 21 & 84 & 0.38 & & & & & & & 1 & 4 & 0.25 \\
\hline 10 & 10 & 32.3 & 0.30 & & & & & & & 21 & 32.3 & 0.29 \\
\hline 11 & 4 & 33.3 & 0.25 & 1 & 8 & 0 & & & & 2 & 16.7 & 1 \\
\hline 12 & 5 & 50 & 0.20 & 1 & 10 & 0 & & & & & & \\
\hline 13 & 6 & 85.7 & 0.33 & & & & & & & & & \\
\hline 14 & 1 & 33.3 & 0 & & & & & & & 1 & 33.3 & 0 \\
\hline \multicolumn{13}{|l|}{15} \\
\hline \multirow[b]{2}{*}{ Sample \# } & \multicolumn{3}{|c|}{ Mesomphix inornatus } & \multicolumn{3}{|c|}{ Succinea luteola } & \multicolumn{3}{|c|}{ Polygyra cereolus } & $\begin{array}{l}\text { Pupoides } \\
\text { albilabris }\end{array}$ & & \\
\hline & $\#$ & $\%$ & $\mathrm{~A} / \mathrm{J}$ & $\#$ & $\%$ & $\mathrm{~A} / \mathrm{J}$ & $\#$ & $\%$ & $\mathrm{~A} / \mathrm{J}$ & $\#$ & $\%$ & $A / J$ \\
\hline 2 & & & & & & & & & & & & \\
\hline 3 & 1 & 9.1 & 0 & & & & & & & & & \\
\hline 6 & 2 & 18.2 & 0.5 & 2 & 18.2 & 0.5 & 2 & 18.2 & 0 & & & \\
\hline 7 & & & & & & & & & & & & \\
\hline 8 & 2 & 20 & 0.5 & & & & & & & & & \\
\hline 9 & & & & & & & & & & & & \\
\hline 10 & & & & & & & & & & & & \\
\hline 11 & & & & & & & 2 & 16.7 & 2 & & & \\
\hline 12 & & & & & & & & & & & & \\
\hline 13 & & & & & & & 1 & 14.3 & 1 & & & \\
\hline 14 & & & & & & & & & & 1 & 33.3 & 0 \\
\hline 15 & & & & & & & & & & & & \\
\hline
\end{tabular}

* See Chapter 8 for discussion of radiocarbon dates. 


\section{Interpretation}

Rabdotus mooreanus was the dominant species throughout most the stratigraphic sequence distantly followed by Rabdotus dealbatus dealbatus and Helicina (Olygyra) orbiculata. The remaining species sporadically occurred in the record. Dominance of the three species may be interpreted as the result of a favorable climate or anthropogenic selection as these are edible species. The early occurrence of $H$. (O.) orbiculata (a single specimens representing $100 \%$ of the population) appears to be a natural occurrence as the species rapidly disappears from the record not to occur until the end of the Late Archaic ( $2055 \mathrm{BP} ; 250 \mathrm{~cm}$ bgs) when it abruptly increases to 21 specimens. Similarly, R. mooreanus shows a relatively low concentration except for the interval around 2055 BP (250-300 cm bgs) where it reaches its maximum occurrence (10-21 specimens). By contrast, R. dealbatus dealbatus occurs randomly throughout the record except for the uppermost sample (modern surface) where it reaches its maximum occurrence (23 adult specimens).

Neither species is significantly abundant. The relative abundance must be interpreted with caution as often the percentage shows a high value that may bias the true history of events. For example, $H$. (O.) orbiculata is the only species recovered at the base of the stratigraphic sequence yielding a $100 \%$ of the population. The same is true for $R$. mooreanus at $400 \mathrm{~cm}$ bgs, represented by three adult individuals. The combination of total abundance and adulthood ratios is an important element in recognizing natural from anthropogenic assemblages. Granted these considerations, it is possible to infer the environmental history of Onion Creek based on the land snail record.

Regardless of their limited occurrence, other species like P. cereolus, $H$. parallelus, and $M$. inornatus are important because these species require certain level of mesic conditions contrasting with the more xeric conditions indicated by the dominant species. The scarce occurrence of the eurytopic species $P$. albilabris is in contrast with the abundance of the other eurytopic species identified in this study, H. (O.) orbiculata.

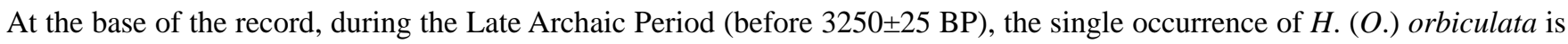
an ambiguous indicator of increasingly mesic conditions (Figure G-1). At this interval (650-450 cm bgs), the appearance of G. cristata, M. inornatus, and C. simplex associated with $H$. (O.) orbiculata and $R$. mooreanus may imply a slight increase in humidity, however, the poor record does not permit us to elaborate on this interpretation. Between $3250 \pm 25 \mathrm{BP}$ and $2870 \pm 25$ BP effective moisture remained low as shown by the increasing presence of $R$. mooreanus. The occurrence of $C$. simplex, $M$. inornatus, $P$. cereolus, and $H$. parallelus, suggest increasing humidity in the environment. None of these species, however, established a biocenosis as most of them are represented by juvenile forms.

The transition from the Late Archaic to the Late Prehistoric (2870 25 BP to $1240 \pm 25$ BP) is marked by an increasingly diverse snail population in the area dominated by $R$. mooreanus and $H$. (O.) orbiculata, accompanied by $R$. dealbatus dealbatus, $H$. parallelus, and $P$. cereolus. The adulthood ratios of $R$. mooreanus, $H$. (O.) orbiculata, and $R$. dealbatus dealbatus indicate the species established an incipient local population, whereas the other two species failed to do it. The rest of the record is poor (post-1240 $\pm 25 \mathrm{BP}$ ), only $R$. mooreanus contained scant adults and juveniles, except for $R$. dealbatus dealbatus represented by adults at the surface sample (mostly fragmented).

\section{DISCUSSION}

\section{Environmental change or anthropogenic impact?}

Even though mollusks constitute a valuable tool for interpreting climate change it is important to highlight that such signature is often masked by anthropogenic activity, particularly if the species identified contribute to sustaining the native people. As there is a difference in the ecological requirements of each individual species, the analysis of the faunal assemblages can provide much information about the archeological site. Land snails are a common associate in archeological sites either as the result of a plethora of resources derived from anthropogenic activity that attract them into the site, or because humans gathered and fed on them. The density of gastropods in archeological sites demands attention for understanding the role these organisms played in an archeological context. The primary goal of this study was to identify the origin of the fauna and to determine if the patterns of land snail occurrence and abundance in the site were in response to environmental change or human impact. Based 


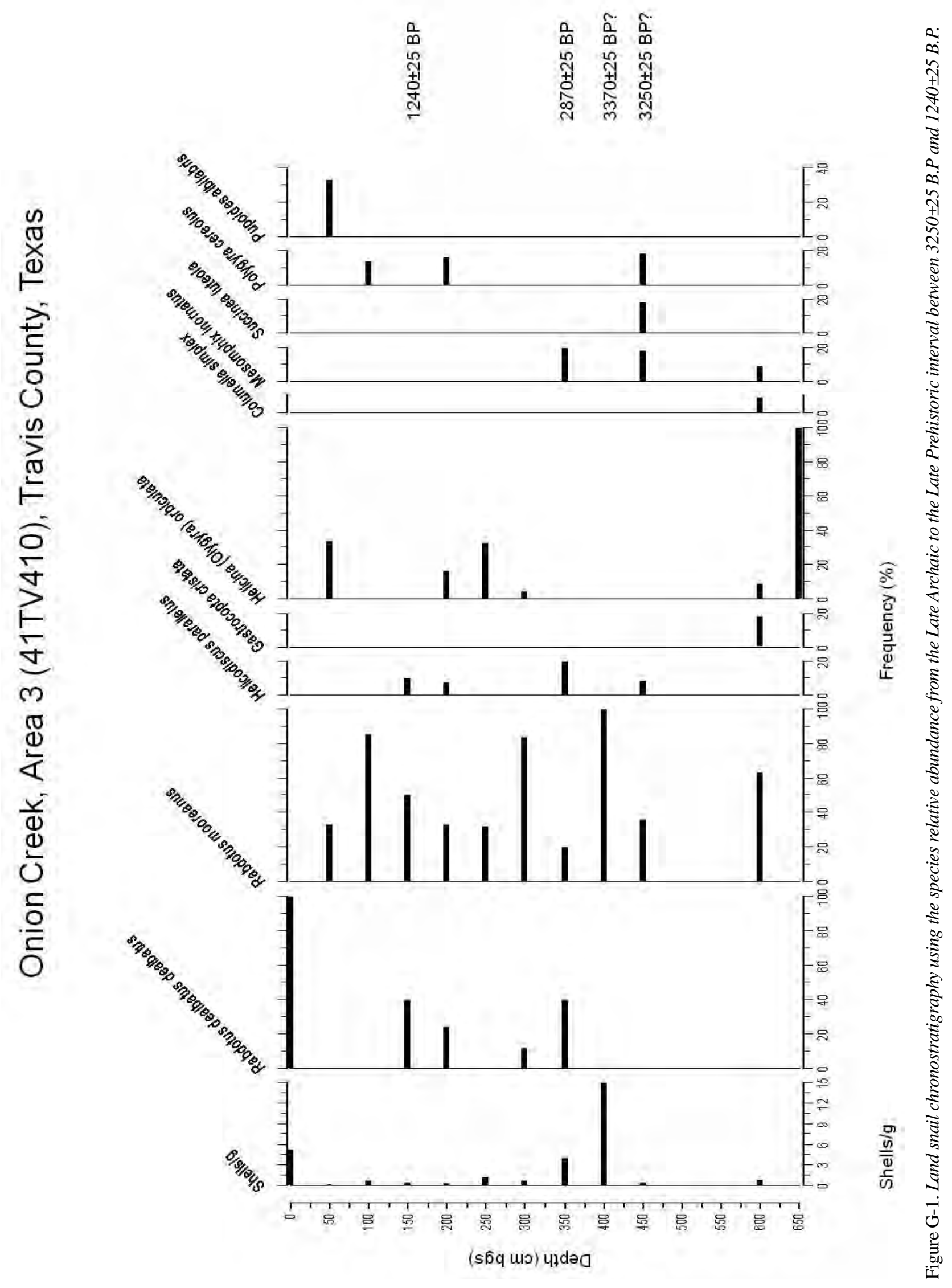


on several lines of evidence to be discussed in this section, this study proposes that land snails at Onion Creek Site $41 \mathrm{TV} 410$ indicate changes in the environment rather than anthropogenic influence.

$R$. mooreanus is a highly adaptive species capable of living in open or forested areas, but $H$. parallelus prefers near-water environments like swamps or fens, as S. luteola and P. cereolus do. G. cristata prefers moist soils under logs or rocks on poorly drained floodplains, an environment similar to that preferred by H. parallelus. P. albilabris prefers an environment like that for $R$. dealbatus dealbatus; whereas $M$. inornatus is better adapted to a temperate forest. Any combination of these species throughout the stratigraphic record of Onion Creek Site 41TV410 indicates the environmental conditions at any given time. No evidence of burning on shells argues for a natural deposition rather than an anthropogenic accumulation. Therefore, a reliable paleoenvironmental reconstruction is feasible using land snails.

Based on the faunal assemblage, it is inferred that mesic conditions in Onion Creek prevailed between around 2900 BP and $1250 \mathrm{BP}$ as $\mathrm{H}$. (O.) orbiculata reached its maximum abundance (32-84\%). The abundance of the species in an archeological feature argues for human gathering and consumption, however, careful optical analysis of the shells showed no evidence of plucking or burning indicative of anthropogenic activity. While boiling, the most likely form of processing, would leave no clear evidence of burning, it may also be the case that the site provided shelter to the species at a time of increasing effective moisture. Medina River does not show a significant change in $\mathrm{C}_{3} / \mathrm{C}_{4}$ plants but Hall's Cave and the bogs (Boriak and Patschke) indicate alternating episodes of $\mathrm{C}_{3}$ and $\mathrm{C}_{4}$ plants during this period. Patterns at Medina River indicate semi-arid conditions in the area; hence it would favor an interpretation of anthropogenic accumulation of $H$. (O.) orbiculata. This alternative, however, has been discarded based on the arguments aforementioned.

The current study shows a positive correlation with the Late Archaic period of the Granberg site (41BX17) previously analyzed by this author (Palacios-Fest 2007). Palacios-Fest (2007) concluded that the Granberg site experienced relatively mesic conditions during the time interval comprised between 2900 and 1900 BP. The present study extends to the Late Prehistoric showing increasingly xeric conditions with respect to the Late Archaic that, however, are not strong enough to support this interpretation. In addition, snail data correlates well with the plant and pollen records discussed by Muñóz et al. (2007:54-56). Shifts in $\mathrm{C}_{3}$ and $\mathrm{C}_{4}$ plants recorded from Medina River area (Nordt et al. 2002), the Hall's Cave (Cooke 2005), and the Boriak (Bousma 1998) and Patschke (Camper 1991; Nickels and Mauldin 2001) bogs show trends that, for most of the snail records, agree with the interpretation presented in this study.

\section{Conclusions}

- Land snail diversity and abundance provided basal information for recognizing climate change from human impact at the site.

- R. mooreanus and $H$. (O.) orbiculata, the two most common species, established a biocenosis sometime between $2870 \pm 25 \mathrm{BP}$ and $1240 \pm 25 \mathrm{BP}$ but were scarce outside this range.

- Through the analysis of gastropods it was possible to infer that, at Onion Creek adjacent to site 41TV410, climate rather than human use was recorded during the Late Archaic to Late Prehistoric period.

\section{REFERENCES}

Adams, K.R., S.J. Smith, and M.R. Palacios-Fest

2002 Pollen and micro-invertebrates from modern earthen canals and other fluvial environments along the Middle Gila River, Central Arizona: Implications for archaeological interpretation. Ms. on file GRIC, Sacaton, 61 pp.

Allen, D.C. and E.P. Cheatum

1960 Ecological Implications of Fresh-Water and Land Gastropods in Texas Archeological Studies. Bulletin of the Texas Archeological Society 31:291-316. 
Bousman, C.B.

1998 Paleoenvironmental Change in Central Texas: The Palynological Evidence. Plains Anthropologist 43(164):201-219.

Camper, H.A.

1991 Pollen Analysis of Patschke Bog. Unpublished M.S. thesis, Department of Botany, Texas A\&M University, Bryant. Data Archive at the World Data Center-A for paleoclimatology data. NOAA/NGDC Paleoclimatology Program, Boulder.

Cooke, M.J.

2005 Soil Formation and Erosion in Central Texas: Insights from Relict Soil and Cave Deposits. Unpublished Doctoral Dissertation. University of Texas at Austin, Austin, Texas.

Goodfriend, G.A.

1992 The Use of Land Snail Shells in Paleoenvironmental Reconstruction. Quaternary Science Reviews 11:665-685.

Malof, A.F.

2007 Texas Snails in Archaeological Context. http://www.dirtbrothers.org/editorial/malof.htm, consulted on September 5, 2007.

Munoz, C., J.L. Thompson, and R.P. Mauldin

2007 Research Design for the Analysis of Archeological Materials Recovered from Significance Testing of the Granberg Site (41BX17), Bexar County, Texas. Center for Archaeological Research, Department of Anthropology, The University of Texas at San Antonio, CSJ No. 0521-04-187, 95 pp.

Nickels, D.L., and R.P. Mauldin

2001 The Project Environment. In Archaeological Survey of Twin Buttes Reservoir, Tom Green County, Texas, Volume 1, by R.P. Mauldin and D.L. Nickels. Archaeological Survey Report, No. 300. Center for Archaeological Research, UTSA.

Nordt, L.C., T.W. Boutton, J.S. Jaco, and R. Mandel

2002 C4 Plant Productivity and Climate CO2 Variations in South-Central Texas during the Late Quaternary. Quaternary Research 58(2):182-188.

Palacios-Fest, M.R.

2007 Land Snails of the Granberg Site (41BX17), Bexar County, Texas: The Paleoenvironmental History. Tucson: TNESR Report 07-08, 18 pp.

Tomka, S.A., C. Fredrick, A.L. Figueroa, J.L. Thompson, and R.P. Mauldin

2007 Research Design for the Analysis of Archeological Materials Recovered from Phase II Significance Testing of 41TV540 and 41TV410, Travis County, Texas. Center for Archaeological Research The University of Texas at San Antonio. CSJ Number: 0440-06-006, 136 PP.

Whatley, R.

1983 Some simple procedures for enhancing the use of Ostracoda in palaeoenvironmental analysis. NPD Bulletin. (2): 129-146. 


\section{APPENDIX H: \\ Modern Land Snails at McKinney Roughs Nature Park, Bastrop County, Texas \\ Antonia Figueroa, Barbra Meissner, and Steve Tomka}





\author{
APPENDIX H \\ Modern Land Snails at McKinney Roughs Nature Park, \\ Bastrop County, Texas \\ Antonia Figueroa, Barbra Meissner, and Steve Tomka \\ The Center for Archaeological Research \\ The University of Texas at San Antonio \\ San Antonio, Texas
}

\title{
Introduction
}

As part of the work associated with the analysis of material collected from 41TV540, we collected and analyzed modern snail assemblages from distinct vegetation communities reflective of the succession of floodplain vegetation including open grassland, brushy woodlands and near-climax forest. Included in this document is a summary of the ecological setting where snail collections were conducted in Bastrop County, along with the data from the snail analysis (presented in Excel tables). This analysis was conducted to provide information about the habitat conditions preferred by the most common snail species found on archeological sites in Texas. Our understanding of the habitat conditions preferred by species of snails commonly found in archeological sites (Polygra texasiana, Oligyra, and Rabdotus dealbatus) is far from complete. There appears to be significant overlap in habitat conditions preferred by the three common species (Brown 2002:219-234; Cheatum and Fullington 1971; Clark 1969, 1973; Malof 2001:26-27). Yet archeologists commonly use snail assemblages as proxies for the reconstruction of vegetation communities.

Therefore, to begin to construct a baseline database of snail species habitat preference and quantify the degree of habitat overlap between species, we collected snail populations from three different ecological settings. The localities of snail collections were along the Colorado River in Bastrop County within the McKinney Roughs Nature Park operated by Lower Colorado River Authority (LRCA). In all, five different locations in three ecological settings were sampled for snail. In each setting, the minimum sample size collected reached 500 specimens for either Polygra, Oligyra, or Rabdotus spp., with the exception of the brushy woodland setting.

\section{Project Area and Ecological Areas}

Collections were conducted in McKinney Roughs Nature Park located in Bastrop County, Texas on May $28^{\text {th }}$ and $29^{\text {th }}$ of 2009. The park consists of 1,110 acres along the Colorado River and contains four distinct ecosystems: Post Oak Savannah, Blackland Prairie, Piney Woods and Riparian (LRCA 2008). Information on soils and vegetation communities were obtained from the Web Soil Survey for Bastrop, Texas (WSS 2009). Vegetation communities are typically defined by the ratio of trees, shrubs, forbs and grasses present along with the percentage of canopy coverage. The historical use of the land in terms of cattle grazing and brush clearing is also used as a criteria in the development stage of vegetation communities.

Areas 1, 2 and 3 representing the brushy woodland area were located in a Ferris clay soil unit with five to 10 percent slopes along ridges (WSS 2009). Erosion was heavy in this area due to the sloping topography and the sparse understory. Elevations range from 450 to $500 \mathrm{ft}$ amsl. The ecological zone described for this soil type is Eroded Blackland Prairie that encompasses four vegetation communities: tallgrass prairie, midgrass prairie, midgrass/mixed-brush, and mix-brush/midgrass (WSS 2009). Areas 1, 2 and 3 were concentrated within the mix-brush/midgrass vegetation community, defined as having 50 percent canopy cover. Dominating species in this vegetation community are cedar elm (Ulmus crassifolia), honey mesquite (Prosopis glandulosa), and juniper (Juniperus spp.). Understory shrubs consist of tasajillo (Opuntia leptucaulis), prickly pear (Opuntia spp.), agarito (Berberis trifoliolata) and elbowbush (Forestiera pubescens). Grasses that are typically found in this vegetation community are curly mesquite (Hilaria belangeri), buffalograss (Buchloe dactyloides) and fall witchgrass (Digitaria cognate). Forbs are gayfeather (Liatris punctata), orange zexmenia (Wedelia texana), croton (Croton spp.) and Mexican sagewort (Artemisia ludoviciana) (WSS 2009).

Area 4, in the climax forest, was characterized by Smithville fine sandy loam soils along flood-plain steps. Elevations in the area ranged from 400 to 450 amsl. The ecological zone in this soil unit is Loamy Bottomland which contains tallgrass savannah, midgrass savannah and dense woodland vegetation communities. Snail collections were conducted within the dense woodland vegetation community that has more than $50 \%$ woody plant canopy dominated by pecan (Carya illinoinensis), elm (Ulmus spp.) and different species of oak (WSS 2009). A particular feature of this vegetation community is the shade from 
the overstory. Typical grasses in this area are bristlegrass (Setaria), flatsedge (Cyperus spp.), rush (Juncus spp.), and fimbry (Fimbristylis spp.) Forbs in the area consist of western ragweed (Ambrosia psilostachya), blood ragweed (Ambrosia trifida var. texana), sumpweed (Iva angustifolia) and mare's tail (Equisetum spp.). Shrubs and vines include sumacs (Rhus spp.) grape (Vitis spp.), greenbriar (Smilax spp.) and ivy treebine (Cissus incisa).

Grassland areas were located on floodplains adjacent to the Colorado River representing the first tier of floodplain succession where Area 5 sampling was conducted. Elevations range from 350 to $400 \mathrm{ft}$. amsl. Soils consist of Gad fine sand (WSS 2009) in floodplain settings. The ecological setting is a sandy bottomland with four ecological niches that include tallgrass-cottonwood savannah, elm shrubland, cottonwood-elm woodland and elm shrubland transition communities. To sample the grassland setting, collections were focused in the tallgrass-cottonwood savannah.

The tallgrass-cottonwood savannah is a hardwood savannah with 30 percent tree and shrub canopy cover (WSS 2009). This vegetation regime is dominated by grasses such as switch grass (Panicum virgatum), Indiangrass (Sorghastrum nutans), beaked panicum (Panicum anceps), little bluestem (Schizachyrium scoparium) and big bluestem (Andropogon geraradii). Forbs in this area are tickclover (Demodium) lespedeza (Lespedeza), broadleaf snoutbean (Rhynchosia latifolia) and wildbean (Strophostyles). Shrubs common in the area are peppervine (Ampelopsis arborea), Alabama supplejack (Berchemia scandens), sumacs (Rhus spp.) and common greenbrier (Similax rotundifolia). Trees in this vegetation regime include pecan (Carya illinoinensis), American sycamore (Platanus occidentallis), eastern cottonwood (Populus deltoids) and American elm (Ulmus americana).

\section{Collection and Analysis Methods}

At each sampling locality measuring approximately 30 -x-30 meters, three individuals collected all snails seen on plants, rocks and on the ground surface. An average of 1.5 hours of surface collecting was spent in each area. The weather was sunny and warm $\left(90^{\circ} \mathrm{F}\right)$ and vegetation was sparse to moderately dense. One sampling locality was visited in each of the three habitat settings (i.e., open grassland, brush woodland, forest) with the exception of the brushy woodland area where three localities were sampled. Localities in the brushy woodland areas were sparsely populated with snails and as the task under which this work was performed called for the collection of 500 individuals of one species from each ecological setting.

In addition to the surface collections, we excavated a 1-x-1 meter unit to $5 \mathrm{cmbs}$ in each locality to recover micro-snails and/or age groups that would not be represented in our surface collections. All soil from the excavation was collected and water screened at the CAR laboratory through 1/16" mesh. Excluding micro-snails, 11 different snail species were observed. In the brushy woodland setting there were six snail species present and 77\% of snails consisted of Rabdotus. However, in the climax forest, 10 species were present and the most frequent species observed included Oligyra (39\%), and Rabdotus (31\%). Ten species were present in grassland/floodplain environment and the largest percentage consisted of Oligyra (32\%) and Rabdotus (26\%). The presence of Mesodon zaletus in central Texas is not seen in Hubricht's (1985) work and both Brown (personal communication, 2009) and Malof (personal communication, 2009) agree with his finding. However, the CAR faunal analyst Barbara Meissner identified this species, and other sources note the presence of this snail near Kerrville and the San Marcos River (Anton 2009).

\section{Results}

This section discusses the results of snail collection and analysis conducted by the CAR in five areas. Surface collections were conducted for a 30-x-30 meter area in each locale along with a 1-x-1 meter test unit. Areas 1,2, and 3 represented brushy woodlands. The near-climax forest setting was represented in Area 4 where surface collections and a single 1-x-1 meter unit was excavated. The open grassland/floodplain setting was tested in Area 5 where surface collections and a 1-x-1 meter unit was excavated.

\section{Brushy Woodland}

In the brushy wood setting, typified by a mix-brush/midgrass vegetation community, collections were conducted in Areas 1,2 , and 3. The excavation of three 1-x-1 meter units in each sampling locality was conducted. Surface visibility in these collection areas was 50-60 percent. Erosion was evident in the collection areas due to the sloping ridge topography. Soils encountered in 
test units were a compact dry brown silty loam (10YR 4/3). In Area 2 the soils were rocky with $40-50 \%$ pebbles. Test units in Areas 1, 2 and 3 failed to produce snail specimens.

Table H-1 lists the snail species recovered from Areas 1, 2 and 3. The presence of Rabdotus sp., Oligyra sp., Polygyra texiana, and Mesodon zaletus was seen in all three localities. In surface collections Rabdotus were most abundant at 76 percent. Thirtyone percent of the collections in Areas 1, 2 and 3 consisted of Polygra and only eight percent were Oligyra.

Table H-1. Species Recovered from Areas 1, 2 and 3

\begin{tabular}{|l|l|r|l|}
\hline \multicolumn{1}{|c|}{ Area } & \multicolumn{1}{|c|}{ Species } & Count & Notes \\
\hline Surface 1 & Rabdotus sp. & 165 & \\
\hline Surface 1 & Oligyra sp. & 18 & \\
\hline Surface 1 & Polygyra texiana & 18 & \\
\hline Surface 1 & Mesodon zaletus & 2 & \\
\hline Surface 1 & Euglandina rosae & 1 & \\
\hline Surface 1 & Unknown \#1 & 1 & Probably a Mesodon sp. or a relative \\
\hline & & 205 & \\
\hline Surface 2 & Rabdotus sp. & 16 & \\
\hline Surface 2 & Oligyra sp. & 12 & \\
\hline Surface 2 & Mesodon zaletus & 11 & \\
\hline Surface 2 & Polygyra texiana & 1 & \\
\hline & & 40 & \\
\hline Surface 3 & Rabdotus sp. & 120 & \\
\hline Surface 3 & Polygyra texiana & 12 & \\
\hline Surface 3 & Mesodon zaletus & 9 & \\
\hline Surface 3 & Oligyra sp. & 6 & \\
\hline Surface 3 & Unknown \#1 & 1 & Probably a Mesodon sp. or a relative \\
\hline & \multicolumn{1}{r|}{ Total } & 148 & \\
\hline
\end{tabular}

\section{Climax Forest}

Area 4 was characterized by a dense woodland vegetation community. A wider variety of snails were collected from this area compared to Areas 1, 2 and 3. Surface visibility in this area was less than $30 \%$ due to heavy leaf litter. One 1-x-1 meter unit was excavated to $5 \mathrm{cmbs}$ in Area 4. Soils encountered in the unit consisted of a dark brown (10 YR 3/3) silty loam. Nine different species were present in this area with the majority being comprised of (37 percent) Oligyra sp., followed by Rabdotus sp. (31 percent; Table H-2). Mesodon thyroids was the next most frequent species present in Area 4.

Table H-2. Species Recovered from Area 4

\begin{tabular}{|l|l|r|l|}
\hline \multicolumn{1}{|c|}{ Area } & \multicolumn{1}{|c|}{ Species } & Count & Notes \\
\hline Surface 4 & Oligyra sp. & 507 & \\
\hline Surface 4 & Rabdotus sp. & 388 & \\
\hline Surface 4 & Mesodon thyroides & 156 & \\
\hline Surface 4 & Unknown \#1 & 93 & Probably a Mesodon sp. or a relative \\
\hline Surface 4 & Mesodon zaletus & 44 & \\
\hline Surface 4 & Zonitoides arboreus & 17 & \\
\hline Surface 4 & Anguispira alternata & 16 & \\
\hline Surface 4 & Misc. Micro snails & 10 & \\
\hline Surface 4 & Euchemotrema leai & 10 & \\
\hline Surface 4 & Polygyra texiana & 3 & \\
\hline Surface 4 & Practicolella sp. & 1271 & \\
\hline & & Surface Total & \\
\hline
\end{tabular}


Table H-2. Continued...

\begin{tabular}{|c|c|c|c|}
\hline Area & Species & Count & Notes \\
\hline 4 (Unit) & Rabdotus sp. & 20 & \\
\hline 4 (Unit) & Mesodon thyroides & 7 & \\
\hline 4 (Unit) & Unknown \#1 & 4 & Probably a Mesodon sp. or a relative \\
\hline 4 (Unit) & Mesodon zaletus & 4 & \\
\hline 4 (Unit) & Anguispira alternata & 3 & \\
\hline 4 (Unit) & Zonitoides arboreus & 1 & \\
\hline 4 (Unit) & Misc. Micro snails & 1 & \\
\hline \multicolumn{4}{|c|}{ Unit Total $\quad 40$} \\
\hline \multicolumn{2}{|r|}{ Overall total for Area 4} & 1311 & \\
\hline
\end{tabular}

\section{Grassland Setting}

The grassland setting (Area 5; Table H-3) was located along the floodplain of the Colorado River within a tallgrass-cottonwood savannah vegetation community. Surface visibility in this area was less than 50 percent. The one $1-x-1$ test unit excavated in this area revealed dark brown (10YR 3/3) sandy clay. Area 5 produced the largest combined population of snails $(\mathrm{n}=1599)$ and greatest variety of species $(\mathrm{n}=12)$ among the three ecological settings sampled. Oligyra sp. (relatives) were the most frequent species $(\mathrm{n}=500)$ collected in this area followed by Rabdotus sp. $(\mathrm{n}=398)$.

Table H-3. Species Recovered from Area 5

\begin{tabular}{|l|l|r|l|}
\hline \multicolumn{1}{|c|}{ Area } & \multicolumn{1}{|c|}{ Species } & Count & \\
\hline Surface 5 & Rabdotus sp. & 321 & \\
\hline Surface 5 & Oligyra sp. & 284 & \\
\hline Surface 5 & Mesodon thyroides & 186 & \\
\hline Surface 5 & Unknown \#1 & 134 & Probably a Mesodon sp. or a relative \\
\hline Surface 5 & Mesodon zaletus & 91 & \\
\hline Surface 5 & Anguispira alternata & 76 & \\
\hline Surface 5 & Misc. Micro snails & 33 & \\
\hline Surface 5 & Euchemotrema leai & 29 & \\
\hline Surface 5 & Zonitoides arboreus & 27 & \\
\hline Surface 5 & Unknown \#2 & 22 & Probably an Oligyra relative \\
\hline Surface 5 & Polygyra texiana & 17 & \\
\hline Surface 5 & Practicolella sp. & 5 & \\
\hline & & 1225 & \\
\hline 5 (Unit 1) & Oligyra sp. & 177 & \\
\hline 5 (Unit 1) & Rabdotus sp. & 77 & \\
\hline 5 (Unit 1) & Unknown \#1 & 23 & Probably a Mesodon sp. or a relative \\
\hline 5 (Unit 1) & Mesodon thyroides & 17 & \\
\hline 5 (Unit 1) & Unknown \#2 & 17 & Probably an Oligyra relative \\
\hline 5 (Unit 1) & Mesodon zaletus & 14 & \\
\hline 5 (Unit 1) & Zonitoides arboreus & 14 & \\
\hline 5 (Unit 1) & Anguispira alternata & 12 & \\
\hline 5 (Unit 1) & Euchemotrema leai & 11 & \\
\hline 5 (Unit 1) & Mesomphix friabilis & 274 & \\
\hline 5 (Unit 1) & Misc. Micro snails & 1599 & \\
\hline 5 (Unit 1) & Glyphalinia umbiicata & & \\
\hline 5 (Unit 1) & Practicolella sp. & & \\
\hline 5 (Unit 1) & Triodopsis fosteri & & \\
\hline & & & \\
\hline
\end{tabular}




\section{Age Determination}

The average length of Rabdotus was $19 \mathrm{~mm}$ while the average width was $10 \mathrm{~mm}$. Rabdotus specimens were also examined for the presence of a carina and callus by the faunal analyst. As noted, the presence of a carina is characteristic of a juvenile snail; while the presence of a callus is evident on adults snails. Forty percent of the Rabdotus had a carina (i.e., juveniles), while 53 percent of the specimens possessed a callus. Twenty-three of the specimens had a carina and callus and were included with the juveniles. Juveniles were shorter and thinner than adults shells. The width to length ratio was greater among carina possessing Rabdotus (i.e. juveniles). According to Malof (2001:70), the width to height ratio of the shell is lower in adult snails and higher in juvenile specimens.

In the brushy woodland setting , 44 percent of the Rabdotus were juveniles and even less were present in the climax forest (35\%) and grassland/floodplain (40\%) settings (Table H-4). There was no apparent relationship between ecological setting and shell size, although it has been argued that shell size could be an indicator of moisture levels (Goodfriend 1986). The amount of calcium carbonate in the substrate may also condition shell size. Studies show that calcareous substrates support larger snails (Goodfriend 1986).

The frequency of juveniles and adults in the Rabdotus population among the three ecological settings is not statically significant. However, in the climax forest setting there is an under representation of juveniles and over representation of adults.

Table H-4. The Presence and Absence of a Carina in

Rabdotus Specimens

\begin{tabular}{|l|l|r|r|r|}
\hline Ecological Setting & & Absent & Present & Total \\
\hline Brushy Woodland & Count & 169 & 132 & 301 \\
\hline Climax Forest & Count & 250 & 138 & 388 \\
\hline Grassland/Floodplain & Count & 192 & 129 & 321 \\
\hline Total & & $\mathbf{6 1 1}$ & $\mathbf{3 9 9}$ & $\mathbf{1 0 1 0}$ \\
\hline
\end{tabular}

\section{Summary}

CAR collected snail samples from three different ecological settings at the McKinney Roughs Nature Park in Bastrop County, Texas. This analysis was conducted in order to provide a baseline about the habitat conditions preferred by the three most common snail species found on archeological sites. The grassland/floodplain setting along the Colorado River produced the most snails and the highest diversity. The brushy woodland areas produced lower numbers and variety. The two ecological settings differed in elevations, moisture and canopy cover. Sixty percent of the Rabdotus populations were adults. At the scale of ecological zones, adults were more frequent than juveniles. Table H-5 presents the raw data of all the snail species including information on length (mm), width (mm), weights (g) and the presence or absence of a carina and callus.

One of the most interesting aspects of the study was the amount of live snails that were present in the collection sample. Of the combined snails collected, less than 10 percent were alive. Of those, only one percent consisted of Rabdotus sp. Considering three people were collecting for 7.5 hours, recovery rates for live Rabdotus were surprising low.

Table H-5. Snail Data by Area for McKinney Roughs Collections

\begin{tabular}{|c|c|c|c|c|c|c|c|}
\hline Area & Genus & Species & length $(\mathrm{mm})$ & width $(\mathrm{mm})$ & Carina & Calus & Weight (g.) \\
\hline 1 & Oligyra & $\mathrm{sp}$. & 6.1 & 8.1 & $\mathrm{~N} / \mathrm{A}$ & $\mathrm{N} / \mathrm{A}$ & 1.33 \\
\hline 1 & Oligyra & $\mathrm{sp}$. & 5.8 & 8.3 & $\mathrm{~N} / \mathrm{A}$ & $\mathrm{N} / \mathrm{A}$ & 1.44 \\
\hline 1 & Oligyra & $\mathrm{sp}$. & 5.6 & 7.5 & $\mathrm{~N} / \mathrm{A}$ & $\mathrm{N} / \mathrm{A}$ & 1.34 \\
\hline 1 & Oligyra & $\mathrm{sp}$ & 6 & 8 & $\mathrm{~N} / \mathrm{A}$ & $\mathrm{N} / \mathrm{A}$ & 1.34 \\
\hline 1 & Oligyra & $\mathrm{sp}$. & 5.5 & 8.1 & $\mathrm{~N} / \mathrm{A}$ & $\mathrm{N} / \mathrm{A}$ & 1.46 \\
\hline 1 & Oligyra & $\mathrm{sp}$ & 6.3 & 8.9 & $\mathrm{~N} / \mathrm{A}$ & $\mathrm{N} / \mathrm{A}$ & 1.4 \\
\hline 1 & Oligyra & $\mathrm{sp}$. & 6.2 & 8.2 & $\mathrm{~N} / \mathrm{A}$ & $\mathrm{N} / \mathrm{A}$ & 1.32 \\
\hline 1 & Oligyra & $\mathrm{sp}$. & 5.7 & 8.6 & $\mathrm{~N} / \mathrm{A}$ & $\mathrm{N} / \mathrm{A}$ & 1.51 \\
\hline 1 & Oligyra & $\mathrm{sp}$. & 5.1 & 7 & $\mathrm{~N} / \mathrm{A}$ & $\mathrm{N} / \mathrm{A}$ & 1.37 \\
\hline 1 & Oligyra & $\mathrm{sp}$. & 6.6 & 8.6 & $\mathrm{~N} / \mathrm{A}$ & $\mathrm{N} / \mathrm{A}$ & 1.29 \\
\hline
\end{tabular}


Table H-5. Continued...

\begin{tabular}{|c|c|c|c|c|c|c|c|}
\hline Area & Genus & Species & length (mm) & width $(\mathrm{mm})$ & Carina & Calus & Weight (g.) \\
\hline 1 & Oligyra & sp. & 5.4 & 8.4 & $N / A$ & $\mathrm{~N} / \mathrm{A}$ & 1.58 \\
\hline 1 & Oligyra & sp. & 5.9 & 8.8 & N/A & $\mathrm{N} / \mathrm{A}$ & 1.48 \\
\hline 1 & Oligyra & sp. & 5.6 & 8.2 & N/A & $\mathrm{N} / \mathrm{A}$ & 1.45 \\
\hline 1 & Oligyra & sp. & 5.9 & 8.7 & N/A & $\mathrm{N} / \mathrm{A}$ & 1.47 \\
\hline 1 & Oligyra & sp. & 6.5 & 8.6 & $N / A$ & $\mathrm{~N} / \mathrm{A}$ & 1.31 \\
\hline 1 & Oligyra & sp. & 5.5 & 7.4 & N/A & $\mathrm{N} / \mathrm{A}$ & 1.35 \\
\hline 1 & Oligyra & sp. & 5.9 & 8.2 & N/A & $\mathrm{N} / \mathrm{A}$ & 1.38 \\
\hline 1 & Oligyra & sp. & 6 & 7.9 & N/A & $\mathrm{N} / \mathrm{A}$ & 1.32 \\
\hline 1 & Polygyra & texiana & 4.4 & 9.1 & N/A & $\mathrm{N} / \mathrm{A}$ & 2.07 \\
\hline 1 & Polygyra & texiana & 4.3 & 8.5 & N/A & $\mathrm{N} / \mathrm{A}$ & 1.98 \\
\hline 1 & Polygyra & texiana & 4 & 8 & N/A & $\mathrm{N} / \mathrm{A}$ & 2 \\
\hline 1 & Polygyra & texiana & 3.9 & 7.5 & $\mathrm{~N} / \mathrm{A}$ & $\mathrm{N} / \mathrm{A}$ & 1.93 \\
\hline 1 & Polygyra & texiana & 4.1 & 8.8 & $N / A$ & $N / A$ & 2.17 \\
\hline 1 & Polygyra & texiana & 4.5 & 7.9 & N/A & $N / A$ & 1.76 \\
\hline 1 & Polygyra & texiana & 4.4 & 8.4 & N/A & $\mathrm{N} / \mathrm{A}$ & 1.9 \\
\hline 1 & Polygyra & texiana & 4.6 & 8.7 & $N / A$ & $\mathrm{~N} / \mathrm{A}$ & 1.89 \\
\hline 1 & Polygyra & texiana & 4.2 & 8 & $N / A$ & $\mathrm{~N} / \mathrm{A}$ & 1.89 \\
\hline 1 & Polygyra & texiana & 4.7 & 9.3 & N/A & $\mathrm{N} / \mathrm{A}$ & 1.95 \\
\hline 1 & Polygyra & texiana & 5.3 & 9.3 & $N / A$ & $N / A$ & 1.75 \\
\hline 1 & Polygyra & texiana & 4.6 & 7.6 & $N / A$ & $\mathrm{~N} / \mathrm{A}$ & 1.65 \\
\hline 1 & Polygyra & texiana & 4.5 & 7.7 & $N / A$ & $\mathrm{~N} / \mathrm{A}$ & 1.73 \\
\hline 1 & Polygyra & texiana & 4.4 & 8.1 & N/A & $N / A$ & 1.83 \\
\hline 1 & Polygyra & texiana & 4.2 & 7.9 & N/A & N/A & 1.9 \\
\hline 1 & Polygyra & texiana & 4 & 7.4 & $N / A$ & $N / A$ & 1.87 \\
\hline 1 & Polygyra & texiana & 4.1 & 8.3 & N/A & $\mathrm{N} / \mathrm{A}$ & 2.01 \\
\hline 1 & Polygyra & texiana & 4.2 & 7.8 & N/A & $\mathrm{N} / \mathrm{A}$ & 1.85 \\
\hline 1 & Rabdotus & sp. & 5.7 & 4.5 & $Y$ & $\mathrm{~N}$ & 0.78 \\
\hline 1 & Rabdotus & sp. & 10.7 & 7.2 & $Y$ & $\mathrm{~N}$ & 0.67 \\
\hline 1 & Rabdotus & sp. & 7.7 & 5.2 & $Y$ & $\mathrm{~N}$ & 0.68 \\
\hline 1 & Rabdotus & sp. & 14.2 & 8.7 & $Y$ & $\mathrm{~N}$ & 0.62 \\
\hline 1 & Rabdotus & sp. & 10.1 & 7 & $Y$ & $\mathrm{~N}$ & 0.69 \\
\hline 1 & Rabdotus & sp. & 10.9 & 7.2 & $Y$ & $\mathrm{~N}$ & 0.66 \\
\hline 1 & Rabdotus & sp. & 8.5 & 5.8 & $\bar{Y}$ & $\mathrm{~N}$ & 0.69 \\
\hline 1 & Rabdotus & sp. & 13.8 & 8.9 & $Y$ & $\mathrm{~N}$ & 0.65 \\
\hline 1 & Rabdotus & sp. & 15.2 & 8.7 & $Y$ & $\mathrm{~N}$ & 0.57 \\
\hline 1 & Rabdotus & sp. & 13.8 & 8.5 & $Y$ & $\mathrm{~N}$ & 0.61 \\
\hline 1 & Rabdotus & sp. & 7.8 & 5.5 & $Y$ & $\mathrm{~N}$ & 0.71 \\
\hline 1 & Rabdotus & sp. & 9.7 & 6.7 & $Y$ & $\mathrm{~N}$ & 0.69 \\
\hline 1 & Rabdotus & sp. & 12.6 & 8.6 & $Y$ & $\mathrm{~N}$ & 0.68 \\
\hline 1 & Rabdotus & sp. & 8.8 & 6.3 & $Y$ & $\mathrm{~N}$ & 0.72 \\
\hline 1 & Rabdotus & sp. & 13.1 & 8.5 & $Y$ & $\mathrm{~N}$ & 0.65 \\
\hline 1 & Rabdotus & sp. & 14.8 & 9.6 & $Y$ & $\mathrm{~N}$ & 0.65 \\
\hline 1 & Rabdotus & sp. & 15.2 & 9.4 & $Y$ & $\mathrm{~N}$ & 0.62 \\
\hline 1 & Rabdotus & sp. & 11.7 & 6.8 & $Y$ & $\mathrm{~N}$ & 0.58 \\
\hline 1 & Rabdotus & sp. & 15.1 & 10.2 & $Y$ & $\mathrm{~N}$ & 0.68 \\
\hline 1 & Rabdotus & sp. & 14.9 & 9.3 & $Y$ & $\mathrm{~N}$ & 0.62 \\
\hline 1 & Rabdotus & sp. & 12.6 & 8 & $Y$ & $\mathrm{~N}$ & 0.63 \\
\hline 1 & Rabdotus & sp. & 16.1 & 10.4 & $Y$ & $\mathrm{~N}$ & 0.64 \\
\hline 1 & Rabdotus & sp. & 14 & 9 & $Y$ & $\mathrm{~N}$ & 0.64 \\
\hline 1 & Rabdotus & sp. & 9.5 & 7.3 & $Y$ & $\mathrm{~N}$ & 0.76 \\
\hline 1 & Rabdotus & sp. & 8.5 & 6 & $Y$ & $\mathrm{~N}$ & 0.7 \\
\hline 1 & Rabdotus & sp. & 9.9 & 7 & $Y$ & $\mathrm{~N}$ & 0.71 \\
\hline 1 & Rabdotus & sp. & 11.1 & 7.7 & $Y$ & $\mathrm{~N}$ & 0.69 \\
\hline 1 & Rabdotus & sp. & 14.6 & 9.4 & $Y$ & $\mathrm{~N}$ & 0.65 \\
\hline 1 & Rabdotus & sp. & 10.6 & 7.1 & $Y$ & $\mathrm{~N}$ & 0.67 \\
\hline
\end{tabular}


Table H-5. Continued...

\begin{tabular}{|c|c|c|c|c|c|c|c|}
\hline Area & Genus & Species & length (mm) & width (mm) & Carina & Calus & Weight (g.) \\
\hline 1 & Rabdotus & sp. & 11.7 & 9 & $Y$ & $\mathrm{~N}$ & 0.77 \\
\hline 1 & Rabdotus & $\mathrm{sp}$. & 12.1 & 8.3 & $\bar{Y}$ & $\mathrm{~N}$ & 0.69 \\
\hline 1 & Rabdotus & sp. & 10.2 & 7.7 & $Y$ & $\mathrm{~N}$ & 0.75 \\
\hline 1 & Rabdotus & $\mathrm{sp}$. & 15.8 & 9.8 & $\bar{Y}$ & $\mathrm{~N}$ & 0.62 \\
\hline 1 & Rabdotus & sp. & 16.3 & 10.3 & $Y$ & $\mathrm{~N}$ & 0.63 \\
\hline 1 & Rabdotus & $\mathrm{sp}$. & 9.9 & 7.7 & $\bar{Y}$ & $\mathrm{~N}$ & 0.78 \\
\hline 1 & Rabdotus & $\mathrm{sp}$. & 8.3 & 6 & $Y$ & $\mathrm{~N}$ & 0.72 \\
\hline 1 & Rabdotus & sp. & 7.4 & 5.7 & $Y$ & $\mathrm{~N}$ & 0.78 \\
\hline 1 & Rabdotus & sp. & 10 & 6.8 & $Y$ & $\mathrm{~N}$ & 0.68 \\
\hline 1 & Rabdotus & $\mathrm{sp}$. & 10.2 & 7.7 & $\bar{Y}$ & $\mathrm{~N}$ & 0.76 \\
\hline 1 & Rabdotus & $\mathrm{sp}$. & 13.3 & 9.2 & $\bar{Y}$ & $\mathrm{~N}$ & 0.69 \\
\hline 1 & Rabdotus & $\mathrm{sp}$. & 11.5 & 8.1 & $Y$ & $\mathrm{~N}$ & 0.7 \\
\hline 1 & Rabdotus & sp. & 16.1 & 10.5 & $Y$ & $\mathrm{~N}$ & 0.65 \\
\hline 1 & Rabdotus & sp. & 7.2 & 5 & $Y$ & $\mathrm{~N}$ & 0.69 \\
\hline 1 & Rabdotus & sp. & 8.1 & 6.1 & $Y$ & $\mathrm{~N}$ & 0.75 \\
\hline 1 & Rabdotus & sp. & 10.9 & 7.5 & $Y$ & $\mathrm{~N}$ & 0.69 \\
\hline 1 & Rabdotus & sp. & 21.9 & 11.1 & $\mathrm{~N}$ & $\bar{Y}$ & 0.51 \\
\hline 1 & Rabdotus & sp. & 25.6 & 13.4 & $\mathrm{~N}$ & $\bar{Y}$ & 0.52 \\
\hline 1 & Rabdotus & $\mathrm{sp}$. & 23.5 & 12.8 & $\mathrm{~N}$ & $\bar{Y}$ & 0.54 \\
\hline 1 & Rabdotus & sp. & 21.3 & 12.8 & $Y$ & $\bar{Y}$ & 0.6 \\
\hline 1 & Rabdotus & $\mathrm{sp}$. & 24.6 & 14 & $\mathrm{~N}$ & $\bar{Y}$ & 0.57 \\
\hline 1 & Rabdotus & sp. & 24.2 & 13.5 & $\mathrm{~N}$ & $\bar{Y}$ & 0.56 \\
\hline 1 & Rabdotus & $\mathrm{sp}$. & 23.6 & 14 & $\mathrm{~N}$ & $\bar{Y}$ & 0.59 \\
\hline 1 & Rabdotus & $\mathrm{sp}$. & 23.8 & 13.6 & $\mathrm{~N}$ & $Y$ & 0.57 \\
\hline 1 & Rabdotus & sp. & 21.4 & 12.7 & $\mathrm{~N}$ & $\bar{Y}$ & 0.59 \\
\hline 1 & Rabdotus & sp. & 25 & 12.9 & $\mathrm{~N}$ & $Y$ & 0.52 \\
\hline 1 & Rabdotus & $\mathrm{sp}$. & 24.9 & 13.3 & $\mathrm{~N}$ & $\bar{Y}$ & 0.53 \\
\hline 1 & Rabdotus & sp. & 23.1 & 13.3 & $\mathrm{~N}$ & $\bar{Y}$ & 0.57 \\
\hline 1 & Rabdotus & sp. & 25.3 & 12.9 & $\mathrm{~N}$ & $\bar{Y}$ & 0.51 \\
\hline 1 & Rabdotus & $\mathrm{sp}$. & 24 & 13.6 & $\mathrm{~N}$ & $\bar{Y}$ & 0.57 \\
\hline 1 & Rabdotus & sp. & 24.6 & 13.9 & $\mathrm{~N}$ & $\bar{Y}$ & 0.57 \\
\hline 1 & Rabdotus & sp. & 24.7 & 13.9 & $\mathrm{~N}$ & $\bar{Y}$ & 0.56 \\
\hline 1 & Rabdotus & sp. & 23.8 & 12.9 & $\mathrm{~N}$ & $\bar{Y}$ & 0.54 \\
\hline 1 & Rabdotus & sp. & 22.8 & 13 & $\mathrm{~N}$ & $\bar{Y}$ & 0.57 \\
\hline 1 & Rabdotus & $\mathrm{sp}$. & 22.6 & 12.4 & $\mathrm{~N}$ & $Y$ & 0.55 \\
\hline 1 & Rabdotus & $\mathrm{sp}$. & 23.9 & 12.7 & $\mathrm{~N}$ & $\bar{Y}$ & 0.53 \\
\hline 1 & Rabdotus & sp. & 24.2 & 13.6 & $\mathrm{~N}$ & $\bar{Y}$ & 0.56 \\
\hline 1 & Rabdotus & $\mathrm{sp}$. & 24.2 & 13.6 & $\mathrm{~N}$ & $\bar{Y}$ & 0.56 \\
\hline 1 & Rabdotus & sp. & 26 & 13.9 & $\mathrm{~N}$ & $\bar{Y}$ & 0.54 \\
\hline 1 & Rabdotus & $\mathrm{sp}$. & 23.6 & 12.9 & $\mathrm{~N}$ & $\bar{Y}$ & 0.55 \\
\hline 1 & Rabdotus & sp. & 21.6 & 12.3 & $\mathrm{~N}$ & $Y$ & 0.57 \\
\hline 1 & Rabdotus & $\mathrm{sp}$. & 23.1 & 13.3 & $\mathrm{~N}$ & $\bar{Y}$ & 0.57 \\
\hline 1 & Rabdotus & $\mathrm{sp}$. & 23.8 & 14.6 & $\mathrm{~N}$ & $Y$ & 0.61 \\
\hline 1 & Rabdotus & $\mathrm{sp}$. & 25.3 & 15.1 & $\mathrm{~N}$ & $\bar{Y}$ & 0.6 \\
\hline 1 & Rabdotus & sp. & 22.9 & 13.5 & $\mathrm{~N}$ & $Y$ & 0.59 \\
\hline 1 & Rabdotus & sp. & 23 & 12.9 & $\mathrm{~N}$ & $\bar{Y}$ & 0.56 \\
\hline 1 & Rabdotus & sp. & 21.6 & 12.1 & $\mathrm{~N}$ & $\bar{Y}$ & 0.56 \\
\hline 1 & Rabdotus & sp. & 21.3 & 12.7 & $\mathrm{~N}$ & $Y$ & 0.6 \\
\hline 1 & Rabdotus & sp. & 23.3 & 12.5 & $\mathrm{~N}$ & $\bar{Y}$ & 0.54 \\
\hline 1 & Rabdotus & $\mathrm{sp}$. & 21.8 & 12.4 & $\mathrm{~N}$ & $Y$ & 0.57 \\
\hline 1 & Rabdotus & $\mathrm{sp}$. & 23.2 & 13 & $\mathrm{~N}$ & $\bar{Y}$ & 0.56 \\
\hline 1 & Rabdotus & sp. & 23.4 & 13.1 & $\mathrm{~N}$ & $Y$ & 0.56 \\
\hline 1 & Rabdotus & $\mathrm{sp}$. & 22.9 & 12.6 & $\mathrm{~N}$ & $\bar{Y}$ & 0.55 \\
\hline 1 & Rabdotus & $\mathrm{sp}$. & 21.5 & 12.7 & $\mathrm{~N}$ & $Y$ & 0.59 \\
\hline 1 & Rabdotus & sp. & 23.1 & 12.5 & $\mathrm{~N}$ & $\bar{Y}$ & 0.54 \\
\hline
\end{tabular}


Table H-5. Continued...

\begin{tabular}{|c|c|c|c|c|c|c|c|}
\hline Area & Genus & Species & length (mm) & width (mm) & Carina & Calus & Weight (g.) \\
\hline 1 & Rabdotus & sp. & 23.4 & 12.7 & $\mathrm{~N}$ & $\mathrm{Y}$ & 0.54 \\
\hline 1 & Rabdotus & sp. & 22.1 & 12.3 & $\mathrm{~N}$ & $\mathrm{Y}$ & 0.56 \\
\hline 1 & Rabdotus & sp. & 22 & 12.6 & $\mathrm{~N}$ & $\mathrm{Y}$ & 0.57 \\
\hline 1 & Rabdotus & sp. & 22.1 & 12.5 & $\mathrm{~N}$ & $\mathrm{Y}$ & 0.57 \\
\hline 1 & Rabdotus & sp. & 23.4 & 12.2 & $\mathrm{~N}$ & $Y$ & 0.52 \\
\hline 1 & Rabdotus & sp. & 22.9 & 12.7 & $\mathrm{~N}$ & $Y$ & 0.55 \\
\hline 1 & Rabdotus & sp. & 22 & 13.5 & $\mathrm{~N}$ & $Y$ & 0.61 \\
\hline 1 & Rabdotus & sp. & 24 & 12.7 & $\mathrm{~N}$ & $Y$ & 0.53 \\
\hline 1 & Rabdotus & sp. & 24.4 & 13.6 & $\mathrm{~N}$ & $\mathrm{Y}$ & 0.56 \\
\hline 1 & Rabdotus & sp. & 22.3 & 12.3 & $\mathrm{~N}$ & $\mathrm{Y}$ & 0.55 \\
\hline 1 & Rabdotus & sp. & 23.2 & 13.5 & $\mathrm{~N}$ & $\mathrm{Y}$ & 0.58 \\
\hline 1 & Rabdotus & sp. & 23.1 & 12.8 & $\mathrm{~N}$ & $Y$ & 0.55 \\
\hline 1 & Rabdotus & sp. & 22.6 & 12.8 & $\mathrm{~N}$ & $Y$ & 0.57 \\
\hline 1 & Rabdotus & sp. & 21.4 & 12.5 & $\mathrm{~N}$ & $Y$ & 0.59 \\
\hline 1 & Rabdotus & $\mathrm{sp}$. & 22.3 & 12.5 & $\mathrm{~N}$ & $Y$ & 0.56 \\
\hline 1 & Rabdotus & sp. & 20.5 & 11.2 & $\mathrm{~N}$ & Y & 0.55 \\
\hline 1 & Rabdotus & sp. & 20.9 & 11.6 & $\mathrm{~N}$ & $\mathrm{Y}$ & 0.56 \\
\hline 1 & Rabdotus & $\mathrm{sp}$. & 21.7 & 12.2 & $\mathrm{~N}$ & $\mathrm{Y}$ & 0.56 \\
\hline 1 & Rabdotus & sp. & 23.1 & 13.5 & $\mathrm{~N}$ & $\mathrm{Y}$ & 0.58 \\
\hline 1 & Rabdotus & sp. & 21.1 & 13.1 & $\mathrm{~N}$ & $Y$ & 0.62 \\
\hline 1 & Rabdotus & sp. & 20.7 & 12 & $\mathrm{~N}$ & $Y$ & 0.58 \\
\hline 1 & Rabdotus & $\mathrm{sp}$. & 22.4 & 13.5 & $\mathrm{~N}$ & $Y$ & 0.6 \\
\hline 1 & Rabdotus & sp. & 23.9 & 13.2 & $\mathrm{~N}$ & Y & 0.55 \\
\hline 1 & Rabdotus & sp. & 22.5 & 13.2 & $\mathrm{~N}$ & $Y$ & 0.59 \\
\hline 1 & Rabdotus & sp. & 22.3 & 12.6 & $\mathrm{~N}$ & Y & 0.56 \\
\hline 1 & Rabdotus & $\mathrm{sp}$. & 23 & 12.9 & $\mathrm{~N}$ & $Y$ & 0.56 \\
\hline 1 & Rabdotus & sp. & 21 & 12.1 & $\mathrm{~N}$ & $\mathrm{Y}$ & 0.58 \\
\hline 1 & Rabdotus & sp. & 22 & 12.6 & $\mathrm{~N}$ & $\mathrm{Y}$ & 0.57 \\
\hline 1 & Rabdotus & sp. & 21.6 & 11.8 & $\mathrm{~N}$ & Y & 0.55 \\
\hline 1 & Rabdotus & $\mathrm{sp}$. & 22.8 & 12.4 & $\mathrm{~N}$ & $Y$ & 0.54 \\
\hline 1 & Rabdotus & sp. & 21.9 & 12.8 & $\mathrm{~N}$ & $Y$ & 0.58 \\
\hline 1 & Rabdotus & sp. & 21.1 & 11.7 & $\mathrm{~N}$ & $Y$ & 0.56 \\
\hline 1 & Rabdotus & sp. & 19.4 & 11.6 & $\mathrm{~N}$ & $\mathrm{Y}$ & 0.6 \\
\hline 1 & Rabdotus & $\mathrm{sp}$. & 23.2 & 12.4 & $\mathrm{~N}$ & $\mathrm{Y}$ & 0.54 \\
\hline 1 & Rabdotus & sp. & 21.4 & 12.3 & $\mathrm{~N}$ & $Y$ & 0.57 \\
\hline 1 & Rabdotus & sp. & 22.6 & 12.7 & $\mathrm{~N}$ & $Y$ & 0.56 \\
\hline 1 & Rabdotus & sp. & 19.6 & 11.7 & $\mathrm{~N}$ & $Y$ & 0.59 \\
\hline 1 & Rabdotus & $\mathrm{sp}$. & 18.8 & 11.1 & $Y$ & $\mathrm{~N}$ & 0.59 \\
\hline 1 & Rabdotus & sp. & 20.5 & 12.1 & $\mathrm{~N}$ & $\mathrm{~N}$ & 0.59 \\
\hline 1 & Rabdotus & sp. & 23.5 & 12.8 & $\mathrm{~N}$ & $\mathrm{~N}$ & 0.55 \\
\hline 1 & Rabdotus & sp. & 21.6 & 12.4 & $\mathrm{~N}$ & $\mathrm{~N}$ & 0.57 \\
\hline 1 & Rabdotus & sp. & 22.5 & 12.4 & $\mathrm{~N}$ & $\mathrm{~N}$ & 0.55 \\
\hline 1 & Rabdotus & sp. & 23 & 12.9 & $\mathrm{~N}$ & $\mathrm{Y}$ & 0.56 \\
\hline 1 & Rabdotus & sp. & 20.3 & 10.9 & $\mathrm{~N}$ & $Y$ & 0.53 \\
\hline 1 & Rabdotus & sp. & 21.1 & 13.1 & $\mathrm{~N}$ & $Y$ & 0.62 \\
\hline 1 & Rabdotus & $\mathrm{sp}$. & 21.5 & 11.9 & $\mathrm{~N}$ & $Y$ & 0.55 \\
\hline 1 & Rabdotus & sp. & 21.7 & 12.7 & $\mathrm{~N}$ & $Y$ & 0.59 \\
\hline 1 & Rabdotus & sp. & 21.3 & 13.2 & $\mathrm{~N}$ & $\mathrm{~N}$ & 0.62 \\
\hline 1 & Rabdotus & sp. & 21.7 & 11.5 & $\mathrm{~N}$ & $\mathrm{Y}$ & 0.53 \\
\hline 1 & Rabdotus & $\mathrm{sp}$. & 21.3 & 12.4 & $\mathrm{~N}$ & $Y$ & 0.58 \\
\hline 1 & Rabdotus & sp. & 20.3 & 11.5 & $\mathrm{~N}$ & $\mathrm{Y}$ & 0.57 \\
\hline 1 & Rabdotus & sp. & 21.7 & 12.1 & $\mathrm{~N}$ & Y & 0.56 \\
\hline 1 & Rabdotus & sp. & 23 & 12 & $\mathrm{~N}$ & $Y$ & 0.52 \\
\hline 1 & Rabdotus & sp. & 22 & 12.5 & $\mathrm{~N}$ & $Y$ & 0.57 \\
\hline 1 & Rabdotus & sp. & 21.3 & 11.7 & $\mathrm{~N}$ & $Y$ & 0.55 \\
\hline
\end{tabular}


Table H-5. Continued...

\begin{tabular}{|c|c|c|c|c|c|c|c|}
\hline Area & Genus & Species & length (mm) & width (mm) & Carina & Calus & Weight (g.) \\
\hline 1 & Rabdotus & sp. & 19.3 & 11.9 & $\mathrm{~N}$ & $\mathrm{~N}$ & 0.62 \\
\hline 1 & Rabdotus & sp. & 18.9 & 12 & Y & $\mathrm{N}$ & 0.63 \\
\hline 1 & Rabdotus & sp. & 19.3 & 11.1 & $\mathrm{Y}$ & $\mathrm{N}$ & 0.57 \\
\hline 1 & Rabdotus & sp. & 19.3 & 10.9 & $\mathrm{Y}$ & $\mathrm{N}$ & 0.56 \\
\hline 1 & Rabdotus & sp. & 8.4 & 5.6 & Y & $\mathrm{N}$ & 0.67 \\
\hline 1 & Rabdotus & sp. & 17.2 & 10.6 & $Y$ & $\mathrm{~N}$ & 0.61 \\
\hline 1 & Rabdotus & sp. & 22.8 & 11.4 & Y & $\mathrm{N}$ & 0.5 \\
\hline 1 & Rabdotus & sp. & 20.2 & 11.6 & Y & $\mathrm{N}$ & 0.57 \\
\hline 1 & Rabdotus & sp. & 17.4 & 10.9 & Y & $\mathrm{N}$ & 0.63 \\
\hline 1 & Rabdotus & sp. & 17.3 & 10.8 & $Y$ & $\mathrm{~N}$ & 0.62 \\
\hline 1 & Rabdotus & sp. & 19.8 & 12 & $Y$ & $\mathrm{~N}$ & 0.6 \\
\hline 1 & Rabdotus & sp. & 17.3 & 10.7 & $\mathrm{Y}$ & $\mathrm{N}$ & 0.62 \\
\hline 1 & Rabdotus & sp. & 19.4 & 11.3 & Y & $\mathrm{N}$ & 0.58 \\
\hline 1 & Rabdotus & sp. & 18.2 & 11.6 & $Y$ & $\mathrm{~N}$ & 0.64 \\
\hline 1 & Rabdotus & sp. & 14.9 & 9.9 & $Y$ & $\mathrm{~N}$ & 0.67 \\
\hline 1 & Rabdotus & sp. & 19.1 & 11.6 & Y & $\mathrm{N}$ & 0.61 \\
\hline 1 & Rabdotus & sp. & 18.5 & 11.5 & $\mathrm{~N}$ & $\mathrm{~N}$ & 0.62 \\
\hline 1 & Rabdotus & sp. & 20.2 & 11.6 & $\mathrm{~N}$ & Y & 0.57 \\
\hline 1 & Rabdotus & sp. & 17.5 & 11 & $\mathrm{~N}$ & $\mathrm{Y}$ & 0.63 \\
\hline 1 & Rabdotus & sp. & 16.8 & 11 & $\mathrm{~N}$ & Y & 0.65 \\
\hline 1 & Rabdotus & sp. & 20.9 & 11.1 & $\mathrm{~N}$ & Y & 0.53 \\
\hline 1 & Rabdotus & sp. & 19.8 & 10.4 & $\mathrm{~N}$ & $Y$ & 0.53 \\
\hline 1 & Rabdotus & sp. & 16.8 & 9.8 & Y & $\mathrm{N}$ & 0.58 \\
\hline 1 & Rabdotus & sp. & 18.5 & 11.5 & Y & $\mathrm{N}$ & 0.62 \\
\hline 1 & Rabdotus & sp. & 17.7 & 11.3 & Y & $\mathrm{N}$ & 0.64 \\
\hline 1 & Rabdotus & sp. & 17.4 & 11.4 & $\mathrm{~N}$ & $\mathrm{~N}$ & 0.66 \\
\hline 2 & Mesodon & zaletus & 10 & 19.7 & $\mathrm{~N} / \mathrm{A}$ & $\mathrm{N} / \mathrm{A}$ & 1.96 \\
\hline 2 & Mesodon & zaletus & 9.5 & 19.9 & $N / A$ & N/A & 2.09 \\
\hline 2 & Mesodon & zaletus & 10 & 20.7 & N/A & N/A & 2.08 \\
\hline 2 & Mesodon & zaletus & 10.2 & 19.6 & $N / A$ & $\mathrm{~N} / \mathrm{A}$ & 1.92 \\
\hline 2 & Mesodon & zaletus & 10.2 & 20.8 & $\mathrm{~N} / \mathrm{A}$ & $\mathrm{N} / \mathrm{A}$ & 2.05 \\
\hline 2 & Mesodon & zaletus & 10 & 21.4 & $\mathrm{~N} / \mathrm{A}$ & $\mathrm{N} / \mathrm{A}$ & 2.13 \\
\hline 2 & Mesodon & zaletus & 9.9 & 19.8 & $\mathrm{~N} / \mathrm{A}$ & $\mathrm{N} / \mathrm{A}$ & 1.99 \\
\hline 2 & Mesodon & zaletus & 10.3 & 18.8 & $\mathrm{~N} / \mathrm{A}$ & $\mathrm{N} / \mathrm{A}$ & 1.82 \\
\hline 2 & Mesodon & zaletus & 10.5 & 21.4 & $N / A$ & $\mathrm{~N} / \mathrm{A}$ & 2.04 \\
\hline 2 & Mesodon & zaletus & 10 & 19.7 & $\mathrm{~N} / \mathrm{A}$ & N/A & 1.97 \\
\hline 2 & Oligyra & sp. & 5.9 & 8 & $\mathrm{~N} / \mathrm{A}$ & $\mathrm{N} / \mathrm{A}$ & 1.35 \\
\hline 2 & Oligyra & $\mathrm{sp}$. & 5.7 & 8.2 & $\mathrm{~N} / \mathrm{A}$ & N/A & 1.45 \\
\hline 2 & Oligyra & sp. & 5.8 & 8.2 & $\mathrm{~N} / \mathrm{A}$ & $\mathrm{N} / \mathrm{A}$ & 1.43 \\
\hline 2 & Oligyra & sp. & 6.1 & 8.5 & $\mathrm{~N} / \mathrm{A}$ & $\mathrm{N} / \mathrm{A}$ & 1.39 \\
\hline 2 & Oligyra & sp. & 5.8 & 7.7 & $\mathrm{~N} / \mathrm{A}$ & N/A & 1.32 \\
\hline 2 & Oligyra & sp. & 5.7 & 8.4 & $\mathrm{~N} / \mathrm{A}$ & $\mathrm{N} / \mathrm{A}$ & 1.47 \\
\hline 2 & Oligyra & sp. & 5.8 & 8.1 & $\mathrm{~N} / \mathrm{A}$ & $\mathrm{N} / \mathrm{A}$ & 1.4 \\
\hline 2 & Oligyra & sp. & 5.9 & 8.6 & $N / A$ & N/A & 1.47 \\
\hline 2 & Oligyra & sp. & 5.3 & 7.9 & $\mathrm{~N} / \mathrm{A}$ & $\mathrm{N} / \mathrm{A}$ & 1.48 \\
\hline 2 & Oligyra & sp. & 5.2 & 7.7 & $\mathrm{~N} / \mathrm{A}$ & N/A & 1.47 \\
\hline 2 & Oligyra & sp. & 5.9 & 8.2 & $\mathrm{~N} / \mathrm{A}$ & $\mathrm{N} / \mathrm{A}$ & 1.39 \\
\hline 2 & Oligyra & sp. & 5.9 & 8.2 & $\mathrm{~N} / \mathrm{A}$ & $\mathrm{N} / \mathrm{A}$ & 1.39 \\
\hline 2 & Rabdotus & sp. & 21.1 & 12.3 & $\mathrm{~N}$ & $\mathrm{~N}$ & 0.58 \\
\hline 2 & Rabdotus & sp. & 23.2 & 13.2 & $\mathrm{~N}$ & $Y$ & 0.57 \\
\hline 2 & Rabdotus & sp. & 21.3 & 12.4 & $\mathrm{~N}$ & $\mathrm{Y}$ & 0.58 \\
\hline 2 & Rabdotus & sp. & 23.3 & 13.5 & $\mathrm{~N}$ & Y & 0.58 \\
\hline 2 & Rabdotus & sp. & 20.7 & 12 & $\mathrm{~N}$ & Y & 0.58 \\
\hline 2 & Rabdotus & sp. & 25.4 & 13.7 & $\mathrm{~N}$ & $Y$ & 0.54 \\
\hline 2 & Rabdotus & sp. & 25.7 & 13.9 & $\mathrm{~N}$ & $\mathrm{Y}$ & 0.54 \\
\hline
\end{tabular}


Table H-5. Continued...

\begin{tabular}{|c|c|c|c|c|c|c|c|}
\hline Area & Genus & Species & length (mm) & width (mm) & Carina & Calus & Weight (g.) \\
\hline 2 & Rabdotus & sp. & 22.3 & 11.5 & $\mathrm{~N}$ & $Y$ & 0.52 \\
\hline 2 & Rabdotus & sp. & 23.3 & 13.7 & $\mathrm{~N}$ & Y & 0.59 \\
\hline 2 & Rabdotus & sp. & 23.9 & 13.7 & $\mathrm{~N}$ & $Y$ & 0.57 \\
\hline 2 & Rabdotus & sp. & 23.5 & 12.9 & $\mathrm{~N}$ & $\mathrm{Y}$ & 0.55 \\
\hline 2 & Rabdotus & sp. & 23.7 & 13.5 & $\mathrm{~N}$ & Y & 0.57 \\
\hline 2 & Rabdotus & sp. & 22.5 & 13 & $\mathrm{~N}$ & $Y$ & 0.58 \\
\hline 2 & Rabdotus & sp. & 21.3 & 12.4 & $Y$ & $\mathrm{~N}$ & 0.58 \\
\hline 2 & Rabdotus & sp. & 17.9 & 10.7 & $Y$ & $\mathrm{~N}$ & 0.6 \\
\hline 2 & Rabdotus & sp. & 21.3 & 12.7 & $y$ & Y & 0.59 \\
\hline 3 & Mesodon & zaletus & 10.4 & 20.9 & $\mathrm{~N} / \mathrm{A}$ & $\mathrm{N} / \mathrm{A}$ & 2 \\
\hline 3 & Mesodon & zaletus & 9.6 & 19.5 & $\mathrm{~N} / \mathrm{A}$ & $\mathrm{N} / \mathrm{A}$ & 2.04 \\
\hline 3 & Mesodon & zaletus & 10.1 & 19.1 & $\mathrm{~N} / \mathrm{A}$ & $\mathrm{N} / \mathrm{A}$ & 1.89 \\
\hline 3 & Mesodon & zaletus & 9.9 & 18 & $\mathrm{~N} / \mathrm{A}$ & $\mathrm{N} / \mathrm{A}$ & 1.82 \\
\hline 3 & Mesodon & zaletus & 9.6 & 19.7 & $\mathrm{~N} / \mathrm{A}$ & $\mathrm{N} / \mathrm{A}$ & 2.06 \\
\hline 3 & Mesodon & zaletus & 10.2 & 20.4 & $\mathrm{~N} / \mathrm{A}$ & $\mathrm{N} / \mathrm{A}$ & 2 \\
\hline 3 & Mesodon & zaletus & 9.6 & 19.1 & $\mathrm{~N} / \mathrm{A}$ & $\mathrm{N} / \mathrm{A}$ & 1.98 \\
\hline 3 & Mesodon & zaletus & 9.6 & 19.4 & N/A & $\mathrm{N} / \mathrm{A}$ & 2.03 \\
\hline 3 & Mesodon & zaletus & 11.1 & 21.4 & $\mathrm{~N} / \mathrm{A}$ & $\mathrm{N} / \mathrm{A}$ & 1.93 \\
\hline 3 & Polygyra & texiana & 4.2 & 8.9 & $\mathrm{~N} / \mathrm{A}$ & $\mathrm{N} / \mathrm{A}$ & 2.11 \\
\hline 3 & Polygyra & texiana & 4.7 & 7.7 & $\mathrm{~N} / \mathrm{A}$ & N/A & 1.65 \\
\hline 3 & Polygyra & texiana & 4.1 & 8 & $\mathrm{~N} / \mathrm{A}$ & $\mathrm{N} / \mathrm{A}$ & 1.93 \\
\hline 3 & Polygyra & texiana & 4.1 & 8.1 & $\mathrm{~N} / \mathrm{A}$ & $N / A$ & 2 \\
\hline 3 & Polygyra & texiana & 4.4 & 7.5 & $\mathrm{~N} / \mathrm{A}$ & $\mathrm{N} / \mathrm{A}$ & 1.7 \\
\hline 3 & Polygyra & texiana & 4.4 & 8 & $\mathrm{~N} / \mathrm{A}$ & $\mathrm{N} / \mathrm{A}$ & 1.84 \\
\hline 3 & Polygyra & texiana & 4.3 & 8.1 & $\mathrm{~N} / \mathrm{A}$ & $\mathrm{N} / \mathrm{A}$ & 1.91 \\
\hline 3 & Polygyra & texiana & 4.3 & 8 & $\mathrm{~N} / \mathrm{A}$ & $\mathrm{N} / \mathrm{A}$ & 1.85 \\
\hline 3 & Polygyra & texiana & 4.1 & 7.4 & $\mathrm{~N} / \mathrm{A}$ & $\mathrm{N} / \mathrm{A}$ & 1.78 \\
\hline 3 & Polygyra & texiana & 4.3 & 7.7 & $\mathrm{~N} / \mathrm{A}$ & $\mathrm{N} / \mathrm{A}$ & 1.79 \\
\hline 3 & Polygyra & texiana & 4.1 & 8.2 & $\mathrm{~N} / \mathrm{A}$ & $\mathrm{N} / \mathrm{A}$ & 1.98 \\
\hline 3 & Polygyra & texiana & 4.1 & 8.8 & $\mathrm{~N} / \mathrm{A}$ & $\mathrm{N} / \mathrm{A}$ & 2.17 \\
\hline 3 & Rabdotus & $\mathrm{sp}$. & 22.2 & 11.9 & $\mathrm{~N}$ & $Y$ & 0.54 \\
\hline 3 & Rabdotus & sp. & 25.5 & 13.4 & $\mathrm{~N}$ & $Y$ & 0.53 \\
\hline 3 & Rabdotus & $\mathrm{sp}$. & 21.9 & 13.4 & $\mathrm{~N}$ & $Y$ & 0.61 \\
\hline 3 & Rabdotus & sp. & 23.4 & 12.5 & $\mathrm{~N}$ & $\mathrm{Y}$ & 0.54 \\
\hline 3 & Rabdotus & $\mathrm{sp}$. & 22.7 & 13.1 & $\mathrm{~N}$ & $Y$ & 0.58 \\
\hline 3 & Rabdotus & sp. & 22.9 & 13 & $\mathrm{~N}$ & $\mathrm{Y}$ & 0.57 \\
\hline 3 & Rabdotus & $\mathrm{sp}$. & 22.8 & 12.7 & $\mathrm{~N}$ & $\mathrm{~N}$ & 0.56 \\
\hline 3 & Rabdotus & sp. & 23.8 & 13.9 & $\mathrm{~N}$ & $\mathrm{~N}$ & 0.58 \\
\hline 3 & Rabdotus & sp. & 23.4 & 13.3 & $\mathrm{~N}$ & $\mathrm{Y}$ & 0.57 \\
\hline 3 & Rabdotus & sp. & 23.2 & 12.8 & $\mathrm{~N}$ & $Y$ & 0.55 \\
\hline 3 & Rabdotus & sp. & 24.4 & 12.6 & $\mathrm{~N}$ & $\mathrm{Y}$ & 0.52 \\
\hline 3 & Rabdotus & $\mathrm{sp}$. & 23.8 & 13.8 & $\mathrm{~N}$ & $Y$ & 0.58 \\
\hline 3 & Rabdotus & sp. & 22.9 & 13 & $\mathrm{~N}$ & Y & 0.57 \\
\hline 3 & Rabdotus & $\mathrm{sp}$. & 23.2 & 12.5 & $\mathrm{~N}$ & $Y$ & 0.54 \\
\hline 3 & Rabdotus & sp. & 21.1 & 12.6 & $\mathrm{~N}$ & Y & 0.6 \\
\hline 3 & Rabdotus & $\mathrm{sp}$. & 21 & 11.8 & $\mathrm{~N}$ & $Y$ & 0.56 \\
\hline 3 & Rabdotus & sp. & 23 & 12.6 & $\mathrm{~N}$ & Y & 0.55 \\
\hline 3 & Rabdotus & $\mathrm{sp}$. & 21.5 & 12.4 & $\mathrm{~N}$ & $Y$ & 0.58 \\
\hline 3 & Rabdotus & $\mathrm{sp}$. & 24.3 & 13.5 & $\mathrm{~N}$ & $Y$ & 0.56 \\
\hline 3 & Rabdotus & $\mathrm{sp}$. & 24 & 13.4 & $\mathrm{~N}$ & $Y$ & 0.56 \\
\hline 3 & Rabdotus & sp. & 23 & 13.8 & $\mathrm{~N}$ & $Y$ & 0.6 \\
\hline 3 & Rabdotus & $\mathrm{sp}$. & 22.8 & 13.2 & $\mathrm{~N}$ & $Y$ & 0.58 \\
\hline 3 & Rabdotus & sp. & 22.3 & 12.6 & $\mathrm{~N}$ & $\mathrm{~N}$ & 0.56 \\
\hline 3 & Rabdotus & $\mathrm{sp}$. & 22.1 & 12.4 & $\mathrm{~N}$ & $Y$ & 0.56 \\
\hline 3 & Rabdotus & sp. & 20.7 & 12 & $\mathrm{~N}$ & Y & 0.58 \\
\hline
\end{tabular}


Table H-5. Continued...

\begin{tabular}{|c|c|c|c|c|c|c|c|}
\hline Area & Genus & Species & length (mm) & width (mm) & Carina & Calus & Weight (g.) \\
\hline 3 & Rabdotus & sp. & 24.4 & 14.8 & $\mathrm{~N}$ & $Y$ & 0.6 \\
\hline 3 & Rabdotus & $\mathrm{sp}$. & 21.8 & 12.8 & $Y$ & $\mathrm{~N}$ & 0.58 \\
\hline 3 & Rabdotus & sp. & 17.2 & 10.8 & $Y$ & $\mathrm{~N}$ & 0.63 \\
\hline 3 & Rabdotus & sp. & 14.9 & 9.1 & $Y$ & $\mathrm{~N}$ & 0.61 \\
\hline 3 & Rabdotus & sp. & 7.8 & 6 & $Y$ & $\mathrm{~N}$ & 0.77 \\
\hline 3 & Rabdotus & $\mathrm{sp}$. & 8.3 & 6.4 & $Y$ & $\mathrm{~N}$ & 0.76 \\
\hline 3 & Rabdotus & sp. & 7.8 & 5.6 & $Y$ & $\mathrm{~N}$ & 0.71 \\
\hline 3 & Rabdotus & $\mathrm{sp}$. & 13.1 & 9.1 & $Y$ & $\mathrm{~N}$ & 0.69 \\
\hline 3 & Rabdotus & $\mathrm{sp}$. & 6.5 & 5.2 & $Y$ & $\mathrm{~N}$ & 0.8 \\
\hline 3 & Rabdotus & $\mathrm{sp}$. & 15 & 9.9 & $Y$ & $\mathrm{~N}$ & 0.66 \\
\hline 3 & Rabdotus & $\mathrm{sp}$. & 17.2 & 10.2 & $Y$ & $\mathrm{~N}$ & 0.6 \\
\hline 3 & Rabdotus & $\mathrm{sp}$. & 20.3 & 12.2 & $\mathrm{~N}$ & $Y$ & 0.6 \\
\hline 3 & Rabdotus & $\mathrm{sp}$. & 22.9 & 12.5 & $\mathrm{~N}$ & $\mathrm{~N}$ & 0.55 \\
\hline 3 & Rabdotus & $\mathrm{sp}$. & 20.3 & 11.7 & $\mathrm{~N}$ & $\mathrm{~N}$ & 0.58 \\
\hline 3 & Rabdotus & $\mathrm{sp}$. & 22.3 & 12.8 & $\mathrm{~N}$ & $Y$ & 0.57 \\
\hline 3 & Rabdotus & sp. & 19.5 & 11.9 & $\mathrm{~N}$ & $Y$ & 0.61 \\
\hline 3 & Rabdotus & $\mathrm{sp}$. & 24.1 & 14 & $\mathrm{~N}$ & $Y$ & 0.58 \\
\hline 3 & Rabdotus & sp. & 23.6 & 13.8 & $\mathrm{~N}$ & $Y$ & 0.58 \\
\hline 3 & Rabdotus & $\mathrm{sp}$. & 22.9 & 13 & $\mathrm{~N}$ & $Y$ & 0.57 \\
\hline 3 & Rabdotus & sp. & 21.6 & 13.1 & $Y$ & $\mathrm{~N}$ & 0.61 \\
\hline 3 & Rabdotus & sp. & 11.3 & 7.7 & $Y$ & $\mathrm{~N}$ & 0.69 \\
\hline 3 & Rabdotus & $\mathrm{sp}$. & 20.9 & 12.2 & $Y$ & $\mathrm{~N}$ & 0.58 \\
\hline 3 & Rabdotus & sp. & 20.3 & 11.8 & $Y$ & $\mathrm{~N}$ & 0.58 \\
\hline 3 & Rabdotus & $\mathrm{sp}$. & 18.8 & 11.3 & $Y$ & $\mathrm{~N}$ & 0.6 \\
\hline 3 & Rabdotus & $\mathrm{sp}$. & 19.6 & 11.3 & $Y$ & $\mathrm{~N}$ & 0.58 \\
\hline 3 & Rabdotus & $\mathrm{sp}$. & 20.8 & 12.3 & $Y$ & $\mathrm{~N}$ & 0.59 \\
\hline 3 & Rabdotus & $\mathrm{sp}$. & 22.1 & 12.7 & $Y$ & $\mathrm{~N}$ & 0.57 \\
\hline 3 & Rabdotus & $\mathrm{sp}$. & 21.5 & 12.3 & $Y$ & $\mathrm{~N}$ & 0.57 \\
\hline 3 & Rabdotus & $\mathrm{sp}$. & 22.9 & 12.8 & $Y$ & $\mathrm{~N}$ & 0.56 \\
\hline 3 & Rabdotus & $\mathrm{sp}$. & 20.6 & 11.9 & $Y$ & $\mathrm{~N}$ & 0.58 \\
\hline 3 & Rabdotus & $\mathrm{sp}$. & 23.1 & 13.1 & $Y$ & $\mathrm{~N}$ & 0.57 \\
\hline 3 & Rabdotus & $\mathrm{sp}$. & 21.6 & 12.9 & $Y$ & $\mathrm{~N}$ & 0.6 \\
\hline 3 & Rabdotus & sp. & 21.9 & 11.9 & $Y$ & $\mathrm{~N}$ & 0.54 \\
\hline 3 & Rabdotus & $\mathrm{sp}$. & 20.9 & 11.2 & $Y$ & $\mathrm{~N}$ & 0.53 \\
\hline 3 & Rabdotus & sp. & 19.4 & 11.3 & $Y$ & $\mathrm{~N}$ & 0.58 \\
\hline 3 & Rabdotus & $\mathrm{sp}$. & 21.1 & 11.9 & $Y$ & $\mathrm{~N}$ & 0.56 \\
\hline 3 & Rabdotus & sp. & 22.6 & 12.6 & $Y$ & $\mathrm{~N}$ & 0.56 \\
\hline 3 & Rabdotus & sp. & 19.7 & 11.5 & $Y$ & $\mathrm{~N}$ & 0.58 \\
\hline 3 & Rabdotus & $\mathrm{sp}$. & 23.4 & 13.5 & $Y$ & $\mathrm{~N}$ & 0.58 \\
\hline 3 & Rabdotus & sp. & 22.4 & 12.8 & $Y$ & $\mathrm{~N}$ & 0.57 \\
\hline 3 & Rabdotus & $\mathrm{sp}$. & 22.3 & 12.8 & $Y$ & $\mathrm{~N}$ & 0.57 \\
\hline 3 & Rabdotus & $\mathrm{sp}$. & 20.7 & 12.9 & $Y$ & $\mathrm{~N}$ & 0.62 \\
\hline 3 & Rabdotus & $\mathrm{sp}$. & 23.1 & 12.5 & $Y$ & $\mathrm{~N}$ & 0.54 \\
\hline 3 & Rabdotus & $\mathrm{sp}$. & 20 & 10.7 & $Y$ & $\mathrm{~N}$ & 0.54 \\
\hline 3 & Rabdotus & $\mathrm{sp}$. & 18.8 & 11.1 & $Y$ & $\mathrm{~N}$ & 0.59 \\
\hline 3 & Rabdotus & $\mathrm{sp}$. & 21.9 & 12.7 & $Y$ & $\mathrm{~N}$ & 0.58 \\
\hline 3 & Rabdotus & $\mathrm{sp}$. & 20.3 & 12.2 & $Y$ & $\mathrm{~N}$ & 0.6 \\
\hline 3 & Rabdotus & $\mathrm{sp}$. & 23.2 & 12.1 & $Y$ & $\mathrm{~N}$ & 0.52 \\
\hline 3 & Rabdotus & $\mathrm{sp}$. & 22.2 & 12.9 & $Y$ & $\mathrm{~N}$ & 0.58 \\
\hline 3 & Rabdotus & sp. & 22.6 & 12.8 & $Y$ & $\mathrm{~N}$ & 0.57 \\
\hline 3 & Rabdotus & sp. & 19.8 & 12 & $Y$ & $\mathrm{~N}$ & 0.61 \\
\hline 3 & Rabdotus & sp. & 18.3 & 12.2 & $Y$ & $\mathrm{~N}$ & 0.66 \\
\hline 3 & Rabdotus & $\mathrm{sp}$. & 22.7 & 13 & $Y$ & $\mathrm{~N}$ & 0.57 \\
\hline 3 & Rabdotus & sp. & 20.6 & 12.2 & $Y$ & $\mathrm{~N}$ & 0.59 \\
\hline 3 & Rabdotus & sp. & 22.1 & 12.1 & $Y$ & $\mathrm{~N}$ & 0.55 \\
\hline
\end{tabular}


Table H-5. Continued...

\begin{tabular}{|c|c|c|c|c|c|c|c|}
\hline Area & Genus & Species & length (mm) & width (mm) & Carina & Calus & Weight (g.) \\
\hline 3 & Rabdotus & sp. & 22.3 & 12.2 & $Y$ & $\mathrm{~N}$ & 0.55 \\
\hline 3 & Rabdotus & sp. & 20.5 & 12 & $Y$ & $\mathrm{~N}$ & 0.59 \\
\hline 3 & Rabdotus & sp. & 22.1 & 11.7 & $Y$ & $\mathrm{~N}$ & 0.53 \\
\hline 3 & Rabdotus & sp. & 18.8 & 11.2 & $Y$ & $\mathrm{~N}$ & 0.6 \\
\hline 3 & Rabdotus & sp. & 22.7 & 11.8 & $Y$ & $\mathrm{~N}$ & 0.52 \\
\hline 3 & Rabdotus & sp. & 23 & 12.1 & $Y$ & $\mathrm{~N}$ & 0.53 \\
\hline 3 & Rabdotus & sp. & 23.2 & 13.2 & $Y$ & $\mathrm{~N}$ & 0.57 \\
\hline 3 & Rabdotus & $\mathrm{sp}$. & 21 & 12 & $Y$ & $\mathrm{~N}$ & 0.57 \\
\hline 3 & Rabdotus & sp. & 22.9 & 12.4 & $Y$ & $\mathrm{~N}$ & 0.54 \\
\hline 3 & Rabdotus & $\mathrm{sp}$. & 21.9 & 12.9 & $Y$ & $\mathrm{~N}$ & 0.59 \\
\hline 3 & Rabdotus & sp. & 19 & 11.7 & Y & $\mathrm{N}$ & 0.61 \\
\hline 3 & Rabdotus & sp. & 20.5 & 12.1 & $Y$ & $\mathrm{~N}$ & 0.59 \\
\hline 3 & Rabdotus & $\mathrm{sp}$. & 22.4 & 12.7 & $Y$ & $\mathrm{~N}$ & 0.57 \\
\hline 3 & Rabdotus & sp. & 21.1 & 12.5 & $Y$ & $\mathrm{~N}$ & 0.59 \\
\hline 3 & Rabdotus & sp. & 21.3 & 12.2 & $Y$ & $\mathrm{~N}$ & 0.57 \\
\hline 3 & Rabdotus & sp. & 21.5 & 11.5 & $Y$ & $\mathrm{~N}$ & 0.54 \\
\hline 3 & Rabdotus & sp. & 21.6 & 12.8 & $Y$ & $\mathrm{~N}$ & 0.59 \\
\hline 3 & Rabdotus & sp. & 18.8 & 11 & $\mathrm{~N}$ & $\mathrm{~N}$ & 0.59 \\
\hline 3 & Rabdotus & sp. & 19.4 & 10.5 & $\mathrm{~N}$ & $\mathrm{~N}$ & 0.54 \\
\hline 3 & Rabdotus & sp. & 22.7 & 12.3 & $\mathrm{~N}$ & $\mathrm{~N}$ & 0.54 \\
\hline 3 & Rabdotus & sp. & 21.3 & 12.3 & $\mathrm{~N}$ & $\mathrm{~N}$ & 0.58 \\
\hline 3 & Rabdotus & sp. & 20.5 & 12.6 & $\mathrm{~N}$ & $\mathrm{~N}$ & 0.61 \\
\hline 3 & Rabdotus & sp. & 22.5 & 12.7 & $\mathrm{~N}$ & $\mathrm{~N}$ & 0.57 \\
\hline 3 & Rabdotus & sp. & 17.9 & 10.4 & $\mathrm{~N}$ & $\mathrm{~N}$ & 0.58 \\
\hline 3 & Rabdotus & $\mathrm{sp}$. & 18.7 & 11.7 & $\mathrm{~N}$ & $\mathrm{~N}$ & 0.62 \\
\hline 3 & Rabdotus & sp. & 21.7 & 12.8 & $\mathrm{~N}$ & $\mathrm{~N}$ & 0.59 \\
\hline 3 & Rabdotus & sp. & 18.1 & 10.9 & $\mathrm{~N}$ & $\mathrm{~N}$ & 0.6 \\
\hline 3 & Rabdotus & sp. & 18.1 & 11.1 & $\mathrm{~N}$ & $\mathrm{~N}$ & 0.61 \\
\hline 3 & Rabdotus & $\mathrm{sp}$. & 20.1 & 11.8 & $\mathrm{~N}$ & $\mathrm{~N}$ & 0.59 \\
\hline 3 & Rabdotus & sp. & 16.6 & 10.8 & $Y$ & $\mathrm{~N}$ & 0.65 \\
\hline 3 & Rabdotus & sp. & 16.1 & 10.3 & $\mathrm{~N} / \mathrm{A}$ & N/A & 0.64 \\
\hline 3 & Rabdotus & sp. & 16.6 & 10.5 & $\mathrm{~N} / \mathrm{A}$ & N/A & 0.63 \\
\hline 3 & Rabdotus & sp. & 20.7 & 11.8 & N/A & N/A & 0.57 \\
\hline 3 & Rabdotus & sp. & 21 & 11.7 & $\mathrm{~N} / \mathrm{A}$ & $\mathrm{N} / \mathrm{A}$ & 0.56 \\
\hline 3 & Rabdotus & sp. & 19 & 12.6 & N/A & $\mathrm{N} / \mathrm{A}$ & 0.66 \\
\hline 3 & Rabdotus & sp. & 7.3 & 5.5 & $\mathrm{~N} / \mathrm{A}$ & $\mathrm{N} / \mathrm{A}$ & 0.76 \\
\hline 3 & Rabdotus & sp. & 17.3 & 11.2 & $\mathrm{~N} / \mathrm{A}$ & $\mathrm{N} / \mathrm{A}$ & 0.65 \\
\hline 3 & Rabdotus & sp. & 18.9 & 11 & $\mathrm{~N} / \mathrm{A}$ & $\mathrm{N} / \mathrm{A}$ & 0.58 \\
\hline 3 & Rabdotus & sp. & 17.5 & 10.8 & $\mathrm{~N} / \mathrm{A}$ & $\mathrm{N} / \mathrm{A}$ & 0.62 \\
\hline 3 & Rabdotus & sp. & 17 & 10.3 & $\mathrm{~N} / \mathrm{A}$ & $\mathrm{N} / \mathrm{A}$ & 0.6 \\
\hline 4 & Mesodon & thyroides & 10.3 & 18.5 & $\mathrm{~N} / \mathrm{A}$ & $\mathrm{N} / \mathrm{A}$ & 1.79 \\
\hline 4 & Mesodon & thyroides & 10 & 17.3 & $\mathrm{~N} / \mathrm{A}$ & $\mathrm{N} / \mathrm{A}$ & 1.73 \\
\hline 4 & Mesodon & thyroides & 11.5 & 19.5 & $\mathrm{~N} / \mathrm{A}$ & $\mathrm{N} / \mathrm{A}$ & 1.7 \\
\hline 4 & Mesodon & thyroides & 9.9 & 17.4 & $\mathrm{~N} / \mathrm{A}$ & $\mathrm{N} / \mathrm{A}$ & 1.76 \\
\hline 4 & Mesodon & thyroides & 11.2 & 18.1 & $\mathrm{~N} / \mathrm{A}$ & $\mathrm{N} / \mathrm{A}$ & 1.62 \\
\hline 4 & Mesodon & thyroides & 8.9 & 15.5 & $\mathrm{~N} / \mathrm{A}$ & $\mathrm{N} / \mathrm{A}$ & 1.74 \\
\hline 4 & Mesodon & thyroides & 10.6 & 18.2 & $\mathrm{~N} / \mathrm{A}$ & $\mathrm{N} / \mathrm{A}$ & 1.72 \\
\hline 4 & Mesodon & thyroides & 9.6 & 17.9 & N/A & N/A & 1.87 \\
\hline 4 & Mesodon & thyroides & 10.7 & 17.7 & $\mathrm{~N} / \mathrm{A}$ & $\mathrm{N} / \mathrm{A}$ & 1.66 \\
\hline 4 & Mesodon & thyroides & 11.1 & 18.9 & $\mathrm{~N} / \mathrm{A}$ & N/A & 1.69 \\
\hline 4 & Mesodon & thyroides & 10.5 & 18.5 & N/A & $\mathrm{N} / \mathrm{A}$ & 1.77 \\
\hline 4 & Mesodon & thyroides & 10.1 & 16.7 & N/A & N/A & 1.65 \\
\hline 4 & Mesodon & thyroides & 11.4 & 18.9 & $\mathrm{~N} / \mathrm{A}$ & $\mathrm{N} / \mathrm{A}$ & 1.66 \\
\hline 4 & Mesodon & thyroides & 10.8 & 18.7 & $\mathrm{~N} / \mathrm{A}$ & $\mathrm{N} / \mathrm{A}$ & 1.74 \\
\hline 4 & Mesodon & thyroides & 10.2 & 17.1 & $\mathrm{~N} / \mathrm{A}$ & $\mathrm{N} / \mathrm{A}$ & 1.67 \\
\hline
\end{tabular}


Table H-5. Continued...

\begin{tabular}{|c|c|c|c|c|c|c|c|}
\hline Area & Genus & Species & length (mm) & width (mm) & Carina & Calus & Weight (g.) \\
\hline 4 & Mesodon & thyroides & 11.5 & 20.6 & $\mathrm{~N} / \mathrm{A}$ & $\mathrm{N} / \mathrm{A}$ & 1.78 \\
\hline 4 & Mesodon & thyroides & 11.4 & 19.2 & $\mathrm{~N} / \mathrm{A}$ & $N / A$ & 1.69 \\
\hline 4 & Mesodon & thyroides & 12.6 & 20.3 & $\mathrm{~N} / \mathrm{A}$ & N/A & 1.61 \\
\hline 4 & Mesodon & thyroides & 9.6 & 16.8 & $\mathrm{~N} / \mathrm{A}$ & $N / A$ & 1.75 \\
\hline 4 & Mesodon & thyroides & 10.8 & 18.6 & $\mathrm{~N} / \mathrm{A}$ & N/A & 1.73 \\
\hline 4 & Mesodon & thyroides & 11.1 & 19.2 & $\mathrm{~N} / \mathrm{A}$ & $\mathrm{N} / \mathrm{A}$ & 1.73 \\
\hline 4 & Mesodon & thyroides & 11.8 & 19.8 & $\mathrm{~N} / \mathrm{A}$ & N/A & 1.67 \\
\hline 4 & Mesodon & thyroides & 11.6 & 19.4 & $\mathrm{~N} / \mathrm{A}$ & $\mathrm{N} / \mathrm{A}$ & 1.67 \\
\hline 4 & Mesodon & thyroides & 10.7 & 18.9 & N/A & $\mathrm{N} / \mathrm{A}$ & 1.77 \\
\hline 4 & Mesodon & thyroides & 11.5 & 18.2 & $\mathrm{~N} / \mathrm{A}$ & $N / A$ & 1.58 \\
\hline 4 & Mesodon & thyroides & 10 & 18.1 & $\mathrm{~N} / \mathrm{A}$ & $\mathrm{N} / \mathrm{A}$ & 1.81 \\
\hline 4 & Mesodon & thyroides & 10.2 & 17.4 & $\mathrm{~N} / \mathrm{A}$ & $\mathrm{N} / \mathrm{A}$ & 1.7 \\
\hline 4 & Mesodon & thyroides & 10.5 & 18.4 & $\mathrm{~N} / \mathrm{A}$ & $\mathrm{N} / \mathrm{A}$ & 1.75 \\
\hline 4 & Mesodon & thyroides & 10.3 & 19.2 & $\mathrm{~N} / \mathrm{A}$ & $\mathrm{N} / \mathrm{A}$ & 1.86 \\
\hline 4 & Mesodon & thyroides & 10.4 & 17.3 & $\mathrm{~N} / \mathrm{A}$ & $\mathrm{N} / \mathrm{A}$ & 1.67 \\
\hline 4 & Mesodon & thyroides & 11.8 & 17.9 & $\mathrm{~N} / \mathrm{A}$ & N/A & 1.52 \\
\hline 4 & Mesodon & thyroides & 10.2 & 16.2 & $\mathrm{~N} / \mathrm{A}$ & $\mathrm{N} / \mathrm{A}$ & 1.58 \\
\hline 4 & Mesodon & thyroides & 10.3 & 18.2 & $\mathrm{~N} / \mathrm{A}$ & N/A & 1.76 \\
\hline 4 & Mesodon & thyroides & 10.7 & 19.7 & $\mathrm{~N} / \mathrm{A}$ & $\mathrm{N} / \mathrm{A}$ & 1.85 \\
\hline 4 & Mesodon & thyroides & 10 & 16.3 & $\mathrm{~N} / \mathrm{A}$ & N/A & 1.62 \\
\hline 4 & Mesodon & thyroides & 11.1 & 19.9 & $\mathrm{~N} / \mathrm{A}$ & $\mathrm{N} / \mathrm{A}$ & 1.78 \\
\hline 4 & Mesodon & thyroides & 12 & 19.2 & $\mathrm{~N} / \mathrm{A}$ & N/A & 1.59 \\
\hline 4 & Mesodon & thyroides & 10.2 & 17.5 & $\mathrm{~N} / \mathrm{A}$ & $\mathrm{N} / \mathrm{A}$ & 1.71 \\
\hline 4 & Mesodon & thyroides & 10.6 & 18.7 & $\mathrm{~N} / \mathrm{A}$ & $\mathrm{N} / \mathrm{A}$ & 1.76 \\
\hline 4 & Mesodon & thyroides & 10.7 & 19.3 & $\mathrm{~N} / \mathrm{A}$ & $\mathrm{N} / \mathrm{A}$ & 1.79 \\
\hline 4 & Mesodon & thyroides & 17.7 & 10.2 & $\mathrm{~N} / \mathrm{A}$ & $\mathrm{N} / \mathrm{A}$ & 0.58 \\
\hline 4 & Mesodon & thyroides & 10.1 & 16.6 & $\mathrm{~N} / \mathrm{A}$ & $\mathrm{N} / \mathrm{A}$ & 1.64 \\
\hline 4 & Mesodon & thyroides & 10.4 & 17.4 & $\mathrm{~N} / \mathrm{A}$ & $\mathrm{N} / \mathrm{A}$ & 1.67 \\
\hline 4 & Mesodon & thyroides & 9.5 & 16.6 & $\mathrm{~N} / \mathrm{A}$ & $\mathrm{N} / \mathrm{A}$ & 1.75 \\
\hline 4 & Mesodon & thyroides & 9.4 & 16.1 & $\mathrm{~N} / \mathrm{A}$ & $\mathrm{N} / \mathrm{A}$ & 1.71 \\
\hline 4 & Mesodon & thyroides & 10 & 17.2 & $\mathrm{~N} / \mathrm{A}$ & $\mathrm{N} / \mathrm{A}$ & 1.73 \\
\hline 4 & Mesodon & thyroides & 11 & 18 & $\mathrm{~N} / \mathrm{A}$ & $\mathrm{N} / \mathrm{A}$ & 1.64 \\
\hline 4 & Mesodon & thyroides & 9.7 & 18.1 & $\mathrm{~N} / \mathrm{A}$ & $\mathrm{N} / \mathrm{A}$ & 1.87 \\
\hline 4 & Mesodon & thyroides & 9.2 & 16.9 & $\mathrm{~N} / \mathrm{A}$ & N/A & 1.84 \\
\hline 4 & Mesodon & thyroides & 10.5 & 18.4 & $\mathrm{~N} / \mathrm{A}$ & $\mathrm{N} / \mathrm{A}$ & 1.76 \\
\hline 4 & Mesodon & thyroides & 10.9 & 19 & $\mathrm{~N} / \mathrm{A}$ & $\mathrm{N} / \mathrm{A}$ & 1.74 \\
\hline 4 & Mesodon & thyroides & 11.6 & 18.4 & $\mathrm{~N} / \mathrm{A}$ & N/A & 1.59 \\
\hline 4 & Mesodon & thyroides & 10.8 & 19.3 & $\mathrm{~N} / \mathrm{A}$ & $\mathrm{N} / \mathrm{A}$ & 1.79 \\
\hline 4 & Mesodon & thyroides & 11.1 & 17.7 & $\mathrm{~N} / \mathrm{A}$ & $\mathrm{N} / \mathrm{A}$ & 1.59 \\
\hline 4 & Mesodon & thyroides & 11.3 & 18.6 & $\mathrm{~N} / \mathrm{A}$ & $\mathrm{N} / \mathrm{A}$ & 1.64 \\
\hline 4 & Mesodon & thyroides & 11.6 & 18.5 & $\mathrm{~N} / \mathrm{A}$ & $\mathrm{N} / \mathrm{A}$ & 1.59 \\
\hline 4 & Mesodon & thyroides & 10.2 & 17 & $\mathrm{~N} / \mathrm{A}$ & $\mathrm{N} / \mathrm{A}$ & 1.67 \\
\hline 4 & Mesodon & thyroides & 10.7 & 18.3 & $\mathrm{~N} / \mathrm{A}$ & $\mathrm{N} / \mathrm{A}$ & 1.7 \\
\hline 4 & Mesodon & thyroides & 9.3 & 16.6 & $\mathrm{~N} / \mathrm{A}$ & $\mathrm{N} / \mathrm{A}$ & 1.78 \\
\hline 4 & Mesodon & thyroides & 10.4 & 18.9 & $\mathrm{~N} / \mathrm{A}$ & $\mathrm{N} / \mathrm{A}$ & 1.82 \\
\hline 4 & Mesodon & thyroides & 9.9 & 16.5 & $\mathrm{~N} / \mathrm{A}$ & $\mathrm{N} / \mathrm{A}$ & 1.67 \\
\hline 4 & Mesodon & thyroides & 10.7 & 17.5 & $\mathrm{~N} / \mathrm{A}$ & $\mathrm{N} / \mathrm{A}$ & 1.64 \\
\hline 4 & Mesodon & thyroides & 10.7 & 19.3 & $\mathrm{~N} / \mathrm{A}$ & $\mathrm{N} / \mathrm{A}$ & 1.8 \\
\hline 4 & Mesodon & thyroides & 10.9 & 19 & $\mathrm{~N} / \mathrm{A}$ & $\mathrm{N} / \mathrm{A}$ & 1.74 \\
\hline 4 & Mesodon & thyroides & 9.5 & 16 & $\mathrm{~N} / \mathrm{A}$ & $\mathrm{N} / \mathrm{A}$ & 1.7 \\
\hline 4 & Mesodon & thyroides & 10.9 & 19 & $\mathrm{~N} / \mathrm{A}$ & $\mathrm{N} / \mathrm{A}$ & 1.74 \\
\hline 4 & Mesodon & thyroides & 10.4 & 19.3 & $\mathrm{~N} / \mathrm{A}$ & $\mathrm{N} / \mathrm{A}$ & 1.85 \\
\hline 4 & Mesodon & thyroides & 10.1 & 17.8 & $\mathrm{~N} / \mathrm{A}$ & $\mathrm{N} / \mathrm{A}$ & 1.77 \\
\hline 4 & Mesodon & thyroides & 10.7 & 16.9 & $\mathrm{~N} / \mathrm{A}$ & $\mathrm{N} / \mathrm{A}$ & 1.59 \\
\hline 4 & Mesodon & thyroides & 9.4 & 15.9 & $\mathrm{~N} / \mathrm{A}$ & $\mathrm{N} / \mathrm{A}$ & 1.7 \\
\hline
\end{tabular}


Table H-5. Continued...

\begin{tabular}{|c|c|c|c|c|c|c|c|}
\hline Area & Genus & Species & length (mm) & width $(\mathrm{mm})$ & Carina & Calus & Weight (g.) \\
\hline 4 & Mesodon & thyroides & 9 & 16.9 & $N / A$ & $\mathrm{~N} / \mathrm{A}$ & 1.88 \\
\hline 4 & Mesodon & thyroides & 10 & 18 & $N / A$ & $N / A$ & 1.81 \\
\hline 4 & Mesodon & thyroides & 11.3 & 19 & $\mathrm{~N} / \mathrm{A}$ & $N / A$ & 1.68 \\
\hline 4 & Mesodon & thyroides & 10.7 & 19.4 & $N / A$ & $N / A$ & 1.82 \\
\hline 4 & Mesodon & thyroides & 10.5 & 18.3 & $N / A$ & $N / A$ & 1.76 \\
\hline 4 & Mesodon & thyroides & 10 & 17.2 & $\mathrm{~N} / \mathrm{A}$ & $\mathrm{N} / \mathrm{A}$ & 1.71 \\
\hline 4 & Mesodon & thyroides & 10.7 & 17.4 & $N / A$ & $N / A$ & 1.63 \\
\hline 4 & Mesodon & thyroides & 11.1 & 18.3 & $N / A$ & N/A & 1.64 \\
\hline 4 & Mesodon & thyroides & 10.4 & 18.7 & $N / A$ & N/A & 1.79 \\
\hline 4 & Mesodon & thyroides & 11.6 & 19.4 & $\mathrm{~N} / \mathrm{A}$ & $N / A$ & 1.67 \\
\hline 4 & Mesodon & thyroides & 9.7 & 16.7 & $\mathrm{~N} / \mathrm{A}$ & $N / A$ & 1.71 \\
\hline 4 & Mesodon & thyroides & 10.3 & 18.5 & $N / A$ & $N / A$ & 1.79 \\
\hline 4 & Mesodon & thyroides & 10.7 & 18.5 & $\mathrm{~N} / \mathrm{A}$ & $\mathrm{N} / \mathrm{A}$ & 1.73 \\
\hline 4 & Mesodon & thyroides & 10.1 & 18.6 & $\mathrm{~N} / \mathrm{A}$ & $\mathrm{N} / \mathrm{A}$ & 1.84 \\
\hline 4 & Mesodon & thyroides & 10.5 & 18 & $\mathrm{~N} / \mathrm{A}$ & $\mathrm{N} / \mathrm{A}$ & 1.71 \\
\hline 4 & Mesodon & thyroides & 11.1 & 19.4 & $N / A$ & $N / A$ & 1.74 \\
\hline 4 & Mesodon & thyroides & 11.1 & 18.2 & $N / A$ & $N / A$ & 1.63 \\
\hline 4 & Mesodon & thyroides & 11 & 18.2 & $\mathrm{~N} / \mathrm{A}$ & $\mathrm{N} / \mathrm{A}$ & 1.66 \\
\hline 4 & Mesodon & thyroides & 10.7 & 17.8 & $N / A$ & $\mathrm{~N} / \mathrm{A}$ & 1.66 \\
\hline 4 & Mesodon & thyroides & 10 & 17.3 & $N / A$ & $N / A$ & 1.74 \\
\hline 4 & Mesodon & thyroides & 10.3 & 16.5 & $N / A$ & $N / A$ & 1.6 \\
\hline 4 & Mesodon & thyroides & 10.4 & 19 & $\mathrm{~N} / \mathrm{A}$ & $\mathrm{N} / \mathrm{A}$ & 1.83 \\
\hline 4 & Mesodon & thyroides & 9.3 & 17.4 & $N / A$ & $N / A$ & 1.87 \\
\hline 4 & Mesodon & thyroides & 11.4 & 18.5 & $N / A$ & $\mathrm{~N} / \mathrm{A}$ & 1.62 \\
\hline 4 & Mesodon & thyroides & 10.7 & 18.6 & $\mathrm{~N} / \mathrm{A}$ & $N / A$ & 1.73 \\
\hline 4 & Mesodon & thyroides & 11.4 & 17.5 & $\mathrm{~N} / \mathrm{A}$ & $\mathrm{N} / \mathrm{A}$ & 1.54 \\
\hline 4 & Mesodon & thyroides & 11 & 18 & $N / A$ & $\mathrm{~N} / \mathrm{A}$ & 1.64 \\
\hline 4 & Mesodon & thyroides & 10.2 & 17.3 & $N / A$ & $\mathrm{~N} / \mathrm{A}$ & 1.7 \\
\hline 4 & Mesodon & thyroides & 11.8 & 18.2 & $\mathrm{~N} / \mathrm{A}$ & $\mathrm{N} / \mathrm{A}$ & 1.54 \\
\hline 4 & Mesodon & thyroides & 11 & 19.1 & $\mathrm{~N} / \mathrm{A}$ & $\mathrm{N} / \mathrm{A}$ & 1.74 \\
\hline 4 & Mesodon & thyroides & 12.3 & 19.5 & $N / A$ & $N / A$ & 1.59 \\
\hline 4 & Oligyra & sp. & 5.2 & 6.7 & $N / A$ & $N / A$ & 1.28 \\
\hline 4 & Oligyra & sp. & 4.9 & 6.2 & $\mathrm{~N} / \mathrm{A}$ & $\mathrm{N} / \mathrm{A}$ & 1.28 \\
\hline 4 & Oligyra & sp. & 5.4 & 7.3 & $\mathrm{~N} / \mathrm{A}$ & $\mathrm{N} / \mathrm{A}$ & 1.36 \\
\hline 4 & Oligyra & sp. & 5 & 7.5 & $N / A$ & $N / A$ & 1.51 \\
\hline 4 & Oligyra & sp. & 5.1 & 7.2 & $\mathrm{~N} / \mathrm{A}$ & $\mathrm{N} / \mathrm{A}$ & 1.41 \\
\hline 4 & Oligyra & sp. & 4.9 & 7.1 & $\mathrm{~N} / \mathrm{A}$ & $\mathrm{N} / \mathrm{A}$ & 1.45 \\
\hline 4 & Oligyra & sp. & 5.3 & 7.2 & $\mathrm{~N} / \mathrm{A}$ & $\mathrm{N} / \mathrm{A}$ & 1.37 \\
\hline 4 & Oligyra & sp. & 5 & 7 & $N / A$ & $N / A$ & 1.38 \\
\hline 4 & Oligyra & sp. & 5 & 7 & $N / A$ & $N / A$ & 1.39 \\
\hline 4 & Oligyra & sp. & 5.3 & 7.1 & $\mathrm{~N} / \mathrm{A}$ & $\mathrm{N} / \mathrm{A}$ & 1.32 \\
\hline 4 & Oligyra & sp. & 4.9 & 6.6 & $\mathrm{~N} / \mathrm{A}$ & $\mathrm{N} / \mathrm{A}$ & 1.33 \\
\hline 4 & Oligyra & sp. & 5.3 & 7.2 & $\mathrm{~N} / \mathrm{A}$ & $\mathrm{N} / \mathrm{A}$ & 1.35 \\
\hline 4 & Oligyra & sp. & 5.1 & 7.5 & $\mathrm{~N} / \mathrm{A}$ & $\mathrm{N} / \mathrm{A}$ & 1.47 \\
\hline 4 & Oligyra & sp. & 5.2 & 7.6 & $\mathrm{~N} / \mathrm{A}$ & $\mathrm{N} / \mathrm{A}$ & 1.45 \\
\hline 4 & Oligyra & sp. & 4.7 & 7.1 & $N / A$ & $\mathrm{~N} / \mathrm{A}$ & 1.52 \\
\hline 4 & Oligyra & sp. & 5 & 7.2 & $\mathrm{~N} / \mathrm{A}$ & $\mathrm{N} / \mathrm{A}$ & 1.45 \\
\hline 4 & Oligyra & sp. & 5.2 & 7.7 & $\mathrm{~N} / \mathrm{A}$ & $\mathrm{N} / \mathrm{A}$ & 1.49 \\
\hline 4 & Oligyra & sp. & 5.5 & 7.6 & $\mathrm{~N} / \mathrm{A}$ & $\mathrm{N} / \mathrm{A}$ & 1.37 \\
\hline 4 & Oligyra & sp. & 5.4 & 7.7 & $\mathrm{~N} / \mathrm{A}$ & $\mathrm{N} / \mathrm{A}$ & 1.41 \\
\hline 4 & Oligyra & sp. & 5 & 7.3 & $\mathrm{~N} / \mathrm{A}$ & $\mathrm{N} / \mathrm{A}$ & 1.47 \\
\hline 4 & Oligyra & sp. & 4.9 & 7.2 & $\mathrm{~N} / \mathrm{A}$ & $\mathrm{N} / \mathrm{A}$ & 1.46 \\
\hline 4 & Oligyra & $\mathrm{sp}$. & 5.6 & 7.1 & $\mathrm{~N} / \mathrm{A}$ & $\mathrm{N} / \mathrm{A}$ & 1.26 \\
\hline 4 & Oligyra & sp. & 5.7 & 7.4 & $N / A$ & $\mathrm{~N} / \mathrm{A}$ & 1.3 \\
\hline 4 & Oligyra & $\mathrm{sp}$. & 5.6 & 7.5 & $\mathrm{~N} / \mathrm{A}$ & $\mathrm{N} / \mathrm{A}$ & 1.34 \\
\hline
\end{tabular}


Table H-5. Continued...

\begin{tabular}{|c|c|c|c|c|c|c|c|}
\hline Area & Genus & Species & length (mm) & width (mm) & Carina & Calus & Weight (g.) \\
\hline 4 & Oligyra & $\mathrm{sp}$. & 5.3 & 6.9 & $\mathrm{~N} / \mathrm{A}$ & $\mathrm{N} / \mathrm{A}$ & 1.32 \\
\hline 4 & Oligyra & sp. & 5.7 & 7.9 & $\mathrm{~N} / \mathrm{A}$ & $\mathrm{N} / \mathrm{A}$ & 1.39 \\
\hline 4 & Oligyra & sp. & 5.4 & 7.6 & $\mathrm{~N} / \mathrm{A}$ & $\mathrm{N} / \mathrm{A}$ & 1.41 \\
\hline 4 & Oligyra & sp. & 5.3 & 7.4 & $\mathrm{~N} / \mathrm{A}$ & $\mathrm{N} / \mathrm{A}$ & 1.4 \\
\hline 4 & Oligyra & $\mathrm{sp}$. & 5.3 & 7.5 & $\mathrm{~N} / \mathrm{A}$ & $\mathrm{N} / \mathrm{A}$ & 1.4 \\
\hline 4 & Oligyra & $\mathrm{sp}$. & 5.5 & 7.3 & $\mathrm{~N} / \mathrm{A}$ & $\mathrm{N} / \mathrm{A}$ & 1.32 \\
\hline 4 & Oligyra & sp. & 5.5 & 8 & $\mathrm{~N} / \mathrm{A}$ & $\mathrm{N} / \mathrm{A}$ & 1.45 \\
\hline 4 & Oligyra & $\mathrm{sp}$. & 5.1 & 7.3 & $\mathrm{~N} / \mathrm{A}$ & $\mathrm{N} / \mathrm{A}$ & 1.43 \\
\hline 4 & Oligyra & $\mathrm{sp}$. & 5.9 & 7.4 & $\mathrm{~N} / \mathrm{A}$ & $\mathrm{N} / \mathrm{A}$ & 1.25 \\
\hline 4 & Oligyra & sp. & 5.5 & 6.8 & $\mathrm{~N} / \mathrm{A}$ & $\mathrm{N} / \mathrm{A}$ & 1.25 \\
\hline 4 & Oligyra & sp. & 5.4 & 7.8 & $\mathrm{~N} / \mathrm{A}$ & N/A & 1.44 \\
\hline 4 & Oligyra & $\mathrm{sp}$. & 5.3 & 7.9 & $\mathrm{~N} / \mathrm{A}$ & $\mathrm{N} / \mathrm{A}$ & 1.49 \\
\hline 4 & Oligyra & sp. & 5.6 & 7.6 & $\mathrm{~N} / \mathrm{A}$ & $\mathrm{N} / \mathrm{A}$ & 1.36 \\
\hline 4 & Oligyra & sp. & 4.9 & 7.1 & $\mathrm{~N} / \mathrm{A}$ & $\mathrm{N} / \mathrm{A}$ & 1.45 \\
\hline 4 & Oligyra & sp. & 5.3 & 7.4 & $\mathrm{~N} / \mathrm{A}$ & $\mathrm{N} / \mathrm{A}$ & 1.4 \\
\hline 4 & Oligyra & $\mathrm{sp}$. & 4.4 & 6.9 & $\mathrm{~N} / \mathrm{A}$ & $\mathrm{N} / \mathrm{A}$ & 1.59 \\
\hline 4 & Oligyra & $\mathrm{sp}$. & 5.4 & 7.6 & $\mathrm{~N} / \mathrm{A}$ & $\mathrm{N} / \mathrm{A}$ & 1.41 \\
\hline 4 & Oligyra & sp. & 5.8 & 7.1 & $\mathrm{~N} / \mathrm{A}$ & $\mathrm{N} / \mathrm{A}$ & 1.24 \\
\hline 4 & Oligyra & $\mathrm{sp}$. & 5.5 & 7 & $\mathrm{~N} / \mathrm{A}$ & $\mathrm{N} / \mathrm{A}$ & 1.27 \\
\hline 4 & Oligyra & $\mathrm{sp}$. & 5.2 & 7.3 & $\mathrm{~N} / \mathrm{A}$ & $\mathrm{N} / \mathrm{A}$ & 1.41 \\
\hline 4 & Oligyra & sp. & 5.8 & 7.2 & $\mathrm{~N} / \mathrm{A}$ & $\mathrm{N} / \mathrm{A}$ & 1.23 \\
\hline 4 & Oligyra & sp. & 5.8 & 8 & $\mathrm{~N} / \mathrm{A}$ & $\mathrm{N} / \mathrm{A}$ & 1.4 \\
\hline 4 & Oligyra & $\mathrm{sp}$. & 5.1 & 7.6 & N/A & $\mathrm{N} / \mathrm{A}$ & 1.49 \\
\hline 4 & Oligyra & sp. & 5 & 7.5 & $\mathrm{~N} / \mathrm{A}$ & $\mathrm{N} / \mathrm{A}$ & 1.5 \\
\hline 4 & Oligyra & sp. & 5.5 & 7.8 & $\mathrm{~N} / \mathrm{A}$ & N/A & 1.42 \\
\hline 4 & Oligyra & sp. & 5.1 & 7.7 & $\mathrm{~N} / \mathrm{A}$ & $\mathrm{N} / \mathrm{A}$ & 1.51 \\
\hline 4 & Oligyra & $\mathrm{sp}$. & 5.2 & 7.5 & $\mathrm{~N} / \mathrm{A}$ & $\mathrm{N} / \mathrm{A}$ & 1.44 \\
\hline 4 & Oligyra & $\mathrm{sp}$. & 5.7 & 6.9 & $\mathrm{~N} / \mathrm{A}$ & $\mathrm{N} / \mathrm{A}$ & 1.22 \\
\hline 4 & Oligyra & sp. & 5.6 & 7.8 & $\mathrm{~N} / \mathrm{A}$ & $\mathrm{N} / \mathrm{A}$ & 1.41 \\
\hline 4 & Oligyra & sp. & 5.1 & 7.4 & $\mathrm{~N} / \mathrm{A}$ & $\mathrm{N} / \mathrm{A}$ & 1.43 \\
\hline 4 & Oligyra & $\mathrm{sp}$. & 5.2 & 7.5 & $\mathrm{~N} / \mathrm{A}$ & $\mathrm{N} / \mathrm{A}$ & 1.45 \\
\hline 4 & Oligyra & sp. & 5.3 & 7.6 & $\mathrm{~N} / \mathrm{A}$ & $\mathrm{N} / \mathrm{A}$ & 1.43 \\
\hline 4 & Oligyra & sp. & 6.2 & 7 & $\mathrm{~N} / \mathrm{A}$ & $\mathrm{N} / \mathrm{A}$ & 1.12 \\
\hline 4 & Oligyra & $\mathrm{sp}$. & 5.2 & 7.5 & $\mathrm{~N} / \mathrm{A}$ & $\mathrm{N} / \mathrm{A}$ & 1.44 \\
\hline 4 & Oligyra & $\mathrm{sp}$. & 5.3 & 7.7 & $\mathrm{~N} / \mathrm{A}$ & $\mathrm{N} / \mathrm{A}$ & 1.44 \\
\hline 4 & Oligyra & sp. & 5.4 & 7.5 & $\mathrm{~N} / \mathrm{A}$ & $\mathrm{N} / \mathrm{A}$ & 1.4 \\
\hline 4 & Oligyra & $\mathrm{sp}$. & 4.8 & 6.9 & $\mathrm{~N} / \mathrm{A}$ & $\mathrm{N} / \mathrm{A}$ & 1.45 \\
\hline 4 & Oligyra & $\mathrm{sp}$. & 5.1 & 7.5 & $\mathrm{~N} / \mathrm{A}$ & $\mathrm{N} / \mathrm{A}$ & 1.46 \\
\hline 4 & Oligyra & $\mathrm{sp}$. & 6.3 & 7.6 & $\mathrm{~N} / \mathrm{A}$ & $\mathrm{N} / \mathrm{A}$ & 1.21 \\
\hline 4 & Oligyra & sp. & 4.9 & 7.1 & $\mathrm{~N} / \mathrm{A}$ & $\mathrm{N} / \mathrm{A}$ & 1.45 \\
\hline 4 & Oligyra & sp. & 5.4 & 7.8 & $\mathrm{~N} / \mathrm{A}$ & $\mathrm{N} / \mathrm{A}$ & 1.43 \\
\hline 4 & Oligyra & sp. & 5.3 & 7.2 & $\mathrm{~N} / \mathrm{A}$ & $\mathrm{N} / \mathrm{A}$ & 1.35 \\
\hline 4 & Oligyra & $\mathrm{sp}$. & 4.9 & 6.9 & $\mathrm{~N} / \mathrm{A}$ & $\mathrm{N} / \mathrm{A}$ & 1.4 \\
\hline 4 & Oligyra & $\mathrm{sp}$. & 5 & 7.3 & $\mathrm{~N} / \mathrm{A}$ & $\mathrm{N} / \mathrm{A}$ & 1.46 \\
\hline 4 & Oligyra & sp. & 5.6 & 7.5 & N/A & $\mathrm{N} / \mathrm{A}$ & 1.35 \\
\hline 4 & Oligyra & sp. & 5.2 & 7.8 & $\mathrm{~N} / \mathrm{A}$ & $\mathrm{N} / \mathrm{A}$ & 1.49 \\
\hline 4 & Oligyra & $\mathrm{sp}$. & 5.4 & 7.3 & $\mathrm{~N} / \mathrm{A}$ & $\mathrm{N} / \mathrm{A}$ & 1.36 \\
\hline 4 & Oligyra & $\mathrm{sp}$. & 4.7 & 6.8 & $\mathrm{~N} / \mathrm{A}$ & $\mathrm{N} / \mathrm{A}$ & 1.43 \\
\hline 4 & Oligyra & sp. & 5.6 & 7.6 & $\mathrm{~N} / \mathrm{A}$ & $\mathrm{N} / \mathrm{A}$ & 1.35 \\
\hline 4 & Oligyra & $\mathrm{sp}$. & 4.5 & 6.4 & $\mathrm{~N} / \mathrm{A}$ & $\mathrm{N} / \mathrm{A}$ & 1.41 \\
\hline 4 & Oligyra & sp. & 5.1 & 7.4 & $\mathrm{~N} / \mathrm{A}$ & $\mathrm{N} / \mathrm{A}$ & 1.44 \\
\hline 4 & Oligyra & sp. & 4.6 & 7 & $\mathrm{~N} / \mathrm{A}$ & $\mathrm{N} / \mathrm{A}$ & 1.51 \\
\hline 4 & Oligyra & sp. & 5.3 & 7.4 & $\mathrm{~N} / \mathrm{A}$ & $\mathrm{N} / \mathrm{A}$ & 1.39 \\
\hline 4 & Oligyra & $\mathrm{sp}$. & 5 & 7.1 & $\mathrm{~N} / \mathrm{A}$ & $\mathrm{N} / \mathrm{A}$ & 1.43 \\
\hline 4 & Oligyra & $\mathrm{sp}$. & 5.2 & 7.4 & $\mathrm{~N} / \mathrm{A}$ & $\mathrm{N} / \mathrm{A}$ & 1.42 \\
\hline
\end{tabular}


Table H-5. Continued...

\begin{tabular}{|c|c|c|c|c|c|c|c|}
\hline Area & Genus & Species & length (mm) & width (mm) & Carina & Calus & Weight (g.) \\
\hline 4 & Oligyra & sp. & 5.3 & 6.9 & $\mathrm{~N} / \mathrm{A}$ & $\mathrm{N} / \mathrm{A}$ & 1.31 \\
\hline 4 & Oligyra & sp. & 5.5 & 7.5 & N/A & $N / A$ & 1.36 \\
\hline 4 & Oligyra & sp. & 4.6 & 7.2 & $\mathrm{~N} / \mathrm{A}$ & N/A & 1.58 \\
\hline 4 & Oligyra & sp. & 5.4 & 7.6 & $\mathrm{~N} / \mathrm{A}$ & N/A & 1.4 \\
\hline 4 & Oligyra & sp. & 5.3 & 7.1 & N/A & $\mathrm{N} / \mathrm{A}$ & 1.35 \\
\hline 4 & Oligyra & sp. & 5.3 & 7.5 & N/A & $\mathrm{N} / \mathrm{A}$ & 1.42 \\
\hline 4 & Oligyra & sp. & 5.1 & 7.1 & $\mathrm{~N} / \mathrm{A}$ & $N / A$ & 1.38 \\
\hline 4 & Oligyra & sp. & 5 & 7.6 & N/A & $\mathrm{N} / \mathrm{A}$ & 1.51 \\
\hline 4 & Oligyra & sp. & 5.1 & 7.5 & $\mathrm{~N} / \mathrm{A}$ & $N / A$ & 1.47 \\
\hline 4 & Oligyra & sp. & 4.8 & 7.5 & N/A & N/A & 1.57 \\
\hline 4 & Oligyra & sp. & 4.8 & 6.6 & $\mathrm{~N} / \mathrm{A}$ & $\mathrm{N} / \mathrm{A}$ & 1.38 \\
\hline 4 & Oligyra & sp. & 5.2 & 7.6 & $\mathrm{~N} / \mathrm{A}$ & $\mathrm{N} / \mathrm{A}$ & 1.46 \\
\hline 4 & Oligyra & sp. & 5.4 & 7.7 & N/A & $\mathrm{N} / \mathrm{A}$ & 1.43 \\
\hline 4 & Oligyra & sp. & 4.8 & 7 & N/A & $\mathrm{N} / \mathrm{A}$ & 1.47 \\
\hline 4 & Oligyra & sp. & 5.8 & 7.8 & $N / A$ & $N / A$ & 1.34 \\
\hline 4 & Oligyra & sp. & 5.5 & 7.3 & N/A & $\mathrm{N} / \mathrm{A}$ & 1.33 \\
\hline 4 & Oligyra & sp. & 5.2 & 7.7 & N/A & $N / A$ & 1.48 \\
\hline 4 & Oligyra & sp. & 4.6 & 7.4 & N/A & $N / A$ & 1.6 \\
\hline 4 & Oligyra & sp. & 5.6 & 7.6 & N/A & $\mathrm{N} / \mathrm{A}$ & 1.36 \\
\hline 4 & Oligyra & sp. & 5.2 & 7.6 & $\mathrm{~N} / \mathrm{A}$ & N/A & 1.44 \\
\hline 4 & Oligyra & sp. & 5.2 & 7.2 & $\mathrm{~N} / \mathrm{A}$ & $\mathrm{N} / \mathrm{A}$ & 1.4 \\
\hline 4 & Oligyra & $\mathrm{sp}$. & 5 & 7.4 & $\mathrm{~N} / \mathrm{A}$ & $\mathrm{N} / \mathrm{A}$ & 1.48 \\
\hline 4 & Oligyra & sp. & 5.6 & 7.5 & $N / A$ & $\mathrm{~N} / \mathrm{A}$ & 1.35 \\
\hline 4 & Oligyra & sp. & 5 & 6.7 & N/A & $N / A$ & 1.35 \\
\hline 4 & Oligyra & sp. & 5.7 & 7.2 & $\mathrm{~N} / \mathrm{A}$ & $\mathrm{N} / \mathrm{A}$ & 1.27 \\
\hline 4 & Oligyra & sp. & 4.9 & 6.9 & $\mathrm{~N} / \mathrm{A}$ & $\mathrm{N} / \mathrm{A}$ & 1.4 \\
\hline 4 & Oligyra & sp. & 5.1 & 7.3 & $\mathrm{~N} / \mathrm{A}$ & $\mathrm{N} / \mathrm{A}$ & 1.43 \\
\hline 4 & Oligyra & sp. & 4.6 & 6.4 & $\mathrm{~N} / \mathrm{A}$ & $\mathrm{N} / \mathrm{A}$ & 1.38 \\
\hline 4 & Oligyra & sp. & 5.5 & 7.3 & $\mathrm{~N} / \mathrm{A}$ & $\mathrm{N} / \mathrm{A}$ & 1.34 \\
\hline 4 & Oligyra & sp. & 5.4 & 7.6 & $\mathrm{~N} / \mathrm{A}$ & $N / A$ & 1.4 \\
\hline 4 & Oligyra & sp. & 5.5 & 7.1 & $\mathrm{~N} / \mathrm{A}$ & $N / A$ & 1.3 \\
\hline 4 & Oligyra & sp. & 5.4 & 7.6 & $\mathrm{~N} / \mathrm{A}$ & $\mathrm{N} / \mathrm{A}$ & 1.42 \\
\hline 4 & Oligyra & sp. & 5.3 & 7.2 & $\mathrm{~N} / \mathrm{A}$ & $\mathrm{N} / \mathrm{A}$ & 1.35 \\
\hline 4 & Oligyra & sp. & 5.3 & 7.3 & $\mathrm{~N} / \mathrm{A}$ & $\mathrm{N} / \mathrm{A}$ & 1.38 \\
\hline 4 & Oligyra & $\mathrm{sp}$. & 5.1 & 7.2 & $\mathrm{~N} / \mathrm{A}$ & $\mathrm{N} / \mathrm{A}$ & 1.41 \\
\hline 4 & Oligyra & sp. & 5 & 6.7 & $\mathrm{~N} / \mathrm{A}$ & $\mathrm{N} / \mathrm{A}$ & 1.35 \\
\hline 4 & Oligyra & sp. & 5.1 & 7.6 & $\mathrm{~N} / \mathrm{A}$ & N/A & 1.49 \\
\hline 4 & Oligyra & sp. & 4.9 & 7.5 & $\mathrm{~N} / \mathrm{A}$ & $\mathrm{N} / \mathrm{A}$ & 1.54 \\
\hline 4 & Oligyra & sp. & 5.5 & 7 & N/A & $\mathrm{N} / \mathrm{A}$ & 1.27 \\
\hline 4 & Oligyra & sp. & 5.4 & 7.5 & N/A & $\mathrm{N} / \mathrm{A}$ & 1.39 \\
\hline 4 & Oligyra & sp. & 5 & 7.6 & $\mathrm{~N} / \mathrm{A}$ & $\mathrm{N} / \mathrm{A}$ & 1.52 \\
\hline 4 & Oligyra & sp. & 5 & 7 & $\mathrm{~N} / \mathrm{A}$ & $\mathrm{N} / \mathrm{A}$ & 1.38 \\
\hline 4 & Oligyra & sp. & 5.2 & 7.6 & $\mathrm{~N} / \mathrm{A}$ & $\mathrm{N} / \mathrm{A}$ & 1.45 \\
\hline 4 & Oligyra & sp. & 5.7 & 6.9 & $\mathrm{~N} / \mathrm{A}$ & $\mathrm{N} / \mathrm{A}$ & 1.22 \\
\hline 4 & Oligyra & sp. & 5.3 & 7.1 & $\mathrm{~N} / \mathrm{A}$ & $\mathrm{N} / \mathrm{A}$ & 1.35 \\
\hline 4 & Oligyra & sp. & 5.4 & 8.1 & $\mathrm{~N} / \mathrm{A}$ & $\mathrm{N} / \mathrm{A}$ & 1.49 \\
\hline 4 & Oligyra & sp. & 4.8 & 7.2 & $\mathrm{~N} / \mathrm{A}$ & $N / A$ & 1.51 \\
\hline 4 & Oligyra & sp. & 5.2 & 7.4 & N/A & $\mathrm{N} / \mathrm{A}$ & 1.44 \\
\hline 4 & Oligyra & sp. & 5.2 & 7.5 & N/A & $\mathrm{N} / \mathrm{A}$ & 1.44 \\
\hline 4 & Oligyra & $\mathrm{sp}$. & 5.3 & 7.4 & $\mathrm{~N} / \mathrm{A}$ & $\mathrm{N} / \mathrm{A}$ & 1.4 \\
\hline 4 & Oligyra & sp. & 4.9 & 6.8 & $\mathrm{~N} / \mathrm{A}$ & $\mathrm{N} / \mathrm{A}$ & 1.4 \\
\hline 4 & Oligyra & sp. & 4.8 & 7.1 & $\mathrm{~N} / \mathrm{A}$ & $\mathrm{N} / \mathrm{A}$ & 1.48 \\
\hline 4 & Oligyra & sp. & 5.1 & 7.3 & $\mathrm{~N} / \mathrm{A}$ & N/A & 1.43 \\
\hline 4 & Oligyra & $\mathrm{sp}$. & 5 & 7.5 & $\mathrm{~N} / \mathrm{A}$ & $\mathrm{N} / \mathrm{A}$ & 1.51 \\
\hline 4 & Oligyra & sp. & 3.7 & 5.4 & N/A & $\mathrm{N} / \mathrm{A}$ & 1.43 \\
\hline
\end{tabular}


Table H-5. Continued...

\begin{tabular}{|c|c|c|c|c|c|c|c|}
\hline Area & Genus & Species & length (mm) & width (mm) & Carina & Calus & Weight (g.) \\
\hline 4 & Oligyra & sp. & 2.9 & 5 & $\mathrm{~N} / \mathrm{A}$ & $\mathrm{N} / \mathrm{A}$ & 1.69 \\
\hline 4 & Oligyra & sp. & 5.3 & 7.5 & $\mathrm{~N} / \mathrm{A}$ & $N / A$ & 1.42 \\
\hline 4 & Oligyra & $\mathrm{sp}$. & 4.1 & 7.2 & $\mathrm{~N} / \mathrm{A}$ & $\mathrm{N} / \mathrm{A}$ & 1.77 \\
\hline 4 & Oligyra & sp. & 4.9 & 6.9 & $\mathrm{~N} / \mathrm{A}$ & $N / A$ & 1.4 \\
\hline 4 & Oligyra & sp. & 6.1 & 7.8 & N/A & N/A & 1.27 \\
\hline 4 & Oligyra & $\mathrm{sp}$. & 4.2 & 6.6 & $\mathrm{~N} / \mathrm{A}$ & $\mathrm{N} / \mathrm{A}$ & 1.57 \\
\hline 4 & Oligyra & $\mathrm{sp}$. & 4.9 & 7.4 & $\mathrm{~N} / \mathrm{A}$ & $\mathrm{N} / \mathrm{A}$ & 1.49 \\
\hline 4 & Oligyra & sp. & 5.3 & 7 & $\mathrm{~N} / \mathrm{A}$ & $\mathrm{N} / \mathrm{A}$ & 1.34 \\
\hline 4 & Oligyra & $\mathrm{sp}$. & 5.2 & 7.3 & $\mathrm{~N} / \mathrm{A}$ & $\mathrm{N} / \mathrm{A}$ & 1.4 \\
\hline 4 & Oligyra & sp. & 6 & 7.3 & $\mathrm{~N} / \mathrm{A}$ & $\mathrm{N} / \mathrm{A}$ & 1.22 \\
\hline 4 & Oligyra & $\mathrm{sp}$. & 5.2 & 7.4 & $\mathrm{~N} / \mathrm{A}$ & $\mathrm{N} / \mathrm{A}$ & 1.43 \\
\hline 4 & Oligyra & sp. & 5.5 & 7.7 & $\mathrm{~N} / \mathrm{A}$ & $\mathrm{N} / \mathrm{A}$ & 1.39 \\
\hline 4 & Oligyra & $\mathrm{sp}$. & 5.9 & 7.3 & $\mathrm{~N} / \mathrm{A}$ & $\mathrm{N} / \mathrm{A}$ & 1.25 \\
\hline 4 & Oligyra & sp. & 4.9 & 7.7 & $\mathrm{~N} / \mathrm{A}$ & $\mathrm{N} / \mathrm{A}$ & 1.57 \\
\hline 4 & Oligyra & $\mathrm{sp}$. & 5.4 & 7 & $\mathrm{~N} / \mathrm{A}$ & $\mathrm{N} / \mathrm{A}$ & 1.3 \\
\hline 4 & Oligyra & $\mathrm{sp}$. & 4.3 & 6.8 & $\mathrm{~N} / \mathrm{A}$ & $\mathrm{N} / \mathrm{A}$ & 1.58 \\
\hline 4 & Oligyra & $\mathrm{sp}$. & 5.4 & 7 & $\mathrm{~N} / \mathrm{A}$ & $\mathrm{N} / \mathrm{A}$ & 1.3 \\
\hline 4 & Oligyra & $\mathrm{sp}$. & 4.8 & 7.5 & $\mathrm{~N} / \mathrm{A}$ & N/A & 1.56 \\
\hline 4 & Oligyra & sp. & 5.3 & 7.7 & $\mathrm{~N} / \mathrm{A}$ & $\mathrm{N} / \mathrm{A}$ & 1.45 \\
\hline 4 & Oligyra & $\mathrm{sp}$. & 5.6 & 7.5 & $\mathrm{~N} / \mathrm{A}$ & N/A & 1.34 \\
\hline 4 & Oligyra & $\mathrm{sp}$. & 4.7 & 7.1 & $\mathrm{~N} / \mathrm{A}$ & $\mathrm{N} / \mathrm{A}$ & 1.51 \\
\hline 4 & Oligyra & sp. & 5.2 & 7.5 & $\mathrm{~N} / \mathrm{A}$ & $\mathrm{N} / \mathrm{A}$ & 1.44 \\
\hline 4 & Oligyra & sp. & 5.3 & 7.8 & $\mathrm{~N} / \mathrm{A}$ & $\mathrm{N} / \mathrm{A}$ & 1.46 \\
\hline 4 & Oligyra & $\mathrm{sp}$. & 4.7 & 7.2 & $\mathrm{~N} / \mathrm{A}$ & N/A & 1.54 \\
\hline 4 & Oligyra & sp. & 5.1 & 7.2 & $\mathrm{~N} / \mathrm{A}$ & $\mathrm{N} / \mathrm{A}$ & 1.39 \\
\hline 4 & Oligyra & $\mathrm{sp}$. & 5.3 & 7.5 & $\mathrm{~N} / \mathrm{A}$ & $\mathrm{N} / \mathrm{A}$ & 1.42 \\
\hline 4 & Oligyra & sp. & 5.6 & 7.7 & $\mathrm{~N} / \mathrm{A}$ & $\mathrm{N} / \mathrm{A}$ & 1.37 \\
\hline 4 & Oligyra & $\mathrm{sp}$. & 5.3 & 7.6 & $\mathrm{~N} / \mathrm{A}$ & $\mathrm{N} / \mathrm{A}$ & 1.43 \\
\hline 4 & Oligyra & sp. & 4.8 & 6.7 & $\mathrm{~N} / \mathrm{A}$ & $\mathrm{N} / \mathrm{A}$ & 1.4 \\
\hline 4 & Oligyra & $\mathrm{sp}$. & 5.3 & 7.9 & $\mathrm{~N} / \mathrm{A}$ & $\mathrm{N} / \mathrm{A}$ & 1.48 \\
\hline 4 & Oligyra & $\mathrm{sp}$. & 5.7 & 7.3 & $\mathrm{~N} / \mathrm{A}$ & $\mathrm{N} / \mathrm{A}$ & 1.28 \\
\hline 4 & Oligyra & $\mathrm{sp}$. & 5.2 & 6.3 & $\mathrm{~N} / \mathrm{A}$ & $\mathrm{N} / \mathrm{A}$ & 1.22 \\
\hline 4 & Oligyra & sp. & 4.9 & 6.9 & $\mathrm{~N} / \mathrm{A}$ & $\mathrm{N} / \mathrm{A}$ & 1.41 \\
\hline 4 & Oligyra & sp. & 4.8 & 7.3 & $\mathrm{~N} / \mathrm{A}$ & $\mathrm{N} / \mathrm{A}$ & 1.53 \\
\hline 4 & Oligyra & sp. & 5.5 & 7.5 & $\mathrm{~N} / \mathrm{A}$ & $\mathrm{N} / \mathrm{A}$ & 1.35 \\
\hline 4 & Oligyra & $\mathrm{sp}$. & 5.2 & 7.6 & $\mathrm{~N} / \mathrm{A}$ & $\mathrm{N} / \mathrm{A}$ & 1.47 \\
\hline 4 & Oligyra & $\mathrm{sp}$. & 5 & 6.9 & N/A & N/A & 1.37 \\
\hline 4 & Oligyra & sp. & 5.8 & 7.1 & $\mathrm{~N} / \mathrm{A}$ & $\mathrm{N} / \mathrm{A}$ & 1.22 \\
\hline 4 & Oligyra & sp. & 5.4 & 7.1 & $\mathrm{~N} / \mathrm{A}$ & N/A & 1.32 \\
\hline 4 & Oligyra & $\mathrm{sp}$. & 5.3 & 7.5 & $\mathrm{~N} / \mathrm{A}$ & $\mathrm{N} / \mathrm{A}$ & 1.42 \\
\hline 4 & Oligyra & $\mathrm{sp}$. & 4.4 & 7.1 & $\mathrm{~N} / \mathrm{A}$ & $\mathrm{N} / \mathrm{A}$ & 1.62 \\
\hline 4 & Oligyra & $\mathrm{sp}$. & 4.3 & 6.1 & $\mathrm{~N} / \mathrm{A}$ & $\mathrm{N} / \mathrm{A}$ & 1.43 \\
\hline 4 & Oligyra & sp. & 4.6 & 7.3 & $\mathrm{~N} / \mathrm{A}$ & $\mathrm{N} / \mathrm{A}$ & 1.57 \\
\hline 4 & Oligyra & sp. & 5 & 7.4 & $\mathrm{~N} / \mathrm{A}$ & $\mathrm{N} / \mathrm{A}$ & 1.47 \\
\hline 4 & Oligyra & $\mathrm{sp}$. & 4.6 & 6.9 & $\mathrm{~N} / \mathrm{A}$ & $\mathrm{N} / \mathrm{A}$ & 1.5 \\
\hline 4 & Oligyra & sp. & 5.2 & 7.2 & $\mathrm{~N} / \mathrm{A}$ & $\mathrm{N} / \mathrm{A}$ & 1.38 \\
\hline 4 & Oligyra & $\mathrm{sp}$. & 4.9 & 7.8 & $\mathrm{~N} / \mathrm{A}$ & $\mathrm{N} / \mathrm{A}$ & 1.6 \\
\hline 4 & Oligyra & sp. & 6.3 & 8.3 & $\mathrm{~N} / \mathrm{A}$ & $\mathrm{N} / \mathrm{A}$ & 1.32 \\
\hline 4 & Oligyra & $\mathrm{sp}$. & 4.7 & 6.7 & $\mathrm{~N} / \mathrm{A}$ & $\mathrm{N} / \mathrm{A}$ & 1.42 \\
\hline 4 & Oligyra & sp. & 4.3 & 7.2 & $\mathrm{~N} / \mathrm{A}$ & $\mathrm{N} / \mathrm{A}$ & 1.66 \\
\hline 4 & Oligyra & sp. & 5.5 & 7.2 & $\mathrm{~N} / \mathrm{A}$ & $\mathrm{N} / \mathrm{A}$ & 1.32 \\
\hline 4 & Oligyra & $\mathrm{sp}$. & 5.1 & 7.6 & $\mathrm{~N} / \mathrm{A}$ & $\mathrm{N} / \mathrm{A}$ & 1.5 \\
\hline 4 & Oligyra & sp. & 5.2 & 7.7 & $\mathrm{~N} / \mathrm{A}$ & $\mathrm{N} / \mathrm{A}$ & 1.48 \\
\hline 4 & Oligyra & $\mathrm{sp}$. & 5.2 & 7.5 & $\mathrm{~N} / \mathrm{A}$ & $\mathrm{N} / \mathrm{A}$ & 1.45 \\
\hline 4 & Oligyra & sp. & 4.9 & 7.1 & $\mathrm{~N} / \mathrm{A}$ & $\mathrm{N} / \mathrm{A}$ & 1.44 \\
\hline
\end{tabular}


Table H-5. Continued...

\begin{tabular}{|c|c|c|c|c|c|c|c|}
\hline Area & Genus & Species & length (mm) & width $(\mathrm{mm})$ & Carina & Calus & Weight (g.) \\
\hline 4 & Oligyra & sp. & 4.7 & 7 & $\mathrm{~N} / \mathrm{A}$ & $N / A$ & 1.47 \\
\hline 4 & Oligyra & sp. & 4.8 & 7.2 & N/A & $\mathrm{N} / \mathrm{A}$ & 1.5 \\
\hline 4 & Oligyra & sp. & 5.7 & 7.4 & N/A & $\mathrm{N} / \mathrm{A}$ & 1.31 \\
\hline 4 & Oligyra & sp. & 5.3 & 7.6 & $N / A$ & $\mathrm{~N} / \mathrm{A}$ & 1.42 \\
\hline 4 & Oligyra & sp. & 5.4 & 6.9 & N/A & $\mathrm{N} / \mathrm{A}$ & 1.29 \\
\hline 4 & Oligyra & sp. & 5.2 & 7 & N/A & $\mathrm{N} / \mathrm{A}$ & 1.33 \\
\hline 4 & Oligyra & sp. & 5 & 7.5 & $\mathrm{~N} / \mathrm{A}$ & N/A & 1.51 \\
\hline 4 & Oligyra & sp. & 5.9 & 8.2 & $\mathrm{~N} / \mathrm{A}$ & N/A & 1.38 \\
\hline 4 & Oligyra & sp. & 6 & 8 & N/A & $\mathrm{N} / \mathrm{A}$ & 1.32 \\
\hline 4 & Oligyra & sp. & 5 & 7.2 & N/A & $N / A$ & 1.45 \\
\hline 4 & Oligyra & sp. & 4.8 & 6.7 & N/A & $\mathrm{N} / \mathrm{A}$ & 1.39 \\
\hline 4 & Oligyra & sp. & 6 & 7.1 & $N / A$ & $\mathrm{~N} / \mathrm{A}$ & 1.19 \\
\hline 4 & Oligyra & sp. & 5.4 & 7.6 & N/A & $\mathrm{N} / \mathrm{A}$ & 1.4 \\
\hline 4 & Oligyra & sp. & 6.1 & 7.4 & N/A & $\mathrm{N} / \mathrm{A}$ & 1.21 \\
\hline 4 & Oligyra & sp. & 4.8 & 7.1 & N/A & $N / A$ & 1.48 \\
\hline 4 & Oligyra & sp. & 5.2 & 7.2 & $\mathrm{~N} / \mathrm{A}$ & N/A & 1.38 \\
\hline 4 & Oligyra & sp. & 5.5 & 7 & $\mathrm{~N} / \mathrm{A}$ & N/A & 1.29 \\
\hline 4 & Oligyra & sp. & 5.2 & 7.1 & N/A & $\mathrm{N} / \mathrm{A}$ & 1.35 \\
\hline 4 & Oligyra & sp. & 4.7 & 7.6 & N/A & $\mathrm{N} / \mathrm{A}$ & 1.62 \\
\hline 4 & Oligyra & sp. & 4.6 & 6.1 & $N / A$ & $N / A$ & 1.34 \\
\hline 4 & Oligyra & sp. & 3.9 & 6 & N/A & $N / A$ & 1.54 \\
\hline 4 & Oligyra & sp. & 5.7 & 7.3 & $\mathrm{~N} / \mathrm{A}$ & $N / A$ & 1.29 \\
\hline 4 & Oligyra & sp. & 5.1 & 7.2 & $\mathrm{~N} / \mathrm{A}$ & N/A & 1.42 \\
\hline 4 & Oligyra & sp. & 5 & 7.3 & $\mathrm{~N} / \mathrm{A}$ & $\mathrm{N} / \mathrm{A}$ & 1.45 \\
\hline 4 & Oligyra & sp. & 5.6 & 7.6 & $\mathrm{~N} / \mathrm{A}$ & N/A & 1.36 \\
\hline 4 & Oligyra & sp. & 5.1 & 7 & $\mathrm{~N} / \mathrm{A}$ & N/A & 1.38 \\
\hline 4 & Oligyra & sp. & 6 & 7.1 & N/A & $\mathrm{N} / \mathrm{A}$ & 1.18 \\
\hline 4 & Oligyra & sp. & 5.4 & 7.5 & $\mathrm{~N} / \mathrm{A}$ & $N / A$ & 1.38 \\
\hline 4 & Oligyra & sp. & 5.8 & 7.8 & N/A & $\mathrm{N} / \mathrm{A}$ & 1.34 \\
\hline 4 & Oligyra & sp. & 4.3 & 6.1 & N/A & $\mathrm{N} / \mathrm{A}$ & 1.41 \\
\hline 4 & Oligyra & sp. & 5.1 & 7.2 & $\mathrm{~N} / \mathrm{A}$ & $\mathrm{N} / \mathrm{A}$ & 1.4 \\
\hline 4 & Oligyra & $\mathrm{sp}$. & 4 & 6.4 & $\mathrm{~N} / \mathrm{A}$ & $\mathrm{N} / \mathrm{A}$ & 1.59 \\
\hline 4 & Oligyra & sp. & 5.1 & 7.3 & $\mathrm{~N} / \mathrm{A}$ & $\mathrm{N} / \mathrm{A}$ & 1.44 \\
\hline 4 & Oligyra & sp. & 5.1 & 7.7 & $\mathrm{~N} / \mathrm{A}$ & $\mathrm{N} / \mathrm{A}$ & 1.52 \\
\hline 4 & Oligyra & sp. & 4.7 & 6.9 & $\mathrm{~N} / \mathrm{A}$ & $\mathrm{N} / \mathrm{A}$ & 1.47 \\
\hline 4 & Oligyra & sp. & 5.1 & 7.7 & $\mathrm{~N} / \mathrm{A}$ & $\mathrm{N} / \mathrm{A}$ & 1.51 \\
\hline 4 & Oligyra & sp. & 5.1 & 6.9 & N/A & $N / A$ & 1.35 \\
\hline 4 & Oligyra & sp. & 5.5 & 7.8 & N/A & $\mathrm{N} / \mathrm{A}$ & 1.4 \\
\hline 4 & Oligyra & sp. & 5.5 & 8 & $\mathrm{~N} / \mathrm{A}$ & $\mathrm{N} / \mathrm{A}$ & 1.45 \\
\hline 4 & Oligyra & sp. & 5.7 & 8 & $\mathrm{~N} / \mathrm{A}$ & N/A & 1.4 \\
\hline 4 & Oligyra & sp. & 4.5 & 6.7 & $\mathrm{~N} / \mathrm{A}$ & $\mathrm{N} / \mathrm{A}$ & 1.48 \\
\hline 4 & Oligyra & sp. & 4.9 & 7.3 & $\mathrm{~N} / \mathrm{A}$ & $\mathrm{N} / \mathrm{A}$ & 1.48 \\
\hline 4 & Oligyra & sp. & 4.8 & 6.8 & $N / A$ & $N / A$ & 1.43 \\
\hline 4 & Oligyra & sp. & 5.3 & 7.6 & $N / A$ & $N / A$ & 1.44 \\
\hline 4 & Oligyra & sp. & 3.7 & 5.6 & $\mathrm{~N} / \mathrm{A}$ & $\mathrm{N} / \mathrm{A}$ & 1.52 \\
\hline 4 & Oligyra & $\mathrm{sp}$. & 4.9 & 6.8 & $\mathrm{~N} / \mathrm{A}$ & $\mathrm{N} / \mathrm{A}$ & 1.39 \\
\hline 4 & Oligyra & sp. & 5.4 & 7.2 & $\mathrm{~N} / \mathrm{A}$ & $\mathrm{N} / \mathrm{A}$ & 1.33 \\
\hline 4 & Oligyra & sp. & 5.1 & 7.1 & $\mathrm{~N} / \mathrm{A}$ & $\mathrm{N} / \mathrm{A}$ & 1.39 \\
\hline 4 & Oligyra & sp. & 4.6 & 7.1 & $\mathrm{~N} / \mathrm{A}$ & N/A & 1.55 \\
\hline 4 & Oligyra & sp. & 5.3 & 6.7 & $\mathrm{~N} / \mathrm{A}$ & $\mathrm{N} / \mathrm{A}$ & 1.27 \\
\hline 4 & Oligyra & sp. & 5.1 & 7.2 & N/A & $\mathrm{N} / \mathrm{A}$ & 1.41 \\
\hline 4 & Oligyra & sp. & 4.8 & 6.9 & N/A & $\mathrm{N} / \mathrm{A}$ & 1.43 \\
\hline 4 & Oligyra & sp. & 5.5 & 7.4 & N/A & $N / A$ & 1.33 \\
\hline 4 & Oligyra & sp. & 5.6 & 7.5 & $\mathrm{~N} / \mathrm{A}$ & N/A & 1.33 \\
\hline 4 & Oligyra & sp. & 4.9 & 7 & $N / A$ & $\mathrm{~N} / \mathrm{A}$ & 1.45 \\
\hline
\end{tabular}


Table H-5. Continued...

\begin{tabular}{|c|c|c|c|c|c|c|c|}
\hline Area & Genus & Species & length (mm) & width (mm) & Carina & Calus & Weight (g.) \\
\hline 4 & Oligyra & sp. & 4.6 & 7 & $\mathrm{~N} / \mathrm{A}$ & $\mathrm{N} / \mathrm{A}$ & 1.54 \\
\hline 4 & Oligyra & sp. & 4.8 & 6.8 & N/A & N/A & 1.41 \\
\hline 4 & Oligyra & sp. & 5 & 7 & N/A & $\mathrm{N} / \mathrm{A}$ & 1.39 \\
\hline 4 & Oligyra & sp. & 4.4 & 6.4 & N/A & $\mathrm{N} / \mathrm{A}$ & 1.45 \\
\hline 4 & Oligyra & sp. & 5.5 & 7.9 & $\mathrm{~N} / \mathrm{A}$ & N/A & 1.42 \\
\hline 4 & Oligyra & sp. & 3.9 & 6.5 & $\mathrm{~N} / \mathrm{A}$ & $\mathrm{N} / \mathrm{A}$ & 1.66 \\
\hline 4 & Oligyra & sp. & 4.4 & 7.2 & $\mathrm{~N} / \mathrm{A}$ & $\mathrm{N} / \mathrm{A}$ & 1.66 \\
\hline 4 & Oligyra & sp. & 5.3 & 7.1 & $\mathrm{~N} / \mathrm{A}$ & $\mathrm{N} / \mathrm{A}$ & 1.33 \\
\hline 4 & Oligyra & sp. & 5 & 7.2 & N/A & N/A & 1.43 \\
\hline 4 & Oligyra & sp. & 4.8 & 7 & $\mathrm{~N} / \mathrm{A}$ & $\mathrm{N} / \mathrm{A}$ & 1.44 \\
\hline 4 & Oligyra & sp. & 5.1 & 6.9 & $N / A$ & $\mathrm{~N} / \mathrm{A}$ & 1.36 \\
\hline 4 & Oligyra & sp. & 5.6 & 7.6 & N/A & N/A & 1.34 \\
\hline 4 & Oligyra & sp. & 5.5 & 7.9 & $\mathrm{~N} / \mathrm{A}$ & N/A & 1.44 \\
\hline 4 & Oligyra & sp. & 3.9 & 6 & $\mathrm{~N} / \mathrm{A}$ & $\mathrm{N} / \mathrm{A}$ & 1.54 \\
\hline 4 & Oligyra & sp. & 4.6 & 7.3 & $\mathrm{~N} / \mathrm{A}$ & $\mathrm{N} / \mathrm{A}$ & 1.59 \\
\hline 4 & Oligyra & sp. & 5.4 & 7.2 & $\mathrm{~N} / \mathrm{A}$ & $\mathrm{N} / \mathrm{A}$ & 1.34 \\
\hline 4 & Oligyra & sp. & 4.9 & 7.5 & $\mathrm{~N} / \mathrm{A}$ & $\mathrm{N} / \mathrm{A}$ & 1.55 \\
\hline 4 & Oligyra & $\mathrm{sp}$. & 5.8 & 7.7 & $\mathrm{~N} / \mathrm{A}$ & N/A & 1.34 \\
\hline 4 & Oligyra & sp. & 4.9 & 7.2 & $N / A$ & N/A & 1.47 \\
\hline 4 & Oligyra & sp. & 5 & 7 & N/A & N/A & 1.39 \\
\hline 4 & Oligyra & sp. & 5.1 & 7.6 & $\mathrm{~N} / \mathrm{A}$ & N/A & 1.49 \\
\hline 4 & Oligyra & $\mathrm{sp}$. & 4.5 & 7.2 & $\mathrm{~N} / \mathrm{A}$ & N/A & 1.59 \\
\hline 4 & Oligyra & sp. & 4.7 & 7.5 & $\mathrm{~N} / \mathrm{A}$ & $\mathrm{N} / \mathrm{A}$ & 1.6 \\
\hline 4 & Oligyra & sp. & 5.3 & 7.5 & $\mathrm{~N} / \mathrm{A}$ & $\mathrm{N} / \mathrm{A}$ & 1.4 \\
\hline 4 & Oligyra & sp. & 5.1 & 7.8 & $\mathrm{~N} / \mathrm{A}$ & $\mathrm{N} / \mathrm{A}$ & 1.52 \\
\hline 4 & Oligyra & sp. & 5.1 & 7.4 & $\mathrm{~N} / \mathrm{A}$ & N/A & 1.46 \\
\hline 4 & Oligyra & sp. & 4.8 & 7.1 & N/A & N/A & 1.46 \\
\hline 4 & Oligyra & sp. & 5.7 & 7.2 & $N / A$ & N/A & 1.26 \\
\hline 4 & Oligyra & sp. & 5.8 & 7.3 & $\mathrm{~N} / \mathrm{A}$ & N/A & 1.25 \\
\hline 4 & Oligyra & sp. & 5.7 & 7.5 & $\mathrm{~N} / \mathrm{A}$ & N/A & 1.31 \\
\hline 4 & Oligyra & sp. & 5.3 & 7.6 & $\mathrm{~N} / \mathrm{A}$ & $\mathrm{N} / \mathrm{A}$ & 1.43 \\
\hline 4 & Oligyra & sp. & 5.4 & 7.3 & $\mathrm{~N} / \mathrm{A}$ & N/A & 1.35 \\
\hline 4 & Oligyra & sp. & 4.7 & 7.7 & $\mathrm{~N} / \mathrm{A}$ & $\mathrm{N} / \mathrm{A}$ & 1.62 \\
\hline 4 & Oligyra & sp. & 5.3 & 7.7 & $\mathrm{~N} / \mathrm{A}$ & N/A & 1.46 \\
\hline 4 & Oligyra & sp. & 5.5 & 7.6 & N/A & N/A & 1.37 \\
\hline 4 & Oligyra & sp. & 4.6 & 5.9 & N/A & $\mathrm{N} / \mathrm{A}$ & 1.29 \\
\hline 4 & Oligyra & sp. & 4.5 & 6.5 & $\mathrm{~N} / \mathrm{A}$ & N/A & 1.43 \\
\hline 4 & Oligyra & sp. & 4.8 & 6.7 & $\mathrm{~N} / \mathrm{A}$ & N/A & 1.38 \\
\hline 4 & Oligyra & sp. & 5.2 & 7.1 & $\mathrm{~N} / \mathrm{A}$ & $\mathrm{N} / \mathrm{A}$ & 1.35 \\
\hline 4 & Oligyra & sp. & 4.8 & 6.7 & $\mathrm{~N} / \mathrm{A}$ & $\mathrm{N} / \mathrm{A}$ & 1.39 \\
\hline 4 & Oligyra & sp. & 5.4 & 6.7 & $\mathrm{~N} / \mathrm{A}$ & N/A & 1.24 \\
\hline 4 & Oligyra & sp. & 4.9 & 7 & $\mathrm{~N} / \mathrm{A}$ & N/A & 1.42 \\
\hline 4 & Oligyra & sp. & 4.9 & 7.3 & $\mathrm{~N} / \mathrm{A}$ & N/A & 1.47 \\
\hline 4 & Oligyra & sp. & 5.3 & 7.3 & $\mathrm{~N} / \mathrm{A}$ & $\mathrm{N} / \mathrm{A}$ & 1.38 \\
\hline 4 & Oligyra & $\mathrm{sp}$. & 5.3 & 7.6 & $\mathrm{~N} / \mathrm{A}$ & N/A & 1.43 \\
\hline 4 & Oligyra & sp. & 5.1 & 6.9 & $\mathrm{~N} / \mathrm{A}$ & N/A & 1.36 \\
\hline 4 & Oligyra & sp. & 5.7 & 7.8 & $\mathrm{~N} / \mathrm{A}$ & N/A & 1.38 \\
\hline 4 & Oligyra & sp. & 5.4 & 7.7 & $\mathrm{~N} / \mathrm{A}$ & $\mathrm{N} / \mathrm{A}$ & 1.44 \\
\hline 4 & Oligyra & sp. & 4.9 & 7.2 & $\mathrm{~N} / \mathrm{A}$ & N/A & 1.47 \\
\hline 4 & Oligyra & $\mathrm{sp}$. & 5.5 & 7.4 & $\mathrm{~N} / \mathrm{A}$ & N/A & 1.35 \\
\hline 4 & Oligyra & sp. & 4.8 & 7.4 & N/A & N/A & 1.53 \\
\hline 4 & Oligyra & sp. & 5.3 & 7.5 & $\mathrm{~N} / \mathrm{A}$ & $\mathrm{N} / \mathrm{A}$ & 1.41 \\
\hline 4 & Oligyra & sp. & 5.8 & 7 & $\mathrm{~N} / \mathrm{A}$ & $\mathrm{N} / \mathrm{A}$ & 1.21 \\
\hline 4 & Oligyra & sp. & 5.2 & 7.1 & $\mathrm{~N} / \mathrm{A}$ & $\mathrm{N} / \mathrm{A}$ & 1.38 \\
\hline 4 & Oligyra & sp. & 4.6 & 7.3 & $\mathrm{~N} / \mathrm{A}$ & $\mathrm{N} / \mathrm{A}$ & 1.57 \\
\hline
\end{tabular}


Table H-5. Continued...

\begin{tabular}{|c|c|c|c|c|c|c|c|}
\hline Area & Genus & Species & length $(\mathrm{mm})$ & width (mm) & Carina & Calus & Weight (g.) \\
\hline 4 & Oligyra & sp. & 4.5 & 7.3 & N/A & $\mathrm{N} / \mathrm{A}$ & 1.6 \\
\hline 4 & Oligyra & $\mathrm{sp}$. & 2.9 & 3.9 & $\mathrm{~N} / \mathrm{A}$ & $\mathrm{N} / \mathrm{A}$ & 1.35 \\
\hline 4 & Oligyra & sp. & 4.7 & 7 & $\mathrm{~N} / \mathrm{A}$ & N/A & 1.5 \\
\hline 4 & Oligyra & sp. & 5.7 & 7.8 & N/A & $N / A$ & 1.38 \\
\hline 4 & Oligyra & sp. & 3.8 & 5.9 & N/A & $\mathrm{N} / \mathrm{A}$ & 1.55 \\
\hline 4 & Oligyra & sp. & 5.5 & 7.6 & $\mathrm{~N} / \mathrm{A}$ & $\mathrm{N} / \mathrm{A}$ & 1.39 \\
\hline 4 & Oligyra & sp. & 5.2 & 7.4 & $\mathrm{~N} / \mathrm{A}$ & N/A & 1.41 \\
\hline 4 & Oligyra & sp. & 5.3 & 7.8 & $\mathrm{~N} / \mathrm{A}$ & N/A & 1.47 \\
\hline 4 & Oligyra & sp. & 5.1 & 7.1 & $\mathrm{~N} / \mathrm{A}$ & N/A & 1.39 \\
\hline 4 & Oligyra & sp. & 5 & 7.2 & $\mathrm{~N} / \mathrm{A}$ & $\mathrm{N} / \mathrm{A}$ & 1.43 \\
\hline 4 & Oligyra & sp. & 5 & 7.1 & $\mathrm{~N} / \mathrm{A}$ & $\mathrm{N} / \mathrm{A}$ & 1.42 \\
\hline 4 & Oligyra & $\mathrm{sp}$. & 5 & 7 & $\mathrm{~N} / \mathrm{A}$ & N/A & 1.4 \\
\hline 4 & Oligyra & sp. & 4.8 & 6 & $N / A$ & $N / A$ & 1.24 \\
\hline 4 & Oligyra & sp. & 5.2 & 7.2 & N/A & $N / A$ & 1.38 \\
\hline 4 & Oligyra & sp. & 4.5 & 7 & $\mathrm{~N} / \mathrm{A}$ & $\mathrm{N} / \mathrm{A}$ & 1.55 \\
\hline 4 & Oligyra & sp. & 4.8 & 6.9 & $\mathrm{~N} / \mathrm{A}$ & $\mathrm{N} / \mathrm{A}$ & 1.45 \\
\hline 4 & Oligyra & $\mathrm{sp}$. & 5.2 & 7.5 & $\mathrm{~N} / \mathrm{A}$ & $\mathrm{N} / \mathrm{A}$ & 1.45 \\
\hline 4 & Oligyra & sp. & 4.8 & 6.9 & $\mathrm{~N} / \mathrm{A}$ & N/A & 1.44 \\
\hline 4 & Oligyra & sp. & 5 & 7.2 & $\mathrm{~N} / \mathrm{A}$ & N/A & 1.45 \\
\hline 4 & Oligyra & sp. & 5 & 7.1 & $\mathrm{~N} / \mathrm{A}$ & $\mathrm{N} / \mathrm{A}$ & 1.43 \\
\hline 4 & Oligyra & sp. & 4.7 & 6.7 & $\mathrm{~N} / \mathrm{A}$ & $\mathrm{N} / \mathrm{A}$ & 1.43 \\
\hline 4 & Oligyra & sp. & 5.2 & 7.2 & $\mathrm{~N} / \mathrm{A}$ & $\mathrm{N} / \mathrm{A}$ & 1.39 \\
\hline 4 & Oligyra & sp. & 5 & 7.3 & $\mathrm{~N} / \mathrm{A}$ & $\mathrm{N} / \mathrm{A}$ & 1.46 \\
\hline 4 & Oligyra & sp. & 5 & 6.9 & $\mathrm{~N} / \mathrm{A}$ & $\mathrm{N} / \mathrm{A}$ & 1.36 \\
\hline 4 & Oligyra & $\mathrm{sp}$. & 5.2 & 7.3 & $\mathrm{~N} / \mathrm{A}$ & $\mathrm{N} / \mathrm{A}$ & 1.41 \\
\hline 4 & Oligyra & sp. & 4.2 & 6.2 & $\mathrm{~N} / \mathrm{A}$ & $\mathrm{N} / \mathrm{A}$ & 1.48 \\
\hline 4 & Oligyra & sp. & 5.2 & 7.7 & $\mathrm{~N} / \mathrm{A}$ & $\mathrm{N} / \mathrm{A}$ & 1.46 \\
\hline 4 & Oligyra & sp. & 4.8 & 7 & $\mathrm{~N} / \mathrm{A}$ & $\mathrm{N} / \mathrm{A}$ & 1.48 \\
\hline 4 & Oligyra & $\mathrm{sp}$. & 5.2 & 7.3 & $\mathrm{~N} / \mathrm{A}$ & $\mathrm{N} / \mathrm{A}$ & 1.39 \\
\hline 4 & Oligyra & sp. & 5.3 & 7.3 & N/A & $N / A$ & 1.39 \\
\hline 4 & Oligyra & sp. & 4.9 & 7.1 & $\mathrm{~N} / \mathrm{A}$ & $\mathrm{N} / \mathrm{A}$ & 1.43 \\
\hline 4 & Oligyra & sp. & 4.6 & 6.4 & $\mathrm{~N} / \mathrm{A}$ & $\mathrm{N} / \mathrm{A}$ & 1.4 \\
\hline 4 & Oligyra & $\mathrm{sp}$. & 5.1 & 7.3 & $\mathrm{~N} / \mathrm{A}$ & $\mathrm{N} / \mathrm{A}$ & 1.42 \\
\hline 4 & Oligyra & sp. & 5.2 & 6.7 & $\mathrm{~N} / \mathrm{A}$ & N/A & 1.29 \\
\hline 4 & Oligyra & sp. & 5.3 & 7.5 & $\mathrm{~N} / \mathrm{A}$ & $\mathrm{N} / \mathrm{A}$ & 1.4 \\
\hline 4 & Oligyra & $\mathrm{sp}$. & 5.6 & 7.4 & $\mathrm{~N} / \mathrm{A}$ & $\mathrm{N} / \mathrm{A}$ & 1.32 \\
\hline 4 & Oligyra & sp. & 5 & 7.8 & $\mathrm{~N} / \mathrm{A}$ & $N / A$ & 1.56 \\
\hline 4 & Oligyra & sp. & 5.1 & 7.4 & $\mathrm{~N} / \mathrm{A}$ & $\mathrm{N} / \mathrm{A}$ & 1.47 \\
\hline 4 & Oligyra & sp. & 4.8 & 6.6 & N/A & $\mathrm{N} / \mathrm{A}$ & 1.38 \\
\hline 4 & Oligyra & $\mathrm{sp}$. & 5.8 & 7.6 & $\mathrm{~N} / \mathrm{A}$ & $\mathrm{N} / \mathrm{A}$ & 1.31 \\
\hline 4 & Oligyra & $\mathrm{sp}$. & 5 & 7 & $\mathrm{~N} / \mathrm{A}$ & $\mathrm{N} / \mathrm{A}$ & 1.4 \\
\hline 4 & Oligyra & sp. & 4.8 & 7.3 & $\mathrm{~N} / \mathrm{A}$ & $\mathrm{N} / \mathrm{A}$ & 1.51 \\
\hline 4 & Oligyra & sp. & 5.7 & 7.9 & $\mathrm{~N} / \mathrm{A}$ & $\mathrm{N} / \mathrm{A}$ & 1.4 \\
\hline 4 & Oligyra & sp. & 5 & 7.1 & $\mathrm{~N} / \mathrm{A}$ & $\mathrm{N} / \mathrm{A}$ & 1.42 \\
\hline 4 & Oligyra & sp. & 4.7 & 6.7 & $\mathrm{~N} / \mathrm{A}$ & $\mathrm{N} / \mathrm{A}$ & 1.42 \\
\hline 4 & Oligyra & sp. & 5.9 & 7.9 & $\mathrm{~N} / \mathrm{A}$ & $N / A$ & 1.34 \\
\hline 4 & Oligyra & sp. & 4.7 & 6.8 & $\mathrm{~N} / \mathrm{A}$ & $\mathrm{N} / \mathrm{A}$ & 1.45 \\
\hline 4 & Oligyra & $\mathrm{sp}$. & 4.7 & 7.3 & $\mathrm{~N} / \mathrm{A}$ & $\mathrm{N} / \mathrm{A}$ & 1.55 \\
\hline 4 & Oligyra & sp. & 5.6 & 7.4 & $\mathrm{~N} / \mathrm{A}$ & $\mathrm{N} / \mathrm{A}$ & 1.31 \\
\hline 4 & Oligyra & sp. & 5.2 & 7.4 & $\mathrm{~N} / \mathrm{A}$ & $\mathrm{N} / \mathrm{A}$ & 1.42 \\
\hline 4 & Oligyra & sp. & 4.3 & 6.6 & $\mathrm{~N} / \mathrm{A}$ & $\mathrm{N} / \mathrm{A}$ & 1.51 \\
\hline 4 & Oligyra & $\mathrm{sp}$. & 5.3 & 7.4 & $\mathrm{~N} / \mathrm{A}$ & $\mathrm{N} / \mathrm{A}$ & 1.41 \\
\hline 4 & Oligyra & sp. & 5 & 7 & $\mathrm{~N} / \mathrm{A}$ & $\mathrm{N} / \mathrm{A}$ & 1.4 \\
\hline 4 & Oligyra & sp. & 5.7 & 7.7 & $\mathrm{~N} / \mathrm{A}$ & $\mathrm{N} / \mathrm{A}$ & 1.36 \\
\hline 4 & Oligyra & sp. & 5.7 & 7.7 & $\mathrm{~N} / \mathrm{A}$ & $\mathrm{N} / \mathrm{A}$ & 1.37 \\
\hline
\end{tabular}


Table H-5. Continued...

\begin{tabular}{|c|c|c|c|c|c|c|c|}
\hline Area & Genus & Species & length (mm) & width (mm) & Carina & Calus & Weight (g.) \\
\hline 4 & Oligyra & $\mathrm{sp}$. & 4.6 & 7.2 & $\mathrm{~N} / \mathrm{A}$ & $\mathrm{N} / \mathrm{A}$ & 1.56 \\
\hline 4 & Oligyra & sp. & 4.7 & 6.5 & $\mathrm{~N} / \mathrm{A}$ & $\mathrm{N} / \mathrm{A}$ & 1.38 \\
\hline 4 & Oligyra & sp. & 5 & 7.5 & $\mathrm{~N} / \mathrm{A}$ & $\mathrm{N} / \mathrm{A}$ & 1.5 \\
\hline 4 & Oligyra & sp. & 5.3 & 7.5 & $\mathrm{~N} / \mathrm{A}$ & $\mathrm{N} / \mathrm{A}$ & 1.42 \\
\hline 4 & Oligyra & $\mathrm{sp}$. & 5.2 & 6.9 & $\mathrm{~N} / \mathrm{A}$ & $\mathrm{N} / \mathrm{A}$ & 1.33 \\
\hline 4 & Oligyra & $\mathrm{sp}$. & 3.7 & 5.8 & $\mathrm{~N} / \mathrm{A}$ & $\mathrm{N} / \mathrm{A}$ & 1.57 \\
\hline 4 & Oligyra & sp. & 5.1 & 6.9 & $\mathrm{~N} / \mathrm{A}$ & $\mathrm{N} / \mathrm{A}$ & 1.34 \\
\hline 4 & Oligyra & $\mathrm{sp}$. & 5.1 & 7.7 & $\mathrm{~N} / \mathrm{A}$ & $\mathrm{N} / \mathrm{A}$ & 1.5 \\
\hline 4 & Oligyra & $\mathrm{sp}$. & 4.9 & 6.9 & $\mathrm{~N} / \mathrm{A}$ & N/A & 1.42 \\
\hline 4 & Oligyra & sp. & 4.8 & 7 & $\mathrm{~N} / \mathrm{A}$ & $\mathrm{N} / \mathrm{A}$ & 1.44 \\
\hline 4 & Oligyra & sp. & 5.9 & 7.9 & $\mathrm{~N} / \mathrm{A}$ & N/A & 1.35 \\
\hline 4 & Oligyra & $\mathrm{sp}$. & 4.9 & 7.2 & $\mathrm{~N} / \mathrm{A}$ & $\mathrm{N} / \mathrm{A}$ & 1.46 \\
\hline 4 & Oligyra & sp. & 5.2 & 7.9 & $\mathrm{~N} / \mathrm{A}$ & $\mathrm{N} / \mathrm{A}$ & 1.5 \\
\hline 4 & Oligyra & sp. & 5.5 & 7.6 & $\mathrm{~N} / \mathrm{A}$ & $\mathrm{N} / \mathrm{A}$ & 1.39 \\
\hline 4 & Oligyra & sp. & 5.1 & 7.2 & $\mathrm{~N} / \mathrm{A}$ & $\mathrm{N} / \mathrm{A}$ & 1.41 \\
\hline 4 & Oligyra & $\mathrm{sp}$. & 5.2 & 7.4 & $\mathrm{~N} / \mathrm{A}$ & $\mathrm{N} / \mathrm{A}$ & 1.44 \\
\hline 4 & Oligyra & $\mathrm{sp}$. & 5.1 & 6.9 & $\mathrm{~N} / \mathrm{A}$ & $\mathrm{N} / \mathrm{A}$ & 1.36 \\
\hline 4 & Oligyra & sp. & 5 & 6.7 & $\mathrm{~N} / \mathrm{A}$ & $\mathrm{N} / \mathrm{A}$ & 1.35 \\
\hline 4 & Oligyra & $\mathrm{sp}$. & 4.1 & 6.2 & $\mathrm{~N} / \mathrm{A}$ & $\mathrm{N} / \mathrm{A}$ & 1.51 \\
\hline 4 & Oligyra & $\mathrm{sp}$. & 2.9 & 4.8 & $\mathrm{~N} / \mathrm{A}$ & $\mathrm{N} / \mathrm{A}$ & 1.66 \\
\hline 4 & Oligyra & sp. & 5.3 & 6.9 & $\mathrm{~N} / \mathrm{A}$ & $\mathrm{N} / \mathrm{A}$ & 1.3 \\
\hline 4 & Oligyra & sp. & 5.6 & 7.5 & $\mathrm{~N} / \mathrm{A}$ & $\mathrm{N} / \mathrm{A}$ & 1.33 \\
\hline 4 & Oligyra & $\mathrm{sp}$. & 5.3 & 7.5 & N/A & $\mathrm{N} / \mathrm{A}$ & 1.4 \\
\hline 4 & Oligyra & sp. & 5.1 & 7 & $\mathrm{~N} / \mathrm{A}$ & $\mathrm{N} / \mathrm{A}$ & 1.38 \\
\hline 4 & Oligyra & sp. & 4.8 & 7 & $\mathrm{~N} / \mathrm{A}$ & N/A & 1.46 \\
\hline 4 & Oligyra & sp. & 5.5 & 7.3 & $\mathrm{~N} / \mathrm{A}$ & $\mathrm{N} / \mathrm{A}$ & 1.33 \\
\hline 4 & Oligyra & $\mathrm{sp}$. & 5.2 & 6.8 & $\mathrm{~N} / \mathrm{A}$ & $\mathrm{N} / \mathrm{A}$ & 1.32 \\
\hline 4 & Oligyra & $\mathrm{sp}$. & 5.4 & 7 & $\mathrm{~N} / \mathrm{A}$ & N/A & 1.31 \\
\hline 4 & Oligyra & sp. & 4.9 & 7.2 & $\mathrm{~N} / \mathrm{A}$ & $\mathrm{N} / \mathrm{A}$ & 1.48 \\
\hline 4 & Oligyra & sp. & 5.7 & 7.7 & $\mathrm{~N} / \mathrm{A}$ & $\mathrm{N} / \mathrm{A}$ & 1.35 \\
\hline 4 & Oligyra & $\mathrm{sp}$. & 5 & 7.8 & $\mathrm{~N} / \mathrm{A}$ & $\mathrm{N} / \mathrm{A}$ & 1.57 \\
\hline 4 & Oligyra & sp. & 4.8 & 7.5 & $\mathrm{~N} / \mathrm{A}$ & $\mathrm{N} / \mathrm{A}$ & 1.58 \\
\hline 4 & Oligyra & sp. & 5.3 & 7.5 & $\mathrm{~N} / \mathrm{A}$ & $\mathrm{N} / \mathrm{A}$ & 1.41 \\
\hline 4 & Oligyra & $\mathrm{sp}$. & 5.2 & 7.6 & $\mathrm{~N} / \mathrm{A}$ & $\mathrm{N} / \mathrm{A}$ & 1.46 \\
\hline 4 & Oligyra & $\mathrm{sp}$. & 4.9 & 6.9 & $\mathrm{~N} / \mathrm{A}$ & $\mathrm{N} / \mathrm{A}$ & 1.41 \\
\hline 4 & Oligyra & sp. & 4.9 & 7.2 & $\mathrm{~N} / \mathrm{A}$ & $\mathrm{N} / \mathrm{A}$ & 1.46 \\
\hline 4 & Oligyra & $\mathrm{sp}$. & 5.1 & 7.2 & $\mathrm{~N} / \mathrm{A}$ & $\mathrm{N} / \mathrm{A}$ & 1.43 \\
\hline 4 & Oligyra & $\mathrm{sp}$. & 4.9 & 7.4 & $\mathrm{~N} / \mathrm{A}$ & $\mathrm{N} / \mathrm{A}$ & 1.53 \\
\hline 4 & Oligyra & $\mathrm{sp}$. & 5.3 & 7.7 & $\mathrm{~N} / \mathrm{A}$ & $\mathrm{N} / \mathrm{A}$ & 1.45 \\
\hline 4 & Oligyra & sp. & 5 & 7 & $\mathrm{~N} / \mathrm{A}$ & N/A & 1.41 \\
\hline 4 & Oligyra & sp. & 5.1 & 7 & $\mathrm{~N} / \mathrm{A}$ & $\mathrm{N} / \mathrm{A}$ & 1.38 \\
\hline 4 & Oligyra & sp. & 5.3 & 7.6 & $\mathrm{~N} / \mathrm{A}$ & $\mathrm{N} / \mathrm{A}$ & 1.44 \\
\hline 4 & Oligyra & $\mathrm{sp}$. & 5.1 & 6.9 & $\mathrm{~N} / \mathrm{A}$ & $\mathrm{N} / \mathrm{A}$ & 1.34 \\
\hline 4 & Oligyra & $\mathrm{sp}$. & 4.9 & 7 & $\mathrm{~N} / \mathrm{A}$ & $\mathrm{N} / \mathrm{A}$ & 1.43 \\
\hline 4 & Oligyra & sp. & 5.8 & 7.8 & N/A & $\mathrm{N} / \mathrm{A}$ & 1.33 \\
\hline 4 & Oligyra & sp. & 4.6 & 7.1 & $\mathrm{~N} / \mathrm{A}$ & $\mathrm{N} / \mathrm{A}$ & 1.56 \\
\hline 4 & Oligyra & $\mathrm{sp}$. & 5 & 6.9 & $\mathrm{~N} / \mathrm{A}$ & $\mathrm{N} / \mathrm{A}$ & 1.38 \\
\hline 4 & Oligyra & $\mathrm{sp}$. & 4.8 & 7.5 & $\mathrm{~N} / \mathrm{A}$ & $\mathrm{N} / \mathrm{A}$ & 1.57 \\
\hline 4 & Oligyra & sp. & 5 & 7 & $\mathrm{~N} / \mathrm{A}$ & $\mathrm{N} / \mathrm{A}$ & 1.4 \\
\hline 4 & Oligyra & $\mathrm{sp}$. & 5.1 & 6.9 & $\mathrm{~N} / \mathrm{A}$ & $\mathrm{N} / \mathrm{A}$ & 1.35 \\
\hline 4 & Oligyra & sp. & 5.3 & 7.6 & $\mathrm{~N} / \mathrm{A}$ & $\mathrm{N} / \mathrm{A}$ & 1.43 \\
\hline 4 & Oligyra & sp. & 5.1 & 7.2 & $\mathrm{~N} / \mathrm{A}$ & $\mathrm{N} / \mathrm{A}$ & 1.41 \\
\hline 4 & Oligyra & sp. & 5.6 & 7.6 & $\mathrm{~N} / \mathrm{A}$ & $\mathrm{N} / \mathrm{A}$ & 1.37 \\
\hline 4 & Oligyra & $\mathrm{sp}$. & 5.1 & 7.3 & $\mathrm{~N} / \mathrm{A}$ & $\mathrm{N} / \mathrm{A}$ & 1.43 \\
\hline 4 & Oligyra & $\mathrm{sp}$. & 4.9 & 6.6 & $\mathrm{~N} / \mathrm{A}$ & $\mathrm{N} / \mathrm{A}$ & 1.35 \\
\hline
\end{tabular}


Table H-5. Continued...

\begin{tabular}{|c|c|c|c|c|c|c|c|}
\hline Area & Genus & Species & length (mm) & width (mm) & Carina & Calus & Weight (g.) \\
\hline 4 & Oligyra & sp. & 5.3 & 7 & $N / A$ & $\mathrm{~N} / \mathrm{A}$ & 1.33 \\
\hline 4 & Oligyra & sp. & 5.1 & 7.8 & N/A & $\mathrm{N} / \mathrm{A}$ & 1.54 \\
\hline 4 & Oligyra & sp. & 4.7 & 6.4 & N/A & $\mathrm{N} / \mathrm{A}$ & 1.37 \\
\hline 4 & Oligyra & sp. & 5.3 & 7.3 & N/A & $\mathrm{N} / \mathrm{A}$ & 1.38 \\
\hline 4 & Oligyra & sp. & 5.9 & 7.1 & N/A & $\mathrm{N} / \mathrm{A}$ & 1.2 \\
\hline 4 & Oligyra & sp. & 5.2 & 7.3 & $\mathrm{~N} / \mathrm{A}$ & $\mathrm{N} / \mathrm{A}$ & 1.4 \\
\hline 4 & Oligyra & sp. & 4.8 & 7.2 & $\mathrm{~N} / \mathrm{A}$ & $\mathrm{N} / \mathrm{A}$ & 1.5 \\
\hline 4 & Oligyra & sp. & 5.1 & 7.5 & N/A & $\mathrm{N} / \mathrm{A}$ & 1.46 \\
\hline 4 & Oligyra & sp. & 4.9 & 7.4 & N/A & $\mathrm{N} / \mathrm{A}$ & 1.5 \\
\hline 4 & Oligyra & sp. & 4.9 & 7.6 & $N / A$ & $\mathrm{~N} / \mathrm{A}$ & 1.56 \\
\hline 4 & Oligyra & sp. & 3.2 & 5.2 & $\mathrm{~N} / \mathrm{A}$ & $\mathrm{N} / \mathrm{A}$ & 1.64 \\
\hline 4 & Oligyra & sp. & 4.8 & 7.1 & N/A & $N / A$ & 1.47 \\
\hline 4 & Oligyra & sp. & 4.4 & 6.8 & $\mathrm{~N} / \mathrm{A}$ & $\mathrm{N} / \mathrm{A}$ & 1.53 \\
\hline 4 & Oligyra & sp. & 3.9 & 5.7 & $\mathrm{~N} / \mathrm{A}$ & $\mathrm{N} / \mathrm{A}$ & 1.47 \\
\hline 4 & Oligyra & sp. & 4.4 & 6.3 & $\mathrm{~N} / \mathrm{A}$ & $\mathrm{N} / \mathrm{A}$ & 1.42 \\
\hline 4 & Oligyra & sp. & 5.1 & 7.4 & N/A & $N / A$ & 1.46 \\
\hline 4 & Oligyra & sp. & 4.7 & 7.1 & N/A & $\mathrm{N} / \mathrm{A}$ & 1.5 \\
\hline 4 & Oligyra & sp. & 4.9 & 7 & $\mathrm{~N} / \mathrm{A}$ & $N / A$ & 1.45 \\
\hline 4 & Oligyra & sp. & 5 & 7.3 & N/A & $N / A$ & 1.47 \\
\hline 4 & Oligyra & sp. & 5.2 & 7.2 & N/A & $\mathrm{N} / \mathrm{A}$ & 1.36 \\
\hline 4 & Oligyra & sp. & 5.1 & 7.1 & $\mathrm{~N} / \mathrm{A}$ & $N / A$ & 1.38 \\
\hline 4 & Oligyra & sp. & 4.3 & 6.5 & $\mathrm{~N} / \mathrm{A}$ & $\mathrm{N} / \mathrm{A}$ & 1.52 \\
\hline 4 & Oligyra & $\mathrm{sp}$. & 5.8 & 7.2 & $\mathrm{~N} / \mathrm{A}$ & $\mathrm{N} / \mathrm{A}$ & 1.23 \\
\hline 4 & Oligyra & sp. & 6.2 & 7.5 & $\mathrm{~N} / \mathrm{A}$ & $\mathrm{N} / \mathrm{A}$ & 1.22 \\
\hline 4 & Oligyra & sp. & 5.5 & 7.4 & N/A & $\mathrm{N} / \mathrm{A}$ & 1.36 \\
\hline 4 & Oligyra & sp. & 4.9 & 7.2 & $\mathrm{~N} / \mathrm{A}$ & $\mathrm{N} / \mathrm{A}$ & 1.46 \\
\hline 4 & Oligyra & sp. & 5 & 7.2 & N/A & $\mathrm{N} / \mathrm{A}$ & 1.46 \\
\hline 4 & Oligyra & sp. & 5.3 & 7.1 & $\mathrm{~N} / \mathrm{A}$ & $\mathrm{N} / \mathrm{A}$ & 1.33 \\
\hline 4 & Oligyra & sp. & 4.1 & 6.3 & $\mathrm{~N} / \mathrm{A}$ & $N / A$ & 1.53 \\
\hline 4 & Oligyra & sp. & 5.1 & 6.8 & $\mathrm{~N} / \mathrm{A}$ & N/A & 1.35 \\
\hline 4 & Oligyra & $\mathrm{sp}$. & 4.5 & 6.5 & $\mathrm{~N} / \mathrm{A}$ & $\mathrm{N} / \mathrm{A}$ & 1.43 \\
\hline 4 & Oligyra & sp. & 5.4 & 7.4 & N/A & $\mathrm{N} / \mathrm{A}$ & 1.38 \\
\hline 4 & Oligyra & sp. & 5.1 & 6.9 & $\mathrm{~N} / \mathrm{A}$ & $\mathrm{N} / \mathrm{A}$ & 1.35 \\
\hline 4 & Oligyra & sp. & 5 & 6.9 & $\mathrm{~N} / \mathrm{A}$ & $N / A$ & 1.38 \\
\hline 4 & Oligyra & sp. & 5 & 7.2 & N/A & $N / A$ & 1.44 \\
\hline 4 & Oligyra & sp. & 5 & 7.7 & $\mathrm{~N} / \mathrm{A}$ & $\mathrm{N} / \mathrm{A}$ & 1.54 \\
\hline 4 & Oligyra & sp. & 5 & 7 & $\mathrm{~N} / \mathrm{A}$ & $\mathrm{N} / \mathrm{A}$ & 1.41 \\
\hline 4 & Oligyra & sp. & 5.4 & 6.9 & $\mathrm{~N} / \mathrm{A}$ & $\mathrm{N} / \mathrm{A}$ & 1.27 \\
\hline 4 & Oligyra & sp. & 5 & 7 & N/A & $\mathrm{N} / \mathrm{A}$ & 1.38 \\
\hline 4 & Oligyra & sp. & 5 & 7.1 & N/A & $\mathrm{N} / \mathrm{A}$ & 1.42 \\
\hline 4 & Oligyra & sp. & 5.5 & 7.3 & N/A & $\mathrm{N} / \mathrm{A}$ & 1.33 \\
\hline 4 & Oligyra & sp. & 5.2 & 6.9 & $\mathrm{~N} / \mathrm{A}$ & $\mathrm{N} / \mathrm{A}$ & 1.34 \\
\hline 4 & Oligyra & sp. & 5.5 & 6.8 & $\mathrm{~N} / \mathrm{A}$ & $\mathrm{N} / \mathrm{A}$ & 1.24 \\
\hline 4 & Oligyra & sp. & 5 & 6.6 & $\mathrm{~N} / \mathrm{A}$ & $\mathrm{N} / \mathrm{A}$ & 1.31 \\
\hline 4 & Oligyra & sp. & 3.4 & 4.2 & $\mathrm{~N} / \mathrm{A}$ & $\mathrm{N} / \mathrm{A}$ & 1.24 \\
\hline 4 & Oligyra & sp. & 5.4 & 7.3 & $\mathrm{~N} / \mathrm{A}$ & N/A & 1.35 \\
\hline 4 & Oligyra & sp. & 5.3 & 7.3 & $\mathrm{~N} / \mathrm{A}$ & $\mathrm{N} / \mathrm{A}$ & 1.38 \\
\hline 4 & Oligyra & sp. & 5.2 & 7.4 & N/A & $\mathrm{N} / \mathrm{A}$ & 1.44 \\
\hline 4 & Oligyra & sp. & 5.5 & 7.7 & $\mathrm{~N} / \mathrm{A}$ & $\mathrm{N} / \mathrm{A}$ & 1.39 \\
\hline 4 & Oligyra & sp. & 4.9 & 7.4 & N/A & $\mathrm{N} / \mathrm{A}$ & 1.51 \\
\hline 4 & Oligyra & sp. & 4.4 & 6.6 & $\mathrm{~N} / \mathrm{A}$ & $\mathrm{N} / \mathrm{A}$ & 1.48 \\
\hline 4 & Oligyra & sp. & 4 & 6 & $\mathrm{~N} / \mathrm{A}$ & $\mathrm{N} / \mathrm{A}$ & 1.5 \\
\hline 4 & Oligyra & sp. & 3.6 & 5.5 & $\mathrm{~N} / \mathrm{A}$ & $\mathrm{N} / \mathrm{A}$ & 1.54 \\
\hline 4 & Oligyra & sp. & 5.4 & 7.2 & $\mathrm{~N} / \mathrm{A}$ & $\mathrm{N} / \mathrm{A}$ & 1.34 \\
\hline 4 & Oligyra & $\mathrm{sp}$. & 5.2 & 7.4 & N/A & $\mathrm{N} / \mathrm{A}$ & 1.43 \\
\hline
\end{tabular}


Table H-5. Continued...

\begin{tabular}{|c|c|c|c|c|c|c|c|}
\hline Area & Genus & Species & length $(\mathrm{mm})$ & width $(\mathrm{mm})$ & Carina & Calus & Weight (g.) \\
\hline 4 & Oligyra & sp. & 5.4 & 7.2 & $N / A$ & $N / A$ & 1.34 \\
\hline 4 & Oligyra & sp. & 5.4 & 7.4 & $N / A$ & $\mathrm{~N} / \mathrm{A}$ & 1.39 \\
\hline 4 & Oligyra & sp. & 5.1 & 7 & N/A & $N / A$ & 1.37 \\
\hline 4 & Oligyra & sp. & 4.7 & 5.7 & $\mathrm{~N} / \mathrm{A}$ & $\mathrm{N} / \mathrm{A}$ & 1.21 \\
\hline 4 & Oligyra & sp. & 5 & 6.9 & $N / A$ & $N / A$ & 1.37 \\
\hline 4 & Oligyra & sp. & 5.4 & 7.1 & $N / A$ & $N / A$ & 1.32 \\
\hline 4 & Oligyra & sp. & 5.1 & 7.9 & $N / A$ & $N / A$ & 1.53 \\
\hline 4 & Oligyra & sp. & 4.8 & 6.9 & $N / A$ & $N / A$ & 1.45 \\
\hline 4 & Oligyra & sp. & 5 & 7.5 & $N / A$ & $N / A$ & 1.5 \\
\hline 4 & Oligyra & sp. & 5.1 & 7 & $N / A$ & $\mathrm{~N} / \mathrm{A}$ & 1.38 \\
\hline 4 & Oligyra & sp. & 5.4 & 7 & N/A & $N / A$ & 1.28 \\
\hline 4 & Oligyra & sp. & 5.8 & 7.3 & $\mathrm{~N} / \mathrm{A}$ & $N / A$ & 1.26 \\
\hline 4 & Oligyra & sp. & 5.3 & 7.5 & $N / A$ & $N / A$ & 1.41 \\
\hline 4 & Oligyra & sp. & 4.9 & 7.4 & $N / A$ & $N / A$ & 1.51 \\
\hline 4 & Oligyra & sp. & 5.4 & 7.6 & $N / A$ & $N / A$ & 1.4 \\
\hline 4 & Oligyra & sp. & 4.8 & 7.2 & $N / A$ & $N / A$ & 1.49 \\
\hline 4 & Oligyra & sp. & 5.3 & 7.3 & $N / A$ & $\mathrm{~N} / \mathrm{A}$ & 1.36 \\
\hline 4 & Oligyra & sp. & 4.3 & 6.4 & $\mathrm{~N} / \mathrm{A}$ & $\mathrm{N} / \mathrm{A}$ & 1.51 \\
\hline 4 & Oligyra & sp. & 5 & 7.2 & $\mathrm{~N} / \mathrm{A}$ & N/A & 1.44 \\
\hline 4 & Oligyra & sp. & 4.7 & 7.3 & N/A & N/A & 1.54 \\
\hline 4 & Oligyra & sp. & 4.8 & 7.5 & $N / A$ & $N / A$ & 1.57 \\
\hline 4 & Oligyra & $\mathrm{sp}$. & 3.4 & 5.3 & $N / A$ & $N / A$ & 1.53 \\
\hline 4 & Oligyra & sp. & 5.2 & 7.5 & $N / A$ & $N / A$ & 1.43 \\
\hline 4 & Oligyra & sp. & 5.6 & 7.3 & $N / A$ & $N / A$ & 1.31 \\
\hline 4 & Oligyra & sp. & 5.2 & 7.3 & $\mathrm{~N} / \mathrm{A}$ & $N / A$ & 1.4 \\
\hline 4 & Oligyra & sp. & 4.5 & 6.7 & N/A & $\mathrm{N} / \mathrm{A}$ & 1.48 \\
\hline 4 & Oligyra & sp. & 3.3 & 5.3 & N/A & $\mathrm{N} / \mathrm{A}$ & 1.61 \\
\hline 4 & Oligyra & sp. & 4.8 & 7.2 & N/A & N/A & 1.51 \\
\hline 4 & Oligyra & sp. & 4.3 & 7.2 & $N / A$ & $N / A$ & 1.68 \\
\hline 4 & Oligyra & sp. & 3.1 & 4.7 & $N / A$ & $N / A$ & 1.52 \\
\hline 4 & Oligyra & sp. & 5.7 & 7.6 & $N / A$ & $N / A$ & 1.34 \\
\hline 4 & Oligyra & sp. & 5.3 & 7 & $N / A$ & $N / A$ & 1.32 \\
\hline 4 & Oligyra & sp. & 3.9 & 6 & $N / A$ & $N / A$ & 1.54 \\
\hline 4 & Oligyra & sp. & 5.5 & 7.3 & N/A & $\mathrm{N} / \mathrm{A}$ & 1.32 \\
\hline 4 & Oligyra & sp. & 4.9 & 7.4 & N/A & $\mathrm{N} / \mathrm{A}$ & 1.49 \\
\hline 4 & Oligyra & sp. & 4.6 & 7.2 & N/A & $N / A$ & 1.56 \\
\hline 4 & Oligyra & sp. & 5.2 & 7.1 & $\mathrm{~N} / \mathrm{A}$ & $\mathrm{N} / \mathrm{A}$ & 1.38 \\
\hline 4 & Oligyra & sp. & 4.9 & 7.2 & $N / A$ & $N / A$ & 1.48 \\
\hline 4 & Oligyra & sp. & 4.4 & 6.2 & $N / A$ & $N / A$ & 1.4 \\
\hline 4 & Oligyra & sp. & 5.1 & 7 & $N / A$ & $\mathrm{~N} / \mathrm{A}$ & 1.37 \\
\hline 4 & Oligyra & sp. & 4.9 & 7.3 & N/A & $N / A$ & 1.51 \\
\hline 4 & Oligyra & sp. & 4.6 & 5.9 & $\mathrm{~N} / \mathrm{A}$ & N/A & 1.28 \\
\hline 4 & Rabdotus & sp. & 19.8 & 12.2 & $\mathrm{~N}$ & $\mathrm{Y}$ & 0.62 \\
\hline 4 & Rabdotus & sp. & 20.7 & 11.9 & $\mathrm{~N}$ & $Y$ & 0.57 \\
\hline 4 & Rabdotus & sp. & 23.3 & 11.7 & $\mathrm{~N}$ & $\mathrm{Y}$ & 0.5 \\
\hline 4 & Rabdotus & sp. & 23.3 & 13.7 & $\mathrm{~N}$ & $\mathrm{Y}$ & 0.59 \\
\hline 4 & Rabdotus & sp. & 18.9 & 10.5 & $\mathrm{~N}$ & $\mathrm{~N}$ & 0.56 \\
\hline 4 & Rabdotus & sp. & 13 & 8 & $Y$ & $\mathrm{~N}$ & 0.62 \\
\hline 4 & Rabdotus & sp. & 16.5 & 10 & Y & $\mathrm{N}$ & 0.61 \\
\hline 4 & Rabdotus & sp. & 18.2 & 9.9 & Y & $\mathrm{N}$ & 0.54 \\
\hline 4 & Rabdotus & sp. & 16.2 & 10.2 & $\mathrm{Y}$ & $\mathrm{N}$ & 0.63 \\
\hline 4 & Rabdotus & sp. & 22.3 & 12.3 & $\mathrm{~N}$ & Y & 0.55 \\
\hline 4 & Rabdotus & sp. & 21.2 & 12.5 & $\mathrm{Y}$ & $\mathrm{N}$ & 0.59 \\
\hline 4 & Rabdotus & sp. & 17.3 & 10.5 & $\mathrm{~N}$ & $\mathrm{~N}$ & 0.61 \\
\hline 4 & Rabdotus & sp. & 23.6 & 12.8 & $\mathrm{~N}$ & Y & 0.54 \\
\hline
\end{tabular}


Table H-5. Continued...

\begin{tabular}{|c|c|c|c|c|c|c|c|}
\hline Area & Genus & Species & length (mm) & width $(\mathrm{mm})$ & Carina & Calus & Weight (g.) \\
\hline 4 & Rabdotus & sp. & 19.9 & 11.7 & $\mathrm{~N}$ & $\mathrm{~N}$ & 0.59 \\
\hline 4 & Rabdotus & sp. & 22.7 & 11.8 & $\mathrm{~N}$ & $\mathrm{~N}$ & 0.52 \\
\hline 4 & Rabdotus & sp. & 21.6 & 11.7 & $\mathrm{~N}$ & $Y$ & 0.54 \\
\hline 4 & Rabdotus & sp. & 24.2 & 13.8 & $\mathrm{~N}$ & $Y$ & 0.57 \\
\hline 4 & Rabdotus & sp. & 27.5 & 14.4 & $\mathrm{~N}$ & $Y$ & 0.52 \\
\hline 4 & Rabdotus & sp. & 24.5 & 12.1 & $\mathrm{~N}$ & $Y$ & 0.49 \\
\hline 4 & Rabdotus & sp. & 22.5 & 13.3 & $\mathrm{~N}$ & $Y$ & 0.59 \\
\hline 4 & Rabdotus & sp. & 23.9 & 13.1 & $\mathrm{~N}$ & $Y$ & 0.55 \\
\hline 4 & Rabdotus & sp. & 22.8 & 12.7 & $\mathrm{~N}$ & $Y$ & 0.56 \\
\hline 4 & Rabdotus & sp. & 21.2 & 11.3 & $\mathrm{~N}$ & $\mathrm{~N}$ & 0.53 \\
\hline 4 & Rabdotus & sp. & 24.7 & 13.3 & $\mathrm{~N}$ & $Y$ & 0.54 \\
\hline 4 & Rabdotus & sp. & 23.5 & 12 & $\mathrm{~N}$ & $\mathrm{~N}$ & 0.51 \\
\hline 4 & Rabdotus & sp. & 22.1 & 12.2 & $\mathrm{~N}$ & $Y$ & 0.55 \\
\hline 4 & Rabdotus & sp. & 22.1 & 11.4 & $\mathrm{~N}$ & $Y$ & 0.52 \\
\hline 4 & Rabdotus & sp. & 19.5 & 11.4 & $\mathrm{~N}$ & $\mathrm{~N}$ & 0.58 \\
\hline 4 & Rabdotus & sp. & 22.2 & 12.2 & $\mathrm{~N}$ & Y & 0.55 \\
\hline 4 & Rabdotus & sp. & 14.4 & 9.8 & $Y$ & $\mathrm{~N}$ & 0.68 \\
\hline 4 & Rabdotus & sp. & 12.8 & 8.2 & $Y$ & $\mathrm{~N}$ & 0.64 \\
\hline 4 & Rabdotus & sp. & 22.9 & 11.9 & $\mathrm{~N}$ & $Y$ & 0.52 \\
\hline 4 & Rabdotus & sp. & 24.2 & 12.8 & $\mathrm{~N}$ & $Y$ & 0.53 \\
\hline 4 & Rabdotus & sp. & 22.3 & 11.3 & $\mathrm{~N}$ & $Y$ & 0.51 \\
\hline 4 & Rabdotus & sp. & 24.4 & 11.9 & $\mathrm{~N}$ & $Y$ & 0.49 \\
\hline 4 & Rabdotus & sp. & 27.2 & 13.4 & $\mathrm{~N}$ & $Y$ & 0.49 \\
\hline 4 & Rabdotus & sp. & 22.8 & 12.7 & $\mathrm{~N}$ & $Y$ & 0.56 \\
\hline 4 & Rabdotus & sp. & 10.3 & 7 & $Y$ & $\mathrm{~N}$ & 0.68 \\
\hline 4 & Rabdotus & sp. & 22.9 & 12.5 & $\mathrm{~N}$ & $Y$ & 0.55 \\
\hline 4 & Rabdotus & sp. & 24.2 & 12.9 & $\mathrm{~N}$ & $Y$ & 0.53 \\
\hline 4 & Rabdotus & sp. & 24.8 & 13.2 & $\mathrm{~N}$ & $Y$ & 0.53 \\
\hline 4 & Rabdotus & sp. & 25.1 & 13.9 & $\mathrm{~N}$ & $Y$ & 0.55 \\
\hline 4 & Rabdotus & sp. & 26.7 & 13.7 & $\mathrm{~N}$ & $Y$ & 0.51 \\
\hline 4 & Rabdotus & sp. & 6.2 & 4.3 & $Y$ & $\mathrm{~N}$ & 0.69 \\
\hline 4 & Rabdotus & sp. & 25.1 & 12.8 & $\mathrm{~N}$ & $Y$ & 0.51 \\
\hline 4 & Rabdotus & sp. & 22.9 & 12.2 & $\mathrm{~N}$ & $Y$ & 0.53 \\
\hline 4 & Rabdotus & sp. & 23.6 & 13.6 & $\mathrm{~N}$ & $Y$ & 0.58 \\
\hline 4 & Rabdotus & sp. & 22.2 & 12 & $\mathrm{~N}$ & $Y$ & 0.54 \\
\hline 4 & Rabdotus & sp. & 23.2 & 12.3 & $\mathrm{~N}$ & $Y$ & 0.53 \\
\hline 4 & Rabdotus & sp. & 22.6 & 13.7 & $\mathrm{~N}$ & $Y$ & 0.61 \\
\hline 4 & Rabdotus & sp. & 21.5 & 11.1 & $\mathrm{~N}$ & $Y$ & 0.52 \\
\hline 4 & Rabdotus & $\mathrm{sp}$. & 20.4 & 12 & $\mathrm{~N}$ & Y & 0.59 \\
\hline 4 & Rabdotus & sp. & 22.3 & 11.9 & $\mathrm{~N}$ & Y & 0.53 \\
\hline 4 & Rabdotus & sp. & 21.9 & 12.1 & $Y$ & $\mathrm{~N}$ & 0.55 \\
\hline 4 & Rabdotus & sp. & 22.1 & 11.7 & $\mathrm{~N}$ & $Y$ & 0.53 \\
\hline 4 & Rabdotus & sp. & 23.1 & 12.5 & $\mathrm{~N}$ & $Y$ & 0.54 \\
\hline 4 & Rabdotus & sp. & 12.1 & 7.8 & $Y$ & $\mathrm{~N}$ & 0.64 \\
\hline 4 & Rabdotus & sp. & 22.8 & 11.3 & $\mathrm{~N}$ & $\mathrm{~N}$ & 0.5 \\
\hline 4 & Rabdotus & sp. & 23.8 & 13.2 & $\mathrm{~N}$ & $Y$ & 0.55 \\
\hline 4 & Rabdotus & sp. & 25.2 & 13.8 & $\mathrm{~N}$ & Y & 0.55 \\
\hline 4 & Rabdotus & sp. & 22 & 11.7 & $\mathrm{~N}$ & $\mathrm{~N}$ & 0.53 \\
\hline 4 & Rabdotus & sp. & 25.2 & 12.9 & $\mathrm{~N}$ & $Y$ & 0.51 \\
\hline 4 & Rabdotus & sp. & 21.3 & 12.4 & $\mathrm{~N}$ & $Y$ & 0.58 \\
\hline 4 & Rabdotus & sp. & 21.1 & 11.6 & $\mathrm{~N}$ & $Y$ & 0.55 \\
\hline 4 & Rabdotus & sp. & 21.1 & 12.5 & $\mathrm{Y}$ & $\mathrm{N}$ & 0.59 \\
\hline 4 & Rabdotus & sp. & 25.8 & 14.2 & $\mathrm{~N}$ & $Y$ & 0.55 \\
\hline 4 & Rabdotus & sp. & 21.7 & 11.8 & $\mathrm{~N}$ & $\mathrm{Y}$ & 0.54 \\
\hline 4 & Rabdotus & sp. & 23.2 & 12.1 & $\mathrm{~N}$ & $Y$ & 0.52 \\
\hline
\end{tabular}


Table H-5. Continued...

\begin{tabular}{|c|c|c|c|c|c|c|c|}
\hline Area & Genus & Species & length $(\mathrm{mm})$ & width (mm) & Carina & Calus & Weight (g.) \\
\hline 4 & Rabdotus & sp. & 21.1 & 12.2 & $\mathrm{~N}$ & $Y$ & 0.58 \\
\hline 4 & Rabdotus & $\mathrm{sp}$. & 22.9 & 11.5 & $\mathrm{~N}$ & $\bar{Y}$ & 0.51 \\
\hline 4 & Rabdotus & sp. & 12.2 & 8.1 & $Y$ & $\mathrm{~N}$ & 0.66 \\
\hline 4 & Rabdotus & sp. & 13.6 & 8.7 & $\bar{Y}$ & $\mathrm{~N}$ & 0.64 \\
\hline 4 & Rabdotus & $\mathrm{sp}$. & 21.7 & 11.1 & $\mathrm{~N}$ & $\mathrm{~N}$ & 0.51 \\
\hline 4 & Rabdotus & $\mathrm{sp}$. & 22.7 & 12.2 & $\mathrm{~N}$ & $\bar{Y}$ & 0.54 \\
\hline 4 & Rabdotus & $\mathrm{sp}$. & 22.3 & 13.2 & $\mathrm{~N}$ & $Y$ & 0.59 \\
\hline 4 & Rabdotus & sp. & 22.7 & 11.6 & $\mathrm{~N}$ & $Y$ & 0.51 \\
\hline 4 & Rabdotus & sp. & 22.9 & 11.5 & $\mathrm{~N}$ & $Y$ & 0.5 \\
\hline 4 & Rabdotus & sp. & 21.1 & 12.4 & $\bar{Y}$ & $\mathrm{~N}$ & 0.59 \\
\hline 4 & Rabdotus & sp. & 20 & 10.4 & $Y$ & $\mathrm{~N}$ & 0.52 \\
\hline 4 & Rabdotus & $\mathrm{sp}$. & 20.4 & 11.1 & $\bar{Y}$ & $\mathrm{~N}$ & 0.54 \\
\hline 4 & Rabdotus & sp. & 22.7 & 11.6 & $Y$ & $\bar{Y}$ & 0.51 \\
\hline 4 & Rabdotus & sp. & 17.5 & 10.8 & $\mathrm{~N}$ & $Y$ & 0.61 \\
\hline 4 & Rabdotus & sp. & 23.3 & 12.1 & $\mathrm{~N}$ & $Y$ & 0.52 \\
\hline 4 & Rabdotus & sp. & 22.2 & 11.5 & $\mathrm{~N}$ & $\bar{Y}$ & 0.52 \\
\hline 4 & Rabdotus & sp. & 26 & 12.6 & $\mathrm{~N}$ & $\bar{Y}$ & 0.48 \\
\hline 4 & Rabdotus & sp. & 26.3 & 13.5 & $\mathrm{~N}$ & $\bar{Y}$ & 0.51 \\
\hline 4 & Rabdotus & $\mathrm{sp}$. & 21.4 & 11.9 & $\mathrm{~N}$ & $\bar{Y}$ & 0.55 \\
\hline 4 & Rabdotus & sp. & 26.4 & 13.7 & $\mathrm{~N}$ & $\bar{Y}$ & 0.52 \\
\hline 4 & Rabdotus & $\mathrm{sp}$. & 23.9 & 13.1 & $\mathrm{~N}$ & $\bar{Y}$ & 0.55 \\
\hline 4 & Rabdotus & $\mathrm{sp}$. & 23.4 & 12.7 & $\mathrm{~N}$ & $Y$ & 0.54 \\
\hline 4 & Rabdotus & $\mathrm{sp}$. & 20.3 & 12.2 & $\bar{Y}$ & $Y$ & 0.6 \\
\hline 4 & Rabdotus & $\mathrm{sp}$. & 21.6 & 12.7 & $\mathrm{~N}$ & $Y$ & 0.59 \\
\hline 4 & Rabdotus & $\mathrm{sp}$. & 24.4 & 12.4 & $\mathrm{~N}$ & $\bar{Y}$ & 0.51 \\
\hline 4 & Rabdotus & sp. & 22.4 & 11.7 & $Y$ & $\mathrm{~N}$ & 0.52 \\
\hline 4 & Rabdotus & sp. & 22.8 & 12.9 & $\mathrm{~N}$ & $Y$ & 0.57 \\
\hline 4 & Rabdotus & sp. & 19 & 10.5 & $\mathrm{~N}$ & $Y$ & 0.55 \\
\hline 4 & Rabdotus & sp. & 23.8 & 13.2 & $\mathrm{~N}$ & $\bar{Y}$ & 0.55 \\
\hline 4 & Rabdotus & sp. & 22.5 & 12.1 & $\mathrm{~N}$ & $Y$ & 0.54 \\
\hline 4 & Rabdotus & sp. & 23.9 & 13.4 & $\mathrm{~N}$ & $Y$ & 0.56 \\
\hline 4 & Rabdotus & sp. & 22.7 & 12.2 & $\mathrm{~N}$ & $Y$ & 0.54 \\
\hline 4 & Rabdotus & sp. & 23.2 & 12.6 & $\mathrm{~N}$ & $\bar{Y}$ & 0.54 \\
\hline 4 & Rabdotus & sp. & 21.8 & 12 & $\mathrm{~N}$ & $Y$ & 0.55 \\
\hline 4 & Rabdotus & sp. & 23.5 & 11.9 & $\mathrm{~N}$ & $Y$ & 0.51 \\
\hline 4 & Rabdotus & $\mathrm{sp}$. & 26 & 12.6 & $\mathrm{~N}$ & $\bar{Y}$ & 0.48 \\
\hline 4 & Rabdotus & sp. & 23 & 11.7 & $\mathrm{~N}$ & $\bar{Y}$ & 0.51 \\
\hline 4 & Rabdotus & sp. & 12.7 & 7.5 & $\bar{Y}$ & $\mathrm{~N}$ & 0.59 \\
\hline 4 & Rabdotus & $\mathrm{sp}$. & 17.2 & 9.9 & $Y$ & $\mathrm{~N}$ & 0.57 \\
\hline 4 & Rabdotus & $\mathrm{sp}$. & 10.7 & 6.8 & $\bar{Y}$ & $\mathrm{~N}$ & 0.64 \\
\hline 4 & Rabdotus & $\mathrm{sp}$. & 18.5 & 9.8 & $\mathrm{~N}$ & $Y$ & 0.53 \\
\hline 4 & Rabdotus & sp. & 22.2 & 12.7 & $\mathrm{~N}$ & $\bar{Y}$ & 0.57 \\
\hline 4 & Rabdotus & sp. & 22.4 & 11.4 & $\mathrm{~N}$ & $Y$ & 0.51 \\
\hline 4 & Rabdotus & $\mathrm{sp}$. & 23.1 & 12.3 & $\mathrm{~N}$ & $\bar{Y}$ & 0.53 \\
\hline 4 & Rabdotus & sp. & 23.6 & 11.9 & $\mathrm{~N}$ & $Y$ & 0.51 \\
\hline 4 & Rabdotus & sp. & 23.6 & 11.7 & $\mathrm{~N}$ & $Y$ & 0.5 \\
\hline 4 & Rabdotus & sp. & 22 & 12.3 & $Y$ & $\mathrm{~N}$ & 0.56 \\
\hline 4 & Rabdotus & sp. & 12.2 & 7.7 & $Y$ & $\mathrm{~N}$ & 0.63 \\
\hline 4 & Rabdotus & sp. & 15.1 & 9.7 & $Y$ & $\mathrm{~N}$ & 0.64 \\
\hline 4 & Rabdotus & sp. & 19.3 & 9.7 & $Y$ & $\mathrm{~N}$ & 0.5 \\
\hline 4 & Rabdotus & sp. & 21.3 & 11.5 & $Y$ & $\mathrm{~N}$ & 0.54 \\
\hline 4 & Rabdotus & sp. & 20.4 & 10.8 & $\mathrm{~N}$ & $Y$ & 0.53 \\
\hline 4 & Rabdotus & $\mathrm{sp}$. & 22.2 & 12.2 & $\mathrm{~N}$ & $\bar{Y}$ & 0.55 \\
\hline 4 & Rabdotus & sp. & 20.8 & 12.1 & $\mathrm{~N}$ & $Y$ & 0.58 \\
\hline 4 & Rabdotus & $\mathrm{sp}$. & 23.1 & 11.9 & $\mathrm{~N}$ & $Y$ & 0.52 \\
\hline
\end{tabular}


Table H-5. Continued...

\begin{tabular}{|c|c|c|c|c|c|c|c|}
\hline Area & Genus & Species & length (mm) & width (mm) & Carina & Calus & Weight (g.) \\
\hline 4 & Rabdotus & sp. & 26.7 & 12.6 & $\mathrm{~N}$ & $\bar{Y}$ & 0.47 \\
\hline 4 & Rabdotus & sp. & 23.8 & 12.2 & $\mathrm{~N}$ & $Y$ & 0.51 \\
\hline 4 & Rabdotus & sp. & 21.6 & 12.6 & $\mathrm{~N}$ & $Y$ & 0.58 \\
\hline 4 & Rabdotus & sp. & 22.4 & 12.7 & $\mathrm{~N}$ & $Y$ & 0.57 \\
\hline 4 & Rabdotus & sp. & 23 & 11.9 & $Y$ & $\mathrm{~N}$ & 0.52 \\
\hline 4 & Rabdotus & sp. & 20.4 & 11.2 & $\mathrm{~N}$ & $Y$ & 0.55 \\
\hline 4 & Rabdotus & sp. & 21.6 & 10.5 & $\mathrm{~N}$ & $\bar{Y}$ & 0.49 \\
\hline 4 & Rabdotus & sp. & 23.2 & 13.3 & $\mathrm{~N}$ & $Y$ & 0.57 \\
\hline 4 & Rabdotus & sp. & 22.2 & 12.3 & $\mathrm{~N}$ & $Y$ & 0.55 \\
\hline 4 & Rabdotus & sp. & 22.5 & 12.2 & $\mathrm{~N}$ & $\bar{Y}$ & 0.54 \\
\hline 4 & Rabdotus & sp. & 23.5 & 12.6 & $\mathrm{~N}$ & $Y$ & 0.54 \\
\hline 4 & Rabdotus & sp. & 21.6 & 11.6 & $Y$ & $\mathrm{~N}$ & 0.54 \\
\hline 4 & Rabdotus & sp. & 20.7 & 11.3 & $\mathrm{Y}$ & $\mathrm{N}$ & 0.55 \\
\hline 4 & Rabdotus & sp. & 22.2 & 11.8 & $\mathrm{Y}$ & $\mathrm{Y}$ & 0.53 \\
\hline 4 & Rabdotus & sp. & 19.1 & 10.8 & $\mathrm{~N}$ & $Y$ & 0.57 \\
\hline 4 & Rabdotus & sp. & 19.9 & 11.6 & $\bar{Y}$ & $\mathrm{~N}$ & 0.58 \\
\hline 4 & Rabdotus & sp. & 21.6 & 11.7 & $\mathrm{~N}$ & $Y$ & 0.54 \\
\hline 4 & Rabdotus & sp. & 22.2 & 11.7 & $\mathrm{~N}$ & $Y$ & 0.53 \\
\hline 4 & Rabdotus & sp. & 23.2 & 12.2 & $\mathrm{~N}$ & $Y$ & 0.53 \\
\hline 4 & Rabdotus & sp. & 20.8 & 11.6 & $Y$ & $Y$ & 0.56 \\
\hline 4 & Rabdotus & sp. & 18.1 & 11.4 & $Y$ & $Y$ & 0.63 \\
\hline 4 & Rabdotus & sp. & 22.8 & 11.4 & $\mathrm{~N}$ & $Y$ & 0.5 \\
\hline 4 & Rabdotus & sp. & 22.8 & 11.6 & $\mathrm{~N}$ & $Y$ & 0.51 \\
\hline 4 & Rabdotus & sp. & 22 & 12 & $\mathrm{~N}$ & $Y$ & 0.55 \\
\hline 4 & Rabdotus & sp. & 19.7 & 10.6 & $\bar{Y}$ & $\mathrm{~N}$ & 0.54 \\
\hline 4 & Rabdotus & sp. & 22.1 & 12.3 & $\mathrm{~N}$ & $Y$ & 0.56 \\
\hline 4 & Rabdotus & sp. & 18.2 & 10.6 & $\mathrm{~N}$ & $Y$ & 0.58 \\
\hline 4 & Rabdotus & sp. & 8.4 & 5.4 & $Y$ & $\mathrm{~N}$ & 0.64 \\
\hline 4 & Rabdotus & sp. & 20.9 & 11 & $\mathrm{~N}$ & $\mathrm{~N}$ & 0.53 \\
\hline 4 & Rabdotus & sp. & 23.4 & 12.8 & $\mathrm{~N}$ & $Y$ & 0.55 \\
\hline 4 & Rabdotus & sp. & 22.8 & 11.5 & $\mathrm{~N}$ & $\mathrm{~N}$ & 0.5 \\
\hline 4 & Rabdotus & sp. & 21.5 & 12.1 & $\mathrm{~N}$ & $Y$ & 0.56 \\
\hline 4 & Rabdotus & sp. & 20 & 12 & $Y$ & $\mathrm{~N}$ & 0.6 \\
\hline 4 & Rabdotus & sp. & 19.9 & 11.6 & $\mathrm{~N}$ & $\mathrm{~N}$ & 0.58 \\
\hline 4 & Rabdotus & sp. & 22.3 & 12 & $\mathrm{~N}$ & $Y$ & 0.54 \\
\hline 4 & Rabdotus & sp. & 14.3 & 8.1 & $Y$ & $\mathrm{~N}$ & 0.56 \\
\hline 4 & Rabdotus & sp. & 15.9 & 9.9 & $Y$ & $\mathrm{~N}$ & 0.62 \\
\hline 4 & Rabdotus & sp. & 22.5 & 12.1 & $\mathrm{~N}$ & $Y$ & 0.54 \\
\hline 4 & Rabdotus & sp. & 21.8 & 12.5 & $\mathrm{~N}$ & Y & 0.58 \\
\hline 4 & Rabdotus & sp. & 21 & 11.4 & $\mathrm{~N}$ & $Y$ & 0.54 \\
\hline 4 & Rabdotus & sp. & 21.9 & 10.6 & $Y$ & $\mathrm{~N}$ & 0.48 \\
\hline 4 & Rabdotus & sp. & 21.6 & 11.1 & $\mathrm{~N}$ & $Y$ & 0.51 \\
\hline 4 & Rabdotus & sp. & 21.9 & 11.8 & $\mathrm{Y}$ & $\mathrm{N}$ & 0.54 \\
\hline 4 & Rabdotus & sp. & 24 & 12 & $\mathrm{~N}$ & $Y$ & 0.5 \\
\hline 4 & Rabdotus & sp. & 24.7 & 12.9 & $\mathrm{~N}$ & $Y$ & 0.52 \\
\hline 4 & Rabdotus & sp. & 22.1 & 11.2 & $\mathrm{~N}$ & $Y$ & 0.51 \\
\hline 4 & Rabdotus & sp. & 20 & 10.7 & $\mathrm{~N}$ & $Y$ & 0.53 \\
\hline 4 & Rabdotus & sp. & 21.8 & 12.5 & $\mathrm{~N}$ & Y & 0.57 \\
\hline 4 & Rabdotus & sp. & 21.2 & 11.6 & $\mathrm{~N}$ & 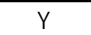 & 0.55 \\
\hline 4 & Rabdotus & sp. & 21.4 & 11.5 & $\mathrm{~N}$ & $Y$ & 0.54 \\
\hline 4 & Rabdotus & sp. & 22.7 & 12.3 & $\mathrm{~N}$ & $Y$ & 0.54 \\
\hline 4 & Rabdotus & sp. & 19.8 & 10.8 & $\mathrm{Y}$ & $\mathrm{Y}$ & 0.55 \\
\hline 4 & Rabdotus & sp. & 24.1 & 12 & $\mathrm{~N}$ & $Y$ & 0.5 \\
\hline 4 & Rabdotus & sp. & 24.3 & 14.6 & $\mathrm{~N}$ & $Y$ & 0.6 \\
\hline 4 & Rabdotus & sp. & 23.1 & 12.8 & $\mathrm{~N}$ & $Y$ & 0.55 \\
\hline
\end{tabular}


Table H-5. Continued...

\begin{tabular}{|c|c|c|c|c|c|c|c|}
\hline Area & Genus & Species & length $(\mathrm{mm})$ & width (mm) & Carina & Calus & Weight (g.) \\
\hline 4 & Rabdotus & sp. & 22.2 & 11.1 & $\mathrm{~N}$ & $Y$ & 0.5 \\
\hline 4 & Rabdotus & sp. & 23 & 11.8 & $\mathrm{~N}$ & $Y$ & 0.51 \\
\hline 4 & Rabdotus & sp. & 21.2 & 11.8 & $\mathrm{~N}$ & $Y$ & 0.56 \\
\hline 4 & Rabdotus & sp. & 24.8 & 13.5 & $\mathrm{~N}$ & $\mathrm{Y}$ & 0.54 \\
\hline 4 & Rabdotus & sp. & 21.4 & 11.2 & $\mathrm{~N}$ & $\mathrm{Y}$ & 0.52 \\
\hline 4 & Rabdotus & sp. & 22.4 & 11.7 & $\mathrm{~N}$ & $\bar{Y}$ & 0.52 \\
\hline 4 & Rabdotus & sp. & 21.2 & 11.9 & $\mathrm{~N}$ & $Y$ & 0.56 \\
\hline 4 & Rabdotus & sp. & 21.3 & 11.6 & $\mathrm{~N}$ & $\mathrm{Y}$ & 0.55 \\
\hline 4 & Rabdotus & sp. & 20.8 & 10.9 & $\mathrm{~N}$ & $Y$ & 0.53 \\
\hline 4 & Rabdotus & sp. & 20.6 & 11.5 & $\mathrm{~N}$ & $Y$ & 0.56 \\
\hline 4 & Rabdotus & sp. & 22.9 & 12 & $\mathrm{~N}$ & Y & 0.52 \\
\hline 4 & Rabdotus & sp. & 20.6 & 11.2 & $\mathrm{~N}$ & $\bar{Y}$ & 0.54 \\
\hline 4 & Rabdotus & sp. & 22.3 & 11.7 & $\mathrm{~N}$ & Y & 0.53 \\
\hline 4 & Rabdotus & sp. & 18.4 & 9.9 & $\mathrm{~N}$ & $Y$ & 0.53 \\
\hline 4 & Rabdotus & sp. & 19.7 & 10.5 & $\mathrm{~N}$ & $\bar{Y}$ & 0.53 \\
\hline 4 & Rabdotus & sp. & 19 & 10.6 & $\mathrm{~N}$ & $\mathrm{Y}$ & 0.56 \\
\hline 4 & Rabdotus & $\mathrm{sp}$. & 20.1 & 10.6 & $\mathrm{~N}$ & $\bar{Y}$ & 0.53 \\
\hline 4 & Rabdotus & sp. & 23.8 & 11.9 & $\mathrm{~N}$ & $Y$ & 0.5 \\
\hline 4 & Rabdotus & sp. & 22.1 & 11.5 & $\mathrm{~N}$ & $\mathrm{Y}$ & 0.52 \\
\hline 4 & Rabdotus & sp. & 23.4 & 12.1 & $\mathrm{~N}$ & Y & 0.52 \\
\hline 4 & Rabdotus & sp. & 19.2 & 10.6 & $\mathrm{~N}$ & $\mathrm{~N}$ & 0.55 \\
\hline 4 & Rabdotus & sp. & 20.8 & 11.1 & $Y$ & $\mathrm{~N}$ & 0.53 \\
\hline 4 & Rabdotus & sp. & 20.3 & 11 & $\mathrm{Y}$ & $\mathrm{N}$ & 0.54 \\
\hline 4 & Rabdotus & sp. & 18.8 & 11.6 & $\mathrm{~N}$ & $\mathrm{~N}$ & 0.62 \\
\hline 4 & Rabdotus & sp. & 13.2 & 7.6 & $\mathrm{Y}$ & $\mathrm{N}$ & 0.58 \\
\hline 4 & Rabdotus & sp. & 19.5 & 10.8 & $\mathrm{~N}$ & $Y$ & 0.55 \\
\hline 4 & Rabdotus & sp. & 20.1 & 11.1 & $\mathrm{~N}$ & $Y$ & 0.55 \\
\hline 4 & Rabdotus & sp. & 22.2 & 11.3 & $\mathrm{~N}$ & Y & 0.51 \\
\hline 4 & Rabdotus & sp. & 19.6 & 10 & $\mathrm{~N}$ & Y & 0.51 \\
\hline 4 & Rabdotus & sp. & 23.7 & 11.9 & $\mathrm{~N}$ & $Y$ & 0.5 \\
\hline 4 & Rabdotus & sp. & 24.1 & 12.3 & $\mathrm{~N}$ & $Y$ & 0.51 \\
\hline 4 & Rabdotus & sp. & 22 & 12 & $\mathrm{~N}$ & $Y$ & 0.55 \\
\hline 4 & Rabdotus & sp. & 21.7 & 11.1 & $\mathrm{~N}$ & $Y$ & 0.51 \\
\hline 4 & Rabdotus & sp. & 21.7 & 11.6 & $\mathrm{~N}$ & $Y$ & 0.53 \\
\hline 4 & Rabdotus & sp. & 20.2 & 11 & $\mathrm{~N}$ & Y & 0.54 \\
\hline 4 & Rabdotus & sp. & 19 & 10.2 & Y & Y & 0.53 \\
\hline 4 & Rabdotus & sp. & 19.5 & 11.5 & $\mathrm{~N}$ & $Y$ & 0.59 \\
\hline 4 & Rabdotus & sp. & 21.4 & 11.2 & $\mathrm{~N}$ & $Y$ & 0.52 \\
\hline 4 & Rabdotus & sp. & 21.8 & 11.7 & $\mathrm{~N}$ & Y & 0.54 \\
\hline 4 & Rabdotus & sp. & 21.6 & 11.5 & $\mathrm{~N}$ & $Y$ & 0.53 \\
\hline 4 & Rabdotus & sp. & 22.2 & 11.9 & $\mathrm{~N}$ & $\mathrm{Y}$ & 0.54 \\
\hline 4 & Rabdotus & sp. & 22.1 & 11.6 & $\mathrm{~N}$ & $\mathrm{Y}$ & 0.53 \\
\hline 4 & Rabdotus & $\mathrm{sp}$. & 22.5 & 12.4 & $\mathrm{~N}$ & $Y$ & 0.55 \\
\hline 4 & Rabdotus & sp. & 24.7 & 12.1 & $\mathrm{~N}$ & Y & 0.49 \\
\hline 4 & Rabdotus & sp. & 21.8 & 11.8 & $\mathrm{~N}$ & Y & 0.54 \\
\hline 4 & Rabdotus & sp. & 23.9 & 12.6 & $\mathrm{~N}$ & $\mathrm{~N}$ & 0.53 \\
\hline 4 & Rabdotus & sp. & 20.2 & 12.4 & $\mathrm{~N}$ & $Y$ & 0.61 \\
\hline 4 & Rabdotus & sp. & 20.6 & 11.5 & $\mathrm{~N}$ & $Y$ & 0.56 \\
\hline 4 & Rabdotus & sp. & 18.4 & 10.5 & $\mathrm{~N}$ & $\mathrm{~N}$ & 0.57 \\
\hline 4 & Rabdotus & sp. & 22.2 & 11.6 & $\mathrm{~N}$ & $Y$ & 0.53 \\
\hline 4 & Rabdotus & sp. & 20.8 & 12.2 & $\mathrm{~N}$ & $Y$ & 0.59 \\
\hline 4 & Rabdotus & sp. & 20.2 & 11.2 & $\mathrm{~N}$ & $Y$ & 0.56 \\
\hline 4 & Rabdotus & sp. & 20.6 & 11.2 & $\mathrm{~N}$ & $\mathrm{~N}$ & 0.55 \\
\hline 4 & Rabdotus & sp. & 22.2 & 12.7 & $\mathrm{~N}$ & Y & 0.57 \\
\hline 4 & Rabdotus & sp. & 22.3 & 11.6 & $\mathrm{~N}$ & $Y$ & 0.52 \\
\hline
\end{tabular}


Table H-5. Continued...

\begin{tabular}{|c|c|c|c|c|c|c|c|}
\hline Area & Genus & Species & length $(\mathrm{mm})$ & width $(\mathrm{mm})$ & Carina & Calus & Weight (g.) \\
\hline 4 & Rabdotus & sp. & 19.8 & 11.2 & $\mathrm{~N}$ & $Y$ & 0.57 \\
\hline 4 & Rabdotus & sp. & 23.1 & 11.3 & $\mathrm{~N}$ & $Y$ & 0.49 \\
\hline 4 & Rabdotus & sp. & 21.8 & 12.3 & $\mathrm{~N}$ & $\mathrm{Y}$ & 0.56 \\
\hline 4 & Rabdotus & sp. & 23.1 & 12.2 & $\mathrm{~N}$ & $\mathrm{Y}$ & 0.53 \\
\hline 4 & Rabdotus & sp. & 19.3 & 11.2 & $\mathrm{~N}$ & $\mathrm{~N}$ & 0.58 \\
\hline 4 & Rabdotus & sp. & 24.5 & 12 & $\mathrm{~N}$ & $\mathrm{Y}$ & 0.49 \\
\hline 4 & Rabdotus & sp. & 21.1 & 11.5 & $\mathrm{~N}$ & $Y$ & 0.55 \\
\hline 4 & Rabdotus & sp. & 21.4 & 12.2 & $\mathrm{~N}$ & $Y$ & 0.57 \\
\hline 4 & Rabdotus & $\mathrm{sp}$. & 22.1 & 12.6 & $\mathrm{~N}$ & $\mathrm{~N}$ & 0.57 \\
\hline 4 & Rabdotus & sp. & 21.9 & 12.7 & $\mathrm{~N}$ & $Y$ & 0.58 \\
\hline 4 & Rabdotus & sp. & 22.3 & 12.3 & $\mathrm{~N}$ & $\mathrm{Y}$ & 0.55 \\
\hline 4 & Rabdotus & sp. & 21.2 & 11.5 & $\mathrm{~N}$ & $\mathrm{~N}$ & 0.54 \\
\hline 4 & Rabdotus & sp. & 21 & 11.1 & $\mathrm{~N}$ & $\mathrm{Y}$ & 0.53 \\
\hline 4 & Rabdotus & sp. & 19.7 & 10.6 & $\mathrm{~N}$ & $Y$ & 0.54 \\
\hline 4 & Rabdotus & sp. & 20.1 & 11.7 & $\mathrm{~N}$ & $Y$ & 0.58 \\
\hline 4 & Rabdotus & $\mathrm{sp}$. & 21.4 & 12.3 & $\mathrm{~N}$ & $Y$ & 0.57 \\
\hline 4 & Rabdotus & sp. & 20.3 & 11 & $\mathrm{~N}$ & $Y$ & 0.54 \\
\hline 4 & Rabdotus & sp. & 17.5 & 10.2 & $\mathrm{~N}$ & $Y$ & 0.59 \\
\hline 4 & Rabdotus & $\mathrm{sp}$. & 22 & 12.2 & $\mathrm{~N}$ & $Y$ & 0.55 \\
\hline 4 & Rabdotus & sp. & 24.2 & 12.7 & $\mathrm{~N}$ & $\mathrm{Y}$ & 0.53 \\
\hline 4 & Rabdotus & sp. & 17.3 & 10 & $\mathrm{~N}$ & $\mathrm{~N}$ & 0.58 \\
\hline 4 & Rabdotus & sp. & 19.4 & 11 & $\mathrm{~N}$ & $\mathrm{~N}$ & 0.57 \\
\hline 4 & Rabdotus & sp. & 17.9 & 10.4 & $\mathrm{~N}$ & Y & 0.58 \\
\hline 4 & Rabdotus & sp. & 20.4 & 10.7 & $\mathrm{~N}$ & $Y$ & 0.53 \\
\hline 4 & Rabdotus & sp. & 17.9 & 10.1 & $\mathrm{~N}$ & $Y$ & 0.57 \\
\hline 4 & Rabdotus & sp. & 19.9 & 11.9 & $\mathrm{~N}$ & $Y$ & 0.6 \\
\hline 4 & Rabdotus & sp. & 21.2 & 11.9 & $\mathrm{~N}$ & $\mathrm{~N}$ & 0.56 \\
\hline 4 & Rabdotus & sp. & 13.7 & 8.6 & $Y$ & $\mathrm{~N}$ & 0.63 \\
\hline 4 & Rabdotus & sp. & 11.5 & 7.2 & $\mathrm{Y}$ & $\mathrm{N}$ & 0.63 \\
\hline 4 & Rabdotus & sp. & 12.5 & 7.3 & $Y$ & $\mathrm{~N}$ & 0.59 \\
\hline 4 & Rabdotus & sp. & 14.4 & 8.7 & $Y$ & $\mathrm{~N}$ & 0.6 \\
\hline 4 & Rabdotus & $\mathrm{sp}$. & 19 & 10.4 & $Y$ & $\mathrm{~N}$ & 0.55 \\
\hline 4 & Rabdotus & sp. & 10.6 & 7.1 & $Y$ & $\mathrm{~N}$ & 0.67 \\
\hline 4 & Rabdotus & sp. & 11.8 & 7.3 & $Y$ & $\mathrm{~N}$ & 0.62 \\
\hline 4 & Rabdotus & sp. & 12.2 & 7.5 & $\mathrm{Y}$ & $\mathrm{N}$ & 0.62 \\
\hline 4 & Rabdotus & $\mathrm{sp}$. & 17.2 & 10.1 & $\mathrm{~N}$ & $Y$ & 0.59 \\
\hline 4 & Rabdotus & sp. & 13.3 & 8.4 & $Y$ & $\mathrm{~N}$ & 0.63 \\
\hline 4 & Rabdotus & sp. & 14.3 & 8 & $Y$ & $\mathrm{~N}$ & 0.56 \\
\hline 4 & Rabdotus & sp. & 19.8 & 10.3 & $Y$ & $\mathrm{~N}$ & 0.52 \\
\hline 4 & Rabdotus & $\mathrm{sp}$. & 16.5 & 8.6 & $Y$ & $\mathrm{~N}$ & 0.52 \\
\hline 4 & Rabdotus & sp. & 11.7 & 7.4 & $\mathrm{Y}$ & $\mathrm{N}$ & 0.64 \\
\hline 4 & Rabdotus & sp. & 21.3 & 11.1 & $\mathrm{~N}$ & $Y$ & 0.52 \\
\hline 4 & Rabdotus & sp. & 20.1 & 11.5 & $\mathrm{~N}$ & $Y$ & 0.57 \\
\hline 4 & Rabdotus & $\mathrm{sp}$. & 20.2 & 11.3 & $\mathrm{~N}$ & $Y$ & 0.56 \\
\hline 4 & Rabdotus & sp. & 18.2 & 10 & $\mathrm{~N}$ & Y & 0.55 \\
\hline 4 & Rabdotus & sp. & 21.1 & 11 & $\mathrm{~N}$ & Y & 0.52 \\
\hline 4 & Rabdotus & sp. & 19.3 & 11.4 & $\mathrm{~N}$ & $Y$ & 0.59 \\
\hline 4 & Rabdotus & sp. & 19.7 & 11.7 & $\mathrm{~N}$ & $Y$ & 0.6 \\
\hline 4 & Rabdotus & sp. & 15.2 & 10 & $Y$ & $\mathrm{~N}$ & 0.66 \\
\hline 4 & Rabdotus & sp. & 18.3 & 9.8 & $Y$ & $\mathrm{~N}$ & 0.54 \\
\hline 4 & Rabdotus & sp. & 19.6 & 10.7 & $\mathrm{Y}$ & $\mathrm{N}$ & 0.55 \\
\hline 4 & Rabdotus & sp. & 13.7 & 8.1 & $Y$ & $Y$ & 0.59 \\
\hline 4 & Rabdotus & sp. & 19.4 & 10.8 & $\mathrm{~N}$ & $Y$ & 0.56 \\
\hline 4 & Rabdotus & sp. & 16.5 & 8.9 & $\mathrm{~N}$ & $\mathrm{~N}$ & 0.54 \\
\hline 4 & Rabdotus & sp. & 18.2 & 10.7 & $\mathrm{~N}$ & $\mathrm{~N}$ & 0.59 \\
\hline
\end{tabular}


Table H-5. Continued...

\begin{tabular}{|c|c|c|c|c|c|c|c|}
\hline Area & Genus & Species & length $(\mathrm{mm})$ & width (mm) & Carina & Calus & Weight (g.) \\
\hline 4 & Rabdotus & sp. & 17.6 & 9.8 & $\mathrm{Y}$ & $\mathrm{N}$ & 0.56 \\
\hline 4 & Rabdotus & sp. & 11.9 & 7.4 & Y & $\mathrm{N}$ & 0.62 \\
\hline 4 & Rabdotus & sp. & 12 & 8 & Y & $\mathrm{N}$ & 0.67 \\
\hline 4 & Rabdotus & sp. & 11.2 & 7.3 & Y & $\mathrm{N}$ & 0.65 \\
\hline 4 & Rabdotus & sp. & 11.3 & 7.5 & $\mathrm{Y}$ & $\mathrm{N}$ & 0.66 \\
\hline 4 & Rabdotus & sp. & 8 & 5.5 & $\mathrm{Y}$ & $\mathrm{N}$ & 0.69 \\
\hline 4 & Rabdotus & sp. & 10.9 & 7 & $\mathrm{Y}$ & $\mathrm{N}$ & 0.64 \\
\hline 4 & Rabdotus & sp. & 14.1 & 8.3 & Y & $\mathrm{N}$ & 0.59 \\
\hline 4 & Rabdotus & sp. & 11.9 & 8.4 & $\mathrm{Y}$ & $\mathrm{N}$ & 0.7 \\
\hline 4 & Rabdotus & sp. & 9.9 & 6.9 & Y & $\mathrm{N}$ & 0.7 \\
\hline 4 & Rabdotus & sp. & 15.2 & 9.4 & Y & Y & 0.62 \\
\hline 4 & Rabdotus & sp. & 13.5 & 8.4 & Y & $\mathrm{N}$ & 0.62 \\
\hline 4 & Rabdotus & sp. & 16.6 & 9.4 & Y & Y & 0.57 \\
\hline 4 & Rabdotus & $\mathrm{sp}$. & 12.8 & 8.3 & $Y$ & $\mathrm{~N}$ & 0.65 \\
\hline 4 & Rabdotus & sp. & 15 & 10 & $\mathrm{Y}$ & $\mathrm{N}$ & 0.67 \\
\hline 4 & Rabdotus & sp. & 11.5 & 7.2 & $\mathrm{Y}$ & $\mathrm{N}$ & 0.63 \\
\hline 4 & Rabdotus & sp. & 14.9 & 9.2 & $Y$ & $Y$ & 0.62 \\
\hline 4 & Rabdotus & sp. & 10.4 & 6.9 & Y & $\mathrm{N}$ & 0.66 \\
\hline 4 & Rabdotus & sp. & 12.2 & 7.9 & Y & $\mathrm{N}$ & 0.64 \\
\hline 4 & Rabdotus & sp. & 12.6 & 8.3 & $\mathrm{Y}$ & $\mathrm{N}$ & 0.66 \\
\hline 4 & Rabdotus & sp. & 19.8 & 10.9 & $\mathrm{Y}$ & $\mathrm{N}$ & 0.55 \\
\hline 4 & Rabdotus & sp. & 13.9 & 8.5 & $\mathrm{Y}$ & $\mathrm{N}$ & 0.61 \\
\hline 4 & Rabdotus & sp. & 14 & 8.7 & $\mathrm{Y}$ & $\mathrm{N}$ & 0.62 \\
\hline 4 & Rabdotus & sp. & 11.8 & 6.9 & Y & $\mathrm{N}$ & 0.59 \\
\hline 4 & Rabdotus & sp. & 11.6 & 6.5 & Y & $\mathrm{N}$ & 0.56 \\
\hline 4 & Rabdotus & sp. & 15.6 & 9.7 & $\mathrm{Y}$ & $\mathrm{N}$ & 0.62 \\
\hline 4 & Rabdotus & sp. & 8.9 & 6.2 & Y & $\mathrm{N}$ & 0.69 \\
\hline 4 & Rabdotus & sp. & 6.7 & 4.7 & $\mathrm{Y}$ & $\mathrm{N}$ & 0.7 \\
\hline 4 & Rabdotus & sp. & 14.6 & 9.1 & Y & $\mathrm{N}$ & 0.63 \\
\hline 4 & Rabdotus & sp. & 13.2 & 8.1 & $\mathrm{Y}$ & $\mathrm{N}$ & 0.61 \\
\hline 4 & Rabdotus & sp. & 20.3 & 10.8 & Y & $y$ & 0.53 \\
\hline 4 & Rabdotus & sp. & 11.5 & 8.3 & Y & $\mathrm{N}$ & 0.72 \\
\hline 4 & Rabdotus & sp. & 17.5 & 10.4 & Y & $\mathrm{N}$ & 0.6 \\
\hline 4 & Rabdotus & sp. & 19.3 & 10.2 & $\mathrm{~N}$ & $\mathrm{~N}$ & 0.53 \\
\hline 4 & Rabdotus & sp. & 13.5 & 8.5 & $Y$ & $Y$ & 0.63 \\
\hline 4 & Rabdotus & sp. & 18.5 & 10.8 & $\mathrm{~N}$ & $Y$ & 0.58 \\
\hline 4 & Rabdotus & sp. & 19.4 & 10.9 & $\mathrm{~N}$ & $\mathrm{~N}$ & 0.56 \\
\hline 4 & Rabdotus & sp. & 16.8 & 9 & Y & $\mathrm{N}$ & 0.54 \\
\hline 4 & Rabdotus & sp. & 11.8 & 7.5 & $\mathrm{Y}$ & $\mathrm{N}$ & 0.64 \\
\hline 4 & Rabdotus & sp. & 14.5 & 8.8 & Y & $\mathrm{N}$ & 0.61 \\
\hline 4 & Rabdotus & sp. & 16.5 & 10 & Y & $\mathrm{N}$ & 0.61 \\
\hline 4 & Rabdotus & sp. & 12.9 & 8.3 & Y & $\mathrm{N}$ & 0.64 \\
\hline 4 & Rabdotus & sp. & 14.1 & 8.8 & $\mathrm{~N}$ & $\mathrm{~N}$ & 0.62 \\
\hline 4 & Rabdotus & sp. & 8.2 & 5.6 & $Y$ & $\mathrm{~N}$ & 0.68 \\
\hline 4 & Rabdotus & sp. & 23.4 & 10.6 & $\mathrm{~N}$ & $Y$ & 0.45 \\
\hline 4 & Rabdotus & sp. & 17.6 & 10.4 & Y & $\mathrm{N}$ & 0.59 \\
\hline 4 & Rabdotus & sp. & 15.3 & 9.1 & Y & $\mathrm{N}$ & 0.59 \\
\hline 4 & Rabdotus & sp. & 12.2 & 8.1 & Y & $\mathrm{N}$ & 0.66 \\
\hline 4 & Rabdotus & sp. & 14.8 & 8.5 & $Y$ & $Y$ & 0.58 \\
\hline 4 & Rabdotus & sp. & 16.8 & 10.1 & $\mathrm{Y}$ & $\mathrm{N}$ & 0.6 \\
\hline 4 & Rabdotus & sp. & 17.2 & 10.6 & $\mathrm{~N}$ & $Y$ & 0.61 \\
\hline 4 & Rabdotus & sp. & 17.3 & 10.9 & $\mathrm{~N}$ & $Y$ & 0.63 \\
\hline 4 & Rabdotus & sp. & 20.6 & 11.6 & $\mathrm{~N}$ & $Y$ & 0.57 \\
\hline 4 & Rabdotus & sp. & 19.9 & 11.5 & $\mathrm{~N}$ & $\mathrm{~N}$ & 0.58 \\
\hline 4 & Rabdotus & sp. & 10.7 & 7.2 & Y & $\mathrm{N}$ & 0.67 \\
\hline
\end{tabular}


Table H-5. Continued...

\begin{tabular}{|c|c|c|c|c|c|c|c|}
\hline Area & Genus & Species & length $(\mathrm{mm})$ & width $(\mathrm{mm})$ & Carina & Calus & Weight (g.) \\
\hline 4 & Rabdotus & sp. & 16.4 & 10.1 & $Y$ & $\mathrm{~N}$ & 0.62 \\
\hline 4 & Rabdotus & sp. & 16 & 9.7 & $Y$ & $\mathrm{~N}$ & 0.61 \\
\hline 4 & Rabdotus & sp. & 20.5 & 10.8 & $\mathrm{~N}$ & $\mathrm{~N}$ & 0.53 \\
\hline 4 & Rabdotus & sp. & 19.7 & 10.6 & $Y$ & $\mathrm{~N}$ & 0.54 \\
\hline 4 & Rabdotus & sp. & 14.7 & 8.2 & $Y$ & $Y$ & 0.56 \\
\hline 4 & Rabdotus & sp. & 19.8 & 10.4 & $\mathrm{~N}$ & $Y$ & 0.52 \\
\hline 4 & Rabdotus & sp. & 19.9 & 10.6 & $\mathrm{~N}$ & $Y$ & 0.53 \\
\hline 4 & Rabdotus & sp. & 19.2 & 10.7 & $\mathrm{~N}$ & $\mathrm{~N}$ & 0.56 \\
\hline 4 & Rabdotus & sp. & 14.3 & 9.2 & $Y$ & $\mathrm{~N}$ & 0.64 \\
\hline 4 & Rabdotus & sp. & 16.4 & 10.2 & $\mathrm{~N}$ & $Y$ & 0.62 \\
\hline 4 & Rabdotus & sp. & 16.9 & 10 & $\mathrm{Y}$ & $\mathrm{Y}$ & 0.59 \\
\hline 4 & Rabdotus & sp. & 17.6 & 9.6 & $\mathrm{~N}$ & $\mathrm{Y}$ & 0.54 \\
\hline 4 & Rabdotus & sp. & 14.6 & 8.5 & $Y$ & $\mathrm{~N}$ & 0.58 \\
\hline 4 & Rabdotus & sp. & 16.7 & 10.3 & $\mathrm{~N}$ & $\mathrm{~N}$ & 0.62 \\
\hline 4 & Rabdotus & sp. & 17.8 & 10.3 & $\mathrm{~N}$ & $Y$ & 0.58 \\
\hline 4 & Rabdotus & sp. & 16.8 & 9.7 & $\mathrm{~N}$ & $\mathrm{~N}$ & 0.58 \\
\hline 4 & Rabdotus & sp. & 13.7 & 9.3 & $Y$ & $\mathrm{~N}$ & 0.68 \\
\hline 4 & Rabdotus & sp. & 9.1 & 6.1 & $\mathrm{Y}$ & $\mathrm{N}$ & 0.67 \\
\hline 4 & Rabdotus & sp. & 13 & 8.1 & $\mathrm{Y}$ & $\mathrm{N}$ & 0.62 \\
\hline 4 & Rabdotus & sp. & 19.4 & 11 & $\mathrm{~N}$ & $\mathrm{~N}$ & 0.57 \\
\hline 4 & Rabdotus & sp. & 14.5 & 8.6 & $Y$ & $\mathrm{~N}$ & 0.59 \\
\hline 4 & Rabdotus & sp. & 12.4 & 8.2 & $Y$ & $\mathrm{~N}$ & 0.66 \\
\hline 4 & Rabdotus & sp. & 13.9 & 8.6 & $Y$ & $\mathrm{~N}$ & 0.62 \\
\hline 4 & Rabdotus & sp. & 14.9 & 8.7 & $Y$ & $\mathrm{~N}$ & 0.58 \\
\hline 4 & Rabdotus & sp. & 17.8 & 10.6 & $\mathrm{~N}$ & $\mathrm{~N}$ & 0.59 \\
\hline 4 & Rabdotus & sp. & 13.7 & 8.7 & $\mathrm{Y}$ & $\mathrm{N}$ & 0.64 \\
\hline 4 & Rabdotus & sp. & 8.2 & 5.5 & $\mathrm{Y}$ & $\mathrm{N}$ & 0.67 \\
\hline 4 & Rabdotus & sp. & 7.2 & 4.7 & $Y$ & $\mathrm{~N}$ & 0.65 \\
\hline 4 & Rabdotus & sp. & 17.8 & 10 & $\mathrm{~N}$ & $\mathrm{~N}$ & 0.56 \\
\hline 4 & Rabdotus & sp. & 15 & 8.7 & Y & Y & 0.58 \\
\hline 4 & Rabdotus & $\mathrm{sp}$. & 15.5 & 9 & $\mathrm{~N}$ & $\mathrm{~N}$ & 0.58 \\
\hline 4 & Rabdotus & sp. & 18.6 & 10.6 & $\mathrm{~N}$ & $\mathrm{~N}$ & 0.57 \\
\hline 4 & Rabdotus & sp. & 12.3 & 8.1 & $Y$ & $\mathrm{~N}$ & 0.65 \\
\hline 4 & Rabdotus & sp. & 13 & 8.4 & $\mathrm{~N}$ & $\mathrm{~N}$ & 0.64 \\
\hline 4 & Rabdotus & sp. & 11.6 & 7.3 & $\mathrm{Y}$ & $\mathrm{N}$ & 0.63 \\
\hline 4 & Rabdotus & sp. & 12.3 & 8 & $Y$ & $\mathrm{~N}$ & 0.65 \\
\hline 4 & Rabdotus & sp. & 14.5 & 8.3 & $\mathrm{~N}$ & $\mathrm{~N}$ & 0.57 \\
\hline 4 & Rabdotus & sp. & 17.1 & 9.5 & $Y$ & $\mathrm{~N}$ & 0.55 \\
\hline 4 & Rabdotus & sp. & 13.6 & 8 & $Y$ & $\mathrm{~N}$ & 0.59 \\
\hline 4 & Rabdotus & sp. & 13.5 & 7.8 & $Y$ & $\mathrm{~N}$ & 0.58 \\
\hline 4 & Rabdotus & sp. & 16.6 & 9.7 & $\mathrm{~N}$ & $\mathrm{~N}$ & 0.58 \\
\hline 4 & Rabdotus & sp. & 11.8 & 6.8 & $Y$ & $\mathrm{~N}$ & 0.58 \\
\hline 4 & Rabdotus & sp. & 10.2 & 6.7 & $\mathrm{Y}$ & $\mathrm{N}$ & 0.66 \\
\hline 4 & Rabdotus & sp. & 14.9 & 8.7 & $Y$ & $\mathrm{~N}$ & 0.59 \\
\hline 4 & Rabdotus & sp. & 13.1 & 7.9 & $Y$ & $\mathrm{~N}$ & 0.6 \\
\hline 5 & Mesodon & thyroides & 9.7 & 18.1 & $\mathrm{~N} / \mathrm{A}$ & $\mathrm{N} / \mathrm{A}$ & 1.86 \\
\hline 5 & Mesodon & thyroides & 10.5 & 17.5 & $\mathrm{~N} / \mathrm{A}$ & N/A & 1.68 \\
\hline 5 & Mesodon & thyroides & 11 & 18.5 & $\mathrm{~N} / \mathrm{A}$ & $\mathrm{N} / \mathrm{A}$ & 1.69 \\
\hline 5 & Mesodon & thyroides & 12.4 & 20.7 & $\mathrm{~N} / \mathrm{A}$ & $\mathrm{N} / \mathrm{A}$ & 1.67 \\
\hline 5 & Mesodon & thyroides & 9.7 & 17.1 & $\mathrm{~N} / \mathrm{A}$ & $\mathrm{N} / \mathrm{A}$ & 1.77 \\
\hline 5 & Mesodon & thyroides & 10.5 & 18.9 & $\mathrm{~N} / \mathrm{A}$ & N/A & 1.8 \\
\hline 5 & Mesodon & thyroides & 10.2 & 18.3 & N/A & N/A & 1.79 \\
\hline 5 & Mesodon & thyroides & 11.1 & 19.7 & N/A & N/A & 1.77 \\
\hline 5 & Mesodon & thyroides & 9.9 & 17.5 & N/A & N/A & 1.76 \\
\hline 5 & Mesodon & thyroides & 10.1 & 18.6 & $\mathrm{~N} / \mathrm{A}$ & $N / A$ & 1.85 \\
\hline
\end{tabular}


Table H-5. Continued...

\begin{tabular}{|c|c|c|c|c|c|c|c|}
\hline Area & Genus & Species & length $(\mathrm{mm})$ & width $(\mathrm{mm})$ & Carina & Calus & Weight (g.) \\
\hline 5 & Rabdotus & sp. & 24.6 & 12.7 & $\mathrm{~N}$ & Y & 0.51 \\
\hline 5 & Rabdotus & sp. & 20.8 & 12 & $\mathrm{~N}$ & Y & 0.58 \\
\hline 5 & Rabdotus & sp. & 24.5 & 12.6 & $\mathrm{~N}$ & Y & 0.52 \\
\hline 5 & Rabdotus & sp. & 23.6 & 12.6 & $\mathrm{~N}$ & Y & 0.53 \\
\hline 5 & Rabdotus & sp. & 22 & 11.7 & $\mathrm{~N}$ & $\mathrm{Y}$ & 0.53 \\
\hline 5 & Rabdotus & sp. & 23.4 & 12.1 & $\mathrm{~N}$ & $Y$ & 0.52 \\
\hline 5 & Rabdotus & sp. & 24.8 & 12.7 & $\mathrm{~N}$ & Y & 0.51 \\
\hline 5 & Rabdotus & sp. & 25 & 12 & $\mathrm{~N}$ & Y & 0.48 \\
\hline 5 & Rabdotus & sp. & 21.1 & 11.6 & $\mathrm{~N}$ & $\mathrm{~N}$ & 0.55 \\
\hline 5 & Rabdotus & sp. & 22.1 & 11.8 & $\mathrm{~N}$ & $Y$ & 0.53 \\
\hline 5 & Rabdotus & sp. & 20.9 & 11.2 & $\mathrm{~N}$ & $Y$ & 0.54 \\
\hline 5 & Rabdotus & sp. & 22.7 & 11.8 & $\mathrm{~N}$ & $Y$ & 0.52 \\
\hline 5 & Rabdotus & sp. & 23.8 & 12.2 & $\mathrm{~N}$ & $Y$ & 0.51 \\
\hline 5 & Rabdotus & sp. & 24.4 & 12.2 & $\mathrm{~N}$ & $Y$ & 0.5 \\
\hline 5 & Rabdotus & sp. & 23.8 & 11.7 & $\mathrm{~N}$ & Y & 0.49 \\
\hline 5 & Rabdotus & sp. & 23.8 & 12.9 & $\mathrm{~N}$ & Y & 0.54 \\
\hline 5 & Rabdotus & $\mathrm{sp}$. & 24 & 14.2 & $\mathrm{~N}$ & $Y$ & 0.59 \\
\hline 5 & Rabdotus & sp. & 23.4 & 12.4 & $\mathrm{~N}$ & Y & 0.53 \\
\hline 5 & Rabdotus & sp. & 22.7 & 12.8 & $\mathrm{~N}$ & Y & 0.56 \\
\hline 5 & Rabdotus & sp. & 22 & 11.7 & $\mathrm{~N}$ & $\mathrm{Y}$ & 0.53 \\
\hline 5 & Rabdotus & sp. & 22 & 11.1 & $\mathrm{~N}$ & Y & 0.51 \\
\hline 5 & Rabdotus & sp. & 23.3 & 12.6 & $\mathrm{~N}$ & Y & 0.54 \\
\hline 5 & Rabdotus & sp. & 24.7 & 12.8 & $\mathrm{~N}$ & Y & 0.52 \\
\hline 5 & Rabdotus & sp. & 23 & 12 & $\mathrm{~N}$ & Y & 0.52 \\
\hline 5 & Rabdotus & sp. & 25.3 & 14.5 & $\mathrm{~N}$ & Y & 0.57 \\
\hline 5 & Rabdotus & sp. & 22.6 & 12.1 & $\mathrm{~N}$ & Y & 0.53 \\
\hline 5 & Rabdotus & sp. & 23.4 & 12.3 & $\mathrm{~N}$ & Y & 0.52 \\
\hline 5 & Rabdotus & sp. & 21.6 & 11.9 & $\mathrm{~N}$ & $\mathrm{Y}$ & 0.55 \\
\hline 5 & Rabdotus & sp. & 24.9 & 12.7 & $\mathrm{~N}$ & $\mathrm{Y}$ & 0.51 \\
\hline 5 & Rabdotus & sp. & 24.6 & 12.5 & $\mathrm{~N}$ & Y & 0.51 \\
\hline 5 & Rabdotus & sp. & 22.6 & 11.9 & $\mathrm{~N}$ & Y & 0.53 \\
\hline 5 & Rabdotus & sp. & 22.5 & 12.3 & Y & $\mathrm{N}$ & 0.55 \\
\hline 5 & Rabdotus & sp. & 24.9 & 12.4 & $\mathrm{~N}$ & Y & 0.5 \\
\hline 5 & Rabdotus & sp. & 25.1 & 12.4 & $\mathrm{~N}$ & Y & 0.49 \\
\hline 5 & Rabdotus & sp. & 22.5 & 11.8 & $\mathrm{~N}$ & $Y$ & 0.53 \\
\hline 5 & Rabdotus & sp. & 22.7 & 12.3 & $\mathrm{~N}$ & $Y$ & 0.54 \\
\hline 5 & Rabdotus & sp. & 25.2 & 13.4 & $\mathrm{~N}$ & $\mathrm{Y}$ & 0.53 \\
\hline 5 & Rabdotus & sp. & 25.5 & 13.5 & $\mathrm{~N}$ & $Y$ & 0.53 \\
\hline 5 & Rabdotus & sp. & 23.7 & 12.5 & $\mathrm{~N}$ & Y & 0.53 \\
\hline 5 & Rabdotus & sp. & 23.8 & 12.5 & $\mathrm{~N}$ & Y & 0.52 \\
\hline 5 & Rabdotus & sp. & 20.7 & 11.6 & $\mathrm{~N}$ & Y & 0.56 \\
\hline 5 & Rabdotus & sp. & 20.9 & 11.5 & $\mathrm{~N}$ & Y & 0.55 \\
\hline 5 & Rabdotus & sp. & 24.8 & 12.7 & $\mathrm{~N}$ & $Y$ & 0.51 \\
\hline 5 & Rabdotus & sp. & 21.9 & 11.9 & $\mathrm{~N}$ & $Y$ & 0.54 \\
\hline 5 & Rabdotus & sp. & 19.6 & 11.1 & $\mathrm{Y}$ & $\mathrm{N}$ & 0.57 \\
\hline 5 & Rabdotus & sp. & 23.5 & 12.1 & $\mathrm{~N}$ & Y & 0.51 \\
\hline 5 & Rabdotus & sp. & 23.9 & 12.3 & $\mathrm{~N}$ & Y & 0.52 \\
\hline 5 & Rabdotus & sp. & 23.2 & 11.6 & $\mathrm{~N}$ & Y & 0.5 \\
\hline 5 & Rabdotus & sp. & 22.2 & 11.6 & $\mathrm{~N}$ & Y & 0.53 \\
\hline 5 & Rabdotus & sp. & 21.3 & 12.5 & $\mathrm{~N}$ & Y & 0.59 \\
\hline 5 & Rabdotus & sp. & 22.1 & 11.4 & $\mathrm{~N}$ & Y & 0.52 \\
\hline 5 & Rabdotus & sp. & 22.4 & 13.2 & $\mathrm{~N}$ & $\mathrm{~N}$ & 0.59 \\
\hline 5 & Rabdotus & sp. & 21.6 & 11.4 & $\mathrm{~N}$ & $\mathrm{~N}$ & 0.53 \\
\hline 5 & Rabdotus & sp. & 22.4 & 11.7 & $\mathrm{~N}$ & $\mathrm{~N}$ & 0.52 \\
\hline 5 & Rabdotus & sp. & 21.3 & 11.8 & $\mathrm{~N}$ & $\mathrm{~N}$ & 0.56 \\
\hline
\end{tabular}


Table H-5. Continued...

\begin{tabular}{|c|c|c|c|c|c|c|c|}
\hline Area & Genus & Species & length $(\mathrm{mm})$ & width $(\mathrm{mm})$ & Carina & Calus & Weight (g.) \\
\hline 5 & Rabdotus & sp. & 19.9 & 10.8 & $\mathrm{~N}$ & $\mathrm{~N}$ & 0.54 \\
\hline 5 & Rabdotus & sp. & 20.4 & 11.1 & $\mathrm{~N}$ & $\mathrm{~N}$ & 0.54 \\
\hline 5 & Rabdotus & sp. & 20 & 11.9 & $\mathrm{~N}$ & $\mathrm{~N}$ & 0.59 \\
\hline 5 & Rabdotus & sp. & 21.3 & 11.8 & $\mathrm{~N}$ & $\mathrm{~N}$ & 0.56 \\
\hline 5 & Rabdotus & sp. & 20.7 & 11.3 & $\mathrm{~N}$ & $\mathrm{~N}$ & 0.54 \\
\hline 5 & Rabdotus & $\mathrm{sp}$. & 22.6 & 11.9 & $\mathrm{~N}$ & $\mathrm{~N}$ & 0.53 \\
\hline 5 & Rabdotus & sp. & 24 & 12.8 & $\mathrm{~N}$ & $\mathrm{~N}$ & 0.53 \\
\hline 5 & Rabdotus & sp. & 19.4 & 11.4 & $Y$ & $\mathrm{~N}$ & 0.59 \\
\hline 5 & Rabdotus & sp. & 14.9 & 8.6 & $\mathrm{Y}$ & $\mathrm{N}$ & 0.58 \\
\hline 5 & Rabdotus & $\mathrm{sp}$. & 16.3 & 9.9 & $Y$ & $\mathrm{~N}$ & 0.61 \\
\hline 5 & Rabdotus & sp. & 10.1 & 7.1 & $\mathrm{Y}$ & $\mathrm{N}$ & 0.7 \\
\hline 5 & Rabdotus & sp. & 16.1 & 9.3 & $Y$ & $\mathrm{~N}$ & 0.58 \\
\hline 5 & Rabdotus & sp. & 10.7 & 7.4 & $Y$ & $\mathrm{~N}$ & 0.69 \\
\hline 5 & Rabdotus & sp. & 12.9 & 7.8 & Y & $\mathrm{N}$ & 0.61 \\
\hline 5 & Rabdotus & sp. & 10.9 & 6.3 & $Y$ & $\mathrm{~N}$ & 0.57 \\
\hline 5 & Rabdotus & sp. & 15.3 & 9 & $Y$ & $\mathrm{~N}$ & 0.59 \\
\hline 5 & Rabdotus & sp. & 13 & 8.5 & $\mathrm{Y}$ & $\mathrm{N}$ & 0.65 \\
\hline 5 & Rabdotus & sp. & 14.8 & 9.6 & $\mathrm{Y}$ & $\mathrm{N}$ & 0.65 \\
\hline 5 & Rabdotus & sp. & 11.9 & 7.6 & $\mathrm{Y}$ & $\mathrm{N}$ & 0.64 \\
\hline 5 & Rabdotus & sp. & 10.2 & 6.3 & $Y$ & $\mathrm{~N}$ & 0.62 \\
\hline 5 & Rabdotus & sp. & 13.1 & 8.5 & $Y$ & $\mathrm{~N}$ & 0.65 \\
\hline 5 & Rabdotus & $\mathrm{sp}$. & 10.3 & 7.1 & $Y$ & $\mathrm{~N}$ & 0.69 \\
\hline 5 & Rabdotus & sp. & 15.9 & 9.4 & $Y$ & $\mathrm{~N}$ & 0.59 \\
\hline 5 & Rabdotus & sp. & 14.6 & 8.5 & $Y$ & $\mathrm{~N}$ & 0.58 \\
\hline 5 & Rabdotus & sp. & 15.6 & 9.4 & $\mathrm{Y}$ & $\mathrm{N}$ & 0.6 \\
\hline 5 & Rabdotus & $\mathrm{sp}$. & 17.1 & 9.6 & $Y$ & $\mathrm{~N}$ & 0.56 \\
\hline 5 & Rabdotus & sp. & 23.6 & 12.4 & $\mathrm{~N}$ & $Y$ & 0.53 \\
\hline 5 & Rabdotus & sp. & 22.7 & 11.6 & $\mathrm{~N}$ & Y & 0.51 \\
\hline 5 & Rabdotus & sp. & 21.5 & 11.1 & $\mathrm{~N}$ & $Y$ & 0.52 \\
\hline 5 & Rabdotus & $\mathrm{sp}$. & 19.9 & 11.2 & $\mathrm{~N}$ & $Y$ & 0.56 \\
\hline 5 & Rabdotus & sp. & 23.4 & 12.5 & $\mathrm{~N}$ & $Y$ & 0.54 \\
\hline 5 & Rabdotus & sp. & 20.5 & 11.6 & $\mathrm{Y}$ & $\mathrm{N}$ & 0.57 \\
\hline 5 & Rabdotus & sp. & 23.8 & 12.8 & $\mathrm{~N}$ & $Y$ & 0.54 \\
\hline 5 & Rabdotus & sp. & 21.7 & 12.5 & $\mathrm{~N}$ & $\mathrm{Y}$ & 0.57 \\
\hline 5 & Rabdotus & sp. & 18.9 & 11.8 & $Y$ & Y & 0.62 \\
\hline 5 & Rabdotus & sp. & 23.4 & 12.5 & $\mathrm{~N}$ & $Y$ & 0.54 \\
\hline 5 & Rabdotus & sp. & 20.9 & 12 & $\mathrm{~N}$ & Y & 0.57 \\
\hline 5 & Rabdotus & $\mathrm{sp}$. & 19 & 11 & $\mathrm{~N}$ & $Y$ & 0.58 \\
\hline 5 & Rabdotus & sp. & 6.7 & 4.6 & $Y$ & $\mathrm{~N}$ & 0.69 \\
\hline 5 & Rabdotus & sp. & 20.1 & 11.7 & $\mathrm{Y}$ & $\mathrm{N}$ & 0.58 \\
\hline 5 & Rabdotus & sp. & 23.2 & 11.3 & $\mathrm{~N}$ & $\mathrm{Y}$ & 0.49 \\
\hline 5 & Rabdotus & $\mathrm{sp}$. & 22.4 & 11.8 & $\mathrm{~N}$ & $Y$ & 0.53 \\
\hline 5 & Rabdotus & sp. & 19.4 & 11.2 & $\mathrm{~N}$ & $Y$ & 0.58 \\
\hline 5 & Rabdotus & sp. & 19.4 & 10.8 & $\mathrm{~N}$ & Y & 0.56 \\
\hline 5 & Rabdotus & sp. & 19.2 & 10.5 & $\mathrm{~N}$ & Y & 0.54 \\
\hline 5 & Rabdotus & sp. & 18.3 & 10.6 & $\mathrm{~N}$ & $Y$ & 0.58 \\
\hline 5 & Rabdotus & sp. & 19.2 & 10.4 & $\mathrm{~N}$ & Y & 0.54 \\
\hline 5 & Rabdotus & sp. & 21.4 & 10.5 & $\mathrm{~N}$ & $\mathrm{Y}$ & 0.49 \\
\hline 5 & Rabdotus & $\mathrm{sp}$. & 19.4 & 10.9 & $\mathrm{~N}$ & $Y$ & 0.56 \\
\hline 5 & Rabdotus & sp. & 21.3 & 11.6 & $\mathrm{~N}$ & $Y$ & 0.54 \\
\hline 5 & Rabdotus & sp. & 21.3 & 10.8 & $\mathrm{~N}$ & Y & 0.51 \\
\hline 5 & Rabdotus & sp. & 21 & 11.8 & $\mathrm{~N}$ & $Y$ & 0.56 \\
\hline 5 & Rabdotus & sp. & 21.1 & 11 & $\mathrm{~N}$ & Y & 0.52 \\
\hline 5 & Rabdotus & sp. & 20.2 & 12 & $\mathrm{~N}$ & $Y$ & 0.59 \\
\hline 5 & Rabdotus & sp. & 22.5 & 11.7 & $\mathrm{~N}$ & $Y$ & 0.52 \\
\hline
\end{tabular}


Table H-5. Continued...

\begin{tabular}{|c|c|c|c|c|c|c|c|}
\hline Area & Genus & Species & length (mm) & width (mm) & Carina & Calus & Weight (g.) \\
\hline 5 & Rabdotus & $\mathrm{sp}$. & 23 & 12.4 & $\mathrm{~N}$ & $Y$ & 0.54 \\
\hline 5 & Rabdotus & $\mathrm{sp}$. & 23.6 & 12.7 & $\mathrm{~N}$ & $Y$ & 0.54 \\
\hline 5 & Rabdotus & sp. & 21.2 & 12.1 & $\mathrm{~N}$ & $Y$ & 0.57 \\
\hline 5 & Rabdotus & sp. & 18.4 & 10.8 & $Y$ & $\mathrm{~N}$ & 0.59 \\
\hline 5 & Rabdotus & sp. & 20.2 & 11.4 & $\mathrm{~N}$ & $Y$ & 0.57 \\
\hline 5 & Rabdotus & sp. & 20.3 & 11.4 & $\mathrm{~N}$ & $Y$ & 0.56 \\
\hline 5 & Rabdotus & sp. & 18.9 & 10.7 & $\mathrm{~N}$ & Y & 0.57 \\
\hline 5 & Rabdotus & sp. & 20 & 11.1 & $\mathrm{~N}$ & $Y$ & 0.55 \\
\hline 5 & Rabdotus & sp. & 20.9 & 11.2 & $\mathrm{~N}$ & $Y$ & 0.53 \\
\hline 5 & Rabdotus & sp. & 18.2 & 10.4 & $Y$ & $\mathrm{~N}$ & 0.57 \\
\hline 5 & Rabdotus & sp. & 15.4 & 9.6 & $Y$ & $\mathrm{~N}$ & 0.62 \\
\hline 5 & Rabdotus & $\mathrm{sp}$. & 16.3 & 9.4 & $\mathrm{~N}$ & $Y$ & 0.58 \\
\hline 5 & Rabdotus & sp. & 18.6 & 11 & $\mathrm{~N}$ & Y & 0.59 \\
\hline 5 & Rabdotus & sp. & 22.2 & 11.7 & $\mathrm{~N}$ & Y & 0.53 \\
\hline 5 & Rabdotus & sp. & 18.4 & 11.2 & $\mathrm{~N}$ & $\mathrm{~N}$ & 0.61 \\
\hline 5 & Rabdotus & sp. & 21.2 & 11.3 & $\mathrm{~N}$ & $Y$ & 0.53 \\
\hline 5 & Rabdotus & $\mathrm{sp}$. & 18.6 & 10.8 & $Y$ & $\mathrm{~N}$ & 0.58 \\
\hline 5 & Rabdotus & $\mathrm{sp}$. & 14.5 & 8.7 & $Y$ & $\mathrm{~N}$ & 0.6 \\
\hline 5 & Rabdotus & sp. & 14.8 & 9.1 & $Y$ & $\mathrm{~N}$ & 0.61 \\
\hline 5 & Rabdotus & $\mathrm{sp}$. & 18 & 10.5 & $Y$ & $\mathrm{~N}$ & 0.59 \\
\hline 5 & Rabdotus & $\mathrm{sp}$. & 16.3 & 10.4 & $Y$ & $\mathrm{~N}$ & 0.64 \\
\hline 5 & Rabdotus & sp. & 12.2 & 7.4 & $Y$ & $\mathrm{~N}$ & 0.6 \\
\hline 5 & Rabdotus & $\mathrm{sp}$. & 14.2 & 8.6 & $Y$ & $\mathrm{~N}$ & 0.61 \\
\hline 5 & Rabdotus & $\mathrm{sp}$. & 15.2 & 8.9 & $Y$ & $\mathrm{~N}$ & 0.59 \\
\hline 5 & Rabdotus & $\mathrm{sp}$. & 13.6 & 8.8 & $Y$ & $\mathrm{~N}$ & 0.64 \\
\hline 5 & Rabdotus & sp. & 14.9 & 9.1 & $Y$ & $\mathrm{~N}$ & 0.61 \\
\hline 5 & Rabdotus & $\mathrm{sp}$. & 14.1 & 8.9 & $Y$ & $\mathrm{~N}$ & 0.63 \\
\hline 5 & Rabdotus & $\mathrm{sp}$. & 11.9 & 7.9 & $Y$ & $\mathrm{~N}$ & 0.67 \\
\hline 5 & Rabdotus & $\mathrm{sp}$. & 15.5 & 8.8 & $Y$ & $\mathrm{~N}$ & 0.57 \\
\hline 5 & Rabdotus & sp. & 11 & 7.5 & $Y$ & $\mathrm{~N}$ & 0.68 \\
\hline 5 & Rabdotus & $\mathrm{sp}$. & 20.9 & 12 & $\mathrm{~N}$ & Y & 0.57 \\
\hline 5 & Rabdotus & $\mathrm{sp}$. & 21.4 & 11.1 & $\mathrm{~N}$ & $\mathrm{~N}$ & 0.52 \\
\hline 5 & Rabdotus & sp. & 18.7 & 10.9 & $Y$ & $\mathrm{~N}$ & 0.59 \\
\hline 5 & Rabdotus & $\mathrm{sp}$. & 14.5 & 9.2 & $Y$ & $\mathrm{~N}$ & 0.63 \\
\hline 5 & Rabdotus & $\mathrm{sp}$. & 16.2 & 9.3 & $Y$ & $\mathrm{~N}$ & 0.57 \\
\hline 5 & Rabdotus & $\mathrm{sp}$. & 13.5 & 8.4 & $Y$ & $\mathrm{~N}$ & 0.62 \\
\hline 5 & Rabdotus & sp. & 10.2 & 6.8 & $Y$ & $\mathrm{~N}$ & 0.67 \\
\hline 5 & Rabdotus & sp. & 10.7 & 7.3 & $Y$ & $\mathrm{~N}$ & 0.68 \\
\hline 5 & Rabdotus & sp. & 11.7 & 7 & $Y$ & $\mathrm{~N}$ & 0.59 \\
\hline 5 & Rabdotus & $\mathrm{sp}$. & 21.5 & 11 & $\mathrm{~N}$ & Y & 0.51 \\
\hline 5 & Rabdotus & sp. & 14.5 & 8.8 & $Y$ & $\mathrm{~N}$ & 0.61 \\
\hline 5 & Rabdotus & sp. & 18.1 & 10.6 & $Y$ & $\mathrm{~N}$ & 0.59 \\
\hline 5 & Rabdotus & sp. & 22.9 & 11.7 & $\mathrm{~N}$ & $Y$ & 0.51 \\
\hline 5 & Rabdotus & $\mathrm{sp}$. & 21.5 & 11.2 & $\mathrm{~N}$ & $Y$ & 0.52 \\
\hline 5 & Rabdotus & sp. & 22.6 & 11.7 & $\mathrm{~N}$ & Y & 0.52 \\
\hline 5 & Rabdotus & sp. & 20.4 & 11.7 & $Y$ & $\mathrm{~N}$ & 0.57 \\
\hline 5 & Rabdotus & $\mathrm{sp}$. & 18.6 & 10.7 & $Y$ & $\mathrm{~N}$ & 0.58 \\
\hline 5 & Rabdotus & sp. & 15.8 & 9.2 & $\bar{Y}$ & $\mathrm{~N}$ & 0.58 \\
\hline 5 & Rabdotus & sp. & 16.5 & 9.8 & $Y$ & $\mathrm{~N}$ & 0.59 \\
\hline 5 & Rabdotus & $\mathrm{sp}$. & 16.6 & 10.1 & $Y$ & $\mathrm{~N}$ & 0.61 \\
\hline 5 & Rabdotus & $\mathrm{sp}$. & 15.2 & 9.8 & $Y$ & $\mathrm{~N}$ & 0.64 \\
\hline 5 & Rabdotus & sp. & 17.4 & 10.1 & $Y$ & $\mathrm{~N}$ & 0.58 \\
\hline 5 & Rabdotus & sp. & 18.2 & 11 & $Y$ & $\mathrm{~N}$ & 0.61 \\
\hline 5 & Rabdotus & sp. & 16.9 & 9.9 & $Y$ & $\mathrm{~N}$ & 0.58 \\
\hline 5 & Rabdotus & sp. & 17.6 & 10 & $Y$ & $\mathrm{~N}$ & 0.57 \\
\hline
\end{tabular}


Table H-5. Continued...

\begin{tabular}{|c|c|c|c|c|c|c|c|}
\hline Area & Genus & Species & length $(\mathrm{mm})$ & width $(\mathrm{mm})$ & Carina & Calus & Weight (g.) \\
\hline 5 & Rabdotus & sp. & 17.8 & 9.8 & $Y$ & $\mathrm{~N}$ & 0.55 \\
\hline 5 & Rabdotus & sp. & 17.6 & 10.4 & $\mathrm{~N}$ & $\mathrm{Y}$ & 0.59 \\
\hline 5 & Rabdotus & sp. & 17.9 & 9.7 & $\mathrm{~N}$ & $Y$ & 0.54 \\
\hline 5 & Rabdotus & sp. & 21.2 & 11.8 & $\mathrm{~N}$ & $Y$ & 0.56 \\
\hline 5 & Rabdotus & sp. & 16.7 & 9.9 & $Y$ & $\mathrm{~N}$ & 0.6 \\
\hline 5 & Rabdotus & $\mathrm{sp}$. & 13.3 & 8 & $Y$ & $\mathrm{~N}$ & 0.6 \\
\hline 5 & Rabdotus & sp. & 17.7 & 9.9 & $Y$ & $\mathrm{~N}$ & 0.56 \\
\hline 5 & Rabdotus & sp. & 19.2 & 11 & $Y$ & $\mathrm{~N}$ & 0.57 \\
\hline 5 & Rabdotus & sp. & 21.4 & 11.5 & $\mathrm{~N}$ & $\mathrm{~N}$ & 0.54 \\
\hline 5 & Rabdotus & $\mathrm{sp}$. & 19.9 & 10.3 & $\mathrm{~N}$ & $Y$ & 0.52 \\
\hline 5 & Rabdotus & sp. & 15 & 9.3 & $Y$ & $\mathrm{~N}$ & 0.62 \\
\hline 5 & Rabdotus & sp. & 19.7 & 11.1 & $\mathrm{~N}$ & $\mathrm{~N}$ & 0.56 \\
\hline 5 & Rabdotus & sp. & 17.9 & 9.7 & $Y$ & $\mathrm{~N}$ & 0.54 \\
\hline 5 & Rabdotus & $\mathrm{sp}$. & 16.7 & 10.1 & $Y$ & $\mathrm{~N}$ & 0.61 \\
\hline 5 & Rabdotus & $\mathrm{sp}$. & 19.9 & 10.6 & $Y$ & $Y$ & 0.54 \\
\hline 5 & Rabdotus & sp. & 21.7 & 10.9 & $\mathrm{~N}$ & $Y$ & 0.5 \\
\hline 5 & Rabdotus & $\mathrm{sp}$. & 18.8 & 10.1 & $\mathrm{Y}$ & $\mathrm{N}$ & 0.54 \\
\hline 5 & Rabdotus & $\mathrm{sp}$. & 19.4 & 10.8 & $\mathrm{~N}$ & $Y$ & 0.56 \\
\hline 5 & Rabdotus & $\mathrm{sp}$. & 21.9 & 11.5 & $\mathrm{~N}$ & $Y$ & 0.53 \\
\hline 5 & Rabdotus & sp. & 19.6 & 10.8 & $\mathrm{~N}$ & $Y$ & 0.55 \\
\hline 5 & Rabdotus & $\mathrm{sp}$. & 18.8 & 11.5 & $\mathrm{~N}$ & $\mathrm{~N}$ & 0.61 \\
\hline 5 & Rabdotus & $\mathrm{sp}$. & 5.4 & 3 & $Y$ & $\mathrm{~N}$ & 0.56 \\
\hline 5 & Rabdotus & sp. & 11.3 & 7.1 & $Y$ & $\mathrm{~N}$ & 0.63 \\
\hline 5 & Rabdotus & sp. & 18.9 & 9.3 & $\mathrm{~N}$ & 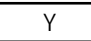 & 0.49 \\
\hline 5 & Rabdotus & $\mathrm{sp}$. & 16.2 & 9.9 & $Y$ & $\mathrm{~N}$ & 0.61 \\
\hline 5 & Rabdotus & $\mathrm{sp}$. & 19.4 & 10.7 & $Y$ & $\mathrm{~N}$ & 0.55 \\
\hline 5 & Rabdotus & $\mathrm{sp}$. & 14.7 & 9.2 & $Y$ & $\mathrm{~N}$ & 0.63 \\
\hline 5 & Rabdotus & sp. & 19.7 & 10.3 & $Y$ & $\mathrm{~N}$ & 0.52 \\
\hline 5 & Rabdotus & sp. & 19.7 & 10.6 & $Y$ & $\mathrm{~N}$ & 0.54 \\
\hline 5 & Rabdotus & $\mathrm{sp}$. & 15.5 & 9.1 & $Y$ & $\mathrm{~N}$ & 0.59 \\
\hline 5 & Rabdotus & sp. & 19.3 & 10.6 & $\mathrm{~N}$ & $Y$ & 0.55 \\
\hline 5 & Rabdotus & sp. & 16.8 & 9.5 & $Y$ & $\mathrm{~N}$ & 0.57 \\
\hline 5 & Rabdotus & $\mathrm{sp}$. & 4.9 & 4.1 & $y$ & $n$ & 0.84 \\
\hline 5 & Rabdotus & $\mathrm{sp}$. & 17.5 & 10.1 & $Y$ & $\mathrm{~N}$ & 0.57 \\
\hline 5 & Rabdotus & $\mathrm{sp}$. & 20.3 & 11.2 & $Y$ & $\mathrm{~N}$ & 0.55 \\
\hline 5 & Rabdotus & $\mathrm{sp}$. & 18.1 & 10.4 & $\mathrm{~N}$ & $\mathrm{~N}$ & 0.57 \\
\hline 5 & Rabdotus & $\mathrm{sp}$. & 17.9 & 10.1 & $Y$ & $\mathrm{~N}$ & 0.57 \\
\hline 5 & Rabdotus & $\mathrm{sp}$. & 20.6 & 11 & $\mathrm{~N}$ & $Y$ & 0.53 \\
\hline 5 & Rabdotus & sp. & 18.5 & 10.6 & $\mathrm{~N}$ & $\mathrm{~N}$ & 0.57 \\
\hline 5 & Rabdotus & sp. & 17.2 & 10.2 & $Y$ & $\mathrm{~N}$ & 0.59 \\
\hline 5 & Rabdotus & $\mathrm{sp}$. & 17.6 & 10.1 & $\mathrm{~N}$ & $\mathrm{~N}$ & 0.57 \\
\hline 5 & Rabdotus & $\mathrm{sp}$. & 19.2 & 10.8 & $\mathrm{~N}$ & $Y$ & 0.56 \\
\hline 5 & Rabdotus & $\mathrm{sp}$. & 21.8 & 11 & $Y$ & $\mathrm{~N}$ & 0.51 \\
\hline 5 & Rabdotus & $\mathrm{sp}$. & 19.3 & 11 & $\mathrm{~N}$ & $Y$ & 0.57 \\
\hline 5 & Rabdotus & $\mathrm{sp}$. & 17.9 & 10.7 & $\mathrm{~N}$ & $\mathrm{~N}$ & 0.6 \\
\hline 5 & Rabdotus & sp. & 21.3 & 11.3 & $\mathrm{~N}$ & $Y$ & 0.53 \\
\hline 5 & Rabdotus & sp. & 19.8 & 11.4 & $\mathrm{~N}$ & $\bar{Y}$ & 0.58 \\
\hline 5 & Rabdotus & $\mathrm{sp}$. & 20.4 & 10.9 & $\mathrm{~N}$ & $Y$ & 0.53 \\
\hline 5 & Rabdotus & $\mathrm{sp}$. & 20.1 & 11.4 & $\mathrm{~N}$ & $Y$ & 0.57 \\
\hline 5 & Rabdotus & $\mathrm{sp}$. & 20.3 & 11.8 & $\mathrm{~N}$ & $Y$ & 0.58 \\
\hline 5 & Rabdotus & $\mathrm{sp}$. & 19.4 & 10.7 & $\mathrm{~N}$ & $Y$ & 0.55 \\
\hline 5 & Rabdotus & $\mathrm{sp}$. & 19.5 & 11.2 & $\mathrm{~N}$ & $Y$ & 0.57 \\
\hline 5 & Rabdotus & $\mathrm{sp}$. & 18.7 & 10.6 & $\mathrm{~N}$ & $Y$ & 0.56 \\
\hline 5 & Rabdotus & sp. & 18.2 & 11.1 & $Y$ & $\mathrm{~N}$ & 0.61 \\
\hline 5 & Rabdotus & sp. & 21.7 & 10.9 & $\mathrm{~N}$ & $Y$ & 0.5 \\
\hline
\end{tabular}


Table H-5. Continued...

\begin{tabular}{|c|c|c|c|c|c|c|c|}
\hline Area & Genus & Species & length (mm) & width $(\mathrm{mm})$ & Carina & Calus & Weight (g.) \\
\hline 5 & Rabdotus & sp. & 18.5 & 10.4 & $\mathrm{~N}$ & Y & 0.56 \\
\hline 5 & Rabdotus & sp. & 19.9 & 10.6 & $\mathrm{~N}$ & Y & 0.53 \\
\hline 5 & Rabdotus & sp. & 17.3 & 9.9 & $\mathrm{Y}$ & $\mathrm{N}$ & 0.57 \\
\hline 5 & Rabdotus & sp. & 17.3 & 10.3 & $\mathrm{Y}$ & $\mathrm{N}$ & 0.6 \\
\hline Unit in 4 & Mesodon & thyroides & 10 & 19.9 & $N / A$ & $\mathrm{~N} / \mathrm{A}$ & 1.99 \\
\hline Unit in 4 & Mesodon & thyroides & 11.2 & 19.3 & $\mathrm{~N} / \mathrm{A}$ & $\mathrm{N} / \mathrm{A}$ & 1.73 \\
\hline Unit in 4 & Mesodon & thyroides & 10.8 & 18.5 & $\mathrm{~N} / \mathrm{A}$ & $\mathrm{N} / \mathrm{A}$ & 1.71 \\
\hline Unit in 4 & Mesodon & thyroides & 11.5 & 20.2 & $\mathrm{~N} / \mathrm{A}$ & $\mathrm{N} / \mathrm{A}$ & 1.75 \\
\hline Unit in 4 & Mesodon & thyroides & 10.6 & 17.7 & $\mathrm{~N} / \mathrm{A}$ & $\mathrm{N} / \mathrm{A}$ & 1.67 \\
\hline Unit in 4 & Mesodon & thyroides & 11.4 & 18.3 & $\mathrm{~N} / \mathrm{A}$ & $\mathrm{N} / \mathrm{A}$ & 1.61 \\
\hline Unit in 4 & Mesodon & thyroides & 11.7 & 19.8 & $N / A$ & $\mathrm{~N} / \mathrm{A}$ & 1.69 \\
\hline Unit in 4 & Mesodon & zaletus & 10.7 & 18.4 & N/A & $\mathrm{N} / \mathrm{A}$ & 1.72 \\
\hline Unit in 4 & Mesodon & zaletus & 11.2 & 18.6 & $N / A$ & $\mathrm{~N} / \mathrm{A}$ & 1.66 \\
\hline Unit in 4 & Mesodon & zaletus & 10.9 & 19.1 & $\mathrm{~N} / \mathrm{A}$ & $\mathrm{N} / \mathrm{A}$ & 1.76 \\
\hline Unit in 4 & Mesodon & zaletus & 11.3 & 19.4 & $\mathrm{~N} / \mathrm{A}$ & $\mathrm{N} / \mathrm{A}$ & 1.72 \\
\hline Unit in 4 & Rabdotus & sp. & 24.6 & 11.8 & $\mathrm{~N} / \mathrm{A}$ & $\mathrm{N} / \mathrm{A}$ & 0.48 \\
\hline Unit in 4 & Rabdotus & sp. & 15.9 & 9.8 & Y & $\mathrm{N}$ & 0.62 \\
\hline Unit in 4 & Rabdotus & sp. & 18.6 & 10.4 & $\mathrm{~N}$ & Y & 0.56 \\
\hline Unit in 4 & Rabdotus & sp. & 21.2 & 11.7 & $\mathrm{~N}$ & $\mathrm{Y}$ & 0.55 \\
\hline Unit in 4 & Rabdotus & sp. & 23 & 11.9 & $\mathrm{~N}$ & $\mathrm{Y}$ & 0.52 \\
\hline Unit in 4 & Rabdotus & sp. & 22.6 & 12.6 & $\mathrm{~N}$ & Y & 0.56 \\
\hline Unit in 4 & Rabdotus & sp. & 21 & 11.3 & $\mathrm{~N}$ & Y & 0.54 \\
\hline Unit in 4 & Rabdotus & sp. & 21 & 10.4 & $\mathrm{~N}$ & Y & 0.49 \\
\hline Unit in 4 & Rabdotus & sp. & 20 & 11.4 & $\mathrm{~N}$ & Y & 0.57 \\
\hline Unit in 4 & Rabdotus & sp. & 20.7 & 11.6 & Y & $\mathrm{N}$ & 0.56 \\
\hline Unit in 4 & Rabdotus & sp. & 14.5 & 9 & $\mathrm{Y}$ & $\mathrm{N}$ & 0.62 \\
\hline Unit in 4 & Rabdotus & sp. & 20.4 & 11.3 & $\mathrm{Y}$ & $\mathrm{N}$ & 0.55 \\
\hline Unit in 4 & Rabdotus & sp. & 13.7 & 8.3 & $\mathrm{Y}$ & $\mathrm{N}$ & 0.6 \\
\hline Unit in 4 & Rabdotus & sp. & 20 & 10.8 & $\mathrm{~N}$ & $\mathrm{~N}$ & 0.54 \\
\hline Unit in 4 & Rabdotus & sp. & 21.3 & 10.9 & $\mathrm{~N}$ & $Y$ & 0.51 \\
\hline Unit in 4 & Rabdotus & sp. & 21 & 12.5 & $\mathrm{~N}$ & Y & 0.59 \\
\hline Unit in 4 & Rabdotus & sp. & 19.3 & 11.1 & Y & $\mathrm{N}$ & 0.58 \\
\hline Unit in 4 & Rabdotus & sp. & 17.1 & 10.5 & Y & $\mathrm{N}$ & 0.61 \\
\hline Unit in 4 & Rabdotus & sp. & 16.6 & 9.6 & $Y$ & $\mathrm{~N}$ & 0.58 \\
\hline Unit in 4 & Rabdotus & $\mathrm{sp}$. & 16 & 8.8 & $\mathrm{Y}$ & $\mathrm{N}$ & 0.55 \\
\hline Unit in 4 & Unknown & $\# 1$ & 8.9 & 16.1 & $N / A$ & $\mathrm{~N} / \mathrm{A}$ & 1.81 \\
\hline Unit in 4 & Unknown & $\# 1$ & 9.4 & 15.7 & $\mathrm{~N} / \mathrm{A}$ & $\mathrm{N} / \mathrm{A}$ & 1.66 \\
\hline Unit in 4 & Unknown & $\# 1$ & 9.4 & 14 & $\mathrm{~N} / \mathrm{A}$ & $\mathrm{N} / \mathrm{A}$ & 1.48 \\
\hline Unit in 4 & Unknown & $\# 1$ & 7.3 & 11.4 & $\mathrm{~N} / \mathrm{A}$ & $\mathrm{N} / \mathrm{A}$ & 1.56 \\
\hline Unit in 5 & Mesodon & thyroides & 10.9 & 19.4 & $\mathrm{~N} / \mathrm{A}$ & $\mathrm{N} / \mathrm{A}$ & 1.78 \\
\hline Unit in 5 & Mesodon & thyroides & 10.6 & 19.5 & $\mathrm{~N} / \mathrm{A}$ & $\mathrm{N} / \mathrm{A}$ & 1.84 \\
\hline Unit in 5 & Mesodon & thyroides & 11.8 & 18 & $\mathrm{~N} / \mathrm{A}$ & $\mathrm{N} / \mathrm{A}$ & 1.52 \\
\hline Unit in 5 & Mesodon & thyroides & 10.2 & 18.4 & $\mathrm{~N} / \mathrm{A}$ & $\mathrm{N} / \mathrm{A}$ & 1.8 \\
\hline Unit in 5 & Mesodon & thyroides & 10.2 & 16.5 & $N / A$ & $\mathrm{~N} / \mathrm{A}$ & 1.61 \\
\hline Unit in 5 & Mesodon & thyroides & 10 & 18.4 & $\mathrm{~N} / \mathrm{A}$ & $\mathrm{N} / \mathrm{A}$ & 1.84 \\
\hline Unit in 5 & Mesodon & thyroides & 10.1 & 16.4 & $\mathrm{~N} / \mathrm{A}$ & $\mathrm{N} / \mathrm{A}$ & 1.62 \\
\hline Unit in 5 & Mesodon & thyroides & 10 & 18.9 & $\mathrm{~N} / \mathrm{A}$ & $\mathrm{N} / \mathrm{A}$ & 1.89 \\
\hline Unit in 5 & Mesodon & thyroides & 10.6 & 18.3 & $\mathrm{~N} / \mathrm{A}$ & $\mathrm{N} / \mathrm{A}$ & 1.73 \\
\hline Unit in 5 & Mesodon & thyroides & 10.8 & 17.9 & $\mathrm{~N} / \mathrm{A}$ & $\mathrm{N} / \mathrm{A}$ & 1.65 \\
\hline Unit in 5 & Mesodon & thyroides & 10.4 & 16.6 & $\mathrm{~N} / \mathrm{A}$ & N/A & 1.59 \\
\hline Unit in 5 & Mesodon & thyroides & 10.4 & 17.6 & $N / A$ & $\mathrm{~N} / \mathrm{A}$ & 1.69 \\
\hline Unit in 5 & Mesodon & thyroides & 10.8 & 20 & $\mathrm{~N} / \mathrm{A}$ & $\mathrm{N} / \mathrm{A}$ & 1.85 \\
\hline Unit in 5 & Mesodon & thyroides & 10.6 & 19.5 & $\mathrm{~N} / \mathrm{A}$ & $\mathrm{N} / \mathrm{A}$ & 1.84 \\
\hline Unit in 5 & Mesodon & thyroides & 9.8 & 17 & $\mathrm{~N} / \mathrm{A}$ & $\mathrm{N} / \mathrm{A}$ & 1.74 \\
\hline Unit in 5 & Mesodon & thyroides & 9.7 & 15.9 & $N / A$ & N/A & 1.64 \\
\hline
\end{tabular}


Table H-5. Continued...

\begin{tabular}{|c|c|c|c|c|c|c|c|}
\hline Area & Genus & Species & length $(\mathrm{mm})$ & width $(\mathrm{mm})$ & Carina & Calus & Weight (g.) \\
\hline Unit in 5 & Mesodon & thyroides & 10.6 & 18.4 & $\mathrm{~N} / \mathrm{A}$ & $\mathrm{N} / \mathrm{A}$ & 1.74 \\
\hline Unit in 5 & Oligyra & sp. & 5.5 & 7.9 & N/A & N/A & 1.43 \\
\hline Unit in 5 & Oligyra & sp. & 5.3 & 7.1 & $N / A$ & N/A & 1.33 \\
\hline Unit in 5 & Oligyra & sp. & 5.9 & 7.4 & $\mathrm{~N} / \mathrm{A}$ & N/A & 1.26 \\
\hline Unit in 5 & Oligyra & sp. & 5.4 & 7.6 & $\mathrm{~N} / \mathrm{A}$ & N/A & 1.39 \\
\hline Unit in 5 & Oligyra & sp. & 5.3 & 8.5 & $N / A$ & $N / A$ & 1.6 \\
\hline Unit in 5 & Oligyra & sp. & 5 & 7.2 & $\mathrm{~N} / \mathrm{A}$ & N/A & 1.44 \\
\hline Unit in 5 & Oligyra & sp. & 5 & 7.4 & $\mathrm{~N} / \mathrm{A}$ & N/A & 1.48 \\
\hline Unit in 5 & Oligyra & sp. & 5.3 & 7.5 & $\mathrm{~N} / \mathrm{A}$ & $\mathrm{N} / \mathrm{A}$ & 1.4 \\
\hline Unit in 5 & Oligyra & sp. & 5 & 7.8 & N/A & N/A & 1.54 \\
\hline Unit in 5 & Oligyra & sp. & 6.4 & 8 & N/A & N/A & 1.25 \\
\hline Unit in 5 & Oligyra & sp. & 5.4 & 7.6 & N/A & N/A & 1.4 \\
\hline Unit in 5 & Oligyra & sp. & 5.4 & 7.1 & $\mathrm{~N} / \mathrm{A}$ & $\mathrm{N} / \mathrm{A}$ & 1.33 \\
\hline Unit in 5 & Oligyra & sp. & 5.1 & 7 & N/A & $N / A$ & 1.37 \\
\hline Unit in 5 & Oligyra & sp. & 5.8 & 8.2 & $\mathrm{~N} / \mathrm{A}$ & $\mathrm{N} / \mathrm{A}$ & 1.41 \\
\hline Unit in 5 & Oligyra & sp. & 5.5 & 7.8 & $\mathrm{~N} / \mathrm{A}$ & $\mathrm{N} / \mathrm{A}$ & 1.43 \\
\hline Unit in 5 & Oligyra & sp. & 5.7 & 6.9 & $\mathrm{~N} / \mathrm{A}$ & N/A & 1.2 \\
\hline Unit in 5 & Oligyra & sp. & 5.8 & 7.6 & $\mathrm{~N} / \mathrm{A}$ & $\mathrm{N} / \mathrm{A}$ & 1.3 \\
\hline Unit in 5 & Oligyra & sp. & 5.9 & 7.5 & N/A & N/A & 1.27 \\
\hline Unit in 5 & Oligyra & sp. & 5.2 & 6.3 & $\mathrm{~N} / \mathrm{A}$ & N/A & 1.22 \\
\hline Unit in 5 & Oligyra & sp. & 5.5 & 7.5 & $\mathrm{~N} / \mathrm{A}$ & $N / A$ & 1.37 \\
\hline Unit in 5 & Oligyra & sp. & 5.3 & 7.5 & N/A & $N / A$ & 1.4 \\
\hline Unit in 5 & Oligyra & sp. & 5.8 & 7 & N/A & N/A & 1.21 \\
\hline Unit in 5 & Oligyra & sp. & 5.4 & 7.4 & $\mathrm{~N} / \mathrm{A}$ & $\mathrm{N} / \mathrm{A}$ & 1.39 \\
\hline Unit in 5 & Oligyra & sp. & 5.8 & 7.6 & $\mathrm{~N} / \mathrm{A}$ & $\mathrm{N} / \mathrm{A}$ & 1.3 \\
\hline Unit in 5 & Oligyra & sp. & 4.8 & 6.8 & N/A & N/A & 1.41 \\
\hline Unit in 5 & Oligyra & sp. & 5.7 & 7.9 & N/A & N/A & 1.38 \\
\hline Unit in 5 & Oligyra & sp. & 5.9 & 7.8 & $\mathrm{~N} / \mathrm{A}$ & N/A & 1.33 \\
\hline Unit in 5 & Oligyra & sp. & 5.7 & 7.8 & N/A & $N / A$ & 1.36 \\
\hline Unit in 5 & Oligyra & sp. & 5.5 & 7.6 & $\mathrm{~N} / \mathrm{A}$ & $N / A$ & 1.38 \\
\hline Unit in 5 & Oligyra & sp. & 5.8 & 7.5 & $\mathrm{~N} / \mathrm{A}$ & $\mathrm{N} / \mathrm{A}$ & 1.31 \\
\hline Unit in 5 & Oligyra & $\mathrm{sp}$. & 5.4 & 7 & $\mathrm{~N} / \mathrm{A}$ & $\mathrm{N} / \mathrm{A}$ & 1.31 \\
\hline Unit in 5 & Oligyra & sp. & 4.9 & 7 & N/A & N/A & 1.44 \\
\hline Unit in 5 & Oligyra & sp. & 5.8 & 7.6 & N/A & N/A & 1.32 \\
\hline Unit in 5 & Oligyra & sp. & 5.5 & 7.3 & N/A & N/A & 1.34 \\
\hline Unit in 5 & Oligyra & sp. & 5.2 & 7.1 & $\mathrm{~N} / \mathrm{A}$ & $\mathrm{N} / \mathrm{A}$ & 1.38 \\
\hline Unit in 5 & Oligyra & sp. & 5 & 7.4 & $\mathrm{~N} / \mathrm{A}$ & $\mathrm{N} / \mathrm{A}$ & 1.47 \\
\hline Unit in 5 & Oligyra & sp. & 5.2 & 7.3 & $\mathrm{~N} / \mathrm{A}$ & N/A & 1.39 \\
\hline Unit in 5 & Oligyra & sp. & 5.1 & 7.4 & $\mathrm{~N} / \mathrm{A}$ & $\mathrm{N} / \mathrm{A}$ & 1.45 \\
\hline Unit in 5 & Oligyra & sp. & 5.7 & 7.5 & N/A & N/A & 1.32 \\
\hline Unit in 5 & Oligyra & sp. & 5.5 & 7.3 & $\mathrm{~N} / \mathrm{A}$ & $\mathrm{N} / \mathrm{A}$ & 1.34 \\
\hline Unit in 5 & Oligyra & sp. & 5.5 & 7.6 & N/A & N/A & 1.37 \\
\hline Unit in 5 & Oligyra & sp. & 5.4 & 7.3 & $\mathrm{~N} / \mathrm{A}$ & $\mathrm{N} / \mathrm{A}$ & 1.34 \\
\hline Unit in 5 & Oligyra & sp. & 5.4 & 7.8 & $\mathrm{~N} / \mathrm{A}$ & $\mathrm{N} / \mathrm{A}$ & 1.44 \\
\hline Unit in 5 & Oligyra & sp. & 5.3 & 7.3 & N/A & $N / A$ & 1.38 \\
\hline Unit in 5 & Oligyra & sp. & 5 & 7.7 & $\mathrm{~N} / \mathrm{A}$ & $\mathrm{N} / \mathrm{A}$ & 1.54 \\
\hline Unit in 5 & Oligyra & sp. & 5.6 & 7.2 & $\mathrm{~N} / \mathrm{A}$ & $\mathrm{N} / \mathrm{A}$ & 1.28 \\
\hline Unit in 5 & Oligyra & sp. & 5.1 & 6.9 & $\mathrm{~N} / \mathrm{A}$ & $\mathrm{N} / \mathrm{A}$ & 1.36 \\
\hline Unit in 5 & Oligyra & sp. & 5.3 & 7.1 & $\mathrm{~N} / \mathrm{A}$ & N/A & 1.34 \\
\hline Unit in 5 & Oligyra & sp. & 5.6 & 7.4 & N/A & N/A & 1.33 \\
\hline Unit in 5 & Oligyra & sp. & 5.4 & 7.8 & $\mathrm{~N} / \mathrm{A}$ & N/A & 1.46 \\
\hline Unit in 5 & Oligyra & sp. & 5.1 & 7 & $\mathrm{~N} / \mathrm{A}$ & N/A & 1.36 \\
\hline Unit in 5 & Oligyra & sp. & 4.9 & 7 & $\mathrm{~N} / \mathrm{A}$ & N/A & 1.43 \\
\hline Unit in 5 & Oligyra & sp. & 5.6 & 6.8 & $\mathrm{~N} / \mathrm{A}$ & $\mathrm{N} / \mathrm{A}$ & 1.21 \\
\hline Unit in 5 & Oligyra & sp. & 5.7 & 7.7 & $\mathrm{~N} / \mathrm{A}$ & $N / A$ & 1.36 \\
\hline
\end{tabular}


Table H-5. Continued...

\begin{tabular}{|c|c|c|c|c|c|c|c|}
\hline Area & Genus & Species & length (mm) & width (mm) & Carina & Calus & Weight (g.) \\
\hline Unit in 5 & Oligyra & $\mathrm{sp}$. & 5.3 & 7.4 & $\mathrm{~N} / \mathrm{A}$ & $\mathrm{N} / \mathrm{A}$ & 1.4 \\
\hline Unit in 5 & Oligyra & $\mathrm{sp}$. & 5.5 & 7.8 & $\mathrm{~N} / \mathrm{A}$ & $\mathrm{N} / \mathrm{A}$ & 1.41 \\
\hline Unit in 5 & Oligyra & sp. & 5.5 & 6.6 & $\mathrm{~N} / \mathrm{A}$ & $\mathrm{N} / \mathrm{A}$ & 1.21 \\
\hline Unit in 5 & Oligyra & $\mathrm{sp}$. & 4.8 & 6.9 & $\mathrm{~N} / \mathrm{A}$ & $\mathrm{N} / \mathrm{A}$ & 1.42 \\
\hline Unit in 5 & Oligyra & $\mathrm{sp}$. & 5 & 6.7 & $\mathrm{~N} / \mathrm{A}$ & $\mathrm{N} / \mathrm{A}$ & 1.34 \\
\hline Unit in 5 & Oligyra & $\mathrm{sp}$. & 5.5 & 7.3 & $\mathrm{~N} / \mathrm{A}$ & $\mathrm{N} / \mathrm{A}$ & 1.33 \\
\hline Unit in 5 & Oligyra & $\mathrm{sp}$. & 5.3 & 7.6 & $\mathrm{~N} / \mathrm{A}$ & $\mathrm{N} / \mathrm{A}$ & 1.42 \\
\hline Unit in 5 & Oligyra & sp. & 5.5 & 7.2 & $\mathrm{~N} / \mathrm{A}$ & $\mathrm{N} / \mathrm{A}$ & 1.3 \\
\hline Unit in 5 & Oligyra & sp. & 5.5 & 7.7 & $\mathrm{~N} / \mathrm{A}$ & $\mathrm{N} / \mathrm{A}$ & 1.4 \\
\hline Unit in 5 & Oligyra & $\mathrm{sp}$. & 5.2 & 7.6 & $\mathrm{~N} / \mathrm{A}$ & $\mathrm{N} / \mathrm{A}$ & 1.46 \\
\hline Unit in 5 & Oligyra & $\mathrm{sp}$. & 5.4 & 7.5 & $\mathrm{~N} / \mathrm{A}$ & $\mathrm{N} / \mathrm{A}$ & 1.4 \\
\hline Unit in 5 & Oligyra & $\mathrm{sp}$. & 6.1 & 8.2 & $\mathrm{~N} / \mathrm{A}$ & $\mathrm{N} / \mathrm{A}$ & 1.36 \\
\hline Unit in 5 & Oligyra & sp. & 5.2 & 7.1 & $\mathrm{~N} / \mathrm{A}$ & $\mathrm{N} / \mathrm{A}$ & 1.36 \\
\hline Unit in 5 & Oligyra & sp. & 5.6 & 7.4 & $\mathrm{~N} / \mathrm{A}$ & $\mathrm{N} / \mathrm{A}$ & 1.33 \\
\hline Unit in 5 & Oligyra & $\mathrm{sp}$. & 5 & 7.7 & $\mathrm{~N} / \mathrm{A}$ & $\mathrm{N} / \mathrm{A}$ & 1.54 \\
\hline Unit in 5 & Oligyra & sp. & 5.3 & 7.2 & $\mathrm{~N} / \mathrm{A}$ & $\mathrm{N} / \mathrm{A}$ & 1.37 \\
\hline Unit in 5 & Oligyra & sp. & 5.4 & 7.6 & $\mathrm{~N} / \mathrm{A}$ & $\mathrm{N} / \mathrm{A}$ & 1.43 \\
\hline Unit in 5 & Oligyra & $\mathrm{sp}$. & 5.2 & 7 & $\mathrm{~N} / \mathrm{A}$ & $\mathrm{N} / \mathrm{A}$ & 1.34 \\
\hline Unit in 5 & Oligyra & $\mathrm{sp}$. & 4.7 & 7.5 & $\mathrm{~N} / \mathrm{A}$ & $\mathrm{N} / \mathrm{A}$ & 1.59 \\
\hline Unit in 5 & Oligyra & sp. & 5.8 & 8.1 & $\mathrm{~N} / \mathrm{A}$ & $\mathrm{N} / \mathrm{A}$ & 1.38 \\
\hline Unit in 5 & Oligyra & $\mathrm{sp}$. & 5.7 & 7.9 & $\mathrm{~N} / \mathrm{A}$ & $\mathrm{N} / \mathrm{A}$ & 1.39 \\
\hline Unit in 5 & Oligyra & $\mathrm{sp}$. & 4.7 & 6.8 & $\mathrm{~N} / \mathrm{A}$ & $\mathrm{N} / \mathrm{A}$ & 1.44 \\
\hline Unit in 5 & Oligyra & $\mathrm{sp}$. & 5.6 & 7.9 & $\mathrm{~N} / \mathrm{A}$ & $\mathrm{N} / \mathrm{A}$ & 1.42 \\
\hline Unit in 5 & Oligyra & sp. & 5.4 & 7.6 & $\mathrm{~N} / \mathrm{A}$ & $\mathrm{N} / \mathrm{A}$ & 1.4 \\
\hline Unit in 5 & Oligyra & sp. & 5.4 & 7.7 & $\mathrm{~N} / \mathrm{A}$ & $\mathrm{N} / \mathrm{A}$ & 1.41 \\
\hline Unit in 5 & Oligyra & $\mathrm{sp}$. & 5.6 & 7.3 & $\mathrm{~N} / \mathrm{A}$ & $\mathrm{N} / \mathrm{A}$ & 1.32 \\
\hline Unit in 5 & Oligyra & $\mathrm{sp}$. & 5.9 & 7.5 & $\mathrm{~N} / \mathrm{A}$ & $\mathrm{N} / \mathrm{A}$ & 1.28 \\
\hline Unit in 5 & Oligyra & sp. & 5.2 & 7.2 & $\mathrm{~N} / \mathrm{A}$ & $\mathrm{N} / \mathrm{A}$ & 1.39 \\
\hline Unit in 5 & Oligyra & sp. & 5.8 & 7.3 & $\mathrm{~N} / \mathrm{A}$ & $N / A$ & 1.26 \\
\hline Unit in 5 & Oligyra & sp. & 5.2 & 7 & $\mathrm{~N} / \mathrm{A}$ & $\mathrm{N} / \mathrm{A}$ & 1.36 \\
\hline Unit in 5 & Oligyra & $\mathrm{sp}$. & 5.3 & 7.7 & $\mathrm{~N} / \mathrm{A}$ & $\mathrm{N} / \mathrm{A}$ & 1.45 \\
\hline Unit in 5 & Oligyra & $\mathrm{sp}$. & 5.6 & 7.2 & $\mathrm{~N} / \mathrm{A}$ & $\mathrm{N} / \mathrm{A}$ & 1.29 \\
\hline Unit in 5 & Oligyra & $\mathrm{sp}$. & 5.5 & 7.4 & $\mathrm{~N} / \mathrm{A}$ & $\mathrm{N} / \mathrm{A}$ & 1.36 \\
\hline Unit in 5 & Oligyra & $\mathrm{sp}$. & 5.5 & 7.6 & $\mathrm{~N} / \mathrm{A}$ & $\mathrm{N} / \mathrm{A}$ & 1.38 \\
\hline Unit in 5 & Oligyra & sp. & 5.8 & 6.8 & $\mathrm{~N} / \mathrm{A}$ & $\mathrm{N} / \mathrm{A}$ & 1.18 \\
\hline Unit in 5 & Oligyra & sp. & 5.3 & 7.5 & $\mathrm{~N} / \mathrm{A}$ & $\mathrm{N} / \mathrm{A}$ & 1.41 \\
\hline Unit in 5 & Oligyra & $\mathrm{sp}$. & 5.3 & 7.4 & $\mathrm{~N} / \mathrm{A}$ & $\mathrm{N} / \mathrm{A}$ & 1.39 \\
\hline Unit in 5 & Oligyra & sp. & 5.2 & 7.2 & $\mathrm{~N} / \mathrm{A}$ & $\mathrm{N} / \mathrm{A}$ & 1.39 \\
\hline Unit in 5 & Oligyra & $\mathrm{sp}$. & 5 & 7.5 & $\mathrm{~N} / \mathrm{A}$ & $\mathrm{N} / \mathrm{A}$ & 1.52 \\
\hline Unit in 5 & Oligyra & sp. & 5.3 & 7.1 & $\mathrm{~N} / \mathrm{A}$ & $\mathrm{N} / \mathrm{A}$ & 1.34 \\
\hline Unit in 5 & Oligyra & $\mathrm{sp}$. & 5.2 & 7.3 & $\mathrm{~N} / \mathrm{A}$ & $\mathrm{N} / \mathrm{A}$ & 1.41 \\
\hline Unit in 5 & Oligyra & $\mathrm{sp}$. & 5.7 & 7.6 & $\mathrm{~N} / \mathrm{A}$ & $\mathrm{N} / \mathrm{A}$ & 1.32 \\
\hline Unit in 5 & Oligyra & $\mathrm{sp}$. & 5.5 & 6.9 & $\mathrm{~N} / \mathrm{A}$ & $\mathrm{N} / \mathrm{A}$ & 1.26 \\
\hline Unit in 5 & Oligyra & $\mathrm{sp}$. & 5.1 & 7.7 & $\mathrm{~N} / \mathrm{A}$ & $\mathrm{N} / \mathrm{A}$ & 1.51 \\
\hline Unit in 5 & Oligyra & $\mathrm{sp}$. & 5.3 & 7.3 & $\mathrm{~N} / \mathrm{A}$ & $\mathrm{N} / \mathrm{A}$ & 1.38 \\
\hline Unit in 5 & Oligyra & sp. & 5.5 & 7.6 & $\mathrm{~N} / \mathrm{A}$ & $\mathrm{N} / \mathrm{A}$ & 1.38 \\
\hline Unit in 5 & Oligyra & sp. & 5.1 & 7.6 & $\mathrm{~N} / \mathrm{A}$ & N/A & 1.5 \\
\hline Unit in 5 & Oligyra & $\mathrm{sp}$. & 5.2 & 7.6 & $\mathrm{~N} / \mathrm{A}$ & $\mathrm{N} / \mathrm{A}$ & 1.46 \\
\hline Unit in 5 & Oligyra & sp. & 5.8 & 7.6 & $\mathrm{~N} / \mathrm{A}$ & $\mathrm{N} / \mathrm{A}$ & 1.31 \\
\hline Unit in 5 & Oligyra & sp. & 5.2 & 7.4 & $\mathrm{~N} / \mathrm{A}$ & $\mathrm{N} / \mathrm{A}$ & 1.42 \\
\hline Unit in 5 & Oligyra & sp. & 4.9 & 7.2 & $\mathrm{~N} / \mathrm{A}$ & $\mathrm{N} / \mathrm{A}$ & 1.47 \\
\hline Unit in 5 & Oligyra & sp. & 5.5 & 7.5 & $\mathrm{~N} / \mathrm{A}$ & $\mathrm{N} / \mathrm{A}$ & 1.36 \\
\hline Unit in 5 & Oligyra & $\mathrm{sp}$. & 5.9 & 7.9 & $\mathrm{~N} / \mathrm{A}$ & $\mathrm{N} / \mathrm{A}$ & 1.35 \\
\hline Unit in 5 & Oligyra & sp. & 5.5 & 7 & $\mathrm{~N} / \mathrm{A}$ & $\mathrm{N} / \mathrm{A}$ & 1.27 \\
\hline Unit in 5 & Oligyra & $\mathrm{sp}$. & 5.3 & 8 & $\mathrm{~N} / \mathrm{A}$ & $\mathrm{N} / \mathrm{A}$ & 1.51 \\
\hline
\end{tabular}


Table H-5. Continued...

\begin{tabular}{|c|c|c|c|c|c|c|c|}
\hline Area & Genus & Species & length $(\mathrm{mm})$ & width $(\mathrm{mm})$ & Carina & Calus & Weight (g.) \\
\hline Unit in 5 & Oligyra & sp. & 5.7 & 7.3 & $\mathrm{~N} / \mathrm{A}$ & $\mathrm{N} / \mathrm{A}$ & 1.29 \\
\hline Unit in 5 & Oligyra & sp. & 5.6 & 7.6 & $\mathrm{~N} / \mathrm{A}$ & $\mathrm{N} / \mathrm{A}$ & 1.35 \\
\hline Unit in 5 & Oligyra & sp. & 5.1 & 7.3 & $N / A$ & N/A & 1.42 \\
\hline Unit in 5 & Oligyra & sp. & 5.5 & 7.4 & $N / A$ & $N / A$ & 1.35 \\
\hline Unit in 5 & Oligyra & sp. & 5.5 & 7.4 & $N / A$ & $N / A$ & 1.36 \\
\hline Unit in 5 & Oligyra & sp. & 5.8 & 7.7 & N/A & N/A & 1.34 \\
\hline Unit in 5 & Oligyra & $\mathrm{sp}$. & 5.6 & 7.3 & $\mathrm{~N} / \mathrm{A}$ & $\mathrm{N} / \mathrm{A}$ & 1.3 \\
\hline Unit in 5 & Oligyra & sp. & 5.2 & 7.4 & $\mathrm{~N} / \mathrm{A}$ & $\mathrm{N} / \mathrm{A}$ & 1.42 \\
\hline Unit in 5 & Oligyra & sp. & 5.6 & 7.8 & $\mathrm{~N} / \mathrm{A}$ & $\mathrm{N} / \mathrm{A}$ & 1.4 \\
\hline Unit in 5 & Oligyra & sp. & 5.6 & 7.4 & $\mathrm{~N} / \mathrm{A}$ & $\mathrm{N} / \mathrm{A}$ & 1.33 \\
\hline Unit in 5 & Oligyra & sp. & 5.3 & 7.6 & $\mathrm{~N} / \mathrm{A}$ & $\mathrm{N} / \mathrm{A}$ & 1.43 \\
\hline Unit in 5 & Oligyra & sp. & 6.4 & 7.8 & N/A & $N / A$ & 1.22 \\
\hline Unit in 5 & Oligyra & sp. & 5.1 & 6.9 & N/A & N/A & 1.35 \\
\hline Unit in 5 & Oligyra & sp. & 5.6 & 7.2 & N/A & N/A & 1.3 \\
\hline Unit in 5 & Oligyra & $\mathrm{sp}$. & 5.6 & 7.2 & $\mathrm{~N} / \mathrm{A}$ & $\mathrm{N} / \mathrm{A}$ & 1.29 \\
\hline Unit in 5 & Oligyra & sp. & 5.5 & 8 & $\mathrm{~N} / \mathrm{A}$ & $\mathrm{N} / \mathrm{A}$ & 1.44 \\
\hline Unit in 5 & Oligyra & sp. & 5.4 & 7.7 & $\mathrm{~N} / \mathrm{A}$ & $\mathrm{N} / \mathrm{A}$ & 1.43 \\
\hline Unit in 5 & Oligyra & $\mathrm{sp}$. & 5.4 & 7.8 & $N / A$ & N/A & 1.44 \\
\hline Unit in 5 & Oligyra & sp. & 5.6 & 7.5 & N/A & N/A & 1.33 \\
\hline Unit in 5 & Oligyra & sp. & 5 & 7 & N/A & N/A & 1.39 \\
\hline Unit in 5 & Oligyra & sp. & 5.1 & 7.2 & N/A & N/A & 1.41 \\
\hline Unit in 5 & Oligyra & $\mathrm{sp}$. & 5.5 & 7.4 & $\mathrm{~N} / \mathrm{A}$ & N/A & 1.35 \\
\hline Unit in 5 & Oligyra & sp. & 4.9 & 7.3 & $\mathrm{~N} / \mathrm{A}$ & $\mathrm{N} / \mathrm{A}$ & 1.49 \\
\hline Unit in 5 & Oligyra & sp. & 5.5 & 7.4 & $\mathrm{~N} / \mathrm{A}$ & $\mathrm{N} / \mathrm{A}$ & 1.34 \\
\hline Unit in 5 & Oligyra & sp. & 6 & 7.4 & $\mathrm{~N} / \mathrm{A}$ & $\mathrm{N} / \mathrm{A}$ & 1.24 \\
\hline Unit in 5 & Oligyra & $\mathrm{sp}$. & 5 & 7.2 & $\mathrm{~N} / \mathrm{A}$ & $\mathrm{N} / \mathrm{A}$ & 1.45 \\
\hline Unit in 5 & Oligyra & sp. & 5.4 & 6.9 & N/A & $N / A$ & 1.29 \\
\hline Unit in 5 & Oligyra & sp. & 5.5 & 6.9 & N/A & N/A & 1.26 \\
\hline Unit in 5 & Oligyra & sp. & 5.5 & 7.2 & $\mathrm{~N} / \mathrm{A}$ & N/A & 1.32 \\
\hline Unit in 5 & Oligyra & $\mathrm{sp}$. & 5.2 & 7.5 & $\mathrm{~N} / \mathrm{A}$ & N/A & 1.44 \\
\hline Unit in 5 & Oligyra & sp. & 5.9 & 7.4 & $\mathrm{~N} / \mathrm{A}$ & $\mathrm{N} / \mathrm{A}$ & 1.26 \\
\hline Unit in 5 & Oligyra & sp. & 5.5 & 6.9 & $\mathrm{~N} / \mathrm{A}$ & $\mathrm{N} / \mathrm{A}$ & 1.27 \\
\hline Unit in 5 & Oligyra & sp. & 5.5 & 7.3 & $\mathrm{~N} / \mathrm{A}$ & $\mathrm{N} / \mathrm{A}$ & 1.34 \\
\hline Unit in 5 & Oligyra & sp. & 5.3 & 7.1 & $\mathrm{~N} / \mathrm{A}$ & $\mathrm{N} / \mathrm{A}$ & 1.34 \\
\hline Unit in 5 & Oligyra & sp. & 5 & 6.8 & $N / A$ & $N / A$ & 1.36 \\
\hline Unit in 5 & Oligyra & sp. & 5.3 & 7.3 & N/A & N/A & 1.36 \\
\hline Unit in 5 & Oligyra & sp. & 5.4 & 6.9 & $\mathrm{~N} / \mathrm{A}$ & N/A & 1.27 \\
\hline Unit in 5 & Oligyra & sp. & 5.2 & 6.9 & $\mathrm{~N} / \mathrm{A}$ & $\mathrm{N} / \mathrm{A}$ & 1.33 \\
\hline Unit in 5 & Oligyra & $\mathrm{sp}$. & 5.4 & 7.8 & $\mathrm{~N} / \mathrm{A}$ & $\mathrm{N} / \mathrm{A}$ & 1.44 \\
\hline Unit in 5 & Oligyra & sp. & 5.8 & 7 & $\mathrm{~N} / \mathrm{A}$ & $\mathrm{N} / \mathrm{A}$ & 1.21 \\
\hline Unit in 5 & Oligyra & $\mathrm{sp}$. & 5.6 & 7.3 & $\mathrm{~N} / \mathrm{A}$ & N/A & 1.31 \\
\hline Unit in 5 & Oligyra & sp. & 5.5 & 7.6 & $\mathrm{~N} / \mathrm{A}$ & $N / A$ & 1.37 \\
\hline Unit in 5 & Oligyra & sp. & 5.1 & 7.8 & $\mathrm{~N} / \mathrm{A}$ & $N / A$ & 1.52 \\
\hline Unit in 5 & Oligyra & sp. & 5.7 & 7.1 & N/A & N/A & 1.25 \\
\hline Unit in 5 & Oligyra & $\mathrm{sp}$. & 4.7 & 6.8 & $\mathrm{~N} / \mathrm{A}$ & $\mathrm{N} / \mathrm{A}$ & 1.46 \\
\hline Unit in 5 & Oligyra & sp. & 5.3 & 7.4 & $\mathrm{~N} / \mathrm{A}$ & $\mathrm{N} / \mathrm{A}$ & 1.38 \\
\hline Unit in 5 & Oligyra & sp. & 4.8 & 4.8 & $\mathrm{~N} / \mathrm{A}$ & $\mathrm{N} / \mathrm{A}$ & 1 \\
\hline Unit in 5 & Oligyra & sp. & 5.5 & 7.2 & $\mathrm{~N} / \mathrm{A}$ & N/A & 1.32 \\
\hline Unit in 5 & Oligyra & $\mathrm{sp}$. & 5.9 & 7.7 & $\mathrm{~N} / \mathrm{A}$ & N/A & 1.31 \\
\hline Unit in 5 & Oligyra & sp. & 5.2 & 7.2 & $\mathrm{~N} / \mathrm{A}$ & $N / A$ & 1.38 \\
\hline Unit in 5 & Oligyra & sp. & 5.5 & 7.3 & $N / A$ & $\mathrm{~N} / \mathrm{A}$ & 1.33 \\
\hline Unit in 5 & Oligyra & sp. & 6.2 & 8.1 & $\mathrm{~N} / \mathrm{A}$ & N/A & 1.29 \\
\hline Unit in 5 & Oligyra & sp. & 5.1 & 7.3 & $\mathrm{~N} / \mathrm{A}$ & $\mathrm{N} / \mathrm{A}$ & 1.44 \\
\hline Unit in 5 & Oligyra & sp. & 5.6 & 7.5 & $\mathrm{~N} / \mathrm{A}$ & $\mathrm{N} / \mathrm{A}$ & 1.32 \\
\hline Unit in 5 & Oligyra & sp. & 5.9 & 7.3 & N/A & N/A & 1.22 \\
\hline
\end{tabular}


Table H-5. Continued...

\begin{tabular}{|c|c|c|c|c|c|c|c|}
\hline Area & Genus & Species & length (mm) & width (mm) & Carina & Calus & Weight (g.) \\
\hline Unit in 5 & Oligyra & sp. & 5.5 & 7.6 & $\mathrm{~N} / \mathrm{A}$ & $\mathrm{N} / \mathrm{A}$ & 1.39 \\
\hline Unit in 5 & Oligyra & sp. & 5.1 & 7.3 & $N / A$ & $\mathrm{~N} / \mathrm{A}$ & 1.42 \\
\hline Unit in 5 & Oligyra & sp. & 4.9 & 7.3 & $N / A$ & $N / A$ & 1.48 \\
\hline Unit in 5 & Oligyra & sp. & 5.2 & 7 & $N / A$ & $\mathrm{~N} / \mathrm{A}$ & 1.36 \\
\hline Unit in 5 & Oligyra & sp. & 4.7 & 6.5 & $N / A$ & $\mathrm{~N} / \mathrm{A}$ & 1.38 \\
\hline Unit in 5 & Oligyra & sp. & 5.4 & 7.3 & $\mathrm{~N} / \mathrm{A}$ & $\mathrm{N} / \mathrm{A}$ & 1.35 \\
\hline Unit in 5 & Oligyra & sp. & 4.9 & 7.4 & $\mathrm{~N} / \mathrm{A}$ & $\mathrm{N} / \mathrm{A}$ & 1.5 \\
\hline Unit in 5 & Oligyra & sp. & 5.7 & 7.5 & $\mathrm{~N} / \mathrm{A}$ & $\mathrm{N} / \mathrm{A}$ & 1.32 \\
\hline Unit in 5 & Oligyra & sp. & 5.5 & 7.5 & $\mathrm{~N} / \mathrm{A}$ & $\mathrm{N} / \mathrm{A}$ & 1.36 \\
\hline Unit in 5 & Oligyra & sp. & 5.7 & 7.4 & $\mathrm{~N} / \mathrm{A}$ & $\mathrm{N} / \mathrm{A}$ & 1.31 \\
\hline Unit in 5 & Oligyra & sp. & 5.6 & 7.3 & $N / A$ & $\mathrm{~N} / \mathrm{A}$ & 1.31 \\
\hline Unit in 5 & Oligyra & sp. & 5.3 & 7.5 & $N / A$ & $N / A$ & 1.41 \\
\hline Unit in 5 & Oligyra & sp. & 5.1 & 6.8 & $\mathrm{~N} / \mathrm{A}$ & $\mathrm{N} / \mathrm{A}$ & 1.34 \\
\hline Unit in 5 & Rabdotus & sp. & 24.3 & 12.6 & $\mathrm{~N}$ & Y & 0.52 \\
\hline Unit in 5 & Rabdotus & sp. & 22.9 & 11.8 & $\mathrm{~N}$ & Y & 0.52 \\
\hline Unit in 5 & Rabdotus & sp. & 21.7 & 11.6 & $\mathrm{~N}$ & Y & 0.54 \\
\hline Unit in 5 & Rabdotus & sp. & 22.8 & 12.2 & $\mathrm{~N}$ & $Y$ & 0.54 \\
\hline Unit in 5 & Rabdotus & sp. & 22.9 & 11.5 & $\mathrm{~N}$ & $\mathrm{Y}$ & 0.5 \\
\hline Unit in 5 & Rabdotus & sp. & 21.2 & 11.7 & $\mathrm{~N}$ & $\mathrm{Y}$ & 0.55 \\
\hline Unit in 5 & Rabdotus & sp. & 22.6 & 13.2 & $\mathrm{~N}$ & $\mathrm{Y}$ & 0.59 \\
\hline Unit in 5 & Rabdotus & sp. & 22 & 12.3 & $\mathrm{~N}$ & $Y$ & 0.56 \\
\hline Unit in 5 & Rabdotus & sp. & 18.9 & 11.1 & $\mathrm{~N}$ & Y & 0.59 \\
\hline Unit in 5 & Rabdotus & sp. & 18.6 & 10.4 & $\mathrm{~N}$ & Y & 0.56 \\
\hline Unit in 5 & Rabdotus & sp. & 20.9 & 11 & $\mathrm{~N}$ & $\mathrm{Y}$ & 0.53 \\
\hline Unit in 5 & Rabdotus & sp. & 20.3 & 10.6 & $\mathrm{~N}$ & Y & 0.52 \\
\hline Unit in 5 & Rabdotus & sp. & 19.1 & 10.3 & $\mathrm{~N}$ & $\mathrm{Y}$ & 0.54 \\
\hline Unit in 5 & Rabdotus & sp. & 21.3 & 12.3 & $\mathrm{~N}$ & $\mathrm{Y}$ & 0.58 \\
\hline Unit in 5 & Rabdotus & sp. & 19.6 & 11 & $\mathrm{~N}$ & $\mathrm{Y}$ & 0.56 \\
\hline Unit in 5 & Rabdotus & sp. & 22.6 & 11 & $\mathrm{~N}$ & Y & 0.49 \\
\hline Unit in 5 & Rabdotus & $\mathrm{sp}$. & 21.9 & 12.2 & $\mathrm{~N}$ & Y & 0.55 \\
\hline Unit in 5 & Rabdotus & sp. & 22.4 & 10.6 & $\mathrm{~N}$ & $Y$ & 0.47 \\
\hline Unit in 5 & Rabdotus & sp. & 20 & 10.4 & $\mathrm{~N}$ & Y & 0.52 \\
\hline Unit in 5 & Rabdotus & sp. & 22.5 & 11.7 & $\mathrm{~N}$ & $Y$ & 0.52 \\
\hline Unit in 5 & Rabdotus & sp. & 21.9 & 11.4 & Y & $\mathrm{N}$ & 0.52 \\
\hline Unit in 5 & Rabdotus & sp. & 21 & 11 & $\mathrm{Y}$ & $\mathrm{N}$ & 0.53 \\
\hline Unit in 5 & Rabdotus & sp. & 17.8 & 10.7 & Y & $\mathrm{N}$ & 0.6 \\
\hline Unit in 5 & Rabdotus & sp. & 17.4 & 10.1 & Y & $\mathrm{N}$ & 0.58 \\
\hline Unit in 5 & Rabdotus & sp. & 16.1 & 10.3 & $Y$ & $\mathrm{~N}$ & 0.64 \\
\hline Unit in 5 & Rabdotus & sp. & 15.6 & 8.5 & Y & $\mathrm{N}$ & 0.55 \\
\hline Unit in 5 & Rabdotus & sp. & 18.9 & 10.3 & Y & $\mathrm{N}$ & 0.55 \\
\hline Unit in 5 & Rabdotus & sp. & 15 & 9.1 & $Y$ & $\mathrm{~N}$ & 0.61 \\
\hline Unit in 5 & Rabdotus & sp. & 17.8 & 10.1 & $\mathrm{Y}$ & $\mathrm{N}$ & 0.57 \\
\hline Unit in 5 & Rabdotus & sp. & 19.3 & 10.2 & $\mathrm{Y}$ & $\mathrm{N}$ & 0.53 \\
\hline Unit in 5 & Rabdotus & sp. & 16.5 & 9.6 & $Y$ & $\mathrm{~N}$ & 0.58 \\
\hline Unit in 5 & Rabdotus & sp. & 12.6 & 8 & Y & $\mathrm{N}$ & 0.64 \\
\hline Unit in 5 & Rabdotus & sp. & 19.4 & 9.9 & $Y$ & $\mathrm{~N}$ & 0.51 \\
\hline Unit in 5 & Rabdotus & sp. & 14.4 & 8.5 & Y & $\mathrm{N}$ & 0.59 \\
\hline Unit in 5 & Rabdotus & sp. & 14.9 & 9.2 & Y & $\mathrm{N}$ & 0.62 \\
\hline Unit in 5 & Rabdotus & sp. & 19.3 & 10.8 & $Y$ & $\mathrm{~N}$ & 0.56 \\
\hline Unit in 5 & Rabdotus & sp. & 14.6 & 9 & $\mathrm{Y}$ & $\mathrm{N}$ & 0.62 \\
\hline Unit in 5 & Rabdotus & sp. & 16 & 9.1 & $\mathrm{Y}$ & $\mathrm{N}$ & 0.57 \\
\hline Unit in 5 & Rabdotus & sp. & 16.9 & 9 & Y & $\mathrm{N}$ & 0.54 \\
\hline Unit in 5 & Rabdotus & sp. & 15.8 & 9.4 & Y & $\mathrm{N}$ & 0.6 \\
\hline Unit in 5 & Rabdotus & sp. & 15.1 & 9.3 & Y & $\mathrm{N}$ & 0.62 \\
\hline Unit in 5 & Rabdotus & sp. & 15.2 & 8.5 & $\mathrm{Y}$ & $\mathrm{N}$ & 0.56 \\
\hline
\end{tabular}


Table H-5. Continued...

\begin{tabular}{|c|c|c|c|c|c|c|c|}
\hline Area & Genus & Species & length $(\mathrm{mm})$ & width $(\mathrm{mm})$ & Carina & Calus & Weight (g.) \\
\hline Unit in 5 & Rabdotus & sp. & 17.5 & 11 & $\mathrm{Y}$ & $\mathrm{N}$ & 0.63 \\
\hline Unit in 5 & Rabdotus & sp. & 16.1 & 9.7 & $Y$ & $\mathrm{~N}$ & 0.6 \\
\hline Unit in 5 & Rabdotus & sp. & 17.9 & 9.9 & $Y$ & $\mathrm{~N}$ & 0.56 \\
\hline Unit in 5 & Rabdotus & sp. & 15.6 & 9.5 & $Y$ & $\mathrm{~N}$ & 0.61 \\
\hline Unit in 5 & Rabdotus & sp. & 15.5 & 9.6 & $Y$ & $\mathrm{~N}$ & 0.62 \\
\hline Unit in 5 & Rabdotus & sp. & 20.5 & 11.3 & $\mathrm{~N}$ & $Y$ & 0.55 \\
\hline Unit in 5 & Rabdotus & sp. & 18.3 & 10 & $Y$ & $\mathrm{~N}$ & 0.54 \\
\hline Unit in 5 & Rabdotus & sp. & 13.1 & 7.5 & $Y$ & $\mathrm{~N}$ & 0.57 \\
\hline Unit in 5 & Rabdotus & sp. & 13.9 & 8.6 & $Y$ & $\mathrm{~N}$ & 0.62 \\
\hline Unit in 5 & Rabdotus & sp. & 12.9 & 7.5 & $\bar{Y}$ & $\mathrm{~N}$ & 0.58 \\
\hline Unit in 5 & Rabdotus & sp. & 7.7 & 4.9 & $Y$ & $\mathrm{~N}$ & 0.64 \\
\hline Unit in 5 & Rabdotus & sp. & 11.8 & 6.9 & $Y$ & $\mathrm{~N}$ & 0.59 \\
\hline Unit in 5 & Rabdotus & sp. & 7.7 & 5.9 & $Y$ & $\mathrm{~N}$ & 0.77 \\
\hline Unit in 5 & Rabdotus & sp. & 13.4 & 7.9 & $\bar{Y}$ & $\mathrm{~N}$ & 0.59 \\
\hline Unit in 5 & Rabdotus & sp. & 12.7 & 7.7 & $Y$ & $\mathrm{~N}$ & 0.61 \\
\hline Unit in 5 & Rabdotus & sp. & 11.6 & 7.8 & $Y$ & $\mathrm{~N}$ & 0.67 \\
\hline Unit in 5 & Rabdotus & sp. & 11.4 & 7.5 & $Y$ & $\mathrm{~N}$ & 0.65 \\
\hline Unit in 5 & Rabdotus & sp. & 12.9 & 8.5 & $\bar{Y}$ & $\mathrm{~N}$ & 0.66 \\
\hline Unit in 5 & Rabdotus & sp. & 11.3 & 7.6 & $Y$ & $\mathrm{~N}$ & 0.68 \\
\hline Unit in 5 & Rabdotus & sp. & 8.4 & 5.9 & $Y$ & $\mathrm{~N}$ & 0.7 \\
\hline Unit in 5 & Rabdotus & sp. & 13.3 & 7.6 & $Y$ & $\mathrm{~N}$ & 0.57 \\
\hline Unit in 5 & Rabdotus & sp. & 12.2 & 7.6 & $\bar{Y}$ & $\mathrm{~N}$ & 0.62 \\
\hline Unit in 5 & Rabdotus & sp. & 4.9 & 3.8 & $Y$ & $\mathrm{~N}$ & 0.77 \\
\hline Unit in 5 & Rabdotus & sp. & 14.3 & 8.4 & $Y$ & $\mathrm{~N}$ & 0.59 \\
\hline Unit in 5 & Rabdotus & sp. & 14.2 & 9 & $Y$ & $\mathrm{~N}$ & 0.63 \\
\hline Unit in 5 & Rabdotus & sp. & 13.3 & 7.3 & $Y$ & $\mathrm{~N}$ & 0.55 \\
\hline Unit in 5 & Rabdotus & sp. & 9.1 & 6.5 & 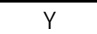 & $\mathrm{N}$ & 0.71 \\
\hline Unit in 5 & Rabdotus & sp. & 10.5 & 6.5 & $Y$ & $\mathrm{~N}$ & 0.61 \\
\hline Unit in 5 & Rabdotus & sp. & 12.1 & 8 & $Y$ & $\mathrm{~N}$ & 0.66 \\
\hline Unit in 5 & Rabdotus & sp. & 8 & 5.9 & $Y$ & $\mathrm{~N}$ & 0.74 \\
\hline Unit in 5 & Rabdotus & sp. & 10.5 & 6.6 & $Y$ & $\mathrm{~N}$ & 0.63 \\
\hline Unit in 5 & Rabdotus & sp. & 12.6 & 7.7 & $Y$ & $\mathrm{~N}$ & 0.61 \\
\hline Unit in 5 & Rabdotus & sp. & 14.8 & 8.8 & $\bar{Y}$ & $\mathrm{~N}$ & 0.59 \\
\hline Unit in 5 & Rabdotus & sp. & 12.3 & 7.7 & $Y$ & $\mathrm{~N}$ & 0.63 \\
\hline Unit in 5 & Rabdotus & sp. & 9.2 & 6.6 & $\bar{Y}$ & $\mathrm{~N}$ & 0.71 \\
\hline
\end{tabular}




\section{References Cited}

Brown, K.M.

2002 Appendix F: Snails from the Quarter -Inch and Eighteen-Inch Screens. In The Smith Creek Bridge Site (41DW270): A Terrace Site in DeWitt County, Texas. Eds. D. Hudler, K. Prilliman, and T. Gustavon, pp. 213-275. Studies in Archaeology 35. Texas Archeological Research Laboratory, The University of Texas at Austin.

Cheatum, E.P., R.W. Fullington, W.L. Pratt

1971 The aquatic and land mollusca of Texas. Dallas Natural Science Association : Dallas Museum of Natural History, Dallas.

Clark, J.W., Jr.

1969 Implications of Land and Fresh-Water Gastropods in Archeological Sites. Arkansas Academy of Science Proceedings, Vol. 23:39-52.

1973 The Problem of the Land Snail Genus Rabdotus in Texas Archeological Sites. The Nautilus 87(1):24.

Goodfriend, G. A.

1986 Variation in Land-Snail Shell Form and Size and its Causes: A Review. Systematic Zoology 35(2): 204-222.

Lower Colorado River Authority

2008 McKinney Roughs Nature Park: Trail Guide. Lower Colorado River Authority, Austin.

Malof, A.F.

2001 Feast or Famine: The Dietary Role of Rabdotus Species Snails in Prehistoric Central Texas. Unpublished MA thesis, Anthropology Department, The University of Texas at San Antonio.

Web Soil Survey (WSS)

2009 Natural Resources Conservation Service, http://websoilsurvey.nrcs.usda.gov/app/WebSoilSurvey.aspx, Accessed June 25, 2009, United States Department of Agriculture. 



\section{APPENDIX I:}

Micro-snails from McKinney Roughs Nature Park, Bastrop County, Texas

Manuel R. Palacios-Fest 



\author{
APPENDIX I \\ Macro-snails from McKinney Roughs Nature Park, \\ Bastrop County, Texas \\ Manuel R. Palacios-Fest \\ Terra Nostra Earth Sciences Research, \\ P.O. 37195 Tucson, AZ 85740-7195 \\ TNESR Report No. 0912
}

\begin{abstract}
The study of modern land snail assemblages from Texas may provide a valuable analog for interpreting the relationship between humans and the environment in prehistoric archeological sites. The present study offers an interpretation of modern gastropod assemblages that should enable Texas archeologists to address questions concerning how land snails may reflect the environment and the potential use by humans.
\end{abstract}

\title{
INTRODUCTION
}

Archeological research has, for many years, included the analysis of plant and animal remains as a means to understanding both their ecological implications and potential anthropogenic use. Land snails are not an exception. Incorporating the study of land snails has allowed archeologists in the interpretation of the environmental setting or how people created shell artifacts sometimes from specimens imported from remote regions (e.g., Busycon shell ornaments; Dreiss 2009). The local fauna, however, is no less important, some species constitute part of the natives' diet (e.g., Rabdotus dealbatus). Excessive abundance of Rabdotus shells or accumulation of shell middens are a good indication of the human use of this resource. In this sense, the study of modern faunas in or around archeological sites is increasingly important because it provides the background information of what is present and what may have been introduced purposely or accidentally to the region. Snails are relatively short-lived, so using the appropriate methods they may be used for reconstructing prehistoric humanenvironment relationships (Malof 2007).

The land snails documented in this report belong to the phylum Mollusca, class Gastropoda, subclass Pulmonata, order Stylommatophora, and the families Helicinidae, Pupillidae, Buliminidae, Discidae, Helicarionidae, Zonitidae, and Polygyridae (Burch 1962; Johnson 2006; Perez 2006). Identification to the species level was based on shell morphology using current literature. The ecological implications of the species were derived also from current literature listed within the text. Because the ecological requirements of many species are known (Bequaert and Miller 1973), these organisms are an excellent proxy for environmental reconstructions.

The material gathered by the Center for Archaeological Research (CAR) of the University of Texas at San Antonio (UTSA) was submitted to Terra Nostra Earth Sciences Research, LLC (TNESR) for species identification and interpretation. Palacios-Fest identified the species to the best of his ability and submits below a listing of species (as ascertained) together with short discussions concerning them. Included herein are remarks concerning some taxonomic, distributional, ecological, and paleontological aspects of the fauna. Some minor speculations of a zoogeographic nature are also suggested.

\section{AREA OF STUDY}

As summarized in Appendix H, McKinney Roughs Nature Park located in Bastrop County, Texas consists of 500 Ha (1,100 acres) along the Colorado River and contains four distinct ecosystems: Post Oak Savannah, Blackland Prairie, Piney Woods and Riparian (LRCA 2008). The Web Soil Survey for Bastrop, Texas (WSS 2009) shows the information on soils and vegetation communities. The vegetation communities are basically defined in terms of the ratio of trees, shrubs, forbs and grasses present along with the percentage of canopy coverage. However, the historical use of the land for cattle grazing and brush clearing is also used as a criterion in the development stage of vegetation communities. Vegetation communities delineate the patterns of land snail distribution discussed below. 


\section{MATERIALS, METHODS, and RESULTS}

Seven bags containing mollusk shells from the same number of $1 / 4$-inch screen samples collected from McKinney Roughs were sent to Terra Nostra Earth Sciences Research in Tucson, Arizona for identification, quantification, and ecological analysis. One bag from Areas 1, 3 and 5 and two bags from Areas 2 and 4 were shipped for analysis, large and small screen fractions; each often containing several different snail species. The specimens were, when possible, identified to the species level. Diversity, total and relative abundance, and population maturity (a ratio of adult/juvenile shells) were recorded for determining the ecological implications of the fauna to the site. To estimate the snail population per square meter, the total count of shells was divided by $900 \mathrm{~m}^{2}$ (30-X-30 m) for each of the areas sampled for this study. In addition, the collectors sampled test units (1-x-1 $\mathrm{m})$ within each one of the areas cited above.

\section{Species Identification}

The taxa of mollusks listed hereafter are in the sequence employed by Johnson (2006) and Perez (2006) in their websites "Land Snails of Texas" and "Land Snails of Texas List-Preliminary", respectively. Perez (2006) listed the families systematically (e.g., phylogenetically), but within families genera taxa were arranged alphabetically. Johnson (2006) cited the common names along with the species names. I attempt to combine Johnson's with Perez's arrangement herein.

Areas 1 and 2 contained no snails. Areas 3, 4, and 5 had variable populations. In all, 1326 snail were assigned to 13 land species from McKinney Roughs Nature Park, including Helicina (Olygyra) orbiculata (Say 1818), Gastrocopta cristata (Pilsbry and Vanatta 1900), Rabdotus mooreanus (Pfeiffer 1868), Anguispira alternatus (Say 821), Discus whitneyi (Newcomb 1864), Euconulus chersinus (Say 1821), Euconulus fulvus (Müller 1774), Hawaiia minuscula (A. Binney 1841), Mesomphix inornatus (Say 1821), Euchemotrema leai (A. Binney 1841), Mesodon thyroidus (Say, 1816), and Polygyra texasiana (Moricand, 1833). Table I-1 shows the taxonomy, ecological requirements, and known distribution of the species recovered from the site. The

Table I-1. Taxonomy and ecological requirements of the Class Gastropoda taxa identified from McKinney Roughs (Taxonomy after Johnson 2006 and Perez 2006)

\begin{tabular}{|c|c|c|c|c|}
\hline Family & Species & Common Name & Environment & Habitat \\
\hline Helicinidae & Helicina (Olygyra) orbiculata (Say, 1818) & Globular Drop & Diverse & Widespread in disturbed habitats ${ }^{4}$ \\
\hline Pupillidae & $\begin{array}{l}\text { Gastrocopta cristata (Pilsbry and } \\
\text { Vanatta, 1900) }\end{array}$ & $\begin{array}{l}\text { Crested } \\
\text { Snaggletooth }\end{array}$ & Forest & $\begin{array}{l}\text { Moist soils under logs or stones on wooded slopes and poorly } \\
\text { drained floodplains and among grass on open slopes }{ }^{2}\end{array}$ \\
\hline Bulimulidae & Rabdotus mooreanus (Pfeiffer, 1868) & Prairie Rabdotus & Grassland & $\begin{array}{l}\text { A semi-arboreal species. Found on grass and shrubs, usually in } \\
\text { open country. }{ }^{1}\end{array}$ \\
\hline Discidae & Anguispira alternata (Say, 1816) & Flamed Tigersnail & Diverse & Soil, gravel, or decayed wood, woodlands ${ }^{7}$ \\
\hline Discidae & Discus whitneyi (Newcomb, 1864) & Forest Disc & Diverse & $\begin{array}{l}\text { Forests and at open sites, under fallen branches, logs, stones, } \\
\text { debris and in leaf litter. }{ }^{7}\end{array}$ \\
\hline Helicarionidae & Euconulus chersinus (Say, 1821) & Wild Hive Snail & $\begin{array}{l}\text { Deciduous } \\
\text { tree forest }\end{array}$ & Woodlands; able to withstand seasonal droughts. ${ }^{9}$ \\
\hline Helicarionidae & Euconulus fulvus (Müller, 1774) & Brown Hive Snail & Diverse & $\begin{array}{l}\text { In a wide variety of moist, sheltered, undisturbed habitats - in } \\
\text { coniferous and deciduous woods, mossy hedge banks, dune } \\
\text { slacks and marshes. }{ }^{6}\end{array}$ \\
\hline Zonitidae & Hawaiia minuscula (A. Binney, 1841) & Minute Gem & $\begin{array}{l}\text { Deciduous } \\
\text { tree forest }\end{array}$ & Leaf-litter habitats, forest ${ }^{5}$ \\
\hline Zonitidae & Mesomphix inornatus (Say, 1821) & Plain Button & Forest & Leaf-litter habitats, forest ${ }^{3}$ \\
\hline Polygiridae & Euchemotrema leai (A. Binney, 1841) & Lowland Pillsnail & Diverse & $\begin{array}{l}\text { Rocky outcrops, upland forest, lowland forest, upland grassland, } \\
\text { lowland grassland. }{ }^{8}\end{array}$ \\
\hline Polygyridae & Mesodon thyroidus (Say, 1816) & White-Lip Globe & $\begin{array}{l}\text { Forest/ } \\
\text { Disturbed }\end{array}$ & $\begin{array}{l}\text { Leaf-litter habitats, forest }{ }^{3} \text {; Usually more common around disturbed } \\
\text { areas like old fields and homesteads; less common in rich woods }{ }^{10}\end{array}$ \\
\hline Polygiridae & Polygyra texasiana (Moricand, 1833) & Texas Liptooth & $\begin{array}{l}\text { Woodland/ } \\
\text { Prairie }\end{array}$ & Low ground under litter ${ }^{1}$ \\
\hline \multicolumn{4}{|l|}{${ }^{1}$ Hubricht (1985) } & ${ }^{5}$ Oliver and Bosworth III (1999) \\
\hline \multicolumn{4}{|c|}{${ }^{2}$ Zimmerman (1960) } & ${ }^{7}$ Nekola (2008) \\
\hline \multicolumn{4}{|c|}{${ }^{3}$ http://www.carnegiemnh.org/mollusks/palandsnails/accounts/me_inor.htm } & ${ }^{8}$ Nekola (2003) \\
\hline \multicolumn{4}{|c|}{${ }^{6} \mathrm{http}: / /$ www.livinglandscapes.bc.ca/upperfraserbasin/ufb_snails/family2.html } & ${ }^{9}$ Allen and Cheatum (1960) \\
\hline
\end{tabular}

thyroidus.shtml 
table shows the family to which the species belongs, species identification, common name, and the general and specific environmental conditions the species prefers.

Table I-2 shows the total and relative abundance of the species identified, as well as the population maturity of each species. The land snail population ranged from extremely rare to extremely abundant ${ }^{1 *}$. The modern samples collected for this study are intended to provide analog data for interpreting prehistoric and historical environments associated with archeological sites in south-central Texas.

Table I-2.Total and relative abundance, and adulthood (A/J) ratios of gastropods identified from areas at McKinney Roughs, Bastrop County, Texas

\begin{tabular}{|c|c|c|c|c|c|c|c|c|c|}
\hline \multirow[b]{2}{*}{ Species } & \multicolumn{3}{|c|}{ Area 1: Brushy Woodland } & \multicolumn{3}{|c|}{ Area 2: Brushy Woodland } & \multicolumn{3}{|c|}{ Area 3: Brushy Woodland } \\
\hline & $\#$ & $\%$ & $\mathrm{~A} / \mathrm{J}$ & $\#$ & $\%$ & $\mathrm{~A} / \mathrm{J}$ & $\#$ & $\%$ & $\mathrm{~A} / \mathrm{J}$ \\
\hline Helicina (Olygyra) orbiculata & 0 & 0 & 0 & 0 & 0 & 0 & 18 & 17.5 & 0.28 \\
\hline Gastrocopta cristata & 0 & 0 & 0 & 0 & 0 & 0 & 3 & 2.9 & 1 \\
\hline Rabdotus mooreanus & 0 & 0 & 0 & 0 & 0 & 0 & 9 & 8.7 & 0.11 \\
\hline Anguispira alternata & 0 & 0 & 0 & 0 & 0 & 0 & 8 & 7.8 & 0.25 \\
\hline Discus whitneyi & 0 & 0 & 0 & 0 & 0 & 0 & 2 & 1.9 & 0 \\
\hline Euconulus chersinus & 0 & 0 & 0 & 0 & 0 & 0 & 0 & 0 & 0 \\
\hline Euconulus fulvus & 0 & 0 & 0 & 0 & 0 & 0 & 19 & 18.4 & 0.11 \\
\hline Hawaiia minuscula & 0 & 0 & 0 & 0 & 0 & 0 & 8 & 7.8 & 0.38 \\
\hline Mesomphix inornatus & 0 & 0 & 0 & 0 & 0 & 0 & 33 & 32 & 0.21 \\
\hline Euchemotrema leai & 0 & 0 & 0 & 0 & 0 & 0 & 0 & 0 & 0 \\
\hline Mesodon thyroidus & 0 & 0 & 0 & 0 & 0 & 0 & 2 & 1.9 & 1 \\
\hline Polygyra texasiana & 0 & 0 & 0 & 0 & 0 & 0 & 1 & 1 & 1 \\
\hline \# of Shells & 0 & & & 0 & & & 103 & & \\
\hline Population (specimens per $900 \mathrm{~m}^{2}$ ) & 0 & & & 0 & & & 0.114 & & \\
\hline
\end{tabular}

\begin{tabular}{|l|c|c|c|c|c|c|}
\hline \multirow{2}{*}{ Species } & \multicolumn{3}{|c|}{ Area 4: Climax Forest } & \multicolumn{2}{c|}{ Area 5: Open Grassland/Floodplain } \\
\cline { 2 - 7 } & $\#$ & $\%$ & A/J & $\#$ & $\%$ & A/J \\
\hline Helicina (Olygyra) orbiculata & 156 & 47.9 & 0.33 & 202 & 22.5 & 0.39 \\
\hline Gastrocopta cristata & 4 & 1.2 & 0 & 14 & 1.6 & 0 \\
\hline Rabdotus mooreanus & 26 & 8 & 0.15 & 120 & 13.4 & 0.13 \\
\hline Anguispira alternata & 19 & 5.8 & 0.11 & 1 & 0.1 & 0 \\
\hline Discus whitneyi & 3 & 0.9 & 1 & 37 & 4.1 & 0.03 \\
\hline Euconulus chersinus & 3 & 0.92 & 1 & 0 & 0 & 0 \\
\hline Euconulus fulvus & 0 & 0 & 0 & 219 & 24.4 & 0.05 \\
\hline Hawaiia minuscula & 7 & 2.1 & 1 & 13 & 1.4 & 1 \\
\hline Mesomphix inornatus & 77 & 23.6 & 0.1 & 244 & 27.2 & 0.02 \\
\hline Euchemotrema leai & 3 & 0.9 & 1 & 0 & 0 & 0 \\
\hline Mesodon thyroidus & 0 & 0 & 0 & 32 & 3.6 & 0.22 \\
\hline Polygyra texasiana & 28 & 8.6 & 1 & 14 & 1.6 & 1 \\
\hline \# of Shells & 326 & & & 897 & & \\
\hline Population (specimens per $900 \mathrm{~m}^{2}$ ) & 0.362 & & & 0.997 & & \\
\hline
\end{tabular}

\section{Family Helicinidae}

\section{Helicina (Olygyra) orbiculata (Say, T. 1818. Journal of the Academy of Natural Sciences 1: 276).}

Bequaert and Miller (1973:9-10, 19) recognized the distribution of the genus Helicina in the eastern section of the Southwestern Molluscan Province (New Mexico and Texas) between $30^{\circ} \mathrm{N}$ and $36^{\circ} \mathrm{N}$ where it gradually merges with the "Eastern Molluscan Division over a transitional strip of generally level, moderately high country with a depauperate

$1 \quad{ }^{*}$ Abundance explanation: extremely abundant $(>501)$, very abundant $(>101<500)$, abundant $(>51<100)$, common $(>21<50)$, rare $(>11<20)$, very rare $(>6<10)$, and extremely rare $(<5)$. 
molluscan fauna.” A significant characteristic of this division is that Helicina, a southeastern component along with Rabdotus and Polygyra (also present in McKinney Roughs Nature Park), frequently replaces the distinctive southwestern genera (e.g., Sonorella, Ashmunella, Oreohelix, Chaenaxis). The authors point out that south of the Llano Estacado and east of the Pecos River (at the west end of the Comanchian Biotic Province of Dice [1943:28]; the Balconian Biotic Province of W. F. Blair [1950:112]), not only lacks the distinctive southwestern genera abovementioned, but hosts many of the widespread mollusks of central Texas (Polygyra, Microceramus, Euglandina, Helicina, Retinella roemeri, Rabdotus alternatus, subspecies of Rabdotus dealbatus, and more). The latter species are characteristic of the Mexican Plateau.

In McKinney Roughs Nature Park, H. (O.) orbiculata occurred in Areas 3, 4 and 5 (Figure I-1; Table I-2). In Area 3, it represents $17 \%$ of the total population; whereas in Area 4 it is the dominant species with almost $48 \%$, declining in Area 5 to less than $23 \%$. The widespread occurrence of the species is consistent with its current ecological requirements. The species may be ubiquitous due to its ability to adapt to disturbed areas (Table I-1).

\section{Family Pupillidae}

\section{Gastrocopta cristata (Pilsbry, H.A. 1916. Manual of Conchology, 24: 68-69; pl. 13, figs. 6, 8-12 [shell]).} Originally, H.A. Pilsbry and E.G. Vanatta (1900) identified the species as Bifidaria procera cristata.

Bequaert and Miller (1973:169-170) reported the species as widely distributed across Arizona but also present in Recent Nebraska, Kansas, Oklahoma, western Texas (east of Robertson, Brazos, and Austin counties), New Mexico, and Sonora (as far south as Ciudad Obregón) along the drifts of the Río Bavispe, Río Yaqui, and Río Sonoyta. The species occurs in Pliocene and Pleistocene sediments of Cochise County (San Pedro Valley Sites: Post Ranch, California Wash, and El Paso Pipeline; Lehner Mammoth and Murray Springs, associated with mammoth remains (10,000 to 11,000 years old) suggesting that the modern occurrence in the eastern part of the Southwestern Molluscan Province might be due to anthropogenic impact.

The species is extremely rare in Areas 3 and 4 but rare in Area 5 (Figure I-1; Table I-2). G. cristata in Area 5 responds well to the ecological conditions defined for the species. It prefers poorly drained floodplains and open grassland environments; however, it remained poorly represented (Table I-1).

\section{Family Bulimidae}

\section{Rabdotus mooreanus (Pfeiffer, 1868) (Pilsbry, H.A. 1946-1948. Monograph of the Academy of Natural Sciences of Philadelphia, 3(2). 1102 pp.)}

Bequaert and Miller (1973:100) cite that the most conspicuous Neotropical elements of the Southwestern Molluscan Province include four species of the genus Bulimulus (subgenus Rabdotus) that originated and speciated profusely south of the Tropic of Cancer along with Humboldtiana (seven species) and Holospira (25 species) particularly in Mexico and Central America. Bulimulus is a characteristic xerophilous group widespread in the Southwestern Molluscan Province. These groups migrated north probably sometime during the late Mesozoic or early Tertiary providing them with the conditions to adapt and evolve to subtropical and more arid environments.

The relatively limited occurrence of $R$. mooreanus in all three areas containing snails is a significant indicator of its natural occurrence in the McKinney Roughs Nature Park (Figure I-1; Table I-2). Usually, the species is one of the main sources of food recorded in shell middens of prehistoric people. The implication of the scarcity of $R$. mooreanus at the park is that the species developed in situ under the open country conditions acknowledged in the literature as shown in Table I-1. 


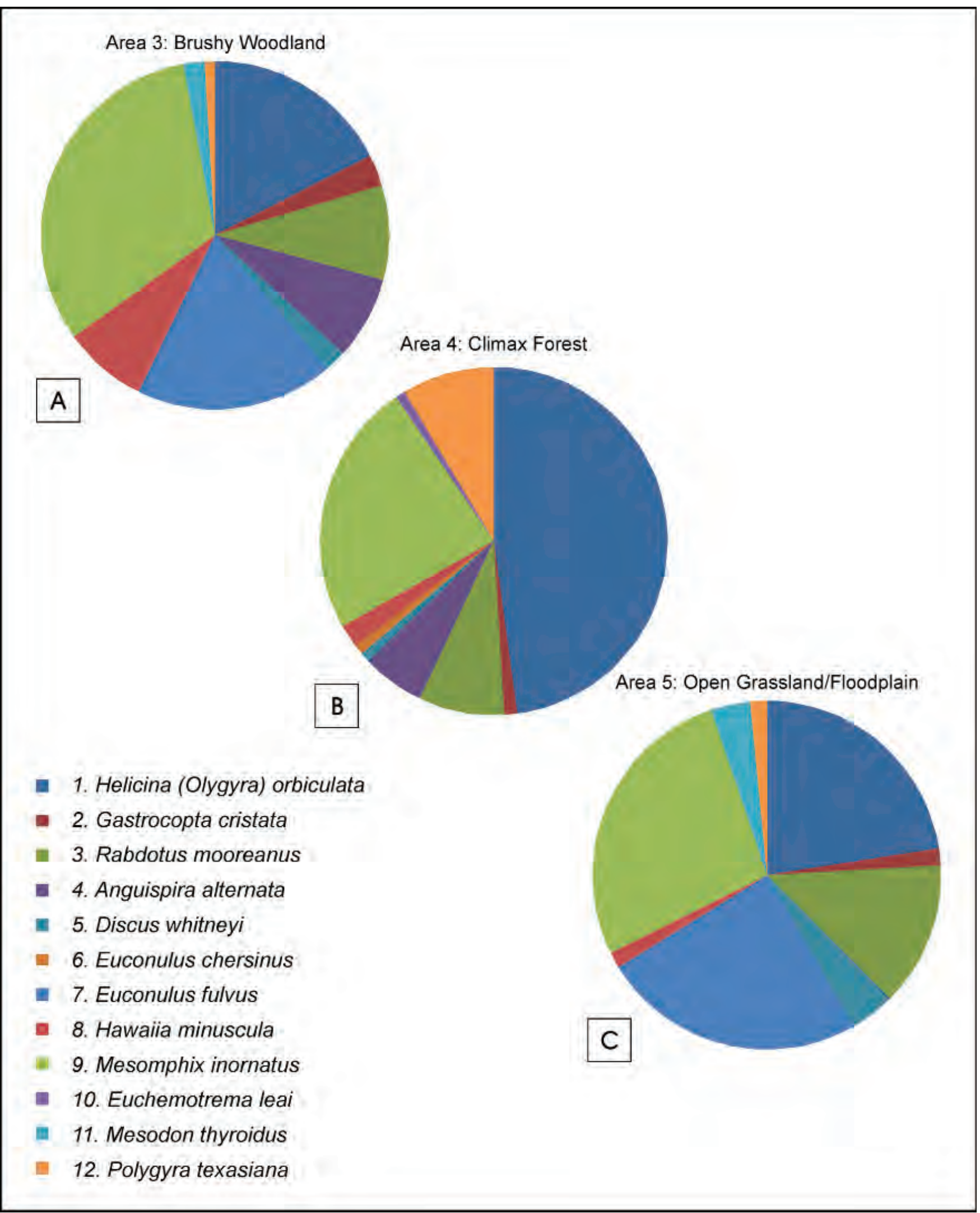

Figure I-1. Distribution of land snail species by vegetation type (Brushy Woodland, A; Climax Forest, B; Open Grassland/ Floodplain, C) within McKinney Roughs Nature Park, Bastrop County, Texas. 


\title{
Family Discidae
}

\author{
Anguispira alternata (Say, T. 1817. Journal of the Academy of Natural Sciences of Philadelphia 1(1):13-16; \\ and (2):17-18.)
}

Strecker (1935) and Webb (1942) reported this species almost everywhere east of the Rockies. Strecker, for example indicated that this is a common species in Texas; whereas Webb relates the species variability to climatic and the widely diverse environmental conditions where it has been recorded.

A. alternata was recovered from Areas 3 and 4, but only one specimen from Area 5 (Figure I-1; Table I-2). The species remained very rare to rare in the former two areas indicating that it prefers wooded conditions over open environments (Table I-1). However, the McKinney Roughs Nature Park does not seem to provide an adequate environment for the species.

\section{Discus whitneyi (Newcomb, 1864) (Pilsbry, H.A. 1946-1948. Monograph of the Academy of Natural Sciences of Philadelphia, 3(2). 1102 pp.)}

Bequaert and Miller (1973:83-84) recognized the genus Discus as an essentially autochthonous holartic element that more likely evolved outside the Southwestern Molluscan Province in the Eastern Molluscan Division of the Neartic Region. The genus Discus with many fossil and recent species occurs in the Old and New Worlds since at least the Upper Mesozoic in Eurasia. Thus, the authors consider this group an intruder in the arid Southwest. Just a few of the typically eastern land mollusks have succeeded in spreading by natural means west of the Mississippi River, and even fewer beyond the $100^{\text {th }}$ Meridian. It occurs from Alaska (Aleutian Islands) to Labrador, south of California, Arizona, New Mexico, and Texas.

This widely spread and well-known species was previously called Discus cronkhitei, but Discus whitneyi predates that name (Roth 1987). Dall (1905), Bequaert and Miller (1973) and Roth and Lindberg (1981) have alluded to the strong resemblance of this snail to D. ruderatus (Férussac, 1821) of the northern Europe and Asia.

The species occurred in all three areas (3, 4, and 5); however, it was more abundant in Area 5 (Figure I-1; Table I-2). Unexpectedly, the species is extremely rare (less than $2 \%$ ) in the forested areas of the brushy woodland and climax forest that are supposed to be the preferred environments by the D. whitneyi (Table I-1). It, nonetheless, reached around 4\% in Area 5 . In any case, the species is not significantly abundant in the McKinney Roughs Nature Park.

\section{Family Helicarionidae}

\section{Euconulus chersinus (Say), (Pilsbry, H.A. 1899. Nautilus, vol. 12, p. 116.)}

Strecker (1935) reported the species across Texas including McLennan and Live Oak counties, Hondo River in Medina County, Sinkning Springs in Hays County, New Braunfels in Comal County, Rio San Felipe, Devils and Nueces River drift. Bequaert and Miller (1973) do not mention the species.

Absent in Areas 3 and 5, E. chersinus was extremely rare in Area 4 where it merely reached around 1\% of the population (Figure I-1; Table I-2). Apparently, the record from the McKinney Roughs Nature Park is consistent with the ecological requirements of the species. However, more analysis would be required to verify the current interpretation (Table I-1).

\section{Euconulus fulvus (Müller, 1774) (Helix fulva Müller, O.F. 1774; Pilsbry, H.A. 1946-1948. Monograph of the Academy of Natural Sciences of Philadelphia, 3(2). 1102 pp.).}

The species prefers sedge lowlands, seeps, and other calcareous hygric habitats. It occurs throughout most of Ontario in wet calcareous habitats from Hudson River area southward (Oughton 1948). Its distribution extends from the Great Lakes - upper Mississippi Basin eastward, south to Georgia into the Appalachians (Hubricht 1985). In the Southwestern Molluscan Province, Bequaert and 
Miller (1973:66) reported the species confined to high elevations and often only as disjunct relicts. The species, however, has a worldwide distribution in the Holartic Realm including north of Greenland, Iceland, Sacndinavia, Alaska, Manitoba, Labrador, and New Foundland. At lower latitudes it is found in mountains of Europe, North Africa, and North America (from North Carolina to California and the Mexican Plateau). In addition, E. fulvus is known fossil from the Middle Pliocene and the Pleistocene on both sides of the Atlantic. For example, Bequaert and Miller (1973:67) mentioned that it was common in Late Pleistocene sediments of the San Pedro Valley at Lehner Mammoth and Murray Spring Sites in Arizona, associated with mammoth remains 10,000 to 11,000 years old.

E. fulvus was indentified at Areas 3 and 5 but not 4 (Figure I-1; Table I-2). In Area 3 it was rare representing about $18 \%$ of the total population. At Area 5, however, the species was very abundant constituting more than $24 \%$ of the population recorded in the site. It is well adapted to a wide variety of environmental conditions. It may be considered cosmopolitan (Table I-1).

\section{Family Zonitidae}

\section{Hawaiia minuscula (Helix minuscule Binney, A. 1841; Boston Journal of Natural History, 3: 435)}

Bequaert and Miller (1973:76) reported this monotypic species throughout most of North America in Pliocene, Pleistocene, and Holocene deposits in the Mid-West, Southwest, and eventually in some regions of Wyoming and Idaho. In a controversial statement the authors, however, suggested that $H$. minuscula is a truly recent species presumably native to the Holartic Region. The controversy, it seems to me, lies on the species chronology. It is possible that these authors meant the species became more abundant and widely distributed during the Holocene. A synanthropic and eurytopic species, $H$. minuscula, swiftly invaded the southern United States, Mexico, and Central America. More likely, H. minuscula was introduced by humans to the latter region.

In spite of its widespread distribution across North America, $H$. minuscula is not abundant in any of the three areas where it occurred. Areas 3, 4, and 5 contained less than $8 \%$ of the total population implying that McKinney Roughs Nature Park does not provide the optimal conditions for the species to succeed or that competition with other species is stressful (Figure I-1; Table I-2). As shown in Table I-1, the species prefers to live under leaf-litter in deciduous forests; therefore, Areas 3 and 4 appear to offer shelter to the species. Area 5 does not.

\section{Mesomphix inornatus (Say, 1821). (Pilsbry, H.A. 1946-1948. Monograph of the Academy of Natural Sciences of Philadelphia, 3(2). 1102 pp.)}

The species occurs along eastern North America from Ontario and Quebec to Guatemala, in regions of moderate or high humidity (Pilsbry 1946). Four subgenera are recognized. One occurs in the study area. Oughton (1948) reported the genus Mesomphix in Canada. Grimm (2005) documented it as "rare and scattered from isolated stations mostly at and near the boundary of the Shield,... from Renfrew [County, Ontario], southwestward, and known from the Gatineau highlands in Quebec”. Its occurrence is to be expected in undisturbed forest sites from New England and New York south in and near Appalachians to Tennessee, with outlying peripheral populations in the Ohio and Great Lakes Basins (Hubricht 1985). Bequaert and Miller (1973) did not report the species for the Southwest.

M. inornatus ranged from common (Area 3) to abundant (Area 4) to very abundant (Area 5) (Figure I-1; Table I-2). The plain button, however, is reported to prefer forested areas (Table I-1). Its occurrence in Area 5 is rather controversial, particularly given its high abundance (more than 27\%).

\section{Family Polygyridae}

\section{Euchemotrema leai (Binney, A. 1841. Boston Journal of Natural History, 3: 435).}

Allen and Cheatum (1960) identified this species in archeological sites of Texas around permanently moist environments; usually in well protected heavily wooded borders of permanent streams and rivers. Bequaert and Miller (1973) did not report E. leai aliciae for the Southwestern Molluscan Province. The species occurs across the eastern United States and Canada 
(from New Brunswick, Ontario, and Quebec as far south as Texas, but is missing in Florida). Two subspecies of $E$. leai are known: E. leai aliciae (Pilsbry 1893) and E. leai leai (A. Binney 1841). The latter, however, appears to be reported only from pre-Holocene sites according the "Land Snails of Southern Illinois" website of Marla L. Coppolino (accessed on 11/30/2009).

This species is extremely rare in Aarea 4, the climax forest implying that the McKinney Roughs Nature Park is not its optimal environment or that competition is stressful (Figure I-1; Table I-2). In the literature (Table I-1) the species is reported from diverse conditions. Therefore, its limited occurrence may be the result of competing with other species.

\section{Mesodon thyroidus (Say, 1816). (Helix thyroidus Say, T. 1816. Nicholson's Encyclopedia, II, article Conchology, under Helix albolabris (no pagination).}

This species is common in the eastern forested portion of the United States from Texas to Minnesota. It also occurs eastward to central Florida and New England (Hubricht 1985). In Canada it is mostly present in southern Ontario southwest of Toronto (Grimm 2005).

M. thyroidus occurred in Areas 3 and 5, the brushy woodland and the open grassland/floodplain, where it is more abundant (greater than 3\%). The species, however, is extremely rare in Area 3 (Figure I-1; Table I-2). Although identified as a forest species (see Table I-1), it has also been associated with disturbed environments. It is plausible that its greater abundance in Area 5 responds to anthropogenic disturbance.

\section{Polygyra texasiana (Moricand, 1833). (Pilsbry, H. A. 1940. Acad. Nat. Sci. Philadelphia, Monograph 3, vol. 1(2): 617-620.)}

Polygyra texasiana ranges from eastern Texas through central Texas to the western Hill Country, where it is found in woodlands, savannahs, and those prairies with sufficient downed wood to provide cover for reduction of water loss. The species appears to be well adapted to anthropogenic impact. Neck (1986) reported the species in disturbed sites along the Balcones Escarpment in central Texas.

Present in Aareas 3, 4, and 5, P. texasiana is extremely rare to common in the McKinney Roughs Nature Park (Figure I-1; Table I-2). It is more abundant in Area 4, the climax forest, but the open grassland/floodplain contained some specimens consistent with the records of the species in woodland/prairie environments (Table I-1).

\section{DISCUSSION}

Gastropods are sensitive to environmental changes and tend to be limited to a varying extent, to a particular set of conditions. Chemicals in the soils (e.g., lime), soil moisture, and food availability are some of the major factors controlling diversity and abundance. Temperature and proper light conditions also contribute to regulate the presence/absence patterns of these mollusks (Clark 1969; Sharpe 2002). Reconstructing paleoclimate records using land snails, however, is not easy because, as Clark (1969) noticed it, the ecological and biological requirements of the species may permit them to adapt to a number of environments. Endemic species may offer a better opportunity for understanding climate change in an area. Also, as Cheatum (1966) demonstrated, small species may be more useful for reconstructing past environments. In order to make wise interpretations of past climate at archeological sites using land snails, it is appropriate to recognize the natural from the anthropogenic populations in modern settings.

In the current study, I attempt to establish the faunal assemblages characterizing each of the modern environments identified in the field by the CAR staff at the McKinney Roughs Nature Park, Bastrop County, Texas. That is, the brushy woodland, the climax forest, and the open grassland/floodplain. Three faunal assemblages are: (1) Brushy Woodland- dominated by $M$. inornatus, followed by $H$. (O.) orbiculata and E. fulvus; R. mooreanus occurs in a minor concentration; (2) Climax Forestdominated by H. (O.) orbiculata followed by M. inornatus, R. mooreanus, A. alternata, and P. texasiana; and (3) Open Grassland/Floodplain- dominated by H. (O.) orbiculata, E. fulvus and M. inornatus in almost equal proportions (see Table I-2; 
Figure I-1c), followed by $D$. whytneyi and $M$. thyroidus. It is important to notice that the three assemblages identified in this study contain the same species, but in different proportions.

At the Brushy Woodland (Area 3), the plain button (M. inornatus) appears to be the marker of forested, leaf-litter habitat (32\%) , whereas the other two species (H. [O.] orbiculata and E. fulvus), representing less than $19 \%$, are well adapted to a variety of environments ranging from deciduous forests to grassland, disturbed or undisturbed areas (Figure I-1a; Table I-2). The mixedbrush/midgrass vegetation community and the arboreal vegetation offer $M$. inornatus the appropriate conditions to thrive throughout the area. Leaf-litter is provided by cedar elm (Ulmus crassifolia), and to a lesser extent honey mesquite (Prosopis glandulosa) and juniper (Juniperus spp.). Shrubs, forbs, and grasses may offer better conditions to $H$. (O.) orbiculata and $E$. fulvus. However, the understory is sparse which would explain the lower proportion of these two species. By contrast with Appendix $\mathrm{H}$ which shows $R$. mooreanus as the dominant species, in this study it is a minor component of the assemblage with less than $9 \%$ of the total population. This grassland and semi-arboreal species is also sparse in Area 4 but more abundant in Aarea 5. With a few exceptions, the faunal assemblage at Area 3 is dominated by juveniles (between 89 and 62\%) (Table I-2) indicating an in situ cluster.

Area 4 (Climax Forest), characterized by a dense woodland vegetation, shows a different pattern with $H$. $(O$.) orbiculata as the dominant species (around 48\%) (Figure I-1b; Table I-2). M. inornatus, however, is a significant element in the assemblage with near $23 \%$ of the population. The minor occurrence of $R$. mooreanus, A. alternata, and P. texasiana provide mixed signatures. $R$. mooreanus prefers grassland conditions although it is found in semi-arboreal environments as well. On the other hand, $A$. alternata, a species adapted to a variety of conditions, does not appear to succeed in the woodland setting characteristic of Area 4. In contrast, P. texasiana reached its maximum occurrence in the climax forest, consistent with the known ecological preference reported elsewhere (see Table I-1). The adulthood ratio at Area 4 indicates 90 to 67\% juveniles, but small species where represented only by adults (Table I-2).

The Open Grassland/Floodplain environment typical of Area 5 shows a tripartite faunal assemblage where $H$. (O.) orbiculata shares the environment with $E$. fulvus and $M$. inornatus. While $H$. (O.) orbiculata is common in disturbed areas, E. fulvus appears to prefer undisturbed conditions ranging from moist, sheltered regions associated with deciduous woods. According to the available literature (see Table I-1), the occurrence of $M$. inornatus seems somehow conflicting due to the association of this species to forested areas. However, depending on the proximity of Area 5 to Area 3 where M. inornatus is most abundant it might reflect the ability of the species to thrive in grassland environments. In addition, based on altitude, it is quite possible that elevation is not a factor controlling the distribution of $M$. inornatus. $R$. mooreanus is a minor element in Area 5, in contrast with Appendix $\mathrm{H}$ where the species was recorded in greater abundance. Based on the species preferences (grassland), it is not clear why the discrepancy exists. A significant difference between Area 5 and the previous areas is that most species were mainly represented by juveniles, implying a local population.

\section{CONCLUSIONS}

The land snails collected from three different settings at the McKinney Roughs Nature Park in Bastrop County, Texas provide the baseline to understand the relationship between these organisms and the environment. This relationship, at the same time, offers the opportunity to infer how humans interacted with the environment and the fauna. The open grassland/floodplain setting along the Colorado River produced the richest and most diverse assemblage dominated by three species. The same three species were common or dominant in the brushy woodland and climax forest settings. In this sense, the current study reached a similar conclusion to that of Appendix $\mathrm{H}$.

In spite of the attempt to establish a pattern between ecological setting and faunal assemblages, it is unclear if the interpretations in this study generate enough information to be useful for paleo-environmental interpretations. Analysis of other modern sites will provide analogs for archeological sites in the region. 


\section{REFERENCES}

Allen, D.C. and E.P. Cheatum

1960 Ecological Implications of Fresh-Water and Land Gastropods in Texas Archeological Studies. Bulletin of the Texas Archeological Society 31:291-316.

Bequaert, J.C. \& W.B. Miller 1973 The Mollusks of the Arid Southwest, with an Arizona Checklist. University of Arizona Press, Tuscon. 271 pp.

Binney, A.

1841 A monograph of the Helices inhabiting the United States. Boston Journal of Natural History, 3: 435

Blair, W.F.

1950 The Biotic Provinces of Texas. Texas Journal of Science, 2(1):93-117.

Burch, J.B.

1962 How to Know the Eastern Land Snails. Dubuque.

Cheatum, E.P.

1966 Report on the Mollusk Shells Recovered from Four Archaeological Sites in the Amistad Reservoir. In A Preliminary Study of the Paleoecology of the Amistad Reservoir Area, edited by D.A. Story and M.B. Vaughan, Jr.

Clark, J.W. Jr.

1969 Implications of Land and Fresh-Water Gastropods in Archaeological Sites. Arkansas Academy of Science Proceedings, 23:38-52.

Coppolino, M.L.

2009 Land Snails of Southern Illinois website: http://mypage.siu.edu/mlcopp/index.html, consulted on 11/28/2009.

Dall, W.H.

1905 Land and freshwater mollusks of Alaska and adjoining regions. Harriman Alaska Expedition 13: i-xii, 1-171, pls. i-ii.

Doubleday Page \& Company, New York.

Dreiss, M.L.

2009 Marine Shell Ornaments, Icons and Offerings. Website: http://www.texasbeyondhistory.net/coast/nature/images/shellornaments.html.

Grimm, F.W.

2005 Terrestrial Gastropod Molluscs of the Mixedwood Plain Ecozone. From Assessment of Species Diversity in the Mixedwood Plains Ecozone. Website: http://www.naturewatch.ca/Mixedwood/landsnai/lsnail8.htm, consulted 11/28/2009.

Hubricht, L.

1985 The distribution of the native land mollusks of the eastern United States. Fieldiana 1359.

Johnson, D.

2006 Land Snails of Texas. Website: http://209.198.131.150/gastropods/land_snails_of_texas.html, consulted on 11/28/2009.

Lower Colorado River Authority

2008 McKinney Roughs Nature Park: Trail Guide. Lower Colorado River Authority. Austin. 
Malof, A. F.

2007 Texas Snails in Archaeological Context. http://www.dirtbrothers.org/editorial/malof.htm, consulted on 9/5/2007.

Neck, R. W.

1986 The Balcones Fault Zone as a Major Zoogeographic Feature. In The Balcones Escarpment, edited by P. L. Abbott and C.M. Woodruff, Jr. p.35-40. Website: http://www.lib.utexas.edu/geo/balcones_escarpment/page35-40.html, consulted on $11 / 30 / 2009$.

Oughton, J.

1948 A Zoogeographical Study of the Land Snails of Ontario. University of Toronto Press, Toronto, 128 pp. plus maps, charts, diagrams.

Perez, K.E.

2006 Land Snail List for Texas- Preliminary. Land Snail Website: http://www.unc.edu/ keperez/land_snails_of_Texas.html, consulted on 11/30/2009.

Pilsbry, H.A.

1899 Remarks on the American Species Conulus. Nautilus, 12:111-117.

1916 Helices of Lower California and Sonora. Nautilus, 29:97-104.

1940 Land Mollusca of North America (north of Mexico). Monographs of the Academy of Natural Science of Philadelphia, 3, 1(2):617-620.

1946 Land Mollusca of North America (north of Mexico). Vol. II, Pt. 1: 1-520. Monographs of the Academy of Natural Science of Philadelphia, 3.

Roth, B.

1987 Identities of two Californian land mollusks described by Wesley Newcomb. Malacological Review 20:129-132.

Roth, B., and D.R. Lindberg

1981 Terrestrial mollusks of Attu, Aleutian Islands, Alaska. Arctic 34:43-47.

Say, T.

1816 Nicholson’s Encyclopedia, II, article Conchology, under Helix albolabris (no pagination).

1817 Descriptions of seven species of American fresh water and land shells, not noticed in the systems. Journal of the Academy of Natural Sciences of Philadelphia 1(1):13-16; and (2):17-18.

1818 Descriptions of land and freshwater shells of the United States (cont'd). Journal of the Academy of Natural Sciences 1: 276.

Sharpe, S.

2002 Solute composition: a parameter affecting the distribution of freshwater gastropods. Conference proceedings: Springfed wetlands: Important scientific and cultural resources of the Intermontane Region. http://wetlands.dri.edu.

Strecker, J. K., Jr.

1935 Land and Fresh-Water snails of Texas. Proceedings of Annual Meeting, October 20 and 21, 1933. Texas Academy of Science. 
Web Soil Survey (WSS)

2009 Natural Resources Conservation Service, http://websoilsurvey.nrcs.usda.gov/app/WebSoilSurvey.aspx, Accessed June 25, 2009. United States Department of Agriculture.

Webb, W.F.

1942 United States Mollusca: A Descriptive Manual of many of the Marine, Land and Fresh Water Shells of North America, North of Mexico. New York: Bookcraft, Inc. 


\section{APPENDIX J:}

\section{Snail Collection and Analysis Protocol}

Antonia Figueroa, Raymond Mauldin, Steve Tomka, and Barbara Meissner 



\author{
APPENDIX J \\ Snail Collection and Analysis and Protocol \\ Antonia Figueroa, Raymond Mauldin, Steve Tomka and Barbra Meissner \\ The Center for Archaeological Research \\ The University of Texas at San Antonio \\ San Antonio, Texas
}

As part of the overall investigation into the potential use of snails at site 41TV540, we reviewed regional and topical literature on snails in archeological contexts in order to produce a protocol for collecting, analyzing and interpreting land snail data. As noted in Chapter 10, several features, composed primarily of Rabdotus snail shells, were documented at $41 \mathrm{TV} 540$. The presence of these features, and subsequent questions concerned whether or not the snails were eaten by site occupants (see Chapter 10 and Appendix O), led to the development of this protocol. We initially discuss the role of land snails in prehistoric subsistence. That discussion includes a comparison of snail analysis conducted by CAR described in Appendix H and I, as well as earlier work by Malof (2001). The various ways in which snails can be used to reconstruct the paleoenvironment is then discussed. The document concludes with suggested methods of collecting, quantifying, curating and analyzing snails.

\title{
The Role of Land Snails in Subsistence
}

Land snails are commonly used for food in many regions of the world (see Bonizzoni et al. 2009; Healy et al. 1990; Honea 1962:318; Lubell 2004a, 2004b, Lubell et al. 1976; Miracle 2002; Radmilli 1960). The modern Hadza of Tanzania are reported to harvest a particular species of land snail during the rainy season (Woodburn 1970:45). Moreover, the modern Maya collect snails for subsistence and evidence suggests that the prehistoric populations consumed them as well (Healy et al. 1990). Generally processed by boiling, steaming, or indirect heating under beds of coals or near fires (e.g., Bonizzoni et al. 2009:167; Miracle 2002), land snails are seldom the primary source of protein, but their consumption can make an important contribution to subsistence in specific cases (e.g., Klippel and Morey 1986; Lubell et al. 1976; Miracle 2002).

In Texas archeological discussions, the role of land snails in subsistence has centered on the possible use of members of the genus Rabdotus as a food source. Early researchers commonly assumed that dense concentrations of Rabdotus shell, often found in archeological deposits, was clear evidence that these land snails were consumed by prehistoric populations (see Allen and Cheatum 1960; Jelks 1962; Johnson 1964). Clark $(1973,1976)$ was perhaps the first to suggest that while snails may have been part of the prehistoric diet, clear empirical and ethnohistoric data were lacking. In counterpoint, Hester and Hill (1975) argued that ethnohistoric accounts of native snail consumption did exist, and that the high densities of snail shell encountered at archeological sites were clear evidence of consumption. Experimental archeology, conducted by T.C. Hill (Hester and Hill 1975), indicated the boiling of snails made the meat easy to extract from shells without breakage, thereby accounting for the plethora of unbroken Rabdotus shell found at many archeological sites (see Clark 1976). Ethnohistoric evidence of snail consumption in Texas, however, is not well documented. Cabeza de Vaca's description of practices among Texas natives suggests that snails may have been picked at the same time as prickly pears in August and September, although the translations of these accounts have been debated (Clark 1976; Hester and Hill 1975). However, possible evidence of the processing of Rabdotus was uncovered at the Tucker site (41NU46) in the mid-1980s. Excavators uncovered a clay lined pit that contained the remains of Rabdotus, charcoal, and ash (Deisler 1986). Radiocarbon dates obtained from the feature produced an age of $2800 \pm 70$ BP. Deisler (1986:17) assumed that the feature represented a cooking facility where land snails were steamed between layers of damp vegetation (Deisler 1986:17).

In recent years, researchers in Texas have continued to grapple with the role of land snails in prehistoric diets (e.g., Brown 2002, 2006; Gadus et al. 2006; Malof 2001; Neck 1994). Most researchers continue to assume that dense accumulations of Rabdotus in archeological deposits indicate their use in subsistence. However, as Brown (2002: 243, 2006) notes, dense snail populations could conceivably be attracted to human refuse, and therefore could represent a natural accumulation. While an occupied site may not provide a good environment for snails, a recently abandoned location could provide an opportunity for land snails to accumulate. Organically enriched trash deposits may be common in these settings, possibly providing decaying vegetation and fungus that appear to attract snails (Brown 2002). While these settings may enhance feeding options for Rabdotus, details of their diet remain unclear. 
Most studies infer dietary preference based on habitat association rather than any direct study (see Randolph 1973). However, a number of isotopic studies of Rabdotus, usually focused on shell carbonates, have been conducted that provide some more direct measures of diet in this genus. Goodfriend and Ellis (2002) focus on shell carbonate in two species of modern Rabdotus from about 75 different locations stretching from the dry Big Bend area across into Central Texas and up into North Texas near the town of Paris (Goodfriend and Ellis 2002: Figure 2). They conclude that while stable carbon isotope values in shell are highly variable and subject to local conditions, snails shell carbonate from more arid regions, those regions with a higher frequency of $\mathrm{C}_{4}$ and CAM vegetation, are enriched in $\delta^{13} \mathrm{C}$ suggesting some consumption of plants or fungus that use $\mathrm{C}_{4}$ or CAM pathways.

Recently Mauldin (2010) has conducted carbon isotope analysis of 15 modern Rabdotus bodies (soft organic tissue) collected from two different areas in Bexar County. These samples produced carbon ${ }^{13} \mathrm{C}$ values that range from -22.78 to -26.22 mill (Mauldin 2010). As previous work suggests no significant fractionation between carbon isotopic composition of diets and snail organic tissues (see DeNiro and Epstein 1978; Liu et al. 2007; Stott 2002), these data demonstrate that modern Rabdotus diets in these two areas are almost exclusively composed of plants or fungus that use $\mathrm{C}_{3}$ pathways. Figure J-1 uses data from Mauldin (2010) and compares the carbon isotopic values of these modern snail bodies (Y-axis) with carbon values derived from their respective aragonite shells (X-axis) to demonstrate a strong positive relationship $\left(\mathrm{R}^{2}=0.864\right)$. $\delta^{13} \mathrm{C}$ shell values are significantly depleted relative to ${ }^{13} \mathrm{C}$ values in soft tissue, and by extension, Rabdotus diets.

Applying the Figure J-1 regression to the shell carbonate values derived by Goodfriend and Ellis (2002) from across Texas produces diets that range from about -18.6 to $-25.2 \%$ o $\delta^{13} \mathrm{C}$. Assuming that $C_{3}$ plants used average around $-27 \%$, then somewhere between about 69 and $93 \%$ of the Rabdotus diet is composed of $C_{3}$ vegetation or fungus that feeds on $C_{3}$ plants. While additional studies from other areas are necessary, if these modern dietary patterns are applicable to past preferences, then we can suggest that Rabdotus primarily consume $\mathrm{C}_{3}$ vegetation, with additional inputs from CAM plants. While Goodfriend and Ellis (2002) suggest, based on individual comparisons of snails from adjacent plots, that some $\mathrm{C}^{4}$ grasses are consumed, warmseason grasses clearly are not a significant food source for Rabdotus.

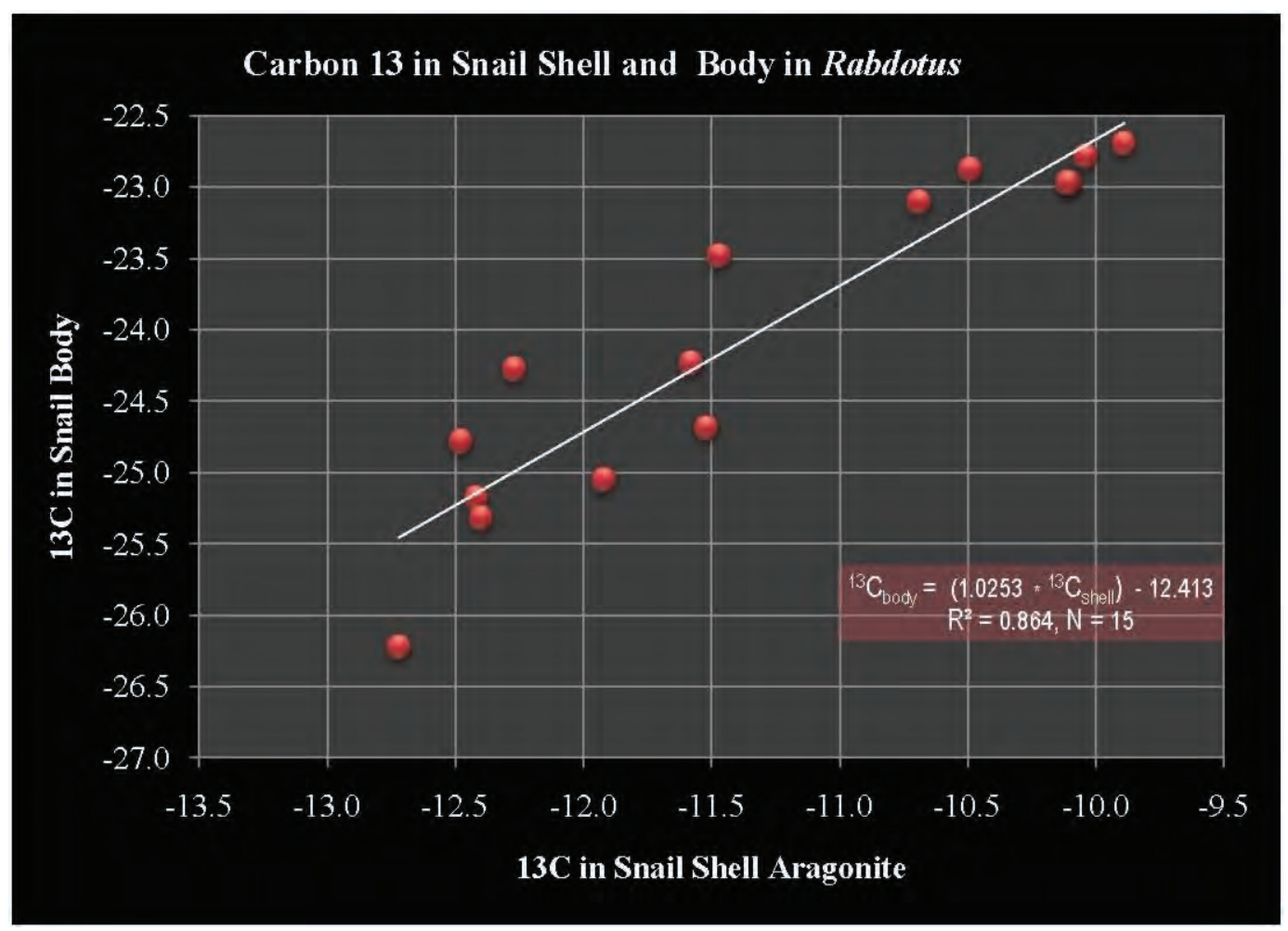

Figure J-1. $\delta^{13} \mathrm{C}$ from modern Rabdotus shell carbonate and organic tissue, Bexar County (data from Mauldin 2010). 
Unfortunately, which specific $\mathrm{C}^{3}$ plants or fungus are being used, and whether these items have an increased probability of being concentrated in abandoned archeological features, remains unclear. In addition, as we discuss subsequently and as noted in Chapter 10 of the current report, snails may be attracted to features for reasons other than potential food availability. In many environments, moisture appears to be one of the determining factors for the presence of snails, and features may have higher moisture or other soil characteristics that snails find attractive. Additional studies of snail diets through direct means such as isotopic research, as well as through observations of what snails consume in natural settings, should continue. These will serve to more narrowly define the parameters that may condition Rabdotus distributions. However, given that other, non-dietary environmental factors may also play a role in where snails accumulate, these types of investigations will probably not determine if snail accumulations are the result of human predation.

When faced with deciding if dense concentrations of snails seen in archeological deposits reflect natural accumulations or are the remains of human consumption, researchers have most frequently use two criteria. First, if hunter-gatherers were collecting, processing, and consuming Rabdotus, it is assumed that the size distributions of the resulting discarded shell will be different than the size distributions reflected in a natural population. While collection methods will certainly influence size, researchers anticipate that human collectors would select bigger specimens because larger snails are more likely to be seen, are easier to handle, and larger snails should produce higher returns (see Malof 2001). Several researchers have investigated, both directly and more commonly through age profiles, the notion that human procured snails would produce snail size ranges different from those in nature. Secondly, several researchers (e.g., Neck 1994) have suggested that in natural populations, a dominance of Rabdotus over other snail species is not the norm. They suggest that when a dominance of a single species is present, human consumption is likely to be the underlying cause. Each of these arguments are reviewed below, along with a third set of criteria centered on amino acid racemization shifts as a result of processing.

\section{Natural and Collected Rabdotus Age and Size Structures}

The first of these arguments most frequently uses age profiles as a proxy for size. Pioneered primarily by Malof (2001), these investigations center on comparisons of the ratios of adults to sub-adult individuals collected from archeological sites with those ratios found in natural Rabdotus populations. When the ratios from archeological deposits differentially reflect more adult Rabdotus than are present in a natural population, the probability that the archeological deposits reflect subsistence remains is significantly increased. This type of investigation requires 1) the establishment of criteria for distinguishing adult and sub-adult Rabdotus and 2) the establishment of a natural population baseline for comparison. Research conducted by Malof (2001), following on early work by Brown (2002; see also 2006), has addressed both the development of age criteria and the establishment of a modern baseline.

Malof's (2001) conducted his work in the context of investigating snails recovered from site 41BL116. To establish age criteria, Malof relied on previous work by Brown (1999) and Goodfriend (1987). While size alone is useful in identifying adult Rabdotus, there is significant overlap in the diameter and length of adults and sub-adult specimens (see Brown 2002). Malof (2001: 68-81) argued that depending exclusively on size to distinguish age is further complicated by size differences between different species of Rabdotus and differences in snail size as a function of different environmental settings. Malof relied on the presence or absence of a carina, a ridge formed near the basal whorl of sub-adult or juvenile snails, lip reflection, and the presence of a callus, a thickened shell deposit with a distinctive sheen, in adult snails, along with size data to define adult and sub-adult groups. Malof (2001:73-74) also established a width to height ratio for shells that clearly separates adults from juvenile specimens, and lessens the complications associated with comparing different species and populations.

Malof (2001:65-68) established the percentage of juveniles and adults expected in a natural assemblage by applying these age criteria to Rabdotus shell collected from Brackenridge Field Laboratory in Austin, Texas. All Rabdotus observed within the selected study area were collected. This material was passed through 1/4- inch screens. Of the 315 remaining snails larger than 1/4-inch, 171 (54\%) were juveniles and 144 (46\%) were adults (Malof 2001:71). Comparison with a sample of snails from the archeological deposits with width to height ratios established for the natural assemblage allowed Malof (2001: 76-78) to conclude that the site assemblage of Rabdotus was structured differently from the natural assemblage. This suggests that the site snail assemblage reflected prehistoric subsistence remains rather than natural accumulations (see also Brown 2002; Gadus et al. 2006). 
As outlined previously in Appendix H, CAR recently collected all snails from three different ecological settings (brushy woodland, near climax forest and floodplain/open grassland) along the Colorado River in Bastrop County within the McKinney Roughs Nature Park. While the goal of that collection was to generate quantitative information on the distribution of land snails, and specifically on species that typically occur on archeological sites, we can use the data here in the context of developing age profiles, understanding the general diversity in species composition, and understanding snail habitat preferences.

Details of the collection method and sampling procedures (Appendix $\mathrm{H}$ ), as well as summaries of the macro (Appendix $\mathrm{H}$ ) and micro (Appendix I) results, are presented above. The habitat results will be discussed subsequently, but as a component of that work, collected Rabdotus were measured and classified as either adult or juveniles by the presence or absence of a carina (see Goodfriend 1986; Malof 2001). In all, 1010 Rabdotus from three different settings were collected from the surface. Focusing on the age distributions of the 973 Rabdotus that would likely be caught in a 1/4-inch screen (greater than $8.9 \mathrm{~mm}$ in size), $38.2 \%$ have a carina present and are classified as juveniles. At the habitat level, the relative frequency of adult snails in the CAR collection was $65.8 \%$ in the climax forest, $60.6 \%$ in the grasslands, and $57.6 \%$ in the brushy habitat. Previously Malof (2001) identified $54 \%$ of his snails as adult in his natural collection using a similar (1/4 inch) sample.

Figure J-2 presents the mean width/length ratios, and associated confidence limits, for the entire CAR collected snails by environmental zone. There is considerable variability, with the brush land setting averaging .587, the forest averaging .564, and the grasslands averaging .560. Also shown (red) is the mean ratio and confidence intervals developed by Malof (2001:77) from his naturally collected sample (total mean in Figure J-2), as well as the ratios from the archeological sample collected at 41BL116 (red, 5\% Sample Mean). The fact that there is considerable variability in the width/length ratios, and by extension the make-up of natural populations, clearly casts doubt on the utility of this measure, as well as Malof's (2001) conclusions regarding the nature of the 41BL116 snail population. The sample mean from 41BL116 overlaps with the mean of the CAR collected natural sample from grasslands at a 95\% confidence interval (Figure J-2). However, Malof (personal communication, 2009) has questioned the validity of the CAR collections. He suggests, based on personal experience, that a thorough collection of a 30-x-30 m area requires considerably more time than the roughly 4.5 person hours used by CAR. This undercounting would presumably miss smaller, juvenile snails and could account for the relatively high percentages of adults in the CAR collections.

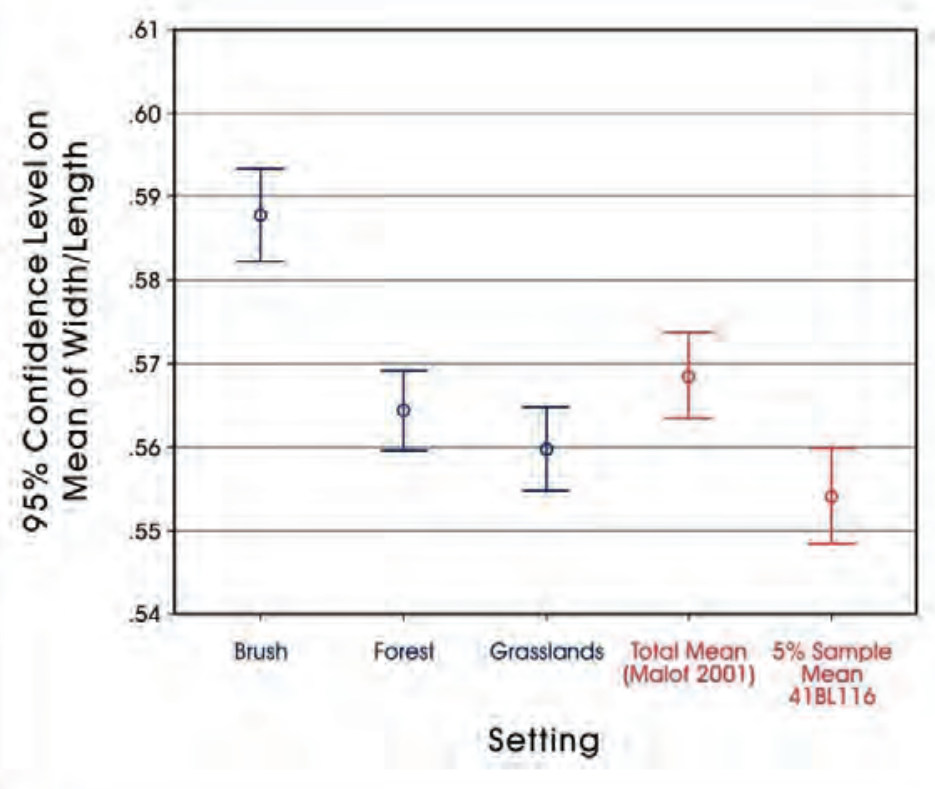

Figure J-2. Comparison of the CAR's snail data from three vegetation settings (>1/4 inch-blue) and Malof's (2001) natural and site snail samples.
We cannot clearly evaluate the possibility of an undercount with extant data. However, the adult percentages in CAR's brush land populations varies from Malof's "natural" adult ratio by only $3.6 \%$ (57.6 to 54), and the shell width/height in the brush land is considerable higher than Malof's, suggesting a population dominated by younger and smaller snails. In addition, the CAR forest width/length ratio is statistically indistinguishable from Malof's natural (total mean) population figures. An undercounting by CAR could account for lower ratios in the grasslands, but not the brush land or forest setting. Alternatively, the variability shown in Figure J-2 may reflect real differences in population structures. There could certainly be differences in adults and juvenile ratios in different habitats, as suggested by the Figure J-2 data. These could also be seasonal differences. Collections of Rabdotus in a given area in late spring/ early summer (such as the CAR collection) should have lower frequencies of adults when compared to that same population later in the year. It seems unlikely, then that even the four different natural age structures shown in Figure J-2 exhausts the variability in age structure. 
As Abbott (2009) notes, the arguments regarding the validity of the various age ratio comparisons and the attempt to develop natural age profiles for comparison with archeological profiles obscures the underlying argument that human predation would, under various collection methods, impose a size bias, presumably resulting in an over-representation of larger (adult) snails in archeological refuse. He suggests that processing bulk samples through the use of graduated screens, with counts or weights in various size fractions (e.g., $1 / 8^{\text {th }}, 1 / 4,1 / 2$-inch), would efficiently characterize size distributions. While we lacked samples smaller than $1 / 4$-inch for most proveniences because of collection bias, we used a similar approach to characterize Rabdotus size in the 41TV540 material with success. With collections of unbiased samples, probably through the recovery of standard sized soil samples from features, off-feature, and off-site contexts, this procedure would efficiently allow the characterization of Rabdotus sizes from multiple contexts, begin to build a data base for off-site size distributions, and highlight any potential collections bias that may be present in features. While, in specific situations, additional studies of age characterizations might be useful, we suggest that future investigations should minimally purse a strategy based initially on size grades and unbiased samples from multiple contexts.

\section{Comparison of Species Composition}

Beside size and age structure, the variety and frequency of different species observed in features and non-feature contexts has also been used to analyze snail samples and determin if archeological snail assemblages represent natural populations or are the result of snail consumption. The premise of this argument is that the frequency of snail species in natural versus cultural assemblages should differ. Brown (2002) suggests in the Smith Creek report that the ratio of Rabdotus to other snail species in archeological and non-archeological samples should be examined. Some snails, as part of their natural behavior, tend to inhabit areas in large groups. For instance, Rabdotus alternatus colonies can occupy an area roughly the size of one city block and colonies are separated by several miles (Fullington and Pratt 1974:15). Oligyra also occur in large colonies (Fullington and Pratt 1974).

Brown (2002) identified nine different species from $1 / 4$ inch screening and ten species from $1 / 8^{\text {th }}$ inch mesh. It appears that Oligyra were the dominant species recovered from both the 1/8-inch and 1/4-inch screen followed by Rabdotus. Brown (2006:1075) notes that only 53\% of Oligyra were encountered through the 1/4- inch mesh at the Smith Creek Bridge site, quite possibly missing juveniles and smaller adults. Neck (1994), working with midden deposits from 41HY209, speculated that Rabdotus was consumed based on the overall dominance of this species in the archeological deposits. Neck (1994) observed 16 different terrestrial species, with $91 \%$ of the assemblage consisting of Rabdotus mooreanus.

However, in our investigations of species variety from several contexts at 41TV540 we documented that Rabdotus accounted for over $95 \%$ of the individual snails in all contexts, including several contexts that had snails that were unlikely to reflect human predation. In part, this dominance is related to biases imposed by $1 / 4$-inch screens and the relative size differences of Rabdotus and other commonly occurring species. The dominance of Rabdotus, especially in the off-feature settings that are likely to reflect natural populations, suggests that other factors may account for the distributions. As we suggested in Chapters 9 and 10, and as we note subsequently in this appendix, small scale, micro-environmental conditions (e.g., surface relative humidity, temperature, sun light, soil moisture content, food availability) are likely to control the distribution of snail species in the natural environment. Features, as well as archeological sites in general, create specific micro-conditions that may be attractive to snails for a variety of reasons. Unfortunately, as we demonstrate below as well as in Chapters 9 and Chapter 10 (see also Appendices G, H, I, and O), we have a limited understanding of these particular micro-environmental preferences. Until malacologists develop a better understanding of specific preferences, especially for species of Rabdotus, arguments connecting the dominance of a single species in an archeological deposit with evidence of human predation will be suspect.

\section{Amino-Acid Racemization}

The final line of inquiry suggested here involves possible evidence of snail processing. That is, if Rabdotus was consumed prehistorically, how were they processed and what evidence might remain? Ethnographic and ethonhistoric accounts seem to suggest that boiling was the most likely means of cooking and extracting snails from their shell (see Hester and Hill 1975; Malof 2001), though other options, such as steaming in clay lined pits such as suggested by Deisler (1986), might also have occurred. Here, rather than focus on the specific method of processing and what processing facilities might look like, we consider a more general level. Whether prehistoric populations boiled snails, steamed them between layers of vegetation in clay lined pits, or 
heated indirectly by simply wrapping them in vegetation and placing them in coals, processing scenarios all seem to involve the application of heat, usually in combination with moisture. This combination should produce accelerated rates of amino acid deterioration. Amino acid racemization (AAR) of snail shell has the potential to identify heating (see Goodfriend 2003; Goodfriend and Ellis 2000; Kaufman 2006) through accelerated shifts in L-forms to D-forms of specific amino acids. While snail shell can be heated without necessarily being a dietary item, it is unlikely that snails were consumed without having been heated. The absence of heating, then, can be used to eliminate, but not confirm, snails as a dietary item.

We need, then, to be able to recognize the impact of heating on shell from other changes in amino acids that result from long term exposure to sunlight, ambient temperatures, and other factors that may impact racemization rates (see Abbott et al. 1995; Ellis et al. 1996). Previous research on AAR in Rabdotus relevant to this discussion includes boiling experiments conducted by Goodfriend (Abbott et al. 1995). As noted in Abbott et al. (1995: 801), boiling of shell, even for several hours, had no noticeable effect focused on the conversion of L-isoleucine to D-alloisoleucine, the A/I ratio. Here we focus on D/L ratios in other amino acids, specifically changes in glutamic and aspartic acid. Both of these have shown potential for monitoring aspects of heating (see Goodfriend 2003; Kaufman 2006). We have conducted controlled heating experiments with modern Rabdotus (Mauldin 2007). These experiments, the results of which were summarized in Chapter 10, involved two modern shells collected from Bexar County. These were heated to $125^{\circ} \mathrm{C}$ and sampled at various intervals from 0 to 228 hours. Samples were subsequently submitted to Dr. Darrell Kaufman of the Amino Acid Geochronology Laboratory (AAGL) at Northern Arizona University for analysis. The AAGL analyses used reverse phase liquid chromatography (RP-LC) to separate the D and L forms of aspritic and glutamic acid. Results with RP-LC are highly reproducible, especially for aspartic and glutamic acid (see Kaufman and Manley 1998). Plots of the D/L ratios of aspartic and glutamic acid (see Figure 10-9) showed that heating at high temperatures over several days clearly results in dramatic and rapid increases in the $\mathrm{D} / \mathrm{L}$ ratios of these amino acids. We also conducted experiments with the impacts of boiling on these ratios. As summarized in Appendix L (see also Chapter 10, Figure 10-10), the results were opposite of what we expected. Increased boiling time should result in an increase in the $\mathrm{D} / \mathrm{L}$ ratios, but our data show a slight, but consistent, decrease. We cannot explain this pattern, but are undertaking additional research with variable boiling times to further define the impacts of boiling.

In spite of this ambiguity with regards to boiling, our results from several features at 41TV540 (see Chapter 10; Appendix L) are encouraging. We submitted nine samples from three features that all dated between 6200 and 5900 BP to Dr. Kaufman at the AAGL. Five of the nine samples, including all three samples from Feature 13 and one sample each from Feature 14 and Feature 27/29, cluster around the .128 glutamic and .419 aspartic point (Figure 10-11). It seems likely that this clustering reflects racemization over the last 6,000 years and that these snails were not exposed to excessive heat. The remaining $\mathrm{D} / \mathrm{L}$ ratios show a significant spread, suggesting that some snails within Feature 14 and Feature 27/29 have variable temporal and/ or heating histories. This spread could simply mean that older snails were incorporated within these two features, but given the magnitude of the differences, it is likely that some of these snails in these two features have been exposed to high heat, while others have not. Of course, we can envision a number of different scenarios that would produce heating, and many of these do not necessarily involve snail predation by hunter-gatherers. Nevertheless, the AAR results do allow us to more clearly identify what features were likely to reflect natural accumulations (e.g., Feature 13) and which ones required additional investigations.

\section{Summary and Discussion}

Researchers in Texas have commonly assumed that dense accumulations of Rabdotus specimens at sites reflect the debris from consumption of these land snails. It is only within the past decade that criteria for assessing the validity of that assumption have been developed. The two most commonly used appear to be measure of age structure as an indication of size differences, and consideration of the diversity of snail populations within features as indicative of human selection. While Malof's (2001) work introduces an innovative method of using age determination, CAR's recent collections have suggests that there may be significant variability in natural age structures and in width to length ratios. Furthermore, it is unlikely that the four cases shown in Figure J-2 document the full range of variability in natural populations. We would suggest that if the goal is to document differences in Rabdotus size distributions as a possible indicator of human predation, then procedures focused on assessing species-specific size patterns, such as the use of nested screens suggested previously, should be used. While agespecific patterns may be of interest in specific situations or for investigating specific questions, they are probably not the most effective means to address size biases potentially present in archeological assemblages. The routine collection of sediment samples from feature, off-feature, and off-site contexts for snails will ultimately allow the development of data sets that will refine size based expectations. Of course, specific prehistoric collection procedures can be envisioned that would not produce 
significant differences when natural and cultural, and other, non-cultural processes may be operating in specific cases (e.g., size grading, see Binford 1983; Waters 1992). However, consistently collected data (e.g., sediment samples), analyzed with consistent methods (size graded screens), from multiple contexts (feature, off-feature, off0site) will result in a data base that can clearly define size expectations, and highlight cases that do not fit those general patterns. If human predation does produce size differences, then these size differences should emerge relatively quickly should researchers adopt these procedures as a minimum standard.

Beyond size differences, researchers have focused on the dominance of certain species at various scales as a possible indicator of human predation. However, any use of the dominance of particular snail species as an indicator of human predation clearly must account for the fact that at sites like 41TV540, over $95 \%$ of all snails recovered for $1 / 4$-inch screens, regardless of context, were Rabdotus. Snail distributions are anticipated to be conditioned by species-specific, small-scale, micro-environmental conditions, and we currently have no real understanding of what those conditions at either the macro or the micro-snail (see Chapters 9 and 10). Without that understanding, which is unlikely to be developed by archeologists, arguments connecting the dominance of Rabdotus in an archeological deposit with evidence of human predation will be suspect. With more study by malacologists, this measure may prove useful. However, we see limited archeological application given our present lack of understanding.

Finally, we explored the potential of amino acid racemization for recognition of heating in snails. While research into boiling proved inclusive, the analysis of nine samples from three dated features at site 41TV540 demonstrates the potential of this particular approach. AAR focused on amino acids such as glutamic and aspartic acids clearly has the potential to identify heating. While additional work on establishing racemization rates for these particular amino acids under non-heated conditions is necessary, the approach has the potential to identify heated and non-heated snails. As heating appears to be a necessary condition for snail consumption, the technique has the potential to eliminate features from consideration. When used in conjunction with feature size data, the AAR approach has good potential for identifying snail accumulations that have a high probability of having resulted from human predation.

\section{Paleoenvironmental Reconstruction}

The second major issue surrounding the use of snail shell discussed in this protocol focuses on paleoenvironmental reconstruction. Two different approaches are common. The first relies on assumed preferences of certain snail species, or mixes of species, for particular vegetation or moisture regimes. The second approach relies primarily on analyzing stable carbon and oxygen isotopes from snail shell to reconstruct vegetation and temperature regimes. We discuss each of these approaches in this section.

\section{Land Snail Habitat Preferences as Environmental Proxy}

A variety of land snail species are present at sites in Texas and researchers have used these to attempt to monitor a wide variety of environmental conditions. Reviews of macro and micro snail habitat preference distributions derived from the literature can be found in Appendix G and I, as well as general discussions in Chapter 9 and 10 of the current report. In addition, studies of archeological interest in Texas have been done by Brown (1999, 2002, 2006), Ferring (2001), Johnson (2000), Malof et al. (2007) and Neck $(1987,1994)$. A review of these, as well as other reports, suggests that members of four genera, Rabdotus, Praticolella, Polygyra, and Oligyra, are most commonly present in archeological collections in the state. We focus our initial review, therefore, on these four types, though that may not represent the most environmentally sensitive species. We are specifically concerned with looking at the habitat preferences as described in the literature. That review is followed by a more quantitative review focused primarily on these species relative to environments in the CAR collections from McKinney Rough (see Appendix H, I).

Oligyra orbiculata, formerly known as Helicina orbiculata, has shell characteristics that appear designed to limit water loss, leading Brown (2006:1073) to suggest that the species is drought resistant. Fullington and Pratt (1974) note that while the snail is rarely present in the hardwood forests of east Texas, and is essentially absent from grasslands, Oligyra is common in deciduous and juniper woodlands. Cheatum (1934) notes that the species is drought resistant, and that it is common in both woodlands and open settings. At the Bessie Kruze site (41WM13), Johnson (2000) describes Oligyra as a "hardy 
and drought resistant species", but also suggests that the species is never present in "dry and exposed earth" where large numbers of Rabdotus are common (Johnson 2000:64-65). Fullington (2003:273) lists Helicina as preferring open grass lands to sparse woodlands. Tomka and Mauldin (2003:100-101) suggest, based on the distribution of Helicina relative to Rabdotus, that a dominance of Helicina reflects a "wooded" habitat. Brown (2006:1076) notes that under extreme drought conditions, Oligyra may out-compete most other species, suggesting it is drought tolerant. When this land snail occurs in large numbers in archeological deposits, especially in situations where few other species are present, a xeric setting can be inferred. However, in most situations, Oligyra is one of several species common in a given level or stratigraphic zone. Interpretations under these conditions are problematic, given the diverse habitats that this land snail occupies.

There are two species of Polygyra, .P mooreana and P. texasiana. According to Cheatum and Fullington (1971), P. mooreana occurs in a variety of distinct habitats, including relativity wet, dense woodlands to "sparsely-timbered hillsides" (1971:17). P. texasiana can be found in habitats characterized as woodlands, as well as in open prairies (Cheatum and Fullington 1971). Marie (2006:159) classifies Polygyra as consistent with a woodland dominance. Johnson (2000) suggests that while this land snail is present in woodlands and prairies, it prefers "relatively dry" conditions (2000:65). Fullington (2003:273) suggests that P. mooreana is present in open grassy areas and sparse woodlands, a habitat similar to that occupied by Olygyra.

While several species are present in Texas, the genus Praticolella appears to be primarily represented in archeological deposits by two species, P. pachyloma and P. berlandieriana (Brown 2002, Hubricht 1985). While less commonly recovered from archeological settings when contrasted to Oligyra and Polygyra, P. berlandieriana is commonly present in wooded floodplains, brushy settings, and grasslands, while P. pachyloma is common in open habitats (Brown 2002, 2006). Johnson (2000:65) suggests that P. berlandieriana "likes woodlands but will also thrive in moist places" in open settings. Tomka and Mauldin (2003:99) classify P. berlandieriana as thriving in open grassy or brushy settings.

Rabdotus is one of the most frequent of the genera of land snails encountered at archeological sites in Texas. Five species, Rabdotus mooreanus, Rabdotus dealbatus dealbatus, Rabdotus dealbatus ragsdalei, Rabdotus alternate, (Hubricht 1985) and Rabdotus pilsbryl (personal communication, Brown 2009) are found in Texas. The geographical range of $R$. alternatus and $R$. dealbatus overlap in south Texas (Goodfriend and Ellis 2002). Fullington and Pratt (1974) suggest that an open grassland, prairie, or sparse woodland setting was the preferred habitat for the genus. R. mooreanus can endure dry conditions (Brown 2002:230-231) and is likely to be found in open grasslands (Brown 2006: 10999), while $R$. dealbatus is adapted to slightly more mesic conditions. Gardner (2000) and Johnson (2000:64) report the presence of Rabdotus mooreanus/dealbatus at the Bessie Kruze site and that they are a semi-arboreal species that typically inhabit under-vegetated areas within grasslands and shrub dominated settings. Marie (2006:159-160; see also Fullington 2003:273) also concludes that increases in the presence of Rabdotus, in combination with changes in other species, is indicative of drier conditions (see also Tomka and Mauldin 2003: 99-102).

The above descriptions are essentially qualitative in nature. We turn to CAR's data generated from collections at McKinney Roughs Nature Park to begin to consider quantitative differences in snail habitat preference. As described earlier, all surface snails were collected from three different areas in a brushy woodland habitat, a single area was collected in a forest setting, and snails were collected from a single area in a grassland dominated section on the floodplain of the Colorado River. Figure J-3 presents the surface density (snails per $900 \mathrm{~m}^{2}$ ) for Rabdotus, Oligyra, Polygyra, and Praticolella by habitat for the CAR collection. Overall, these land snails have the highest densities in the climax forest setting and the lowest densities in the brushy or shrubby area. Brown (Personal Communication, 2009) conveys that the high recovery of Rabdotus and Oligyra in the climax forest setting seem anomalous with his previous finding and experience. Surprisingly, the highest density of Rabdotus is not in grasslands, but in the climax forest habitat. A similar pattern is present for Oligyra. Both Polygyra and Praticolella are underrepresented in the collections, with the later absent from the brushy area. The highest density of Polygyra is present in the grassland setting, along with Praticolella, though the samples are small.

The patterns shown in Figure J-3 are especially interesting when they are contrasted with information on snail distribution from the Brackenridge Field Laboratory in Austin. Figures J-4 and J-5 use transect data, gathered by Randolph (1973: 955) to consider habitat preference in Rabdotus and Oligyra. Three different habitats (forest/ woods, brush/ shrubs, grassland) are present in the Randolph study, with multiple collections made in each area. The box plots (see Tukey 1977) in Figures J-4 and J-5 show the various density measures for each collection area for Rabdotus (Figure J-4) and Oligyra (Figure J-5). Focusing initially on Figure J-4, densities of Rabdotus are highest in grasslands and lowest in woods/ forest setting. The median density recorded 




Figure J-3. Distribution of land genera in CAR collections.

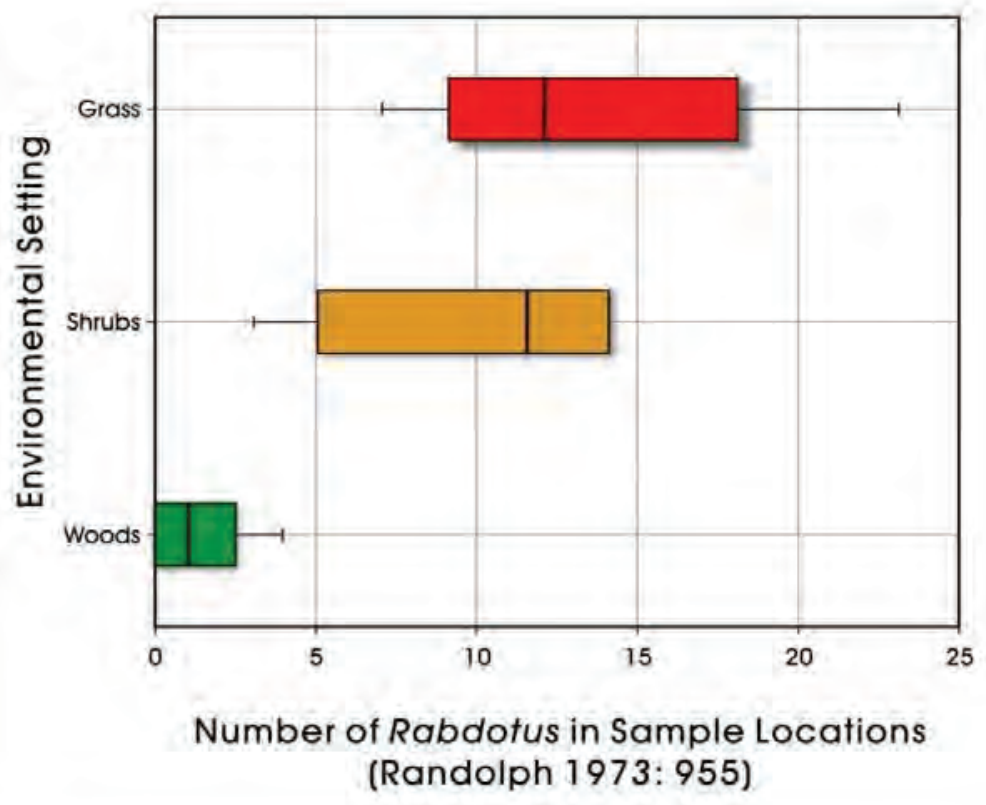

Figure J-4. Distribution of Rabdotus by environmental setting. 
for the grasslands (solid vertical bar within the red box) is comparable to that for the brush/ shrubs setting (brown box), though the range of grass densities is significantly greater than shown in the brush/shrub habitats. The higher grassland densities are what we would expect for Rabdotus given the literature review, though it is significantly different from the densities shown for this genus in Figure J-3. Densities of Oligyra (Figure J-5) are significantly higher in grasslands relative to either brush/shrubs or woods/ forest. As with Rabdotus, this is not the pattern shown in Figure J-3 for the McKinney Rough data, and while the literature review on this genus is mixed, the low densities of snails from this genus in the brush/shrub setting was not anticipated.

Figure J-6 presents quantitative data on three of our four common genera, again using data taken from Randolph (1973:955). The figure shows counts of land snails in equally sized areas made along a single transect that

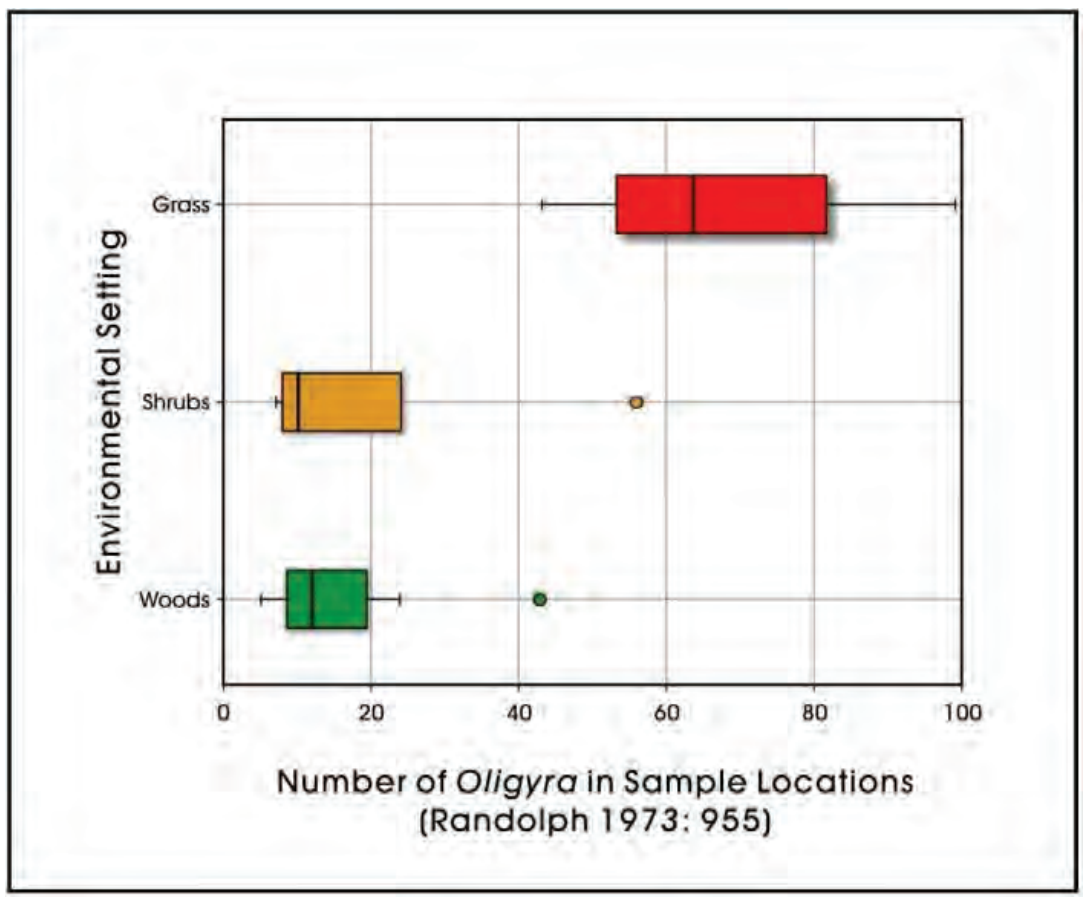

Figure J-5. Distribution of Oligyra by environmental setting.

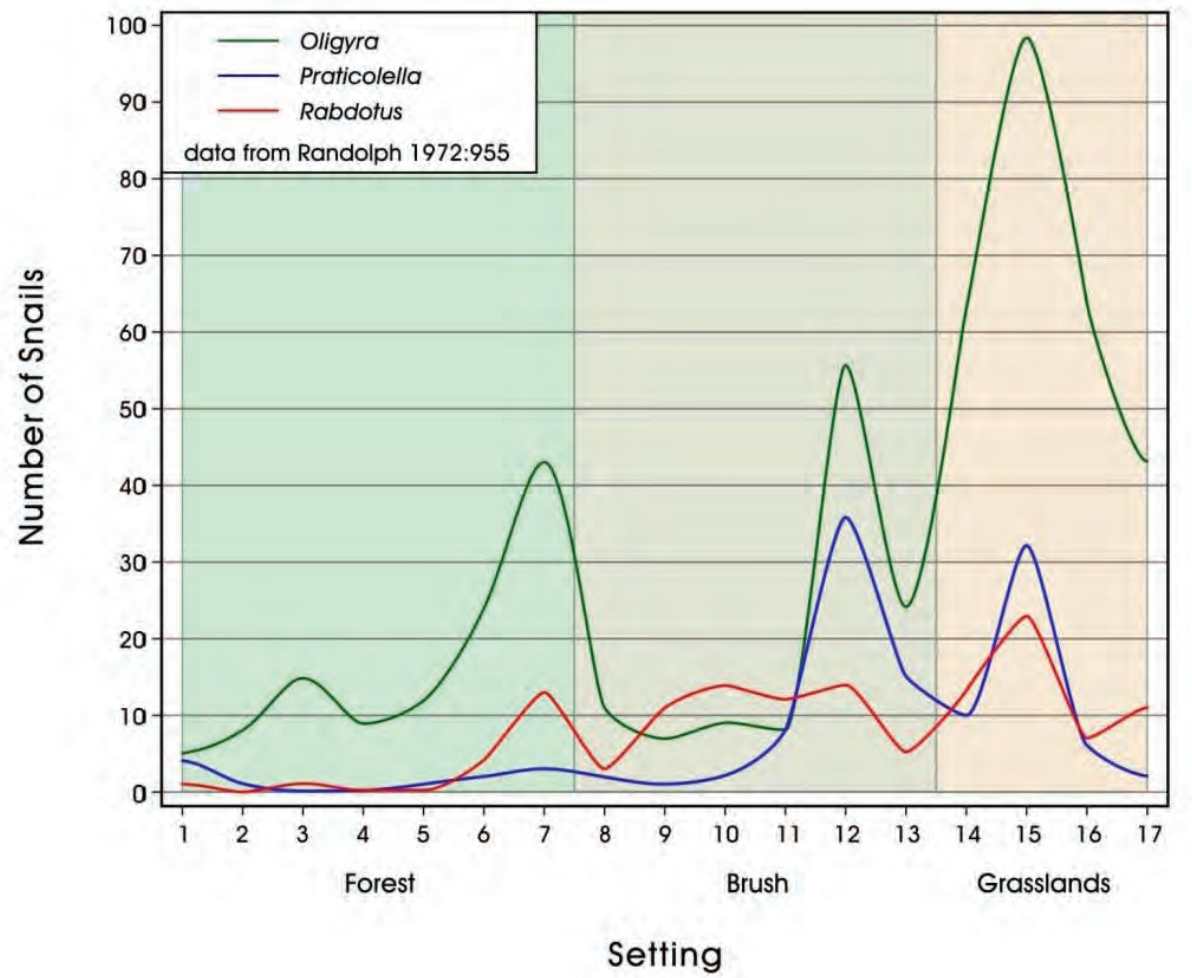

Figure J-6. Distribution of land snail genera along a moisture and cover transect. 
transitions along what should be a moisture and canopy cover gradient from a forest through a brushy setting and into a grassland. These data clearly show that in this particular area, all three of these genera are most common in drier settings with lower canopy cover, with forested settings having the lowest density. While Oligyra have the highest densities of the three genera in each of the settings, this land snail is most common in the grassland area. Both Praticolella and Rabdotus are not common in forests, with Praticolella having their greatest density in brush settings. As expected, Rabdotus favor grasslands, though this is not the pattern seen in Figure J-3. Note also that the overall pattern of the three curves have some similarity. Peaks and dips in multiple genera are present at transect point $7,12,13,15,17$. These suggest that smaller scale environmental conditions that cross-cut the more general habitat characteristics might be of critical importance to understanding snail distributions.

Our literature review suggests that there is some difference of opinion among researchers regarding preferred habitat for commonly recovered land snails representing the genera Oligyra, Praticolella, Polygyra, and even Rabdotus. Some of this variability is certainly a function of the qualitative nature of many of the descriptions. However, quantitative data, such as those developed by CAR (Appendix H, I) and Randolph (1973) continue to show significant variability in habitat distributions. Some of this variability probably represents real flexibility in habitat tolerance, at least at the level that researchers perceive snail habitats. That is, for a snail, the critical habitat elements are probably centered on fluctuations in moisture, temperature, and light, as well as the distribution of leaf litter and food, at a small scale, rather than concerns regarding the suitability of "open grasslands" relative to "climax forests." The scale that we wish to describe is probably much larger than the scale of concern to a snail. Before we can make well grounded inferences about the meaning of past shifts in land snail populations, we clearly need to better understand modern distributions. Additional research by malacologists at the scale of the snail, such as the transect data undertaken by Randolph (1973) and summarized in Figure 6, should prove useful. While it is tempting to focus on micro-snails, which should be more environmentally sensitive (see Brown 2006:939), comparisons of recovered species from our excavations at McKinney Roughs (see Appendix I) with expectations derived from the literature for habitat preferences (Appendix I and Table 9-1 in Chapter 9) are not encouraging. At present, however, the lack of consistent, broad scale patterns in the macro-snail data sets suggest that any environmental reconstruction based on the habitat preference of any particular snail species should be viewed with caution.

\section{Variation in Stable Oxygen and Carbon Isotopes in Snail Shell}

A second line of argument with regards to reconstructing paleoenvironmental conditions uses stable carbon and oxygen isotopes in land snail shell (e.g., Balakrishnan et al. 2005a, 2005b; Goodfriend 1990, 1992; Goodfriend and Ellis 2000; Yapp 1979). Research has centered on documenting variation in stable isotopic ratios of oxygen $\left({ }^{18} \mathrm{O} /{ }^{16} \mathrm{O}\right)$ as indicators of shifts in the isotopic composition of rainfall (e.g., Goodfriend 1987; Goodfriend and Hood 1983; Goodfriend and Magaritz 1987; Yates et al. 2002). Variation in stable isotopes of carbon $\left({ }^{13} \mathrm{C} /{ }^{12} \mathrm{C}\right)$ are used to reconstruct vegetation types and density (e.g., Goodfriend and Ellis 2000, 2002; Goodfriend and Magaritz 1987).

The stable oxygen isotopic ratios $\left({ }^{18} \mathrm{O} /{ }^{16} \mathrm{O}\right)$ in carbonates found in land snail shell appears to be primarily a reflection of the oxygen signatures of rainwater (e.g., Goodfriend and Ellis 2002; Yapp 1979), though the relationship is not direct in all cases (see Balakrishnan and Yapp 2005). The ${ }^{18} \mathrm{O}$ values in rainfall, conversely, are a function of multiple factors, including moisture source, distance from that source, the amount of rainfall in a given rainfall event (Levin et al. 1980), and the temperature differences during the rainfall event (Dansgaard 1964). Recent work (e.g., Balakrishnan et al. 2005b; Balakrishnan and Yapp 2005) documents that any oxygen isotopic signal present in land snail shell is probably related to several different climate variables, including temperature, rainfall, and relative humidity. In spite of this potential variability in climate signals, Goodfriend and Ellis (2002: 2001) suggest that the oxygen isotopic composition of modern Rabdotus shell from Texas has low variability across a rainfall gradient, and thus would be a "relatively sensitive indicator of changes in the oxygen isotopic composition of rain over time.” However, shell growth only occurs when snails are active. As many land snails are active under restricted temperature and moisture constraints (e.g., immediately after rainfall events), or at night when humidity is high (see Thompson and Cheny 1996), climate variability, as expressed in oxygen isotopes in land snail shell, may be narrowly restricted relative to actual climate variation (Decker et al. 2000:161). There is, then, considerable ambiguity in the climate signals that can be derived from variation in $\delta^{18} \mathrm{O}$ values derived from land snail shell.

We suggest that at present, research can be more productively focused on exploring variation in stable carbon isotopes in snail shell. As noted above, studies of variation in stable carbon isotopes in land snail shell document that carbon values in shell 
are primarily a function of snail diet. As snails are primarily herbivores, it is probable that different mixes of $\mathrm{C}_{3}$ and, to lesser degrees $\mathrm{C}_{4} / \mathrm{CAM}$ plants, should be reflected in those carbon signatures (e.g., Goodfriend and Magaritz 1987; Metref et al. 2003). However, shell isotopic signatures are also complicated by snail age (Goodfriend and Ellis 2002; Metref et al. 2003) and possibly by the ingestion of old (dead) carbonate that is eventually incorporated into the shell in some settings (see Goodfriend and Magaritz 1987; Magaritz and Heller 1980; Stott 2002). Diagenetic processes in shell may alter the isotopic ratios, especially when land snails are exposed to heating as might be expected in some prehistoric contexts. As discussed previously, heating has been shown to result in the differential loss of some amino acids in shell (Goodfriend and Ellis 2002). Goodfriend and Ellis (2002) further suggest that heating may result in carbon exchanges between carbonate and atmospheric $\mathrm{CO}_{2}$ resulting in shifts in the isotopic composition of the carbonate, though the degree of this impact appears to be variable and species specific. If, in fact, heating does significantly alter the stable carbon isotopic values of shell carbonate, heated samples can be recognized, and eliminated from samples, by amino acid racemization (see Ellis et al. 1996 and discussions in previous section).

In spite of these potential complications, studies of several different land snail species from Texas and other areas of the Southern Great Plains (e.g., Balakrishnan et al. 2005a) show that variation in $\delta^{13} \mathrm{C}$ derived from shell carbonate track vegetation types. Using multiple samples from several different locations, Balakrishman et al. (2005b) conclude that while there is considerable variability for carbon values in a given setting, in general snail shells collected from settings where $\mathrm{C}_{4}$ vegetation was dominate averaged $-2.8 \%$ (range from $-4.3 \%$ to $-1.9 \%$ ). In contrast, $\delta^{13} \mathrm{C}$ isotope values from shells collected in $\mathrm{C}_{3}$ vegetation regimes averaged $-9.0 \%$, with a range of $-10.0 \%$ to $-8.8 \%$. Furthermore, intermediate, mixed settings where both $C_{3}$ and $C_{4}$ vegetation were present produced carbon isotopic signatures between these two extremes. Additional support for the relationship between stable carbon isotope values in snail shell carbonate and snail diet is provided by Goodfriend and Ellis (2002), which was discussed previously. They conclude that while stable carbon isotope values in shell are highly variable and subject to extremely local conditions, snails found in more arid regions, those that have a higher frequency of $\mathrm{C}_{4}$ and CAM vegetation, are enriched in $\delta^{13} \mathrm{C}$. In addition, Goodfriend and Ellis (2002) demonstrate a significant relationship between vegetation cover and $\delta^{13} \mathrm{C}$ values in shell, with heavier vegetation cover yielding isotopic values in shell that are depleted in $\delta^{13} \mathrm{C}$, and isotopic values in shell being enriched in areas of lower vegetation density.

The utility of oxygen stable isotope variability in land snails may be limited. However, while the interpretation of land snail assemblages in buried soils must be based on the assemblage's stratigraphic position, must consider taphonomic processes (see Carter 1990), and must consider the impacts of heating, we suggest that variability in carbon isotopes in land snail shell can provide detailed information on past vegetation.

\section{Collecting, Quantifying, Analyzing and Curating Snails}

As presented in this document, there are different methods for collecting and analyzing snail that are dictated by research objectives that typically surround identifying the role of land snails in subsistence and their use in paleoenvironment reconstruction. This section presents our suggestions for collection, quantitative analysis, and curation methods for land snails in Phase II and Phase III excavation efforts.

\section{Collection, Initial Processing, and Identification Methods}

As we summarized earlier, our literature review, as well as our own analyses presented in Chapters 9 and 10 (see also Appendices G, H, I, and L) investigating the possible role of Rabdotus in prehistoric subsistence within Texas, highlighted two research directions that seem promising. These are the direct estimation of Rabdotus size at a species level and a reliance on Amino Acid Racemization (AAR) to determine the presence or absence of heating in selected samples. In terms of paleoenvironmental reconstruction, the most productive line of research appears to be associated with stable isotope investigations, with an emphasis on carbon isotopic studies of shell carbonate. While individual research priorities and financial considerations will certainly vary from project to project that will affect collection decisions, we can make some general recommendations based on these research directions. These collection, processing, and initial identifications methods will provide samples for a variety of studies, including those specifically concerned with the potential use of Rabdotus for subsistence and the use of a variety of species in paleoclimate reconstruction for stable isotopic research.

We see little utility in continuing to routinely collect snails from 1/4-inch screens in the field during general excavations. We would suggest eliminating this practice unless specific research goals requiring these samples are articulated. Rather than 
continue these collections, we would suggest that sediment samples from selected proveniences be the principal snail sampling method. These samples should be at least 2 liter in size, when possible. They should be collected from all features, from selected levels of 1-x-1 m excavation units, and from off-site excavations. The off-feature samples could be collected from general excavation and would not require any additional excavation units. The off-site collections need not be formal units, but could simply consist of sediment collected from levels excavated by shovel tests. The number of off-feature and off-site samples, as well as the locations, should be roughly equivalent to the number of features samples, with depths being roughly equivalent to features where possible.

Finally, we would suggest that all snail sediment samples be return to a lab for processing. Sediment volume should be recorded for each sample to allow for comparison of snail densities per liter, and all sediment should be water screened through $1 / 16^{\text {th }}$-inch mesh to insure consistent, comparable collection of all snails from various contexts. Some preliminary sorting of snails may be useful and can be accomplished by most archeological lab technicians. However, any detailed macro or micro-snail species level identification should be done by a qualified researcher such as Manuel Palacios-Fest of Terra Nostra Earth Sciences Research in Tucson, Dr. James Theler at the University of Wisconsin-La Crosse, or other qualified researchers interested in land snails in North America (see Perez 2010 for a list of over 50 North American researchers). Having confident identifications at the species level is especially critical for investigations focused on Rabdotus, where species vary in size and where size is an important element in identifying potential incidents of snail predation by humans.

\section{Quantification and Analytical Directions}

For most purposes discussed here, quantification of snails should occur at the species level. Focusing on Rabdotus, we would initially suggest that shell from a given species and context be separated into whole shell and broken shell. We would then size-sort whole specimens by passing them through nested screens (e.g.,1/2, $1 / 4,1 / 8^{\text {th }}$, and less than $1 / 8^{\text {th }}$-inch) and count individuals in each screen size. While weight of fractions would be quick, the results would be questionable unless we could be assured that each individual shell was free from dirt that is often packed deep in the shell. Broken shells could be quantified by using a recognizable element such as an aperture fragment that typically occurs only once in an individual (Brown, personal communication 2009). There is no need to size sort the broken shell, though the counts by context should be noted and used in any density calculations. At the present time, we would not recommend the calculations of width/length ratios in Rabdotus, assuming that snail identification at the species level has been securely accomplished.

The resulting data should allow comparisons of size by context for a given species. Comparison of feature data to off-site and off-feature distributions will allow the isolation of features that have snail size data that might reflect snail predation, as well as those that do not. Both sets of features are of interest for AAR. The analysis can eliminate or confirm heating in features that have Rabdotus size distributions suggestive of human predation, especially if these features are independently dated. Dated features that do not have evidence of heating can contribute to the establishing unheated $\mathrm{D} / \mathrm{L}$ curves for aspartic and glutamic acids. The AAR analysis will also help indentify snails that were not heated. These will be good candidates for paleoecological isotopic analysis.

The quantification and analytical framework suggested above is relatively straightforward and is derived primarily for species of Rabdotus. Suggested procedures for quantification and analysis in other species of land snails that will be acquired from sediment are not so straightforward. The primary research interest in other species centers on their use in arguments related to species diversity, primarily for comparisons to the distributions of Rabdotus, and in habitat preference as an indicator of past environments. Both of these, in effect, involve some understanding of the habitat requirements of particular species of snails. We have found little consistency in this area, at either the macro or the micro-snail scale, suggesting that our current understanding is not well developed. At the present time, we would suggest that in the absence of well-founded arguments to the contrary, no detailed quantification or other analysis beyond identifying what species are present within samples should be undertaken.

\section{Curation}

Finally, the storage and curation of snail shells is an issue that needs to be considered on projects. Storing and curation of snail assemblages will be beneficial for future researchers, especially if malacologists develop a more fine grained understanding of habitat tolerances of snail species within Texas. Assuming that our recommended collection procedures are followed, we would suggest that for Rabdotus, curation of whole shell samples should occur by species, size grade, and recovery context (features, 
off-feature, off-site), with broken shells discarded following quantification. A minimum of $25 \%$ of the whole shells should be curated. For other species, we would recommend curation by species and recovery context. We would again recommend a minimally sample of $25 \%$, with snails stored in plastic vials or other appropriate containers that would resist crushing.

\section{Summary}

This appendix reviewed regional and topical literature on land snail assemblages found at archeological sites. Our primary focused was on Texas, with the discussion dictated by snail analysis in association with work at 41TV540. Additional information relevant to this discussion can be found in Chapters 9 and 10 of the current document, as well as Appendices G, H, I, L and O. The principal recommendations for subsequent collection and analysis procedures are as follows:

- The replacement of snails collected in 1/4-inch mesh with sediment samples from feature, off-feature, and off-site contexts.

- Identification of snails by qualified researchers to the species level.

- The abandonment of age profiles for estimates of the dietary characteristics of Rabdotus, and their replacement by a direct focus on size with whole shell counts within a series of nested screens at the species level.

- The use of amino acid racemization to identify heated and non-heated snails, and the continued development of $\mathrm{D} / \mathrm{L}$ curves for Rabdotus as well as refinement of the D/L signatures of heated and non-heated samples.

- The collection and identification of other species by context (feature, off-feature, off-site), but with no additional analysis beyond identification unless specific research questions can be generated.

- Appropriate curation and storage of snail shell assemblages.

- Continued use of stable carbon isotope analysis on unheated Rabdotus for climate reconstruction.

Finally, if these recommendations are implemented, we would suggest that they be viewed as minimum requirements. In addition, these recommendations should be reviewed periodically both for their effectiveness and in light of other developments in both paleoenvironmental research and general research by malacologists on snail habitat preference. 


\section{References Cited}

Abbott, J.T.

2009 Comments on Task 4: Snail Collection and Analysis Protocol. Manuscript on File, Center for Archaeological Research, University of San Antonio, San Antonio.

Abbott, J.T., G.L. Ellis and G.A. Goodfriend

1995 Chronometric and Integrity Analyses Using Land Snails. In NRHP Significance Testing of 57 Prehistoric Archeological Sites on Fort Hood, Texas, Vollume II, edited by J.T. Abbott and W.N. Trierweiler, pp. 801-814. Archaeological Resource Managegment Series, Research Report No. 34, United States Army Fort Hood, Texas.

Allen, D.C. and E.P. Cheatum

1960 Ecological Implications of Fresh-Water and Land Gastropods in Texas Archeological Studies. Bulletin of the Texas Archeological Society 31:291-316.

Balakrishnan, M. and C.J. Yapp

2005 Flux balance Models for the Oxygen and Carbon Isotope Compositions of Land Snail Shells. Geochimica et Cosmochimica Acta 68: 2007-2024.

Balakrishnan, M., C.J. Yapp, D.J. Meltzer, J.L. Theler

2005aPaleoenvironment of the Folsom Archaeological Site, New Mexico, USA, Approximately $10,500{ }^{14} \mathrm{C}$ yr. B.P. as inferred from the Stable Isotope Composition of Fossil Land Snail Shells. Quaternary Research 63:31-44.

Balakrishnan, M., C.J.Yapp, J.L. Theler, B.J. Carter, and D.G. Wyckoff

2005b Environmental significance of ${ }^{13} \mathrm{C} /{ }^{12} \mathrm{C}$ and ${ }^{18} \mathrm{O} /{ }^{16} \mathrm{O}$ Ratios of Modern Land-Snail Shells from the Southern Great Plains of North America. Quaternary Research 63:15-30.

Binford, L.R.

1983 Working at Archaeology. Academic Press, New York.

Bonizzoni, S., A. Bruni, A. Girod and V. Guglielmi

2009 Archaeometric Study of Shells of Helicidae from the Edera Cave (Northeastern Italy). Archaeometry 51(1): 151-173.

Brown, K.M.

1999 Snails from the Quarter-inch and Eight-Inch Screens. Appendix F. In The Smith Creek Bridge Site (41DW270) A Terrace Site in DeWitt County, Texas. D. Hudler, K. Prilliman, and T. Gustavson authors, Pp. 213-275. Texas Archeological Research Laboratory, Studies in Archeology No. 35. Archeology Studies Program, Report Number 17. Environmental Affairs Division. Texas Department of Transportation. Austin.

2002 Appendix F: Snails from the Quarter-Inch and Eighteen-Inch Screens. In The Smith Creek Bridge Site (41DW70): A Terrace Site in DeWitt County, Texas., edited by D. Hudler, K. Prilliman, and T. Gustavson, pp. 213-275. Studies in Archeology 35. Texas Archeological Research Laboratory, Austin.

2006 The Bench Deposits at Berger Bluff: Early Holocene-Late Pleistocene Depositional and Climatic History. Unpublished $\mathrm{PhD}$ dissertation, Anthropology Department, The University of Texas at Austin.

2009 Personal Communication to S. Tomka. 
Carter, S.P.

1990 The Stratification and Taphonomy of Shells in Calcareous Soils: Implications for Land Snail Analysis in Archaeology. Journal of Archaeological Science 17:495-507.

Cheatum, E.P.

1934 Arboreal Behavior of Helicina orbiculata tropica “Jan” Pfr. The Nautilus 47 (4): 147-148.

Cheatum, E.P. and R.W. Fullington

1971 Part One: The Recent Pleistocene Members of the Gastropod Family Polygyridae in Texas. Bulletin 1: The Aquatic and Land Mollusca of Texas. Dallas Museum of Natural History, Dallas.

Clark, J.W., Jr. 1973 The Problem of the Land Snail Genus Rabdotus in Texas Archeological Sites. The Nautilus 87 (1):24.

1976 Alvar Nuñez and the Snail Rabdotus in Texas. The Nautilus 1(13-14).

Dansgaard, W.

1964 Stable Isotopes in Precipitation. Tellus 16: 436-468.

Decker, S., S.L. Black and T. Gustavson

2000 The Woodrow Heard Site, 41UV88: A Holocene Terrace Site in the Western Balcones Canyonlands of Southwestern Texas. Archeological Studies Program, Report 14. Texas Archeological Research Laboratory, The University of Texas at Austin.

Deisler, J.E.

1986 Consumption of Rabdotus Alternatus Alternatus by the Aboriginal Inhabitants of the Tucker Archeological Site, 41NU46, in South Texas. Malacology Data Net. 1:13-20

DeNiro M.J., and S. Epstein

1978 Influence of diet on the distribution of carbon isotopes in animals. Geochim Cosmochim Acta, 42: 495-506.

Ellis, L.G., G.A. Goodfriend, J.T. Abbott, P.E. Hare and D.W. Von Endt

1996 Assessment of Integrity and Geochronology of Archaeological Sites Using Amino Acid Racemization in Land Snail Shells: Examples from Central Texas. Geoarchaeology: An International Journal 11(3): 189-213.

Ferring, R.F.

2001 The Archaeology and Paleoecology of the Aubrey Clovis Site (41DN479) Denton County, Texas. Center for Environmental Archaeology, Department of Geography, University of North Texas, Denton.

Fullington, R.W.

2003 Appendix H: Gastropod Analysis. In Data Recovery Excavations at 41MM340: A Late Archaic Site along Little River in Milam County, Texas. R.B. Mahoney, S.A. Tomka, R.P. Mauldin, H.J. Shafer, L.C. Nordt, R.D. Greaves, and R.R. Galdeano. Pp.246-270. Texas Department of Transportation, Archeological Studies Program, Report No. 54 and Center for Archaeological Research, Archaeological Survey Report, No. 340. The University of Texas at San Antonio.

Fullington, R.W. and W.L. Pratt

1974 The Aquatic and Land Mollusca of Texas Part Three: The Helicinidae, Carychiidae, Achatinidae, Bradybaenidae, Bulimidae, Cionellidae, Haplotrematidae, Helicdae, Oreohelicidae, Spiraxidae, Streptaxidae, Strobilopsidae, Thysanophoridae, Valloniidae (Gastropoda) in Texas. Bulletin 1. Dallas Museum of Natural History, Dallas. 
Gadus, E.F., R.C. Fields, K.W. Kibler and K.M. Gardner

2006 Data recovery excavations at the J.B. White site (41MM340), Milam County, Texas. Reports of Investigations, No. 145. Prewitt and Associates, Austin.

Gardner, K.M.

2000 Appendix III: Invertebrates from the Bessie Kruze Site. In Life and Dead as Seen at the Bessie Kruze site (41WM13) on the Blackland Prairie of Williamson County, Texas. edited by L. Johnson, pp. Report 44, Texas Department of Transportation, Environmental Affairs Division, Archeology Studies Program.

Goodfriend, G.A.

1986 Variation in Land-Snail Shell and Size and its Causes: A Review. Systematic Zoology, Vol. 35, No. 2: $204-222$.

1987 Radiocarbon age anomalies in shell carbonate of land snails from semi-arid areas. Radiocarbon 29: 159-167.

1990 Rainfall in the Negev Desert during the Middle Holocene, Based on ${ }^{13} \mathrm{C}$ of organic matter in land snail shells. Quaternary Research 34: 186-197.

1992 The Use of Land Snail Shells in Paleoenvironmental Reconstruction. Quaternary Science Reviews 11: 665-685.

2003 Appendix D: Mussel Shell Analysis. In Archaeological Testing to Determine the National Register Eligibility Status of 18 Prehistoric Sites on Camp Bowie, Brown County, Texas, Volume 2. eds. R.P. Mauldin, D.L. Nickels, and C.J. Broehm. Archaeological Survey Report, No. 334. Center for Archaeological Research, The University of Texas at San Antonio.

Goodfriend, C.A. and G.L. Ellis

2000 Stable Carbon Isotope Record of Middle to Late Holocene Climate Changes from Land Snail Shells at Hinds Cave, Texas. Quaternary International 67: 47-60.

2002 Stable Carbon and Oxygen Isotopic Variations in Modern Rabdotus Land Snail Shells in the Southern Great Plains, USA, and their Relation to Environment. Geochimica Et Cosmochimica Acta 66(11): 1987-2002.

Goodfriend, G.A. and D.G. Hood

1983 Carbon Isotope Analysis of land snail shells: Implications for carbon sources and Radiocarbon Dating. Radiocarbon 25: $810-830$.

Goodfriend, G.A. and M. Magaritz

1987 Carbon and Oxygen Isotope Composition of Shell Carbonate of Desert Land Snails. Earth and Planetary Science Letters 86: 377-388.

Healy, P.F., K. Emery and L.E. Wright

1990 Ancient and Modern Maya Exploitation of the Jute Snail (Pachychilus) Latin American Antiquity 1(2): 37-38.

Hester, T.R. and T.C. Hill, Jr.

1975 Eating Land Snails in Prehistoric Southern Texas: Ethnohistoric and Experimental Data. The Nautilus 89(2): 37-38.

Honea, K.H.

1962 The Rammadyat of Northwest Africa and the Burned Rock Middens of Texas. Bulletin of the Texas Archeological Society 32: 317-320. 
Hubricht, L.

1985 The Distributions of the Native Land Mollusks of the Eastern United States. Fieldiana, Zoology New Ser: 24. Field Museum of Natural History, Chicago.

Jelks, E.B.

1962 The Kyle Site: A Stratified Central Texas Aspect Site in Hill County, Texas. Anthropology Series, No. 5. Department of Anthropology, The University of Texas at Austin.

Johnson, L.

1964 The Devil's Mouth Site: A Stratified Campsite at Amistad Reservoir, Val Verde County, Texas. Archaeology Series, No. 6. Department of Anthropology, The University of Texas at Austin.

2000 Life and Death as Seen at the Bessie Kruze Site (41WM13) on the Blackland Prairie of Williamson County, Texas. Report No. 22. Texas Department of Transportation, Environmental Affairs Division, Archeology Studies Program. Austin.

Kaufman, D.S.

2006 Temperature sensitivity of aspartic and glutamic acid racemization in the foraminifera Pulleniatina. Quaternary GeoChronology 1(3):188-207.

Kaufman, D.S., and Manley, W.F.,

1998 A new procedure for determining enantiomeric (D/L) amino acid ratios in fossils using reverse phase liquid chromatography. Quaternary Science Reviews 17, 987-1000.

Klippel, W.E. and D.F. Morey

1986 Contextual and Nutritional Analysis of Freshwater Gastropods from Middle Archaic Deposits at the Hayes Site, Middle Tennessee. American Antiquity 51(4): 799-813.

Levin, M., Gat, J.R., and A. Issar,

1980 Precipitation, Flood- and Groundwaters of the Negev Highlands: an Isotopic Study of Desert Hydrology. Arid-zone Hydrology: Investigations with Isotope Techniques, (pp. 3-22). Vienna: International Atomic Energy Commission.

LIU, ZongXiu, GU ZhaoYan, WU NaiQin, and XU Bing

2007 Diet control on carbon isotopic composition of land snail shell carbonate. Chinese Science Bulletin, 52: 388-394.

Lubell, D.

2004aAre Land Snails a Signature for the Mesolithic-Neolithic Transition? Documenta Praehistorica XXXI: 1-24.

2004b Prehistoric Edible Land Snails in the Circum-Mediterranian: the Archaeological Evidence. In Petits Animaux et Societes Humaines: du Complement Alimentaire Resources Utilitaires, edited by J. Brugal and J. Desse, pp. 77-98. APDCA, Antibes.

Lubell, D., F.A. Hassan, A. Gautier and J.L. Ballais

1976 Capsian Escargotieres. Science 191(4230): 910-920.

Magaritz, M., and J. Heller

1980 A Desert Migration Indicator-Oxygen Isotopic Composition of Land Snail Shells. Palaeogeography, Palaeoclimatology, Palaeoecology 32: 153-162. 
Malof, A.F.

2001 Feast or Famine: the Dietary Role of Rabdotus Species Snails in Prehistoric Central Texas. Unpublished Master’s thesis, The University of Texas at San Antonio.

Malof, A.F., Prikryl, D.J., Goode, G.T. and Bousman, C.B.

2007 Excavations at 41CM25, Comal Power Plant Redevelopment Project, Comal County, Texas. Cultural Resource Report No. 12. The Lower Colorado River Authority.

Marie, R.

2006 Invertebrate Faunal Analysis: Land Snails. In Testing and Data Recovery 41WM1010 Williamson County, Texas, edited by B. Dixon and R. Rogers. PBS\&J, Austin.

Mauldin, R.

2007 Amino Acid Racemization in Rabdotus exposed to high temperatures. Report on file at Center for Archeological Research, The University of Texas at San Antonio.

2010 Data files for organic carbon (NAU) and shell carbon (Tx A\&M) isotopes from La Paloma and McAlister Park. On file at Center for Archeological Research, The University of Texas at San Antonio.

Metref, S., D.D. Rousseau, I. Bentaleb, M. Labonne and M. Vianey-Liaud,

2003 Study of the diet effect on $\delta^{13} \mathrm{C}$ of shell carbonate of the land snail Helix aspersa in experimental conditions, Earth and Planetary Science Letters 211: 381-393.

Miracle, P.

2002 Mesolithic Meals from Mesolithic Middens. In Consuming Passions and Patterns of Consumption, edited by N. Milner and P. Miracle, pp. 65-88. McDonald Institute for Archaeological Research, Cambridge.

Neck, R.W.

1987 Changing Holocene Snail Faunas and Environments Along the Eastern Caprock Escarpment of Texas. Quaternary Research 27 (3):312-322.

1994 Interpretations of Molluscan Remains from the Mustang Branch Site (41HY209). In Human Ecology in the Middle Onion Creek Valley, Hays County, Texas, edited by R.A. Ricklis and M.B. Collins, pp. 491-497. Studies in Archeology 10. Texas Archeological Research Laboratory, The University of Texas at Austin.

Perez, K.E.

2010 Land Snail Researchers. University of North Carolina website. http://www.unc.edu/ keperez/land\%20snail\%20 researchers.html.

Radmilli, A.M.

1960 Considerazioni sul Mesolithico Italiano. Annali dell’ Universita id Ferrara 1(3): 29-48.

Randolph, P.A.

1973 Influence of Environmental Variability on Land Snail Population Properties. Ecology 54(4): 933-955.

Stott, L.

2002 The Influence of Diet on the $\delta^{13} \mathrm{C}$ of Shell Carbon in the Pulmonate Snail helix aspersa. Earth and Planetary Science Letters 195: 249-259. 
Thompson, R. and S. Cheny

1996 Raising Snails. National Agriculture Library Special reference briefs. NAL 96-05

Tomka, S.A. and R.P. Mauldin

2003 Paleoenvironment Reconstruction. In Data Recovery Excavations at 41MM340: A Late Archaic Site along Little River in Milam County, Texas. R.B. Mahoney, S.A. Tomka, R.P. Mauldin, H.J. Shafer, L.C. Nordt, R.D. Greaves, and R.R. Galdeano, pp.95-108. Texas Department of Transportation, Archeological Studies Program, Report No. 54 and Archaeological Survey Report, No. 340. Center for Archaeological Research, The University of Texas at San Antonio.

Tukey, J.W.

1977 Exploratory Data Analysis. Addison-Wesley. Reading, MA.

Waters, M.R.

1992 Principles of Geoarchaeology. The University of Arizona Press, Tucson.

Woodburn, J.

1970 Hunters and Gatherers: The Material Culture of the Nomadic Hadza. Trustees of the British Museum, London.

Yapp, C.J.

1979 Oxygen and Carbon Isotope Measurements of Land Snail Shell Carbonate. Geochima et Cosmochimica Acta 43: $629-635$.

Yates, T.J.S., Spiro, B.F. and C. Vita-Finzi

2002 Stable Isotope Variability and the Selection of Mollusk Shell Samples for 14C Dating. Quaternary International 87: 87-100. 


\section{APPENDIX K: \\ Thermal Feature and Rock Fracture Experiments Raymond Mauldin and Steve Tomka}





\author{
APPENDIX K \\ Thermal Feature and Rock Fracture Experiments \\ Raymond Mauldin and Steve Tomka \\ The Center for Archaeological Research \\ The University of Texas at San Antonio \\ San Antonio, Texas
}

This document summarizes a series of investigations of thermal characteristics and breakage patterns of rock in experimentally produced hearths, as well as the thermal characteristics of rock under controlled conditions. Specifically, we conducted controlled thermal feature use experiments to document and quantify trends in rock fracturing with repeated re-use of rock-lined hearths.

\title{
Controlled Experiments
}

For the controlled experiments, we focused on three different raw material types. We initially selected a single limestone nodule, collected from Onion Creek in Travis County near site 41TV410 and weighing 650 grams. For contrast, we also selected a single quartzite nodule (575 grams) and two different sandstone pieces (283 grams and 224 grams) of different density but similar size and shape. In addition to weights, the surface area of each piece was estimated by Xeroxing the sides of the item onto paper gridded into $1 \times 1 \mathrm{~cm}$ squares. The squares were counted and summed to provide an overall area estimate. We then heated each sample to $200^{\circ} \mathrm{C}$ in a Thermolyne 1300 furnace for 1 hour. The sample was then removed, and placed in a metal box into which a K- type thermocouple attached to a digital thermometer was inserted (Figure K-1). We set the digital thermometer to record temperatures at 1 minute intervals. The box was closed and changes in the air temperature within the box were recorded for 120 minutes.

In all, we conducted ten different controlled experiments using the set up and procedures described above and shown in Figure K-1. Table K-1 presents the results of these experimental runs. The first column in the Table records the time in 1 minute intervals. The remaining ten columns provide recorded temperatures in Celsius for four runs on quartzite (labeled 1 through 4), two runs on sandstone (labeled 1 and 2), and four runs on Onion Creek Limestone. Note that following each run on both the limestone and the quartzite, the sample was broken into smaller fragments, and the surface area again recorded. The weight of the sample, then, remained roughly constant, while the surface area increased. For example, the initial surface area of the Onion Creek Limestone sample was $241 \mathrm{sq}$. cm. The second run (labeled "limestone 2" in Table K-1) had a surface area of 322 sq. cm., but the same weight ( 650 grams). The weight remained the same for runs three and four, but the area increased to $415 \mathrm{sq}$. cm and 497 sq. cm, respectively.

Figure K-2 plots the patterns of cooling for the four runs of the 650 gram sample of Onion Creek limestone with varying surface areas identified by color. These data are presented in Table K-1 (columns 8, 9, 10, 11). Keeping the weight roughly constant, the figure shows a clear relationship



Figure K-1. Metal Box with sample area and Thermocouple. 
Table K-1. Controlled Heating Experiments (1 hour @ 200o C)

\begin{tabular}{|c|c|c|c|c|c|c|c|c|c|c|}
\hline Time & $\begin{array}{c}\text { Quartzitte } \\
1\end{array}$ & $\begin{array}{c}\text { Quatzite } \\
2\end{array}$ & $\begin{array}{c}\text { Quartzite } \\
3\end{array}$ & $\begin{array}{c}\text { Quartzite } \\
4\end{array}$ & $\begin{array}{c}\text { Sandstone } \\
1\end{array}$ & $\begin{array}{c}\text { Sandstone } \\
2\end{array}$ & \begin{tabular}{|c|} 
Limestone \\
1 \\
\end{tabular} & \begin{tabular}{|c|} 
Limestone \\
2 \\
\end{tabular} & $\begin{array}{c}\text { Limestone } \\
3 \\
\end{array}$ & \begin{tabular}{|c} 
Limestone \\
4
\end{tabular} \\
\hline 1 & 23.35 & 23.3 & 23.25 & 23.25 & 22.28 & 22.06 & 22.11 & 21.17 & 21.83 & 22.83 \\
\hline 2 & 27.95 & 25.25 & 25.35 & 26.15 & 22.78 & 22.89 & 23.39 & 23.5 & 24.28 & 25.28 \\
\hline 3 & 30.45 & 30.55 & 31.25 & 32.8 & 23.39 & 23.83 & 24.89 & 25.61 & 26.67 & 27.67 \\
\hline 4 & 32.15 & 32.65 & 33.6 & 35.5 & 23.94 & 24.67 & 26.28 & 27.44 & 28.67 & 29.71 \\
\hline 5 & 33.3 & 33.95 & 35.05 & 37.2 & 24.39 & 25.39 & 27.56 & 29.11 & 30.39 & 31.29 \\
\hline 6 & 34.2 & 35 & 36.15 & 38.3 & 24.83 & 26.11 & 28.72 & 30.56 & 31.94 & 32.9 \\
\hline 7 & 34.95 & 35.7 & 36.9 & 39.15 & 25.17 & 26.78 & 29.78 & 31.89 & 33.28 & 34.3 \\
\hline 8 & 35.5 & 36.2 & 37.6 & 39.75 & 25.5 & 27.39 & 30.72 & 33 & 34.39 & 35.49 \\
\hline 9 & 35.9 & 36.6 & 37.95 & 40.2 & 25.78 & 27.89 & 31.67 & 33.94 & 35.39 & 36.32 \\
\hline 10 & 36.3 & 36.95 & 38.3 & 40.7 & 26.06 & 28.39 & 32.39 & 34.78 & 36.28 & 37.28 \\
\hline 11 & 36.65 & 37.15 & 38.45 & 40.8 & 26.28 & 28.78 & 33.11 & 35.5 & 37.06 & 38.15 \\
\hline 12 & 36.9 & 37.4 & 38.65 & 40.85 & 26.44 & 29.17 & 33.72 & 36.17 & 37.61 & 38.61 \\
\hline 13 & 37.1 & 37.55 & 38.75 & 40.95 & 26.61 & 29.44 & 34.28 & 36.72 & 38.11 & 39.13 \\
\hline 14 & 37.2 & 37.55 & 38.9 & 40.9 & 26.78 & 29.72 & 34.72 & 37.11 & 38.44 & 39.44 \\
\hline 15 & 37.35 & 37.65 & 38.95 & 40.8 & 26.89 & 29.94 & 35.17 & 37.5 & 38.78 & 39.77 \\
\hline 16 & 37.55 & 37.7 & 38.95 & 40.6 & 26.94 & 30.17 & 35.5 & 37.72 & 38.94 & 39.9 \\
\hline 17 & 37.5 & 37.8 & 38.9 & 40.4 & 27.06 & 30.33 & 35.83 & 37.94 & 39.11 & 40.05 \\
\hline 18 & 37.45 & 37.75 & 38.85 & 40.25 & 27.11 & 30.44 & 36.06 & 38.06 & 39.17 & 40 \\
\hline 19 & 37.5 & 37.75 & 38.75 & 40 & 27.17 & 30.5 & 36.22 & 38.11 & 39.11 & 39.95 \\
\hline 20 & 37.65 & 37.75 & 38.7 & 39.75 & 27.17 & 30.61 & 36.33 & 38.17 & 39 & 39.75 \\
\hline 21 & 37.7 & 37.7 & 38.6 & 39.55 & 27.17 & 30.67 & 36.44 & 38.22 & 38.89 & 39.64 \\
\hline 22 & 37.55 & 37.6 & 38.5 & 39.35 & 27.17 & 30.67 & 36.56 & 38.17 & 38.72 & 39.45 \\
\hline 23 & 37.55 & 37.5 & 38.35 & 39.15 & 27.17 & 30.67 & 36.61 & 38.06 & 38.56 & 39 \\
\hline 24 & 37.5 & 37.4 & 38.15 & 38.95 & 27.11 & 30.61 & 36.61 & 38 & 38.39 & 38.6 \\
\hline 25 & 37.4 & 37.25 & 37.95 & 38.65 & 27.11 & 30.61 & 36.61 & 37.89 & 38.22 & 38.3 \\
\hline 26 & 37.35 & 37.1 & 37.75 & 38.5 & 27.11 & 30.56 & 36.56 & 37.72 & 37.94 & 37.9 \\
\hline 27 & 37.2 & 36.9 & 37.5 & 38.25 & 27.06 & 30.5 & 36.5 & 37.61 & 37.72 & 37.35 \\
\hline 28 & 37.15 & 36.8 & 37.25 & 38.05 & 27 & 30.44 & 36.44 & 37.44 & 37.39 & 37 \\
\hline 29 & 37.05 & 36.6 & 37 & 37.8 & 26.89 & 30.33 & 36.33 & 37.22 & 37.17 & 36.61 \\
\hline 30 & 36.85 & 36.4 & 36.8 & 37.55 & 26.83 & 30.28 & 36.22 & 37.06 & 36.89 & 36.38 \\
\hline 31 & 36.7 & 36.3 & 36.6 & 37.35 & 26.72 & 30.17 & 36.11 & 36.83 & 36.61 & 36.22 \\
\hline 32 & 36.55 & 36.1 & 36.45 & 37.05 & 26.67 & 30 & 35.94 & 36.61 & 36.33 & 35.8 \\
\hline 33 & 36.4 & 35.9 & 36.25 & 36.85 & 26.56 & 29.89 & 35.83 & 36.39 & 36.06 & 35.52 \\
\hline 34 & 36.25 & 35.7 & 36.05 & 36.6 & 26.5 & 29.78 & 35.72 & 36.17 & 35.72 & 35.22 \\
\hline 35 & 36.1 & 35.5 & 35.9 & 36.3 & 26.39 & 29.67 & 35.56 & 35.94 & 35.44 & 34.86 \\
\hline 36 & 36 & 35.35 & 35.7 & 36.05 & 26.28 & 29.56 & 35.39 & 35.72 & 35.17 & 34.69 \\
\hline 37 & 35.8 & 35.15 & 35.55 & 35.8 & 26.17 & 29.44 & 35.22 & 35.5 & 34.89 & 34.42 \\
\hline 38 & 35.65 & 35 & 35.35 & 35.55 & 25.94 & 29.28 & 35.06 & 35.28 & 34.61 & 34.14 \\
\hline 39 & 35.45 & 34.8 & 35.2 & 35.25 & 25.83 & 29.22 & 34.89 & 35 & 34.33 & 33.75 \\
\hline 40 & 35.3 & 34.65 & 35.05 & 35.1 & 25.72 & 29.11 & 34.72 & 34.78 & 34.06 & 33.33 \\
\hline 41 & 35.2 & 34.5 & 34.85 & 34.85 & 25.61 & 28.94 & 34.56 & 34.56 & 33.78 & 33.06 \\
\hline 42 & 35.05 & 34.3 & 34.7 & 34.6 & 25.5 & 28.83 & 34.39 & 34.28 & 33.5 & 32.78 \\
\hline 43 & 34.9 & 34.15 & 34.5 & 34.35 & 25.44 & 28.78 & 34.22 & 34.06 & 33.22 & 32.5 \\
\hline 44 & 34.7 & 34 & 34.35 & 34.05 & 25.33 & 28.61 & 34.06 & 33.83 & 32.89 & 32.22 \\
\hline 45 & 34.6 & $\begin{array}{l}33.8 \\
\end{array}$ & 34.15 & 33.9 & 25.22 & 28.5 & 33.89 & 33.56 & 32.67 & 31.89 \\
\hline 46 & 34.45 & 33.7 & 34.05 & 33.65 & 25.11 & 28.39 & 33.72 & 33.39 & 32.39 & 31.55 \\
\hline 47 & 34.25 & 33.55 & 33.85 & 33.45 & 25.06 & 28.28 & 33.5 & 33.17 & 32.11 & 31.39 \\
\hline 48 & 34.1 & 33.35 & 33.65 & 33.2 & 24.94 & 28.17 & 33.39 & 32.94 & 31.89 & 31.11 \\
\hline 49 & 33.95 & 33.2 & 33.45 & 33.05 & 24.83 & 28.06 & 33.22 & 32.67 & 31.67 & 30.85 \\
\hline 50 & 33.8 & 33.05 & 33.2 & 32.8 & 24.78 & 27.94 & 33 & 32.5 & 31.44 & 30.66 \\
\hline
\end{tabular}


Table K-1. Continued...

\begin{tabular}{|c|c|c|c|c|c|c|c|c|c|c|}
\hline Time & $\begin{array}{c}\text { Quartzitte } \\
1 \\
\end{array}$ & $\begin{array}{c}\text { Quatzite } \\
2 \\
\end{array}$ & $\begin{array}{c}\text { Quartzite } \\
3 \\
\end{array}$ & \begin{tabular}{|c} 
Quartzite \\
4 \\
\end{tabular} & $\begin{array}{c}\text { Sandstone } \\
1 \\
\end{array}$ & $\begin{array}{c}\text { Sandstone } \\
2 \\
\end{array}$ & \begin{tabular}{|c|} 
Limestone \\
1 \\
\end{tabular} & \begin{tabular}{|c|} 
Limestone \\
2 \\
\end{tabular} & $\begin{array}{c}\text { Limestone } \\
3 \\
\end{array}$ & \begin{tabular}{|c} 
Limestone \\
4 \\
\end{tabular} \\
\hline 51 & 33.6 & 32.9 & 33.05 & 32.6 & 24.67 & 27.83 & 32.89 & 32.28 & 31.22 & 30.44 \\
\hline 52 & 33.45 & 32.75 & 32.8 & 32.5 & 24.61 & 27.72 & 32.72 & 32.06 & 30.94 & 30.23 \\
\hline 53 & 33.35 & 32.6 & 32.65 & 32.25 & 24.56 & 27.61 & 32.5 & 31.89 & 30.72 & 29.94 \\
\hline 54 & 33.1 & 32.45 & 32.4 & 32.05 & 24.44 & 27.56 & 32.33 & 31.67 & 30.56 & 29.7 \\
\hline 55 & 33 & 32.35 & 32.25 & 31.9 & 24.39 & 27.44 & 32.22 & 31.44 & 30.33 & 29.56 \\
\hline 56 & 32.85 & 32.15 & 32 & 31.75 & 24.33 & 27.39 & 32.06 & 31.28 & 30.11 & 29.22 \\
\hline 57 & 32.65 & 32 & 31.85 & 31.55 & 24.22 & 27.28 & 31.89 & 31.11 & 29.89 & 29.05 \\
\hline 58 & 32.5 & 31.9 & 31.65 & 31.3 & 24.17 & 27.17 & 31.72 & 30.94 & 29.78 & 28.75 \\
\hline 59 & 32.4 & 31.8 & 31.5 & 31.15 & 24.11 & 27.11 & 31.56 & 30.72 & 29.56 & 28.53 \\
\hline 60 & 32.25 & 31.65 & 31.3 & 31.05 & 24.06 & 27 & 31.39 & 30.56 & 29.39 & 28.31 \\
\hline 61 & 32.15 & 31.45 & 31.15 & 30.8 & 24 & 26.94 & 31.28 & 30.39 & 29.17 & 28.14 \\
\hline 62 & 32 & 31.35 & 31 & 30.65 & 23.94 & 26.94 & 31.11 & 30.22 & 29 & 27.92 \\
\hline 63 & 31.9 & 31.2 & 30.9 & 30.4 & 23.83 & 26.89 & 31 & 30.06 & 28.83 & 27.71 \\
\hline 64 & 31.75 & 31.05 & 30.75 & 30.3 & 23.83 & 26.78 & 30.83 & 29.89 & 28.67 & 27.58 \\
\hline 65 & 31.6 & 30.9 & 30.6 & 30.15 & 23.78 & 26.67 & 30.72 & 29.67 & 28.44 & 27.4 \\
\hline 66 & 31.45 & 30.8 & 30.5 & 30 & 23.72 & 26.61 & 30.56 & 29.56 & 28.33 & 27.18 \\
\hline 67 & 31.35 & 30.65 & 30.4 & 29.9 & 23.67 & 26.56 & 30.44 & 29.39 & 28.11 & 27.08 \\
\hline 68 & 31.15 & 30.55 & 30.25 & 29.75 & 23.61 & 26.5 & 30.33 & 29.28 & 27.94 & 26.86 \\
\hline 69 & 31.1 & 30.4 & 30.15 & 29.6 & 23.56 & 26.39 & 30.17 & 29.11 & 27.83 & 26.67 \\
\hline 70 & 30.95 & 30.3 & 30 & 29.45 & 23.5 & 26.33 & 30.06 & 28.94 & 27.67 & 26.58 \\
\hline 71 & 30.85 & 30.2 & 29.9 & 29.3 & 23.44 & 26.28 & 29.94 & 28.89 & 27.56 & 26.42 \\
\hline 72 & 30.75 & 30.05 & 29.8 & 29.2 & 23.44 & 26.22 & 29.83 & 28.72 & 27.39 & 26.22 \\
\hline 73 & 30.65 & 29.95 & 29.7 & 29 & 23.33 & 26.17 & 29.72 & 28.61 & 27.22 & 26.04 \\
\hline 74 & 30.5 & 29.75 & 29.5 & 28.9 & 23.33 & 26.11 & 29.61 & 28.44 & 27.11 & 25.87 \\
\hline 75 & 30.4 & 29.7 & 29.45 & 28.8 & 23.28 & 26.06 & 29.5 & 28.33 & 27 & 25.76 \\
\hline 76 & 30.3 & 29.6 & 29.35 & 28.7 & 23.22 & 26 & 29.39 & 28.22 & 26.83 & 25.66 \\
\hline 77 & 30.15 & 29.5 & 29.25 & 28.55 & 23.17 & 25.94 & 29.28 & 28.11 & 26.72 & 25.48 \\
\hline 78 & 30 & 29.4 & 29.15 & 28.45 & 23.17 & 25.89 & 29.17 & 28 & 26.61 & 25.37 \\
\hline 79 & 29.95 & 29.25 & 29 & 28.35 & 23.06 & 25.83 & 29.06 & 27.89 & 26.44 & 25.26 \\
\hline 80 & 29.85 & 29.15 & 28.95 & 28.25 & 23.06 & 25.83 & 29 & 27.72 & 26.39 & 25.04 \\
\hline 81 & 29.75 & 29.05 & 28.85 & 28.15 & 23 & 25.78 & 28.89 & 27.67 & 26.22 & 24.99 \\
\hline 82 & 29.65 & 28.95 & 28.75 & 28.05 & 23 & 25.72 & 28.78 & 27.56 & 26.17 & 24.88 \\
\hline 83 & 29.55 & 28.85 & 28.65 & 27.95 & 22.94 & 25.67 & 28.72 & 27.44 & 26 & 24.77 \\
\hline 84 & 29.45 & 28.75 & 28.55 & 27.85 & 22.94 & 25.61 & 28.61 & 27.33 & 25.89 & 24.65 \\
\hline 85 & 29.35 & 28.65 & 28.45 & 27.75 & 22.89 & 25.56 & 28.56 & 27.22 & 25.83 & 24.49 \\
\hline 86 & 29.25 & 28.6 & 28.35 & 27.7 & 22.83 & 25.56 & 28.44 & 27.11 & 25.67 & 24.43 \\
\hline 87 & 29.15 & 28.5 & 28.25 & 27.6 & 22.83 & 25.5 & 28.39 & 27.06 & 25.56 & 24.28 \\
\hline 88 & 29.05 & 28.4 & 28.15 & 27.5 & 22.78 & 25.44 & 28.22 & 26.94 & 25.5 & 24.16 \\
\hline 89 & 29 & 28.3 & 28.1 & 27.45 & 22.78 & 25.44 & 28.17 & 26.89 & 25.39 & 24.1 \\
\hline 90 & 28.85 & 28.2 & 27.95 & 27.4 & 22.72 & 25.39 & 28.06 & 26.78 & 25.28 & 23.99 \\
\hline 91 & 28.75 & 28.15 & 27.85 & 27.3 & 22.67 & 25.39 & 28 & 26.67 & 25.17 & 23.86 \\
\hline 92 & 28.65 & 28.1 & 27.75 & 27.2 & 22.67 & 25.33 & 27.94 & 26.61 & 25.11 & 23.77 \\
\hline 93 & 28.65 & 28 & 27.7 & 27.15 & 22.61 & 25.33 & 27.83 & 26.5 & 25 & 23.69 \\
\hline 94 & 28.5 & 27.9 & 27.6 & 27.05 & 22.61 & 25.28 & 27.78 & 26.44 & 24.94 & 23.59 \\
\hline 95 & 28.4 & 27.8 & 27.55 & 26.95 & 22.56 & 25.22 & 27.72 & 26.33 & 24.83 & 23.54 \\
\hline 96 & 28.3 & 27.75 & 27.4 & 26.95 & 22.56 & 25.22 & 27.61 & 26.28 & 24.78 & 23.43 \\
\hline 97 & 28.25 & 27.65 & 27.3 & 26.85 & 22.5 & 25.17 & 27.56 & 26.22 & 24.72 & 23.38 \\
\hline 98 & 28.15 & 27.55 & 27.25 & 26.75 & 22.5 & 25.17 & 27.5 & 26.11 & 24.61 & 23.32 \\
\hline 99 & 28.05 & 27.45 & 27.15 & 26.65 & 22.5 & 25.11 & 27.44 & 26.06 & 24.56 & 23.18 \\
\hline 100 & 27.95 & 27.45 & 27.1 & 26.6 & 22.44 & 25.06 & 27.39 & 26 & 24.44 & 23.06 \\
\hline
\end{tabular}


Table K-1. Continued...

\begin{tabular}{|c|c|c|c|c|c|c|c|c|c|c|}
\hline Time & $\begin{array}{c}\text { Quartzitte } \\
1\end{array}$ & $\begin{array}{c}\text { Quatzite } \\
\text { Quartzite }\end{array}$ & $\begin{array}{c}\text { Quartzite } \\
\text { Sandstone }\end{array}$ & $\begin{array}{c}\text { Sandstone } \\
4\end{array}$ & $\begin{array}{c}\text { Limestone } \\
1\end{array}$ & $\begin{array}{c}\text { Limestone } \\
2\end{array}$ & $\begin{array}{c}\text { Limestone } \\
3\end{array}$ & $\begin{array}{c}\text { Limestone } \\
4\end{array}$ \\
\hline 101 & 27.85 & 27.35 & 27 & 26.5 & 22.44 & 25.06 & 27.28 & 25.89 & 24.39 & 22.94 \\
\hline 102 & 27.8 & 27.3 & 26.95 & 26.45 & 22.39 & 25.06 & 27.22 & 25.78 & 24.33 & 22.86 \\
\hline 103 & 27.7 & 27.25 & 26.8 & 26.4 & 22.39 & 25 & 27.17 & 25.72 & 24.22 & 22.83 \\
\hline 104 & 27.65 & 27.15 & 26.75 & 26.25 & 22.39 & 25 & 27.11 & 25.67 & 24.17 & 22.72 \\
\hline 105 & 27.55 & 27.1 & 26.7 & 26.25 & 22.39 & 25 & 27.06 & 25.61 & 24.06 & 22.67 \\
\hline 106 & 27.45 & 27.05 & 26.6 & 26.15 & 22.33 & 24.94 & 26.94 & 25.56 & 24 & 22.58 \\
\hline 107 & 27.4 & 27 & 26.55 & 26.1 & 22.33 & 24.94 & 26.94 & 25.5 & 23.94 & 22.5 \\
\hline 108 & 27.35 & 26.95 & 26.55 & 26.05 & 22.33 & 24.89 & 26.89 & 25.44 & 23.89 & 22.44 \\
\hline 109 & 27.25 & 26.85 & 26.45 & 25.95 & 22.28 & 24.89 & 26.83 & 25.39 & 23.83 & 22.39 \\
\hline 110 & 27.2 & 26.8 & 26.4 & 25.85 & 22.28 & 24.89 & 26.78 & 25.33 & 23.78 & 22.31 \\
\hline 111 & 27.1 & 26.7 & 26.3 & 25.8 & 22.22 & 24.89 & 26.72 & 25.28 & 23.72 & 22.28 \\
\hline 112 & 27.1 & 26.65 & 26.3 & 25.7 & 22.22 & 24.83 & 26.67 & 25.22 & 23.61 & 22.22 \\
\hline 113 & 26.95 & 26.55 & 26.25 & 25.55 & 22.22 & 24.83 & 26.61 & 25.17 & 23.61 & 22.11 \\
\hline 114 & 26.9 & 26.5 & 26.2 & 25.55 & 22.17 & 24.78 & 26.56 & 25.11 & 23.56 & 22.09 \\
\hline 115 & 26.85 & 26.45 & 26.15 & 25.5 & 22.17 & 24.78 & 26.56 & 25.06 & 23.5 & 22.06 \\
\hline 116 & 26.8 & 26.35 & 26.1 & 25.45 & 22.17 & 24.78 & 26.5 & 25 & 23.44 & 22 \\
\hline 117 & 26.75 & 26.35 & 26.1 & 25.4 & 22.17 & 24.72 & 26.39 & 24.94 & 23.39 & 21.94 \\
\hline 118 & 26.7 & 26.3 & 26 & 25.35 & 22.11 & 24.78 & 26.33 & 24.94 & 23.33 & 21.88 \\
\hline 119 & 26.65 & 26.2 & 26 & 25.3 & 22.11 & 24.72 & 26.28 & 24.89 & 23.28 & 21.82 \\
\hline 120 & 26.65 & 26.15 & 25.95 & 25.25 & 22.11 & 24.72 & 26.22 & 24.83 & 23.22 & 21.77 \\
\hline
\end{tabular}

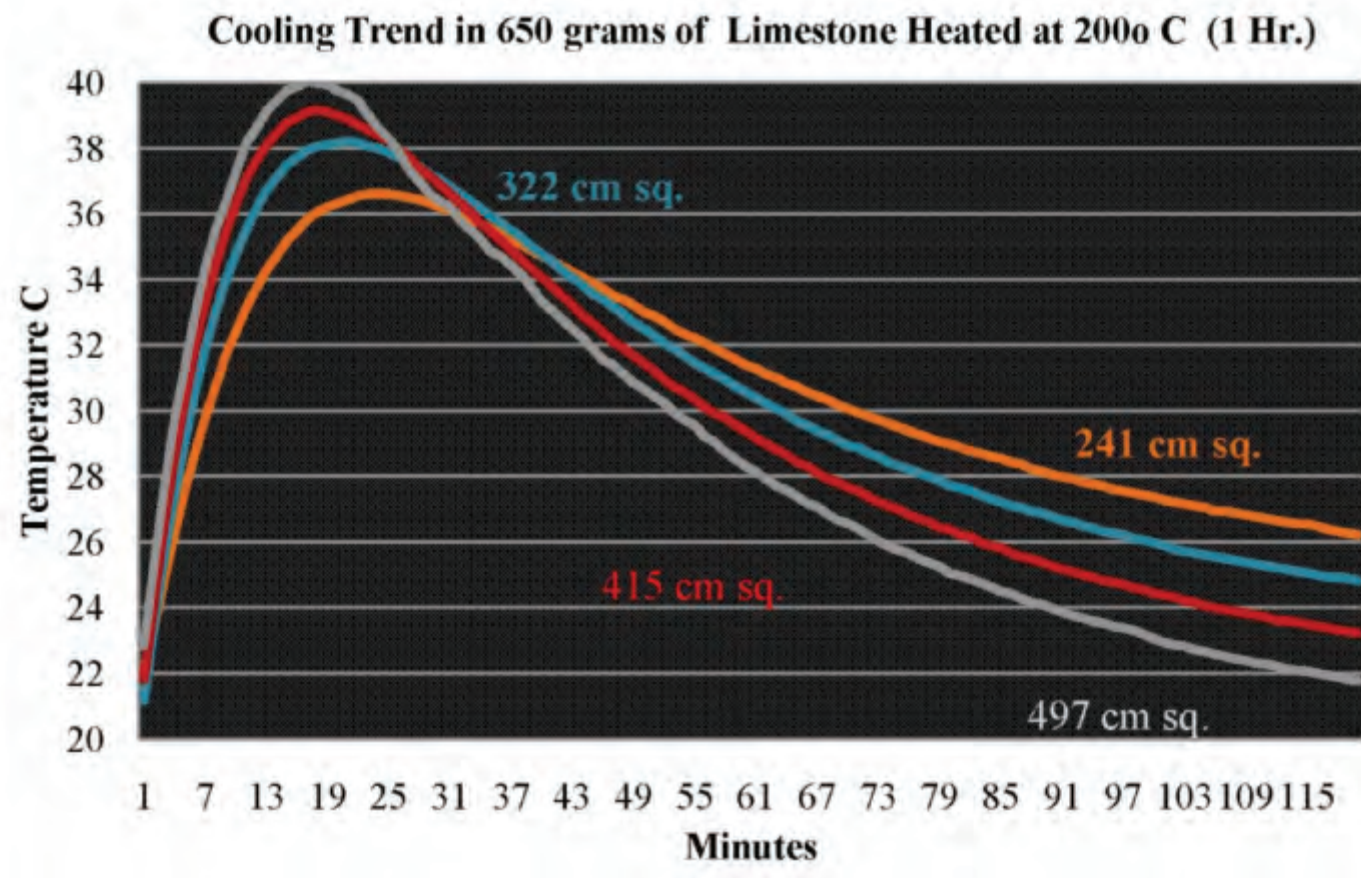

Figure K-2. Cooling trends following controlled heating of Onion Creek Limestone. 
between the pattern of heat dissipation and area. The limestone run with the largest surface area (497 sq. cm.- limestone 4 in Table K-1) has the highest peak temperature and that temperature occurs early in the 120 minute experiment. This item also has the lowest termination temperature. In contrast, the sample with the smallest surface area (241 sq cm- limestone 1 in Table K-1) has the lowest maximum temperature, that temperature occurs later in time, and that sample has the highest overall temperature after 120 minutes. Limestone runs 2 and 3 fall between these two extremes.

Figure K-3 provides a summary of similar data for controlled experiments in quartzite (see Table K-1, columns 2 through 5). Again, the weights are constant, but the surface area varies. While there are differences between the two materials, the overall relationships seen in Figure K-2 for limestone are also present in the quartzite data. The sample run with the smallest area has the lowest peak temperature, that temperature occurs late in time, and the termination temperature is highest. The sample run with the largest area (548 sq. cm.) has the highest maximum temperature, that temperature occurs earliest, and the termination temperature is lowest.

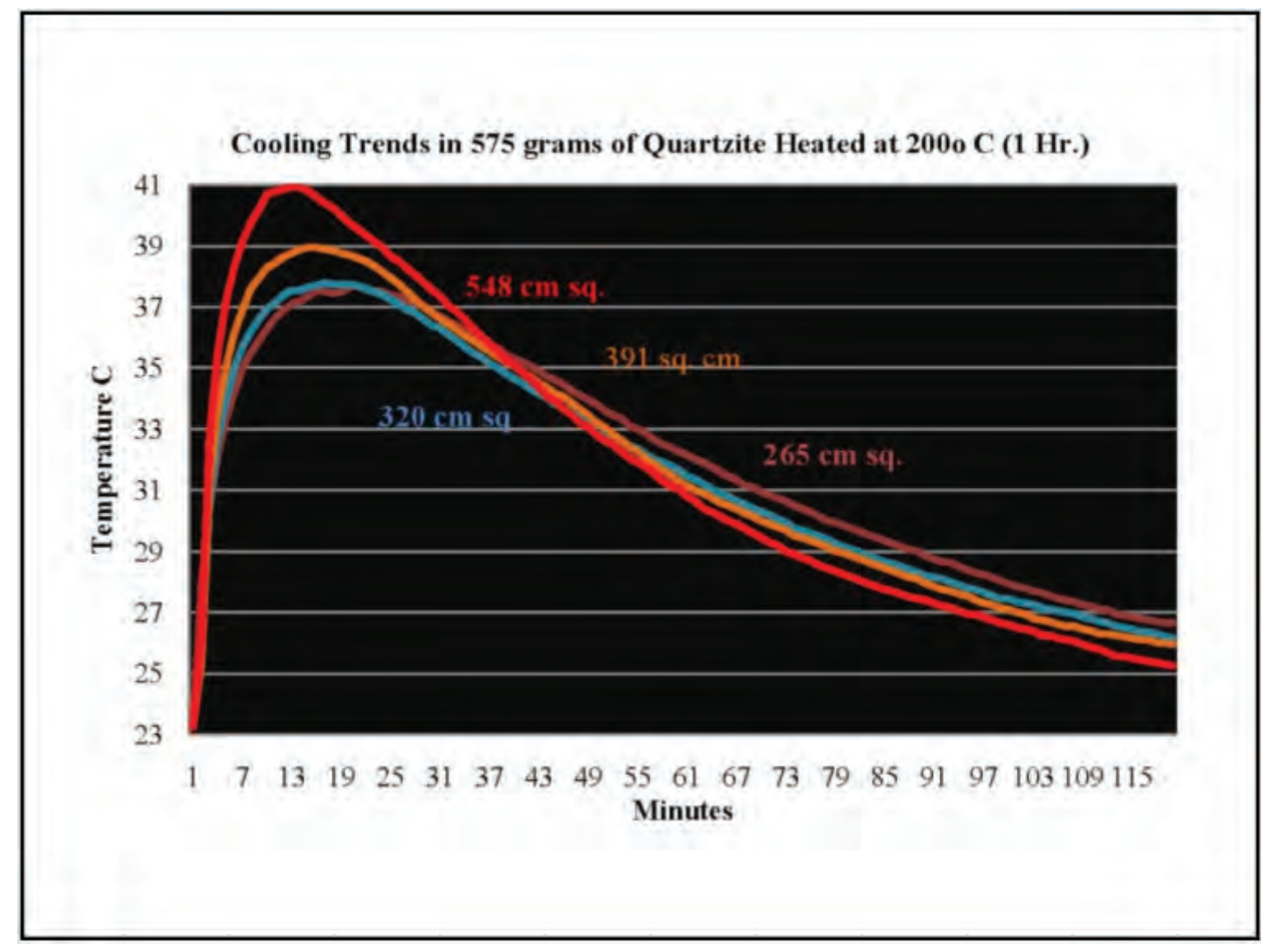

Figure K-3. Cooling trends following controlled heating of quartzite.

It appears that in both limestone and quartzite, when weight is held constant, smaller surface areas dissipate heat more slowly and maintain heat for a longer period of time. Conversely, when surface area increases, as would be the case with rock breakage, heat is dissipated more quickly. A related phenomena is that rocks with larger surface area for a given mass will take longer to heat relative to rocks with smaller surface areas.

Finally, Figure K-4 presents the results for two runs on sandstone. Here, weight varies, but surface area and shape are roughly constant (see Table K-1, columns 6, 7). Overall, temperatures are lower in sandstone relative to either quartzite or limestone. In addition, the denser, heavier piece of sandstone has significantly higher overall temperatures, and roughly similar patterns of heat dissipation. 




Figure K-4. Two runs on two different samples of sandstone with similar surface areas and different weights.

While additional work on the impacts of different raw materials is certainly needed, these experiments clearly demonstrate relationships between surface area, rock weight, heating, and heat dissipation that have implications for prehistoric rock use. If the goal in a given situation is to maintain relatively consistent heat for long periods (e.g., baking), then larger rock with low surface area to weight would be the most effective option. Conversely, if the goal is to dissipate heat rapidly (e.g., stone boiling), then we should anticipate the selection of smaller rock with higher surface area to weight relationships.

\section{Hearth Experiments with Onion Creek Limestone}

The second component of this investigation involved experimental hearths and differences in breakage patterns. Here we focused on a small number $(n=5)$ of limestone cobbles collected from Onion Creek directly across from 41TV410. These were photographed and the maximum size measured. They were then placed in an experimental feature with a known quantity of wood (20 wooden stakes of standard size and weight) and the fire was ignited. After the fire burned down, the rocks were allowed to cool in air for 24 hours. They were then removed, maximum size measured and, when necessary, photographed. This process was repeated for the maximum number of allowable events ( $\mathrm{n}=7)$.

Table K-2 provides the maximum size for each event. Fourteen columns are present, with the maximum rock size (cm) entered in columns 1, 3, 5, 7, 9, 11, and 13. Following each rock size is the associated event number. Five rocks are present before event one. There is no breakage following the initial two events. However, following event three, rocks began to fracture. Fracture appeared to primarily occur during cooling rather than during heating. Following event seven, there are 21 rocks present.

Figure K-5 shows the impact of repeated burnings on average rock size. Following event 2, there is a steady decrease in the average size of the rocks presents in the experimental feature. The weight of the rock is the same, but the surface area has increased substantially. 
Table K-2. Onion Creek Limestone Breakage Patterns

\begin{tabular}{|c|c|c|c|c|c|c|c|c|c|c|c|c|c|}
\hline $\begin{array}{c}\text { max } \\
\text { size }\end{array}$ & event & $\begin{array}{c}\text { max } \\
\text { size }\end{array}$ & event & $\begin{array}{c}\max \\
\text { size }\end{array}$ & event & $\begin{array}{c}\text { max } \\
\text { size }\end{array}$ & event & $\begin{array}{c}\max \\
\text { size }\end{array}$ & $\begin{array}{c}\text { max } \\
\text { size }\end{array}$ & $\begin{array}{c}\text { max } \\
\text { size }\end{array}$ & event \\
\hline 13.5 & 1 & 13.5 & 2 & 13.5 & 3 & 3.8 & 4 & 3.8 & 5 & 3.8 & 6 & 8.9 & 7 \\
\hline 13.8 & 1 & 13.8 & 2 & 13.8 & 3 & 9.5 & 4 & 9.5 & 5 & 9.5 & 6 & 3.8 & 7 \\
\hline 13.1 & 1 & 13.1 & 2 & 13.1 & 3 & 9.6 & 4 & 9.6 & 5 & 9.6 & 6 & 9.6 & 7 \\
\hline 12.1 & 1 & 12.1 & 2 & 11.9 & 3 & 9.5 & 4 & 7.6 & 5 & 7.6 & 6 & 3.9 & 7 \\
\hline 18.2 & 1 & 18.2 & 2 & 8.6 & 3 & 8.9 & 4 & 8.7 & 5 & 8.7 & 6 & 5.4 & 7 \\
\hline & & & & 12 & 3 & 8.1 & 4 & 8.9 & 5 & 8.9 & 6 & 6.6 & 7 \\
\hline & & & & 12.5 & 3 & 8.6 & 4 & 8.1 & 5 & 8.1 & 6 & 9.7 & 7 \\
\hline & & & & & & 12 & 4 & 8.6 & 5 & 8.6 & 6 & 9.6 & 7 \\
\hline & & & & & & 11.9 & 4 & 5.9 & 5 & 5.9 & 6 & 7.1 & 7 \\
\hline & & & & & & 13 & 4 & 9.5 & 5 & 9.5 & 6 & 8.9 & 7 \\
\hline & & & & & & 12.5 & 4 & 11.9 & 5 & 11.9 & 6 & 10 & 7 \\
\hline & & & & & & 9.5 & 4 & 13 & 5 & 10 & 6 & 5.9 & 7 \\
\hline & & & & & & & & 12.5 & 5 & 7.4 & 6 & 7.9 & 7 \\
\hline & & & & & & & & 9.5 & 5 & 12.5 & 6 & 12.5 & 7 \\
\hline & & & & & & & & 9 & 5 & 9.5 & 6 & 8.6 & 7 \\
\hline & & & & & & & & & & 9 & 6 & 8.1 & 7 \\
\hline & & & & & & & & & & & & 7.6 & 7 \\
\hline & & & & & & & & & & & & 8.7 & 7 \\
\hline & & & & & & & & & & & 7.4 & 7 \\
\hline & & & & & & & & & & & & 5.8 & 7 \\
\hline & & & & & & & & & & & & & \\
\hline
\end{tabular}



Figure K-5. Average rock size (cm) by event for Onion Creek Limestone. 
Given results in the previous section, the increase in surface area should have had a significant impact on temperature. However, while we have some temperature data, we did not consistently record temperature in these events. For temperature, we suspended the thermocouple over the fire once the flames had subsided. We were able to consistently record temperatures at 5 minute intervals between 60 and 180 minutes for events 1 through 6. Sometime during event 7 , however, we were in need of a new thermocouple. Figure K-6 presents these data, and contrasts the average sizes relative to the average temperatures.

Not surprisingly, the Figure K-5 pattern demonstrates that with repeated heating and cooling cycles, rocks break down into smaller and smaller pieces (see Black et al. 1997; Johnson 2000; Leach et al. 2001; Mauldin et al. 1998; Pagoulotus 2005). Given the patterns demonstrated previously in Figures K-2, K-3, and

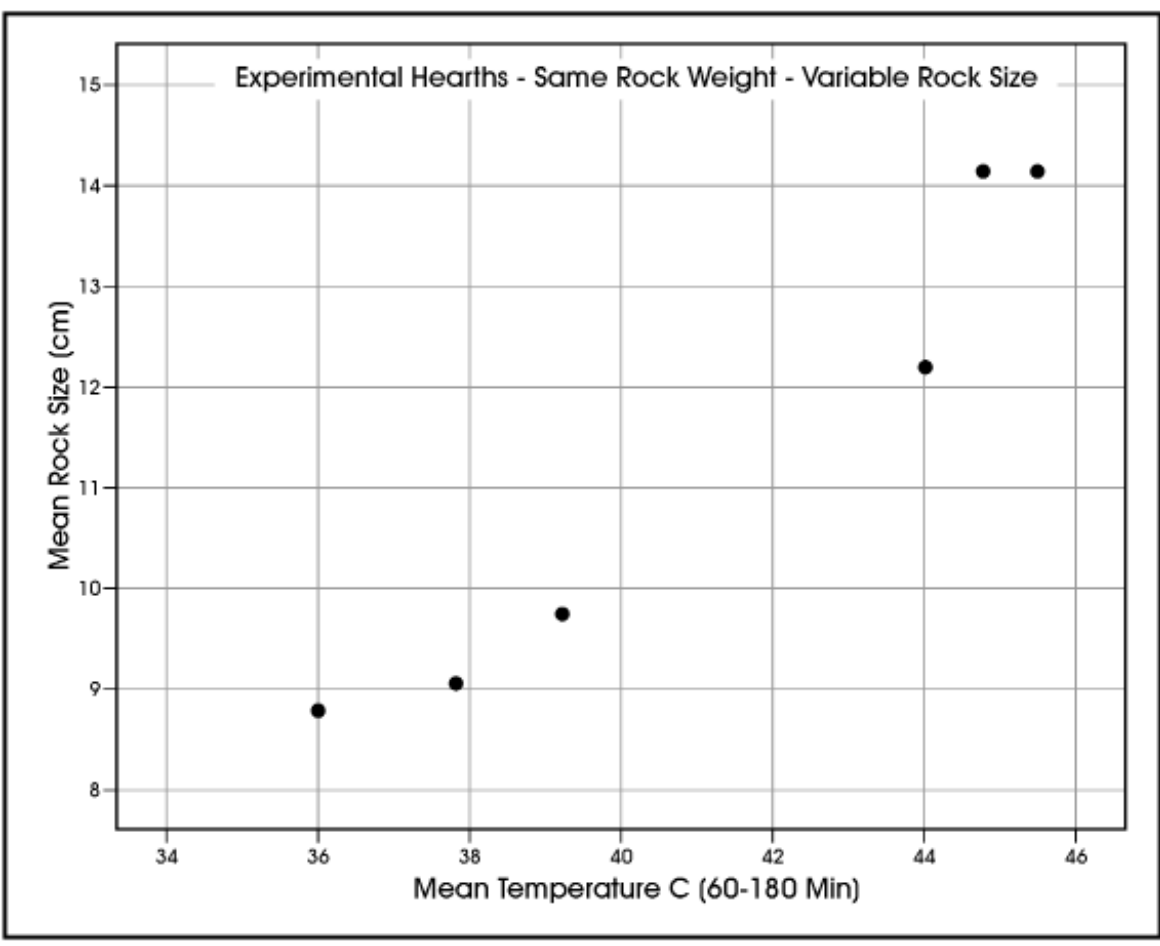

Figure K-6. Temperatures and average rock size above small onion creek limestone hearth. $\mathrm{K}-4$, these size reductions should affect temperatures, a pattern clearly demonstrated in Figure K-6. If the goal in a given situation is to maintain constant heat over time, then repeated use of the same feature will require the addition of new, larger rock.

\section{Temperature and Size patterns in Experimental Hearths with Onion Creek Limestone and Assorted Quartzite Cobbles}

The final set of experiments conducted under this task order involved attempts to control both temperature and rock size data in light of the results presented above. We conducted seven experimental burns with a mixture of Onion Creek Limestone and Quartzite Cobbles, measuring the size of the rocks prior to the initial burning event, and then following the $3^{\text {rd }}, 5^{\text {th }}$, and $7^{\text {th }}$ event. We recorded temperature using a K type thermocouple and thermometer described previously. Previous research with experimental hearths had suggested that there are two major problems that must be overcome to accurately measure temperature differences. The first involves variability in external conditions, including air temperature and wind. If the air temperature varies significantly over the period of investigation, then that will have a significant impact on the rate and pattern of heat dissipation. Similarly, wind can have a significant impact, resulting in very different heating characteristics. Secondly, the placement of the thermocouple can have a significant impact on the overall pattern. If the thermocouple happens to come in contact with a series of live coals, that will have a major impact (see Mauldin et al. 1998). We took several steps in an attempt to overcome these problems. First, during each experiment, we placed the end of the thermocouples in a small potato. This insulated the temperature probe from any direct contact with the coals, and also is somewhat analogous to the potential use of many burned rock features (see Black et al. 1997). Secondly, we covered the feature with sand to insulate it from outside air temperature. Again, the covering of features following burning is commonly suggested for burned rock features in Texas (see Black 2003 Black et al. 1997). In addition, wind conditions were monitored, with events only being initiated if wind was under $5 \mathrm{mph}$. This was primarily done for fire safety concerns, but did have the affect of reducing variability. Finally, in burn Events 1, 3, 5, and 7, we simultaneously measure the temperature on an adjacent hearth which was fired at the same time with the same amount of wood. However, that hearth lacked rock. This provided a direct measure of the impact of the rock on the overall temperature.

Figure K-7 provides a photograph of the experimental burn area, with the feature on the left containing a variety of limestone and quartzite, and the feature on the right containing no rock. Figure K-8 and K-9 shows the initial firing of these two features. 


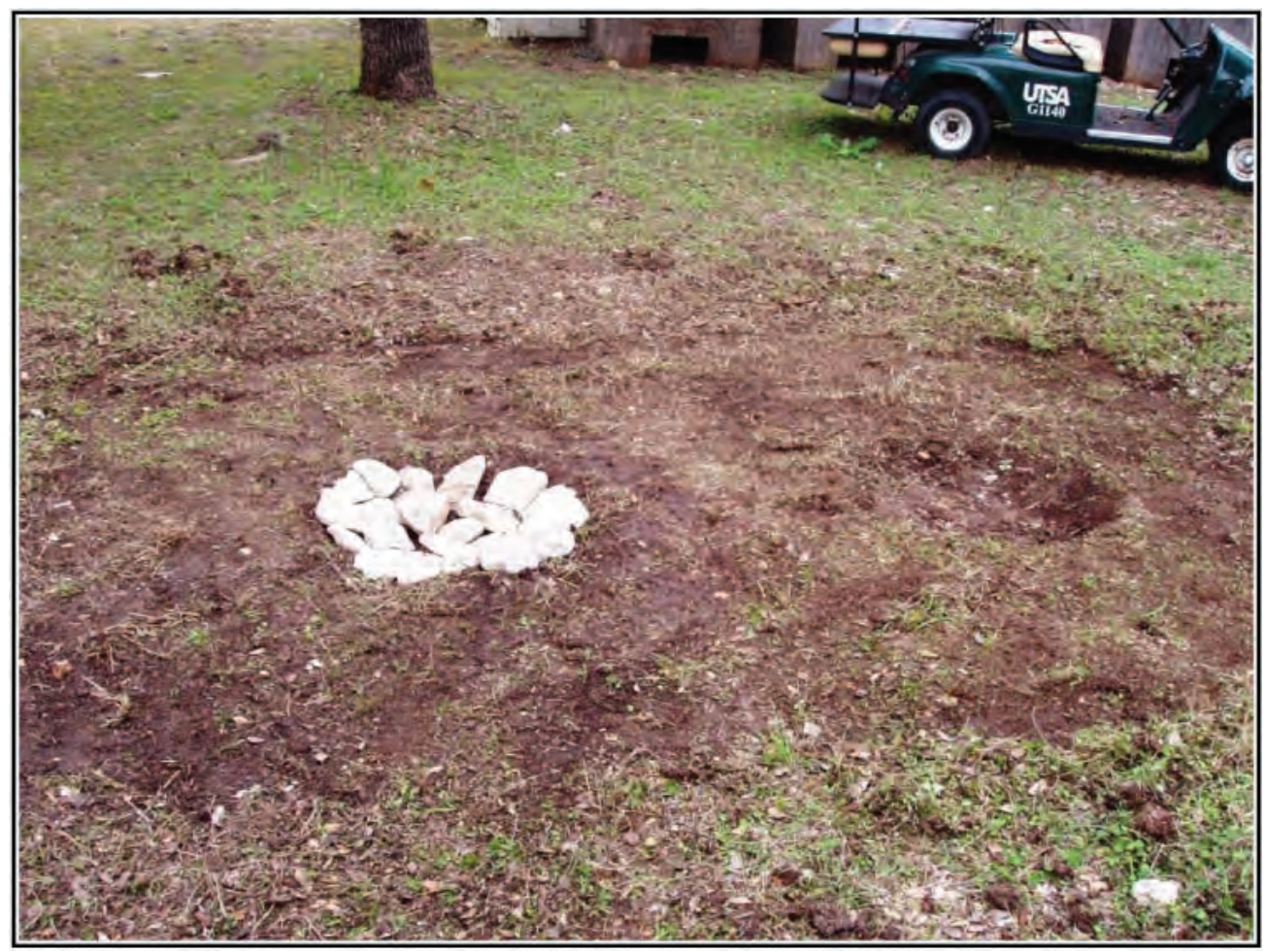

Figure K-7. Experimental hearth area- limestone and quartzite (left feature) and no rock (right feature).

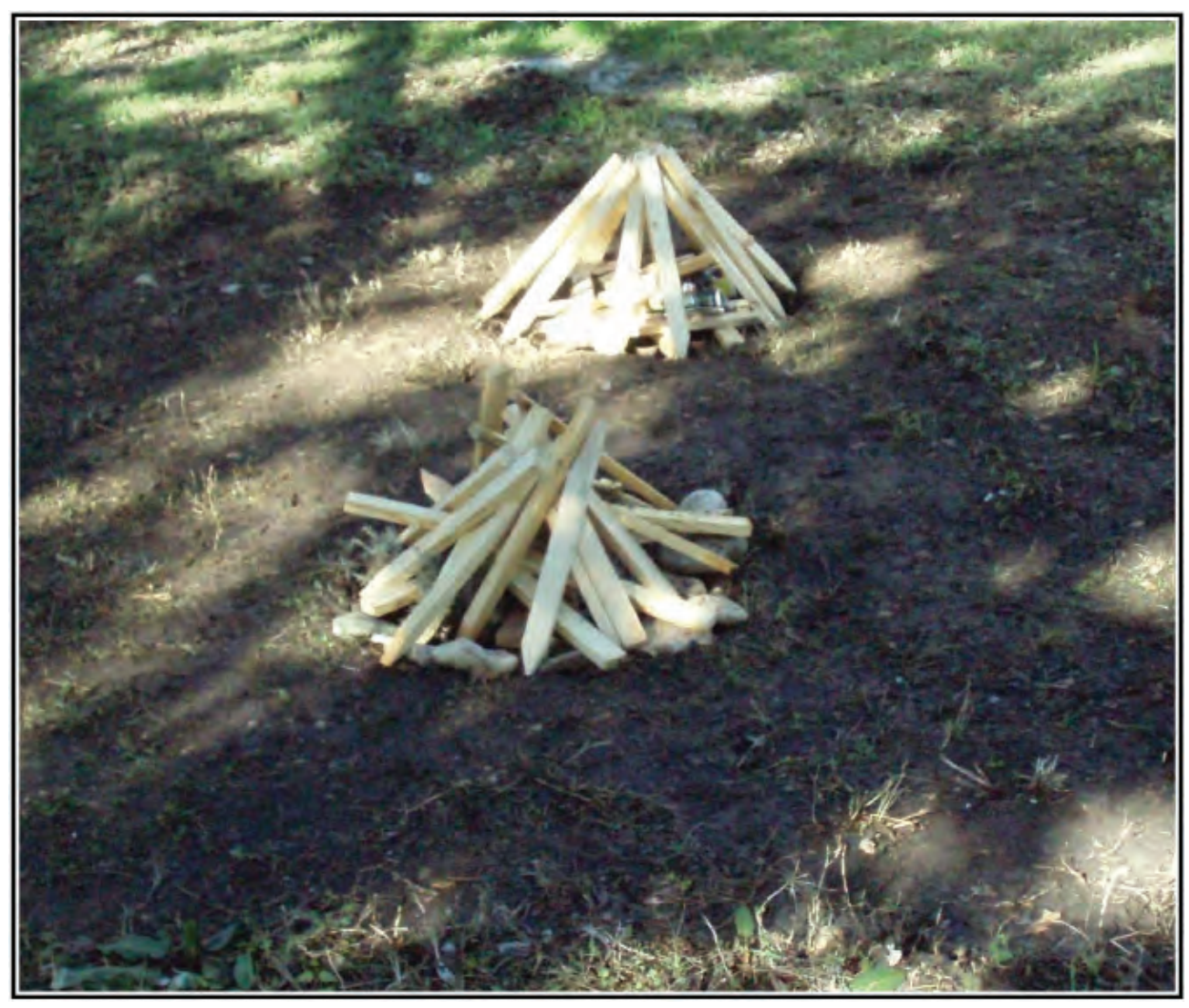

Figure K-8. Initial set up prior to ignition of the features. 


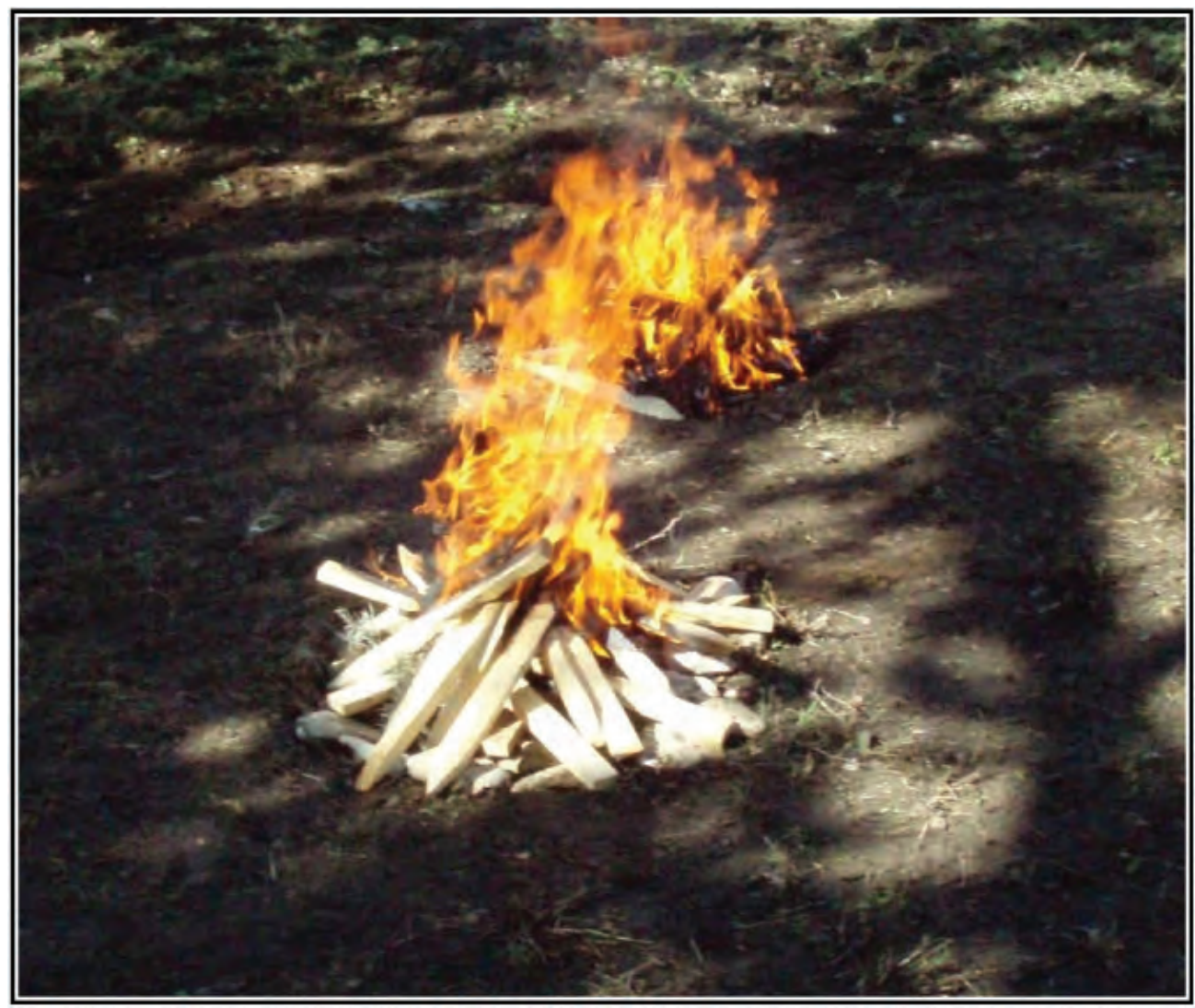

Figure K-9. Initial burning events of side by side features.

Following the initiation of the burn, the flames were allowed to consume the wooden survey stakes, which usually took less than 15 minutes. When no flame was visible in either hearth, the thermocouples inside the small potatoes were placed in the feature center and both features were covered with an equivalent amount of clean, dry sand. Temperatures were then recorded at five minute intervals in Fahrenheit for the next seven hours (see Figure K-10).

Table K-3 presents the temperature data for the seven events with rock and the four events without rock. Figure K-11 presents summary data on these patterns, with the rock data identified in red. Consideration of Figure K-11, and the Table K-3 data, will show that the temperatures in the hearth with rock generally peak higher temperature, peak later in time, and, with one exception, have higher overall terminal temperatures when compared to those features that lack rock. The single "exception" is event 5 (Table K-3). This event had a matching "no rock" burn event (Table K-3). While there is a 6.5 degree difference over the life of the event, with the rock feature averaging $96.1 \mathrm{~F}^{\circ}$ and the no-rock feature averaging $89.6 \mathrm{~F}^{\circ}$, and while the temperature of the rock feature at termination exceeds the no-rock counterpart, differences are minimal (Table K-3). While this particular event had different temperature dissipation patterns is unclear.

Table K-4 provides data on rock type and maximum length $(\mathrm{cm}$.) for the 23 rocks that made up the initial

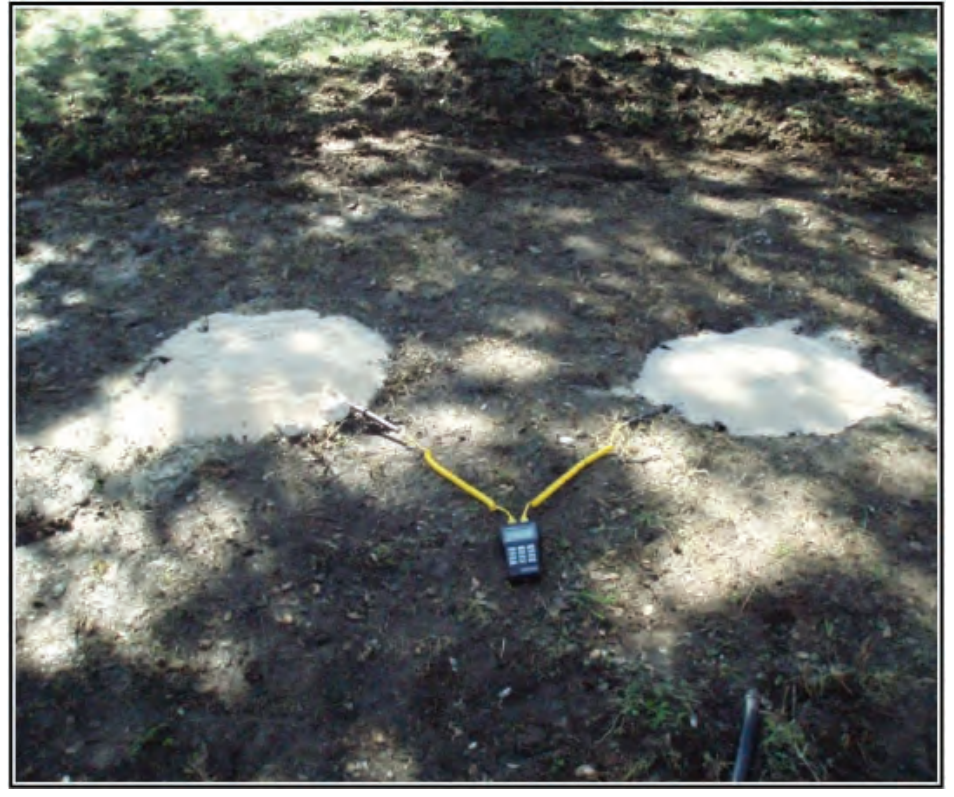

Figure K-10. Simultaneous recording of temperatures for Event 1. 
Table K-3. Experimental Hearth Temperatures-(Fahrenheit) with and without Rock

\begin{tabular}{|c|c|c|c|c|c|c|c|c|c|c|c|}
\hline Min. & $\begin{array}{c}\text { event } \\
1 \text { with } \\
\text { rock }\end{array}$ & $\begin{array}{c}\text { event } 1 \\
\text { without } \\
\text { rock }\end{array}$ & $\begin{array}{c}\text { event } \\
2 \text { with } \\
\text { rock }\end{array}$ & $\begin{array}{c}\text { event } \\
3 \text { with } \\
\text { rock }\end{array}$ & $\begin{array}{c}\text { event } 3 \\
\text { without } \\
\text { rock }\end{array}$ & $\begin{array}{c}\text { event } \\
4 \text { with } \\
\text { rock }\end{array}$ & $\begin{array}{c}\text { event } \\
5 \text { with } \\
\text { rock }\end{array}$ & $\begin{array}{c}\text { event } 5 \\
\text { without } \\
\text { rock }\end{array}$ & $\begin{array}{c}\text { event } 6 \\
\text { with rock }\end{array}$ & $\begin{array}{c}\text { event } \\
7 \text { with } \\
\text { rock }\end{array}$ & $\begin{array}{c}\text { event } 7 \\
\text { without } \\
\text { rock }\end{array}$ \\
\hline 5 & 70.5 & 70.6 & 55.9 & 55 & 55 & 81.8 & 59.1 & 57.3 & 44.4 & 66.2 & 67.5 \\
\hline 10 & 80.7 & 77.5 & 55.9 & 59.8 & 67.1 & 84.2 & 67.5 & 62.2 & 57.7 & 78.3 & 79.2 \\
\hline 15 & 87.1 & 77.9 & 54.9 & 66.5 & 82.6 & 90.5 & 84.1 & 84.1 & 65.9 & 93.2 & 98.4 \\
\hline 20 & 91.1 & 79.4 & 55.2 & 75.2 & 92.1 & 97.9 & 99.8 & 102.5 & 69.2 & 97.4 & 108.8 \\
\hline 25 & 96.3 & 82.2 & 56.1 & 85.1 & 98.3 & 105.3 & 110.4 & 114.5 & 81.3 & 110.9 & 116.3 \\
\hline 30 & 101.5 & 85.7 & 56.2 & 94.6 & 102.3 & 112.4 & 118.3 & 120.7 & 97.3 & 125.1 & 121.3 \\
\hline 35 & 106.8 & 88.4 & 61.1 & 103 & 103.5 & 118.9 & 123.9 & 122.1 & 111 & 137.8 & 124.6 \\
\hline 40 & 111 & 90.6 & 72.3 & 111.1 & 107.5 & 124.6 & 128.1 & 123.1 & 117.3 & 148.8 & 126.6 \\
\hline 45 & 114.8 & 92.8 & 83 & 117.5 & 109.5 & 129.6 & 131.2 & 123.4 & 124.1 & 156.9 & 127.3 \\
\hline 50 & 118 & 94 & 90.9 & 122.4 & 110.2 & 133.6 & 133.6 & 123.6 & 129.4 & 163 & 127.4 \\
\hline 55 & 121.3 & 95.6 & 96.3 & 125.5 & 110.6 & 137 & 134.7 & 123 & 134 & 167.5 & 127.1 \\
\hline 60 & 123.4 & 96.4 & 100.4 & 127.9 & 110.7 & 139.7 & 135 & 120.8 & 138.5 & 171.1 & 126.5 \\
\hline 65 & 125.2 & 97.3 & 103.6 & 129.6 & 111 & 142 & 134.9 & 120.5 & 142.3 & 172 & 125.7 \\
\hline 70 & 126.3 & 97.7 & 106.3 & 130.7 & 110.8 & 143.6 & 134.5 & 119.5 & 145.8 & 173 & 124.6 \\
\hline 75 & 127.7 & 97.9 & 109.4 & 131.2 & 110.5 & 144.9 & 133.6 & 118.3 & 148.9 & 173.5 & 123.7 \\
\hline 80 & 127.2 & 98.2 & 111.1 & 131.7 & 110.3 & 145.9 & 132.3 & 117.1 & 151 & 173.8 & 122.8 \\
\hline 85 & 127 & 99 & 112.6 & 131.5 & 109.8 & 146.5 & 131.5 & 115.8 & 152.5 & 174.4 & 121.7 \\
\hline 90 & 127.2 & 98.6 & 113.8 & 131.4 & 109.2 & 146.8 & 130 & 114.4 & 153.4 & 174.9 & 120.7 \\
\hline 95 & 127.9 & 98.7 & 114.9 & 130.9 & 108.5 & 147.1 & 128.4 & 113.1 & 153.9 & 174.8 & 119.2 \\
\hline 100 & 127.9 & 98.5 & 115.8 & 130.5 & 107.9 & 147.1 & 126.8 & 111.7 & 154.2 & 174.4 & 117.9 \\
\hline 105 & 128.3 & 98.6 & 116.4 & 129.7 & 107.3 & 147.1 & 125.1 & 110.4 & 154.2 & 173.8 & 116.9 \\
\hline 110 & 128.8 & 99.5 & 116.8 & 129.6 & 106.6 & 146.8 & 123.6 & 109.2 & 153.1 & 172.7 & 115.6 \\
\hline 115 & 128.3 & 98.9 & 117.2 & 127.9 & 105.9 & 146.5 & 121.5 & 108.1 & 152.7 & 172.3 & 115 \\
\hline 120 & 127.6 & 98.1 & 117.3 & 127.2 & 105.4 & 146.1 & 119.9 & 106.8 & 152.1 & 172 & 114.2 \\
\hline 125 & 127.1 & 97.4 & 117.4 & 126.4 & 104.8 & 145.6 & 118.1 & 105.7 & 151.4 & 170.6 & 112.6 \\
\hline 130 & 126.4 & 96.8 & 117.3 & 125.4 & 104 & 145.1 & 116.5 & 104.5 & 150.7 & 168.9 & 111.1 \\
\hline 135 & 125.7 & 96.2 & 117.3 & 124.4 & 103.4 & 144.5 & 114.8 & 103.3 & 149.8 & 167.4 & 110.2 \\
\hline 140 & 125 & 96 & 117 & 123.6 & 102.9 & 143.8 & 113.1 & 102.2 & 148.9 & 166.5 & 109.4 \\
\hline 145 & 124.3 & 95.4 & 116.5 & 122.8 & 102.4 & 143.1 & 111.7 & 101.3 & 147.9 & 165.5 & 108.2 \\
\hline 150 & 123.5 & 95 & 115.7 & 121.8 & 101.6 & 142.4 & 110.1 & 100.1 & 146.9 & 163.9 & 106.4 \\
\hline 155 & 122.9 & 94.4 & 115.1 & 120.7 & 100.9 & 141.6 & 108.6 & 99 & 145.8 & 162.6 & 105.6 \\
\hline 160 & 122.2 & 94 & 114.5 & 119.9 & 100.2 & 140.8 & 106.8 & 97.8 & 144.8 & 161.4 & 105.2 \\
\hline 165 & 121.2 & 93.4 & 113.9 & 119 & 99.4 & 140 & 105.2 & 97.1 & 143.7 & 160 & 104.2 \\
\hline 170 & 120.4 & 92.8 & 113.5 & 118.4 & 98.8 & 139.3 & 103.8 & 96.1 & 142.6 & 158.5 & 102.9 \\
\hline 175 & 119.6 & 92.4 & 113.1 & 117.9 & 98 & 138.5 & 102.5 & 95 & 141.6 & 157.1 & 101.6 \\
\hline 180 & 118.9 & 93.6 & 111.4 & 116.9 & 97.3 & 137.7 & 101.1 & 94 & 140.4 & 155.7 & 99.6 \\
\hline 185 & 117.9 & 91 & 111.5 & 116.1 & 96.6 & 137 & 100 & 93 & 139.3 & 154 & 98.5 \\
\hline 190 & 117.2 & 90.5 & 110.6 & 115.2 & 96 & 136.1 & 98.9 & 92.1 & 138.3 & 152.8 & 98.7 \\
\hline 195 & 116.5 & 90 & 109.6 & 114.3 & 95.3 & 135.3 & 97.9 & 91.1 & 137.2 & 151.1 & 97.9 \\
\hline 200 & 115.9 & 89.5 & 108.6 & 113.5 & 94.8 & 134.4 & 96.8 & 90.2 & 136.1 & 148.8 & 95.7 \\
\hline 205 & 115.3 & 89.3 & 107.7 & 112.5 & 94.1 & 133.7 & 95.7 & 89.2 & 135 & 146.8 & 95.4 \\
\hline 210 & 115 & 89.5 & 106.9 & 111.6 & 93.5 & 132.8 & 94.4 & 88.2 & 133.9 & 144.9 & 94.9 \\
\hline 215 & 114.5 & 89.5 & 106 & 110.7 & 93 & 132.2 & 93.4 & 87.4 & 132.8 & 143.5 & 94.1 \\
\hline 220 & 113.9 & 89.1 & 104.1 & 109.8 & 92.4 & 131.5 & 92.4 & 86.6 & 131.7 & 141.8 & 92.3 \\
\hline 225 & 113.2 & 88.7 & 104.2 & 109 & 91.8 & 130.7 & 91.6 & 85.8 & 130.5 & 140.1 & 91.7 \\
\hline 230 & 112.3 & 88.2 & 103.3 & 108.2 & 91.4 & 130 & 90.6 & 84.9 & 129.4 & 139.1 & 91.2 \\
\hline 235 & 111.5 & 87.6 & 102.5 & 107.4 & 90.8 & 129.2 & 89.6 & 84 & 128.2 & 137.6 & 90.3 \\
\hline 240 & 110.4 & 87 & 101.8 & 106.5 & 90.4 & 128.4 & 88.6 & 83.2 & 127.1 & 135.8 & 89.4 \\
\hline 245 & 109.4 & 86 & 101.1 & 105.39 & 89.8 & 127.6 & 87.7 & 82.5 & 126 & 134.2 & 88.3 \\
\hline 250 & 108.4 & 85.4 & 99.9 & 105.1 & 88.9 & 126.9 & 86.7 & 81.5 & 124.9 & 133 & 87.3 \\
\hline
\end{tabular}


Table K-3. Continued...

\begin{tabular}{|c|c|c|c|c|c|c|c|c|c|c|c|}
\hline Min. & $\begin{array}{c}\text { event } \\
1 \text { with } \\
\text { rock }\end{array}$ & $\begin{array}{c}\text { event } 1 \\
\text { without } \\
\text { rock }\end{array}$ & $\begin{array}{l}\text { event } \\
2 \text { with } \\
\text { rock }\end{array}$ & $\begin{array}{c}\text { event } \\
3 \text { with } \\
\text { rock }\end{array}$ & $\begin{array}{c}\text { event } 3 \\
\text { without } \\
\text { rock }\end{array}$ & $\begin{array}{l}\text { event } \\
4 \text { with } \\
\text { rock }\end{array}$ & $\begin{array}{l}\text { event } \\
5 \text { with } \\
\text { rock }\end{array}$ & $\begin{array}{c}\text { event 5 } \\
\text { without } \\
\text { rock }\end{array}$ & $\begin{array}{c}\text { event } 6 \\
\text { with rock }\end{array}$ & $\begin{array}{l}\text { event } \\
7 \text { with } \\
\text { rock }\end{array}$ & $\begin{array}{c}\text { event } 7 \\
\text { without } \\
\text { rock }\end{array}$ \\
\hline 255 & 107.3 & 84.8 & 99.6 & 104.4 & 88.3 & 126.1 & 85.9 & 80.8 & 123.8 & 131.4 & 86.7 \\
\hline 260 & 106.3 & 84 & 98.9 & 103.7 & 87.8 & 125.3 & 85.2 & 80 & 122.7 & 129.8 & 86.2 \\
\hline 265 & 105.4 & 83.3 & 98.2 & 103.1 & 87.5 & 124.6 & 84.5 & 79.5 & 121.6 & 128.2 & 85.6 \\
\hline 270 & 104.4 & 82.7 & 97.5 & 102.4 & 87.1 & 123.8 & 83.8 & 78.8 & 120.5 & 126.6 & 84.6 \\
\hline 275 & 103.4 & 81.9 & 96.9 & 101.9 & 86.8 & 123 & 83.2 & 78.2 & 119.5 & 125.2 & 83.9 \\
\hline 280 & 102.6 & 81.3 & 96.2 & 101.3 & 86.6 & 122.3 & 82.4 & 77.6 & 118.3 & 123.9 & 83.3 \\
\hline 285 & 101.6 & 80.9 & 95.6 & 100.9 & 86.3 & 121.5 & 81.6 & 76.9 & 117.2 & 122.7 & 82.5 \\
\hline 290 & 100.7 & 80.3 & 95.1 & 99.9 & 86 & 120.7 & 81 & 76.3 & 116.1 & 121.4 & 82 \\
\hline 295 & 99.7 & 79.7 & 94.5 & 99.2 & 85.4 & 120 & 80.4 & 75.8 & 115.1 & 120.1 & 80.8 \\
\hline 300 & 98.9 & 79 & 93.9 & 98.5 & 84.9 & 119.2 & 80 & 75.2 & 114.2 & 118.7 & 80.7 \\
\hline 305 & 98 & 78.4 & 92.8 & 97.7 & 84.5 & 118.3 & 79.6 & 74.9 & 113.2 & 117.2 & 80.1 \\
\hline 310 & 97.3 & 78 & 91.7 & 97.2 & 84.1 & 117.6 & 79 & 74.5 & 112.2 & 115.6 & 79.4 \\
\hline 315 & 96.3 & 77.2 & 91.2 & 96.5 & 83.7 & 116.9 & 78.5 & 74 & 111.3 & 114 & 78.8 \\
\hline 320 & 95.7 & 76.8 & 90.8 & 95.9 & 83.3 & 116.2 & 77.7 & 73.4 & 110.2 & 112.4 & 78.2 \\
\hline 325 & 94.7 & 76.2 & 90.4 & 95.3 & 82.9 & 115.5 & 77.1 & 71.9 & 109.1 & 111.1 & 77.8 \\
\hline 330 & 93.7 & 75.7 & 89.5 & 94.6 & 82.5 & 114.7 & 76.4 & 71.5 & 108.1 & 109.5 & 77.1 \\
\hline 335 & 92.9 & 74.2 & 89.8 & 93.9 & 82.1 & 113.9 & 75.7 & 71.1 & 107 & 108.1 & 76.6 \\
\hline 340 & 92.4 & 74.6 & 89.2 & 93.2 & 81.8 & 112.9 & 75 & 70.7 & 106.1 & 106.9 & 76 \\
\hline 345 & 91.5 & 74.2 & 88.7 & 92.6 & 81.3 & 112.1 & 74.3 & 70.3 & 105.1 & 105.8 & 76.1 \\
\hline 350 & 90.8 & 73.6 & 88.5 & 92.1 & 81 & 111.3 & 73.8 & 70 & 104.1 & 104.7 & 75.6 \\
\hline 355 & 90 & 73 & 88.5 & 91.5 & 80.6 & 110.4 & 73.3 & 69.7 & 103.1 & 103.5 & 75.1 \\
\hline 360 & 89.3 & 72.6 & 88.4 & 90.9 & 80.2 & 109.8 & 72.8 & 69.5 & 102.2 & 102.2 & 74.4 \\
\hline 365 & 88.5 & 72.3 & 87.9 & 90.6 & 80 & 108.8 & 72.3 & 69.3 & 101.2 & 101 & 73.8 \\
\hline 370 & 87.8 & 71.4 & 87.3 & 90.3 & 79.8 & 108.1 & 71.9 & 69.2 & 100.3 & 99.9 & 73.2 \\
\hline 375 & 86.9 & 71.2 & 86.8 & 89.8 & 79.4 & 107.3 & 71.5 & 69.1 & 99.5 & 98.7 & 72.7 \\
\hline 380 & 86.3 & 70.7 & 86.5 & 89.6 & 79.4 & 106.5 & 71.1 & 69 & 98.6 & 97.7 & 72.2 \\
\hline 385 & 85.8 & 70.4 & 86.3 & 89.2 & 79.3 & 106.3 & 70.7 & 69 & 97.6 & 96.6 & 71.7 \\
\hline 390 & 84.9 & 70 & 86.5 & 88.9 & 79.1 & 105.8 & 70.3 & 69 & 96.7 & 95.9 & 71 \\
\hline 395 & 84.4 & 69.4 & 85.9 & 88.5 & 78.8 & 105.2 & 70.3 & 69 & 95.7 & 95 & 70.2 \\
\hline 400 & 83.6 & 69 & 85.4 & 87.8 & 78.2 & 104.2 & 70.2 & 69 & 94.7 & 93.9 & 70.1 \\
\hline 405 & 82.9 & 68.5 & 84.4 & 87.1 & 77.7 & 103.3 & 70.2 & 69 & 93.8 & 92.8 & 70 \\
\hline 410 & 82.4 & 68.1 & 84.2 & 86.4 & 77.3 & 102.8 & 70.2 & 69 & 92.8 & 91.6 & 69.8 \\
\hline 415 & 81.6 & 67.7 & 84.2 & 85.8 & 77 & 102.1 & 70.1 & 69 & 91.9 & 90.5 & 69.4 \\
\hline 420 & 80.9 & 67.1 & 84.1 & 84.7 & 76.9 & 101.3 & 70 & 69 & 90.9 & 89.3 & 69 \\
\hline average & 107.0167 & 85.10714 & 96.7774 & 106.11 & 92.4131 & 125.1417 & 96.1238 & 89.609524 & 121.7083 & 134.063 & 95.075 \\
\hline
\end{tabular}

burn. Rocks were numbered in an attempt to track individual rocks. Overall, the average maximum rock size prior to the first burn was $14.83 \mathrm{~cm}$. Table K-5 presents the patterns after the third, fifth, and seventh burn. When possible, the original rock number listed in Table K-4 is maintained. However, with each burn event, it became increasingly difficult to link specific rocks with spalls. In those cases where we were not confident of the rock assignment, we listed the rock number as " 0 ", and recorded the maximum size. If rock spalls were under $3 \mathrm{~cm}$ in length, we did not record them. Note that at the bottom of Table K-5, the average rock size for that feature is provided. After 3 events, the initial average of $14.83 \mathrm{~cm}$ has been reduced to 9.59 . By 7 events, the size is $7.88 \mathrm{~cm}$.

The final experiment involved the comparison of two features, both fired with the same amount of wood and at the same time. Here, however, we varied the quantity of rock. Our primary interest is on the impact of the amount of rock on temperature dissipation following the point at which the flames died down and the hearths were covered with sand, rather than on breakage as such given that this was only a single event. Table K-6 present the weight, number of rock, and overall maximum size of rock in the two features, with the first feature listed in the top portion of the table, and the second feature listed in the bottom portion of the table. Figure K-12 present the temperature patterns of the two features. Table K-7 presents these raw temperature 


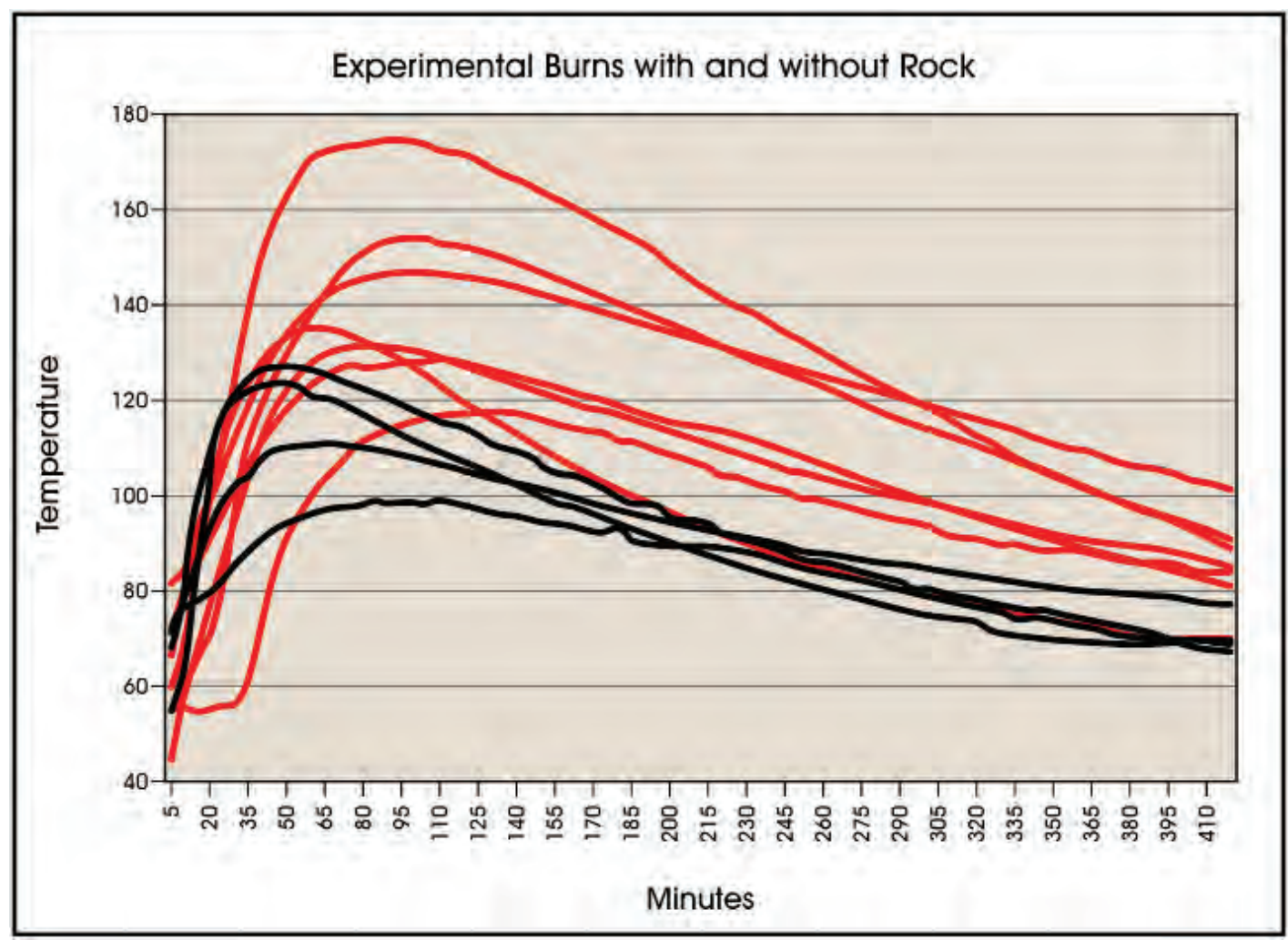

Figure K-11. Temperature patterns with (RED) and without (BLACK) rock for experimental burnings.

Table K-4. Rock size and Type Prior to Burning Events

\begin{tabular}{|c|c|c|}
\hline rock \# & length cm & type \\
\hline 6 & 15.5 & quartzite \\
\hline 13 & 15.5 & limestone \\
\hline 49 & 11.5 & limestone \\
\hline 56 & 10.5 & quartzite \\
\hline 58 & 11.5 & limestone \\
\hline 60 & 16.5 & limestone \\
\hline 61 & 14.5 & limestone \\
\hline 62 & 14.5 & quartzite \\
\hline 64 & 16 & limestone \\
\hline 69 & 14 & limestone \\
\hline 70 & 14.5 & limestone \\
\hline 74 & 12.5 & limestone \\
\hline 76 & 14.5 & limestone \\
\hline 77 & 16.5 & limestone \\
\hline 78 & 19.5 & limestone \\
\hline 79 & 12 & limestone \\
\hline 82 & 13.5 & limestone \\
\hline 83 & 19 & quartzite \\
\hline 84 & 14.5 & limestone \\
\hline 85 & 18 & limestone \\
\hline 86 & 16 & quartzite \\
\hline 87 & 16.5 & limestone \\
\hline 90 & 14 & quartzite \\
\hline
\end{tabular}

Table K-5. Rock Size Data for Events 3, 5, and 7

\begin{tabular}{|c|c|c|c|c|c|}
\hline \multicolumn{2}{|c|}{ After 3 Events } & \multicolumn{2}{c|}{ After 5 Events } & \multicolumn{2}{c|}{ After 7 Events } \\
\hline Rock \# & Size cm. & Rock \# & Size cm. & Rock \# & Size cm. \\
\hline 6.0 & 15.5 & 6 & 15.5 & 6 & 15.5 \\
\hline 13.0 & 15.5 & 13 & 15.5 & 13 & 15.5 \\
\hline 49.0 & 11.5 & 49 & 11.5 & 49 & 11.5 \\
\hline 56.0 & 10.5 & 56 & 10.5 & 56 & 10.5 \\
\hline 58.0 & 11.5 & 58 & 11.5 & 61 & 14.5 \\
\hline 61.0 & 14.5 & 61 & 14.5 & 62 & 14.5 \\
\hline 62.0 & 14.5 & 62 & 14.5 & 70 & 14.5 \\
\hline 64.0 & 16 & 64 & 16 & 74 & 12.5 \\
\hline 69.0 & 14 & 70 & 14.5 & 76 & 14.5 \\
\hline 70.0 & 14.5 & 74 & 12.5 & 77 & 16.5 \\
\hline 74.0 & 12.5 & 76 & 14.5 & 82 & 13.5 \\
\hline 76.0 & 14.5 & 77 & 16.5 & 84 & 14.5 \\
\hline 77.0 & 16.5 & 78 & 19.5 & 85 & 18 \\
\hline 78.0 & 19.5 & 82 & 13.5 & 86 & 16 \\
\hline 79.0 & 12 & 84 & 14.5 & 0 & 3.5 \\
\hline 82.0 & 13.5 & 85 & 18 & 0 & 4 \\
\hline 84.0 & 14.5 & 86 & 16 & 0 & 3.5 \\
\hline 85.0 & 18 & 87.1 & 16 & 0 & 3.5 \\
\hline 86.0 & 16 & 87.2 & 6.5 & 0 & 4 \\
\hline 60.1 & 16 & 69.1 & 11.5 & 0 & 3 \\
\hline 60.2 & 10.5 & 69.2 & 7 & 0 & 3 \\
\hline 87.1 & 16 & 79.1 & 9.5 & 0 & 3 \\
\hline 87.2 & 6.5 & 79.2 & 10 & 0 & 3.5 \\
\hline
\end{tabular}


Table K-5. Continued...

\begin{tabular}{|c|c|c|c|c|c|}
\hline \multicolumn{2}{|c|}{ After 3 Events } & \multicolumn{2}{|c|}{ After 5 Events } & \multicolumn{2}{|c|}{ After 7 Events } \\
\hline Rock \# & Size $\mathrm{cm}$. & Rock \# & Size $\mathbf{c m}$. & Rock \# & Size $\mathrm{cm}$. \\
\hline 83.1 & 14.5 & 79.3 & 11.5 & 0 & 3.5 \\
\hline 83.2 & 12.5 & 60.1 & 6 & 0 & 3 \\
\hline 83.3 & 9.5 & 60.2 & 10.5 & 0 & 3.5 \\
\hline 83.4 & 9.5 & 60.3 & 10.5 & 0 & 3.5 \\
\hline 83.5 & 7.5 & 60.4 & 11 & 0 & 3 \\
\hline 83.6 & 6.5 & 60.5 & 11 & 0 & 3 \\
\hline 83.7 & 3.5 & 90 & 9.5 & 0 & 3 \\
\hline 83.8 & 3.5 & 83 & 14.5 & 0 & 3.5 \\
\hline 83.9 & 3.5 & 0 & 9.5 & 0 & 3 \\
\hline 90.1 & 11.5 & 0 & 9 & 0 & 3 \\
\hline 90.1 & 6.5 & 0 & 7 & 0 & 3 \\
\hline 90.1 & 7.5 & 0 & 6.5 & 0 & 3.5 \\
\hline 90.1 & 5.5 & 0 & 6.5 & 0 & 6.5 \\
\hline 90.1 & 6.5 & 0 & 6 & 0 & 4.5 \\
\hline 90.1 & 3.5 & 0 & 5 & 0 & 4.5 \\
\hline 90.1 & 4.5 & 0 & 4.5 & 0 & 3.5 \\
\hline 90.1 & 4.5 & 0 & 2.5 & 0 & 3.5 \\
\hline 83.1 & 3 & 0 & 3 & 0 & 4 \\
\hline 90.1 & 4.5 & 0 & 4.5 & 0 & 4.5 \\
\hline 90.1 & 4 & 0 & 3.5 & 0 & 4.5 \\
\hline 90.1 & 3.5 & 0 & 4 & 0 & 6 \\
\hline 90.1 & 3.5 & 0 & 3 & 0 & 5 \\
\hline 90.1 & 3.5 & 0 & 3 & 0 & 6.5 \\
\hline 90.1 & 3.5 & 0 & 3 & 0 & 4.5 \\
\hline 90.1 & 3.5 & 0 & 4.5 & 0 & 6.5 \\
\hline 90.1 & 3 & 0 & 6 & 0 & 6 \\
\hline \multirow[t]{28}{*}{90.1} & 3 & 0 & 6.5 & 0 & 6.5 \\
\hline & & 0 & 4 & 0 & 5.5 \\
\hline & & 0 & 5 & 0 & 4 \\
\hline & & 0 & 4 & 0 & 6 \\
\hline & & 0 & 3 & 0 & 9.5 \\
\hline & & 0 & 3 & 0 & 13.5 \\
\hline & & 0 & 3 & 0 & 7 \\
\hline & & 0 & 3 & 0 & 9.5 \\
\hline & & 0 & 3 & 0 & 9.5 \\
\hline & & 0 & 3 & 0 & 8.5 \\
\hline & & 0 & 4.5 & 0 & 15.5 \\
\hline & & 0 & 3.5 & 0 & 12.5 \\
\hline & & 0 & 3.5 & 0 & 6 \\
\hline & & 0 & 3.5 & 0 & 6.5 \\
\hline & & 0 & 4 & 0 & 6.5 \\
\hline & & 0 & 3 & 0 & 7 \\
\hline & & & & 0 & 10.5 \\
\hline & & & & 0 & 10.5 \\
\hline & & & & 0 & 11.5 \\
\hline & & & & 0 & 11 \\
\hline & & & & 0 & 9 \\
\hline & & & & 0 & 17 \\
\hline & & & & 0 & 7.5 \\
\hline & & & & 0 & 10.5 \\
\hline & & & & 0 & 9.5 \\
\hline & & & & 0 & 12 \\
\hline & & & & 0 & 10.5 \\
\hline & & & & 0 & 12.5 \\
\hline
\end{tabular}


Table K-6. Rock in Feature 1 (Top) and 2 (Bottom)

\begin{tabular}{|c|c|c|}
\hline rock \# & weight gr. & $\max$ size $\mathrm{cm}$. \\
\hline 18 & 792.1 & 16 \\
\hline 21 & 1498 & 15.5 \\
\hline 26 & 946.8 & 16.5 \\
\hline 29 & 372.9 & 11 \\
\hline 34 & 349.7 & 11 \\
\hline 43 & 274.9 & 8.5 \\
\hline 52 & 621 & 15 \\
\hline 53 & 1171.4 & 16.5 \\
\hline 55 & 788.6 & 12.5 \\
\hline 89 & 878.2 & 14 \\
\hline$n=10$ & sum $=7693.6$ & average $=13.65$ \\
\hline 1 & 1400 & 12 \\
\hline 3 & 774 & 12.5 \\
\hline 5 & 559.7 & 10.5 \\
\hline 15 & 2089.3 & 16 \\
\hline 17 & 928.7 & 16.5 \\
\hline 19 & 1209.8 & 15 \\
\hline 22 & 1984.2 & 17.5 \\
\hline 23 & 925.8 & 15.5 \\
\hline 24 & 1024.6 & 12 \\
\hline 25 & 937.4 & 15 \\
\hline 31 & 838 & 14.5 \\
\hline 33 & 376.3 & 10.5 \\
\hline 35 & 405.1 & 12.5 \\
\hline 36 & 321.6 & 12.5 \\
\hline 39 & 881.5 & 15 \\
\hline 40 & 366.5 & 9 \\
\hline 44 & 1889.6 & 17.5 \\
\hline 46 & 364.3 & 10.5 \\
\hline 48 & 407.3 & 10.5 \\
\hline 50 & 1024.6 & 16.5 \\
\hline 68 & 1237.9 & 17.5 \\
\hline 72 & 1661 & 17.5 \\
\hline \multicolumn{2}{|r|}{ sum $=21607.2$} & average $=13.93$ \\
\hline
\end{tabular}

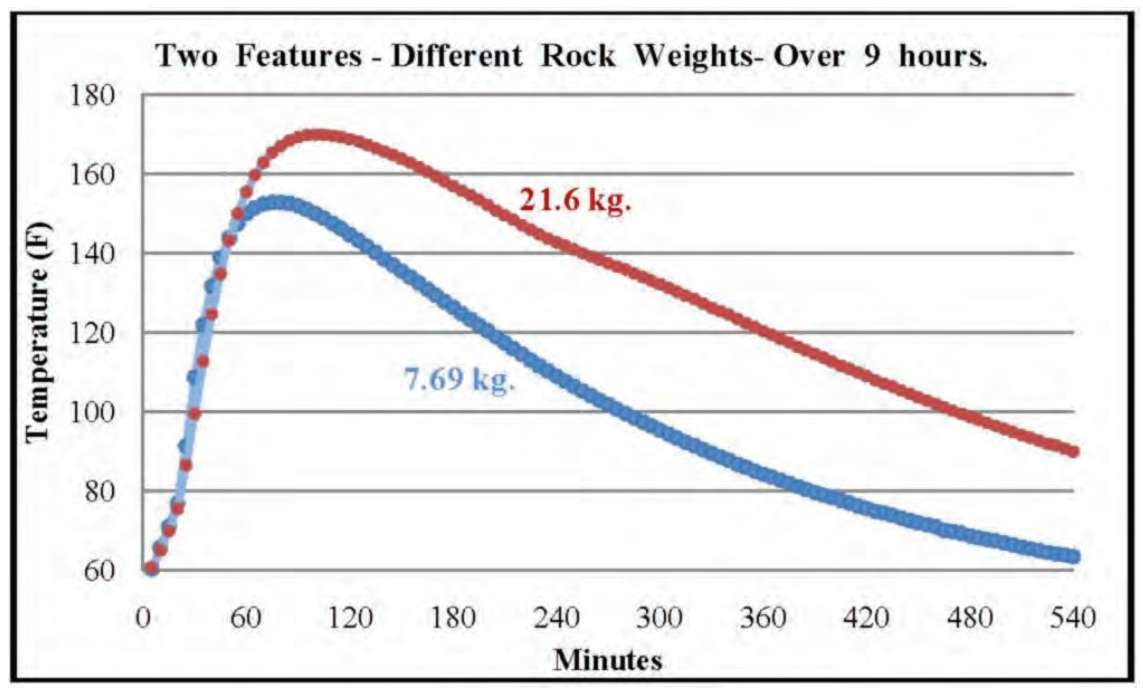

Figure K-12. Temperature differences over 9 hours with differing quantities of rock. 
Table K-7. Temperatures for Two Feature Comparisons

\begin{tabular}{|c|c|c|}
\hline time & feature $1-(7.69 \mathrm{~kg})$. & feature $2(21.6 \mathrm{~kg})$. \\
\hline 5 & 60.4 & 60.8 \\
\hline 10 & 65.8 & 65.1 \\
\hline 15 & 71.1 & 70 \\
\hline 20 & 76.9 & 75.6 \\
\hline 25 & 91.4 & 86.6 \\
\hline 30 & 108.7 & 99.6 \\
\hline 35 & 121.9 & 112.7 \\
\hline 40 & 131.7 & 124.6 \\
\hline 45 & 138.8 & 134.8 \\
\hline 50 & 143.8 & 143.2 \\
\hline 55 & 147.4 & 150 \\
\hline 60 & 149.9 & 155.4 \\
\hline 65 & 151.5 & 159.7 \\
\hline 70 & 152.4 & 162.9 \\
\hline 75 & 152.8 & 165.4 \\
\hline 80 & 152.8 & 167.1 \\
\hline 85 & 152.5 & 168.4 \\
\hline 90 & 151.9 & 169.2 \\
\hline 95 & 151 & 169.7 \\
\hline 100 & 150 & 169.9 \\
\hline 105 & 148.8 & 169.9 \\
\hline 110 & 147.5 & 169.6 \\
\hline 115 & 146.2 & 169.3 \\
\hline 120 & 144.7 & 168.8 \\
\hline 125 & 143.3 & 168.2 \\
\hline 130 & 141.7 & 167.4 \\
\hline 135 & 140.2 & 166.5 \\
\hline 140 & 138.5 & 165.6 \\
\hline 145 & 137 & 164.8 \\
\hline 150 & 135.5 & 163.8 \\
\hline 155 & 134 & 162.8 \\
\hline 160 & 132.5 & 161.7 \\
\hline 165 & 130.9 & 160.5 \\
\hline 170 & 129.4 & 159.3 \\
\hline 175 & 127.8 & 158.1 \\
\hline 180 & 126.3 & 156.9 \\
\hline 185 & 124.8 & 155.8 \\
\hline 190 & 123.3 & 154.7 \\
\hline 195 & 121.8 & 153.4 \\
\hline 200 & 120.4 & 152.2 \\
\hline 205 & 118.9 & 150.8 \\
\hline 210 & 117.4 & 149.5 \\
\hline 215 & 115.9 & 148.4 \\
\hline 220 & 114.5 & 147.1 \\
\hline 225 & 113 & 145.9 \\
\hline
\end{tabular}

Table K-7. Continued...

\begin{tabular}{|c|c|c|}
\hline 230 & 111.6 & 144.8 \\
\hline 235 & 110.3 & 143.6 \\
\hline 240 & 109 & 142.7 \\
\hline 245 & 107.7 & 141.9 \\
\hline 250 & 106.5 & 141 \\
\hline 255 & 105.3 & 140 \\
\hline 260 & 104.1 & 139.2 \\
\hline 265 & 102.9 & 138.4 \\
\hline 270 & 101.8 & 137.5 \\
\hline 275 & 100.7 & 136.7 \\
\hline 280 & 99.6 & 135.9 \\
\hline 285 & 98.6 & 134.9 \\
\hline 290 & 97.5 & 134 \\
\hline 295 & 96.5 & 133.1 \\
\hline 300 & 95.4 & 132.2 \\
\hline 305 & 94.4 & 131.3 \\
\hline 310 & 93.4 & 130.3 \\
\hline 315 & 92.4 & 129.3 \\
\hline 320 & 91.5 & 128.4 \\
\hline 325 & 90.5 & 127.4 \\
\hline 330 & 89.6 & 126.3 \\
\hline 335 & 88.7 & 125.4 \\
\hline 340 & 87.8 & 124.5 \\
\hline 345 & 86.8 & 123.4 \\
\hline 350 & 86 & 122.3 \\
\hline 355 & 85.1 & 121.4 \\
\hline 360 & 84.3 & 120.4 \\
\hline 365 & 83.6 & 119.4 \\
\hline 370 & 82.8 & 118.5 \\
\hline 375 & 82 & 117.5 \\
\hline 380 & 81.2 & 116.4 \\
\hline 385 & 80.4 & 115.5 \\
\hline 390 & 79.7 & 114.6 \\
\hline 395 & 79 & 113.7 \\
\hline 400 & 78.4 & 112.6 \\
\hline 405 & 77.7 & 111.7 \\
\hline 410 & 77 & 110.9 \\
\hline 415 & 76.3 & 109.9 \\
\hline 420 & 75.6 & 109 \\
\hline 425 & 75 & 108 \\
\hline 430 & 74.5 & 107.2 \\
\hline 435 & 73.9 & 106.4 \\
\hline 440 & 73.3 & 105.4 \\
\hline 445 & 72.7 & 104.6 \\
\hline 450 & 72 & 103.7 \\
\hline 455 & 71.6 & 102.8 \\
\hline 460 & 71.1 & 102 \\
\hline
\end{tabular}


Table K-7. Continued...

\begin{tabular}{|c|c|c|}
\hline 465 & 70.1 & 101.1 \\
\hline 470 & 69.9 & 100.3 \\
\hline 475 & 69.4 & 99.6 \\
\hline 480 & 68.8 & 98.8 \\
\hline 485 & 68.3 & 98 \\
\hline 490 & 67.8 & 97.2 \\
\hline 495 & 67.5 & 96.5 \\
\hline 500 & 67 & 95.7 \\
\hline 505 & 66.5 & 94.9 \\
\hline 510 & 66 & 94.2 \\
\hline 515 & 65.5 & 93.5 \\
\hline 520 & 65.1 & 92.8 \\
\hline 525 & 64.6 & 92 \\
\hline 530 & 64.2 & 91.5 \\
\hline 535 & 64 & 90.7 \\
\hline 540 & 63.5 & 90 \\
\hline
\end{tabular}
Limestone and Quartzite, and focused on breakage patterns and temperature relationships. These sets of experimental features with rock were supplemented by four simultaneous burns, using identical quantities of wood, but in features without rock. Finally, we conducted two simultaneous burns using the same quantity of wood, but with variable weights of rock. These were monitored over a nine hour period. Several aspects of these results are used in Chapter 10 in discussions of feature reuse at 41TV540, and the results should be widely applicable under conditions where rock is used in the context of heat retention. 


\section{References}

Black, S.L.

2003 Research Module 2: Studying the Hearths of the Greater Edwards Plateau. In Pavo Real (41BX52): A Paleoindian and Archaic Camp and Workshop on the Balcones Escarpment, South-Central Texas, edited by M.B. Collins, D.B. Hudler and S.L. Black, pp. 375-405. Studies in Archeology, No. 41, Texas Archeological Research Laboratory, The University of Texas at Austin. Archeological Studies Program, Report No. 50, Environmental Affairs Division, Texas Department of Transportation, Austin.

Black, S.L., L.W. Ellis, D.G. Creel and G.T. Goode

1997 Hot Rock Cooking on the Greater Edwards Plateau: Four Burned Rock Midden Sites in West Central Texas. Studies in Archaeology, No. 22. 2 vols. Texas Archaeological Research Laboratory, The University of Texas at Austin.

Johnson, L.

2000 Life and Death as Seen at the Bessie Kruze Site (41WM13) on the Blackland Prairie of Williamson County, Texas. Report 22, Texas Department of Transportation, Austin.

Leach, J.D., D.L. Nickels, B.K. Moses, and R. Jones

2001 Appendix D: Estimating Rates of Burned Rock Discard: Results from an Experimental Earth Oven, In Test Excavations at the Culebra Creek Site, 41BX126, Bexar County, Texas, by D.L. Nickels, C.B. Bousman, J.D. Leach, and D.A. Cargill, pp. 275-283. Archaeological Survey Report, No. 265, Center for Archaeological Research, The University of Texas at San Antonio; Archeology Studies Program, Report 3, Environmental Affairs Division, Texas Department of Transportation,

Mauldin, R., T. Graves, and M. Bentley

1998 Small Sites in the Central Hueco Bolson: A Final Report on Project 90-11. Published by Lopez and Associates, Dallas, Texas for Ft. Bliss Environmental Office, Ft. Bliss, Texas.

Pagoulotus, P.

2005 Experimental Burned Rock Studies on the Edwards Plateau: A view from Camp Bullis, Texas. North American Archaeologist 23: 289-329. 


\section{APPENDIX L: \\ Amino Acid Racemization Results for Modern and Archeological Snails Associated with 41TV540 \\ Darrell S. Kaufman}





\section{APPENDIX L \\ Amino Acid Racemization Results for Modern and Archeological Snails Associated with 41TV410 \\ Dr. Darrell S. Kaufman \\ Amino Acid Geochronology Laboratory \\ Northern Arizona University, Flagstaff, Arizona}

Twelve snail shell samples were submitted to the Amino Acid Geochronology Laboratory (AAGL) by UTSA. Three live snails were boiled for 10, 20, and 30 minutes. Nine samples were from archeological features. We analyzed the boiled modern snails using three different preparation procedures. The standard preparation (UAL-7446) yielded very high amino acid concentrations, which is indicative of contamination associated with the snail body (organic). In an effort to avoid this, we bleached the shells, and we analyzed both the total acid hydrolyzable (THAA) and the free (FAA) amino acids. The results of these tests were utterly unexpected: The shell that was boiled for 30 minutes had lower D/L values than the shell boiled for 10 minutes. I don't have an explanation for this. The difference in $\mathrm{D} / \mathrm{L}$ is minor, but seems to be reproducible. The nine archeological samples show some variability, especially those samples from Feature 14. Tables L-1 through L-3 presents the raw data. See additional discussion in Chapter 10 of this report.

Table L-1. Samples, Procedures, and D/L Ratios for Selected Amino Acids

\begin{tabular}{|c|c|c|c|c|c|c|}
\hline UAL & Sample & Genus & DL Asp & DL Glu & DL Ser & DL Ala \\
\hline $7446 \mathrm{~A}$ & modern heated $10 \mathrm{~min}$ to boil & Rabdotus & 0.047 & 0.037 & 0.024 & 0.041 \\
\hline 7446 B & modern heated $20 \mathrm{~min}$ to boil & Rabdotus & 0.04 & 0.019 & 0.006 & 0.02 \\
\hline $7446 \mathrm{C}$ & modern heated $30 \mathrm{~min}$ to boil & Rabdotus & 0.043 & 0.022 & 0.028 & 0.047 \\
\hline $7450 \mathrm{~A}$ & modern heated 10 min bleached & Rabdotus & 0.1 & 0.048 & 0.188 & 0.052 \\
\hline $7450 \mathrm{~B}$ & modern heated 10 min bleached & Rabdotus & 0.097 & 0.049 & 0.19 & 0.056 \\
\hline $7450 \mathrm{C}$ & modern heated 10 min bleached & Rabdotus & 0.094 & 0.046 & 0.188 & 0.055 \\
\hline $7450 \mathrm{D}$ & modern heated 10 min bleached - FREE & Rabdotus & & & & \\
\hline $7450 \mathrm{E}$ & modern heated 10 min bleached - FREE & Rabdotus & & & & \\
\hline $7450 \mathrm{~F}$ & modern heated 10 min bleached - FREE & Rabdotus & & & & \\
\hline $7451 \mathrm{~A}$ & modern heated 20 min bleached & Rabdotus & 0.087 & 0.042 & 0.154 & 0.053 \\
\hline $7451 \mathrm{~B}$ & modern heated 20 min bleached & Rabdotus & 0.088 & 0.042 & 0.158 & 0.052 \\
\hline $7451 \mathrm{C}$ & modern heated 20 min bleached & Rabdotus & 0.088 & 0.043 & 0.158 & 0.053 \\
\hline $7452 \mathrm{~A}$ & modern heated 30 min bleached & Rabdotus & 0.079 & 0.038 & 0.132 & 0.047 \\
\hline 7452 B & modern heated 30 min bleached & Rabdotus & 0.082 & 0.037 & 0.132 & 0.046 \\
\hline $7452 \mathrm{C}$ & modern heated 30 min bleached & Rabdotus & 0.081 & 0.038 & 0.145 & 0.068 \\
\hline $7452 \mathrm{D}$ & modern heated 30 min bleached - FREE & Rabdotus & & & & \\
\hline $7452 \mathrm{E}$ & modern heated 30 min bleached - FREE & Rabdotus & & & & \\
\hline $7452 \mathrm{~F}$ & modern heated 30 min bleached - FREE & Rabdotus & & & & \\
\hline \multicolumn{7}{|c|}{ three individual shells per UAL } \\
\hline $7447 \mathrm{~A}$ & 41TV540 - 27 Archeological - standard & Rabdotus & 0.422 & 0.134 & 0.66 & 0.263 \\
\hline $7447 \mathrm{~B}$ & 41TV540 - 27 Archeological - standard & Rabdotus & 0.623 & 0.235 & 0.613 & 0.377 \\
\hline $7447 \mathrm{C}$ & 41TV540 - 27 Archeological - standard & Rabdotus & 0.471 & 0.161 & 0.676 & 0.296 \\
\hline $7448 \mathrm{~A}$ & 41TV540 - 14 Archeological - standard & Rabdotus & 0.734 & 0.404 & 0.505 & 0.679 \\
\hline 7448 B & 41TV540 - 14 Archeological - standard & Rabdotus & 0.689 & 0.286 & 0.573 & 0.525 \\
\hline $7448 \mathrm{C}$ & 41TV540 - 14 Archeological - standard & Rabdotus & 0.419 & 0.122 & 0.65 & 0.235 \\
\hline $7449 \mathrm{~A}$ & 41TV540 - 13 Archeological - standard & Rabdotus & 0.418 & 0.131 & 0.674 & 0.254 \\
\hline $7449 \mathrm{~B}$ & 41TV540 - 13 Archeological - standard & Rabdotus & 0.413 & 0.124 & 0.638 & 0.253 \\
\hline $7449 \mathrm{C}$ & 41TV540 - 13 Archeological - standard & Rabdotus & 0.423 & 0.13 & 0.612 & 0.242 \\
\hline
\end{tabular}


Table L-2. Peak L and D Readings for Selected Amino Acids

\begin{tabular}{|c|c|c|c|c|c|c|c|c|}
\hline \multicolumn{9}{|c|}{ peak areas } \\
\hline UAL & L Asp & D Asp & L Glu & D Glu & L Ser & D Ser & L Ala & D Ala \\
\hline $7446 \mathrm{~A}$ & 1083 & 50 & 1123 & 41 & 883 & 21 & 901 & 37 \\
\hline 7446 B & 5514 & 218 & 5582 & 107 & 3569 & 22 & 4123 & 83 \\
\hline $7446 \mathrm{C}$ & 715 & 31 & 686 & 15 & 506 & 14 & 522 & 25 \\
\hline $7450 \mathrm{~A}$ & 2884 & 287 & 3421 & 165 & 1864 & 351 & 1989 & 104 \\
\hline 7450 B & 3012 & 293 & 3607 & 176 & 1947 & 369 & 2019 & 113 \\
\hline $7450 \mathrm{C}$ & 2193 & 207 & 2592 & 120 & 1440 & 270 & 1542 & 84 \\
\hline $7450 \mathrm{D}$ & 83 & 4 & 36 & 0 & 50 & 0 & 28 & 0 \\
\hline $7450 \mathrm{E}$ & 77 & 0 & 33 & 0 & 43 & 0 & 21 & 0 \\
\hline $7450 \mathrm{~F}$ & 76 & 0 & 33 & 0 & 40 & 0 & 20 & 0 \\
\hline $7451 \mathrm{~A}$ & 2517 & 220 & 3093 & 129 & 1712 & 264 & 1722 & 91 \\
\hline 7451 B & 2950 & 261 & 3442 & 144 & 1927 & 304 & 1978 & 104 \\
\hline $7451 \mathrm{C}$ & 2173 & 191 & 2478 & 106 & 1404 & 222 & 1447 & 76 \\
\hline $7452 \mathrm{~A}$ & 3005 & 237 & 3507 & 132 & 2045 & 271 & 1957 & 92 \\
\hline 7452 B & 2500 & 204 & 2869 & 107 & 1635 & 215 & 1617 & 75 \\
\hline $7452 \mathrm{C}$ & 2528 & 204 & 2873 & 110 & 1596 & 232 & 1614 & 110 \\
\hline $7452 \mathrm{D}$ & 178 & 0 & 68 & 0 & 57 & 0 & 24 & 0 \\
\hline $7452 \mathrm{E}$ & 185 & 0 & 69 & 0 & 50 & 0 & 23 & 0 \\
\hline $7452 \mathrm{~F}$ & 202 & 0 & 73 & 0 & 44 & 0 & 19 & 0 \\
\hline \multicolumn{9}{|c|}{ three individual shells per UAL } \\
\hline $7447 \mathrm{~A}$ & 842 & 355 & 1269 & 170 & 170 & 112 & 492 & 129 \\
\hline 7447 B & 963 & 599 & 1319 & 310 & 132 & 81 & 645 & 244 \\
\hline $7447 \mathrm{C}$ & 808 & 381 & 1202 & 193 & 139 & 94 & 498 & 147 \\
\hline $7448 \mathrm{~A}$ & 502 & 368 & 844 & 341 & 50 & 25 & 410 & 278 \\
\hline 7448 B & 625 & 431 & 1179 & 337 & 71 & 41 & 431 & 226 \\
\hline 7448 C & 920 & 385 & 1280 & 156 & 199 & 129 & 598 & 140 \\
\hline 7449 A & 955 & 399 & 1517 & 199 & 187 & 126 & 507 & 129 \\
\hline 7449 B & 936 & 387 & 1472 & 183 & 197 & 126 & 531 & 134 \\
\hline 7449 C & 1079 & 456 & 1515 & 197 & 217 & 133 & 630 & 153 \\
\hline
\end{tabular}


Table L-3. Concentrations (pMol per mg) for Selected Amino Acids

\begin{tabular}{|c|c|c|c|c|c|}
\hline UAL & [Asp] & [Glu] & [Ser] & [Ala] & [total] \\
\hline $7446 \mathrm{~A}$ & 1937 & 1990 & 1545 & 1603 & 7075 \\
\hline 7446 B & 10422 & 10344 & 6529 & 7647 & 34942 \\
\hline 7446 C & 1275 & 1198 & 889 & 935 & 4297 \\
\hline $7450 \mathrm{~A}$ & 610 & 690 & 426 & 403 & 2128 \\
\hline $7450 \mathrm{~B}$ & 697 & 797 & 488 & 449 & 2431 \\
\hline $7450 \mathrm{C}$ & 463 & 523 & 330 & 314 & 1629 \\
\hline $7450 \mathrm{D}$ & 17 & 7 & 10 & 5 & 39 \\
\hline $7450 \mathrm{E}$ & 14 & 6 & 8 & 4 & 32 \\
\hline $7450 \mathrm{~F}$ & 14 & 6 & 7 & 4 & 31 \\
\hline $7451 \mathrm{~A}$ & 547 & 644 & 395 & 363 & 1950 \\
\hline 7451 B & 599 & 669 & 416 & 388 & 2073 \\
\hline $7451 \mathrm{C}$ & 450 & 492 & 309 & 290 & 1541 \\
\hline $7452 \mathrm{~A}$ & 599 & 672 & 428 & 378 & 2077 \\
\hline 7452 B & 497 & 547 & 340 & 311 & 1695 \\
\hline $7452 \mathrm{C}$ & 493 & 538 & 330 & 311 & 1673 \\
\hline $7452 \mathrm{D}$ & 32 & 12 & 10 & 4 & 59 \\
\hline $7452 \mathrm{E}$ & 33 & 12 & 9 & 4 & 59 \\
\hline $7452 \mathrm{~F}$ & 37 & 13 & 8 & 3 & 62 \\
\hline \multicolumn{6}{|c|}{ three individual shells per UAL } \\
\hline $7447 \mathrm{~A}$ & 445 & 535 & 105 & 231 & 1316 \\
\hline $7447 \mathrm{~B}$ & 575 & 600 & 78 & 327 & 1581 \\
\hline $7447 \mathrm{C}$ & 436 & 512 & 86 & 237 & 1270 \\
\hline $7448 \mathrm{~A}$ & 311 & 423 & 27 & 246 & 1006 \\
\hline 7448 B & 381 & 546 & 40 & 237 & 1204 \\
\hline $7448 \mathrm{C}$ & 465 & 512 & 117 & 263 & 1357 \\
\hline $7449 \mathrm{~A}$ & 480 & 609 & 111 & 226 & 1425 \\
\hline 7449 B & 463 & 579 & 113 & 233 & 1387 \\
\hline $7449 \mathrm{C}$ & 524 & 584 & 119 & 267 & 1495 \\
\hline
\end{tabular}





\section{APPENDIX M:}

Lithic Data from 41TV540

Antonia Figueroa, Steve A. Tomka, and Jason Perez 



\author{
APPENDIX M \\ Lithic Data from 41 T540 \\ Antonia Figueroa, Steve A. Tomka, and Jason Perez \\ The Center for Archaeological Research \\ The University of Texas at San Antonio \\ San Antonio, Texas
}

This appendix summarizes the results of lithic analyses in a series of tables and also presents brief interpretations of observed trends. The lithic tool and debitage assemblages were analyzed by the senior lithic analyst assisted by the junior lithic analyst to: 1) define the richness of the tool collection; 2) categorize tools into specialized versus generalized forms (i.e., the use-life categories); 3) search for refits present in the debitage collection; and 4) identify the Minimum Analytical Nodules (MAN) represented in the assemblage.

\title{
Lithic Tools
}

The identification of the classes of functional tools present at a site can provide relatively direct evidence of the subset of activities that require the use of chipped or ground stone tools. Therefore, we classified each of the small number of informal and formal tools (from the Early Archaic Analysis Unit) into functional tool categories (i.e., scraper, knife, etc). While scanning each tool for macroscopic traces indicative of use, we also examined the specimens under low power magnification (30X) to define whether they represented single or multi-functional specimens. Specimens that exhibited use-wear were classified into functional tool categories while those that lacked use wear were categorized into miscellaneous bifaces and/or unifaces dependent on the location of retouch.

Although the number of lithic tools is small, the richness of the sample (i.e., number of functional tool classes) and the specialized (i.e., limited function) versus generalized (i.e., used for performance of a number of distinct tasks) nature of the tools can be related to a number of broad hunter-gatherer organizational aspects. Activities at special-purpose locations are, by definition, more restricted and require the use of fewer tools and some of the tools employed may be specialized rather than generalized instruments. Reoccupations of most special purpose locations will differentially increase the number of artifacts relative to the number of artifact types. That is, conducting the same set of activities at a location and discarding the same set of tools will increase the number of items in the sample without a concomitant increase in the number of artifact types. Within the context of a residentially mobile land use system, we expect that the number of different artifact types will increase at a faster rate at a site that is occupied for a longer duration, due to the fact that a wider variety of activities are conducted.

With these parameters in mind, and based on the earlier summarized shifts in resource base between geomorphically active and stable periods, we propose that during dynamic periods hunter-gatherers would have visited the locality for short periods in possession of generalized tools that will be discarded only upon failure. Some tool manufacture and repair debris maybe generated during such site visits but the majority of the lithic tools will be expedient specimens discarded immediately following use. During stable periods, as the floodplain forests mature and mast production increases, hunter-gatherers will increase residence time along the stream. The increase in occupation length will lead to the discard of a wider range of tools involved in a broader range of activities and lithic debris derived from a wider range of lithic tool manufacture and rejuvenation activities. Therefore, the analysis of the small tool assemblage may serve as an independent test of the hypothesis that the use of the site changed over time as the conditions on the Onion Creek floodplain oscillated between dynamic and stable conditions.

Table M-1 presents the lithic tools and cores recovered from 41TV540. As seen in Table M-1, four functional tool classes have been identified. Expedient scrapes on flakes are the largest group followed by a chopper with crushed portions of the working edge and a bifacially retouched cortex-backed cobble tool that appears to be a wedge based on use wear. The fourth functional tool class is a mano used on both faces. Seven other artifacts were classified as miscellaneous bifaces that were discarded following manufacture failure or due to poor raw material quality. Two of the seven specimens, a medial and a proximal fragment, are late-reduction stage bifaces. Four of the remaining five miscellaneous bifaces are large flakes with bifacial retouch only along a small portion of one edge. The final miscellaneous biface is an early reduction stage specimen made on 
Table M-1. Lithic Tools and Cores Recovered from 41TV540

\begin{tabular}{|c|c|c|c|c|c|}
\hline Feature & Level & $\begin{array}{c}\text { Revised } \\
\text { Color } \\
\text { Group } \\
\end{array}$ & Functional Category & Manufacture & Comments \\
\hline 13 & 3 & 13 & scraper & expedient & on incomplete tertiary flake \\
\hline \multirow[t]{4}{*}{13} & 4 & 1 & scraper & expedient & on complete tertiary flake \\
\hline & 0 & 15 & scraper & expedient & Incomplete tool; on distal flake fragment \\
\hline & 7 & 1 & scraper & expedient & on large longitudinally split secondary flake \\
\hline & 16 & 13 & chopper & formal & cortex-backed with partially refurbished working edge; \\
\hline \multirow[t]{2}{*}{25} & 0 & 1 & bifacial cobble tool & formal & possible wedge; shows battering on corticate backing \\
\hline & 6 & $\mathrm{n} / \mathrm{a}$ & mano & formal & bifacially used mano; quartzite \\
\hline 14 & 3 & 9 & miscellaneous biface & formal & retouched flake; no use wear \\
\hline \multirow[t]{4}{*}{14} & 3 & 1 & miscellaneous biface & formal & medial fragment of thin biface \\
\hline & & 1 & miscellaneous biface & formal & $\begin{array}{l}\text { found in backdirt; lanceolate biface proximal fragment; manufacture } \\
\text { break }\end{array}$ \\
\hline & 10 & 9 & miscellaneous biface & $\mathrm{n} / \mathrm{a}$ & marginally retouched: discarded due to poor raw mat., quality \\
\hline & 13 & 18 & miscellaneous biface & formal & marginally retouched flake; no use wear \\
\hline 13 & 3 & 14 & miscellaneous biface & formal & $\begin{array}{l}\text { large flake frag with bifacial retouch along one edge; medial flake } \\
\text { frag }\end{array}$ \\
\hline 13 & 3 & 21 & miscellaneous biface & formal & nodule fragment with cortex on proximal end; \\
\hline 13 & 3 & 18 & miscellaneous uniface & formal & retouched flake; no use wear \\
\hline \multirow[t]{3}{*}{13} & 3 & 20 & miscellaneous uniface & formal & retouched flake; no use wear \\
\hline & 10 & 22 & multi-directional core & $n / a$ & with cortex; may be very small biface fragment; \\
\hline & 8 & 1 & multi-directional core & $\mathrm{n} / \mathrm{a}$ & small multi-directional core \\
\hline 13 & 3 & 18 & multi-directional core & $\mathrm{n} / \mathrm{a}$ & may be end fragment of biface; \\
\hline 14 & 3 & 16 & bifacial core & $\mathrm{n} / \mathrm{a}$ & small bifacial core; could also be considered multi-directional core \\
\hline
\end{tabular}

a nodule. It has cortex on one end and may represent a heavily rejuvenated cobble tool although its working edge is missing. Formally manufactured items outnumber expedient tools although two of the miscellaneous bifaces and the two miscellaneous unifaces are only minimally retouched along the margins. Cores tend to be small and multi-directional.

\section{Lithic Debitage}

The overall range of activities carried out at a location varies among other things with the length of stay. Paralleling this trend, the range of lithic reduction activities engaged in at a site also will co-vary with the length of occupation. While some short occupations may not leave behind any lithic debris from tool use, as the length of occupation increases the likelihood that worn tools will be resharpened and failed tools will be rejuvenated will increase. So will the likelihood that some tools will be exhausted or will fail resulting in the need to manufacture fresh replacements. Therefore, we expect that short occupations, either within the context of a special purpose site or a forager residential camp, will yield a limited range of lithic debitage correlated with a narrow range of lithic reduction activities. As occupation length increases, the need to carry out tool maintenance (i.e., resharpening and rejuvenation) and the manufacture of new and/or replacement specimens will result in the performance of a wider range of lithic reduction activities (i.e., tool rejuvenation, resharpening, staged reduction of performs or quarry blanks, manufacture of replacement tools) that will, in turn, correlate with wider range of lithic debitage.

Based on these parameters, we expect that the composition of the lithic debitage will vary between short periods of site use that took place during geomorphologically active as opposed to stable periods. Other things being equal, lithic debris recovered from stable surfaces should be characterized by a greater range of tool manufacture and reduction activities while collections 
from rapidly aggrading surfaces should exemplify a limited range of reduction activities. We further proposed that during short occupation periods, the bulk of the lithic debris deposited on site will derive from core reduction while in the process of production debitage for use as expedient tools. In contrast, during stable periods, the refurbishing and replacement of failed or exhausted formal tools will produce debris from tool rejuvenation and manufacture and much of this debris should be representative of bifacial reduction. Therefore, we propose that the identification of the lithic raw material reduction strategies (i.e., core vs. bifacial reduction) represented at the site will aid in defining and serving as independent measures of site use.

To document this relationship, we performed the following analyses on all 310 pieces of lithic debitage from the Early Archaic Analysis Unit: (1) classified each piece of unmodified lithic debitage into size categories using a maximum dimension measured in mm (i.e., 1-10 mm, 11-20 mm; etc); (2) noted the cortex category for each piece (i.e., primary secondary, tertiary); and (3) classified each flake into one of the following categories: a) biface thinning; b) early and/or middle reduction stage debitage; c) uniface manufacture and resharpening debitage; and d) tool resharpening debitage. To aid in classification, the archeological specimens were compared to experimentally produced items representing each category.

Table M-2 lists these attributes for each item. The results of the debitage analysis indicate that $63 \%$ of the platform-bearing flakes (i.e., complete flakes and proximal fragments) were single faceted and an additional $12 \%$ had cortical platforms. Only 25 percent of the platform-bearing flakes had two (9\%) or more (16\%) platform facets. The majority of debitage assemblage (58\%) was characterized by tertiary flakes, followed by secondary flakes at $37 \%$. Over $80 \%$ of the assemblage consisted of early (40\%) and middle (41\%) reduction stage debitage. Only $15(5 \%)$ flakes fit into the late reduction stage and/or biface thinning category. In addition, 13 specimens were classified as having been removed from flake cores during unifacial tool manufacture. Early reduction stage debitage consists of those flakes that have cortex on their platforms and/or dorsal faces, and also retain only one or two flake scars on their dorsal faces. Middle reduction stage specimens retain no cortex on their dorsal faces but exhibit a small number of flake scars oriented in the same direction. Late reduction stage specimens are the same as biface thinning flakes and have complex dorsal flake scar patterning and longitudinal curvatures. Uniface manufacture flakes are small, have a single faceted platform and a trapezoidal shape.

Table M-2. 41TV540 Debitage Analysis

\begin{tabular}{|c|c|c|c|c|c|}
\hline Unique \# & Color & \begin{tabular}{|c|} 
Size Category \\
$(\mathrm{mm})$
\end{tabular} & Cortex & Platform Faceting & $\begin{array}{c}\text { Flake Type } \\
\text { Category }\end{array}$ \\
\hline 1 & 18 & $30-40$ & Tertiary & Single & Middle \\
\hline 2 & 18 & $40-50$ & Primary & N/A & Early \\
\hline 3 & 20 & $60-70$ & Tertiary & Single & Middle \\
\hline 4 & 23 & $30-40$ & Secondary & Single & Early \\
\hline 5 & 12 & $20-30$ & Tertiary & Multiple & Middle \\
\hline 6 & 16 & $30-40$ & Tertiary & N/A & Uniface \\
\hline 7 & 20 & $10-20$ & Tertiary & Indeterminate & Late \\
\hline 8 & 16 & $30-40$ & Tertiary & Single & Middle \\
\hline 9 & 23 & $30-40$ & Secondary & N/A & Early \\
\hline 10 & 15 & $30-40$ & Tertiary & Single & Middle \\
\hline 11 & 17 & $40-50$ & Secondary & Corticate & Early \\
\hline 12 & 14 & $20-30$ & Tertiary & N/A & Middle \\
\hline 13 & 19 & $20-30$ & Tertiary & Single & Middle \\
\hline 14 & 16 & $20-30$ & Tertiary & Single & Middle \\
\hline 15 & 16 & $30-40$ & Tertiary & Multiple & Thinning \\
\hline 16 & 19 & $20-30$ & Secondary & Single & Early \\
\hline 17 & 15 & $30-40$ & Tertiary & Single & Middle \\
\hline 18 & 30 & $20-30$ & Tertiary & N/A & $\mathrm{N} / \mathrm{A}$ \\
\hline 19 & 23 & $30-40$ & Secondary & Single & Early \\
\hline 20 & 25 & $20-30$ & Primary & Single & Early \\
\hline 21 & 16 & $30-40$ & Tertiary & Multiple & Thinning \\
\hline 22 & 18 & $60-70$ & Tertiary & N/A & Middle \\
\hline 23 & 16 & $30-40$ & Secondary & \begin{tabular}{|l|} 
Single \\
\end{tabular} & Uniface \\
\hline 24 & 21 & $30-40$ & Tertiary & Multiple & Middle \\
\hline
\end{tabular}


Table M-2. Continued...

\begin{tabular}{|c|c|c|c|c|c|}
\hline Unique \# & Color & $\begin{array}{l}\text { Size Category } \\
(\mathrm{mm})\end{array}$ & Cortex & Platform Faceting & $\begin{array}{c}\text { Flake Type } \\
\text { Category }\end{array}$ \\
\hline 25 & 10 & $20-30$ & Secondary & Corticate & Early \\
\hline 26 & 23 & $50-60$ & Secondary & Corticate & Early \\
\hline 27 & 18 & $30-40$ & Tertiary & Single & Middle \\
\hline 28 & 30 & $10-20$ & Tertiary & N/A & N/A \\
\hline 29 & 18 & $30-40$ & Tertiary & Single & Middle \\
\hline 30 & 18 & $10-20$ & Tertiary & Single & Middle \\
\hline 31 & 23 & $10-20$ & Tertiary & Single & Indeterminate \\
\hline 32 & 16 & $50-60$ & Tertiary & Multiple & Middle \\
\hline 33 & 16 & $30-40$ & Secondary & Corticate & Early \\
\hline 34 & 18 & $30-40$ & Secondary & Single & Early \\
\hline 35 & 18 & $20-30$ & Tertiary & N/A & Middle \\
\hline 36 & 23 & $50-60$ & Secondary & Indeterminate & Early \\
\hline 37 & 25 & $40-50$ & Secondary & Single & Early \\
\hline 38 & 14 & $20-30$ & Secondary & Corticate & Early \\
\hline 39 & 14 & $30-40$ & Secondary & $N / A$ & Early \\
\hline 40 & 13 & $20-30$ & Secondary & Indeterminate & Early \\
\hline 41 & 30 & $60-70$ & Secondary & N/A & N/A \\
\hline 42 & 14 & $30-40$ & Tertiary & Two & Middle \\
\hline 43 & 14 & $20-30$ & Tertiary & Single & Middle \\
\hline 44 & 23 & $20-30$ & Tertiary & Single & Middle \\
\hline 45 & 16 & $10-20$ & Tertiary & Multiple & Middle \\
\hline 46 & 10 & $10-20$ & Secondary & Indeterminate & Middle \\
\hline 47 & 20 & $10-20$ & Tertiary & Indeterminate & Middle \\
\hline 48 & 23 & $10-20$ & Tertiary & Single & Uniface \\
\hline 49 & 23 & $10-20$ & Tertiary & N/A & Middle \\
\hline 50 & 16 & $10-20$ & Tertiary & N/A & Middle \\
\hline 51 & 10 & $10-20$ & Tertiary & Indeterminate & Middle \\
\hline 52 & 15 & $20-30$ & Tertiary & Multiple & Middle \\
\hline 53 & 15 & $20-30$ & Tertiary & Multiple & Middle \\
\hline 54 & 23 & $20-30$ & Secondary & Indeterminate & Early \\
\hline 55 & 15 & $20-30$ & Tertiary & Multiple & Late \\
\hline 56 & 15 & $20-30$ & Tertiary & Single & Uniface \\
\hline 57 & 15 & $30-40$ & Tertiary & Multiple & Middle \\
\hline 58 & 20 & $10-20$ & Tertiary & Indeterminate & Early \\
\hline 59 & 15 & $20-30$ & Tertiary & Two & Late \\
\hline 60 & 15 & $10-20$ & Tertiary & Multiple & Middle \\
\hline 61 & 20 & $10-20$ & Tertiary & Multiple & Middle \\
\hline 62 & 15 & $10-20$ & Tertiary & Single & Middle \\
\hline 63 & 20 & $10-20$ & Tertiary & Single & Middle \\
\hline 64 & 20 & $10-20$ & Tertiary & Multiple & Middle \\
\hline 65 & 11 & $30-40$ & Tertiary & Indeterminate & Middle \\
\hline 66 & 16 & $20-30$ & Tertiary & Single & Early \\
\hline 67 & 19 & $30-40$ & Secondary & Single & Early \\
\hline 68 & 19 & $20-30$ & Secondary & Indeterminate & Early \\
\hline 69 & 19 & $30-40$ & Tertiary & Indeterminate & Middle \\
\hline 70 & 19 & $20-30$ & Tertiary & Indeterminate & Middle \\
\hline 71 & 19 & $20-30$ & Tertiary & Multiple & Middle \\
\hline 72 & 19 & $10-20$ & Tertiary & Indeterminate & Middle \\
\hline 73 & 10 & $10-20$ & Secondary & Single & Early \\
\hline 74 & 19 & $10-20$ & Tertiary & Indeterminate & Middle \\
\hline 75 & 19 & $10-20$ & Tertiary & Indeterminate & Late \\
\hline
\end{tabular}


Table M-2. Continued..

\begin{tabular}{|c|c|c|c|c|c|}
\hline Unique \# & Color & $\begin{array}{c}\text { Size Category } \\
(\mathrm{mm})\end{array}$ & Cortex & Platform Faceting & $\begin{array}{c}\text { Flake Type } \\
\text { Category }\end{array}$ \\
\hline 76 & 13 & $20-30$ & Tertiary & Indeterminate & Middle \\
\hline 77 & 13 & $20-30$ & Secondary & Multiple & Early \\
\hline 78 & 13 & $20-30$ & Secondary & Indeterminate & Early \\
\hline 79 & 23 & $10-20$ & Tertiary & Single & Uniface \\
\hline 80 & 21 & $20-30$ & Tertiary & Single & Middle \\
\hline 81 & 18 & $10-20$ & Secondary & Single & Early \\
\hline 82 & 3 & $50-60$ & Secondary & $N / A$ & Early \\
\hline 83 & 23 & $20-30$ & Secondary & Single & Early \\
\hline 84 & 20 & $20-30$ & Tertiary & Single & Early \\
\hline 85 & 22 & $20-30$ & Tertiary & Indeterminate & Middle \\
\hline 86 & 15 & $10-20$ & Tertiary & Multiple & Middle \\
\hline 87 & 30 & $10-20$ & Tertiary & $N / A$ & N/A \\
\hline 88 & 15 & $10-20$ & Tertiary & Indeterminate & Late \\
\hline 89 & 15 & $1-10$ & Tertiary & Single & Middle \\
\hline 90 & 33 & $10-20$ & Tertiary & Indeterminate & Middle \\
\hline 91 & 32 & $1-10$ & Tertiary & Multiple & Middle \\
\hline 92 & 9 & $20-30$ & Secondary & Single & Early \\
\hline 93 & 22 & $40-50$ & Tertiary & Single & Late \\
\hline 94 & 16 & $20-30$ & Tertiary & Single & Early \\
\hline 95 & 10 & $20-30$ & Secondary & Single & Early \\
\hline 96 & 5 & $40-50$ & Tertiary & Multiple & Middle \\
\hline 97 & 28 & $10-20$ & Secondary & Single & Early \\
\hline 98 & 26 & $30-40$ & Tertiary & Single & Middle \\
\hline 99 & 25 & $20-30$ & Primary & Corticate & Early \\
\hline 100 & 20 & $30-40$ & Secondary & Single & Early \\
\hline 101 & 18 & $10-20$ & Tertiary & Single & Middle \\
\hline 102 & 9 & $30-40$ & Tertiary & Single & Middle \\
\hline 103 & 16 & $50-60$ & Secondary & Single & Early \\
\hline 104 & 16 & $40-50$ & Secondary & Single & Early \\
\hline 105 & 14 & $30-40$ & Secondary & Single & Early \\
\hline 106 & 31 & $30-40$ & Tertiary & Single & Middle \\
\hline 107 & 23 & $30-40$ & Secondary & Corticate & Early \\
\hline 108 & 18 & $40-50$ & Tertiary & N/A & Middle \\
\hline 109 & 7 & $70-80$ & Secondary & Single & Early \\
\hline 110 & 14 & $30-40$ & Tertiary & Two & Middle \\
\hline 111 & 35 & $40-50$ & Secondary & Two & Early \\
\hline 112 & 14 & $40-50$ & Secondary & Corticate & Early \\
\hline 113 & 21 & $30-40$ & Secondary & Single & Early \\
\hline 114 & 8 & $30-40$ & Secondary & Corticate & Early \\
\hline 115 & 12 & $20-30$ & Secondary & Two & Early \\
\hline 116 & 15 & $30-40$ & Tertiary & Single & Early \\
\hline 117 & 12 & $20-30$ & Tertiary & Single & Middle \\
\hline 118 & 20 & $10-20$ & Secondary & Indeterminate & Early \\
\hline 119 & 10 & $40-50$ & Tertiary & Indeterminate & Middle \\
\hline 120 & 18 & $40-50$ & Secondary & N/A & Early \\
\hline 121 & 11 & $40-50$ & Secondary & Single & Early \\
\hline 122 & 10 & $20-30$ & Tertiary & Single & Middle \\
\hline 123 & 30 & $20-30$ & Tertiary & N/A & N/A \\
\hline 124 & 15 & $30-40$ & Tertiary & Single & Early \\
\hline 125 & 19 & $20-30$ & Tertiary & Indeterminate & Uniface \\
\hline 126 & 30 & $10-20$ & Secondary & N/A & N/A \\
\hline
\end{tabular}


Table M-2. Continued...

\begin{tabular}{|c|c|c|c|c|c|}
\hline Unique \# & Color & $\begin{array}{c}\text { Size Category } \\
(\mathrm{mm})\end{array}$ & Cortex & Platform Faceting & $\begin{array}{c}\text { Flake Type } \\
\text { Category }\end{array}$ \\
\hline 127 & 19 & $20-30$ & Tertiary & Single & Middle \\
\hline 128 & 14 & $20-30$ & Tertiary & Three & Middle \\
\hline 129 & 30 & $10-20$ & Secondary & N/A & N/A \\
\hline 130 & 18 & $40-50$ & Secondary & Single & Early \\
\hline 131 & 13 & $20-30$ & Secondary & Single & Early \\
\hline 132 & 36 & $30-40$ & Tertiary & Single & Middle \\
\hline 133 & 4 & $50-60$ & Tertiary & N/A & Middle \\
\hline 134 & 18 & $30-40$ & Tertiary & Single & Middle \\
\hline 135 & 19 & $30-40$ & Tertiary & Single & Middle \\
\hline 136 & 19 & $20-30$ & Tertiary & Single & Middle \\
\hline 137 & 18 & $20-30$ & Tertiary & N/A & Middle \\
\hline 138 & 18 & $20-30$ & Secondary & Single & Early \\
\hline 139 & 16 & $10-20$ & Tertiary & N/A & Middle \\
\hline 140 & 2 & $20-30$ & Secondary & Two & Early \\
\hline 141 & 2 & $10-20$ & Primary & Corticate & Early \\
\hline 142 & 25 & $30-40$ & Primary & Single & Early \\
\hline 143 & 15 & $20-30$ & Tertiary & Two & Middle \\
\hline 144 & 25 & $20-30$ & Secondary & Single & Early \\
\hline 145 & 23 & $20-30$ & Secondary & Single & Early \\
\hline 146 & 8 & $30-40$ & Secondary & Single & Early \\
\hline 147 & 30 & $30-40$ & Tertiary & N/A & N/A \\
\hline 148 & 25 & $20-30$ & Secondary & Single & Early \\
\hline 149 & 15 & $20-30$ & Secondary & Two & Early \\
\hline 150 & 9 & $20-30$ & Secondary & Single & Early \\
\hline 151 & 10 & $30-40$ & Tertiary & Single & Middle \\
\hline 152 & 19 & $20-30$ & Tertiary & Single & Middle \\
\hline 153 & 23 & $10-20$ & Tertiary & N/A & Indeterminate \\
\hline 154 & 23 & $40-50$ & Primary & Corticate & Early \\
\hline 155 & 28 & $20-30$ & Secondary & Single & Early \\
\hline 156 & 18 & $20-30$ & Secondary & Single & Early \\
\hline 157 & 18 & $20-30$ & Tertiary & Single & Middle \\
\hline 158 & 22 & $10-20$ & Secondary & Single & Uniface \\
\hline 159 & 30 & $10-20$ & Secondary & N/A & N/A \\
\hline 160 & 28 & $10-20$ & Tertiary & Indeterminate & Middle \\
\hline 161 & 19 & $1-10$ & Tertiary & Indeterminate & Middle \\
\hline 162 & 13 & $1-10$ & Tertiary & Indeterminate & Middle \\
\hline 163 & 25 & $10-20$ & Tertiary & Indeterminate & Early \\
\hline 164 & 4 & $40-50$ & Secondary & Multiple & Early \\
\hline 165 & 5 & $50-60$ & Tertiary & Two & Middle \\
\hline 166 & 23 & $20-30$ & Tertiary & Indeterminate & Late \\
\hline 167 & 14 & $40-50$ & Tertiary & Single & Middle \\
\hline 168 & 20 & $20-30$ & Tertiary & Multiple & Middle \\
\hline 169 & 19 & $30-40$ & Tertiary & Single & Middle \\
\hline 170 & 17 & $10-20$ & Tertiary & N/A & Middle \\
\hline 171 & 28 & $10-20$ & Primary & Corticate & Early \\
\hline 172 & 18 & $20-30$ & Tertiary & N/A & Thinning \\
\hline 173 & 9 & $40-50$ & Secondary & Single & Early \\
\hline 174 & 11 & $30-40$ & Secondary & Indeterminate & Early \\
\hline 175 & 29 & $30-40$ & Secondary & Single & Early \\
\hline 176 & 29 & $30-40$ & Secondary & Single & \begin{tabular}{|l|l|} 
Early \\
\end{tabular} \\
\hline 177 & 13 & $20-30$ & Primary & Corticate & Early \\
\hline
\end{tabular}


Table M-2. Continued..

\begin{tabular}{|c|c|c|c|c|c|}
\hline Unique \# & Color & $\begin{array}{c}\text { Size Category } \\
(\mathrm{mm})\end{array}$ & Cortex & Platform Faceting & $\begin{array}{c}\text { Flake Type } \\
\text { Category }\end{array}$ \\
\hline 178 & 10 & $20-30$ & Tertiary & Indeterminate & Early \\
\hline 179 & 19 & $20-30$ & Secondary & Indeterminate & Early \\
\hline 180 & 10 & $10-20$ & Tertiary & Single & Middle \\
\hline 181 & 23 & $30-40$ & Secondary & Single & Early \\
\hline 182 & 12 & $10-20$ & Tertiary & Multiple & Late \\
\hline 183 & 15 & $10-20$ & Tertiary & Multiple & Late \\
\hline 184 & 15 & $20-30$ & Secondary & Multiple & Middle \\
\hline 185 & 15 & $10-20$ & Tertiary & Multiple & Late \\
\hline 186 & 15 & $20-30$ & Tertiary & Multiple & Late \\
\hline 187 & 15 & $10-20$ & Tertiary & Multiple & Middle \\
\hline 188 & 20 & $10-20$ & Tertiary & Indeterminate & Middle \\
\hline 189 & 15 & $10-20$ & Tertiary & $N / A$ & Late \\
\hline 190 & 18 & $20-30$ & Tertiary & N/A & Indeterminate \\
\hline 191 & 19 & $10-20$ & Tertiary & Indeterminate & Middle \\
\hline 192 & 14 & $10-20$ & Tertiary & Single & Uniface \\
\hline 193 & 30 & $10-20$ & Tertiary & N/A & N/A \\
\hline 194 & 12 & $20-30$ & Tertiary & Two & Middle \\
\hline 195 & 23 & $20-30$ & Secondary & Single & Early \\
\hline 196 & 20 & $20-30$ & Tertiary & Single & Middle \\
\hline 197 & 30 & $20-30$ & Secondary & N/A & N/A \\
\hline 198 & 34 & $10-20$ & Secondary & Single & Early \\
\hline 199 & 16 & $20-30$ & Tertiary & Single & Middle \\
\hline 200 & 15 & $10-20$ & Tertiary & Single & Middle \\
\hline 201 & 26 & $60-70$ & Tertiary & Single & Middle \\
\hline 202 & 16 & $60-70$ & Secondary & Corticate & Early \\
\hline 203 & 12 & $50-60$ & Secondary & Two & Early \\
\hline 204 & 3 & $10-20$ & Tertiary & Single & Middle \\
\hline 205 & 23 & $30-40$ & Secondary & Single & Early \\
\hline 206 & 9 & $20-30$ & Tertiary & Single & Middle \\
\hline 207 & 18 & $10-20$ & Tertiary & Single & Early \\
\hline 208 & 23 & $10-20$ & Secondary & N/A & Early \\
\hline 209 & 12 & $20-30$ & Tertiary & Two & Middle \\
\hline 210 & 14 & $40-50$ & Secondary & Corticate & Early \\
\hline 211 & 15 & $30-40$ & Tertiary & Single & Middle \\
\hline 212 & 16 & $40-50$ & Secondary & Corticate & Early \\
\hline 213 & 3 & $20-30$ & Tertiary & Single & Middle \\
\hline 214 & 8 & $20-30$ & Tertiary & Indeterminate & Middle \\
\hline 215 & 30 & $10-20$ & Tertiary & N/A & N/A \\
\hline 216 & 23 & $40-50$ & Secondary & N/A & Early \\
\hline 217 & 22 & $40-50$ & Secondary & Single & Early \\
\hline 218 & 23 & $20-30$ & Secondary & Corticate & Early \\
\hline 219 & 16 & $10-20$ & Tertiary & N/A & Uniface \\
\hline 220 & 14 & $20-30$ & Tertiary & Two & Middle \\
\hline 221 & 18 & $20-30$ & Tertiary & Multiple & Early \\
\hline 222 & 14 & $20-30$ & Secondary & Corticate & Early \\
\hline 223 & 29 & $10-20$ & Secondary & Corticate & Middle \\
\hline 224 & 18 & $40-50$ & Tertiary & Single & Middle \\
\hline 225 & 18 & $20-30$ & Tertiary & Single & Middle \\
\hline 226 & 27 & $30-40$ & Secondary & Corticate & early \\
\hline 227 & 14 & $10-20$ & Secondary & N/A & Early \\
\hline 228 & 9 & $20-30$ & Tertiary & Multiple & Middle \\
\hline
\end{tabular}


Table M-2. Continued..

\begin{tabular}{|c|c|c|c|c|c|}
\hline Unique \# & Color & $\begin{array}{l}\text { Size Category } \\
(\mathrm{mm})\end{array}$ & Cortex & Platform Faceting & $\begin{array}{c}\text { Flake Type } \\
\text { Category }\end{array}$ \\
\hline 229 & 16 & $20-30$ & Tertiary & N/A & Middle \\
\hline 230 & 16 & $10-20$ & Tertiary & N/A & Indeterminate \\
\hline 231 & 2 & $40-50$ & Tertiary & Multiple & Early \\
\hline 232 & 2 & $20-30$ & Tertiary & N/A & Middle \\
\hline 233 & 2 & $20-30$ & Tertiary & Two & Middle \\
\hline 234 & 2 & $20-30$ & Tertiary & Multiple & Middle \\
\hline 235 & 2 & $10-20$ & Tertiary & N/A & Middle \\
\hline 236 & 2 & $10-20$ & Tertiary & Single & Middle \\
\hline 237 & 22 & $30-40$ & Secondary & Single & Early \\
\hline 238 & 20 & $20-30$ & Secondary & Corticate & Early \\
\hline 239 & 30 & $20-30$ & Tertiary & $\mathrm{N} / \mathrm{A}$ & N/A \\
\hline 240 & 12 & $10-20$ & Tertiary & N/A & Middle \\
\hline 241 & 26 & $40-50$ & Tertiary & Single & Middle \\
\hline 242 & 11 & $30-40$ & Secondary & Single & Early \\
\hline 243 & 3 & $20-30$ & Tertiary & Two & Middle \\
\hline 244 & 1 & $30-40$ & Tertiary & N/A & Middle \\
\hline 245 & 16 & $30-40$ & Secondary & Single & Early \\
\hline 246 & 3 & $20-30$ & Tertiary & Two & Middle \\
\hline 247 & 32 & $20-30$ & Tertiary & Indeterminate & Middle \\
\hline 248 & 19 & $10-20$ & Tertiary & Single & Middle \\
\hline 249 & 12 & $20-30$ & Tertiary & Two & Middle \\
\hline 250 & 27 & $50-60$ & Secondary & Single & Early \\
\hline 251 & 19 & $20-30$ & Tertiary & Indeterminate & Middle \\
\hline 252 & 30 & $10-20$ & Tertiary & N/A & $N / A$ \\
\hline 253 & 16 & $40-50$ & Secondary & Single & Early \\
\hline 254 & 16 & $40-50$ & Tertiary & N/A & Early \\
\hline 255 & 7 & $20-30$ & Tertiary & Single & Uniface \\
\hline 256 & 36 & $20-30$ & Tertiary & Single & Early \\
\hline 257 & 16 & $10-20$ & Tertiary & N/A & Indeterminate \\
\hline 258 & 20 & $10-20$ & Tertiary & Indeterminate & Middle \\
\hline 259 & 9 & $40-50$ & Primary & Single & Early \\
\hline 260 & 9 & $60-70$ & Secondary & Indeterminate & Early \\
\hline 261 & 23 & $20-30$ & Primary & Single & Early \\
\hline 262 & 9 & $20-30$ & Secondary & Single & Early \\
\hline 263 & 21 & $20-30$ & Secondary & Single & Early \\
\hline 264 & 21 & $20-30$ & Tertiary & Indeterminate & Middle \\
\hline 265 & 21 & $10-20$ & Tertiary & Single & Middle \\
\hline 266 & 23 & $30-40$ & Secondary & Single & Early \\
\hline 267 & 16 & $20-30$ & Secondary & $\mathrm{N} / \mathrm{A}$ & Early \\
\hline 268 & 17 & $30-40$ & Secondary & Single & Early \\
\hline 269 & 17 & $30-40$ & Tertiary & Multiple & Middle \\
\hline 270 & 30 & $20-30$ & Secondary & N/A & N/A \\
\hline 271 & 6 & $10-20$ & Secondary & Single & Early \\
\hline 272 & 30 & $10-20$ & Secondary & N/A & N/A \\
\hline 273 & 30 & $10-20$ & Secondary & N/A & $N / A$ \\
\hline 274 & 16 & $30-40$ & Secondary & N/A & Early \\
\hline 275 & 10 & $10-20$ & Secondary & Indeterminate & Early \\
\hline 276 & 28 & $10-20$ & Primary & Single & Early \\
\hline 277 & 21 & $10-20$ & Tertiary & Single & Uniface \\
\hline 278 & 15 & $10-20$ & Tertiary & $N / A$ & Middle \\
\hline 279 & 20 & $10-20$ & Tertiary & Indeterminate & Middle \\
\hline
\end{tabular}


Table M-2. Continued..

\begin{tabular}{|c|c|c|c|c|c|}
\hline Unique \# & Color & $\begin{array}{c}\text { Size Category } \\
(\mathrm{mm})\end{array}$ & Cortex & Platform Faceting & $\begin{array}{c}\text { Flake Type } \\
\text { Category }\end{array}$ \\
\hline 280 & 30 & $10-20$ & Secondary & N/A & N/A \\
\hline 281 & 25 & $10-20$ & Tertiary & Indeterminate & Middle \\
\hline 282 & 24 & $30-40$ & Tertiary & Single & Middle \\
\hline 283 & 23 & $40-50$ & Secondary & Single & Early \\
\hline 284 & 24 & $20-30$ & Tertiary & N/A & Middle \\
\hline 285 & 22 & $30-40$ & Secondary & Single & Early \\
\hline 286 & 12 & $20-30$ & Tertiary & N/A & $\mathrm{N} / \mathrm{A}$ \\
\hline 287 & 9 & $20-30$ & Tertiary & Two & Middle \\
\hline 288 & 16 & $10-20$ & Tertiary & N/A & Middle \\
\hline 289 & 25 & $50-60$ & Primary & Indeterminate & Early \\
\hline 290 & 18 & $30-40$ & Tertiary & Single & Early \\
\hline 291 & 6 & $30-40$ & Secondary & N/A & Early \\
\hline 292 & 21 & $10-20$ & Secondary & Single & Early \\
\hline 293 & 17 & $20-30$ & Tertiary & Two & Middle \\
\hline 294 & 9 & $30-40$ & Secondary & Single & Early \\
\hline 295 & 29 & $20-30$ & Secondary & Single & Uniface \\
\hline 296 & 30 & $10-20$ & Tertiary & N/A & N/A \\
\hline 297 & 25 & $50-60$ & Primary & Corticate & Early \\
\hline 298 & 3 & $30-40$ & Secondary & Single & Early \\
\hline 299 & 20 & $20-30$ & Secondary & Single & Uniface \\
\hline 300 & $\mathrm{~N} / \mathrm{A}$ & $\mathrm{N} / \mathrm{A}$ & N/A & N/A & $\mathrm{N} / \mathrm{A}$ \\
\hline 301 & 18 & $60-70$ & Secondary & Single & Early \\
\hline 302 & 8 & $30-40$ & Secondary & Single & Early \\
\hline 303 & 18 & $40-50$ & Tertiary & Corticate & Early \\
\hline 304 & 23 & $30-40$ & Primary & N/A & Early \\
\hline 305 & 23 & $40-50$ & Secondary & Corticate & Early \\
\hline 306 & 16 & $30-40$ & Tertiary & Single & Middle \\
\hline 307 & 23 & $20-30$ & Tertiary & Single & Middle \\
\hline 308 & 30 & $20-30$ & Tertiary & N/A & $\mathrm{N} / \mathrm{A}$ \\
\hline 309 & 27 & $10-20$ & Secondary & Indeterminate & Early \\
\hline 310 & 30 & $10-20$ & Secondary & N/A & N/A \\
\hline
\end{tabular}

Once this portion of the analyses the lithic debitage was completed, we sorted all of the chert debitage from the Early Archaic Analysis Unit sample into sub-groups based on color and inclusions. The debitage was separated by colors defined by reference to a standardized rock color chart. These groups were further divided based on inclusions and raw material grain (fine, medium, coarse) to arrive to the Minimum Analytical Nodule as the analytical unit (Larson and Kornfeld1997; Hall 2004; Pletka 2005). A preliminary inspection of the debitage indicated that with some work one can identify sub-groups of debitage that are likely to derive from the same nodule.

As results of the color/texture analysis, thirty-six groupings of debitage were identified representing Minimum Analytical Nodules (see Table M- 2 Color). They are listed below. Following each description is a notation that provides the revised (new) color groupings ultimate used in Chapter 10.

Category 1: Thick banded material, with alternating bands of 10YR 4/1 dark gray and 10YR 7/1 light gray. None of the specimens were corticate. Material is fine-grained. These items were placed in revised (new) color group 1.

Category 2: Heavily banded material, with alternating bands consisting of 10YR 5/1 gray, 10YR 8/2 very pale brown, and 10YR 6/3 pale brown. Cortex color of 10YR5/4 yellowish brown. Material is coarse-grained. These items were placed in revised (new) color group 2. 
Category 3: Banded material with 10YR 5/1 gray and 10YR 7/1 light gray bands. Cortex color of 10YR 6/8 brownish yellow. Material is medium-grained. These were placed in revised (new) color group 3.

Category 4: Uniform color of 5Y 2.5/1 black, with light inclusions of 5Y 8/1 white. Cortex color of 5Y 8/1 white. Material is very fine-grained. These items were placed in revised (new) color group 1.

Category 5: Base color of 10YR 5/1 gray. Splotches of 10R 3/4 dusky red intermixed with inclusions of a 10YR 6/1 gray color surrounded by a 10YR 8/1 white circle. One artifact has a color of 10YR 8/4 very pale brown on its dorsal side, this artifact also has a band of 10YR 2/1 black surrounding its main inclusion. Material is very fine-grained. These items were placed in revised (new) color group 1.

Category 6: Color of 10R 5/3 weak red turning into a 10YR 2/1 black towards the cortex. Cortex color is 10R 4/6 red. Material is medium-grained. These items were placed in revised (new) color group 1.

Category 7: Base color of 5Y gray with a swirl of 5Y 7/1 light gray. Cortex color of 10YR 7/4 very pale brown. Material is coarse-grained. These items were placed in revised (new) color group 1.

Category 8: Uniform color of 10YR 4/1 dark gray. One artifact has faint bands of a 10YR 3/1 very dark gray color. Cortex color of 10YR 5/8 yellowish brown, and 10YR 8/1 white. Material is medium-grained. These items were placed in revised (new) color group 1.

Category 9: Color of 10YR 6/1 gray. Cortex color of 10YR 5/6 yellowish brown. Material is fine-grained. One artifact is very mottled with colors consisting of 10YR 6/1 gray, 10YR 7/1 light gray, and 10YR 8/2 very pale brown. These items were placed in revised (new) color group 9.

Category 10: Uniform color of 10YR 6/2 light brownish gray. Cortex color of 10YR 6/6 brownish yellow. Material is medium-grained. These items were placed in revised (new) color group 10.

Category 11: Color variation within artifacts of 10YR 6/1 gray and 10YR 6/3 pale brown. Cortex color of 10YR 8/4 very pale brown and 10YR 5/4 yellowish brown. Artifacts have inclusions of a 10YR 4/1 dark gray and 10YR 7/1 light gray color. Material is fine-grained with one artifact having a 10YR 7/1 light gray band surrounded by a 10YR 8/1 flowing mark. One artifact has 10YR 8/3 very pale brown mottling. These items were placed in revised (new) color group 1.

Category 12: Base color of 10YR 3/1 very dark grey with inclusions of a 10YR 8/2 very pale brown color. Cortex color of 10YR 8/1 white. Material is fine-grained. These items were placed in revised (new) color group 12.

Category 13: Uniform color of 10YR 5/4 yellowish brown. Cortex color of 10YR 7/4 very pale brown. Material is finegrained. These were placed in revised (new) color group 13.

Category 14: Color variation within artifacts of 10YR 6/1 gray and 10YR 6/2 light brownish gray. Cortex color of 10YR 7/3 very pale brown. Material is very fine-grained with most artifacts having 10YR 4/4 dark yellowish brown specks. These items were placed in revised (new) color group 14.

Category 15: Uniform color of 10YR 4/1 dark gray. Cortex color of 7.5YR 4/6 strong brown. Material is very fine-grained. These items were placed in revised (new) color group 15.

Category 16: Color variation in artifacts of 10YR 7/1 light gray and 10YR 4/1 dark gray. Cortex color of 10YR 6/4 light yellowish brown, with some having colors of 10YR 6/6 brownish yellow and 10YR 5/6 yellowish brown. Material is fine-grained with lighter colored mottling breaking up a dark base. These were placed in revised (new) color group 16.

Category 17: Uniform color of 10YR 7/2 light gray with specks of a 10YR 4/4 dark yellowish brown color. Cortex color of 10YR 5/4 yellowish brown. Material is medium-grained. These items were placed in revised (new) color group 1. 
Category 18: Base color of $5 \mathrm{Y} 5 / 1$ gray with dots and inclusions of a $10 \mathrm{YR} 8 / 2$ very pale brown color. A few in the group also have swirls and dots of a 10YR 5/4 yellowish brown color. Cortex color is a 10YR 5/6 yellowish brown. Material is medium-grained. These were placed in revised (new) color group 18.

Category 19: Uniform color of 10YR 6/1 with one artifact having a few dots of color 10YR 3/2 very dark grayish brown. Cortex color of 10YR 8/3 very pale brown. Material is very fine-grained These items were placed in revised (new) color group 19.

Category 20: Uniform color of 10YR 5/1 gray. Cortex color of 5YR 5/6 yellowish red. Material is medium-grained. These items were placed in revised (new) color group 20.

Category 21: Uniform color of 10YR 5/1 gray with dots of a 10YR 4/4 dark yellowish brown and 10YR 4/1 dark gray. Inclusions of a 10YR 6/2 light brownish gray color. Cortex color of 10YR 7/4 very pale brown. Material is coarsegrained. These items were placed in revised (new) color group 21.

Category 22: Heavily mottled group of artifacts with colors consisting of 10YR 5/1 gray, 10Yr 7/1 light gray, and 10YR 4/1 dark gray, and artifacts that have no mottling and a base color of 10YR 5/1 gray. Both groups include inclusions of the same color, 7.5YR 7/2 pinkish gray surrounded by 7.5YR 8/1 white. Cortex color of 10YR 8/3 very pale brown. Material is medium-grained. These items were placed in revised (new) color group 22.

Category 23: Base color of 10YR 7/2 light gray, with swirls of 10YR 4/1 dark gray and 10R 6/6 light red. Some have dots of a 10R 4/6 red color. Cortex color of 10YR 5/8 yellowish brown. Material is medium-grained. These items were placed in revised (new) color group 23.

Category 24: Color of 10YR 5/1 grey that gradually fades into 10YR 4/3 brown. Small specks of a 10R 3/4 dusky red color. No cortex left on either example. Material is fine-grained. These items were placed in revised (new) color group 1.

Category 25: Uniform color of 10YR 4/1 dark gray with inclusions of a 10YR 8/1 white color. Band of color 10YR 8/4 very pale brown right before cortex. Cortex color of $10 \mathrm{Yr} 7 / 6$ yellow. Material is fine-grained. These items were placed in revised (new) color group 25.

Category 26: Uniform color of 2.5Y 5/4 light olive brown. Crystalline inclusions of a 2.5Y white color. No cortex on any of the examples. Material is fine-grained. These items were placed in revised (new) color group 1.

Category 27: Base color of 10YR 6/1 gray with swirls of 10YR 5/6 yellowish brown, and 10YR 8/1 white. Very small amount of heavily patinated cortex left on one artifact. Material is fine-grained. These items were placed in revised (new) color group 1.

Category 28: Mottled group of artifacts with colors ranging from 10YR 6/4 light yellowish brown, 10YR 4/4 dark yellowish brown and 10YR 6/3 pale brown. Cortex color of 10YR 8/4 very pale brown. Material is very fine-grained. These items were placed in revised (new) color group 1.

Category 29: Base color of 10YR 6/1 gray with swirls of 10YR 5/4 yellowish brown. Cortex color of 10YR 5/4 yellowish brown. Material is fine-grained. These items were placed in revised (new) color group 1.

Category 30: Burned or heated pieces of debitage with altered colors. Not used.

Category 31: One example. Slight banding with color band of 10YR 5/1 gray between thicker bands of 10YR 7/1 light gray. No cortex left on artifact. Material is very fine-grained with 10YR 4/2 dark grayish brown specks. These items were placed in revised (new) color group 1.

Category 32: Base color of 10YR 4/2 dark grayish brown. One artifact has inclusions of 10YR 4/1 dark gray outlined by 10YR 6/1 gray. The other has splotches of color 10YR 7/1 light gray. No cortex on either artifact. Artifact with 
inclusions is coarse-grained, while artifact without inclusions is fine-grained. These items were placed in revised (new) color group 1.

Category 33: One example. Uniform color of 10YR 6/2 light brownish gray. No cortex on dorsal face. Material is very fine-grained. These items were placed in revised (new) color group 1.

Category 34: One example. Base color of 10YR 7/4 very pale brown with spots of a 10YR 2/1 color, and inclusions of a 10YR 3/3 dark brown color. Cortex color of 10R 4/6 red. Material is coarse-grained. These items were placed in revised (new) color group 1.

Category 35: One example. Base color of 10YR 7/1 light gray, with swirls of color 10YR 3/4 dark yellowish brown and dots of colors 10YR 3/4 dark yellowish brown, and 10YR 8/1 white. Crystalline inclusions of a 10YR 4/1 dark gray color. Cortex color of 10YR 5/6 yellowish brown. Material is medium-grained. These items were placed in revised (new) color group 1.

Category 36: Uniform color of 10YR 2/1 black. Cortex left on one artifact is heavily patinated. Material is very finegrained. These items were placed in revised (new) color group 1.

The brief attempts to find refits across these color groups did not identify any suggesting that the specimens may come from different nodules. Some color groups, such as Color 12, are represented by a few small flakes that are decorticate and fall either in the middle or late stages of reduction. These flakes may represent debitage derived from non-local artifacts. Interestingly, however, with the exception of one pair of refits, no others were identified during our brief attempts to refit pieces of debitage. The high proportion of single faceted flakes, coupled with the small number of flakes representing other stages of reduction and bifacial reduction in particular indicates that lithic reduction activities carried out on site represent a narrow range. The low tool assemblage richness coupled with the limited types of reduction activities reflected in the debitage does support the hypothesis that the Early Archaic occupation of the site consisted of repeated revisits each lasting relatively short periods of time and representing a limited set of activities.

\section{References Cited}

Hall, C.T.

2004 Evaluating Prehistoric Hunter-Gatherer Mobility, Land Use, and Technological Organization Strategies Using Minumum Analytical Nodule Analysis. In Aggregate Analysis in Chipped Stone, edited by C.T. Hall and M.L. Larson, pp. 139-155. The University of Utah Press, Salt Lake City.

Larson, M.L. and M. Kornfeld

1997 Chipped Stone Nodules: Theory, Method, and Examples. Lithic Technology 22(1):4-8.

Pletka, S.

2005 Research Design for Upland Archeological Experimental Module Cuatro Vientos Roadway Project Webb County, Texas. CSJ 0086-14-025. Manuscript on file, Center for Archaeological Research, The University of Texas at San Antonio. 


\section{APPENDIX N:}

Faunal Material from 41TV540

Barbara Meissner 



\section{APPENDIX N \\ Faunal Material from 41TV540 \\ Barbara Meissner \\ The Center for Archaeological Research \\ The University of Texas at San Antonio \\ San Antonio, Texas}

Only a very small number of faunal remains were recovered during the excavation at 41TV540. Two hundred and sixty vertebrate bones, weighing $88.95 \mathrm{~g}$, were collected during the excavation. In addition, there were 31 identified freshwater mussels. The total weight of all invertebrates collected, including those that were identifiable, was $371.1 \mathrm{~g}$. Table N-1 presents the list of faunal material recovered, with counts and weights.

Table N-1. Faunal Material Recovered from 41TV540

\begin{tabular}{|c|c|c|c|}
\hline Taxon & Common Name & & \\
\hline Aves & Birds & Count & Wgt. (g) \\
\hline Anseriformes & Ducks, Geese, Swans & 1 & 1.17 \\
\hline Anas sp. & Dabbling Ducks & 1 & 0.05 \\
\hline Aves--VLg & Turkey-sized & 24 & 5.49 \\
\hline Aves--Lg & Duck-sized & 72 & 10.65 \\
\hline Aves--Med & Pidgeon-sized & 4 & 0.31 \\
\hline Aves--Sm & Robin-sized & 2 & 0.07 \\
\hline Aves & Size indeterminate & 53 & 1.59 \\
\hline \multicolumn{2}{|r|}{ Total Birds } & 157 & 19.33 \\
\hline Mammalia & Mammals & Count & Wgt. (g) \\
\hline Artiodactyla & Deer, sheep, goats & 2 & 17.12 \\
\hline Odocoileus virginianus & Whitetailed Deer & 3 & 29.97 \\
\hline Sylvilagus $\mathrm{sp}$. & Cottontail Rabbits & 3 & 0.39 \\
\hline Lepus californicus & Backtailed Jackrabbit & 2 & 1.19 \\
\hline Rodentia & Rodents & 2 & 0.13 \\
\hline Mammal--Lg & Deer-sized & 30 & 11.53 \\
\hline Mammal--Med & Coyote-sized & 4 & 1.01 \\
\hline Mammal--Sm & Rabbit-sized & 26 & 2.46 \\
\hline Mammal & Size indeterminate & 16 & 0.65 \\
\hline \multicolumn{2}{|r|}{ Total Mammals } & 88 & 64.45 \\
\hline Reptilia & Reptiles & Count & Wgt. (g) \\
\hline Colubridae & Non-poisonous Snake & 2 & 0.26 \\
\hline Emydidae & Emydid Turtles & 3 & 3.25 \\
\hline Testudines & Unidentified Turtles & 9 & 1.52 \\
\hline \multicolumn{2}{|r|}{ Total Reptiles } & 14 & 5.03 \\
\hline Chondrichthyes & Cartilaginous Fishes & Count & Wgt. (g) \\
\hline Isurus sp. & Mako Shark & 1 & 0.14 \\
\hline \multicolumn{2}{|r|}{ Total Sharks } & 1 & 0.14 \\
\hline \multicolumn{2}{|r|}{ Total Vertebrates } & 260 & 88.95 \\
\hline \multicolumn{2}{|r|}{ Bivalve Invertebrates } & Count & Wgt. (g) \\
\hline Bivalvia & Unidentified marine shell & 5 & 0.38 \\
\hline Mytilidae & Saltwater Mussels & 1 & 0.52 \\
\hline & Total Marine Shells & 6 & 0.9 \\
\hline
\end{tabular}


Table N-1. Continued...

\begin{tabular}{|c|c|c|c|}
\hline Taxon & Common Name & & \\
\hline Unionidae & Freshwater Mussels & Count & Wgt. (g) \\
\hline Amblema plicata & Threeridge & 1 & 5.82 \\
\hline Cyrtonaias tampicoensis & Tampico Pearlymussel & 11 & 177.23 \\
\hline Lampsilis hydiana & Louisiana Fatmucket & 3 & 14.24 \\
\hline Lampsilis teres & Yellow Sandshell & 4 & 26.31 \\
\hline Potamilus ohiensis & Bleufer & 1 & 2.82 \\
\hline Potamilus purpuratus & Pink Papershell & 1 & 2 \\
\hline Quadrula aplicata & Southern Mapleleaf & 2 & 7.22 \\
\hline Quadrula aureas & Golden Orb & 2 & 7.27 \\
\hline Quadrula houstonensis & Smooth Pimpleback & 3 & 10.12 \\
\hline Toxolasma parvus & Lilliput & 2 & 0.57 \\
\hline Tritogonia verruocosa & Pistol Grip & 1 & 0.97 \\
\hline \multicolumn{2}{|r|}{ Total Identified Freshwater Mussels } & 31 & 254.57 \\
\hline Unionidae & Unidentified Freshwater Mussels & & 116.53 \\
\hline \multicolumn{2}{|r|}{ Total Invertebrates } & 31 & 371.1 \\
\hline
\end{tabular}

In the laboratory all bone was washed, dried, and then bagged by unit and level. The bone was identified to the most specific taxon possible using the comparative collection at CAR, as well as several standard reference texts (Boessneck 1970, Gilbert 1990; Gilbert et al. 1981; Hildebrand 1955, Hillson 1986; Olsen 1964, 1968; Sobolik and Steele 1996). Taxonomic names are those defined at the Integrated Taxonomic Information System (ITIS 2009) available online at <http:// www.itis.gov/index. html>. Identifications were conservative, i.e., bone which appeared to be from a deer-sized artiodactyl was not identified as Whitetailed Deer (Odocoileus virginianus) unless it could be differentiated from Pronghorn (Antilocapra americana) and domesticated artiodactyls such as sheep (Ovis aries) and goats (Capra hircus). All bone and shell was weighed. Shell too fragmented to identify to the Family taxonomic level was weighed but not counted. Evidence of exposure to heat was noted on all bone. Element, portion of element, evidence of immaturity, butcher marks and evidence of damage from gnawing was noted on bone identified to the order taxonomic level. When bone could be identified only as Mammal or Bird, an estimate of the size of the animal (i.e., very small, small, medium, large, very large) was made when possible.

In general, the bone was sparse and very highly fragmented, with an average bone weight of only $0.34 \mathrm{~g}$ (Table $\mathrm{N}-1$ ). Bone preservation at the site does not appear to be very good. Most bones showed severe damage due to chemical weathering as a result of microorganism activity. The poor preservation and highly fragmented nature of the collection resulted in only 10 specimens (3.85 percent) being identified to the Genus taxonomic level, and one of these was a shark tooth, from a Mako shark (Isurus sp.). This tooth appears to be at least partially fossilized. The other identified bones included those of Whitetailed Deer (Odocoileus virginianus), Cottontail Rabbit (Sylvilagus sp.), Blacktailed Jackrabbit (Lepus californicus), and a duck (Anas sp.).

Table N-2 lists vertebrate faunal material recovered from features. Five of the features had 171 pieces of vertebrate fauna recovered, with the highest number associated with Feature 13, and the highest density associated with Feature 27/29. Feature 13 also had the greatest diversity, though like Feature 27/29, avian fauna dominated the recovery. Most material was highly fragmentary and small in overall size as indicated by the total weight (gr.) by taxon for a feature (Table N-2). Mussel shell was also present in Features 13 and 24, as well as outside of features. Feature 13 contained 125.9 grams of mussel shell representing a variety of different species.

Table N-2. Distribution of Bone In Features at 41TV540

\begin{tabular}{|c|c|c|c|c|c|c|}
\hline Feature & $\begin{array}{c}\text { L. Mammal } \\
\text { Cnt. (wt.) }\end{array}$ & $\begin{array}{c}\text { M. Mammal } \\
\text { Cnt. (wt.) }\end{array}$ & $\begin{array}{c}\text { S. Mammal } \\
\text { Cnt. (wt.) }\end{array}$ & $\begin{array}{c}\text { Aves } \\
\text { Cnt. (wt.) }\end{array}$ & $\begin{array}{c}\text { testudines } \\
\text { Cnt. (wt.) }\end{array}$ & $\begin{array}{c}\text { Other } \\
\text { Cnt. (wt.) }\end{array}$ \\
\hline 9 & $18(18.9)$ & 0 & 0 & 0 & 0 & 0 \\
\hline 13 & $5(4.09)$ & $2(0.31)$ & $7(0.91)$ & $55(6.71)$ & $9(1.52)$ & $5(1.33)$ \\
\hline 14 & 0 & 0 & $3(0.56)$ & 0 & 0 & 0 \\
\hline 26 & 0 & 0 & 0 & $7(0.65)$ & 0 & 0 \\
\hline $27 / 29$ & 0 & 0 & 0 & $56(6.27)$ & 0 & $4(3.30)$ \\
\hline
\end{tabular}


Although the small sample size limits interpretations, the assemblage does contain an unusually large percentage of bird bones. Most of these were not identifiable except to a general size category, but the total number of bird bones exceeds the number of bones in all other vertebrate classes recovered (see Table N-1). Mammal bones constituted 30.4 percent of the total vertebrate bone count.

Table N-3 shows a comparison of the bone recovered at 41TV540 with bone from four other sites that were recently reexamined as part of an ongoing research project. For each site, the bone that could be assigned to one of four classes (Mammals, Birds, Reptiles and Fish) was compared as a percentage of the total. Table N-3 shows considerable variation in the five sites shown, but only 41TV540 has a large percentage of bird bone.

The unusual number of bird bones and the complete lack of fish (with the exception of the shark tooth) in the collection is notable and may be a reflection of the habitat conditions in the vicinity of the site during Early Archaic times.

Table N-3. Comparison of Bone Recovered from 41TV540 to Other Sites

\begin{tabular}{|l|l|l|l|l|l|}
\hline & Mammals & \multicolumn{1}{|c|}{ Birds } & \multicolumn{1}{|c|}{ Reptiles } & \multicolumn{1}{|c|}{ Fish } & $\begin{array}{l}\text { Total Bone } \\
\text { Compared }\end{array}$ \\
\hline JW8 & $45.20 \%$ & $0.70 \%$ & $51.70 \%$ & $2.40 \%$ & 2605 \\
\hline LK201 & $28.50 \%$ & $0.50 \%$ & $32.00 \%$ & $39.10 \%$ & 2586 \\
\hline MM340 & $74.60 \%$ & $1.20 \%$ & $23.90 \%$ & $0.30 \%$ & 753 \\
\hline MC296 & $69.00 \%$ & $0.50 \%$ & $23.50 \%$ & $7.10 \%$ & 2963 \\
\hline 41TV540 & $33.90 \%$ & $60.60 \%$ & $5.40 \%$ & $0.00 \%$ & 259 \\
\hline
\end{tabular}

\section{References Cited}

Boessneck, J.

1970 Osteological Differences Between Sheep (vis aries Linné) and Goats (Capra hircus Linné). In Science in Archaeology, edited by D. Brothwell and E. Higgs, pp. 331-358. Praeger, New York.

Gilbert, B.M.

1990 Mammalian Osteology. Missouri Archaeological Society, Columbia.

Gilbert, B.M., L.D. Martin and H.G. Savage

1981 Avian Osteology. B. Miles Gilbert, Publisher, Laramie, WY.

Hall, C.T.

2004 Evaluating Prehistoric Hunter-Gatherer Mobility, Land Use, and Technological Organization Strategies Using Minumum Analytical Nodule Analysis. In Aggregate Analysis in Chipped Stone, edited by C.T. Hall and M.L. Larson, pp. 139-155. The University of Utah Press, Salt Lake City.

Hildebrand, M.

1955 Skeletal Differences Between Deer, Sheep, and Goats. California Fish and Game 41:327-346.

Hillson, S.

1986 Teeth. Cambridge University Press, Cambridge.

ITIS

2009 Integrated Taxonomic Information System. Available online at http://www.itis.gov/index.html. Accessed October 18, 2007. 
Larson, M.L. and M. Kornfeld

1997 Chipped Stone Nodules: Theory, Method, and Examples. Lithic Technology 22(1):4-8.

Olsen, S.J.

1964 Mammal Remains from Archaeological Sites Part I; Southeastern and Southwestern United States. Peabody Museum, Cambridge.

1968 Fish, Amphibian, and Reptile Remains from Archaeological Sites Part I: Southeastern and Southwestern United States. Peabody Museum, Cambridge.

Sobolik, K.D. and D.G. Steele

1996 A Turtle Atlas to Facilitate Archaeological Identifications. Mammoth Site of Hot Springs, SD, Inc., Rapid City. 


\begin{abstract}
APPENDIX 0:
TxDOT Comments on the UTSA Conclusions Regarding Dense Concentrations of Snail Shells Observed within Archeological Sites Jon Budd
\end{abstract}





\section{APPENDIX $O$ TxDOT Comments on the UTSA Conclusions Regarding Dense Concentrations of Snail Shells Observed within Archeological Sites Jon Budd \\ Texas Department of Transportation Environmental Affairs Division Austin}

UTSA has concluded that the snail shell concentrations observed at 41TV540 and 41TV410 are due to natural snail behavior and not to human predation. Whether dense snail concentrations observed on archeological sites are due to natural causes or due to human predation is a topic for debate in Texas Archeology. TxDOT is interested in objectively and accurately investigating the reasons for such phenomena. In TxDOT's opinion, the data utilized by UTSA to reach their conclusion is inconclusive and therefore no definitive conclusions can be made regarding this debate. TxDOT therefore recommends caution for future researchers when citing the current UTSA research.

One of the primary reasons that the archeological site 41TV540 was deemed significant was due to the presence of a large concentration of Rabdotus snail shells estimated to encompass approximately five cubic meters of site matrix and mixed with limited amounts of charcoal, animal bone, fire cracked rock, and to a much lesser degree, debitage. This concentration was labeled as Feature 13 and was estimated to contain approximately 55,000 shells, almost all exclusively Rabdotus. According to the geomorphologist investigating the Onion Creek landform, this shell concentration does not appear to be associated with any fluviatile episodes. In consultation with TxDOT, UTSA proposed detailed research to determine whether the formation of Feature 13 was due to natural snail behavior or due to human gathering, consumption, and discard.

One of the main lines of evidence that UTSA relied on to conclude that the formation of Feature 13 was due to natural snail behavior is the presence of juvenile snail shells within the feature's shell assemblage. According to their reasoning, a natural population of snails would contain significant numbers of juvenile relative to adult snail shells. In contrast, a concentration based upon predation would be expected to be predominately adult snails. The UTSA analysis defines adult snails as shells large enough to be captured within $1 / 4$ inch wire mesh screen while juvenile shells are defined as shells small enough to pass through the $1 / 4$ inch mesh. UTSA utilized only $1 / 4$ inch screens during their field investigations. Therefore, there was very limited opportunity to quantify the actual numbers of snail shells small enough to pass through the $1 / 4$ inch screens. The only opportunity to estimate any quantity of juveniles from the field investigations derived from a total of eight liters of sediment samples recovered from the feature.

The UTSA laboratory analysis of the eight liters of sediment samples obtained from Feature 13 resulted in a total of 55 adult shells and a total of 16 juvenile shells. Based upon these numbers and the UTSA estimations of the approximate size of the feature (five cubic meters), UTSA extrapolated that the feature contained roughly 10,000 juvenile snails and 45,000 adults. The estimated presence of 10,000 juveniles is a primary reason for UTSA to conclude that the feature is not the result of human predation. TxDOT questions the validity of this conclusion.

In TxDOT's opinion, the eight liters of feature sediments utilized by UTSA to reach this conclusion is much too small to be a representative sample. Eight liters of sediments within a five cubic feature equates to only a $0.16 \%$ sample. This sample is much too small to base any conclusions on. However, even if this small sample is taken into account, juveniles would constitute only18\% of the Feature 13 assemblage. Conversely, adult snails would constitute $82 \%$ of the assemblage. These numbers appear to be counter-intuitive to the UTSA conclusion that the Feature 13 snail shell assemblage represents a natural snail population in that a much higher percentage of juvenile snail shells would be expected in a natural population. The $82 \%$ adult presence would seem to reinforce the notion that the assemblage is the result of human predation and not natural. Of course the context of the preservation of the more fragile juvenile snail shells must be accounted for. However, UTSA has made no attempt to assess this aspect. No discussion of snail shell depredation in the form of shell pitting or decomposition was significantly included in any of their explanations.

In addition, UTSA has not addressed the question as to whether the presence of sixteen juveniles within the eight liters of soil sediments or two juveniles per one liter of sediment can be considered as "background noise". In other words, absent cultural 
Feature 13, what would be the expected age quantification of the natural snail population on the Onion Creek Floodplain setting? Is there a baseline snail population occurring in this riparian area? In TxDOT's opinion, recognition that the UTSA data is inconclusive in regard to determining whether the shell concentration is natural versus human predation is a more appropriate conclusion.

In TxDOT's opinion, there exists yet another inconsistency in the UTSA reasoning. The investigators conclude that a major contribution to the significance of 41TV540 and 41TV410 is that the site deposits reflect very ephemeral occupations lasting only a few days at most. However, they do not offer any explanation on how these short term occupations could have generated enough organic refuse or other footprint attractive enough to draw tens of thousands of snails. If the concentrations of snails are based upon natural snail behavior, then why did so many snails gather on a site that could offer very little organic residue to feed on?

TxDOT does not advocate either conclusion regarding concentrations of snail shells on archeological sites. TxDOT does recommend however that the more appropriate conclusion would be that the UTSA data is inconclusive and more research is required to ultimately resolve the question as to whether dense concentrations of snail shells observed on archeological sites are due to natural snail behavior or due to human predation. 
ISBN 1-935545-04-0 